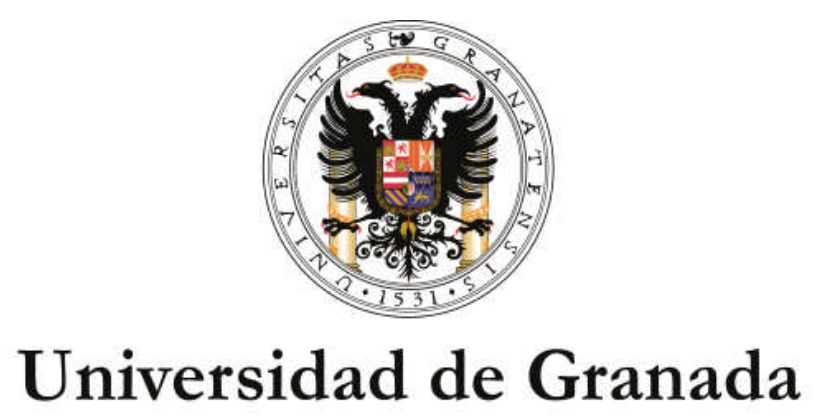

\title{
LA APLICACIÓN DEL MOTU PROPRIO SOBRE MÚSICA SAGRADA DE PÍO X EN LA ARCHIDIÓCESIS DE SEVILLA (1903-1910): GESTIÓN INSTITUCIONAL Y CONFLICTOS IDENTITARIOS
}

TESIS DOCTORAL

presentada para la obtención del Título de Doctor

\section{Miguel López Fernández}

Realizada bajo la dirección de la Dra. Gemma Pérez Zalduondo

FACULTAD DE FILOSOFÍA Y LETRAS DEPARTAMENTO DE HISTORIA Y CIENCIAS DE LA MÚSICA PROGRAMA DE DOCTORADO EN ARTE GRANADA, 2014 
Editor: Editorial de la Universidad de Granada Autor: Miguel López Fernández

D.L.: GR 2055-2014

ISBN: 978-84-9083-239-4 

El doctorando Miguel López Fernández y la directora de la tesis Gemma Pérez Zalduondo Garantizamos, al firmar esta tesis doctoral, que el trabajo ha sido realizado por el doctorando bajo la dirección de los directores de la tesis y hasta donde nuestro conocimiento alcanza, en la realización del trabajo, se han respetado los derechos de otros autores a ser citados, cuando se han utilizado sus resultados o publicaciones.

Granada, a 23 de junio de 2014

Directorles de la Tesis

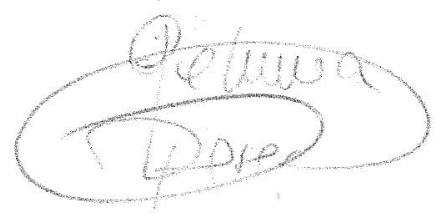

Fdo.: Gemma Pérez Zalduondo

\section{Doctorando}

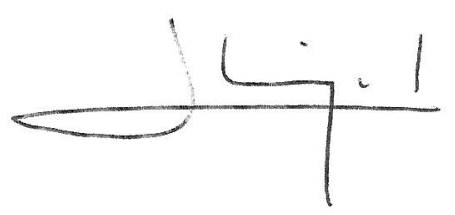

Fdo.: Miguel López Fernández 

A Elena. A Jorge y Lara.

A mis padres y hermanos.

A Álvaro. A Juan María. 



\section{ÍNDICE GENERAL}

$\begin{array}{ll}\text { Agradecimientos } & \text { XIII }\end{array}$

$\begin{array}{ll}\text { Consideraciones preliminares } & \text { XV }\end{array}$

$\begin{array}{ll}\text { Abreviaturas } & \text { XVII }\end{array}$

INTRODUCCIÓN

1. Planteamiento 3

2. Estado de la cuestión 6

3. Objetivos e hipótesis 23

4. Fuentes 24

5. Metodología 31

6. Estructura de la tesis 40

0. Breve introducción al Motu Proprio "Tra le sollecitudini” de Pío X 43

\section{PARTE I: ARCHIDIÓCESIS}

La reforma de la música sagrada en la archidiócesis de Sevilla: concreción normativa y gestión institucional

\section{CAPÍTULO 1. LA REFORMA DURANTE EL PONTIFICADO DE MARCELO SPÍNOLA Y MAESTRE (1904-1906)}

1. El arzobispo Marcelo Spínola frente a la reforma: "perseverancia, discreción y prudencia exquisita"

2. Comisión Diocesana de Música Sagrada: naturaleza y funciones

3. Inicio y suspensión del proceso de reformas: causas y consecuencias

4. Concreción en el ámbito diocesano de la normativa papal: el plan de reformas desarrollado por la Comisión Diocesana de Música Sagrada (I)

4.1. Centros para la formación de los agentes musicales diocesanos:

Escuela Oficial Archidiocesana de Canto Gregoriano y Seminario

4.2. Labor de censura y depuración del repertorio litúrgico-musical

4.3. Regulación del uso de los instrumentos

5. Recepción y respuesta de administradores de templos a la reforma

\section{CAPÍTULO 2. LA REFORMA DURANTE EL PONTIFICADO DE ENRIQUE} ALMARAZ Y SANTOS (1907-1910)

1. Periodo de interregno: nueva suspensión del proceso de reformas

2. El arzobispo Enrique Almaraz frente a la reforma: continuidad y severidad $\quad 120$

3. La reconstituida Comisión Diocesana de Música Sagrada 125

4. Concreción en el ámbito diocesano de la normativa papal: el plan de reformas desarrollado por la Comisión Diocesana de Música Sagrada (II)

4.1.1. Canto gregoriano: la adopción de las ediciones típicas vaticanas

4.1.2. Música figurada: la depuración del patrimonio musical 
4.2. Agentes musicales diocesanos

4.2.1. Regulación de los oficios musicales eclesiásticos: hacia la constitución de una estructura oficial diocesana

4.2.1.1. Directores musicales

4.2.1.2. Scholae cantorum y capillas musicales

4.2.1.3. Recepción por parte de directores y grupos de las medidas para la regulación de sus oficios en el ámbito eclesiástico

4.2.1.4. Sochantres y organistas

4.2.2. Medidas conminadoras para administradores de templos

5. La culminación del proceso normativo: El Reglamento de Música Sagrada para la Archidiócesis de Sevilla (1910)

PARTEII: CATEDRAL

La aplicación del Motu proprio en la catedral de Sevilla: reforma litúrgico-musical versus defensa identitaria

CAPÍTULO 3. EL PROCESO DE REFORMAS EN LA CATEDRAL (1905-1910): LAS REACCIONES A LA MODIFICACIÓN DEL CANON LITÚRGICO-MUSICAL

1. Reforma de la música en las solemnidades de Semana Santa (1905) 171

1.1. Oficio de Tinieblas

1.1.1. Salmo Miserere

1.1.2. Lamentaciones

1.2. Otras partes litúrgico-musicales del ceremonial

2. Plan para el arreglo de la música sagrada en la Catedral (1908) 197

3. Sustitución del canto llano tradicional por el canto gregoriano restaurado: adopción de la edición típica del Graduale (1908)

4. La revisión del repertorio musical para las fiestas y grandes solemnidades (1909-1910)

4.2. Salmos de vísperas para el Corpus y la Inmaculada 211

CAPÍTULO 4. FUNCIONES SIMBÓLICAS DE LA MÚSICA EN LAS FIESTAS LITÚRGICAS CATEDRALICIAS A PRINCIPIOS DEL S. XX 221

1. Definición del problema e hipótesis de partida

2. Fiestas litúrgicas e identidad en los discursos históricos del catolicismo local de entresiglos: el Corpus y la Inmaculada

2.2. La figura de la Inmaculada

2.3. Corpus e Inmaculada: símbolos de un concepto de cultura y sociedad determinado por lo religioso

3. El "canon Eslava"

3.1. El lenguaje musical de Eslava: un dialecto artístico "moderno" transmutado en tradición

3.2. El mito de Eslava

3.3. El fenómeno del Miserere de Eslava

3.3.1. La secularización del "templo": la liturgia como acto sociocultural 274

3.3.2. La sacralización de la cultura: reasignación de significados 
religiosos al lenguaje musical "profano"

3.3.3. El Miserere como producto híbrido religioso-profano:

un espacio de influencia cultural eclesiástica en la Edad

Contemporánea

4. El proyecto regeneracionista de Vicente Ripollés en Sevilla

en la base del conflicto

los prejuicios y vengan al suelo las prácticas rutinarias"

4.2.1. La educación, fundamento de la regeneración. La formación de los seises y la fundación de un conservatorio

4.2.2. La obra musical de Ripollés en Sevilla: la sustitución

del repertorio de las solemnidades litúrgicas catedralicias

4.2.2.1. Producción musical para las solemnidades del Corpus, Inmaculada y Asunción

4.2.2.2. Alabado y bailes de seises

4.2.3. Ripollés y Sevilla, regeneración versus identidad.

Una historia de incomprensión

PARTE III: CONGRESO NACIONAL DE MÚSICA SAGRADA Sevilla y el proceso de institucionalización del movimiento reformista en España

\section{CAPÍTULO 5. LA INSTITUCIONALIZACIÓN DEL MOVIMIENTO ESPAÑOL DE REFORMAS DURANTE EL II CONGRESO NACIONAL DE MÚSICA SAGRADA (SEVILLA, 1908)}

1. Antecedente del congreso de Sevilla: el I Congreso Nacional de Música Sagrada (Valladolid, 1907)

1.1. Los orígenes del primer congreso "nacional"

1.2. Dimensión "nacional" y problemas de organización

2. Génesis del congreso de Sevilla

3. Organización del congreso de Sevilla

3.1. Junta Organizadora y documentos fundamentales

3.2. Difusión y propaganda. El Congreso en el contexto socioeconómico

3.2.1. La respuesta del episcopado español a los requerimientos del Congreso

3.2.2. La contribución al Congreso de arciprestes, curas y fieles diocesanos

3.2.3. La situación económica de los músicos eclesiásticos

3.3. El tándem Ripollés-Otaño

4. El congreso de Sevilla, escenario para la consolidación del movimiento de reformas como "espacio artístico-social"

4.1. La cuestión gregoriana: las primeras grietas en el movimiento

4.2. Las revistas de música religiosa en torno al congreso de Sevilla: instrumentos para el liderazgo

4.2.1. Música Sacro-Hispana durante el congreso de Sevilla

4.2.2. El grupo dominante: Otaño-Ripollés-Goicoechea-Viñaspre

4.2.3. Las alternativas: Olmeda, Villalba

4.2.4. El negocio editorial y las instituciones de la reforma 
5. Apuntes para una valoración general del Congreso 482

5.1. Balance económico y de participación 482

5.2. El fracaso institucional 486

5.3. El congreso del "sur" periférico 490

CAPÍTULO 6. MODELOS, SÍMBOLOS Y DISCURSOS MUSICALES PARA LA INSTITUCIONALIZACIÓN DE UN NUEVO CANON DE MÚSICA RELIGIOSA. LA OPOSICIÓN A LA PROPUESTA DEL CONGRESO

1. La estrategia regeneracionista del Congreso: "por vía de modelo y ejemplo" 499

1.1. La interpretación modélica del canto gregoriano 501

1.2. Intérpretes de música religiosa propuestos por el Congreso como ejemplares $\quad 509$

1.3. La función de la prensa en un escenario ideal $\quad 519$

2. El congreso de Sevilla, una manifestación del nacionalismo musical español en el ámbito religioso

2.1. La institucionalización de un nuevo canon musical religioso: entre el

Motu Proprio y los postulados del nacionalismo musical español

2.1.1. Polifonía clásica: la sustitución de los modelos romanos por los autóctonos

2.1.2. Música religiosa moderna: el supuesto éxito del programa regeneracionista

2.2. Canto popular religioso: la omnipresencia de las ideas del nacionalismo musical español

2.3. El intento de exaltación de la figura de Pedrell y su significación para el joven movimiento reformista

2.4. La confrontación de dos identidades musicales. Francisco Guerrero versus Hilarión Eslava: el estallido de una guerra de símbolos

3. La polémica en torno a Eslava tras el congreso de Sevilla: identidad consolidada versus identidad en proyecto

CONCLUSIONES

RELACIÓN DE FUENTES

BIBLIOGRAFÍA

APÉNDICES

Apéndice 1. Mapa de la archidiócesis de Sevilla en 1909

Apéndice 2. Circulares y otros documentos sobre música sagrada publicados en el Boletín Oficial del Arzobispado de Sevilla entre 1904 y 1910

2. 1. Pontificado del arzobispo Marcelo Spínola y Maestre

2. 2. Pontificado del arzobispo Enrique Almaraz y Santos

Apéndice 3. Documentos relacionados con la petición de dispensa en la aplicación del Motu Proprio para el caso del Miserere de Eslava

3. 1. Relación cronológica de los principales documentos 
3. 2. Transcripción de la solicitud elevada por el arzobispo Marcelo Spínola y Maestre a Pío X

Apéndice 4. Síntesis del Reglamento de música sagrada para la Archidiócesis de Sevilla

Apéndice 5. Transcripción de los inventarios musicales estudiados

5. 1. Inventario 1: Índice de las Obras que existen en el Archivo musical de esta Santa Iglesia

5. 2. Inventario 2: Catálogo de Obras musicales

683

5. 3. Inventario 3: Archivo musical de Scalas

Apéndice 6. Relación de obras compuestas por Vicente Ripollés para la catedral de Sevilla, conservadas en su archivo musical

Apéndice 7. Cartas en las que se informa sobre las clases de canto gregoriano de preparación al Congreso

Apéndice 8. Transcripción del borrador en castellano de la petición dirigida al papa de constitución de un Tribunal superior nacional para la censura de la música sagrada

Apéndice 9. Programas del II Congreso Nacional de Música Sagrada 709

9. 1. Programa general $\quad 709$

9. 2. Programas de los conciertos de órgano 711

9. 2. 1. Programa inicial 711

$\begin{array}{ll}\text { 9. 2. 2. Programa definitivo } & 712\end{array}$

9. 3. Programa del concierto de música vocal religiosa 713

9. 4. Programa del concierto ofrecido por la Capilla Isidoriana en el Teatro San Fernando 

C1Bnt

\section{AGRADECIMIENTOS}

Quiero expresar mi gratitud, en primer lugar, a la Dra. Gemma Pérez Zalduondo, directora de esta tesis, por su apoyo y su confianza en mí, por su disponibilidad y paciencia ante mis dudas e inseguridades, por descubrirme las claves para encontrar soluciones en los momentos menos lúcidos.

Conste mi agradecimiento a todas aquellas personas que me han facilitado la labor en los centros donde he desarrollado mi trabajo de búsqueda de información: a Nuria Casquete de Prado Sagrera, Isabel González Ferrín y al atento y diligente equipo de la Institución Colombina; a las amables y solícitas Olatz Berasategi Olazábal y Mertxe Marín Sanz, del Archivo y Biblioteca del Santuario de Loiola; a Marco Grilli, secretario de la Prefectura del Archivo Secreto Vaticano; a Vanessa Torres y demás integrantes del Servicio de Información y Referencia de la Biblioteca de Catalunya. Gracias al personal de la Biblioteca del Seminario Metropolitano de Sevilla, Hemeroteca Municipal de Sevilla, Hemeroteca de El Correo de Andalucía; de las bibliotecas General, de Humanidades, del departamento de Historia del Arte, de Historia Contemporánea de la Universidad de Sevilla, en especial a María Covadonga LucioVillegas Menéndez; de la Biblioteca de la Facultad de Filosofía y Letras de la Universidad de Granada, de la Biblioteca de Andalucía, del Centro de Documentación Musical de Andalucía y a su director, Reynaldo Fernández Manzano

Gracias a Francisco José Sánchez García, Francisco Javier López Fernández, María del Carmen Guerrero Picó, Alejandro Pastor del Castillo, Julia Esther García Manzano, por poner generosamente a mi disposición sus conocimientos, capacidades, tiempo y energias. Gracias a todos aquellos con los que he ido aprendiendo a dilatar el corazón.

Esta tesis no hubiera sido posible sin el incondicional apoyo de mis padres, a quienes no sé si hay algo que no les deba, de mis hermanos y mi tía; sin la heróica paciencia y edificantes lecciones de mis hijos, alegría y luz de mis días, razones de mi resistencia; sin Elena, por ella, para ella, con ella, gracias a ella. 



\section{CONSIDERACIONES PRELIMINARES}

- En la transcripción de documentos se ha normalizado la ortografía según los usos actuales del castellano, excepto en algunos casos, en los que se indica pertinentemente.

- Aquellas abreviaturas de difícil comprensión presentes en los textos manuscritos se han desarrollado para facilitar la lectura.

- Las referencias bibliográficas a pie de página se presentan abreviadas a partir de la segunda vez que aparecen. Se indican sólo apellido del autor y primeras palabras del título de la obra cuando es excesivamente extenso. Este criterio no se sigue en aquellos casos en los que pudiera dar lugar a confusión; por ejemplo, cuando distintos artículos tienen un mismo título, y son o bien anónimos o de un mismo autor. En alguna ocasión hemos considerado oportuno volver a presentar la referencia completa si han transcurrido varios capítulos desde su primera aparición.

- Se ha usado cursiva en la escritura de los extranjerismo, excepto en aquellas palabras o expresiones no castellanas de uso común contenidas en el Diccionario de la Real Academia Española. Las expresiones que hemos acuñado (“canon Eslava”, “espacio artístico-social”) se presentan entre comillas. 



\author{
ABREVIATURAS \\ AC Actas Capitulares \\ ACS Archivo de la catedral de Sevilla \\ ADC Autos de la Diputación de Ceremonias \\ AMSL Archivo Musical "Nemesio Otaño" del Santuario de Loyola \\ ASV Archivio Segreto Vaticano. \\ AA.VV. Autores varios \\ BC Biblioteca de Catalunya \\ BdC Boletín del Congreso. Revista quincenal litúrgico musical, órgano del \\ congreso. \\ CDMS Comisión Diocesana de Música Sagrada \\ ca. $\quad$ circa \\ cit. citado \\ coord./coords. coordinado, coordinador/ coordinadores \\ dir./dirs. dirigido, director/directores \\ DMEH Emilio Casares Rodicio, ed., Diccionario de la Música Española e \\ Hispanoamericana, 10 vols. Madrid: SGAE, 1999-2003. \\ ECA: $\quad$ El Correo de Andalucía. Diario católico de noticias. \\ ed./eds. $\quad$ editado, editor/editores \\ ENS El Noticiero Sevillano. Diario independiente de noticias, avisos y \\ anuncios. \\ exp. expediente \\ FFP Fondo Felip Pedrell \\ FO Fondo Otaño \\ fol./fols. folio/folios \\ gr. graves [voces]
}




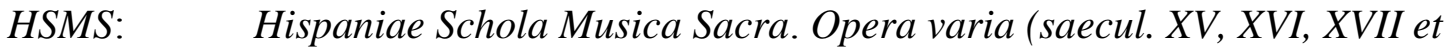
XVIII) diligenter excerpta, accurate revisa, sedulo concinnata a Philippo Pedrell, 8 vols. Barcelona: Juan Bautista Pujol y Cía., 1894-1898.

Imp. Imprenta

LCD La Ciudad de Dios. Revista quincenal, religiosa, científica y literaria dedicada al gran padre San Agustín y publicada por los PP. Agustinos de El Escorial.

leg. legajo

LSH Lira Sacro-Hispana. Gran colección de obras de música religiosa, compuesta por los más acreditados maestros Españoles, tanto antiguos como modernos: publicación que se hace bajo la protección de S. M. la Reina $D^{a}$ Isabel II, (Q.D.G.) y dirigida por Hilarión Eslava, Maestro de su Real Capilla, 10 vols. Madrid: Martín Salazar, 1852-1860.

m. mixtas [voces]

MP Pío X, Motu proprio "Tra le sollecitudini”, 1903.

MSH: $\quad$ Música Sacro-Hispana. Revista mensual litúrgico-musical, órgano de los congresos españoles de música sagrada [A partir de junio de 1909, segunda época, sólo Música Sacro-Hispana]

s. d. $\quad$ sin indicación de día

S.E.R. Su Excelencia Reverendísima [frecuente en las fuentes originales]

s. f. $\quad$ sin indicación de fecha

s. p. $\quad$ sin paginar

s. $\quad$ siglo

s.e. $\quad$ sin indicación de editorial.

sign. signatura

Ss. $\quad$ siguientes

U. Usted [frecuente en la correspondencia]

V. Usted [frecuente en la correspondencia]

v. $\quad$ voces

vol./vols. volumen/volúmenes 


\section{INTRODUCCIÓN}

El conjunto de preceptos y disposiciones legales contenidas en el Motu Proprio "Tra le sollecitudini" de Pío X constituyó, probablemente, el intento de regulación de la música sacra católica más importante emprendido por el papado desde el Concilio de Trento $^{2}$. Tras su promulgación se fueron inaugurando en las distintas Iglesias locales procesos particulares para la adecuación de sus realidades litúrgico-musicales a las nuevas directrices romanas. La responsabilidad de su implementación recayó sobre la administración diocesana, con el obispo a la cabeza.

Durante la primera etapa de estos procesos, las autoridades eclesiásticas locales debieron acoger el documento pontificio como marco legal básico, y desarrollar a partir de él sus propias normativas de acuerdo a las características y circunstancias específicas de sus diócesis. Nuestro estudio se ubica en este momento de recepción y concreción del Motu Proprio (MP) en forma de proyectos reformistas diocesanos.

Tal y como se planteó en el rescripto papal, la reforma de la música sagrada se abordó desde una perspectiva legal, y se contempló como un deber pastoral, que, desde el momento en el que se categorizaron determinados lenguajes y expresiones musicales como "sagradas" o "profanas", estuvo ligado indefectiblemente a un criterio estético. Sin embargo, en ocasiones, la música de uso litúrgico se integra en solemnidades de un particular significado para la sociedad local, pudiendo trascender su mera función al servicio del culto y convertirse, al igual que aquellas, en una expresión cultural y

1 En el epígrafe 0. "Breve introducción al Motu Proprio" nos detenemos a pormenorizar las características del documento y sus antecedentes.

${ }^{2}$ Junto al Motu Proprio de Pío X, los pronunciamientos más destacados del papado respecto a la música desde la Edad Media hasta el s. XX son la bula Docta Sanctorum de Juan XXII (1325) y la encíclica Annus qui (1749) de Benedicto XIV. En Valentino Donella, Musica e liturgia. Indagini e Riflessioni Musicologiche (Bergamo: edizioni Carrara, 1991), pp. 377-381 se puede encontrar el texto íntegro de Juan XXII, y un resumen del escrito de Benedicto XIV, en latín y en traducción italiana. Nemesio Otaño incluye ambos traducidos al castellano en La Música Religiosa y la Legislación Eclesiástica (Barcelona: Musical Emporium, 1912). 
simbólica. Desde esta premisa, la reforma no reduciría su impacto a la esfera litúrgica, sino que se ubicaría en unas coordenadas en donde confluyen la liturgia y el hecho religioso entendido como cultura. Esta tesis pretende dirigir su mirada a este punto de confluencia, y contempla el texto del $M P$ no sólo como un código jurídico, una iniciativa pastoral o un tratado estético, sino también como el producto de una determinada mentalidad que entra en contacto con el universo cultural que lo recibe. Las instituciones eclesiásticas dejan de constituir estructuras administrativas para pasar a ser observadas, además, como comunidades histórico-culturales y ámbitos de contraste ideológico.

A otro espacio de recepción y asimilación del $M P$ como propuesta sustentada en unas determinadas bases ideológicas y estéticas hemos de referirnos: el que configuraron aquellas tendencias de pensamiento y corrientes de acción que en torno a la música española se fueron definiendo en las últimas décadas del s. XIX y principios del s. XX. La dialéctica entre la dimensión local y la general española caracteriza, en gran medida, el discurso que desarrollamos en este estudio.

En el caso sevillano, dos acontecimientos definen con nitidez el periodo inaugural de la reforma. Por un lado, la promulgación del MP el 22 de noviembre de 1903, cuyo texto fue dado a conocer en el Boletín Oficial del Arzobispado de Sevilla $(B O A S)$ el 15 de enero de $1904^{3}$. Por otro, la publicación del Reglamento de la Música Sagrada de la Archidiócesis de Sevilla a partir del 2 de mayo de 1910 4 . Ambos hitos articulan y definen como puntos inicial y final el proceso hispalense en su primera etapa. Constituyen, por tanto, las acotaciones temporales de nuestra investigación. Tras la aparición del Reglamento de la Música Sagrada, las referencias a la cuestión de la reforma de la música presentes en fuentes como el propio BOAS o los libros de actas capitulares, por citar sólo aquellas que proporcionan gran parte de la información sobre la actividad de las principales instituciones diocesanas -administración arzobispal y cabildo catedralicio-, son extraordinariamente escasas en comparación con la abundancia de datos que en estos apenas seis años y medio ofrecen. De ello se infiere que el Reglamento significó el producto final de todo el proceso.

\footnotetext{
3 “Otro [Motu Proprio] acerca de la música sagrada", BOAS, 534 (1904), pp. 13-27.

${ }^{4}$ Aparece también como Reglamento del Canto Sagrado en la Archidiócesis de Sevilla. Fue publicado en tres entregas: "Circular de Ntro. Excmo. Prelado y Reglamento de Música Sagrada para esta Diócesis" $B O A S, 690$ de 2 de mayo (1910), pp. 451-461; "Reglamento de Música Sagrada (continuación)", BOAS, 691 de 16 de mayo (1910), pp. 562-567; "Reglamento de la Música Sagrada (conclusión)", BOAS, 692 de 1 de junio (1910), pp. 571-577.
} 
Este periodo transcurrió entre los pontificados de Marcelo Spínola y Maestre (1896-1906) y Enrique Almaraz y Santos (1907-1920), separados por un interregno que duró unos veintidós meses. Los márgenes temporales que nos hemos impuesto son rebasados cuando es necesario indagar en los orígenes de algún aspecto relevante del proceso, o seguir sus consecuencias inmediatas para comprender toda su dimensión y proyección futura.

\section{Planteamiento}

Nuestro planteamiento inicial ha consistido en el análisis de la gestión llevada a cabo por la Iglesia católica como institución con el fin de transformar una realidad litúrgico-musical estimada por sus principales responsables como reprobable y condenable ${ }^{5}$.

La estructura de la institución que pretendemos estudiar se puede describir de forma sintética y útil para nuestros propósitos en los siguientes términos. En principio, habría que distinguir entre dos grandes niveles de decisión: la administración central romana, que gobierna para la Iglesia universal, por un lado; y las administraciones diocesanas, por otro. A la cabeza de este organigrama piramidal se sitúa el papa, quien, de acuerdo a la potestad que le confiere su condición de máxima autoridad de la Iglesia católica, promulgó el que él mismo denominó “Código jurídico de la música sagrada" Con el $M P$ pretendió dar solución a una situación indeseada, y responder, además, a "las muchísimas quejas que de todas partes" le habían sido dirigidas desde que, tan sólo tres meses y medio antes, accedió al solio pontificio ${ }^{7}$.

\footnotetext{
${ }^{5}$ Una vez puesto de relieve la mejora que había experimentado la música sagrada "durante los últimos decenios en nuestra ilustre ciudad de Roma y en multitud de iglesias de nuestra patria; pero de modo particular en algunas naciones," el texto continua: "creemos que nuestro primer deber es levantar la voz sin más dilaciones en reprobación y condenación de cuanto en las solemnidades del culto y los oficios sagrados resulte disconforme con la recta norma indicada." MP. [Exposición de motivos previa a la Instrucción legal].
}

${ }^{6} M P$. [Exposición de motivos previa a la Instrucción legal]. El texto del MP "Tra le sollecitudini" utilizado a lo largo de todo el trabajo ha sido la versión electrónica en su traducción castellana disponible en la web de la Santa Sede. Al ser el documento fundamental y generador de todo el proceso de reformas objeto de nuestro estudio ha sido continuamente consultado desde el comienzo de nuestro trabajo hasta la conclusión del mismo. Por ello, hemos considerado innecesario especificar los días exactos de consulta en las diferentes citas. <http://www.vatican.va/holy_father/pius_x/motu_proprio/documents/hf_px_motu-proprio_19031122_sollecitudini_sp.html.> [la versión digital no está paginada]

${ }^{7}$ Pío X aludía, además de a las "quejas" recibidas, a su "personal experiencia": "Pero aún dista mucho este bien de ser general, y si consultamos nuestra personal experiencia y oímos las muchísimas quejas que de todas partes se nos han dirigido en el poco tiempo pasado desde que plugo al Señor elevar nuestra humilde persona a la suma dignidad del apostolado romano, creemos que nuestro primer deber es levantar la voz sin más dilaciones en reprobación y condenación de cuanto en las solemnidades del culto y los 
La Sagrada Congregación de Ritos era el órgano vaticano responsable de las cuestiones relacionadas con la liturgia, por tanto, también con la música. De acuerdo con el papa y la tradición, en sus decretos y otros documentos emitía disposiciones y desarrollaba preceptos, así como despejaba las dudas que podían suscitar su aplicación concreta. Fue esta congregación la que, por mandato de Pío X, ordenó el cumplimiento del $M P$ como ley universal de la Iglesia y derogó cualquier privilegio anterior ${ }^{8}$.

En el ámbito diocesano, el obispo era el principal responsable de la aplicación de la instrucción sobre música, por tanto, bajo su gobierno se gestionaba la reforma. Una de las principales novedades que trajo consigo el $M P$ fue la creación de un nuevo órgano a acomodar en el seno de la estructura administrativa diocesana, la Comisión Diocesana de Música Sagrada (CDMS). Según se disponía en el documento papal, estas comisiones tenían la misión de "vigilar cuanto se refiere a la música que se ejecuta en las iglesias"9.

En el último eslabón de este orden jerárquico se encontraban aquellos que por encontrarse en contacto directo y cotidiano con la realidad musical concreta tenían la obligación de poner en práctica, respetar, y hacer respetar los mandatos papales y las disposiciones episcopales. Este grupo lo componían superiores y directores de institutos y comunidades religiosas, así como párrocos y rectores de iglesias. En nuestro texto nos referimos a todos estos colectivos bajo la denominación genérica de "administradores de templos". Los canónigos catedralicios no han sido incluidos en dicho grupo por varias razones. En primer lugar, como alta jerarquía eclesiástica formaban parte de los órganos de decisión y gestión diocesanos. En segundo lugar, debido a su excepcional relevancia en todos los sentidos, el templo que gobernaban poseía una casuística particular, diferente a la del resto.

El MP no otorgó a los músicos al servicio de las iglesias poder de decisión alguno, por tanto, debían someterse a la autoridad de los administradores de templos. Si alguno de aquellos asumió en algún momento determinadas responsabilidades directivas

oficios sagrados resulte disconforme con la recta norma indicada." MP. [Exposición de motivos previa a la Instrucción legal]. <http://www.vatican.va/holy_father/pius_x/motu_proprio/documents/hf_p-x_motuproprio_19031122_sollecitudini_sp.html.> (consultado de forma recurrente).

${ }^{8}$ Decreto de la Sagrada Congregación de Ritos de 8 de enero, publicado bajo el título de "Orbis et orbis" en el BOAS, 535 (1904), pp. 97-98.

9 MP. Título VIII. Medios principales, art. 24. [versión digital no paginada] $<$ http://www.vatican.va/holy_father/pius_x/motu_proprio/documents/hf_p-x_motuproprio_19031122_sollecitudini_sp.html.> 
no fue en su condición de músico eclesiástico sino por otras razones. Su categoría laboral no era más que la de mero empleado al servicio de la institución.

Con el avance de nuestra investigación y la consiguiente profundización en el conocimiento de nuestro objeto de estudio, el planteamiento puramente institucional de partida ha ido paulatinamente revelándose como insuficiente. Desde el primer contacto con las fuentes es posible hallar signos de resistencia a la implementación de las reformas. Estos indicios insinúan algo que, por otra parte, resulta razonable considerar como inherente a procesos de estas características si aceptamos el supuesto de que toda reforma se sustenta en un cuestionamiento de una realidad, susceptible o necesitada de mejora o rectificación, e implica una aspiración a superarla. La reducción de la escala de observación que va aparejada a la traslación del punto de mira de la administración general diocesana a la Catedral pone al descubierto las actitudes y disposiciones ante la reforma adoptadas por los personajes que daban vida a la institución. En este nuevo marco de análisis emerge con mayor nitidez uno de los elementos, el factor humano, conformantes de una dialéctica presente durante todo nuestro estudio: agente, por un lado, e institución como estructura histórica, por otro.

Todo ello ha hecho madurar un cambio de concepción y orientación. El estudio de un proceso de aplicación normativa y de gestión institucional se ha tornado en análisis e interpretación de un conflicto de mentalidades, que se manifiestan en sus posicionamientos a favor -reformistas- o en contra de la reforma -conservadores del statu quo-. Este nuevo planteamiento, en el que se contempla la noción de conflicto, se refuerza y justifica por varias razones, ligadas entre sí, además de las ya expuestas. En primer lugar, el carácter impositivo del texto papal, dada su naturaleza legal de obligado cumplimiento. En segundo lugar, el hecho de que la reforma sea promovida por una institución -el papa y la administración central de la Iglesia- que, aunque superior, es externa a aquella que la debe implantar -la diócesis-. Por último, la ley eclesiástica sobre música es portadora de unos principios litúrgicos y estéticos que no tienen que ser necesariamente compartidos por la organización y cultura receptoras. Nuestro estudio requiere, en consecuencia, una perspectiva cultural más amplia, que trascienda, aunque la incluya, la visión de la problemática derivada del MP como una cuestión meramente legal, litúrgica o estética.

Algunas de las consideraciones derivadas del examen de la reforma en Sevilla nos servirán como punto de partida para el análisis y la reflexión sobre el II Congreso Nacional de Música Sagrada. En él convergen, por un lado, la dimensión local y la 
general española; y por otro, la administración eclesiástica diocesana y el movimiento español para la reforma de la música sagrada, dos dimensiones que conviene diferenciar, aunque estén relacionadas y, en ocasiones, imbricadas. Contemplaremos el Congreso no sólo como una gran convocatoria para coordinar esfuerzos y allanar el camino a la instauración de unos nuevos principios musicales religiosos, sino también como un espacio en el que se desplegaron discursos ideológicos y estéticos, reflejos de determinadas corrientes de pensamiento y acción que pretendieron en aquel contexto orientar el sentido de la evolución de la música española en términos generales.

\section{Estado de la cuestión}

La música en el ámbito de una institución eclesiástica, generalmente una catedral, ha sido uno de los temas que más interés ha suscitado entre los investigadores $^{10}$. En la musicología hispana, el corpus compuesto por las numerosas monografías publicadas sobre la música en catedrales representa un importante patrimonio de conocimiento y experiencia, a pesar de lo que queda aún por hacer. Como se ha puesto de manifiesto en varias ocasiones, el trabajo de José López-Calo sobre la catedral de Granada en el siglo XVI marcó un punto de inicio para estos estudios $^{11}$. El tipo de aproximación a la institución catedralicia desarrollada en esta obra y el método empleado ${ }^{12}$, se convirtió en paradigma para trabajos posteriores tanto del propio López-Calo como de otros autores.

\footnotetext{
${ }^{10}$ Hace ya algunos años, María Gembero Ustárroz, trasladando las apreciaciones de Nicholas Temperley sobre el caso inglés al español, ponía el acento en la escasa atención que los especialistas han dedicado a la música sacra en instituciones religiosas de menor rango, entre ellas, las parroquias o conventos. "El patronazgo ciudadano en la gestión de la música eclesiástica: la Parroquia de San Nicolás de Pamplona (1700-1800)", Nassarre, XIV/1 (1998) [separata], pp. 269-362, p. 269. Un reciente estado de la cuestión sobre los estudios consagrados a la música en parroquias en: Victoriano J. Pérez Mancilla, "Historiografía musical de las parroquias en España: estado de la cuestión”, Anuario Musical, 68 (2013), pp. 47-80. Sobre música en conventos femeninos, véase, entre otros, los trabajos de María Julieta Vega García: La música en los conventos de clausura femeninos de Granada (Granada: Universidad de Granada y Junta de Andalucía, 2005); o Colleen Baade, "Two Centuries of Nuns Musicians in Spain's Imperial City", TRANS-Revista Transcultural de Música, 15 (2011). $<\mathrm{http} / / /$ www.sibetrans.com/trans/public/docs/trans_15_03_Baade.pdf $>$ (consultado 4-11-13).

${ }^{11}$ José López-Calo, La música en la catedral de Granada en el siglo XVI, 2 vols. (Granada: Fundación Rodríguez Acosta, 1963).

${ }^{12}$ Juan José Carreras lo denominó "modelo institucional puro". Juan José Carreras, "Música y ciudad: de la historia local a la historia cultural", en: Música y cultura urbana en la Edad Moderna, ed. por A. Bombi, Juan J. Carreras y Miguel A. Marín (Valencia: Universitat de València, 2005), pp. 17-52, p. 33.
} 
Desde entonces, los diversos estudios que se han ido realizando han supuesto un enorme avance en todos los sentidos ${ }^{13}$. Las reflexiones sobre la historiografía musical catedralicia en España, aparecidas a modo de revisiones críticas en las últimas dos décadas, han subrayado y contemplado con satisfacción la evolución que este campo de la investigación musicológica ha experimentado en cuanto a adopción de nuevas metodologías, así como al desarrollo de novedosas perspectivas de estudio ${ }^{14}$. Emilio Ros-Fábregas destacaba en 1998 la labor realizada en sus respectivas tesis doctorales por María Gembero y Pilar Ramos, como ejemplos de una "nueva generación de jóvenes musicólogos”. Ambas presentaban sendos tomos con música inédita, por un lado; y el contexto cultural e histórico de la ciudad en la que se incardinaba la institución catedralicia, por otro ${ }^{15}$. Juan José Carreras sometía a crítica el modelo institucional que presenta a la catedral aislada del espacio urbano en la que estaba inserta, entendiendo tal espacio según las nuevas tendencias historiográficas enmarcadas en la nueva historia cultural. En cambio, proponía el estudio de Miguel

${ }^{13}$ En Emilio Ros-Fábregas, "Historiografía de la música en las catedrales españolas: nacionalismo y positivismo en la investigación musicológica”, CODEXXI. Revista de la comunicación musical, 1 (1998), pp. 68-135 se puede consultar una extensa "Bibliografía musicológica sobre catedrales españolas (15001800)", pp. 96-135, cuyos ítems están clasificados por ciudades. A este listado habría que incluir, entre otros, los siguientes estudios monográficos, dedicados a instituciones eclesiásticas pertenecientes a la provincia eclesiástica hispalense, y realizados con posteridad a la fecha de publicación del citado artículo: Herminio González Barrionuevo, Francisco Guerrero (1528-1599): vida y obra: la música en la Catedral de Sevilla a finales del siglo XVI (Sevilla: Cabildo Metropolitano de la Catedral de Sevilla, 2000); Rosa Isusi Fagoaga, La música en la Catedral de Sevilla en el siglo XVIII: la obra de Pedro Rabassa y su difusión en España e Hispanoamérica (Granada: Universidad de Granada, 2003); Marcelino Diez Martínez, La música en Cádiz: la Catedral y su proyección urbana durante el siglo XVIII (Cádiz: Universidad de Cádiz, 2004); Francisco Javier Lara Lara, El canto llano en la Catedral de Córdoba (Granada: Universidad de Granada, 2004); Juan María Suárez Martos, Música Sacra Barroca en la Catedral Hispalense: Los maestros del siglo XVII. Tesis doctoral inédita, Universidad de Sevilla (2007); Juan Ruíz Jiménez, La librería de Canto de Órgano: Creación y pervivencia del repertorio del Renacimiento en la actividad musical de la catedral de Sevilla (Granada: Consejería de Cultura, 2007); Rosario Gutiérrez Cordero, La música en la Colegiata de San Salvador de Sevilla (Granada: Centro de Documentación Musical de Andalucía, 2008); el conjunto de estudios incluidos en Antonio GarcíaAbásolo, coord., La música de las catedrales andaluzas y su proyección en América (Córdoba: Universidad de Córdoba. Obra Social y Cultural Cajasur, 2010); Rafael Jesús Luque Vela, Los repertorios de canto llano para las fiestas de los santos patronos hispalenses. Tesis doctoral inédita, Universidad de Sevilla (2012); José Sánchez Herrero, ed., La Música Coral del Cabildo Catedral de Sevilla durante el siglo XVII. Estudio musicológico y analítico (Sevilla: Universidad de Sevilla, 2013).

14 Véanse Ros-Fábregas, "Historiografía de la música"; Xosé Manuel Carreira, "La visión congelada: Autarquía y fideísmo en la historiografía musical de las catedrales", disponible en $<$ http://www.mundoclasico.com/ed/documentos/doc-ver.aspx?id=0003746> $\quad$ (consultado 2-11-13); Carreras, "Música y ciudad", pp. 17-52.

${ }^{15}$ Ros Fábregas; "Historiografía de la música”, p. 80. 
Ángel Marín sobre la catedral de Jaca" como ejemplo de una "alternativa historiográfica a los tradicionales estudios catedralicios" en la que la "institución dejaba de ser así una especie de nave espacial posada en el entorno urbano para integrarse en una compleja trama institucional de conventos y cofradías, de rituales festivos y representativos $[\ldots]^{, 17}$.

Sin embargo, este extraordinario aporte musicológico e historiográfico se ha circunscrito, salvo excepciones, a la Edad Moderna ${ }^{18}$. La acotación temporal del seminario celebrado en Ávila en 1996, "La Catedral como institución musical (15001800)" es bastante significativa ${ }^{19}$. Las causas que explicarían el enorme contraste existente entre la intensa dedicación de los investigadores al estudio de la música en las instituciones eclesiásticas de la Edad Moderna y el desinterés predominante en la Edad Contemporánea pueden ser múltiples, y su dilucidación difícilmente abordable en unas pocas páginas. No obstante, y al margen de otras razones posibles, el drástico cambio

${ }^{16}$ Miguel Ángel Marín, Music on the margin. Urban musical life in eighteenth-century Jaca (Spain), (Kassel: Reichenberg, 2002).

17 Carreras, "Música y ciudad", pp. 35-36. El recientemente publicado Clara Bejarano Pellicer, El mercado de la música en la Sevilla del Siglo de Oro (Sevilla: Universidad de Sevilla, 2013), se encarga de estudiar la música en otras instituciones del entorno urbano menos atendidas.

${ }^{18}$ Entre esas excepciones hay que destacar la monografía de Victoria Cavia Naya, La vida musical en la Catedral de Valladolid en el siglo XIX (Valladolid: Diputación Provincial de Valladolid, 2004). Véanse, además: M a Antonia Virgili Blanquet, "La música en el siglo XIX español”, en La música española en el siglo XIX, ed. por Emilio Casares Rodicio y Celsa Alonso González (Oviedo: Universidad de Oviedo, 1995), pp. 375-405; los capítulos XXV (música vocal) y XXVI (música instrumental), dedicados al s. XIX de José López-Calo, La música en las catedrales españolas (Madrid: ICCMU, 2013), pp. 595-656; José Martín González, "Oposiciones al magisterio de capilla de la Catedral de Valladolid durante el siglo XIX", Revista de Musicología (Actas del III Congreso Nacional de Musicología "La música en la España del s. XIX”), XIV/1-2 (1991), pp. 511-534; Ma Pilar Barrios, "La música en la catedral de Coria (Cáceres) durante el magisterio de capilla de Francisco Bernal (1814-1823)", ibídem, pp. 535-548; José Ignacio Palacios Sanz, "Aproximación histórica a la capilla de música en la Catedral de Burgo de Osma durante el siglo XIX. De Bernardo Pérez al 'Motu Proprio"”, ibídem, pp. 549-560; Germán Tejerizo Robles, "La música en la Capilla Real de Granada desde 1800”, ibídem, pp. 561-582; "La estancia en Cuenca del organista Manuel María Caballero (1855-1860)", ibídem, pp. 583-596; Ma Pilar Barrios, "La transición del siglo XVIII al XIX en la Catedral de Coria (Cáceres). Magisterio de Juan José Bueno", Nassarre: Revista aragonesa de musicología, IX/2 (1993), pp. 193-195; Francisco Javier Garbayo Montabes, "La estancia del organista Joaquín Pedrosa en la catedral de Orense (1805-1835)", Porta da aira: revista de historia del arte orensano, 6 (1994-1995), pp. 99-111; del mismo autor, "El magisterio de la capilla de música de la Catedral de Ourense entre 1780 y 1819: José Quiroga y Manuel Rábago”, ibídem, 10 (2004), pp. 237-260; del mismo autor, "Las reformas de Mariano Tafall y otras intervenciones posteriores en los órganos del coro de la catedral de Ourense (1963-1924)", ibídem, 11 (2006), pp. 187-208; del mismo autor, "La viola en el ámbito eclesiástico hispano. La orquesta de la capilla de música de la catedral de Santiago y el uso de dos violas en la música de Melchor López (1783- 1822)", Anuario Musical, 62 (2007), pp. 229-255.

${ }^{19}$ El seminario fue organizado por la Fundación Cultural Santa Teresa de Ávila y el Departamento de Historia del Arte de la Universidad de Zaragoza, bajo la dirección de Juan José Carreras y la coordinación de Alfonso de Vicente. 
de estatus social, político y económico que experimentó la Iglesia tras la caída del Antiguo Régimen, y la consecuente crisis de recursos que hizo tambalear y, en muchos casos, tumbar las estructuras que sostenían la vida musical en sus principales instituciones -catedrales, colegiatas, parroquias importantes, etc.- es, seguramente, una de las principales.

El universo ideológico y nuevo orden social que emergieron como efecto de las ideas ilustradas primero y el idealismo romántico después, por un lado, así como de las revoluciones burguesas e industrial, por otro, configuraron un escenario radicalmente distinto, e influyeron en el pensamiento y la práctica musicales en todas sus vertientes. Un nuevo contexto -una nueva edad histórica- y un objeto de estudio transfigurado -la música- obligan a incorporar claves de interpretación distintas en la praxis investigadora. En el caso concreto de la música sacra en las últimas décadas del siglo XIX y primeras del XX, Ángel Medina apunta a unas nuevas circunstancias: la diversificación de los espacios religiosos que acogen la actividad musical, las limitaciones que en el estudio de esta época muestran los archivos de las instituciones eclesiásticas, el nuevo significado e importancia que adquiere tanto la prensa como la imprenta musical en la contemporaneidad. Una situación que exige la consideración de otros centros de documentación y otras fuentes, junto a los puramente eclesiásticos ${ }^{20}$.

Los estudios sobre el MP tampoco se han prodigado en demasía en comparación con otros temas. La consideración de la propuesta musical contenida en el documento papal como retrógrada y trasnochada en el contexto del modernismo musical de entresiglos ha constituido un hándicap a la hora de contemplar la reforma como un objeto de estudio atractivo $^{21}$. Francisco Javier Legasa ha formulado la posibilidad de considerar dicha propuesta como una suerte de modernismo de carácter historicista, una idea que situaría el programa estético del $M P$ en aquel contexto ${ }^{22}$. Sin embargo, el planteamiento de Legasa implicaría necesariamente reconocer en la cuestión musical

\footnotetext{
${ }^{20}$ Ángel Medina Álvarez, "La música en el templo tras el Motu Proprio de San Pío X: una mirada desde los archivos de la Iglesia", Memoria ecclesiae (Actas del XXI Congreso de la Asociación de archiveros de la Iglesia en España), 31 (2008), ed. por Agustín Hevia Ballina, pp. 21-44, pp. 21-22.

21 "Modernismo musical" en el sentido conceptual y de época propuesto por Carl Dalhaus en "Die Musik des 19. Jahrhunderts", Neues Handbuch der Musikwissenschaft, vol. 6 (Wiesbaden: Laaben, 1980).

${ }^{22}$ Francisco Javier Legasa adopta el concepto de "modernismo historicista" propuesto por Walter Fisch para entender la música compuesta según las directrices del MP. "Bonifacio Iráizoz (1883-1951) y el modernismo musical en el contexto del Motu Proprio", Principe de Viana (Ejemplar dedicado a: Conmemoración del VIII Centenario de la Chantría de la Catedral de Pamplona como dignidad eclesiástica (1206-2006)), coord. por María Gembero Ustárroz, 238 (2006), pp. 675-693.
} 
una excepción dentro de los posicionamientos abiertamente antimodernistas defendidos por la Iglesia católica en esos momentos ${ }^{23}$. Los principios estéticos del MP podrían ubicarse igualmente en otras tendencias contemporáneas, al menos en el caso español, como son el regeneracionismo musical, en el que los componentes historicista y esencialista presentes en sus tesis casarían a la perfección con la propuesta romana ${ }^{24}$. Más abajo nos referiremos a las consideraciones que al respecto hacen Antonia Virgili o María Nagore en sus trabajos.

Por otra parte, es frecuente en los estudios sobre música durante el s. XIX destacar el acusado declive económico sufrido por la Iglesia a lo largo del siglo, y la emergencia de nuevos y prometedores espacios de producción y práctica musicales en el ámbito civil. En estas circunstancias los cargos musicales de las instituciones eclesiásticas dejaron de ser los más codiciados. La situación de precariedad en términos de salario y de medios a disposición de los maestros de capilla estuvo lejos de ser resuelta o, al menos, atenuada, por las disposiciones del Concordato entre la Santa Sede y el Estado español de $1851^{25}$. Especialistas como Yvan Nommick han puesto de relieve, por un lado, el contraste existente entre el cada vez mayor éxito experimentado por la música religiosa destinada al concierto y el acusado declive de la música litúrgica; y por otro, que en el marco general de la Europa decimonónica, la creación e

\footnotetext{
${ }^{23}$ Pío X definió definitivamente la postura católica frente a las corrientes modernistas de pensamiento, incluidas las teológicas, en su encíclica Pascendi dominici gregis (1907).

${ }^{24}$ Más adelante proporcionamos bibliografía sobre el regeneracionismo musical español.

${ }^{25}$ Una visión sobre la situación de la música eclesiástica y sus estructuras en el contexto del s. XIX de gran impacto en la historiografía musical española en: Emilio Casares Rodicio, "La música en el siglo XIX español. Conceptos fundamentales", pp. 13-122; y M $\mathrm{a}^{\mathrm{a}}$ Antonia Virgili Blanquet "La música religiosa en el siglo XIX español”, pp. 375-405, ambos en La música española en el siglo XIX. ed. por Emilio Casares y Celsa Alonso (Oviedo: Universidad de Oviedo, 1995). El artículo $16^{\circ}$ del Concordato disponía que el personal al servicio de las catedrales - "dignidades, canónigos, beneficiados y capellanes"debían ser presbíteros, impidiendo de esta manera el acceso a los puestos musicales catedralicios de aquel personal laico que demostrara una mayor competencia y talento: "Así las dignidades y canónigos, como los beneficiados o capellanes, aunque para el mejor servicio de las respectivas catedrales se hallen divididos en presbiterales, diaconales y subdiaconales, deberán ser todos presbíteros, según lo dispuesto por Su Santidad; y los que no lo fueren al tomar posesión de sus beneficios, deberán serlo precisamente dentro del año, bajo las penas canónicas." Art. $16^{\circ}$ del Concordato celebrado entre Su Santidad, el Sumo Pontífice Pío IX y S. M. Católica Doña Isabel II, Reina de las Españas, en: Carlos Ramón Fort, El Concordato de 1851 comentado y seguido de un Resumen con las disposiciones adoptadas por el Gobierno de S. M. sobre materias eclesiásticas, desde la celebración de aquel convenio hasta enero de 1853 (Madrid: Imprenta y Fundición de Don José Aguado, 1853), p. 13.
} 
interpretación de la música en el templo no estaba siempre en las manos más cualificadas $^{26}$.

Junto a todo ello, una serie de ideas se han afianzado a la hora de configurar la imagen del MP. En primer lugar, la composición en base a sus preceptos ha dado lugar a una uniformidad estilística, e incluso, a una creación musical estandarizada, técnicamente correcta según los modelos musicales históricos recuperados -la polifonía clásica y la textura contrapuntística- aunque carente de inspiración, insulsa y mediocre. En segundo lugar, las restrictivas disposiciones contenidas en el documento papal han coartado la libertad creadora de los compositores. Si bien estas consideraciones serían válidas a la hora de valorar la producción de una buena parte del heterogéneo grupo de compositores que desarrollaron sus carreras en la órbita del $M P$, necesitarían ser matizadas y precisadas, y en algunos casos concretos, contrastadas ${ }^{27}$. A todo ello habría que sumar una última observación, repetida con frecuencia: la apreciación de la llamada "Generación del Motu Proprio" como una generación fracasada o "estafada" -término utilizado por Tomás Marco- al estimarse vanos todos sus esfuerzos de reforma y mejora de la música sagrada tras el importante golpe de timón dado por el Concilio Vaticano II a la liturgia católica ${ }^{28}$. Toda esta casuística, creemos, refleja la problemática de fondo: el $M P$ entendido como fenómeno histórico-artístico fue producto de una época en la que la Iglesia mantenía una difícil y, en ocasiones, conflictiva relación con la modernidad y el mundo contemporáneo, en el que no acababa de encontrar acomodo.

La celebración en 2003 de un simposio internacional sobre el MP, organizado por la Sociedad Española de Musicología, marcó un punto de inflexión, pues significó una alentadora oportunidad para promover y difundir las investigaciones sobre el tema. Las actas, publicadas al año siguiente, incluyeron los textos de veintisiete intervenciones, entre ponencias y comunicaciones. Esta obra colectiva sobe el MP

\footnotetext{
${ }^{26}$ Yvan Nommick, "Sobre las implicaciones del Motu Proprio de San Pío X en materia de composición musical", Revista de Musicología (Actas del Simposio Internacional "El Motu proprio de San Pío X y la Música (1903-2003)”), ed. por Mariano Lambea, XXVII/1 (2004), pp. 125-136, pp. 127-128.

${ }^{27}$ En este sentido se pronunciaba la Dra. Virgili en: "La música religiosa en el siglo XIX español", Revista Catalana de Musicología, 2 (2004), pp. 181-202, p. 192, insistiendo, además, en la necesidad de emprender nuevos estudios sobre la música y los compositores religiosos del s. XIX y de las primeras décadas del s. XX.

${ }^{28}$ Tomás Marco, aplicando la teoría de las generaciones en su Historia de la música española. 6. Siglo XX. (Madrid: Alianza Editorial, 1983) acuñó la expresión "Generación del Motu Proprio", pp. 103-112. El juicio de Marco es el siguiente: "[...] no se puede dejar de tener la sensación de que nos hallamos ante una generación que sacrificó su talento creador en una tarea a la postre inutilizada; una generación explotada si no simple y llanamente estafada.", p. 112.
} 
constituye la mayor contribución a su conocimiento hasta el momento ${ }^{29}$. Los trabajos presentados abordaron diversos aspectos: contexto y antecedentes de la reforma; propuesta estética contenida en el documento; implicaciones estilísticas y sobre el lenguaje musical; vida y obra de distintos compositores o personajes vinculados de una u otra manera con la reforma; consideraciones teológicas y magisteriales; canto gregoriano, polifonía clásica, y música para órgano. Sin embargo, tan sólo la comunicación presentada por Francisco Javier Garbayo Montabes acometió el estudio de la recepción de las disposiciones papales en una institución eclesiástica ${ }^{30}$. Esta circunstancia no deja de ser llamativa toda vez que el $M P$ era un texto, de naturaleza legal -independientemente de que fuera el reflejo de un determinado pensamiento estético, litúrgico y musical-, que pretendía impulsar un proceso de reformas cuya gestión se encomendó a diócesis y catedrales de forma particular.

En 2004 y 2008 aparecieron sendos artículos firmados por $\mathrm{M}^{\mathrm{a}}$ Antonia Virgili y Ángel Medina respectivamente, en los que se ofrecían interesantes reflexiones sobre el estado de la cuestión ${ }^{31}$. Al tiempo que subrayaban el camino que resta aún por recorrer para poder poseer un conocimiento más completo sobre el tema, sugerían futuras vías de investigación. La Dra. Virgili enumeraba una serie de actuaciones necesarias, entre las que incluía ampliar el conocimiento sobre la situación de las catedrales y "las posturas ideológicas de sus cabildos". Con este objetivo instaba a estudiar las obligaciones de los maestros de capilla, la evolución del gusto, la recepción en esas instituciones de las normativas eclesiásticas generales así como de las generadas por el propio centro

\footnotetext{
${ }^{29}$ Mariano Lambea, ed., “Actas del Simposio Internacional 'El Motu proprio de San Pío X y la Música (1903-2003)"”, Revista de Musicología, 17 (2004).

${ }^{30}$ Francisco Javier Garbayo Montabes, "Recepción e influencia del Motu Propio de San Pío X en la capilla de música de la catedral de Ourense: protagonistas y repertorio", Revista de Musicología, XXVII/1 (2004), pp. 313-334. Este artículo nos proporciona una visión general sobre los antecedentes del $M P$ en Galicia y su recepción en la diócesis de Orense, además de aportarnos interesantes datos sobre los músicos catedralicios que ejercieron su profesión a principios de siglo. Sin embargo, el interés de su autor a la hora de valorar el impacto que tendría el documento papal en la catedral orensana se centra, más que en el análisis de la gestión institucional de la reforma, en su incidencia en el repertorio catedralicio.

${ }^{31} \mathrm{M}^{\mathrm{a}}$ Antonia Virgili Blanquet, "La música religiosa en el siglo XIX español", Revista Catalana de Musicología, 2 (2004), pp. 181-202 [repetimos la referencia completa para evitar confusiones con la otra publicación de esta autora con el mismo título, aparecida en La música española en el siglo XIX. ed. por Emilio Casares y Celsa Alonso (Oviedo: Universidad de Oviedo, 1995)]; Medina Álvarez, "La música en el templo", pp. 21-44. La Dra. Virgili incluye como extensión del s. XIX la música religiosa de las primeras décadas del s. XX, es decir, la compuesta bajo el influjo del $M P$.
} 
(“estatutos, consuetas, etc.", a las que habría que añadir reglamentos, planes de reformas y otros), etc. ${ }^{32}$

Ángel Medina apuntaba, desde la clave de una revisión crítica de la labor realizada hasta ahora, sugestivas y, a nuestro juicio, atinadas consideraciones. Se refería a problemas derivados, por un lado, de una "falta de capacidad crítica" a la hora de manejar determinadas fuentes, como son las producidas por los grandes impulsores de la reforma en forma de libros, revistas o actas de los distintos congresos de música sagrada; y por otro lado, la no consideración por parte de los investigadores de otras fuentes, como las generadas por las propias instituciones eclesiásticas. La utilización de estas últimas permitiría confrontar la información que nos proporcionan las primeras ${ }^{33}$. En consecuencia, según Medina,

[...] los efectos del motu proprio de 1903 han sido tradicionalmente valorados por la teoría de los propios reformadores pero faltan por analizar los apoyos y rechazos que, de hecho, tuvo el motu proprio en la práctica cotidiana de la música en el seno de la iglesia española" 34 .

En un artículo posterior insistía en la necesidad de emprender estudios sobre la aplicación de la reforma desde la perspectiva institucional, y adoptar ante las fuentes disponibles la imprescindible distancia crítica para evitar aquellos discursos que, llevados por visiones parciales, trasladan una idea excesivamente optimista o favorable sobre la recepción del $M P$, así como sobre la efectividad de las medidas puestas en $\operatorname{marcha}^{35}$.

${ }^{32}$ Virgili, "La música religiosa en el siglo XIX español", Revista Catalana de Musicología, 2 (2004), p. 200 .

${ }^{33}$ Medina parte de la siguiente hipótesis: "la historia de la música sagrada de las primeras décadas del siglo XX no estará ni siquiera esbozada si no procedemos a confrontar las consignas de una teoría entusiasta con las realidades de los lugares donde, de hecho, se desarrolla habitualmente la música sagrada [subrayado original], desde las catedrales hasta las parroquias capaces de tener un coro, pasando por monasterios, colegiatas y seminarios" Medina, "La música en el templo", p. 22.

${ }^{34}$ Medina, "La música en el templo”, p. 26.

${ }^{35}$ El Dr. Medina apunta sin ambages en esa dirección. Tras referirse a los fallidos intentos reformistas emprendidos por el papado, como los de Juan XXII (Docta sanctorum, s. XIV) y Benedicto XIV (Annus qui, s. XVIII), afirma: "Sin embargo, la reforma de Pío X ha venido considerándose como algo distinto y muy alejado del papel mojado en que se convirtieron los textos reformistas anteriores. En nuestra consideración, se ha magnificado el alcance de la reforma sancionada por Pío X y, por tanto, es un tema que requiere una seria revisión." "La romería en el templo y otras licencias del canto gregoriano en el siglo XX”, Música oral del Sur, 8 (2009), pp. 11-23, p. 12. 
La necesidad de aproximación crítica a las fuentes, tanto a las generadas por los principales líderes del llamado movimiento de reforma de la música religiosa como por la propias instituciones; el aterrizaje en la cotidianeidad de la práctica -y nosotros añadiríamos, de la gestión, del pensamiento y de la significación cultural en sentido amplio- de la música; y la focalización del punto de mira en las instituciones eclesiásticas son ideas que hemos asimilado en nuestra práctica investigadora y en nuestra reflexión sobre los fenómenos que hemos sometido a estudio. El artículo del Dr. Medina es un ejemplo de utilización de fuentes procedentes de dichas instituciones y de verificación, desde la información que ofrecen, del alcance de las medidas reformistas puestas en marcha. Por su carácter panorámico, se puede asumir como punto de partida para estudios monográficos profundos sobre la gestión de la reforma en las distintas instituciones eclesiásticas del país.

Hasta ahora este tipo de estudios son muy escasos. Este déficit es paliado en parte por algunos artículos, así como por aquellas obras que consideran un periodo temporal más dilatado, y dedican algunas páginas o algún epígrafe al $M P$. Tales son los casos del capítulo dedicado a la música en El libro de la catedral de Granada, firmado por Antonio Martín Moreno; de la monografía de José Climent sobre la catedral de Valencia en el siglo XX; o la reciente publicación de José López-Calo, La música en las catedrales españolas ${ }^{36}$. El profesor Martín Moreno repasa la labor de aquellos maestros de capilla que debieron encargarse de la aplicación de las nuevas prescripciones musicales papales en la seo granadina, Celestino Vila de Forns, Rafael Salguero García y Valentín Ruíz-Aznar; proporciona interesantes apuntes sobre la recepción del Cabildo a las peticiones de participación cursadas por los organizadores de los dos primeros congresos nacionales de música sagrada; y destaca la posible influencia de la propuesta estética planteada por el $M P$ en los músicos del ámbito civil, incluido Manuel de Falla. José Climent suministra algunos datos interesantes sobre el intento de reforma en la catedral valenciana, aunque al tratarse de una obra que pretende abarcar la totalidad del s. XX, la atención dedicada al MP es necesariamente relativa. Sobre la reforma en la diócesis de Valencia ofrece interesante información Elena Micó Terol en su tesis Amancio Amorós Sirvent (1854-1925) y su proyección en la vida

\footnotetext{
36 Antonio Martín Moreno, "Cinco siglos de historia musical”, en El libro de la catedral de Granada, coord. por Lázaro Gila Medina (Granada: Cabildo Metropolitano de la Catedral de Granada, 2005), 2 vols., vol. 2, pp. 812-857. José Climent, La catedral de Valencia. Devenir musical en el siglo XX, (Valencia: Real Acadèmia de Cultura Valenciana, 2005); José López-Calo, La música en las catedrales españolas (Madrid: ICCMU, 2013).
} 
musical valenciana ${ }^{37}$. López-Calo escoge como "fuente básica [...] para resumir los profundos cambios experimentados por la música de las catedrales en este primer periodo del siglo XX" las actas capitulares de las catedrales de Palencia, Santiago y Jaén $^{38}$. Previamente recurre a la información que dispensan crónicas de congresos nacionales de música sagrada y revistas de música religiosa. Con estos documentos proporciona la versión de los principales líderes del movimiento reformista español, promotores de todo el aparato de divulgación -"vulgarización"- y propaganda del MP en España. El muestrario ofrecido por López-Calo puede servir también como punto de inicio para ulteriores estudios monográficos sobre las diócesis a las que pertenecen dichas catedrales, en los que se consideren, junto a las catedralicias, otras fuentes tales como las generadas por otras instituciones bajo la autoridad episcopal o por la propia administración central diocesana.

Entre los artículos dedicados a la acogida y consecuencias del $M P$ en instituciones habría que destacar la investigación realizada por María Sanhuesa sobre la recepción de la propuesta reformista y los resultados que su intento de aplicación tuvo en la capilla catedralicia y seminario conciliar ovetenses. Este trabajo posee el valor añadido de no confinar su análisis al interior de los muros de la catedral, y considerar, por el contrario, otras instituciones diocesanas como el propio seminario, algo ciertamente inusual $^{39}$.

Por otra parte, los posicionamientos a favor o en contra de la reforma se pueden entender, en realidad, como formas de manifestación de mentalidades y sistemas de valores diversos. Por tanto, constituyen oportunidades para el estudio de los universos culturales de los que son reflejos. Dadas las características de estos objetos de estudio es necesaria la utilización de instrumentos metodológicos que proporcionan los estudios histórico-culturales. Desde esta perspectiva, la música es abordada no sólo como un objeto o una práctica, sino también como una forma de representación ideológica y como un discurso cultural. La aproximación a la música litúrgica en el

\footnotetext{
${ }^{37}$ Véase el apartado "7. Música religiosa”, pp. 155-172. Elena Micó Terol, Amancio Amorós Sirvent (1854-1925) y su proyección en la vida musical valenciana (Barcelona: Universitat de Barcelon, 2011); disponible en <http://www.tdx.cat/handle/10803/81929> (consultado 2-2-2014).

${ }^{38}$ Además de las citadas actas, recurre a los estatutos de la catedral de Orense. Finalmente ofrece algunas referencias sobre colecciones de obras incorporadas a los archivos de las catedrales de Palencia o Valladolid. López-Calo, La música en las catedrales, pp. 681-692.

${ }^{39}$ María Sanhuesa, "Resonancias del Motu Proprio en la diócesis de Oviedo: la capilla catedralicia y el Seminario Conciliar", Recerca Musicològica, 16 (2006), pp. 177-201.
} 
contexto de la reforma impulsada por Pío X como un fenómeno simbólico cuyo significado cultural hay que interpretar es inédita en la historiografía musical española.

Los trabajos sobre la música en la catedral de Sevilla durante los siglos XIX y XX se reducen a los realizados por el, hasta no hace mucho, canónigo-organista en activo, José Enrique Ayarra Jarne ${ }^{40}$. Tanto en aquellas publicaciones acotadas temporalmente a los márgenes de la Edad Contemporánea como en las que considera un periodo mucho más amplio, el $M P$ constituye el acontecimiento que marca una nueva etapa en el templo metropolitano, junto al estreno de los nuevos órganos construidos por Aquilino Amezua. No obstante, dado que no se trata del objeto central de sus estudios, la reforma no se aborda en profundidad, y las referencias tanto a la incidencia en el repertorio, a los distintos protagonistas -Vicente Ripollés, Eduardo Torres, Luis Leandro Mariani sobre todo-, o al propio II Congreso Nacional de Música Sagrada son introductorias $^{41}$. Entre sus publicaciones hay que mencionar de manera particular la

\begin{abstract}
${ }^{40}$ Véanse: José Enrique Ayarra Jarne, Hilarión Eslava en Sevilla (Sevilla: Excma. Diputación Provincial de Sevilla, 1978); La música en la Catedral de Sevilla. (Sevilla: Caja de Ahorros Provincial San Fernando de Sevilla, [s. f.]); "La música en el culto catedralicio hispalense", en La catedral de Sevilla (Sevilla: Guadalquivir, 1991), pp. 699-748; "El maestro D. Eduardo Torres en Sevilla", Temas de estética y arte, 12 (1998), pp. 87-99; "La música en las funciones litúrgicas de Semana Santa de la catedral hispalense", en Las cofradías de Sevilla en el siglo de las crisis (Sevilla: Universidad de Sevilla, 1999);"500 años de Música de Órgano en Sevilla", Ars sacra: Revista de patrimonio cultural, archivos, artes plásticas, arquitectura, museos y música, XXXIX (2006), pp. 28-37; "La música de órgano española en el siglo XIX”, Temas de estética y arte, XXIV (2010), pp. 295-314.
\end{abstract}

${ }^{41}$ La información que se puede encontrar sobre músicos catedralicios hispalenses de finales del s. XIX y principios de s. XX en el $D M E H$ se completa con la ofrecida en algunos trabajos publicados. Véanse: Juan Cruz Labeaga Mendiola, "Buenaventura Íñiguez, organista de la catedral de Sevilla, y su ciudad natal, Sangüesa (Navarra)", Revista de Musicología, XIV/1-2 (1991), pp. 597-603; María Isabel Osuna Lucena, "La música en el monasterio de Santa Inés: D. Buenaventura Íñiguez", Laboratorio de Arte: Revista del Departamento de Historia del arte, V/2 (1992), pp. 177-218; Virginia Borrero Gaviño y Manuel Martín Riego, "Don Evaristo García Torres, maestro de capilla de la catedral de Sevilla (18641902)", Memoria ecclesiae (Actas del XXI Congreso de la Asociación de archiveros de la Iglesia en España), 31 (2008), ed. por Agustín Hevia Ballina, pp. 697-712; Mauricio Carrillo Cabeza, "Evaristo García Torres. Oposición al Magisterio de Capilla de la Catedral de Sevilla, 1864: una aproximación estilística a través de sus misas", Anuario de Historia de la Iglesia andaluza, IV (2011), pp. 273-300; Ayarra, "El maestro Don Eduardo Torres en Sevilla", Temas de estética y arte, 12 (1998), pp. 87-99. Sobre Eduardo Torres, véase, además: Miguel Barberá Soler, "Eduardo Torres Pérez: historia de su amistad con Manuel de Falla y Matheu", Academia: Boletín de la Real Academia de Bellas Artes de San Fernando, 70 (1990), pp. 273-316; Esteban Elizondo Iriarte, "La obra para órgano de Eduardo Torres (1872-1934)", Revista de Musicología, XXXI/1 (2008), pp. 151-169; Miguel Ángel Picó Pascual, "La aportación musicológica del canónigo Vicente Ripollés Pérez", Revista de Musicología (Actas del Simposio Internacional "El Motu proprio de San Pío X y la Música (1903-2003)"), ed. por Mariano Lambea , XXVII/1 (2004), pp. 287-294; Ma Carmen Genovés Carmona, "Una mirada al 'motu proprio' valenciano: Vicente Ripollés y Eduardo Soler", Archivo de arte valenciano, 86 (2005), pp. 67-76; Andrea Bombi, "Ripollés Pérez, Vicente", Diccionario de la Música valenciana, 2 vols., ed. por Emilio Casares (Madrid: Iberautor Promociones Culturales, 2006), vol. 2, pp. 344-346; Miguel López Fernández, "El papel del maestro de capilla en la reforma de la música litúrgica promovida por Pío X: el caso de Vicente Ripollés en Sevilla", en Música y reforma litúrgica desde 1611 hasta el presente, ed. por Rosa Isusi Fagoaga y Greta Olson (en prensa). Aunque pertenece a una época un poco anterior a la que nos atañe, incluimos en esta nómina: María Luisa Montero Muñoz, Domingo Arquimbau: Maestro de Capilla de la 
monografía sobre Hilarión Eslava, pues en ella traza la historia del Miserere compuesto por el navarro en 1835-1837, obra que va a tener un especial protagonismo en nuestro trabajo. Sin duda, se trata de un estudio cuyo conocimiento es indispensable para acometer investigaciones relacionadas con el tema ${ }^{42}$.

Los trabajos sobre la gestión musical de la administración central archidiocesana son inexistentes. Algo parecido habría que afirmar en el caso de otras instituciones eclesiásticas hispalenses, al margen de los esfuerzos dedicados por Ignacio Otero Nieto a rescatar la música litúrgica y paralitúrgica de las hermandades y cofradías locales ${ }^{43}$. Los datos que ofrece Otero Nieto son interesantes y numerosos, y llenan en gran medida un vacío en un ámbito histórico-cultural de gran valor antropológico por el que la musicología no ha mostrado gran interés ${ }^{44}$.

Otro de los asuntos al que dedicaremos una buena parte de nuestros esfuerzos será el II Congreso Nacional de Música Sagrada (Sevilla, 1908). Dos artículos monográficos dedicados a los congresos de música sagrada aparecieron en las actas del

Santa Iglesia Catedral de Sevilla 1790-1829: un estudio estilístico de sus Misas. Tesis Doctoral inédita, Universidad de Sevilla (2001).

${ }^{42}$ José Enrique Ayarra Jarne, Hilarión Eslava en Sevilla (Sevilla: Diputación Provincial de Sevilla, 1979), pp. 87-110. Hasta ahora la principal obra de referencia sobre Eslava es: Monografía de Hilarión Eslava, ed. por equipo Musikaste-Eresbil (Pamplona, Diputación Foral de Navarra, 1978). Véanse, además, otros trabajos sobre Eslava en Sevilla: José López-Calo, "El Miserere de Eslava", Boletín de Bellas Artes, 27 (1999), pp. 199-259; Rafael Bermúdez Medina, "Las coplas de Hilarión Eslava”, Boletín de las cofradías de Sevilla, 506 (2001), pp. 125-127; Rafael Romero Domínguez, "Los efectos de la desamortización de Mendizábal en el Miserere de Hilarión Eslava”, Boletín de las cofradías de Sevilla, 541 (2004), pp. 152153; Miguel López Fernández, "El Miserere de Hilarión Eslava: los documentos del privilegio de Sevilla”, en Musicología global, musicología local, ed. por Javier Marín López, Germán Gan Quesada, Elena Torres Clemente, Pilar Ramos López (Madrid: Sociedad Española de Musicología, 2013), pp. 951968. Tres ediciones del Miserere han visto recientemente la luz: Hilarión Eslava, Miserere (Barcelona: Tritó, 2009), a cargo de Lorenzo Ramos; José Manuel Delgado Rodríguez, Miserere de Hilarión Eslava (Granada: Junta de Andalucía. Consejería de Cultura, 2010); y José López-Calo. Tres Misereres andaluces de Hilarión Eslava. Vol. I Miserere de la Catedral de Sevilla, 1835-37 (Granada: Junta de Andalucía. Consejería de Cultura, 2011). De la primera de ellas se ha publicado, además, una reducción para voces y piano a cargo de Adriá Barbosa.

43 Ignacio Otero Nieto, "La música litúrgica y procesional de las hermandades" en Sevilla Penitente vol. I, ed. por Enrique Pareja López (Sevilla: Gever, 1995), pp. 271- 304; La música de las cofradías de Sevilla (Sevilla: Guadalquivir, 1997); "La música de culto de las hermandades de Sevilla", Boletín de Bellas Artes, 32 (2004), pp. 201-227; "La música litúrgica de las cofradías y el Miserere de Eslava en el siglo XX”, Boletín de Bellas Artes, 28 (2000), pp. 173-199.

${ }^{44}$ Para una aproximación antropológica a la Semana Santa de Sevilla y andaluza en general, véanse las publicaciones de Isidoro Moreno Navarro. Especial impacto ha tenido su libro La Semana Santa de Sevilla. Conformación, mixtifiación y significaciones (Sevilla: Ayuntamiento de Sevilla, 2006 [1982]), que ha sido editado por quinta vez. 
simposio internacional sobre el $M P$ celebrado en $2003^{45}$. Xosé Aviñoa, tras perfilar el contexto en el que se celebraron, apunta algunas consideraciones interesantes de carácter sociológico, y recoge los principales acuerdos reflejados en las crónicas y actas de cada uno de ellos. El objetivo de Jordi Rifé es analizar la recepción de la música de Bach en el contexto del MP. Para ello se centra en comprobar en qué medida estuvo presente la música del músico alemán en las discusiones mantenidas así como en los conciertos celebrados en el marco de estos importantes acontecimientos eclesiásticomusicales.

$\mathrm{M}^{\mathrm{a}}$ Antonia Virgili dedica algunas páginas de su monografía La música en Valladolid en el siglo XX al I Congreso Nacional de Música Sagrada celebrado en esa ciudad. En ellas alude a la buena acogida que tuvieron los reglamentos de música sagrada promulgados por los prelados de la provincia eclesiástica vallisoletana como el hecho que alentó la iniciativa de su celebración. Proporciona, además, de manera sintética, una idea general sobre el repertorio musical que se ofreció y las conclusiones que se propusieron ${ }^{46}$.

La contribución más importante al conocimiento de los congresos es la realizada por José López-Calo en distintas publicaciones. En síntesis, López-Calo resalta el, según su opinión, ambiente -“espíritu”- favorable a la reforma que reinaba entre los músicos eclesiásticos españoles en aquel momento; insiste en la importancia de la labor de Otaño, "alma y motor de todo"; y ofrece una visión general de cómo se desarrollaron así como de los principales proyectos que se plantearon en estas asambleas $^{47}$. Con todo, como ya pusiera de manifiesto M ${ }^{\text {a }}$ Antonia Virgili en 2004 está aún por realizar un análisis profundo y detenido de cada una de ellas ${ }^{48}$.

${ }^{45}$ Xosé Aviñoa, "Los congresos del Motu proprio (1907-1928). Repercusión e influencias", Revista de Musicología (Actas del Simposio Internacional "El Motu proprio de San Pío X y la Música (19032003)"), ed. por Mariano Lambea, XXVII/1 (2004), pp. 381-399; Jordi Rifé i Santaló, “Los congresos del Motu proprio y la música de J. S. Bach”, ibídem, pp. 401-422. Aviñoa se ocupa, además de los nacionales del Congreso Litúrgico de Montserrat (1915).

${ }^{46}$ La música en Valladolid en el siglo XX (Valladolid: Ateneo de Valladolid, 1985), pp. 31-34. En "La música religiosa en el siglo XIX español", en La música española en el siglo XIX, ed. por Emilio Casares y Celsa Alonso (Oviedo: Universidad de Oviedo, 1995), pp. 403-404, presenta una síntesis de la información que proporciona en aquella monografía.

${ }^{47}$ José López-Calo, "Congresos de música religiosa", D.M.E.H., 10 vols., ed. por Emilio Casares (Madrid: SGAE, 1999), vol. 4, pp. 876-878. Véase, además, el apartado "Los congresos de música sagrada", pp. 301-304, en: "Cien años de asociaciones de música religiosa en España, 1850-1950", Cuadernos de Música Iberoamericana, 8-9 (2001), pp. 287-306. En su biografía sobre Nemesio Otaño estudia la importante labor realizada por el jesuita en estas grandes reuniones, así como la significación que tuvieron en su carrera como líder y animador del movimiento reformista español. En el epígrafe que dedica al congreso de Sevilla, López-Calo se centra en el análisis de las causas y graves circunstancias 
Es común en la mayoría de los trabajos que, ya sea de una forma más directa o transversal, abordan el estudio de los congresos de música sagrada, poner de relieve la importancia de la figura de Nemesio Otaño como su gran promotor y artífice. Sin duda, el peso del jesuita en la organización de los primeros congresos y en la misma conformación del movimiento de reformas tal y como se fue definiendo fue determinante. No obstante, es posible que el hecho de situar continuamente el enfoque en la tarea desarrollada por Otaño haya ensombrecido a otros personajes, cuya labor presumiblemente relevante pudiera ser igualmente merecedora de atención. Esta circunstancia pudiera haber colaborado, además, en una percepción y comprensión del movimiento desde un sólo punto de vista, en menoscabo de otras perspectivas alternativas y/o complementarias, cuya incorporación sería necesaria para un conocimiento más rico y profundo de esta poderosa corriente en la que participaron personalidades variopintas y perfiles profesionales y eclesiásticos diversos.

Al hilo de esta última consideración, creemos necesario una aproximación al movimiento reformista español, no sólo desde la clave biográfica o como el ámbito en el que desarrollaron sus actividades las distintas figuras involucradas en la reforma, sino como un sujeto, de naturaleza colectiva, de estudio. Esta perspectiva abre la posibilidad

que impidieron a Otaño asistir a la cita. Véanse los apartados "El primer Congreso Nacional de Música Sagrada", pp. 33-37; "El congreso de Sevilla", pp. 50-61; y "Manresa, Barcelona y Pedrell", pp. 80-82, en: Nemesio Otaño, S.J.: Medio siglo de música religiosa en España (Madrid: ICCMU, 2010). En La música en las catedrales españolas dedica un subapartado a los congresos ("Los congresos", pp. 665673). Sobre Nemesio Otaño, véase, además, las siguientes publicaciones de Albano García Sánchez, "José María Nemesio Otaño Eguino (1880-1956): una aportación a la verdadera reforma de la música religiosa", Revista de Musicología, XXXII/1 (2009), pp. 475-489; "El músico José María Nemesio Otaño Eguino (1800-1956): Perfil biográfico, pensamiento estético y análisis de su obra”, en I Congreso Científico de Investigadores en Formación, coord. por José Carlos Gómez Villamandos (Córdoba: Universidad de Córdoba, 2010), pp. 387-389; "Contribución de Nemesio Otaño (1880-1956) a la memoria de Tomás Luis de Victoria, paradigma de universalidad", Revista de Musicología, XXXV/1 (2012), pp. 459-472.

${ }^{48}$ Virgili se expresaba en los siguientes términos: "Como material de base, de interés para llegar a establecer las coordenadas en las que se desarrolla nuestra música religiosa, consideramos también la conveniencia de un estudio sistemático de las Actas de los Congresos Nacionales de Música Sagrada. En muchas de estas publicaciones, así como en los numerosos artículos que salpican las revistas especializadas en fechas cercanas a sus celebraciones, se reseñan las conclusiones de las secciones, los trabajos presentados, las actividades musicales desarrolladas, con los repertorios que los componen, intérpretes, etc. Es sin duda un buen hilo conductor que permite acercarse a una visión más completa de la evolución de las mentalidades, de la comprensión de determinadas propuestas. Ello puede completar el perfil personal de algunas figuras no del todo ubicadas ideológicamente, etc.". "La música religiosa en el siglo XIX español”, Revista Catalana de Musicología, 2 (2004), p. 200. 
a su contemplación como un espacio social dinámico y orgánico, en la que se prioriza la observación de las relaciones y la forma en la que sus integrantes interactuaron ${ }^{49}$.

La cuestión de la música religiosa se convirtió desde las últimas décadas del s. XIX en uno de los asuntos en el candelero junto con la ópera nacional, la educación musical, la competencia y el nivel cultural de los músicos, o el restablecimiento de estructuras que patrocinaran, soportaran, y promovieran la actividad musical. Por tanto, resultaría desacertado abstraer nuestro tema de estudio del contexto ideológico y la situación de la música española, ambos marcados por las tendencias historicistas, el espíritu nacionalista y la voluntad regeneracionista. Los estudios sobre el nacionalismo y regeneracionismo musical español son numerosos. La historiografía ha prestado especial atención a Francisco Asenjo Barbieri ${ }^{50}$ y a Felipe Pedrell ${ }^{51}$, considerados como

49 El artículo de Albano García Sánchez, "Sobre la reforma de la música religiosa en España”, en Musicología global, musicología local, ed. por Javier Marín López, Germán Gan Quesada, Elena Torres Clemente, Pilar Ramos López (Madrid: Sociedad Española de Musicología, 2013), pp. 969-983 trata sobre las rivalidades existentes entre Nemesio Otaño, Federico Olmeda y Luis Villalba en torno a las revistas de música religiosa, un tema que estudiamos dentro de nuestro análisis del movimiento reformista como "espacio artístico-social". Algunos de los otros asuntos que trata tocan asímismo a algún aspecto de nuestro trabajo. Aunque su fecha de edición sea 2013, no estuvo disponible hasta marzo de 2014, momento en el que esta tesis se encontraba en un estado muy avanzado de elaboración.

${ }^{50}$ Véanse, entre otros, los estudios introductorios de Robert Stevenson, José López-Calo y Emilio Casares Rodicio, en Francisco A. Barbieri, Biografías y documentos sobre música y músicos españoles, ed. por Emilio Casares Rodicio (Madrid: Fundación Banco Exterior, 1986); Emilio Casares Rodicio, "Pedrell, Barbieri y la restauración musical española”, Recerca musicològica, 11-12 (1991-1992), pp. 259-271. Este último artículo ha tenido un importante impacto en la historiografía musical hispana desde su aparición. Teresa Cascudo y María Palacios opinan que Casares introdujo y generalizó en este el concepto de restauración o regeneración, inaugurando una "tendencia historiográfica" de enorme peso en la musicología española; véase: Teresa Cascudo y María Palacios, "Introducción”, en Los señores de la crítica. Periodismo musical e ideología del modernismo en Madrid (1900-1950), ed. por Teresa Cascudo y María Palacios (Sevilla: Doble J, 2011), pp. I-XX, pp. VIII-IX.

51 Las actas de los congresos internacionales "Felip Pedrell i el nacionalisme musical" (BarcelonaTortosa, 1991) y "La música catalana entre 1875 i 1936" (Barcelona, 1999), así como el simposio internacional "Felip Pedrell i Els Pirineus" (Barcelona, 2003) proporcionan abundante información desde variados puntos de vista sobre Pedrell y el nacionalismo musical. Las actas del primero de los congresos citados fueron publicadas en: Recerca musicològica, 11-12 (1991-1992); las del segundo y las del simposio en: Recerca musicològica, 14-15 (2004-2005). Con ocasión de la celebración del cuarto centenario de la muerte de Tomás Luis de Victoria en 2011 han sido publicados varios trabajos sobre la recuperación y revalorización de Tomás Luis de Victoria por parte de la musicología decimonónica y principios del s. XX. Se trata de un tema de especial relevancia para nosotros, dado que convergen en él nacionalismo y regeneracionismo español, por un lado, y reforma eclesiástica, por otro: Manuel Sancho García, "De Teixidor a Pedrell: Tomás Luis de Victoria en la historiografía musical española del siglo XIX”, Revista de Musicología, XXXV/1 (2012), pp. 443-457; del mismo autor: “Tomás Luis de Victoria en la obra musicológica de Felipe Pedrell: la creación de un mito nacional", en Tomás Luis de Victoria: Estudios/Studies, ed. por Manuel del Sol y Javier Suárez-Pajares (Madrid: ICCMU, 2013), pp. 489-500; Albano García Sánchez, "Contribución de Nemesio Otaño (1880-1956) a la memoria de Tomás Luis de Victoria, paradigma de universalidad”, Revista de Musicología, XXXV/1 (2012), pp. 459-472; Magín Arroyas Serrano y Vicente Martínez Molés, "La primera transcripción moderna del Oficio de Difuntos de Victoria: el manuscrito del maestro José Perpiñán”, ibídem, pp. 473-489; Marta Nieto Calleja, 
los principales motores de este impulso regenerador ${ }^{52}$ que adquirió una especial fortaleza a finales del s. XIX e inicios del $\mathrm{XX}^{53}$. La discusión estética que suscitó el deseo de regeneración y modernización de la música española fue ciertamente compleja, además de cambiante con el avance del siglo XX. El esencialismo, tradicionalismo, historicismo, casticismo, convivieron con el modernismo, europeísmo o krausismo ${ }^{54}$ conformando un universo cultural difícil de reducir ${ }^{55}$.

"Recuperación de la figura de Tomás Luis de Victoria desde los primeros años del siglo XX. Una visión a través de los textos de Vicente Salas Viu”, ibídem, pp.492-501.

52 Emilio Casares les denomina "“figuras clave de la inteligencia musical del XIX", "Pedrell, Barbieri y la restauración musical española”, Recerca musicològica, 11-12 (1991-1992), p. 259.

${ }^{53}$ Sobre regeneracionismo, nacionalismo y modernismo, véase, además: Beatriz Martínez del Fresno, "El pensamiento nacionalista en el ámbito madrileño (1900-1936). Fundamentos y paradojas", en De Musica Hispana et aliis. Miscelanea en honor al profesor Dr. José López-Calo en su $65^{\circ}$ cumpleaños, coord. por Emilio Casares y Carlos Villanueva (Santiago de Compostela: Universidad de Santiago, 1990), pp. 351397; de la misma autora, "Nacionalismo e internacionalismo en la música española de la primera mitad del siglo XX", (Actas del XV Congreso de Musicología), Revista de Musicología, XVI/1 (1993), pp. 640657; Jorge de Persia, "Distintas aproximaciones al estudio del hecho musical en España durante el siglo XIX”, Revista de Musicología (Actas del III Congreso Nacional de Musicología "La música en la España del s. XIX”), XIV/1-2 (1991), pp. 307-324; María Nagore Ferrer, La revolución coral. Estudio sobre la Sociedad Coral de Bilbao y el movimiento coral europeo (1800-1936) (Madrid: ICCMU; 2001); Emilio Casares Rodicio y Celsa Alonso González, La música española en el siglo XIX (Oviedo: Universidad de Oviedo, 1995); Celsa Alonso González, "La música española y el espíritu del 98”, Cuadernos de Música Iberoamericana, 5 (1998), pp. 79-108; Ramón Sobrino Sánchez, "El epistolario inédito de Tomás Bretón a Isaac Albéniz (1890-1908): nuevos documentos sobre la música nacional del paso del siglo XIX al XX, ibídem, 163-184; Víctor Sánchez Sánchez, “Tomás Bretón y el regeneracionismo. Una reflexión sobre la valoración de la música en el contexto cultural de la España de 1898", Cuadernos de Música Iberoamericana, 6 (1998), pp. 35-48; del mismo autor, Tomás Bretón: un músico de la Restauración (Madrid: ICCMU, 2002); Malena Kuss, "Nacionalismo, identificación y Latinoamérica", Cuadernos de Música Iberoamericana, 5 (1998), pp. 133-150; Celsa Alonso, "Nacionalismo", DMEH, 10 vols., ed. por Emilio Casares (Madrid: SGAE, 2001), vol. 7, pp. 924-944; Teresa Cascudo y María Palacios, eds., Los señores de la crítica. Aunque muchos de los trabajos contenidos en esta obra colectiva se ubican en un marco temporal alejado del fijado en nuestro estudio, resulta imprescindible su lectura: Pilar Ramos López, ed., Discursos y prácticas musicales nacionalistas (1900-1970) (Logroño: Universidad de La Rioja, 2012).

${ }^{54}$ Sobre krausismo y música, véanse las diversas publicaciones de Leticia Sánchez de Andrés; entre ellas: "El pensamiento estético del krausismo español y su proyección en la investigación musicológica y la crítica musical", (Actas del VI Congreso de la SedeM), Revista de Musicología, XXVIII/2 (2005), pp. 961-976; Música para un ideal: pensamiento y actividad musical del krausismo e institucionismo españoles (1854-1936) (Madrid: SedeM, 2009).

${ }^{55}$ La obra de José Carlos Mainer, La Edad de Plata (1902-1939): ensayo de interpretación de un proceso cultural (Madrid: Cátedra, 1987) constituye una obra de consulta obligada para aproximarse a la cultura literaria y artística de la España del momento. Véase también: Eugenio Carmona Mata, José Moreno Villa y los orígenes de las vanguardias artísticas en España (1909-1936) (Málaga: Universidad de Málaga, 1985; Xosé Aviñoa, La música i el modernisme (Barcelona: Curial, 1985); Maya Smerdeu Altolaguirre, coord., Ecos de la Generación del 98 en la del 27 (Madrid: Ediciones Caballo Griego para la Poesía, 1998); de este volumen resulta especialmente interesante José Luis Abellán, "Manuel de Falla, hombre intergeneracional", pp. 17-22; del mismo autor, Historia crítica del pensamiento español. Tomo 5/I. La crisis contemporánea (1875-1936), 5 vols. (Madrid: Espasa Calpe, 1989); Carol Hess, Manuel de Falla and Modernism in Spain. 1898-1936 (Chicago: University of Chicago Press, 2001); David T. Gies, The Cambridge Companion to Modern Spanish Culture (Cambridge: Cambridge University Press, 1999) 
Si bien especialistas como $\mathrm{M}^{\mathrm{a}}$ Antonia Virgili Blanquet y María Nagore Ferrer han estudiado en sus trabajos sobre el periodo inmediatamente anterior al $M P$ los intentos reformistas emprendidos desde las claves contextuales definidas por el nacionalismo y el regeneracionismo, en el caso de aquellos dedicados a los congresos nacionales de música sagrada y al movimiento que brotó en torno a ellos no se ha puesto de manifiesto suficientemente hasta qué punto pudieron ser esas asambleas producto y expresiones de aquellas corrientes ${ }^{56}$.

Estas circunstancias determinaron la forma en la que se forjó y desarrolló durante décadas la musicología moderna en España como disciplina ${ }^{57}$. Los principales protagonistas de nuestro estudio, siguiendo la estela marcada por Felipe Pedrell, se implicaron en la investigación musical desde premisas historiográficas condicionadas por aquellas ideas. En los últimos años se han publicado varios trabajos críticos en los que se ha analizado el impacto que el nacionalismo o el positivismo han tenido en la historiografía musical española desde entonces. Asimismo, se han revisado determinados discursos o ideas considerándolos mitos historiográficos e incluso lugares comunes aceptados sin el suficiente sentido crítico. Las distintas visiones sobre la historia de la música española son ciertamente útiles a la hora de tratar de comprender

\footnotetext{
${ }^{56} \mathrm{M}^{\mathrm{a}}$ Antonia Virgili comenta lo siguiente sobre el movimiento reformistas anterior al MP: "No debemos olvidar que algunos de los nombres que aparecían como punta de lanza de la reforma religiosa, formando parte de la Junta Directiva de la Asociación Isidoriana para la Reforma de la Música Religiosa [...], eran los mismos que escribieron manifiestos nacionalistas, que clamaron por la existencia de una ópera española y que consideraron que el acervo popular y nuestro pasado histórico eran los puntos de inspiración para consolidar una música española que tuviera a su vez vocación europeísta por su calidad técnica y artística. [...] Todo este mundo de relaciones podría también establecerse en el ámbito general de la inquietud regeneracionista que fue en aumento hacia finales de siglo. Muchos de estos autores reclamaron asimismo la necesidad de la formación intelectual del músico; denunciaron la ignorancia de nuestro pasado histórico musical; la crítica musical evolucionó de forma muy interesante y se apeló a la necesidad de formación del público, etc. De ahí que insistamos también en otro rasgo más de esta necesidad de estudio conjunto con las otras manifestaciones de la música española, de la mano del interés que en aquel momento suscitaron los momentos florecientes de la música eclesiástica, es decir, el gregoriano y la música polifónica del siglo XVI." Virgili, "La música religiosa”, p. 193. María Nagore, por su parte, afirma: 'La 'cuestión de la música religiosa' será una más de las cuestiones debatidas en los cenáculos musicales decimonónicos, entre las que destacan las de la ópera española y la enseñanza musical”. "Tradición y renovación en el movimiento de reforma de la música religiosa anterior al Motu Proprio", Revista de Musicología (Actas del Simposio Internacional "El Motu proprio de San Pío X y la Música (1903-2003)”), ed. por Mariano Lambea, XXVII/1 (2004), PP. 211-236, p. 212.

${ }^{57}$ En varias ocasiones se ha puesto de manifiesto la cercana relación existente entre la cuestión de la música religiosa y el nacimiento de la historiografía musical española. Sin ir más lejos, la Dra. Virgili ha insistido en el contacto de Eslava con los fondos musicales conservados en la catedral de Sevilla como una de las circunstancias que provocaron su cambio de tendencia estilística y de pensamiento sobre la música religiosa, así como su interés por la búsqueda de fuentes del pasado, uno de cuyos frutos más valiosos fue la publicación de la Lira Sacro-Hispana. Virgili, "La música religiosa en el siglo XIX español", Revista Catalana de Musicología, 2 (2004), p. 189; La música española en el siglo XIX. ed. por Emilio Casares y Celsa Alonso (Oviedo: Universidad de Oviedo, 1995), pp. 399-400.
} 
los afanes y propósitos de los principales líderes reformistas protagonistas de nuestro trabajo. Sus pensamiento y acciones inciden directamente en las instituciones y universo cultural que analizamos, siendo, por ello, otros objetos de estudio entre los considerados $^{58}$.

\section{Objetivos e hipótesis}

Esta tesis doctoral tiene como primer objetivo estudiar en profundidad la aplicación del MP sobre música sagrada en la archidiócesis de Sevilla entre 1903 y 1910. Pretende, por tanto, arrojar luz sobre el proceso diocesano de reformas y la problemática que en torno al mismo se pudo haber generado. Prestaremos atención a la recepción, gestión y aplicación del documento papal por parte de las dos principales instituciones diocesanas, administración general arzobispal y Catedral. Analizaremos las características y trascendencia del proyecto local de reformas, los avatares de su implementación y el papel jugado por los distintos agentes y estamentos de la Diócesis. Trataremos de ubicar la reforma dentro del plan de acción diocesano así como en el

${ }^{58}$ Además de Ros Fábregas, "Historiografía de la música en las catedrales españolas", ya citado, véanse del mismo autor: "Musicological Nationalism or How to Market Spanish Olive Oil", Newsletter of the International Hispanic Music Study Group, IV/2 (1998), pp. 6-15, en: $<$ http://digital.csic.es/handle/10261/19902> (consultado 24-9-2013); y "Historiografías de la música española e hispanoamericana: algunos problemas comunes y perspectivas para el siglo XXI", Boletín de música de la Casa de las Américas, 9 (2002), pp. 25-49, consultado en versión on-line $<$ http://www.casa.cult.cu/publicaciones/boletinmusica/9/emilio.htm> (consultado 24-9-2013). Véanse, además: Xosé Manuel Carreira, "La Musicologia spagnola: un'illusione autarchica?", Il saggiatore musicale, II/1 (1995), pp. 105-143; Juan José Carreras, "Hijos de Pedrell. La historiografía musical española y sus orígenes nacionalistas (1780-1980)", Il saggiatore musicale VIII/1 (2001), pp. 212-169; Pilar Ramos López, "The construction of the myth of Spanish Renaissance Music as Golden Age". Volumen Early Music-Context and Ideas International Conference in Musicology, Cracovia: Universidad de Cracovia (2003), en: $<$ http://www.campusvirtual.unirioja.es/titulaciones/musica/fotos/ramos_krakow_2003.pdf >; de la misma autora: "Mysticism as a Key Concept of Spanish Early Music Historiography". Volumen Early MusicContext and Ideas II International Conference in Musicology, Cracovia: Universidad de Cracovia (2008), en: <http://www.campusvirtual.unirioja.es/titulaciones/musica/fotos/13_ramos.pdf $>$ (consultados 25-92013). Además de estas, resulta imprescindible mencionar las importantes contribuciones al estudio de la historiografía musical española realizada en trabajos como los siguientes: Antonio Martín Moreno, "Hilarión Eslava polemista: la polémica en torno a la historia de la música española", en Monografía de Hilarión Eslava, ed. por equipo Musikaste-Eresbil (Pamplona: Diputación Foral de Navarra, 1978), pp. 267-306; del mismo autor, "La musicología catalana, des de Pedrell a la actualitat", en Història crítica de la música catalana, coord. por Francesc Bonastre i Beltrán (Barcelona: Universitat Autònoma de Barcelona, 2009), pp. 515-572; Ismael Fernández de la Cuesta, "Apuntes sobre la musicología en España", en La musicología española en el contexto internacional: los congresos internacionales de musicología (Madrid: Consejería de Educación y Cultura. Comunidad de Madrid, 1992), pp. 61-82; Begoña Lolo Herranz, "El sentido de la historicidad en música. España versus Europa", Anuario del Departamento de Historia y Teoría del Arte, 4 (1992), pp. 359-365; "La obra teórica de José Texidor y Barceló y el asentamiento de la historiografía musical en España", (Actas del XV Congreso de la Sociedad Internacional de Musicología "Culturas musicales del Mediterraneo"), Revista de Musicología, XVI/6 (1993), pp. 3630-3639. Véanse, además, los trabajos presentados al ya citado congreso "Felip Pedrell i el nacionalisme musical" (1991) y publicados en Recerca musicològica 11-12 (1991-1992). 
contexto histórico-cultural local, y observaremos las alteraciones que pudo provocar en el propio diseño de la estructura administrativa eclesiástica. La reforma en la Catedral, por su relevancia, su condición referencial y emblemática, así como por su capacidad como institución dotada de gran autonomía para desarrollar un proyecto reformista propio, ocupará un lugar destacado en nuestro estudio.

Nuestro segundo objetivo consiste en desvelar las razones de las resistencias a la reforma de las que dan testimonio las fuentes, e interpretar los significados simbólicos que la música litúrgica pudiera albergar para entender junto al proceso, el conflicto que, presumiblemente, se debió generar. Para ello, y de acuerdo al cambio de orientación que hemos explicado en el apartado de planteamiento, hemos partido de la siguiente hipótesis de trabajo: el proceso de reformas devino en conflicto cultural.

El análisis del congreso de Sevilla como reto organizativo, en su dimensión socio-económica, y como escenario para el proceso de institucionalización del movimiento reformista español y de un nuevo canon de música religiosa constituye nuestro tercer gran objetivo.

\section{Fuentes}

La tipología de las fuentes que hemos usado es variada: administrativas y oficiales, hemerográficas, epistolares, obras históricas y literarias, así como de otras características. Cada una de ellas cubre parte de las necesidades de provisión de información de nuestro trabajo, y juntas componen un corpus que hemos contemplado, además, como un conjunto de textos y discursos a interpretar.

De acuerdo al planteamiento inicial del trabajo, nuestras primeras exploraciones se han llevado a cabo en aquellos centros en los que se conservan las fuentes que proporcionan información sobre el gobierno y gestión de las instituciones sometidas a estudio: el Archivo General del Arzobispado de Sevilla (AGAS), la Biblioteca del Arzobispado de Sevilla (BAS), el Archivo de la Catedral de Sevilla (ACS), así como la Biblioteca Capitular y Colombina (BCC). Como fruto de nuestra búsqueda hemos recopilado un importante corpus de documentación oficial y administrativa relacionada con la música que abarca aproximadamente las dos décadas que transcurren entre 1893 y 1913.

Se ha procedido al vaciado de información y referencias musicales contenidas en los números del BOAS publicados entre noviembre de 1894 y diciembre de 1912. Como órgano de información oficial archidiocesano, el BOAS contiene profusa 
información sobre el proceso de reformas, pues a través de él se fueron dando a conocer a todo el clero y fieles diocesanos los edictos que iba promulgando la Sagrada Congregación de Ritos desde Roma, así como las medidas y disposiciones ideadas por la administración episcopal para su aplicación. Importantes documentos fueron publicados en formato separata en este medio, entre los que hay que destacar el Reglamento de Música Sagrada para la Archidiócesis de Sevilla (1910), desconocido hasta el momento ${ }^{59}$.

Como fuente, el BOAS atesora otro importante valor. Además de la sección oficial, en donde se publicaba la documentación de carácter legal y normativo, incluía otras secciones como las doctrinal, de noticias, variedades o bibliografía. A partir de sus contenidos es posible estudiar la mentalidad, ideología y cultura de la Iglesia de la época, tal y como esta pretendía ser conocida y reconocida en su propio entorno. Desde otra perspectiva, el $B O A S$ ofrece, además, la imagen de la sociedad desde el prisma católico.

La condición pública del $B O A S$ es una importante ventaja, y al mismo tiempo, un inconveniente. Las fuentes archivísticas suministran aquella información de carácter reservado, así como referente a la vida interna de la institución. Estas fuentes y el $B O A S$ se complementan, y cubren gran parte de las posibilidades de acceso al conocimiento de la administración diocesana. En las distintas secciones del AGAS y del ACS hemos obtenido documentación fundamental para nuestro estudio. Además de crónicas de los congresos católicos, decretos de los concilios provinciales, informes inéditos de las distintas reuniones de la CDMS, disposiciones varias del arzobispo, y otras informaciones relacionadas con la actividad de los órganos administrativos diocesanos $^{60}$, quisiéramos destacar sendas colecciones de cartas de los obispos españoles por un lado, y de los arciprestes de la archidiócesis hispalense, por otro, enviadas como respuestas a los requerimientos de Enrique Almaraz en el contexto de la

\footnotetext{
59 Además de como separata, fue publicado en tres entregas: "Circular de Ntro. Excmo. Prelado y Reglamento de Música Sagrada para esta Diócesis” BOAS, 690 de 2 de mayo (1910), pp. 451-461; "Reglamento de Música Sagrada (continuación)", BOAS, 691 de 16 de mayo (1910), pp. 562-567; "Reglamento de la Música Sagrada (conclusión)", BOAS, 692 de 1 de junio (1910), pp. 571-577. La separata contiene unas interesantes notas aclaratorias que no aparecen en la publicación por entregas.

${ }^{60}$ En los archivos hemos hallado, además, correspondencia entre el arzobispo y el deán y cabildo catedralicio; correspondencia entre distintas instancias del arzobispado y diferentes instituciones como parroquias $\mathrm{u}$ órdenes religiosas, o de naturaleza civil como el Ayuntamiento o el Ateneo; documentación sobre músicos catedralicios, y de músicos residentes en la Archidiócesis, solicitudes hechas por estos y las respuestas de la institución diocesana, etc. Véase el apartado "Relación de Fuentes".
} 
preparación y organización del II Congreso Nacional de Música Sagrada ${ }^{61}$. Este corpus epistolar nos proporciona nuevas perspectivas sobre estos grandes eventos: las del conjunto del episcopado español, y la de los curas y fieles diocesanos, ignoradas hasta ahora. Asimismo, se han localizado fuentes de un importante valor histórico y simbólico, como la petición de dispensa en la aplicación del MP para el caso del Miserere de Eslava, elevada por Marcelo Spínola a la Santa Sede, y la consiguiente resolución de Roma; ambas custodiadas en el Archivo Secreto Vaticano (ASV) ${ }^{62}$.

Para el estudio de la reforma en la principal institución litúrgico-musical de la Archidiócesis, la Catedral, hemos procedido al vaciado de toda información relacionada con la música contenida en las actas capitulares entre 1903 y 1913. Estas fuentes proporcionan el discurso oficial de la institución sobre su propia gestión. Como testimonios de los debates que se produjeron, descubren los distintos posicionamientos adoptados por los capitulares respecto a la reforma. A pesar de su carácter oficial, en ocasiones traslucen la fuerte implicación personal de algunos de ellos, lo que lleva a pensar en la relevancia que para estos eclesiásticos y la institución en su conjunto poseía la cuestión musical. En algunos casos, debemos lamentar las omisiones que nos privan del conocimiento de determinadas claves del proceso.

El examen de las actas capitulares ha abarcado desde 1887 hasta 1917. Hemos indagado, además, en fuentes generadas por otros órganos catedralicios como libros de autos de la Diputación de Ceremonias, o documentación procedente de la sección "I. Secretaría" del Fondo Capitular ${ }^{63}$. Hemos trabajado con dos reglas de coro: el resumen de la Regla de Coro realizado en 1608, actualizado y reimpreso en 1760, Regla del Coro y Cabildo de la S. Iglesia Patriarcal de Sevilla y Memoria de las procesiones y manuales que son a cargo de los señores Deán y Cabildo de ella; y la nueva Regla de Coro de la Santa, Metropolitana y Patriarcal Iglesia Catedral de Sevilla (Sevilla: Imp. Sobrino de Izquierdo, 1923), cuyo proyecto fue encargado precisamente por Enrique Almaraz al cabildo catedralicio en $1913^{64}$.

\footnotetext{
${ }^{61}$ AGAS. Sección Gobierno. Asuntos Despachados, leg. 04907 (1908). Se conservan las cartas de treinta y cuatro obispos españoles, y veintiún arciprestes hispalenses.

${ }^{62}$ La solicitud de Spínola en: ASV, Segretaria di Stato, anno 1905, rubrica 283, fascicolo 2, fols. 46r47r. La respuesta vaticana en ibídem, fol. 48. Véase Apéndice 3.

${ }^{63}$ La gran parte de la documentación del s. XX relacionada con la contaduría está aún por inventariar, por lo que no es accesible. El libro de actas de la Diputación de Ceremonias 357. ACS. Sección Secretaría abarca desde el año 1885 al de 1914.

${ }^{64}$ AC 27/11/1913. ACS. Sección Secretaría, libro 229, fol. 176r.
} 
El repertorio musical vigente en esos momentos así como el canon litúrgicomusical catedralicio se ha investigado, además de a partir de los datos que suministran las fuentes administrativas mencionadas más arriba, en base a una serie de tres inventarios históricos que se pueden datar entre ca. 1900 y segunda mitad de la década de los años veinte ${ }^{65}$.

Las fuentes administrativas y oficiales resultan, a todas luces, insuficientes para indagar en aquella mentalidad y aquel universo cultural, así como en el significado simbólico que la música litúrgica poseía tanto para los miembros de la institución como para el conjunto de la sociedad local. La trascendencia de algunos de los fenómenos culturales originados a partir de ciertas obras litúrgico-musicales obliga a incorporar no sólo la perspectiva catedralicia, sino también la exterior, dado que las imágenes compuestas desde fuera colaboran igualmente en la configuración de las identidades de las comunidades que se contemplan. Hemos procurado reunir un conjunto de fuentes de diversas tipologías para poder desarrollar, a partir de ellas, un intento de interpretación y explicación de las polémicas, así como de sus bases ideológicas y culturales que, como apuntan los indicios y testimonios encontrados en las fuentes administrativas, se debieron originar. Nos hemos servido, por un lado, de una serie de obras de carácter histórico o histórico-teológico, cuyos autores, íntimamente relacionados con la institución eclesiástica hispalense o el catolicismo local, eran en aquellas décadas significados personajes de la intelectualidad sevillana. En sus narrativas sobre la historia de Sevilla, de cuya lectura no es difícil inferir o destilar los presupuestos ideológicos y culturales sobre los que descansan, es posible hallar todo un muestrario de símbolos identitarios, así como el relato de sus procesos de nacimiento y consolidación como tales. Entre ellas, debemos destacar las publicaciones de José Gestoso y Pérez, Servando Arbolí y Faraudo, Manuel Serrano y Ortega, o Simón de la Rosa y López ${ }^{66}$. El libro de este último dedicado a los seises de la catedral de Sevilla constituye una

\footnotetext{
${ }^{65}$ ACS. Sección Medios de Información, leg. 11160. Véase Apéndice 5.
}

${ }^{66}$ José Gestoso y Pérez, Curiosidades antiguas sevillanas (Serie segunda) (Sevilla: Correo de Andalucía, 1910); Servando Arbolí y Faraudo, La Eucaristía y la Inmaculada, devoción española. Homenaje al Congreso Eucarístico de Valencia (Sevilla: Imp. de E. Rasco, 1895); Manuel Serrano y Ortega, Glorias sevillanas: noticia histórica de la devoción y culto que la muy noble y muy leal ciudad de Sevilla ha profesado a la Inmaculada Concepción de la Virgen María desde los tiempos de la Antigüedad hasta la presente época (Sevilla: Consejería de Relaciones Institucionales, 2004), reproducción facsimilar de la edición de Sevilla: Imp. de E. Rasco, 1893; Simón de la Rosa y López, Los seises de la catedral de Sevilla. Ensayo de investigación histórica (Sevilla: Imp. de Francisco de P. Díaz, 1904). 
fuente de singular valor, pues convergen en él historia cultural catedralicia, pensamiento católico oficial, y música.

Hemos recopilado, asimismo, discursos, artículos, exhortaciones y otros escritos, generados por las figuras más relevantes del proceso de reformas (arzobispos, canónigos catedralicios y profesores del seminario, músicos religiosos, etc.). Estos documentos han sido extraidos de diversas publicaciones como actas de congresos católicos nacionales y de congresos nacionales de música sagrada, el BOAS o la prensa.

El pensamiento del maestro de capilla Vicente Ripollés, quien merece mención aparte, ha sido estudiado a partir, en primer lugar, de sus numerosos artículos y discursos, editados en distintas publicaciones -crónicas de congresos nacionales de música sagrada, prensa local o revistas especializadas en música religiosa-; en segundo lugar, de su producción musical para catedral hispalense; por último, de la correspondencia que mantuvo durante esos años con importantes personalidades musicales, entre las que hay que destacar su mentor, consejero, e incluso confidente, Felipe Pedrell. Las fuentes epistolares, de carácter privado e incluso íntimo, permiten acceder a estos personajes sin los condicionantes, formalismos o precauciones propias de sus escritos públicos. Esta colección de cartas -originales manuscritas-, conservadas en la Biblioteca de Catalunya ${ }^{67}$, nos ha proporcionado, además, importantes datos sobre el canon musical catedralicio o sobre el proceso de reformas en general, silenciados u omitidos por las fuentes administrativas. De este mismo fondo hemos manejado correspondencia de otros personajes relacionados con la reforma como Nemesio Otaño, Luis Villalba, Mauro Sablayrollés. En total hemos estudiado unos ochenta y tres documentos entre cartas y tarjetas postales.

Las fuentes literarias colaboran, como productos culturales, en la construcción de la imagen e identidad de una comunidad sociocultural. Las miradas que desde la literatura ofrecen escritores tanto autóctonos como foráneos sobre la Catedral y Sevilla en general, nos han servido como otros canales de acceso al conocimiento y a la comprensión de fenómenos culturales como la función del Miserere de Eslava y su significado. Hemos manejado obras de escritores andaluces como el representante de un primer modernismo peninsular Salvador Rueda ${ }^{68}$, o el costumbrista Juan Francisco Muñoz y Pabón. Este último, como canónigo lectoral del capítulo catedralicio, vivió en

\footnotetext{
${ }^{67}$ Fondo Felip Pedrell. M 964.

${ }^{68}$ Salvador Rueda, Granada y Sevilla. Bajo-relieves. (Madrid: Fuentes y Capdeville, 1890).
} 
primera persona todo el proceso reformista en el templo hispalense ${ }^{69}$. Blasco Ibáñez o Eugenio Noel nos han proporcionado otras visiones ciertamente interesantes, testimonios que representan la perspectiva foránea ${ }^{70}$.

Otras de nuestras principales fuentes han sido las hemerográficas. Hemos realizado un barrido de noticias sobre música religiosa en los principales diarios locales como son El Noticiero Sevillano (ENS), El Liberal, y El Correo de Andalucía (ECA). Este último fue fundado por el propio Marcelo Spínola en 1899 como diario católico de noticias. De la edición sevillana del $A B C$, nacida en fecha posterior a nuestro ámbito temporal hemos extraído alguna información de interés. Hemos llevado a cabo, además, un trabajo de búsqueda de información relacionada con el proceso sevillano, los distintos personajes que intervinieron en él, así como con el movimiento reformista español en general, en revistas especializadas de música sacra (La Música Religiosa en España, Boletín del Congreso (BdC), Música Sacro-Hispana (MSH), Biblioteca SacroMusical (BSM)); en revistas de información religiosa en general (Razón y $\mathrm{Fe}$, La Ciudad de Dios ( $L C D)$ ); así como en prensa generalista de filiación católica o política tradicionalista (España y América, El Siglo Futuro, El Debate, o La Hormiga de Oro) en cuyas páginas salieron a la luz escritos de los principales líderes e ideólogos del movimiento reformista. $M S H$ y $L C D$ han sido fundamentales para el estudio del movimiento de reformas en torno al II Congreso Nacional de Música Sagrada, celebrado en Sevilla. A través de $L C D$ hemos podido conocer el punto de vista de Luis Villalba tanto sobre el movimiento como sobre los primeros congresos. Los escritos del músico agustino son fuentes valiosas, pues aportan una visión distinta, complementaria, y en cierta manera, alternativa a la más oficialista, encarnada por Otaño y su círculo. Otras publicaciones indispensables para el estudio del movimiento de reformas son las crónicas y actas de los cuatro congresos nacionales de música sagrada celebrados en Valladolid (1907), Sevilla (1908), Barcelona (1912) y Vitoria (1928) ${ }^{71}$.

\footnotetext{
${ }^{69}$ Juan Francisco Muñoz y Pabón, En el cielo de la tierra (Sevilla: Imp. Sobrinos de Izquierdo, 1918).

${ }^{70}$ Vicente Blasco Ibáñez, Sangre y arena (Madrid: Espasa Calpe, 1990 [Valencia, 1908]); Eugenio Noel, Semana Santa en Sevilla (Madrid: Renacimiento, 1916).

${ }^{71}$ Crónica del Primer Congreso Nacional de Música Sagrada: celebrado en Valladolid en abril de 1907 (Valladolid: Imp. y Lib. Religiosa de Andrés Martín, 1908); Crónica del Segundo Congreso Nacional de Música Sagrada celebrado en Sevilla los días 12, 13, 14 y 15 de noviembre de 1908 (Sevilla: Izquierdo y C. a, 1909); Crónica y actas oficiales del Tercer Congreso Nacional de Música Sagrada, Barcelona, 21-24 de noviembre 1912 (Barcelona: La Hormiga de Oro, 1913); Crónica del IV Congreso Nacional de Música Sagrada: celebrado en Vitoria del 19 al 22 de noviembre de 1928 (Vitoria: Montepío Diocesano, 1930).
} 
La copiosa correspondencia custodiada en el Archivo Musical "Nemesio Otaño" del Santuario de Loyola (AMSL) proporciona una gran cantidad de información sobre el desarrollo de la reforma en España ${ }^{72}$. Hemos manejado un total de doscientas cincuenta y ocho cartas conservadas en este archivo. En él hemos consultado, además, la autobiografía inédita que Otaño escribió en $1944^{73}$.

Proporcionamos una relación de las fuentes manejadas en apartado "Relación de fuentes".

Además de en las sedes donde se encuentran los archivos y bibliotecas gestionados por la Institución Colombina (AGAS, ACS, BAS y BCC), nuestras indagaciones han tenido lugar en otros centros andaluces: Biblioteca del Seminario Metropolitano de Sevilla, Hemeroteca Municipal de Sevilla, Hemeroteca de El Correo de Andalucía ${ }^{74}$, Sala de Investigadores de la Biblioteca General de la Universidad de Sevilla (US), diversas bibliotecas públicas y de la US, Biblioteca de la Facultad de Filosofía y Letras de la Universidad de Granada, Biblioteca de Andalucía, Centro de Documentación Musical de Andalucía, Archivo Manuel de Falla. Asimismo, hemos realizado sendas estancias investigadoras en la Biblioteca de Catalunya, y en el Archivo y Biblioteca del Santuario de Loyola (Guipúzcoa), en donde se encuentra el Archivo Musical "Nemesio Otaño". Hemos recabado documentación de la Universidad de

En 1954 se celebró un quinto congreso en Madrid, aunque pertenece a otro momento histórico diferente del estudiado por nosotros.

72 Archivo y Biblioteca del Santuario de Loyola. Archivo Musical "Nemesio Otaño" (AMSL [Archivo Musical del Santuario de Loyola]). Además de las cartas manuscritas conservadas, en este archivo se encuentra un epistolario transcrito a máquina de escribir, recopilado y preparado por Victoriano Larrañaga, que no llegó a publicar: AMSL. FO [Fondo Otaño]. T01. Como paso previo, Larrañaga reunió la correspondencia de Otaño en otros cuatro volúmenes a partir de los cuales realizó la selección con la que finalmente compuso el citado epistolario. En el primero de ellos figura escrito a máquina: Epistolario del P. Nemesio Otaño, S. J. Recogido y anotado por el P. Victoriano Larrañaga. Estos volúmenes, denominados por el personal del archivo como "Tomos Azules", han sido recientemente inventariados (AMSL. FO. TA01-TA04). Durante nuestra estancia investigadora en Loiola aún no se había realizado dicho inventariado, por lo que agradecemos a Mercedes Marín Sanz, archivera-bibliotecaria ayudante, haberlos puesto a nuestra disposición en aquel momento. En ellos hemos podido hallar misivas descartadas por Larrañaga de gran valor para nuestros propósitos, entre las que hemos de destacar todas las enviadas al maestro de capilla hispalense, Vicente Ripollés. Asimismo, es posible comprobar que al pasar al epistolario, algunas de las cartas seleccionadas sufrieron la supresión de algunos párrafos, y la sustitución u omisión de algunas palabras.

73 AMSL. FO. Conferencias y otros escritos. 005/013. Se nos facilitó una muestra de algunas hojas del original manuscrito y una transcripción. El original está foliado, mientras que la transcripción está paginada. Ambas tienen la misma signatura.

${ }^{74}$ En la Hemeroteca Municipal de Sevilla no se conservan números anteriores a 1908, lo que nos obligó a acudir a la Hemeroteca de El Correo de Andalucía para consultar aquellos ejemplares publicados entre 1899, año de nacimiento del rotativo, y 1908. 
Valladolid, la Universidad San Pablo-CEU de Valencia, y del Archivo Secreto Vaticano; y utilizado fondos digitales de diversas bibliotecas como la Biblioteca Nacional de España, Biblioteca Virtual de Andalucía o Biblioteca Virtual de Prensa Histórica, entre otras.

\section{Metodología}

Dada la naturaleza de nuestro objeto de estudio, en principio, nuestro trabajo se inscribe en el ámbito de la historia institucional ${ }^{75}$. Para abordar el estudio del proceso a nivel archidiocesano hemos optado por diseñar un patrón básico de análisis que aplicaremos a los dos pontificados en los que se desarrolló la reforma. Este instrumento metodológico resulta útil pues está elaborado según las características de la institución diocesana y las circunstancias históricas del periodo que nos ocupa. En primer lugar, el protagonista de nuestras observaciones es el arzobispo, receptor principal de la norma sobre música como autoridad máxima, y responsable último del diseño general del proceso local a poner en marcha ${ }^{76}$. Tras el arzobispo, centramos la atención en la Comisión Diocesana de Música Sagrada. Nos interesa conocer la naturaleza de este nuevo órgano para la reforma, así como las funciones que le fueron confiadas, no sólo por el $M P$ sino por el propio prelado. En tercer lugar, analizamos con minuciosidad el resultado del ejercicio de concreción normativa realizado por la CDMS, esto es, el conjunto de disposiciones que como traducción adaptada a la realidad diocesana de los preceptos generales romanos generó la alta administración eclesiástica local. El interés del que denominaremos "plan de reformas" radica, además, en su virtud especular, es decir, su facultad de reflejar, por un lado, los criterios en base a los que arzobispo y CDMS ejercían su poder de decisión; y por otro, la situación local y problemas específicos litúrgico-musicales a los que trataron de dar respuesta. El siguiente nivel de

\footnotetext{
${ }^{75}$ Con la publicación de su monografía La música en la catedral de Granada en el siglo XVI (1963), José López-Calo fijó el modelo "institucional puro", en términos de Juan José Carreras, en los estudios sobre música en catedrales. Carreras, "Música y ciudad", p. 33. Conviene advertir que nuestro análisis no se reduce a la Catedral, aunque goce en él de especial protagonismo por razones obvias. La Catedral es contemplada dentro del organigrama eclesiástico local como una de las instituciones, de especial relevancia, que lo conforman.

${ }^{76}$ Pío X encomendó de forma particular la reforma a los obispos: "y sobre todo a los Ordinarios diocesanos, que favorezcan con todo celo estas prudentes reformas, desde hace mucho deseadas y por todos unánimemente pedidas, para que no caiga en desprecio la misma autoridad de la Iglesia, que repetidamente las ha propuesto y ahora de nuevo las inculca.” MP. Título IX. Conclusión, art. 9.
} 
análisis está dedicado a los administradores de templos, colectivo que, como hemos señalado, poseía en última instancia el poder de aplicación real de la reforma.

Junto a estos cuatro aspectos a examinar (tres estamentos diocesanos arzobispo, CDMS y administradores de templo- y un producto de la gestión musical de la institución -plan de reformas-) resulta necesario fijar la mirada en un quinto objeto de estudio, este de carácter contingente y circunstancial, aunque decisivo. Se trata de sendas interrupciones del proceso, causadas por determinados acontecimientos o por el advenimiento de situaciones a las que tuvo que adaptarse la institución. Estos factores ambientales y contextuales coadyuvan a la contemplación de la reforma incardinada en el complejo mundo al que se enfrentaba la Iglesia hispalense. Este último punto se ha insertado en distintos lugares de nuestro patrón analítico, pues resulta indispensable respetar el orden cronológico de los acontecimientos para preservar su sentido histórico y sus lógicas de causa-efecto. Así, en el estudio de la reforma durante el pontificado de Marcelo Spínola se sitúa en tercer lugar, y en primer lugar en el que se dedica a la etapa de Enrique Almaraz.

Esta tesis pertenecería a una segunda tradición historiográfica conocida como historia local. Dentro de esta, nuestra aproximación no se reduce al espacio urbano sino que tiene un alcance regional, dado el carácter territorial de las diócesis ${ }^{77}$. Las pretensiones y alcance de este estudio obligan, no obstante, a superar las limitaciones de aquellas historias locales que, por un lado, reducen la dimensión local a un espacio retraído en sí mismo, y, por otro, desarrollan discursos autorreferenciales ${ }^{78}$. La demarcación archidiocesana hispalense, que se extendía por la práctica totalidad del

${ }^{77}$ En este mismo sentido, Juan José Carreras refiere la particularidad de la historia local tal y como se había desarrollado en Alemania, de acuerdo, precisamente a las características histórico-geográficas del país: "Por su parte, la musicología germana ha preferido categorizar los estudios locales de la música desde el punto de vista no tanto de las distintas ciudades sino de la historia regional, atendiendo más a los conjuntos de diversas ciudades y su articulación en zonas (perspectiva que tiene naturalmente mucho que ver con su propia historia y geografía)". "Música y ciudad", pp. 17-18.

\footnotetext{
${ }^{78}$ Ricardo García Cárcel arremete contra la historia local española con una dura crítica: "la historia local que se ha hecho en España no tiene nada que ver con la microhistoria a la italiana, ni con el ejercicio inductivo que toda investigación histórica a la anglosajona presupone: ha sido mero caldo de cultivo del chovinismo parroquial o de estériles erudiciones de diletantes curiosos." En: El País "Babelia”, 3 de julio (1993); cit. en: Justo Serna y Anaclet Pons, "El ojo de la aguja ¿De qué hablamos cuando hablamos de microhistoria?", Ayer, 12 (1993), pp. 93-133, p. 94, nota a pie no 2. Una de las pocas reflexiones historiográficas sobre el trato dentro de la musicología española a la historia local en: Carreras, "Música y ciudad". En su revisión, Carreras hace confluir distintas corrientes como Historia Institucional, Historia Local, Nueva Historia Cultural, etc. Todas presentes de una u otra forma en nuestro trabajo.
} 
tercio occidental andaluz ${ }^{79}$, no fija los límites geográficos y sociales de este trabajo. Aún focalizando la atención en la institución eclesiástica andaluza, este estudio tiene una proyección general española. En nuestros análisis, razonamientos y reflexiones sobre la reforma en Sevilla se proporcionan referencias a otros procesos con el objeto de establecer una relación entre lo local y lo general. Este procedimiento se nos antoja imprescindible para poder conocer, explicar e interpretar el propio proceso local, pues proporciona claves de interpretación suministradas por el contexto hispano en el que está inserto. Además, el estudio del caso andaluz, desconocido hasta ahora, constituye una aportación que debe colaborar en una mayor comprensión de la reforma a nivel general español.

Por otra parte, la exigencia de aproximación a nuestro objeto de estudio, dada su naturaleza, desde una perspectiva cultural más amplia hace necesario la aclaración de algunos conceptos y una nueva ubicación historiográfica, junto a las ya señaladas.

La liturgia, acontecimiento teológico y acto ritual en el que se integra la música, se ha considerado en su dimensión antropológica, es decir, como un hecho religioso lleno de significación, o, en otras palabras, una manifestación y representación de la cultura ${ }^{80}$. Hemos adoptamos el ya clásico concepto de cultura formulado por Peter

79 A principios del siglo XX, la archidiócesis de Sevilla comprendía, además de las actuales demarcaciones episcopales de Sevilla, Huelva -coincidentes con el área de sus respectivas provincias- y Jerez, algunas comarcas y poblaciones de Córdoba y Málaga. La administración eclesiástica andaluza estaba dividida en veintitrés arciprestazgos, de los que dependían doscientas ochenta y tres parroquias repartidas en doscientos veinticuatro pueblos. Contaba, además, con la Real e Insigne Iglesia Colegial de Jerez de la Frontera, cuyo cabildo estaba compuesto por once canónigos, y a la que servían seis beneficiados, entre ellos un sochantre y un organista. "Estadística general del arzobispado de Sevilla", BOAS, 557 (1909), pp. 77-85. Según los datos ofrecidos en la relación ad limina elaborada por el arzobispo Marcelo Spínola en 1898, la población archidiocesana ascendía a unos 850.000 habitantes. Dicha relación citada en: José María Javierre, "La diócesis de Sevilla en el siglo XX", en Historia de las diócesis españolas, vol. X (Iglesias de Sevilla, Huelva, Jerez, Cádiz y Ceuta), coord. por José Sánchez Herrero (Madrid: BAC, 2002), pp. 327-500, p. 347. Véase Apéndice 1.

${ }^{80}$ Los aspectos teológicos se consideran en la medida en la que ayudan a comprender e interpretar el significado y valor que el ceremonial litúrgico tenían para la microsociedad de la institución, así como para el conjunto de la comunidad. Aldo N. Terrin pone el énfasis en la necesidad de aproximaciones antropológicas a la liturgia, pues "no es nunca un hecho teológicamente puro": "[...] lo importante será observar ante todo que la celebración litúrgica -si valen para ella las observaciones hechas acerca del ritual - no es nunca un hecho teológicamente puro, por lo que, partiendo del hombre que celebra la liturgia, deberán tenerse en cuenta los elementos biológico-ecológicos, las necesidades individuales y sociales, las situaciones históricas, los contextos culturales omnicomprensivos e ideológicos que más o menos veladamente se encontrarán en la liturgia misma o que, aun admitiendo la pureza del dato litúrgico, proyectará instintivamente el hombre mismo sobre la liturgia, encontrando en ella lo que en ella trata de buscar." Aldo N. Terrin, "Antropología cultural", en Nuevo diccionario de liturgia, 2 vols., ed. por D. Sartore y Achille M. Triacca, (Madrid: Ediciones Paulinas, 1987), vol. 1, pp. 111-136, p. 132. En el estudio de las religiones, Margaret Miles aboga por integrar dos perspectivas normalmente polarizadas, aunque complementarias, la teológica y la más cercana a la antropológica: "I use, then, the providentially ambiguous term 'religious studies' to integrate the falsely polarized terms, 'theological studies' and "study of religion". Margaret R. Miles, "Becoming answerable for what we see", Journal of the 
Burke: "a system of shared meanings, attitudes and values, and the symbolic forms (performances, artifacts) in which they are expressed or embodied” ${ }^{\prime 81}$. Esta idea, inspirada en la propuesta de los antropólogos Alfred Kroeber y Clyde Kluckhohn, representa para nosotros un marco general ${ }^{82}$. Nos interesan, dentro de una determinada cultura contemplada como un espacio de cierta coherencia -aunque uniforme según esta definición-, aquellas tendencias diversas que puedan llegar a situaciones de confrontación o litigio, precisamente por atribuir en determinados momentos, especialmente aquellos de transición o transformación, significados diversos a las formas simbólicas, y adoptar, de acuerdo a unos criterios de valoración no coincidentes, unos posicionamientos polémicos.

El propio Burke reconocía años después, haciendo suya una idea de Michael Baxandall, lo simplista de las ideas sobre la cultura como alguno unitario o uniforme ${ }^{83}$. Sus afirmaciones se enmarcan en un contexto en el que defiende la necesidad de reformular las propuestas teóricas propias a partir de la influencia de otras, incluidas aquellas que se pudieran considerar opuestas ${ }^{84}$. De hecho, tras aludir a cinco modelos historiográficos considerados como diferentes momentos ${ }^{85}$ en el proceso de

American Academy of Religion, LXVIII/3, p. 472; cit. en Gregory D. Alles, "Introduction", en Religious Studies: A Global View, ed. por Gregory D. Alles (Abingdon: Routledge, 2007), pp. 1-13, p. 5. Se pueden encontrar distintas aproximaciones antropológicas a la liturgia en el capítulo preliminar “Antropología litúrgica” de: Julián López Martín, En el espíritu y la verdad: introducción antropológica a la liturgia (Salamanca: Secretariado Trinitario Ediciones, 2002 [1994]), pp. 23-58.

${ }^{81}$ Peter Burke, Popular culture in early modern Europe (Farnham: Ashgate, 2009 [1978]), p. XIII.

${ }^{82}$ Alfred Kroeber y Clyde Kluckhonh, Culture: a critical Review of Concepts and Definitions (Nueva York: Vintage books, 1952).

${ }^{83}$ La referencia a Michael Baxandall es: The Limewood Sculptors of Renaissance Germany (New Haven, Yale University Press, 1980).

${ }^{84}$ “'The point is that each approach has something to offer which the others cannot. Each has its own weaknesses, perils or excesses which the others help correct. Some ideas cannot be reconciled, notably cultural unity and shared meanings (emphasised by Panofsky, say, and Geertz etc.) with cultural diversity and conflicts between meanings (emphasised by Thompson and Sahlins). All the same, each idea can be reformulated more subtly thanks to awareness of the other. The simple assumption of unity is simplistic, but it remains possible to make analogies between different cultural domains. Again, although the fashion for structuralism has passed, it has sensitised historians and anthropologists to parallels, inversions, and more generally to relations between elements, whether in a text or a whole culture." Peter Burke, "From Cultural History to Histories of Cultures", Memoria y civilización ,1 (1998), pp. 7-24, p. 24.

${ }^{85}$ El concepto de "momento" empleado por Burke está tomado del usado en el círculo del crítico literario Frank Leavis. Peter Burke, "From Cultural History", p. 7. Se hacen referencias a las siguientes obras: Patrick Cruttwell, The Shakespearian Moment (London: Chatto and Windus, 1954); Francis Mulhern, The Moment of 'Scrutiny' (London: Verso, 1979). 
transformación de la "historia cultural" en "historias de las culturas", confiesa su esperanza en haber logrado una síntesis personal producto de la influencia benéfica de todos ellos ${ }^{86}$. En consonancia con la visión de Burke, nuestro método de trabajo se podría definir como una síntesis de ideas y procedimientos tomados de diversos planteamientos y sistemas teóricos adaptados a nuestras necesidades.

Desde este momento, esta tesis podría recalar en la denominada nueva historia cultural. Las propuestas que han ido planteando las distintas corrientes incluidas por la historiografía en este espacio heterogéneo, tremendamente sensible y permeable a la influencia de otros ámbitos epistemológicos como la sociología o la antropología, han constituido para nosotros fuentes donde proveernos y apropiarnos, en función de nuestros intereses, de categorías conceptuales y herramientas metodológicas con las que enfrentar nuestro cometido ${ }^{87}$. Entre ellas, han sido las prácticas propias de la microhistoria las que más adecuadas se mostraban a la naturaleza y las características de nuestro objeto de investigación. El estudio exhaustivo de las fuentes documentales o la paulatina reducción de la escala de observación en nuestras aproximaciones a los fenómenos histórico-culturales que afrontamos son procedimientos incorporados como rutinarios a nuestro método de trabajo. El ejercicio hermenéutico consustancial a los

86 "To conclude, then. Five moments, five contexts, five models. Each appears inadequate by itself. Yet we all have something to learn from each one. To speak more personally: as a student of the Renaissance, I have learned a good deal from Burckhardt and Warburg. As a critical enthusiast for Annales, I have learned from Bloch, Febvre, Braudel. As a member of the circle of Past and Present, from Hobsbawm, Thompson, and Williams. I participated in the British discovery of Lévi-Strauss in the sixties and of Geertz in the seventies. Finally, a late discovery of South America has included an acquaintance with the work of Freyre and Ortiz. The result is I hope personal synthesis." Peter Burke, "From Cultural History", pp. 23-24.

${ }^{87}$ La bibliografía sobre Nueva Historia Cultural es extensa. Es un común denominador de prácticamente todos los autores que han reflexionado sobre ella, poner el énfasis en la diversidad y el eclecticismo que la caracteriza. Sólo en una de las publicaciones que se pueden considerar como de referencia, Formas de hacer historia, ed. por Peter Burke (Madrid: Alianza Editorial, 2003), se incluyen estudios historiográficos que responden a títulos como "Historia desde abajo", "Historia de las mujeres", "Historia de ultramar", "Sobre microhistoria", "Historia Oral", "Historia de la lectura", "Historia visual", "Historia del cuerpo revisada", etc. La edición original inglesa: New Perspectives on Historical Writing (Cambridge: Polity Press, 1991). En Justo Serna y Anaclet Pons, Historia cultural. Autores, obras, lugares (Madrid: Akal, 2013), pp. 25-27, podemos encontrar una larga lista compuesta por cerca de centenar y medio de referencias a historias culturales. Jesús A. Martínez Martín señala: "La nueva historia socio-cultural, pues, no es una escuela historiográfica, ni una corriente, ni una forma unívoca de hacer historia. Se manifiesta en tantas versiones como autores, con distancias y contradicciones entre ellos, pero que comparten una dimensión cultural de sociedad, rescatando la cultura como marco de comprensión de una sociedad compleja y cambiante que construye símbolos y representaciones y les permite una interpretación más que la búsqueda de categorías generales." "Historia socio-cultural. El tiempo de la historia de la cultura", Revista de historia Jerónimo Zurita, 82 (2007), pp. 237-252, p. 239. Este artículo ha sido consultado en su versión electrónica disponible en: $<$ http://ifc.dpz.es/recursos/publicaciones/27/38/09martinez.pdf $>$ (consultado 16-10-2013). 
análisis microhistóricos es para nosotros una necesidad al toparnos con formas, prácticas y manifestaciones simbólicas cuyos significados hay que desvelar o, al menos, tratar de interpretar.

Nos parece haber asimilado una modalidad de microhistoria cercana a una especie de historia de las mentalidades, pues, en último término, arribamos al universo ideológico y simbólico de una determinada comunidad -en consecuencia, de los individuos que la componen-, vinculada, e incluso confundida con la institución sometida a estudio en su contexto cultural. Hemos indagado en fuentes generadas por personajes relacionados de una forma $\mathrm{u}$ otra con la institución, o implicados en el proceso de algún modo, en el intento de entender los sistemas de pensamiento y referentes identitarios que estaban detrás de las actitudes enfrentadas. Así, la música litúrgica y su reforma se muestra, no sólo como objeto de estudio en sí mismo, sino también como medio para el conocimiento de una cultura en unas coordenadas espaciotemporales concretas.

Los modelos de inferencia inductiva -y abductiva ${ }^{88}$ - empleados en los discursos microhistóricos resultan idóneos para el cumplimiento de uno de nuestros objetivos, tratar de proporcionar suposiciones razonadas, abrir vías para la comprensión de la reforma a nivel español desde las conclusiones, e hipótesis explicativas productos del estudio del caso sevillano. Como declara el propio Giovanni Levi, uno de los principales problemas de la microhistoria es el de la generalización. Las aportaciones que como fruto del análisis del proceso hispalense ofrezcamos para explicar el proceso

\footnotetext{
${ }^{88}$ En el curso de su explicación sobre el método de conocimiento de los análisis microhistóricos, Justo Serna y Anaclet Pons afirman que el proceso de inferencia propio de la historia es la abducción, tal y como es descrita por Charles S. Peirce: "Desde luego, si comparamos los procedimientos históricos con los mecanismos inferenciales propios de las ciencias naturales, la consecuencia es evidente: la forma característica del historiador con su material no pasa fundamentalmente por estas opciones enunciadas [deducción e inducción], aun cuando los historiadores no se priven en ocasiones de desarrollar modelos deductivos e inductivos. Por tanto, otro debe ser el rasgo básico de la operación histórica: no nos referimos al uso de inferencias hipotético-deductivas, sino a los cimientos del saber histórico. Pues bien, en este caso, el procedimiento característico pertenece al proceso inferencial de la abducción." Serna y Pons, "El ojo de la aguja", p. 116. Peirce explica así los distintos modelos de inferencia: "La deducción prueba que algo tiene que ser; la inducción muestra que algo es actualmente operativo; la abducción sugiere que algo puede ser". Charles Peirce, El hombre, un signo (Barcelona: Crítica, 1988), p. 36, cit. en Serna y Pons, "El ojo de la aguja", p. 116. En cualquier caso, la explicación a la que nos conduce la inferencia abductiva debe ser verificada: "naturalmente (...) dever esser verificata", Umberto Ecco, Semiotica e filosofia del linguaggio (Turín: Einaudi, 1984), p. 42, cit en: Serna y Pons, "El ojo de la aguja", p. 116.
} 
español deben ser completadas y verificadas por las que puedan brindar otros estudios dedicados a otras diócesis ${ }^{89}$.

En esta introducción metodológica debemos aludir a uno de los enfoques desde los que hemos abordado el análisis del Congreso; aquel que tiene su fundamento en la consideración de esta asamblea como escenario e instrumento para la institucionalización del denominado movimiento reformista español. Lo contemplamos, por tanto, como un espacio social en proceso de definición y consolidación compuesto por individuos que de una $u$ otra forma y por unos $u$ otros motivos muestran interés en la música litúrgica y su reforma. En consecuencia, los recursos metodológicos aplicados a su estudio se han tomado de aquellas aproximaciones al arte desde una perspectiva sociológica.

Las teorías institucionalistas sobre el arte surgidas en el ámbito anglosajón constituyeron una solución alternativa a los tradicionales discursos estéticos, cada vez más limitados para ofrecer explicaciones satisfactorias a las nuevas tendencias artísticas contemporáneas $^{90}$. El concepto de art world, término utilizado por primera vez por Arthur Danto en 1964 y desarrollado por autores como George Dickie o Howard S. Becker, entre otros, nos ha sido especialmente útil ${ }^{91}$. Refiere un sistema en el que distintos actores desempeñando diferentes roles colaboran dentro de una serie de convenciones en la creación de un producto que pueda ser percibido como arte. La noción de "campo" propuesta por Pierre Bourdieu constituye un importante avance,

\footnotetext{
${ }^{89}$ Uno de los componentes de la tríada representativa de la corriente microhistórica tal y como apareció en Italia en los años setenta, Giovanni Levi -los otros dos fueron Carlo Ginzburg y Edoardo Grendiaclara las diferencias entre historia local y microhistoria: "Si queremos dar una definición de microhistoria diremos que es una reducción de escala de análisis usando el microscopio[...]Yo he tratado de ver si ciertas cosas, y en particular el mercado de la tierra, por ejemplo, estudiados al nivel local, al nivel micro, estudiados con el microscopio, podían decirnos más, podían revelarnos los mecanismos que a una escala mayor no conseguiríamos ver. En este sentido, el problema de la microhistoria es siempre un problema de generalizaciones. Creo que didácticamente, necesariamente, lo ideal es no tener ningún interés específico por la localidad que se estudia. Es una tarea instrumental, se busca una escala reducida como un laboratorio, para devenir al problema general." José Luis Bertrán y otros, "Antropología y microhistoria: conversación con Giovanni Levi”, Manuscrits, 11 (1993), pp. 15-28, pp. 17-18.
}

90 En la definición de arte como un objeto dotado de ciertas virtudes intrínsecas (belleza, forma, expresión) capaz de suscitar una experiencia estética dio paso a aquella que lo entendía como el producto de un proceso en el que intervenían numerosos actores que tejían un red de colaboración. Véase: Hans van Maanen, How to study art worlds. On the Societal Funcioning of Aesthetic Values (Amsterdam: Amsterdam University Press, 2009), pp. 17-18.

91 Danto hacía uso de la idea de "art world" por primera vez en "The Artworld", The Journal of Philosophy, 61/19 (1964), pp. 571-584. Véase: George Dickie, Art and the Aesthetic: An Institutional Analysis (Ithaca: Cornell University Press, 1974); y The Art Circle: A Theory of Art (New York: Haven, 1984); así como Howard S. Becker, Art Worlds (Berckley: University of California Press, 1982). 
según sostiene el propio sociólogo ${ }^{92}$, respecto al concepto de art world, pues a diferencia de este, el "campo artístico"

no es reductible a una población, es decir, a una suma de agentes individuales vinculados por meras relaciones de interacción y, con mayor precisión, de cooperación: lo que falta, entre otras cosas, en esta evocación meramente descriptiva y enumerativa, son las relaciones objetivas que son constitutivas de la estructura del campo y que orientan las luchas que tratan de conservarla o transformarla. ${ }^{93}$

Las contribuciones de Bourdieu desde el postestructuralismo son especialmente valiosas para comprender las dinámicas relacionales entre los distintos agentes en liza y las causas que las mueven y rigen dentro de este espacio en ebullición que es el movimiento reformista 94 . A tenor de la descripción anterior, el "campo" bourdieuano no es sólo un espacio de colaboración, sino también de "luchas", e implica una consideración de las relaciones entre los agentes como objetivas, independientemente de ellos mismos. Estas dos ideas enriquecen el anterior concepto de art world y acercan aún más la herramienta metodológica a la realidad de nuestro objeto de estudio. Hemos acuñado el término "espacio socio-artístico" que designa un concepto resultado de la apropiación adaptada a nuestras necesidades de la idea de world art y la noción de "campo" de Bourdieu. Obviamente, los otros dos conceptos sin los que el aparato teórico del francés se desarticularía, “habitus" y "capital”, están presentes en el repertorio conceptual que acomodamos y aplicamos en nuestros análisis.

Por último, hemos de hacer mención a la distinción entre uso y función de la música planteada por el etnomusicólogo Allan P. Merriam. Esta conceptualización funcionalista de la música nos es tremendamente útil como punto de partida para

\footnotetext{
${ }^{92}$ Bourdieu compara el concepto de art world con la idea de República de las letras de Pierre Bayle y con la noción de "campo" que él mismo propone, y afirma: "[...] la noción de art world, de uso corriente en Estados Unidos en los campos sociológico y filosófico, se inspira en una filosofía social absolutamente opuesta a la que existe en la idea de República de las letras tal y como la presenta Bayle, y marca una regresión con respecto a la teoría del campo tal como yo la había presentado." Pierre Bourdieu, Las reglas del arte. Génesis y estructura del campo literario (Barcelona: Anagrama, 1995), p. 307.

${ }^{93}$ Ibídem.

94 Entre la vasta producción de Pierre Bourdieu, las siguientes constituyen, además de la ya citada Reglas del arte, obras de referencia en lo que a nuestro ámbito de trabajo respecta: La distinción. Criterios y bases sociales del gusto (Madrid: Taurus, 2012 [1988, en castellano]); o la colección de ensayos publicados como The Field of Cultural Production:Enssays of Art and Literature (New York: Columbia University Press, 1993).
} 
entender e interpretar la música litúrgica y los significados simbólicos que pudiera poseer para la institución y la propia sociedad hispalenses ${ }^{95}$.

En esta tesis conviven diversas perspectivas analíticas y se entrelazan distintos planos y ámbitos de estudio: la Iglesia-institución, dentro de la cual existen varios estamentos y niveles que diferenciar, comparte un mismo espacio con el movimiento reformista español y sus grandes proyectos; la dimensión local y general se vinculan e incluso confunden; los principios litúrgico-musicales entran en comunicación con las ideas regeneracionistas y nacionalistas; el propio impulso regeneracionista mueve iniciativas reformistas religioso-musicales; la perspectiva analítica institucional de partida deriva en un intento de sondear los pilares que sustentan mentalidades y tendencias culturales e ideológicas diversas; los grandes eventos se contemplan, desde una clave sociológica, como escenarios en los que se constituyen espacios socioartísticos complejos, además de como discursos estéticos, ideológicos y culturales. Cada uno de estos aspectos y ámbitos posee la suficiente entidad como para ser considerados como objetos de estudio independientes. Sin embargo, dado que todos representan vertientes de un mismo fenómeno, poliédrico, e incluso vectores interrelacionados que confluyen en un mismo punto, su plena comprensión, así como del todo del que son parte, depende de su acertada puesta en relación.

Uno de los principales retos de este trabajo ha consistido en disponer todas estas "piezas" en una estructura discursiva lo más coherente y comprensible posible. Hemos optado por organizar la exposición tomando como ejes las tres principales instituciones sometidas a examen: la administración central de la Archidiócesis, la Catedral, y el Congreso. Sin duda, no es la única posibilidad, y, desde luego, no está exenta de inconvenientes; entre ellos, la necesidad de someter a este armazón temas que por su importancia e interés reclamarían la elaboración de un discurso que girara en torno a ellos, si no estuvieran integrados en un hilo argumental y unos razonamientos que los trascienden y en los que cumplen una función determinada. Sin embargo, creemos que estas instituciones, obviamente, con los agentes que las rigen y componen,

${ }^{95}$ Desde el comienzo del capítulo dedicado a explicar la diferencia entre uso y función de la música, Merriam concentra su atención en los significados que la música pueda adquirir para una determinada sociedad, elevando así su aproximación al plano simbólico: "The uses and funtions of music represent one of the most important problems in ethnomusicology, for in the study of human behavior we search constantly, as has been pointed out time and time again in this pages, not only for the descriptive facts about music, but, more important, for the meaning of music." Alan P. Merriam, The Anthropology of Music (Evanston: Northwestern University Press, 1964), p. 209. El capítulo XI "Uses and Funtions" de dicha obra ha sido traducido al castellano y recogido en: Francisco Cruces y otros (eds.), Las culturas musicales. Lecturas de etnomusicología (Madrid: Trotta, 2001), pp. 275-295. 
constituyen los marcos fundamentales y los espacios históricos básicos -igualmente imbricados y relacionados- en los que se producen los fenómenos que sometemos a estudio. Por esta razón consideramos que deben articular y definir en aras de la claridad la organización de la presente tesis.

\section{Estructura de la tesis}

Esta tesis doctoral está articulada en tres partes. En las partes I y II concentramos nuestra atención en las dos principales instituciones eclesiásticas hispalenses: la administración general archidiocesana, y la Catedral, respectivamente. La parte III está dedicada al II Congreso Nacional de Música Sagrada, entendiéndolo, no sólo como acontecimiento, sino sobre todo como escenario e instrumento para la institucionalización del movimiento español para la reforma de la música religiosa. Cada una de ellas consta de dos capítulos. Antes de iniciar nuestro estudio hemos creído necesario proporcionar una idea general e introductoria sobre el Motu Proprio como el documento fundamental que desencadenó todo el proceso. Por ello, el apartado "Breve introducción al Motu Proprio 'Tra le sollecitudini' de Pío X" se ha ubicado antes de la parte I.

En los capítulos 1 y 2 se aplica el patrón de análisis que exponíamos en el apartado de "Metodología". Con ello pretendemos llevar a cabo el estudio del proceso de reformas puesto en marcha por las autoridades eclesiásticas locales durante los pontificados de Marcelo Spínola (capítulo 1), y Enrique Almaraz (capítulo 2). Se somete a examen la recepción del documento papal por parte de la jerarquía eclesiástica local, su labor de desarrollo normativo y su gestión del proceso de reformas. Asimismo se observa la acogida dispensada por los distintos estamentos a las disposiciones ideadas por las autoridades y órganos diocesanos con capacidad de decisión y gobierno. Se persigue detectar las actitudes favorables así como las resistencias ante la reforma para evaluar su grado de aceptación. El proceso hispalense se pone continuamente en relación con los procesos desarrollados en otras diócesis peninsulares, situando de esta manera el andaluz en el contexto general hispano.

En el capítulo 3 trasladamos nuestro enfoque al primer templo diocesano. La reforma en la Catedral se estudia, al mismo tiempo, como una aplicación particular del plan general diocesano, y como un proceso llevado a cabo por una institución con suficiente autonomía como para idear y desplegar un plan propio. La reducción de la escala de observación permite ahondar, más allá de la institución como estructura, en 
los propios agentes y actores históricos. Estudiamos sus reacciones y distintas tomas de posición frente a las modificaciones que se van introduciendo en el canon litúrgicomusical.

Iniciamos el capítulo 4 planteando una serie de hipótesis que nos sirven como puntos de partida para tratar de profundizar en, e interpretar los universos culturales que asoman a través de las actitudes ante la reforma mantenidas por los miembros de la comunidad catedralicia. Indagamos en obras históricas, académicas y literarias, en discursos, conferencias, o artículos el valor simbólico que la música sacra y las fiestas litúrgicas a las que está asociada pudiera poseer para aquellos. La trascendencia de los fenómenos culturales que sometemos a estudio traspasa con creces los límites de la institución catedralicia. Por ello, nuestra mirada se proyecta necesariamente al conjunto de la sociedad local a la que pertenece y, en cierta forma, aspira a representar como uno de los principales emblemas de la ciudad. Por último, centramos nuestra atención en el pensamiento y labor del maestro de capilla Vicente Ripollés, una figura particularmente relevante en el proceso.

En la Parte III confluyen de forma especial la dimensión local y la general. En el capítulo 5 abordamos el análisis de la organización y celebración del II Congreso Nacional de Música Sagrada. El periodo que trascurre entre su gestación y los meses posteriores a su clausura se contempla como un camino hacia la institucionalización del movimiento español para la reforma de la música religiosa emprendido por sus principales líderes.

En el capítulo 6, el Congreso como objeto de estudio pasa a ser un gran y complejo discurso desplegado para la institucionalización de un nuevo canon de música religiosa. Se estudian las crónicas, ponencias y comunicaciones, los programas de los conciertos así como las actuaciones musicales en la liturgia, artículos de revistas especializadas o aparecidos en la prensa y la correspondencia de los principales actores históricos. Se trata con ello de identificar los fundamentos ideológicos, estéticos, estilísticos del canon que se propone. Observaremos asímismo la recepción que las distintas sensibilidades le brindaron.

Finalmente se proporcionan una serie de apéndices documentales, cuyo contenido está descrito en el índice general. 



\section{Breve introducción al Motu Proprio "Tra le sollecitudini” de Pío X}

Con la promulgación el 22 de noviembre de 1903 del Motu Proprio "Tra le sollecitudini”, Pío X sentó las bases de una profunda reforma de la música en la liturgia católica. La aparición de este documento tan sólo tres meses y medio después de acceder al solio pontificio indica la importancia que dentro de su programa pontifical de corte restaurador, condensado en el lema instaurare omnia in Christo -restaurar todo en Cristo- $^{1}$, atribuyó a la cuestión litúrgico-musical ${ }^{2}$.

Desde el punto de vista del derecho canónico, un motu proprio es un rescripto papal, es decir, una respuesta que proporciona el pontífice por escrito a requerimientos o peticiones hechas por parte de determinadas personas o colectivos ${ }^{3}$. En el caso del MP sobre música, los motivos que llevaron a Pío X a su publicación fueron, según él mismo expresa, "las muchísimas quejas que de todas partes se nos han dirigido en el poco tiempo pasado desde que plugo al Señor elevar nuestra humilde persona a la suma

\footnotetext{
1 "Instaurare [...] significa rimettere a nuovo ciò che è guasto, solidare ciò che è debole, vivificare ciò che sta per languire, ricomporre ciò che sta per sfaciarsi". Angelo Marchesan, "L'opera di Pio X nella restaurazione della musica sacra", en Bollettino ceciliano, 5 (1910), 210; cit. en Giordano Monzio, La parte della musica nel programa "Instaurare omnia in Christo". Obiettivi e contenuti del Motu proprio "Tra le sollecitudini”" (Roma: [s.e.], 2003), 1."A questo punto è ormai evidente come il lemma paolino che costituiva il motto di Pio X -perduta la dimensione escatologica e acquistate connotazioni più marcatamente «restauratrici» ed ecclesiocentriche- avesse ormai subito una significativa reinterpretazione." Monzio, La parte della musica, 7.

${ }^{2}$ Giuseppe Sarto, entonces patriarca de Venecia, inició su pontificado el 4 de agosto de 1903.

${ }^{3}$ El Código de Derecho Canónico define el rescripto como "un acto administrativo que la competente autoridad ejecutiva emite por escrito, y que por su propia naturaleza concede un privilegio, una dispensa u otra gracia, a petición del interesado." Capítulo III "De los rescriptos", canon 59.1. $<$ http://www.vatican.va/archive/ESL0020/_P7.HTM.> (consultado 27-10-2013) Por su parte, The Catholic Encyclopedia señala: "Rescripts are responses of the pope or a Sacred Congregation, in writing, to queries or petitions of individuals. Some rescripts concern the granting of favours; others the administration of justice, e.g. the interpretation of a law, the appointment of a judge." Meehan, Andrew. "Papal Rescripts", en The Catholic Encyclopedia (New York: Robert Appleton Company, 1911), vol. 12. $<$ http://www.newadvent.org/cathen/12783b.htm> (consultado 26-10-2013).
} 
dignidad del apostolado romano"4. La expresión motu proprio no indica, en consecuencia, que la iniciativa de emitir el documento parta del papa, sino que las disposiciones que este ordena son decididas según su proprio criterio, sin necesidad de consejo por parte de cardenales u otras autoridades ${ }^{5}$. El documento sobre música sagrada tenía, por tanto, una naturaleza fundamentalmente legal y un fin normativo ${ }^{6}$. De hecho, la "Instrucción acerca de la música sagrada" propiamente dicha, es decir, la sección en la que se relacionaban los distintos preceptos llamados a regular a partir de ese momento la música en los templos, venía precedida de la siguiente declaración:

Con este motivo, y para que de hoy en adelante nadie alegue la excusa de no conocer claramente su obligación y quitar toda duda en la interpretación de algunas cosas que están mandadas, estimamos conveniente señalar con brevedad los principios que regulan la música sagrada en las solemnidades del culto y condensar al mismo tiempo, como en un cuadro, las principales prescripciones de la Iglesia contra los abusos más comunes que se cometen en esta materia. Por lo que de Motu Proprio y ciencia cierta publicamos esta nuestra Instrucción, a la cual, como si fuese Código jurídico de la música sagrada, queremos con toda plenitud de nuestra Autoridad Apostólica se reconozca fuerza de ley, imponiendo a todos por estas letras de nuestra mano la más escrupulosa obediencia. ${ }^{7}$

Como se ha puesto de manifiesto en diversas ocasiones, el $M P$ no sólo fue el punto de inicio de una ambiciosa reforma de la música litúrgica. Constituyó, además, la consecuencia lógica y el resultado final de una tendencia que apareció en torno al segundo tercio del s. XIX, y que a final de siglo había cristalizado en un potente movimiento, cuyos planteamientos ideológicos y estéticos terminarían siendo asumidos

\footnotetext{
${ }^{4}$ Como hemos apuntado más arriba, Pío X aludía, además de a las "quejas" recibidas, a su "personal experiencia”. MP. [Exposición de motivos previa a la Instrucción legal].

5 "[Motu proprio:] The name given to certain papal rescripts on account of the clause Motu Proprio (of his own accord) used in the document. The words signify that the provisions of the rescript were decided on by the pope personally, that is, not on the advice of the cardinals or others, but for reasons which he himself deemed sufficient." MacErlean, Andrew, "Motu Proprio.", en The Catholic Encyclopedia (New York: Robert Appleton Company, 1911), vol. 10. <http://www.newadvent.org/cathen/10602a.htm> (consultado 22-10-2013).

${ }^{6}$ Ismael Fernández de la Cuesta advertía en el simposio sobre el Motu Proprio celebrado en 2003 de la importancia de conocer el carácter jurídico del documento para su correcta interpretación. "La reforma del canto gregoriano en el entorno del Motu Proprio de Pío X", Revista de Musicología (Actas del Simposio Internacional "El Motu proprio de San Pío X y la Música (1903-2003)"), ed. por Mariano Lambea, XXVII/1 (2004), pp. 43-76, p. 46. La introducción al MP que desde un punto de vista canónico hace este autor es ciertamente clarificadora.
}

${ }^{7} M P$. [Exposición de motivos previa a la instrucción legal]. 
por las autoridades eclesiásticas. María Antonia Virgili ha tratado de definir los rasgos principales, según su punto de vista, del contexto ideológico en el que se enmarcó todo este proceso de gestación y maduración de una nueva mentalidad y sensibilidad en lo que a la música sacra se refiere: las filosofías racionalistas, empiristas e idealistas impulsaron los debates sobre la belleza y la estética, y esta como ciencia; el relativismo y el subjetivismo sustituyeron a la Verdad; el arte dejó de ser "un reflejo de la creatividad divina", pasando a ser un producto de la inspiración humana; movimientos de renovación litúrgica recuperaron el sentido teológico de la liturgia, que se contempló no sólo como un acto de culto sino como un acontecimiento salvífico; se produjo una fractura entre cultura y fe, que se manifestó en la crisis de la música litúrgica, y en la contraposición música sacra y música profana, teniendo; consecuencia de ello fue la falta de interés de los grandes compositores en los textos litúrgicos, y el abandono por parte de la Iglesia de su condición de mecenas ${ }^{8}$.

Dos acontecimientos han sido subrayados como hitos para el nacimiento y desarrollo de estas corrientes litúrgico-musicales de aspiraciones renovadoras: por un lado, el inicio de la actividad de restauración del canto llano por parte de la comunidad que se instaló en el monasterio francés de Solesmes; y por otro, la fundación de la Asociación Ceciliana alemana. En 1833, el monje benedictino Prosper Guéranger compró el priorato de Solesmes, abandonado tras la Revolución Francesa, con el objetivo de convertirlo en un centro modélico según sus ideales ${ }^{9}$. Devolver a la liturgia su condición mistérica y su importancia ${ }^{10}$, teniendo como paradigma la vida social y religiosa medieval, fue su principal objetivo ${ }^{11}$. La necesidad de vuelta a unos valores

8 “Antecedentes y contexto ideológico de la recepción del Motu Proprio en España", Revista de Musicología (Actas del Simposio Internacional "El Motu proprio de San Pío X y la Música (19032003)”), ed. por Mariano Lambea , XXVII/1 (2004), pp. 23-42, pp. 23-27.

${ }^{9}$ Virgili aclara en relación a la iniciativa de Gueranguer: "La restauración del verdadero canto gregoriano, liderado por P. Guéranger (1805-1875) y que encaja muy bien en el marco de las corrientes románticas de recuperación de la historia y de retorno a lo primigenio, a lo autóctono. Sin embargo este hecho no puede únicamente explicarse en sintonía con el gusto y la vuelta al medievalismo que propugna el espíritu romántico, sino enmarcado y tomando parte de la reflexión teológica de la liturgia, y que caracteriza todo el movimiento reformista, [...]. Virgili, “Antecedentes y contexto ideológico”, p. 31.

10 "Para Guéranger, la liturgia, como culto público, es el alma de esa sociedad." P. de Clerck, La belle nouveauté de la tradition, en Les grandes révolutions de la théologie moderne, dir. por F. Bousquet (Paris: Bayard, 2003), p. 202; cit. en Xabier Basurko, Historia de la Liturgia (Barcelona: Centre de Pastoral Litúrgica, 2006), pp. 361-362.

11 "La Edad Media aparece ahora como la época social y religiosa 'arquetípica' hacia la cual había que tender." Basurko, Historia de la Liturgia, p. 364. "[...] frente al clasicismo y academicismo nació el deseo de asumir y estudiar la cultura, la tradición, la historia con el fin de conseguir la identidad de los hombres, de las naciones y, también, la de una institución milenaria como la Iglesia católica, identidad 
litúrgicos propios de un pasado idealizado revela las componentes historicista romántica y restauradora presentes en las tesis de este movimiento, que hay que entender como una corriente de reacción emergida en la Iglesia católica ante la situación provocada por el efecto de las ideas ilustradas ${ }^{12}$.

La restauración del canto litúrgico, por tanto, constituyó una prioridad. Guéranger junto con sus monjes inició en Solesmes una labor de recopilación, análisis y, posteriormente, edición del gregoriano según los antiguos códices medievales, desde la premisa de que en ellos se hallaba el auténtico canto eclesiástico ${ }^{13}$. La recuperación de las melodías se realizó con una intención científica, desde presupuestos positivistas, y aplicando un método comparativo. Estos trabajos dieron como resultados más destacados Les mélodies grégoriennes d'après la tradition (1880), editada por Joseph Pothier; Paléographie musicale, por André Mocquereau, cuya publicación se inició en $1889^{14}$; así como los libros que contuvieron el repertorio gregoriano sancionado como oficial por el Vaticano una vez en vigor el MP: el Kyriale (1905), el Graduale (1908) y el Antiphonale (1912) ${ }^{15}$.

perturbada por los vaivenes de la transición política del antiguo al nuevo régimen y por los brutales cambios ocurridos en la vida social, ejercida hasta entonces sin sobresaltos, de manera más o menos serena y homogénea. Los hombres del romanticismo volvieron, así pues, sus ojos al pasado, particularmente a la Edad Media, para encontrar allí, entre sus brumas, las claves de la restauración y regeneración personal, social, institucional.

En este caldo de cultivo emergió un personaje cuya influencia sería determinante en la restauración de la liturgia de la Iglesia catóica y, consiguientemente, del canto, Prosper Louis Pascal Guéranguer (1805-1875)." Fernández de la Cuesta, "La reforma del canto gregoriano", p. 51.

12 “Contra el postulado de una religión dentro de los límites de la mera razón, proclamado por la Ilustración, ahora en el siglo XIX se reafirma el principio de la revelación, del dogma y de la tradición, así como el respeto debido a la constitución jerárquica de la Iglesia." Basurko, Historia de la liturgia, pp. $361-362$

${ }^{13}$ Las tesis solesmenses arribarían a España con la repoblación del monasterio de Silos en 1880 por monjes provenientes del propio Solesmes. La nueva forma del canto llano practicado en Silos se difundiría gracias a Eustoquio Uriarte. Fernández de la Cuesta, "La reforma del canto gregoriano", pp. $60-61$.

${ }^{14}$ Paléographie musicale es una colección de volúmenes con reproducciones facsimilares de diferentes códices de canto llano: gregoriano, mozárabe, galicano y ambrosiano, tal y como reza su título completo. André Mocquereau, Paléographie musicale. Les principaux manuscrits de chant gregorien, ambrosien, mozarabe, gallican publiés en fac-similés phototypiques. 17 vols. (Tournay: Descleé \& $C^{\mathrm{a}}$, [desde] 1889).

15 Véase Pierre Combé, The Restoration of Gregorian Chant. Solesmes \& the Vatican Edition (The Catholic University of America Press, 2003). La edición original francesa es: Histoire de la restauration du chant grégorien d'après des documents inédits. Solesmes et l'Edition vaticane (Solesmes: Abbaye Saint-Pierre, 1969). 
La fundación en Bamberg de la Allgemeiner Deutscher Cäcilienverein, la asociación que aglutinó al llamado movimiento cecilianista alemán, data de $1868^{16}$. Su objetivo fue restituir la, según sus criterios, verdadera y auténtica música sacra al servicio de la liturgia ${ }^{17}$. Con este fin, desarrollaron un proyecto de restauración musical centrado en la purificación del gregoriano según la Edición Medicea (1614), por un lado; y, por otro, la recuperación de la polifónica clásica, en especial Palestrina, como modelos perfectos de música sagrada ${ }^{18}$. El espíritu cecilianista prendió rápidamente en el resto de Europa y Norteamérica, en donde se crearon numerosas sociedades para la restauración de la música sagrada ${ }^{19}$. Al calor de este impulso se celebraron varios congresos que reflejaron las inquietudes y el compromiso de un cada vez más vasto movimiento por la regeneración y dignificación de la música litúrgica ${ }^{20}$. Este contexto

${ }^{16} \mathrm{Su}$ creación se debe fundamentalmente al entonces maestro de capilla de la catedral de Ratisbona, Franz Xaver Witt (1834-1888).

17 "A 19th-century movement, centred in Germany, for the reform of Catholic church music. Reacting to the liberalization of the Enlightenment, the Cecilians sought to restore traditional religious feeling and the authority of the church. They regarded 'true, genuine church music' as being subservient to the liturgy, and intelligibility of words and music as more important than artistic individuality". Siegfried Gmeinwieser, "Cecilian Movement". Grove Music Online. Oxford Music Online $<$ http://www.oxfordmusiconline.com/subscriber/article/grove/music/05245?q=cecilian+movement\&searc $\mathrm{h}=$ quick\&pos=1\&_start=1\#firsthit.> (consultado 24-04-2009).

18 A finales de siglo, este intento de restauración del canto llano sobre el fundamento de la edición medicea entraría en conflicto con el llevado a cabo por los monjes de Solesmes según los manuscritos medievales. Para profundizar en este tema véanse, entre otros: Fernández de la Cuesta, "La reforma del canto gregoriano", pp. 45-74; Klemens Schnorr, "El cambio de la edición oficial del canto gregoriano de la editorial Pustet/Ratisbona a la de Solesmes en la época del Motu Proprio", Revista de Musicología (Actas del Simposio Internacional "El Motu proprio de San Pío X y la Música (1903-2003)”), ed. por Mariano Lambea, XXVII/1 (2004), pp. 197-209.

${ }^{19}$ Entre ellas hay que destacar la Associazione Italiana Santa Cecilia (1880), que recibió el apoyo del cardenal Sarto, futuro Pío X, y que contó con la implicación de Lorenzo Perosi. Otros países en donde se fundaron otras asociaciones cecilianas, tomando como ejemplo la germana, fueron: EE.UU. (1873), Holanda (1876), Irlanda (1878), Inglaterra (1884), además de en Polonia, Bohemia, Hungría, Suiza. A estas hay que sumar la creación de determinadas instituciones educativas de gran repercusión. La más destacada entre ellas fue la prestigiosa Schola cantorum fundada en 1894 por Charles Bordes con la colaboración de Vincent d'Indy y Alexandre Guilmant. La enseñanza del canto gregoriano y la polifonía clásica ocupaba un lugar preponderante en los estudios que ofertaba. Algunas décadas antes Louis Niedermeyer había creado la École de musique religieuse et classique (1853).

${ }^{20}$ Congreso de Música Religiosa de París (1860), I Congreso Nacional de Música Sagrada italiano (Milán, 1880), Congreso Internacional de Canto Gregoriano (Arezzo, 1882). En Italia se celebraron, además, sendos congresos en Venecia (1874) y Soave (Verona, 1889). Otros congresos católicos no específicamente musicales, sino de carácter general, incluyeron secciones de música. Los de Malinas en 1863 y 1864 son un ejemplo de ello. Una fuente valiosa para el estudio de estos dos últimos congresos, así como para el de Paris de 1860: T. J. de Vroye y X. van Elewyck, De la musique religieuse. Les congrès de Malines (1863 et 1864) et Paris (1860) et la législation de l'Église sur cette matiére (Paris: Librairie Lethielleux, 1866). El primer congreso tras la publicación del $M P$ se celebró en Estrasburgo en 1905. 
favorable a la renovación litúrgico-musical propició la actuación de la autoridad eclesiástica. En 1884, la Sagrada Congregación de Ritos elaboró un documento dirigido al episcopado italiano en el que se establecía las normas para la regulación de la música en el culto. Diez años más tarde, la misma congregación publicó un nuevo reglamento ampliado y corregido. Ambos escritos fueron un reflejo del ideario que sustentaba las nuevas corrientes renovadoras, y constituyeron los antecedentes inmediatos del $M P^{21}$.

El propio Pío X, durante su periodo como patriarca de Venecia (1893-1903), se comprometió con este movimiento, convirtiéndose en uno de sus principales impulsores ${ }^{22}$. Mantuvo un contacto estrecho con los principales personajes de la reforma en Italia como Lorenzo Perosi o Angelo de Santi, a quien, según apunta Valentí Miserachs, encargó en 1888 un escrito sobre música religiosa que sería, con algunos retoques, el texto del $M P^{23}$. Probablemente, la iniciativa más importante llevada a cabo por el todavía cardenal Sarto antes de su proclamación papal, fue la publicación el 1 de mayo de 1895 de una carta pastoral con la que pretendió impulsar en su diócesis la reforma litúrgico-musical. Dicha carta se considera otro precedente directo del $M P$.

En España es posible reconocer durante la segunda mitad del s. XIX inquietudes similares a las que dieron lugar al movimiento cecilianista en países como Alemania o Italia. Al igual que en estos, se materializaron con el paso de los años en una corriente de opinión y acción en pos de una renovación de la música religiosa. La figura de Hilarión Eslava ha sido señalada por los especialistas como la iniciadora de esta tendencia reformista previa al $M P$ en el ámbito musical español ${ }^{24}$. Sus actividades y obras abordaron prácticamente todos $\operatorname{los}$ frentes $^{25}$ : investigación y recuperación de la

${ }^{21}$ El texto del Reglamento sobre la música religiosa de 1894 se puede consultar en: Nemesio Otaño, La Música Religiosa, pp. 77-81.

${ }^{22}$ En las memorias de Pío X escritas por el que fuera su Secretario de Estado, cardenal Merry del Val, se pone de relieve la particular inclinación del papa Sarto por la música. Rafael Merry de Val, El papa San Pío X: memorias (Madrid: Sociedad de Educación Atenas, 1954).

${ }^{23}$ Valentí Miserachs, "La polifonía clásica, punto cardinal de la reforma del 'Motu Proprio' de San Pío X”, Revista de Musicología (Actas del Simposio Internacional "El Motu proprio de San Pío X y la Música (1903-2003)”), ed. por Mariano Lambea , XXVII/1 (2004), pp. 257-272, p. 263.

${ }^{24}$ Véanse entre otros: Nagore, "Tradición y renovación”, p. 213; José López Calo, "Hilarión Eslava (1807-1878), precursor del Cecilianismo en España", Principe de Viana (Ejemplar dedicado a: Conmemoración del VIII Centenario de la Chantría de la Catedral de Pamplona como dignidad eclesiástica (1206-2006)), coord. por María Gembero Ustárroz, 238 (2006), pp. 577-608; del mismo autor, "Cien años de asociaciones de música religiosa en España (1850-1950)", Cuadernos de Música Iberoamericana, 8-9 (2001), 287-306.

25 Nuestro propósito a la hora de aludir a las iniciativas de Eslava, obviamente, no es exhaustivo. Presentamos tan sólo aquellas más relevantes. 
música religiosa del pasado -Lira Sacro-Hispana, cuyo primer volumen apareció en 1852-; reflexiones teórico-históricas -Breve memoria histórica de la música religiosa en España- ${ }^{26}$; actividad divulgadora y crítica, desarrollada especialmente en La Gaceta Musical de Madrid (1855-1856) ${ }^{27}$; iniciativas para la mejora de la situación de los músicos y las estructuras musicales, canalizadas a través de la sociedad Orfeo Español $(1854)^{28}$; compositor de obras adscritas a una estética de rasgos cecilianistas, lejana del italianismo reinante y del que él mismo participaba ${ }^{29}$.

Tras Eslava, otras voces comprometidas con la renovación de la música religiosa salpicaron la segunda mitad del siglo XIX. Entre ellas las de José Inzenga, Francisco Asenjo Barbieri o Eustoquio Uriarte. Como se ha apuntado en diversas ocasiones, el impulso para la superación de la difícil situación de la música eclesiástica en España, según el análisis que se hacía de ella, no partió de la jerarquía, sino de la iniciativa de algunos músicos y otras personas sensibilizadas con la cuestión, como, por otra parte, ocurrió en el resto de Europa ${ }^{30}$. Las condenas en el plano litúrgico y estético a las derivas profanizantes y teatrales a las que se había abandonado la música sacra convivieron con las denuncias sobre las penosas circunstancias en las que se encontraban las estructuras musicales eclesiásticas como consecuencia del empobrecimiento que la propia Iglesia había experimentado con el correr del siglo ${ }^{31}$ El

${ }^{26}$ La Breve memoria histórica de la música religiosa en España apareció con el volumen décimo y último de la Lira Sacro-Hispana (LSH). A ella habría que añadir la Breve memoria histórica de los organistas españoles, publicada en el Museo Orgánico Español, 2 partes, parte primera (Madrid: [s. e.], 1854-1862).

\footnotetext{
27 Antonio Martín Moreno, "Hilarión Eslava polemista: La polémica en torno a la historia de la música española", en Monografía de Hilarión Eslava, ed. por equipo Musikaste-Eresbil (Pamplona: Diputación Foral de Navarra, 1978), pp. 267-306. La mencionada Breve memoria histórica apareció en el contexto de la polémica que entonces mantenía Eslava con Mariano Soriano Fuertes.

${ }^{28}$ En el primer número de la Gaceta Musical de Madrid, órgano de difusión del Orfeo Español, figuran las pretensiones que llevaron a la fundación de esta sociedad. La declaración comienza: "El Orfeo Español dirigirá al gobierno cuantos proyectos considere útiles al arte, tanto acerca de los ramos que abarca la música religiosa, como la profana [...]". Gaceta Musical de Madrid, 1 de 4 de febrero (1855), p. 3; cit. en José Luis Ansorena, "Biografía de D. Hilarión Eslava”, en Monografía de Hilarión Eslava, ed. por equipo Musikaste-Eresbil (Pamplona: Diputación Foral de Navarra, 1978), p. 83.
}

${ }^{29} \mathrm{M}^{\mathrm{a}}$ Antonia Virgili menciona varios casos de compositores españoles en cuyas obras se puede advertir una proximidad estilística al cecilianismo. Véase: "La música religiosa en el siglo XIX español", en $L a$ música española en el siglo XIX. ed. por Emilio Casares y Celsa Alonso (Oviedo: Universidad de Oviedo, 1995), pp. 375-405, pp. 393-398.

${ }^{30}$ Virgili, “Antecedentes y contexto ideológico", pp. 23-39; Nagore, “Tradición y renovación”, p. 212; López Calo, “Cien años de asociaciones”, p. 293.

${ }^{31}$ Sobre la situación de las estructuras musicales eclesiásticas en el siglo XIX, véase, entre otros: Emilio Casares Rodicio, "La música del siglo XIX español. Conceptos fundamentales”, en La música española 
Concordato firmado por la Santa Sede y el Estado español en 1851 fue considerado como insuficiente para resolver las dificultades por las que atravesaban las instituciones eclesiástico-musicales, así como los propios músicos a su servicio.

En las últimas décadas del siglo, el problema de la música religiosa se había integrado como un ámbito de discusión más en los debates generales sobre la música española. El espíritu regeneracionista y el pensamiento nacionalista se sumaron al historicismo decimonónico como los fundamentos ideológicos desde los que se entendió y proyectó la renovación de la música sacra. En los trabajos de Felipe Pedrell, el gran ideólogo del nacionalismo musical español, la reforma de la música religiosa se confundió con su empresa de recuperación del patrimonio musical histórico para proveer a la nueva música española del sustrato necesario para su resurrección -tal y como él la concebía-, así como para volver a elevar a España ante Europa y los propios españoles como una potencia musical. Sin duda, la iniciativa más importante, ya en las postrimerías del siglo, fue la fundación de la Asociación Isidoriana para la reforma de la música sagrada (1895), bajo los auspicios José María Cos y Macho, uno de los prelados más comprometidos con la reforma musical. Importantes personalidades de la música y la intelectualidad del momento, como Pedrell, Jesús de Monasterio, Uriarte, Esperanza y Sola, o Menéndez Pelayo entre otros, participaron en esta empresa, impulsada como respuesta a la publicación del Reglamento sobre la Música Sagrada de 1894 por parte de la Sagrada Congregación de Ritos. En su seno nacieron la revista La Música Religiosa de España (1896), y la Capilla Isidoriana (1899). Esta última sobrevivió varios años más a las actividades de la propia asociación ${ }^{32}$.

El potente movimiento coral que brotó en las décadas últimas del siglo, especialmente en aquellas ciudades económica e industrialmente pujantes, colaboró en la difusión del nuevo repertorio religioso acorde con la propuesta estética -con un fuerte

en el siglo XIX, ed. por Emilio Casares y Celsa Alonso (Oviedo: Universidad de Oviedo, 1995), pp. 13122, pp. 53-55; del mismo autor, "Pedrell, Barbieri y la restauración musical española", Recerca musicològica, XI-XII (1991-1992), pp. 259-271. Xosé María Carreira somete a crítica la "tradición historiográfica" que atribuye exclusivamente a la caída del Antiguo Régimen y al consiguiente empobrecimiento de la vida musical española durante el siglo XIX la desaparición de las capillas musicales eclesiásticas. Encuentra las causas de dicha desaparición en el fin de la sociedad gremial y de las estructuras que sucumbieron tras la época de las revoluciones. "La visión congelada: autarquía y fideísmo". <http://www.mundoclasico.com/ed/documentos/doc-ver.aspx?id=0003746> (consultado 2-112013).

${ }^{32}$ Véanse, entre otros: Nagore, “Tradición y renovación”, pp. 217-220; Virgili, “Antecedentes y contexto ideológico", pp. 35-36. 
componente historicista- planteada por las tendencias reformistas eclesiásticomusicales ${ }^{33}$.

Un último acontecimiento merece ser reseñado en este trazado panorámico sobre las corrientes reformistas en España anteriores al MP. Se trata del Congreso Internacional de Música Sacra celebrado en Bilbao en $1896^{34}$. El hecho de que se dieran cita importantes personalidades de la música religiosa en Europa como Charles Bordes, Vincent d'Indy o Giovanni Tebaldini, junto al propio Pedrell o a Uriarte; o que estuvieran representadas, además de la Asociación Isidoriana, la Schola cantorum de Paris o la Cappella Antoniana de Padua ofrece una idea de la importancia del evento en el contexto del estado de ebullición reformista que vivían determinados círculos musicales españoles.

Antes de adentrarnos de lleno en nuestro estudio, conviene de forma muy sintética ofrecer los principios y disposiciones recogidas en el texto papal. A lo largo del presente estudio tendremos ocasión de discutir detenidamente, interpretar y analizar cada uno de estos aspectos que ahora, a modo de introducción, relacionamos. La instrucción sobre la música sagrada viene precedida de un análisis de la situación así como de una declaración de los motivos que llevaron al pontífice a publicar el documento. Estas son las ideas principales:

- Es deber del papa y la Iglesia mantener el decoro y la dignidad del Templo.

- Uno de los abusos "difíciles de desarraigar" es el que se comete en relación a la música, un arte que por diversas causas -por su naturaleza "variable", la influencia que recibe del arte profano y teatral, lo incontrolable del "placer" que produce, o los prejuicios arraigados, incluso entre las autoridades- ha experimentado un proceso de desviación de la "recta norma".

\footnotetext{
33 Véanse: La revolución coral. Estudio sobre la Sociedad Coral de Bilbao y el movimiento coral europeo (1800-1936) (Madrid: ICCMU, 2001). pp. 120-122; Xosé Aviñoa, "Los congresos del Motu Proprio (1907-1928): Repercusión e influencias", Revista de Musicología (Actas del Simposio Internacional "El Motu proprio de San Pío X y la Música (1903-2003)"), ed. por Mariano Lambea, XXVII/1 (2004), pp. 381-400, p. 382. María Nagore Ferrer ha estudiado el movimiento coral en diversas publicaciones, además de la mencionada: "Aportaciones al estudio del movimiento coral en España", en Miscel-lània Oriol Martorell (Barcelona: Universitat de Barcelona, 1998), pp. 345-358; "Un aspecto del asociacionismo musical en España: las sociedades corales", Cuadernos de Música Iberoamericana, 8-9 (2001), 211-226; "Santiago de Masarnau, precursor del movimiento coral en España"”, Cuadernos de Música Iberoamericana, 25-26 (2013), 257-274.

34 Esta reunión de músicos notables duró sólo una jornada. Pedrell lo calificó como "conato de congreso", Uriarte de "conferencias". Véase: María Nagore Ferrer, "Una aportación al estudio de la música religiosa en España: el 'Congreso Internacional de Música Sacra' (Bilbao, 1896)”, Revista de Musicología, XX/1(1997), pp. 605-615.
} 
- A pesar de los frutos que las reformas puestas en marcha en determinados lugares han proporcionado, es necesario, dado el general estado de la música litúrgica y las quejas expresadas "de todas partes", condenar lo que se opone a lo promulgado hasta ahora por la Iglesia. Por esta razón, el papa publica este motu proprio que debe ser recibido como un "Código jurídico de la música sagrada".

La Instrucción propiamente dicha está dividida en varios epígrafes y consta de un total de veintinueve artículos, que vienen a disponer lo siguiente:

- "I. Principios generales": la música sagrada tiene el mismo fin -la glorificación de Dios y la santificación de los fieles- y las mismas cualidades que la liturgia -santidad, bondad de formas y universalidad-. Por tanto, debe excluir todo lo profano, ser "arte verdadero" y universal.

- “II. Géneros musicales” sacros: son el canto gregoriano, modelo de música litúrgica y criterio para evaluar la naturaleza religiosa de cualquier expresión musical; la polifonía clásica, por su parentesco con este; y la música moderna, siempre y cuando excluya lo profano y lo teatral. Esto último se considera opuesto "a las condiciones más importantes de toda buena música sagrada".

- "III. Texto litúrgico": sólo en lengua latina, y no se puede omitir o alterar bajo ningún concepto.

- "IV. Forma externa de las composiciones sagradas": en términos generales, hay que respetar la forma tradicional de los cantos litúrgicos, evitar fraccionarlos en distintas piezas independientes, así como renunciar a cualquier influencia teatral o a las formas propias de la música de concierto.

- "V. Cantores": los cantores desarrollan un oficio litúrgico, por tanto, deben ser personas de "conocida piedad y probidad de vida", y vestir hábito litúrgico, aún siendo seglares. Las mujeres, “incapaces de desempeñar tal oficio", no son admitidas en el coro.

- "VI. Órgano e instrumentos": la música eclesiástica es exclusivamente vocal, aunque se permite el acompañamiento del órgano. Para el uso de otros instrumentos se necesita permiso del obispo.

- "VII. Extensión de la música religiosa": la música debe estar siempre al servicio de la liturgia y debe ser "su humilde sierva", por tanto, su duración no debe interferir en el ritmo de la celebración. La inversión de este orden constituye un "abuso gravísimo". 
- "VIII. Medios principales": constitución de comisiones diocesanas de música sagrada, fundación de Scholae cantorum, especialmente en las grandes iglesias y seminarios -donde se procurará una buena formación en música sagrada-, y creación de escuelas superiores.

- "IX. Conclusión": por último se apela a todos los agentes involucrados en la cuestión de la música litúrgica a que favorezcan la reforma, de modo especial al obispo.

A pesar de su carácter legal, el $M P$ era portador de una mentalidad y un ideario estético que en muchos lugares eran absolutamente novedosos. El rescripto papal sobre música fue recibido no sólo como un código regulador de las prácticas litúrgicomusicales sino también como un auténtico tratado estético. Numerosos son los testimonios que se podrían aportar en este sentido. Ofrecemos algunos ejemplos a modo de muestra. El siguiente es una de las conclusiones del I Congreso Nacional de Música Sagrada celebrado en Valladolid en 1907:

El Congreso considerando que el MOTU PROPRIO [sic] de Su Santidad acerca de la Música Sagrada es no sólo Código jurídico de prescripciones eclesiásticas, sino también verdadero tratado $\mathrm{y}$ código de arte y norma segura, hace votos porque los compositores modernos lo estudien profundamente y lo tomen como norma fija para sus trabajos artístico religiosos. ${ }^{35}$

Este fragmento pertenece a una circular de la Junta diocesana de música sagrada de Barcelona: “[...] el Documento pontificio de que se trata, aun haciendo abstracción de lo esencial que es su valor litúrgico y religioso, supone una evolución progresiva para el saneamiento del Arte de su historia"36. Este otro fue escrito con ocasión del II Congreso Nacional de Música Sagrada celebrado en Sevilla en 1908: “el Motu Proprio es no sólo la restauración de la disciplina eclesiástica en música religiosa, sino también la restauración del sentimiento artístico y bello [...]"37.

Así pues, y en síntesis, el MP constituyó un punto de inflexión histórica. La jerarquía eclesiástica cerró una etapa al asumir las nuevas propuestas litúrgicomusicales generadas por determinadas corrientes renovadoras, y traducirlas en preceptos

\footnotetext{
${ }^{35}$ Crónica del Primer Congreso, p. 25.

36 Salvador, cardenal Casañas, obispo de Barcelona, "Circular de la Junta Diocesana sobre Música Sagrada del Obispado de Barcelona”, BOAS, 556 (1904), pp. 500-505, p. 501.

37 Franculus, "Un Congreso", Crónica del Segundo Congreso Nacional de Música Sagrada (Sevilla: Izquierdo y C. a , 1909), p. 47.
} 
legales de obligado cumplimiento. Y abrió otra, que se prolongaría hasta el Concilio Vaticano II, en la que se trató de transformar la realidad de acuerdo a la nueva norma, cuyos primeros momentos en la archidiócesis de Sevilla nos encargaremos de estudiar a continuación. 


\section{Parte I. ARCHIDIÓCESIS}

LA REFORMA DE LA MÚSICA SAGRADA EN LA ARCHIDIÓCESIS DE SEVILLA: CONCRECIÓN NORMATIVA Y GESTIÓN INSTITUCIONAL

Capítulo 1. La reforma durante el pontificado de Marcelo Spínola y Maestre (1904-1906)

p. 57

Capítulo 2. La reforma durante el pontificado de Enrique Almaraz y Santos (1907-1910) 



\section{CAPÍTULO 1 \\ LA REFORMA DURANTE EL PONTIFICADO DE MARCELO SPÍNOLA Y MAESTRE (1904-1906)}

Como hemos apuntado más arriba, el Motu Proprio "Tra le sollecitudini" fue promulgado el día de Santa Cecilia de 1903, es decir, a las puertas del ciclo de navidad. La Iglesia concentraba en esos momentos su atención en la celebración de las grandes solemnidades que el calendario litúrgico prescribía. La intensa actividad de esos días, pensamos, debió ser la razón por la que la publicación del texto del $M P$ en el BOAS, órgano de difusión oficial archidiocesano, se pospusiera hasta el 15 de enero de $1904^{1}$. En el número siguiente ${ }^{2}$, apareció otro importante documento, el Decreto de la Sagrada Congregación de Ritos de 8 de enero, en el que, por mandato de Pío X, se ordenaba el cumplimiento del $M P$ como código jurídico de la música sacra, y se derogaban los "privilegios y exenciones" de los que hasta entonces hubieran disfrutado las distintas Iglesias locales, incluidas aquellas "[exenciones] dignas de especial mención" ${ }^{3}$. Con la

\footnotetext{
1 “Otro [Motu Proprio] acerca de la música sagrada”, BOAS, 534 (1904), pp. 13-27.

${ }^{2}$ El BOAS tenía una periodicidad quincenal.
}

3 “[...] Quare idem Sanctissimus Dominus Noster per hanc Sacrorum Rituum Congregationem mandate et praecipit, ut Instructio praedicta ab omnibus accipiatur Ecclesiis sanctissimeque servetur, non obstantibus privilegiis atque exemptionibus quibuscumque, etiam speciali nomine dignis, ut sunt privilegia et exemptions ab Apostolica Sede maioribus urbis Basilicis, praesertim vero Sacrosanctae Ecclesiae Lateranensi concessa. [...]" Seraphinus Card. Cretoni, S.R.C. Praefectus, "Urbis et orbis" [En índice del tomo figura como: "Otro [Motu proprio] acerca de la música sagrada"], BOAS, 535 (1904), p. 97. "[...] Por lo cual el mismo Santísimo Señor por medio de esta Sagrada Congregación de Ritos, manda y ordena que la citada Instrucción sea recibida por todas las Iglesias y santamente observada, no obstante cualesquiera privilegios y exenciones, aun dignas de especial mención, como son los privilegios y exenciones concedidas a las Basílicas mayores de Roma y especialmente a la santa Iglesia de Letrán." Traducción castellana extraída de Otaño, La Música Religiosa, pp. 103-104. 
difusión de estos dos escritos se trasladó a la Iglesia de Sevilla la naturaleza y el alcance del proyecto de transformación litúrgico-musical pretendido por Pío $\mathrm{X}^{4}$.

Una vez sentadas por parte del papado las bases de la reforma en los documentos que acabamos de mencionar, la tarea de gestionarla sobre el terreno, y hacerla realidad recayó sobre la institución diocesana, liderada por el obispo como máximo responsable ${ }^{5}$.

\section{El arzobispo Marcelo Spínola frente a la reforma: "perseverancia,}

\section{discreción y prudencia exquisita"}

Marcelo Spínola y Maestre había sido proclamado arzobispo de Sevilla el 11 de febrero de 1896, tras haber gobernado las diócesis de Coria y Málaga ${ }^{6}$. Su nombramiento significó el regreso a la ciudad en la que había desarrollado su labor durante catorce años. Esta experiencia le había proporcionado un profundo conocimiento de la Iglesia local. El que fuera, antes de su traslado a Coria, párroco de San Lorenzo, teniente arcipreste de Sevilla, canónigo catedralicio y obispo auxiliar durante el pontificado del Cardenal Lluch y Garriga, inició su cometido con la publicación de una circular sobre música sagrada el 15 de febrero, un mes después de la aparición del $M P$ en el $B O A S^{7}$. El largo y complejo proceso de implantación de la reforma en la Archidiócesis quedó de esta forma inaugurado.

Los múltiples frentes abiertos relacionados con el desafío de la Iglesia por reubicarse en la cultura contemporánea, la grave crisis económica por la que atravesaba la Baja Andalucía, así como los importantes compromisos contraídos en ese mismo año de 1904 con la organización y celebración del quincuagésimo aniversario de la

\footnotetext{
${ }^{4}$ En Apéndice 2 proporcionamos una relación de las circulares y otros documentos relacionados con la reforma de la música sagrada publicados en el BOAS.

${ }^{5}$ En el artículo con el que concluye el Motu Proprio, Pío X confía a todos los agentes diocesanos el logro de la reforma, aunque de forma especial al obispo: "Por último, se recomienda a los maestros de capilla, cantores, eclesiásticos, superiores de seminarios, de institutos eclesiásticos, y de comunidades religiosas, a los canónigos de colegiatas y catedrales, y, sobre todo, a los Ordinarios diocesanos, que favorezcan con todo celo estas prudentes reformas, desde hace mucho deseadas [...]". MP. Título IX. Conclusión, artículo $n^{0} 29$.

${ }^{6}$ Sobre Marcelo Spínola y Maestre véanse las siguientes obras biográficas: José María Javierre, Don Marcelo de Sevilla (Salamanca: Sígueme, 1992); José Leonardo Ruíz Sánchez, Beato Marcelo Spínola y Maestre, Cardenal Arzobispo de Sevilla (1835-1906) (Sevilla: Servicio de Publicaciones del Ayto. de Sevilla, 2002).

${ }^{7}$ Marcelo [Spínola], Arzobispo de Sevilla, "Circular sobre la música sagrada", BOAS, 536 (1904), pp. 115-118.
} 
proclamación del dogma de la Inmaculada, componían un contexto nada propicio para afrontar el reto que suponía la reforma musical.

La circular de 15 de febrero a la que acabamos de hacer referencia contiene un breve preámbulo introductorio de cuya lectura podemos inferir la forma en la que el arzobispo andaluz recibió y asimiló la propuesta pontificia, así como la naturaleza de la problemática que intuyó desde el primer momento. Spínola entendió el MP como un instrumento para transformar la liturgia en uno de sus aspectos más importantes y delicados, la música sagrada. La expresión que utilizó para calificar los efectos que debía producir, "favorable revolución", así lo atestigua ${ }^{8}$. Para el arzobispo hispalense, la música sagrada era fundamentalmente un componente litúrgico de especial relevancia, más allá de consideraciones estéticas o artísticas. No obstante, como se demostrará más adelante, fue absolutamente consciente del enorme potencial que poseía como expresión cultural en sentido amplio?.

Resultan especialmente interesantes aquellos pasajes de la circular en los que descendió a la cruda realidad y ofreció una primera estimación de lo que podía suponer un proceso de reformas de estas características, teniendo en cuenta las circunstancias de aquel momento y la particular idiosincrasia de la Archidiócesis. Describió la reforma como una "empresa ardua", "difícil", e incluso dilatada en el tiempo; y lo que creemos más sintomático -pues sugiere la naturaleza cultural del problema-, aludía a la necesidad de una gran capacidad diplomática, de "discreción y prudencia exquisitas", así como de una "perseverancia incontrastable" cuando se refería a los hábitos a desarraigar. Un discurso en estos términos, creemos, descarta cualquier idealización de la reforma, y revela el intento de cimentación del proceso desde la realidad:

Que la reforma intentada por el Papa es difícil nadie puede dudarlo; pues aparte de que el llevarla a término supone dispendios, que no todas las iglesias sufragarán sin trabajo, el acabar con añejos hábitos, encarnados y arraigados en los pueblos es empresa ardua, y

\footnotetext{
8 “'[El Motu proprio] está destinado a producir lo que se denomina hoy una favorable revolución en ese tan importante ramo de la liturgia católica, pues parte de la liturgia, tomado el vocablo en un amplio sentido, reputamos la música sagrada”. Marcelo [Spínola], "Circular sobre la música sagrada”, p. 115.

${ }^{9}$ La trascendencia cultural y social que Spínola atribuyó a las expresiones litúrgico-musicales se pone de manifiesto nítidamente en el caso del Miserere de Eslava. Véase el apartado 1.1. "El canon Eslava I: el oficio de Tinieblas" del capítulo tercero, en el que discutimos el intento de reforma de este salmo del oficio de Tinieblas.
} 
que reclama perseverancia incontrastable, a la vez que discreción y prudencia exquisitas. $^{10}$

Por tanto, los dos grandes problemas a los que se tendría que hacer frente la administración diocesana, según el criterio de Spínola, eran el económico ("llevarla a término supone dispendios, que no todas las iglesias sufragarán sin trabajo") y el cultural ("acabar con añejos hábitos, encarnados y arraigados en los pueblos") ${ }^{11}$. Como veremos a lo largo de este trabajo, este análisis, en el que sintetizó en unas pocas líneas el grueso de la problemática que acompañó a la reforma, resultó bastante certero. Sin embargo, erró al predecir que la principal resistencia ante la eliminación de los "añejos hábitos" la encontraría en los pueblos. Serán, por el contrario, los templos emblemáticos y que debían ejercer de modelo, como la Catedral, los más obstinados en este sentido.

Para poner en relación la recepción que Spínola brindó al $M P$ con la que dispensaron otros obispos españoles, son pocos los datos concretos que poseemos. Ángel Medina describe en términos generales la recepción del MP por parte del episcopado español, y señala que la publicación de una carta pastoral o similar en los primeros meses de 1904 en el boletín oficial diocesano correspondiente fue algo común entre los prelados ${ }^{12}$. Si comparamos la fecha de la primera circular publicada por Spínola con los documentos publicados por otros obispos españoles, comprobamos que la respuesta del arzobispo hispalense es algo más inmediata que en otros lugares ${ }^{13}$. Martínez Vigil, obispo de Oviedo, publicó su carta pastoral La música sagrada entre el 15 de mayo y el 1 de junio de $1904^{14}$. Climent en su trabajo sobre la música en la

${ }^{10}$ Marcelo, "Circular sobre la música sagrada", pp. 115-116.

${ }^{11}$ Uno de los personajes destacados del movimiento reformista a nivel español, Federico Olmeda, creía que las dificultades para llevar a cabo la reforma en España se podían "reducir a tres órdenes: unas procedentes de las circunstancias personales de los artistas; otras del estado precario en que se hallan los maestros de capilla y organistas en relación con la cultura musical que han de tener para cumplir regularmente las prescripciones del Motu Proprio y otras radican en la actual constitución de los Cabildos". Federico Olmeda, Pío X y el canto romano o aplicación práctica del código jurídico de Su Santidad Pío X (del 22 Noviembre de 1903) sobre la música sagrada en cuanto al canto gregoriano (Burgos: Tip. de El Monte Carmelo, 1904).

${ }^{12}$ Medina, "La música en el templo", p. 27.

${ }^{13}$ Los datos que los contados trabajos publicados en España sobre los procesos de reforma en las distintas diócesis poseemos actualmente no nos permiten efectuar más que afirmaciones provisionales al respecto, que deberán confirmarse o desestimarse según futuras aportaciones.

14 La fecha de redacción de la misma es de 12 de marzo, festividad de San Gregorio. Sanhuesa, "Resonancias del Motu Proprio en la diócesis de Oviedo", p. 183. 
catedral de Valencia en el siglo XX no menciona ninguna carta pastoral o documento similar del ordinario de aquella archidiócesis, aunque sí cita las primeras acciones llevadas a cabo por la recién creada Comisión Diocesana de Música Sagrada en julio y noviembre de $1904^{15}$. Elena Micó proporciona la fecha de fundación de la Comisión Diocesana de Música Sagrada valenciana, abril de $1904^{16}$. Medina recoge las fechas de otros documentos, como son sendas comunicaciones de los obispos de Oviedo y Jaén a sus respectivos cabildos catedralicios, que sí coinciden temporalmente con la circular de Spínola, aunque ni tienen alcance general diocesano, ni son públicos, sino de carácter interno ${ }^{17}$.

Según Medina, estos documentos muestran una recepción de las directrices papales por parte de los obispos españoles "sin objeciones ni resistencias", y traslucen, incluso, la admiración que estos profesaban al recién elegido papa ${ }^{18}$. En el caso de Spínola, como hemos visto, la concepción positiva que tenía del MP así como su adhesión incondicional a la propuesta papal no significó una idealización de esta. Si bien no hubo objeciones ni resistencias, sí existió en su posición una conexión con la realidad que le llevó no tanto a cuestionar los medios propuestos por el papa, algo no de esperar en un documento público dirigido su clero y fieles diocesanos, sino a concienciarles de la dificultad de su aplicación en la Diócesis. El mensaje que quiso transmitir a todos aquellos agentes que debían implicarse en la reforma fue la necesidad de un compromiso proporcional a las dificultades que suponía ${ }^{19}$.

${ }^{15}$ José Climent, La catedral de Valencia. Devenir musical en el siglo XX. (Valencia: Real Academia de Cultura Valenciana, 2005), p. 18.

${ }^{16}$ El texto del MP fue publicado en el Boletín Oficial del Arzobispado de Valencia el 17 de febrero de 1904, es decir, un mes después que en el BOAS. Elena Micó Terol, Amancio Amorós Sirvent (1854-1925) y su proyección en la vida musical valenciana, Tesis Doctoral (Barcelona: Universitat de Barcelona, 2011), pp. 160-161; disponible en: <http://hdl.handle.net/10803/81929> (consultado 12-12-2013).

${ }^{17}$ La comunicación del obispo de Jaén al Cabildo con unas primeras instrucciones para la aplicación del $M P$ en la Catedral son registradas en las actas el 4 de febrero de 1904. El documento ovetense tiene fecha de 27 de febrero. P. Jiménez Cavallé, Documentario musical de la Catedral de Jaén. I. Actas capitulares. (Granada: CDMA, 1998), p. 584; Raúl Arias del Valle, La orquesta de la S.I. Catedral de Oviedo (15721933). (Oviedo: Instituto de Estudios Asturianos, 1990), p. 442. Ambos citados en: Medina, "La música en el templo", p. 27.

\footnotetext{
${ }^{18}$ Medina, "La música en el templo", p. 27.

19 "Que la reforma intentada por el Papa es difícil, nadie puede dudarlo; [...] Pero las obras buenas, y muy especialmente las preceptuadas por quien tiene poder y autoridad para ello, no por penosas han de dejarse, sino acometerse con esfuerzo, [...]." Marcelo, "Circular sobre la música sagrada", pp. 115-116.
} 
Una vez trasladada su concepción del $M P$, así como sus consideraciones sobre los previsibles problemas que supondría su implantación, el arzobispo hispalense arrancó la reforma con el dictamen de una serie de medidas, que no eran más que una selección de los preceptos propuestos por Pío X en el $M P$ :

$1^{\circ}$ Queda prohibido en todas las iglesias del Arzobispado el uso del piano, e igualmente de los instrumentos fragorosos, como los llama el Papa, vedándose por de contado asimismo que dentro del lugar santo toquen las denominadas bandas de música.

$2^{\circ}$ En las Misas cantadas solo se empleará el canto rigurosamente litúrgico, no tolerándose en adelante ningún motete castellano, por piadoso y edificante que parezca.

$3^{\circ}$ No se cantará ni se tocará en las iglesias nada que por su corte $\mathrm{o}$ aire tenga sabor o reminiscencias profanas.

$4^{\circ}$ Las mujeres no tomarán parte en el canto rigurosamente litúrgico, a no ser que se trate de Religiosas claustradas y aun de las no claustradas, si cantan en lugar donde no puedan ser vistas del público, que concurre el templo.

En tanto que otra cosa no se dispone, se tolerará como hasta aquí, que en los ejercicios de sus respectivas asociaciones canten mujeres, haciéndolo en sitio, en que no se les vea, ni penetre hombre alguno.

$5^{\circ}$ Se crea una Comisión $[\ldots]^{20}$

Es posible que esta relación de instrucciones de carácter prohibitivo representara prioridades para Spínola, aunque, por otra parte, es evidente que resultaba incompleta si pensamos en el más vasto alcance y en los más ambiciosos objetivos del documento papal. Se echan en falta junto a las expuestas, otras prescripciones que afectaran a cuestiones tales como el canto gregoriano y su restauración, uno de los puntos fundamentales de la reforma; o sobre otras cuestiones en las que también se producían continuos "abusos" según el ideario reformista, como la forma de cantar las distintas partes del ordinario de la misa o de las vísperas; el papel de los instrumentos "permitidos"; o la extensión de las intervenciones musicales en las celebraciones litúrgicas. Si consideramos que entre la publicación del $M P$ en el BOAS y esta última circular transcurrió tan sólo un mes, no parece que hubiera tiempo suficiente para realizar una evaluación a fondo de la situación y planificar detenidamente la reforma. Nos inclinamos por pensar que la intención de Spínola con la difusión de estas medidas

${ }^{20}$ Ibídem. Señalamos el precepto del $M P$ al que corresponden cada uno de estos mandatos de Spínola: el primer punto corresponde al Título VI. Órgano e instrumentos, artículos $\mathrm{n}^{\circ} 19$ y 20 . El segundo al Título III. Texto litúrgico, art. 7. Tercero: Título II. Géneros de música sagrada, art. 5. Cuarto: Titulo V. Cantores, art. 13. Y quinto al Título VIII. Medios principales, art. 24. 
fue dar el primer paso, más simbólico que efectivo, para la inauguración del proceso, en coherencia con el mensaje de adhesión al proyecto papal y de compromiso que precedió a las mismas, dejando para la recién creada CDMS la verdadera ejecución en la práctica de la reforma. La credibilidad de esta suposición se refuerza si pensamos en las importantes atribuciones y poderes que otorgó a dicha Comisión, convirtiéndola de esta forma en el órgano fundamental, y principal responsable -responsabilidad delegada- de la aplicación en la Archidiócesis de los nuevos preceptos papales.

\section{Comisión Diocesana de Música Sagrada: naturaleza y funciones}

La medida más trascendental de entre las propugnadas por Spínola, y la única que se aplicó de forma inmediata fue la constitución de la CDMS. Su composición quedó como sigue:

Presidente: Santiago Fernández, chantre de la Catedral;

Vicepresidente: Rafael González Merchant, canónigo, otra de las figuras destacadas, como veremos más adelante, de la reforma en Sevilla;

Vocales: Ricardo Lagares, beneficiado de la Catedral; Agapito Insausti, beneficiado tenor de la capilla catedralicia ${ }^{21}$; Vicente Ripollés, recientemente nombrado maestro de dicha capilla; Antonio Peña y Ojeda, párroco de Santa María Magdalena; Francisco Pino, capellán de las Hijas de María Reparadora; y Manuel Lerdo de Tejada, músico de prestigio en la ciudad, titular de los órganos de la Capilla Real de San Fernando y de la parroquia de Santa $\mathrm{Cruz}^{22}$.

\footnotetext{
${ }^{21}$ Agapito Insausti Morras, navarro de nacimiento, murió en Sevilla en 1911. Discípulo de Eslava, fue organista en Jerez de la Frontera, desde donde trasladó a la catedral de Málaga. Beneficiado tenor de la catedral hispalense, ejerció el magisterio de capilla de forma interina tras la muerte de su titular, Evaristo García Torres. Emilio Casares cifra en unas doscientas obras su producción como compositor. Emilio Casares, "Insausti Morras, Agapito", DMEH, 10 vols., ed. por Emilio Casares (Madrid: SGAE, 2001), vol. 6 , p. 428 .
}

${ }^{22}$ Manuel Lerdo de Tejada (Puerto Real, 1851-Sevilla 1919). Organista y compositor. Se formó con Buenaventura Iñiguez, organista de la Catedral, y con Hilarión Eslava. Además de la titularidad de los órganos de la Capilla Real de San Fernando y de la parroquia de Santa Cruz, ostentó el cargo de director de la Capilla del Palacio de San Telmo, residencia de los Duques de Montpensier. Impartió clases en la Academia de Música de la Sociedad Económica de Amigos del País. Es autor de más de trescientas obras, la mayoría de ellas religiosas. Aficionado a la literatura y la arqueología, era un gran especialista en numismática. Francisco Cuenca Benet, Galería de músicos andaluces contemporáneos, ed. por Manuel del Campo y Antonio Martín Moreno (Málaga: Unicaja, 2002) [Facsímil de la edición de La Habana: Cultura, S.A., 1927.], pp. 155-156. Sobre Francisco Cuenca Benet y su obra Galería de músicos andaluces contemporáneos, véase los trabajos publicados por Consuelo Pérez Colodrero. Entre ellos, "El nacimiento de la historiografía musical andaluza: la Galería de músicos andaluces contemporáneos de Francisco Cuenca Benet y la reivindicación de la identidad cultural de Andalucía", en Musicología global, musicología local, ed. por Javier Marín López, Germán Gan Quesada, Elena Torres Clemente, Pilar Ramos López (Madrid: Sociedad Española de Musicología, 2013), pp. 1599-1619; "Francisco 
Podría sorprender la no inclusión del sochantre catedralicio dada la tremenda importancia que la restauración del gregoriano tendría en la reforma. Sin embargo, por la información que nos proporcionan las actas capitulares de estas fechas podemos saber que desde finales de enero la plaza de sochantre se encontraba vacante por traslación de su titular, Crispín Hernández Pérez, a otra plaza - un beneficio de gracia- en la misma Catedral $^{23}$. El puesto no fue cubierto hasta mayo ${ }^{24}$. José Domínguez Recio, nuevo sochantre, sí entró a formar parte de la Comisión tras la ampliación que realizó Spínola en 1905.

Si comparamos las fechas de fundación de las, contadas, comisiones hispanas de las que hemos hallado noticias, se constata que el prelado hispalense fue el más ágil en alumbrar este órgano para la reforma, que el propio papa instaba a crear en el MP. La comisión diocesana valenciana, fundada en abril de 1904 fue la más temprana después de la andaluza ${ }^{25}$. La ovetense, creada por decreto episcopal publicado en el Boletín Oficial Eclesiástico del Arzobispado de Oviedo, data de 1 de junio de ese mismo $\mathrm{año}^{26}$. Las de las diócesis de Santiago de Compostela y Murcia tuvieron que esperar a

Cuenca Benet (1872-1943) y su aportación a la cultura andaluza”. Tesis doctoral. Universidad de Granada (2011). Disponible en: <http://digibug.ugr.es/handle/10481/17609\#.U5WUmWGKDIU> (consultado 2-62012).

23 "Se leyó una comunicación del Sr. Arzobispo participando que ha tenido a bien nombrar Beneficiado de esta Santa Iglesia para ocupar la vacante de D. Claudio Amorin y Álvarez, a D. Crispín Hernández y Pérez, Beneficiado Sochantre de esta misma Santa Iglesia, a quien correspondía de derecho en virtud de las Leyes concordadas, por haber acreditado su imposibilidad física para seguir desempeñando su cargo, mediante expediente aprobado por Real Orden de 26 de Diciembre de 1902. Acto continuo se leyó una solicitud del referido D. Crispín Hernández acompañando el título de colación del expresado Beneficio y el mandato de posesión expedido por S. E. el Sr. Arzobispo en 29 de Enero último y pidiendo que se le dé la posesión, se acordó que pasen estos documentos al Sr. Doctoral para que con el Fiscal de Bulas informe lo que proceda.”. AC 1/2/1904. ACS. Sección Secretaría, libro 226, fol. 228v.

24 “Se leyó una comunicación del Sr. Arzobispo con fecha 29 de Abril próximo pasado dando traslado literal de un oficio que le ha dirigido el Excelentísimo. Sr. Ministro de Gracia y Justicia firmado el 26 de dicho mes, en el que participa que S. M. el Rey (que Dios guarde) ha tenido a bien por resolución de igual fecha nombrar para el Beneficio con cargo de Sochantre, que ha vacado en esta Santa Iglesia Metropolitana por traslación de D. Crispín Hernández, al Presbítero D. Francisco Domínguez Recio, Beneficiado Sochantre de la Catedral de Tarragona, propuesto en primer lugar de acuerdo en la censura del Tribunal técnico que calificó los ejercicios de los opositores. Asimismo manifiesta el Sr. Arzobispo haber dado colación canónica del Beneficio en el mismo día 29 al mencionado Presbítero, D. Francisco Domínguez Recio. Acto continuo se leyó una solicitud suscrita por este último pidiendo la posesión del Beneficio de Sochantre, y acompañando el título de colación y mandato de innmittendo in possessionem expedido por S. E. el Sr. Arzobispo con fecha 30 de Abril próximo pasado. Se acordó que pase este documento al Sr. Doctoral para que emita el informe que previenen nuestro Estatutos, y en cumplimiento de este acuerdo se le entregó en el acto." AC 2/5/1904. ACS. Sección Secretaría, libro 226, fol. 248r.

${ }^{25}$ Micó Terol, Amancio Amorós Sirvent, pp. 160-161.

${ }^{26}$ AC no 79, Ángulo de 12-3-1904, fols. 344v-345r, cit. en Sanhuesa. "Resonancias del Motu Proprio", p. 181. 
mediados de 1907, y se pueden considerar como frutos directos del I Congreso Nacional de Música Sagrada, celebrado en Valladolid en abril de ese año ${ }^{27}$. La CDMS del obispado de Orense fue erigida en virtud de la constitución $n^{\circ} 129$ del Sínodo diocesano celebrado en $1908^{28}$. Las comisiones de música sagrada que se debieron ir creando en la provincia eclesiástica de Valladolid para dar cumplimiento al Reglamento general para la Música Sagrada en la Provincia Eclesiástica de Valladolid fueron necesariamente más tardías que la andaluza, dado que dicho reglamento fue promulgado por el arzobispo y todos sus obispos sufragáneos a finales de $1905^{29}$. Los datos que poseemos sobre la CDMS de la archidiócesis vallisoletana, de donde saldría el proyecto de organizar el citado congreso, apuntan a que debió ser instituida en la primera mitad de $1905^{30}$.

${ }^{27}$ La CDMS de Santiago de Compostela fue nombrada el 28 de junio de 1907. Este dato nos lo proporciona el mismo cardenal arzobispo santiagués en una circular fechada el 3 de julio de 1908: "En cumplimiento de nuestro deber, Nos hemos publicado también más de una Circular con el mismo objeto [la restauración del canto y música sagrada] y hemos nombrado una Comisión Diocesana en 28 de junio de 1907". Dicha circular fue transcrita íntegra en: Crónica del Segundo Congreso, pp. 32-35. MSH en su número de junio-julio de 1907 informaba del nacimiento del órgano compostelano: "Nos comunican de Santiago de Compostela que el Eminentísimo señor Cardenal Arzobispo, guiado por su elevado celo y por los deseos de llevar inmediatamente a la práctica los acuerdos del Congreso, ha nombrado una Comisión Diocesana [...] Felicitamos con todo entusiasmo al Emmo. Sr. Cardenal y a tan escogida y digna Comisión. Nos consta que los Reglamentos de esta Archidiócesis de Valladolid se implantarán allí tal cual en el Congreso se acordó. Ad multos annos!". "Memoranda. Frutos del Congreso", MSH, 1y 2 [publicados en una única entrega] (1907), p. 54. En el número siguiente se da cuenta de la creación de la CDMS murciana: "De esta capital recibimos noticias sumamente consoladoras. El Ilmo. Sr. Obispo trata de llevar en aquella diócesis a cabo la reforma de la música con tal seriedad, con tan exquisito gusto y prudencia, que está mereciendo las alabanzas de todos los buenos músicos de iglesia y de todos los admiradores del Canto sagrado. Nosotros no podemos menos de aplaudir estas hermosas iniciativas de aquel ilustre y virtuoso prelado y le enviamos desde estas columnas, nuestra más sincera e íntima felicitación. Su Ilma. trata de acomodar a su diócesis y poner en vigor los reglamentos de esta sede metropolitana." (1907), p. 72.

La Comisión diocesana ha sido nombrada ya [...]" "[Noticias de] España. Murcia”, MSH, 3

${ }^{28}$ Constituciones sinodales promulgadas por el Excmo. E Ilmo. Señor Dr. D. Eustaquio Ilundain y Estéban, Obispo de Orense, Senador del Reino [...] en el Sínodo Diocesano celebrado en la Santa Iglesia Catedral de Orense los días 14, 15 y 16 de julio de 1908, Imprenta de A. Otero, 1908, 78-80., cit. en Garbayo, "Recepción e influencia del Motu Proprio", p. 321.

29 "Edicto y Reglamentos sobre música sagrada promulgados por los Rmos. Prelados de la Provincia Eclesiástica de Valladolid", Boletín Oficial Eclesiástico del Arzobispado de Valladolid, 11 [de 22 de noviembre] (1905), pp. 317-398.

${ }^{30}$ La primera mención a la CDMS de Valladolid que hemos podido hallar data del 22 de agosto de 1905 , en una carta remitida por el obispo de Astorga al maestro de capilla de la catedral pucelana, Vicente Goicoechea. El prelado solicitaba la colaboración del músico para unas conferencias de los obispos de la provincia eclesiástica a celebrar en la ciudad leonesa, y en la que estaba previsto abordar la cuestión de la música religiosa. En ella propuso a Goicoechea: "[...] También puesto que por entonces [finales de septiembre] han de celebrarse la[s] Conferencias episcopales de dicha Provincia eclesiástica y en ellas ha de tratarse el punto de la Música que debe adoptarse en las iglesias, dígame si le parece que podría 
La comisión de la diócesis de Oviedo ${ }^{31}$ y, en principio, también la de Orense, estuvo compuesta por clero catedralicio ${ }^{32}$. La hispalense, así como las de Murcia y Santiago de Compostela tenían un carácter más abierto y representativo, al incluir a personas asociadas a otras instituciones diocesanas además de la Catedral, entre ellas músicos seglares ${ }^{33}$. No obstante, si consideramos las desproporcionadas dimensiones y la complejidad de la archidiócesis andaluza, dicha representatividad parece insuficiente $^{34}$. La presencia en la comisión de algún representante de, al menos, la

organizarse una velada sobre Música religiosa en la cual cantase algún trozo escogido el mencionado coro [que debía organizar el propio Goicoechea]. De la parte doctrinal podrían encargarse los que juzgase más a propósito la Junta de Música creada en esa Diócesis." Carta del obispo de Astorga [Julián de Diego y García Alcolea] a Vicente Goicoechea, 22 de agosto de 1905. AMSL. FO. Correspondencia, 009/004.27. Por su parte, Albano García Sánchez afirma que nació como consecuencia de un acto celebrado en abril de 1905 en el Colegio de San José para la difusión del MP, aunque no cita la fuente: "Unos años más tarde, en abril de 1905, se realizó en el salón de actos del Colegio de San José de Valladolid una jornada solemne en la que se pronunciaron tres discursos con ejemplos musicales -los tres escritos por Otañoexplicando las normas del Motu Proprio. Este acto fue presidido por Monseñor Cos y Macho que era por aquel entonces- arzobispo vallisoletano. De este acto nació la Comisión Archidiocesana para la Reforma de la Música Sagrada, con Goicoechea y Otaño como cabezas visibles". "José María Nemesio Otaño Eguino (1880-1956)", pp. 477-478. En sus apuntes autobiográficos, Nemesio Otaño refiere su incorporación a la CDMS vallisoletana, aunque no cita fechas: "Sabedor el Cardenal Cos, gran amigo y protector de Goicoechea, de los entusiasmos de su joven discípulo, y deseando poner en práctica el Motu Proprio de Pío X, promulgado el 22 de noviembre de 1903, recabó de los superiores la cooperación del Padre Otaño en la Comisión por él creada de música sagrada". Apuntes autobiográficos (1944), p. 5. AMSL. FO. Conferencias y otros escritos. 005/013. Conviene aclarar que Otaño comenzó a redactar estos apuntes en tercera persona.

${ }^{31}$ En ese momento la actual archidiócesis de Oviedo tenía rango de diócesis.

${ }^{32}$ Composición de la CDMS de la diócesis de Oviedo: D. Joaquín de la Villa Pajares, canónigo doctoral, como presidente; D. Paciente Méndez Mori, canónigo, vice-presidente; y los beneficiados sochantre, organista, y maestro de capilla. AC n ${ }^{0}$ 79, Ángulo de 12-3-1904, fols. 344v-345r, cit. en Sanhuesa. "Resonancias del Motu Proprio", p. 181. Composición de CDMS de la diócesis de Orense: vocales natos el Muy Ilustre señor Deán de la catedral, Muy Ilustre señor Dignidad de Chantre, Señor Maestro de Capilla de la iglesia catedral y dos miembros más a voluntad de Nos y Nuestros sucesores." Constituciones sinodales promulgadas por el Excmo. E Ilmo. Señor Dr. D. Eustaquio Ilundain y Estéban, Obispo de Orense, Senador del Reino [...] en el Sínodo Diocesano celebrado en la Santa Iglesia Catedral de Orense los días 14, 15 y 16 de julio de 1908, Imprenta de A. Otero, 1908, 78-80., cit. en Garbayo, "Recepción e influencia del Motu Proprio", p. 321.

${ }^{33}$ Composición de la CDMS de la archidiócesis de Santiago de Compostela: "Ilmo. Sr. Obispo auxiliar, Presidente; M. I. Sr. D. Santiago Tafall, Canónigo de la S.I.M. y compositor distinguido, Vice-presidente; y vocales el señor Maestro de Capilla y Organistas de aquella ilustre capilla Metropolitana, el P. Celestino Garnica, S. J. y un R. Sr. Párroco de aquella ciudad." "Memoranda. Frutos del Congreso", p. 54. Composición de la CDMS de la diócesis de Murcia: "M.I. Sr. D. Manuel Mérida, Dignidad de Chantre de la S.I.C. Presidente.- R. Sr. D. Ángel Larroca, Maestro de Capilla de la S.I.C. Vice-presidente.- R. Sr. D. José Jubés, Beneficiado de la S.I.C. Secretario.- Vocales: R. P. Superior de los Franciscanos por el Clero Regular; Lic. Sr. D. Pedro Hernández, Cura Ecónomo de Santa María, por el Clero Parroquial; Sr. D. Vicente Espada, Organista de la S.I.C.; Sr. D. Mariano Moreno Pretel, Profesor de Música; Sr. D. Mariano Alarcón, Profesor de Música." “[Noticias de] España. Murcia.”, p. 72.

${ }^{34}$ Como hemos señalado en la introducción, la archidiócesis hispalense cubría el tercio occidental de Andalucía. Además de las provincias íntegras de Sevilla y Huelva, pertenecía a ella más de la mitad de la provincia de Cádiz -el actual obispado de Jerez de la Frontera-, y algunos municipios de las de Córdoba 
colegiata que aún existía en el Arzobispado, la de Jerez de la Frontera, o de determinados arciprestazgos como el de Huelva, $\mathrm{u}$ otros territorios especialmente relevantes o poblados, hubieran hecho de ella una auténtica comisión de alcance archidiocesano. La procedencia de sus miembros demuestra que esa representatividad se redujo a los límites de la capital.

Todas estas comisiones compartían un mismo patrón en cuanto a la distribución de funciones y cargos. Las dignidades y canónigos catedralicios copaban los puestos de un mayor peso administrativo y simbólico -presidencias y vicepresidencias-, mientras que los músicos eran relegados a ocupar vocalías ${ }^{35}$. En general, los músicos eclesiásticos -incluido el maestro de capilla catedralicio, máxima autoridad musical diocesana- tuvieron, dentro del organigrama diocesano de gestión de la reforma, una influencia relativa y un poder de decisión minimizado y siempre subordinado al que poseían las autoridades capitulares. Este desequilibrio de poderes no es más que un reflejo o una reproducción a nivel diocesano del que históricamente se había dado en el seno de la institución catedralicia, en la que la ausencia hasta no hace mucho de los responsables músicos en los cabildos había dejado en manos de los canónigos las decisiones últimas en los asuntos musicales ${ }^{36}$. La aplicación de este criterio en el caso de las comisiones diocesanas de música sagrada suponía un alejamiento de lo que el MP postulaba: "para el puntual cumplimiento de cuanto aquí queda dispuesto, nombren los Obispos, si no las han nombrado ya, comisiones especiales de personas verdaderamente competentes en cosas de música sagrada"37. Es

y Málaga. En 1909 su población ascendía a 850.000 habitantes. A la Catedral, la colegiata jerezana, las 283 parroquias, los monasterios tanto masculinos como femeninos que estaban bajo la autoridad de la mitra hispalense, etc. hay que sumar las innumerables hermandades, cofradías, y demás asociaciones religiosas que salpicaban la geografía diocesana.

${ }^{35}$ Así ocurría también en el caso de la comisión valenciana según señala José Climent: "La letra de la disposición romana era plenamente entendida en aquello que la curia arzobispal quería, porque 'hombres competentes en materia musical' no lo eran los tres capitulares, (Roque Chabás, Joaquín Navarro y José Vila) que como presidente y vicepresidentes, dirigían la comisión. Los músicos eran meros vocales." Climent, La Catedral de Valencia, p. 18. Elena Micó proporciona la relación de miembros de la CDMS valenciana y los cargos que ocuparon en Amancio Amorós Sirvent, pp. 162. La CDMS murciana representa una excepción, pues el maestro de capilla catedralicio, Ángel Larroca, ostentó el cargo de vicepresidente.

${ }^{36}$ En el congreso de Sevilla se planteó la propuesta de elevar al maestro de capilla a la dignidad de chantre catedralicio. El congreso de Barcelona, siguiendo la línea iniciada por el hispalense, volvió a insistir en la necesidad de promover a canongías de gracia a los músicos catedralicios. Véase capítulo 5 , epígrafe 3.2.3. La situación económica de los músicos eclesiásticos, pp. 411-412.

${ }^{37}$ MP. Título VIII. Medios principales, art. 24. 
evidente que el criterio de competencia "en cosas de música sagrada" debía prevalecer como principio fundamental más allá de la autoridad o jerarquía a la hora de configurar el perfil de las comisiones, en consecuencia, de otorgar capacidad de decisión "para el puntual cumplimiento" de las instrucciones reformistas papales ${ }^{38}$. Sin embargo, como evidencian los datos que ofrecemos sobre las comisiones de otras diócesis hispanas, no ocurrió así ni en Sevilla ni en otros lugares.

Independientemente del puesto más o menos importante que se le concediera a cada uno en el seno de las comisiones, las funciones confiadas por Spínola a la hispalense superaron bastante las recomendadas por el MP para estos órganos. La instrucción papal asignaba a las comisiones sólo la labor de vigilancia y supervisión musical: "[los obispos nombrarán] comisiones especiales de personas verdaderamente competentes en cosas de música sagrada, a las cuales, en la manera que juzguen más oportuna, se encomiende el encargo de vigilar cuanto se refiere a la música que se ejecuta en las iglesias". Spínola le encomendó, además, idear la manera de realizar la reforma: en primer lugar, "proponernos los medios, que convendrá emplear, para que sea una realidad en esta diócesis y en plazo breve la reforma de la música sagrada"; en segundo lugar, “indicarnos dónde y con qué condiciones podrán establecerse las Scholae cantorum"; y por último "velar por que se cumplan las anteriores disposiciones, y las que en lo sucesivo dictemos" $"$.

Además de los ojos que debieron velar por su cumplimiento, la CDMS hispalense fue el cerebro de la reforma. Como tendremos ocasión de comprobar, de ella partieron todas las iniciativas y medidas que se generaron para la aplicación del $M P$. En consecuencia, fue el órgano que tuvo que interpretar y aplicar este documento según las circunstancias propias de la Archidiócesis ${ }^{40}$. El acomodo de este nuevo órgano con estas importantes atribuciones en materia de música -un aspecto cuya trascendencia trataremos de ir analizando y descubriendo- en el organigrama institucional diocesano no fue nada fácil ${ }^{41}$.

\footnotetext{
${ }^{38}$ Climent sugiere en el pasaje citado en la nota 26 esta misma idea, que nosotros defendemos igualmente en: "El papel del maestro de capilla" (en prensa). En este artículo, en el que tratamos como caso de estudio el de Vicente Ripollés en Sevilla, profundizamos, entre otras cosas, en el papel subordinado que le tocó jugar al maestro de capilla y sus consecuencias.

${ }^{39}$ Marcelo, "Circular sobre la música sagrada”, p. 117.

${ }^{40}$ MP. Título VIII. Medios principales, art. 24.

${ }^{41}$ Véase epígrafe 3. "Inicio y suspensión del proceso de reformas: causas y consecuencias”, p. 73.
} 
Para hacer una estimación sobre la importancia relativa de la CDMS hispalense, tomando como criterio de valoración las funciones que le fueron asignadas, son pocas las comisiones de otras diócesis de las que hemos podido hallar datos en este sentido. La comisión orensana estuvo especialmente pensada para actuar en la Catedral, ámbito este en el que sí tenía importantes cometidos: "el expurgo del Archivo de música de la catedral, la elección de partituras polifónicas que se ajusten al código de la música dado por su Santidad Pío X; procurar que los cantorales del coro de la catedral se adapten a las ediciones típicas de la Sagrada Congregación de los Ritos [...]"42. Para el resto de la Diócesis su función se reducía a la supervisión: "y denunciarnos los abusos musicales que haya en las iglesias de la diócesis, aún Regulares"43.

El Reglamento general para la Música Sagrada en la Provincia Eclesiástica de Valladolid ya citado, es un documento único en España, pues representó la plasmación concreta de la voluntad de los prelados casatellanos de dotarse de un marco normativo común para la aplicación de la reforma en sus respectivas jurisdicciones diocesanas. Detrás de este logro estuvieron tres figuras de especial importancia, el entonces arzobispo vallisoletano, José María Cos y Macho; el maestro de capilla de la catedral de esta ciudad, Vicente Goicoechea ${ }^{44}$; y Nemesio Otaño, entonces joven postulante jesuita $^{45}$. Por estas razones el Reglamento constituye un documento de referencia $^{46}$. Su tercera parte está dedicada en exclusiva a definir el perfil y las funciones de las comisiones diocesanas a establecer. Sobre la función que debían cumplir señala: "se establecen en cada una de las diócesis de esta provincia eclesiástica

${ }^{42}$ Constituciones sinodales promulgadas por el Excmo. E Ilmo. Señor Dr. D. Eustaquio Ilundain y Estéban, Obispo de Orense, Senador del Reino [...] en el Sínodo Diocesano celebrado en la Santa Iglesia Catedral de Orense los días 14, 15 y 16 de julio de 1908, Imprenta de A. Otero, 1908, 78-80., cit. en Garbayo, "Recepción e influencia del Motu Proprio", p. 321.

${ }^{43}$ Ibídem.

${ }^{44}$ Sobre Vicente Goicoechea Errasti (Ibarra-Aramayona, 1854-Valladolid, 1916), véase: Pedro Aizpurúa, "Vicente Goicoechea Errasti: centenario de su magisterio musical en la catedral de Valladolid", Revista de Musicología XV/1 (1992), pp. 281-302; Antonia Virgili Blanquet, “1. Goicoechea Errasti, Vicente”, $D M E H, 10$ vols., ed. por Emilio Casares (Madrid: SGAE, 2001), vol. 5, pp. 672-673. En prensa se encuentra Óscar Candendo Zabala, "Vicente Goicoechea Errasti (1854-1916): un compositor del Motu Proprio y el canto religioso popular", en Música y reforma litúrgica desde 1611 hasta el presente, ed. por Rosa Isusi Fagoaga y Greta Olson.

${ }^{45}$ Sobre José María Nemesio Otaño Eguino (Azcoitia, 1880-San Sebastián, 1956), véanse las referencias que proporcionamos en la "Introducción", p. 18, nota a pie n' 47.

${ }^{46}$ Véase capítulo 5, epígrafe 1. "Antecedente del congreso de Sevilla: el I Congreso Nacional de Música Sagrada (Valladolid, 1907)”, p. 341. 
de Valladolid, Comisiones de Música Sagrada, con el cargo de vigilar sobre cuanto se refiere a la música de Iglesia" ${ }^{\natural 7}$. A continuación especifica un poco más:

Incumbe a la Comisión: censurar y calificar todas las obras musicales que han de ejecutarse en lo sucesivo en los actos religiosos de esta archidiócesis: cuidar de que las composiciones se adapten a las fuerzas y facultades de los ejecutantes: velar porque la ejecución no desdiga de la santidad de la casa de Dios y de los sagrados misterios: vigilar finalmente por el cumplimiento de las disposiciones eclesiásticas $[\ldots]^{48}$

Por tanto, tampoco las comisiones de música sagrada erigidas de acuerdo al modelo prescrito por este reglamento -las de las diócesis de la provincia eclesiástica castellana, así como las de Santiago de Compostela y Murcia ${ }^{49}$ - tuvieron otras atribuciones que las de vigilar, velar y, en su caso, censurar. El titulo de esta tercera parte del Reglamento es ilustrativo: De la Comisión Diocesana y censura de la música sagrada. Además, el proceso de reformas en aquellas, incluido la constitución y regulación de las comisiones diocesanas, tuvo como documento base el Reglamento. En cambio, en la archidiócesis de Sevilla, la CDMS fue anterior a cualquier reglamento o disposición, siendo esta la encargada de generarlos, por tanto, de gestionar el proceso hispalense en todos sus extremos.

A la luz de estos datos debemos concluir que la comisión andaluza fue la única que poseyó, según unas disposiciones oficiales dictadas por el prelado, la facultad de concebir y planear el procedimiento y los medios para la aplicación del $M P$ además de vigilar su cumplimiento.

La bien pertrechada de competencias CDMS hispalense inició su cometido inmediatamente. El 4 de marzo, tan sólo diecisiete días después de ser nombrada, celebró una primera reunión, y elaboró un primer informe que presentó al arzobispo. En él se enumeraron nuevas medidas que completaban las que ya había propuesto Spínola

\footnotetext{
47 “Edicto y Reglamentos sobre música sagrada”, p. 351.

${ }^{48}$ Ibídem, p. 352.

${ }^{49}$ El arzobispo de Santiago de Compostela refiere así las funciones de la CDMS instituida por él: "[La CDMS será la] encargada de examinar y censurar todas las obras que hayan de ejecutarse en los templos, y que funciona ya desde aquella época, aprobando o tolerando todas las que se hallan conformes con las reglas pontificias y rechazando las que por su forma o ritmo, por su carácter profano o falta de arte no se ajustan a ellas, ni son propósito para fomentar la devoción de los fieles y realzar la grandeza y majestad del culto divino". Circular del arzobispo de Santiago de Compostela de 3 de julio de 1908, transcrita en: Crónica del Segundo Congreso, pp. 32-35.
} 
en su circular de 15 de febrero. Además se sugirieron los medios para aplicarlas en diez puntos:

$1^{\circ}$ Para restablecer el canto gregoriano en las solemnidades de culto "según la antigua tradición", propone la creación de una Escuela oficial de la Archidiócesis, para formar a los que ocupen los puestos de cantores en ella.

$2^{\circ}$ Aplaude la existencia de la Escuela de canto gregoriano existente en el Seminario, creada por Spínola como medio indispensable para la preparación del clero en estas materias. ${ }^{50}$

$3^{\text {o }}$ Promover la creación de una Schola cantorum en el Seminario para "interesar y convencer al clero de la importancia del asunto". Su misión sería la interpretación de polifonía sagrada y "buena música litúrgica”, al tiempo que proporcionará maestros y organistas de buen gusto a las iglesias, y tomaría parte en las funciones solemnes de la Catedral.

$4^{\circ}$ Prohibir cantar en lengua vulgar, y alterar o cambiar el texto sagrado. En cuanto a este asunto, establece en la misa cantada la obligatoriedad del introito, gradual, ofertorio, comunión propios. Sólo está permitido algún motete al Santísimo Sacramento tras el Benedictus, y otro tras el ofertorio hasta prefacio.

$5^{\circ}$ Las piezas en lengua vulgar sólo están permitidas en funciones extralitúrgicas: novenas, ejercicios de hermandades, previa aprobación de sus textos por la autoridad eclesiástica. ${ }^{51}$

$6^{\circ}$ Erigir un tribunal revisor que indique a la autoridad eclesiástica competente las obras que merezcan ser aprobadas.

$7^{\circ}$ Se consideran abusivos los intermedios instrumentales en la misa y oficio de difuntos. Los instrumentos se limitarán a acompañar las voces. ${ }^{52}$

$8^{\circ}$ Se exige a los salmistas que entonen el gregoriano según libros autorizados para evitar "profanaciones e indignidades", y a los organistas no capaces de hacerlo según las normas litúrgicas se les prohíbe improvisar. ${ }^{53}$

\footnotetext{
${ }^{50}$ Las clases de canto gregoriano eran obligatorias para todos los seminaristas, y su materia estaba sujeta a evaluación: "amparada con sanción de premios y penas".

${ }^{51}$ Esta medida se fundamenta en los decretos de 17 de septiembre de 1864 y 27 de febrero de 1882 de la Sagrada Congregación de Ritos.

${ }^{52}$ En realidad se trata de una prescripción del Ceremonial de Obispos.

${ }^{53}$ Según Reglamento de la Sagrada Congregación de Ritos de 1894.
} 
$9^{\text {o }}$ La Comisión estima como instrumentos a prohibir la percusión en todo caso, $\mathrm{y}$ trombones y cornetines en las orquestas si no hay una amplia base de cuerda $\mathrm{y}$ voces. $^{54}$

$10^{\circ}$ Por último, aconseja confeccionar una lista de abusos y estudiar cómo evitarlos. $^{55}$

Este informe constituyó el primer proyecto u hoja de ruta propiamente local para el cumplimiento del MP. A diferencia de aquella primera circular de Spínola, incompleta como comentamos, el documento confeccionado por la CDMS sí recogió prácticamente todos los objetivos y aspectos en los que pretendía incidir el documento papal, concretado a nivel diocesano.

Este plan de reformas se puede sintetizar en dos grandes líneas de actuación. Por un lado, la eliminación de abusos y corrección de costumbres "desviadas", según los criterios litúrgico-musicales del $M P$, a través de medidas prohibitivas y rectificadoras (cuatro primeras medidas de la circular de Spínola, y medidas de la $4^{\mathrm{a}}$ a la 10 del informe). Por otro, el intento de llevar a cabo una auténtica regeneración del clero y del colectivo de músicos eclesiásticos a través de la formación en nuevos valores, no sólo litúrgicos, sino también culturales y estéticos. Esta regeneración necesitaba de nuevas estructuras (tres primeras medidas del informe, además de la $5^{\text {a }}$ de la circular de Spínola). Como trataremos de mostrar, la estrategia hispalense para lograr esta transformación se diferenció, en principio, del modelo propuesto por los grandes ideólogos del movimiento reformista español, quienes presentaron el seminario como su centro fundamental. En la archidiócesis andaluza se trataron de fundar nuevos centros cuyos fines tratarían de dar respuesta, además, a otros problemas sistémicos como la falta de regulación profesional de los músicos eclesiásticos diocesanos en general. La precaria situación laboral de este colectivo así como su deficiente formación fueron causas del fracaso de la reforma en muchos lugares del país, como se desprende de algunas intervenciones y conclusiones recogidas en las actas de los distintos congresos nacionales de música sagrada ${ }^{56}$.

\footnotetext{
${ }^{54} M P$, Título VI. Órgano e instrumentos, art. 16.

${ }^{55}$ El informe al que hacemos referencia fue publicado en: Marcelo, Arzobispo de Sevilla, "Sobre música sagrada” BOAS, 560 (1905), p. 90.

${ }^{56}$ Véase capítulo 5, epígrafe 3.2.3. “La situación económica de los músicos eclesiásticos”, p. 404.
} 


\section{Inicio y suspensión del proceso de reformas: causas y consecuencias}

El impulso que en estos primeros meses del año había experimentado la reforma en Sevilla, sustanciado en la rápida respuesta de Spínola y en la elaboración por parte de la CDMS de un proyecto para su desarrollo y aplicación, se congeló, quedando sin continuidad durante el resto de 1904. La ausencia en el BOAS de cualquier referencia a la cuestión litúrgico-musical, la absoluta inactividad de la CDMS, que no volvió a reunirse, y la no publicación para conocimiento general en la archidiócesis de las medidas que constituyeron el plan de reformas indican que el proceso se paralizó. Las razones de esta interrupción súbita encuentran explicación, a nuestro juicio, según las siguientes consideraciones.

En primer lugar, existió un problema de cohabitación institucional y de definición de competencias. Su origen está en la aparición en la estructura diocesana de un nuevo órgano con grandes atribuciones y responsabilidades como fue la CDMS. En una circular publicada el 15 de enero de 1905 el arzobispo ofrecía la siguiente explicación sobre la inacción de dicho órgano desde principios de marzo de 1904, fecha de su primera y única reunión:

La Comisión estudió el punto [la aplicación del $M P$ ], nos propuso lo que estimó oportuno, y nosotros lo aceptamos desde luego, seguros de su acierto.

Fue sin embargo nuestro ánimo al crear dicha Comisión, no sólo que nos aconsejara, sino que vigilara la ejecución de lo dispuesto por el Papa y de las medidas nuevas que se adoptaran; mas sin duda nos explicamos mal. La Comisión juzgó terminado su mandato con el informe que nos dio, y temerosa sin duda de traspasar el límite de sus atribuciones, ya nada ha vuelto a hacer $[\ldots] .{ }^{57}$

Es decir, la Comisión cumplió sólo con uno de sus cometidos -el menos problemático-, como era el de elevar propuestas a Spínola y someterlas a su criterio para su consiguiente aprobación. Sin embargo, aquel otro relacionado con el deber de supervisión (vigilar "la ejecución de lo dispuesto por el Papa y de las medidas nuevas") no se atrevió a cumplirlo por prudencia ("temerosa sin duda de traspasar el límite de sus atribuciones"). Aunque Spínola cargó con la responsabilidad de un supuesto malentendido ("más sin duda nos explicamos mal"), gesto con el que probablemente intentaría evitar posibles malestares, el prelado fue absolutamente claro a la hora de

\footnotetext{
${ }^{57}$ Marcelo, Arzobispo de Sevilla, "Sobre la música sagrada", BOAS, 558 (1905), p. 6.
} 
describir las competencias que trasfería a la CDMS (entre ellas, "velar por que se cumplan las anteriores disposiciones, y las que en lo sucesivo dictemos") ${ }^{58}$. Por tanto, cabe pensar que, aunque en teoría la Comisión no tenía por qué preocuparse en este sentido, en la realidad, hubiera razones para la cautela. Consideremos a este respecto, por una parte, la recepción, no precisamente favorable, que el clero dispensó al MP como comprobaremos más adelante-; por otra, el poder que ostentaban instituciones como el cabildo catedralicio de un gran peso histórico y simbólico; y por último, relacionado con esto último, la falta de una mayor claridad en la definición de los ámbitos competenciales de la CDMS. Es decir, si las medidas, acuerdos, o prescripciones propuestas por la CDMS eran de obligado cumplimiento en el caso de instituciones diocesanas que poseían un gobierno o ámbitos de decisión propios. En la la Catedral, por ejemplo, habría que plantearse si debía prevalecer o no el criterio de la Comisión en asuntos de música por encima de las decisiones del Cabildo. Hay que pensar que si esas disposiciones recibían la sanción positiva del arzobispo habrían de ser acatadas por todos, aunque, como pondrá en evidencia nuestro estudio, el asunto era ciertamente delicado.

Por otro lado, se produjo, además, otra situación que, pensamos, contribuyó a disuadir a la CDMS de enfrentarse al compromiso que significaba poner en ejercicio algunas de sus facultades potencialmente más polémicas. El informe producto de aquella primera y única reunión celebrada el 4 de marzo de 1904 no fue hecho público hasta el 15 de febrero de 1905, casi un año después. Este retraso generó dos problemas importantes. En primer lugar, impidió que el conjunto del clero y demás diocesanos conocieran las medidas propuestas, con el consiguiente perjuicio que ello acarreaba para el proyecto. En segundo lugar, debió ser interpretada como una falta de respaldo a la labor realizada por el nuevo órgano reformista, precisamente en un momento en el que había que asentarla con firmeza ante otras instituciones con las que habrían de producirse fricciones. De hecho, en la circular de 15 de enero de 1905 se hacía evidente que el objetivo principal de Spínola con la divulgación de dicho informe fue subsanar este error apoyándola públicamente, insistiendo en su sobrada competencia y sus capacidades, así como reafirmándola en los poderes otorgados:

\footnotetext{
${ }^{58}$ Marcelo, Arzobispo de Sevilla, "Circular sobre la música sagrada”, BOAS, 536 (1904), p. 117.
} 
Debemos ante todo por lo mismo reiterar nuestra confianza a la Comisión, nombrada en Abril último, y cuya inteligencia y celo reconocemos y aplaudimos.

Cúmplenos además declarar que deseamos y queremos que la misma Comisión nos denuncie las infracciones, que lleguen a su noticia de lo decretado por su Santidad, a fin de que le pongamos sin dilación el conveniente remedio; como asimismo cualquier otro abuso en el particular de su incumbencia, que crea digno de corregirse. ${ }^{59}$

Para hallar la segunda causa de la suspensión del proyecto de reformas es necesario reparar en la saturada agenda diocesana de 1904, y analizar la compleja situación que vivía la Iglesia. El 8 de abril Spínola escribía esta en extremo negativa evaluación del escenario cultural y social, moral y político al que se enfrentaba:

Que nos encontramos al presente en uno de esos periodos apretados y de gran peligro, que de tiempo en tiempo ocurren en los pueblos, es indudable.

Una nube de periódicos, hojas e impresos de cien clases ha caído sobre nosotros, y lleva a todas partes veneno mortífero, en forma a veces de astutos y pérfidos ataques a nuestra fe, a veces de insultos a la moral católica, a veces de vivas excitaciones de las concupiscencias. El teatro abre sus puertas para poner a la vista de espectadores, más celosos de divertirse y gozar, que de cumplir con el deber, escenas asquerosas, en que el vicio ostenta sus desnudeces y el pecado recibe ovaciones y alcanza triunfos. Mil centros de reunión ofrecen a la juventud ocasiones de satisfacer los malos instintos y pasiones, que en el corazón del hombre se anidan, esperando ocultos oportunidad para salir a luz y hacer explosión. Asambleas literarias o científicas, políticas o filantrópicas bautizadas con títulos diversos, brindan a gentes ya sedientas de popularidad, ya ansiosas de acabar con lo que les estorba, oportunidad para pronunciar discursos verdaderamente subversivos, porque son destructores de todo orden social o político y demoledores, permítasenos decirlo así, hasta del buen sentido mismo, de que no pueden olvidarse la ciencia y la literatura sin suicidarse. [...]

[...] las fauces del abismo aparecen abiertas ante nuestros espantados ojos, y nos urge tomar medidas para conjurar el inminente riesgo de ser tragados por ellas. ${ }^{60}$

\footnotetext{
${ }^{59}$ Marcelo, “Sobre la música sagrada”, BOAS, 558 (1905), p. 6.

${ }^{60}$ [Marcelo Spínola], La coronación de la Virgen de los Reyes. Exhortación que con motivo de solemnidad tan fausta que será una de las principales del año jubilar de la Inmaculada Concepción dirige el Excmo. Sr. Arzobispo de Sevilla a sus amados diocesanos (Sevilla: Imprenta de Izquierdo y

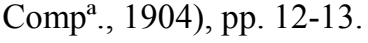


En 1904, por decreto de León XIII, se conmemoró en todo el orbe católico el cincuenta aniversario de la declaración del dogma de la concepción inmaculada de María. Dada la particular e histórica significación que para la Iglesia de Sevilla tenía la Inmaculada $^{61}$, Spínola quiso celebrar por todo lo alto esta onomástica, y aprovechar la ocasión para que sirviera de revulsivo. Pretendió proporcionar un revitalizado impulso a su acción pastoral, cuyas estrategias y medidas puestas en práctica no habían producido los frutos deseados ante las difíciles circunstancias según su punto de vista. En opinión de José María Javierre, biógrafo del arzobispo, el objetivo de Spínola era que la cita provocara una renovación en la Archidiócesis tanto a nivel espiritual como institucional $^{62}$.

Desde el comienzo de su pontificado, algunas de las líneas maestras de actuación con las que el arzobispo hispalense trató de dar respuesta a la situación de la Iglesia local fueron, por un lado, conciliar y hacer converger en una fuerza de acción común las distintas facciones católicas politizadas en liza: integristas, carlistas, neocatólicos; y por otro, contrarrestar los envites de la prensa liberal y anticlerical que, además de poner con frecuencia como objetivo de sus críticas y ataques a la institución eclesial, difundía unos valores culturales, y unos principios políticos y morales opuestos a los defendidos por la Iglesia ${ }^{63}$. Estas ideas se concretaron, en el terreno político, en la constitución de la Liga Católica, y en el de propaganda -la "buena prensa", según se autodenominaba la católica-, en la fundación de un diario de noticias, El Correo de Andalucía, y de la Asociación Diocesana de Buenas Lecturas ${ }^{64}$.

El 18 de enero de 1904, al mismo tiempo que se daba a conocer el $M P$ y se iniciaba el proceso de su aplicación en la Archidiócesis, la junta organizadora del jubileo en honor a la Inmaculada celebró una reunión para decidir el programa de actividades a llevar a cabo ${ }^{65}$. En ella, se aprobaron una docena de iniciativas que,

\footnotetext{
${ }^{61}$ José $\mathrm{M}^{\mathrm{a}}$ Javierre, "La diócesis de Sevilla en el siglo XX”, en Historia de las diócesis españolas, vol. X (Iglesias de Sevilla, Huelva, Jerez, Cádiz y Ceuta), coord. por José Sánchez Herrero (Madrid: BAC, 2002), pp. 327-500, p. 356.

${ }^{62}$ Javierre, "La diócesis de Sevilla", p. 364.

63 Sobre la archidiócesis de Sevilla durante el pontificado de Spínola, véanse, además de José M ${ }^{\mathrm{a}}$ Javierre, "La diócesis de Sevilla", pp. 329-368; Carlos Ros, dir., Historia de la Iglesia de Sevilla, (Sevilla: Castillejo, 1992), pp.717-732.

${ }^{64}$ Sobre prensa católica en Andalucía véase: Lorena R. Romero Domínguez, La buena prensa. Prensa católica en Andalucía durante la Restauración (Sevilla: Centro de Estudios Andaluces, 2009).

${ }^{65}$ [Spínola], La coronación de la Virgen de los Reyes, p. 3.
} 
lógicamente, exigirían a la Diócesis un considerable esfuerzo de organización, en detrimento de otros proyectos como la reforma musical. Cabe destacar algunas de gran alcance como la celebración en Sevilla de la primera Asamblea Nacional de la Buena Prensa; la coronación canónica de la Virgen de los Reyes, algunos años después proclamada patrona de la Archidiócesis; y una peregrinación a Roma. Esta última tuvo lugar a comienzos del mes de junio. La Asamblea, cuyos trabajos se prolongaron durante cuatro días, se inauguró el 15 de ese mes, tan sólo tres días después del regreso de la comitiva hispalense. Los festejos culminaron el 4 de diciembre con la celebración de misa pontifical presidida por el nuncio de la Santa Sede en España y la coronación de la Virgen de los Reyes. Durante la semana anterior la Catedral recibió peregrinaciones provenientes de más de cien pueblos de todos los rincones del territorio diocesano. Al margen de otros actos de menor relevancia, estas actividades nos proporcionan una idea de la envergadura que adquirió la conmemoración concepcionista y que, en palabras de Javierre, "conmovieron la diócesis." 66

En el año de 1904, por tanto, el proceso de reformas litúrgico-musicales coincidió con la celebración del jubileo de la Inmaculada, acontecimiento que para Spínola representó una gran oportunidad, y para el aparato administrativo y de gobierno diocesano un compromiso en cuya preparación habría de volcarse. Es lógico pensar, en consecuencia, que la reforma litúrgico-musical debió pasar a un segundo plano. Habría que preguntarse por la consideración en que los responsables eclesiásticos tenían a la música, y si le reconocían alguna capacidad de incidencia en la sociedad, en un momento de intensa lucha de la Iglesia por mantener posiciones de influencia sobre ella. La respuesta, creemos, nos la proporciona Federico Roldán, futuro secretario del II Congreso Nacional de Música Sagrada, quien expresó de forma gráfica y sintética la importancia que la cuestión de la música religiosa poseía en aquel difícil contexto, desde el prisma católico ${ }^{67}$ :

[...] cuando en el campo católico se oyen por doquier los clarines que llaman al combate, cuando ya resuena el estruendo de la más terrible batalla, cuando se percibe por todas partes el olor de la pólvora, dedicarse [...] a ordenar papeles de Música, parece

\footnotetext{
${ }^{66}$ Javierre, "La diócesis de Sevilla”, pp. 363-365.

${ }^{67}$ Véase, además, capítulo 5, epígrafe 3.2.2. "La contribución al Congreso de arciprestes, curas y fieles diocesanos", pp. 402-404.
} 
reproducir el hecho de aquel que, embebido en la resolución de áridos problemas de matemáticas, no se daba cuenta de que su ciudad y su patria eran presas de las llamas. ${ }^{68}$

Para Roldán, la reforma constituía una especie de distracción irresponsable frente al desafío que, con metáforas de efecto, dibujaba.

Otros puntos de vista cuestionaron este sistema de prioridades. En el siguiente capítulo comprobaremos la importancia social que el futuro arzobispo de Sevilla, Enrique Almaraz, atribuía al canto litúrgico de la comunidad de fieles. Vicente Ripollés, recientemente incorporado al puesto de maestro de capilla catedralicio, rechazaba aquellos posicionamientos que justificaban la postergación de los asuntos musicales por los problemas que atravesaba la Iglesia ${ }^{69}$. Ripollés esgrimió argumentos como el siguiente:

Ya sé yo que el Clero tiene múltiples asuntos a qué atender, pero esto no ha de apartarle de aplicar su encendido celo a favor de la música sagrada: grandes atenciones embargaban la mente de San Gregorio Magno en la gobernación de todo el mundo cristiano, pero aún le quedaban energías para la fundación y régimen personal de la escuela de cantores romanos: en medio de sus continuas luchas con la herejía se ocupaban en reglamentar el canto eclesiástico hombres tan eminentes como San Ambrosio, San Agustín, San Isidoro, San Basilio, San Juan Crisóstomo y San Bernardo. ${ }^{70}$

${ }^{68}$ Federico Roldán, “Un Congreso de música?”, Crónica del Segundo Congreso, p. 42.

69 Vicente Ripollés Pérez (Castellón, 1867- Rocafort, Valencia, 1943). Se formó, según el propio Ripollés afirma, con Francisco Pachés, Roque Domingo y Salvador Giner. En 1902, un año antes de incorporarse al puesto de maestro de capilla en la catedral hispalense, asistió a los cursos sobre historia de la música que impartió Felipe Pedrell en la Escuela de Estudios Superiores del Ateneo de Madrid. A este centro, activo entre 1896 y 1902, estuvieron ligadas importantes personalidades como Clarín, Álvarez Buylla, Gumersindo de Azcárate, Canalejas, Menéndez Pelayo, Pardo Bazán, Ramón y Cajal, Julián Ribera, Juan Valera. Ripollés fue maestro de capilla de la catedral de Tortosa entre 1893 y 1895 , y del Colegio del Corpus Christi de Valencia entre 1895 y 1902. Tras su salida de Sevilla en junio de 1909, ocupó el cargo de director de canto litúrgico de la catedral y profesor del seminario de Valencia, creado ex profeso para él por el entonces arzobispo Victoriano Guisasola. En 1927 fue nombrado canónigo. Su dedicación a la investigación de la música histórica española tuvo como frutos más sobresalientes las monografías Músicos castellonenses y El villancico i la cantata, ambas de 1935, a las que hay que añadir sus dos publicaciones sobre las epístolas farcidas aparecidas en el Boletín de la Sociedad Castellonense de Cultura (1943). Su producción como compositor es exclusivamente religiosa. Una buena parte de ella fue editada por diversas casas editoriales como las valencias Dotesio y Antich y Tena, o la barcelonesa Musical Emporium. Andrea Bombi, "Ripollés Pérez, Vicente", Diccionario de la Música valenciana, 2 vols., ed. por Emilio Casares (Madrid: Iberautor Promociones Culturales, 2006), vol. 2, pp. 344-346; M $^{\mathrm{a}}$ Carmen Genovés Carmona, "Una mirada al "motu proprio" valenciano: Vicente Ripollés y Eduardo Soler”, Archivo de arte valenciano, 86 (2005), pp. 67-76; Miguel Ángel Picó Pascual, "La aportación musicológica del canónigo Vicente Ripollés Pérez”, Revista de Musicología, XXVII/1 (2004), pp. 287292.

${ }^{70}$ [Vicente Ripollés], “La cultura litúrgica-musical del Clero”, Crónica del Primer Congreso, p. 61. 
Este pasaje pertenece al discurso que preparó para el I Congreso Nacional de Música Sagrada celebrado en Valladolid en 1907. Unos meses después de su clausura escribió a Pedrell este otro fragmento en el que ponía de manifiesto el bajo concepto que tanto la jerarquía eclesiástica como el clero en general tenían de la música y los músicos:

Los de Valladolid pidiéndonos suscripciones y material para la revista $[M S H]$ : yo me hago el tonto porque qué vamos a decir allí? Tronaremos contra el clero y sus elementos directores que nada hacen para fomentar el buen gusto? Entonces me expongo a recibir algún garrotazo de los de arriba y de los de abajo. Les diremos que el Papa pide el concurso de todos? Vaya V. con ello a los que miran a la música por cosa la más despreciable y a los músicos como a entes que no merecen atención. ${ }^{71}$

Todas estas consideraciones nos llevan a cuestionarnos sobre lo que, creemos, constituye el asunto de fondo: la función que cumple la música. En este caso, su incapacidad de ejercer una función de transformación social, según la mayoría del clero, llevó a considerar la reforma musical como un asunto secundario. Más adelante comprobaremos la profunda implicación que mostraron en todo lo que afectaba a la reforma de la música litúrgica un numeroso grupo de capitulares catedralicios, y que contrasta radicalmente con este "desprecio" y bajo concepto de los que nos dan testimonio Ripollés o Roldán. En el capítulo cuarto plantearemos algunas hipótesis a partir de las cuales tratar de dar respuesta a estas cuestiones.

Al margen de las razones expuestas para explicar la interrupción del proceso: la aparición de un nuevo órgano en la administración diocesana, y la coincidencia con el jubileo de la Inmaculada, creemos, existe otra circunstancia a sumar a estas. Desde una perspectiva más amplia, el programa pastoral desplegado por Spínola fue un intento de aplicación en el ámbito de su jurisdicción de la doctrina de León XIII, que tuvo, entre otros, los objetivos de reubicar al catolicismo política y socialmente en el mundo moderno, y articular una respuesta adecuada ante las amenazas que este representaba en algunos aspectos para la Institución eclesial ${ }^{72}$. Pío $\mathrm{X}$ representó un cambio de

${ }^{71}$ Carta de Ripollés a Pedrell, 29 de octubre de 1907. BC [Biblioteca de Catalunya]. FFP [Fondo Felip Pedrell]. M 964 R.

${ }^{72}$ Un análisis sobre la cuestión social y el efecto de la encíclica Rerum Novarum en la archidiócesis de Sevilla durante el periodo inmediatamente anterior al pontificado de Spínola en: José Domínguez León, 
orientación respecto a su antecesor. Ludwig Hertling, en su ya clásica Historia de la Iglesia, apunta las etiquetas que se generalizaron para calificar a grandes rasgos a ambos papas, "político" el primero, y "pastor" el segundo. El papa Sarto inició su pontificado de signo restaurador volviendo la mirada al Templo, es decir, a la liturgia y los sacramentos, como origen de la vida cristiana, en consecuencia, como punto de partida de la misión social católica. El MP sobre música fue una de sus primeras iniciativas en este sentido ${ }^{73}$. La reforma de la música sagrada en las diócesis se planteó en un momento en el que ni Spínola ni el resto del colegio episcopal habían tenido tiempo de asumir el cambio en la línea de acción del papado, a pesar de la voluntad expresada desde el primer momento por el prelado hispalense de emplearse sin reservas en "cooperar al pensamiento de Pío X"74.

En esta situación general de paralización del proceso de reformas, sólo dos referencias al MP encontramos en el BOAS. La primera de ellas, la inclusión de criterios extraídos de la instrucción papal en las bases que regulaban el concurso de la sección de música de un certamen literario que se organizó en el marco de las celebraciones inmaculistas. ${ }^{75}$ El programa de dicho certamen, en el que llegaría a participar Menéndez Pelayo, rezaba: "las melodías evitarán las reminiscencias de motivos teatrales, acercándose en aire, inspiración y sabor a las melodías gregorianas.

"La doctrina social católica en Andalucía occidental a finales del siglo XIX y el impacto de la Rerum Novarum. El caso sevillano", en Las Fiestas de Sevilla en el siglo XV. Otros estudios, dir. por José Sánchez Herrero (Madrid: Deimos, 1991), pp. 207-232. El autor pone de manifiesto la grave situación socio-económica de los trabajadores, por un lado, y la escasa eficacia de las pocas iniciativas no bien planteadas impulsadas por la jerarquía, más centrada en condenar el socialismo o el anarquismo que en proponer alternativas desde la doctrina social católica.

${ }^{73}$ Los primeros párrafos del MP apuntan en esa dirección: "Entre los cuidados propios del oficio pastoral, [...] uno de los principales es el mantener y procurar el decoro de la Casa del Señor, donde se celebran los augustos misterios de la religión y se junta el pueblo cristiano a recibir la gracia de los sacramentos. [...] Nada, por consiguiente, debe ocurrir en el templo que turbe, ni siquiera disminuya, la piedad y devoción de los fieles; [...]

[...] nuestra atención se fija hoy solamente en uno de los [abusos] más generales, de los más difíciles de desarraigar [...]: tal es el abuso en todo lo concerniente al canto y a la música sagrada". MP. [Exposición de motivos previa a la Instrucción legal].

${ }^{74}$ Así se expresó Spínola: "Pero las obras buenas, y muy especialmente las preceptuadas por quien poder y autoridad para ello tiene, no por penosas han de dejarse, sino acometerse con esfuerzo, pues así es como se prueba la sumisión perfecta de los inferiores a los superiores y el amor con que se pone en ejecución la voluntad de los mismos.

Por lo que a nosotros toca, nada hemos de omitir para cooperar al pensamiento de Pío X". Marcelo, Arzobispo de Sevilla, “Circular sobre la música sagrada”, BOAS, 536 (1904), p. 116.

75 "Programa del certamen literario que para honrar a la Inmaculada Concepción de la Sma. Virgen María en el quincuagésimo aniversario de la definición dogmática de este misterio, se ha de celebrar en Sevilla", BOAS, 546 (1904), pp. 74-77. 
El acompañamiento se escribirá en estilo ligado polifónico a cuatro partes reales"76. Los participantes debían componer una obra para tenor y barítono, órgano y quinteto de cuerda, basada en el texto Bendita sea tu pureza. La influencia del MP en las bases de este concurso se explica por los componentes del jurado. Dos de sus tres integrantes eran miembros de la CDMS nombrada por Spínola, Vicente Ripollés y Agapito Insausti, tenor de la capilla catedralicia ${ }^{77}$. El ganador del premio, donado por el Ministro de Instrucción Pública, fue el tercero de sus miembros, Manuel Lerdo de Tejada ${ }^{78}$.

La segunda referencia demuestra que las cinco primeras medidas adoptadas por Spínola -las únicas publicadas, por tanto, conocidas- a principios de año no pasaron del todo desapercibidas, al menos para algunos responsables eclesiásticos. Cercana las fechas de navidad algunos párrocos y rectores de iglesias formularon una consulta al prelado sobre la compatibilidad de las llamadas misas de Expectación con los nuevos principios sobre música ${ }^{79}$. Hay que señalar que estas tradicionales misas tenían un marcado carácter popular y festivo. En ellas se acompañaba el canto con instrumentos de percusión típicos de las fiestas navideñas como panderetas, zambombas, etc. De acuerdo con las prescripciones del $M P$ el dictamen del arzobispo no podía ser otro que prohibir "que se usen en dichas Misas de Expectación los ruidosos instrumentos que se empleaban" 80 . Más adelante, cuando tratemos de hacer una evaluación del cumplimiento de las medidas propuestas durante el pontificado de Spínola, comprobaremos si este mandato, relacionado con el uso de los "instrumentos fragorosos", fue realmente respetado por aquellos que la debían aplicar.

En definitiva, el año de 1904 resultó a la postre un año perdido para la reforma. Por contra, la publicación de dos importantes circulares a comienzos de 1905, la $\mathrm{n}^{\mathrm{o}} 558$ de 16 de enero y la $n^{\circ} 560$ de 15 de febrero marcó un punto de inflexión ${ }^{81}$. En la

\footnotetext{
${ }^{76}$ Ibídem, p. 76.

${ }^{77}$ El tercer componente era el organista de la Catedral, Bernardo Salas.

78 “La adjudicación de premios del Certamen”, BOAS, 556 (1904), p. 494.

79 "Se nos han acercado algunos Párrocos y Sacerdotes rectores de Iglesias, consultándonos si después del Motu proprio de Pío X, nuestro amadísimo Padre, acerca de la música sagrada, podrían celebrarse las Misas llamadas de Expectación en la forma acostumbrada entre nosotros desde inmemorial fecha". Marcelo. Arzobispo de Sevilla, "Circular núm 315" [en índice del tomo figura como "Circular de Ntro. Excmo. y Rvmo. Prelado acerca de la Música Sagrada”], BOAS, 556 (1904), p. 487.

${ }^{80}$ Ibídem.

${ }^{81}$ Véase en Apéndice 2 una relación de los documentos relacionados con la reforma publicados en el $B O A S$.
} 
primera, como ya hemos apuntado, Spínola pretendió subsanar el problema que constituyó la no difusión de las medidas ideadas por la CDMS expresando públicamente su apoyo, y ratificando sus importantes competencias. La segunda de ellas $\left(B O A S \mathrm{n}^{\mathrm{o}}\right.$ 560) significó la reanudación del proceso. El prelado insertó los dos informes elaborados por la CDMS en sus dos primeras reuniones, aquella de marzo de 1904 con la que inició sus trabajos, y la recién celebrada de 23 de enero, que representó su vuelta a la actividad tras este año perdido. Se dieron a conocer así más de una veintena de disposiciones y propuestas con su sanción positiva para su cumplimiento. Nos parece significativo, además, que comenzara la redacción de esta última circular volviendo a reiterar nuevamente su apoyo a la Comisión:

La Comisión, que nombramos en Febrero del año anterior, y a la que en el pasado mes de Enero hemos ratificado nuestra confianza y nuestros poderes, nos dirigió en 4 de Marzo de 1904 un informe, y otro nos ha vuelto a dirigir en 26 de Enero, que nos ha parecido conveniente insertar en el Boletín [en versales en el original], para conocimiento de los Párrocos y Rectores de Iglesias $[\ldots]^{82}$

Spínola tradujo todas estas declaraciones a favor de este órgano en una actuación concreta como fue su ampliación con nuevos miembros. Aunque dicha ampliación nunca fue dada a conocer en el BOAS, sabemos, por un borrador de la carta que remitió el arzobispo a los nuevos integrantes conservado en el AGAS, que entre finales de febrero y marzo se incorporaron a la CDMS cuatro nuevos vocales: Bernardo Salas y Seguí, organista ${ }^{83}$; Luis Leandro Mariani, organista segundo ${ }^{84}$; José Otero

82 "Marcelo, "Sobre música sagrada", BOAS, 560 (1905), p. 89.

${ }^{83}$ Bernardo Salas y Seguí (Campanet, 1874-Palma de Mallorca, 1932). Compositor y organista. Estudió con Juan Torandell, Guillermo Massot y Bartolomé Torres. Fue organista de las catedrales de Segovia, Sevilla y Palma de Mallorca. Ofreció conciertos en Francia e Inglaterra. Compuso obras religiosas y algunas armonizaciones de cantos populares. Joan Company Florit, "Salas Seguí, Bernat", DMEH, 10 vols., ed. por Emilio Casares (Madrid: SGAE, 2001), vol. 9, pp. 568-569.

${ }^{84}$ Luis Leandro Mariani y González (Sevilla, 1864-1925). Organista segundo de la catedral de Sevilla (1891-1921), fue pianista y compositor. Se formó con su tío Emigdio Mariani y con el maestro de capilla catedralicio, Evaristo García Torres. Escribió un folleto teórico, Un nuevo acorde, en el que planteó un nuevo sistema de modulación a cualquier tonalidad a partir de un único acorde. Destaca su producción escénica así como su obra pianística, sinfónica. Algunas de ellas fueron estrenadas por las orquestas Sinfónica y Filarmónica de Madrid, e interpretadas en diversas salas europeas. En 1907 ganó el Premio Nacional con Tres suites españolas. Refiriéndose a su obra para piano, Álvarez Cañibano describe su estilo como romántico de tono andalucista. En sus últimas obras participa de un nacionalismo vanguardista que usa el elemento folclórico sin la cita expresa. En1880 fundó la Academia Filarmónica, que durante muchos años fue la principal institución educativa musical de Sevilla. Antonio Álvarez Cañibano, "Mariani González, Luis Leandro", DMEH, 10 vols., ed. por Emilio Casares (Madrid: SGAE, 
Cascales, salmista; Juan Domínguez Recio, sochantre. Todos músicos catedralicios ${ }^{85}$. La CDMS hispalense aumentó aún más su peso y su poder relativo gracias a esta actitud favorable del arzobispo. Bien es verdad que ese aumento de integrantes no redundó en una mayor representatividad, sino que se concentró aún más en el templo catedralicio.

El efecto de estas circulares fue el pretendido. Para la Comisión significaron el revulsivo y el respaldo necesario para afrontar con ciertas garantías su delicada labor. La CDMS, por su parte, respondió con una actitud comprometida y activa, como veremos. Durante todo el año de 1905 celebró diversas reuniones, fruto de las cuales fueron varios informes elaborados y elevados a la sanción del prelado, quien los aprobó y publicó inmediatamente para conocimiento de todos sus diocesanos ${ }^{86}$. En un total de ocho circulares publicadas en el BOAS y algunos informes no publicados, la CDMS ideó un paquete de cerca de medio centenar de iniciativas. La compenetración entre la máxima autoridad eclesiástica hispalense y el órgano diocesano para la aplicación de la reforma fue un hecho.

\section{Concreción en el ámbito diocesano de la normativa papal: el plan de reformas desarrollado por la Comisión Diocesana de Música Sagrada (I)}

Pretendemos a continuación recoger y analizar el conjunto de disposiciones promulgadas durante el pontificado de Spínola. Este conjunto de medidas y propuestas constituyó el plan local hispalense que, como desarrollo normativo particular del $M P$, se desplegó para la realización de la reforma. Más adelante, cuando unamos a estas disposiciones las correspondientes al pontificado de Almaraz, podremos tener una

2001), vol. 7, pp. 170-171; Cuenca Benet, Galería de músicos andaluces, pp. 174-182; Ángela Ruíz Carbayo, "Nuevas fuentes para el estudio de la música sevillana: el archivo musical de Luis Leandro Mariani González (¿1858?-1925)”, en Musicología global, musicología local, ed. por Javier Marín López, Germán Gan Quesada, Elena Torres Clemente, Pilar Ramos López (Madrid: Sociedad Española de Musicología, 2013), pp. 1637-1651.

${ }^{85}$ Sus nombramientos se hicieron efectivos a finales de febrero o en marzo, pues el informe emitido por la CDMS y firmado por ellos tiene fecha de 12 de abril y el último sin sus firmas data de 25 de febrero. Dicho borrador se conserva en: AGAS. Sección Gobierno. Asuntos Despachados, leg. 04900 (1905). Es posible que algunos de los que figuran en dicho borrador no aceptaran la propuesta de Spínola de formar parte de la Comisión, pues en ninguno de los documentos generados por esta aparece su firma. Tal es el caso de Luis Leandro Mariani.

${ }^{86}$ El 15 de febrero, la CDMS hacía la siguiente declaración: "Para corresponder a la confianza que V. E. Reverendísima se ha dignado depositar en la Comisión, esta estudiará con diligencia y vigilará celosamente el exacto cumplimiento de las disposiciones pontificias, suplicando humildemente a V. E. Rma. se digne bendecir sus trabajos como a feliz presagio de acierto en todos su actos." Dicha declaración forma parte del informe inserto en: Marcelo, "Sobre música sagrada", BOAS, 560 (1905), p. 96. 
visión acabada del conjunto del plan desplegado por la institución diocesana hispalense en estos años.

Organizaremos nuestra exposición en tres epígrafes. En el primero de ellos nos dedicaremos a analizar el intento de establecer nuevas instituciones de formación. En el segundo, centraremos nuestra atención en la censura y depuración del repertorio vigente. Por último, estudiaremos las medidas relacionadas con la participación de los instrumentos en la liturgia.

\subsection{Centros para la formación de los agentes musicales diocesanos:} Escuela Oficial Archidiocesana de Canto Gregoriano y Seminario

La música sagrada, según el $M P$, debía poseer las mismas cualidades que la liturgia como parte integrante de ella: santidad, bondad de formas y universalidad ${ }^{87}$. El canto gregoriano contenía estas cualidades "en grado sumo", razón por la que fue presentado como arquetipo ${ }^{88}$. La cercanía estilística a este "supremo modelo" se estableció como criterio fundamental para evaluar la naturaleza sagrada y la adecuación litúrgica de cualquier obra ${ }^{89}$. El gregoriano, por tanto, no sólo se impuso como ideal litúrgico-musical, sino también estético. De esta forma, invadió el espacio propio de otros géneros, condicionando su orientación estética, estilística e incluso formal.

La reforma, por tanto, dependía en buena medida, de la restitución del "antiguo canto gregoriano tradicional", restaurado recientemente en "su pureza en integridad" gracias a "estudios recientísimos"90. La recuperación del, según el documento papal, auténtico y purificado canto llano como género sacro por antonomasia tuvo como centro el seminario diocesano. El MP disponía en su artículo 25: "En los seminarios de clérigos y en los institutos eclesiásticos se ha de cultivar con amor y diligencia,

\footnotetext{
${ }^{87} M P$, Título I. Principios generales, art. 2.

${ }^{88} M P$, Título II. Géneros de música sagrada, art. 3.

${ }^{89}$ MP, Título II. Géneros de música sagrada, art. 4. "una composición religiosa será más sagrada y litúrgica cuanto más se acerque en aire, inspiración y sabor a la melodía gregoriana, y será tanto menos digna del templo cuanto diste más de este modelo soberano.[subrayado original]”. Ibídem, art. 3.

${ }^{90}$ MP , Título II. Géneros de música sagrada, art. 3. Se trata de una referencia al trabajo realizado por los benedictinos de Solesmes de restauración del canto llano a partir de los códices medievales, considerados por la Santa Sede como el canto gregoriano impoluto y auténtico.
} 
conforme a las disposiciones del Tridentino, el ya alabado canto gregoriano tradicional, $[\ldots]^{391}$.

La estrategia de los reformadores españoles consistió en la educación de nuevas generaciones de sacerdotes formados en los principios litúrgico-musicales y artístico-estéticos concentrados en el nuevo canto gregoriano. Estos sacerdotes, llamados a copar puestos de gran responsabilidad en las estructuras de decisión eclesiales, o como poco a ejercer de párrocos o rectores de templos, debían operar la reforma diseminando estos nuevos valores en sus diócesis o institutos religiosos. Los términos en los que se pronunció Otaño en el siguiente pasaje sobre el trabajo que desarrolló en Comillas son bastante ilustrativos ${ }^{92}$, aunque no se refiera a la formación específica sobre canto gregoriano, sino a la cultura musical en general -incluida la música profana-: "Todo es hacer obra de cultura, formar apóstoles. Estos han de ser, por la brillante carrera que tienen, los canónigos y obispos de España, y que sepan qué es lo que tenemos. Sembrar es mi tarea de hoy: trabajo oscuro, pero de gran provecho, en el que tengo todas mis esperanzas"93. Sobre el canto gregoriano en particular, manifestó a Pedrell: "Cuanto más trato estos asuntos de música sagrada, más hondo convencimiento adquiero de la absoluta necesidad de empezar la reforma por los seminarios"94. Se podrían recoger infinidad de testimonios como estos para probar la puesta en práctica de esta línea de acción, auténtica estrategia de regeneración cultural ${ }^{95}$.

\footnotetext{
${ }^{91} M P$, Título VIII. Medios principales, art. 25.

92 El trabajo desarrollado en el seminario de Comillas por Nemesio Otaño, uno de los principales ideólogos y promotores del movimiento en España, y gran defensor del seminario como corazón de la reforma, representó un caso paradigmático en estos primeros años. Sobre la labor de Otaño en Comillas véanse: López-Calo, Nemesio Otaño, pp. 69-86; García Sánchez, "José María Nemesio Otaño Eguino (1880-1956)", pp. 480-484.
}

\footnotetext{
${ }^{93}$ Carta de Otaño a Pedrell, [sin día] diciembre de 1910. AMSL. FO. Correspondencia, T01/079.

${ }^{94}$ Carta de Otaño a Pedrell, 27 de febrero de 1912. AMSL. FO. Correspondencia, T01/117.

${ }^{95}$ La memoria que envió Nemesio Otaño al congreso de Sevilla era un fuerte alegato del seminario como centro de la reforma, y de la regeneración del clero en el aspecto musical. Comenzaba así: "Es cosa que se ha comprendido ya con toda claridad, y en ello convienen todos sin excepción, que no puede darse reforma verdadera de la música religiosa, si esta no parte de los seminarios y en ellos no echa sus más hondas raíces". Crónica del Segundo Congreso, pp. 250-260. Ripollés hablaba así de su labor en el seminario de Valencia, tras su marcha de Sevilla: "En el Seminario trabajando con gusto y fruición formando a mis alumnos, materia dispuesta, todavía no maleada, y propicia a recibir la forma quiera dársela: canto gregoriano, polifónico, moderno, música orgánica, todo lo tocamos y con no poco resultado, con esperanza de formar una generación de gusto fino y depurado que sea propagadora de muchos ideales por esta vasta archidiócesis. Fuera del Seminario me aburro y asfixio y esto continúa como 20 años atrás, como si el arte no hubiera progresado ni el Papa hubiera hablado solemnemente como lo ha hecho: [...]
} 
En el momento de la aparición del $M P$, la enseñanza del canto gregoriano en el Seminario de Sevilla ya estaba organizada. La CDMS alababa en su primer informe (marzo de 1904) la existencia de la "Escuela de canto gregoriano en este Seminario", cuya clase era obligatoria para todos los seminaristas y que, al igual que el resto de materias, estaba sometida a evaluación ${ }^{96}$. Hemos podido averiguar que el origen de dicha escuela o clase de canto llano se remonta al Concilio Provincial celebrado en 1893, todavía durante el pontificado del cardenal Benito Sanz y Forés ${ }^{97}$. En la primera de sus disposiciones sobre el canto y la música religiosa (Título XV) se nos revela que el establecimiento de la clase de gregoriano en el Seminario fue consecuencia del intento de aplicación en la provincia eclesiástica hispalense del Reglamento para la música religiosa promulgado en 1894 por la Sagrada Congregación de Ritos, precedente inmediato del $M P^{98}$. En el nuevo plan de estudios del Seminario, fechado el

Fortuna que me consuela el estado floreciente del Seminario: a todo pasto tienen allá obras del más puro género religioso, y puertas cerradas a cal y canto para toda esta musiquilla que por aquí gastan, y es de ver el fervor y entusiasmo con que estos jóvenes cantan a Victoria, Haller Mitterer, etc.: alguna que otra vez llevo mi coro del Seminario a la Catedral para que canten las partes gregorianas; los del oficio no se dan por aludidos y continúan berreando y coreando a lo Juanote sin querer entender de otras cosas que no sean sus rutinas.” Carta de Ripollés a Pedrell, 18 de enero de1910. BC. FFP, M 964 R.

En otras muchas cartas de Otaño o Ripollés se evidencia la importancia central que para los reformadores tenía el seminario como origen de la reforma. Véanse: Cartas de Otaño a Pedrell, 15 de octubre de 1910. BC. FFP, M 964 O; a Goicoechea, 17 de octubre de 1910. AMSL. FO. Correspondencia, T01/074; a Ripollés, 11 de enero de 1910 y 31 de diciembre de 1910. AMSL. FO. Correspondencia, TA01/075 y TA01/100. Además del MP y del Reglamento general para la música sagrada en la provincia eclesiástica de Valladolid, en los Reglamentos sobre música sagrada promulgados por los obispos de esa provincia eclesiástica se incluyó un minucioso Reglamento particular para la enseñanza del canto litúrgico en los seminarios, y un Plan o programa que ha de servir para la enseñanza del canto coral y gregoriano en los seminarios de esta provincia eclesiástica. Estos documentos situaron al seminario como centro de la reforma. Véase: "Edicto y Reglamentos sobre música sagrada", pp. 379-396.

96 " 2 ' . Como el clero es el llamado por su ministerio a dirigir las alabanzas divinas, por lo mismo, conviene que, durante sus estudios, se prepare en estas materias y por lo tanto aplaude la creación que tiene hecha V.E. de la Escuela de canto gregoriano en este Seminario, siendo la clase obligatoria para todos los Seminaristas, como los demás estudios, y amparada con la sanción de premios y penas". Marcelo, Arzobispo de Sevilla, "Sobre música sagrada”, BOAS, 560 (1905), p. 90.

${ }^{97}$ Benito Sanz y Forés ocupó la silla arzobispal hispalense entre los años 1889 y 1895 . Fue el antecesor de Marcelo Spínola. Sobre dicho concilio véase: Synodicon Baeticum II: Constituciones Conciliares y Sinodales del Arzobispado de Sevilla, Siglos XIX-XX, coord. por Miguel Ángel Núñez Beltrán y dir. por José Sánchez Herrero (Sevilla: Universidad de Sevilla, 2012).

${ }^{98}$ La no coincidencia entre las fechas de celebración del Concilio (1893) y de publicación del Reglamento (1894) indica que las normas decretadas sobre música se incorporaron una vez concluido aquel. La segunda parte titulada "Instrucciones para promover el estudio de la música sagrada y para evitar los abusos." de dicho reglamento, disponía: "I.- Siendo la música sagrada parte de la liturgia, se recomienda a los Reverendísimos Ordinarios que tengan cuidado especial y den prescripciones oportunas sobre ella, especialmente en los Sínodos diocesanos y provinciales, pero ajustándose siempre a este Reglamento.” El Reglamento se ha consultado en Otaño, La Música Religiosa, p. 80. Las actas y decretos del Concilio salieron a la luz en: Acta et decreta Concilii Provincialis Hispalensis Anno MDCCCXCIII Celebrati sub mo. Archiepiscopo Cardinali Dño. Benedicto Sanz et Forés, Promulgata ab ejus successore Excmo. ac Rmo. Dño. Marcello Spinola et Maestre (Sevilla: Imprenta Izquierdo y Cía, 1893). Disposición I del 
13 de julio de 1894, sólo una semana después de que se diera a conocer el Reglamento para la música religiosa ${ }^{99}$, se introdujo la clase de canto gregoriano, tal y como había dispuesto el Concilio. Las lecciones se debían impartir dos veces por semana, los jueves y los domingos, aunque no para todos los alumnos, según había dictaminado la asamblea eclesiástica, sino para aquellos "que reúnan condiciones para este arte"100.

En 1897, Spínola logró que la Santa Sede aceptara su solicitud de erigir la Universidad Pontificia de Sevilla ${ }^{101}$. Se hubieron de confeccionar nuevos planes de estudio para las tres facultades de la recién creada universidad: Teología, Derecho Canónico y Filosofía. La clase de canto gregoriano sobrevivió a estos cambios, pues consta entre las asignaturas a impartir en la Facultad de Teología, con algunas diferencias. Estaba destinada a todos los alumnos que cursaran los tres primeros años de Teología, y se impartía sólo los domingos ${ }^{102}$. Sabemos, además, que el profesor designado para dar las clases fue el beneficiado tenor catedralicio Agapito Insausti (1851-1914), cargo que ostentó hasta $1909^{103}$.

“Titulus V. De religiosa musica et cantu.": "I.-Cantus vere et proprie ecclesiasticus est ille, qui firmus dicitur, seu Gregorianus a S. Gregorio Magno, qui illius instaurator ac promotor fuit, et de quo fovendo et rite instaurando, litterae datae sunt a Summis Pontificibus Pio IX, et Domino nostro Leone XIII. Hic cantus cultui divino est adaptatus, et ad glorificandum Deum mentesque sursum levandas aptissimus, adeo ut illius harmonia, si recta fuerit, castis auribus cordibusque piis maxime conveniat. Itaque, attento praesertim decreto S. Cong. Rit. 7 Julii 1894, adlaborandum est maxime ab Episcopis, quam a Capitulis, et $\mathrm{ab}$ omnibus ecclesiarum rectoribus, ut huius praestantissimi cantus foveatur et restituatur usus, ita ut omnes abusus et corruptelae in illius modo et methodo introductae prorsus et quam citius eliminentur. Hoc ut facilius obtineatur, statuimus in primis, ut in omnibus seminariis cantus scholae instituantur vel foveantur, ubi a peritissimis viris in veri cantus gregoriani congnitione et praxi, iuxta praeceptum Tridentinorum PP. et SSmi. Domini Leonis XIII monita omnes alumni edoceantur: [...]". Acta et decreta Concilii Provincialis Hispalensis, pp. 268-269. El Reglamento para la música religiosa de 1894 fue dado a conocer en la archidiócesis de Sevilla en noviembre de ese año: BOAS, 299 (1894), pp. 269-278.

${ }^{99}$ Este reglamento tiene fecha de 6 de julio de 1894.

100 “[Nota] I. a Los Jueves y los Domingos se dará clase de Canto Gregoriano a los alumnos, que reúnan condiciones para este arte. También habrá repaso del Catecismo y Conferencias de disciplina escolar y Urbanidad." "Seminario Conciliar de San Isidoro y San Francisco Javier de Sevilla. Plan de Estudio que, por disposición de S. Eminencia Rma, el Sr. Cardenal Arzobispo de esta Diócesis, ha de regir en lo sucesivo en este Seminario.” BOAS, 292 (1894), pp. 46-50.

${ }^{101}$ Sobre la Universidad Pontificia de Sevilla véase: Manuel Martín Riego, La formación intelectual del clero. El seminario conciliar de Sevilla (1831-1931) (Sevilla: ed. Caja Rural, 1994), pp. 161 y ss.

102 Erectio Apostolica Facultatum Sacrae Theologiae, Iuris Canonici et Philosophiae Scholasticae in Seminario Hispalensi (Hispali, 1897), pp. 49-52, cit. en: Martín Riego, La formación intelectual del clero, p. 169.

${ }^{103}$ Ibídem, p. 187. El profesor Martín Riego cita, además, el profesor que impartió la asignatura entre 1924 y 1930, José Moreno Melendo, y el curso 1930-31, Zósimo Saldaña. Ibídem, pp. 188-189. El libro de texto usado entre los cursos 1927 y 1930 fue el Método de canto gregoriano de Casiano Rojo, editado por los benedictinos de Silos en 1906. 
La existencia de la clase de canto gregoriano en el seminario de Sevilla hizo que la línea de actuación de la CDMS en este aspecto se centrara en un proyecto ciertamente ambicioso, la creación de un nuevo centro de formación. En aquella reunión celebrada en marzo de 1904 propuso como medio fundamental "para restablecerse [el canto gregoriano] ampliamente en las solemnidades del culto [subrayado original] según la antigua tradición' la fundación de una Escuela Oficial Archidiocesana"104.

Los fines de esta nueva institución educativa, tal y como se concibió en un principio, eran, por un lado, formar a los futuros cantores que ejercieran su oficio en el vasto ámbito de la Archidiócesis, y por otro, reciclar a aquellos que en ese momento ya estuvieran desarrollando esa labor ${ }^{105}$. Con la Escuela Oficial Archidiocesana de Canto Gregoriano se cubría la pretendida regeneración de todos los agentes diocesanos relacionados con el canto llano. En el Seminario se educarían a los futuros sacerdotes, y en la Escuela a los cantores de oficio tanto futuros como en activo.

Tras el parón de 1904, la CDMS volvió a retomar el tema en su primera junta celebrada el 23 de enero de $1905^{106}$. Esta vez la propuesta fue expresada con mayor energía, apelando a la urgencia de la necesidad de su fundación, dado que "la conveniente ejecución del canto gregoriano [es] la mejor base para la deseada reforma", en sintonía con los principios estéticos que situaban al gregoriano como el modelo y el fundamento de la nueva música sagrada apuntados antes ${ }^{107}$. En esta ocasión, la CDMS aterrizó en lo concreto y especificó la forma en la que el centro regularía la profesión de sochantre de oficio en la Archidiócesis. El certificado de aptitud expedido por la Escuela sería una condición necesaria e ineludible para poder aspirar a algún puesto de sochantre en el Arzobispado, o para poder mantenerlo en caso de estar en activo en ese momento. Para obtener dicho certificado los aspirantes tenían que superar un examen

\footnotetext{
${ }^{104}$ Marcelo, "Sobre música sagrada", BOAS, 560 (1905), p. 90. Las palabras subrayadas son una cita del MP.

${ }^{105}$ Ibídem.

${ }^{106}$ Ibídem, p. 93.

107 "Siendo la conveniente ejecución del canto gregoriano la mejor base para la deseada reforma, se propone la inmediata fundación de la escuela de dicho canto a V. E. Rma. propuesta en 4 de Marzo de 1904 [...]". Ibídem.
} 
ante un tribunal nombrado por el arzobispo ${ }^{108}$. A los sochantres en ejercicio se les concedía todo el año de 1905 como plazo para prepararse y someterse a dichas pruebas, con el riesgo, suponemos, de ser apartados de sus puestos en caso de no superarlas ${ }^{109}$. La Comisión recomendó el libro de texto a utilizar tanto por la Escuela de Canto Gregoriano como por los sochantres obligados a pasar por el trance del examen para conservar su empleo. Dicho texto fue La Gramática Elemental de Canto Gregoriano de Cartaud, editado en Barcelona, "por sus condiciones de claridad, justa precisión y economía"110. Asimismo, abordó las cuestiones más problemáticas como era la designación del local, profesor y comisión permanente para dejar su resolución al criterio del arzobispo ${ }^{111}$.

Al igual que la CDMS hispalense, el Reglamento general para la Música Sagrada en la Provincia Eclesiástica de Valladolid de 1905 estableció la exigencia de superar un examen ante un tribunal tanto para poder ser nombrado cantor u organista, como para que pudieran conservar su plaza aquellos que ya estuvieran ejerciendo ${ }^{112}$. A estos últimos se les concedía, como en Sevilla, un plazo de un año tras el cual debían presentarse al examen ${ }^{113}$. El Reglamento vallisoletano incluía además sendos programas para el examen de los cantores parroquiales y organistas en activo, en los que

108 “Creada que sea la Escuela antedicha, no se expedirá nombramiento alguno de Sochantre para las Iglesias de la Archidiócesis sin la certificación de competencia demostrada ante el tribunal examinador por V. E. Rma. nombrado.” Ibídem.

109 "Se concede a los actuales Sres. Sochantres de las Iglesias del Arzobispado todo el presente año de 1905 para prepararse a sufrir un examen ante la misma Comisión examinadora, requisito necesario para poder ejercer el cargo de cantor, transcurrido que sea el tiempo de preparación.” Ibídem.

${ }^{110}$ Ibídem, p. 94.

111 “....] dejando a la acertada iniciativa de V. E. Reverendísima designar local, maestro instructor y comisión permanente examinadora para el recto funcionamiento de la escuela.” Ibídem, p. 93.

112 “[Art.] 6. Nadie en lo sucesivo será nombrado para estos cargos sin que antes sea aprobado en examen de suficiencia, (al tenor de un programa que irá adjunto al presente Reglamento), ante un tribunal nombrado por el Rmo. Diocesano." "Edicto y reglamentos sobre música sagrada”, pp. 336-337.

113 "[Art.] 7. Los que hasta el presente disfruten de dichos nombramientos sin haber llenado este requisito, se presentarán ante el expresado tribunal al año de la publicación del presente Reglamento, teniendo en cuenta que los que no se presenten al cabo de dicho plazo, renuncian ipso facto la plaza que tienen en posesión". Ibídem, p. 337. En la Segunda Parte "De los géneros de música eclesiástica", Título I "Canto gregoriano" se aconsejaba el mismo método gregoriano que en Sevilla: la Gramática elemental de Canto Gregoriano, de C. Cartaud. Además se anunciaba la próxima publicación del método de Casiano Rojo, y se aconsejan los de las editoriales Desclée, Lefebure \& Cie. Es posible que el método de Cartaud fuera en esos momentos el generalmente utilizado, ante la falta de otras obras actualizadas, según se desprende del comentario incluido en el Reglamento. Ibídem, pp. 340-341, nota a pie no 2. 
se detallaban los ejercicios de los que constaban dichas pruebas ${ }^{114}$. Estas coincidencias llevan a pensar en una posible influencia en un sentido $u$ otro entre ambos grupos reformistas, el sevillano y el vallisoletano, aunque la falta de más datos impide confirmar esta hipótesis ${ }^{115}$.

Al margen de estos puntos en común, existió una diferencia fundamental entre la propuesta castellana y la andaluza: en la primera de ellas no se proyectó ningún nuevo centro de formación. Por tanto, su línea de actuación se centró en asegurar la competencia de los músicos eclesiásticos a través de exámenes, es decir, exigencias, aunque sin proporcionarles para ello los medios formativos necesarios, es decir, apoyo. Como veremos más adelante, este modo de afrontar lo que para muchos constituían los principales problemas de la música religiosa -la incompetencia, incultura e indisciplina de este colectivo-, fue una constante ${ }^{116}$.

Hasta el momento desconocemos la existencia de una iniciativa semejante a la hispalense en ninguna diócesis del país. El congreso de Valladolid, celebrado tres años después de que la CDMS sevillana formulara el proyecto de erigir la Escuela, planteó, por primera y única vez en la historia de los congresos nacionales de música sagrada, la necesidad de crear "escuelas de canto eclesiástico" además de en los seminarios, "en las capitales y ciudades de alguna importancia”, aunque no hemos encontrado ninguna prueba o indicio de que tal propuesta tuviera algún eco ${ }^{117}$.

\footnotetext{
${ }^{114}$ Programa para el examen de cantores de parroquias y cantoras de oficio en los conventos: constaba de “a) Ejercicios de extensión y calidad de voz", “b) Solfeo y canto figurado": cuatro ejercicios que se detallan con bastante minuciosidad, “c) Canto Gregoriano": dos ejercicios. Ibídem, 371-2. Programa para el examen de organistas que sirven ya alguna parroquia: constaba de cinco ejercicios que se detallan minuciosamente. Ibídem, p. 375.
}

115 La publicación de las disposiciones de la CDMS hispalense datan de nueve meses antes que el reglamento vallisoletano, aunque Otaño afirma en una carta remitida a Dessy que los trabajos para la confección de dicho reglamento se iniciaron un año antes: "Mi muy apreciado Sr. Dessy: Ya voy saliendo del enmarañado asunto de la confección de un gran Reglamento de la Música Sagrada, asunto que al Maestro de Capilla de aquí [escribe desde Valladolid, se trata por tanto de Vicente Goicoechea] y a mí nos ha ocupado más de un año." Carta de Otaño a Dessy y Cía [editores musicales], 20 de noviembre de 1905. AMSL. FO. Correspondencia, T01/002. Por otro lado, no nos consta por el momento que existiera relación alguna entre los miembros de la CDMS hispalense y el grupo vallisoletano, encabezado por Otaño y Goicoechea antes del congreso de Valladolid de 1907. La primera carta enviada por Otaño a Ripollés conservada en el archivo Nemesio Otaño de Loiola data del 23 de octubre de 1908, TA01/045.

${ }^{116}$ Véase capítulo 5, epígrafe 3.2.3. "La situación económica de los músicos eclesiásticos”, p. 404.

117 "Punto 7. - Modo y medios de mejorar la educación musical y litúrgica de los músicos de iglesia.

[...] El Congreso estima necesario que los Rvdmos. Prelados procuren establecer escuelas de canto eclesiástico en los Seminarios principalmente, y también donde es posible, en las capitales y ciudades de alguna importancia. Asimismo hace votos por el establecimiento de los exámenes periódicos, de gran provecho para los músicos de iglesia ya en posesión de sus cargos.” Crónica del Primer Congreso, p. 14. 
Durante el congreso de Sevilla se propuso el proyecto de fundación de una Escuela Superior de Música Sagrada, a pesar de que en principio no estaba incluido entre los temas a debatir ${ }^{118}$. Luis Villalba ${ }^{119}$ cuenta que fue iniciativa de Federico Olmeda la idea de definición de un sistema educativo musical completo, desde la enseñanza básica a la superior ${ }^{120}$. El organero Aquilino Amezua había preparado, por su parte, una detallada memoria sobre la creación de un conservatorio nacional de música sagrada. A petición de Olmeda, Villalba, que presidió una de las sesiones de debate, lanzó la propuesta ${ }^{121}$. La acogida que se le dispensó fue excelente, pues se

El Congreso no se ocupó de especificar las características generales de estos centros, por lo que no podemos saber exactamente cuál era su propuesta de escuela.

${ }^{118}$ El MP instaba a la creación de estas instituciones de educación musical en los siguientes términos: "Procúrese sostener y promover del mejor modo donde ya existan las escuelas superiores de música sagrada, y concúrrase a fundarlas donde aún no existan, porque es muy importante que la Iglesia misma provea a la instrucción de sus maestros, organistas y cantores, conforme a los verdaderos principios del arte sagrado."MP, Título VIII. Medios principales, art. 28.

${ }^{119}$ Sobre Luis Villalba Muñoz (Valladolid, 1873-Madrid, 1921), véase María Antonia Virgili Blanquet, "Felipe Pedrell y el músico vallisoletano Luis Villalba: correspondencia inédita", Recerca musicològica, 1 (1981), 151-192; de la misma autora, "Luis Villalba", en La música en Valladolid en el siglo XX (Valladolid: Ateneo de Valladolid, 1985) pp. 43-72; "La idea regeneracionista en la música española y la creación de la Sociedad Nacional de Música a través de la correspondencia de Luis Villalba Muñoz", en De Musica Hispana et Aliis. Miscelánea en homenaje al Profesor José López-Calo, ed. por Emilio Casares y Carlos Villanueva (Santiago: Universidad de Santiago, 1990), 2 vols., vol. 2, pp. 307-319; "Luis Villalba y Eustoquio Uriarte. Sus contribuciones al estudio de la música lírica y al nacionalismo musical español", en Actas del Simposium "La música en el Monasterio de El Escorial" (Madrid: Instituto Escurialense de Investigaciones Históricas y Artísticas, 1992), pp. 751-763; "2. Luis [Villalba Muñoz]", DMEH, 10 vols, ed. por Emilio Casares (Madrid: SGAE, 2002), vol. 10, p. 913-915.

${ }^{120}$ Sobre Federico Olmeda de San José (El Burgo de Osma, 1865-Madrid, 1909), véase: Miguel Ángel Palacios Garoz, Federico Olmeda, un maestro de capilla atípico, (Burgos: Instituto Municipal de Cultura, 2003); del mismo autor, El hispanismo musical de Raoul Laparra y Henri Collet. Dos discípulos franceses de Federico Olmeda en Burgos (Burgos: Institución Fernán González, Academia Burguense de Historia y Bellas Artes, 1999); Emilio Casares Rodicio, "Federico Olmeda de San José", DMEH, 10 vols., ed. por Emilio Casares (Madrid: SGAE, 2001), vol. 8, pp. 67-70; Emilio Ros-Fábregas, "La Biblioteca Musical de Federico Olmeda (1865-1909) en la 'Hispanic Society of America' de Nueva York", Revista de Musicología, XX/1 (1997), pp. 553-570.

121 "En el punto $e$ ) de los métodos, me salí de propósito de la índole particular del caso; Olmeda me había hablado de la conveniencia de trazar un plan completo de enseñanza con centros educadores graduados desde la enseñanza primera de la música hasta la superior. El cuestionario del Congreso no ofrecía puerta franca a esta idea, pero aun dado caso que se buscara entrada haciendo derivar una cuestión cualquiera a este fin, a Olmeda le venía la cosa un poco tarde, y en una de nuestras conversaciones me preguntó si la podía introducir yo. La idea me era agradable, aunque a decir verdad no tenía gran fe en que llegara a realizarse; pero, en fin, nada se perdía con lanzarla al público, y se me ofreció el punto de los métodos, etcétera, etc., como el más a propósito, y convenimos en ello; hablamos con quienes debíamos y lo encontraron bueno, y a ello estaba ya decidido, cuando a la entrada de la iglesia del Salvador, donde iba yo a oír el concierto, me habló Amezua de una Memoria que tenía hecha para pedir la fundación de un Conservatorio nacional de música sagrada. Ni a propósito se venía la cosa. Perfectamente. Me dio la Memoria, y al dármela me la explicó, señalando párrafos. El Conservatorio se había de fundar en El Escorial, a ello contribuirían los Prelados con una cuota, y al caso hacía una porción de cuentas galanas, con su pedazo de matemáticas en números." Villalba, "El Segundo Congreso Nacional”, p. 805. 
trataba de un tema en el que convergían los intereses de todos los asistentes. El ponente hubo de contener las expectativas creadas y propuso finalmente a la asamblea una conclusión comedida y realista ${ }^{122}$ : solicitar a los prelados la creación de una comisión que estudiara "en término fijo y breve" la forma de hacer realidad el proyecto. La conclusión quedó aprobada como sigue:

Punto e). 1. ${ }^{\text {a }}$ El Congreso estima que mejor que recomendar libros y estudios particulares, es conveniente organizar un sistema completo de enseñanza musical religiosa en todos sus ramos y en todos sus grados. Y siendo imposible planear acertadamente asunto tan difícil, pide a los Rvmos. Prelados el nombramiento de una comisión que en término fijo y breve estudie el asunto, y trate de llevarlo a la práctica, principalmente en lo relativo a la creación de una Escuela superior o Conservatorio Nacional de Música Sagrada. ${ }^{123}$

En cualquier caso, el proyecto de creación de una Escuela Superior de Música Sagrada de carácter nacional no es comparable con el intento por parte de una diócesis de erigir centros propios para la formación de sus músicos y responsables eclesiásticos. Tanto la naturaleza como la dimensión de ambas ideas son ciertamente distintas. Además, partieron de dos esferas de la reforma que, aunque relacionadas e imbricadas, conviene diferenciar: el denominado movimiento español para la reforma de la música sagrada, y la administración diocesana, en este caso hispalense, como la institución eclesiástica que tenía el poder de gestión y gobierno del proceso. Volvamos, por tanto, a ella.

La respuesta de Spínola a este proyecto -recordemos, propuesto por la Comisión- fue favorable. ${ }^{124}$ El arzobispo hispalense incluyó, además, como futuros alumnos del centro a los organistas junto a los cantores. Sin embargo, a la hora de afrontar las cuestiones materiales y económicas devolvió el problema a la CDMS:

Mas como esa Escuela ha de originar gastos, encargamos a la Comisión de Música Sagrada la formación del presupuesto, así como

\footnotetext{
122 "La cosa se animó bien pronto, todos se mostraban favorables a la idea, de modo que más bien que discusión era una conversación viva acerca del asunto, y de tal modo se inclinaban al proyecto, que poco menos que creían que iba a salir ya hecho, Conservatorio, Escuelas técnicas, etc., etc. -Poco a poco, señores; la materia es tan importante, que de sobra comprenden que no puede planearse en media hora [...]”. Ibídem, pp. 806-807.

${ }^{123}$ Crónica del Segundo Congreso, pp. 272-273.

${ }^{124}$ Marcelo, "Sobre música sagrada”, BOAS, 560 (1905), p. 97.
} 
también le confiamos el encargo de idear y arbitrar recursos, con que atender a la dotación de profesores y a cuanto ofrecerse pueda. ${ }^{125}$

Sobre la cuestión de la Escuela Oficial de Canto Gregoriano no se volvió a publicar ninguna disposición más en el BOAS. No obstante, el informe inédito de una reunión celebrada por la CDMS siete días después, el 22 de febrero, y que hemos podido hallar en el AGAS, revela que la Comisión se vio incapaz de encontrar los medios necesarios para la creación de dicho centro, y cedió en su empeño. La solución que propuso a Spínola fue: "Para obviar a los inconvenientes materiales que ofrece la fundación de la Escuela oficial de canto gregoriano, la Junta propone a V. E. Rma. que se asimile a la clase del mismo canto existente en el Seminario" ${ }^{\text {"26 }}$. Así pues, los planes para la creación de una Escuela Oficial Archidiocesana de Canto Gregoriano tropezaron con el problema económico, ya anunciado por Spínola al comienzo del proceso, y que a la postre resultó insuperable. El éxito en la fundación de la Escuela hubiera supuesto la aparición en la ciudad de un nuevo centro de formación musical, este de titularidad eclesiástica, que se hubiera sumado a los por entonces existentes. José María de Mena enumera junto a otras academias particulares de menor importancia, la escuela de música de la Real Sociedad Económica de Amigos del País, y el llamado Conservatorio de Música de la Academia Filarmónica, regentado por el organista segundo de la Catedral, Luis Leandro Mariani ${ }^{127}$.

Por tanto, la imposibilidad de fundar una institución independiente para la formación en el canto gregoriano obligó a centralizar la enseñanza musical religiosa, incluida la polifónica, en el Seminario. De esta forma, el modelo sevillano se terminó ajustando al que se fue aplicando en el resto del país en términos generales. Las propuestas de la Comisión y las disposiciones del arzobispo estuvieron dirigidas, a partir de ese momento, a la mejor organización posible de la clase del Seminario. La

${ }^{125}$ Ibídem.

126 Acuerdos tomados en la reunión celebrada el 22 de febrero de 1905. AGAS. Sección Gobierno. Asuntos Despachados, leg. 04900 (1905).

${ }^{127}$ José María de Mena, Historia del Conservatorio Superior de Música y Escuela de Arte Dramático de Sevilla (Madrid: Conservatorio Superior de Música de Sevilla y ed. Alpuerto, 1984), p. 20. De Mena afirma que las enseñanzas de este último centro disfrutaban de reconocimiento oficial por el Conservatorio de Madrid. Sobre la incorporación de estos dos centros al conservatorio madrileño, véase: Fernando Delgado García, Los gobiernos de España y la formación del músico (1812-1956). Universidad de Sevilla (Tesis doctoral), pp. 264-265 y 307-317. Texto disponible en: http://fondosdigitales.us.es/tesis/tesis/540/los-gobiernos-de-espana-y-la-formacion-del-musico-18121956/ (consultado 18-2-2013). 
CDMS elevó al criterio del prelado propuestas tales como la dotación del profesor y material para la enseñanza o la organización docente. Con respecto a la primera planteó:

Para atender a los gastos de Profesor y material de enseñanza que ocasione la clase de canto, [...] se imponga a todos los alumnos una matrícula de cinco pesetas anuales que añadidas a lo que actualmente destina el Seminario para la clase de canto, podrían remunerar con alguna decencia los trabajos del Profesor. ${ }^{128}$

Es decir, el problema económico en este punto se solucionó cargando a los seminaristas los gastos que no alcanzaba a cubrir el presupuesto del Seminario. Respecto a la organización docente, se propuso que la clase fuera obligatoria para los alumnos de los tres cursos iniciales de Filosofía y tuviera un carácter introductorio y teórico. Las clases prácticas se iniciarían, una vez conocidos los fundamentos teóricos, durante los posteriores cursos de Teología. Para ponerla en valor, la asignatura sería evaluable $^{129}$.

El documento regulador de la enseñanza del canto religioso en los seminarios más completo que hasta ahora se conoce es el promulgado por los prelados de la provincia eclesiástica de Valladolid en $1905^{130}$. Como el resto de reglamentos que componen este conjunto, del que ya hemos aportado algunos datos, se trata de un escrito de gran interés. En sus veintitrés artículos se definen y concretan hasta el detalle todos los aspectos relacionados con una buena organización de estas enseñanzas. Anexo al mismo se incluye, además, el Plan o programa que ha de servir para la enseñanza del canto coral y gregoriano en los seminarios de esta provincia eclesiástica en el que, a

${ }^{128}$ AGAS. Sección Gobierno. Asuntos Despachados, leg. 04900 (1905).

129 " $2 .^{\circ}$ Con el fin de obtener resultados satisfactorios, conviene que las lecciones se repitan con alguna frecuencia, lo cual podría obtenerse estableciendo la clase alterna y obligatoria para todos los alumnos de los tres cursos de Filosofía.

3. ${ }^{\circ}$ Será medio útil para poner en estima el estudio del canto gregoriano, el sancionarlo con notas obtenidas previo formal examen.

4. ${ }^{\text {o }}$ Todos los alumnos de Sagrada Teología, adquiridos los conocimientos teóricos y elementales del gregoriano, asistirán a la clase de práctica, tomando parte los que más se distingan en las funciones de la Catedral, y preparándose los de mejores disposiciones para ayudar a la capilla en las funciones solemnes." Acuerdos tomados en la reunión celebrada el 22 de febrero de 1905. AGAS. Sección Gobierno. Asuntos Despachados, leg. 04900 (1905).

${ }^{130}$ Reglamento particular para la enseñanza del canto litúrgico en los seminarios. "Edicto y reglamentos sobre música sagrada", pp. 379-384. 
modo casi de una programación didáctica se especifican los contenidos de la asignatura y se distribuyen en sus cuatro cursos ${ }^{131}$.

El hecho de no existir o no haber podido hallar hasta el momento un documento similar en Sevilla nos priva de poder conocer hasta este punto de detalle cómo se terminaron desarrollando aquellas propuestas básicas de la Comisión. Impide, además, realizar una comparación entre el proyecto andaluz y el castellano. Tan sólo podemos apuntar algunas coincidencias o diferencias y deducir a partir de ellas alguna idea relevante.

En primer lugar, en ambos planes se presentó la asignatura como obligatoria y evaluable con la intención, que en el caso de Sevilla se hace explícita, de poner en valor una materia que a buen seguro no hubiera sido bienvenida ni estimada de acuerdo a la importancia que le otorgaba el MP por parte de los responsables de los seminarios ${ }^{132}$.

En segundo lugar, el Reglamento vallisoletano contemplaba que la asignatura fuera cursada en niveles más básicos de la carrera eclesiástica, lo que implicaba a edades más tempranas y, por lo tanto, con una línea metodológica, queremos suponer, adecuada a las mismas. En las diócesis de la provincia eclesiástica vallisoletana se cursaría durante los cursos de $3^{\circ}$ y $4^{\circ}$ de Latinidad y Humanidades, y $1^{\circ}$ y $2^{o}$ de Filosofía. En Sevilla, como hemos visto, se incluiría en los programas de los tres cursos de Filosofía y los siguientes de Teología.

Por último, nos llama especialmente la atención la diferente consideración de que disfrutó el profesor, según se desprenden de estos documentos. En el caso de Valladolid, y todas sus diócesis sufragáneas, tendría categoría de catedrático del seminario, con el sueldo correspondiente a tal nivel profesional ${ }^{133}$. En Sevilla, para poder cubrir la dotación del profesor, que no fue investido de aquel rango académico, y los materiales didácticos se hubo de idear una matrícula de cinco pesetas por alumno. Es decir, como apuntamos, no se le hizo sitio en el presupuesto ordinario del Seminario.

${ }^{131}$ Plan o programa que ha de servir para la enseñanza del canto coral y gregoriano. Ibídem, pp. $387-$ 399.

${ }^{132}$ El reglamento vallisoletano dispone en su artículo primero: "le damos el carácter de asignatura estricta y rigurosamente obligatoria, con lección diaria durante cuatro cursos"; y en el tercero: "El alumno de canto que no obtuviere la aprobación en los exámenes ordinarios ni en los extraordinarios, para el curso siguiente no podrá matricularse en asignaturas nuevas, y sólo en aquella o aquellas que haya perdido en el pasado". Reglamento particular para la enseñanza del canto litúrgico en los seminarios. Ibídem, p. 379.

133 Artículo 22 del reglamento: "El Profesor de canto gregoriano tendrá la categoría de Catedrático del Seminario, el haber de los que explican una cátedra diaria y la obligación de enseñar en la clase y en la academia y de dirigir por sí o por otro el canto de la Capilla”. Ibídem, p. 384. 
Habría que afirmar, por tanto, que la labor de dignificación de la profesión musical eclesiástica, esta vez en su vertiente docente, fue más ambiciosa en las diócesis castellanas que en la andaluza, al menos sobre el papel. Sería necesario realizar un estudio en profundidad en cada una de las diócesis sufragáneas vallisoletanas para comprobar si realmente esas disposiciones se aplicaron en la práctica tal y como se idearon, así como para conocer las dificultades que, como es de esperar, debieron encontrar. En un artículo publicado en Boletín del Congreso, antecedente de $M S H$, en el que la Junta organizadora solicitaba a las comisiones diocesanas de la provincia eclesiástica de Valladolid su cooperación ante la inminente celebración del I Congreso Nacional de Música Sagrada, se alude al problema que supuso la aplicación de los reglamentos, así como la necesidad de la Comisión metropolitana de llevar a cabo acciones dirigidas a mantener la unidad de acción, tal y como se había dispuesto en aquellos documentos:

Desde que los Reglamentos de música sagrada, promulgados por nuestros Rvmos. Prelados el día 22 de Noviembre de 1905, unieron con vínculos comunes las Comisiones de esta provincia eclesiástica, envió esta junta metropolitana un cariñoso saludo a sus hermanas las diocesanas; y si bien la dificultad de los principios y los trabajos múltiples para llevar a cabo las disposiciones pontificias y episcopales no han luego establecido continuas y estrechas relaciones cual en el art. 19 de nuestro interior reglamento se deseaban, no por eso el buen acuerdo y el mejor espíritu ha dejado de animar las acciones todas de nuestra empresa loable ${ }^{134}$

Respecto a la formación en la polifonía sagrada, se dispuso por parte de Spínola que aquellos alumnos "aventajados" de la clase de canto gregoriano fueran instruidos en canto polifónico, sin más concreción. No se especifica la planificación de estas clases, si es que llegaron a ser clases o simplemente ensayos, ni ningún aspecto más. Lo que sí dejaron claro Spínola y la Comisión es que estos alumnos compondrían una Schola cantorum en el Seminario con el especial cometido de reforzar el Coro de la Catedral en las grandes solemnidades litúrgicas ${ }^{135}$. De esta forma cumplió con las

\footnotetext{
${ }^{134}$ La Comisión, “A las Comisiones de la provincia eclesiástica de Valladolid”, Boletín del Congreso, 1 (1907), p. 6.

135 "Llamamos por último la atención de la Comisión sobre la creación de las Scholae Cantorum, de que en su Motu Proprio habló el Papa. Pensamos que no sería difícil empezar en el ensayo por el Seminario, y que el tiempo más oportuno sería el presente, pues instruidos los jóvenes mejor dispuestos en los tres meses que faltan para la Semana Santa, acaso podrían, al llegar esta, estrenarse en el canto gregoriano". Marcelo, Arzobispo de Sevilla, "Sobre la música sagrada", BOAS, 558 (1905), p. 7. "Los más
} 
directrices papales que instaban a "restablecer, por lo menos en las Iglesias principales, las antiguas Scholae Cantorum", optimizando los recursos humanos y materiales de los que disponía ${ }^{136}$. Además, los términos utilizados indican la intención regeneradora que movía al prelado hispalense: "Los más aventajados y mejor dispuestos de estos alumnos, serán instruidos en la polifonía sagrada a fin de que se forme una escuela de música religiosa capaz de llevar la reforma a todos los rincones de la diócesis."

Por tanto, los objetivos principales del plan de reformas en lo que al gregoriano se refiere fueron la revalorización de este canto como la expresión musical religiosa por excelencia en "esencia" y como modelo, y la restauración en su "pureza" primitiva y en su digna interpretación. Esta recuperación en su valor y en su naturaleza se trató de conseguir a través de la formación, la educación y la concienciación de los principales agentes encargados de la reforma: los sacerdotes actuales y futuros, y los músicos eclesiásticos. El epicentro de esa regeneración sería, además de la clase de canto gregoriano del seminario, la finalmente frustrada Escuela Oficial Archidiocesana de Canto Gregoriano. Esos agentes, formados y preparados en los nuevos principios conformarían una red extendida por toda la Diócesis que consumarían una auténtica regeneración.

\subsection{Labor de censura y depuración del repertorio litúrgico-musical}

La reforma de la música sagrada se integraba en un plan general de restauración y reforma profunda de la liturgia católica diseñado por Pío X para la reanimación y recomposición del culto. De acuerdo con su programa pontifical, condensado en el lema "Instaurare omnia in Christo", el MP fue promulgado con una intención restauradora: "Siendo, en verdad, nuestro vivísimo deseo que el verdadero

aventajados y mejor dispuestos de estos alumnos, serán instruidos en la polifonía sagrada a fin de que se forme una escuela de música religiosa capaz de llevar la reforma a todos los rincones de la diócesis." Marcelo, Arzobispo de Sevilla, "Sobre música sagrada" BOAS, 560 (1905), p. 97. "Todos los alumnos de Sagrada Teología, adquiridos los conocimientos teóricos y elementales del gregoriano, asistirán a la clase de práctica, tomando parte los que más se distingan en las funciones de la Catedral, y preparándose los de mejores disposiciones para ayudar a la capilla en las funciones solemnes." Acuerdos tomados en la reunión celebrada el 22 de febrero de 1905. AGAS. Sección Gobierno. Asuntos Despachados, leg. 04900 (1905).

${ }^{136}$ MP Título VIII. Medios principales art. 27. La participación de las Scholae cantorum y coros de seminaristas en las solemnidades de las catedrales fue una de las soluciones propuestas por los principales ideólogos del movimiento reformista para mejorar dentro de lo posible el lamentable estado -tal y como lo describían- de las capillas musicales de los templos catedralicios españoles.

${ }^{137}$ Marcelo, Arzobispo de Sevilla, “Sobre música sagrada” BOAS, 560 (1905), p. 97. 
espíritu cristiano vuelva a florecer" ${ }^{\prime 138}$. Pero al mismo tiempo, en la medida en la que se situaba enfrentado a unas costumbres y concepciones litúrgico-musicales estimadas como corruptas o desviadas, poseía un carácter censor, rectificador y depurador:

Y en vano será esperar que para tal fin descienda copiosa sobre nosotros la bendición del cielo, si nuestro obsequio al Altísimo no asciende en olor de suavidad; antes bien, pone en la mano del Señor el látigo con que el Salvador del mundo arrojó del templo a sus indignos profanadores. ${ }^{139}$

Una de las claves del éxito de la reforma se encontraba en la capacidad de corregir abusos y desviaciones de la "recta norma", así como de "arrojar del templo" aquellas obras del repertorio en uso no conformes con sus principios. Ello suponía una profunda revisión del canon litúrgico-musical vigente, que se traducía en la práctica en la purga de una buena parte de las obras que lo componían y su sustitución por otras. Así, el MP no sólo incidía en las costumbres de las Iglesias locales o en el aspecto meramente litúrgico, sino también en el gusto, por la imposición de un nuevo canon musical. Como ya hemos apuntado, el documento papal no sólo era un código que venía a regular las prácticas litúrgico-musicales, sino también un tratado estético ${ }^{140}$.

Las primeras disposiciones que al respecto dieron a conocer tanto arzobispo como Comisión hispalenses se limitaron a reproducir las normas generales prescritas en el $M P$. En su primera circular Spínola ordenó:

2. ${ }^{\circ}$ En las Misas cantadas solo se empleará el rigurosamente litúrgico, no tolerándose en adelante ningún motete castellano, por piadoso y edificante que parezca.

3. ${ }^{\circ}$ No se cantará ni se tocará en las iglesias nada que por su corte o aire tenga sabor o reminiscencias profanas. ${ }^{141}$

La CDMS, por su parte, transcribió el artículo 8 del $M P$ de forma casi literal en el informe que recogió los acuerdos de su primera reunión ${ }^{142}$. Incluyó, además, otra

\footnotetext{
${ }^{138} M P$. [Exposición de motivos previa a la Instrucción legal].

${ }^{139}$ Ibídem.

${ }^{140}$ Véase el apartado "Breve introducción al Motu Proprio "Tra le sollecitudini” de Pío X".

${ }^{141}$ Marcelo, Arzobispo de Sevilla, “Circular sobre la música sagrada”, 536 (1904), p. 116.
}

142 "4 Prohibido en las celebraciones litúrgicas no solamente el canto en lengua vulgar, sino también alterar el orden de los textos y cambiarlos por otros de elección privada, en las Misas cantadas es 
propuesta que no figuraba en el rescripto de Pío $\mathrm{X}$, aunque tampoco era original: imponer la obligación de que los textos empleados en lengua vulgar en aquellas funciones extralitúrgicas, "como son Novenarios, Ejercicios de Cofradía o Hermandades, etc., aún expuesto el Smo. Sacramento", estuvieran aprobados por la autoridad eclesiástica $^{143}$. La primera disposición ideada por la CDMS hispalense en lo que a este aspecto se refiere fue la constitución de un tribunal censor con la misión de "indicar a la Autoridad competente las obras que merezcan ser aprobadas." Este fue, a su juicio, "uno de los medios de desterrar del lugar santo los cantos indignos del culto divino.", 144

La falta de unidad de criterio a la hora de juzgar si una obra debía ser desechada por incompatibilidad con los principios litúrgicos y estéticos del MP representó un serio obstáculo para la realización de la reforma en todo el país. Los desacuerdos en este punto fueron motivo de grandes controversias no sólo en el seno de las diócesis como órganos administrativos, sino especialmente en el espacio de actuación y debate que se dio en llamar movimiento reformista español. Como veremos más adelante, la cuestión de la censura de la música religiosa estuvo, además, asociada a intereses económicos y editoriales, lo que hizo aún más complejo el problema ${ }^{145}$. La solución que durante los distintos congresos de música sagrada se barajó para atajarlo fue la erección de un Tribunal Nacional que dirimiera las profundas diferencias de criterio existentes entre las distintas comisiones diocesanas. Sin embargo, a nivel diocesano, la iniciativa sevillana para la creación de un tribunal censor es la única de la que hasta ahora tenemos noticia en España.

No obstante, esta idea no se concretó. Spínola no la asumió en ninguna de sus circulares y la Comisión, por su parte, no hizo más hincapié en ello. Al igual que en el resto de diócesis, la función censora que debía ejercer el tribunal fue encomendada a la

obligatorio el canto del Introito, Gradual, Ofertorio y Communio propios, y únicamente, después del Benedictus, podrá cantarse algún Motete al Smo. Sacramento, y, terminando el Ofertorio propio, un breve Motete hasta el Prefacio. (M.P. n 8)". "Sobre música sagrada”, BOAS, 560 (1905), p. 91.

143 " $5^{\circ}$ En las funciones extralitúrgicas, como son Novenarios, Ejercicios de Cofradías ó Hermandades, etc., aún expuesto el Smo. Sacramento, puede tolerarse el canto en lengua vulgar; pero a condición de tener el texto la aprobación eclesiástica; según declaración de la Congregación de Ritos por decretos del 27 de Septiembre de 1864 y 27 de Febrero de 1882." "Sobre música sagrada", Ibídem.

${ }^{144}$ Ibídem.

${ }^{145}$ Véase capítulo 5, epígrafe 4.2.4. "El negocio editorial y las instituciones de la reforma: el problema de la disparidad de criterios de las comisiones diocesanas de música sagrada”, p. 472. 
CDMS. De ello se deduce que el arzobispo sevillano debió considerar innecesaria la institución de otro órgano con una función tan específica, pudiéndola llevar a cabo la propia Comisión. Así, en la siguiente circular (16 de enero de 1905), Spínola le encargó denunciar "las infracciones, que lleguen a su noticia de lo decretado por Su Santidad"; "cualquier otro abuso en el particular de su incumbencia"; así como la formación de "un catálogo de las obras musicales más usadas, que deben proscribirse en absoluto"146. Además, cuidó de que el criterio a aplicar estuviera en consonancia con el romano oficial, pues le instó a ponerse en contacto directamente con la Santa Sede ${ }^{147}$.

Siguiendo la dinámica que caracterizó este segundo año de reformas, la CDMS asumió inmediatamente el mandato de Spínola y en su siguiente informe incluyó una serie de abusos a proscribir. La mayoría de ellos estaban relacionados con el uso de los instrumentos en la liturgia, por lo que le dedicaremos un epígrafe propio. Los demás se referían a prácticas reprobadas por el $M P$ arraigadas en la Archidiócesis, como en tantos otros lugares. Se prohibió "cantar el texto litúrgico con melodías ad libitum de los cantores, prescindiendo de las indicaciones de los cantorales" y "cantar después de la Epístola motetes con letra distinta de la del gradual propio, práctica muy común en las funciones solemnes"148.

El catálogo de obras prohibidas no vio la luz. Suponemos que su confección requería un cierto tiempo. Además, es posible que la Comisión se encontrara de nuevo con un aspecto espinoso e impopular, pues se le encomendó la sustitución drástica de un repertorio que, como hemos señalado, constituía el canon musical religioso oficial, y que, por tanto, había formado el gusto estético general.

Al delicado encargo de depurar el repertorio en uso hay que sumar otro que la dotó aún de más poder. Se trató de la responsabilidad de juzgar la idoneidad de todas las obras que a partir de ese momento se compusieran y aspiraran a formar parte del repertorio oficial de la Diócesis. Ello significó poner en sus manos intereses personales, prestigio y otras formas de capital simbólico de problemática gestión ${ }^{149}$.

\footnotetext{
${ }^{146}$ Marcelo, Arzobispo de Sevilla, "Sobre la música sagrada”, BOAS, 558 (1905), pp. 6-7.

147 "Poniéndose al intento al habla con la Junta, que en Roma entiende en estos asuntos; pues nos consta que han merecido censura de la referida Junta trabajos o producciones de autores muy celebrados y de notable valor artístico, pero que por su sabor profano no encajan en el severo molde de las armonías sagradas". Ibídem.

${ }^{148}$ Marcelo, Arzobispo de Sevilla, “Sobre música sagrada” BOAS, 560 (1905), p. 96.

149،'será asimismo incumbencia de la Comisión examinar las nuevas producciones, que salgan a la luz, en la inteligencia de que sin su autorización no podrán ejecutarse.” Ibídem, pp. 97-98.
} 
Sabemos por los informes de las reuniones celebradas el 22 de febrero y el 24 de mayo, no publicados en su totalidad, que, durante este año, la Comisión sólo incluyó en la lista negra de la proscripción, "mientras se forme lista más completa de los autores que deban desecharse", el conjunto de la obra de Prado y Solís (por "indignas de los actos del culto [...] [y] antilitúrgicas,") ${ }^{150}$, y las misas "Pastorela" de García y la "Eucharística" de Arquimbau (porque "no están conformes con las ordenaciones del M. P.”). ${ }^{151}$ Nada más.

Por el contrario, recomendó como apropiadas para las funciones litúrgicas "más solemnes" las misas en la y mi bemol "y otras obras impresas del Maestro Eslava"152. Estas misas que, como hemos podido averiguar, se interpretaban en la Catedral durante las grandes celebraciones del Corpus y la Inmaculada, superaron la importante revisión a la que fue sometido el canon musical catedralicio durante 1909. Más adelante veremos que el canon musical de las grandes solemnidades en aquel templo estaba dominado por Eslava, cuyas obras, en su gran mayoría, fueron estimadas como incompatibles con los principios del $M P$ y, por ello, desechadas. Ambas misas constituyeron una excepción, pues no hemos hallado objeción alguna a su conservación en el ceremonial de las grandes festividades litúrgicas. Además, hemos podido localizar en la prensa local referencias que demuestran su vigencia a lo largo de la segunda década del s. XX. El siguiente fragmento está extraído de una detallada reseña sobre la

\footnotetext{
${ }^{150}$ Informe con fecha de 25 de febrero de 1905 con los acuerdos tomados en la reunión celebrada el 22 de ese mes. AGAS. Sección Gobierno. Asuntos Despachados, leg. 04900 (1905).

${ }^{151}$ Informe con fecha de 27 de mayo de 1905 con los acuerdos tomados en la reunión celebrada el 24 de ese mes. Ibídem. Spínola asumió públicamente estas decisiones de la CDMS poco después: "La Comisión que entiende en los asuntos relativos a la Música Sagrada nos ha llamado la atención sobre dos puntos que juzga interesantes, [...] El segundo es la necesidad de que se prohíban en absoluto la Misa pastorela del maestro García y la Eucarística de Arquimbau, porque ni uno ni otra se ajustan a la disposición del Papa sobre la materia."

152 “[...] así como recomienda para las funciones más solemnes las misas en La y Mi bemol y otras obras impresas del Maestro Eslava." Acuerdos tomados en la reunión de 1905. Ibídem. Estas misas fueron compuestas durante el periodo madrileño de Eslava y según apunta López-Calo, fueron, junto a otras del mismo periodo, "las que más fama dieron a su autor y las que causaron el profundo influjo de Eslava en la música española de la segunda mitad del siglo XIX”. Sobre la Misa en mi $b$ afirma que fue la más difundida y famosa entre sus misas. José López-Calo, "Catálogo provisional de las obras religiosas de Hilarión Eslava" [apéndice], en Monografía de Hilarión Eslava, ed. por equipo Musikaste-Eresbil (Pamplona: Diputación Foral de Navarra, 1978), pp. 347-375, p. 359. El grueso de la producción madrileña de Eslava fue publicada por su sobrino Bonifacio Eslava. Colección escogida de las obras músico-religiosas de Don Hilarión Eslava, maestro director de la Real Capilla de Música de S.M. y profesor de composición del Real Conservatorio de música y declamación (Madrid: Calcografía de B. Eslava, 1861). En el ACS se conservan varias obras pertenecientes a esta colección. Entre ellas, los dos juegos completos de lamentaciones para el Miércoles y Jueves Santos: ACS. Archivo de la Capilla Musical, sign. 31-B-1-15 y sign. 31-B-1-16, respectivamente.
} 
celebración en 1915 de la festividad de la Inmaculada en la Catedral ${ }^{153}$ : "Se cantó la misa en 'mi bemol' del maestro Eslava y la 'Tota-Pulchra', de Guzmán, dirigiendo la orquesta el maestro de capilla don Eduardo Torres, luciendo su hermosa voz el primer tenor de la Catedral señor García Muniesa"154. Esta otra, sobre el Corpus, data de 1916: "Después de Tercia se cantó la misa solemne, trasladándose acto seguido a la Custodia el Santísimo. A las ocho se cantó a gran orquesta la misa en 'mi' bemol del maestro

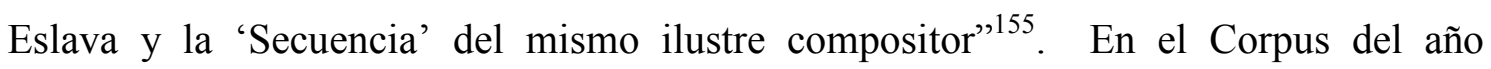
siguiente se repitieron ambas obras:

A las seis de la mañana, después del canto de Sexta, se expuso en el trascoro de la Catedral el Santísimo Sacramento, viéndose en torno de la Custodia el lujosísimo aparato que solamente se usa en este día.

Su Divina Majestad se colocó en la Custodia después de celebrada la misa solemne.

A las ocho se cantó a gran orquesta la misa en "mi bemol" y la "Secuentia" del maestro Eslava. [...]"156

Resulta difícil saber si en 1905 se juzgaban tales obras como adecuadas a los principios del MP y, en consecuencia, si el criterio de la CDMS hispalense al recomendarlas se mantenía dentro de lo considerado mayoritariamente entonces como ortodoxo. Habría que empezar por plantearse si realmente estaba clara la frontera entre lo ortodoxo y heterodoxo en todos los casos ${ }^{157}$. En algunos, como el del Miserere de

153 Las descripciones detalladas del aspecto del templo contrastan con la escueta y contadísima información musical que se puede hallar en ellas.

154 “En la Catedral”. El Noticiero Sevillano [ENS], 9003 de 9 de diciembre (1915), p. 1.

155 “Corpus Christi”. ENS, 9194 de 23 de junio (1916), p. 1.

156 “Corpus Christi. En la Catedral”. ENS, 9542 de 9 de junio (1917), p. 1.

${ }^{157}$ En el mismo artículo del que extractamos las valoraciones sobre las misas que proporcionamos a continuación, Otaño ofreció lo que desde nuestro punto de vista constituye una síntesis de su posicionamiento respecto de la producción de Eslava. En ella se advierte la dificultad de establecer con claridad los límites de lo admisible o no, al convivir virtudes con defectos. El músico jesuita consideraba la gran mayoría de las obras eslavianas "artísticamente medianas o litúrgicamente deficientes", y por tanto, no recomendables: “[...]; y si esto [la grandiosidad y el buen gusto del que habla el Sr. Miravalles] puede probarse en algunas, pocas, obras de Eslava, como desde un principio lo hemos confesado, nunca se probará en la generalidad de las obras, que no carecen de alguna de las cualidades requeridas: unas veces faltará la bondad de las formas, como en la mayor parte de las piezas del Museo Orgánico; otras faltará la santidad o acomodación litúrgica, como en las Lamentaciones; y muchas veces andarán tan mezcladas ciertas buenas cualidades con ciertos, no pocos, notables defectos, que será cuestión de apreciación u oportunidad inclinar a una y otra parte de la balanza. En este caso, unos dirán que el arte de Eslava es siempre flojo y rutinario, y que, por consiguiente, no hay por qué excederse en levantarlo y traerlo en palmas, puesto que obras más completas e inmaculadas existen en abundancia; otros, por el 
Eslava, el acuerdo sobre su incompatibilidad con el $M P$ era mayoritario ${ }^{158}$. Sin embargo, en otros, las consideraciones en este sentido se llevaban al terreno de los matices e incluso de lo opinable. En cualquier caso, la CDMS hispalense debió estimar ambas misas como conformes a lo preceptuado en el $M P$, juicio que justificaría su conservación.

En 1910, una vez nacido el llamado movimiento reformista español y decantado en su seno aquellos líderes que lograrían ejercer una mayor influencia en la fijación de criterios de juicio litúrgico-musical, Nemesio Otaño, quizás el más influyente entre ellos, nos dejaba la siguiente valoración sobre estas dos misas ${ }^{159}$ :

En cuanto a las restantes obras citadas por el señor Miravalles, confesando de buen grado que en algunos pasajes de la Misa en Mi bemol y La se sostiene bien Eslava, sólo os daré unos consejos, lectores míos: que al hacer música de iglesia os apartéis lo más posible de la manera de hacer [énfasis original] de Eslava: que si ponéis esas misas alguna vez, sea para evitar mayores males y por no tener cosa mejor; y que si no las ponéis nunca, ningún artista, ninguno que sienta bien de las cosas de iglesia os reprochará por ello, antes os aplaudirán, os bendecirán y os considerarán muy devotos fieles de la religión y del arte. ${ }^{160}$

Estas apreciaciones fueron publicadas en un artículo en el que el jesuita refutaba los argumentos a favor de Eslava esgrimidos en El pensamiento navarro por un sacerdote pamplonés que firmaba como Sr. Miravalles. Otaño inició así “una campaña

contrario, se empeñarán en defender la relativa bondad de aquellas piezas, y se esforzarán en servirse de ellas; estos defensores, por punto general, serán hombres de pocos horizontes, de escasa cultura, parecidos a aquellos honrados aldeanos para quienes no hay cosa mejor que la iglesia de su pueblo, en tanto que no conozcan poblaciones y monumentos de alguna más importancia y hermosura. Lo que ciertamente será difícil es encontrar, entre verdaderos competentes, muchos que crean al señor Miravalles cuando trata a Eslava de gran genio, [...]", y concluye su argumentación: "[...]; y los que tienen el cargo de formar el criterio y señalar orientaciones, no podrán jamás recomendar a un autor de obras artísticamente medianas o litúrgicamente deficientes. Goethe fue el que dijo, si no me equivoco, que 'el gusto se forma con la contemplación, no de lo mediano, sino de lo excelente y perfecto.'“ Cecilio [Nemesio Otaño], "Eslava. En defensa de D. Gregorio", MSH, 10 (1910), p. 92.

${ }^{158}$ Resulta revelador, en este sentido, el hecho de que los argumentos que se defendieron para preservar esta obra en los oficios de Tinieblas en la catedral de Sevilla no fueran de naturaleza litúrgico-musical, sino cultural. Sobre el Miserere de Eslava véase capítulo 3, epígrafe 1.1.1. "Salmo Miserere", p. 171.

159 Sobre el proceso de su gestación y desarrollo durante el congreso de Sevilla, véase el capítulo 5, epígrafe 4. "El congreso de Sevilla, escenario para la consolidación del movimiento de reformas como 'espacio artístico-social"”, p. 428.

${ }^{160}$ Cecilio [Nemesio Otaño], "Eslava. En defensa de D. Gregorio", MSH, 9 (1910), p. 84. El artículo fue publicado en dos números: Cecilio, "Eslava. En defensa de D. Gregorio", MSH, 9 (1910), pp. 84-87; y Cecilio, "Eslava. En defensa de D. Gregorio", MSH, 10 (1910), pp. 91-95. 
anti-Eslavista en toda forma", según sus propias palabras, en un momento en el que, tras lo ocurrido en el II Congreso Nacional de Música Sagrada (Sevilla, 1908), la polémica en torno a Eslava se había recrudecido considerablemente ${ }^{161}$. Avanzado el escrito volvía a referirse a dichas obras:

Entre las obras de pura transición [de Eslava], en que al lado de buenas virtudes aparecen notables defectos, sean de gusto, sean de conveniencia litúrgica, colocaremos, sin género de duda, las misas en la y mi bemol. La Salve grande en re menor, el Te Deum solemne (la menor) y otros que en este género se mantienen. Nuestra apreciación no pasa de tolerarlas [énfasis original], a falta de cosas mejores y más dignas. ${ }^{162}$

Por su parte, Vicente Ripollés, durante su etapa como principal responsable musical del colegio del Corpus Christi de Valencia, incluyó el Gloria de la Misa en la en el programa de obras a interpretar el Jueves Santo de $1898^{163}$. Dicho programa fue publicado en la revista La Música Religiosa en España, órgano de la Asociación Isidoriana de Madrid, en cuya fundación colaboraron, entre otros, Felipe Pedrell, Eustoquio Uriarte, Jesús de Monasterio o José Ma Esperanza y Sola ${ }^{164}$.

Por tanto, según el criterio de Otaño que, como decimos, llegó a ser referente para la gran mayoría del movimiento reformista español, estas misas de "buenas virtudes" y "notables defectos", se podían tolerar "para evitar mayores males y por no tener cosa mejor", aunque no eran aconsejables -es más, había que huir de obras de tal factura- ${ }^{165}$. Ripollés, de forma excepcional, pues no hemos encontrado más ejemplos,

${ }^{161}$ Véase capítulo 6, epígrafe 3. "La polémica en torno a Eslava tras el congreso de Sevilla: identidad musical versus identidad en proyecto", p. 572.

${ }^{162}$ Cecilio, "Eslava. En defensa de D. Gregorio", MSH, 10 (1910), p. 93.

${ }^{163}$ El efecto que produciría la pieza de Eslava sería ciertamente contrastante, pues el resto del ordinario de la misa correspondió a la misa $O$ quam gloriosum, de Victoria. Transcribimos el programa completo del Jueves Santo: "Jueves Santo. [Misa:] Gloria in excelsis de la Misa en la, de Eslava. Kyrie, Credo, Sanctus y Agnus de la Misa $O$ quam gloriosum, de Victoria. [Exposición:] Tantum ergo, de Ginés de Boluda, Maestro de la Catedral de Toledo (XVI). [oficio de Tinieblas:] Lamentaciones: La 1. a de Eslava; la 2. ${ }^{\mathrm{a}}$ y 3. a canto gregoriano. Responsorios, de Victoria. Miserere, de Allegri. De ocho a diez de la noche en el Monumento.- Jesus dulcis y Domine non sum dignus, de Victoria.- Coenantibus illis, de Palestrina.- Hoc Corpus, de autor desconocido." "Semana Santa de 1898. Repertorios y programas de funciones. Capilla del Real Colegio del 'Corpus Christi', dirigida por el maestro D. Vicente Ripollés, presbítero.", $L a$ Música Religiosa en España, 25, 26 y 27 (1898), pp. 38-44, p. 41.

164 Para más información sobre la Asociación Isidoriana véase: Virgili, "Antecedentes y contexto ideológico", pp.35-36.; Nagore, “Tradición y renovación”, pp. 217-220.

${ }^{165}$ Otaño relacionó las únicas obras de Eslava que, desde su punto de vista, "sin que sean maravillas, ni mucho menos, conservan la suficiente dignidad": los motetes " $O$ sacrum, en mi bemol, a 4 voces y 
hizo uso de una de las partes de la Misa en la en el programa litúrgico-musical presentado en La Música Religiosa en España, la principal revista difusora de los valores reformistas anteriores al MP. Habría que concluir, en consecuencia, que tanto en los años inmediatamente anteriores al $M P$ como en los primeros tras su promulgación, figuras reformistas del peso de Otaño o Ripollés toleraban la interpretación de estas misas en la liturgia, a pesar de estar lejos de ser paradigmas de música sagrada, y de los defectos que desde un punto de vista estético y litúrgico encontraban en ellas.

El concepto de "obra tolerada" tuvo una significación exacta en términos de censura de la música litúrgica en el Reglamento general para la Música Sagrada en la Provincia Eclesiástica de Valladolid de 1905, un documento que fue propuesto en el congreso de Valladolid como ejemplar y exportable a todas las diócesis españolas, y cuya elaboración se debió en buena parte al trabajo de Otaño. En el artículo 43 del epígrafe dedicado a la Comisión diocesana y a la censura de la música sagrada se definieron los términos con los que enjuiciar las obras musicales a supervisar: aprobada, tolerada o prohibida ${ }^{166}$. El artículo siguiente aclaraba:

44. Las obras aprobadas, que serán las que tengan las debidas cualidades litúrgicas, llevarán estampado el sello de la Comisión con el de la calificación y serán las únicas [énfasis originales] que en lo sucesivo podrán ejecutarse sin restricción en las funciones religiosas.

Las toleradas serán obras no destinadas generalmente a funciones litúrgicas y que por no poderse sustituir por de pronto con otras de carácter religioso, podrán ejecutarse por tiempo limitado. Llevarán una declaración firmada por el Secretario de la Comisión, haciendo constar las condiciones en que se deben ejecutar y se podrán cantar mediante el cumplimiento exacto de las expresadas condiciones.

Todas las demás composiciones quedan del todo prohibidas, y deberán ser eliminadas de los actos religiosos. ${ }^{167}$

órgano, O sacrum a 4 voces solas, Bone Pastor en la bemol, $O$ salutaris a 8 voces, Jesu dulcis memoria en la mayor, Panis Angelicus en re mayor, Ecce panis en fa mayor, los tres motetes a 4 voces y órgano, obra 156 (Ave Maria, etc.)", además de "la Misa a solas voces para adviento y cuaresma, (obra 136), y el Tu es Petrus a coro de bajos y 4 voces". Cecilio, "Eslava. En defensa de D. Gregorio", MSH, 10 (1910), p. 93.

166 "43. La Comisión calificará las composiciones con las notas de aprobada o tolerada". "Edicto y Reglamentos sobre música sagrada”, p. 352.

${ }^{167}$ Ibídem. 
Así pues, en base a estas consideraciones, el criterio aplicado por la CDMS hispalense en relación en relación con las misas en la y mi $b$ de Eslava entraba dentro de la ortodoxia, según estaba siendo definida en aquellos momento por las más influyentes figuras reformistas, pero sólo en parte. La recomendación para las funciones más solemnes abría el camino a su perpetuación, precisamente lo que pretendían evitar dichas figuras con la etiqueta, transitoria y provisional, de tolerables.

\subsection{Regulación del uso de los instrumentos}

La regulación del uso de los instrumentos en la archidiócesis hispalense se intentó desde la primera circular emitida por el arzobispo en febrero de 1904. En ella Spínola se limitó a reproducir algunas de las medidas contenidas en el documento papal como la prohibición del uso del piano, de los instrumentos fragorosos -que la Comisión aclarará como aquellos de percusión-, y las bandas de música en el interior de los templos ${ }^{168}$.

Por su parte, la Comisión, en su primera reunión (4 de marzo de 1904), amplió estas escuetas medidas de Spínola $^{169}$. Tres de las diez disposiciones acordadas en dicha reunión "conducentes al desarraigo de los lamentables abusos que se vienen observando tanto en el canto como en la música de nuestras Iglesias" tenían que ver con la utilización de los instrumentos en las funciones religiosas ${ }^{170}$. Especial importancia tienen aquellas referidas a la participación de la orquesta. En estas últimas nos centraremos una vez hechas algunas puntualizaciones sobre las relacionadas, en primer lugar, con determinadas intervenciones del órgano y otros instrumentos, y, en segundo lugar, con la Semana Santa.

Respecto a las primeras, dispuso:

7. ${ }^{\circ}$ Se aprecian como abusivos y contrarios al Ceremonial de Obispos, los preludios e intermedios del Armonium o de otros

\footnotetext{
168 “Queda prohibido en todas las Iglesias del Arzobispado el uso del piano, e igualmente de los instrumentos fragorosos, como los llama el Papa, vedándose por de contado asimismo que dentro del lugar santo toquen las denominadas bandas de música". Marcelo, "Circular sobre la música sagrada", $B O A S, 536$ (1904), p. 116.

${ }^{169}$ Ya hemos advertido en un par de ocasiones que el informe resultante de esa reunión no se hizo público hasta casi un año después, en febrero de 1905. Es decir, no se pudo aplicar en la práctica hasta esa fecha al permanecer sin difusión, por lo tanto, desconocido.

${ }^{170}$ Marcelo, "Sobre música sagrada”, BOAS, 560 (1905), p. 90.
} 
instrumentos en la Misa y Oficio de Difuntos: en estos actos los instrumentos deben limitarse a acompañar suavemente a las voces.

8..$^{\circ}$ Muchas profanaciones e indignidades evitaría [...] prohibir la improvisación o fantasía a los Sres. Organistas, que no lo sepan hacer convenientemente, [cursiva original] respetando las reglas del arte y la liturgia (Artículo 12 del Reglamento publicado por la S. C. de Ritos en 1894). ${ }^{171}$

La segunda medida que figura como punto octavo no era más que una transcripción de lo dispuesto en el Reglamento sobre la música religiosa aprobado por la Sagrada Congregación de Ritos en 1894, en relación a la costumbre extendida entre los organistas religiosos de improvisar, independientemente de sus capacidades.

El punto séptimo merece una aclaración, ya que contemplaba como abusivos todos los preludios e intermedios instrumentales. En el $M P$, sin embargo, no se consideran abusivos los preludios e intermedios per se sino los "largos" ". Suponemos que se refería a aquellos que interrumpían el ritmo de la ceremonia y que, por tanto, constituían la materialización de un abuso calificado en el texto papal como "gravísimo": la inversión del orden natural que suponía poner el acto litúrgico al servicio de la música ${ }^{173}$. En relación a aquellos que no representaban un abuso según el $M P$, el artículo 18 precisaba la forma en la que debía tocarse, en este caso, el órgano: "En el acompañamiento del canto, en los preludios, intermedios y demás pasajes parecidos, el órgano debe tocarse según la índole del mismo instrumento, y debe participar de todas las cualidades de la música sagrada recordadas precedentemente" ${ }^{\text {174 }}$. Es decir, el $M P$ no sólo no los prohibía sino que los regulaba. Hay que afirmar, por consiguiente, que la Comisión estableció una norma que partía de una interpretación excesivamente rigurosa del texto papal, y que se explicaría en el caso de que efectivamente estuviera generalizada en la Archidiócesis la costumbre de ejecutar al órgano largos preludios e intermedios.

\footnotetext{
${ }^{171}$ Ibídem, pp. 91-92.

172 "No está permitido anteponer al canto largos preludios o interrumpirlo con piezas de intermedio." MP. Título VI. Órgano e instrumentos, art. 17.
}

\footnotetext{
173 "En general, ha de condenarse como abuso gravísimo que, en las funciones religiosas, la liturgia quede en lugar secundario y como al servicio de la música, cuando la música forma parte de la liturgia y no es sino su humilde sierva.” MP. Título VII. Extensión de la música religiosa, art. 23.
}

${ }^{174}$ MP. Título VI. Órgano e instrumentos, art. 18. 
La apelación que el $M P$ hacía en su artículo 18 a mantenerse fieles a la naturaleza del órgano a la hora de tocarlo se debe entender en su contexto. La música para órgano se vio influida tanto por los tipismos melódicos propios de la estilo lírico de moda, como por la textura propia de la música pianística de salón del s. XIX. La textura contrapuntística y fugada, históricamente considerada connatural al instrumento, había sido olvidada en gran medida. Ya a mediados del s. XIX, Eslava denunció estas prácticas en su Museo orgánico español:

Los organistas que se dedicaron al género libre casi exclusivamente no se contentaron con lucir su habilidad en el órgano, sino que quisieron también ser pianistas y hacerse aplaudir en los salones; y así como el género libre influyó en la decadencia del género fugado, el de piano influyó a su vez en la decadencia del libre orgánico. $^{175}$

Y más adelante:

Sin embargo de todo esto, es necesario reconocer, que las escuelas citadas y todas las de su tiempo relajaron, unas más y otras menos, la severa educación de nuestros antiguos organistas. Los hijos de ellas (permítaseme llamarlos así) dieron gran impulso al género libre, ensancharon demasiado sus límites, y empezaron a mirar con cierto desdén el género fugado. Pero los que han saltado la valla de todo lo justo, y han abusado del género libre de un modo severamente censurable son sus nietos. Estos, con algunas honrosas excepciones, han llegado a confundir hasta cierto punto el género religioso con el profano, y el de piano con el orgánico. No son ya organistas, sino pianistas de más o menos habilidad, a quienes por lo general les falta de cabeza todo lo que les sobra de dedos. ${ }^{176}$

La lista de medidas pensadas por la Comisión se completó con las contenidas en el informe dirigido al prelado el 26 de enero 1905, dedicadas a regular el papel de los instrumentos en las solemnidades de Semana Santa. Esta atención prioritaria a la participación de los instrumentos en las funciones litúrgicas pascuales es una actitud bastante significativa y nos adelanta uno de los asuntos más problemáticos de la reforma, como comprobaremos en la Parte II de esta tesis. Resulta interesante observar, además, que todas estas medidas figuran en el último punto, el dedicado a informar al

\footnotetext{
${ }^{175}$ Hilarión Eslava, Museo orgánico español. Parte $1^{a}$ (Madrid: [s.e.], [1854]), p. 18.

${ }^{176}$ Ibídem, pp. 18-19.
} 
arzobispo de los abusos que se cometían y debían ser "desarraigados". La Comisión prohibió:

b) Acompañar con instrumentos los motetes de la Comunión y Monumento el jueves santo.

c) Tocar el órgano en la misa del jueves santo, excepción hecha del Gloria in excelsis.

d) Acompañar el Gloria de la misa in Coena Domini y del sábado santo con improvisaciones indebidas de la música que se canta. $^{177}$

Si invertimos los términos, es obvio que lo que había que prohibir era lo que se hacía. El valor informativo de estas disposiciones se encuentra, además, en proporcionarnos importantes datos sobre las prácticas litúrgico-musicales en vigor en ese momento.

Centrémonos, por último, en la problemática concreta de la orquesta en las celebraciones litúrgicas. Las primeras disposiciones para regular la intervención de la orquesta en la liturgia están contenidas en el informe de la Comisión de 4 de marzo de 1904. Resulta interesante analizar la redacción del punto $9^{\circ}$ de dicho informe:

Admitida la orquesta en algún caso particular, en los términos debidos, con los debidos miramientos y con licencia especial de la Autoridad eclesiástica, (M.P. 15) debe ejecutar música en estilo grave, conveniente y parecida en todo a la del órgano (M.P. 20) ${ }^{178}$ [subrayado y referencias entre paréntesis al Motu Proprio (M.P.) originales]

El párrafo está compuesto por una fusión de dos pasajes extraídos de los artículos 15 y 20 del $M P$. Sin embargo, el artículo 15 trata sobre los instrumentos en general, no específicamente sobre la orquesta:

15. Si bien la música de la Iglesia es exclusivamente vocal, esto no obstante, también se permite la música con acompañamiento de órgano. En algún caso particular, en los términos debidos y con los debidos miramientos, podrán asimismo admitirse otros instrumentos; pero no sin licencia especial del Ordinario, según prescripción del Caeremoniale episcoporum. ${ }^{179}$

\footnotetext{
${ }^{177}$ Marcelo, “Sobre música sagrada”, BOAS, 560 (1905), p. 96.

${ }^{178}$ Ibídem, p. 92.

${ }^{179} M P$, Título VI. Órgano e instrumentos, art. 15.
} 
y el 20 sobre las bandas de música e instrumentos de viento:

20. Está rigurosamente prohibido que las llamadas bandas de música toquen en las iglesias, y sólo en algún caso especial, supuesto el consentimiento del Ordinario, será permitido admitir un número juiciosamente escogido, corto y proporcionado al ambiente, de instrumentos de aire, que vayan a ejecutar composiciones o acompañar al canto, con música escrita en estilo grave, conveniente y en todo parecida a la del órgano. ${ }^{180}$

Ninguno de los dos está dedicado a la orquesta como tal. En realidad, el término "orquesta" no se menciona en el Motu Proprio en ningún momento. Este vacío normativo en cuanto a su regulación daba lugar a un espacio donde cabía la interpretación. Unos años después, en 1910, apareció en $M S H$, la revista más influyente dentro del movimiento reformista español, un artículo titulado La orquesta en el templo. En él se ponían de manifiesto las diversas lecturas de que había sido objeto la imprecisa regulación sobre el uso de instrumentos en la nueva norma papal, así como la necesidad de contar con una "interpretación auténtica, anhelada por muchos para recta inteligencia y exacto cumplimiento de los deseos de Su Santidad"181.

Enderezada, sin duda, esta disposición a corregir añosas y culpables rutinas, ha sido, en parte, objeto de juicios diversos y aun contrarios. Creyeron unos ver en ella una prohibición absoluta [énfasis original] de la orquesta en el templo, y se persuadieron otros de que no era necesario recabar o tener la licencia del Ordinario más que una vez, para hacer ilimitadamente uso de los instrumentos musicales en las solemnidades del culto.

Era, por tanto, muy conveniente que una interpretación más autorizada, poniendo de manifiesto el genuino y verdadero espíritu de esa disposición, diera una norma fija para poner fin a caprichosas o erróneas interpretaciones, y prevenir los abusos que, procederes injustificados y arbitrarios, hubieran de engendrar. ${ }^{182}$

\footnotetext{
${ }^{180}$ Ibídem., art. 20.

181 Una de las pocas publicaciones sobre la orquesta en relación con los principios del $M P$ es el interesante estudio de Federico Olmeda, Comentario sobre el Motu Proprio de Su Santidad Pio X en cuanto a la Orquesta Religiosa (Burgos: Imp. de Cariñena, 1904). Algunos años antes, el mismo autor había sacado a la luz: Discurso sobre la orquesta religiosa presentado en el Segundo Congreso Eucarístico Nacional que se celebró en Lugo a fines de Agosto de 1896 (Burgos: [s.e.], 1896).
}

182 J. Martínez de Nanclares, "La orquesta en el templo”, MSH, 10 (1910), pp. 95-96. 
La "interpretación auténtica" a la que seguidamente aludía el sacerdote autor del artículo no apareció hasta abril de 1905 -mes y medio después de que se publicara en el BOAS el plan de reformas hispalense-, aunque no supuso grandes novedades ${ }^{183}$. Tampoco el posterior de 13 de noviembre de 1908. Ambos limitaban el uso de los instrumentos -que se citan individualmente, evitando el término, y suponemos, concepto de orquesta- a aquellas partes del culto y periodos del año litúrgico en que estaba autorizado el uso del órgano, e insistían en la necesidad de autorización en cada caso particular por parte del Ordinario:

Esta interpretación auténtica [...], nos la da la Sagrada Congregación de Ritos en su decreto de 5 de Abril de 1905, que regula el uso de los instrumentos musicales en las funciones sagradas disponiendo "que podrán emplearse los violines, violas, violoncello, contrabajo, flautas, clarinetes, fagotes y trompas en aquellas funciones y tiempos en que no está prohibido el sonido del órgano y de otros instrumentos por el Ceremonial de los Obispos o por dicho Motu Proprio, etc., etc.; empero, según el prudente arbitrio del Ordinario, con dispensa, in singulis casibus, en cada caso de la ley y práctica común de emplear en las funciones sagradas el canto gregoriano o música polifónica u otra aprobada.

En consonancia con la precitada disposición, la misma Sagrada Congregación resuelve, en decreto de 13 de Noviembre de 1908, que tolera el uso de los instrumentos de música, oboes y clarinetes, con tal que se empleen moderadamente, y se obtenga, pro quovis opere, licencia del Ordinario. ${ }^{184}$

La CDMS hispalense solucionó la cuestión aplicando las directrices dadas sobre instrumentos en general, que era lo más lógico ante la falta de normas para la orquesta como tal, a las que sumó las específicas sobre los de viento ${ }^{185}$.

Spínola, por su lado, en su primera toma de posición al respecto, dispuso: "Las orquestas en el templo no están absolutamente prohibidas por el papa; pero lo están determinados instrumentos, que desde luego han de tenerse por proscritos en nuestra diócesis."186 Este posicionamiento era problemático, pues obviaba la necesidad de

\footnotetext{
${ }^{183}$ Decreto de la Sagrada Congregación de Ritos de 15 de abril de 1905 Ibídem, p. 96.

${ }^{184}$ Ibídem, p. 95.

${ }^{185}$ Para terminar el punto $9^{\circ}$ al que hacemos referencia, la comisión desaconseja la inclusión en la plantilla orquestal de los trombones y cornetines cuando "no formen la base un buen número de voces e instrumentos de cuerda", mostrando su preocupación por el buen balance sonoro del conjunto. Marcelo, "Sobre música sagrada”, BOAS, 560 (1905), p. 92.

${ }^{186}$ Ibídem, p. 98.
} 
autorización expresa del Ordinario que en todo caso prescribía el $M P$, siguiendo lo dispuesto en el Caeremoniale episcoporum, para la participación de cualquier otro instrumento que no fuera el órgano ${ }^{187}$. Ésta era precisamente la fórmula planteada en dicho texto para el control de unas prácticas y costumbres que constituían uno de los principales frentes de la reforma. El planteamiento en estos términos de Spínola constituía, por tanto, una posición excesivamente permisiva, y conllevaba el riesgo, al prescindirse en la práctica del procedimiento que debía garantizar el uso de la orquesta ajustado al $M P$, de que los encargados de llevarla a la práctica sobre el terreno, párrocos y rectores de Iglesias, mantuvieran una actitud excesivamente laxa. La queja que la Comisión elevó al arzobispo poco tiempo después -en su informe de 12 de abril- en relación a los incumplimientos por parte de los párrocos de esta normativa demuestra que, efectivamente, así ocurrió. Para contrarrestar esta circunstancia propuso

como medio de que tales disposiciones sean fielmente cumplimentadas $[\ldots]$ atendiendo a las facultades que el Ceremonial de Obispos libro $1^{\circ}$ Cap. 28 concede a los Sres. Ordinarios, propone a V. E. R. que en todos y en cada uno de los casos en que haya de tomar parte una pequeña o grande orquesta, se eleve a V. E. R. por los párrocos o encargados de las Iglesias, una solicitud expresando la clase y número de voces e instrumentos y las obras que habrán de ejecutarse con el fin de ser examinadas; y de este modo se irán formando también los Archivos de música religiosa en este Arzobispado. ${ }^{188}$

Es decir, instaba al prelado a que se empleara el medio contemplado en el $M P$ para evitar dichos incumplimientos. Además, proponía aprovechar esas futuras solicitudes para ir conformando poco a poco lo que llamó los "Archivos de música religiosa en este Arzobispado". Suponemos que se trataría de un procedimiento para cumplir con otro de sus cometidos, como era la depuración del repertorio litúrgicomusical diocesano.

Tres días después, en la circular en la que publicó los acuerdos y propuestas de la Comisión, Spínola incorporó lo que esta le había propuesto y el MP prescribía:

187 "Si bien la música de la Iglesia es exclusivamente vocal, esto no obstante, también se permite la música con acompañamiento de órgano. En algún caso particular, en los términos debidos y con los debidos miramientos, podrán asimismo admitirse otros instrumentos; pero no sin licencia especial del Ordinario, según prescripción del Caeremoniale episcoporum.” MP, VI. Órgano e instrumentos, art. 15.

${ }^{188}$ Acuerdos tomados en la reunión celebrada el 12 de abril de 1905. AGAS. Sección Gobierno. Asuntos Despachados, leg. 04900 (1905). 
Siempre que en funciones litúrgicas haya de tomar parte una pequeña o grande orquesta, el Párroco, Rector o encargado de la Iglesia acudirá a nuestra autoridad para obtener el debido permiso, $\mathrm{y}$ expresará la obra u obras, que hayan de ejecutarse, y la clase y número de los instrumentos, que han de concurrir. ${ }^{189}$

Con esta declaración, la postura de Spínola se ajustó al MP. Sin embargo, en contra de lo que la Comisión opinaba, el mandato del prelado no garantizó el cumplimiento de la instrucción papal por parte de los eclesiásticos infractores, como comprobaremos a continuación.

\section{Recepción y respuesta de administradores de templos a la reforma}

Durante 1905, la Comisión trasladó a Spínola sucesivas quejas sobre los repetidos incumplimientos de las normas que se habían establecido. Todos estos informes negativos, a los que Spínola reaccionó con inmediatez, culpabilizaban a administradores de templos. Precisamente en este colectivo había depositado Spínola su confianza una vez hubo relanzado la reforma a comienzos de año:

7. ${ }^{\circ}$ En una palabra, hacemos nuestras las indicaciones en los dos preinsertos informes [elaborados por la Comisión en marzo de 1904 y enero de 1905] y deseamos que puntualmente se cumplan por todos aquellos a quienes corresponda, haciendo responsables de su fiel ejecución a los Párrocos y Arciprestes. ${ }^{190}$

Tan sólo dos meses después de que se dieran a conocer dichos informes, y que, en consecuencia, entraran en vigor las disposiciones que contenían, la CDMS escribía: "Esta Comisión no puede menos de lamentar el olvido en que ponen algunos Sres. Párrocos lo propuesto por la misma y sancionado por V. E. R. sobre música sagrada, en su circular de 15 de Febrero del presente año; [...]."191

La segunda denuncia no tardó en llegar. El 24 de mayo, la Comisión volvió a informar al arzobispo sobre el general desacato a sus resoluciones:

\footnotetext{
${ }^{189}$ Marcelo, Arzobispo de Sevilla, “Circular núm. 320”, BOAS, 565 (1905), pp. 262-263.

${ }^{190}$ Marcelo, "Sobre la música sagrada, BOAS, 560 (1905), p. 98.

${ }^{191}$ Acuerdos tomados en la reunión celebrada el 12 de abril de 1905. AGAS. Sección Gobierno. Asuntos Despachados, leg. 04900 (1905).
} 
5. ${ }^{\circ}$ La Comisión se cree en el deber de elevar a V. E. R. la extrañeza que le causa el no haber recibido desde la fecha de la publicación de la última circular sobre música sagrada más que dos peticiones de autorización para la celebración de funciones con orquesta cuando es bien notorio la frecuencia con que se celebran estas funciones en las iglesias de la ciudad y Arzobispado. ${ }^{192}$

Estas quejas de la Comisión movieron al arzobispo a incidir de nuevo en lo dispuesto. El 15 de junio hacía públicas sus advertencias:

El primero [de los puntos que la Comisión ha juzgado interesante llamar la atención del prelado] es el general olvido en que se tiene el mandato de Su Santidad sobre el uso de orquestas en las funciones solemnes, pues sin los debidos permisos y sin sujetarse a los preceptos pontificios acerca de las composiciones que según el Motu proprio de Su Santidad pueden ejecutarse en la Iglesia, se las ve tomar parte en dichos actos religiosos con harta frecuencia. ${ }^{193}$

Junto a esta cuestión, Spínola se vio obligado a reiterar otras disposiciones ya dictadas. Ante la cercanía de las fiestas navideñas, Spínola publicó una nueva circular para volver a recordar a los párrocos lo prescrito en el $M P$, y de forma especial, sobre las misas de Expectación, lo que indica que las instrucciones dadas hacía justo un año tampoco fueron respetadas ${ }^{194}$ :

Aunque parezca impertinencia recordar por anticipado el cumplimiento de los deberes, cuando no hay razones para creer que puedan olvidarse, en nuestro deseo de que se guarden las prescripciones de $\mathrm{Su}$ Santidad en orden a la seriedad del culto católico, nos atrevemos a llamar la atención de los Curas, con motivo de la proximidad de la fiesta del Nacimiento de Nuestro Señor Jesucristo, acerca de la necesidad de que en las Misas de Expectación, vulgarmente llamadas de aguinaldo, se suprima todo lo que una antigua costumbre, más digna que de este nombre del de corruptela o abuso, había introducido entre nosotros, a saber, el empleo de instrumentos de ruido y el cántico de villancicos, que nada tiene litúrgico, sino antes se opone en absoluto a lo que la liturgia católica

\footnotetext{
${ }^{192}$ Informe con fecha de 27 de mayo en el que se recogen los acuerdos tomados en la reunión celebrada el día 24 de ese mes. AGAS. Sección Gobierno. Asuntos Despachados, leg. 04900 (1905). Spínola dio a conocer esta queja de la comisión en la siguiente circular: "[Circular] Sobre música sagrada”, BOAS, 569 [de 15 de junio], pp. 432-433.

${ }^{193}$ Marcelo, “[Circular] Sobre música sagrada” BOAS, 569 (1905), pp. 432-433.

194 Spínola publicó su instrucción de eliminar las misas de Expectación tal y como se celebraban en: Marcelo, Arzobispo de Sevilla, “Circular núm. 315”, BOAS, 556 (1904), pp. 487-488.
} 
exige, y que en su Motu proprio sobre la Música sagrada ha confirmado y ratificado Pío X. ${ }^{195}$

Con la circular que contiene este pasaje se cerró el periodo del proceso de reformas que discurrió durante el pontificado del hoy declarado beato Marcelo Spínola.

Por tanto, y en síntesis, resulta bastante significativo, en primer lugar, que tan sólo dos meses después de reanudado el proceso, la CDMS elevara la primera queja relativa a los incumplimientos de las normas establecidas para la realización de la reforma en la Archidiócesis; en segundo lugar, que entre el 12 de abril y el 15 de junio de 1905 todos los informes generados por la Comisión en sus reuniones y todas circulares publicadas por el arzobispo contuvieran avisos y denuncias en este sentido; y por último, que terminara la fase del proceso de reformas bajo su pontificado con una apelación a que se respetaran las prescripciones papales, volviendo a insistir en la necesidad de suprimir unas prácticas que ya había denunciado como abusos un año antes. A partir de estos hechos se puede concluir que en términos generales el esfuerzo realizado por el arzobispo hispalense y la CDMS para la implantación de los nuevos preceptos del $M P$ en la archidiócesis de Sevilla resultaron, en gran medida, infructuosos. La respuesta de aquellos que tenían en sus manos la aplicación en última instancia y en la realidad cotidiana de las disposiciones que se iban ideando fue de indiferencia o de no colaboración. Esas reacciones negativas tenían una importancia mayor de lo que en principio se pudiera pensar, pues al tratarse de incumplimientos de normas promulgadas en un texto con categoría de ley universal de obligado acatamiento, significaban infracciones y una postura de desobediencia.

\footnotetext{
195 Marcelo, Arzobispo de Sevilla, "Circular núm. 328” [en índice del tomo: "Circular recordando a los Párrocos el ‘Motu proprio’ sobre música sagrada”], BOAS, 583 (1905), pp. 553-554.
} 



\section{CAPÍTULO 2}

\section{LA REFORMA DURANTE EL PONTIFICADO DE ENRIQUE ALMARAZ Y SANTOS (1907-1910)}

\section{Periodo de interregno: nueva suspensión del proceso de reformas}

Marcelo Spínola falleció el 19 de enero de 1906. Su muerte marcó el comienzo de una nueva suspensión del proceso. La reactivación de la reforma promovida por el purpurado a principios de 1905 se topó de nuevo con las adversidades impuestas por las circunstancias.

La sucesión de Spínola en la silla episcopal hispalense estuvo determinada por un suceso inesperado. El 6 de diciembre de 1906 fue preconizado nuevo arzobispo de Sevilla Salvador Castellote, entonces obispo de Jaén. Castellote, sin embargo, nunca llegaría a tomar posesión de su nueva Sede, pues falleció diecisiete días después de su nombramiento. Esta circunstancia imprevista tuvo como consecuencia la prolongación de la Sede vacante casi un año más. Bartolomé Romero Gago, canónigo catedralicio, fue el encargado de asumir el gobierno hasta la llegada de un nuevo prelado.

En los estudios dedicados a la archidiócesis sevillana se subrayan los efectos negativos que este periodo de interregno excesivamente largo provocó. Los proyectos más importantes emprendidos por Spínola durante su mandato, especialmente aquellos de carácter socio-político, acusaron profundamente la ausencia durante tanto tiempo de la autoridad episcopal. La Liga Católica, que aglutinaba a tendencias políticas de signo católico y antiliberal (integristas, carlistas, católicos sin definición) sufrió, tras la muerte de su impulsor y principal garante de su cohesión, graves disensiones y rupturas. Las tensiones que desde hacía algún tiempo predominaban entre las distintas facciones de la coalición desembocaron en una situación insostenible a mediados de 1906. A finales de marzo de 1907 tanto integristas como carlistas anunciaron su salida de la unión políticosocial católica fundada con la entrada del siglo. Como realidades en mayor o menor 
medida relacionadas con la Liga, las desavenencias y divisiones de sus integrantes afectaron considerablemente a otras grandes apuestas del prelado recién fallecido: $E l$ Correo de Andalucía -tanto integristas como carlistas fundaron órganos de expresión propios-, o los centros sociales católicos ${ }^{1}$.

La reforma litúrgico-musical, como un frente abierto más que atender por parte de la administración diocesana, fue otra víctima de esta situación anómala que suponía la ausencia de la cabeza del gobierno eclesiástico. Durante los veintidós meses que transcurrieron entre la muerte de Spínola y la llegada de quien finalmente le sucedió, Enrique Almaraz, no encontramos más referencia a la reforma que una circular con fecha de 29 de marzo de 1906, publicada en el BOAS el 5 de abril. Esta circular, firmada por el vicario capitular, Romero Gago, se limitó a recordar las directrices dadas en años anteriores para la celebración de los cultos que tenían lugar en Semana Santa. Entre ellas remitía a las dadas en la circular no 320 de 15 de abril de $1905^{2}$. Se trató, por tanto, del mero trámite de hacer presentes las disposiciones vigentes al respecto para su cumplimiento. La CDMS creada por Spínola desapareció con su fundador. Con ellos se esfumó del escenario diocesano el plan para la transformación de la realidad litúrgico-musical desarrollado durante el año de 1905.

Enrique Almaraz y Santos, hasta entonces obispo de Palencia, hizo su entrada en Sevilla como nuevo prelado hispalense el 15 de octubre de 1907. Sus primeros meses en la capital andaluza sirvieron como periodo de adaptación, y para tomar las riendas de su nueva archidiócesis ${ }^{3}$. Una vez establecido, comenzó su labor de preparación de los varios eventos a celebrar a finales de 1908. Entre ellos, el II Congreso Nacional de Música Sagrada. El compromiso de organizar la segunda gran cita del movimiento español pro reforma obligó a la administración diocesana a concentrar una gran parte de su atención en la cuestión litúrgico-musical. Sin embargo,

\footnotetext{
${ }^{1}$ Véanse, entre otros: Javierre, "La diócesis de Sevilla"; José Leonardo Ruíz Sánchez, Política e Iglesia durante la Restauración. La liga católica de Sevilla (1901-1923) (Sevilla: Diputación de Sevilla, 1994), pp. 186-200.

2 Bartolomé Romero Gago. "Circular" [en índice del tomo: "Circular dictando las disposiciones de la Semana Santa”], BOAS, 590 (1906), pp. 88.

${ }^{3}$ La Crónica del Segundo Congreso Nacional de Música Sagrada comenzaba: "Terminadas las suntuosas fiestas de Semana Santa, que han hecho célebre a Sevilla en el mundo entero, y desembarazado el Excmo. Sr. Arzobispo de los múltiples negocios trascendentales que en el largo periodo de Sede vacante se habían acumulado para su resolución, dio comienzo a los trabajos preliminares de organización del Congreso de Música con la actividad que le distingue en cuantas obras pone en sus manos". Crónica del Segundo Congreso, p. 9.
} 
aunque parezca una paradoja, tuvo como consecuencia la dilatación aún más de la suspensión del proceso propiamente local.

El congreso de Sevilla será objeto de un profundo análisis en la tercera parte de esta tesis. No obstante, resulta oportuno en este momento hacer un par de puntualizaciones. En primer lugar, la iniciativa de organizar este importante evento musical eclesiástico no partió de las autoridades diocesanas locales. La elección de Sevilla como su sede no fue un logro al que aspirara la Iglesia hispalense, como se pudiera suponer, sino una decisión tomada, con el beneplácito de Enrique Almaraz, en el I Congreso Nacional de Música Sagrada (Valladolid, 1907). En ese momento, el recién proclamado arzobispo de Sevilla aún no había tomado posesión de su nuevo cargo. Por tanto, el Congreso fue un proyecto asumido personalmente, e importado por Almaraz. En segundo lugar, como se pondrá en evidencia en el capítulo quinto, los congresos fueron grandes empresas promovidas por determinados líderes del, en aquel momento, aún incipiente movimiento reformista español. Si bien este movimiento contó con el apoyo de algunos obispos y otras autoridades eclesiásticas, se constituyó como un espacio paralelo a la propia estructura administrativa de la Iglesia, aunque en continuo contacto, e incluso, imbricado con ella. Se trata de dos dimensiones de una misma realidad: por un lado, las diócesis y sus procesos particulares de reforma; y por otro, el movimiento reformista de alcance general español y sus grandes proyectos, como los congresos. Estos últimos tenían como una de sus principales finalidades servir de acicate para la realización de la reforma en todo el país, pero no estaban integrados en los proyectos reformistas locales.

La reanudación de la reforma a nivel local, que se verificó en primer lugar en la Catedral, debió esperar a la clausura del Congreso; a nivel general diocesano no se produjo hasta marzo de 1909. Un largo interregno, la llegada de un nuevo arzobispo, y la celebración en la capital andaluza del II Congreso Nacional de Música Sagrada hicieron que la aplicación del $M P$ en Sevilla permaneciera paralizada durante tres años $\mathrm{y}$ tres meses. En realidad, las fases en las que durante estos cinco años estuvieron activos arzobispo y Comisión se redujeron al primer trimestre de 1904 y buena parte de 1905. Es lógico que esta intermitencia y falta de perseverancia neutralizaran la potencial eficacia de su trabajo. A cada uno de sus impulsos siguió una interrupción que enfrió sistemáticamente el proceso. 


\section{El arzobispo Enrique Almaraz frente a la reforma: continuidad y}

\section{severidad}

La primera circular sobre música sagrada publicada por Almaraz data del 13 de marzo de $1909^{4}$. Almaraz no escribió ningún preámbulo a modo de introducción a las medidas que venía a proponer, en el que comunicara su visión y concepción de la reforma, o apelara en un tono pastoral a la voluntad y deber de sus diocesanos en secundar los proyectos del papa como hiciera Spínola. El prelado salmantino, por el contrario, fue mucho más escueto. Para trasladar su posición frente a la reforma se limitó a manifestar: "[Nuestro Venerable Predecesor] Adoptó prudentísimas disposiciones, y a Nos solamente nos corresponde el hacer que aquellas se cumplan" Esta declaración revela, en primer lugar, que la línea que caracterizó la etapa conducida por Almaraz fue pretendidamente continuista ${ }^{6}$; y en segundo lugar, que las directrices dictadas por Spínola seguían sin cumplirse. El siguiente pasaje confirma esta aseveración:

Después de celebrado con tanta solemnidad el segundo Congreso de Música Sagrada en esta ciudad de Sevilla, y cuando en la Santa Iglesia Catedral se ha comenzado a poner en ejecución lo prescrito y mandado por el Papa, no hay ya razón ni pretexto siquiera para que continúen las cosas como hasta aquí. ${ }^{7}$

Para acercarnos a la idea que sobre la música sagrada y la reforma tenía Almaraz, nos puede servir el discurso que pronunció con motivo de la clausura del congreso de Sevilla. Almaraz ubicó el MP como la primera acción de Pío X dentro del programa restaurador que trataría de desplegar durante su pontificado, sintetizado en el lema Instaurare omnia in Christo:

${ }^{4}$ Enrique [Almaraz], Arzobispo de Sevilla, "Circular no 18 sobre Música Sagrada", BOAS, 661 (1909), pp. 248-252. Véase la relación de circulares relacionadas con el proceso de reformas publicadas en el $B O A S$ en Apéndice 2.

${ }^{5}$.Las primeras palabras de esta circular están dedicadas a Spínola y a alabar su labor en lo que a la reforma se refiere: "No descuidó Nuestro Venerable Predecesor el dar cumplimiento a las disposiciones del Romano Pontífice acerca de la reforma del canto litúrgico en la Iglesia. Las hermosas circulares que publicó, y que se conservan en el BOLETÍN ECLESIÁSTICO [sic], buena prueba son del interés y celo con que procuró dicha reforma en esta Diócesis de Sevilla.” Ibídem, p. 248.

${ }^{6}$ Javierre describe las líneas maestras de su programa pastoral: "propaganda católica; lucha frente al anticlericalismo; acción social; participación política", y sugiere igualmente el carácter continuista en términos generales respecto al pontificado de Spínola: "Líneas que coinciden con el tronco del trabajo realizado por Spínola". Javierre, "La diócesis de Sevilla", p. 370.

${ }^{7}$ Enrique [Almaraz], “Circular no 18”, pp. 248-249. 
Restaurar todas las cosas en Cristo; todas, es decir, el hombre, la familia, los pueblos, la sociedad, las ciencias, las letras, las artes $[\ldots]$

Natural y lógico era que al comenzar Pío X su Pontificado, después de haber expuesto solemnemente, lo que en él se proponía, fijase primeramente su mirada en el Santuario, [...] para restaurar en él todo aquello que por la natural condición de las cosas humanas, hubiera perdido o siquiera desvirtuado el sello de nobleza, de modestia y de piedad que conviene a la casa de Dios [...]. El canto de nuestros templos, se había dejado inficcionar más o menos con aires profanos, y a esto obedeció el célebre Motu proprio de 22 de Noviembre de $1903 .^{8}$

El principal valor que para Almaraz tenía la doctrina sobre música sagrada contenida en el MP residía en tener como objetivo la participación activa de los fieles en la liturgia a través del canto sagrado. Con ello, se restauraba un ideal litúrgico, según entendía, que se remontaba a una época de especial devoción e intensidad espiritual, los tiempos de San Gregorio o San Ambrosio:

en las vigilias de los Santos y en las fiestas principales de la Iglesia, pasaban la mayor parte de la noche en los templos del Señor, ocupados en cantar las Divinas alabanzas y en escuchar las magníficas y preciosas homilías que sobre el Evangelio predicaban aquellos Santos Padres $[\ldots]^{9}$

Una intensidad espiritual que había podido experimentar personalmente. Con especial emoción expresaba la impresión que le produjo escuchar a comunidades de peregrinos entonar juntos cantos sagrados durante sus visitas a Jerusalén y Lourdes. Respecto a esta última, realizada ya como arzobispo de Sevilla, señaló:

De 30 a 40.000 peregrinos coincidían con nosotros en aquel pedazo de cielo, que está en la tierra y se llama Lourdes. Preguntad a los 300 sevillanos la impresión que les causó aquella inmensa muchedumbre, que, con el mayor sentimiento, con uniformidad pasmosa, y sin que hubiera director de orquesta, cual adiestrada masa coral, cantaba el Credo en latín, al terminar la procesión de las antorchas, cantaba el Pange Lingua, y el Tantum ergo y Genitori en la exposición, procesión y reserva del Santísimo Sacramento; cantaba el Parce Domine, después de escuchar los sermones, que excitaban a la Penitencia, cantaba el Magnificat a la Virgen Santísima, cantaba el

\footnotetext{
8 "Discurso de clausura por el Excmo. y Rvmo. Sr. Dr. D. Enrique Almaraz y Santos, Arzobispo de Sevilla", Crónica del Segundo Congreso, p. 144.

${ }^{9}$ Ibídem, p. 146.
} 
Benedictus y el Laudate en otros actos de devoción, pero de modo tan sublime y con tonos tan majestuosos, que parecían imponer respeto y recogimiento a las excelsas cumbres de los Pirineos. [...] Esta sí que es oración fervorosa, $[\ldots]$ sostenida por la esperanza y confortada con la caridad y con el amor, del cual son fruto las melódicas y armónicas notas musicales, como son las saetas que en Sevilla se ofrecen a Cristo Crucificado y a la Virgen Dolorosa en los días de Semana Santa. ${ }^{10}$

Esta imagen de una Iglesia unida y fervorosa que canta "melódicas y armónicas notas" fruto del amor representaba el ideal de Almaraz. La música sagrada era para el nuevo arzobispo hispalense un canto colectivo que, restituidas sus virtudes de "nobleza, modestia y piedad", era capaz de reanimar en el seno de la liturgia el auténtico espíritu cristiano como primer paso para la restauración de la sociedad en todos los órdenes.

Las consignas que Almaraz lanzó al grueso de congresistas reunidos en Sevilla antes de partir a sus lugares de origen fueron: conceder "a este asunto toda la importancia y significación” y "trabajar con empeño" hasta conseguir los objetivos. Se podrían considerar, por tanto, como una síntesis de la posición con la que enfrentó el reto de la reforma en su nueva Sede:

Yo desearía, y conmigo lo desean todos los Prelados españoles, que, concediendo a este asunto toda la importancia y significación que tiene, se procurara de hoy en adelante trabajar con empeño, hasta conseguir que en Catedrales y en Parroquias, en Conventos y en Santuarios y en todas partes donde a Dios se dé culto externo, tenga el canto litúrgico el aire de piedad y devoción, el sentimiento cristiano, que es el que únicamente excita en nosotros ideas y pensamientos de lo divino y celestial, para cuya vida hemos sido criados. ${ }^{11}$

Durante su estancia en la capital andaluza en agosto de 1908, Otaño aludió al firme compromiso de Almaraz con la reforma, al tiempo que ponía en evidencia la resistencia que hasta ese momento había encontrado en Sevilla, según le había mostrado Vicente Ripollés:

Puede ser que nuestra labor sea tan titánica como esa otra del saneamiento de la moneda: por de pronto yo le puedo asegurar a $\mathrm{V}$. que hay por nuestro arte muchos, muchísimos duros (de cabeza) y que sobre todo abundan los sevillanos, bien me lo ha probado el buen

\footnotetext{
${ }^{10}$ Ibídem, p. 147.

${ }^{11}$ Ibídem, p. 145.
} 
amigo, nuestro D. Vicente Ripollés, que es aquí un lirio entre espinas. Pero el Sr. Arzobispo es un hombre de gran fe: se ha metido en la danza con tanto afán como el de Valladolid [Cos y Macho] y así....algo se hace. ${ }^{12}$

Ripollés, por su parte, en la carta que escribió a Pedrell a finales de octubre de 1907, además de comunicarle el nulo progreso de la reforma en Sevilla, expresaba sus expectativas sobre Almaraz: "En lo demás [la reforma] nada hemos hecho; pero espero que algo haremos si contamos con benevolencia y apoyo del nuevo arzobispo"13. Sin embargo, en otra misiva de apenas mes y medio después, se percibe un cierto desencanto con el prelado y su equipo:

Terminamos ayer las tareas de la octava de Concepción con sus obligados bailes de seises, y hoy algo más libre copio lo que V. pide del Lazarillo, y le dedico estos renglones.

De Reformas estamos a la misma altura y según voy viendo por la calma que todos aquí gastan, y por las aficiones que muestran en Palacio a las cosas de los seises, preveo que no adelantaremos gran cosa y que en la gente nueva hay mucha fachada, pero poca decisión para ir por el camino de la verdad. En el Seminario, base de toda reforma, continúan sin profesor ni clase de gregoriano; $[\ldots]^{14}$

Al margen de las opiniones de Otaño y Ripollés, o del pronunciamiento del propio Almaraz en su discurso, informaciones valiosas, sin duda, a tener en cuenta, iniciamos, a continuación, el análisis de la gestión de la reforma desarrollada por el prelado salmantino en Sevilla. El cuerpo normativo de la primera circular de Almaraz sobre música sagrada está compuesto por seis disposiciones de carácter general con pocas novedades. La naturaleza continuista, que, como decimos, caracterizó la posición del nuevo arzobispo, predomina en el escrito. De hecho, tras cada uno los puntos de los que estaba compuesto se insertó lo que sobre el particular había dispuesto Spínola ${ }^{15}$. El

\footnotetext{
${ }^{12}$ Carta de Otaño a Pedrell, 29 de agosto de 1908. BC. FFP. M 964 O.

${ }^{13}$ Carta de Ripollés a Pedrell, 29 de octubre de 1907. BC. FFP. M 964 R.

${ }^{14}$ Carta de Ripollés a Pedrell, 16 de diciembre de 1907. BC. FFP. M 964 R.

${ }^{15}$ Por ejemplo, la primera de las disposiciones de Almaraz establecía: "1. a Los Sres. Curas Párrocos y Rectores de Iglesias no permitirán el uso de orquestas en sus respectivos templos, sin obtener o exigir, según los casos, el permiso de la Autoridad eclesiástica. Además de estar así preceptuado en el Caerem. Episcop. y en el Motu Proprio VI. 15, véase lo que sobre el particular mandó el Sr. Spínola.

[y a continuación con tamaño de letra más pequeño lo dispuesto por su antecesor:] La Comisión que entiende en los asuntos relativos a la Música Sagrada nos ha llamado la atención sobre dos puntos que juzga interesantes.
} 
tercero de ellos, además, estaba dedicado exclusivamente a apelar al cumplimiento de un buen número de las medidas propuestas por el difunto cardenal ${ }^{16}$.

Por tanto, el objetivo de Almaraz con esta comunicación no fue más que volver a sentar los principios básicos de la reforma, así como recuperar para su aplicación definitiva el proyecto planteado durante el pontificado anterior. Las novedades aportadas por el nuevo metropolitano hispalense se redujeron, por un lado, a un cambio de actitud ante los administradores de templos -párrocos y rectores de iglesias-, a los que todas las pruebas apuntaban como los principales responsables del fracaso de la reforma durante la etapa de Spínola; y, por otro, a la propuesta de un procedimiento para llevar a cabo la depuración del repertorio musical religioso, a cuyo análisis nos dedicaremos más adelante. Respecto a la primera, resulta sintomático que centrara en primer lugar la atención, tras alabar el trabajo realizado por Spínola, en el colectivo de responsables eclesiásticos para apelar a su colaboración en términos no exentos de una severidad ausente en el tono empleado por su antecesor:

Es, pues, necesario, que los Sres. Párrocos, Rectores de Iglesias y Comunidades religiosas, presten la atención debida a lo que con tanto encarecimiento ordena la Iglesia; pues de lo contrario, sería la resistencia pasiva un acto muy cercano a la rebeldía y desobediencia. $^{17}$

El primero es el general olvido en que se tiene el mandato de Su Santidad sobre el uso de orquestas en las funciones solemnes, pues sin los debidos permisos y sin sujetarse a los preceptos pontificios acerca de las composiciones que según el Motu Proprio de Su Santidad pueden ejecutarse en la Iglesia, se las ve tomar parte en dichos actos religiosos con harta frecuencia.

El segundo es la necesidad de que se prohíban en absoluto la Misa pastorela del maestro García u la Eucarística de Arquimbau, porque ni uno [sic] ni otra se ajustan a las disposiciones del Papa sobre la materia.

En su virtud recordamos a los Curas y Rectores de Iglesia lo dispuesto sobre ambos particulares, y les encargamos con el mayor encarecimiento cuiden de evitar las infracciones, que se nos denuncian, de lo prescrito. [y nota a pie de página con la referencia al BOAS en el que se publicó estas disposiciones]". Enrique [Almaraz], “Circular n' 18”, p. 249.

16 “3. ${ }^{\circ}$ Encarecemos el exacto cumplimiento de las disposiciones adoptadas por Nuestro Venerable Predecesor sobre los siguientes puntos:". A continuación se transcriben un total cinco preceptos dispuestos por Spínola: la prohibición sobre los instrumentos fragosos, sobre la utilización de obras en castellano, sobre obras profanas, sobre la participación de las mujeres en el canto, y, por último, la creación de la CDMS y sus competencias. Ibídem, pp. 250-251.

${ }^{17}$ Ibídem, p. 248. 


\section{La reconstituida Comisión Diocesana de Música Sagrada}

Como conclusión de esta primera circular, Almaraz, al igual que hiciera Spínola, dio a conocer los miembros de su nueva -reconstituida- Comisión Diocesana de Música Sagrada. Sus atribuciones fueron las mismas que las otorgadas por Spínola. Almaraz, de hecho, reprodujo literalmente las disposiciones en las que el arzobispo andaluz delegó aquellas importantes competencias a las que nos referimos en el capítulo anterior $^{18}$. La composición de la nueva CDMS quedó como sigue:

Presidente: Rafael González Merchant, canónigo catedralicio.

Vicepresidente: Jerónimo Armario, canónigo.

Secretario: Manuel Lerdo de Tejada, organista de la Real Capilla de San Fernando.

Vocales: Vicente Ripollés, maestro de capilla.

Bernardo Salas, organista de la Catedral.

Agapito Insausti, tenor de la capilla catedralicia.

José Otero, bajo de la misma.

Manuel Camacho, maestro de ceremonias de la Catedral.

José $\mathrm{M}^{\mathrm{a}}$ Molina, cura de San Pedro y San Juan.

El perfil de la comisión de Almaraz no cambió respecto a la anterior: los puestos relevantes fueron ocupados por canónigos, y las vocalías por músicos catedralicios, excepto la cubierta por el cura de la parroquia de San Pedro y San Juan de la ciudad. La representatividad se redujo, también en esta, a los límites de la capital, especialmente al templo metropolitano. Las diferencias o novedades son de menor importancia, aunque nos permiten aportar algunas reflexiones, a nuestro juicio, de interés. Nos llaman la atención las ausencias del chantre, que había ejercido de presidente durante la etapa de Spínola, y del sochantre catedralicio.

El relevo en la presidencia de Santiago Fernández, chantre, por Rafael González Merchant, canónigo, refleja que, también en el caso de Sevilla, el paso del tiempo había vaciado de contenido la chantría como dignidad en la que descansaba de manera especial el gobierno de los asuntos relativos al canto y música litúrgicos. González Merchant será, a partir de este momento, el gran referente musical dentro del colectivo constituido por la alta jerarquía diocesana. Se podría afirmar que fue él quien ejerció de verdadero chantre, según el cometido que históricamente había caracterizado

\footnotetext{
${ }^{18}$ Ibídem. p. 251.
} 
el cargo ${ }^{19}$. Este canónigo nacido en Carmona fue designado, además, para ocupar la presidencia de la Junta Organizadora del II Congreso Nacional de Música Sagrada; y fue el encargado de cualquier asunto que tuviera que ver con la música en la Catedral, tal y como testimonian las actas capitulares ${ }^{20}$.

La no inclusión del sochantre catedralicio -con el que sí había contado Spínolacomo principal autoridad técnica en lo que al canto llano se refiere, constituye una ausencia especialmente significativa por producirse una vez que habían sido publicadas

${ }^{19}$ Simón de la Rosa describe a partir de datos extraídos de las Constituciones de la Catedral, los deberes y atribuciones del chantre en el caso hispalense: "ejercía jurisdicción, en nombre del Deán y Cabildo eclesiástico, sobre el personal dedicado a las funciones del coro, sobre cantores y ministriles, ya directamente por sí, ya por medio de su lugarteniente denominado el sochantre.

Además de comenzar todos los cantos en el coro, el Chantre daba las veintenas, nombraba y separaba los mozos del mismo, era quien certificaba de su condición para el goce de los privilegios de la Iglesia y, como juez privativo, conocía de sus pleitos civiles, así como de los promovidos entre los veinteneros". Simón de la Rosa y López, Los seises de la catedral de Sevilla. Ensayo de investigación histórica (Sevilla: Imp. de Francisco de P. Díaz, 1904), p. 35.

${ }^{20}$ Sobre la vida y obra de Rafael González Merchant, uno de los personajes clave de la reforma en la Archidiócesis, nos proporcionan contados aunque interesantes datos dos obras históricas relevantes como son Biblioteca de autores andaluces modernos y contemporáneos, del polígrafo almeriense Francisco Cuenca, y Diccionario de escritores, maestros y oradores naturales de Sevilla y su actual provincia, de Mario Méndez Bejarano. Según estas fuentes, González Merchant nació en Carmona el 9 de junio de 1867, y cursó la carrera eclesiástica en el seminario de Sevilla, opositando tras su ordenación sacerdotal a una canonjía de la Catedral. Adquirió celebridad como orador y escritor, lo que le llevó a ser elegido miembro de la Real Academia Hispalense de Buenas Letras. Entre sus obras destacan sermones y publicaciones como Panegírico del Santísimo Cristo del Amor. Sermón predicado en Sevilla en 1902; Revolución y cristianismo. Conferencias predicadas en el solemne novenario de Nuestra Señora de Gracia, patrona de Carmona, año de 1902; El conflicto social. Sevilla: El Correo de Andalucía, 1903; Panegírico de San Agustín, Obispo de Hipona. Sermón predicado en la basílica del Real Monasterio de El Escorial el año 1904; La verdadera civilización. (Sevilla: Tip. Agapito López, 1906); Las Siete Palabras de Nuestro Señor Jesucristo en la Cruz. Sermón predicado en la Real Capilla de Palacio por su autor (tarde del Viernes Santo en 1906); El gerundianismo. Discurso en la Academia de Buenas Letras. Contestación de Luis Montoto y Rautenstrauch. (Sevilla: Imprenta Izquierdo, 1907); Discurso necrológico que a la memoria de don Servando Arboli y Faraudo leyó en la solemne sesión celebrada por la Real Academia de Buenas Letras el 29 de junio de 1908; Oración fúnebre en honor del excelentísimo Señor Don Marcelino Menéndez Pelayo, predicada por acuerdo de la Real Academia Hispalense de Buenas Letras. (Sevilla: [s.e.], 1912). Francisco Cuenca Benet, Biblioteca de autores andaluces modernos y contemporáneos. (La Habana: [s.n.], 1921-1925), vol. II, p. 160; Mario Méndez Bejarano, Diccionario de escritores, maestros y oradores naturales de Sevilla y su actual provincia. Tomo I (Sevilla: Tipografía Gironés, 1922), p. 272. En la actualidad, hay una calle en Carmona con su nombre. Además, hemos podido saber, por diferentes fuentes, que tuvo formación musical. Ripollés le llamaría "el canónigo del clarinete" en sendas cartas a Pedrell (Cartas de Ripollés a Pedrell, 17 de octubre de 1908 y 8 de febrero de 1909. BC. FFP. M 964 R). Villalba refería en uno de sus artículos sobre el congreso de Sevilla: "Y no te vayas a creer que el orador es un profano en el arte, no; de buena tinta sé yo que ha compuesto sus cosas, y yo escuché una de ellas en el mismo Sevilla." Luis Villalba Muñoz, "El Segundo Congreso Nacional de Música Sagrada de Sevilla”, LCD, 78 (1908), p. 496. José Manuel Delgado Rodríguez ha publicado una de sus composiciones en: "Las coplas a San Teodomiro, Patrón de Carmona”, Carel. Carmona. Revista de estudios locales, 2 (2004), pp. 350-402. Incluye una grabación de la obra por la Capella Clásica Hispalense bajo la dirección del autor del artículo. En el archivo musical de la catedral de Sevilla se conserva un cuadernillo compuesto de varias obras de distintos autores (Rinck, Palestrina, Bach, Winter y Mozart) que forman un juego del ordinario de la misa, recopiladas por González Merchant: ACS. Archivo de la Capilla Musical, sign. 99-1-1. 
las ediciones típicas vaticanas del kyrial y gradual ${ }^{21}$; es decir, cuando por fin se disponía de los libros litúrgico-musicales oficiales para la reforma del canto gregoriano. Este objetivo fue, además, prioritario, incluso urgente para la Comisión, como se demostrará a continuación.

Manuel Lerdo de Tejada debió de ser otro de los comisionados relevantes, junto a Ripollés y al ya veterano alumno de Eslava, Agapito Insausti, quien había ejercido interinamente la función de maestro de capilla entre la muerte de Evaristo García Torres (diciembre de 1902), y la llegada de Ripollés (junio de 1903) ${ }^{22}$. Estos tres fueron los únicos músicos que formaron parte de la CDMS desde su constitución por Spínola en 1904. La condición de seglar de Lerdo de Tejada, el único del total de los quince miembros que en un momento u otro llegaron a componer la CDMS, hace aún más significativo el hecho de que tanto Spínola como Almaraz depositaran su confianza en él.

Con todo, fue el tándem Ripollés-González Merchant el motor de la reforma durante esta nueva etapa. Una de las primeras decisiones del nuevo arzobispo fue delegar en el castellonense todos sus poderes respecto a la música sagrada. Así se lo confesaba Ripollés a Pedrell sólo catorce días después de la llegada del prelado a Sevilla: "El Sr. Arzobispo me llamó para darme todas sus facultades en materia de Música religiosa."23 El maestro de capilla, por su parte, se refirió a González Merchant tras la celebración del Congreso como una gran "adquisición"24. Más adelante

${ }^{21}$ El Kyriale seu ordinarium missae y el Graduale sacrosanctae romanae ecclesiae datan de 1905 y 1908, respectivamente. Junto al Antiphonale sacrosanctae romanae ecclesiae (1912) constituyen los productos últimos de la larga y no exenta de polémicas historia de restauración del canto gregoriano que se desarrolló especialmente durante la segunda mitad del siglo XIX, y culminó con la definitiva asunción por parte de la Santa Sede de las propuestas planteadas por los monjes del monasterio de Solesmes. Para profundizar en este tema véase, entre otros: Fernández de la Cuesta, "La reforma del canto gregoriano", pp. 45-74; Schnorr, "El cambio de la edición oficial del canto gregoriano”, pp. 197-209.

${ }^{22}$ Sobre Evaristo García Torres, véase: Virginia Borrero Gaviño y Manuel Martín Riego, "Don Evaristo García Torres, maestro de capilla de la catedral de Sevilla (1864-1902)", Memoria ecclesiae (Actas del XXI Congreso de la Asociación de archiveros de la Iglesia en España), 31 (2008), ed. por Agustín Hevia Ballina, pp. 697-712; Mauricio Carrillo Cabeza, "Evaristo García Torres. Oposición al Magisterio de Capilla de la Catedral de Sevilla, 1864: una aproximación estilística a través de sus misas", Anuario de Historia de la Iglesia andaluza, IV (2011), pp. 273-300.

${ }^{23}$ Carta de Ripollés a Pedrell, 29 de octubre de 1907. BC. FFP. M 964 R.

${ }^{24}$ Carta de Ripollés a Pedrell, 8 de febrero de 1909. BC. FFP. M 964 R. Sobre la importancia de González Merchant en la reforma tras la celebración del congreso de Sevilla, véase capítulo 5, epígrafe 5.2. "El fracaso institucional", pp. 489-490. 
tendremos ocasión de comprobar el crucial papel que jugaron cada uno de ellos tanto en la Catedral como en el Congreso.

Una vez fijado con claridad el punto de partida, restablecidos los principios fundamentales, y recuperada la labor emprendida por Spínola, se acometió la tarea de regeneración de las estructuras con medidas concretas y prácticas. Como ocurriera durante la etapa anterior, la encargada de desarrollarla fue la CDMS.

\section{Concreción en el ámbito diocesano de la normativa papal: el plan de reformas desarrollado por la Comisión Diocesana de Música Sagrada (II)}

Nos proponemos a continuación, al igual que hiciéramos durante el pontificado de Spínola, analizar el conjunto de medidas y propuestas que constituyeron el plan desplegado por la recién reconstituida CDMS para el cumplimiento del $M P$ en la archidiócesis hispalense. Con ello perseguimos nuestro objetivo de estudiar la recepción, gestión y aplicación del proyecto de renovación litúrgico-musical propuesto desde Roma por parte de la administración archidiócesana de Sevilla, esta vez durante el pontificado de Enrique Almaraz. En síntesis, la situación de partida en la que se enmarca este plan, descrita en las páginas anteriores, se caracterizó por: un largo periodo de suspensión del proceso que había desactivado e inutilizado el trabajo hecho durante la etapa de Spínola; una indiferente recepción por parte párrocos, responsables de templos y comunidades que hizo fracasar el primer intento de reforma; la celebración del II Congreso Nacional de Música Sagrada que congregó a cientos de músicos y autoridades eclesiásticas de todo el país; y por último, la línea pretendidamente continuista con la seguida por Spínola adoptada por el nuevo arzobispo.

El paquete de medidas ideado por la CMDS fue dado a conocer entre marzo y julio de 1909, en un total de cinco documentos. Entre ellos destaca la exposición de medios propuesta al arzobispo a principios de mayo y publicada el 1 de junio, pues contenía el grueso de las disposiciones que constituyeron el nuevo plan reformista. El pasaje con el que concluye el párrafo introductorio al listado de propuestas es una declaración de intenciones que nos descubre otra de las claves que caracterizaron este periodo:

Celosa esta Comisión nombrada por S.E.R. del cumplimiento de la honrosa misión que se le ha confiado, y procurando con el mayor interés que la restauración de la Música Sagrada mandada por Ntro. Smo. Padre el Papa Pío X y tan sabia y oportunamente perseguida por 
V. E. R. sea un hecho en esta Archidiócesis a la mayor brevedad posible [el subrayado es nuestro], ha acordado elevar a V.E.R. esta exposición comprensiva de los medios que, después de maduro y detenido examen, ha juzgado necesarios [...]". ${ }^{25}$

Es la primera vez que se establecía un plazo temporal para consecución de la reforma $\mathrm{y}$, aunque de duración inespecífica, debía ser corto. Esto apunta a la determinación con la que la Comisión de Almaraz abordó este nuevo intento de aplicación del $M P$ que entendería como el definitivo, sin más dilación ni interrupciones. De hecho, los trabajos de la Comisión se prolongaron durante apenas un año más, tras el cual apareció el Reglamento de Música Sagrada para la Archidiócesis de Sevilla, que constituyó al mismo tiempo, el producto acabado y definitivo del proceso y su punto final $^{26}$.

La urgencia en la consumación de la reforma que caracterizó esta nueva etapa representó otra importante diferencia respecto al concepto de Spínola. Recordemos que el cardenal andaluz advirtió de la gran dificultad que suponía la reforma; en consecuencia, presentaba como las actitudes idóneas para afrontarla la "discreción y prudencia exquisitas" y una "perseverancia incontrastable" 27.

Como demuestra el comienzo de uno de los fragmentos de la circular de Almaraz transcrito más arriba, la experiencia del recién clausurado Congreso espoleó tanto a la Comisión como al prelado, quienes, como contraste del escenario ideal que recreó esta gran asamblea, valoraron negativamente la situación de la Archidiócesis tras los frustrados esfuerzos de la etapa de Spínola. Al margen de las diferencias de carácter y talante que pudieran existir entre este y Almaraz, es posible que tanto el nuevo arzobispo como su Comisión consideraran llegado el momento de sustituir la exquisita diplomacia de Spínola por una mayor rectitud; y la perseverancia como actitud dentro un proyecto a medio plazo por el apremio en el logro de unos resultados que tras cinco años habían sido escasos.

Las medidas planteadas por la Comisión evidencian que su objetivo fue actuar de forma preferente, por un lado, sobre el repertorio vigente, y por otro, sobre los

\footnotetext{
${ }^{25}$ La Comisión, "Música Sagrada” [en índice del tomo figura como: "Exposición a Ntro. Excmo. Prelado sobre Música Sagrada y Circular sobre el mismo punto”], BOAS, 667 (1909), p. 393.

${ }^{26}$ Véase capítulo 2, epígrafe 5. "La culminación del proceso normativo: El Reglamento de Música Sagrada para la Archidiócesis de Sevilla (1910)", p. 164.

${ }^{27}$ Marcelo, “Circular sobre la música sagrada”, BOAS, 536 (1904), p. 116.
} 
recursos humanos: administradores de templos y músicos eclesiásticos. Representaron nuevas medidas para objetivos aún incumplidos ${ }^{28}$. En esta ocasión el nivel de concreción fue mucho mayor que en la etapa de Spínola. La presentación de una determinada medida iba acompañada de una detallada descripción del procedimiento para su aplicación. Sin duda, la experiencia acumulada durante este tiempo ayudó en el discernimiento y plasmación en función de la realidad de esas disposiciones.

Organizaremos nuestro análisis, de acuerdo a estas dos grandes líneas de actuación, en dos grandes bloques: repertorio, y agentes diocesanos. Dentro del primero diferenciaremos entre el canto gregoriano y la música figurada. En el segundo, estudiaremos la estrategia de la Comisión, centrada en la regulación de los oficios musicales religiosos por un lado, y, por otro, en la orientación, y en cierto sentido, reconducción del papel de los que venimos denominando "administradores de templos", es decir, responsables eclesiásticos como párrocos, rectores de templos o responsables de comunidades religiosas, hermandades, asociaciones religiosas.

\subsection{Repertorio litúrgico-musical diocesano}

\subsubsection{Canto gregoriano: la adopción de las ediciones típicas vaticanas}

Más arriba hemos tratado de trasladar una idea de la importancia que el gregoriano tuvo dentro de la doctrina inspiradora del $M P$ no sólo como modelo de música litúrgica sino también como ideal estético. Señalábamos que, dado que el éxito de la reforma dependía en gran medida, además de su restauración, de la imposición como criterio de juicio artístico la cercanía a los valores que poseía y simbolizaba, durante la etapa de Spínola se siguió una estrategia regeneracionista basada en la inculcación de sus nuevos principios estéticos. La finalidad fue crear una nueva "escuela" de responsables y músicos eclesiásticos que los encarnara y difundiera por doquier desde sus cargos y responsabilidades ${ }^{29}$. Para formar a las nuevas generaciones

\footnotetext{
${ }^{28}$ Dado que estos ya habían merecido una gran parte de la atención de la Comisión durante el pontificado de Spínola en forma de un considerable número de disposiciones, la necesidad de volver a concentrar en ellos los esfuerzos confirman una vez más que la reforma en estos puntos fue un fracaso. Ángel Medina afirma que "este proceso de expurgo duró bastantes años y que, aún en fechas muy lejanas al Motu Proprio continuaba analizándose el patrimonio musical de un archivo en función de las premisas recogidas en el famoso texto papal." Como ejemplo pone el caso de la catedral de Granada, en la que parece que su maestro de capilla, Valentín Ruíz-Aznar fue especialmente riguroso. Medina, "La música en el templo", pp. 37-38.
}

\footnotetext{
${ }^{29}$ Véase capítulo 1, p. 97.
} 
se necesitaba unas estructuras básicas. Se optó por aprovechar las existentes como el Seminario, y en el caso particular de Sevilla se intentó, además, erigir otras complementarias como la Escuela Archidiocesana de Canto Gregoriano.

En esta ocasión, la Comisión centró su atención únicamente en la imposición inmediata de las ediciones típicas vaticanas del kyrial y el gradual en las iglesias de la Archidiócesis, un objetivo mucho más concreto y a muy corto plazo. La consideración de este objetivo como prioritario se justificó en el párrafo introductorio de la exposición de medios presentada al prelado como nuevo plan de reformas. En dicho párrafo, la Comisión expresó su estimación de la situación del canto llano en la Diócesis como intolerable en lo que a la misa se refiere ${ }^{30}$. El motivo de tal juicio fue que seguían en uso los cantorales que, tras el Decreto de la Sagrada Congregación de Ritos ( 7 de agosto de 1907) que imponía la nueva edición típica vaticana, debían haber quedado obsoletos $^{31}$.

Por tanto, el proyecto regeneracionista a medio plazo fue arrinconado en beneficio de lo urgente. El plan para la reforma del canto gregoriano, reducido a cuatro medidas muy específicas, desatendió absolutamente todo lo que tenía que ver con la formación y educación de los agentes diocesanos que debían obrar sobre el terreno la transformación de la realidad litúrgico-musical en base a los principios gregorianos. La enseñanza del canto litúrgico en el Seminario, que, como hemos visto, fue el centro que terminó acogiéndola en exclusiva, no mereció una sola disposición. Esta despreocupación podría estar justificada si el sistema implantado funcionara a la perfección y cumpliera con todas las expectativas. Sabemos que la clase de canto gregoriano del Seminario mereció la atención prioritaria de Almaraz desde su llegada a Sevilla en octubre de 1907. Ripollés contaba a Pedrell los pormenores de la reunión que había mantenido con el arzobispo a los pocos días de su toma de posesión, entre ellos, los nuevos planes para la reactivación de dicha clase. El prelado había pensado, al

\footnotetext{
${ }^{30}$ Para el caso del oficio, como hemos dicho, no se contaría con la edición típica vaticana del Antifonal hasta 1912.

31 “Teniendo en cuenta las terminantes palabras con que la S. C. de Ritos impone la 'Edición Vaticana del Gradual y Kyrial' como única típica, auténtica y obligatoria, por su Decreto de 7 de Agosto de 1907, [...] esta Comisión entiende que no puede tolerarse ya por más tiempo el uso de los cantorales o libros de coro hoy existentes en las Iglesias del Arzobispado, en lo que al Canto de la Santa Misa se refiere, debiendo adoptarse inmediatamente en todas la 'Edición Vaticana', [...]" La Comisión, "Música Sagrada", pp. 393-394.
} 
igual que había hecho Cos y Macho en Valladolid y se haría en otras diócesis ${ }^{32}$, contar con las enseñanzas de algún monje benedictino, en principio, del monasterio de Silos. No obstante, las preferencias de Ripollés, en quien había confiado la decisión, estaban del lado de los catalanes de Montserrat y Parramon (diócesis de Urgel) ${ }^{33}$ :

Desde luego le hablé de la clase del Seminario y quedéme sorprendido cuando me dijo que él tenía sus compromisos con los PP. de Silos, pero que conociendo mi predilección por los de Cataluña, él descansaba completamente en mí y dejaba el asunto en mis manos. Después de mis declaraciones de que yo no había de recibir mal a los PP. de Silos, pero que tenía el convencimiento de la mejor aptitud de los PP. catalanes, y ante la insistencia del Prelado en dejarlo a mi decisión, le presenté al P. Mauro de Parramon y al P. Suñol para que él escogiera, dejando la definitiva para una reunión que tendremos el Rector del Seminario y yo con el Prelado. Cuando esta reunión llegue yo pienso recomendar con preferencia al P. Mauro por creerlo más profundamente gregorianista, y en último caso al P. Suñol. Le parece a V. acertada mi propuesta? Si no lo creyera V. así, escriba V. pues aún es hora de rectificar. Estoy muy satisfecho pues la cuestión que yo tenía me la dio resue[1] ta el mismo Prelado con sus indicaciones. ${ }^{34}$

Sin embargo, la falta de más referencias a la venida de estos gregorianistas

hasta octubre de 1908 unida a este otro testimonio de Ripollés, que data de mes y medio después, apuntan a que la idea no se debió hacer realidad ${ }^{35}$ : "De reformas estamos a la

${ }^{32}$ Fue una iniciativa de muchas diócesis que el prelado o el cabildo catedralicio invitaran a algún monje de reconocido prestigio, o bien del monasterio de Silos o bien de algún monasterio catalán como Montserrat o Besalú, para que impartiera clases tanto a los músicos religiosos como al común del clero sobre canto gregoriano restaurado. En el caso del obispado de Oviedo, el obispo Baztán invitó al discípulo de Casiano Rojo en Silos, Carlos Azcárate. Sanhuesa, "Resonancias del Motu Proprio", pp. 197-199. En Valladolid fueron dos benedictinos, uno de ellos Casiano Rojo, los encargados de dicha tarea. En el caso de Jaén, el monje del monasterio de Besalú, Mauro Sablayrolles. Medina, "La música en el templo", p. 30. A Valencia acudieron dos padres benedictinos venidos del propio Solesmes. José Climent, La Catedral de Valencia, pp. 18-19. En MSH se refiere la intensa labor que desarrolló Mauro Sablayrolles en Murcia, en donde implantó el sistema rítmico de Mocquereau: "Su Excmo. Prelado de acuerdo con la Comisión Diocesana, invitó al Rvdo. P. Mauro Sablayrolles, para que con su autoridad de sabio gregorianista, fuera el encargado de iniciar en esta Diócesis, la Reforma [...]. Clase en el Seminario para los jóvenes alumnos, Conferencias prácticas para el Clero en la Capilla del Palacio Episcopal, y Coro de la Catedral; Conferencias teórico-prácticas para los Organistas y Cantores parroquiales; y hasta visitas de instrucción gregoriana a las Comunidades Religiosas. [...], empezó los ensayos de la Misa de Ángeles a los doscientos jóvenes Seminaristas que componen el plantel Fulgentino de esta Ciudad.”. A. L., “Crónica. 'El Canto Gregoriano en Murcia", MSH, 10 (1908), p. 45.

${ }^{33}$ En 1908 la comunidad benedictina procedente de Francia instalada provisionalmente en Parramon se estableció en Besalú.

${ }^{34}$ Carta de Ripollés a Pedrell, 29 de octubre de 1907. BC. FFP. M 964 R.

35 José López-Calo da por cierto que, no uno de ellos, sino los dos benedictinos catalanes estuvieron en Sevilla durante el curso 1907/08; véase Nemesio Otaño, S.J., pp. 54-55. Según nuestras fuentes, sólo acudió a Sevilla Gregorio $\mathrm{M}^{\mathrm{a}}$ Suñol, para impartir unas clases que sirvieran de preparación al clero y 
misma altura. En el Seminario, base de toda reforma, continúan sin profesor ni clase de gregoriano." ${ }^{36}$ Ninguna referencia más hemos encontrado desde entonces al asunto, salvo la información que proporciona el profesor Martín Riego sobre el tiempo en el que Agapito Insausti, tenor de la capilla de la Catedral, ejerció como profesor de canto eclesiástico: 1887-1909 ${ }^{37}$. La situación de la clase de canto gregoriano del Seminario, tal y como es descrita por Ripollés, contrasta con el reconocimiento público que mereció por parte de la CDMS en 1904. Es posible que la enseñanza musical en dicho centro se viera influenciada negativamente, al igual que otras tantas realidades, por el largo periodo de interregno, aunque no hemos hallado ningún dato al respecto que nos sirva para ofrecer algo más que la mera conjetura.

Las cuatro medidas dispuestas por la Comisión para hacer realidad la implantación de las nuevas ediciones típicas vaticanas de canto gregoriano. En primer lugar, el arzobispo autorizó a los administradores de los templos a comprar los ejemplares necesarios con cargo a la Fábrica, y permitió realizar copias parciales o totales de los mismos por motivos económicos, o simplemente para una mayor comodidad en el uso ${ }^{38}$. No obstante, la tercera de las medidas advertía que antes de poder ser utilizadas debían ser revisadas por la Comisión y contar con su visto bueno ${ }^{39}$. Más adelante comprobaremos, sobre todo cuando nos dediquemos a estudiar el procedimiento seguido para la depuración del repertorio de música figurada, la ingente carga de trabajo que las funciones de supervisión y filtrado impusieron a dicho órgano reformista.

cantores diocesanos ante la inminente celebración del II Congreso Nacional de Música Sagrada en Sevilla. Esto ocurrió en octubre de 1908, es decir, a comienzos del curso 1908/09. En Apéndice 7 transcribimos sendas cartas de Miguel Castillo, Vicario general, comunicando la celebración de estas actividades de formación previas al Congreso.

${ }^{36}$ Carta de Ripollés a Pedrell, 16 de diciembre de 1907. BC. FFP. M 964 R.

${ }^{37}$ Martín Riego, La formación intelectual del clero, p. 187.

38 “a) Que por tratarse de un Libro Litúrgico de uso obligatorio en todas las iglesias, se autorice a los Sres. Administradores de ellas para adquirir el ejemplar o ejemplares del mismo, necesarios para el servicio del Culto, con cargo a la Fábrica y quedando de propiedad de esta." La Comisión, "Música Sagrada”, p. 394.

39 “c) Consentir que, para mayor economía o comodidad de cada iglesia, puedan hacerse copia de todas o alguna parte del 'Kyrial o Gradual'; pero sin que pueda usarse de ellas hasta que esta Comisión, a la que habrán de remitirse, cotejándolas con sus originales, las declare absolutamente conforme con estos, así en la melodías como en su puntuación, y previo este examen, sean debidamente aprobadas y autorizadas." Ibídem. 
La segunda fue imponer un plazo preciso para alcanzar el objetivo de instaurar el canto gregoriano restaurado. Se concedieron dos meses para que las distintas iglesias del Arzobispado adquirieran y comenzaran a usar los libros oficiales vaticanos ${ }^{40}$. Esto confirma lo que venimos afirmando sobre la celeridad con la que la Comisión quiso arreglar los problemas.

Por último, la CDMS descargó toda la responsabilidad de sustitución del repertorio de canto llano en los párrocos y demás administradores de templos ${ }^{41}$. Se trataba del colectivo al que le correspondía tal función, aunque también, al que la propia Comisión había señalado como el menos colaborador con el proyecto reformista durante la etapa de Spínola. El contacto directo y cotidiano con la realidad eclesial en todos los órdenes, incluido el litúrgico-musical, hacía de ellos el grupo que, en última instancia, tenía en sus manos la aplicación real de la reforma. De su cooperación dependía el éxito de las medidas que desde las altas instancias diocesanas se iban proponiendo. Aquí se halla la razón de la especial atención -en muchas ocasiones traducida en presión, e incluso amenazas- que les dedicaron tanto Almaraz como su CDMS.

La condición de inmediata autoridad eclesial que los administradores de templos ostentaban ante sochantres, cantores y organistas, fue aprovechada también para cargarles con otra difícil obligación, la de vigilar el cumplimiento de lo dispuesto por parte de sus subordinados directos. Por tanto, durante este segundo intento reformista, la CDMS siguió una estrategia de delegación de funciones -algunas tan propiamente suyas como la de vigilar el cumplimiento del $M P$ - en este colectivo, haciendo depender aún más de él la reforma. Así, el último de los "medios eficaces para conseguir este fin" de implantación del nuevo gregoriano consistió en:

que los Sres. Párrocos y Rectores con su reconocido celo y prudencia, procedan, si en el exacto cumplimiento de estas disposiciones encontraran, lo que no es de presumir, resistencia por parte de los ministros inferiores, como procederían en cualquier otro caso análogo de desobediencia a la autoridad Episcopal. ${ }^{42}$

\footnotetext{
40 “b) Que se conceda para adquirir los ejemplares de que se habla en el párrafo anterior, y comenzar a usarlos, un plazo prudente que pudiera ser de dos meses." Ibídem.

${ }^{41}$ La Comisión no consiente "por título alguno [que] los Sres. Párrocos, Rectores o Encargados de Iglesias que en las que respectivamente estén a su cargo se ejecuten otras melodías, así para el canto de las partes 'variables' como de las 'fijas' de la Santa Misa y demás funciones litúrgicas, que las publicadas en la citada 'Edición [Vaticana]'”. Ibídem.

${ }^{42}$ Ibídem, p. 395.
} 
Constatamos de nuevo, el cambio de estilo a la hora de dirigirse a estos eclesiásticos respecto a la etapa de Spínola.

Al margen de estas medidas, la cuestión de la instauración del nuevo canto gregoriano mereció la publicación en el BOAS de 13 de marzo de lo que parece ser un artículo extraído de alguna revista de música religiosa que no hemos podido localizar. En él se daba a conocer un novedoso método con el que aprender de una forma sencilla y rápida el nuevo repertorio gregoriano. Se trataba del gramófono o fonógrafo, que era presentado como un paciente maestro de canto siempre a disposición del alumno en su propia casa. El éxito del método, ya contrastado en el extranjero, según se afirmaba, estaba asegurado pues "no habrá ninguno, por medianas disposiciones musicales que tenga, que no llegue a cantar lo que tan repetidamente entró por sus oídos"43. En virtud de un acuerdo especial con la francesa Casa Odeón, poseedora de los privilegios de comercialización para España y América Latina, se ofrecían las máquinas por un precio de setenta y cinco pesetas, cuando su coste era de entre doscientas ciencuenta y trescientas ${ }^{44}$. Así se proporcionaba un procedimiento práctico y eficaz para aprender el nuevo canto con una inversión que se calculaba en torno a las ciento diez y ciento quince pesetas entre el coste de la máquina, los discos -se recomendaba adquirir al menos tres impresionados por las dos caras, a cinco pesetas y media cada una- más las cuatro pesetas de gastos de envío. El nombre de la empresa o emprendedores que estaban detrás de esta iniciativa no se hace constar. No obstante, sabemos que estaban involucrados los Padres Carmelitas de Burgos así como la capilla de la catedral de dicha ciudad. Estos tenían previsto hacer la grabación de los discos en España, puesto que la pronunciación latina de los editados por la Casa Odeón resultaba afrancesada. Unos años después, el propio Otaño iniciará con su coro del seminario de Comillas una empresa similar con la misma casa discográfica ${ }^{45}$.

Sobre el uso del gramófono en las iglesias debió pronunciarse la Sagrada Congregación de Ritos en febrero de 1910 para dar respuesta a algunas dudas que le habían sido dirigidas. La cuestión, tal y como se recoge en $M S H$, fue planteada en los siguientes términos:

\footnotetext{
43 "El canto gregoriano", BOAS, 662 (1909), p. 265.

${ }^{44}$ El precio extraordinariamente rebajado así como el hecho de tratarse de aparatos "en inmejorables condiciones" hacen pensar en la posibilidad de que fueran gramófonos o fonógrafos de segunda mano. Ibídem.

${ }^{45}$ Véase: López Calo, Nemesio Otaño, S.J., p. 75.
} 
Se pregunta (Squilace) "si en la misa solemne y otras funciones, en las iglesias que carecen de organista y cantores, aun laicos, es lícito usar el aparato llamado gramófono para el canto, ya sea gregoriano, o de las partes variables de la misa solemne, o de himnos y otros cualesquier cantos. ${ }^{, 46}$

La respuesta fue negativa. Como aclara el anónimo redactor de la noticia, el gramófono debía ser utilizado sólo como recurso pedagógico, en ningún caso para sustituir a los cantores en las funciones litúrgicas:

El gramófono será un maestro que, llegando a los pueblos donde no haya elementos para el culto solemne, los forme a fuerza de repetir la impresión de sus placas, pero no puede tomar parte personal en el culto: las razones son claras teniendo en cuenta las nociones más elementales del culto, de la liturgia, de sus fines y medios. ${ }^{47}$

No quedaba tan claro, sin embargo, que no pudieran sustituir al órgano, lo que llevaba a apelar, para ofrecer una respuesta, al "espíritu del decreto": "Todavía queda la duda, porque no aparece clara en la pregunta, si podrán suplirse las piezas propias del organista (ofertorio, etc.), pero el espíritu del decreto es tan manifiesto, que, indudablemente, hay que responder a esto negativamente" ${ }^{\prime 48}$.

El artículo publicado en el BOAS sobre el gramófono muestra cómo el intento de reforma propició el surgimiento de determinadas iniciativas discográficas, además de las editoriales. De ello se desprende que la reforma no consistió únicamente en la aplicación de unas nuevas disposiciones legales sobre música, ni dependió exclusivamente de la transformación de las mentalidades según unos nuevos principios litúrgicos y estéticos, ni siquiera del conocimiento o disposición favorable de aquellos que tenían en sus manos su implantación. Eran necesarios, además, medios, en consecuencia, estructuras que los proporcionasen. En este sentido, las industrias discográfica en menor medida, y sobretodo editorial, debieron cumplir una función imprescindible. La reforma dependía también de la capacidad de la industria editorial

\footnotetext{
46 “Un decreto de la Sagrada Congregación de Ritos, sobre el gramófono”, MSH, 14 (1910), p. 162.

${ }^{47}$ Ibídem.

${ }^{48}$ Ibídem. La reseña concluía pintando una escena grotesca: "Recordamos haber leído en una revista que, en alguna parte de los Estados Unidos, hace tres o cuatro años, murió un cantor, en cuyo entierro tuvieron sus aficionados la ocurrencia de colocar un gramófono en el catafalco, para que, durante las honras fúnebres, se oyera la voz del difunto a una con los sollozos de los que lamentaban su irreparable pérdida!". Ibídem.
} 
española, junto a investigadores y compositores, de reaccionar a las nuevas circunstancias impuestas por el $M P$, y responder a las demandas y necesidades de aquellos que habían iniciado la vía reformista. Habría que preguntarse si en ese momento se disponía de la música alternativa con la que reemplazar las obras que se consideraran incompatibles con el $M P$, o en otros términos, si realmente era posible llevar a cabo la ambiciosa tarea de sustituir un repertorio consagrado por la costumbre y la práctica, tal y como reclamaban las disposiciones litúrgico-musicales papales. A lo largo de la tercera parte de esta tesis tendremos ocasión de comprobar la íntima relación existente entre editoriales, compositores, musicógrafos, líderes reformistas o clero, y cómo todos estos agentes implicados en la reforma configuraron un espacio de interacción, colaboración y competencia.

\subsubsection{Música figurada: la depuración del patrimonio musical}

La depuración del repertorio vigente, sin duda uno de los grandes retos de la reforma, era una empresa pendiente para la CDMS. Ya durante el pontificado de Spínola se había abordado el tema aunque no pasó de ser más que un tímido intento. Recordemos que la CDMS se limitó a señalar como proscritas la obra de Prado y Solís, así como las misas "Pastorela" de García y la "Eucharística" de Arquimbau". La propuesta de erección de un tribunal censor como órgano exclusivamente dedicado a la inspección del repertorio no encontró eco en el arzobispo.

En la nueva etapa de Almaraz, sin embargo, el objetivo se planteó con firmeza. Su circular $n^{\circ} 18$ de 13 de marzo convirtió a la CDMS en un gran filtro por el que debía pasar todo el repertorio de música "figurada" en uso en las distintas iglesias, parroquias, congregaciones, asociaciones y hermandades bajo la autoridad episcopal ${ }^{50}$. Sin la aprobación de la Comisión, los "Sres. Párrocos no permitirán, pues, en sus respectivas Iglesias, la ejecución de obras del género polifónico o figurado" ${ }^{„ 51}$. El procedimiento era sencillo: las obras debían ser presentadas con la debida antelación en la Secretaría de Cámara del Arzobispado, desde donde eran entregadas a la Comisión para su estudio;

\footnotetext{
${ }^{49}$ Véase capítulo 1, p. 101.

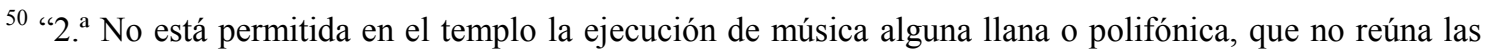
condiciones de fondo y forma, exigidas por Nuestro Santísimo Padre en el Motu Proprio, (cap. I, IV, VI y VII especialmente), disponiéndose que se encomiende a la Comisión diocesana, nombrada al efecto, el encargo de vigilar cuanto a la música religiosa se refiere, a fin de que se observen fielmente las disposiciones Pontificias.” Enrique [Almaraz], "Circular no 18 sobre Música Sagrada”, pp. 249-250.

${ }^{51}$ Ibídem, p. 250.
} 
esta elaboraría un informe por escrito haciendo constar las "advertencias, reparos y correcciones" que estimara oportuno, y lo sometería a la aprobación del prelado; en caso de que se obtuviera, el secretario de la Comisión autorizaría la partitura y particellas de la obra en cuestión ${ }^{52}$. La CDMS, por tanto, debía examinar obra por obra todos los archivos musicales de las iglesias del Arzobispado, y emitir un juicio a la luz de las prescripciones del $M P$ que las absolvía o condenaba a la proscripción. Dadas las dimensiones y características de la Archidiócesis es razonable afirmar que se enfrentaba a una labor ímproba, además de polémica.

El 1 de junio, la CDMS afirmó no poder estudiar "con el detenimiento debido y al mismo tiempo con la necesaria urgencia el considerable número de obras que a diario recibe para su examen, $[\ldots]^{, 53}$. Ante la incapacidad de atender todas las solicitudes que se presentaban, el órgano reformista propuso reemplazar el mecanismo aprobado por Almaraz, que se había mostrado como poco eficiente, por otro basado en un sistema de turnos $^{54}$. El nuevo procedimiento, que comenzó a estar operativo a partir de junio de 1909, no dejaba a iniciativa de cada estamento o institución diocesana el envío de su archivo. Por el contrario, debía ser la Secretaría de Cámara la que de forma ordenada y sucesiva los solicitara. El examen de las obras se debía realizar por parroquias en el caso de la capital, y por arciprestazgos para el resto de la Archidiócesis ${ }^{55}$. Los párrocos o arciprestes, según el caso, debían reclamar los archivos musicales a curas, rectores de templos, comunidades religiosas, hermandades y asociaciones de sus respectivas jurisdicciones, a medida que fueran siendo requeridos por parte de la Secretaría de Cámara. Una vez recogidos, debían ser enviados a esta, adjuntando a cada uno de ellos una nota en la que figurara un listado de las obras indicando número de voces, tono y

52 "El procedimiento para obtenerla es sencillo. Habrán de presentarse las obras en la Secretaría de Cámara con la debida anticipación. Se entregarán después a la Comisión, la cual emitirá su informe por escrito, consignando en él las advertencias, reparos y correcciones que estime procedentes, sometiéndolo después a la aprobación del Rvmo. Prelado. Obtenida esta, el Secretario de la Comisión diocesana autorizará las hojas de la partitura y particellas de la composición musical aprobada.” Ibídem.

${ }^{53}$ La Comisión, "Música Sagrada”, pp. 393-394.

54 "A fin de no aglomerar excesivamente el trabajo de la Comisión, que no puede estudiar con el detenimiento debido y al mismo tiempo con la necesaria urgencia el considerable número de obras que a diario recibe para su examen, es indispensable que se establezca un turno ordenado". La Comisión, "Música Sagrada", pp. 395-396.

55 “a) No envíen obra alguna al examen de la Comisión Parroquias, Comunidades ni Asociaciones y Hermandades hasta que por la Secretaría de Cámara se pidan, lo que se hará directamente en la Capital, y por medio de los señores Arciprestes en toda la Diócesis”. Ibídem, p. 396. 
autor respectivos ${ }^{56}$. Entre tanto les llegaba el turno, parroquias de la capital y arciprestazgos del resto de la Archidiócesis tenían permitida la utilización de su patrimonio musical sin depurar, "aunque con la mayor discreción y prudencia". No obstante, se advertía que era preferible en las fiestas litúrgicas el uso del canto gregoriano restaurado a la música "figurada o polifónica" no aprobada $^{57}$. Si, por circunstancias especiales, se necesitaba usar alguna obra antes de que finalizara el proceso de examen y expurgo, se debía enviar diez días antes de que fuera interpretada a la Secretaría de Cámara por vía de urgencia y siempre a través del párroco o arcipreste correspondiente $^{58}$. Este sistema contemplaba dos excepciones: aquellos que solicitaran la obtención del título de director de capilla musical, quienes podían presentar sus archivos personales directamente en la Secretaría de Cámara ${ }^{59}$; y las scholae cantorum que se fundaran, las cuales, por el hecho de ser aprobados sus reglamentos estaban exentas de la inspección de sus repertorios, como se deduce de la norma que las regulaba ${ }^{60}$. De estos dos casos nos ocuparemos en el siguiente epígrafe.

Resulta obvio que para conseguir los objetivos reformistas en lo que a la música figurada se refiere, el sistema de depuración y censura de aquellas obras incompatibles con el $M P$ era insuficiente. Hemos de suponer que los archivos que

56 "b) Cuando en virtud del turno que se establezca se pida a los Sres. Párrocos y Arciprestes en su caso los Archivos musicales para su examen, exigirán a los Sres. Rectores de iglesias, Comunidades religiosas sujetas a la Jurisdicción Episcopal y Hermandades y Asociaciones establecidas en el territorio de su Jurisdicción, los archivos musicales de su pertenencia, que, juntos con el de la Parroquia respectiva, se enviarán a la Secretaría de Cámara, acompañados de una nota sellada con el de la entidad a que corresponda, y en la que se numeren las obras y se exprese el título, número de voces, tono y autor de cada una, para poderla distinguir en todo caso de las demás." Ibídem.

57 "Entretanto, usen en sus funciones la música que actualmente posean, aunque con la mayor discreción y prudencia, teniendo en cuenta los señores Párrocos y Rectores que es preferible usar de sólo el Canto Gregoriano en las fiestas que hayan de celebrarse, a usar música figurada o polifónica antes de que sea examinada y aprobada bien entendido que 'ninguna función religiosa perderá nada de su solemnidad aunque no se cante en ella otra música que la gregoriana. (Motu proprio. II-3.)". Ibídem.

58 “c) Si antes de concluir el examen de todos los archivos musicales de la Archidiócesis, alguna Comunidad o Asociación necesita, por circunstancias especiales, utilizar algunas obras de su repertorio, puede remitirlas inmediatamente, acompañadas de la nota de que se habla en el párrafo anterior, y siempre por conducto del Párroco o Arcipreste respectivo. En todo caso, estas obras que han de examinarse con urgencia, habrán de entregarse en la Secretaría de Cámara con diez días al menos de anticipación al en que hayan de utilizarse.” Ibídem.

59 “d) Los que hayan de solicitar el título de Director u Organizador de Capilla musical, presentarán directamente en la Secretaría de Cámara su archivo para su examen, junto con la solicitud de que se habla antes y sin tener que esperar turno". Ibídem, p. 397.

${ }^{60 ،}$ Estas 'Schola' y 'Capillas', por el solo hecho de ser aprobado por la Jurisdicción Ordinaria el 'Reglamento' que habrán de formar al constituirse, [...], quedarán autorizadas para el servicio de toda clase de funciones religiosas en la Archidiócesis [...]” Ibídem. 
pasaran por las manos de la Comisión serían fuertemente esquilmados, dado el severo juicio que sobre el repertorio en uso le merecía. La labor de sustitución de las obras desechadas por otras más acordes con los nuevos preceptos litúrgico-musicales era tan decisiva e ingente como la de depuración. Sin embargo, en el plan reformista, la Comisión no incluyó ninguna disposición en este sentido. Su única actuación al respecto fue la publicación de una circular dirigida a los administradores de templos, a quienes les recomendó para proveerse de obras ajustadas a las nuevas prescripciones papales se hicieran con los catálogos publicados por algunas casas editoriales, tanto españolas como extranjeras, en los que se proporcionaban sólo obras ya aprobadas por la autoridad eclesiástica:

Para facilitar la adquisición de obras musicales religiosas, hechas ya con arreglo a las disposiciones pontificias, obras con las que es indispensable sustituir, en el más breve plazo posible, las que forman el repertorio actual y que, casi en su totalidad, son menos dignas de ser ejecutadas en la Casa del Señor y en las graves solemnidades de su culto por su sabor profano y factura teatral, esta Comisión, cumpliendo el honroso encargo que nuestro Excmo. y Reverendísimo Prelado se ha dignado confiarle, recomienda a los señores Párrocos y Rectores de Iglesias, así como a las Comunidades, Cofradías y Asociaciones religiosas, que se provean de aquellas composiciones musicales que sean necesarias para el servicio de sus cultos, y que por muy módicos precios, pronta y fácilmente pueden adquirir, por estar ya editadas con la necesaria aprobación, con solo pedir los Catálogos de obras religiosas aprobadas de las casas españolas editoriales y de fondo ${ }^{61}$

Las editoriales españolas relacionadas eran la madrileña de Ildefonso Alier, José Ma ${ }^{\mathrm{a}}$. Llobet de Barcelona, y Lazcano y Mar de Bilbao; las extranjeras, las italianas Bertarelli, y Capra, y la alemana Pustet ${ }^{62}$.

Mientras que la Comisión asumió absolutamente la responsabilidad de sanear el repertorio vigente en la Archidiócesis, la tarea de la restauración según los nuevos principios litúrgico-musicales del patrimonio musical descartado quedó en manos de administradores de templos; precisamente el colectivo responsable de los archivos musicales que tan negativa valoración le merecía -a la Comisión-, e, insistamos, aquel que menos colaborador se había mostrado durante el pontificado de Spínola. No parece

\footnotetext{
${ }^{61}$ La Comisión, “Comisión Diocesana de Música Sagrada. Circular”, BOAS, 663 (1909), p. 287.

${ }^{62}$ Ibídem.
} 
que la mera recomendación de editoriales en las que encontrar obras sancionadas por la autoridad eclesiástica fuera una medida suficiente para el objetivo que se pretendía.

Desafortunadamente, no hemos hallado hasta el momento en el AGAS rastro documental alguno sobre la labor de depuración del repertorio realizada por la Comisión $^{63}$. Una actividad que debió ser intensa a juzgar por el objetivo perseguido, así como por las dimensiones y características de la Archidiócesis.

Este vacío de información nos priva de conocer tanto el desarrollo como los resultados reales de este ambicioso proyecto para la reforma. Tampoco podemos averiguar, por la misma causa, en qué medida se llevarían a la práctica las directrices para la sustitución de los libros de canto llano por las ediciones típicas vaticanas del Kyriale y el Graduale, que se debía realizar en un plazo de dos meses, es decir, entre junio y julio de 1909. Ante esta falta de documentación, no es posible hacer una valoración fundamentada sobre el éxito de estas disposiciones. No obstante, las frecuentes advertencias y denuncias hechas por la Comisión desde el comienzo del proceso reformista diocesano sobre los incumplimientos de las disposiciones episcopales por parte de párrocos y rectores de iglesia apuntan a una actitud poco colaboracionista de estos. Dado que se trataba del colectivo clave para la implantación del nuevo canto gregoriano y la sustitución de la música polifónica, resulta lógico suponer que el plan para la renovación del repertorio en las iglesias de la Archidiócesis encontraría importantes dificultades. En este sentido se pronunciaba la Comisión en su exposición de medios cuando afirmaba: "Graves son sin duda las dificultades y obstáculos que a esta, como a toda reforma y corrección de inveterados abusos, se oponen;" "64, para luego denunciar la no observancia de los mandatos sobre música sagrada dictados por Almaraz. No obstante, la estimación positiva sobre la marcha de la reforma que el propio Almaraz haría en 1910, y que transcribimos más abajo, obliga a ser cautos a la hora de hacer un balance excesivamente negativo.

\footnotetext{
${ }^{63}$ La circunstancia adversa que para el investigador representa la desaparición de testimonios que permitan conocer los pormenores de estas tareas de filtrado no se ha dado sólo en Sevilla, sino que se trata de una situación compartida por muchas otras diócesis hispanas. Ángel Medina, refiriéndose al caso ovetense, apunta como uno de los motivos de esta escasez de fuentes el hecho de que los fondos depurados constituyeron un material inútil desde ese momento. Medina menciona dos excepciones, la catedral de Santiago, investigado por López Calo, y el de la diócesis de Mallorca, por Roselló i Literas. Medina, "La música en el templo", pp. 36-37.

${ }^{64}$ Ibídem, p. 398.
} 


\subsection{Agentes musicales diocesanos}

A continuación analizaremos aquellas disposiciones que, con el beneplácito del arzobispo, fueron decretadas por la Comisión con el objetivo de sentar las bases para una mejor organización de los recursos humanos que más cercanos a la realidad concreta se encontraban. Se pretendía la redefinición del papel de aquellos de los que dependían la concreción y aplicación de todo el bloque normativo que se había ido generando en estos años. Este capital humano se debe disgregar en dos grandes colectivos, los administradores de templos y los músicos que, de una forma $\mathrm{u}$ otra, estaban al servicio de las iglesias. Obviamente las medidas dedicadas a cada uno de ellos eran de diferentes características y perseguían fines distintos, lo que justifica su estudio en distintos epígrafes. No obstante, si se contemplan en su conjunto constituyen el intento sin precedentes de remodelar la estructura diocesana para ajustarla y ponerla al servicio de la música en la litúrgica.

\subsubsection{Regulación de los oficios musicales eclesiásticos: hacia la} constitución de una estructura oficial diocesana

Los músicos eclesiásticos eran aquellos que cubrían las necesidades musicales de los templos diocesanos. Excluimos en este apartado a los catedralicios, pues su estatus y regulación dependían de las leyes concordadas, es decir, estaban fuera de las competencias del prelado diocesano ${ }^{65}$. El Reglamento sobre Música Sagrada vallisoletano distinguió tres grupos entre los que estaban bajo la autoridad episcopal: en primer lugar, el "director, festero o encargado de la parte musical en las iglesias de este provincia eclesiástica [vallisoletana]"; en segundo lugar, el "sacristán-organista o cantor de parroquia u oratorio"; por último, la "organista o cantora de oficio en las comunidades religiosas donde existan estos cargos" ${ }^{\$ 66}$. Los músicos pertenecientes al primer grupo, directores y sus grupos de instrumentistas y cantores ("festeros") 67 ,

${ }^{65}$ El I Congreso Nacional de Música Sagrada (Valladolid, 1907) concluyó: "Músicos de iglesia son los destinados a la ejecución de la música sagrada, ya sean nombrados por oposición con arreglo al Concordato en las Catedrales, ya sean señalados por el Ordinario o por delegación de éste en las parroquias o comunidades de religiosas donde existen estos cargos." "Crónica del Congreso. 26, 27 y 28 de Abril", MSH, 1 (1907), p. 6.

66 "Edicto y Reglamentos sobre música sagrada", p. 335.

${ }^{67}$ Durante la sesión del congreso de Valladolid en la que se discutió lo relacionado con los músicos eclesiásticos, Mariano Baixaulí intervino para, entre otras cosas, expresar lo inconveniente de la denominación de "festero", tal y como figuraba en el Reglamento citado: "El nombre de festero, dice parece poco digno: debe decir concertador, (Aprobación)." “Crónica del Congreso", p. 5. 
mantenían una relación laboral con la institución eclesiástica de carácter ocasional, pues eran reclamados ad hoc para una o varias funciones religiosas. Por su parte, sochantres y organistas parroquiales eran nombrados por el obispo para ocupar las plazas existentes en la diócesis.

La importancia para la reforma del colectivo de músicos de iglesias se entiende por las dos consideraciones siguientes. En primer lugar, dado que eran los intérpretes que en última instancia traducían las premisas y presupuestos estéticos, religiosos, legales, etc. en un acontecimiento musical real poseían el poder de facto de dignificar el culto católico en este aspecto. Por otro lado, independientemente de su estado -clerical o seglar-, según la legislación eclesiástica, los músicos que participaban en las funciones religiosas desempeñaban un oficio litúrgico, como era el de coro eclesiástico. El artículo 12 del MP establecía:

Excepto las melodías propias del celebrante y los ministros, las cuales han de cantarse siempre con música gregoriana, sin ningún acompañamiento de órgano, todo lo demás del canto litúrgico es propio del coro de levitas; de manera que los cantores de iglesia, aun cuando sean seglares, hacen propiamente el oficio de coro eclesiástico. ${ }^{68}$

En el artículo 13 del mismo documento se justificaba la prohibición a las mujeres de formar parte del coro o capilla musical en estos términos: "Del mismo principio se deduce que los cantores desempeñan en la Iglesia un oficio litúrgico; por lo cual las mujeres, que son incapaces de desempeñar tal oficio, no pueden ser admitidas a formar parte del coro o la capilla musical",69. El artículo 14, por su parte, advertía: "no se admitan en las capillas de música sino hombres de conocida piedad y probidad de vida, que con su modesta y religiosa actitud durante las solemnidades litúrgicas se muestren dignos del santo oficio que desempeñan”. Además se especifica la vestimenta litúrgica que corresponde a los músicos como actores litúrgicos: "Será, además, conveniente que, mientras cantan en la iglesia, los músicos vistan hábito talar y sobrepelliz, y que, si el coro se halla muy a la vista del público, se le pongan celosías" ${ }^{70}$.

\footnotetext{
${ }^{68} M P$. Título V. Cantores, arts. 12.

${ }^{69}$ Ibídem, art. 13.

${ }^{70}$ Ibídem, art. 14.
} 
En consecuencia, garantizar la competencia, pericia y recto juicio de estos músicos, así como su responsabilidad y piedad -tal es el término que se empleaba en la circular-, fueron las razones que motivaron y justificaron la ambiciosa empresa que la CDMS planteó ${ }^{71}$. Esta consistió en el intento de regularización de todos los oficios musicales eclesiásticos, tanto de los fijos -organista y sochantres-, de los que ya se había ocupado la Comisión en la etapa de Spínola; como de aquellos que no disfrutaban de un estatus oficial por lo eventual y circunstancial de su vínculo con la institución eclesial, directores y grupos vocales-instrumentales. Esta regularización se materializó a través de la creación de títulos oficiales -en el caso de los grupos de reconocimientos de oficialidad- expedidos por la administración arzobispal, que facultaban a sus poseedores para ejercer su trabajo en cualquier templo de la Archidiócesis.

Pasamos a continuación a describir las características y condiciones de cada uno de estos títulos o reconocimientos oficiales así como las competencias que otorgaban y, en su caso, los privilegios que concedían. Nos centraremos, en primer lugar, en los de nueva creación, que son denominados, uno "Director" u "Organizador de capilla musical", y otro "Schola cantorum" o "Capilla" oficial" ${ }^{72}$ posteriormente nos dedicaremos a aquellos que fueron instituidos durante el pontificado de Spínola, organista y sochantre.

\subsubsection{Directores musicales}

El título de "Director" u "Organizador de capilla musical" sería concedido a aquellos "que reúnan las debidas condiciones de piedad y pericia en el arte musical religioso" ${ }^{\text {73 }}$. El interesado debía entregar junto con la solicitud el archivo musical que habría de utilizar en las funciones religiosas en las que tomara parte. La Comisión emitiría un juicio sobre la idoneidad de su repertorio así como sobre su competencia. No se especifica de qué forma se verificaría esta última, aunque, según está redactada la

\footnotetext{
71 “2. 'Desempeñando los cantores de iglesia, aunque sean seglares, un oficio litúrgico, el de coro eclesiástico', según el 'Motu Proprio' (V 12 y 13), y para el debido cumplimiento de lo que en el mismo Documento Pontificio (V 14) se dispone, se creará un título especial de 'Director' o simplemente 'Organizador de Capilla musical', que se expedirá por la Secretaría de Cámara, en los términos comunes a los de su clase (de Sochantres y Organistas), a favor de los que reúnan las debidas condiciones de piedad y de pericia en el arte musical religioso". La Comisión, "Música Sagrada”, p. 395.

${ }^{72}$ La denominación definitiva de este título no está claro tal y como figura en la exposición de medios presentada por la comisión al prelado. Véase la cita anterior.

${ }^{73}$ Ibídem.
} 
norma, parece que se debía deducir de las características del archivo que presentara. El título autorizaba a su acreedor a "servir toda clase de funciones religiosas en todas las iglesias de la Archidiócesis" ${ }^{\text {,4 }}$.

El valor de este título residía fundamentalmente, en primer lugar, en otorgar a sus poseedores un estatus de músico oficial archidiocesano homologable al que disfrutaban aquellos músicos que ocupaban plazas musicales eclesiásticas -sochantres y organistas-: “[el título] se expedirá por la Secretaría de Cámara, en los términos comunes a los de su clase (de Sochantres y Organistas) ${ }^{\text {,75; }}$ y por otro, en su condición de exclusividad. Respecto a esto último, los términos en los que se expresaba la Comisión eran tajantes:

Por tanto, los Sres. Párrocos y Rectores no podrán en adelante admitir en sus iglesias en concepto de Organizador o director de la Capilla musical a ninguno que no les exhiba el Título oficial que ha de habilitarle para el desempeño de este ministerio $[\ldots]^{76}$

A partir de ese momento ser director $u$ organizador de conjuntos vocalesinstrumentales con título oficial eclesiástico era requisito indispensable para poder desarrollar esta labor en el ámbito de la archidiócesis andaluza. Esto significaba, al mismo tiempo, que aquellos que no ostentaran esa condición tenían vedado el acceso a un mercado de trabajo que, aunque eventual, proporcionaría ingresos nada desdeñables a personas que formaban parte de un colectivo no precisamente privilegiado ni social, ni económicamente, como defenderemos en su momento ${ }^{77}$.

También en este caso se cargaba a los párrocos y rectores con la obligación de impedir la participación en las funciones religiosas de los directores no oficiales. Puesto que el valor de estos títulos residía precisamente en proporcionar la facultad en exclusiva de ejercer en el interior de las iglesias, y eran los administradores de templos

\footnotetext{
74 "[Los aspirantes] habrán de solicitarlo en forma del Excmo. y Rvdo. Prelado, acompañando a su solicitud el archivo musical que hayan de utilizar en las funciones sagradas cuyo servicio se les encomiende, para que la Comisión Diocesana lo examine y emita dictamen sobre las composiciones religiosas comprendidas en él y sobre la competencia técnica del recurrente; título que autorizará al que así lo haya obtenido para servir todo género de funciones religiosas en todas las iglesias de la Archidiócesis, y que la Jurisdicción Ordinaria que lo expide podrá revocar 'ad nutum' cuando a su juicio así convenga para el mejor servicio del Culto divino.” Ibídem.

${ }^{75}$ Ibídem.

${ }^{76}$ Ibídem.

${ }^{77}$ Véase capítulo 5, epígrafe 3.2.3. "La situación económica de los músicos eclesiásticos”, p. 404.
} 
quienes tenían en sus manos la salvaguarda de tal exclusividad, de ellos dependió el éxito de este intento de instaurar un sistema de oficios musicales eclesiásticos en la Archidiócesis. Con ello, atesoraron, además, el poder, con el consiguiente compromiso, de encontrase en la posición de gestores de lo que constituía una interesante fuente de ingresos.

En el apartado que dedicamos a estudiar el intento de creación de la Escuela Oficial Archidiocesana de Canto Gregoriano referíamos las considerables similitudes, así como las diferencias, que encontrábamos entre lo aprobado por los prelados castellanos en el Reglamento general para la Música Sagrada en la Provincia Eclesiástica de Valladolid y lo dispuesto por la CDMS andaluza en relación a la ordenación de los oficios de sochantre o cantor y organista. Dicho Reglamento se ocupó igualmente de la regulación de los directores musicales ${ }^{78}$. El Reglamento vallisoletano y las disposiciones de la CDMS hispalense respondían a un mismo espíritu y a las mismas pretensiones de regular y ordenar los distintos colectivos musicales eclesiásticos. Las diferencias existentes son pocas, y parecen apuntar a un mayor peso del "título oficial" que otorgaba la Secretaría de Cámara hispalense frente a la "autorización expresa del Prelado" que debían poseer los directores castellanos.

Como hemos visto, en el caso de la archidiócesis andaluza, se dispuso un procedimiento particular e independiente del general para la supervisión de los archivos musicales de estos músicos, que debían obtener además una valoración favorable sobre sus capacidades y competencias. En el caso de la provincia eclesiástica castellana, la inspección de sus repertorios se hacía según el procedimiento ordinario y común, además no se emitía juicio alguno respecto a sus aptitudes ${ }^{79}$. Tan sólo se reseñaban las obligaciones a las que estaban sujetos: "no ejecutar sino la música señalada en el Motu Proprio de S. S. Pío X” (canto gregoriano, polifonía clásica, y “música moderna de

${ }^{78}$ Artículos 2, 3 y 4 del epígrafe I. "De los encargados de dirigir la música", de la Primera parte. "De los músicos de Iglesia". "Edicto y Reglamentos sobre música sagrada", pp. 335-336.

${ }^{79}$ El procedimiento de depuración y censura de la música en la Provincia eclesiástica de Valladolid quedó regulado en el artículo 45 del Reglamento: "Las personas o corporaciones que posean obras musicales o adquieran otras destinadas a funciones de Iglesia, deberán presentarlas a la respectiva Comisión para su censura, acompañadas de doble lista que contendrá los datos siguientes: Nombre y residencia del remitente.- Título o clase de las obras.-Elementos de la composición.-Nombre del autor.-Número y forma de los papeles (v.g. una partitura, cuatro voces sueltas, una parte de órgano, etc.)- Correspondiente a cada obra una casilla en blanco, para escribir la calificación y observaciones de la Comisión. Una de las listas se devolverá al interesado con las obras musicales ya censuradas, la otra quedará archivada." El artículo 43 señala: "La Comisión calificará las composiciones con las notas de aprobada o tolerada [...]. Todas las demás composiciones quedan del todo prohibidas, y deberán ser eliminadas de los actos religiosos.". Ibídem, pp. 352-353. 
buena factura religiosa"), contar sólo con músicos preparados en sus grupos, y someterse a lo dispuesto en el Reglamento ${ }^{80}$. Por el contrario, dedicaba un artículo al otro requisito que se exigía a los directores en Sevilla junto al de la "pericia", la "piedad":

5. Tengan presente los directores y encargados, y esfuércense por hacer verdadero lo que el Concilio Provincial Vallisoletano recuerda, "que los seglares admitidos en la Iglesia para el oficio del canto sean de vida religiosa y cristiana; es decir, tales, que crean de corazón y con sus obras comprueben lo que con la boca cantan" $" 81$

Los administradores de templos -párrocos y rectores de iglesia- desempeñaban la misma función que los andaluces:

3. [Los directores] Deberán presentar las composiciones que han de ejecutarse a los señores Párrocos o Rectores de las iglesias, siempre que lo reclamen, a fin de que cerciorados estos de su aprobación y buen expediente, puedan estar seguros de que se cumplen fielmente las disposiciones del Reglamento.

4. Los Párrocos o Rectores podrán exigirles la presentación de la autorización del Prelado para desempeñar el cargo de director, si ya de antes no les constase. ${ }^{82}$

Estas consideraciones mueven a sostener que el proyecto de oficialización de los oficios musicales emprendido en Sevilla en 1909 debió estar inspirado, al menos en parte, en el Reglamento vallisoletano que, recordemos, data de 1905, y fue propuesto por el congreso de Valladolid como idóneo para ser aplicado en el conjunto de diócesis españolas.

\footnotetext{
80 "2. Los encargados de dirigir la parte musical en las funciones religiosas, se obligan: $1^{\circ}{ }^{\circ}$ ) a no ejecutar sino la música señalada en el Motu Proprio de S. S. Pío X; cual es el Canto Gregoriano, canto oficial de la Iglesia; el género polifónico, a tan alta cumbre elevado por nuestros grandes compositores del siglo XVI, y la música moderna de buena factura religiosa, previamente aprobada por la Comisión diocesana. $\left.2 .^{\circ}\right)$ Se obligan también a proveerse de elementos adecuados y convenientemente preparados (V. los núms. 26 y 27), y $3 .^{\circ}$ ) al estricto cumplimiento y observancia de cuanto en el presente reglamento queda dispuesto." Ibídem, pp. 335-336.

81 “Edicto y Reglamentos", p. 336.

${ }^{82}$ Ibídem.
} 


\subsubsection{Scholae cantorum y capillas musicales}

Centrémonos a continuación en las scholae cantorum y capillas oficiales. Ya hemos hecho alusión en alguna ocasión a la importancia que el MP otorgaba a la creación de scholae cantorum como uno de los medios principales para la realización de la reforma. En dos artículos del texto pontificio se insta al clero a fundar estos coros: "[...] Asimismo, promuévase con el clero, [en los seminarios de clérigos y en los institutos eclesiásticos] donde sea posible, la fundación de una Schola cantorum para la ejecución de la polifonía sagrada y de la buena música litúrgica." ${ }^{\natural 3}$; y

Póngase cuidado en restablecer, por lo menos en las iglesias principales, las antiguas Scholae cantorum, como se ha hecho ya con excelente fruto en buen número de localidades. No será difícil al clero verdaderamente celoso establecer tales Scholae hasta en las iglesias de menor importancia y de aldea; antes bien, eso le proporcionará el medio de reunir en torno suyo a niños y adultos, con ventaja para sí y edificación del pueblo. ${ }^{84}$

De la lectura de estos dos artículos se infiere el modelo sugerido en el texto papal. En primer lugar, la iniciativa en la promoción de estos grupos debía partir en todo caso de los responsables eclesiásticos de cada templo o institución de las diócesis. En el caso de las catedrales y colegiatas, suponemos, correspondería al cabildo y/o al maestro de capilla, y en el de los seminarios e institutos religiosos al obispo o superiores, según el caso. Más arriba hemos dado cuenta de la fórmula que se siguió en Sevilla en lo que a la Catedral se refiere para optimizar los recursos: la schola cantorum fundada en el Seminario, formado por seminaristas, participaría en las funciones solemnes, apoyando al coro y capilla catedralicios. En el caso de "las iglesias de menor importancia y de aldea", le correspondería al párroco o responsable asumir la función de alentador y protector de estos coros. Parece claro que estos se concebían como grupos parroquiales de fieles sin conocimientos musicales y con la finalidad de proporcionar un servicio desinteresado a su comunidad ${ }^{85}$. A la vista de los curas se presentaba como una

\footnotetext{
${ }^{83}$ MP. Título VIII. Medios principales. Art. 25.

${ }^{84}$ Ibídem. Art. 27.

${ }^{85}$ Este tema fue tratado con cierta frecuencia en las revistas y congresos nacionales de música sagrada. Particularmente interesantes nos parecen sendas memorias presentadas por Ripollés a los puntos b). "Scholae cantorum: elementos para su fundación y medios para su sostenimiento en las Parroquias" y c) "Puntos fundamentales para los reglamentos de dichas Scholae" de la Sección IV. "De la propaganda, organización y personal" del congreso de Sevilla, en las que detallaba de forma pormenorizada cómo debían fundarse y regirse estas scholae parroquiales. Crónica del Segundo Congreso, pp. 230-234.
} 
estrategia pastoral con la que consolidar y catequizar su grey, además del fin litúrgico que se perseguía.

La idea de la CDMS hispalense no fue en esa dirección. De los datos que nos proporciona el punto de la exposición de medios en el que se aborda la cuestión de las scholae cantorum, se deduce que la tipología de coro eclesiástico a la que iban destinadas sus resoluciones no era la de un grupo constituido por parroquianos desinteresados y profanos en lo musical. La Comisión pretendió, más bien, dar solución al problema de garantizar la ortodoxia y sometimiento a los nuevos cánones litúrgicomusicales de aquellos grupos vocales-instrumentales de carácter semiprofesional que servían en las funciones religiosas en las iglesias de la Archidiócesis.

Según la propuesta de la Comisión, refrendada por el arzobispo hispalense, un grupo musical obtenía el reconocimiento oficial de Schola cantorum o Capilla musical si el reglamento que las debía regir conseguía la aprobación de la "Jurisdicción Ordinaria". Las ventajas que tal reconocimiento otorgaban eran realmente importantes, pues, aunque no proporcionaban la exclusividad en el servicio musical de las ceremonias litúrgicas, como ocurría en el caso de los directores, concedían unas ventajas y privilegios que dificultaban enormemente a las no oficiales competir con ellas. Una vez erigidas como tales, contarían con un trato preferente y la recomendación expresa de la Comisión como representante de la administración diocesana:

Las "Schola Cantorum" y "Capillas" que se formen y que tan eficazmente recomienda Nuestro Santísimo Padre en su "Motu Proprio" (VII 25, 27 y 28), deberán por esta razón tener la preferencia para el servicio de la parte musical en las funciones religiosas de la Archidiócesis; recomendándose a todos los Sres. Encargados de Iglesias, Comunidades y Hermandades esta preferencia en igualdad de circunstancias, por ser este el medio más apto y eficaz, a juicio de su Santidad, para realizar la restauración ordenada en este orden. ${ }^{86}$

Sin duda, el privilegio más importante del que disfrutarían era la potestad de usar orquesta en el ámbito de la liturgia según el propio criterio, sin necesidad de permiso especial por parte del Ordinario:

Véase capítulo 6, epígrafe 1.2. "Intérpretes de música religiosa propuestos por el Congreso como ejemplares", p. 509.

${ }^{86}$ La Comisión, "Música sagrada", p. 397. 
Estas "Schola" y "Capillas", por el solo hecho de ser aprobado por la Jurisdicción Ordinaria el "Reglamento" que habrán de formar al constituirse, y presentarán por duplicado en la Secretaría de Cámara, acompañado de una solicitud en forma, quedarán autorizadas para el servicio de toda clase de funciones religiosas en la Archidiócesis, con o sin orquesta, sin necesitar en cada caso permiso especial para usar de esta. ${ }^{87}$

De esta forma, el arzobispo delegaba en estos grupos una competencia que, según la ley eclesiástica, sólo a él correspondía. De este privilegio no disfrutaron ni siquiera aquellos que habían obtenido el título de director de capilla musical ${ }^{88}$. Naturalmente, la autoridad episcopal se reservaba el derecho a revocar el título de director o a disolver la schola o capilla en caso de incumplimiento o ineptitud ${ }^{89}$.

Si cotejamos, de nuevo, lo dispuesto por la CDMS hispalense y el Reglamento vallisoletano, hallamos en la regulación de los grupos musicales que intervenían en las funciones litúrgicas, la diferencia más importante entre los intentos por reestructurar e institucionalizar los recursos humanos relacionados con la música llevados a cabo por la administración eclesiástica andaluza y las castellanas. La norma vallisoletana no contempló la posibilidad de incorporar a la oficialidad estos conjuntos. Su propuesta de regulación de los músicos eclesiásticos se redujo, además de a organistas y cantores de oficio, a los directores. Sobre los músicos que bajo su autoridad actuaran en los actos de culto se limitó a disponer:

12. En las funciones religiosas podrán tomar parte los aficionados o profesores, ya cantores ya instrumentistas, no sujetos en la iglesia a cargo alguno oficial, ni autorizados para estos servicios con nombramiento alguno particular; pero de su gestión y comportamiento en el coro responderá el director o encargado de la parte musical. ${ }^{90}$

${ }^{87}$ Ibídem.

88 "Privilegio que, para fomentar la formación de tales 'Schola' y 'Capillas', se le concede y de que no disfrutarán los 'Directores' u 'Organizadores' de que hace mención el párrafo anterior, quienes por tanto, cuando hayan de servir funciones religiosas con pequeña o grande orquesta, quedarán obligados a solicitarlo de la Jurisdicción Episcopal en cada caso, [...]." La Comisión, "Música sagrada", p. 397.

89 “Las 'Capillas' y 'Schola' podrán ser disueltas por su Excelencia Reverendísima, cuando por incumplimiento de su Reglamento o ineptitud para cumplir los fines de su institución, a juicio de la Comisión Diocesana de Música Sagrada, sean por esta denunciadas en informe razonado.” Ibídem.

90 “Edicto y Reglamentos", p. 338. 
Hay que sostener, por tanto, que el proyecto hispalense fue más ambicioso que el vallisoletano, pues creó el concepto de grupo musical eclesiástico oficial, coral o coral-instrumental, con un estatus, además, envidiable. De esta forma, trató de integrar en la oficialidad a la totalidad del colectivo de músicos al servicio del templo, independientemente de su perfil o relación previa con la institución eclesiástica.

La cita anterior muestra que, en la provincia eclesiástica castellana, los cantores e instrumentistas que componían los grupos musicales litúrgicos, potenciales miembros, en caso de que existiera la posibilidad, de scholae y capillas musicales oficiales, siguieron excluidos del organigrama oficial sin derechos adquiridos en base a una norma aprobada por la autoridad eclesiástica, como era un reglamento. Mantuvieron como único derecho el de tener permiso para servir en el templo, eso sí, bajo la autoridad y responsabilidad del director. Por tanto, los coros y conjuntos vocales-instrumentales se debieron seguir contemplando como agrupaciones más o menos eventuales de músicos con fines lucrativos, sin necesidad de regulación, formadas para cubrir las necesidades musicales asociadas a determinadas funciones religiosas. En este sentido, el título del epígrafe en el que figura el artículo 12 -el único que contiene- antes transcrito es bastante significativo: "IV. De los aficionados y músicos que no lo son de oficio"91. En el caso castellano, la figura en la que se concentró toda la responsabilidad fue la del director, cuyas competencias desbordaban lo meramente musical, ante la ausencia de una norma interna que gobernara estos grupos. No obstante, la importante facultad de poder decidir sobre el uso o no de orquesta permaneció, a diferencia del caso de las capillas musicales sevillanas, en manos del prelado, como establecía el $M P$.

\subsubsection{Recepción por parte de directores y grupos de las medidas para la} regulación de sus oficios en el ámbito eclesiástico

Restaría, en último lugar, hacer un intento de balance sobre la respuesta que este intento de oficialización de directores y grupos musicales tuvo por parte de los interesados, en consecuencia, si las disposiciones alcanzaron su objetivo de regularizar estos colectivos en el seno de la institución diocesana. En contraste con la falta de documentación con la que fundamentar una evaluación pormenorizada del proceso de

\footnotetext{
${ }^{91}$ Ibídem.
} 
renovación del repertorio vigente en la Archidiócesis, contamos, en este caso, con valiosos datos, unos publicados en el BOAS, y otros, inéditos.

El apartado e) del punto $3^{\circ}$ de la exposición de medios, dedicado a establecer los principios para la constitución y promoción de scholae cantorum y capillas musicales de carácter oficial, contemplaba el siguiente compromiso: “Así la institución como la disolución de cada 'Capilla' o 'Schola Cantorum' de esta Archidiócesis, se anunciará para conocimiento y tranquilidad de todos aquellos a quienes interesar debe, en la parte Oficial del Boletín Eclesiástico." ${ }^{92}$ Esta disposición se comenzó a llevar a efecto tan sólo mes y medio después con la publicación en el BOAS de la primera relación de scholae y capillas que habían obtenido la certificación oficial ${ }^{93}$. Junto a estos grupos figuraron, además, los solicitantes a los que se les concedió el título de director de capilla musical. Esta fue la primera y única vez que se cumplió aquel compromiso, no volviéndose a insertar en el BOAS ninguna comunicación más al respecto.

No obstante, en nuestras indagaciones en el AGAS hemos podido hallar las solicitudes hechas por cada aspirante a obtener el título de director de capilla, así como los informes correspondientes de la Comisión con la valoración de sus capacidades y el dictamen favorable respecto a su archivo personal ${ }^{94}$. Tanto las solicitudes de los candidatos como los informes de la Comisión nos suministran interesantes datos referidos tanto a los aspectos personal como profesional de estos músicos religiosos en activo en aquel momento. Gracias a este documentario podemos saber, además, que las solicitudes estimadas por la Comisión y los títulos de director de capilla concedidos fueron algunos más que los que finalmente se dieron a conocer en el BOAS. Concesión de títulos que, en perjuicio de los intereses de sus beneficiarios, no serían jamás difundidas.

Sólo tres grupos obtuvieron la certificación oficial: la Capilla Mariana, la Schola Cantorum de Santa Cecilia, y la Capilla Isidoriana. La Capilla Mariana estaba presidida por Agapito Insausti, y dirigida por Vicente Ripollés. Se trataba, por tanto, de una iniciativa de los propios músicos catedralicios, integrantes, además, de la $\mathrm{CDMS}^{95}$.

\footnotetext{
92 La Comisión, "Música sagrada”, pp. 397-398.

${ }^{93}$ La Comisión, “Comisión Diocesana de Música Sagrada”, BOAS, 671 (1909), pp. 39-40.

${ }^{94}$ AGAS. Sección Gobierno. Asuntos Despachados, leg. 04909 (1909).

${ }^{95}$ La Comisión, “Comisión Diocesana de Música Sagrada”, p. 39.
} 
En principio, este proyecto nació con el nombre de Capilla de Música de María Inmaculada, y estuvo ya perfilado a finales de 1908. Así lo atestigua un acta capitular de 22 de diciembre de ese año, en la que se hace constar la solicitud realizada al Cabildo por José Ibáñez, José Otero -contralto y salmista catedralicios respectivamente- y Vicente Ripollés. El objeto de esta solicitud fue conseguir el permiso del Cabildo para poder disponer de algún local en el Colegio de San Miguel como lugar de ensayos ${ }^{96}$. La Capilla Mariana fue el único grupo de Sevilla capital que obtuvo la credencial de Capilla de música oficial. La Schola Cantorum de Santa Cecilia, y la Capilla Isidoriana tenían sus sedes en Carmona. Estaban presididas y dirigidas por organistas de distintas parroquias de esta ciudad, ubicada al noreste de la capital, en la comarca de Los Alcores $^{97}$.

Contemplando estos datos, llaman la atención dos hechos significativos. Por un lado, la parca respuesta que tuvo esta medida en el conjunto de la Archidiócesis; especialmente en la capital, con tan sólo una solicitud de título oficial, realizada, además, por aquellos que la habían ideado y propuesto. Por otro, el notable éxito que la iniciativa conoció en Carmona. Es posible que detrás de este éxito estuviera la influencia efectiva del propio presidente de la CDMS, Rafael González Merchant, carmonense de nacimiento.

Si tres fueron los títulos oficiales de scholae y capillas expedidos por la jurisdicción arzobispal, cuatro fueron los concedidos de director u organizador de capilla musical. Los publicados en el BOAS fueron los obtenidos por Álvaro Infante y Florencio Orge, sochantres de las parroquias sevillanas de San Pedro y San Esteban respectivamente ${ }^{98}$. Los que no llegaron a publicarse fueron los concedidos a Francisco J. Caballero y Maldoqui, y a Manuel Pardo García ${ }^{99}$.

Francisco J. Caballero, vecino de El Puerto de Santa María aunque natural de Cádiz, se presentaba como "Director de Orquesta, Maestro Concertador y profesor de

\footnotetext{
${ }^{96}$ AC 22/12/1908. ACS. Sección Secretaría, libro 228, fol. 44v.

${ }^{97}$ La Schola Cantorum de Santa Cecilia estaba presidida por Antonio Salas, organista de la Iglesia parroquial del Salvador. Su director era José Ma Álvarez, organista de la Iglesia prioral de Santa María. Francisco Rodríguez, organista de la Iglesia de San Felipe, era el presidente y director de la Capilla Isidoriana. La Comisión, "Comisión Diocesana de Música Sagrada”, p. 39.

${ }^{98}$ Sus solicitudes tienen fecha de 7 y 12 de junio, siendo resueltas la primera el 13 y la segunda el 15 de
dicho mes. Ibídem.
} ${ }^{99}$ AGAS. Sección Gobierno. Asuntos Despachados, leg. 04909 (1909). 
violín de la Academia de Bellas Artes de esta Ciudad [de El Puerto]". Afirmaba llevar quince años encargado de las funciones religiosas que se celebraban tanto en la ciudad como en toda la comarca, en las que dirigía una capilla vocal acompañada de pequeña o gran orquesta $^{100}$. Este músico gaditano debió gozar de cierto renombre a juzgar por las tres páginas que en su Galería de músicos andaluces (1927) le dedicó Francisco Cuenca $^{101}$.

Manuel Pardo, “de profesión Tenor de las capillas de música Sagrada de esta Capital [Sevilla]" fue el último de los beneficiarios del título de director ${ }^{102}$. Pardo disfrutó de concesiones especiales, "habida consideración de razones muy atendibles en este caso", como, nada más y nada menos, "la facultad pro gratia y ad nutum de poder usar en las funciones sagradas que se le encomienden de pequeña orquesta (órgano, harmonium, cuarteto de cuerda y los instrumentos de madera convenientes)". Estaba obligado únicamente a solicitar la autorización debida en el caso de usar instrumentos de metal ${ }^{103}$. Recordemos que este privilegio estaba reservado, de forma exclusiva, a las scholae y capillas musicales oficiales. Es obvio que gozó de la plena confianza de la CDMS.

En cualquier caso, a todos los solicitantes, incluido Manuel Pardo, se les exigió adjuntar a sus solicitudes el repertorio de obras a utilizar en las funciones religiosas en las que tomaran parte, para ser examinado por la Comisión. A los dos primeros se les concedió el título previa promesa de no usar más que aquellas obras presentadas y aprobadas por la Comisión. Todos debían, además, enseñar el título a los párrocos o rectores de las iglesias donde fueran a actuar, aunque estos no se lo requirieran. Los informes emitidos sobre la capacitación profesional de los aspirantes y sobre la idoneidad de sus archivos estaban sellados con cuño y número de registro propio de la $\mathrm{CDMS}^{104}$.

\footnotetext{
${ }^{100}$ Ibídem.

${ }^{101}$ Cuenca Benet, Galería de músicos andaluces, pp. 45-47.

${ }^{102}$ AGAS. Sección Gobierno. Asuntos Despachados, leg. 04909 (1909).

${ }^{103}$ Ibídem.
}

104 Ibídem. Debió existir, pues, un libro de registro en el que debieron figurar los archivos de las parroquias, comunidades y hermandades examinados. Este libro de registro sería una fuente ciertamente importante de la que no hemos hallado rastro alguno en el AGAS. La Comisión de Música Sagrada de la diócesis de Mallorca produjo el Registro de composiciones musicales aprobadas por la Comisión de Arte Sacro Musical. Véase: J. Roselló i Literas, "Registro de composiciones musicales aprobadas por la Comisión de Arte Sacro Musical." Actas del X Simpòsium i Jornades Internacionals de l'Orgue Históric 
Si consideramos, por un lado, las enormes dimensiones de la Archidiócesis y la prolífica actividad litúrgica-musical, nutrida, además, de la religiosidad popular, cuyas manifestaciones tenían un peso bastante importante en la cultura autóctona; y por otro, que sólo se expidieron tres títulos oficiales de schola o capilla musical -uno de los cuales lo obtendrían los propios responsables de la Comisión y los otros dos estarían concentrados en una sola localidad-, y cuatro de director y organizador de capilla -tan sólo uno concedido a un músico de fuera de la capital-, tenemos que concluir que el intento de oficialización de los oficios musicales religiosos fue, en gran medida, un fracaso. Fracaso achacable, suponemos, principalmente a esta ínfima respuesta del colectivo de músicos religiosos, aunque también a una cierta inconstancia de la propia Comisión reflejada, por ejemplo, en su falta de cumplimiento del compromiso de publicar en el BOAS los títulos que se fueran expidiendo. La publicación periódica de la relación de beneficiarios de estos títulos habría lanzado, a nuestro juicio, un mensaje de seriedad a músicos religiosos y a administradores de templos.

\subsubsection{Sochantres y organistas}

Del resto del personal músico, sochantres y organistas, se ocupó la Comisión en una circular posterior, la $\mathrm{n}^{\mathrm{o}} 20$ publicada el 30 de julio ${ }^{105}$. En realidad, las disposiciones que en ella se establecieron no distaron mucho de las fijadas en su momento durante el pontificado de Spínola: en primer lugar, que los sochantres y organistas que aspiraran a ocupar una plaza en alguna de las iglesias o congregaciones de la Archidiócesis debían poseer el título oficial que acreditara su capacidad. Para ello debían superar un examen ante un tribunal nombrado por el arzobispo. En segundo lugar, que los que ya estuvieran en posesión de dicho título podían seguir ejerciendo sin someterse a este examen aunque -citamos literalmente para mostrar el estilo usado al dirigirse a estos músicos-

no lo harán, sin embargo, sino sometiéndose inmediatamente y en absoluto, bajo la vigilancia y responsabilidad de los Sres. Párrocos y Rectores de las iglesias en que prestan sus servicios, a los preceptos emanados de la S. Sede en este punto, y a las disposiciones,

de les Balears. X Trobada de Documentalistes Musicals Palma de Mallorca 2003. (Palma de Mallorca: Fundación ACA, 2004).

${ }^{105}$ La Comisión, “Circular núm. 20. Comisión Diocesana de Música Sagrada”, BOAS, 672 (1909), pp. 5859. 
que de conformidad con ellos, ha dictado y dictare en lo sucesivo la Autoridad de V.E.R. ${ }^{106}$

Por último, se prohibía a aquellos no titulados seguir ejerciendo en sus puestos a partir de ese momento. A igual que ocurrió en el caso de los directores, se cargó a los administradores de templos con la responsabilidad de la aplicación de todas estas medidas, convirtiéndose también en este punto en el colectivo del que dependía el éxito de la reforma ${ }^{107}$.

Así pues, el intento de regulación de los oficios de sochantre y organista consistió en la recuperación de lo fijado al respecto por la Comisión de Spínola, aunque en esta segunda etapa sin la existencia de la Escuela Oficial de Canto Gregoriano, y con una diferencia formal: el certificado que hubiera expedido la escuela finalmente frustrada pasaría a ser un título oficial concedido directamente por la autoridad arzobispal. El hecho de que en 1909 se volviera a prescribir la obligación de someter a un examen a aquellos que estuvieran ejerciendo sin el correspondiente título indica que la pretensión de la CDMS de Spínola consistente en que todos los sochantres y organistas con plazas y en activo estuvieran en posesión del certificado de capacitación en 1906 no se hizo realidad.

En síntesis, con la recuperación de las disposiciones que regulaban los oficios de organista y sochantre dictadas durante el pontificado de Spínola se completó la propuesta de establecer un sistema institucional que integrara a todos los músicos eclesiásticos bajo la condición de oficialidad. La implantación de los principios del MP relacionados con la dignidad de los músicos en su condición de actores litúrgicos llevó a la CDMS hispalense a la regulación de las distintas actividades musicales religiosas a través de títulos oficiales. Estos otorgaron a los músicos eclesiásticos ciertos derechos y comportaron, a su vez, obligaciones; les reconocieron capacidades, cualidades y formación; y les facultaron para ejercer un trabajo, colaborando en una mayor dignificación de estas profesiones o actividades. Creemos entrever en este proyecto una suerte de impulso regeneracionista, inscrito en las tendencias del momento, y que demostraría que el $M P$ operó como un catalizador dentro de la esfera eclesial de las

\footnotetext{
${ }^{106}$ La Comisión, "Circular núm. 20.", p. 59. El Reglamento General para la música sagrada en la Provincia Eclesiástica de Valladolid disponía que sochantres y organistas debían someterse a exámenes periódicos. El prelado podía eximir de cualquier examen a los mayores de sesenta años y aquellos que estuvieran en circunstancias particulares. "Edicto y Reglamentos", p. 337.

107،“Circular núm. 20.”, p. 59.
} 
energías renovadoras y rehabilitadoras, que circulaban en determinados grupos y ambientes culturales y musicales de la España de la Restauración. Sin duda, la celebración del II Congreso Nacional de Música Sagrada, un acontecimiento animado por un espíritu regeneracionista, como demostraremos en su momento, sirvió de revulsivo, al menos para la alta jerarquía diocesana -Comisión y arzobispo-, a la hora de asumir estas ambiciosas empresas ${ }^{108}$.

Aún reconociendo el valor de este importante paso para la dignificación de los músicos religiosos, hay que admitir que resultó insuficiente. En las discusiones mantenidas en distintos congresos nacionales de música sagrada siguió aflorando como cuestión irresoluta la situación de este colectivo. Como ya hemos apuntado, sus indisciplina, irresponsabilidad e incluso actitudes inmorales, así como ignorancia e incompetencia fueron denunciadas en repetidas ocasiones. Algunas de las voces que tomaron parte activa en los congresos nacionales de música sagrada, apuntaron como raíces de estos males a la falta de formación y precariedad laboral que sufrían ${ }^{109}$. Y es que ni la administración eclesial ni el movimiento reformista, como comprobaremos, se ocuparon de solucionar estos problemas, o no fueron capaces de hacerlo. En el caso de Sevilla, la Iglesia no encontró medios para crear una estructura educativa básica con la que formar a sus músicos seglares, como demuestra el fracaso de la Escuela Oficial Archidiocesana de Canto Gregoriano; y, ni siquiera se planteó, de forma paralela a la creación de estos títulos, el problema que suponía la paupérrima remuneración que recibían, especialmente los fijos, sochantres y organistas, para lograr una verdadera dignificación de estos oficios ${ }^{110}$.

Esta casuística, pensamos, no es más que el reflejo de la delicada situación social y económica que atravesaba la Iglesia, sufrida de forma más cruda por sus grupos humanos más vulnerables. Este impulso regenerador, insuficiente por no contar con los medios necesarios, estaba abocado al fracaso. La situación de acentuada decadencia en

\footnotetext{
${ }^{108}$ Sobre la influencia del espíritu regeneracionista en el Congreso, véase el capítulo 6.

${ }^{109}$ Véanse las intervenciones de dos participantes andaluces en el congreso de Vitoria (1928), Antonio Gessa Loaysa y Carmelo Codinach, en epígrafe 3.2.2. "La situación económica de los músicos eclesiásticos" del capítulo quinto.
}

110 En el apartado 3.2.3. "La situación económica de los músicos eclesiásticos" del capítulo 5 nos encargamos de la situación de los músicos eclesiásticos y toda la problemática que les rodeaba. 
la que se encontraba la Iglesia a principios de siglo fue un obstáculo insalvable. Las afirmaciones de Spínola al comienzo del proceso resultaron proféticas.

\subsubsection{Medidas conminadoras para administradores de templos}

A lo largo de todo este capítulo se ha ido poniendo en evidencia que el estamento clave dentro del organigrama archidiocesano para la consecución de la reforma fue el de los administradores de templos. La razón de su importancia radicó, como ya hemos señalado, en la posición estratégica que ocupaba al estar en contacto directo con la realidad litúrgico-musical concreta y cotidiana. Ya Spínola en 1905 les hizo responsable de la "fiel ejecución" de las disposiciones que él mismo había promulgado $^{111}$. Acabamos de comprobar que durante la etapa de Almaraz, la Comisión fue trasvasando a los administradores de templos la responsabilidad de hacer cumplir todas y cada una de las medidas que iba tomando. En consecuencia, hizo depender de este colectivo el éxito de este nuevo intento reformista, además, en un plazo breve, cual era su objetivo. Compendiamos, a continuación, las resoluciones que en este sentido fue tomando:

1) Responsables en la implantación de la nueva edición vaticana de canto gregoriano:

[...] esta Comisión entiende que no puede tolerarse ya por más tiempo el uso de los cantorales o libros de coro hoy existentes en las iglesias del Arzobispado, en lo que al canto de la Santa Misa se refiere, debiendo adoptarse inmediatamente en todas la "Edición Vaticana", y no consintiendo por título alguno los Sres. Párrocos, Rectores y Encargados de iglesias que en las que respectivamente están a su cargo se ejecuten otras melodías, así para el canto de las partes "variables" como de las fijas de la Santa Misa y demás funciones litúrgicas, que las publicadas en la citada "Edición".112

2) Colaboradores imprescindibles en el mecanismo de depuración del repertorio establecido por la Comisión:

b) Cuando en virtud del turno que se establezca se pida a los Sres. Párrocos y Arciprestes en su caso [los primeros eran los responsables en la capital; los segundos para el resto de la Diócesis]

\footnotetext{
${ }^{111}$ Véase capítulo 1, epígrafe 5. "Recepción y respuesta de administradores de templos a la reforma", p. 113.

${ }^{112}$ La Comisión, “Música Sagrada”, BOAS, 667 (1909), p. 394.
} 
los archivos musicales para su examen, exigirán a los Sres. Rectores de iglesias, Comunidades religiosas sujetas a la Jurisdicción Episcopal y Hermandades y Asociaciones establecidas en el territorio de su Jurisdicción, los archivos musicales de su pertenencia, que, juntos con el de la Parroquia respectiva, se enviarán a la Secretaría de Cámara, acompañados de una nota sellada con el de la entidad a que corresponda, y en la que se numeren las obras y se exprese el título, $[\ldots]$

c) $\mathrm{Si}$ antes de concluir el examen de todos los Archivos musicales de la Archidiócesis, alguna Comunidad o Asociación necesita, por circunstancias especiales, utilizar algunas obras de su repertorio, puede remitirlas inmediatamente, [...] siempre por conducto del Párroco o Arcipreste respectivo. ${ }^{113}$

3) Únicos encargados de la sustitución del patrimonio musical desechado por la Comisión:

[...] esta Comisión, cumpliendo el honroso encargo que nuestro Excmo. y Reverendísimo Prelado se ha dignado confiarle, recomienda a los señores Párrocos y Rectores de Iglesias, así como a las Comunidades, Cofradías y Asociaciones religiosas, que se provean de aquellas composiciones musicales que sean necesarias para el servicio de sus cultos $[\ldots]^{114}$

4) Garantes del efecto de la exclusividad y de los privilegios de los títulos de director y capilla musical respectivamente, por tanto, del éxito del proyecto de regulación y oficialización de los cargos musicales diocesanos:

Por tanto, los Sres. Párrocos y Rectores no podrán en adelante admitir en sus iglesias en concepto de Organizador o director de la Capilla musical a ninguno que no les exhiba el Título oficial que ha de habilitarle para el desempeño de este ministerio $[\ldots]^{115}$

Las "Schola Cantorum" y "Capillas" que se formen $[\ldots]$ deberán por esta razón tener la preferencia para el servicio de la parte musical en las funciones religiosas de la Archidiócesis; recomendándose a todos los Sres. Encargados de Iglesias, Comunidades y Hermandades esta preferencia en igualdad de

\footnotetext{
${ }^{113}$ Ibídem, p. 396.

${ }^{114}$ La Comisión, “Comisión Diocesana de Música Sagrada. Circular”, BOAS, 663 (1909), p. 287. En esta circular la comisión aconsejaba para ello, solicitar los catálogos de obras con aprobación eclesiástica que a su disposición ponían las editoriales que a continuación se enumeraban.

${ }^{115}$ La Comisión, “Música Sagrada”, p. 395.
} 
circunstancias, por ser este el medio más apto y eficaz, a juicio de su Santidad, para realizar la restauración ordenada en este orden. ${ }^{116}$

[...] la Comisión Diocesana para toda la Archidiócesis, y los Sres. Arciprestes y Párrocos respecto de los territorios sometidos a su jurisdicción [quedan] obligados bajo su más estrecha responsabilidad a velar por el exacto cumplimiento de estas disposiciones. ${ }^{117}$

Se hacen patentes, por tanto, las funciones que terminaron desarrollando tanto la Comisión como los administradores de templos. La primera estableció normas y procedimientos, e ideó medios. Sobre el segundo recayó todo el peso de procurar, y vigilar por, que se cumplieran las disposiciones de aquella, así como las episcopales y papales. Sin embargo, en contraste con las importantes responsabilidades que se le confiaron, las continuas denuncias y advertencias sobre incumplimientos hechas por la Comisión durante la etapa de Spínola indican que su comportamiento no fue precisamente favorable ni dócil respecto a la reforma.

A finales de 1907, Ripollés confesaba a Pedrell su pesimismo en relación a la actitud del clero frente a la cuestión litúrgico-musical, y planteaba la que, según su punto de vista, representaba la única solución al problema:

Nulla est redemtio [sic]: si no se coje [sic] el báculo por quién puede y se descargan suspensiones a dextris et sinistris, en vano trabajaremos, escribiremos y predicaremos. El clero es completamente indiferente a la Música sagrada, y mientras no se le haga salir de ese frio glacial en que está, in vanum laboraverunt. Estoy bastante pesimista, pero es porque a diario palpo lo que a diario pasa en el interior del santuario. ${ }^{118}$

Casi un par de años antes, Otaño comentaba, también a Pedrell, la seriedad con que el arzobispo de Valladolid había enfrentado el reto de la reforma. Una seriedad que se traducía en lo que al clero respecta en la adopción de una actitud severa, y, en caso necesario, de fuertes medidas sancionadoras, en la línea apuntada por Ripollés:

El Sr. Arzobispo va por lo sano. Ha mandado venir a dos Benedictinos: uno de ellos el P. Casiano Rojo, y ha obligado a todos

\footnotetext{
${ }^{116}$ Ibídem, p. 397.

${ }^{117}$ La Comisión, “Circular núm. 20.”, p. 59. Ignoramos el modo en el que la Comisión debía ejercer de hecho su vigilancia sobre toda la Archidiócesis. Suponemos que, en realidad, este párrafo venía a hacer constar, más como mero trámite que con otra intención, la estructura jerarquía de la autoridad establecida.

${ }^{118}$ Carta de Ripollés a Pedrell, 29 de octubre de 1907. BC. FFP. M 964 R.
} 
los de la Catedral y a todos los de las Parroquias se impongan en el canto gregoriano. A las cinco faltas pierden la plaza que poseen. Esto por lo tanto va bien. ${ }^{119}$

Este testimonio prueba que el desacato y resistencia a la colaboración que exhibieron los administradores de templos en Sevilla fue un mal generalizado, cuyo único remedio a corto plazo, imponer medidas drásticas, nos proporciona una idea del grado de enquistamiento del problema.

Como pudimos comprobar, desde su primera circular en marzo de 1909, Almaraz empleó a la hora de dirigirse a este colectivo un tono mucho más duro que el de su antecesor. Es evidente que el objetivo era reconducir la actitud de estos eclesiásticos:

Es, pues, necesario, que los Sres. Párrocos, Rectores de Iglesia y Comunidades religiosas, presten la atención debida a lo que con tanto encarecimiento ordena la Iglesia; pues de lo contrario sería la resistencia pasiva un acto muy cercano a la rebeldía y desobediencia. $^{120}$

Efectivamente, dado que el $M P$ había adquirido rango de ley universal de obligado cumplimiento, el no acatamiento a sus mandatos suponía un acto de desobediencia, e incluso, de desprecio a la autoridad de la Iglesia:

Por último, se recomienda a los maestros de capilla, cantores, eclesiásticos, superiores de seminarios, de institutos eclesiásticos y de comunidades religiosas, a los párrocos y rectores de iglesias, a los canónigos de colegiatas y catedrales, y sobre todo a los Ordinarios diocesanos, que favorezcan con todo celo estas prudentes reformas, desde hace mucho deseadas y por todos unánimemente pedidas, para que no caiga en desprecio la misma autoridad de la Iglesia, que repetidamente las ha propuesto y ahora de nuevo las inculca. ${ }^{121}$

Sin embargo, el cambio de registro de Almaraz no surtió gran efecto. El incumplimiento de las disposiciones dictadas por el prelado hispalense en la citada circular llevó a la Comisión a realizar un nuevo apercibimiento; esta vez en forma de amenaza, enfatizada, además, por el uso de mayúsculas:

\footnotetext{
${ }^{119}$ Carta de Otaño a Pedrell, 16 de diciembre de 1905. AMSL. FO. Correspondencia, T01/004.

${ }^{120}$ Enrique [Almaraz], “Circular nº 18 sobre Música Sagrada”, BOAS, 661 (1909), p. 248.

${ }^{121}$ MP. Título IX. Conclusión, art. 29.
} 
Es necesario que se reproduzcan con nuevo vigor los mandatos contenidos en la referida Circular [ $\left.\mathrm{n}^{\circ} 18\right]$, intimando ya a los Sres. Arciprestes respecto de los territorios de su Jurisdicción, a los Sres. Párrocos y Rectores de iglesias, Superiores de Comunidades religiosas, Hermanos mayores o Presidentes de Hermandades y Asociaciones, y en una palabra, a todos aquellos a quienes afectan, su más estricto y exacto cumplimiento, ya que para todos son de suma autoridad indiscutible y sagrada estas palabras: "Vigilen mucho los Reverendísimos Ordinarios sobre Párrocos y Rectores de iglesias, para que no permitan ejecuciones musicales contrarias a las prescripciones de este Reglamento, VALIÉNDOSE SEGÚN SU ARBITRIO Y PRUDENCIA, DE LAS PENAS CANÓNICAS CONTRA LOS DESOBEDIENTES [Mayúsculas originales, tal y como figuran en el texto presentado por la CDMS sevillana]."122

La cita es del Reglamento para la Música Sagrada sancionado por la Sagrada Congregación de Ritos por Decreto de 21 de julio de $1894^{123}$. En el texto original del Reglamento todo el fragmento está en minúsculas.

No hemos hallado dato alguno o indicio que pueda llevar a pensar en que estas amenazas se materializaran realmente en la aplicación de la ley canónica a los infractores. Por tanto, a no ser que aparezcan pruebas que demuestren lo contrario, habría que afirmar que la fórmula empleada para conseguir que los administradores de templos asumieran su responsabilidad y cumplieran con los importantes cometidos asignados no pasó del discurso conminador; una respuesta insuficiente, si asumimos, con Ripollés y el arzobispo de Valladolid, que la única solución para conseguir la colaboración del clero era castigar con "penas canónicas" a los "desobedientes", tal y como disponía la Sagrada Congregación de Ritos. De hecho, el pasaje en la que figura la advertencia de dicha Congregación -transcrito en mayúsculas más arriba- venía antecedido de otra denuncia sobre incumplimientos realizada por la Comisión. Esta vez las disposiciones no respetadas eran las contenidas en la circular $\mathrm{n}^{\circ} 18$, publicada sólo dos meses y medio antes, en la que Almaraz, en un tono mucho más severo, estableció el punto de partida del intento reformista tras la celebración del Congreso:

Graves son sin duda las dificultades y obstáculos que a esta, como a toda reforma y corrección de inveterados abusos, se oponen; y esto es, a no dudarlo, la causa de que aún no se observen, como comprueban hechos lamentables y recientes, con entera fidelidad y

\footnotetext{
${ }^{122}$ La Comisión, "Música Sagrada”, BOAS, 667(1909), p. 395.

${ }^{123}$ Cotejado con la traducción al castellano publicada en Otaño, La Música Religiosa, p. 81.
} 
exactitud las disposiciones dictadas sobre este punto por V.E.R. en la circular antes citada. ${ }^{124}$

Con todo, un año después de esta queja de la Comisión, Almaraz hacía la siguiente valoración sobre la marcha de la reforma:

Gracias sean dadas a Dios y a la buena voluntad de nuestros amados sacerdotes, no es poco lo que se ha conseguido hasta la hora presente; pues tanto en la Santa Iglesia Metropolitana como en otros muchos templos de la Diócesis, la reforma del canto litúrgico puede asegurarse que no ha encontrado aquellas dificultades que a muchos parecían insuperables.

Mas todavía son de esperar mayores adelantos y progresos. ${ }^{125}$

Sin duda, contrasta radicalmente tanto en el fondo como en la forma con las que hasta ahora hemos ido proporcionando. Por primera vez durante todo el proceso se hacía una apreciación positiva sobre la actitud -"buena voluntad"- de "nuestros amados sacerdotes", y se rebajaba el grado de dificultad que suponía la reforma. Aunque pueda extrañar un cambio tan drástico en tan poco tiempo, esta declaración de Almaraz obliga a rehuir cualquier conclusión excesivamente negativa, y a contemplar la posibilidad de que, al menos, en determinados lugares, estas medidas causaran efecto. En este sentido, tenemos constancia de la fructífera labor que desarrolló el cura Manuel González Serna junto con el resto de sus coadjutores en la parroquia de San Pedro, perteneciente al entonces arciprestazgo de Huelva ${ }^{126}$. Por invitación de Almaraz, el párroco onubense expuso su experiencia en una de las sesiones del II Congreso Nacional de Música Sagrada. Se trata, no obstante, del único testimonio que podemos aportar.

En conclusión, el proceso de reformas durante el pontificado de Enrique Almaraz se topó, al igual que ocurriera en la etapa de Spínola, con la resistencia e indiferencia de administradores de templos -párrocos y rectores de iglesias-, colectivo clave para el éxito de la reforma. Tan sólo al final del proceso de concreción normativa dentro del ámbito archidiocesano del MP, que concluyó a mediados de 1910, encontramos una valoración favorable sobre la actitud de estos eclesiásticos por parte

\footnotetext{
${ }^{124}$ La Comisión, "Música Sagrada”, p. 398.

${ }^{125}$ Enrique [Almaraz]. Arzobispo de Sevilla, "Circular" [en índice del tomo figura como:"Circular de Ntro. Excmo. Prelado y Reglamento de Música Sagrada para esta Diócesis”, BOAS, 690 (1910), p. 451.

${ }^{126}$ Véase capítulo 5, epígrafe 5.2. "El fracaso institucional”, pp. 496-497.
} 
del arzobispo. De estas apreciaciones de Almaraz se desprende que, tras varios años de resultados, en gran medida, infructuosos, se empezó a reconocer una cierta transformación de la realidad, empezando por la Catedral y otros templos.

$\mathrm{Al}$ análisis del proceso de reformas en la Iglesia metropolitana dedicaremos la Parte II de esta tesis. Indagaremos, además, en los avatares relacionados con el intento de implantación de las disposiciones papales, episcopales y de la CDMS en la Catedral como primer y referencial templo de la Archidiócesis, en busca de claves ideológicas y culturales a interpretar para explicar las razones de la resistencia exhibida por el clero a la renovación litúrgico-musical. No obstante, dedicaremos antes un último epígrafe a un documento valioso y trascendental del proceso propiamente hispalense.

\section{La culminación del proceso normativo: El Reglamento de Música} Sagrada para la Archidiócesis de Sevilla (1910)

El 2 de mayo de 1910 se dio a conocer el fruto definitivo del esfuerzo de Almaraz y su CDMS por hacer realidad la reforma: el Reglamento de Música Sagrada para la Archidiócesis de Sevilla. Se trata de un extenso y minucioso documento pensado como la norma general que debía regular a partir de entonces todo lo referente con la música sagrada en la Archidiócesis. En un principio, fue publicado en tres entregas a lo largo del mes de mayo y principios de junio ${ }^{127}$. Más adelante, se imprimió en un único volumen como separata del BOAS.

Consta de dieciséis capítulos más un apéndice, y un total de sesenta y dos artículos. El formato separata incluye, además, doscientas cuarenta y cuatro notas aclaratorias, con explicaciones, algunas de ellas ciertamente extensas, sobre los fundamentos legales de cada una de sus disposiciones. Está articulado en dos grandes secciones. La primera está dedicada a establecer los fundamentos generales de la música sagrada en todas sus expresiones, así como su interpretación. La segunda es un ceremonial que regula la intervención musical en cada momento de las funciones. Se trata del ceremonial de acuerdo al $M P$ más detallado del que tenemos conocimiento hasta el momento en España. En la siguiente tabla ofrecemos el título de cada uno de los capítulos, y en el Apéndice 4 una síntesis de ellos.

127 "Circular de Ntro. Excmo. Prelado y Reglamento de Música Sagrada para esta Diócesis” BOAS, 690 [de 2 de mayo] (1910), pp. 451-461; "Reglamento de Música Sagrada (continuación)”, BOAS, 691 [de 16 de mayo] (1910), pp. 562-567; "Reglamento de la Música Sagrada (conclusión)”, BOAS, 692 [de 1 de junio] (1910), pp. 571-577. 


\section{Secciones del Reglamento de música sagrada para la Archidiócesis de Sevilla.}

- Primera Parte. De la música sagrada en general

Capítulo I: De la música gregoriana. Artículos $1^{\circ}-3^{\circ}$

Capítulo II: De la música figurada. Art. $4^{\circ}-8^{\circ}$

Cap. III: De la música vocal. Art. $9^{\circ}-11^{\circ}$

Cap. IV: De la música orgánica. Art. $12^{\circ}-16^{\circ}$

Cap. V: De la música instrumental. Art. $17^{\circ}-20^{\circ}$

Cap. VI: De la ejecución de la música sagrada en general. Art. $21^{\circ}-22^{\circ}$

Cap. VII: De la ejecución de la música gregoriana. Art. $23^{\circ}$

Cap. VIII: De la ejecución de la música figurada. Art. $24-25^{\circ}$

- Segunda Parte. De la Música Sagrada en los actos del Culto divino

Cap. IX: De la música en las Misas de fiestas. Art. $26^{\circ}-30^{\circ}$

Cap. X: De la música en las Misas de feria y de réquiem. Art. $31^{\circ}-35^{\circ}$

Cap. XI: De la música en las Vísperas. Art. $36^{\circ}-38^{\circ}$

Cap. XII: De la música en Completas. Art. $39^{\circ}-41^{\circ}$

Cap. XIII: De la música en Maitines y Laudes. Art. $42^{\circ}-44^{\circ}$

Cap. XIV: De la música en las Horas menores. Art. $45^{\circ}-49^{\circ}$

Cap. XV: De la música en los actos litúrgicos fuera del oficio. Art. $50^{\circ}-54^{\circ}$

Cap. XVI: De la música en otras funciones del culto. Art. $55^{\circ}-57^{\circ}$

- Apéndice. De la música sagrada en las funciones de Semana Santa. Art. 58 $-62^{\circ}$

La publicación del Reglamento de Música Sagrada supuso el punto y final del proceso de concreción normativa de los principios y preceptos generales contenidos en el MP según los criterios de la autoridad eclesiástica local y la CDMS en la archidiócesis de Sevilla. Ni Almaraz ni su Comisión volvieron a emitir disposición o medida alguna en forma de circular u otro documento. Con el Reglamento, la cuestión quedó zanjada definitivamente. 
Parte II. CATEDRAL

La APLicación del Motu Proprio en la Catedral de Sevilla: REFORMA LITÚRGICO-MUSICAL VERSUS DEFENSA IDENTITARIA

Capítulo 3. El proceso de reformas en la Catedral (1905-1910): las reacciones a la modificación del canon litúrgico-musical p. 169

Capítulo 4. Funciones simbólicas de la música en las fiestas litúrgicas catedralicias a principios del siglo XX 



\section{CAPÍTULO 3 \\ EL PROCESO DE REFORMAS EN LA CATEDRAL (1905-1910): LAS REACCIONES A LA MODIFICACIÓN DEL CANON LITÚRGICO-MUSICAL}

Las primeras pruebas sobre la implementación en la Catedral de las prescripciones pontificias y las disposiciones ideadas por la CDMS datan de finales de febrero de 1905. El inicio del proceso particular catedralicio debió esperar al nuevo impulso dado por Spínola a la reforma tras la paralización sufrida en 1904. Al margen de la acción puramente institucional, Vicente Ripollés, desde su responsabilidad como maestro de capilla, había emprendido desde incluso antes de la promulgación del MP el desafío de ajustar los usos locales a las nuevas directrices dictadas por la Santa Sede en la última década del s. XIX. De la labor realizada por el castellonense nos ocuparemos más adelante. Centrémonos, en primer lugar, en el análisis del proceso a nivel institucional.

Por un acta capitular de 27 de febrero sabemos que las primeras medidas reformistas fueron propuestas al Cabildo por el chantre, Santiago Fernández, en calidad de presidente de la $\mathrm{CDMS}^{1}$. Fernández desempeñó durante el proceso bajo el pontificado de Spínola un papel de nexo y mediador entre la CDMS que presidía y el capítulo catedralicio del que formaba parte. Además, ejerció de portavoz del órgano de gobierno de la Catedral, encabezando las comisiones que este nombraba para departir con el arzobispo cualquier asunto que tuviera que ver con la reforma de la música.

Las medidas comunicadas por el chantre representaron, en realidad, una concreción al caso particular de la Catedral de algunas de las dictadas para la Archidiócesis en general en los dos informes confeccionados por la CDMS en marzo de

\footnotetext{
${ }^{1}$ AC 27/2/1905. ACS. Sección Secretaría, libro 227, fol. 8v.
} 
1904 -que se mantuvo inédito hasta el 15 de febrero de 1905- y enero de 1905. Los puntos propuestos "a la deliberación del Cabildo" por parte de la CDMS fueron:

$1^{\circ}$. que se prohíba cantar ad libitum, como se viene haciendo el verso "Adjuva nos" obligando a los cantores a sujetarse a la canturía que se halla en los libros de coro. $2^{\circ}$. Que en la Misa del Miércoles de Ceniza no se cante el motete "Inter vestibulum et altare" después de la elevación; y que en caso de cantarlo, sea después del ofertorio propio, y $3^{\circ}$. que se cante el ofertorio [propio, se entiende] todos los días. ${ }^{2}$

Estas medidas correspondían con los siguientes puntos del plan reformista general archidiocesano:

a) [Prohibido] Cantar los textos litúrgicos con melodías ad libitum de los cantores, prescindiendo de las indicadas en los cantorales. ${ }^{3}$

$4^{\circ}$ Prohibido en las funciones litúrgicas no sólo el canto en lengua vulgar, sino también alterar el orden de los textos y cambiarlos por otros de elección privada [énfasis original], en las Misas cantadas es obligatorio el canto del Introito, Gradual, Ofertorio y Communio propios, y únicamente, después del Benedictus, podrá cantarse algún Motete al Santísimo Sacramento, y, terminado el Ofertorio propio, un breve Motete hasta el Prefacio. ${ }^{4}$

La siguiente declaración indica que el Cabildo las asumió sin ningún problema: "se acordó que se hiciera todo como lo propone el Sr. Chantre". Como comprobaremos a lo largo de este capítulo, esta no fue la tónica general, al menos, cuando se planteó la alteración o eliminación de la música en determinadas festividades.

La reforma litúrgico-musical catedralicia en toda su dimensión y con todos los problemas que suscitó, comenzó cuando se abordó la revisión del canon musical vigente en las grandes solemnidades de Semana Santa. Desde el principio, la controversia se

\footnotetext{
${ }^{2}$ AC 27/2/1905. ACS. Sección Secretaría, libro 227, fols. 8v-9r.

${ }^{3}$ En informe de 26 de enero de 1905. Marcelo, Arzobispo de Sevilla, "Sobre música sagrada" BOAS, 560 (1905), p. 96.

${ }^{4}$ En informe de 4 de marzo de 1904. Ibídem, p. 91.
} 
concentró en la música de las lamentaciones y Miserere correspondientes a los oficios de Tinieblas del Miércoles y Jueves Santo ${ }^{5}$.

\section{Reforma de la música en las solemnidades de Semana Santa (1905)}

\subsection{Oficio de Tinieblas}

\subsubsection{Salmo Miserere}

La reforma en los cultos de Semana Santa y, concretamente, del oficio de Tinieblas se abordó en la circular en la que Spínola reactivó el proceso a nivel general diocesano y reforzó a su CDMS. Resulta significativo que la iniciativa partiera del arzobispo y no del cabildo catedralicio ${ }^{6}$ :

Cercana por otra parte la Cuaresma, y por ende la Semana Santa, época del año eclesiástico, en que tan a menudo se quebrantan las reglas dictadas por su Santidad, nos atrevemos a pedir a la Comisión que nos indique el modo de concordar con las normas señaladas por Pío $\mathrm{X}$, los antiquísimos usos y costumbres de esta nuestra Iglesia, merecedores de profundo respeto, y que fuera imposible destruir o cambiar sin promover conflictos. ${ }^{7}$

En este pasaje Spínola no pidió a la CDMS una revisión de las prácticas en vigor en la Iglesia hispalense a la luz de los preceptos del MP y, en caso de incompatibilidad, acometer las reformas necesarias para ajustarlas a dichos preceptos, como correspondería a una posición estrictamente alineada con las disposiciones pontificias y sus fines. El prelado sevillano, por el contrario, le encomendó que encontrara el modo de conciliar (“concordar") $M P$ y usos locales, situándose, de esta forma, en un punto equidistante entre ambos, y elevando a un mismo nivel de estimación las costumbres hispalenses y el documento reformador. Por un lado, el MP representó para Spínola la voluntad del papa, a la que se adhería incondicionalmente ${ }^{8}$;

\footnotetext{
${ }^{5}$ Los Oficios de Tinieblas eran los Maitines y Laudes correspondientes al Jueves, Viernes y Sábado Santos, que se adelantaban a la tarde-noche del día anterior, teniendo lugar en la práctica el Miércoles, Jueves y Viernes Santo respectivamente.

${ }^{6}$ Este epígrafe es una versión revisada y ampliada de parte del texto de la comunicación que presentamos al VIII Congreso de la Sociedad Española de Musicología "Musicología global, musicología local", celebrado en Logroño en septiembre de 2012, y ha sido publicada en: "El Miserere de Hilarión Eslava: los documentos del privilegio de Sevilla", en Musicología global, musicología local, ed. por Javier Marín López, Germán Gan Quesada, Elena Torres Clemente, Pilar Ramos López (Madrid: Sociedad Española de Musicología, 2013), pp. 951-968.

${ }^{7}$ Marcelo, Arzobispo de Sevilla, "Sobre la música sagrada", BOAS, 558 (1905), p. 7.

${ }^{8}$ Véase p. 80 , nota a pie $\mathrm{n}^{\mathrm{0}} 74$
} 
por otro, el respeto que merecía la tradición, y la polémica que desataría su alteración justificaban los intentos de salvaguardarla.

El encargo dado a la CDMS era ciertamente complicado, dada la imposibilidad de hacer compatibles ambas "tendencias". Como demuestra este otro fragmento, Spínola era consciente de ello: "Y por si acaso no hallaren fórmula, que concilie esas al parecer opuestas tendencias, se servirá manifestárnoslo para que, elevando a Roma la debida consulta, quede nuestra conciencia perfectamente tranquila"9. La incompatibilidad existente entre propuesta pontificia y "los antiquísimos usos y costumbres" locales hacía igualmente complicado mantener en equilibrio la posición intermedia asumida por Spínola, que, desde el punto de vista de una autoridad del regeneracionismo musical español como Felipe Pedrell, se contemplaba como tibia y contemporizadora: "He leído la circular y los pasteleos del diocesano. Nada entre dos platos, como en todas partes"

El deseo inicial del prelado por conciliarlas se transformó, en último término, en una apuesta por la preservación de la tradición, estando dispuesto a agotar todas las posibilidades. No obstante, con la consulta a Roma, Spínola sometió su propio parecer al criterio del papa, permaneciendo así en plena sintonía con su superior. Aunque hasta ahora en ningún momento se ha hecho mención explícita del mismo, el asunto que tenían encima de la mesa tanto arzobispo como CDMS no era la música en las funciones de Semana Santa en su conjunto, sino el salmo Miserere en particular ${ }^{11}$.

La CDMS, asumiendo el encargo del arzobispo, realizó un estudio que cristalizó en un informe fechado el 26 de enero de 1905. En su dictamen, el órgano fundado por Spínola sentenció: "la comisión aprecia con sentimiento que no pueden concordarse las disposiciones litúrgicas con las costumbres introducidas y actualmente en vigor; $[\ldots]^{\prime 12}$. Para llegar a esta conclusión, acudió a lo dispuesto en el Ceremonial

\footnotetext{
${ }^{9}$ Marcelo, “Sobre la música sagrada”, BOAS, 558 (1905), p. 7.

${ }^{10}$ Carta de Pedrell a Ripollés, 27 de febrero de 1905. BC. FFP. M 964. Pedrell tuvo conocimiento de la circular de Spínola gracias a Ripollés, con quien mantenía una cercana relación.

${ }^{11}$ Un recorrido por la historia del Miserere desde su composición hasta la década de los setenta en Ayarra, Hilarión Eslava en Sevilla, pp. 87-110. El autor dedica un par de páginas a tratar la reacción de la jerarquía eclesiástica local ante la posibilidad de su prohibición según las nuevas normas litúrgicomusicales. Cita las circulares sobre música sagrada de 15 de febrero de 1904, de 16 de enero, 15 de febrero y 15 de abril de 1905 publicadas por Spínola en el BOAS. Ibídem, pp. 102-103.
}

12 Marcelo, “Sobre música sagrada” BOAS, 560 (1905), p. 95. 
de Obispos ${ }^{13}$, así como a tres decretos dados por la Sagrada Congregación de Ritos en 1893, 1903 y 1904. En ellos, dicha Congregación respondió a las correspondientes consultas realizadas por el arzobispo de Goa, el deán de la catedral de Pisa y el arzobispo de Santiago de Compostela, respectivamente. Estas autoridades eclesiásticas preguntaron sobre la licitud del uso de la orquesta o instrumentos, incluido el órgano, en las lamentaciones, responsorios y Miserere de los oficios de Semana Santa. Las respuestas dadas a todas ellas fue "negative", es decir, no se permitía el uso de recursos instrumentales ${ }^{14}$.

Ante esto, la CDMS sugirió a Spínola como última posibilidad para conservar las prácticas locales tradicionales, la solicitud de un "permiso especial”. Así, la consulta que Spínola elevó a Roma contó con el aval y respaldo del principal órgano, de carácter técnico, encargado del estudio y concreción en la práctica de la reforma ${ }^{15}$. Además de los argumentos ya esgrimidos por el arzobispo (respeto por la tradición, evitar conflictos), la CDMS añadió dos razones más para justificar la petición: la condición mítica que los sevillanos habían otorgado a Eslava; y los perjuicios económicos que conllevaría la supresión del Miserere, que redundarían, a su vez, en una considerable merma de la ya de por sí disminuida magnificencia que históricamente había caracterizado las solemnidades de la Semana Santa en la catedral hispalense:

[...] sin embargo, atendida la índole especial de las solemnidades de la Semana Santa en la Iglesia de Sevilla, teniendo en cuenta que el canto del salmo Miserere puede considerarse como homenaje de veneración, respeto y honor del pueblo hispalense a su antiguo maestro, el con justicia llamado patriarca de la moderna

13 “Ceremonial de Obispos, edición típica de 1886; libro $2^{\circ}$ cap. 20: Los cantores, excepto el himno angélico de la feria V. in Coena Domini, usen del canto gregoriano o del figurado polífono”. Ibídem, p. 94.

14 "El Patriarca de las Indias Orientales, Arzobispo de Goa, preguntaba a la S. Congregación de Ritos: Puede tolerarse que en los oficios de las ferias IV, V y VI de la Semana Santa, se canten las Lamentaciones, Responsorios y Salmo Miserere con acompañamiento de órgano o de otros instrumentos? La S. C. de R. en 16 de Julio de 1893 respondía «Negative en las partes litúrgicas de los oficios.

El Deán de la Catedral de Pisa proponía a la S. C. de R. las siguientes dudas:

$1^{\circ}$ Atendida la antigua costumbre en vigor, se puede tolerar que en el miércoles, jueves y viernes de la Semana Santa las Lamentaciones, Responsorios y salmo Miserere se acompañen con el Armonium y con otros instrumentos no fragorosos como son violines, violas y contrabajos?

$2^{\circ}$ Se puede tolerar por lo menos el acompañamiento de solo el Armonium?

La S. C. de R. respondía el 20 de Marzo de 1903. 'Negative a ambos puntos.

Igual contestación obtuvo una consulta elevada el próximo pasado año de 1904 por el Arzobispo de Santiago de Compostela”. Ibídem, pp. 94-95.

${ }^{15}$ A este se le sumaría posteriormente el cabildo catedralicio. 
música religiosa española, D. Hilarión Eslava, y en previsión de los sucesos desagradables que indudablemente ocasionaría la supresión de una obra en tanta estima tenida por el pueblo fiel hispalense, y a la que concurre el Cabildo municipal con subvenciones que se hacen extensivas a la colocación y ornato del Monumento, podría intentarse un permiso especial de la Santa Sede para seguir cantando el salmo Miserere, en la forma acostumbrada y tradicional $[\ldots]^{16}$

A continuación del informe de 26 de enero, al que venimos haciendo referencia, Spínola adjuntó un escrito en el que asumía públicamente las propuestas de la CDMS, que concluía con la siguiente declaración:

En cuanto a las funciones de Semana Santa, en las que tiene la Catedral de Sevilla especiales prácticas, no muy acordes con las prescripciones del Papa en su Motu Proprio, pero que se fundan en razones muy dignas de atención, elevaremos a su Santidad la oportuna consulta, esperando hará en nuestro obsequio una excepción, que poderosos motivos abonan ${ }^{17}$.

Debemos remitirnos, llegados a este punto, a una de las sesiones de estudio celebradas en el I Congreso Nacional de Música Sagrada (Valladolid, 1907), pues, en el curso del debate sobre el uso de la orquesta en la liturgia, surgió la cuestión del Miserere de Eslava en Sevilla. Agapito Insausti, uno de los representantes del cabildo hispalense junto con Ripollés, se dio por aludido cuando el presidente de la sesión, Nemesio Otaño, puso de manifiesto que en muchos lugares aún se incumplían las disposiciones papales respecto a la prohibición del uso de la orquesta en los oficios de Tinieblas, o en los de difuntos. Insausti, vocal de la CDMS hispalense aclaró: "en Sevilla se da todos los años este caso, pero que conste que contra el parecer de la Comisión"18. Ripollés también intervino para, por un lado, insistir en el posicionamiento de la CDMS tanto en 1905 como posteriormente, y por otro, explicar las razones que llevaron a Spínola a tratar de preservar la costumbre: "especiales circunstancias" y "la oposición por parte de algunos elementos":

\footnotetext{
16 Marcelo, "Sobre música sagrada" BOAS, 560 (1905), p. 95. El Monumento que se instalaba en el trascoro era uno de los elementos que de forma más determinante contribuían al fastuoso aspecto del templo en esas fechas.

${ }^{17}$ Ibídem, p. 98.

${ }^{18}$ Se trataba de la III sesión privada celebrada el 28 de abril, discusión sobre el punto $7^{\mathrm{o}}$ del cuestionario sobre "Cómo deberá manejarse la instrumentación religiosa". "Crónica del Congreso. 26, 27 y 28 de Abril”, MSH, 1 (1907), p. 43.
} 
Lo que en Sevilla ha podido suceder no lo sabemos: es cierto que la Comisión quiso se observaran las prescripciones en la materia, pero dadas las especiales circunstancias y cierta oposición por parte de algunos elementos, nos consta que el difunto Sr. Cardenal acudió a Roma, pero ignoramos lo que de Roma se le respondió; lo que vemos es que allí continúan las cosas en el mismo estado, bien a pesar de la Comisión. $^{19}$

Tras la declaración de Ripollés, el arzobispo José María Cos y Macho, anfitrión del Congreso, pidió a los asistentes "un aplauso a la digna Comisión de Sevilla, que ha sabido sostener los verdaderos principios." 20

Resulta llamativo el secretismo con el que se trató este asunto una vez hecha la solicitud a Roma. A finales de abril de 1907, fecha de celebración del Congreso, aquellos que habían aconsejado a Spínola la realización de dicha solicitud -a pesar de que quisieron "se observaran las prescripciones en la materia"- seguían desconociendo la resolución papal, según declararon en aquel momento ${ }^{21}$.

La consulta que elevó Spínola a la Santa Sede y la respuesta que mereció han permanecido desconocidas hasta ahora. Por fortuna, hemos podido localizar estos documentos, y acceder así a su contenido ${ }^{22}$. El documento de la consulta efectuada por Spínola a la Santa Sede tiene fecha de 25 de febrero de 1905. Por tanto, fue escrito diez días después de que el prelado declarara públicamente, asumiendo las sugerencias de la Comisión, su intención de hacerlo. La lectura del escrito nos aclara que Spínola, además de poner en conocimiento las circunstancias que rodeaban al Miserere y someter a juicio del papa la resolución a tomar, efectuó una petición o súplica de dispensa:

Así pues, el arzobispo abajo firmante junto a su Cabildo, estudiado este asunto a propósito, ha considerado oportuno someterlo al juicio supremo de Su Santidad, no dudando que, tenidas en cuenta

\footnotetext{
${ }^{19}$ Ibídem.

${ }^{20}$ Ibídem.

${ }^{21}$ Como comprobaremos a continuación, Santiago Fernández, chantre y presidente de la CDMS, sí tuvo conocimiento de la respuesta vaticana.

22 Véanse una relación cronológica de los principales documentos sobre este caso, así como las transcripciones de la petición de dispensa realizada por Spínola y el borrador de la respuesta dada por la Santa Sede en Apéndice 3. Dichas transcripciones han sido publicadas en López Fernández, "El Miserere de Hilarión Eslava", pp. 967-968.
} 
estas premisas, [...], querría hacer de ella una excepción a las normas generales de su Motu Proprio del día 22 de noviembre de 1903.

$[\ldots]^{23}$

Por ello, el solicitante implora a Su Santidad esta dispensa,

Las "premisas" a las que aludió el arzobispo son las razones que tanto él como la CDMS alegaron en las circulares de 16 de enero y 15 de febrero de 1905 respectivamente para justificar la consulta ${ }^{24}$. Así son recogidas igualmente en ella:

$1^{\circ} \mathrm{La}$ antigüedad de la costumbre unida a la popularidad de la composición musical del maestro Eslava, la cual, divulgada por todas partes, es muy considerada entre los expertos, tantos locales como foráneos: $2^{\circ} \mathrm{La}$ enorme y verdaderamente extraordinaria afluencia de público, de tal manera que el amplísimo templo apenas llega a albergar a la cantidad de gente que escucha las sublimes notas con las que el autor interpretó el sentido de cada uno de los versos del salmo: $3^{\circ}$ El Ayuntamiento hispalense quien con sus propios ingresos ha acostumbrado a pagar todos los gastos no sólo para el esplendor de la fiestas de la Semana Santa, cuya grandiosidad goza de fama universal, sino también incluso como testimonio de admiración y de estima del pueblo hispalense para con el genial maestro que, con razón, es considerado entre los famosos como un padre y un icono de la instauración de la música sacra en España: $4^{\circ}$ Igualmente, el grave conflicto que se debe temer por la supresión de esta costumbre y desgracias mayores que forzosamente se conseguirían no sólo en el orden moral, sino también en el material y económico; cuantos beneficios que son reportados gracias a la afluencia de público a solemnidades de este tipo, cesarían, sin duda, con gran perjuicio de la utilidad pública ${ }^{25}$.

\footnotetext{
23 "Infrascriptus igitur Archiepiscopus una cum suo Capitulo, re mature perpensa, opportunum duxit eam supremo S.V. judicio summitere haud dubitans quin, habita praemissorum ratione, de benignitate Apostolica ob speciales circumstantias praefactae consuetudinis huyus inclytae Ecclesiae, eamdem excipere velit a praescriptionibus generalibus sui Motus Propii diei XXII Novembris MCMIII.

Dum ergo supplex hanc dispensationem a S.V. implorat, ipsemet Archiepiscopus Ejusdem pedes omni cum reverentia deosculatur. [sigue la firma de Spínola]." ASV, Segretaria di Stato, anno 1905, rubrica 283, fascicolo 2, fol. 47r. Agradecemos al profesor Alejandro Pastor del Castillo y a la Dra. María del Carmen Guerrero Picó la inestimable ayuda prestada en las traducciones de los originales latinos e italianos respectivamente.

${ }^{24}$ Marcelo, "Sobre la música sagrada”, BOAS, 558 (1905), p. 7; Marcelo, "Sobre música sagrada” BOAS, 560 (1905), p. 95.

25 “ 1 a . Antiquitas moris una cum popularitate compositionis musicalis magistri Eslava, quae undequaque divulgata apud peritos tam proprios quam exteros magno in pretio habetur: $2^{\mathrm{a}}$. ingens ac vere extraordinaria populi frequentia, ita ut amplissimum templum vix capere valeat multitudinem audientium sublimes notas quibus el. auctor sensum interpretatus est singulorum versiculorum Psalmi: $3^{\mathrm{a}}$. Concursus Hispalensis Senatus, qui ex proprio fisco expensas omnes solvere consuescit tum ad splendorem festivitatum Majoris Hebdomadae, quarum magnificentia universali gaudet fama, tum etiam in testimonium admirationis et amoris populi hispalen. erga insignem Magistrum, qui jure optimo apud gnaros habetur velut parens ac signifer instaurationis musicae sacrae nostra in Hispania: $4^{\mathrm{a}}$ Gravis proinde conflictus ex hujusmodi consuetudinis abrogatione pertimescendus, gravioraque mala, quae necesario
} 
Estos fueron, además, los motivos que llevaron a Spínola a adoptar hasta el momento de efectuar la consulta una posición prudente respecto al Miserere, es decir, decidir, bajo su responsabilidad, no aplicar para dicho caso lo estipulado en el MP. A pesar de ello, el prelado quiso transmitir al papa su plena adhesión y sumisión al proyecto de reforma litúrgico-musical, comunicándole que

desde que vio la luz el nuevo decreto de Su Santidad sobre la música sacra, el mismo arzobispo no pudo más que poner toda su atención y su preocupación para que en su diócesis fuese llevado fielmente a la práctica, tras haber revocado y prohibido cualesquiera costumbres contrarias [a lo preceptuado en el $M P]^{26}$.

Los argumentos esgrimidos, así como las decisiones tomadas por el prelado evidencian que el problema que representaba el fenómeno del Miserere no era baladí ni desde luego de naturaleza litúrgico-musical, sino de hondo calado y de gran trascendencia cultural, social e incluso económica; hasta el punto, como decimos, de llevar a Spínola a dejar de aplicar en 1904, aunque de forma excepcional, unas disposiciones legales de obligado cumplimiento.

La respuesta dada por la Santa Sede desvela que el papa concedió a Spínola un permiso para que tolerara la interpretación de la obra de Eslava "durante algún tiempo más": "el Augusto Pontífice permite benignamente a su Excelencia que, adecuándose a la necesidad impuesta por las circunstancias del caso en cuestión, tolere durante algún tiempo más la interpretación de este salmo" ${ }^{\text {27 }}$. La razón que llevó a Pío X a conceder esta autorización fue evitar los serios conflictos y las graves consecuencias de orden moral y material de las que informaba el arzobispo hispalense en caso de que se produjera la supresión inmediata del Miserere.

consequutura forent non solum in ordine morali, sed etiam in materiali et oeconomico, quatenus beneficia, quae reportantur ex populorum affluentia ad ejusmodi solemnitates tunc procul dubio cessarent cum magno publicae utilitatis detrimento". ASV, Segretaria di Stato, anno 1905, rubrica 283, fascicolo 2 , fols. $46 \mathrm{v}-47 \mathrm{r}$.

26 “Jam vero, cum primum in lucem prodiit novissimum S.V. Decretum circa musicam sacram, idem Archiepiscopus non potuit quin omnem impenderet curam omnemque sollicitudinem, ut in sua dioecesi illud fideliter ad praxim redigeretur, revocatis et interdictis quibuslibet consuetudinibus in contrarium. Sed quoad cantum ps. 'Miserere' in Ecclesia Cathedrali nihil tentare ausus est, diversas prae oculis causas habens". Ibídem, fol. 46.

27 'l'augusto Pontifice benignamente permette a V. S. che uniformandosi alla necessitá imposta delle circostanze del caso in questione, tolleri per qualche altro tempo l'esecuzione di quel salmo". Ibídem, fol. $48 \mathrm{v}$. 
Sin embargo, este permiso no constituye una respuesta favorable a la petición de Spínola sino todo lo contrario. Un examen detenido del texto lleva a realizar las siguientes observaciones. En primer lugar, se hace evidente la naturaleza provisional y transitoria de dicha licencia, que exoneraba de la observancia de los preceptos del $M P$ pero "sólo" durante algún tiempo más; es decir, que una vez alcanzado el objetivo, expiraría. Aunque no se especifica en términos cronológicos la duración del periodo de excepción concedido por el papa, el punto indicado en el que debía llegar a su fin ("hasta que [...] pueda obtener un nuevo género de música, que satisfaga las disposiciones pontificias") lleva a pensar en un plazo más bien breve que dilatado ${ }^{28}$. En segundo lugar, el documento poseía un carácter estratégico, pues, entretanto, se debían ir creando, con la garantía del fiable criterio del arzobispo, unas condiciones más favorables para que la supresión de la costumbre se aceptara sin que tuviera las indeseables consecuencias a las que aludía Spínola en su misiva. Por tanto, su objetivo último era precisamente la eliminación definitiva del canto del Miserere eslaviano, justo lo contrario a lo que perseguían arzobispo, cabildo y comisión hispalenses al hacer la petición. Lo cual significa que el papa no renunció a la plena aplicación de los preceptos del MP en la archidiócesis de Sevilla, no accediendo a la súplica de Spínola:

[...] Considerando, pues, las serias y graves razones aducidas por su Excelencia, por las que ahora no se podría proceder, sin considerables consecuencias materiales y morales, a la supresión del canto del citado salmo, preciado por su composición artística, pero no conforme a la majestuosa gravedad de las sagradas armonías, el Augusto Pontífice permite benignamente a su Excelencia que, adecuándose a la necesidad impuesta por las circunstancias del caso en cuestión, tolere durante algún tiempo más la interpretación de este salmo, hasta que, guiándose por el sabio criterio y por la prudencia que le caracterizan e insinuando en los ánimos la oportunidad del cambio, pueda obtener un nuevo género de música, que satisfaga las disposiciones pontificias y que sea al mismo tiempo pasto saludable para la piedad de los fieles. $[\ldots]^{29}$

\footnotetext{
28 "finche ['] regolandosi con quel savio criterio e prudenza che le é propria ed insinuando negli animi l'opportunitá di un cambiamento, possa ottenere un nuovo genere di música soddisfi alle pontifici prescrizioni”. Ibídem, fol. 48v.

29 "Considerando adunque le serie e gravi ragioni addotte da V. S. e per le quali non potrebbesi ora procedere, senza notevoli consequenze materiali e morali, alla soppressione del canto del citato salmo, pregevole per l'artistica composizione, ma non conforme alla maestosa gravitá dei sacri concenti; l'augusto Pontifice benignamente permette a V. S. che uniformandosi alla necessitá imposta delle circostanze del caso in questione, tolleri per qualche altro tempo l'esecuzione di quel salmo finché regolandosi con quel savio criterio e prudenza che le é propria ed insinuando negli animi l'opportunitá di un cambiamento, possa ottenere un nuovo genere di musica, che soddisfi alle pontifici precezioni e che sia nel contempo di salutare pascolo alla pietá dei fedeli”. Ibídem.
} 
La costumbre del canto del Miserere superó, en consecuencia, este momento crítico que supuso la revisión en 1905 del repertorio musical vigente en el oficio de Tinieblas. Spínola, aunque finalmente no alcanzó su objetivo de conseguir una dispensa, logró de la Santa Sede, al menos, una prórroga, gracias a la cual la obra eslaviana se cantó con la venía papal esa Semana Santa.

El Cabildo tuvo conocimiento de esta concesión el 27 de marzo a través del chantre y presidente de la CDMS:

[...] le consta [al Chantre] haber consultado a Roma el Sr. Arzobispo si, no obstante lo que se previene en el Motu proprio acerca del canto de la Semana Santa, puede tolerarse que se ejecute el Miserere de Eslava en atención a graves razones alegadas por S. E. y que la contestación ha sido favorable. ${ }^{30}$

Días después fue el propio arzobispo quien comunicó la noticia a una comisión capitular compuesta por el propio chantre, el doctoral José Cañamache, y el secretario del Cabildo, Modesto Abín:

La Comisión nombrada en el cabildo último para conferenciar con el Sr. Arzobispo sobre si han de cantarse con acompañamiento de música las Lamentaciones en los Maitines de Tinieblas dijo que S. E. manifestó haber pedido a Su Santidad que no obstante lo dispuesto en su Motu proprio sobre música sagrada se dignase hacer un excepción en favor del Miserere de Eslava que se canta en esta Santa Iglesia, alegando los graves inconvenientes que podrían seguirse de suprimirlo, dado el empeño que muestra en oír esta obra del inmortal compositor la ciudad de Sevilla representada por el Municipio que todos los años se dirige al Cabildo haciéndole la misma petición y ofreciéndose a costear los gastos, y atendiendo además el gran concurso de fieles, entre los que se cuentan muchos extranjeros, que acude[n] a escucharla, y que Su Santidad se había dignado acceder benignamente a lo pedido por S. E. ${ }^{31}$

Los dos autos capitulares que acabamos de citar no reflejan la verdadera naturaleza del permiso concedido por la Santa Sede a Spínola. Tal y como están redactados, los documentos catedralicios omiten, por un lado, el carácter provisional y estratégico que caracterizó dicho permiso; por otro, su supeditación a la consecución del fin, no deseado por Spínola y su Comisión, de derogar la costumbre del Miserere. Por

\footnotetext{
${ }^{30}$ AC 27/3/1905. ACS. Sección Secretaría, libro 227, fol. 14v.

${ }^{31}$ AC 3/4/1905. ACS. Sección Secretaría, libro 227, fols. 16v-17r.
} 
tanto, la lectura de estas actas conduce al error de concluir la efectiva concesión de un privilegio que permitía su perpetuación.

De hecho, la creencia sobre esta concesión por parte de la Santa Sede se había extendido y asumido rápidamente como una realidad fuera de toda duda. En 1910, el cabildo de la catedral de Jaén apeló a la supuesta "gracia", de la que disfrutaba el hispalense, como precedente para efectuar su propia solicitud:

Se acuerda que el señor magistral redacte preces a $\mathrm{Su}$ Santidad, en nombre del Cabildo, pidiendo que se conceda cantar el Miserere en el Miércoles y Jueves Santo con orquesta, como se hizo siempre y por gracia se hace actualmente en la iglesia de Sevilla. ${ }^{32}$

José Luis Ansorena en su Biografía de D. Hilarión Eslava afirma la concesión del privilegio aunque no ofrece más información, ni cita sus fuentes ${ }^{33}$. Por su parte, José Enrique Ayarra, ante la falta de pruebas definitivas, deja entre interrogantes si Spínola realizaría finalmente la consulta ${ }^{34}$. El cardenal Segura negó en 1945 la existencia del privilegio y sugirió que hasta entonces había servido para justificar la pervivencia de la costumbre:

¿Qué podrán responder quienes tratan de legitimar los abusos introducidos, apoyándose precisamente en privilegios que no existen ni pueden existir, y en costumbres que están positivamente reprobadas? ${ }^{35}$

Spínola, en la circular publicada en la víspera del Domingo de Ramos con las directrices conformes al $M P$ a seguir en Semana Santa, se limitó a disponer respecto al

\footnotetext{
32 “AC 15/2/1910, en: Pedro Jiménez Cavallé, Documentario musical de la Catedral de Jaén. vol. I. Actas capitulares (Granada: Centro de Documentación Musical de Andalucía, 1998), p. 551. El Cabildo de la otra sede metropolitana andaluza elevó igualmente una petición de dispensa para conservar el canto del Miserere tradicional en Granada, el de Vicente Palacios. De ello informa Martín Moreno en "Cinco siglos de historia musical", p. 839.

33 "Su partitura fue incluida entre las prohibidas. Pero el Cabildo con su prelado a la cabeza, el Cardenal Spínola, alcanzó del Santo Padre privilegio exclusivo de seguirlo interpretando en la Catedral de Sevilla". José Luis Ansorena, "Biografía de D. Hilarión Eslava", en: Monografía de Hilarión Eslava, ed. por equipo Musikaste-Eresbil (Pamplona: Diputación Foral de Navarra, 1978), pp. 51-52.

34 “Llegó a escribir a Roma? No he encontrado por ninguna parte la respuesta de la Sagrada Congregación correspondiente, y los arzobispos sevillanos que le siguieron jamás apelarán a esa posible decisión vaticana para censurar o justificar el Miserere”. José Enrique Ayarra Jarne. Hilarión Eslava en Sevilla (Sevilla: Diputación Provincial, 1979), p. 103.

35 Pedro, Cardenal Segura y Sáez, Arzobispo de Sevilla, "Instrucción pastoral de su Emcia. Rvdma. Sobre la Música Sagrada”, BOAS, 1470 (1945), p. 130.
} 
Miserere: "pueden seguirse las antiguas costumbres, mientras otra cosa no se disponga"36. A diferencia de las dos actas capitulares que, como hemos apuntado, pueden llevar a conclusiones equivocadas, el arzobispo andaluz sí recogió en su declaración, a pesar del estilo lacónico en el que está expresado, el carácter provisional del permiso otorgado por el Vaticano.

Hay que suponer que la muerte de Spínola, acaecida el 19 de enero de 1906, daría vía libre a que la provisionalidad y transitoriedad que caracterizaba la disposición papal se fuera obviando y olvidando ${ }^{37}$. Con ello se inauguró una nueva etapa para la obra eslaviana, cuya pervivencia en el ceremonial catedralicio estaría legitimada por un -inexistente- privilegio del propio papa promotor de la reforma. Estos avatares hicieron que el pontífice, lejos de cumplir sus objetivos reformistas en el caso de la liturgia pascual hispalense, reforzara involuntariamente las prácticas que él mismo venía a condenar, colaborando en una mayor mitificación del Miserere y su compositor.

En marzo de 1909, Ripollés hacía referencia a una supuesta autorización de Roma conseguida por Almaraz, aunque, a diferencia de lo ocurrido en 1905, no existe rastro alguno ni en las fuentes custodiadas en Sevilla, ni en el Archivo Secreto Vaticano $^{38}$ :

respecto a este punto [Eslava y su Miserere] creo que el actual Arzobispo [Almaraz] ha empeorado la situación trayendo de Roma no sé qué autorización; por lo visto también allá pastelean; y cuando uno se entera de estas cosas le entran ganas de dejarlo correr todo y no incomodarse por nada. ${ }^{39}$

Los términos en los que se expresa Ripollés -que no pasan de la suposición, y el desconocimiento de las características del permiso- y la ausencia absoluta de referencia alguna en cualquier otra fuente, hacen que nos inclinemos por pensar que, o bien se trató de una información incierta, o que el permiso del que le habían llegado noticias fuera el otorgado a Spínola, desconocido para él, tal y como afirmó en el congreso de Valladolid.

\footnotetext{
${ }^{36}$ Marcelo, Arzobispo de Sevilla, “Circular núm. 320”, BOAS, 565 (1905), pp. 263-264.

${ }^{37}$ Al fallecimiento de Spínola le siguió el excesivamente dilatado periodo de interregno ya aludido.

${ }^{38}$ Las consultas que realizamos a esta última institución fueron amablemente atendidas por Marco Grilli, secretario de la Prefectura, a quien expresamos nuestro agradecimiento.

${ }^{39}$ Carta de Ripollés a Pedrell, 30 de marzo de 1909. BC. FFP. M 964 R.
} 
Nos parece importante hacer notar que durante este proceso de estudio, revisión, e incluso cuestionamiento según los principios del MP del Miserere de Eslava, el Cabildo permaneció al margen, al menos oficialmente, no tomando parte alguna ni en la confección de los informes necesarios ni en el proceso de adopción de decisiones. La CDMS fue la encargada de cumplir con estos cometidos bajo la autoridad del arzobispo, su impulsor. Esta realidad nos aclara cómo se terminó resolviendo el problema de la ubicación de la CDMS como nuevo órgano archidiocesano en el sistema institucional de la Diócesis ${ }^{40}$.

Otro extracto, esta vez de una acta capitular de 27 de marzo, viene a confirmar nuestras afirmaciones respecto al nuevo orden jerárquico institucional en lo que a las decisiones sobre música se refiere. Además, nos sugiere la posición y forma de proceder que pretendió adoptar el Cabildo ante las nuevas circunstancias: adelantarse desde un espíritu, en principio, colaboracionista, a las posibles objeciones que la Comisión pudiera interponer a las costumbres ceremoniales vigentes, aunque al mismo tiempo, tratando de "armonizar" usos locales y $M P$. En última instancia, esto se traducía en un intento de preservar aquellas prácticas que considerara dignas de ser perpetuadas, imitando la toma de posición de Spínola respecto al Miserere:

Igualmente y en atención a que no obstante el carácter religioso que distingue a las composiciones musicales que se conservan en el archivo de esta Santa Iglesia pudiera oponer algún reparo la Comisión Diocesana bien sobre la parte de música que se canta en los oficios de la Semana Mayor, bien sobre alguna otra que se ejecute en el resto del año, se acordó que la Comisión Capitular mencionada estudie el asunto e informe lo que a su juicio, el Cabildo debe hacer para ver la manera de armonizar lo mandado por S. S. con las prácticas de esta Santa Iglesia. ${ }^{41}$

\footnotetext{
${ }^{40}$ Véase capítulo 1, epígrafe 3. "Inicio y suspensión del proceso de reformas: causas y consecuencias", p. 73.

${ }^{41}$ AC 27/3/1905. ACS. Sección Secretaría, libro 227, fol. 15r.
} 


\subsubsection{Lamentaciones}

A pesar de tener que ceder en beneficio de la Comisión parte de las competencias que históricamente le habían correspondido, el Cabildo no había opuesto ninguna resistencia a la reforma hasta el momento. Hay que suponer que los cambios de los usos litúrgico-musicales catedralicios solicitados por el chantre en nombre de la CDMS no habían supuesto para la corporación catedralicia ninguna amenaza a su ceremonial, ni a sus valores litúrgicos y culturales. Además, la crisis que había supuesto el cuestionamiento de la costumbre más emblemática, el canto del Miserere de Eslava, se había saldado favorablemente -al menos, a corto plazo-. Sin embargo, la recepción de otra resolución de la CDMS, que transcribimos a continuación, fue bien distinta:

El Sr. Chantre dijo que en virtud de lo dispuesto por S. S. en su Motu proprio del año último sobre la música sagrada, se cree en el deber de hacer presente al Cabildo que, a juicio de la Comisión Diocesana nombrada por el Sr. Arzobispo para la ejecución de este documento pontificio, no pueden cantarse las Lamentaciones con acompañamiento de música en las Tinieblas del Miércoles, Jueves y Viernes de la Semana Mayor, $[\ldots]^{42}$

La posibilidad cierta de eliminación de las lamentaciones con orquesta y su sustitución por otras sin acompañamiento instrumental provocó la reacción del Cabildo, moviéndolo a definir y fijar una posición frente a la reforma cuando esta representó un peligro para determinados usos tradicionales, considerados como incompatibles con el MP. El órgano de gobierno catedralicio acordó que una comisión compuesta por chantre, doctoral y secretario transmitiera al arzobispo la posición oficial de la Corporación ante los cambios no deseados:

Varios Sres. hicieron uso de la palabra y discutido el asunto se acordó que una Comisión compuesta de los Sres. Chantre, Doctoral y el infrascrito Secretario visite al Sr. Arzobispo para manifestarle que el Cabildo está dispuesto, como siempre a hacer que se cumplan en esta Santa Iglesia todas las disposiciones de S. S. tanto sobre música sagrada como sobre Liturgia y cuanto con el culto se relacione; pero que al mismo tiempo siente vivos deseos de que no se alteren prácticas tradicionales establecidas para la mayor solemnidad de nuestras funciones religiosas, a no ser que conste de un modo indubitable que no pueden conservarse sin oponerse a lo sabiamente establecido por el

\footnotetext{
${ }^{42}$ Ibídem, fol. $14 \mathrm{v}$.
} 
Vicario de Cristo, Autoridad Suprema, a quien todo fiel cristiano debe sumisión y obediencia. ${ }^{43}$

A partir de este momento las alteraciones propuestas por la CDMS para ajustar el ceremonial a las nuevas prescripciones, y que afectaban a aquellos elementos litúrgico-musicales especialmente estimados por los canónigos, fueron asumidas sólo por imposición y por el deber de "sumisión y obediencia" debida a la "Autoridad Suprema". Entre tanto se llegaba a ese punto, el Cabildo adoptaba una posición de resistencia que le llevaba, como hiciera Spínola en el caso del Miserere, a agotar todas las posibilidades de salvaguarda de sus tradiciones. Su objetivo fue evitar la decadencia del "tradicional esplendor de nuestro culto" y conservar el legado patrimonial heredado de "nuestros mayores". La vocación del capítulo hispalense se puso de manifiesto en su toma de postura: ser los últimos garantes de la preservación del esplendor y la tradición característicos de la institución:

En su virtud, la Comisión pedirá al Sr., Arzobispo, tan interesado como el mismo Cabildo en que no decaiga el tradicional esplendor de nuestro culto y las loables costumbres que nos han legado nuestros mayores, que se digne dar su muy ilustrado y respetable parecer sobre si debe el Cabildo abstenerse desde luego de cantar con música las Lamentaciones o si puede tolerarse esta práctica por las mismas o análogas razones que se hubieren alegado para el canto del Miserere. ${ }^{44}$

Sin embargo, la posición de Spínola de estimar en un mismo nivel de importancia las prácticas locales y las prescripciones del $M P$ se redujo al caso exclusivo del Miserere. De hecho, como hemos apuntado más arriba, quiso dejar constancia en su petición a Roma que, a excepción de aquel salmo puesto en música por Eslava, había "revocado y prohibido cualesquiera costumbres contrarias", tal y como ordenaba el Decreto de la Sagrada Congregación de Ritos de 8 de enero de 1904. Los capitulares, por su parte, trataron de extender esta idea y aplicarla a otras obras vigentes en el ceremonial, momento en el cual sus criterios y los del arzobispo dejaron de ser unánimes:

\footnotetext{
${ }^{43}$ Ibídem.

${ }^{44}$ Ibídem.
} 
La Comisión nombrada en el cabildo último para conferenciar con el Sr. Arzobispo sobre si han de cantarse con acompañamiento de música las Lamentaciones en los Maitines de Tinieblas dijo [...] respecto de la música de las Lamentaciones nada había hecho por entender que para ello no militan los motivos ya enunciados [en relación al Miserere]. Esto no obstante, no se opone a que el Cabildo si estima que puede alegarse alguna razón poderosa se dirija en súplica a la Santa Sede, si bien debería hacerlo con grande urgencia por estar muy próxima la Semana Santa. ${ }^{45}$

Según consta en esa misma acta, la cercanía de la Semana Santa disuadió al Cabildo de tomar en consideración la sugerencia de Spínola consistente en intentar por su cuenta y riesgo obtener un nuevo permiso del papa, esta vez, para preservar el canto de las lamentaciones:

Varios Sres. hicieron uso de la palabra y en vista de que la premura del tiempo no consiente otra cosa se acordó que por el presente año se suprima el acompañamiento de música en las Lamentaciones $[\ldots]^{46}$

Es lógico pensar, además, que el hecho de no contar en esta ocasión con el apoyo del arzobispo, redujera las esperanzas de los capitulares de obtener contestación favorable a su petición. Ignoramos si conocían en todos sus detalles las características y condiciones del permiso concedido a Spínola en el caso del Miserere. Los términos en los que se pronunció el papa en ese caso, como ya comprobamos, no alentaban mucho al optimismo.

Así pues, el canto de las lamentaciones en el seno de los maitines de Tinieblas sufrió en 1905 una gran transformación. Sabemos, gracias una carta enviada por Ripollés a Pedrell con fecha de 10 de mayo de 1904, que las lamentaciones que a principios de siglo XX se cantaban en los maitines de Tinieblas del Miércoles y Jueves Santos en la catedral eran los de Hilarión Eslava:

Mi estimado D. Felipe: Doy fe de vida con estos cuatro renglones, después de los jolgorios de Semana Santa y feria, y en plenos festejos por la venida del Rey.

\footnotetext{
${ }^{45}$ AC 3/4/1905. ACS. Sección Secretaría, libro 227, fols. 16v-17r.

${ }^{46}$ Ibídem, fol. $17 \mathrm{r}$.
} 
De asuntos musicales basta decir que van las aguas por donde solían ir, cantándose las lamentaciones y Miserere de Eslava, a pesar de los pesares y de todos los Motus propios que de Roma salgan. ${ }^{47}$

Las lamentaciones de Eslava no fueron interpretadas en 1905, pues se resolvió que sus textos fueran interpretados a canto llano:

Oído el dictamen de la Comisión encargada de estudiar la forma en que han de cantarse las Lamentaciones de los Maitines de Tinieblas en el presente año y la hora de empezar dichos Maitines en las tardes del Miércoles y Jueves, se acordó que aquellas se canten a canto llano y que los Maitines empiecen el Miércoles a las seis y media y el Jueves una hora después. ${ }^{48}$

No obstante, la resolución de aceptar el dictamen de la CDMS de suprimir las lamentaciones con orquesta fue provisional: "[se acordó] que la misma Comisión estudie si en adelante puede entablarse el mencionado recurso a fin de que no decaiga en este punto la solemnidad de nuestras fiestas religiosas" ${ }^{, 49}$. Los capitulares continuaron en su empeño por conservar la solemnidad de este ritual, según era entendida por ellos.

Como se pone de manifiesto en estas actas capitulares, las lamentaciones de Eslava estaban asociadas a los conceptos de solemnidad y esplendor del culto. $\mathrm{Su}$ sustitución por las gregorianas constituía, desde el punto de vista de los canónigos hispalenses, una considerable merma en la magnificencia que consideraban propia de la tradición litúrgica catedralicia.

Al año siguiente se retomó la cuestión. El 5 de marzo de 1906, tras mes y medio después del fallecimiento del ya cardenal Marcelo Spínola, el canónigo Jerónimo Armario volvió a resucitar el debate. Armario presentó "una moción para que se restablezca si es posible el canto de las Lamentaciones en los oficios de la Semana Mayor con acompañamiento de música" ${ }^{\natural 0}$. En este caso, el Cabildo no elevó la consulta a la CDMS sino que encargó a su Diputación de Ceremonias elaborara un informe para

\footnotetext{
${ }^{47}$ Carta de Ripollés a Pedrell, 10 de mayo de 1904. BC. FFP. M 964 R.

${ }^{48}$ AC 10/4/1905. ACS. Sección Secretaría, libro 227, fol. 18v.

${ }^{49}$ Ibídem.

${ }^{50}$ AC 5/3/1906. ACS. Sección Secretaría, libro 227, fol. 82v.
} 
que aclarara "si dicha práctica se opone a las prescripciones litúrgicas", L La Diputación no cumplió su cometido hasta el 6 de abril, Viernes de Dolores, es decir, justo un mes después, y con apenas margen de maniobra para reorganizar el culto con el canto de las lamentaciones con orquesta, en caso de que el informe fuese favorable. El estudio de los comisionados concluyó:

La Diputación de S. S. Ceremonias cumpliendo el encargo que le hizo V. E. de informar acerca de si se pueden o no cantar las Lamentaciones de los oficios de la Semana Mayor con acompañamiento de orquesta, como se venía haciendo en esta Santa Iglesia, tiene el honor de hacer presente que, a su juicio, no se puede hacer. $^{52}$

La Diputación capitular se apoyó en lo dispuesto hasta ese momento por la CDMS y el arzobispo, quien, como ocurrió en la circular a la que hace referencia este auto, se limitó a publicar con el sello de su autoridad lo que la Comisión le iba proponiendo $^{53}$ :

Para adoptar este criterio ha tenido presente el parecer de la Comisión diocesana, encargada de ejecutar lo dispuesto por S. S. Pío $\mathrm{X}$ en orden a la música sagrada, parecer que manifestó a $\mathrm{V}$. E. en el cabildo de 27 de Marzo del año pasado; lo expuesto por nuestro Emo. Prelado (q.s.g.h.) a la comisión nombrada por V. E. para que oyera su opinión, la cual consta en el acta de 3 de Abril de 1905; y por último la Circular del mismo Sr. Arzobispo, fechada el 15 de Abril en la que en el número $4^{\circ}$. dice así: "No habrá orquesta en las Lamentaciones". 54

\footnotetext{
${ }^{51}$ Ibídem.

${ }^{52}$ Conocemos el contenido del informe al quedar reflejado en un acta de la Diputación de Ceremonias de 6 de abril de 1906. Las actas de las reuniones de esta Diputación se registraban en un libro propio, el Libro de Autos de la Diputación de Ceremonias. Acta de la Diputación de Ceremonias [ADC] 6/4/1906. ACS. Sección Secretaría, libro 357 [paginado sólo hasta la p. 93, año de 1885; resto del libro, que abarca desde este año al de 1914 sin paginar.]

53 Como ya apuntamos en el capítulo primero fue esta la postura adoptada por Spínola desde que a comienzos de 1905 reforzara y confirmara públicamente los poderes otorgados a la Comisión. Como se demuestra en la circular citada, en realidad, la disposición que dicta "No habrá orquesta en las Lamentaciones" fue otra propuesta de la CDMS al arzobispo, que este asumió plenamente: "La Comisión que tenemos nombrada para llevar a cabo del Motu Proprio de Su Santidad, relativo a la Música Sagrada, cumpliendo con loable celo su importante misión, nos ha dirigido un nuevo escrito, proponiéndonos algunas medidas, que ha juzgado no sólo oportuno, sino necesario se adopten; y como en su mayoría se refieren a las funciones y Oficios de la Semana Santa que se acerca, y se fundan en potísimas razones, hemos tenido por bien aceptarlas, y no perdemos momento en publicarlas, a fin de que desde luego se ejecuten.” Marcelo, “Circular núm. 320”, p. 262.
}

${ }^{54}$ ADC 6/4/1906. ACS. Sección Secretaría, libro 357 [sin paginar ni foliar] 
Esta es otra prueba más de la prevalencia del criterio de la CDMS al que el Cabildo no sólo se debió someter sino que incluso, como en este caso, recurrió como fundamento para discernir la dirección en la que había que actuar cuando se planteaban dudas o controversias.

El informe de la Diputación de Ceremonias fue leído en la sesión capitular de 9 de abril, Lunes Santo. Como se solía proceder cuando se trataba de asuntos de importancia que demandaban cierto tiempo de reflexión, el Cabildo decidió: "quede sobre la mesa hasta el primer cabildo ordinario, en el cual previa citación, se tratará de este asunto" ${ }^{25}$. Esta decisión implicaba la aceptación por segundo año del canto de las lamentaciones a canto llano, pues el siguiente cabildo no se celebró hasta pasada la Semana Santa. De hecho, se acordó retrasar media hora el oficio de Maitines de Miércoles y Jueves Santo, pues su interpretación a canto llano acortaba su duración ${ }^{56}$. Finalmente, el informe fue aprobado por unanimidad.

A pesar de todo, un sector de los capitulares volvió a insistir en la necesidad de solicitar un permiso especial a la Santa Sede, similar al supuestamente obtenido por Spínola en el caso del Miserere, "para que en los años venideros pueda conservarse la costumbre de nuestra Santa Iglesia respecto de este punto" ${ }^{, 57}$. Esta vez se advierte, no obstante, una menor firmeza y convicción, pues por vez primera se contempló como bastante probable que tuvieran que ceder definitivamente en sus pretensiones:

[...] usaron de la palabra varios Sres. exponiendo su parecer de que se vaya meditando si ha de pedirse desde luego autorización a la Santa Sede para que en los años venideros pueda conservarse la costumbre de nuestra Santa Iglesia respecto de este punto o bien se supla convenientemente la falta de música a fin de que no decaiga en esta parte el canto de las Tinieblas; ${ }^{58}$

\footnotetext{
${ }^{55}$ AC 9/4/1906. ACS. Sección Secretaría, libro 227, fols. 91v-92r.

56 “puesto que en el presente año, como en el anterior, no ha habido acompañamiento de orquesta para el canto de las Lamentaciones en las Tinieblas del miércoles y Jueves de esta Semana mayor se acordó que se retrase media hora el comienzo de los Maitines en dichos días." Ibídem. El cabildo cuyas deliberaciones registra esta acta tuvo lugar el Lunes Santo, es decir, antes de que se celebraran los oficios de Tinieblas de ese año. La referencia en pasado al canto de las lamentaciones de dichos oficios debe ser atribuido a un lapsus. El secretario capitular debió redactar el acta transcurrida la Semana Santa.

${ }^{57}$ AC 18/4/1906. ACS. Sección Secretaría, libro 227, fol. 94r.

${ }^{58}$ Ibídem, fols. $93 \mathrm{v}-94 \mathrm{r}$.
} 
En cualquier caso, el Cabildo no zanjó definitivamente el asunto y quiso dejar la puerta abierta a modificaciones futuras. Según se desprende de la siguiente acta capitular, su intención fue precisamente volver a tratarlo más adelante, aunque asumiendo los límites impuestos por las normas litúrgico-musicales y las nuevas disposiciones papales:

se acordó dejar consignado que el Cabildo desea que se dé solemnidad al canto de las Lamentaciones y para ello estudiará oportunamente el modo de verificarlo dentro de las prescripciones litúrgicas y acomodándose a lo dispuesto recientemente por $\mathrm{Su}$ Santidad en su motu propio sobre música sagrada, pero que tratará el asunto cuando hubiere tomado posesión de esta Sede el nuevo Sr. Arzobispo. ${ }^{59}$

De nuevo se pone en evidencia que el canto llano se oponía, o al menos, no se ajustaba a la idea de expresión musical litúrgica adecuada a las grandes solemnidades, según era concebida por aquellos canónigos de principios de siglo; algo que sí ocurría con las obras "con orquesta", según se expresa en los registros de las reuniones capitulares, de Eslava. Se descubren con ello las acusadas diferencias de concepto sobre música solemne existentes entre los eclesiásticos sevillanos y la línea oficial de la Iglesia romana. De hecho el MP señala: “Así pues, el antiguo canto gregoriano tradicional deberá restablecerse ampliamente en las solemnidades del culto; teniéndose por bien sabido que ninguna función religiosa perderá nada de su solemnidad aunque no se cante en ella otra música que la gregoriana." 60

El problema, idéntico al caso del Miserere, no era sólo de concepto sino legal. Si la voluntad del Cabildo era permanecer estrictamente dentro de los límites de la ortodoxia litúrgica no había margen alguno de maniobra. Además de lo dispuesto en el $M P$, tanto el capítulo 28 del Ceremonial de Obispos como los decretos 2959 y 3804 de la Sagrada Congregación de Ritos prohibían el uso de cualquier instrumento en el canto de las lamentaciones ${ }^{61}$. Por tanto, resulta difícil encontrar una respuesta satisfactoria si

\footnotetext{
${ }^{59}$ Ibídem, fol. $94 \mathrm{r}$.

${ }^{60}$ MP. Título II. Géneros de música sagrada, art. 3.

${ }^{61}$ En estas disposiciones litúrgicas se basa la Sagrada Congregación de Ritos el 20 de marzo de 1903 para contestar de la forma que sigue la cuestión planteada: “'An attenta consuetudine tolerari possit, ut cantus Lamentationum, Responsoriorum en psalmi MISERERE [sic] in feriis IV etV majoris Hebdomadae, fiat simul cum instrumento HARMONIUM, aliisque instrumentis sine strepitus, a corda: (violini, viole, contrabassi...) nuncupatis? Et quatenus negative ad I, an saltem tolerari possit in casu sonus tantum instrumenti HARMONIUM?- Negative ad utrumque, juxta Caerem Episc. L. I, cap. XXVIII et Decreta
} 
nos preguntamos por las posibles soluciones que tendrían los capitulares en mente para suplir "convenientemente la falta de música" 62 , y poder mantener así el mismo grado de solemnidad ("a fin de que no decaiga en esta parte el canto de las Tinieblas") que había caracterizado los cultos hasta $1904^{63}$. Es de suponer que depositaran su confianza en el hallazgo de alguna fórmula que fuera aceptada por el futuro arzobispo, incluida la opción, que en ningún momento es descartada -aunque no es estimada como oportuna en un momento de sede vacante-, de elevar la pertinente consulta a Roma. En cualquier caso, lo que está claro es que el Cabildo quiso dejar constancia de sus deseos: "[...] que se dé solemnidad al canto de las Lamentaciones [...]", fijando así su postura al respecto de cara a lo venidero ${ }^{64}$. La prolongación más de lo previsto del periodo de interregno afectó también a este asunto, que no fue rescatado hasta1909, ya bajo el pontificado de Enrique Almaraz.

Posiblemente esta, en cierta medida, contradictoria acta capitular refleje la existencia en el seno de la corporación capitular de diversas opiniones y tendencias propias de un debate abierto sobre una cuestión que, como se está poniendo de relieve, era considerada como bastante decisiva para los significativos oficios de Tinieblas catedralicios. La reforma debió situar al Cabildo en una difícil tesitura al forzarle a debatirse entre su histórica vocación de conservar la tradición y personalidad de la institución, y su deber de cumplir con los preceptos legales de obligado cumplimiento fijados por la Santa Sede. En este sentido, nos parece especialmente ilustrativo el contraste entre la posición de defensa y cierta resistencia que adoptó en relación a la exigencia de modificación de la música en las lamentaciones y la siguiente acta capitular, que muestra una actitud absolutamente dócil y abierta a cualquier cambio que desde otras instancias se pudiera requerir:

2959 et 3804' (S.R.C. XX Mart. 1903)". Este último decreto dispone: "Nequit tolerari, ut in triduo majoris Hebdomadae cantentur cum sonitu organi, vel aliorum instrumentorum, Lamentationes, vel psalmus Miserere, vel ALIAE PARTES LITURGICAE [sic]"; cit. en: Reglamento de Música Sagrada para esta Archidiócesis con notas aclaratorias, [separata del BOAS] (Sevilla: Lib. e Imp. de Izquierdo y Cía, 1910), pp. 90-91, nota a pie $\mathrm{n}^{\mathrm{o}} 233$.

${ }^{62}$ Es importante señalar que el término música es usado para referirse a aquella que no era canto llano, es decir, a la llamada por oposición a este figurada (en figuras, medida). La música era competencia exclusiva de la capilla de música, mientras que el canto llano era propio del Coro catedralicio.

${ }^{63}$ AC 18/4/1906. ACS. Sección Secretaría, libro 227, fol. 94r.

${ }^{64}$ Ibídem. 
Asimismo se facultó al Sr. Chantre para que tenga una entrevista con el Sr. Arzobispo y si S. E. dispusiere que se suprima alguna parte de la música que se viene cantando en los oficios de Semana Santa por no concordar con el Motu proprio de S. Santidad, lo ponga en conocimiento del Sr. Deán a fin de que este haga que se cumpla desde luego lo que se mandare. ${ }^{65}$

\subsection{Otras partes litúrgico-musicales del ceremonial}

El 12 de abril de 1905, la CDMS celebró una reunión para definir las medidas a proponer al arzobispo respecto a los cultos de la inminente Semana Santa. El punto central del informe resultante de dicha reunión dictó la prohibición de la participación de la orquesta durante los actos litúrgicos de la Semana Mayor, de acuerdo con las disposiciones litúrgicas vigentes. No obstante, contemplaba como posible y legítimo, "teniendo presentes los comentarios de reputados autores y las prácticas vigentes en donde escrupulosamente se respetan las leyes", el uso de instrumentos siempre y cuando se limitaran a sustituir o doblar las voces, es decir, sin parte propia ${ }^{66}$. La aplicación de esta disposición en la Catedral significó la conservación de numerosas obras consagradas en el ceremonial desde hacía tiempo. En aquel informe se mencionan las siguientes: el himno Gloria laus para la procesión del Domingo de Ramos; las cuatro pasiones; el salmo In exitu Israel de Aegypto; el himno Vexilla regis; la misa del Jueves Santo, con la debida aclaración de que no puede usarse del órgano hasta el Gloria; el Miserere del Viernes Santo, y la misa del Sábado Santo ${ }^{67}$. Esta disposición nos revela,

${ }^{65}$ AC 10/4/1905. ACS. Sección Secretaría, libro 227, fol. 18v.

66 "Por lo que se refiere a los cultos de Semana Santa la Comisión, atendidas las leyes litúrgicas, pertinentes al caso dictamina que en los oficios extralitúrgicos pueden usarse de la orquesta; pero no en los litúrgicos; y teniendo presentes los comentarios de reputados autores y las prácticas vigentes en donde escrupulosamente se respetan las leyes, entiende que, si se proscribe en absoluto la orquesta en estas funciones, no sucede lo propio respecto de algún instrumento en particular que más se amalgame con la voz humana, siempre que no haga otra cosa que doblar las voces para sostenerlas sin cubrirlas, no teniendo parte propia especial como tal instrumento." Informe del 12 de abril de 1905. AGAS. Sección Gobierno. Asuntos despachados, leg. 04900 (1905). Las deliberaciones contenidas en este informe fueron publicadas por Spínola en el BOAS tres días después. Marcelo, "Circular núm. 320”, pp. 262-264. Este mismo día, la Sagrada Congregación de Ritos publicó un decreto sobre el uso de la orquesta y los instrumentos en general en la liturgia. Las normas prescritas en este caso por la CDMS se ajustaron a las dadas por la citada Congregación romana. Se puede encontrar un comentario del decreto de 15 de abril en: J. Martínez de Nanclares, "La orquesta en el templo", MSH, 10 (1910), pp. 95-96.

67 "Según esto, y particularizando los diversos actos de la Semana Santa en nuestra Basílica, proponemos que pueden sostenerse las costumbres de cantar en la forma que viene haciéndose el motete Gloria laus de la Procesión de Ramos, las Pasiones del Domingo, Martes, Miércoles y Viernes Santo, el Salmo In exitu Israel de Egipto, el Vexil[1]a Regis, las Misas del Jueves y Sábado Santo con excepción del órgano en la primera, excepción también hecha del Gloria in excelsis y el Miserere del Viernes.” Informe del 12 
en consecuencia, que la música con la que se cantaban estos textos litúrgicos a comienzos del siglo XX era puramente vocal.

En 1909, con ocasión de la discusión del plan para el arreglo de la música sagrada en la Catedral que discutiremos más adelante, se trató un caso que, aunque con diferencias, guarda cierta similitud con el que nos ocupa. Se pretendía establecer el armonio como el único instrumento permitido "para sostener la parte de música polifónica en la misa de este día [Miércoles de Ceniza]", modificando así la costumbre de usar otros instrumentos. Esta vez se nos ofrece el dato de que esos otros instrumentos que tomaban parte para "sostener" -por tanto, sin parte propia- el canto polifónico eran de cuerda ${ }^{68}$. Es lógico pensar, por tanto, que fueran también de cuerda los instrumentos que acompañaban sin parte propia a las voces en aquellos cantos litúrgicos de Semana Santa citados más arriba ${ }^{69}$.

Entre los tres inventarios que hemos manejado en esta investigación y que abarcan desde aproximadamente mediados del siglo XIX hasta finales de la década de los veinte del siguiente siglo, tan sólo en el último de ellos, el elaborado durante el magisterio de Eduardo Torres, se recogen las piezas que en ese momento estaban a disposición del maestro de capilla para su interpretación en los cultos de Semana Santa $^{70}$. Las pasiones que figuran en él son la de José Sancho Marraco (1879-1960) para el Domingo de Ramos, las de Francisco Guerrero para el Martes y Miércoles Santos, y la de Tomás Luis de Victoria para el Viernes Santo. La presencia de las pasiones de Sancho Marraco y Victoria en este inventario puede ser debida al trabajo de sustitución de obras poco compatibles con las disposiciones del MP que fue realizando Eduardo Torres desde su toma de posesión como maestro de capilla en $1910^{71}$. Sin

de abril de 1905. AGAS. Sección Gobierno. Asuntos despachados, leg. 04900 (1905). En la circular publicada por Spínola no figuraron ni el Miserere del Viernes Santo, ni la misa del Sábado Santo. Marcelo, “Circular n 320", p. 263.

68 "Leído que fue el $6^{\circ}$ se discutió lo que establece el art. $2^{\circ}$ sobre que en las Misas feriales canten los niños el verso Adjuva nos, y que en el Miércoles de Ceniza art. $3^{\circ}$ se use el armonium para sostener la parte de música polifónica en la misa de este día, y después de haber hablado varios Sres, se acordó que siga observándose la costumbre de que un cantor salmista oficie el verso ya citado y que tampoco se altere la práctica de usar los instrumentos de cuerda en la expresada Misa del Miércoles. Con estas variantes fue aprobado por unanimidad el Cap. $6^{\circ}[\ldots]$ ”. AC 15/2/1909. ACS. Sección Secretaría, libro 228 , fol. 58 r.

\footnotetext{
${ }^{69}$ Marcelo, "Circular no 320”, p. 263.

${ }^{70}$ ACS. Sección Medios de información, leg. 11160. Estos inventarios son transcritos en Apéndice 5.

${ }^{71}$ No existe ninguna referencia anterior a la citada, ni en los inventarios musicales históricos ni en otra documentación generada por la catedral hispalense, a la presencia de la pasión para el Viernes Santo
} 
embargo, es bastante posible que en el caso de las pasiones para el Martes y Miércoles Santos de Guerrero, no se trate de obras de reciente reintroducción en el repertorio para remplazar a otras, sino de ejemplos de supervivencia secular en el canon catedralicio hispalense $^{72}$. Tanto Herminio González Barrionuevo como Juan Ruíz Jiménez reseñan anotaciones que datan de mediados del siglo XIX en el manuscrito que contiene las pasiones de Guerrero, y que prueban que aún en esas fechas seguían en uso ${ }^{73}$. La presencia en el inventario de Torres de estas dos obras, que en ese momento no habían sido aún publicadas en edición moderna, apunta a su permanencia en el repertorio catedralicio no sólo hasta 1853, fecha de la anotación más reciente referida por González Barrionuevo y Ruíz Jiménez, sino durante la segunda mitad del siglo XIX y, al menos, primer cuarto del siglo $\mathrm{XX}^{74}$.

Junto a las dos pasiones de Guerrero, otra obra contenida en el inventario de Torres y que pudiera haber sobrevivido en el ritual es el In exitu Israel de Aegypto de Alonso Lobo. El himno Vexilla regis que debió formar parte del canon durante el primer cuarto del siglo XX no figura en dicho inventario, pues fue sustituido por el del propio Torres en 1924. Podríamos especular con la posibilidad de que se tratara también del compuesto por Alonso Lobo, aunque no poseemos pruebas para

compuesta por Victoria. La consolidación del ciclo de pasiones de Francisco Guerrero en el canon catedralicio impidió la introducción de las obras del abulense. Parece ser que a lo largo del siglo XVII y primeras décadas del XVIII la pasión del Viernes Santo compuesta por Alonso Lobo fue ganando terreno hasta terminar imponiéndose a la del compositor sevillano. Sobre la recepción de la producción de Victoria en la catedral de Sevilla, y la evolución del canon musical de las pasiones de Semana Santa, véase: Juan Ruíz Jiménez, La Librería de Canto de Órgano. Creación y pervivencia del repertorio del Renacimiento en la actividad musical de la catedral de Sevilla (Granada: Junta de Andalucía. Consejería de Cultura, 2007), pp. 163-166 y 264-268. La pasión de Victoria se debió incorporar al ceremonial en algún momento del magisterio de capilla de Eduardo Torres (1910-1934).

72 Un estudio de las pasiones de Guerrero en Herminio González Barrionuevo, Francisco Guerrero (1528-1599): vida y obra: la música en la Catedral de Sevilla a finales del siglo XVI (Sevilla: Cabildo Metropolitano de la Catedral de Sevilla, 2000), pp. 504-548.

${ }^{73}$ González Barrionuevo, Francisco Guerrero (1528-1599), pp. 505-506; Ruíz Jiménez, La Librería de Canto de Órgano, p. 268, nota a pie $\mathrm{n}^{\circ}$ 655. El primer autor alude, además, al valor del libro en el que fueron copiadas, a su presencia durante siglos en el coro de la Catedral, así como al desgaste del pergamino como pruebas que apuntan a la pervivencia de estas pasiones hasta el s. XIX. Considera, así mismo, que han sido para el Cabildo "uno de los repertorios más 'tradicionales', valorados y amados" durante siglos. González Barrionuevo, Francisco Guerrero (1528-1599), p. 505.

${ }^{74}$ Las primeras ediciones modernas de pasiones de Guerrero fueron las publicadas por Hilarión Eslava y Felipe Pedrell en la $2^{\mathrm{a}}$ serie del tomo $1^{\mathrm{o}}$ de Lira Sacro-Hispana [LSH], y en el volumen II de Hispaniae Schola Musica Sacra [HSMS], respectivamente. Hilarion Eslava, LSH. 10 vols. (1852-60) (Madrid: Martín Salazar, [s.f.]), tomo $1^{\mathrm{o}}$, serie $2^{\mathrm{a}}$, pp. 77-98. Felipe Pedrell, HSMS vol. II. Franciscus Guerrero, (Barcelona: Juan Bautista Pujol y Cía., 1894), pp. 24-47. En ambos casos, las pasiones seleccionadas para su edición fueron las del Domingo de Ramos y Viernes Santo, es decir, precisamente las que no pervivieron en el repertorio. 
corroborarlo $^{75}$. Igualmente arriesgado se hace, en principio, apostar por la o las misas que el informe confirmó como compatibles con las disposiciones litúrgicas al cumplir con el requisito de ser exclusivamente vocales. El inventario de Torres recoge en el apartado dedicado a las obras de Semana Santa una "Misa Ferial" de Lobo, la "Misa Ferial" de Goicoechea, una "Misa Dominicalis" de Victoria y una "Misa" de Palestrina. La misa de Lobo, al menos, y, posiblemente también la de Palestrina, podría haber superado la criba de 1905 en caso de que ya estuviera en el repertorio en uso en ese momento. Sobre el resto de partes citadas en el informe resulta imposible saber mucho más, pues, por un lado, no figura ningún Gloria laus en este inventario, y, por otro, el único Miserere recogido en él, además del eslaviano, es "anónimo"76.

Aunque es necesario un estudio monográfico que ayude a dilucidar cuáles de estas obras fueron introducidas en el repertorio tras el intento llevado a cabo por Torres de ajustar los usos catedralicios al $M P$, y cuáles formaban parte del canon secular catedralicio, se podría proponer la hipótesis de que la Semana Santa, excluidos los oficios de Tinieblas y algunos motetes eucarísticos de los que nos ocuparemos a continuación, representó un espacio en el que se consagró y pervivió a lo largo de los siglos un canon musical en el que predominaba la polifonía clásica, acompañada por instrumentos colla parte. Este repertorio habría permanecido inmune a la penetración de los modelos barrocos y teatrales italianizantes propios de periodos posteriores ${ }^{77}$.

Aquellas partes de la liturgia que no respondían a estas características fueron condenadas en el informe elaborado por la CDMS. En los puntos cuarto y quinto se citan los cantos en los que se prohibió la participación de la orquesta: las lamentaciones,

${ }^{75}$ Además del Vexilla regis de Alonso Lobo, han llegado hasta nosotros otros seis más. Los de Gaspar de Úbeda: E-Sc 16, fols. 32v-34r; y las posteriores de O. Ravanello: ACS. Archivo de la Capilla Musical, sign.113-8-1; y S. Prieto: ACS. Archivo de la Capilla Musical, sign.112-5-1. Junto a estos, tres anónimos, de los cuales dos están copiados en E-Sc 2. La localización que de estas dos obras se ofrece en Herminio González Barrionuevo, José Enrique Ayarra Jarne y Manuel Vázquez Vázquez, Catálogo de Libros de Polifonía de la Catedral de Sevilla (Granada: Centro de Documentación Musical de Andalucía, 1994), pp. 14 y 20; difiere de la proporcionada por Ruíz Jiménez, La Librería de Canto de Órgano, p. 398. En el primer caso: fols. 32v-34r y 86v-89r; en el segundo: fols. 44v-48r y 141v-144r. El tercer anónimo: ACS. Archivo de la Capilla Musical, sign. 102-20-1.

${ }^{76}$ Como es sabido, era costumbre generalizada que el Miserere del Viernes Santo fuera cantado con una música mucho más austera que la de los dos días anteriores.

77 Se escapa a los objetivos de este trabajo el estudio profundo y pormenorizado del repertorio musical que componía el canon litúrgico en ese momento. Nuestro interés se centra en el comportamiento de los miembros de la Institución ante los cambios que tenían que ir asumiendo. 
responsorios, así como "los motetes acostumbrados en la Comunión del Jueves y al llegar el Preste al Monumento"78.

La eliminación de estos motetes con orquesta no provocó en absoluto la misma reacción que en el caso de las lamentaciones y Miserere. Jerónimo Armario, en la moción ya citada de 5 de marzo de 1906 en la que volvió a plantear la posibilidad de recuperar las lamentaciones con orquesta, incluyó junto a ellas, estos motetes suprimidos la Semana Santa anterior ${ }^{79}$. Sin embargo, mientras que, como hemos comprobado, en el caso de las lamentaciones logró reabrir el debate y hacer que la Diputación de Ceremonias estudiara el caso, los motetes del Jueves Santo no merecieron mayor atención por parte los canónigos.

Junto a la música de las funciones litúrgicas de Semana Santa, en este año de 1905 se llevó a cabo la revisión de otras partes del ceremonial catedralicio. El 24 de mayo, una vez pasadas las solemnidades pascuales ${ }^{80}$, la CDMS celebró una nueva reunión. En el informe correspondiente notificó al arzobispo algunas prácticas incompatibles, no sólo con el $M P$, sino con otras disposiciones litúrgicas. Entre ellas, la

${ }^{78}$ El motete que se cantaba delante del Monumento debía ser sustituido por el Tantum ergo, ya fuera gregoriano o polifónico. Se incluye dentro del grupo de piezas a reformar, además, el Velum templi que se cantaba durante la elevación. Las razones que llevaron a proscribir este motete no tienen que ver con el uso de la orquesta sino con la prescripción de no cantar obra alguna en ese instante. El Caeremoniale episcoporum sólo permitía que se tocara el órgano suave y gravemente: "Ad elevationem SS. Sacramenti pulsatur organum graviori et dulciori modo" (Caerem. episc. L. I, cap. XXVIII, n 9). De hecho, esta pieza no desapareció aunque a partir de ese momento se empezó a interpretar tras el canto del ofertorio, tal y como permitía el MP: "Pero es permitido, conforme a la costumbre de la Iglesia romana, cantar un motete al Santísimo Sacramento después del Benedictus de la misa solemne, como se permite que, luego de cantar el ofertorio propio de la misa, pueda cantarse en el tiempo que queda hasta el prefacio un breve motete con palabras aprobadas por la Iglesia." MP, III. Texto litúrgico, art. $\mathrm{n}^{\circ} 8$.

"4. ${ }^{\circ}$ No habrá orquesta en las Lamentaciones y Responsorios, ni se cantará el miércoles Santo el Velum templi después de la elevación, ni los motetes acostumbrados en la Comunión del Jueves y al llegar el Preste al Monumento.

5. ${ }^{\circ}$ Podrá ejecutarse el motete Velum templi, de que se habla en el párrafo anterior, el Miércoles Santo en la Misa; pero después del canto del Ofertorio propio; y en vez del usado al llegar al Monumento con Su Divina Majestad, el Tantum ergo ya en canto gregoriano, ya en canto polífono." Marcelo, "Circular no 320", p. 265.

79 "El Sr. Armario presentó una moción para que se restablezca si es posible el canto de las Lamentaciones en los oficios de la Semana Mayor con acompañamiento de música y los Motetes que se ejecutaban el Jueves Santo en los divinos oficios de la mañana, tal como venía haciéndose desde antiguo; se acordó que informase la Diputación de Ceremonias si dicha práctica se opone a las prescripciones litúrgicas". AC 5/3/1906. ACS. Sección Secretaría, libro 227, fol. 82v.

${ }^{80}$ En 1905 la Semana Santa se celebró entre los días 16, Domingo de Ramos, y 23 de abril, Domingo de Resurrección. 
costumbre de cantar "el Benedictus, antes de la elevación, formando un solo número con el Sanctus." ${ }^{81}$ La Comisión advirtió:

Abiertamente pugna esta práctica con el Caeremoniale episcoporum que dice en el lib. $2^{\circ}$ cap. $8, \mathrm{n}^{\circ} 70$ : "Chorus proseguitur cantum usque ad 'Benedictus qui venit"' exclusive; quo finito et no prius, elevatur Sacramentum. Tunc, silet chorus et cum aliis adorat"', $\mathrm{Y}$ para mayor claridad añade el mismo Caeremoniale en el $\mathrm{n}^{\circ}$ 71: "Elevato Sacramento, chorus proseguitur cantum Benedictus qui venit;" Corroboran estas disposiciones del Caeremonial las rúbricas del Gradual y las contestaciones dadas por la S. C. de Ritos en 13 de junio de 1643 y 12 Noviembre $1831 .^{82}$

Sin embargo, las obras disponibles en ese momento, según se señalaba en el informe, se ajustaban a la práctica local, es decir, eran piezas en las que el Sanctus y el Benedictus estaban integradas en una única pieza. Resultaban, en consecuencia, inservibles en caso de que se realizara la modificación que exigía la CDMS. Estas requerían que tanto Sanctus como Benedictus constituyeran dos piezas independientes, la primera, para ser cantada antes de la elevación, y la segunda, después de ella. En vista de este impedimento, se tomó la resolución de que "se respete el uso vigente en esta Iglesia ateniéndose a lo mandado en las composiciones que en adelante se escriban" ${ }^{\prime 83}$. En el caso de que se cumpliera rigurosamente esta disposición, debemos afirmar que el año de 1905 representó un importante punto de inflexión en el ceremonial catedralicio en lo que al canto del Sanctus-Benedictus se refiere, pues se debió iniciar una renovación total del repertorio disponible para esta parte del ordinario.

Por último, se pretendió corregir determinadas irregularidades en el canto del Tantum ergo durante las reservas solemnes del Santísimo:

4. ${ }^{\circ}$ Para atender al respeto debido al texto litúrgico, y al acto de adoración que se presta a Jesucristo en el Sacramento de los altares, convendría que la estrofa Tantum ergo del himno eucarístico durante las reservas solemnes en la Santa Iglesia Catedral se cantara en forma más ordenada y con arreglo a lo dispuesto por el autor de la música según debe constar en los papeles del archivo. ${ }^{84}$

\footnotetext{
${ }^{81}$ Informe con fecha de 27 de mayo con los acuerdos tomados en la reunión celebrada el 24 de ese mes. AGAS. Sección Gobierno. Asuntos Despachados, leg. 04900 (1905).

${ }^{82}$ Ibídem.

${ }^{83}$ Ibídem.

${ }^{84}$ Ibídem.
} 
Con estas disposiciones se clausuró el proceso de reformas en la Catedral durante el pontificado de Spínola.

\section{Plan para el arreglo de la música sagrada en la Catedral (1908)}

En la sesión capitular de 2 de diciembre de 1908, un par de semanas después de la clausura del II Congreso Nacional de Música Sagrada, se informó de una comunicación sobre música sagrada enviada por el arzobispo. Aunque las actas capitulares no dan cuenta de su contenido, debemos pensar, a juzgar por la reacción del Cabildo, que Almaraz ordenó en ella una revisión profunda de los usos litúrgicomusicales catedralicios. Leída esta notificación, se nombró una comisión "para que dictaminen las reformas que han de introducirse en el canto de esta Santa Iglesia de conformidad con lo dispuesto por el Motu proprio de su Santidad y por nuestro Excmo. Rmo. Prelado"85. Esta nueva comisión capitular "para el arreglo de la música en armonía con el motu proprio" estuvo compuesta por Rafael González Merchant, Vicente Ripollés, el organista primero Bernardo Salas, el sochantre Francisco Domínguez, el salmista José Otero, y el beneficiado Crispín Hernández, quien durante mucho tiempo había ejercido como sochantre ${ }^{86}$.

En el primer cabildo tras las fiestas navideñas, González Merchant, como presidente de la comisión, presentó a consideración de la corporación catedralicia un "Plan para el arreglo de la música sagrada en la Catedral". A diferencia del proceso catedralicio durante el pontificado de Spínola, centrado casi en exclusiva en las celebraciones de Semana Santa, el plan de González Merchant pretendió llevar a cabo de forma sistemática y completa la reforma litúrgico-musical en el primer templo $\operatorname{archidiocesano}^{87}$. En principio, el examen de dicho documento fue encomendado a la Diputación de Ceremonias y a los Mayordomos, quienes desde el principio debieron advertir la considerable incidencia que tendría en el ceremonial, pues en la siguiente sesión se acordó dejar un plazo de quince días para que el conjunto de los canónigos lo

\footnotetext{
${ }^{85}$ AC 2/12/1908. ACS. Sección Secretaria, libro 228, fol. 40v.

${ }^{86}$ Ibídem.

${ }^{87}$ AC 7/1/1909. ACS. Sección Secretaría, libro 228, fol. 52r.
} 
estudiaran con detenimiento ${ }^{88}$. Transcurrido este tiempo, algunos de ellos propusieron abordar su análisis por capítulos ${ }^{89}$. De esta forma, comenzó la discusión del texto que habría de regular de acuerdo con la norma papal todo lo referente a la música en la Catedral. Una discusión que se prolongó durante más de año y medio, y con un final inesperado, como veremos. El procedimiento que se siguió para la aprobación del plan de reformas musical fue prácticamente idéntico al acostumbrado en los casos de los documentos fundamentales de gobierno y organización de la institución catedralicia ${ }^{90}$. Desgraciadamente, no hemos hallado este escrito ${ }^{91}$. Es bastante posible que su destino final fuera la basura, dado que nunca entraría en vigor. Aunque las actas

\begin{abstract}
88،A Asimismo fue leído el informe de la Comisión acerca del plan presentado en el Cabildo último para el arreglo de la música de esta Santa Iglesia y se acordó que permanezca quince días sobre la mesa a fin de que puedan estudiarlo los Sres. con más detenimiento y que pasado ese plazo se cite para resolver lo que mejor pareciere." AC 11/1/1909. ACS. Sección Secretaría, libro 228, fols. 52v- 53r.
\end{abstract}

89 "se procedió a resolver sobre el informe de la Comisión acerca del nuevo plan de música que ha de regir en esta Santa Iglesia acordado a propuesta de algunos Sres. que se fuese leyendo el dicho plan por capítulos para facilitar su discusión, [...]”AC 26/1/1909. ACS. Sección Secretaría, libro 228, fol. 54v.

${ }^{90}$ En primer lugar, se nombraba a una comisión que elaboraba un primer borrador. Este quedaba sobre la mesa para su estudio durante un determinado periodo de tiempo. Seguidamente se procedía a su discusión por capítulos en distintos cabildos. El debate sobre los Estatutos, iniciado en 1913, se prolongó durante algo más de año y medio, al igual que el Plan para el arreglo de la música en la Catedral, como hemos comprobado. En el caso de la Regla de Coro, el arzobispo dio de plazo al Cabildo un año para la elaboración de un proyecto: "El Excmo. Cabildo en el término de un año, a contar desde esta fecha, Nos presentará un nuevo Proyecto de Estatutos con Cuadro de Distribuciones y nueva Regla de Coro, procurando que en ellos se mantengan y conserven todas las prácticas y costumbres tradicionales de la Iglesia que, directamente no estén en oposición con la legislación canónica vigente" AC 27/11/1913. ACS. Sección Secretaría, libro 229, 176r. Por petición del órgano de gobierno catedralicio, ese plazo se amplió seis meses más: "Se leyó una comunicación de S. Emcia. el Sr. Arzobispo participando que accede con gusto al ruego del Cabildo sobre prorrogar el tiempo señalado para formar el proyecto de Estatutos, Regla de Coro y Plan de distribuciones cuotidianas, y a este efecto concede un plazo de seis meses a contar desde el día $1^{\circ}$ del año corriente [...]”. AC 7/1/1915. ACS. Sección Secretaría, libro 230, 42r. El proyecto de estatutos estuvo listo y fue entregado algo más de año y medio después de su encargo por parte de Almaraz. Sin embargo, para concluir la Regla de Coro se solicitó un nuevo plazo: "El Cabildo acordó que se adicionasen y que se enviara a S. Emcia. El proyecto de nuevos Estatutos, y nuevo plan de distribuciones ordinarias para su aprobación rogándole concediera nuevo plazo de tiempo para poder presentarle también el proyecto de Regla de Coro que aún no está terminado". AC 12/7/1915. ACS. Sección Secretaría, libro 230, 97v. La nueva Regla de Coro se demoró hasta 1923. El estudio y discusión por capítulos del proyecto de Estatutos dio comienzo el 27 de octubre de 1914: "Acordado que se fuese estudiando y aprobando sucesivamente cada uno de los artículos por su orden respectivo se leyó el Titulo 1. ${ }^{\circ}$ que trata del Sr. Arzobispo Capítulo $1 .^{\circ}$ que lleva este título 'De su autoridad y de la obediencia que se le debe', y después de haberse disentido fueron aprobados con ligeras modificaciones los cuatro artículos que contiene. Leyóse después el capitulo $2^{\circ}$ que lleva este epígrafe: 'Del nombramiento, posesión y muerte del Arzobispo' y aprobados que fueron igualmente sus cuatro artículos, se acordó por lo avanzado de la hora, suspender la lectura para continuarla en la próxima sesión, terminando el Cabildo con un responso por nuestros hermanos difuntos, de todo lo que certifico." AC 27/10/1914. ACS. Sección Secretaría, libro 230, fols. 23v-24r.

${ }^{91}$ Desde la hipótesis de que González Merchant y el resto de comisionados se debieron basar en algún modelo para su redacción, hemos comparado la información -más bien escasa- que sobre su contenido nos proporcionan las actas capitulares con el Reglamento General para la Música Sagrada en la Provincia Eclesiástica de Valladolid y con el Reglamento de Música Sagrada para la Archidiócesis de 
capitulares apenas ofrecen información explícita sobre su contenido, proporcionan datos importantes, en primer lugar, sobre la forma en la que un grupo importante de capitulares reaccionaron ante los cambios que planteaba; en segundo lugar, sobre el grado de ortodoxia o heterodoxia de los distintos posicionamientos; en tercer lugar, en relación a la actitud del propio arzobispo con el Cabildo en la gestión de la reforma; por último, sobre los aspectos o las partes de la liturgia que, de nuevo, se revelaron como los más polémicos. Por estas razones estimamos imprescindible el seguimiento de su discusión.

Al margen del plan de música, otros problemas derivados de la introducción de los nuevos libros litúrgicos y de la aplicación del $M P$ se abordaron en este año y medio. Serán objeto igualmente de nuestra atención. Especialmente interesante resulta observar el desarrollo de ciertos debates relacionados con la pervivencia o abolición de determinadas costumbres litúrgicas de difícil encaje en las nuevas prescripciones papales, entre ellos, la recurrente cuestión Eslava.

Los dos primeros capítulos del plan presentado por el "batallador", en opinión de Ripollés, González Merchant fueron aprobados el 26 de enero. La aceptación del primero se verificó sin problema alguno. Sin embargo, el segundo llegó a suscitar cierto debate, tras la que se decidió introducir una enmienda relativa al canto de los salmos. Esta corrección no impidió que el secretario capitular, Modesto Abín, quedara disconforme y salvara su voto ${ }^{92}$. La actitud desfavorable a cualquier revisión o reforma de las costumbres catedralicias por parte de Abín fue una constante a lo largo de todo el proceso de estudio y aprobación del plan de música. Se mostró, sin duda, como el capitular más resistente a los cambios y encabezó el grupo de canónigos, cuyos nombres

Sevilla que finalmente se establecería como válido para el conjunto del Arzobispado. No hemos encontrado ninguna similitud con ninguno de los dos. El Reglamento de Valladolid es de carácter fundamentalmente normativo y organizativo, mientras que el de Merchant es prácticamente un ceremonial. El Reglamento de Música Sagrada para la Archidiócesis de Sevilla o Reglamento del Canto Sagrado de la Archidiócesis de Sevilla -de estas dos formas aparece titulado- tiene también carácter de ceremonial, sin embargo, no existe correspondencia alguna entre la temática de los diferentes capítulos de uno y otro, por lo que no nos atrevemos a sugerir que exista algún tipo de parentesco entre ambos.

${ }^{92}$ Las actas capitulares raramente nos proporcionan el título de los capítulos que se iban abordando. Los temas a los que se dedicaban cada uno de ellos se deducen de los comentarios vertidos sobre algún aspecto de su contenido. Sobre el tema del capítulo I no nos ofrece ninguna pista, aunque es lógico pensar que estuviera dedicado a disposiciones o principios de carácter general. El capítulo II parece que versaba sobre el canto de los salmos, a tenor de la enmienda con que se aprobó: "Leído el $2^{\circ}$ usaron de la palabra varios sres y fue aprobado con la siguiente enmienda: donde dice (art. $2^{\circ}$ )'el sochantre solo canta después el $2^{\circ}$ verso, dirá: "el sochantre acompañado de un salmista canta después antífona; [...]" AC 26/1/1909. ACS. Sección Secretaría, libro 228, fol. 54v. 
se nos irán desvelando durante el proceso, que destacaron por su actitud de defensa de la tradición local.

Seis días después, el 1 de febrero se abordó el capítulo tercero. No tenemos posibilidad de conocer el contenido de dicho capítulo ya que las actas no nos proporcionan dato alguno al respecto. No obstante, se deduce de ellas que durante su discusión debió ocurrir algo que hizo activar determinados resortes en algunos capitulares:

los Sres. Romero Gago y Pérez Córdoba hicieron constar que aceptaban desde luego todas las reformas del nuevo plan que estén contenidas estrictamente en las recientes disposiciones pontificias sobre música sagrada, pero que salvaban su voto en cuanto a modificar las costumbres de esta Santa Iglesia que sean compatibles con aquellas disposiciones. ${ }^{93}$

Es obvio, por tanto, que estos canónigos consideraron el plan como excesiva e injustificadamente invasivo en algunos aspectos. Desde sus puntos de vista, venía a modificar determinados usos catedralicios no discordes con las prescripciones papales. Como comprobaremos a continuación, el plan era en algunos puntos ciertamente riguroso, y apuntaba a un modelo litúrgico-musical que aquellos canónigos debieron sentir como extremada e innecesariamente austero. Por el contrario, el celo por la conservación de las tradiciones frente a reformas impuestas desde fuera llevaron a algunos de ellos a salvar de la proscripción determinadas obras en base a consideraciones cuanto menos discutibles ${ }^{94}$. En cualquier caso, el capítulo finalmente fue aprobado, aunque de nuevo sin el voto favorable de Modesto Abín ${ }^{95}$. La aprobación del capítulo cuarto tampoco contó con su apoyo ${ }^{96}$.

Los capítulos quinto y sexto, dedicados a las misas solemnes y feriales respectivamente, fueron aprobados con varias enmiendas ${ }^{97}$. El capítulo quinto debió ser

${ }^{93}$ AC 1/2/1909. ACS. Sección Secretaría, libro 228, fol. 56r.

${ }^{94}$ Tal fue el caso de los salmos de vísperas de Eslava. Véase epígrafe 4.2. Salmos de vísperas para el Corpus y la Inmaculada.

95 "leído el cap. $3^{\circ}$ fue aprobado; el infrascrito secretario salvó su voto" AC 1/2/1909. ACS. Sección Secretaría, libro 228, fol. 56r.

96 “Se procedió a la lectura del Capítulo $4^{\text {o }}$ del nuevo plan de música para esta S. I. y después de haber usado de la palabra varios Sres. fue aprobado; el infrascrito Secretario salvó su voto respecto de este asunto.” AC 8/2/1909. ACS. Sección Secretaría, libro 228, fol. 57r.

${ }^{97}$ AC 15/2/1909. ACS. Sección Secretaría, libro 228, fol. 58r. 
corregido para obtener el beneplácito del conjunto del Cabildo. En concreto se acordó suprimir una cláusula que figuraba en el artículo segundo que disponía: "se cante sólo por el sochantre Et incarnatus del Credo y el Benedictus después de la elevación”. Además necesitó de la aceptación de la propuesta planteada por Modesto Abín de consultar al prelado o a Roma para conservar las misas de canto figurado de Eslava, una cuestión sobre la que volveremos más adelante. Finalmente fue aprobado por unanimidad.

Sin embargo, el carácter excesivamente riguroso que, como hemos señalado, caracterizaba algunos puntos del plan de González Merchant desencadenó la discusión. Tal fue el caso del capítulo sexto. El artículo tercero, uno de los pocos datos directos que nos ofrecen las actas del contenido del plan, disponía que para acompañar el canto polifónico en la misa del Miércoles de Ceniza sólo se admitía el uso del armonio ${ }^{98}$. No obstante, se admitía como lícito el uso del órgano ${ }^{99}$, e incluso de otros instrumentos en caso de que lo autorizara el obispo, aunque sin parte propia y sólo para doblar o sustituir las voces ${ }^{100}$. Una norma idéntica para el caso de los cultos del Triduo Pascual había permitido, como vimos más arriba, la conservación en el ceremonial de una buena parte

98 "Leído que fue el $6^{\circ}$ se discutió [...] que en el Miércoles de Ceniza art. $3^{\circ}$ se use el armonium para sostener la parte de música polifónica en la misa de este día [...]”. Ibídem.

${ }^{99}$ Un Decreto de la Sagrada Congregación de Ritos dado el 3 de agosto de 1839 hacía lícito continuar con la costumbre de usar el órgano en las misas de Cuaresma: "Potest servari consuetudo pulsandi organa in Missa Rogationum, et tempore Quadragesimae et Adventus, et Vigiliis". Estas disposiciones no coincidían con las prescritas en el Ceremonial de Obispos, que aconsejaba el canto llano a capella para los oficios y misas feriales: "In Missis et Officiis defunctorum, nec organo, nec musica quam figuratam vocant, utimur; sed cantu firmo; quem etiam tempore Adventus et Quadragesimae, in ferialibus diebus convenit adhiberi.", aunque introducía el siguiente matiz respecto a la Misa: "sed in Missis, si musica adhibeatur, silent organa, cum silet cantus". En la catedral de Sevilla se asumieron y aplicaron las interpretaciones que de estas normas no del todo claras hicieron algunos músicos eclesiásticos europeos, entre ellos Haberl, referentes de la ortodoxia. Estos especialistas concluían que se permitía la participación del órgano en las misas de Cuaresma aunque sin parte propia, sólo para suplir o doblar las partes vocales. Véase: Reglamento de Música Sagrada para la Archidiócesis de Sevilla, p. 72, nota a pie $n^{\circ} 108$.

${ }^{100}$ Otro Decreto de la Sagrada Congregación de Ritos de 15 de abril de 1905 aclaraba que en aquellas funciones o tiempos litúrgicos en los que se permitía el empleo del órgano, no se prohibía el uso de otros instrumentos. De esta forma, se asoció la prohibición de los instrumentos y la forma en la que debían participar en la liturgia (con parte propia o colla parte) a los momentos en los que estaba prohibido el órgano y la forma en la que a este se le permitía intervenir. En el artículo 58 del Reglamento de Música Sagrada para la Archidiócesis de Sevilla se evidencia este vínculo: "Siendo regla general que solo puede permitirse el uso de la orquesta en la iglesia, cuando en ella se permite el uso del órgano [...]". "Reglamento de la Música Sagrada (conclusión)", BOAS, 692 (1910), p. 575. "In functionibus et temporibus quibus sonus organi permittitur, non interdicitur sonus aliorum instrumentorum...sed juxta prudens Ordinarii arbitrium”. Véase: Reglamento de Música Sagrada para la Archidiócesis de Sevilla, p. 72 , nota a pie $\mathrm{n}^{\mathrm{o}} 110$. 
del canon musical propio de esos cultos ${ }^{101}$. Como cabría esperar, este artículo dio lugar a debate, tras el cual se resolvió desestimar la propuesta y preservar la costumbre de usar instrumentos de cuerda para doblar el coro. Una vez hecha esta modificación y rechazado igualmente lo estipulado en el artículo segundo sobre el canto del verso Adjuva nos por los niños en lugar de por los salmistas como hasta ahora, el capítulo sexto que trataba sobre la música en las misas feriales, fue aprobado por unanimidad ${ }^{102}$.

La Cuaresma y la cercanía de la Semana Santa obligaron a adelantar la discusión de aquellos capítulos que afectaban a la liturgia de estos importantes periodos del temporal. El 25 de febrero y el 9 de marzo, el Cabildo aprobó respectivamente el capítulo V sobre el canto en la hora de completas, y el capítulo X que regulaba todo lo concerniente a la música en Semana Santa. No obstante, se debió rectificar el texto original propuesto por la Comisión en algunos puntos, pues venían a alterar costumbres

101 Sobre la doctrina contenida en el Motu proprio respecto al uso de los instrumentos, hubo mucha confusión. Fue algo común asumir que el texto papal venía a prohibir los instrumentos en la liturgia, excepción hecha del órgano; algo que no es cierto. A partir de este error de interpretación, intencionado o no, tomaría cuerpo y se extendería una corriente de opinión que tendría bastante peso en el seno del movimiento reformista. En realidad, estas ideas contrarias al uso de los instrumentos en las iglesias habían cuajado mucho antes de la promulgación del texto papal. Una voz singular y en muchos casos discrepante dentro del movimiento reformista antes y después del Motu proprio, como era la de Federico Olmeda, se alzaría para salir al paso de estos planteamientos que, aunque se presentaban como ortodoxos, falseaban en buena medida el documento de Pío X. Muestra de la preocupación de Olmeda al respecto y su posición militante son las dos obras que publicó teniendo como objeto de discusión la orquesta religiosa: Discurso sobre la orquesta religiosa (Burgos: Imprenta del Diario de Burgos, 1896), y Comentario sobre el Motu proprio de Su Santidad sobre la orquesta religiosa (Burgos: Imp. Cariñena, 1904). De especial interés resultan las disputas que mantuvieron el propio Olmeda y Luciano Serrano monje de Silos y uno de los principales divulgadores de las teorías sobre el canto gregoriano procedentes de Solesmes- sobre cuestiones de semiología y notación gregoriana, y sobre el uso de orquestas e instrumentos en la liturgia. Para una mayor información sobre estas porfías véase: Fernández de la Cuesta, "La reforma del canto gregoriano", p. 67. Parece ser que en Sevilla, los que se mostraron más cercanos, en principio, a los principios del $M P$ compartieron estas ideas excesivamente restrictivas sobre los instrumentos. Es posible que esta confusión en la interpretación de ese documento se deba, en parte, a una errónea comprensión del gregoriano como la expresión musical por antonomasia de la Iglesia: de ser el modelo de toda música religiosa a ser la única expresión musical religiosa de la Iglesia. En este sentido, resulta sintomático que tanto el propio arzobispo Enrique Almaraz como González Merchant se refieran en sus documentos al II Congreso Nacional de Música Sagrada como "el congreso de canto gregoriano", y que en las respuestas de los prelados españoles a la carta enviada por Almaraz predomine tal denominación. Véase capítulo 5, epígrafe 3.2.1. "La respuesta del episcopado español a los requerimientos del Congreso", p. 383.

102 "Leído que fue el $6^{\circ}$ se discutió lo que establece el art. $2^{\circ}$ sobre que en las Misas feriales canten los niños el verso Adjuva nos, y que en el Miércoles de Ceniza art. $3^{\circ}$ se use el armonium para sostener la parte de música polifónica en la misa de este día, y después de haber hablado varios Sres. se acordó que siga observándose la costumbre de que un cantor salmista oficie el verso ya citado y que tampoco se altere la práctica de usar los instrumentos de cuerda en la expresada Misa del Miércoles. Con estas variantes fue aprobado por unanimidad el Cap. $6^{\circ}$ [...]”. AC 15/2/1909. ACS. Sección Secretaría, libro 228 , fol. 58 r. 
catedralicias arraigadas $^{103}$. Se desestimaron la propuesta de cantar la antífona mariana al final de completas, y los cambios que se pretendían introducir tanto en el Sanctus de la bendición de palmas del Domingo de Ramos como en las partes de las turbas en el canto de la Pasión del Martes y Miércoles Santo ${ }^{104}$. El acta capitular de 9 de marzo no informa sobre la naturaleza de esas transformaciones. Recordemos que las pasiones para el Martes y Miércoles Santos que figuraban en el inventario elaborado durante el magisterio de Eduardo Torres a finales de los años veinte eran las de Francisco Guerrero. La omisión de esta información nos priva de conocer cómo eran interpretadas tradicionalmente las partes colectivas de las obras del compositor hispalense, ni en qué sentido se pretendieron reformar. Una vez examinados y resueltos estos capítulos, que demandaban atención urgente, el estudio del plan para la reforma litúrgico-musical en la Catedral fue aplazado hasta comienzos de verano.

El 13 de julio de 1909 se celebró una sesión extraordinaria y monográfica sobre el plan de música a petición de González Merchant ${ }^{105}$. En ella se abordaron y aprobaron nueve capítulos: el séptimo sobre la misa de difuntos, el octavo sobre los actos litúrgicos previos o posteriores a la misa, el noveno sobre disposiciones complementarias, así como todos los correspondientes al canto del oficio coral ("I. de los Maitines"; “II. de los Laudes"; “III. de las Horas menores”; "IV. de las Vísperas";

103 A diferencia del resto de capítulos, los relacionados con el canto en el Coro están relacionados con numeración romana, así como el dedicado a la Semana Santa.

\footnotetext{
104 “Al proseguir la lectura del Plan de Música para esta S. I. propuso el Sr. Merchant como Presidente de la Comisión que se tratase del Cap. V que afecta a las reformas del canto del coro en la hora de completas, por ser urgente en vista de hallarnos en el tiempo de Cuaresma. Leído y discutido que fue dicho capitulo se aprobó por unanimidad, con la variante de dejar sin efecto lo que dispone sobre que se cante la Antífona de la Virgen después de Completas, o sea que no se altere en este punto la costumbre seguida de antiguo en esta Santa Iglesia" AC 25/2/1909. ACS, sección I, libro 228, fol. 59v. "Prosiguiendo la lectura del plan de música y acordado a propuesta del Sr. González Merchant que se procediera a leer el C. X que trata de la Semana Santa fue leído y discutido habiéndose aprobado con la variante de que en el canto del Sanctus para la bendición de las palmas el Domingo de Ramos y de la parte de las turbas en la Pasión el Martes y Miércoles de la Semana Mayor no le haga alteración alguna respecto de lo que se ha practicado en los años anteriores." AC 9/3/1909. ACS. sección I, libro 228, fol. $62 \mathrm{v}$.

${ }^{105}$ La petición de González Merchant se remontaba al 21 de abril: "Por lo avanzado de la hora se desistió de continuar el estudio y discusión del plan de música para nuestra Iglesia; y a petición del Sr. González Merchant, se acordó que se cite a una sesión extraordinaria, para tratar especialmente de este particular, quedando el Sr. Deán encargado de fijar el día en que se ha de celebrar.” AC 21/4/1909. ACS. Sección Secretaría, libro 228, fol. 69r. Sin embargo, la sesión extraordinaria no fue convocada hasta el 12 de julio: "Por último se acordó citar para que mañana en sesión extraordinaria se continúe el estudio y discusión del arreglo de canto sagrado en nuestra Basílica.” AC 12/7/1909. ACS. Sección Secretaría, libro 228 , fol. $82 \mathrm{v}$.
} 
"V. de las Completas" y "VI. disposiciones complementaras") ${ }^{106}$. Con la lectura de dichos títulos se completó casi en su totalidad la revisión del conjunto del plan de González Merchant. En principio, todos serían aprobados, aunque los relativos al oficio de las Horas, lo fueron de forma provisional. Las innovaciones que introducía y el grado de modificación del ceremonial seguido hasta ahora eran tan importantes que se decidió, a propuesta de un capitular, encargar a la Diputación de Ceremonias estudiar si los usos hasta ahora vigentes se fundaban en privilegios otorgados al Cabildo tiempo atrás. Según las actas, sufrirían una especial alteración las horas de prima, tercia y vísperas solemnes, así como la sexta del día de la Ascensión. Una vez se pronunciara dicha Diputación se debía aprobar definitivamente el plan y redactar de nuevo con las modificaciones y enmiendas introducidas durante todo este tiempo ${ }^{107}$.

La última referencia sobre la discusión del plan de música que aparece en los registros capitulares es la moción presentada el 11 de octubre por González Merchant para abordar "varios puntos aún no tratados, a fin de completar el plan de música sagrada, según se indica en el acta del cabildo del día 12 de Julio de este año"108. Estos últimos aspectos por tratar constituían igualmente alteraciones drásticas pues, según las

\footnotetext{
106 "Leídos los capítulos $7^{\circ}$ que trata de la Misa de Difuntos; $8^{\circ}$, de los actos litúrgicos inmediatamente antes o después de la Misa y $9^{\circ}$, de disposiciones complementarias, y fueron todos aprobados, (Salen de la Sala Capitular los Sres. Sánchez Vázquez y Lectoral ). Fueron asimismo discutidos y aprobados los Capítulos relativos al canto en el coro que siguen: I. de los Maitines. II. de los Laudes. III. de las Horas menores. IV. de las Vísperas. V, de las Completas y VI. disposiciones complementaras." AC 13/7/1909. ACS. Sección Secretaría, libro 228, fol. 83r. Es posible que los capítulos referidos al canto coral constituyeran una sección aparte. Modesto Abín utilizó, como hemos señalado, números romanos para referirse a ellos, mientras que en el caso del resto de capítulos utiliza numeración árabe.
}

107“Como se nota diferencia entre el modo de cantar actualmente en el coro y el que ahora se propone en virtud de las disposiciones que se hallan en los libros litúrgicos aprobados por la Iglesia, un Sr. Capitular propuso que la Comisión de SS. Ceremonias estudie si esa diferencia se funda en privilegios que en tiempo atrás haya obtenido el cabildo y que después informe. Se acordó que se hiciera así y en vista de lo que resulte se resolverá en definitiva. Se convino en que puede ser objeto de moción especial la manera de cantar las Primas, Tercias y Vísperas solemnes, así como la Sexta del día de la Ascensión, pues también difiere mucho la que ahora se propone de la que de antiguo se viene observando.

Por último, se acordó que luego que este plan sea definitivamente aprobado por el Cabildo se redacte de nuevo y tomando en consideración todos las reformas que se hayan introducido, para que conste de una manera cierta la mente y los deseos de la Corporación en orden al canto." AC 13/7/1909. ACS. Sección Secretaría, libro 228, fol. 83.

108 “El Sr. González Merchant como Presidente de la Comisión nombrada para la reforma de la música en esta S.I. presentó una moción escrita que comprende varios puntos aún no tratados, a fin de completar el plan de música sagrada, según se indica en el acta del cabildo del día 12 de Julio de este año; leída la moción se acordó que quede sobre la mesa hasta el próximo cabildo ordinario, en el cual, previa citación, se resolverá lo que mejor pareciere" AC 11/10/1909. ACS. Sección Secretaría, libro 228, fols. 97v-98r. 
actas, alteraban "profundamente el orden litúrgico seguido en esta Santa Iglesia", razón por la cual se encargó también a la Diputación de Ceremonias su estudio ${ }^{109}$.

A partir de aquí existe un vacío de información que nos impide saber si esas prácticas litúrgicas hispalenses tenían su origen en determinados privilegios y si en base a esta razón se dejaron sin efecto las disposiciones que las alteraban. Por tanto, no podemos conocer el final de la discusión del plan para la reforma de la música en la Catedral en consonancia con la normativa litúrgica oficial de la Iglesia; no sólo con las prescripciones contenidas en el MP sobre música, sino con otras anteriores como son las establecidas en sus distintos decretos por la Sagrada Congregación de Ritos romana o en libros litúrgicos tan importantes como el Ceremonial de Obispos. Como hemos podido comprobar, los usos catedralicios hispalenses no se ajustaban plenamente a ellas.

Sólo podemos aportar dos datos significativos: el primero, que a día de 20 de octubre la Comisión de Ceremonias aún no había dado a conocer su informe al respecto ${ }^{110}$; el segundo, que en el acta correspondiente a la sesión capitular de 5 de noviembre, es decir, algo más de dos semanas después, figura un recordatorio de González Merchant en el que se cita el plan por primera vez como "el plan aprobado por el Cabildo" ". Se ha de deducir de esto que durante este lapso de tiempo se presentó el informe de la Comisión de Ceremonias, en virtud del cual se consideraría definitivo el acuerdo capitular de 13 de julio en el que se aprobaban provisionalmente los capítulos relacionados con el canto coral, no podemos saber si con alguna modificación fundada legalmente o no. No obstante, resulta extraño el silencio de las actas al respecto, si consideramos que, con más o menos datos concretos, todo el debate sobre el plan desde sus inicios había tenido reflejo en ellas. En cualquier caso, su discusión por parte del Cabildo terminó aquí, aunque no sería este su desenlace último.

Antes de tratar el último y definitivo episodio de vicisitudes por las que atravesó el plan de música en su efímera historia, nos detendremos a comentar algunas cuestiones que se trataron de forma paralela -en algunos casos imbricadas-, a su discusión, y que reflejan los problemas e inconvenientes, incluso de carácter práctico,

109 "Leída la cedula de citación para resolver sobre la adición al plan de música, que presentó el Sr. Merchant en el último Cabildo, se acordó que informe por escrito la Comisión de S. Ceremonias acerca de las reformas que se proponen y que alteran profundamente el orden litúrgico seguido en esta Santa Iglesia." AC 20/10/1909. ACS. Sección Secretaría, libro 228, fol. 99r.

${ }^{110}$ Véase nota anterior.

${ }^{111}$ AC 5/11/1909. ACS. Sección Secretaría, libro 228, fol. 102r. 
que encontró la penetración y aplicación del $M P$ en el templo metropolitano. En primer lugar, las dificultades derivadas de la sustitución del repertorio de canto llano vigente hasta entonces por el nuevo canto gregoriano contenido en la recién publicada Edición Típica Vaticana del Gradual (1908). En segundo lugar, los debates persistentes y recurrentes en torno a la cuestión Eslava.

\section{Sustitución del canto llano tradicional por el canto gregoriano} restaurado: adopción de la edición típica del Graduale (1908)

La sustitución de las nuevas melodías oficiales gregorianas por las tradicionales necesitó, lógicamente, de un periodo de aprendizaje y adaptación. En el primer capítulo aludíamos a las soluciones prácticas y económicas propuestas por la CDMS para que esa fase de asimilación condujera en el menor tiempo posible y de una forma eficiente y cómoda al dominio del nuevo repertorio. Los medios que la moderna tecnología ponía a disposición del clero, gramófono y discos, daban la posibilidad de tener en casa a un eficaz y paciente profesor de canto gregoriano ${ }^{112}$.

El contenido de las quejas que al respecto presentaron varios canónigos en distintas sesiones capitulares ilustra las dificultades e inconvenientes de este proceso en el templo catedralicio. Así, uno de los presentes en el cabildo celebrado el 18 de enero de 1909 se lamentaba de que "el Coro no observa siempre la forma de canto establecida para contestar al celebrante, dando lugar con ello a variaciones que alteran la unidad litúrgica". La corporación ordenó que "los cantores se atengan a lo que se halla prescrito para estas contestaciones en el Kirial de la reciente edición vaticana". Además, se confió a González Merchant, como venimos diciendo, convertido en el gran referente del Cabildo para todos los asuntos que tuvieran que ver con la música, el cumplimiento de dicho acuerdo $^{113}$. Algunos meses después, el 6 de julio, la propuesta planteada para evitar "la falta de armonía que resulta de que unos los termina [el primer

\footnotetext{
112 Véase capítulo segundo, epígrafe 4.1.1. Canto gregoriano: la adopción de las ediciones típicas vaticanas

113 "Un Sr. Capitular se quejó de que el Coro no observa siempre la forma de canto establecida para contestar al Celebrante dando lugar con ello a variaciones que alteran la unidad litúrgica; se acordó que los cantores se atengan a lo que se halla prescrito para estas contestaciones en el Kirial de la reciente edición vaticana y que el Sr. González Merchant se encargue de darles las instrucciones oportunas para el cumplimiento de lo acordado”. AC 18/1/1909. ACS. Sección Secretaría, libro 228, fol. 53v.
} 
versículo de los salmos] de una manera y otros de otra", indica que los problemas relacionados con el nuevo canto gregoriano persistían ${ }^{114}$.

Otra importante alteración en las costumbres locales que a algunos capitulares les costó asumir fue la que obligaba al Coro catedralicio a cantar antifonalmente el Gloria y Credo en las misas a canto llano y no de forma directa, es decir, todos los versos por todo el Coro, como se había hecho hasta entonces. Modesto Abín llegó incluso a proponer, como en el caso de las partes litúrgicas cuyos cambios habían suscitado mayor polémica, consultar a Roma la posibilidad de conservar esta práctica, lo que da una idea de la importancia que le debió atribuir. No obstante, la cuestión se dejó sin resolver hasta "otra ocasión”, por lo que, suponemos, se debió proceder según lo estipulado en el nuevo Kyrial típico ${ }^{115}$.

El tradicional canto del Tantum ergo también fue objeto de debate. La petición de un capitular de cantar este himno eucarístico a canto llano tal y como se había hecho hasta las reformas introducidas fue discutida y finalmente aceptada, siempre y cuando no pugnara con las prescripciones del $M P^{116}$. Sin embargo, en el siguiente cabildo González Merchant alegaría lo disconforme de la práctica local respecto al documento papal, por lo que finalmente se desestimó la solicitud ${ }^{117}$.

No obstante, el impulso preservador de los usos locales exhibido por algunos miembros del Capítulo hispalense fue minoritario en lo que respecta al canto llano. Ni

\footnotetext{
114 “Un Sr. Capitular hizo presente la conveniencia de que el sochantre cante la terminación en el primer versículo de los Salmos cuando estos son entonados por los Sres. Capitulares para evitar la falta de armonía que resulta de que unos los termina de una manera y otros de otra. Se acordó encargar a los sochantres que en lo sucesivo lo hagan así.” AC 6/7/1909. ACS. Sección Secretaría, libro 228, fol. 80.

115 "El infrascripto secretario hizo algunas observaciones sobre la variación introducida recientemente en el modo de cantar el coro el Gloria y el Credo de la Misa cuando esta se oficia en canto gregoriano y propuso que se consulte a Roma si puede conservarse la costumbre de esta Santa Iglesia, según la cual el canto de dichas partes se hace por todo el coro, o sea al unísono y no alternativamente como se previene en el nuevo Kirial de la edición vaticana; se acordó tratar este asunto en otra sesión." AC 1/2/1909. ACS. Sección Secretaría, libro 228, fol. 55r.
}

116 "Un Sr. Capitular pidió que si la manera de cantar el Tantum Ergo como se ha hecho hasta las reformas nuevamente introducidas no pugna con los preceptos del Motu Propio de S.S. se cantara así a lo menos durante la octava del Santísimo Corpus Christi. Hicieron uso de la palabra varios Sres. y se acordó acceder a lo pedido en el caso de que aquella manera de cantar el Tantum Ergo por canto llano no se oponga a lo dispuesto por el Papa, pero sólo durante la octava.” AC 2/6/1909. ACS, sección I, libro 228, fol. 76r.

117 "El Sr. Presidente de la Comisión encargada de implantar las reformas necesarias en el canto en conformidad con lo dispuesto en el Motu Propio de S.S. al tener noticia del acuerdo tomado en la sesión anterior, respecto al modo de cantar el Tantum ergo durante la octava del Corpus, dijo que para cumplir exactamente lo preceptuado por el Papa era necesario variar algo en la canturía de dicho himno y puesto que aquel acuerdo fue condicional se resolvió hacerlo así. (Salen los Sres. Romero Gago, González Merchant y Oliva.)" AC 7/6/1909. ACS. Sección Secretaría, libro 228, fol. 78r. 
Modesto Abín ni los demás capitulares de tendencia explícitamente conservadora, cuyos nombres no recogen las actas, sumaron grandes apoyos en el seno de la corporación catedralicia. Sus propuestas no tuvieron apenas eco ni movieron voluntades como para que se deba aludir a ellas como reacciones significativas por parte de un grupo mayoritario del Cabildo a la implementación del $M P$, como ocurrió en otros casos antes mencionados o de los que nos ocuparemos a continuación.

\section{La revisión del repertorio musical para las fiestas y grandes} solemnidades (1909-1910)

\subsection{Misas de canto figurado}

El 15 de febrero de 1909, en plena discusión sobre el capítulo quinto del plan para la reforma de la música, dedicado a las misas solemnes, Modesto Abín propuso conservar la costumbre de usar las llamadas "Misas de canto figurado" de Hilarión Eslava para las fiestas de segunda clase y algunas de primera. Conviene apuntar un par de datos para no confundirlas con otras misas eslavianas de diferentes características.

En un inventario elaborado, muy probablemente por el propio Abín y que podemos datar entre los últimos años del siglo XIX y comienzos del XX, figura "Un cuaderno con las Misas de Eslava de canto figurado y el Credo Romano a cuatro voces"118. Se trata de una colección de cuatro misas en primero, cuarto, quinto y sexto tono que aún se conservan en el Archivo de Música de la Catedral ${ }^{119}$. La información que nos proporciona Abín sobre la costumbre de usar estas misas de Eslava en las fiestas del rango mencionado es relevante, pues confirma una vez más la asociación existente en la catedral hispalense entre relevancia litúrgica y música de Eslava. No obstante, es preciso aclarar que estas misas no participan del estilo ampuloso y teatral de las obras eslavianas asociadas a las grandes solemnidades. Por el contrario, son piezas

\footnotetext{
${ }^{118}$ Hemos cotejado la caligrafía de las actas capitulares y de la Diputación de Ceremonias, redactadas por Abín como secretario de ambos organismos con la del inventario. La semejanza entre ellas es absoluta, por lo que habría que concluir que están escritas por la misma mano. Además, lo inespecífico de la información que proporciona sobre las obras apunta a que su autor no era músico. Este listado contiene obras de Evaristo García Torres y ninguna de Ripollés lo que indica que fue elaborado entre los últimos años del siglo XIX y comienzos del XX. Es posible que Abín redactara esta lista de obras tras la muerte de García Torres en diciembre de 1902, o incluso tras su jubilación en 1895, año en que quedó vacante el magisterio de capilla hasta la llegada de Ripollés en junio de 1903. Durante ese periodo ejerció interinamente Agapito Insausti. La elaboración de los inventarios era obligación del maestro de capilla titular, obviamente-. Véase inventario 1 en Apéndice 5. Juan Ruíz Jiménez ofrece una relación de las obras renacentistas que contiene en: La Librería de Canto de Órgano, pp. 352-353.
}

${ }^{119}$ ACS. Archivo de la Capilla Musical, sign. 32-1-5. 
para una sola parte vocal con acompañamiento de órgano que, desde un punto de vista estilístico, no contravienen las prescripciones del $M P$. Las fuentes no aclaran las razones por las que se pretendieron apartar del repertorio en uso. Los frecuentes interludios para órgano y, sobre todo, la omisión de algunos fragmentos de textos de partes del ordinario, como ocurre en el Sanctus, o incluso, del Benedictus completo, debieron estar entre ellas. La vigencia de obras de tal economía de medios en el ceremonial de algunas de las fiestas de primera clase y todas las de segunda no parece sea fruto de una elección estética o litúrgica, sino más bien indicativo de la mala situación económica de las arcas catedralicias en esos momentos.

En la discusión sobre la conservación de estas misas se repitió el mismo patrón que cuando se intentaba preservar determinadas obras asociadas a las solemnidades catedralicias: algún capitular efectuaba la propuesta de mantenerlas en el repertorio vigente como elementos esenciales del ceremonial tradicional; ante dicha propuesta otros capitulares interponían las alegaciones o reparos oportunos; y finalmente se aprobaba por parte del Cabildo la iniciativa de elevar consultas al arzobispo, y, en caso necesario, incluso al papa:

propuso el infrascripto Secretario que para el canto de las partes fijas de la Misa en determinadas fiestas de $1^{\text {a }}$ clase y en todas las de $2^{\mathrm{a}}$ se conserve la costumbre vigente en esta Santa Iglesia de usar las Misas de canto figurado compuestas por el Maestro Eslava. Varios Sres. expusieron su parecer y en vista de que algunos afirmaron que dichas Misas de canto figurado no se avienen con lo dispuesto por $\mathrm{Su}$ Santidad en su Motu Proprio propuso el referido Capitular que se pregunte al Sr. Arzobispo si pueden permitirse, y en caso de que S. E. no pueda dar solución satisfactoria se consulte a Roma a fin de procurar que se conserve la costumbre; a esta proposición se adhirieron los Sres. Maestrescuela, Pérez Córdoba y Romero Gago: el cabido acordó aceptarla. ${ }^{120}$

Se trataba, en síntesis, de agotar todas las posibilidades antes de renunciar a los usos acostumbrados, aún en el caso de que no estuvieran en consonancia con las prescripciones papales y se necesitara, por esta razón, el permiso del propio papa.

Como indica el acta capitular citada, Abín contó en esta ocasión con el apoyo de otros ilustres miembros de la corporación de gobierno catedralicia. La discusión del plan de música para la Catedral puso de manifiesto las distintas orientaciones existentes

${ }^{120}$ AC 15/2/1909. ACS. Sección Secretaría, libro 228, fol. 57v-58r. 
en el seno del Cabildo respecto a la reforma litúrgico-musical. Por un lado, existía un sector con una tendencia acentuada a la conservación de los usos locales y reacios a la admisión de determinadas modificaciones exigidas por la nueva norma. Este sector estaría compuesto, como se deduce de sus tomas de postura reflejadas en las actas, por personajes de gran peso como las dignidades de arcediano, Luciano Rivas y Santiago, y maestrecuela, Fermín Echeverría y Echaveguren; el secretario capitular, Modesto Abín, sin duda, el más beligerante y activo; y los canónigos Antonio Pérez Córdoba y Bartolomé Romero Gago, este último vicario capitular tras la muerte de Spínola. Por otro lado, la corriente más reformista estuvo representada por Rafael González Merchant, cuyos supuestos apoyos, si es que los tuvo, no se reflejan en las actas. Ripollés refirió a Pedrell la lucha que mantenía el canónigo carmonense con sus compañeros de corporación: "[González Merchant] es un elemento de valía y batallador que riñe en Cabildo las grandes peleas empeñado en enderezar todo esto."121

Volviendo a la cuestión de las misas de Eslava, los registros capitulares no dan cuenta de la contestación que recibiría el Cabildo por parte del arzobispo, aunque debió ser negativa, pues meses después, volvería a insistir; esta vez para que "se pida el parecer del Sr. Arzobispo acerca de consultar a Roma si son compatibles con el Motu proprio las Misas de canto figurado compuestas por el Maestro Eslava, que durante muchos años se han cantado en esta Santa Iglesia"122. Este segundo intento resultó igualmente inútil. La comisión encargada de entrevistarse con el arzobispo para tratar de conservar tanto los salmos de vísperas para la Inmaculada como las misas de Eslava, formada por Modesto Abín y el arcediano Luciano Rivas, informó al Cabildo, como ya hemos apuntado, que "S. S. Rma. [había resuelto] que se esté a lo mandado en este punto por Ntro. Smmo. Padre el Papa Pío X en su Motu proprio sobre música Sagrada."123 El Cabildo terminó aceptando la resolución del arzobispo: "El cabildo quedó enterado". ${ }^{124}$

${ }^{121}$ Carta de Ripollés a Pedrell, 8 de febrero de 1909. BC. FFP. M 964 R. Más adelante, especialmente cuando tratemos del II Congreso Nacional de Música Sagrada, tendremos ocasión de conocer más a fondo el pensamiento de esta importante figura de la reforma en Sevilla, e incluso ofrecer una visión sobre su evolución respecto a la cuestión litúrgico-musical, proporcionada por Vicente Ripollés en su correspondencia con Pedrell.

${ }^{122}$ AC 5/11/1909. ACS. Sección Secretaría, libro 228, fol. 102r.

${ }^{123}$ AC 8/11/1909. ACS. Sección Secretaría, libro 228, fol. 102v.

${ }^{124}$ Ibídem. Estas misas debieron ser repuestas en la liturgia catedralicia en algún momento de la segunda década del siglo, pues existe una transcripción con fecha de 14 de julio de 1921 en el mismo cuaderno 


\subsection{Salmos de vísperas para el Corpus y la Inmaculada}

Además de las misas de canto figurado, otras obras de Eslava fueron sometidas a revisión en 1909. El 5 de noviembre, un mes antes de la celebración de la festividad de la Inmaculada, González Merchant consideró oportuno advertir en cabildo que

según las recientes disposiciones pontificias acerca de la música religiosa y el plan aprobado por el Cabildo, no pueden cantarse las vísperas en la fiesta de la Inmaculada con el acompañamiento de orquesta, tal como se viene verificando hace años; ${ }^{125}$

Es necesario puntualizar que el acta, tal y como está redactada, puede inducirnos a confusión, dado que las disposiciones contenidas en el MP no proscribían en absoluto la participación de la orquesta en el canto de los salmos de vísperas, y que en caso de que lo hiciera el plan, sería el resultado de una interpretación excesivamente severa del documento papal. Como señalamos en el capítulo primero, la orquesta no es mencionada en el $M P$ en ningún momento, lo que constituía un cierto vacío normativo que obligaba a la interpretación. En el caso de la hora de vísperas, el $M P$ dedica algunos puntos del artículo 11 a su regulación, según el cual se permitían varias modalidades en el canto de la salmodia. La única de ellas que quedaba prohibida era la denominada "de concierto", sin más especificación ${ }^{126}$. Se podría explicar la disposición restrictiva del plan en lo que concierne a la música apropiada para el canto salmódico desde una identificación entre "salmos de concierto" y salmos con orquesta. En realidad, el problema no estribaba ni en uno ni otro concepto. Se trataba de un asunto que venía de largo y, además, poseía unas enormes implicaciones culturales, además de

que las contiene. En esta transcripción el cifrado del bajo de la parte de órgano está resuelta. Figura, además, el nombre de Rafael Casto.

${ }^{125}$ AC 5/11/1909. ACS. Sección Secretaría, libro 228, fol. 102r.

126 “B) En el oficio de vísperas deben seguirse ordinariamente las disposiciones del Caeremoniale episcoporum, que prescribe el canto gregoriano para la salmodia y permite la música figurada en los versos del Gloria Patri y en el himno.

Sin embargo, será lícito en las mayores solemnidades alternar, con el canto gregoriano del coro, el llamado de contrapunto, o con versos de parecida manera convenientemente compuestos.

También podrá permitirse alguna vez que cada uno de los salmos se ponga enteramente en música, siempre que en su composición se conserve la forma propia de la salmodia; esto es, siempre que parezca que los cantores salmodian entre sí, ya con motivos musicales nuevos, ya con motivos sacados del canto gregoriano, o imitados de este.

Pero quedan para siempre excluidos y prohibidos los salmos llamados de concierto." MP. Título IV. Forma externa de las composiciones sagradas, art. 11. 
litúrgico-musicales. Los salmos consagrados en el ritual catedralicio de estas fiestas eran desde hacía tiempo los compuestos por Hilarión Eslava.

Los salmos de vísperas de Eslava, que se interpretaban en las grandes solemnidades del Corpus y la Inmaculada, estuvieron por primera vez en el centro del debate en 1905, año en el que, aunque no de forma tan sistemática y profunda como en 1909, se había llevado a cabo una primera revisión de los usos litúrgico-musicales catedralicios para ajustarlos a las nuevas directrices papales ${ }^{127}$. En aquella ocasión, al igual que ocurrió provisionalmente con el Miserere y a diferencia de las lamentaciones con orquesta, los salmos eslavianos superaron la criba. La CDMS encontró la fórmula para justificar su conservación en el ceremonial dentro de los nuevos preceptos legales. El informe que daba cuenta de las resoluciones tomadas en la reunión celebrada el 24 de mayo de 1905 explicaba las razones:

3. ${ }^{\circ}$ Es regla establecida por S. S. en el art. $4^{\circ}$ número 11 del Motu Proprio, que en el Oficio de Vísperas debe seguirse ordinariamente las disposiciones del Caeremoniale episcoporum, (canto gregoriano en la salmodia y permisión de la música figurada en los versos del Gloria Patri y el himno.) Sin embargo en el mismo art. permite S. S. que en las mayores solemnidades alterne el canto gregoriano con el fabordón y aun se ponga cada uno de los salmos enteramente en música siempre que en su composición se conserve la forma propia de la salmodia, esto es, siempre que parezca que los cantores salmodian entre sí, ya con motivos musicales nuevos, y con motivos sacados del canto gregoriano o imitados de éste.

Aplicamos estos textos del Motu Proprio a los salmos puestos en música por el Mtro. Eslava para las solemnidades del SS. Corpus Christi e Inmaculada Concepción, [pues] pueden apreciarse en ellos las condiciones que S. S. exige en los salmos puestos enteramente en música, ya por oírse con frecuencia la melodía litúrgica propia del tono, ya por el dialogado de los coros ya por los motivos musicales diversos que aparecen en los distintos versos $[\ldots]^{128}$

El juicio sobre la compatibilidad de estas obras con el $M P$ basado en estos argumentos parece, en principio, incuestionable. Sin embargo, la misma CDMS reconoció su incompatibilidad en el aspecto estético-estilístico, aunque no consideró que tuviera el peso suficiente como para dictaminar su exclusión:

\footnotetext{
${ }^{127}$ Véase epígrafe 1. Reforma de la música en las solemnidades de Semana Santa

${ }^{128}$ Informe con fecha de 27 de mayo de 1905 con los acuerdos tomados en la reunión celebrada el 24 de ese mes. AGAS. Sección Gobierno. Asuntos Despachados, leg. 04900 (1905).
} 
[...] sin que estas afirmaciones signifique en la Comisión el desconocimiento de que las formas melódicas y rítmicas, frutos de las circunstancias de tiempo, en ellos empleados, no son los más apropósito para la mejor expresión religiosa del texto litúrgico. ${ }^{129}$

Es aquí donde resulta más discutible el criterio de la CDMS, pues uno de los principales objetivos perseguidos por el $M P$ era precisamente expulsar del templo todos aquellas expresiones musicales que pudieran siquiera recordar a un lenguaje cercano a lo teatralizante o a una factura que se estimaba como profanizante e inadecuada desde un punto de vista litúrgico. Como en cierta medida reconoce la CDMS, esos "frutos" lo eran de una época ("circunstancias de tiempo") que se contemplaba desde la óptica de los impulsores de la reforma como nefasta para la música religiosa, aunque no colaboró en su superación como exigía el $M P{ }^{130}$

La siguiente carta, escrita por Pio X tan sólo dieciséis días después de la promulgación del MP y dirigida al cardenal vicario de Roma, revela que la reforma del canto de la salmodia en la hora de vísperas constituía una prioridad para el papa, por el especial valor que le atribuía. Resulta interesante observar cómo en este caso, y a diferencia de la postura que adoptó respecto al Miserere -“método de reforma lentamente progresiva"131 “dilaciones". El interés que posee, pensamos, justifica su transcripción a pesar de su extensión:

Muchas cosas habrán de quitarse o corregirse en el canto de la Misa, la Letanía lauretana y el Himno eucarístico; pero lo que

${ }^{129}$ Ibídem.

130 ، 5 . [...] deberá cuidarse con mayor esmero que las composiciones musicales de estilo moderno que se admitan en las iglesias no contengan cosa ninguna profana ni ofrezcan reminiscencias de motivos teatrales, y no estén compuestas tampoco en su forma externa imitando la factura de las composiciones profanas.

6. Entre los varios géneros de la música moderna, el que aparece menos adecuado a las funciones del culto es el teatral, que durante el pasado siglo estuvo muy en boga, singularmente en Italia.

Por su misma naturaleza, este género ofrece la máxima oposición al canto gregoriano y a la polifonía clásica, y por ende, a las condiciones más importantes de toda buena música sagrada, además de que la estructura, el ritmo y el llamado convencionalismo de este género no se acomodan sino malísimamente a las exigencias de la verdadera música litúrgica." MP. Título II. Géneros de Música Sagrada, arts. 5 у 6.

${ }^{131}$ Así se expresa el redactor del borrador de la respuesta dada por la Santa Sede a la petición de dispensa de Spínola: "Non ignora il Santo Padre le difficoltá che in molti luoghi impediscono o ritardano la completa attuazione del Motu Proprio del 22 Nov 1903, difficoltá non superabili se non col tempo e con un metodo di riforma lentamente progressiva." Archivio Segreto Vaticano, Segretaria di Stato, anno 1905 , rubrica 283, fascicolo 2, fol. 48 . 
necesita una completa renovación es el canto de Vísperas, en basílicas e iglesias, donde ya no se observan las prescripciones litúrgicas del Caeremonial Episcoporum, ni las hermosas tradiciones musicales de la clásica escuela romana. A la devota salmodia del clero, en la cual tomaba parte el pueblo, han sustituido interminables composiciones musicales sobre el texto de los Salmos, todas escritas a la manera de las antiguas óperas teatrales y, generalmente, de tan mezquino valor artístico, que no se tolerarían de fijo ni siquiera en los conciertos profanos de menos importancia. Con tal música no se promueve la devoción ni la piedad cristiana, se alimenta la curiosidad de los menos entendidos, la generalidad de los fieles no recibe sino disgusto y escándalo, y se maravilla de que tanto abuso perdure todavía. Por lo cual es Nuestra voluntad que todo eso se suprima, y que las Vísperas se celebren en todas partes con arreglo a las normas litúrgicas por Nos indicadas. Serán las primeras en dar ejemplo las iglesias patriarcales, merced a la solícita atención y al ilustre celo de los Señores Cardenales a quien están encomendadas, a las cuales, emularán ante todo, las basílicas menores, las iglesias colegiatas y parroquiales, como asimismo las iglesias y capillas de las Órdenes religiosas. Y no se use de indulgencia, Sr. Cardenal, ni consienta dilaciones. Con diferirlas no se amenguan las dificultades, sino que crecen, y puesto que hay que cortar, córtese resuelta e inmediatamente. Tengan todos confianza en Nos y en Nuestra palabra, a la cual van unida la gracia y la bendición celestiales. Al principio la novedad producirá asombro; resultará quizá mal preparado algún maestro de capilla y algún director de coro; mas poco a poco irá prendiendo por su propia virtud, y en la perfecta correspondencia entre la música, las normas litúrgicas y la salmodia, todos descubrirán una bondad y belleza no advertidas antes. A la verdad, esta reforma abreviará considerablemente la duración de las Vísperas; mas si los rectores de las iglesias quisiesen alguna vez prolongar la función y ocupar la atención del pueblo, que laudablemente suele acudir por las tardes a los templos donde se celebra la fiesta, nada impide, antes bien será provechoso a la piedad y edificación de los fieles, que a las Vísperas siga un sermón apropiado a la fiesta, y que se termine con una solemne bendición y reserva del Santísimo" "132

Los reformistas, entre ellos Ripollés, dedicaron igualmente una especial atención al canto de vísperas. Como atestigua una carta de este a Pedrell, una de las ideas que había proyectado de cara al II Congreso Nacional de Música Sagrada a celebrar en Sevilla en 1908 era ofrecer distintos ejemplos de vísperas cantadas según los preceptos del $M P$. Una intención que finalmente no se hizo realidad:

\footnotetext{
${ }^{132}$ Carta de Pío X al Cardenal Vicario de Roma. 8 de diciembre de 1903. Reglamento de Música Sagrada para la Archidiócesis de Sevilla, pp. 73-74, nota no 114.
} 
Para cuando comencemos a planear el futuro Congreso, tengo dos cosas para proponer si a V. le parece bien.[...]

$2^{\mathrm{a}}$ Distintas maneras de cantar vísperas autorizadas por el Motu Proprio; presentando modelos en gregoriano; en fabordón de los variados géneros existentes; y en la forma de salmos de música continua; haciendo oír como a modelo de estos últimos alguno de los musicados por F. Cabo de Valencia. ${ }^{133}$

En definitiva, las decisiones de la CDMS fueron, precisamente en una función litúrgica de especial importancia para el propio papa y la reforma, consecuencia de una lectura excesivamente flexible del $M P$, pues transigía con unas expresiones musicales que eran objetivamente rechazadas en sus prescripciones. En contraste con la interpretación extremadamente rigurosa de González Merchant y su comisión capitular en 1909, la de la CDMS en 1905 lindaba con los límites del texto papal al dar lugar a decisiones demasiado permisivas en puntos fundamentales ${ }^{134}$.

Como ya hemos advertido, parece que existieron tendencias de signos opuestos, que tiraron de la cuerda con excesiva fuerza hacia cada uno de sus extremos, rayando en uno u otro sentido los límites de la nueva ortodoxia establecida en el MP. Se constata, además, que estas tendencias inmoderadas, muy severas o muy flexibles, e incluso cercanas a erróneas lecturas del $M P$, afloraron especialmente en momentos en los que se revisaron determinadas obras compuestas por Eslava, asociadas a solemnidades que poseían un importante valor simbólico para la Iglesia local ${ }^{135}$.

En cualquier caso, los salmos de vísperas compuestos por Eslava para la solemnidad de la Inmaculada superaron la revisión de 1905, consolidando así su permanencia en el ritual de esas grandes festividades marianas hasta 1909. La advertencia hecha por González Merchant el 5 de noviembre de ese año respecto a la

133 Carta de Ripollés a Pedrell, 29 de octubre de 1907. BC. FFP. M 964 R. La primera de las dos propuestas fue una conferencia sobre cantos populares que sí se llevó a cabo. Sobre esta conferencia véase capítulo 6, epígrafe 2.2. "Canto popular religioso: la omnipresencia de las ideas del nacionalismo musical español”, p. 558.

${ }^{134}$ Estas disposiciones afectaron también a partes importantes del ceremonial catedralicio como fueron los tradicionales responsorio Ego ex ore altissimi y motete Conceptio tua que se cantaban en lugar del gradual propio en la misa de la Inmaculada en el primer caso, y después de la elevación de dicha misa en el segundo. " $2 .^{\circ} \mathrm{S}$. S. consigna en el M. P. art. $3 \mathrm{n}^{\circ} 8$ la prohibición de alterar, cambiar u omitir los textos determinados para cada función litúrgica, y a esta prohibición contraviene la costumbre vigente en la Santa Iglesia Catedral de cantar el responsorio "Ego ex ore altissimi" en el gradual de la Misa de la Inmaculada y el motete Conceptio tua después de la elevación de la propia Misa." Informe con fecha de 27 de mayo de 1905 con los acuerdos tomados en la reunión celebrada el 24 de ese mes. AGAS. Sección Gobierno. Asuntos Despachados, leg. 04900 (1905).

${ }^{135}$ En el capítulo 4 tendremos ocasión de detenernos en su estudio. 
incompatibilidad de estos salmos con los preceptos papales, a la que aludíamos al comienzo de este epígrafe, reabrió de nuevo el debate.

Como había ocurrido en otras ocasiones, tras discutir el asunto, se acordó enviar a un par de capitulares en comisión para entrevistarse con el arzobispo. Los encargados fueron, otra vez, el secretario capitular, Modesto Abín, y el arcediano, Luciano Rivas y Santiago. En esta ocasión, el argumento que esgrimieron no tenía que ver con la idoneidad litúrgica o conformidad con el $M P$; lo cual sugiere que se debió considerar desacertado el criterio de la CDMS que legitimó la pervivencia de las piezas eslavianas en 1905. Alegaron, por el contrario, un motivo más trivial, como fue la imposibilidad de adquirir obras acordes con las nuevas normas litúrgico-musicales en el breve espacio de tiempo que restaba para la celebración de la fiesta ${ }^{136}$. Tal y como consta en las actas capitulares, la respuesta que recibieron del arzobispo fue terminante: “se esté a lo mandado en este punto por Ntro. Santísimo Padre el Papa Pío X en su Motu proprio sobre música Sagrada" ${ }^{137}$. Los salmos eslavianos interpretados hasta este momento en el día de la Inmaculada fueron finalmente eliminados.

La respuesta del arzobispo no desanimó a los capitulares conservacionistas, pues en mayo volvieron a intentar preservar los salmos del navarro, esta vez, para la hora vespertina del Corpus Christi. La discusión fue iniciada por un capitular, quien consideraba que la decisión de no usar la orquesta en el canto de las vísperas solemnes se había tomado exclusivamente para el caso de la festividad de la Inmaculada. Por tanto, defendía, no tenía por qué afectar a la del Corpus ${ }^{138}$. Se trataba de salvar, al

136 “varios Sres. usaron de la palabra y se acordó que el Sr. Arcediano y el infrascripto Secretario. visiten a S. E. el Sr. Arzobispo por si teniendo en cuenta que está próxima dicha fiesta y no es ya posible adquirir la música con que puedan cantarse los salmos de las vísperas a tenor de las indicadas disposiciones, juzga S.E. oportuno que por este año no se haga alteración”. AC 5/11/1909. ACS. Sección Secretaría, libro 228, fol. 102 r.

137 "El Sr. Presidente accidental dio cuenta el Excmo Cabildo del resultado de la gestión que cerca del Excmo. y Rmo. Prelado y en unión del Sr. Secretario se le había confiado sobre el canto de los Salmos en las horas de Prima y Vísperas en la próxima fiesta de la Inmaculada Concepción, habiendo resuelto S. S. Rma. que se esté a lo mandado en este punto por Ntro. Smo. Padre el Papa Pío X en su Motu proprio sobre música Sagrada. El Cabildo quedó enterado.”AC 8/11/1909. ACS. Sección Secretaría, libro 228, fol. $102 \mathrm{v}$.

138 “Un Señor Capitular preguntó si en este año se seguirá observando la costumbre de cantar los salmos de vísperas en la fiesta del Corpus con acompañamiento de orquesta, por entender que lo acordado sobre música en el canto de la salmodia sólo se refiere a la fiesta de la Inmaculada." AC 23/5/1910. ACS. Sección Secretaría, libro 228, fol. 146r. De nuevo se planteaba la cuestión desde el punto de vista del uso de la orquesta, cuando ese no era el problema real, como acabamos de explicar. La reiteración de esta aproximación al asunto nos lleva a pensar en la posibilidad de que en el plan de música de González Merchant figurara la prohibición explícita de la orquesta en los salmos de vísperas. De ser así sería una prohibición abusiva e injustificada, no acorde con lo regulado al respecto por el Motu proprio. 
menos, los salmos de vísperas eslavianos para esta solemnidad. Esta vez no se consultó al prelado para tomar la decisión "de decir al Maestro de Capilla que se canten las vísperas como en años anteriores si todo ello se ajusta a lo prescrito por su Santidad en su Motu proprio", lo cual resulta llamativo. Aunque se especificaría "que si no pueden cantarse los salmos con la música acostumbrada, vea si es posible hacerlo con otra que se halle dentro de lo permitido por el Papa". ${ }^{139}$ Como en otras ocasiones en las que se trataba de dilucidar la conveniencia o no de mantener determinadas costumbres litúrgico-musicales, las actas capitulares no nos proporcionan más información sobre la música que finalmente sonaría, en este caso, en la salmodia vespertina del Corpus. Tampoco sobre el juicio a que los capitulares sometieron estos salmos, según los preceptos del MP. En cualquier caso, la aplicación en la Catedral del Reglamento de Música Sagrada para la Archidiócesis de Sevilla lleva a pensar fueron descartados.

El 2 de Mayo, sólo unos días antes de que se planteara en cabildo la cuestión de la música idónea para la salmodia del Corpus, se comenzó a publicar en el BOAS el Reglamento que acabamos de citar $^{140}$. El capítulo que trataba sobre el canto de vísperas se publicó el 16 de mayo. En consecuencia, el Cabildo tomó la decisión sobre las vísperas del Corpus conociendo, además, la regulación al respecto aprobada para toda la Archidiócesis. Hay que inferir de ello que la institución de gobierno catedralicio no debió considerar de aplicación el Reglamento, de alcance diocesano general, en el ámbito de sus competencias propias.

Como hemos descrito más arriba, los propios capitulares, en virtud de sus facultades y obligaciones como regidores y administradores del templo metropolitano y a requerimiento del propio arzobispo, discutieron durante meses y aprobaron finalmente el plan de González Merchant, es decir, su propia norma sobre música sagrada. Sin embargo, en la sesión capitular de 27 de julio se leyó una comunicación de Almaraz que, a juzgar por las reacciones que provocó, debió sorprenderles:

Diose lectura a otra comunicación del Sr. Arzobispo acompañando algunos ejemplares del Reglamento de Música Sagrada que ha tenido a bien aprobar para esta Diócesis por decreto de 2 de

\footnotetext{
${ }^{139}$ AC 23/5/1910. ACS. Sección Secretaría, libro 228, fol. 146r.

${ }^{140}$ Véase capítulo 2, epígrafe 5. "La culminación del proceso normativo: El Reglamento de Música Sagrada para la Archidiócesis de Sevilla (1910)”, p. 164. Una síntesis de dicho Reglamento en Apéndice 4.
} 
Mayo del corriente año y encargando al Cabildo disponga lo necesario para llevarse a la práctica en nuestra Santa Iglesia. ${ }^{141}$

La reacción de Modesto Abín fue inmediata y, tal vez, algo impulsiva: "El infrascrito Secretario [...] propuso al Cabildo que una Comisión de su seno pase a suplicar al Sr. Arzobispo que deje sin efecto en nuestra Santa Iglesia aquellas disposiciones si a bien lo tuviese $[\ldots]^{\prime 142}$. La razón que alegó fue que

algunos artículos del mencionado Reglamento, sobretodo en el capítulo que trata del canto de Vísperas, alteran notablemente el ceremonial que durante siglos se ha observado en esta Santa Iglesia y que a su juicio hay medios de que pueda conservarse no pequeña parte de este ceremonial sin contravenir a lo mandado por S. S. en su Motu proprio. ${ }^{143}$

Tras ser discutida, el propio Abín retiró la moción, y presentó otra más atemperada en la que proponía la formación de una comisión capitular para que "estudie detenidamente el Reglamento en presencia de las prácticas vigentes en esta Santa Iglesia y vea si pueden mantenerse dentro de lo prescrito en el mencionado Reglamento" ${ }^{\prime 144}$. La comisión estuvo compuesta por el arcediano Luciano Rivas, González Merchant y el propio Modesto Abín. En el siguiente cabildo se acordó consultar al arzobispo si su voluntad era que el Reglamento se llevara a efecto sin dilación o si concedía un plazo para que la recién nombrada comisión dispusiera del tiempo necesario para poder realizar el estudio encargado ${ }^{145}$. En el cabildo de 1 de agosto de 1910 se comunicó que

141 AC 27/7/1910. ACS. Sección Secretaría, libro 228, fols. 154v-155r. En el AGAS se conserva el borrador manuscrito de la comunicación enviada al deán por Almaraz, con fecha de 23 de julio de 1910. El texto dice así: "Excmo. E Ilmo. Sr. Aprobado con fecha 2 de Mayo último el Reglamento de Música Sagrada para esta Archidiócesis, remito a manos de V. E. I. los adjuntos ejemplares del mismo, esperando se sirva V. E. I. disponer lo conveniente a fin de que sea puesto en práctica en esa Santa Iglesia." AGAS. Sección Gobierno. Asuntos Despachados, leg. 04911 (1910).

${ }^{142}$ AC 27/7/1910. ACS. Sección Secretaría, libro 228, fol. 155r.

${ }^{143}$ Ibídem. Es posible que los medios para conservar el ceremonial respecto a los salmos de vísperas a los que hace referencia Modesto Abín fueran aquellos con los que finalmente se salvarían precisamente los salmos para las festividades del Corpus y la Inmaculada de Eslava en 1905, como acabamos de comentar.

${ }^{144}$ AC 27/7/1910. ACS. Sección Secretaría, libro 228, fol. 155r.

145 “dijo el mismo Sr. [deán] que la Comisión nombrada en el último cabildo para estudiar si son motivo del último Reglamento de música sagrada aprobado por el Sr. Arzobispo para la Diócesis hay medio de que subsistan ciertas prácticas del ceremonial de nuestra Santa Iglesia, ha manifestado que necesita tomarse algún tiempo para realizar su cometido y que estando para ausentarse el Sr. Arzobispo a fin de tomar aguas medicinales convendría preguntarle si es su voluntad que, sin demora alguna se lleve a la práctica el Reglamento en todas sus partes o bien se digna conceder un plazo prudencial para que 
la respuesta del arzobispo había sido conceder dos meses de plazo ${ }^{146}$. De nuevo el silencio total de las actas al respecto impide conocer el resultado de un estudio que nos hubiera aportado una información valiosísima al comparar el ceremonial vigente ese momento con el que se trataba de imponer. Nos hubiera aclarado, además, si hubiera propiciado ciertas exenciones en la aplicación del reglamento en la Catedral, cual era su finalidad.

A partir de ahora ese silencio será una constante. La información que sobre aspectos relacionados con la música podamos encontrar en las actas capitulares será esporádica y puntual, algo que contrasta con la profusión de datos, noticias, debates que había caracterizado los registros de las reuniones del Cabildo desde $1904^{147}$. Debemos concluir, por tanto, que la cuestión de la reforma de la música quedó resuelta definitivamente desde este momento. Hay que suponer que desde 1910, la música en la Catedral se rigió por el Reglamento de Música Sagrada para la Archidiócesis de Sevilla. La instrucción dada por el arzobispo al Capítulo de aplicar el Reglamento general diocesano en la Catedral marcó un punto de inflexión en el devenir histórico de la música en la basílica hispalense. El plan de música propio elaborado en un principio por González Merchant y debatido durante meses por la corporación capitular fue finalmente desechado, haciendo inútil el esfuerzo desarrollado durante todo este tiempo. Al igual que en el caso general de la Archidiócesis, el proceso de desarrollo normativo a las circunstancias particulares del templo metropolitano hispalense concluyó con la promulgación del Reglamento en 1910.

mientras tanto pueda hacerse aquel estudio; el Sr. Deán propuso al Cabildo que se sirviese deliberar hoy sobre este punto por no poderse diferir hasta la primera sesión ordinaria y se acordó de conformidad con lo propuesto por la comisión y que la misma pase a conferenciar con S. E. y dé cuenta del resultado".

AC 29/7/1910. ACS. Sección Secretaría, libro 228, fol. 156v-157r.

146 “La Comisión designada en el cabildo último para conferenciar con el Sr. Arzobispo sobre la ejecución en nuestra Santa Iglesia del nuevo Reglamento para la música sagrada dio cuenta de haber cumplido su encargo y manifestó que S. E. se ha servido conceder dos meses de plazo para que pueda estudiarse el asunto, al tenor de lo acordado por el Cabildo". AC 1/8/1910. ACS. Sección Secretaría, libro 228, fol. $157 \mathrm{v}$.

${ }^{147}$ Podemos constatar este hecho al haber vaciado las actas capitulares catedralicias hasta marzo de 1913, y haber revisado la información y datos sobre música contenida en dichos documentos hasta finales de 1917. 



\section{CAPÍTULO 4 \\ FUNCIONES SIMBÓLICAS DE LA MÚSICA EN LAS FIESTAS LITÚRGICAS CATEDRALICIAS A PRINCIPIOS DEL S. XX}

\section{Definición del problema e hipótesis de partida}

En varios momentos de este trabajo se ha puesto en evidencia el desinterés que en muchas ocasiones mostró el clero en general respecto al fenómeno musical. En este sentido, en el capítulo primero defendimos que uno de los factores que intervino negativamente en el proceso general archidiocesano en 1904, colaborando incluso en su paralización, fue una mentalidad con una escala de prioridades en la que la música ocupaba un lugar subalterno ${ }^{1}$.

No obstante, el estudio de las reformas litúrgico-musicales puestas en marcha en la Catedral nos lleva a sostener que la cuestión de la música sagrada no siempre se contempló por parte de los distintos estamentos diocesanos como un problema menor. Son varias las pruebas que han ido emergiendo de nuestro análisis y sirven para apoyar esta afirmación: en primer lugar, la reacción de los capitulares ante las continuas exigencias de alteración del canon musical vigente, especialmente en el ceremonial de las grandes solemnidades; en segundo lugar, la dimensión que adquirió la pugna que se generó, y que se resolvió repetidamente con propuestas de consultas a Roma como

\footnotetext{
${ }^{1}$ En el ámbito exclusivamente catedralicio es posible encontrar pruebas significativas al respecto. El siguiente extracto describe el ceremonial de la función religiosa con la que se inauguró la Asamblea Nacional de la Buena Prensa (Sevilla, 1904) a la que ya nos hemos referido. En él se observa que los gastos de música se consignaron junto con los de cera y otros elementos ornamentales del ritual: "[...] la función podría consistir, si así pareciere al Cabildo, en una solemne procesión que tendría lugar por [las] últimas naves, después de Nona, cantándose durante ella por los seises la Letanía Lauretana, y haciéndose estación en la Capilla de S. Fernando ante el altar de Nuestra Señora de los Reyes y terminada la procesión se cantaría Misa votiva de la Inmaculada Concepción para lo cual se ha pedido a Roma la oportuna licencia, oficiando de Pontifical el Señor Arzobispo y predicando alguno de los R[v]dos. Prelados que han de asistir a la Asamblea. Indicó por último que la Capilla Mayor estaría adornada lo mismo que en la fiesta del 8 de Diciembre sufragándose por la Junta [organizadora de la asamblea] todos los gastos que se originen tanto para el exorno como para la cera, música y demás que fuera necesario." AC 16/5/1904. ACS. Sección Secretaría, libro 226, fol. 252v.
} 
única salida ante la deriva discordante de posicionamientos antagónicos; en tercer lugar, el hecho significativo de que el procedimiento para la discusión y aprobación del Plan para el arreglo de la música en la Catedral presentado por González Merchant en 1908 fuera parecido al de aquellos documentos en los que se fundaban las normas de gobierno y funcionamiento del templo metropolitano: los Estatutos y la Regla de Coro.

Por tanto, nos encontramos ante la aparente contradicción de que, en ocasiones, los asuntos de música se abordaban con toda seriedad, recurriendo a las más altas instancias vaticanas en caso de necesidad, o de forma homologable a la seguida en el caso de las más importantes cuestiones catedralicias; y en otras ocasiones, se postergaban y marginaban, o se consideraban dentro del paquete de elementos litúrgicos accesorios como la cera y los exornos.

Creemos que para explicar este comportamiento aparentemente paradójico habría que disociar dos ideas normalmente relacionadas e incluso confundidas, el uso y la función de la música. Esta distinción fue propuesta por Allan P. Merrian en su célebre obra The Anthropology of Music ${ }^{2}$. El etnomusicólogo americano instaba a ir más allá del conocimiento, superficial e incompleto, que proporciona la observación de las diferentes formas de utilización de la música en una determinada comunidad. Persiguió, por el contrario, descubrir o interpretar sus funciones sociales y culturales, en consecuencia, los significados profundos que el fenómeno musical pudiera poseer para dicha comunidad ${ }^{3}$. Obviamente, los métodos de observación directa propios del trabajo etnográfico no son aplicables en nuestro caso de estudio. No obstante, determinadas categorías analíticas empleadas por Merriam nos han orientado en nuestra tarea, aunque nuestras fuentes sean de naturaleza distinta. Según defiende, las consideraciones sobre las funciones de la música se derivan del análisis ("analitycal evaluations") realizado por un observador exterior (“outsider") de las visiones que sobre sus propias prácticas

\footnotetext{
2 Merriam desarrolla sus ideas sobre usos y funciones de la música en el capítulo XI "Uses and functions", The Anthropology of Music (Evanston: Northwestern University Press, 1964). Una traducción al castellano de dicho capítulo se puede encontrar en: Francisco Cruces y otros (eds.), Las culturas musicales. Lecturas de etnomusicología (Madrid: Trotta, 2001), pp. 275-295.

${ }^{3}$ Una vez hecha la distinción entre uso y función, Merriam concentra su atención en los significados que posee la música. "The uses and funtions of music represent one of the most important problems in ethnomusicology, for in the study of human behavior we search constantly, as has been pointed out time and time again in this pages, not only for the descriptive facts about music, but, more important, for the meaning of music.” Alan P. Merriam, The Anthropology of Music, p. 209.
} 
ofrecen los agentes sociales ("folk evaluations") 4 . Estos últimos pueden ser más o menos conscientes del papel (función) asignado en su propia cultura a las distintas manifestaciones o actos musicales (usos).

Asumiendo esta diferenciación conceptual entre uso y función, nos planteamos como punto de partida la siguiente hipótesis: en aquellos casos en los que la música se asoció a manifestaciones religiosas de gran carga simbólica, desempeñó una función de representación identitaria, adquiriendo, por ello, un especial estatus en el seno del culto católico local. En contraste con el desdén mostrado en ocasiones en relación con la música, las actitudes de férrea resistencia a la reforma exhibidas por los capitulares en determinados casos cobrarían sentido como mecanismo de defensa con el que preservar la personalidad de la institución y, por el carácter emblemático del templo catedralicio, de la Archidiócesis. De hecho, como pudimos comprobar en el capítulo tercero, entre las razones aducidas tanto por Spínola para preservar la costumbre del Miserere como por los canónigos en el resto de casos estudiados, predominaron las relacionadas con aspectos culturales o identitarios sobre las litúrgicas.

Trataremos en los siguientes epígrafes de aclarar o interpretar posibles veladas- funciones simbólicas, comunicativas, representativas, de trasmisión de valores culturales que la música de uso ceremonial pudiera tener para la comunidad catedralicia en aquel contexto histórico. Desde esta perspectiva, el valor que para sus miembros poseían las celebraciones a las que estaban asociadas las obras que suscitaron mayor polémica (Corpus, Inmaculada, Triduo pascual) no debió residir solamente en su condición de grandes solemnidades litúrgicas, sino también en su cualidad de importantes fiestas religiosas. Esta consideración introduce un componente cultural que trasciende el ámbito de lo meramente litúrgico-musical, y lleva a contemplarlas, además, como manifestaciones histórico-culturales llenas de contenido.

Partiendo de las hipótesis y consideraciones expuestas procederemos a estudiar el significado que pudieron atesorar en Sevilla las fiestas religiosas antes mencionadas según los discursos católicos dominantes desplegados sobre ellas a finales del s. XIX y principios del s. XX. Con ello pretendemos hallar claves para tratar de determinar, de acuerdo con el objetivo que nos hemos marcado, las funciones simbólicas que en ellas

\footnotetext{
4 Merriam toma en préstamo los conceptos de folk evaluations y analytical evaluations de Paul Bohannan, y los define como sigue: "The folk evaluation is the explanation of the people themselves for their actions, while the analytical evaluation is applied by the outsider, based upon experience in a variety of cultures, and directed toward the broad aim of understanding regularities in human behavior." Ibídem, pp. 31-32.
} 
ejercía la música de Eslava, dominadora, como hemos podido verificar, del canon litúrgico-musical solemne. Lógicamente, resulta imprescindible situar nuestro análisis en la situación que vivía la música en la Sevilla de entresiglos, pues es de suponer que algunas incógnitas para la compresión de estos fenómenos musicales y culturales habrán de despejarse al ponerlos en relación con su contexto. Finalmente, en contraste con los fundamentos ideológicos y culturales en los cuales se apoyaban las posturas de los defensores de la tradición catedralicia, presentaremos las de la parte contraria, intentado ofrecer una explicación cabal de las mismas. Con este propósito nos dedicaremos a confrontar el pensamiento del maestro de capilla, Vicente Ripollés, quien trató de desplegar un programa de regeneración de la música catedralicia de acuerdo con el $M P$, con el del secretario capitular Modesto Abín, sin duda, el miembro del Cabildo más activo y comprometido con la conservación de los usos musicales locales.

En los epígrafes que siguen incorporaremos a nuestro repertorio de fuentes una selección de obras de carácter histórico o histórico-doctrinal aparecidas entre 1893 y 1910: Los seises de la catedral de Sevilla. Ensayo de investigación histórica (1904), de Simón de la Rosa y López; Glorias sevillanas: noticia histórica de la devoción y culto que la muy noble y muy leal ciudad de Sevilla ha profesado a la Inmaculada Concepción de la Virgen María desde los tiempos de la Antigüedad hasta la presente época (1893), de Manuel Serrano y Ortega; Curiosidades antiguas sevillanas (Serie segunda) (1910), de José Gestoso y Pérez; y La Eucaristía y la Inmaculada, devoción española. Homenaje al Congreso Eucarístico de Valencia (1895), de Servando Arbolí y Faraudo 5 .

Las tres primeras han tenido una enorme repercusión en la historiografía sobre las fiestas del Corpus y la Inmaculada en Sevilla. La inmensa mayoría de las investigaciones o ensayos publicados sobre estos temas desde entonces se han nutrido en gran medida de su rico aporte documental, así como de los profusos datos y noticias

\footnotetext{
5 Simón de la Rosa y López, Los seises de la catedral de Sevilla. Ensayo de investigación histórica (Sevilla: Imp. de Francisco de P. Díaz, 1904); Manuel Serrano y Ortega, Glorias sevillanas: noticia histórica de la devoción y culto que la muy noble y muy leal ciudad de Sevilla ha profesado a la Inmaculada Concepción de la Virgen María desde los tiempos de la Antigüedad hasta la presente época (Sevilla: Imp. de E. Rasco, 1893); José Gestoso y Pérez, Curiosidades antiguas sevillanas (Serie segunda) (Sevilla: Correo de Andalucía, 1910); Servando Arbolí y Faraudo, La Eucaristía y la Inmaculada, devoción española. Homenaje al Congreso Eucarístico de Valencia (Sevilla: Imp. de E. Rasco, 1895). De la obra de Serrano y Ortega hemos manejado la reproducción facsimilar editada por la Consejería de Relaciones Institucionales en 2004.
} 
que proporcionan ${ }^{6}$. Al margen de otros matices que las puedan diferenciar, pertenecen a una historiografía de corte decimonónico orientada a la recuperación del patrimonio cultural de la ciudad, y cuyo valor reside, como apunta el profesor Rogelio Reyes refiriéndose al caso de Gestoso, en su labor de erudición más que en sus planteamientos histórico-críticos ${ }^{7}$. La obra de De la Rosa ha constituido una importante fuente de información para numerosos musicólogos como Robert Stevenson, Herminio González Barrionuevo, Juan Ruíz Jiménez, Michael J. Noon, José Luís de la Fuente Charfolé o Clara Bejarano Pellicer ${ }^{8}$. Ha sido, además, la obra de referencia para aquellos autores que de una u otra forma han tocado el tema de los seises de la catedral de Sevilla hasta la aparición de la monografía de González Barrionuevo en $1992^{9}$.

\begin{abstract}
${ }^{6} \mathrm{Tal}$ es el caso de las siguientes obras, entre las que se encuentran aquellas que han tenido un mayor impacto, como el ensayo de Lleó Cañal sobre el Corpus y el libro de Carlos Ros sobre la Inmaculada: Vicente Lleó Cañal, Fiesta Grande: el Corpus Christi en la historia de Sevilla (Sevilla: Ayuntamiento de Sevilla, 1980); Francisco Aguilar Piñar, "II. Danzas del Corpus", en Temas sevillanos (Sevilla: Universidad de Sevilla, 1988); Antonio Romero Abao, "Las Fiestas de Sevilla en el siglo XV", en Las Fiestas de Sevilla en el siglo XV. Otros estudios, dir. José Sánchez Herrero (Madrid: Deimos, 1991), pp. 12-178; Carlos Ros Caballar, La Inmaculada y Sevilla (Sevilla: Castillejo, 1994); del mismo autor, "La Concepción Inmaculada en la historia", en Actas del XV Simposio de Historia de la Iglesia en España y América, coord. por Paulino Castañeda Delgado y Manuel José Cociña y Abella (Córdoba: Obra Social y Cultural de Cajasur, 2007), pp. 15-34; Ma Jesús Sanz, "El Corpus en Sevilla a mediados del siglo XVI. Castillos y danzas", Laboratorio de Arte, 10 (1997), pp. 123-137; "La procesión del Corpus en Sevilla. Influencias sociales y políticas en la evolución del cortejo", Ars Longa, 16 (2007), pp. 55-72.
\end{abstract}

${ }^{7}$ Introducción de Rogelio Reyes Cano a El homenaje al Ateneísta Don José Gestoso y Pérez (Sevilla: Ateneo de Sevilla, 2005 [Gironés, 1918]), pp. 15-17, p. 15.

${ }^{8}$ Robert Stevenson, La música en las catedrales españolas del Siglo de Oro (Madrid: Alianza, 1992 [Spanish Cathedral Music in the Golden Age, Berckley: California University Press, 1961]); Herminio González Barrionuevo, Francisco Guerrero (1528-1599). Vida y obra. La música en la catedral de Sevilla a finales del siglo XVI (Sevilla: Cabildo Metropolitano de la Catedral de Sevilla, 2000); del mismo autor, Los seises de Sevilla (Sevilla: Castillejo, 1992); Ruíz Jiménez, La Librería de Canto de Órgano; Michael J. Noon, Andrés de Torrentes (1510-1580), Spanish polyphonist and Chapelmaster: Opera omnia, biography and source study (Sydney: University of Sidney, 2008), Master Thesis, disponible en $<$ http://ses.library.usyd.edu.au/handle/2123/2247> (consultado 15-4-2014); José Luís de la Fuente Charfolé, "Nuevos hallazgos documentales y biográficos sobre Alonso Xuárez, maestro de Sebastián Durón”, Anuario Musical, 67 (2012), pp. 3-18. Clara Bejarano Pellicer ha manejado el libro de De la Rosa en muchos de sus trabajos, entre ellos: Clara Bejarano Pellicer, El mercado de la música en la Sevilla del Siglo de Oro (Sevilla: Universidad de Sevilla, 2013); “"De la parte de dentro o de la parte de fuera': la capilla paralela de San Salvador de Sevilla a comienzos del siglo XVII", Revista de Humanidades, 20 (2013), disponible en: <http://www.revistadehumanidades.com/articulos/46-de-laparte-de-dentro-o-de-la-parte-de-fuera-la-capilla-paralela-de-san-salvador-de-sevilla-a-comienzos-delsiglo-xvii> (consultado 20-2-2014).

${ }^{9}$ Como manifiesta González Barrionuevo, su libro sobre los seises responde a la necesidad de llevar a cabo un trabajo que, "dejando aparte la visión ocurrente y legendaria que lo envuelve [al tema de los seises] [...], pusiera al día el libro de Simón de la Rosa, corrigiera los puntos inexactos e interpretara los datos no desde una visión 'personal', más o menos 'graciosa', sino a la luz y con el criterio que nos ofrece la musicología actual”. González Barrionuevo, Los seises de Sevilla, p. 10. 
Nuestro interés por estas fuentes no se debe a la información de primera mano que puedieran proporcionar sobre los acontecimientos religioso-festivos que nos interesan en épocas pretéritas. No pretendemos, desde luego, trazar su historia, tema al que se han dedicado numerosas publicaciones tanto en Sevilla como en otros lugares ${ }^{10}$. Por el contrario, nos aproximaremos a estas obras como documentos históricos portadores de discursos -en un sentido del término cercano al foucaultiano-, determinados por el contexto cultural, así como por la adscripción ideológica de sus autores $^{11}$. Nuestro objetivo consiste, desde una perspectiva sincrónica y definidos los límites en el ámbito temporal que nos concierne, en identificar determinados aspectos del pensamiento que sustentaba estos relatos históricos sobre el Corpus y la Inmaculada en aquel momento. Estas obras no sólo fueron investigaciones sobre el pasado de estas fiestas, sino también, en cuanto discursos, un reflejo de una determinada mentalidad, desde la que se contemplaron, y sobre cuya base se construyó y difundió una determinada imagen de las mismas. Nos interesa especialmente dilucidar qué papel jugó la restauración, llevada a cabo por dichos discursos y mediatizada por el

${ }^{10}$ En las siguientes obras colectivas es posible encontrar artículos sobre el Corpus en ciudades de toda la geografía peninsular: Gerardo Fernández Juárez y Fernando Martínez Gil, eds., La fiesta del Corpus Christi (Cuenca: Universidad de Castilla-La Mancha, 2002); Francisco Javier Campos y Fernández de Sevilla, dir., Religiosidad y ceremonias en torno a la Eucaristía, 2 vols. (Madrid: Ediciones Escurialenses, 2003); Fermín Labarga García, ed., Festivas demostraciones: estudios sobre las cofradías del Santísimo y la fiesta del Corpus Christi (Logroño: Instituto de Estudios Riojanos, 2010). Se puede consultar una amplia bibliografía sobre el Corpus en: Alfredo Rodríguez González y Carlos Franco Agudo, "Bibliografía del Corpus Christi", en La Fiesta del Corpus Christi, coord. por Gerardo Fernández Juárez y Fernando Martínez Gil (Cuenca: Universidad de Castilla-La Mancha, 2002), pp. 519-544. Sobre la Inmaculada, consúltense los dos tomos de las actas del simposio La Inmaculada Concepción en España: religiosidad, historia y arte, ed. por Francisco Javier Campos y Fernández de Sevilla (San Lorenzo de El Escorial: Ediciones Escurialenses, 2005). No falta en estas publicaciones trabajos dedicados a la música. Tales son los casos de: Carlos Martínez Gil, "Los sonidos de la fiesta: música y ceremonial en el Corpus Christi”, en La fiesta del Corpus Christi, pp. 215-234; José Sierra Pérez, "Textos eucarísticos castellanos del siglo XVII en el Archivo de Música del Monasterio de San Lorenzo el Real de El Escorial", en Religiosidad y ceremonias en torno a la Eucaristía, vol. 1, pp. 71-130; Rafet Ramón Ortega Trillo, Textos eucarísticos castellanos del siglo XVIII en el Archivo de Música del Monasterio de San Lorenzo el Real de El Escorial", en ibídem, pp. 131-204; María Sanhuesa Fonseca, "Corpus Christi en la Catedral de Oviedo (siglos XVII-XX): el repertorio musical, en ibídem, vol. 2, pp. 991-1012; "Textos castellanos dedicados a la Virgen Inmaculada en el Archivo de Música del Real Monasterio de San Lorenzo de El Escorial", en La Inmaculada Concepción en España: religiosidad, historia y arte, vol. 2, pp. 201-218; Cristina Álvarez Díaz, "La doctirna inmaculista en las Cantigas de Santa María de Alfonso X el Sabío", en íbidem, pp. 1219-1246; Leticia Sánchez de Andrés, "Cosme José de Benito, maestro de la Real Capilla de El Escorial, y su Ofertorio para la festividad de la Inmaculada Concepción", en ibídem, pp. 1247-1268. Sobre la música en la fiesta del Corpus en la Edad Moderna, véase, además: Pilar Ramos López, "Música y autorrepresentación en las procesiones del Corpus en la España moderna", en Música y cultura urbana en la Edad Moderna, ed. por Andrea Bombi, Juan José Carreras y Miguel Ángel Marín (Valencia: Universitat de València, 2005), pp. 243-254.

${ }^{11}$ Sobre la noción de discurso en la epistemología de Michel Foucault, véase: La arqueología del saber (Madrid: Siglo XXI, 1970); El orden del discurso (Barcelona: Tusquets, 2004). 
pensamiento y fines de los autores, de esas formas festivas como manifestaciones de una determinada sociedad -la del Antiguo Régimen-, en el contexto social y cultural de principios del s. XX. Aunque estaban dedicados al pasado, cumplieron una función, también socio-cultural, al incorporarse al universo ideológico de aquel presente. En última instancia, buscamos en estos productos culturales de la época claves para la interpretación del significado y función de la música litúrgica catedralicia asociada a las fiestas de las que tratan.

La Semana Santa, otro de los periodos litúrgicos cuyo intento de reforma musical fue particularmente problemático no había adquirido como fiesta religiosa la importancia del Corpus y la Inmaculada en el Antiguo Régimen, razón que explica la poca atención que estas obras le dedican. No obstante, en la línea apuntada por el profesor Rodríguez Becerra, la Semana Santa reunió en la Edad Contemporánea las características propias de dichas festividades tal y como se definieron en los siglos modernos, y desempeñó una función similar: acontecimientos religiosos urbanos totales en los que lo festivo y lo popular convivieron con, e incluso, desbordaron lo institucional y las formas y prácticas de piedad ortodoxas ${ }^{12}$. Esta idea refuerza nuestra interpretación del fenómeno del Miserere en Sevilla, cuyo significado simbólico se explicaría, desde este enfoque, por las analogías que hallamos entre este -el fenómeno del Miserere- y aquellas fiestas. De ello nos ocuparemos más adelante.

De hecho, como defiende José Domínguez León, el factor religioso siguió siendo, a pesar de la profunda transformación que la sociedad experimentó a lo largo del s. XIX, un elemento determinante en la mentalidad de los sevillanos. Hasta aquellos grupos sociales más alejados en términos afectivos y doctrinales de la ortodoxia católica mantenían una religiosidad que condicionaba su experiencia, creencias y formas de vida, y que se expresaba en unas costumbres con las que se identificaban. La religiosidad popular, diferente de las tradicionales formas religiosas de las clases dirigentes, alcanzó cada vez mayor importancia e incluso peso social a partir de las décadas centrales del s. XIX. A ello colaboró el espacio de poder creciente, al que

\footnotetext{
${ }^{12}$ Salvador Rodríguez Becerra, "El Corpus en Andalucía. De fiesta del poder a fiesta de la identidad", en La fiesta del Corpus Christi, ed. por Gerardo Fernández Juárez y Francisco Martínez Gil (Cuenca: Universidad de Castilla-La Mancha, 2002), pp. 383-398, pp. 385 y 391-392.
} 
podían acceder también aquellos sectores sociales menos empoderados, que constituyeron las hermandades y cofradías en auge ${ }^{13}$.

La cuarta de las obras citadas, La Eucaristía y la Inmaculada, devoción española, de Servando Arbolí, tiene un enfoque más literario-doctrinal, aunque se funda en gran medida en una visión y un discurso históricos afines al de las otras tres. Afinidad también en cuanto a su carácter "sevillano", según subrayó el propio De la Rosa, como veremos. Su génesis y publicación fue consecuencia directa de la celebración del I Congreso Eucarístico Español (Valencia, 1893). La asamblea valenciana no sólo resolvió dar el visto bueno a su publicación sino que, según se hizo constar en sus primeras páginas, aprobó e hizo suyas las conclusiones propuestas en el texto ${ }^{14}$. Se trata, por tanto, de un discurso representante de una línea de pensamiento católico que se impuso como oficial en aquel momento.

La repercusión que tuvieron estas obras, lo similar de los postulados que en ellas se pueden encontrar, así como la relevancia de sus autores nos llevan a considerarlas representantes del discurso católico dominante -aunque seguramente no el único- en la Sevilla de entonces.

${ }^{13}$ José Domínguez León, "La religiosidad en la Sevilla isabelina (1833-1868)", La religiosidad popular I. Antropología e historia, coord. por Carlos Álvarez Santaló (Barcelona: Anthropos, 1989 [2003]), pp. 357373. El creciente interés por el tema de la religiosidad popular está dando lugar a una cada vez más extensa bibliografía. Véanse además del tomo en el que se encuentra el artículo de Domínguez León que acabamos de citar: M $\mathrm{M}^{\mathrm{a}}$ José Buxó Rey, coord., La religiosidad popular II. Vida y muerte: la imaginación religiosa (Barcelona: Anthropos, 1989 [2003]); Salvador Rodríguez Becerra, coord., La religiosidad popular III. Hermandades, santuarios y romerias (Barcelona: Anthropos, 1989 [2003]); J. Carlos Vizuete Mendoza y Palma Martínez-Burgos García, coords., Religiosidad popular y modelos de identidad en España y América (Cuenca: Universidad de Castilla-La Mancha, 2000); José Hurtado Sánchez, ed., Religiosidad popular sevillana (Sevilla: Ayuntamiento de Sevilla y Universidad de Sevilla, 2000); José Hurtado Sánchez, ed., Nuevos aspectos de la religiosidad sevillana. Fiesta, imagen, sociedad (Sevilla: Ayuntamiento de Sevilla, 2002). El tema de la religiosidad popular implica multitud de aspectos y aproximaciones. En él convergen religión, sociedad, identidad, cultura, economía, etc. El propio concepto de "religiosidad popular" es objeto de reflexión y revisión. Algunos autores niegan taxativamente su existencia; véase: Pedro Córdoba Montoya, "Religiosidad popular: arqueología de una noción polémica", en La religiosidad popular I. Antropología e historia, coord. por Carlos Álvarez Santaló (Barcelona: Anthropos, 1989 [2003]), pp. 70-81. A León Carlos Álvarez Santaló, la reflexión sobre el mismo le lleva a cuestionar el binomio cultura elitista y sabia-cultura popular; véase: “"Religiosidad popular' en el Siglo de Oro: la estilística del vaciado y el moldeamiento social”, en Religiosidad popular sevillana, ed. José Hurtado Sánchez (Sevilla: Ayuntamiento de Sevilla y Universidad de Sevilla, 2000), pp. 37-61. Sería absolutamente inabarcable citar la bibliografía existente sobre la Semana Santa. Nos limitamos a consignar las siguientes obras de referencias: Isidoro Moreno Navarro, La Semana Santa de Sevilla: conformación, mixtificación y significaciones (Sevilla: Ayuntamiento de Sevilla, 1982 [2006]); José Sánchez Herrero y otros, Las cofradías de Sevilla: historia, antropología, arte (Sevilla: Universidad de Sevilla, 1985 [1999]); León Carlos Álvarez Santaló, Las cofradías de Sevilla en el siglo de la crisis (Sevilla: Universidad de Sevilla, 1991 [1999]); Leandro Álvarez Rey, Las cofradías de Sevilla en el siglo XX (Sevilla: Universidad de Sevilla, 1992 [1999]; José Sánchez Herrero, La Semana Santa de Sevilla (Madrid: Silex, 2003).

${ }^{14}$ Arbolí, La Eucaristía y la Inmaculada, p. IV. 
Servando Arbolí y Faraundo (Cádiz, 1840-Sevilla, 1908) ostentaba una de las más altas dignidades, capellán mayor de San Fernando, de la institución eclesiástica sevillana. Los cargos y responsabilidades que desempeñó así como los títulos de los que fue merecedor ofrecen una idea de la importancia de este personaje, no sólo en el ámbito eclesiástico sino también en el cultural. Entre ellos, miembro de la Real Académica de la Historia, presidente de la Real Academia Sevillana de Buenas Letras, pronotario apostólico, decano de la Facultad de Derecho del Seminario, comendador de las Reales Ordenes de Carlos III e Isabel la Católica. Fue un destacado orador, filósofo y teólogo, entre cuyas obras cabe mencionar, además de la que nos ocupa, Crítica Filosófica, La Filosofía Contemporánea, El Progreso y lo Absoluto, La Crítica sobre la Escuela Ecléctica, Introducción general al estudio de los Santos Padres o Tratado de la Elocuencia Cristiana en España ${ }^{15}$. Asimismo dirigió la Biblioteca Colombina y comenzó la publicación, junto a De la Rosa, del primer catálogo en siete volúmenes de libros impresos custodiados en dicha institución ${ }^{16}$.

Simón de la Rosa y López (Jerez de la Frontera, 1846-Sevilla, 1915), laico, colaboró codo a codo con Arbolí en la Biblioteca Colombina desde el cargo de oficial primero $^{17}$. En la década de los setenta del siglo XIX dirigió el periódico tradicionalista El Oriente. Participó como uno de los miembros fundadores en el proyecto político del arzobispo Spínola, la Liga Católica (1901), de la que fue candidato a las elecciones municipales de 1909. Resulta interesante apuntar que en el Centro Católico, creado en el seno de la Liga en 1904, pronunció una conferencia titulada "La antigua escuela musical de Sevilla”. Fue catedrático de Derecho Político de la Universidad de Sevilla, socio fundador del Ateneo y miembro de la Real Academia Sevillana de Buenas Letras, en la que ingresó con el discurso Libros y autógrafos de D. Cristóbal Colón, y al que

\footnotetext{
${ }^{15}$ Véase: Ismael Martínez Carretero, “Arbolí y Faraudo, Sevando”, Diccionario de Ateneístas, 3 vols., dir. por Enrique Barrero González (Sevilla: Ateneo de Sevilla, 2005), vol. III, pp. 46-50; Rafael González Merchant, Discurso necrológico que a la memoria del Ilmo. Sr. Dr. D. Servando Arbolí y Faraudo, presbítero, leyó su autor el M. I. Sr. Dr. D. Rafael González Merchant, Pbro. Canónigo de la S. M. y P. Iglesia Catedral de Sevilla en la solemne sesión celebrada por la Real Academia Sevillana de Buenas Letras de la misma ciudad el día 29 de junio de 1908 (Sevilla, Lib. e Imp. de Izquierdo y Cía, 1908; Joaquín Hazañas y la Rúa, Necrológica del Ilmo. Sr. D. Servando Arbolí y Faraudo (Sevilla, 1908).

${ }^{16}$ Biblioteca Colombina. Catálogo de sus libros impresos, 7 vols. (Sevilla: Imp. E. Rasco, 1888-1948)

${ }^{17}$ Véanse: José Leonardo Ruíz Sánchez, Política e Iglesia durante la Restauración. La liga católica de Sevilla (1901-1923) (Sevilla: Diputación de Sevilla, 1994); el artículo necrológico: “D. Simón de la Rosa y López", Bética, 27 (1915), [s. p.].
} 
respondió el propio Servando Arbolí. En la reseña necrológica publicada en la revista Bética se señala: "su nombre era un prestigio en la cultura de nuestra ciudad"18.

La relación del presbítero Manuel Serrano y Ortega (Sevilla, 1856-1919) con la catedral hispalense no fue tan directa, pues sólo en la última etapa de su vida formó parte de la parroquia del Sagrario catedralicio. Participó activamente desde su juventud en diversas iniciativas culturales relacionadas con la Iglesia como la Asociación de Jóvenes de la Inmaculada Concepción, junto a otras destacadas figuras de la cultura y el arte hispalense como Joaquín Hazañas y la Rúa o Virgilio Mattoni; o como la Escuela Patronato de San Joaquín. De la primera llegó a ser presidente, y director de la segunda. Su labor arqueológica e histórica hizo que el Gobierno español le nombrara en 1914 inspector-conservador de las ruinas de Itálica y del Monasterio de San Isidoro del Campo. La Real Academia de Bellas Artes de San Fernando de Madrid declaró de utilidad pública dos de sus obras, Bibliografía de la Catedral de Sevilla (1901) y Guía de los monumentos históricos y artísticos de los pueblos de la provincia de Sevilla (1911). Contó con el mecenazgo de los hermanos Juan y Manuel Pérez de Guzmán y Boza, duque de T'Serclaes de Tilly y marqués de Jerez de los Caballeros, respectivamente, a quienes sirvió como capellán ${ }^{19}$. Pese a la erudición que muestran sus obras, Serrano se posicionó explícitamente en contra del positivismo histórico que, en palabras de José Roda, "se iba imponiendo en la historiografía artística de finales del siglo XIX"20. Precisamente con José Gestoso, convencido positivista, mantuvo importantes disputas ${ }^{21}$.

\footnotetext{
${ }^{18}$ Arbolí se refirió a su compañero en la Colombina en los siguientes términos: "Conocido era ya en la república literaria por el magisterio que ejerce en esta ya renombrada Escuela, por el cargo de confianza con el que le honró el ilustre Cabildo de esta Iglesia Patriarcal, por las notas al índice de los libros de D. Fernando Colón, elaboradas bajo la dirección del mismo Cuerpo con gran contentamiento de los doctos, y por otras producciones dignas de su ingenio y cultura". Libros y autógrafos de D. Cristóbal Colón. Discursos leídos ante la Real Academia Sevillana de Buenas Letras en la recepción pública del Dr. D. Simón de la Rosa y López el 29 de junio de 1891 (Sevilla: Imp. de E. Rasco, 1891), p. 48.

${ }^{19}$ Véase: José Roda Peña, "Estudio preliminar”, en Serrano, Glorias sevillanas, pp. VII-XVI; Alberto Ribelot, "Prólogo", en Manuel Serrano y Ortega, Monumentos de los pueblos de la provincia de Sevilla, ed. por Alberto Ribelot (Sevilla: Universidad de Sevilla, 2006 [Sevilla: Francisco de P. Díaz, 1911]), pp. VII-XV; Mario Méndez Bejarano, Diccionario de escritores, maestros y oradores naturales de Sevilla y su actual provincia. Tomo II (Sevilla: Tipografía Gironés, 1922), p. 403-404.

${ }^{20}$ En su estudio preliminar a la edición facsimilar publicada en 2004, José Roda Peña extrae un pasaje -un "rancio alegato contra el positivismo", según sus propias palabras- del libro para ilustrar su adscripción historiográfica. Afirma José Roda: "Sin duda, nos encontramos ante un experto bibliófilo que declara preferir las leyendas y tradiciones histórico-religiosas, [y continua con la cita del propio Serrano] 'al juicio escueto y descarnado del frío arqueólogo, que no ve en las obras que examina sino pedazos de piedra y madera, ni más valor que el que le han dado los años y los siglos, conservándolos para el estudio del arte en la época en que si hicieron, clasificándolos luego en el museo o en el catálogo que los
} 
La siguiente cita puede servir para ofrecer una idea de la figura de José Gestoso y Pérez (Sevilla, 1852-1917) ${ }^{22}$ :

fue el más conspicuo positivista a caballo entre los siglos XIX y XX; amante de la arqueología; padre de la Historia del Arte hispalense; preocupado rigorista que perseguía con denuedo limpiar de fábulas y leyendas la historia autóctona; defensor de artes menores como la cerámica; enemigo incansable del mal gusto y destacado recolector de manuscritos, legados, a su muerte, a la Biblioteca Colombina de la Catedral de Sevilla. Con todo ello intento rellenar los huecos dejados por el desconocimiento popular en el discurso curricular de su patria chica. ${ }^{23}$

Gestoso fue profesor de la Escuela Superior de Artes e Industrias, vicepresidente de la Comisión de Monumentos, fundador del Museo Arqueológico Municipal, miembro de las Reales Academias de Buenas Letras, Bellas Artes, de la Lengua, de la Historia, y de San Fernando. Aunque no era sacerdote como Arbolí o Serrano, ni estaba implicado públicamente en los proyectos políticos de la Iglesia como

enumera, sin encontrar en estas obras más interés que el que ellos le quieren dar, escapándoseles en su examen la parte más esencial de las mismas, que el espíritu que las envuelve y casi vivifica; en un palabra, su parte estética, el ideal que sirvió de norma para darles forma plástica; y al calor del cual vivieron tantas y tantas generaciones henchidas de fe y entusiasmo, realizando bajo su égida innumerables proezas, que sirvieron para formar la patria y la familia cristiana"'. Manuel Serrano y Ortega, Glorias sevillanas. Noticia histórica de la devoción y culto que la muy noble y muy leal ciudad de Sevilla ha profesado a la Inmaculada Concepción de la Virgen María (Sevilla: Consejo General de Hermandades y Cofradías de Sevilla y Consejería de Relaciones Institucionales, 2004), p. XV.

${ }^{21}$ Gestoso arremetió duramente contra Serrano en una serie de cartas publicadas en La Andalucía Moderna: Contestación a las notas del Pbro. Sr. D. Manuel Serrano y Ortega en su libro Noticia histórica de la Devoción y Culto que la M. N. y M. L. Ciudad de Sevilla ha profesado a la Inmaculada Concepción de la Virgen María desde los tiempos de la antigüedad hasta la presente época (Sevilla: La Andalucía Moderna, 1894); Segundo Bloque Epistolario; que contra el deleznable Propugnáculo de la malaventurada crítica histórico-artística-arqueológica del Pbro. D. Manuel Serrano y Ortega [en versales], lanza el Ldo. Gestoso [en versales], en defensa de la verdad, estropeada lastimosamente por su Paternidad, en el librico Las Tradiciones Sevillanas (Sevilla: La Andalucía Moderna, 1895).

22 Sobre Gestoso véase: Mario Méndez Bejarano, Diccionario de escritores, maestros y oradores naturales de Sevilla y su actual provincia. Tomo I (Sevilla: Tipografía Gironés, 1922), p. 247248;.Marcos Fernández Gómez, "Gestoso y Pérez. José”, Diccionario de Ateneístas, 3 vols., dir. por Enrique Barrero González (Sevilla: Ateneo de Sevilla, 2005), vol. I; la introducción de Rogelio Reyes Cano a El homenaje al Ateneísta Don José Gestoso y Pérez, pp. 15-17; Antonio José Albardonedo Freire, "Precursores del Laboratorio de Arte: Don José Gestoso y sus trabajos patrocinados por el Ayuntamiento de Sevilla", en Estudios de Historia del Arte. Centenario del Laboratorio de Arte 1907-2007. Vol. I (Sevilla: Universidad de Sevilla, 2009), pp. 45-62; María Dolores Ruíz de Lacanal Ruiz-Mateos, "José Gestoso y Pérez. Teoría y Praxis de la Conservación”, Ge-conservación, 5 (2013), pp. 59-70, consultable en $<$ http://ge-iic.com/ojs/index.php/revista/article/view/125/pdf > (consultado 3-5-2014).

23 Álvaro Cabezas García, Gusto orientado y fiesta pública en Sevilla. Análisis de documentos para la comprensión de la historia artística del siglo XVIII (Sevilla: Estípite, 2012), p. 12. 
De la Rosa, "era fama su buena relación con el estado clerical" 24 , como señala Alberto Ribelot, o atestiguan una serie de cartas dirigidas a Servando Arbolí con motivo de la coronación de la Virgen de los Reyes en 1904. En la primera de ellas se puede leer el siguiente fragmento:

[...] porque considero, que, como católico, como sevillano, como amante de las glorias de mi patria, tengo el deber de contribuir con mis pobres fuerzas a cuanto redunde en pro de nuestra ilustración y prestigio; y en tal virtud, si de este rato de charla históricoarqueológica, con que voy a poner a prueba su paciencia de V., resultase, a la postre, que habían salido gananciosas la Divina Efigie [de la Virgen de los Reyes] y el concepto de nuestro cultura religiosa y social, tengo por cierto que a V., tan entusiasta como yo por todo género de antiguallas, y tan amante como el que más del respeto que se debe a las buenas tradiciones, no le pesará del enojo que con mis renglones le procure. ${ }^{25}$

Nos parece significativo, asimismo, que la edición de la obra de Gestoso que hemos manejado corriera a cargo de El Correo de Andalucía, el diario católico local.

Aunque estos autores son frecuentemente citados en multitud de publicaciones, no existen investigaciones monográficas y profundas sobre sus vidas y obras. Pasemos a continuación a desgranar nuestro análisis.

\section{Fiestas litúrgicas e identidad en los discursos históricos del catolicismo}

\section{local de entresiglos: el Corpus y la Inmaculada}

\subsection{La fiesta del Corpus}

La fiesta del Corpus Christi fue instituida por Urbano IV en 1264 mediante la bula Transiturus de hoc Mundo ${ }^{26}$. Esta fue la respuesta definitiva del papado a siglos de controversias y posiciones heréticas relativas a la presencia real de Cristo en la forma eucarística. La fiesta ya se celebraba solemnemente en Lieja desde 1246, en cuya catedral el propio Urbano IV había ejercido como arcediano. Sin embargo, hasta la

\footnotetext{
${ }^{24}$ Alberto Ribelot, "Prólogo", p. IX.

${ }^{25}$ José Gestoso y Pérez, Tres cartas al Ilmo. Sr. Dr. D. Servando Arbolí, capellán mayor de la real de San Fernando, acerca de las reformas que deben efectuarse en la imagen y en el paso de Nuestra Señora de los Reyes con motivo de su próxima coronación (Sevilla: La Andalucía Moderna, 1904), p. IV.

${ }^{26}$ Una interesante introducción sobre el origen y los antecedentes de la fiesta del Corpus en José Sánchez Herrero, "La procesión del Corpus Christi en Sevilla", en Festivas demostraciones: estudios sobre las cofradías del Santísimo y la fiesta del Corpus Christi, ed. por Fermín Labarga García (Logroño: Instituto de Estudios Riojanos, 2010), pp. 351-394.
} 
aparición de la bula mencionada y las siguientes actuaciones de sus sucesores, Clemente V y Juan XXII, no se oficializó para todo el orbe cristiano. Los textos del oficio y la misa propios de la solemnidad fueron escritos por Santo Tomás de Aquino.

La procesión del Santísimo por las calles de la ciudad se celebraba desde hacía tiempo en distintos lugares, habiéndose convertido en el elemento más característico de los festejos ${ }^{27}$. En ella lo sacro y lo profano convergieron, resultando una manifestación religioso-festiva que se vio conformada y enriquecida por múltiples expresiones culturales, promovidas por iniciativas institucional o popular. Tras el concilio de Trento, la fiesta adquirió un significado, muy en la línea del pensamiento contrarreformista, de exaltación de la victoria de lo sacramental ${ }^{28}$.

De la Rosa nos presenta una fiesta ciudadana total, que se celebraba desde "fecha inmemorial", y en cuya instauración y definición colaboraron todos los estamentos de la ciudad. Situó el origen de estos festejos hacia finales del siglo XIV, e incluso recogiendo la tesis de Amador de los Ríos, desde el reinado de Alfonso $\mathrm{X}^{29}$. La Iglesia y la Ciudad, representados por sus respectivos cabildos "congregados a una", establecieron la forma en la que habrían de celebrarse las fiestas según el deseo del papa. A las instituciones se unieron gremios, asociaciones, pueblo para generar una manifestación religioso-cultural configurada por el conjunto de la sociedad y, por tanto, expresión de esta ${ }^{30}$. De la Rosa nos presenta una sociedad ideal, gracias a la concordia existente entre las autoridades civiles y eclesiásticas, y las cercanas y armónicas

27 J. Carlos Vizuete Mendoza, "Teología, liturgia y derecho en el origen de la fiesta del Corpus Christi", en La fiesta del Corpus Christi, coord. por Gerardo Fernández Juárez y Fernando Martínez Gil (Cuenca: Universidad de Castilla-La Mancha, 2002), pp. 17-42, pp. 31-32.

28 Xabier Basurko señala el "carácter netamente apologético y anti-protestante" de la procesión del Corpus Christi tras el concilio tridentino. Basurko, Historia de la Liturgia, p. 311.

${ }^{29}$ De la Rosa, Los seises de la catedral, p. 180. Amador de los Ríos realizó aquellas afirmaciones en Historia crítica de la literatura española. Tomo VII (Madrid: Impr. Joaquín Muñoz, 1865), p. 428. Las afirmaciones de Amador de los Ríos, no obstante, carecen de base documental. La primera referencia documentada data de 1363, y figura en un Libro de Cargo y Data de la catedral de Sevilla. En la península Ibérica, la fiesta se implantó antes en el Reino de Aragón que en el de Castilla. Las primeras noticias sobre su celebración se remontan en Tarragona a 1301, en Gerona a 1312, en Barcelona a 1319, en Valencia a 1326, en Toledo a 1336. Sanz, "La procesión del Corpus en Sevilla. Influencias sociales y políticas", p. 56. En principio, la fiesta del Corpus se celebraba sin procesión. Esta apareció en Colonia en 1279. En el ámbito hispánico, las procesiones más antiguas documentadas son las de Barcelona en 1322, Vich en 1330, Lérida antes de 1340, Valencia en 1355, y León 1378. José Sánchez Herrero, Las diócesis del reino de León: siglos XIV y XV (León: Centro de estudios e investigación "San Isidoro", 1978), pp. 270-271.

30 “el Cabildo eclesiástico y el secular, congregados a una, como lo habían por costumbre, en el corral de los Olmos, acordaron dar cumplimiento a la bula, estableciendo el primitivo ceremonial de la fiesta." De la Rosa, Los seises de la catedral, p. 180. 
relaciones mantenidas entre los gremios y profesiones con ambas corporaciones. Del concierto imperante entonces entre Iglesia, Ciudad, estamentos económicos y comerciales, así como populares surgió la particular ceremonia y fiesta del Corpus en Sevilla. El escritor sevillano parece presentar este orden, definido, según afirma, tras la conquista castellana por los dos grandes referentes regios locales, como una forma de organización social característica de la ciudad, y, aunque deteriorada, persistente a comienzos del s. XX. Una vez conectadas las realidades pasadas y las presentes, justifica su condena al anticlericalismo vigente, en Sevilla "un crimen de lesa nación":

El Cabildo y Regimiento de la ciudad, identificado en todo con el Cabildo de la Iglesia, acudió como bueno al llamamiento de la bula, contribuyendo con el auxilio de los oficios y gremios al esplendor de la fiesta que se inauguraba.

Merecerá estudiarse en todo tiempo, hasta en sus menores detalles, la organización política y social de Sevilla, tal como se trazó por la mano misma de San Fernando y realizó por su hijo Alonso. El Alcázar, la catedral y el corral de los Olmos, con muros contiguos y a veces en comunicación mutua por arcos intermediarios, constituían una especie de asamblea permanente de autoridades. Dentro del corral de los Olmos congregábanse ambos Cabildos y era tanta la concordia de Arzobispos, canónigos, racioneros, Asistentes, alguaciles mayores, alcaldes, veinticuatros y jurados que, no obstante haberse relajado mucho los lazos de comunicación desde entonces acá entre ambas clases de autoridades, subsiste aún la armonía entre la Iglesia y el municipio sevillanos. Por esta causa el anticlericalismo en Sevilla sería siempre un crimen de lesa nación. ${ }^{31}$

Esta "fiesta de la alegría pública",32, según la define De la Rosa, integraba numerosos elementos teatrales, alegóricos, e incluso paganos, que habían adquirido un significado religioso, cristianizándose de esta manera ${ }^{33}$. Tarasca, gigantones, distintos

\footnotetext{
${ }^{31}$ Y continúa: “[...] Enlazábanse los gremios con el Concejo por medio de la jurisdicción privativa que ejercían, especie de prolongación de las facultades municipales, y las juntas de sus alcaldes y oficiales eran presididas por un regidor, a causa de ser su autoridad derivada de la del Concejo. También se relacionaban con la Iglesia por medio de sus hermandades y cofradías, que colocaban bajo el patrocinio de algún Santo, a cuya advocación dedicaban las capillas, hospitales y casas en que se celebraban sus juntas.

De este modo pudo la Ciudad entenderse fácilmente con los oficios y contribuir a la solemnidad de la fiesta y procesión del Corpus con los juegos y danzas populares.” Ibídem, pp. 182-3.

${ }^{32}$ Ibídem, p. 185.

${ }^{33}$ Según $\mathrm{M}^{\mathrm{a}}$ Jesús Sanz, la primera noticia fidedigna de la participación de elementos no estrictamente religiosos como la tarasca o los grupos de danzantes en la procesión del Corpus sevillana la proporciona Ortiz de Zúñiga y data de 1506. "El Corpus en Sevilla a mediados del siglo XVI. Castillos y danzas", Laboratorio de arte, 10 (1997), pp. 123-137, p. 125
} 
artefactos como torres y castillos, carros de representación "muda" o carros de autos eran algunos de ellos. Así describe De la Rosa el carro que llamaban "la roca" que precedía al arca donde se colocaba la Eucaristía ${ }^{34}$ :

Delante del Arca iba empujado por hombres un carro de representación muda llamado la roca, figurando el cielo tachonado de estrellas con el sol y la luna, y bajo la bóveda celeste aparecían, entre seis ángeles de molde, Jesús, María, Santo Domingo y San Francisco, representados por personas, el Jesús con jubón; calzas de cuero cervuno y cabellera larga de cáñamo teñido, y las cabezas de los cuatro individuos ceñidas con diademas. El cielo estaba cubierto por una gran nube de algodón blanco y azul, que abrían y cerraban mediante cierto artificio interior dos mozos vestidos de ángeles. Dos ministriles tañendo y cuatro niños cantando dentro hacían todavía más expresivo aquel sencillo espectáculo.

La tarasca abría el cortejo ${ }^{35}$. Era una “enorme serpiente de siete cabezas, escamada de verde y plata, cuyas fauces se abrían y se cerraban mecánicamente por los hombres escondidos en su interior que la conducían"36. Símbolo del demonio, de la muerte y, junto con los gigantes, de los vicios o pecados capitales, era sometida y derrotada por el Santísimo Sacramento, presencia de la muerte y resurrección de Cristo, que redimía de tales males ${ }^{37}$. Según el abad Sánchez Gordillo, los gigantes ${ }^{38}$, además, representaban y personificaban la magnificencia y la grandeza, cualidades connaturales a la fiesta, tal y como se concebía y celebraba en Sevilla: “en la procesión del Corpus desde el principio hasta el fin todo debía ser grande; magnífico y suntuoso"39.

${ }^{34}$ Sanz aclara que los términos "roca" y "castillo" no refieren dos elementos distintos, tal y como se creía. El vocablo "castillo" es, en realidad, la traducción castellana del italiano "roca". Aunque se han sugerido posibles influencias valencianas, toledanas e incluso europeas, no se ha dilucidado aún cuáles debieron ser los modelos seguidos en Sevilla de estos artilugios móviles en donde se representaban diversas escenas bíblicas o devocionales. Véase Sanz, ibídem, pp. 132-137.

${ }^{35}$ La tarasca era un elemento presente en las procesiones del Corpus, no sólo en el ámbito hispánico, sino en toda Europa. Sanz, "El Corpus en Sevilla a mediados del siglo XVI", p. 125.

${ }^{36}$ De la Rosa, Los seises de la catedral, p. 184.

${ }^{37}$ Estos significados los toma De la Rosa de P. Solís y de Ortiz de Zúñiga.

${ }^{38}$ Jean Sentaurens hace referencia al desfile de Goliath en la procesión del Corpus de Barcelona en fecha tan temprana como 1391. Seville et le theatre de la fin du Moyen Age a la fin du XVIIe siécle (Burdeos: Presses Universitaires de Bordeaux, 1984), p. 39; cit. en Sanz, "El Corpus en Sevilla a mediados del siglo XVI", p. 126. La noticia relacionada con la presencia de gigantes en la procesión sevillana data de 1501. Sanz, "La procesión del Corpus en Sevilla. Influencias sociales", p. 57.

${ }^{39}$ De la Rosa, Los seises de la catedral, p. 186. 
José Gestoso presenta otras dos ideas que revelan la consideración que tenía en la ciudad de principios de siglo la solemnidad y fiesta del Corpus. En primer lugar, en sus Curiosidades antiguas sevillanas habla de la fiesta más celebrada en Sevilla durante siglos ${ }^{40}$. En segundo lugar, al establecer el objetivo de su trabajo, pone de relieve lo particular de la forma en la que se celebraba esta fiesta en la capital andaluza en aquella época, contemplada como ideal por la hegemonía del fervor religioso: "Redúcese nuestro objeto tan solo a consignar algunos curiosos pormenores por los cuales verá el lector de qué distinta manera fue solemnizada en Sevilla en aquellos siglos de fe y de entusiasmo, durante las centurias XV. ${ }^{\mathrm{a}}$ y XVI. ${ }^{\mathrm{a}, 41}$

Precisamente hacia mitad del s. XVI sitúa De la Rosa el punto de inflexión que articula las dos épocas en las que divide la historia de las fiestas del Corpus en Sevilla ${ }^{42}$. El cambio fundamental se produjo cuando las instituciones civiles tuvieron que asumir las responsabilidades de financiar y organizar los festejos una vez que los gremios, encargados hasta ese momento de tales menesteres, dejaron de hacerlo ${ }^{43}$. Esta segunda época evolucionaría con el paso del tiempo hacia una pérdida del carácter popular, espontáneo e incluso cándido propio de la fiesta, y adquirió, en cambio, una condición

\footnotetext{
40 "Mucho más hubiésemos podido aumentar continuando el examen de los libros y documentos de nuestro riquísimo Archivo Municipal, pero, quede reservada esta tarea a quienes especialmente se propongan escribir la historia de una solemnidad, que durante siglos fue la más celebrada de los sevillanos." Gestoso, Curiosidades antiguas sevillanas (Serie segunda), p. 119. Precisamente, el estudio realizado por Antonio Romero Abao sobre las fiestas sevillanas en el siglo XV se nutre fundamentalmente de la documentación que proporciona el Archivo Municipal. Romero dedica uno de sus capítulos al Corpus, y afirma que en ese momento los elementos que configuraban el escenario urbano de la fiestas eran aún "rudimentarios", y que sólo a partir del s. XVI empezarán a hacerse más complejos y solemnes. "Las Fiestas de Sevilla en el siglo XV", en Las Fiestas de Sevilla en el siglo XV. Otros estudios, dir. José Sánchez Herrero (Madrid: Deimos, 1991), pp. 12-178, p. 87. Véase, además, una síntesis de dicho capítulo en: "La fiesta del Corpus en Sevilla en el siglo XV", en La religiosidad popular III. Hermandades, cofradías y santuarios, coord. por Carlos Álvarez Santaló, $\mathrm{M}^{\mathrm{a}}$ José Buxó Rey y Salvador Rodríguez Becerra (Barcelona: Anthropos, 1989 [2003]), pp. 19-30.

${ }^{41}$ Gestoso, Curiosidades antiguas sevillanas (Serie segunda), p. 91.

42 "En dos épocas muy marcadas se divide la historia de los antiguos festejos sevillanos. Extiéndese la primera hasta el año 1554, y en ella los gremios son los encargados de celebrarlos bajo la dirección de los diputados de la Ciudad. La segunda parte desde el año siguiente y se caracteriza por haberse desentendido los gremios de organizar los festejos y costearlos, tomándolos la Ciudad a su cargo. Esta última época subdivídese en dos periodos; el primero termina en 1699, fecha en que se reformaron las danzas a instancia del arzobispo D. Jaime de Palafox, y el segundo en 1780, año en que se suprimieron definitivamente, no solo las danzas sino todos los juegos antiguos." De la Rosa, Los seises de la catedral, p. 188.

${ }^{43}$ Los pleitos entre los gremios y el Ayuntamiento se remontan a algunos años antes, en 1527. La Chancillería de Granada falló a favor de los primeros, que denunciaron la excesiva cuantía que aportaban en comparación con la municipal. Véase: $M^{\mathrm{a}}$ Jesús Sanz, "El Corpus en Sevilla a mediados del siglo XVI", p. 124-125.
} 
de mayor solemnidad, seriedad -a veces impostada- y oficialidad ${ }^{44}$. Estas características dominaban la fiesta del Corpus a principios del siglo $\mathrm{XX}$, como testimonia muy gráficamente De la $\operatorname{Rosa}^{45}$ :

Hoy chocan seguramente aquellas costumbres del pueblo, ya pasadas de moda, habituados, como estamos, a ver en la moderna procesión del Corpus mucho estiramiento de oficio, muchos rostros apretados o indiferentes, mucha etiqueta barata y ninguna o poca espontaneidad. En cambio aquella fiesta de la alegría pública, si se exceptúan los repiques de campanas y músicas oficiales o reglamentadas, desapareció hace más de un siglo. ${ }^{46}$

El apogeo de estas celebraciones coincide con un periodo de la historia local idealizado, y considerado como una edad dorada, la segunda mitad del s. XVI y el s. $\mathrm{XVII}^{47}$.

La historiografía posterior ha descrito las características y la trascendencia social del Corpus de manera muy similar a De la Rosa y Gestoso: la fiesta ciudadana más celebrada de la Edad Moderna, en la que se confundían y mezclaban lo profano con

44 Lleó Cañal se refiere a aquellas formas de celebración popular, espontánea, lúdica, festivas -por oposición a lo cotidiano y normalizado- con el término de "fiesta antigua" y, al igual que estos autores, contempla la evolución hacia una mayor oficialidad y pérdida de aquellos rasgos que la definieron como un declive. Fiesta grande, pp. 11-48.

45 En contraste con los numerosos estudios dedicados a la fiesta del Corpus en la ciudad de la Edad Moderna, no existen trabajos profundos sobre su importancia o significado en la mentalidad de la sociedad decimonónica o de principios del s. XX. Además de las consideraciones que realiza Lleó Cañal sobre el declive de la "fiesta antigua" durante el paso del Antiguo al Nuevo Régimen, se podrían citar algunas excepciones como las siguientes: en el caso de Sevilla, el artículo de Ma Jesús Sanz, "La procesión del Corpus en Sevilla. Influencias sociales y políticas", pp. 55-72 estudia los cambios que la procesión ha ido sufriendo a lo largo de los siglos como reflejo de las transformaciones sociales y políticas. El paso entre el Antiguo y el Nuevo Régimen se evidencia en dos series de dibujos que representan el desfile tal y como tuvo lugar en 1747 y 1866 . Estas series son citadas también por Lleó Cañal. Otro interesante trabajo sobre la fiesta del Corpus, esta vez en la otra sede metropolitana andaluza, como importante acontecimiento ciudadano donde indagar sobre aspectos sociales y políticos, y su evolución desde la Edad Moderna hasta los inicios de la Contemporánea es: María José Cuesta García de Leonardo, "Las fiestas del Corpus Christi en el paso del Antiguo Régimen a la Época Contemporánea. (El caso de Granada).", en La fiesta del Corpus Christi, coord. por Gerardo Fernández Juárez y Fernando Martínez Gil (Cuenca: Universidad de Castilla-La Mancha, 2002), pp. 179-214. La autora muestra la dimensión política, inseparable de la religiosa en el Antiguo Régimen, de los distintos elementos decorativos e imágenes simbólicas, así como los textos que les acompañaban.

${ }^{46}$ De la Rosa, Los seises de la catedral, p. 185.

47 "El apogeo de todas estas fiestas dedicadas a la procesión del Corpus coincide con la segunda mitad del siglo XVI y toda la centuria siguiente. La decadencia se inicia en 1699 con la reforma de las danzas, impuesta por la Real orden de 1699 a instancia del Arzobispo D. Jaime de Palafox. Los autos sacramentales se habían suprimido en 1679 al cerrarse las casas de comedias en tiempo del Arzobispo D. Ambrosio Ignacio de Espínola, a petición del P. Tirso González, General después de los jesuitas, y del piadoso caballero D. Miguel de Mañara.” De la Rosa, Los seises de la catedral, p. 193. 
lo religioso, lo popular con lo institucional; en la que la ciudad se representaba a sí misma -idealizada-, y se escenificaba el orden social, político y jerárquico, una función que cumplía de forma particularmente eficiente la procesión. Además, como evidencian los estudios dedicados a otras ciudades los elementos que la componían y las formas de celebración que la definían respondían a un modelo común seguido, en gran medida, en el conjunto de la península, en incluso en Europa ${ }^{48}$. Sin embargo, la composición de esta imagen en el caso de aquellos autores, especialmente de De la Rosa, tenía, además, una finalidad al ser trasladada a su presente: mostrar una forma de organización social y una cultura que tomar como ideal o, al menos, como referentes para aquella otra sociedad de principios de siglo XX.

\subsection{La figura de la Inmaculada}

El dogma de la inmaculada concepción de María no fue promulgado por la Iglesia católica hasta 1854. Desde que San Bernardo, hacia el año 1140, amonestara a los canónigos de la catedral de Lyon por celebrar solemnemente el 8 de diciembre la fiesta de la concepción de la Virgen, hasta el momento en el que Pío IX sancionó el dogma, mediaron siglos de controversias y desacuerdos teológicos. Durante los siglos XIII y XIV se definieron dos corrientes opuestas. Por un lado, los partidarios de las doctrinas inmaculistas, y aquellos que, o bien se situaban abiertamente en su contra, o bien las contemplaban con escepticismo. Teólogos de la talla de Santo Tomás de Aquino o San Buenaventura, así como la orden dominica se decantaron del lado

\footnotetext{
${ }^{48}$ Salvador Rodríguez Becerra insta a no olvidar lo que denomina "unidad cultural básica" a la hora de "considerar ciertas formas culturales y rituales como únicas y excepcionales", algo a lo que se tiende por desconocimiento o "por el deseo de valorar lo singular y propio frente a lo ajeno". "El Corpus en Andalucía”, p. 383. Véanse, además: Francis G. Very, The Spanish Corpus Christi Procession. A Literary an d Folkloric Study (Valencia: Tipografía Moderna, 1962); Antonio Ariño, Festes, rituals y creencies (Valencia: Alfons el Magnànim, 1988); José Antonio González Alcantud, "Estudio preliminar" en Miguel Ángel Garrido Atienza, Antiguallas granadinas, las fiestas del Corpus, ed. por José Antonio González Alcantud (Granada: Ayuntamiento de Granada, 1990); Javier Portús Pérez, La antigua procesión del Corpus Christi en Madrid (Madrid: Comunidad de Madrid, 1993); Miguel Ángel Catalá Gorgues, La procesión del Corpus en antiguos Dietaris y Llibres de Memories (Valencia: Ayuntamiento de Valencia, 1993); Ramón Miró i Baldrich, La processó del Corpus i els entremosos. Cervera, segles XIV-XIX (Barcelona: Abadía de Montserrat, 1998); Carles Pitarch Alfonso, "La festa del Corpus Christi a València: de les Roques i els Jocs a les danses tradicionals", en El teatre en la festa valenciana, dir. por Antonio Ariño (Valencia: Consell Valencià de Cultura, 1999), pp. 173-198; Yayoi Kawamura, Festividad del Corpus Christi en Oviedo (Oviedo: Nobel, 2001); VV.AA., Corpus, historia de una presencia (Toledo: Instituto Teológico San Ildefonso, 2003).
} 
maculista, mientras que los principales defensores de la concepción inmaculada fueron los franciscanos ${ }^{49}$.

En la catedral de Sevilla, un acuerdo capitular de 14 de septiembre de 1396 testimonia la celebración, con procesión incluida, de la fiesta de la Inmaculada ya en esas fechas. El Libro Blanco, en el que figuran, entre otras cosas, las fundaciones instituidas en el templo catedralicio, recoge la dotada por la reina Isabel la Católica en 1477 para

celebrar et fazer fiesta de la Concepcion de nuestra señora la virgen santa maria en el octavo dia de su ochavario de la misma fiesta de la Concepcion con visperas de ante día et misa solene con cantores et órganos $[\ldots]^{50}$

En el concilio de Sevilla de 1512 consta el día de la Concepción como fiesta de guardar, junto a las otras festividades marianas de la Purificación, Anunciación, Asunción y Natividad ${ }^{51}$. Por tanto, a comienzos del siglo XVI la celebración de la Inmaculada Concepción había adquirido en el primer templo hispalense los atributos propios de las grandes solemnidades religiosas: día festivo, octava y procesión. Con el discurrir del siglo, el arraigo de la devoción inmaculista fue en aumento, como muestra la evolución de sus cultos, según Manuel Serrano:

Distinguióse siempre el Cabildo de esta Santa Iglesia Catedral por su amor y devoción al Santísimo Sacramento de la Eucaristía y a la Concepción Inmaculada de la Virgen, de cuyas dos

\footnotetext{
${ }^{49}$ La polémica sostenida por ambos institutos religiosos dio pie a la intervención en 1476 del entonces pontífice Sixto IV, quien aprobó mediante la constitución Cum praeexcelsa el oficio de la Inmaculada Concepción para toda la Iglesia latina. Siete años más tarde publicó la constitución Grave nimis en la que condenaba las mutuas acusaciones de unos y otros de incurrir en pecado mortal o herejía por defender sus posiciones. A partir de finales del siglo XV prácticamente todas las órdenes religiosas, excepto los dominicos, adoptaron una postura favorable a las tesis inmaculistas. Por su parte, las grandes universidades europeas, empezando por la parisina, establecieron la condición de realizar juramento de defensa de la inmaculada concepción de María para ser admitido como alumno. Las dos primeras universidades peninsulares en sumarse a esta iniciativa fueron la de Valencia en 1530 y la de Osuna en 1548. Ros, "La Concepción Inmaculada en la historia", p. 21. Sobre las doctrinas concepcionistas y la Universidad, véase José Carlos Vizuete Mendoza, "Voto, juramento y fiesta de la Inmaculada en la Universidad de Toledo, La Inmaculada Concepción en España: religiosidad, historia y arte, 2 vols., ed. por Francisco Javier Campos y Fernández de Sevilla (San Lorenzo de El Escorial: Ediciones Escurialenses, 2005), vol. 1, pp. 325-360.
}

${ }^{50}$ fols. 148v-149v. cit. en Ros, "La Concepción Inmaculada en la historia", p. 27, nota a pie 31 . Se recoge también en: Serrano Ortega, Glorias sevillanas, pp. 110-111. Hemos preferido en este caso respetar la ortografía original en la transcripción del fragmento por su antigüedad.

${ }^{51}$ Ros, "La Concepción Inmaculada en la historia”, p. 27. 
devociones puede decirse siempre hizo una, confundiéndola en un solo afecto y tributándoles un solo culto. Desde muy antiguo encontramos en sus Estatutos la predilección especial de que fue objeto; distinción que continúa en grado progresivo, como se puede demostrar por el aumento y grandeza que vino sufriendo a través de los tiempos el culto a la Inmaculada. ${ }^{52}$

Sin embargo, no es hasta las primeras décadas del siglo XVII cuando definitivamente se fragua en la sociedad sevillana la conciencia de haberse creado un particular vínculo entre la Inmaculada y la ciudad. Por esas fechas se vivió con especial intensidad un capítulo más, está vez a nivel local, de la polémica aún candente entre los partidarios de las doctrinas concepcionistas y sus detractores, representados, de nuevo, por los dominicos. Según cuenta el autor anónimo de Carta de un ciudadano de Sevilla a un personaje eclesiástico ${ }^{53}$

Todo el desasosiego, excesos y mal exemplo que en esta ciudad se ha padeçido [...] ha procedido totalmente de sola la oposición y resistencia que los más padres dominicos han querido hazer [...]. Començaron estos padres a despertar o, por mejor dezir, alborotar a este lugar con imprimir y pretender sustentar en su convento de Regina, de que es aora prior el maestro fray Domingo de Molina, caudillo y principal movedor de estos ruydos, unas conclusiones en que tratavan a la Virgen y del misterio de su limpia concepción con palabras menos consideradas de lo que fuera raçón. ${ }^{54}$

Estas acciones de resistencia activa en contra de la doctrina se emprendieron "en medio de una increible piedad y devoçion a la Virgen". Enfrente se encontraron con

el torrente de todo el estado eclesiástico, de onçe religiones, de toda la nobleza, de todo el pueblo, grandes y pequeños, en suma, de toda esta ciudad que tiene y confiessa a boca llena que fue conçebida la Reyna de los Angeles sin mancha de pecado original. ${ }^{55}$

\footnotetext{
${ }^{52}$ Serrano, Glorias sevillanas, p. 105.

53 Este documento fue publicado por Stanko Vranich en "Carta de un ciudadano de Sevilla. La guerra mariana de Sevilla en el siglo XVII", Archivo Hispalense, 137 (1966), pp. 241-274, y Archivo Hispalense, 138 (1966), pp. 59-77.

${ }^{54}$ Vranich, "Carta de un ciudadano", p. 245; cit. en Ros, "La Concepción Inmaculada en la historia”, p. 29.

${ }^{55}$ Ibídem.
} 
El siguiente fragmento constituye una síntesis de la historia de la recepción de la Inmaculada en Sevilla hasta el s. XVII, según lo transmitió Manuel Serrano:

Lo que llevamos hasta aquí relatado prueba muy alto que la devoción concepcionista hallábase arraigada profundamente entre nosotros, y que, por lo tanto, no se engendra ni aparece por vez primera en los comienzos del decimo-sétimo siglo, al calor de las disputas teológicas: solamente la tenacidad de la contraria opinión, con sus alardes y manifestaciones inoportunas, dio pie, con una leve chispa, a que se encendiese y estallara inmenso volcán de la popular devoción, hasta entonces latente y apagada al parecer. Lo que ocurre en ese momento es verdaderamente asombroso. Jamás pueblo alguno dio nunca prueba mayor de respeto y veneración a la Santísima Virgen, como ofreció Sevilla en aquellas circunstancias: la Ciudad en masa puede decirse que se levanta a protestar contra lo que ella creía era un tanto ofensivo a la Inmaculada Pureza de la Reina del Cielo, haciéndolo a porfía, como en un solo haz, los Senados Civil y Eclesiástico, las Comunidades y el Prelado, el guerrero y el magistrado, las Academias, los gremios y las artes bellas, el noble y el hijo humilde del pueblo; así que en público y privadamente, en las plazas y en los templos, en las calles y en las moradas de los ciudadanos, no se oye, no se repite más que una frase, no brota más que una sola expresión: '¡Acudamos en defensa de la Virgen María, no tocada ni manchada con la culpa original!"’,56

En medio del conflicto entre la "opinión rigurosa" y la "creencia piadosa", según los términos empleados por Serrano, el arzobispo hispalense, Pedro de Castro, resolvió, por su parte, enviar a dos emisarios para trasladar a la Corte la versión de los inmaculistas, es decir, la de la causa masivamente abrazada por la sociedad local ${ }^{57}$. Esos delegados fueron el arcediano de Carmona, Mateo Vázquez de Leca, y el presbítero y miembro destacado de la Congregación de la Granada, Bernardo del Toro ${ }^{58}$.

\footnotetext{
${ }^{56}$ Serrano, Glorias sevillanas, pp. 239-40.

${ }^{57}$ Carlos Ros se inclina claramente por el obispo auxiliar Juan de la Sal como el autor del escrito: "La Concepción Inmaculada en la historia", p. 28.
}

58 La Congregación de la Granada era un grupo espiritual hermético y heterodoxo, cuyos miembros fueron considerados como alumbrados y perseguidos por la Inquisición. Como cabeza del grupo, Bernardo del Toro predicaba en el púlpito situado junto a la capilla de la Virgen de la Granada en el Patio de los Naranjos de la catedral hispalense. Este grupo es mencionado ya por Menéndez Pelayo en su Historia de los Heterodoxos Españoles (Alicante: Biblioteca Virtual Miguel de Cervantes, 2003 [18801882]), consultable en <http://www.cervantesvirtual.com/obra-visor/historia-de-los-heterodoxosespanoles/html/> (consultado 28-4-2013). Los primeros estudios sobre esta misteriosa comunidad espiritual son los realizados por Antonio Domínguez Ortíz, "La Congregación de la Granada y la Inquisición de Sevilla. Un episodio de la lucha contra los alumbrados”, en: La Inquisición española: Nueva visión, nuevos horizontes, coord. por J. Pérez Villanueva (Madrid: Caja Provincial de Ahorros de Cuenca, 1980), pp. 637-646; y por Álvaro Huérga. Historia de los alumbrados (1570-1630). IV Los alumbrados de Sevilla (1605-1630) (Madrid: Fundación universitaria española, 1988), pp. 217-237. 
La misión de estos hombres, que se convertirían en auténticos héroes dentro del imaginario colectivo hispalense, era además recabar el apoyo de Felipe III para solicitar al papa la definición del dogma de la Inmaculada. La legación sevillana no consiguió su propósito, aunque el decreto Sanctissimus Dominus publicado por Paulo V en 1617 en el que se vetaba la defensa pública de las posiciones antiinmaculistas fue interpretada en Sevilla como un éxito ${ }^{59}$. Serrano cuenta así la reacción que produjo la llegada de la noticia a la ciudad ${ }^{60}$ :

A aquella misma hora corrió la voz de la nueva que acababa de llegar, e instantáneamente el pueblo se lanzó a la calle, presentando la Ciudad aspecto indescriptible; ilumináronse los edificios públicos $\mathrm{y}$ las casa con tal profusión, que parecía la hora del mediodía, según afirmación de testigos oculares; todos corrían de un lado a otro, y contentos con poseer la noticia, deseaban comunicarla a los demás, dándose unos a otros la más cumplida enhorabuena; gritaban aclamando la Concepción, y turbaban el silencio de la noche con sus vítores y alegría. Se abrió la mayoría de los templos, iluminando sus altares. Organizó la Cofradía de Nazarenos una lucida procesión con más de setecientas personas, que con luces encendidas iban entonando las coplas de Miguel Cid. Rompieron a las doce de la noche en atronador repique las campanas de la Giralda, y tras ellas las de los demás templos. En aquella hora se abrieron las puertas del Palacio Arzobispal, invadiéndolo la muchedumbre, que daba la enhorabuena al ilustre Prelado, que los recibía lleno de entusiasmo y fervor, al ver cumplidos los deseos de nuestro pueblo. Hiciéronse muchas fiestas en los siguientes días, de las que hablaremos en el capítulo correspondiente. $^{61}$

Véase, además: Antonio González Polvillo, “La Congregación de la Granada, el Inmaculismo sevillano y los retratos realizados por Francisco Pacheco de tres de sus principales protagonistas: Miguel Cid, Bernardo de Toro y Mateo Vázquez de Leca”, Atrio, 15-16 (2009-2010), pp. 47-72.

59 Serrano relata la misión llevada a cabo por los emisarios sevillanos en el capítulo IX: Glorias sevillanas, pp. 267-308.

${ }^{60}$ En realidad, la atribución en exclusiva de este supuesto logro a una legación sevillana no es exacto. Felipe III constituyó en 1616 una Junta de Prelados para poner fin a las disputas doctrinales, y envió una embajada a Roma al frente de la cual estaba el benedictino burgalés Plácido Tosantos. En 1618 partió una segunda comitiva nombrada igualmente por el monarca hispano encabezada esta vez por el obispo de Cartagena-Murcia, Antonio Trejo. Vizuete Mendoza, "Voto, juramento y fiesta de la Inmaculada en la Universidad de Toledo, p. 338.

${ }^{61}$ Serrano, Glorias sevillanas, pp. 282-283. 
El 8 de diciembre de ese mismo año la ciudad entera, representada por sus cabildos eclesiástico y municipal hizo solemne juramento de defender la inmaculada concepción de María ${ }^{62}$.

El potente movimiento inmaculista sevillano se proyectó al futuro de diversas maneras. Serrano relata en el siguiente pasaje la implicación de literatos, artistas, teólogos, todos los estamentos de la ciudad al servicio de la causa:

Desde ese instante no se dan mano a descansar de su noble empresa: el artista, idealizando los prodigiosos modelos que nos ofrece como tipos incomparables de la siempre Virgen María; el teólogo, con sus tratados profundos e irrefutables; el poeta, con sus endechas, en que canta las bellezas y perfecciones de la Madre del Divino Amor; el orador sagrado, levantando al pueblo con los arranques de elocuencia que brotan de sus labios al ensalzar los privilegios de la Mujer preservada de la culpa de Adán; las Academias, promoviendo justas literarias para poner en competencia a nuestros ingenios; las corporaciones religiosas, realizando fiestas y procesiones, que son verdaderas marchas triunfales; el noble y el opulento, cediendo sus bienes y cuantiosa fortuna para el esplendor del culto a la Virgen; el caballero, dotando doncellas, como prueba de amor a la Pureza; los egregios capitulares, dejando pingües rentas para que la liturgia resulte digna de la majestad del culto de Nuestra Señora, o cediendo sus patrimonios para correr a Roma, llenos de fe y encendidos en celo religioso, para pedir al Pontífice infalible que hable en defensa de la Concepción. ${ }^{63}$

La narración de estos hechos, tal y como se nos ha transmitido a través de estos relatos, muestran cómo lo que en principio no era más que una disputa teológica se transformó en un conflicto en el que entraron en juego factores de naturaleza devocional, e incluso emocional y afectiva. Estudios recientes van más allá, y encuentran en este conflicto importantes implicaciones sociales. Según sostienen Jorge Jiménez Barrientos y Manuel Gómez Lara, el discurso concepcionista estaba relacionado con una tendencia de pensamiento favorable al igualitarismo y contrario a la exclusión por razones sociales, religiosas o estamentales ${ }^{64}$.

${ }^{62}$ La extensa narración de Serrano de los juramentos de cabildos eclesiástico y secular en el capítulo XII, Glorias sevillanas, pp. 440-482.

\footnotetext{
${ }^{63}$ Serrano, Glorias sevillanas, p. 240.

${ }^{64}$ Estos autores señalan: “[...] pensamos que es legítimo el intento de conectar el discurso inmaculista con un estado de opinión contrario a la exclusión a causa de orígenes sociales, religiosos o estamentales. La definición de la Pura y Limpia subrayaba, a partir de la singularidad de esta figura, que todos los hombres son iguales, hijos del pecado original redimidos por el sacrificio de Cristo. El concepto de pureza y
} 
El activismo de la parte anticoncepcionista fue sentido como una agresión a una figura, la Inmaculada, asentada, desde un punto de vista cultural, en la conciencia del pueblo como un icono, y que congregó en torno a sí a todos los estamentos y clases sociales. La contienda inmaculista fraguó definitivamente una relación de identidad entre Sevilla y la Inmaculada, y colaboró en la consolidación de una conciencia colectiva como comunidad congregada a los pies de su figura. Las artes y la numerosa literatura concepcionista constituyeron los medios de comunicación a través de los cuales se transfirió a las siguientes generaciones esta herencia ${ }^{65}$. Serrano insiste en esta íntima relación entre la Inmaculada y Sevilla en las páginas introductorias de su libro, entre las que extraemos el siguiente pasaje:

Lo repetiremos mil y mil veces: el sentimiento o carácter que siempre distinguió a Sevilla fue la piedad, fue la religiosidad; pero esta piedad y religiosidad, toda concentrada y dirigida hacia María y, como última expresión de este cariño y afecto, María en su momento

limpieza de sangre estaba indisolublemente unido a un discurso religioso excluyente según el cual sólo los cristianos viejos detentaban la verdad religiosa y la pureza. A esto, y sus consecuencias sociales, se oponía la idea de que sólo María, por la gracia divina, estaba libre y los beneficios de la Redención alcanzaban, por tanto, a todos los que habían recibido las aguas bautismales". "La ocupación del espacio urbano como instrumento propagandístico: ornatos efímeros en las fiestas inmaculadistas barrocas de Sevilla”, Stylistica. Revista Internacional de Estudios Estilísticos y Culturales, 5 (1997-1998), p. 124, cit. en Mercedes de los Reyes Peña, "Un pasquín anti-inmaculista en la Sevilla del primer tercio del siglo XVII", en Sevilla y la literatura: homenaje al profesor Francisco López Estrada en su 80 cumpleaños, coord. por Mercedes de los Reyes Peña, Rogelio Reyes Cano y Klaus Wagner (Sevilla: Universidad de Sevilla, 2001), p. 137, nota a pie $\mathrm{n}^{\mathrm{o}}$ 7. González Polvillo habla de un trasfondo heterodoxo en este conflicto, en el que estaban inmersos la ya mencionada Congregación de la Granada, una sociedad religiosa "cuyas características espirituales estaban influenciadas por presupuestos milenaristas, visiones y profecías además de un acendrado evangelismo" y la propia Inquisición, controlada por los dominicos. González Polvillo, "La Congregación de la Granada", p. 48.

${ }^{65}$ Carlos Ros cifra en sesentaicinco las obras que sobre el tema de la Inmaculada se publicaron sólo en el cuatrienio de mayor efervescencia, de 1615 a 1618. Ros, "La Concepción Inmaculada en la historia", p. 33. La disputa teológica se mantenía públicamente mediante sermones y pasquines distribuidos por la ciudad por uno y otro bando. Véase: de los Reyes Peña, "Un pasquín anti-inmaculista en la Sevilla del primer tercio del siglo XVII", pp. 133-160. Las coplas, de fácil asimilación por el pueblo, ejercieron un importante papel como medio para difundir entre la gente llana los principios inmaculistas. En este sentido, resulta ineludible citar la copla Todo el mundo en general con letra del poeta Miguel del Cid. Serrano, Glorias sevillanas, pp. 255-258. El popular estribillo tiene un marcado carácter inmaculista: Todo el mundo en general/ a voces, Reina escogida,/ diga que sois concebida/ sin pecado original. Véase: Miguel Cruz Giráldez, "Religiosidad y Literatura Popular en la Sevilla del Barroco: las coplas de Miguel Cid”, en Homenaje al profesor Klaus Wagner (Sevilla: Universidad de Sevilla, 2008), 2 vols., vol. 2, pp. 573-581. Sobre pintura concepcionista en Sevilla, véase, entre otros: Enrique Valdivieso y Juan Miguel Serrera, Pintura sevillana del primer tercio del siglo XVII (Madrid: Instituto Diego Velázquez. CSIC, 1985). Véanse, además, Suzanne L. Stratton, "La Inmaculada Concepción en el arte español", Cuadernos de arte e iconografía I/2 (1988), pp. 3-128. En el segundo volumen de la obra colectiva a la que ya hemos aludido en varias ocasiones La Inmaculada Concepción en España: religiosidad, historia y arte, 2 vols., ed. por Francisco Javier Campos y Fernández de Sevilla (San Lorenzo de El Escorial: Ediciones Escurialenses, 2005), se pueden encontrar un total de veinticinco trabajos dedicados a la Inmaculada en el arte, desde múltiples perspectivas. 
más glorioso, en el primer instante de su existencia, en el instante primero de su purísimo ser; María en su Inmaculada Concepción. ${ }^{66}$

En realidad, esta explosión concepcionista fue un fenómeno general en todo el mundo hispánico, aunque en Sevilla se manifestara, probablemente, de manera más radical que otros lugares, $\mathrm{y}$, como apuntan algunos especialistas, su origen estuviera en Andalucía $^{67}$. Relatos muy parecidos y acontecimientos y sucesos idénticos a los descritos por Serrano en Sevilla refieren otros muchos historiadores en el caso de otras ciudades peninsulares y novohispanas ${ }^{68}$ : efervescencia inmaculista popular, compromiso por la consecución de la declaración dogmática, votos en defensa de la creencia concepcionista y adopción de la Inmaculada como patrona por parte de instituciones eclesiásticas, político-civiles, académicas, incluido el estamento militar ${ }^{69}$, grandes celebraciones y festejos ante las noticias favorables llegadas de Roma ${ }^{70}$. Para Felipe III la Inmaculada se convirtió en una cuestión de Estado ${ }^{71}$. Un siglo y medio

\footnotetext{
${ }^{66}$ Serrano, Glorias sevillanas, p. 8.

67 Antonio Luis Cortés Peña, “Andalucía y la Inmaculada concepción en el siglo XVII”, en Religión y política durante Antiguo Régimen, ed. por Antonio Luis Cortés Peña (Granada: Universidad de Granada, 2001), pp. 103-148; Francisco Javier Campos y Fernández de Sevilla, "La devoción a la Inmaculada Concepción en las "Relaciones Topográficas", La Inmaculada Concepción en España: religiosidad, historia y arte, 2 vols., ed. por Francisco Javier Campos y Fernández de Sevilla (San Lorenzo de El Escorial: Ediciones Escurialenses, 2005), vol. 1, pp. 7-28, p. 10. Vizuete Mendoza, "Voto, juramento y fiesta de la Inmaculada en la Universidad de Toledo, p. 337.
}

${ }^{68}$ Vizuete Mendoza refiere el voto realizado por la Universidad de México y la ciudad de Mérida de Yucatán, esta última por influencia de Sevilla, en 1618. "Voto, juramento y fiesta de la Inmaculada en la Universidad de Toledo", pp. 340-341.

${ }^{69}$ El arma de infantería adoptó a la Inmaculada como patrona. Este vínculo se remonta al siglo XVI. Pedro Luís Pérez-Frías, "Las élites militares de Alfonso XIII y la Inmaculada Concepción", en $L a$ Inmaculada Concepción en España: religiosidad, historia y arte, 2 vols., ed. por Francisco Javier Campos y Fernández de Sevilla (San Lorenzo de El Escorial: Ediciones Escurialenses, 2005), vol. 1, pp. 305-326, p. 307.

\footnotetext{
${ }^{70}$ Véanse los estudios sobre la cuestión concepcionista en numerosas ciudades españolas contenidos en los ya mencionados volúmenes de La Inmaculada Concepción en España: religiosidad, historia y arte, ed. por Francisco Javier Campos y Fernández de Sevilla (San Lorenzo de El Escorial: Ediciones Escurialenses, 2005).

${ }^{71}$ María Trinidad López García, "El auge del dogma de la Inmaculada Concepción auspiciado por el franciscano fray Antonio de Trejo, obispo de Cartagena, y la implicación del Concejo de Murcia, a principios del siglo XVII", La Inmaculada Concepción en España: religiosidad, historia y arte, 2 vols., ed. por Francisco Javier Campos y Fernández de Sevilla (San Lorenzo de El Escorial: Ediciones Escurialenses, 2005), vol. 1, pp. 119-138, p. 122.
} 
después, el papa Clemente XIII a petición de Carlos III proclamó a la Inmaculada patrona de España y sus dominios ${ }^{72}$.

No obstante el carácter general hispánico del fenómeno concepcionista, la cualidad identitaria alcanzada en Sevilla por la Inmaculada permanecía a principios de s. XX, como demuestra el texto de Serrano, e incluso de manera particular en comparación con otras ciudades. A continuación transcribimos sendos fragmentos especialmente significativos, pues formaron parte de los discursos pronunciados en la I Asamblea Nacional de la Buena Prensa (Sevilla, 1904) por las dos máximas autoridades eclesiásticas hispalenses durante la reforma, el entonces arzobispo de Sevilla, Marcelo Spínola, y el que lo sería en breve, Enrique Almaraz. El primero se dirigió así a la audiencia: "Señores: lo habéis hecho bien. Habéis venido a Sevilla, la hermosa Sevilla, la ciudad histórica, la tierra de los jardines y de las flores, el pueblo de la Inmaculada; $[\ldots]^{, 73}$. El segundo, todavía obispo de Palencia, exclamaría:

A eso hemos venido a Sevilla, la ciudad de antiguo celebrada por las ricas imaginaciones de la poesía; la ciudad Reina y Señora del arte en todas sus magníficas y grandiosas manifestaciones; la ciudad que tiene por nota y carácter distintivo, entre todas las ciudades de la católica España, el amor a María Inmaculada, que aquí apareció en la mente del inmortal Murillo tan hermosa y más hermosa que el firmamento, puesto que de su azul purísimo tomó el vestido, y las estrellas coronaron su frente, y la luna sirvió para escabel y sostén de sus plantas virginales. ¡Quiera Ella que estos nuestros trabajos en el año jubilar consagrado al misterio de su Concepción Inmaculada, sean fecundos para la gloria de Dios, para el florecimiento del reinado de Cristo, para la honra de la Iglesia, para el bienestar de las sociedades, para la salvación de las almas, para el verdadero engrandecimiento de la Patria querida, que tanto debe a la protección de la Inmaculada Virgen $!^{74}$

Este otro extracto de Norberto Torcal, periodista católico aragonés, constata que la particular identificación de la Inmaculada con Sevilla era reconocida también

\footnotetext{
72 Clemente XIII promulgó el Breve “Quantum Ornamenti” por el que aprobaba tal declaración en 1760. Campos y Fernández de Sevilla, “La devoción a la Inmaculada Concepción”, p. 10.

73 "Discurso de clausura pronunciado por el Excmo. y Rvmo. Sr. D. Marcelo Spínola y Maestre. Arzobispo de Sevilla y Presidente General de la Asamblea", Crónica de la Asamblea Nacional de la Buena Prensa (Sevilla: El Correo de Andalucía, 1905), p. 388.

74 "Discurso pronunciado por el Excmo, e Ilmo, Sr. D. Enrique Almaraz y Santos. Obispo de Palencia." Crónica de la Asamblea Nacional de la Buena Prensa (Sevilla: El Correo de Andalucía, 1905), pp. 370371.
} 
desde el exterior: "Permitidme, pues, que desde esta tribuna os dirija yo ahora fraternal saludo en nombre de mi Aragón querido. Zaragoza y Sevilla, la ciudad del Pilar y la ciudad de la Inmaculada, hermanas gemelas son en el amor de María; [...]"75

En la obra de Serrano se suceden las alusiones documentadas a la grandiosidad, pompa y majestuosidad que caracterizaba el culto concepcionista en la Catedral y en el resto de templos de la ciudad entre los siglos XV al XVIII, en las que no faltan las referencias musicales. Los cultos de aquellas otras épocas constituyeron para Serrano los modeloes a la hora de proporcionar una idea de las dos grandes celebraciones inmaculistas organizadas en Sevilla ya en la Edad Contemporánea. Además, planteó algo que consideramos particularmente significativo: el grado de semejanza de las fiestas decimonónicas con las antiguas -paradigmáticas- constituía un indicador para compulsar en qué medida aquella sociedad contemplada por el autor como ideal, civilizada, religiosa pervivía en la Sevilla de la segunda mitad del s. XIX.

La primera de aquellas celebraciones tuvo como motivo la proclamación del dogma de la Inmaculada en 1854 por parte del papa Pío IX. Serrano puso el acento en el valor del esfuerzo que la propia devoción histórica hispalense por la Inmaculada impulsó a hacer a los sevillanos, a pesar de lo desfavorable de las circunstancias "para la Religión y para la patria", a diferencia “de otras edades":

Al narrar las fiestas que hiciera Sevilla con motivo de este gran acontecimiento, si bien en aquellas manifestaciones aún vemos arraigado en sus hijos el espíritu tan acendrado y ferviente de otras edades, ciertamente que no se encuentra nada que iguale al entusiasmo tan universal del décimo-sétimo siglo y del siguiente, no obstante de haber alcanzado el momento por el que tanto habían suspirado nuestros mayores, y por el que tanto se había desvivido esta Ciudad. Mas por desgracia la fe religiosa de la época que atravesábamos no era ni mucho menos la fe de otras edades de más gloria para la Religión y para la patria. [...]

Y si a tan lamentable estado se une la situación angustiosísima en que se encontraba la Religión en nuestra patria el mismo año de la declaración dogmática, y las restricciones que se pusieron al pase de la Bula Ineffabilis Deus en 9 de Mayo de 1855, no extrañará ya que las fiestas realizadas en la Ciudad Mariana por excelencia, la Ciudad de la Inmaculada, no correspondieran a lo que sus tradiciones e historia exigían. Mas no obstante esto, no faltaron

\footnotetext{
75 "Discurso pronunciado por el Sr. D. Norberto Torcal. Subdirector de 'El Noticiero' de Zaragoza" Crónica de la Asamblea Nacional de la Buena Prensa (Sevilla: El Correo de Andalucía, 1905), p. 250.
} 
numerosas funciones, con las [que] se procuró solemnizar el nuevo Dogma. $[\ldots]^{76}$

La segunda, por la que se conmemoraba el XXV aniversario de la proclamación del dogma, fue presentada como una vuelta a aquella edad de esplendor:

En el año 1879 cumplíase el XXV aniversario de la declaración del dogma de la Concepción Inmaculada, con cuyo motivo la ciudad de Sevilla quiso conmemorar solemnemente tan glorioso suceso. Puede decirse que en esta ocasión cumplieron como buenos ambos Cabildos, luciéndose en cuanto proyectaron y se ejecutó, compensando de este modo lo que se omitiera en 1855; pues en verdad se puede decir, que las fiestas del primer Jubileo de la declaración del Dogma superaron con creces a cuanto se hizo en aquella otra fecha. $[\ldots]^{77}$

Aún la luz no había roto las densas tinieblas de la noche, cuando todas las campanas de los templos hispalenses prorrumpieron, después del toque de Alba, en repique universal, pero tan alegra y conmovedor, que parecía que los metales sagrados se anticipaban a dar la enhorabuena al presente día 8 de Diciembre de 1879, cuya prístina luz saludaban, y cuyos primeros albores escucharon llenos de regocijo aquellos mismos acentos, las mismas palabras con que se ensalzara la Concepción Inmaculada de María en 8 de Diciembre de 1617. Habían transcurrido cerca de trescientos años, y el pueblo se alborozaba del mismo modo, lleno de singular afecto y ternura, y entonando los mismos cantares. ${ }^{78}$

Además, el culto sobrepasó los muros de las iglesias y, como ocurría en el caso de la festividad del Corpus, a modo de un gran templo, el escenario urbano se convirtió en estas narraciones en un gran espacio ceremonial. El significado simbólico de este desborde de los espacios rituales era claro: el factor religioso inundaba la sociedad y la cultura, por la celebración de la Inmaculada. El inmaculismo constituía un elemento integrador del conjunto de la ciudad. El ámbito religioso y civil diluían sus fronteras, empezando por las propias autoridades. La colaboración y compenetración de los cabildos catedralicio y municipal representaban esta trabazón.

Así mismo el Cabildo Eclesiástico dispuso que este año se celebraran los Oficios de la Concepción con todo el esplendor y

\footnotetext{
${ }^{76}$ Serrano, Glorias sevillanas, pp. $748-50$.

${ }^{77}$ Ibídem, p. 769.

${ }^{78}$ Ibídem, p. 773.
} 
magnificencia posible, cantándose en las Vísperas la partitura del Mtro. Eslava, y en los Maitines que tuvieron lugar de noche, los Responsorios del actual Maestro de capilla D. Evaristo García Torres, y de los que ya hemos hablado.

Llamó bastante la atención el adorno que colocara en las Casas del pueblo el Excmo. Ayuntamiento, que fiel a sus tradiciones, dio muestras de su devoción a la Inmaculada. En el balcón principal que da vista a la plaza de San Fernando se puso un rico dosel de terciopelo rojo y oro, y bajo él un gran cuadro con pintura de la Concepción, $[\ldots]$

Por el lado de la plaza de San Francisco, en el andén, se colocó el altar de plata que hoy pertenece a la parroquia del Salvador, donde se veía una escultura de la Concepción entre infinidad de hachas de cera y ramos de flores; luciendo todo el resto del edificio sus colgaduras de gala y multitud de luces de gas. [...]

Indescriptible era el efecto que todo esto producía en tan célebre noche: Sevilla en aquellos momentos con toda verdad se podía decir que era la Ciudad de María, pues con emulación santa rivalizaban las autoridades y los ciuda[da]nos para ver cuál le prodigaba las mayores muestras de fe y de amor. $\mathrm{Y}$ en medio de tantas pruebas de alegría, Ella, como verdadera reina de los corazones andaluces, presidiendo el hermoso espectáculo que se desarrollaba a su vista desde el balcón de las Casas del pueblo.

La Catedral preparó la capilla mayor con el magnífico altar de plata, según es costumbre en esta fiesta, vistiendo los pilares con las colgaduras de terciopelo. El eminentísimo Sr. Arzobispo Cardenal D. Fray Joaquín Lluch y Garriga quiso asociarse a tan general movimiento, y dispuso que en la función solemnísima oficiara de gran pontifical, y al par dirigiría su voz a los fieles con tan fausto motivo. ${ }^{79}$

Como ya hemos apuntado, el culto, y la magnificencia en sus expresiones, constituyó un espacio de preservación y representación de un ideal de sociedad y cultura que tenía a la Inmaculada por uno de sus grandes símbolos.

\subsection{Corpus e Inmaculada: símbolos de un concepto de cultura y sociedad} determinado por lo religioso

El propósito principal de Arbolí con su libro La Eucaristía y la Inmaculada, devoción española fue poner de relieve los íntimos vínculos históricos y doctrinales existentes entre Corpus e Inmaculada ${ }^{80}$. Aunque, tal y como reza su título, no se centra

\footnotetext{
${ }^{79}$ Ibídem, pp. 772-3.

80 "Un mundo de ideas se nos descubre. El Sacramento y la Virgen. Hay entre estos dos misterios lazo dogmático y lazo histórico." Arbolí, La Eucaristía y la Inmaculada, p. 72. "Los teólogos de todas las escuelas han encontrado relaciones tan íntimas como dulces y consoladoras. Lo aprendieron de los Padres, quienes no han tenido intérpretes más puros que los teólogos españoles, y andaluces. El caro
} 
en las devociones propiamente hispalense, el protagonismo de la ciudad andaluza en sus páginas es manifiesto. Simón de la Rosa, hombre muy cercano a Arbolí, opinó:

Consultando las fuentes de la bibliografía religiosa española, así antigua como moderna, difícilmente podrá encontrarse en toda ella un libro tan sevillano por los cuatro costados como el que, magistralmente escrito por el Capellán Mayor de San Fernando señor Arbolí, titúlase La Eucaristía y La Inmaculada ${ }^{81}$

El capellán mayor de San Fernando hizo converger las devociones al Corpus y a la Inmaculada en una sola. Ambas comportaban, según su punto de vista, dos manifestaciones de una misma y única forma de piedad, que se expresa en cada una de ellas con un único sentido de lo religioso. En Sevilla, opinaba, esa devoción única se vivía con una especial intensidad, y adquiría unas formas particulares, que se proyectaban como modelo a otras provincias españolas e incluso, a otros lugares como Italia $^{82}$. Al igual que Arbolí, De la Rosa puso de relieve esta relación, y la sintetizó en esta frase: "Son dos devociones distintas y una sola devoción verdadera en los corazones sevillanos." 83

Desde esta premisa, la visión que trasladó Arbolí sobre la historia y el simbolismo de la Inmaculada a sus coetáneos estuvo inseparablemente unida a la del Corpus. Es fácil advertir la cercanía ideológica entre estos dos personajes, compañeros de trabajo en la Biblioteca Colombina, así como en gran medida, entre ellos y Serrano. Los puntos de conexión y coincidencias entre sus narrativas nos parecen evidentes.

En primer lugar, los esfuerzos de todos los estamentos sociales, así como de las instituciones civiles y religiosas, unidas "en fraternal concordia", estuvieron dirigidos, según ellos, a la causa común de rendir culto a la Inmaculada:

Christi, caro María, de San Agustín no encontró mejor expositor, más contundente ni profundo que el eximio Suárez". Ibídem, p. 74. "Síntoma inequívoco de la simultaneidad de ambas devociones en el corazón de los santos, es también la original circunstancia de que el adalid franciscano [Escoto, pionero en la defensa de las tesis inmaculistas] fuese a la par ardientísimo, entusiasta y humilde siervo de la Eucaristía". Ibídem, p. 86.

${ }^{81}$ de la Rosa, Los seises de la catedral, p. 247.

82 "Esta piedad de nuestra Iglesia trascendió, no solamente al resto de la España, sino a Italia, y así pudieron los escritores propalarlo sin que nadie se atreviese a contradecir, porque era asunto indiscutible; y cuanto excedía Sevilla a las demás ciudades en su amor a la Inmaculada, otro tanto plugo al Señor de bendecir sus generosos esfuerzos, concediéndole también, en premio de justicia, la admiración de la posteridad". Ibídem, p. 122.

${ }^{83}$ de la Rosa, Los seises de la catedral, p. 248. 
No sólo el Cabildo hispalense, unido siempre al nobilísimo y piadoso Senado de la Ciudad en fraternal concordia, sino las corporaciones y gremios, y sobre todo las cofradías sacramentales, y al frente de ellas la del Sagrario de la Santa Iglesia, hacían gala de honrar a la Madre de Dios por obligación de instituto. ${ }^{84}$

En segundo lugar, presentaron la segunda mitad del siglo XVI y el siglo XVII como la época dorada de la ciudad, y no por razones de prosperidad económica, o esplendor artístico, sino por la religiosidad que la caracterizó. Producto de esta, surgió lo que Arbolí denominó "escuela religiosa sevillana". La "escuela" pasó a la historia, además de por colaborar determinantemente en el esplendor de una época vista como modelo, por su devoción al Santísimo y la Inmaculada ${ }^{85}$ :

Decíamos más arriba "Escuela religiosa sevillana", y en efecto la hubo, porque no merece otro nombre la reunión de tantos elementos bajo la sabia y santa dirección de varones consumados en la piedad y en las letras. Abraza este período la segunda mitad del siglo XVI y los primeros lustros del XVII, en que brillaban hijos espirituales de tan insignes maestros, movidos del propio resorte, persiguiendo el mismo fin, empleando iguales medios y convidando a que viniesen de lejanas tierras a beber las aguas de la vida que brotaban tan puras y abundantes en este hermoso vergel. [...] ¿no forman una escuela gloriosa? Era el alma de este centro la devoción al Santísimo y a la Inmaculada, [...] ¡Gloria inmortal para capitulares y prebendados insignes que han pasado a nuestros anales con la aureola del más encendido amor a la Eucaristía y a la Virgen! ${ }^{86}$

Sin embargo, por encima de esta "escuela" a la que nutrió en gran medida, situó al cabildo catedralicio, la gran institución hispalense del momento, promotor y defensor de estas devociones. De él surgieron las ambiciosas iniciativas en pro de la causa inmaculista ${ }^{87}$ :

${ }^{84}$ Arbolí, La Eucaristía y la Inmaculada, p. 124.

${ }^{85}$ Entre los miembros más ilustres cuenta a los canónigos y racioneros Hernando de Mata, Alonso Gómez, Alonso de Villafañe, Diego Herber de Medrano, Bernardo de Toro, Mateo Vázquez de Leca, el jesuita Rodrigo Álvarez, el dominico Pablo de Santa María, Francisco de Cervantes o Gaspar Juan de Saavedra Ibídem, pp. 116-117.

${ }^{86}$ Ibídem, pp. 115-118.

${ }^{87}$ Respecto al Corpus señala: "Fomentaba esta devoción aquel 'gran príncipe', como le llaman los escritores de entonces, el Cabildo Metropolitano, a quien dedicaban todos sus libros y tratados eucarísticos los ingenios de la época, y de quien se dijo con razón 'no sabía contar lo que libraba en servicio de su Dios Sacramentado', por lo cual el jesuita Agustín de Herrera escribía en su dedicatoria: ¿AA quién más conviene defender lo que toca a la majestad y grandeza de la Mesa celestial del Divino Sacramento de la Eucharistía, que a quien tiene este por singular empleo y blasón de su gloria?' En él 
Hemos nombrado a varios canónigos de Sevilla que fueron agentes de la causa en Roma: pues bien; si estos eran agentes del Cabildo, "el Cabildo era el agente universal de España"; había que contar con los favores y el apoyo y con la piedad y la ternura entrañable de este gran siervo de María, que ni hablaba ni discurría de otra cosa, pareciéndole que agraviaba a su Soberana si pasaba día sin ocuparse en su servicio y obsequio, instando, cual no otro, hasta recabar del Sucesor de Pedro el fallo inapelable, y anticipándolo, digámoslo así, con sus votos, -con sus fiestas, con su propaganda y hasta con sus sacrificios.

Bendigamos al Señor por haberse dignado hacer con nosotros la gran misericordia de formar parte de tan ilustre Senado, porque sabíamos que formar en él era alistarse de nuevo y con más ardor que nunca en las banderas de la Inmaculada. ${ }^{88}$

La preeminencia y papel destacado jugado por el cabildo catedralicio se extendió también a lo cultural, y dentro de este, a lo musical, según De la Rosa. Este otorgó al cabildo catedralicio el mérito de haber generado figuras como las que a continuación menciona y creado las condiciones, a través de la formación, para el florecimiento musical que experimentó la ciudad renacentista:

$\mathrm{Y}$ al considerar con cuanto vigor renace el arte musical en Sevilla desde los primeros años del siglo XVI y cuanto influyeron nuestros mejores maestros en el marcado movimiento de transformación que se operaba lentamente en Italia, como signo precursor del Renacimiento; será fuerza preguntar: de donde venían aquellas corrientes copiosas y cristalinas de arte que todo lo invadían en nuestra nunca bien ponderada ciudad, y en qué lugar hallábase situado el centro creador de tantos y tan afamados artistas? Nosotros, hablando imparcialmente, no descubrimos por aquel tiempo en Sevilla otra escuela de educación musical, que la academia de los niños cantorcicos fundada por el Cabildo eclesiástico. ${ }^{89}$

La nómina de músicos españoles que contribuyeron a tal engrandecimiento, según De la Rosa, es extensa. El autor cita además de Ramos de Pareja, Victoria, Escobedo, Diego Ortíz o Soto de Langa, otros como Francisco de Bustamante, Francisco Talavera, Pedro de Montoya, Juan Sánchez de Tinco, Diego Vázquez de

resplandecieron, como antorchas luminosísimas, multitud de varones que dieron lustre a la capital andaluza y alcanzaron para ella por sus heroicas virtudes copiosas bendiciones del Señor.” Ibídem, p. 51.

${ }^{88}$ Ibídem, p. 121.

${ }^{89}$ De la Rosa, Los seises de la catedral, pp. 76-77. 
Cuenca, Diego Lorenzo, Tomás Gómez Palencia, Silvio de España o Antonio de Toro ${ }^{90}$. Sin embargo, son los sevillanos Cristóbal de Morales, "el más célebre maestro de Europa entre los antecesores de Palestrina", parafraseando a Barbieri ${ }^{91}$, Pedro Guerrero, y de forma especial, su hermano Francisco, a quienes ensalza entre los españoles ${ }^{92}$ :

Después de Francisco Guerrero no ha tenido la Iglesia de Sevilla otro maestro de su talla. La posteridad le ha hecho justicia considerándolo como una gloria legitima de Sevilla, su ciudad, y de la Iglesia, su patria. Guerrero continuó la historia de aquellos grandes varones eclesiásticos que con los elementos musicales de la cultura antigua formaron a fuerza de siglos un arte nuevo y prepararon el camino a los modernos maestros y compositores. ${ }^{93}$

[...]Francisco Guerrero, como gran figura musical de su tiempo y por el mérito de sus composiciones acogidas con alta estima por todas las Iglesias de España, pareció ser el maestro destinado por la Providencia para orientar a los españoles en el conocimiento del divino arte regenerado. Esta gloria corresponde de derecho a la catedral de Sevilla. ${ }^{94}$

Estas ideas evidencian la influencia en De la Rosa de los postulados del regeneracionismo musical español, que en aquellos momentos, y siguiendo la estela de precedentes como Barbieri o el propio Eslava, estaba empeñado en la recuperación y revalorización de la música renacentista hispana. Guerrero, junto a Morales y Fernández de Castilleja representaron los grandes referentes hispalenses de lo que se denominó "Escuela Andaluza” de polifonía. En aquel momento, el crítico y musicólogo

${ }^{90}$ Ibídem, pp. 75-76.

91 Barbieri es frecuentemente citado y parafraseado por De la Rosa, aunque no cita la o las obras concretas de donde extrae la información. Tan sólo se hace referencia a la publicación del Cancionero de Palacio de 1890. Francisco Asenjo Barbieri, Cancionero musical de los siglos XV y XVI (Madrid: Real Academia de Bellas Artes de San Fernando, 1890). Para Barbieri, Morales representó el paradigma de músico religioso español. Manuel Sancho García, "De Teixidor a Pedrell: Tomás Luis de Victoria en la historiografía musical española del siglo XIX”, Revista de Musicología, XXXV/1 (2012), pp. 443-457.

92 De la Rosa dedica dieciocho páginas -de la setenta y ocho a la noventa y seis- a la biografía de Francisco Guerrero. Otros nombres ilustres aparecen en esta sección del libro aunque en función de aquel, como su antecesor Pedro Fernández de Castilleja, "Maestro de los Maestros de España", o el organista durante su magisterio de capilla, Francisco Peraza. Los seises de la catedral, pp. 68-96. En aquel momento tanto Eslava como Pedrell habían publicado en edición moderna obras de Guerrero: Hilarión Eslava, LSH. 10 vols. (1852-1860), Tomo 1º, Serie 2a (Madrid: Martín Salazar, [s.f.]); Felipe Pedrell, HSMS vol. II. Franciscus Guerrero (Barcelona: Juan Bautista Pujol y Cía., 1896). El segundo de ellos, además, introdujo el tomo dedicado a Guerrero con un amplio estudio sobre el compositor sevillano: Pedrell, "I. Francisco Guerrero", HSMS vol. II. Franciscus Guerrero, pp. III-XXII.

\footnotetext{
93 Ibídem, p. 90.

${ }^{94}$ Ibídem, p. 91.
} 
francés Henry Collet empleó y difundió con particular éxito el concepto de "escuela" como categoría de clasificación y adscripción de los compositores hispánicos ${ }^{95}$. En el capítulo sexto tendremos ocasión de detenernos en todas estas cuestiones.

Este estatus mítico conferido por De la Rosa a Guerrero contrastaba, no obstante, con la total ausencia de su música, a excepción de las pasiones del Martes y Miércoles santos, en el ceremonial catedralicio de principios de siglo, como hemos comprobado $^{96}$. Existe, por tanto, una falta de correspondencia entre la magnitud de la figura y la vigencia de su música. Como constataremos en el capítulo sexto, Guerrero no ostentaba a principios de siglo esa condición referencial para la gran mayoría de la comunidad catedralicia y de la ciudad en general de la que sí disfrutaba Eslava ${ }^{97}$.

Las devociones del Corpus y de la Inmaculada no sólo colaboraron en la configuración de la identidad cultural de la Catedral y la ciudad de Sevilla en general. En el discurso de Arbolí poseen una mayor trascendencia sociológica y política. Ambas figuras religiosas intervinieroen en la construcción del concepto de "nación española"98. Desde unos postulados tradicionalistas, determinados por doctrinas esencialistas y evidentemente confesionales, el canónigo de origen gaditano presentó a España como una nación ahistórica, cuyo rasgo distintivo, y por el que había poseído una cierta supremacía en el concierto internacional, es su particular e ingénito sentido religioso ${ }^{99}$. Según defiendió, el Corpus y la Inmaculada constituían dos grandes pilares de esa religiosidad que ha hecho de la española una nación preeminente, y a su sociedad -

\footnotetext{
${ }^{95}$ Su obra Le mysticisme musical espagnol au XVI siécle (Paris: Felix Alcan, 1913) tuvo una importante repercusión. En la página 245 se puede consultar una tabla con los distintos componentes de las "escuelas musicales españolas en el siglo XVI": Andalucía, Cataluña y Valencia, Castilla y Aragón.

${ }^{96}$ Véase capítulo 3, epígrafe 1.2. “Otras partes litúrgico-musicales del ceremonial”, p. 191.

${ }^{97}$ Véase capítulo 6, epígrafe 2.4. "La confrontación de dos identidades musicales. Francisco Guerrero versus Hilarión Eslava: el estallido de una guerra de símbolos”, p. 565.

${ }^{98}$ Un profundo estudio sobre el concepto, conflictivo, de "nación española" a principios del s. XIX, así como sobre lo problemático de su aplicación a periodos históricos anteriores en: José Álvarez Junco, Mater dolorosa. La idea de España en el siglo XIX (Madrid: Taurus, 2001).

99 “en España el sentido religioso fue, si cabe, mucho más profundo que en el resto de las naciones, y lo fue precisamente por su amor a la Eucaristía." Arbolí, La Eucaristía y la Inmaculada, p. 21. "Simultáneamente con esta tradición general, la española se apoyaba en el doble testimonio de la herencia de los Apóstoles y de la fe de los mártires. Ambas se unían para hacer de esta nación un ejemplar brillantísimo de acendrado amor al Misterio de nuestros altares." Ibídem, p. 28. "España alzóse la primera a protestar contra los agravios inferidos a la Majestad Divina en otras naciones. Nuestros monarcas fueron sus paladines y siervos a los Pontífices llegaban de diario ruegos fervorosos en pro de nuestras solemnidades, para hacer de España un monumento grandioso levantado a la Eucaristía." Ibídem, p. 29.
} 
próspera y armoniosa por su religiosidad y devoción-, cultura -tanto erudita como popular- y clases dirigentes, ejemplo para el mundo en muchos momentos ${ }^{100}$. La relación entre identidad nacional y devoción al Corpus y la Inmaculada, tal y como la planteaba Arbolí, era tan estrecha que "no podía ser español quien no adorase al Santísimo ni cantase a la Inmaculada" ${ }^{\prime 101}$. En este relato, Sevilla fue situada como modelo, vanguardia, y sobre todo, como metonimia de la "nación española", según el concepto de Arbolí. Este discurso ubica al clérigo sevillano en el nacionalismo católico españolista característico de las corrientes tradicionalistas y neocatólicas fraguadas a lo largo del siglo $\mathrm{XIX}^{102}$.

El último punto de coincidencia entre los discursos de De la Rosa y Arbolí está en presentar la magnificencia como atributo predominante de la forma en la que en Sevilla se celebraban esas fiestas, aunque en el caso de la Inmaculada, a diferencia del Corpus, la expresión de grandeza estaba totalmente exenta de elementos populares, y asociada a una solemnidad más oficial ${ }^{103}$. Arbolí se expresó transmitiendo cierta emoción, y cierta nostalgia por una pretérita época de esplendor y devoción:

100 “....] la España eucarística y concepcionista es un hecho tan dominante y tan palmario como los que aducimos en pro de esta solicitud ardorosa en la tierra que nos vio nacer. ¡España del Sacramento! ¡España de la Concepción!” Ibídem, p. 135. "Que celebrásemos la Concepción aun antes que los griegos; que el Doctor de las Españas, S. Isidoro, incluyera en el Breviario esta fiesta que nuestros reyes, a ejemplo de Juan I, la llamaran fiesta de la Casa Real; que se la formara su corte en la cofradía de Concepción instituida por el gran Cisneros; esto, y más todavía, es como nada para lo que hubiera de escribirse si, en vez de ser nuestro objetivo el nexo de ambas devociones, quisiéramos amplificar en orden de sucesos y fechas cuanto concierne a la piedad del pueblo español." Ibídem, p. 137. "Los monarcas de la dinastía austríaca fueron a la par devotísimos de la Eucaristía y de la Concepción. [...] Estos mismos monarcas, inspirándose en la fe católica y en el sentimiento popular, comunicaban a otras el fuego sacro de que se hallaba poseída la nación española.” Ibídem, p. 138.

${ }^{101}$ Ibídem, p. 136.

102 José Luis Abellán encuentra los orígenes ideológicos del neocatolicismo en el Donoso Cortés tradicionalista, y afirma que surgió “con la pretensión de ser el auténtico valedor de los legítimos intereses de la Iglesia". El autor recoge la aclaración propuesta por M $\mathrm{M}^{\mathrm{a}}$ Begoña Urigüen González: "En cuanto a los neos o el neocatolicismo creemos haber aclarado la nebulosa con que ha venido envuelto ese término incluso ante muchos contemporáneos. No se trata meramente del reflejo político del catolicismo ultramontano, sino que es un grupo político concreto, procedente del partido moderado, nutrido de políticos jóvenes y desconocidos, con un buen componente de aristocracia predominantemente del siglo XVIII en el que parece descubrirse una especial presencia de miembros de la Compañía de Jesús"; cit. en José Luis Abellán, Historia crítica del pensamiento español. IV. Liberalismo y Romanticismo (18081874) (Madrid: Espasa-Calpe, 1984), p. 640. Sobre el tradicionalismo en el último cuarto del siglo XIX y principios del s. XX véase: Abellán, Historia crítica del pensamiento español. 5/I. La crisis contemporánea (1875-1936) (Madrid: Espasa-Calpe, 1988), pp. 456-466. La cita de la Dra. Urigüen en Orígen y desarrollo de la derecha española en el siglo XIX. Tesis doctoral inédita, Universidad Complutense (1981), p. 1136.

103 "Período brillantísimo fue aquel, y dejó su estela en la historia para edificación de los venideros. Cabildos, hermandades, próceres, gremios, todos a una empeñáronse con santa porfía por rivalizar en el culto, sobresaliendo Sevilla por haber sido cuna y teatro a la vez de tantos operarios, con cuyos trabajos 
Las hermandades sacramentales de Sevilla, y en particular la citada del Sagrario, se esmeraron luego hasta tal punto en festejar el Patronato de la Inmaculada, que no se puede leer sin lágrimas de ternura el relato de los analistas que nos lo han trasmitido. Fue un incendio de amor, una exuberancia de lujo, un piadoso derroche de magnificencia y de primores de ingenio, como se ve con asombro y edificación. ${ }^{104}$

El relato que estremeció a Arbolí está contenido en un documento escrito por Manuel Antonio Delgado Peres de Cavañas y Sequeiros, y describe las fiestas que se celebraron en Sevilla en 1761 con motivo de la proclamación de la Inmaculada como patrona de España ${ }^{105}$. De ese mismo manuscrito, Arbolí extrajo la siguiente cita, que él mismo amplió, completando y cerrando su alcance: “"el misterio de la Inmaculada Concepción es una de las pupilas de los ojos de esta ciudad.' Podemos completar la idea, diciendo que la otra es el Misterio eucarístico."106

Otro ilustre canónigo coetáneo de Arbolí, Eloy García Vaquero, repitió esta metáfora en los últimos versos de una de sus poesías: "No nos admire, pues, que Ixbilia aclame/Con culto igual al Hijo y a María,/Y que al par Concepción y Eucaristía/Las dos pupilas de sus ojos llame."107

solamente podría tejerse la historia de la grandeza y suntuosidad que por otra parte acreditan nuestras instituciones y nuestros templos. El arte se declaró por la Iglesia, y las catedrales ostentaron riquísimas preseas; y hasta los artistas se hicieron escritores para mejor estudio de sus obras y testimoniar en ellas el pensamiento que les guiaba. Hubo santa emulación entre la mayor parte de las capitales de España; y si puede aseverarse que la pompa y majestad de nuestro culto dio la pauta a las demás naciones." Ibídem, pp. 52-54.

${ }^{104}$ Ibidem, p. 125.

105 Arbolí cita dicho documento como sigue: "M. S. de la Biblioteca Capitular de Sevilla "Reducido compendio de las solemnes fiestas que se han celebrado, en la muy noble y Muy Leal ciudad de Sevilla, en obsequio de María Santísima Señora y madre nuestra, por haber declarado a esta Señora en el terníssimo Misterio de su Concepción por Patrona de España y de las Indias, la santidad de nuestro muy santo Padre Clemente decimotercio, a pedimento de nuestro Cathólico Monarcha Don Carlos tercero Rey de las Españas, y emperador de la América. Escribiólas Manuel Antonio Delgado Peres de Cavañas y Sequeiros; año 1761.” Ibídem, p. 126.

106 Ibídem.

${ }^{107}$ El extracto completo de la oda de García Vaquero: "Y al par los hijos de la fiel Sevilla/La devoción espléndida extremaron/Del altar al augusto Sacramento,/Y en su fe, tan discreta cual sencilla,/La excelsa nota de pureza hallaron/Que en uno y otro dogma revelaba/El profundo divino pensamiento/Que un solo empeño redentor guiaba;/Empeño que restaura y edifica ./Al mundo de pureza en el Misterio,/Y en el común grandioso ministerio/—Que á la creación entera purifica,_/A Madre e Hijo, a quienes firme adora,/Asocia en la misión corredentora;/Que la cristiana mente,/De María en la angélica limpieza/Halla substancia y fuente/De la excelsa eucarística pureza:/No nos admire, pues, que Ixbilia aclame/Con culto igual -al Hijo y á María,/Y que al par Concepción y Eucaristía/Las dos pupilas de sus ojos llame.” Ibídem, p. 185. 
Creemos que esta imagen de "las dos pupilas" sintetiza, en un lenguaje poético, la significación cultural y simbólica que para buena parte del catolicismo local de principios de siglo XX -al igual que para sus antecesores- debió tener el Corpus y la Inmaculada.

Así pues, y en síntesis, los relatos de Arbolí, De la Rosa, Serrano o Gestoso nos ofrecen una imagen del Corpus y de la Inmaculada como grandes acontecimientos festivos, al mismo tiempo, productos y reflejos, en primer lugar, de una sociedad dominada por la piedad y el fervor religioso, y que, sin distinción de clases, profesiones $\mathrm{u}$ otra condición constituyeron una comunidad cohesionada; en segundo lugar, de una cultura en la que lo profano y lo sagrado se confundían, o simplemente eran dos categorías no opuestas o contradictorias; en tercer lugar, de un orden institucional caracterizado por las armónicas relaciones entre los cabildo eclesiásticos y secular, y entre estos y las asociaciones gremiales y el propio pueblo; por último, de una época de paz social, de esplendor y apogeo cultural, que se traducía en la suntuosidad y magnificencia de las formas de celebración, en la que, además, el cabildo catedralicio ejercía un papel de liderazgo. Se trataba, pues, de una imagen idealizada de la sociedad del Antiguo Régimen, que contemplaron con nostalgia y que asumieron como modelo, $\mathrm{y}$, lo que nos parece más importante, como una identidad que preservar.

Las funciones del Corpus y la Inmaculada debieron constituir espacios de comunicación virtual con un pasado idealizado en los que se recuperaba el esplendor perdido, precisamente en una época de franca decadencia. Recordemos el valor que para Serrano tuvieron los cultos celebrados en las dos conmemoraciones concepcionistas decimonónicas como indicadores de la pervivencia de aquella realidad del pasado en la segunda mitad del s. XIX. Los capitulares de principios de siglo XX, entendiéndose a sí mismos como últimos descendientes de una mítica genealogía, debieron concebir y asumir su vocación como los depositarios y custodios de ese patrimonio histórico y simbólico legado por sus mayores.

Volvamos ahora al objeto que constituye el centro de nuestro estudio, el canon musical asociado a los cultos solemnes celebrados en la Catedral durante estas fiestas religiosas a principios del siglo $\mathrm{XX}$, así como al objetivo principal que nos hemos marcado, tratar de interpretar sus posibles funciones simbólicas y de representación identitaria. 


\section{El "canon Eslava"}

Como se desprende de los diversos testimonios que hasta ahora hemos ido ofreciendo, el peso de la obra de Eslava en el repertorio en uso de la catedral de Sevilla a principios de siglo era enorme. En el capítulo primero pudimos proporcionar la información de que en 1905 la CDMS llegó a recomendar para las grandes solemnidades litúrgicas las misas en $l a$ y mi $b$ así como otras obras impresas del navarro $^{108}$. En un acta capitular de febrero de 1909, en plena discusión del plan para la reforma de la música en la Catedral, Modesto Abín nos revelaba que las obras que el canon tradicional catedralicio disponía para las partes del ordinario de la misa en determinadas fiestas de $1^{\mathrm{a}}$ clase $\mathrm{y}$ en todas las de $2^{\mathrm{a}}$ clase eran las misas de canto figurado también de Eslava ${ }^{109}$. A tenor de estos datos, se puede afirmar que en la inmensa mayoría de las misas solemnes del año litúrgico se oía la música compuesta por el otrora maestro de capilla hispalense.

Así ocurría también en las partes del oficio divino de las principales festividades en las que el ceremonial prescribía música figurada. Certificábamos en el capítulo tercero el precepto tradicional hispalense de cantar los salmos de las vísperas solemnes según la música eslaviana en los días del Corpus y de la Inmaculada; así como las lecciones de maitines -las lamentaciones- y el salmo Miserere de los laudes del oficio de Tinieblas ${ }^{110}$. Por tanto, a principios de siglo, en el ritual propio de la catedral de Sevilla, la música de Hilarión Eslava estaba asociada al concepto de solemnidad, o dicho en otros términos, en ese momento el canon musical vinculado a las grandes solemnidades y fiestas catedralicias era el repertorio para ellas compuesta por Eslava. Por estas razones nos referiremos a partir de ahora a este canon como el "canon Eslava". Para responder al interrogante sobre las razones de este éxito planteamos una serie de hipótesis e intentos de explicación. Hemos creído conveniente en este análisis diferenciar entre Eslava como personaje y su música, dos ideas que conviene abordar por separado, pues poseen aspectos particulares en los que profundizar de forma independiente.

\footnotetext{
108 Véase capítulo 1, epígrafe 4.2. "Labor de censura y depuración del repertorio litúrgico-musical diocesano", p. 101.

${ }^{109}$ Véase capítulo 3, epígrafe 4.1. "Misas de canto figurado", p. 208.

${ }^{110}$ Véanse los epígrafes 1. "Reforma de la música en las solemnidades de Semana Santa (1905), y 4.2. "Salmos de vísperas para el Corpus y la Inmaculada".
} 


\subsection{El lenguaje musical de Eslava: un dialecto artístico "moderno"}

\section{transmutado en tradición}

El conjunto de obras de Eslava que se consagró en el ceremonial de las grandes solemnidades catedralicias fueron consideradas en aquellos momentos, y también posteriormente, como casos paradigmáticos de incorporación a la música litúrgica de formas, giros, texturas y otros elementos estilísticos propios de una expresión artística predominante en toda Europa desde la primera mitad del siglo XIX, la ópera belcantista italiana $^{111}$. En virtud del influjo ejercido por esta, la música religiosa del momento terminó categorizándose como teatral, a pesar, obviamente, de no estar asociada a otros aspectos componentes del teatro musical como el libreto -sus temáticas y tramas argumentales tragicómicas- o el elemento escénico.

Moreno Mengíbar ha puesto de manifiesto el impacto social y cultural que, al igual que en el resto del país ${ }^{112}$, tuvo la ópera italiana en la Sevilla del s. XIX ${ }^{113}$. Durante todo el siglo gozó de una posición hegemónica y eclipsó a otras expresiones que tuvieron una presencia en el escenario musical de la ciudad más bien marginal. Los datos que proporciona sobre el número de representaciones anuales de óperas de autores italianos, entre los que destacan Rossini, Donizzeti y un poco después Verdi, son suficientes para hacernos una idea de la magnitud del fenómeno. La primera ópera de Rossini que se escuchó completa en la capital hispalense fue L'Italiana in Algeri,

111 Valgan como ejemplos el fragmento de Joaquín Turina que transcribimos más abajo o las siguientes palabras del propio Ripollés, representativas de un estado de opinión sobre el estilo de Eslava generalizado entre los reformistas. En ellas se advierte, además, una cierta animadversión característica asimismo de sus discursos: "Es aquello [es decir, sus obras no próximas al cecilianismo de su último estilo, según Ripollés] el reinado absoluto y desenfrenado del italianismo, con su obligado cortejo de romanzas y cavatinas, duetos, tercetos y cuartetos, coros del más subido e insustancial ramplonismo, copia y remedo de aquellos inverosímiles y vacíos que se oían a diario en los escenarios de la ópera".

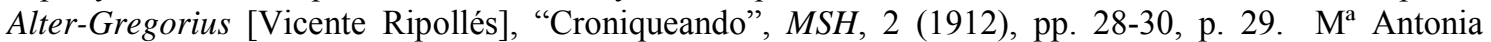
Virgili se refiere la estética de estas obras religiosas de Eslava como representantes de un estilo "teñido de afanes efectistas" y decadente, en el que prolifera el "ornato melódico", "los recursos teatrales, la pobreza creativa". Unos rasgos comunes, por otra parte, en la música religiosa de toda Europa. "La música religiosa en el siglo XIX español”, pp. 383-384. López-Calo encuentra en la ampulosidad, "casi siempre rayana en la exageración", la característica común a todas ellas. "Hilarión Eslava, compositor de música sagrada", pp. 141-142.

112 Emilio Casares sitúa el comienzo de la dominación del italianismo en España con la vuelta de Fernando VII. A partir de ese momento comienza la "época dorada" del "rossinismo", según sus palabras, "una especie de 'huracán’ Rossini”. Señala, además, la fundación del Conservatorio de Música "María Cristina" en Madrid en 1830 como otro factor determinante en la consolidación del monopolio italiano en la España decimonónica, pues, según afirma, se convirtió "en una auténtica cátedra de promoción del canto y la ópera italiana". "La música del siglo XIX español. Conceptos fundamentales", pp. 97-98.

113 Andrés Moreno Mengíbar, La ópera en Sevilla (1731-1992) (Sevilla: Biblioteca de temas sevillanos, 1994). 
estrenada en 1820, y representada otras siete veces más ese año. Su obertura, según Álvarez Cañibano, ya había sonado en el Teatro Cómico dos años antes ${ }^{114}$. Con este estreno arrancó una década que Moreno Mengíbar describe como de furor rossiniano ${ }^{115}$. En 1823 se estrenaron La gazza ladra, La Cenerentolla y Il barbiere di Siviglia, y en 1826, Il Coradino y Torvaldo. En 1827, se pusieron en escena setenta y ocho funciones de trece de sus óperas, mucho más del doble que el año anterior, y dieciséis menos que al año siguiente -cuatro años antes de la llegada de Eslava- ${ }^{116}$. En la década de los treinta, Rossini cedió el paso en las preferencias del público a Bellini y Donizzeti, de cuyas obras se ofrecieron entre esa década y la de los cincuenta, trescientas ochenta y cuatro representaciones y doscientas treinta y cinco, respectivamente ${ }^{117}$. Verdi se hizo presente con fuerza en las programaciones de los teatros desde 1846, convirtiéndose en el autor preferido de los melómanos sevillanos hasta finales de los años sesenta. Entre ambas fechas se contabilizaron ciento cuarenta y dos funciones de sus óperas ${ }^{118}$.

La alta demanda de ópera italiana, que en términos económicos se traducía en un importante filón de negocio, hizo proliferar un considerable número de teatros, entre los que cabe destacar el Teatro Principal o el Teatro San Fernando ${ }^{119}$. Este último contaba, además, con un café, el Café de los Lombardos, y un Casino, que lo convertían

\footnotetext{
${ }^{114}$ M Salud Álvarez Martínez y Antonio Álvarez Cañibano, "Sevilla”, DMEH, 10 vols, ed. por Emilio Casares (Madrid: SGAE, 2002), vol. 9, pp. 968-987, p. 985.

${ }^{115}$ El uso de este tipo de calificativos para ilustrar la potencia de la penetración de Rossini en España se repite con frecuencia en los críticos de la época. Peña y Goñi alude a "La avalancha rossiniana", Mesonero Romanos y Bretón de los Herreros a "aluvión rossiniano" y "furor filarmónico"; cit. en Casares, "La música del siglo XIX español. Conceptos fundamentales”, p. 97, y Antonio Álvarez Cañibano, "Teatros y música escénica. Del Antiguo Régimen al estado burgués", en La música española en el siglo XIX. ed. por Emilio Casares y Celsa Alonso (Oviedo: Universidad de Oviedo, 1995), pp. 123158 , p. 154.

116 Andrés Moreno Mengíbar, La ópera en Sevilla (1731-1992) (Sevilla: Biblioteca de temas sevillanos, 1994), p. 48.

${ }^{117}$ Una sintética panorámica de España durante el reinado de Felipe VII en: Álvarez Cañibano, “Teatros y música escénica”, pp. 153-156.

${ }^{118}$ Moreno Mengíbar, La ópera en Sevilla, pp. 45-78.

119 Un total de doce: Teatro Principal (1795), Teatro de la Misericordia (1838), Teatro Filarmónico (1836), Teatro Vista Alegre (1840), Teatro de la Campana (1841), Teatro Guadalquivir (1844), Teatro de Hércules (1846), Anfiteatro (1846), Teatro San Fernando(1847), Teatro del Duque (1867)Teatro Cervantes (1872), Teatro Eslava (1872). Entre paréntesis el año de inauguración. Ibídem, pp. 43-78. Algunos de los empresarios de estos teatros llegaron a contar con ayuda municipal en momentos difíciles para sostener el negocio. Entre los años 1829 y 1832 la empresa del Teatro Principal se benefició de ayudas públicas que ascendieron a un total de 228.739 reales, lo que da una idea de la importancia económica y socio-cultural que poseía también a los ojos del consistorio hispalense. Ibídem, p. 49.
} 
en un centro, no sólo cultural, sino también de esparcimiento, relación social, intercambios comerciales y exhibición de ostentación. La asistencia a la ópera era un ritual que formaba parte de los usos propios de la burguesía local, y tenía, por ello, una función de definición y representación social ${ }^{120}$.

En realidad, la ópera italiana representó un fenómeno internacional, que formó parte de la cultura europea de entonces, y que se concibió como una "manifestación teatral renovadora" y avanzada desde finales del s. XVIII; un signo de modernidad, en contraste con la decadencia del teatro español ${ }^{121}$.

Hasta ahora sólo tenemos noticias de algunas iniciativas privadas que se inscriben en la tendencia, creciente hacia el último cuarto de siglo, del asociacionismo propio del liberalismo burgués, y que constituyeron el contrapunto a este predominio de la ópera italiana en los últimos años de la centuria. En 1872 se fundó la Sociedad de Conciertos, la primera en especializarse en el repertorio sinfónico en Sevilla, cuyo objetivo era "dar a conocer a los asociados las más importantes sinfonías de Haydn, Mozart, Beethoven, Mendelsohnn, Weber y otros"122. Ese mismo año ofreció su primer concierto, dedicado a los repertorios de cámara clásicos y románticos, la Sociedad de Cuartetos fundada por el ilustre violinista local Antonio Palatín ${ }^{123}$. La sección de música de la institución que poco después estaría llamada a liderar la regeneración cultural de la ciudad, el Ateneo, no fue creada hasta 1901. Los programas de los conciertos que organizó durante su primera década de existencia respondieron al modelo de finales del s. XIX. En ellos convivieron la música de cámara y para piano romántica europea o de músicos locales- con las reducciones de ópera, sobre todo italiana $^{124}$.

En octubre de 1910, Joaquín Turina escribió un artículo en $M S H$ en el que aportaba interesantes apuntes acerca de la historia de la música en la catedral de Sevilla durante el periodo en el que estuvieron ocupando el cargo de maestro de capilla Eslava,

\footnotetext{
${ }^{120}$ Ibídem, p. 66.

${ }^{121}$ Álvarez Cañibano, “Teatros y música escénica”, pp. 124-125.

122 Alvarez Cañibano, "Sevilla", p. 986. Sobre la Sociedad de Conciertos sevillana, véase, además: Andrés Vallés Chordá, Música en Sevilla en el siglo XIX (Sevilla: ICAS. Ayuntamiento de Sevilla, 2010), pp. 167-180.

123 Alvarez Cañibano, “Sevilla”, p. 986.

${ }^{124}$ Véase: Pedro José Sánchez Gómez, La música y el Ateneo de Sevilla (1887-2003) (Sevilla: Ateneo de Sevilla, 2004), pp. 43-58.
} 
García Torres, y Ripollés (1832-1909). Se trata de un testimonio especialmente valioso, pues ubicaba a la Catedral en el contexto de la situación de la música en la Sevilla de la segunda mitad del s. XIX y principios del XX. Lógicamente, dedicaba una buena parte de su atención al fenómeno Eslava. Así justificaba el "amor a Eslava" de los "sevillanos":

Ante todo, disculpemos a los sevillanos por su amor a Eslava, y he aquí por qué. Un sevillano de la época de Don Hilarión (y aún de esta), dotado de la mejor voluntad, no podía oír en todo el año más música que unas cuantas representaciones de ópera, cuyo repertorio lo formaban Rossini, Bellini, Donizetti y Verdi en sus primeras obras, y como el Miserere de Eslava no era más que una continuación de esto, una ópera más, con todo el carácter groseramente dramático de aquellas y en el que no faltaba ni la cavatina al estilo de Lucía, ni el coro estilo Hernani, ni siquiera un bailable, lógicamente el gusto de aquellas obras debía traer el de esta, a lo que se añadía formar un orquestón tan heterogéneo y desequilibrado como el de la ópera, un coro mayor aún y más desafinado, y por último, interpretado por artistas también de la ópera, acostumbrados a los grandes gestos, a los efectazos baratos, a los calderones y gritos de pésimo gusto. ${ }^{125}$

La hegemonía del gusto por la música religiosa italianizante de Eslava era absoluta, y no existía corriente crítica que cuestionara esta realidad. Ni siquiera "las autoridades en la materia" o la crítica, quienes "lejos de combatir esto, lo ensalzaban, y ya de palabra o en artículos, sostenían que el Miserere era una obra genial, más sentida que pensada [énfasis original]". El reproche de Turina a compositores y músicos culminaba con la crítica que seguramente hubiera deseado en ellos: “¡Dios mío! ¿Dónde está el sentimiento en aquella serie de melodías vulgares? De una banalidad exasperante? Sin duda confundían puerilmente el sentimiento verdad[ero] con los gemidos cursis de algún tenor a la moda."126

\footnotetext{
${ }^{125}$ Joaquín Turina, "Crónicas sevillanas. Tres maestros de capilla: Eslava, García Torres y Ripollés", MSH, 18 (1910), p. 206. Turina se refiere únicamente al Miserere por la siguiente razón: "Al hablar de Eslava, sólo he tratado aquí de su Miserere, puesto que sus demás obras son casi desconocidas del público de Sevilla, y sólo a causa de él, se rompen lanzas y las discusiones son infinitas". Como hemos comprobado durante el proceso de reformas en la Catedral, esto no ocurría intramuros del templo metropolitano. Sin duda, el Miserere representó un caso excepcional, aunque la resistencia de los capitulares ante las modificaciones del repertorio musical catedralicio se produjo igualmente en el caso de las otras obras que conformaban el canon Eslava.

${ }^{126}$ Ibídem.
} 
El estilo religioso italianizante de filiación eslaviana fue perpetuado por su sucesor en el magisterio de capilla hispalense, Evaristo García Torres, cuyo talento era superior al de Eslava, según su opinión ${ }^{127}$ :

La mayor víctima de Eslava ha sido su sucesor en la Catedral don Evaristo García Torres. [...] don Evaristo eran un gran admirador de Eslava [...] Comparaba su melodía sencilla, inspirada algo a lo Bellini, pero siempre distinguida, con la melodía eslavista, seca, doctrinal, y casi siempre vulgarota; comparaba su factura, mucho más pura y equilibrada que la otra, deshojada de toda forma de toda construcción, y por último, su orquesta, en la que buscaba instintivamente el color, de lo que no se preocupaba nada su antecesor.

Don Evaristo era muy querido de los sevillanos, que escuchaban con gusto sus misas y sus bailes de seises, [...] nunca pudo oír sus obras con mediana orquesta ni con un coro de cien voces, ni muchísimo menos cantadas con artistas de la ópera, [...] quizás seré yo el único sevillano capaz de gritar muy alto: "don Evaristo García Torres, como compositor, como autor de mil deliciosas melodías, como cultura musical y como orquestador era cien veces superior a su antecesor don Hilarión Eslava" [...]. El que conozca sus alabados verá que, en medio de sus fórmulas eslavistas, hay verdaderas perlas en detalles de orquesta, de harmonia, y sobre todo, de sentimiento melódico. $^{128}$

En el momento de la promulgación del $M P$ la situación permanecía igual. La propuesta wagneriana, una expresión de modernidad en toda Europa, no había tenido apenas incidencia, desvirtuada, además, en su escenificación en Sevilla por la falta de $\operatorname{medios}^{129}$ :

Al morir García Torres [1902] Sevilla no había cambiado en nada en cuestiones musicales. Se habían estrenado el Lohengrin y el Tannhäuser de Wagner con muy poca ropa, es decir, con infinitos cortes, la mitad de orquesta de lo que hacía falta y casi sin ensayar, por lo que creo inútil hacer comentarios; La Bohéme y Tosca

\footnotetext{
${ }^{127}$ Sobre Evaristo García Torres, véase: Virginia Borrero Gaviño y Manuel Martín Riego, "Don Evaristo García Torres, maestro de capilla de la catedral de Sevilla (1864-1902)", Memoria ecclesiae (Actas del XXI Congreso de la Asociación de archiveros de la Iglesia en España), 31 (2008), ed. por Agustín Hevia Ballina, pp. 697-712; Mauricio Carrillo Cabeza, "Evaristo García Torres. Oposición al Magisterio de Capilla de la Catedral de Sevilla, 1864: una aproximación estilística a través de sus misas", Anuario de Historia de la Iglesia andaluza, IV (2011), pp. 273-300.

${ }^{128}$ Ibídem.

129 El estreno de Lohengrin, la primera obra de Wagner interpretada en Sevilla, tuvo lugar en 1892. Moreno Mengíbar, La ópera en Sevilla, p. 111.
} 
siguieron con éxito y no creo que con esto se haya elevado el nivel musical. Werther, de Massenet, fracasó. Algunos virtuosos han pasado, Saüer y Sarasate entre ellos, con un programa uniforme y nada educativo, y las opiniones sobre música son a veces tristemente pintorescas; hay quien dice que entre Rossini y Wagner se queda con Meyerbeer; hay quien rompe lanzas por el señor Tripton, y sobre todo, hay quien de música sinfónica no conoce casi nada; verdad es que esto se encuentra a veces en París.

Estando así las cosas, aparece el motu proprio y entra en Sevilla el señor Ripollés $[\ldots]^{130}$

El testimonio de Turina indica que las mismas formas y expresiones musicales propias del teatro musical italiano que determinaron el estilo de las obras eslavianas consagradas en el ceremonial hispalense conformaron durante décadas de incisiva influencia el gusto musical de la sociedad local. Al igual que en el resto de Europa, la ópera italiana en Sevilla constituyó un signo de época, un componente característico y destacado de la cultura del XIX, a la que contribuyó a definir; una expresión artística, además, colmada de significación sociológica; en suma, una manifestación de modernidad decimonónica, al mismo tiempo producto y reflejo de la situación social y cultural de dicha centuria.

A principios de siglo, los fieles que asistían a las grandes solemnidades litúrgicas catedralicias en los albores del siglo XX encontraban en el eslaviano un lenguaje musical familiar, propio de su época, comprensible, y afín a su sensibilidad. Se trataba de un arte contemplado como de extracción culta aunque extendido, convencionalizado, accesible y popular(izado). Creemos que el "canon Eslava" cumplía así con las condiciones necesarias para que una expresión musical ejerciera una función, además de propiamente litúrgica, comunicativa y representativa.

El lenguaje eslaviano, al integrarse como un elemento más en aquellos cultos en los que la institución desplegaba todo su poder de autorrepresentación mediante el aparato y la ostentación, debió asumir, al igual que el resto de los aspectos del ritual, la función de comunicar y representar la solemnidad propia de las fiestas catedralicias. Y ello, aunque parezca una contradicción, a pesar de que los recursos musicales con que se interpretaban las obras de Eslava no fueran precisamente abundantes, tal y como testimonia el propio Turina: "En las grandes solemnidades es de rigor reemplazar el

${ }^{130}$ Ibídem. 
instrumento litúrgico [órgano] por una orquestilla de catorce o quince músicos y unos cuantos cantores."

Las propiedades semánticas y representativas que para los eclesiásticos y fieles sevillanos debió haber asumido el dialecto artístico eslaviano estaban ausentes en los modelos propuestos por el $M P$ como alternativa, la polifonía clásica -y dentro de esta de la obra del propio Guerrero- y la música religiosa moderna inspirada en ella ${ }^{132}$. El siguiente fragmento, publicado en El pensamiento navarro por un sacerdote pamplonés bajo la firma de Sr. Miravalles y recogido por Otaño en $M S H$, describe las cualidades que en esos momentos atesoraba la música de Eslava como canon para las grandes solemnidades. Demuestra, además, que esta asociación entre lenguaje eslaviano e idea de grandeza no se daba sólo en Sevilla, sino que estaba bastante extendida:

3." "La música de Eslava se canta en las grandes solemnidades. Nadie ha sabido dar una idea de la grandeza de Dios y coadyuvar a la solemnidad de una función religiosa por medio de la música que en ella se cante, como Eslava. Las misas de Eslava oídas en un amplio templo lleno de fieles, dan una gran idea de la grandeza de Dios de las alturas, mejor que todas las partituras que escribió Palestrina. Las lamentaciones son unas páginas musicales de fama mundial"133

La función que terminó adquiriendo el "canon Eslava”, expresión musical litúrgica sucedánea de los estilos teatrales italianizantes de la primera mitad del XIX, nos revela una interesante metamorfosis: la transformación de una "música moderna" de moda, signo de época- en tradición. Como mostramos en el capítulo tercero, durante

\footnotetext{
131 Turina, “Crónicas sevillanas", pp. 205-206.

${ }^{132}$ La cuestión de la fuerza expresiva o su carencia de la música renacentista recuperada por los reformistas y regeneracionistas durante la segunda mitad del s. XIX constituyó uno de los puntos más controvertidos de los debates entre estos y los partidarios de conservar las expresiones musicales religiosas de corte dramático. Véase al respecto: Nagore, “Tradición y renovación”, pp. 224-228. Sobre este tema volveremos en el capítulo sexto.

${ }^{133}$ Cecilio [Nemesio Otaño], "Eslava. En defensa de D. Gregorio", MSH, 10 (1910), p.91. Otaño recogió este fragmento junto a otros para refutarlos, en el marco de una campaña antieslavista que emprendió en finales de 1909 precisamente iniciando una polémica con este sacerdote navarro. Por otro lado, resulta ciertamente llamativo el empleo por parte del anónimo autor de un artículo titulado "La música polifónica" y publicado en La Música Religiosa en España de términos parecidos para referirse al efecto que producía, en esta ocasión, la Misa Papa Marcello de Palestrina. Su objetivo fue defender la expresividad de la polifonía clásica, es decir, representaba la parte opuesta al Sr. Miravalles: "Una misa a grade orquesta no ha ejercido jamás en el auditorio una acción comparable a la Misa del Papa Marcelo, glorificada por tres siglos de admiración”. El artículo fue publicado en el número de febrero de 1896, y lo cita María Nagore, quien apunta la posibilidad de que fuera escrito por Pedrell, en "Tradición y renovación", p. 226.
} 
el proceso de reformas en la Catedral, las apelaciones a la condición de tradición de las obras eslavianas que se pretendían descartar fueron numerosas. La tradición ejercía una función de transmisión en el tiempo y en las distintas situaciones históricas de unos valores asentados como principios, es decir, aseguraba la pervivencia de una identidad. El "canon Eslava", en lo externo expresión moderna, debió servir de vehículo ideal en la contemporaneidad para cumplir ese papel conservador propio de la tradición.

\subsection{El mito de Eslava}

A la consolidación del "canon Eslava" como el canon oficial solemne de la Catedral debió contribuir la condición mítica que alcanzó la figura de Eslava. Durante el episodio de 1905 en el que se planteó la incompatibilidad y posible supresión del Miserere pudimos comprobar hasta qué punto estaba arraigada y latente en la conciencia de los principales responsables diocesanos la imagen de Eslava como personaje de considerable importancia en la historia reciente de la música española. La CDMS se refirió a él como "el con justicia llamado patriarca de la moderna música religiosa española, D. Hilarión Eslava" ${ }^{\text {134 }}$. Spínola se refería a él en parecidos términos: “el insigne maestro que, con razón, es considerado entre los famosos como un padre y un icono de la instauración de la música sacra en España"135. Por su parte, De la Rosa, tras haber repasado las biografías de los maestros de capilla hispalenses desde el siglo XVIII, se preguntaba retóricamente al llegarle el turno a Eslava: “¿Y qué diremos de D. Hilarión Eslava, nacido el 21 de octubre de 1807 en Burlada, pequeña aldea de Navarra inmediata a Pamplona, no para ser gloria de su pequeño país natal, o de su provincia, o de Sevilla, sino de España entera?" "136. En la imagen que De la Rosa trasladó de Eslava incidía en su rol de guía no sólo del "arte español”, sino también del "extranjero, que andaban desorientados [...]", a propósito de la "revista" -término usado por De la Rosa, Lira Sacro Hispana-. Con ello, otorgaba a su relevancia una dimensión

\footnotetext{
${ }^{134}$ Marcelo, Arzobispo de Sevilla, "Sobre música sagrada” BOAS, 560 (1905), p. 95.

135،insignem Magistrum, qui jure optimo apud gnaros habetur velut parens ac signifer instaurationis musicae sacrae nostra in Hispania [...]". ASV, Segretaria di Stato, anno 1905, rubrica 283, fascicolo 2, fols. $46 \mathrm{v}-47 \mathrm{r}$.

${ }^{136}$ De la Rosa, Los seises de la catedral, pp. 330-331.
} 
internacional, que reforzó con citas en las que daba cuenta del reconocimiento del que llegó a disfrutar de figuras como el "gran Rossini"137.

En cuanto compositor religioso, que es como nos toca estudiarlo, su continua labor no pudo ser más meritoria. Publicando en su revista La Lira Sacro Hispana la colección de composiciones pertenecientes a los maestros de los siglos XVI y XVII, señaló nuevo rumbo al arte español y aun al extranjero, que andaban desorientados desde la aparición de la orquesta moderna; porque los compositores se desentendían de la idea, que es lo más esencial en música, y atronaban los templos a fuerza de instrumental para esconder la falta de inspiración bajo la forma sonora y brillante. Ha cultivado como nadie todos los géneros a la vez, y en este concepto no se le conoce competidor, no porque así lo hayan confesado los españoles sino los extranjeros, como lo confesó el gran Rossini, para quien nadie como Eslava sabía escribir las voces en música, ni en Francia ni en Alemania, a partir del gran Cherubini.

[...][Sus obras conservadas en el archivo catedralicio hispalense] bastan para demostrar que la cultura musical española en el género religioso puede competir a veces con la cultura extranjera. ${ }^{138}$

En realidad, como es sabido, la consideración de Eslava como gran figura y referente de la música religiosa española estaba extendida por todo el país desde hacía tiempo ${ }^{139}$. En el capítulo sexto tendremos ocasión de comprobar hasta qué punto el navarro adquirió la condición de símbolo y emblema de aquellas tendencias que se

${ }^{137}$ José Luis Ansorena refiere sendas opiniones sobre Eslava, vertida una en la francesa Revue de musique ancienne et moderne, 8 (1856), y expresada otra por el fundador de la Capilla Musical de San Pedro de Lovaina, Vaullewyck en algún momento del siglo XIX que no precisa Ansorena. La primera la presenta como "el hombre providencial que necesitaba la música en España. La segunda señala: "Don Hilarión no sólo era la mayor gloria musical de su patria, sino Europa le ha proclamado como uno de los maestros más distinguidos de su siglo". "Biografía de Don Hilarión", pp. 4-5.

${ }^{138}$ De la Rosa, Los seises de la catedral, pp. 331-332.

139 Véanse los distintos estudios publicados en la Monografía de Hilarión Eslava, ed. por equipo Musikaste-Eresbil (Pamplona, Diputación Foral de Navarra, 1978), hasta el momento la obra dedicada al músico de Burlada más completa, a pesar de las tres décadas y media transcurridas desde su aparición. En ellos se refleja el impacto que tuvieron sus obras pedagógicas, la difusión de su música religiosa, la importancia de su labor musicológica, o la dimensión que adquirieron los debates y polémicas en las que tomó parte. En la introducción a su "Biografía de D. Hilarión Eslava", José Luis Ansorena refiere el significativo dato de que, aún en vida, fueron publicadas cuatro relaciones biográficas sobre el navarro: uno por entregas en la revista editada en Sevilla Orfeo Andaluz (1843), el artículo de José Parada y Barreto en su Diccionario técnico, histórico y biográfico de la Música (1868), los siete artículos de José María Esperanza y Sola reunidos en Treinta años de crítica musical, y el capítulo que le dedicó Antonio Peña y Goñi en su obra La ópera española y la música dramática en España en el siglo XIX (1881). Este último publicado tres años después de la muerte de Eslava. Antonio Martín Moreno, aludiendo a su enorme capacidad de influencia se refiere al que fuera maestro director de la Real Capilla como "el todopoderoso Eslava". Antonio Martín Moreno, "Felip Pedrell y el descubrimiento del teatro barroco español”, Recerca musicològica, 11-12 (1991-1992), pp. 111-131, p. 115. 
oponían en toda España a los planteamientos de los reformadores españoles tras la celebración del II Congreso Nacional de Música Sagrada (Sevilla, 1908).

La veneración que entonces profesaban a Eslava las autoridades eclesiásticas hispalenses era tal que, como vimos en el capítulo tercero, tanto la CDMS como Spínola esgrimieron ante la Santa Sede el carácter de homenaje que tenía el acto como una de las razones para conseguir el privilegio de conservar la costumbre del Miserere. Un acto que, en sentido estricto, constituía una parte del oficio de las horas, una función litúrgica que bajo ningún concepto se podría concebir como homenaje o "testimonio de admiración" a un músico. Así se pronunciaba la CDMS:

[...] sin embargo, atendida la índole especial de las solemnidades de la Semana Santa en la Iglesia de Sevilla, teniendo en cuenta que el canto del salmo Miserere puede considerarse como homenaje de veneración, respeto y honor del pueblo hispalense a su antiguo maestro, el con justicia llamado patriarca de la moderna música religiosa española, D. Hilarión Eslava, y en previsión de los sucesos desagradables que indudablemente ocasionaría la supresión de una obra en tanta estima tenida por el pueblo fiel hispalense, y a la que concurre el Cabildo municipal con subvenciones que se hacen extensivas a la colocación y ornato del Monumento, podría intentarse un permiso especial de la Santa Sede[... $]^{140}$

Y Spínola:

$3^{\circ}$ El Ayuntamiento hispalense quien con sus propios ingresos ha acostumbrado a pagar todos los gastos no sólo para el esplendor de la fiestas de la Semana Santa, cuya grandiosidad goza de fama universal, sino también incluso como testimonio de admiración y de estima del pueblo hispalense para con el genial maestro que, con razón, es considerado entre los famosos como un padre y un icono de la instauración de la música sacra en España. ${ }^{141}$

En la consolidación del mito sevillano de Eslava, el fenómeno del Miserere jugó un importante papel -y viceversa-. El compositor de Burlada llegó a merecer el calificativo de "inmortal", especialmente frecuente en documentos de cualquier tipo

\footnotetext{
${ }^{140}$ Marcelo, “Sobre música sagrada”, BOAS, 560 (1905), p. 95.

$1413^{\text {a }}$. Concursus Hispalensis Senatus, qui ex proprio fisco expensas omnes solvere consuescit tum ad splendorem festivitatum Majoris Hebdomadae, quarum magnificentia universali gaudet fama, tum etiam in testimonium admirationis et amoris populi hispalen. erga insignem Magistrum, qui jure optimo apud gnaros habetur velut parens ac signifer instaurationis musicae sacrae nostra in Hispania: ASV, Segretaria di Stato, anno 1905, rubrica 283, fascicolo 2, fols. 46v-47r.
} 
relacionados de una u otra forma con dicho fenómeno. Tales son los casos de las siguientes actas capitulares, notas de prensa o el propio libro de De la Rosa.

En el siguiente registro capitular se daba cuenta al Cabildo de la anual petición del Ayuntamiento para la celebración del evento en la Catedral:

Se dio así mismo lectura a una comunicación del Sr. AlcaldePresidente del Exmo. Ayuntamiento pidiendo la venia del Cabildo para que pueda cantarse en las noches del Miércoles y Jueves de la Semana Santa el Miserere del inmortal Eslava, como se ha hecho en los años anteriores $[\ldots]^{142}$

En este otro figura la comunicación que trasladó el chantre al cabildo en 1905 sobre la solicitud de Spínola a la Santa Sede. En ella se refirió a Eslava como "inmortal compositor de la ciudad":

S. E. manifestó haber pedido a Su Santidad que no obstante lo dispuesto en su Motu proprio sobre música sagrada se dignase hacer una excepción en favor del Miserere de Eslava que se canta en esta Santa Iglesia, alegando los graves inconvenientes que podrían seguirse de suprimirlo, dado el empeño que muestra en oír esta obra del inmortal compositor la ciudad de Sevilla representada por el Municipio que todos los años se dirige al Cabildo haciéndole la misma petición y ofreciéndose a costear los gastos $[\ldots]^{143}$

Los siguientes extractos pertenecen a dos reseñas publicadas en El Noticiero Sevillano, una sobre el ensayo general abierto que tradicionalmente se celebraba el Martes santo; y la otra sobre la llegada a la ciudad del afamado tenor Francisco Viñas: "Con la solemnidad de costumbre se ha celebrado esta tarde en la parroquia del Salvador el ensayo del 'Miserere' del inmortal Eslava, que será cantado en la Catedral en las noches del miércoles y jueves santos." "44; "Hay gran entusiasmo por escuchar al tenor Viñas, que interpreta admirablemente la obra del inmortal Eslava."145

En la relación de los maestros de capilla al servicio de la seo hispalense durante los siglos XVIII y XIX presentada por De la Rosa, sólo a Eslava le concedió el apelativo de "inmortal":

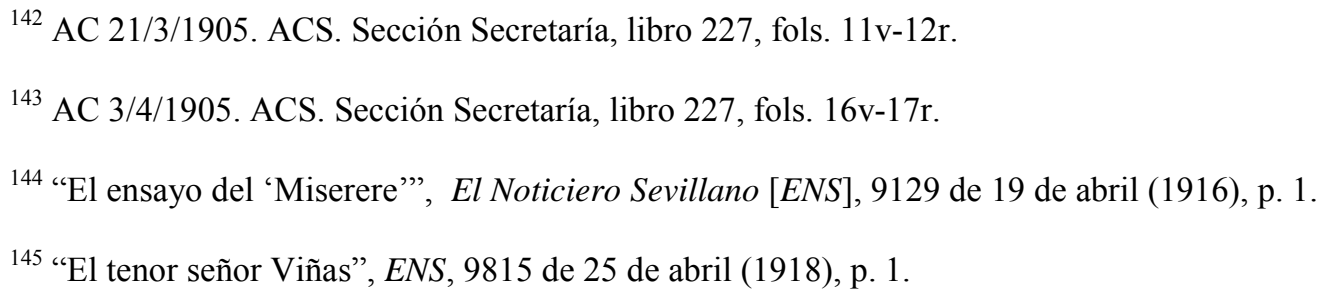


A Diego José de Salazar sucedieron, por el mismo orden que se indica, D. Gaspar de Úbeda y Castelay, oriundo de la Santa Iglesia de Cádiz (8 de Abril de 1710 a 26 de Febrero de 1724), D. Pedro Rabassa (9 de Junio de 1724 a 12 de Diciembre de 1767), D. Antonio Ripa (22 de Junio de 1768 a 3 de Noviembre de 1795), D. Domingo Arquimbau (6 de Noviembre de 1795 a 26 de Enero de 1829), D. Francisco Javier Andreví (1829 a 1830), el inmortal D. Hilarión Eslava (1832 a 1847), el maestro interino D. Ambrosio Sanchís, prebendado contralto que se jubiló sin haber ascendido a órdenes mayores, el seglar D. Joaquín Díaz, que había sido seise en esta Santa Iglesia, el presbítero catalán D. Ramón Miret, (estos dos últimos en el concepto de maestros de seises), y D. Evaristo García de Torres, fallecido al finalizar el año últimamente pasado, (20 de Julio de 1864 a 18 de Diciembre de 1902). ${ }^{146}$

En realidad, De la Rosa otorgó en su libro esta condición sólo a dos personajes, Eslava y Cristóbal Colón, además de a los dos grandes oratorios de Haydn, La Creación y Las estaciones. Ni siquiera Guerrero o Morales, tan ensalzados por el historiador, la merecieron $^{147}$.

Algunas inexactitudes a la hora de detallar el currículum de Eslava ponen en evidencia su pretensión, asumida a priori, de presentar una imagen impoluta del navarro, salvaguardándola de cualquier tacha que pudiera afectarle. Así, afirma: "en 1829 y 1830 fue propuesto por el jurado calificador en primer lugar para los magisterios de Sevilla y de la Capilla Real de Madrid respectivamente, por haber vencido en los ejercicios de oposición a sus contrincantes" ${ }^{\prime 48}$. Sin embargo, Eslava quedó en ambos casos en segundo lugar, tras Francisco Andreví ${ }^{149}$. De la Rosa explicó el hecho de que

\footnotetext{
${ }^{146}$ De la Rosa, Los seises de la catedral, p. 328.

${ }^{147}$ De la Rosa, Los seises de la catedral, pp. 14 y 167. De la Rosa, emplea el calificativo "inmortal" sólo en una ocasión más, para referirse, no a un personaje, sino a un documento de gran valor histórico y jurídico como es el Código de las Siete Partidas: "El inmortal Código de Partidas probablemente se redactó en el Alcázar antiguo de Sevilla, edificio situado junto al solar donde luego se fabricó el Alcázar de D. Pedro, según se declara en la Historia de este mismo rey, compuesta por el obispo don Juan de Castro, escritor contemporáneo del monarca;" Ibídem, p. 11.

${ }^{148}$ Ibídem, p. 331.

149 Tanto José Luis Ansorena como José Enrique Ayarra citan en sus trabajos el fallo del tribunal de la oposición al magisterio de capilla hispalense que testimonia que fue Andreví el elegido por el Cabildo en primer lugar, seguido de Eslava. Véanse: Ansorena, "Biografía de D. Hilarión Eslava", p. 40. Ayarra, Hilarion Eslava, p. 38. Respecto a las oposiciones al magisterio de la Real Capilla, ambos autores coinciden en que Eslava resultó clasificado en segundo lugar. Ayarra, Hilarión Eslava, p. 39; Ansorena, "Biografía de D. Hilarión Eslava", p. 43.
} 
fuera nombrado este último, y no Eslava sugiriendo: "quizás por falta de edad, recayeron los nombramientos en el maestro Andrevi."

El navarro -"inmortal" "patriarca", "padre" e "icono" de la moderna música religiosa española", el que "señaló nuevo rumbo al arte español y aun al extranjero"cumplía con la condición de la preeminencia, teniendo así el camino allanado para su elevación a la categoría de icono en una institución que había configurado su propia identidad en base a la interiorización de esta cualidad como rasgo característico.

En los relatos de De la Rosa o Arbolí sobre el pasado de la catedral de Sevilla y los distintos episodios experimentados a lo largo de su existencia, se exalta el, según ellos, modélico papel histórico ejercido por la sociedad e/o Iglesia sevillanas presentadas ambas como una comunidad histórica unitaria e inseparable- en la construcción de la "nación española" y propagación del cristianismo. Acudir a citas de célebres autores pretéritos, como estas de Alfonso Álvarez de Villasandino (c. 13401424) o Rodrigo Caro (1573-1647), es un procedimiento frecuente para ilustrar y ayudar a sostener sus argumentaciones en torno a la histórica importancia de Sevilla ${ }^{151}$ :

Para los que conocen a fondo los fastos y anales de Sevilla y la significación histórica de su Iglesia en la gloriosa propagación del cristianismo, resolver la cuestión sobre el origen remoto de esta tierna ceremonia [de los seises], es cosa de poca monta. [...]

Por algo un poeta del siglo XV, el trovador Alfonso Álvarez de Villa Sandino, de las cortes de D. Enrique III y de don Juan II, en una de sus célebres cantigas, encomiaba a Sevilla diciéndole: De grant tempo fasta agora/Muchas gentes por fazaña/Vos alaban por señora/De las ciudades de España.

Y el inspirado cantor de las ruinas de Itálica, en una silva muy conocida, la saludaba entusiasmado de esta manera: Salve, ciudad ilustre, honor de España,/Que entre todas al cielo te levantas/Como el ciprés entre menudas plantas/Reina del mar, eternamente salve,/Salve primera fábrica española,/Madre de todas, hija de tí sola. ${ }^{152}$

${ }^{150}$ De la Rosa, Los seises de la catedral, p. 331.

151 Sobre Álvarez de Villasandino, véase: Ingrid Bahler, Alfonso Álvarez de Villasandino, poeta de petición (Madrid: Maizal, 1977); Paola Ambrosi, "La presenza di Alfonso Álvarez nei canzionieri spagnoli", Quaderni di Lingue e Letterature, 6 (1981), pp. 95-105. La obra más famosa escrita por Rodrigo Caro, poeta, sacerdote y abogado nacido en Utrera, es Canción a las ruinas de Itálica. La notoriedad que alcanzaría se demuestra con el hecho de que Francisco Pacheco lo incluyera en la nómina de su Libro de descripción de verdaderos Retratos, Ilustres y Memorables varones (1599). En 1883 se reeditaron sus obras, con introducción de Menéndez Pelayo: Obras de Rodrigo Caro: (Con noticias de M. Menendez y Pelayo sobre la vida y escritos de Rodrigo Caro) (Sevilla: Sociedad de Bibliófilos Andaluces, 1883).

${ }^{152}$ Simón de la Rosa, Los seises de la catedral, pp. 1-2. 
Continúa De la Rosa:

La razón de esta celebridad, por tantos vates cantada, antiguos y modernos, hay que buscarla en su origen. Sevilla abre las épocas de su historia, y cuando no las abre las inmortaliza, con alguno de esos santos extraordinarios escogidos por la mano misma de Dios, para dejar tras de sí, a su paso sobre la tierra, luminosa estela de merecimientos heroicos. ${ }^{153}$

El autor sevillano se refería, por un lado, a Fernando III de Castilla, "el Santo", "iniciador de la unidad legislativa española" e impulsor de la empresa de elaborar "para la nueva patria naciente [...] leyes, lengua, historia, letras, artes, industrias también nuevas, elementos esenciales de las naciones cristianas"154. Y por otro, a San Isidoro de Sevilla, a quien atribuyó la autoría "de la cultura antigua sevillana", y en un nuevo ejercicio metonímico, de la cultura española -“por no llamarla española"-155. El santo hispalense y la "Escuela Isidoriana" surgida en esta ciudad fueron fuentes de generación de la cultura española, y al mismo tiempo, factores de la unidad política y religiosa, gracias a la unificación litúrgica. Dentro de la obra de San Isidoro, De la Rosa puso de relieve la importancia de la liturgia mozárabe, para la que llegó a sugerir la denominación de "hispalense", dado que, según él, nació en esta ciudad. En el uso de una retórica nacionalista y belicista, al rito y canto mozárabe le otorgó además de una virtud mística y mayestática, una facultad de excitación del ánimo patriótico y marcial, que servía "de misterioso acicate [a reconquistadores y mozárabes] que los empujaba gozosos al martirio y a la pelea: y tanto apremiaba aquella veneranda liturgia por la redención de la patria" ${ }^{, 156}$.

${ }^{153}$ Ibídem, p. 2.

${ }^{154}$ Ibídem, pp. 10-11. “[...]fundador de la Universidad de Salamanca; por quien el arzobispo D. Rodrigo puso el primero en romance la Historia Gótica; el que mandó traducir al mismo idioma el Fuero de las Leyes y y cooperó con trovadores y juglares en la formación de la nueva lengua, llamándolos al otorgamiento de mercedes cuando llegó la hora del repartimiento; el que implantó en la ciudad conquistada los primeros trabajos del arte arábigo-cristiano y organizó monasterios y parroquias y levantó hospitales y santuarios, que fueron luego monumentos de indiscutible belleza arquitectónica; inauguró la estatuaria, fomentó la pintura y el decorado, y llevó las artes estéticas á tal grado de sublimidad que las obras y concepciones sevillanas de los siglos XIII y XIV pasan ya por modelos de enseñanza y de buen gusto entre los verdaderos inteligentes.” Ibídem, p. 11.

155 Ibídem, p. 2.

${ }^{156}$ Ibídem, pp. 5-6. "Pero valga la extraordinaria figura de S. Isidoro, personificando en su tiempo todo el saber de la España goda, para que Sevilla resulte colocada en el lugar que le corresponde, allá por los años del siglo séptimo: porque, si mucho brillo el egregio Doctor de las Españas en las ciencias y en las 
No obstante, es la institución catedralicia la que ocupa un lugar central en esos relatos. Para defender su relevancia histórica incidió especialmente en dos ideas: en primer lugar, poseer los mismos "honores y preeminencia" que la catedral peninsular de mayor rango, la Primada de Toledo ${ }^{157}$; y en segundo lugar, su condición de matriz y modelo de las nuevas Iglesias americanas que se iban fundando, momento el que su papel de difusión y propagación del cristianismo y, por extensión, de expansión de los valores de la "nación española", alcanzó su máxima expresión ${ }^{158}$.

artes liberales, su fama en las eclesiásticas y, más que todo, en materia litúrgica, no dejara de pregonarse nunca, mientras exista la humanidad.

En prueba de ello, jamás se borrará de la mente, mejor dicho, del corazón de los españoles, el rito gótico, isidoriano, toledano y muzárabe, cuyas místicas plegarias y delicadas melodías lo mismo tuvieron virtud por espacio de algunos siglos para imprimir severa majestad en las ceremonias del culto, que para encender en sacro fuego a los caudillos cristianos y alentarlos en la pelea hasta dar en tierra con los fanáticos sectarios del islamismo.[...]

Días más gloriosos estaban aun reservados a Sevilla con ocasión de la liturgia gótica. La variedad de ritos litúrgicos era una amenaza constante contra la unidad política y religiosa del reino, y así lo declaro solemnemente el concilio IV de Toledo (633); por lo que los Padres de esta augusta asamblea, conocedores del hombre que se necesitaba para aplacar los ánimos soliviantados por el interés de las localidades, fijaron los ojos en la venerable figura del varón que los presidia y le encomendaron unánimes el cumplimiento de lo que se proyectaba. Era Isidoro de Sevilla, el amigo íntimo de S. Gregorio el Grande, quien tomo sobre si la grandiosa misión de uniformar la liturgia española.

En Sevilla, pues, en donde debían ser abundantes los elementos de cultura desde la creación de la Escuela Isidoriana, realizóse aquella uniformidad; o mejor dicho, en Sevilla nació el oficio gótico y muzárabe; el cual debiera llamarse hispalense por el lugar de su nacimiento.” Ibídem, pp. 3-5.

${ }^{157}$ Del mismo Fernando III el Santo fue la intención de investir a la institución de la misma grandeza que la toledana, ya desde los primeros instantes de la restitución de la sede hispalense tras la conquista castellana: "[...] pero el local destinado al efecto no resultaba digno de los venerables varones designados por San Fernando para inaugurar el Cabildo eclesiástico ni del esplendor y magnificencia que desde el principio quiso imprimir el Santo Rey a la catedral hispalense, habiéndose propuesto igualarla en honores y preeminencias con la Santa Iglesia de Toledo. De no haber ocurrido su fallecimiento a los dos años de la conquista, es seguro que hubiese mandado construir para Sevilla un nuevo templo metropolitano grande y suntuoso, como correspondía a la historia de su iglesia, del mismo modo que se estaba fabricando el de la capital de los godos cuya primera piedra había puesto el mismo en persona el año 1227, acompañado del célebre Arzobispo D. Rodrigo Ximénez de Rada”, ibídem, pp. 103-104. Un propósito que asumieron también sus sucesores: "Originales se conservan en el archivo capitular un privilegio rodado del Rey D. Alonso, su fecha 20 de Marzo de 1294, y las confirmaciones de D. Enrique (Era de 1408), del Infante D. Juan (30 de Mayo de 1412), del Rey D. Juan (6 de Agosto de 1417), y otros muchos Reyes y príncipes concediendo al Cabildo de esta Santa Iglesia gozar de las preeminencias del de la Santa Iglesia de Toledo." Ibídem., p. 104. De la Rosa dedica las siguientes páginas a mostrar con numerosos datos el punto hasta el cual la sevillana igualaba en organización, recursos humanos y materiales a la primada de Toledo, desde el número de dignidades, canónigos y demás personal al servicio de ambas instituciones hasta la riqueza del vestuario que tenían a su disposición, etc.

158 “Al ocurrir los descubrimientos que preparan la Edad moderna, también sorprendemos a Sevilla, como siempre, cumpliendo su misión providencial en la historia. Trátase ahora de la invención del Nuevo Mundo, el centro de actividad está fijo en la Iglesia hispalense y es resorte misterioso que activa el movimiento, la devoción dulcísima a Nuestra Señora de la Antigua. [...].

Lo que entonces aconteció no hay para que repetirlo. Del fondo de los mares surgió de improviso un mundo imaginado por el inmortal genovés y la Catedral de Sevilla fue llamada seguidamente a realizar la obra que le había señalado el destino. Después de todo esto, a nadie podrá extrañar que las iglesias de Indias fuesen capillas, anexos y filiaciones de la de Sevilla hasta el año de 1512, en que se convirtieron en catedrales por bulas de Julio II.” Ibídem, p. 25. 
Es posible que la figura de Eslava, visto como otro vástago ilustre de la catedral hispalense, ejerciera una función de correlato o trasunto en lo musical de la institución, tal y como era concebida, por compartir con ella y su Cabildo un semejante cometido histórico de liderazgo y guía al servicio de la "religión" y la "nación española”, según los discursos de Arbolí o De la Rosa. Este estatus debió favorecer, independientemente de las características intrínsecas de su música, la consideración de su obra como una expresión adecuada y cualificada - por la propia firma del compositorde la propia institución catedralicia en aquel momento.

\subsection{El fenómeno del Miserere de Eslava}

Aunque, como hemos constatado en el capítulo tercero, las reacciones en contra de la reforma se repitieron cada vez que se puso en cuestión la continuidad en el ceremonial catedralicio de cualquiera de las obras que componían el "canon Eslava", sin duda, ninguna tuvo la dimensión que alcanzó la respuesta que provocó la posible prohibición del Miserere. Como pudimos comprobar entonces, las razones que alegó Spínola en su petición a Roma reflejaron la naturaleza sociocultural del problema. A continuación seguiremos indagando para tratar de ofrecer explicación a este fenómeno en el que el "canon Eslava" adquirió, más que en ningún otro caso, una trascendencia cultural.

\subsubsection{La secularización del “templo": la liturgia como acto sociocultural}

Como se ha puesto de manifiesto en otras ocasiones, durante el canto del Miserere de Eslava, la catedral de Sevilla se transmutaba en teatro. Diversas fuentes nos proporcionan información con la que poder formarnos una imagen de la transformación que sufría el templo. Un extracto del informe que el maestro de ceremonias catedralicio elaboró a petición del cardenal Segura, y que se recoge en la conocida y polémica carta pastoral que abolió definitivamente la costumbre del Miserere, describe así la forma en la que tradicionalmente se celebraba el "espectáculo", que "durante tantos años ha venido cantándose, con tanto aparato teatral, en la Santa Iglesia de Sevilla" ${ }^{\prime 159}$ :

\footnotetext{
${ }^{159}$ Pedro, Cardenal Segura y Sáez, Arzobispo de Sevilla, "Instrucción pastoral de su Emcia. Rvdma. Sobre la Música Sagrada", BOAS, 1470 (1945), p. 132.
} 
$1^{\mathrm{o}}$ - Estando toda la masa coral en el mismo presbiterio, lugar reservado de suyo al clero y sacerdocio...

$2^{\mathbf{o}}$ - Colocados todos los cantores de espaldas al Altar, durante el canto solemne del Oficio Coral...

$3^{\text {o }}$ - Situados y distribuidos en forma verdaderamente teatral..., bien puede afirmarse que no es esa la forma más conforme a la mente de la Iglesia y de su liturgia santa, para entonar este Salmo eminentemente penitencial en un acto solemne de culto. ${ }^{160}$

Mientras que el altar adquiría el aspecto de un gran escenario, las naves de la Basílica se convertían en una inmensa platea que a pesar de su capacidad se abarrotaba cuando llegaba la hora en la que daba comienzo el Miserere las noches del Miércoles y Jueves Santos. En el año 1900, año de su reposición tras un paréntesis de más de una década a causa de las obras de reparación del crucero mayor desplomado en 1888, asistieron a la función unas doce mil personas, según los cálculos del autor de una reseña publicada en El Noticiero Sevillano $[E N S]^{161}$.

Otros espacios del templo aparcaban durante esos momentos su carácter devocional, y asumían una función bien distinta. Las capillas hacían las veces de palcos teatrales, y eran ocupabas por la burguesía y aristocracia local: "La capilla de la Antigua la ocuparon por completo distinguidas familias de la aristocracia sevillana."162 Este otro testimonio es de algunos años más tarde: "Las distintas capillas de la Basílica fueron ocupadas por distinguidas familias sevillanas, escuchando desde ellas la brillante página musical [...], gloria de la música religiosa nacional."163 El Coro, por su parte, servía como palco de autoridades. En aquella primera interpretación del siglo XX asistió el que sería poco después presidente del gobierno, Antonio Maura, invitado por su amigo sevillano Pedro Rodríguez de la Borbolla. Maura y Rodríguez de la Borbolla, además de otras personalidades políticas, presenciaron el acto desde este espacio claustral, por tanto vedado a los laicos: "Las autoridades oyeron el Miserere en el coro, donde también estaban los señores Maura y Borbolla con otros diputados a Cortes"164. El resto de fieles -o público- que llenaba las naves se quedaba de pie.

\footnotetext{
${ }^{160}$ Ibídem, p. 143.

161 "Se calcula que han oído la hermosa obra de Eslava unas 12.000 personas". "El Miserere. En la Catedral", ENS, 2468 de 12 de abril (1900), p. 2.

${ }^{162}$ Ibídem.

163 “El Miserere. Brillantísima interpretación”. ENS, 9479 de 5 abril (1916), p. 3.

${ }^{164}$ El Miserere. En la Catedral”, ENS, 2468 de 12 de abril (1900), p. 2.
} 
Junto a las hemerográficas y oficiales, las fuentes literarias proporcionan interesantes cuadros del aspecto del recinto. Blasco Ibañez en Sangre y arena (1908) describió el aspecto de los distintos espacios del templo y las personas que se encontraban en cada uno de ellos:

El templo, con sus arcos ojivales disparatadamente altos, estaba sin otra luz que la de unos cirios rojizos colocados en las pilastras: la necesaria nada más para que la muchedumbre no marchase a tientas. Tras las rejas de las capillas laterales estaban enjauladas las gentes de buena posición social, huyendo del contacto con la muchedumbre sudorosa que se empujaba en las naves. En la obscuridad del coro brillaban como una constelación de estrellas rojas las luces destinadas a los músicos y cantores. ${ }^{165}$

Y unos años después, Eugenio Noel en su Semana Santa en Sevilla (1916):

En la inmensa Basílica no cabe un cuerpo más. Bien resguardadas en las capillas, familias afortunadas ven, no sin impresión, los movimientos angustiados de la multitud que amenazan echar abajo las rejas. Hay mareos, desmayos y voces. Nada más edificante que ver con qué galantería y prontitud acuden los hombres en auxilio de las señoras aunque tengan que venir de un extremo a otro de la catedral. Y sin cesar, la iglesia es invadida por millares de almas que por nada en este mundo dejarían ellas de oír el Miserere de Eslava. ${ }^{166}$

Así retrata la estampa que ofrecía el Coro:

Las velas arden en los atriles del Coro. Ochenta o más individuos se asfixian en el espacio estrecho que hay entre la sillería baja de Nufro el entallador y el facistol prodigioso. La luz destaca sus relieves de bronce y las pilastras, descubre la Virgen del templete y alumbra en artístico claro obscuro el Crucifijo del cupulino. Las grandes tapas y conteras de los libros corales y libretos dominan la orquesta.

Se oyen, como en un teatro, arpegios y escalas, con los que los ejecutantes prueban sus instrumentos. Cerca de nosotros preguntan ciertos sujetos quién hará de tenor. Algunos recuerdan a Viñas, Lohengrin ideal que tendría ocasión aquí de entregar su alma mística y heroica a la Dolorosa, la Elsa sevillana. En el Coro bullen

\footnotetext{
${ }^{165}$ Vicente Blasco Ibáñez, Sangre y arena (Madrid: Espasa Calpe, 1990), p. 282.

${ }^{166}$ Eugenio Noel, Semana Santa en Sevilla (Madrid: Renacimiento, 1916), p. 351.
} 
los niños y charlan las mujeres. Un instante después, el Miserere de Eslava ha empezado. ${ }^{167}$

El panorama que describen estas fuentes nos habla de un evento y un espacio templo transformado en sala de conciertos- que cumplía, además, una función representativa desde un punto de vista sociológico. Durante el canto del Miserere se producía en el interior de la Catedral una escenificación del orden social vigente. En la liturgia no existía ningún mecanismo de selección del público en base a un criterio clasista como el económico. A diferencia de los teatros, los otros grandes centros socioculturales urbanos, en la Catedral toda la ciudad estaba, de una forma $u$ otra, presente. Era una muestra de la ciudad dentro de la propia ciudad. Las clases menos pudientes podían presenciar al igual que las distinguidas, la función litúrgico-artística. Como muestran aquellos testimonios, cada una tenía asignada su ubicación física en la Basílica como escenificación de su posición relativa en la jerarquía social. Dado que la entrada a este gran templo-auditorio era obviamente gratuita, el único aspecto de cierto carácter mercantil, es decir, que suponía un coste, era el alquiler de sillas para poder asistir a la función sentado. Evidentemente no constituía una restricción a las clases humildes, aunque colaboraba, y eficazmente dados los términos en los que se expresa el propio Segura, en la constatación de la diferencia. El prelado denunció esta práctica lucrativa, a su juicio, más propia de los espectáculos de la esfera profana que de las funciones litúrgicas describiéndolo como un "aspecto de lucro extraordinario por el uso de los asientos que habían de ocupar los asistentes;" "168.

La aglomeración de gente de toda calaña y con todo tipo de intenciones, sumada a ciertas condiciones ambientales como la penumbra que dominaba el interior del templo, componía una situación propicia a los abusos, desórdenes e irreverencias. De ello dan testimonios las numerosas medidas tomadas por el Cabildo para evitar esta clase de comportamientos. José Enrique Ayarra se remonta a mediados del s. XVIII, fecha de la prueba más antigua que proporciona sobre resoluciones del Cabildo en este sentido $^{169}$. Según Ayarra, en 1872 la corporación catedralicia llegó a decidir la supresión de "las Lamentaciones y Miserere que se han venido cantando en los años

\footnotetext{
${ }^{167}$ Noel, Semana Santa en Sevilla, p. 353.

${ }^{168}$ Pedro [Segura], "Instrucción pastoral”, p. 141.

${ }^{169}$ En 1756 el Cabildo decidió la separación de hombres y mujeres dentro del templo. Ayarra, Hilarión Eslava en Sevilla, p. 88.
} 
anteriores"170. Estos problemas, que se asociaron al propio acto y a su naturaleza pública y masiva, continuaron en el siglo XX. Eugenio Noel refiere en la obra citada los abusos que se producían en el interior de las naves:

-Mire osté, zeñó, eze é er mal mayó de eta tierra de María Zantísima...

-¿Qué mal?

-Lo der magreo... Aquí no é como en otros laos, aquí se jase eso aguantándolo to: lo da una niña una bofetá, y como zi no: er niño, a la querensia; lo pizotea, y er niño amarrao que ni con liga; en er Miserere, zeñó, en er Miserere, aqueyo é er Guadalquiví de la poca vergüensa... Con desile a osté que han tenío que alumbrá la catedrá como en er teatro eza zanta noche, está to dicho. ${ }^{171}$

Otros aspectos colaboraban en "la apariencia de espectáculo público profano", como "la actitud tan ruidosa, no propia de aquellos días santos, ni del lugar sagrado en que el acto se tenía;" o "[...] la propaganda más bien teatral que propia de un acto sagrado, con que se anunciaba el espectáculo"172.

Por otro lado, las características de la liturgia del oficio de Tinieblas hacían de ella una ceremonia especialmente propicia, posiblemente como ninguna otra del temporal, para la teatralización. La profusión de gestos y signos rituales, la sobrecogedora atmósfera que se debía crear, así como la intensidad emocional de los textos propios componían un conjunto ceremonial complejo, conmovedor y dramático. De nuevo, recurrimos a las fuentes literarias, en las que encontramos interesantes imágenes. Salvador Rueda en Granada y Sevilla (1890) recrea así el ambiente del momento:

Las luces opacas que de columna en columna tendían sus reflejos hacia los altares, entraban como espadas temblorosas a través de la verja de la capilla, y se perdían, lamiendo los muros, en las tinieblas, dejando vagorosos reflejos en los aires. [...]

Había ya resonado el Incipit lamentatio de Jeremías, y aun temblaban bajo los arcos las vibraciones de las voces; el salmo Salvum me fac Deus, había igualmente expirado en aquel ambiente de religiosidad y recogimiento; también pasaron las lamentaciones, a cuyo final repiten los acentos : ¡Jerusalén, Jerusalén, conviértete a tu

\footnotetext{
${ }^{170}$ La cita debe estar extraída de un acta capitular, aunque no se proporciona la fuente. Ibídem, p. 92.

${ }^{171}$ Noel, Semana Santa en Sevilla, p. 197.

${ }^{172}$ Pedro, “Instrucción pastoral”, p. 141.
} 
Dios!, frase que rueda de uno en otro muro en gigantesca onda sonora que llena de armonías el templo; lanzadas por los salmistas y cantores, habían sonado después las sagradas antífonas al principio y al final de cada salmo, y asimismo había sido entonado por las voces el cántico de Zacarías, o Benediclus; todo parecía haber dejado en el ambiente un sublime rastro de divina poesía, y todo incitaba a preparar el ánimo para el grandioso Miserere, [...]

A punto de las nueve, cuando ya acostumbrado el oído a las voces del canto llano mi vista volaba del órgano inmenso a la alta nave, el Miserere dio comienzo con toda majestad, y llegó dulcemente por los oídos al corazón sacudiendo sus fibras de la abstracción en que se hallaban.[...]

El obscuro calado de las mantillas proyectando su sombra sobre los rostros: las rojas colgaduras suspensas de las columnas y de los muros como grandes cortinas de oro: el rutilar de los reflejos sobre la pedrería de las arañas y sobre los cristales de las lámparas; la danza de claridad y de tinieblas en los ángulos y bajo las bóvedas; la noche imponente suspensa en las alturas como fúnebre crespón tejido de alas negras; los rezos; las plegarias; el golpe dado no se sabe dónde que llena sonoramente las naves y se pierde a lo lejos como eco de un mundo desconocido, todo hacía mayor el misterio de la ceremonia y todo contribuía a la severa majestad de la iglesia.

El segundo versículo rodó desde las alturas del coro y la orquesta agitó sus arcos y sonó sus instrumentos lo mismo que si fuese llegada la hora del día del juicio. No era ilusión; entre el diluvio de sonidos se derrumbaba con terrible estrépito el inflamado Sinaí, que desgajaba su corona de tempestades, en tanto que tras las últimas vibraciones atravesaba como una bandada de ángeles por los aires agitando sus alas inmensas que tropezaban en las bruñidas lámparas y en las largas trompetas de los órganos. ${ }^{173}$

Tanto el Miserere como las lamentaciones -las lecciones del primer nocturno de maitines de tinieblas- tenían un marcado carácter penitencial, expresiones de dolor y arrepentimiento $^{174}$. Según las rúbricas, tras la recitación de cada uno de los salmos de maitines y laudes se debía apagar una de las quince velas del tenebrario. Una vez concluido el canto de la serie de catorce salmos y llegado el momento del cántico de Zacarías -Benedictus Dominus- sólo la vela situada en lo más alto del candelabro debía mantenerse encendida además de las seis situadas en el altar. Estas últimas se iban apagando gradualmente con el trascurso del Benedictus, una cada dos versículos, de

${ }^{173}$ Salvador Rueda, Granada y Sevilla. Bajo-relieves. (Madrid: Fuentes y Capdeville, 1890), pp. 101107.

${ }^{174}$ Las lamentaciones son una serie de poemas atribuidos tradicionalmente al profeta Jeremías, expresión del dolor y aflicción que supuso la destrucción de Jerusalem y la deportación de su pueblo, consecuencia de la invasión babilonia en el año 587 a. C. Miserere es el nombre con que se conoce el Salmo 50, de marcado carácter penitencial, una admisión de culpas e imploración de perdón. 
modo que a su final todas las luces del altar debían quedar extintas. Al llegar a la antífona del dicho canto sólo permanecía encendido el cirio central y más alto del triángulo del tenebrario. Esta vela, que en la catedral de Sevilla llamaban la María, se ocultaba sin ser apagada, al comenzar la antífona Christus factus est. El canto del Miserere, por tanto, tenía lugar en un momento tremendo del alegórico ceremonial, esto es, tras el abandono de Jesús por parte de los apóstoles y otros discípulos, simbolizado por los cirios del tenebrario que se iban apagando, y una vez representado "el triste y miserable estado en que quedó el universo cuando se apagó la luz del mundo, es decir, cuando murió Jesucristo [-representado por la última vela que en realidad no se apagaba sino que se ocultaba-] a manos de los hombres"175. Según las rúbricas y la Regla de Coro catedralicia, los clérigos debían permanecer de rodillas durante la hora que duraba su interpretación ${ }^{176}$. Al final del Miserere y tras la recitación de la oración Respice, quae sumus Domine, tenía lugar, probablemente, el momento climático de la ceremonia, como era el ruido que con toda clase de objetos como libros, sillas, matracas etc. producían los asistentes para rememorar el terremoto que se produjo al expirar Cristo. La reaparición de la María en el altar indicaba el cese del estrépito.

En el seno de esta ceremonia que adquiría el carácter de un gran gesto litúrgico-dramático, se producía el hecho que culminaba esta secularización del templo que venimos describiendo: el canto del salmo 50 con la música de estilo teatral profano- de Eslava. Como todo indica, la audición del Miserere eslaviano constituía,

175 Joaquín Bastús, Oficio de la Semana Santa y Semana de Pascua en latín y castellano (Barcelona: Imp. Elzeviriana y y lib. Camí, 1928), p. 183, nota a pie no 15 . Bartús ofrece una doble interpretación de la simbología de la vela más alta que, según la tradición hispana, debía ser blanca, a diferencia de las demás, amarillas: "La más alta de las quince velas no se apaga nunca, y tiene muchos significados. Parece que principalmente simboliza la fe constante que tuvo siempre la Virgen María de la resurrección de su divino Hijo. Es una alegoría también del mismo Jesucristo, que sin embargo de haber muerto en cuanto a la naturaleza humana, vivía en cuanto a la divina; y después de haber estado, digámoslo así, oculto por tres días en el sepulcro, resucitó luego con una luz muy viva ," Ibídem.

${ }^{176}$ La descripción del ceremonial de las Tinieblas en la catedral de Sevilla apenas sufrió cambios en la nueva regla nueva de 1923. Transcribimos a continuación unos fragmentos de ambas: "A las cinco se toca a Tinieblas, las que empiezan luego, que han cessado las campanas [...]. Al fin de Tinieblas esta día, y el siguiente ay Miserere Solemne de Música a tres coros (el Viernes es de Facistol) interin está todo el Coro de rodillas, y dura regularmente una hora. Acabado, el Señor Deán, o el más Digno de el Coro, dice la Oración: Respice quae sumus Domine sin conclusión; y finalizada se hace algún estrépito en las Sillas, el qual dura hasta que se vea sacar de la sacristía la Vela blanca, que llaman la Maria". Regla del Coro y Cabildo de la S. Iglesia Patriarcal de Sevilla y Memoria de las procesiones y manuales que son a cargo de los señores Deán y Cabildo de ella (1760), p. 177. “A las seis y media se cantarán solemnemente los Maitines de Tinieblas [...]. Este salmo [Miserere] se cantará con orquesta, durando desde las nueve hasta las diez, y acabado, el Sr. Deán o el más digno que se hallare en el Coro dirá la oración Respice. Finalmente, como se nota en las rúbricas, se hará algún estrépito, el cual durará hasta que se vea que de la Sacristía sacan la vela blanca que llaman la María". Regla de Coro de la Santa, Metropolitana y Patriarcal Iglesia Catedral de Sevilla (Sevilla: Imp. Sobrino de Izquierdo, 1923), p. 103. 
en realidad, el centro de esta liturgia convertida en espectáculo, ofrecida en este templo transmutado en teatro, además del gran reclamo para los fieles-público. Según los principios litúrgicos, esto representaba una inversión de la jerarquía que debía regir la relación entre música y liturgia, por tanto, un grave abuso. No obstante, la secularización que implicaba la aplicación de la música de Eslava al texto salmódico se podía contemplar no sólo en el sentido negativo de corrupción de la liturgia, según la óptica reformista, sino también en un sentido positivo de culturización del "templo", desde la doctrina que hallamos en De la Rosa:

Los que ignoran todavía como vino la cultura a los pueblos civilizados, deben saber que cuando la Iglesia y la sociedad vivían en perfecta armonía de relaciones y aún no se habían relajado las costumbres públicas, los templos católicos no sólo eran lugares consagrados a Dios, sino palenques abiertos a las aspiraciones nobles del espíritu. Las letras, las ciencias y las artes tuvieron acogida en el santuario del Señor y no parecía ajeno a la santidad del lugar abrir cátedras de enseñanza o celebrar representaciones dramáticas en los claustros o naves de las catedrales, en monasterios y aun en iglesias menores, por lo mismo que todos ellos eran centros de canto y música y otros tantos museos artísticos destinados a encerrar riquezas pictóricas, escultóricas y bibliográficas. ${ }^{177}$

La plasmación material de la belleza como ideal se producía en el interior del "templo". El arte, la cultura, por tanto, necesitaban de la "Religión", se vinculaban con ella, e incluso, en cierto modo, se debían someter a ella dado que la realización de su ideal de belleza no se hallaba "ciertamente al alcance del hombre". La condición religiosa la elevaba por encima de la ordinariez a la que estaba condenada "la belleza mundana":

El ideal de la belleza, innato en la humanidad, inspiro a las almas más delicadas el canto, la música, la pintura, la escultura la poesía y en general todas las bellas artes. La realización de ese supremo ideal, de cuya existencia no puede dudarse por ser tan palpables sus resultados, no se halla ciertamente al alcance del hombre; pero debe estar en relación intima con la Religión, porque las bellas artes nacieron, crecieron y se perfeccionaron dentro de los templos; y, si no, que contesten con sinceridad los que poseen el sentimiento de lo bello: hay asunto de arte más expresivo que la escultura del Crucifijo, poema más elocuente que los salmos

${ }^{177}$ De la Rosa, Los seises de la catedral, p. 233. 
penitenciales, partitura más delicada que la oración del cristiano a Dios o la plegaria a la Virgen Santísima?

La estética positivista, que no es creadora sino imitadora, busca la suprema belleza en los modelos materiales del realismo, del naturalismo, ¡como si pudiera ser supremo lo que no levanta del suelo a los artistas! Las bellezas mundanas, por muy perfectas que se supongan, no dejan de ser un capítulo más que agregar a la prosa ordinaria de la vida. ${ }^{178}$

Desde esta perspectiva, la introducción de lo pro fanum, en su sentido etimológico estricto, es decir, lo que está fuera -en el exterior- del "templo", no constituiría una profanación o corrupción del propio templo, es decir, de las expresiones de lo sagrado. En lugar de ello, representaría una oportunidad de informar a lo secular de lo religioso, y desde el principio de que lo religioso es lo que civiliza, una ocasión de civilización, en realidad, de infundir lo religioso a la cultura.

Esta doctrina, que justificaría y legitimaría la penetración y predominio en el "templo" de los estilos musicales teatrales italianizantes -expresión artística propia de la cultura moderna, de linaje profano- no eran precisamente las predominantes en las principales corrientes de pensamiento de la Iglesia en la segunda mitad del XIX y principios del XX. Eran, por contra, diametralmente opuestas a aquellas que inspiraron los principales documentos vaticanos sobre música previos al $M P$, y el propio $M P^{179}$. Como ya hemos apuntado, este documento venía precisamente a "excluir todo lo profano" de la música y garantizar su santidad como parte de la liturgia ${ }^{180}$. Y declaraba respecto a los estilos teatralizantes, “entre los varios géneros de la música moderna el que aparece menos adecuado a las funciones del culto es el teatral” ${ }^{\text {"181 }}$. El concepto de "templo" exclusivamente como lugar de culto, oración y celebración de los sacramentos contenido en el $M P$ era incompatible con aquel otro que lo entendía, además, como sede de cultura -religiosa- e irradiación de esta, sin menoscabo de su santidad ("no parecía

\footnotetext{
${ }^{178}$ Ibídem, pp. 61-62.

${ }^{179}$ Véase 0. "Breve introducción al Motu Proprio 'Tra le sollecitudini' de Pío X”, p. 43.

${ }^{180}$ Como parte de la liturgia, la música debía poseer las mismas cualidades que esta: "Por consiguiente, la música sagrada debe tener en grado eminente las cualidades propias de la liturgia, conviene a saber: la santidad y la bondad de las formas, de donde nace espontáneo otro carácter suyo: la universalidad." MP. Título I. Principios generales, art. 2
}

${ }^{181}$ MP. Título II. Géneros de música sagrada, art. 6. 
ajeno a la santidad del lugar abrir cátedras de enseñanza $[\ldots]$ " $)^{182}$. Ciertamente, para cumplir esta otra función de "palenque abierto a las aspiraciones nobles del espíritu", "acoger las letras, las ciencias y las artes", e incluso "celebrar representaciones dramáticas", el templo debió secularizarse, al menos, en lo externo.

Por tanto, una expresión artística de origen profano, como era el lenguaje musical eslaviano, asumía la misión de potenciar y transmitir a través de sus propios elementos y recursos -emparentados con el estilo dramático de corte rossiniano- los valores religiosos contenidos en el salmo Miserere. Las supuestas cualidades patéticas de la música de Eslava encajarían con el texto y el entorno ritual de las características descritas. Además, se trataba de un patetismo expresado en un lenguaje moderno, como ya hemos señalado, lo que hacía del lenguaje eslaviano un medio artístico ideal para traducir a la sensibilidad de la época el pathos del salmo milenario en términos emocionales y expresivos.

3.3.2. La sacralización de la cultura: reasignación de significados religiosos al lenguaje musical "profano"

La relación entre la música de Eslava y el texto del Miserere era simbiótica. No sólo el estilo eslaviano ejercía su acción sobre el salmo profanizándolo, por tanto, convirtiéndolo en cultura. El texto sagrado, por su parte, llenó de contenido religioso el lenguaje expresivo de Eslava. El dramatismo teatral -vacío o no- del estilo del compositor navarro se convirtió así en dramatismo religioso, de un efecto tremendamente conmovedor.

No obstante, para excitar hasta el punto que veremos a continuación el ánimo de los oyentes, la expresión eslaviana debió ser traducida mediante un procedimiento de naturaleza hermenéutica, que decodificara lo esencialmente abstracto del lenguaje musical, y adjudicara significados extramusicales y emocionales -religiosos- unívocos a las ideas musicales ${ }^{183}$.

\footnotetext{
182 "uno de los principales [cuidados] es el de mantener y procurar el decoro de la casa del Señor, donde se celebran los augustos misterios de la religión y se junta el pueblo cristiano a recibir la gracia de los sacramentos, asistir al santo sacrificio del altar, adorar al augustísimo sacramento del Cuerpo del Señor y unirse a la común oración de la Iglesia en los públicos y solemnes oficios de la liturgia." MP. [Exposición de motivos previa a la Instrucción legal]

${ }^{183}$ La cuestión sobre el significado de la música como lenguaje ha dado lugar a infinidad de debates en toda época. Probablemente la propuesta de aproximación sistemática al problema más destacada en las últimas décadas sea la procedente del ámbito de la semiología. Jean-Jacques Nattiez ha desarrollado una teoría y un método de análisis musical desde este ámbito. Sus principales influencias se encuentran en Jean Molino, Saussure y Peirce, de quienes toma el modelo de tripartición semiológica, las nociones de
} 
En abril de 1903, Juan Francisco Muñoz y Pabón, canónigo lectoral catedralicio, publicó un artículo en el que interpretaba y descifraba el significado dramático-religioso del Miserere ${ }^{184}$. Las condiciones en las que apareció el texto de Muñoz y Pabón eran idóneas para que ejerciera un importante impacto: figuró en la página de portada en el principal medio de comunicación católico local, el diario El Correo de Andalucía, en un día especialmente señalado, Domingo de Resurrección. Según afirmó en 1896 Joaquín Guichot y Parodi, periodista y cronista de la ciudad, el peso de la prensa en "el concierto de la vida sevillana" de aquellos años era determinante, "influyendo en el desarrollo de su cultura literaria y en sus costumbres públicas, a la vez que reflejando, con especialidad, los diferentes estados y periodos sociales"185. Como ha puesto de manifiesto recientemente Teresa Cascudo y María Palacios, las columnas de los periódicos fueron los medios principales de difusión de las ideas estéticas musicales y de legitimación de opinión ${ }^{186}$. Muñoz y Pabón, por su parte, aseguraba que su texto reflejaba la opinión y el sentimiento mayoritarios de la sociedad sevillana. Así se refería a él algunos años después:

Lo que yo pienso acerca de él como obra de arte ya lo dije en un artículo que escribí para El Correo de Andalucía hace la friolera de quince años. Con esta particularidad: que como yo pensaba entonces y pensando sigo- pensaban y sentían en Sevilla y fuera de ella tirios y troyanos, capuletos y montescos, profanos e iniciados $\mathrm{y}$ hasta maestros, $[\ldots]^{187}$

signo e "interpretante", respectivamente. Véase: Music and Discourse. Toward a Semiology of Music (Princenton: Princenton University Press, 1990 [1987]).

${ }^{184}$ Juan F. Muñoz Pabón, "El Miserere de Eslava. Impresiones". El Correo de Andalucía [ECA], 1315 de 12 de abril (1903), p. 1.

185 Joaquín Guichot y Parodi escribió estas palabras en su prólogo a Manuel Chaves Rey, Historia y bibliografía de la prensa sevillana (Sevilla: Ayuntamiento de Sevilla, 1995); cit. en María José Ruíz Acosta, "La prensa sevillana de principios del siglo XX: el nacimiento de un nuevo modelo informativo (1898-1914)", en Sevilla y su prensa. Introducción a la historia del periodismo andaluz contemporáneo (1898-1998), ed. por Ramón Reig y María José Ruíz Acosta (Sevilla: Universidad de Sevilla, 1998), pp. 13-36, pp. 28. La primera edición de la obra de Chaves Rey data de 1896. Véase, además: Alfonso Braojos Garrido. La prensa y la historia: diez estudios sobre comunicación periodística en Andalucía. Sevilla: Ayuntamiento de Sevilla, 2000.

${ }^{186}$ Teresa Cascudo y María Palacios, "Introducción”, en Los señores de la crítica. Periodismo musical e ideología del modernismo en Madrid (1900-1950), ed. por Teresa Cascudo y María Palacios (Sevilla: Doble J, 2011), pp. I-XX, p. IV.

187 Juan Francisco Muñoz y Pabón, "El Miserere", En el cielo de la tierra (Sevilla: Imp. y Lib. de Sobrinos de Izquierdo, 1918), p. 70. 
La labor exegética de Muñoz y Pabón comenzaba, no en el propio Miserere, sino en la antífona que le precede, Christus factus est, puesto que "Oídos los primeros compases del Christus factus, se oye todo el Miserere [;] en ellos va, como en nebulosa sintética”. En esta unidad es donde encontraba la primera cualidad del Miserere como “obra suprema de arte”, según sus palabras. A continuación comenzó con la traducción religioso-patética de los elementos musicales, compartiendo, además, con todos los lectores las imágenes llenas de dramatismo y contenido teológico que le sugerían:

la abrumadora cascada de armonías, que, ora tristes como el dolor, ora consoladoras como la esperanza; ya imponentes, terribles desgarradas como el llanto de un mundo, ya plácidas, serenas, casi voluptuosas, como los deliquios de la reconciliación, brotan de las gargantas de los cantantes y de los instrumentos de la orquesta.

Yo no puedo oír el Christus factus, sin ver en mi imaginación un Cristo muerto; hermoso, colosal, augusto, como lo es del Amor, rodeado de la humanidad entera, que lo aclama después de haberlo matado, mientras se reprocha a sí misma por tan inicua fechoría, diciendo con nuestro lírico[:]

Todos en él pusisteis vuestras manos...

[...] En el Christus factus est el coro 1lora, aclama, se maldice...aquello es una comunicación del mundo contra sí mismo y una plegaria a Dios de las misericordias: allí hay quejidos, reproches, gritos de júbilo...besos...el Christus factus es el Miserere comprimido. ${ }^{188}$

Y en esta línea continuaba repasando cada uno de los versículos y secciones de la obra literario-musical. Así, por ejemplo, tradujo en visiones y emociones la música del Auditui meo:

Auditui meo dabis gaudium. Bailable, casi profano parece este versículo juguetón y coqueto en medio de tanta severidad y pompa bíblica. Pero es la alegría que brinca como el ciervo y retoza como el gamo. David se ve perdonado, y baila con el salterio delante del arca del Señor. El coro, que le ha seguido en sus lamentos, le sigue en los transportes de su alborozo, y los huesos humillados empiezan a verse saltar de alegría entre las limpias notas de los clarinetes, las sublimes vacilaciones de los instrumentos de cuerda y los destemplados mugidos de metal. Lo que empezó risueño como el Génesis, acaba fúnebremente grandioso como el Apocalipsis... ${ }^{189}$

\footnotetext{
${ }^{188}$ Muñoz y Pabón, “El Miserere de Eslava. Impresiones”, p. 1.

${ }^{189}$ Ibídem.
} 


\section{O el Cor mundum:}

Hermoso, escultural penetra, hasta los tuétanos como el frío de las cofradías de madrugada. Sin más acompañamiento que el del metal, tiene para mí la majestad hierática de las trompetas sacerdotales. Ya veo a la Jericó pecadora derrumbándose, para que se yerga majestuosa, radiante, divina, el arca del nuevo testamento: el alma regenerada, viviendo en caridad, para que el Señor en ella more: Cor mundum crea in me, Deus. ${ }^{190}$

En ocasiones, su propósito interpretativo le llevó a tal grado de divagación que parece olvidarse absolutamente de la materia musical. Su ensayo se asemeja más bien a una meditación sobre determinadas ideas del texto que a un comentario sobre música:

Sí: es menester haber pecado, para sentir en el alma tanto dolor, tan infinito dolor. Con una particularidad: que aquel lamento no parece salir de la garganta de un ladrón, ni de un blasfemo, ni de un conspirador contra el poder: quien así gime ha pecado y su pecado es amor. Amor criminal, vicioso, adúltero...verdad: pero amor: aquel pecho ha amado mal y ahora ama bien: el peccavi es la metamorfosis gloriosa de un amor. Raudal de lágrimas, pero de amor: amor purificado por el llanto: eso es el tibi soli. Amó y pecó: ama y llora. El amor y las lágrimas lo han regenerado. ${ }^{191}$

Sin embargo, este alejamiento al objeto inicial de su comentario, le obligó a aclarar que no dejan de ser ideas y representaciones mentales inspiradas por la música: "Pero no es exégesis lo que estamos haciendo: no estudiamos ahora a David, sino a Eslava"192. En realidad, su percepción, y por tanto, comprensión de la música, estaba mediatizada por la concepción idealizada que de la figura de Eslava poseía, un genio musical y sacerdote virtuoso ${ }^{193}$ :

Yo me quedo para oír el enérgico tunc imponent, que con llave de oro cierra ese poema musical en que palpita pujante el alma

\footnotetext{
${ }^{190}$ Ibídem.

${ }^{191}$ Ibídem.

192 Ibídem.

${ }^{193}$ Esta misma asociación de virtudes como músico y como sacerdote la encontraremos en el discurso que sobre Francisco Guerrero, el símbolo situado por oposición a Eslava, desarrolló el nacionalismo musical español de corte pedrelliano, como veremos en el capítulo sexto.
} 
de un genio: el alma de... un cura, con un talento tan grande como su corazón: el alma de Eslava... ${ }^{194}$

Eslava parece encarnar un nuevo David. Un David contemporáneo junto al David bíblico, que se dirige a Dios como profeta popular(-izado) a través de su música, implorando perdón y purificación en representación de la humanidad: "David y Eslava, el pecador, el hombre, la humanidad, que ama mucho, pide más: la limpieza del oro en crisol: amplius lava me... jlava me! ¡munda me!"195.

Para Muñoz y Pabón el Miserere era una ópera: "El Quoniam es el concertante de aquella ópera [cursiva original]". Es más, no obstante el significado y valor religioso que atribuyó a la música de Eslava, el acontecimiento del Miserere no dejó de ser, según lo concebía, un momento de deleite y disfrute. El Miserere produce un efecto regocijante en el alma de Sevilla: "Enhorabuena a Sevilla que tiene anualmente la buenaventura de refocilar su alma con obra musical tan sin epíteto"196. Al final del artículo, el canónigo se convirtió en crítico musical y, remedando en el fondo y en la forma la tipología convencional de las numerosas reseñas críticas de los diarios de la época, efectuó el siguiente comentario, más propio de una función lírica:

y, por lo que al corriente año respecta, recíbanla [la enhorabuena] los señores Insausti por su acertada dirección; Astillero por el sentimiento artístico con que ha interpretado su papel, y el tenor Alvarez Udoli, que con una maestría inimitable, sobre todo en el ataque de los agudos, y la voz más bien timbrada, más pastosa y más nítida que yo he oído, ha logrado bordar, más que cantar, los difíciles cuanto sentidos versos con que el genio de Eslava completó para siempre la sublime elegía del Profeta Rey. ${ }^{197}$

Con esta práctica, Muñoz y Pabón sentaba principios de recepción, comprensión, interpretación y valoración de una obra musical, así como predisponía al oyente para que la música produjera determinados efectos emocionales y afectivos sobre él. Es decir, fijaba criterios de asimilación cultural, por tanto, orientaba la cultura.

\footnotetext{
${ }^{194}$ Muñoz Pabón, “El Miserere de Eslava. Impresiones”, p. 1.

${ }^{195}$ Ibídem.

${ }^{196}$ Ibídem.

197 Agapito Insausti, beneficiado tenor de la capilla catedralicia, ejerció interinamente las funciones de maestro de capilla entre los magisterios de García Torres y Ripollés. Por tanto, fue a él a quien se le encomendó la dirección de la obra.
} 
La contribución de un discurso de tal naturaleza a la sublimación del Miserere -de una pieza musical, en principio, sin ninguna particularidad- en expresión cultural de gran alcance debió ser imprescindible. El canónigo lectoral sumó así a su autoridad eclesiástica como miembro de la alta jerarquía catedralicia y, por tanto, archidiocesana, una autoridad cultural que legitimó su condición de artista - "he recibido de Dios un alma de artista" $" 198$.

Sus reconocidos por él mismo desconocimiento e incompetencia musicales no le restaron autoridad ni fueron obstáculo para su ejercicio de exégesis desde una, supuestamente posible al margen de la naturaleza genuinamente musical de la obra, perspectiva artística general, o según sus palabras, "como obra de arte in generi". La autoridad y, por tanto, legitimidad de Muñoz y Pabón, mero aficionado a la música aunque artista, quedó a salvo por esta disociación artificial entre obra de arte, y obra de arte musical. Habría que dilucidar, por tanto, cuáles fueron, ya que prescinde del análisis de los elementos musicales, los aspectos artísticos generales en los que incidieron sus valoraciones y comentarios, en consecuencia, qué entendía como obra de arte en sentido genérico. El texto pone en evidencia que, además del requisito de unidad ya apuntado, su concepto de arte estaba ligado a la expresión y a la capacidad de conmover, por un lado; y por otro, debía constituir una materia prima idónea -al menos en este caso- para poder colmarlo de significado. Arte y expresión, arte y semanticidad. Las ideas sobre arte y música de Muñoz y Pabón se inscribieron, por tanto, con claridad, en el pensamiento estético romántico.

Además, su reconocida por él mismo falta de criterio para hacer juicios musicales no le hizo renunciar a deslizar a veces, y a afirmar otras, su opinión sobre el valor puramente musical de la pieza -“obra musical tan sin epíteto"-:

No soy músico. Ni conozco una nota. Tanto, que cuando como sílaba entra una de ellas en un jeroglífico, tengo que echar mano de persona que me la lea. No voy, pues, a aquilatar el mérito, a mi pobre parecer, extraordinario del Miserere de Eslava como obra de arte musical: voy a decir solamente cuatro palabras acerca de él, como obra de arte in generi; pues, aunque inculto en ciertas manifestaciones de arte, he recibido de Dios un alma de artista. ${ }^{199}$

\footnotetext{
${ }^{198}$ Muñoz Pabón, “El Miserere de Eslava. Impresiones”, p. 1.

${ }^{199}$ Ibídem.
} 
Estas estimaciones sobre el valor musical del Miserere, aunque despojadas explícitamente por su autor de cualquier validez desde un punto de vista musical especializado, no dejaban de ejercer como referentes con los que formar la propia opinión para la mayoría de los lectores, al provenir de una voz con el prestigio social y artístico ya referido. Muñoz y Pabón fijaba, o mejor dicho, perpetuaba así, no sólo un determinado gusto artístico "in generi", sino también criterios de gusto musical. Esto demuestra que esta privilegiada función de formación del gusto artístico de una sociedad, -y dado que la música se integra dentro de la categoría general de arte- por tanto, también del musical, no estuvo sólo en manos del especialista músico “autoridades", en palabras de Turina ${ }^{200}$ - sino de otros líderes culturales. Como veremos a continuación, aquí se halla unos de los principales puntos de conflicto entre el movimiento reformista español y los defensores sevillanos del Miserere.

Con todo, habría que valorar hasta qué punto sus comentarios surgieron de la perspectiva y toma de posición de un artista -religioso-, o simplemente fueron los de un ciudadano que gracias a sus dotes literarias reprodujo, como él mismo admite, la opinión y el sentir general, para consagrarlos aún más. Su discurso parece más bien el producto de una postura tomada a priori; una expresión de su pensamiento, de su sensibilidad, así como del carácter de su emotividad. Todo ello fruto de su experiencia personal, de las influencias asumidas no sólo conscientemente o como consecuencia de una elección, sino también las inconscientes, al estar sumergido en una determinada colectividad social histórica a la que perteneció y en la que ocupó una determinada posición. Se trataba, por tanto, de la defensa de una identidad, entendida esta en un sentido cercano al concepto de habitus propuesto por Bourdieu ${ }^{201}$. La trascendencia del ejercicio interpretativo, literario y expresivo de Muñoz y Pabón radicaba en constituir una reobjetivación de estos universos ideológicos y emocionales, anteriores aunque compartidos por él mismo, que los reforzaba y consagraba aún más.

${ }^{200}$ Turina, “Crónicas sevillanas”, p. 206. Véase p. 261.

${ }^{201}$ En el concepto de habitus convergen la experiencia individual y colectiva, como unas disposiciones a percibir, actuar, reaccionar de una determinada forma, de acuerdo a un proceso de aprendizaje, tanto consciente como inconsciente. El individuo adquiere una identidad en el marco de una determinada cultura. Pierre Bourdieu afirma: "Producto de la historia, el habitus origina prácticas, tanto individuales como colectivas, y por ende historia, de acuerdo con los esquemas engendrados por la historia; es el habitus el que asegura la presencia activa de las experiencias pasadas que, registradas en cada organismo bajo la forma de esquemas de perfección, de pensamientos y de acción, tienden, con más seguridad que todas las reglas formales y todas las normas explícitas a garantizar la conformidad de las prácticas y su constancia a través del tiempo. Pasado que sobrevive en lo actual y que tiende a perpetuarse en el porvenir actualizándose en prácticas estructuradas según sus principios [...]". El sentido práctico (Buenos Aires: Siglo XXI, 2007 [1980]), pp. 88-89. 
Este papel jugado por Muñoz y Pabón en relación al Miserere podría contemplarse como una muestra de la influencia cultural que el Cabildo pudiera seguir conservando sobre la sociedad local; un vestigio de aquella preeminencia de los tiempos de esplendor a la que se referían los discursos de De la Rosa o Arbolí, actualizada, incluso en los instrumentos utilizados. La presencia de expresiones culturales de la trascendencia del Miserere así como de personajes instauradores y defensores de valores culturales eclesiásticos en la prensa católica local debió constituir una forma de influencia fáctica de la Iglesia en la sociedad.

\subsubsection{El Miserere como producto híbrido religioso-profano: un espacio de} influencia cultural eclesiástica en la Edad Contemporánea

Al hilo de esta última reflexión se podría desarrollar un razonamiento que nos llevara a plantear una hipótesis sobre la función que el fenómeno del Miserere ejerció en aquel contexto, considerando la problemática que en ese momento rodeaba a la Iglesia católica como la institución en donde adquirió su trascendencia socio-cultural.

Como es sabido, desde el nacimiento del concepto del Estado-nación y de la difusión del pensamiento liberal e ilustrado, la institución eclesiástica y el catolicismo tradicional entraron en una dinámica histórica de crisis y decadencia. Durante el transcurso del siglo XIX, la debilidad de la Iglesia se hizo cada vez más acusada y manifiesta en todos los órdenes, desde el económico hasta el social y cultural. Su relevancia en el nuevo contexto y su capacidad de influencia sobre el mundo contemporáneo, que encontraba otros puntos de referencia, había ido menguado a pasos agigantados. Se produjo un progresivo alejamiento, e incluso una fractura entre Iglesia y cultura contemporánea, a lo que quiso dar respuesta el papado, tratando de reubicarla y reorientarla en esta última ${ }^{202}$. Como señalábamos en el primer capítulo, la acción pastoral de Spínola constituyó una aplicación a nivel diocesano de la respuesta que ante esta situación trató de articular León XIII. Almaraz, por su parte, debió secundar a Pío $\mathrm{X}$ en su refutación y censura de las tesis modernistas, que habían encontrado acomodo incluso en el ámbito teológico ${ }^{203}$.

\footnotetext{
202 Joseph Lortz, Historia de la Iglesia en la perspectiva de la Historia del Pensamiento. Tomo II: Edad Moderna y Contemporánea (Madrid: Ediciones Cristiandad, 2008 [1965, en alemán]); véanse los tres primeros capítulos del apartado "Período segundo: El siglo XIX. La Iglesia centralizada en lucha con la cultura moderna", pp. 425-576.

${ }^{203}$ La encíclica de Pío X contra el modernismo: Pascendi Dominici Gregis de 8 de septiembre de 1907. Diversas reseñas sobre publicaciones católicas contra el modernismo aparecieron durante 1909 en el
} 
Si volvemos a los escritos de Arbolí o De la Rosa, hallamos reflejada la difícil situación que vivía la Iglesia en la cultura moderna, según la contemplaban desde Sevilla estos referentes del pensamiento tradicionalista católico local de entresiglos. Arbolí inauguraba su libro con declaraciones como las siguientes:

Escribir acerca de Misterios, evocar tradiciones, cuando tan espléndida y lozana irgue la frente la gran civilización, reina poderosa de hoy, avara del mañana, ebria de triunfo, y que cifra el mayor de todos en no haber menester del pasado; convidar al celestial Banquete y desplegar el manto de la Virgen Pura, cuando llama el mundo al festín de vida exuberante y al goce destilado en evoluciones de la materia; [...] hablar, en suma, de maravillas de fe, mientras se impone la razón altiva y se abre paso cuanto lleva el sello de novedad, más aún, si la autoriza el éxito y la hermosea el ingenio en obras de realce; una de dos, o arguye rancio apego a lo de ayer, con desdén de lo presente, lo cual sería vituperable, o envuelve generoso intento de buscar compensaciones, sin las cuales no es dado a los más diestros prevenir azares de un vuelo a la sazón falto de rumbo, pues no se marcará jamás sin el norte de los dogmas. ${ }^{204}$

Para Arbolí la misión de la Iglesia en los tiempos que corrían era mantener su autoridad y magisterio por el bien de la -inconsciente- sociedad a la que, como en otros momentos, debía sostener:

[...] El mundo no sabe lo que pide cuando clama contra la autoridad y el magisterio de la que es su única madre; porque, abandonado a sí propio, sin alimento del alma, sin lazo de fraternidad, sin comunión, muy pronto enervaríanse sus fuerzas y moriría en el más terrible abandono. Recordar esto, enseñarlo y repetirlo a una sociedad que desfallece, [subrayados originales] es la obra del momento, $[\ldots]^{205}$

$B O A S$. Entre ellas: "El modernismo sin máscara" de Sabino Olalla en BOAS, 665; "El corazón de Jesús y el modernismo" de José Manuel Ricardo en BOAS, 666. Precisamente en la contraportada de la edición del Reglamento de Música Sagrada para esta Archidiócesis con notas aclaratorias, [separata del BOAS] (Sevilla: Lib. e Imp. de Izquierdo y Cía, 1910) se anunciaba el libro "Análisis y refutación del Modernismo o breve comentario á la Encíclica 'Pascendi' y al Decreto 'Lamentabili', del Dr. Castro Alonso. Todas estas referencias son muestras del movimiento antimodernista que siguió la línea marcada por el papado. Sobre el modernismo véase: Lortz, Historia de la Iglesia. Tomo II, pp. 530-539.

\footnotetext{
${ }^{204}$ Arbolí, La Eucaristía, pp. V-VI.

${ }^{205}$ Ibídem, p. 11.
} 
La voz de De la Rosa, representativa de la intelectualidad católica comprometida políticamente, desplegó, además de argumentos culturales, otros de carácter histórico y sociopolítico. Según el escritor hispalense, el siglo XIX ${ }^{206}$

que acaba de transcurrir, activo y laborioso como ninguno, pasó la mayor parte de su vida planteando problemas sociales de la mayor trascendencia, no para resolverlos él mismo sino para que los resolviera su sucesor. Familia, religión, gobierno, propiedad, las bases sociales todas, las puso en tela de juicio y después se retiro por el foro, dejando en situación crítica de sobresaltos y revueltas a los que vinieran detrás. $^{207}$

Junto a la revisión de "las bases sociales" que se había producido en el siglo XIX, la ciencia moderna y cultura profana, ajena a la "moral del Catolicismo", había generado un hombre y una época que se alejaba de la civilización ${ }^{208}$ :

Cuanto más culto y mas modernista es el hombre del día, tanto más sujeto y apegado se muestra a la bárbara costumbre del desafío; y no hay para que decir que la irreligiosidad y el ateísmo, herencia legitima que nos vino directamente de las tribus sin civilizar, son los vicios más arraigados entre los llamados hombres de ciencia.

Digan cuanto quieran las modernas filosofías, el salvajismo y la barbarie, como el duende del cuento, acompañan al hombre de todas las edades en periodos de ignorancia y de civilización. Podrán quedar

\footnotetext{
${ }^{206}$ Como se ha puesto de manifiesto más arriba, su discurso vincula la religión con la nación española, como dos ideas inseparables y con un mismo destino histórico. Desde el reinado de Carlos III se fueron produciendo hechos que empujaban al declive que vivía tanto la Iglesia como España: "los funestos ministros de D. Carlos III, autores del famoso pacto de familia, habían abierto después en el corazón de la patria dos tremendas heridas que siguen aun manando sangre en abundancia: la guerra a la Religión y la degeneración moral de los españoles. Abrieron la primera con la inicua expulsión de los jesuitas y la segunda con la infiltración del volterianismo en el pueblo." De la Rosa, Los seises de la catedral, p. 324.

${ }^{207}$ Ibídem, p. 135.

${ }^{208}$ José Luis Abellán describe en líneas generales el pensamiento católico del último cuarto del siglo XIX como anclado en una actitud defensiva y apologética. Se apoya el autor en afirmaciones del dominico Guillermo Fraile como estas que transcribimos: "Ante esta situación es perfectamente comprensible, a la vez que disculpable, por una parte, la penuria de la producción científica y la ausencia de la investigación, y por otra, el matiz polémico, defensivo y casi siempre negativo y de oposición que reviste la mayor parte de los escritos que van apareciendo en el curso del siglo. El recelo hacia los peligros más o menos reales o posibles se traduce por reacción en un espíritu de estancamiento y en posiciones o actitudes rígidas y cerradas, centradas casi siempre en torno al problema religioso, en el cual iba de ordinario implicado el político [...]. La actitud polémica, cerrada y negativa de los apologistas católicos se traduce en el abandono de temas verdaderamente científicos y de valor positivo. Se cristalizaron excesivamente en el pasado y descuidaron mirar hacia el porvenir, como también a las nuevas corrientes ideológicas europeas, en las que solamente veían males, errores y desviaciones". La cita de Fraile en Historia de la Filosofía Española (Madrid: Editorial Católica, 1972); extraído de José Luis Abellán, Historia crítica del pensamiento español. 5/I. La crisis contemporánea (1875-1936) (Madrid: Espasa-Calpe, 1988), pp. 441442.
} 
algún tanto subyugados en civilizaciones genuinamente cristianas; pero extirparse de raíz, nunca. ${ }^{209}$

[...] ¡Cuán cierto es que la barbarie no se destierra de los pueblos laicamente, es decir, con los recursos de la cultura profana, si no se les aplica a la vez la moral del Catolicismo! ${ }^{210}$

Con algunos apuntes describe igualmente la grave crisis económica que aquejó a la institución eclesiástica hispalense, y que afectó incluso a su "magnificencia tradicional", carácter tan importante de su liturgia y de su identidad:

Nada próspero había que esperar de estos dos siglos [XVIII y XIX] para la Iglesia. En la hispalense continuo la buena reglamentación del personal de los seises, la fama europea de sus mejores maestros, el fervor religioso del pueblo sevillano y la justa celebridad de la danza de aquellos niños, porque Dios no abandona nunca sus obras; pero en cambio las guerras y las revoluciones políticas se ensañaron cruelmente contra nuestra Santa Iglesia, hasta dejarla pobre y extenuada, porque las obras de los hombres han declarado guerra a muerte a las obras de Dios. [...]

El periodo constitucional de 1820 y la revolución de 1836 disolvieron el antiguo Colegio de San Isidoro, iniciado puede decirse en los tiempos de San Fernando a virtud de los estatutos del Arzobispo D. Remondo, al par que acabaron con la magnificencia tradicional de la catedral hispalense y agotaron sus cuantiosos elementos de vida. ${ }^{211}$

Recordemos, por último, la visión de la situación del propio Spínola, proporcionada en determinados pasajes escritos a propósito de una de las actividades con las que se conmemoró el cincuentenario de la proclamación del dogma de la Inmaculada $^{212}$. El Cardenal pintaba un escenario realmente hostil: conjuras de la prensa en contra de la Iglesia, "ataques a nuestra fe", "insultos a la moral católica", centros en los que se promovía el vicio y los malos instintos, o "asambleas" en las que se difundían ideas "destructoras de todo orden social o político", o se corrompía "el buen sentido" que debía guiar a la ciencia o la literatura.

Este panorama contrasta radicalmente con el presentado por De la Rosa, Gestoso, Arbolí o Serrano cuando describieron las grandes festividades ciudadanas del

\footnotetext{
${ }^{209}$ Ibídem, p. 136.

${ }^{210}$ Ibídem, p. 139.

${ }^{211}$ Ibídem, pp. 322-323.

${ }^{212}$ Véase capítulo 1, epígrafe 3. "Inicio y suspensión del proceso de reformas: causas y consecuencias", p. 75 .
} 
Corpus y la Inmaculada y sus ceremonias litúrgicas, manifestaciones de la sociedad y la cultura de aquellas otras épocas de apogeo.

En el escenario adverso de principios del XX, mantener la magnificencia de los cultos catedralicios debió cobrar un alto valor -no sólo litúrgico-, como es el de la preservación de ciertos espacios en los que la Iglesia aún se podía mostrar y autorreconocerse en su esplendor perdido, y proyectarse hacia la sociedad como una autoridad histórica, a pesar de su crisis económica y su falta de peso en el mundo moderno. El fenómeno Eslava pudo constituir una forma de conservación de cierta influencia cultural sobre el conjunto de la sociedad local, estableciendo un referente artístico de carácter religioso.

La costumbre del canto del Miserere concentró todo el potencial que el "canon Eslava" poseía como expresión cultural de raíz eclesiástica. Al margen de otros aspectos de este fenómeno complejo y poliédrico, igualmente merecedores de estudio, nos resulta clave una idea fundamental con sus consiguientes derivaciones. Se trata de su carácter híbrido, religioso-secular, que es donde residía, pensamos, su fuerza. A principios del s. XX, su naturaleza estrictamente litúrgica había sido sobradamente superada. El canto del Miserere en las noches del Miércoles y Jueves Santos era un acontecimiento anual producto de la confluencia de las energías y recursos de los distintos sectores sociales: las instituciones catedralicia y municipal, y la empresa, representada por el Teatro San Fernando. El cabildo catedralicio acogía -oficialmente permitía, pues el consistorio debía pedirle cada año la venia para que se pudiera celebrar el acto- y regía, al ser el competente en materia litúrgica, el evento; el Ayuntamiento lo organizaba y sufragaba ${ }^{213}$; y la empresa cultural aportaba para las partes solistas las

\footnotetext{
213 En 1905, año de comienzo del proceso de reformas en la Catedral, la cifra inicial destinada por el consistorio fue de cuatro mil pesetas. "Se dio así mismo lectura a una comunicación del Sr. AlcaldePresidente del Exmo. Ayuntamiento pidiendo la venia del Cabildo para que pueda cantarse en las noches del Miércoles y Jueves de la Semana Santa el Miserere del inmortal Eslava, como se ha hecho en los años anteriores y colocarse el Monumento, añadiendo que los gastos que se originen serán con cargo a la cantidad consignada para ello en el presupuesto municipal. Los Sres. Mayordomos hicieron presente que la suma presupuestada por el Ayuntamiento son 4.000 pesetas, que no alcanzan a cubrir los dichos gastos, pues pasan estos de 6.000 ptas, y el Cabildo no tiene otros fondos con que acudir a estas atenciones. Varios Sres. hicieron uso de la palabra y se acordó que antes de adoptar una resolución definitiva se haga saber al Sr. Alcalde la deficiencia de la cantidad presupuestada y la imposibilidad en que se halla el Cabildo de suplir la suma que falta por si el Municipio halla el medio de zanjar esta dificultad. AC 21/3/1905. ACS, Sección Secretaría, libro 227, fols. 11v-12r. El Ayuntamiento finalmente aumentó esa suma inicial: "El Sr. Sánchez Vázquez como Mayordomo dijo que había conferenciado con el Sr. Alcalde para llamar su atención sobre la imposibilidad de atender á los gastos de la colocación del Monumento y canto del Miserere con la suma presupuestada para el presente año y que había ofrecido S.E. aumentar en mil quinientos pesetas la cantidad asignada. El Cabildo quedó enterado." AC 3/4/1905. ACS, Sección Secretaría, libro 227 , fol. $17 \mathrm{v}$.
} 
figuras del belcanto que el Domingo de Resurrección abrían la temporada de ópera ${ }^{214}$. Independientemente de los intereses de cada uno, e incluso del signo político del partido en el gobierno en el caso del Ayuntamiento, la Iglesia concitaba en el seno de una celebración religiosa como era el oficio de Tinieblas a los distintos estamentos de la ciudad, haciéndolos colaboradores y copartícipes del evento.

Los paralelismos y coincidencias entre la realidad del fenómeno del Miserere y la imagen que sobre aquella otra época de esplendor, cultura, armonía social, así como sobre sus fiestas, trasladaron Arbolí o De la Rosa, son evidentes, a pesar de las diferencias que en otros muchos aspectos se puedan encontrar. Recordemos que según estos, los cabildos eclesiásticos y municipal, "congregados a una" en el corral de los Olmos, símbolo del encuentro y la alianza entre la Iglesia y la Ciudad, entre lo religioso y lo civil, establecieron el ceremonial de la fiesta del Corpus, en cuyo desarrollo y definición colaboraron gremios, hermandades y oficios. Y que todos, "en fraternal concordia" aunaban sus esfuerzos en rendir culto a la Inmaculada. Reproducían así un modelo social ansiado y, desde la convicción de que existió en tiempos pasados, virtualmente añorado. Un modelo que asociaban a esplendor, cultura y concordia social, justo lo que no encontraban en los tiempos presentes. Una sociedad ideal dominada por el espíritu religioso, en la que la Iglesia jugaba un papel preponderante, y conservaba su autoridad e influencia.

Como en aquellas fiestas de los siglos modernos, el pueblo participaba, junto a instituciones y otros agentes sociales, en este otro acontecimiento festivo-religioso del s. $\mathrm{XX}$, no sólo con su asistencia a la función, sino sobre todo como colectivo que lo había incorporado a su patrimonio simbólico. En uno de los cuadros costumbristas que dibujó en su libro En el cielo de la tierra (1918), Muñoz y Pabón ofreció una idea de la profunda penetración del Miserere en la vida y costumbres de los sevillanos:

[El Miserere de Eslava es] el poema musical que se saben de memoria en Sevilla hasta los perros; que se tararea distraídamente en el silencio del escritorio o entre las faenas del taller, en la soledad del paseo o en medio de las operaciones del peonaje de albañilería en el andamio; que se oye con deleite en la "meditación" de la novena o al gramófono en la "cachupinada"; que se llega a viciar de tanto repetirlo

${ }^{214}$ Véase: Ayarra, Hilarion Eslava, pp. 87-110. 
y que se aprende a tocar al piano apenas se han empezado a poner las manos sobre las teclas. ${ }^{215}$

El siguiente párrafo es un ejemplo prototípico de la literatura costumbrista con el Miserere como tema. Representa otra muestra más de su arraigo en la sociedad local:

- Anda, Manolo. Canta el Benigne, que lo cantas muy bonito. Yo te lo toco. Aunque no des el "do" de pecho del Jerúsalem.

- ¡No...! ¡Bueno! Sí. Que lo cante; pero a mí me gusta más el Tibi soli, y además, que le sale mejor.

- ¡Qué lo cante...! ¡Qué lo cante!

- ¡Anda, Gayarre!

Y mi hombre, que es el barbero de la esquina o el oficial de sastre de "ahí, a la vera", que no conoce una nota musical, pero que tiene muy buen oído y que no ha perdido un Miserere desde que nació, ni piensa perderlo; que.., ¡no porque él lo crea, sino porque es verdad! tiene una voz de tenorino que es una yema de San Leandro, y que está un poco alegrete, porque el padrino del casamiento le ha hecho beber quizás en demasía, se aproxima al piano, con su "mijita" de contoneo, se desabrocha la tirilla de la pajarita, que eso da mucha importancia, carraspea y se arranca con un Benigne, que junta gente a la puerta.

- ¡Olé y los hombres con facurtaes!

Calentejo con los aplausos de la reunión, la emprende a renglón seguido con el Tibi soli... que tiene que repetir, porque es que lo ha bordado materialmente y el auditorio se ha desgajado aplaudiendo. Y ya, una vez con las manos en la masa, ¿quién es quien se queda sin largar el Miserere mei Deus y toda la particela de tenor de todo el Christus factus?

- ¡Olé, las cajas e música... con bigote a lo Káise!

Ovación y oreja. Y la novia que andaba de monos con él por no sé qué veleidades del muy mariposón de mil demonios, ¡vaya!, que se vuelve tarumba con los gorjeos del peccavi, y aquí no ha pasao na, y en pa y jugando...

¡Para que en Sevilla caduque el Miserere! ${ }^{216}$

Dos años antes que En el cielo de la tierra de Muñoz y Pabón, salió a la luz Semana Santa en Sevilla de Eugenio Noel. Las corrientes tanto de pensamiento como literarias en las que se inscriben ambos escritores están bastante alejadas. Mientras que canónigo lectoral sevillano sigue la línea costumbrista de herencia decimonónica, el madrileño pertenece a una nueva tendencia crítica, en la que se reconoce la influencia del Noventayochismo y el Novecentismo, que revisa y reflexiona sobre la Semana Santa

215 Juan Francisco Muñoz y Pabón, "El Miserere", En el cielo de la tierra (Sevilla: Imp. y Lib. de Sobrinos de Izquierdo, 1918), pp. 67-68.

${ }^{216}$ Muñoz y Pabón, "El Miserere”, pp. 68-70. 
sevillana en un intento por descubrir los entresijos de la esencia de la ciudad ${ }^{217}$. Pese a las importantes diferencias, incluidos sus distintos puntos de vista -insider, en el caso de Muñoz y Pabón, y outsider, de Noel $^{218}$-, que les separaban en todos los sentidos, ambos coincidieron en la profundidad y trascendencia cultural del fenómeno del Miserere. Noel expresaba la omnipresencia de la obra eslaviana en el ambiente propio de las festividades de Semana Santa: "Hoy se canta en Sevilla el Miserere de Eslava y hemos visto esta mañana en los Oficio Santos los preparativos hechos en el Coro. Desde que llegamos a la ciudad de la Gracia el nombre de Eslava ha sonado sin cesar en nuestros oídos. [...]"219

Noel, por un lado, y Muñoz y Pabón, por otro, sintetizaron la dimensión simbólica e identitaria del Miserere a principios del s. XX en dos breves expresiones. El primero se refirió a su condición de esencia de la ciudad, cuando en boca de un sevillano, lo que hacía más verosímil y fidedigna la aseveración, escribía: "El Miserere está en nuestra sangre ya."220 . El segundo aludió a su poder simbólico, representativo e identario, el que posee un himno nacional: "La nota culminante de ese día es el conjunto de notas musicales, más o menos sabiamente colocadas en el pentagrama, que dan por

\footnotetext{
${ }^{217}$ Miguel Cruz Giráldez, "La Semana Santa sevillana en la literatura (III)", ABC Sevilla de 2 de marzo (1990), p. 43. Este artículo fue publicado en un total de ocho entregas. Se trata de la puesta al día y ampliación con nuevos textos de una conferencia que con el mismo título dictó su autor en la Asociación Dante Alighieri en 1985 en el marco del II Ciclo de Conferencias sobre la Semana Santa que dicha asociación organizó en colaboración con la Universidad de Sevilla. Este trabajo fue publicado dos años más tarde en: José María Requena, Miguel Cruz Giráldez y Javier Criado Fernández, Las Cofradías de Sevilla vistas por un novelista, los escritores, un psiquiatra (Sevilla: Universidad de Sevilla, 1987).

${ }^{218}$ Entendidos insider/outsider como dos formas de observación de los fenómenos culturales: el del agente integrado en la propia cultura, que participa de ella, y que, por tanto, comprende sus manifestaciones desde las claves que el propio sistema cultural al que pertenece le suministra; y el que la contempla desde una posición de cierto distanciamiento, tratando de interpretar sus significados en otro nivel de comprensión. Esta distinción estaría emparentada, en cierto sentido, a la propuesta por el lingüista Kenneth L. Pike, emic/etic, en su obra Language in Relation to a Unified Theory of the Structure of Human Behavior (The Hague: Mouton, 1967), y que Marvin Harris reconsideró y aplicó en sus estudios de antropología cultural. Levi-Strauss rechazó este dualismo en "Structuralism and Ecology", Social Science Information, 12 (1973), pp. 7-23. Véase al respecto estas útiles síntesis y reflexiones: Marvin Harris, "History and significance of the emic/etic distinction", Annual Review of Anthropology, 5 (1976), pp. 329-350; Carlo Ginzburg, "Qué he aprendido de los antropólogos", Alteridades XIX/38 (2009), 131-139, traducción realizada por Davide Scalmani de la conferencia que el autor pronunció el 12 de noviembre de 2008 en el Coloquio Internacional "Archipiélagos de la Antropología", celebrado en la Universidad Autónoma Metropolitana de Méjico. En este acto fue nombrado doctor honoris causa.

${ }^{219}$ Eugenio Noel, Semana Santa en Sevilla (Madrid: Renacimiento, 1916), p. 300.

${ }^{220}$ Ibídem, p. 317.
} 
resultado lo que hemos dado en llamar por nuestra cuenta y riesgo el himno nacional de Sevilla: el Miserere de Eslava.,"221

En conclusión, la naturaleza meramente litúrgica del canto del salmo 50 con el que concluían los maitines y laudes del oficio de Tinieblas se enriqueció y transformó, además, en un evento sociocultural de gran valor desde un punto de vista antropológico. El acontecimiento del Miserere verificaba un punto de encuentro entre Iglesia, instituciones civiles y sociedad local en la Edad Contemporánea, y se podría considerar como uno de esos espacios simbólicos en los que se daban, en los inicios del siglo XX, las condiciones de aquella otra época de esplendor, los siglos XVI y XVII. La ciudad se congregaba bajo las bóvedas del templo, en el que asistía a un acto de carácter religiosocultural, festivo y espectacular. El "templo" cumplía así su secular misión, no sólo religiosa, sino civilizadora, según De la Rosa. Lo profano penetró en lo sagrado, convirtiéndolo en cultura. Esta confluencia -corrupción de lo sagrado, según posiciones ortodoxas-, pudo contemplarse como una oportunidad para demostrar el poder de convocatoria e influencia que seguía teniendo la institución eclesial a pesar de la difícil relación que mantenía con la cultura moderna. La Catedral no sólo había sido y seguía siendo un símbolo emblemático de la ciudad, sino, además, una entidad capaz de moldear en términos culturales sectores mayoritarios de la sociedad, y de influir determinantemente en la configuración de la imagen e identidad de la ciudad de Sevilla en general en los albores del siglo XX.

${ }^{221}$ Muñoz y Pabón, “El Miserere”, p. 67. 


\section{El proyecto regeneracionista de Vicente Ripollés en Sevilla}

\subsection{Vicente Ripollés versus Modesto Abín: los antagonismos ideológicos en}

\section{la base del conflicto}

El 1 de octubre de 1903, menos de dos meses antes de la publicación del MP, Modesto $A$ bín $^{222}$, el canónigo que, recordemos, había mostrado una actitud más beligerante ante el intento de aplicación de la reforma en la Catedral, fue el encargado de dictar la lección inaugural del curso en el Seminario diocesano; su título La Sagrada Liturgia. Al final de su disertación efectuó algunos comentarios desde un punto de vista legal. Ante un auditorio llamado a asumir las responsabilidades en la gestión litúrgicomusical como era el compuesto por futuros sacerdotes, el secretario capitular incidió en dos ideas fundamentales. Por un lado, reafirmar la autoridad de la Iglesia como instauradora de los principios y leyes en materia litúrgica. Por otro, concienciar sobre la importancia de la formación del sacerdote, y sobre su papel como encargado de aplicar y respectar dichos principios $^{223}$ :

El valor doctrinal de los ritos y ceremonias tanto en el orden especulativo como práctico, requiere una autoridad que vele por la conservación de tan rico tesoro. [...]

\footnotetext{
${ }^{222}$ Nacido en Sevilla en 1849 fue ordenado sacerdote a los 24 años. Doctor en Teología, nombrado rector del Seminario en 1896 y prefecto de estudios de la Universidad Pontificia en 1902, su vida estuvo ligada a dicha institución, de quien, en palabras de Martín Riego era su "alma mater"; La formación intelectual del clero, p. 201. Disfrutó de un beneficio en la Catedral entre 1880 y 1889, año en el que accedió al canonicato. Fue director del BOAS. Méndez Bejarano destaca entre sus escritos, las cuatro lecciones inaugurales que dictó en el Seminario, una de las cuales es objeto de nuestro análisis. Véase: Mario Méndez Bejarano, Diccionario de escritores, maestros y oradores naturales de Sevilla y su actual provincia. Tomo I (Sevilla: Tipografía Gironés, 1922), p. 2. En el BOAS no 501 de 1902 se puede encontrar la siguiente semblanza de Abín, propia de una personalidad célebre y reconocida en esos momentos en la ciudad: "El Sr. Modesto Abín es también muy conocido del Clero y pueblo de Sevilla y muy justamente estimado de todos por su piedad, manifestada desde niño, por su clarísimo talento y su saber.

Es hoy uno de los primeros oradores sagrados de la capital de Andalucía y uno de los Sacerdotes de más ilustración y cultura que cuenta en su seno la Diócesis de San Isidoro, de lo cual ha dado numerosas muestras, siendo una de las más recientes su discurso en el Congreso Católico de Compostela”, cit. en: Martín Riego, La formación intelectual del clero, p. 201. En 1918 Joaquín Hazañas y La Rúa le dedicó su voluminoso libro sobre Vázquez de Leca, aquel arcediano del siglo XVII convertido en leyenda por su lucha en favor de la causa inmaculista hispalense. En la dedicatoria destacaba su particular afección por las tradiciones de la Iglesia hispalense: "Permítame V., mi venerado amigo, que estampe su respetable nombre al frente de este libro, que no es, en suma, sino un pequeño fragmento de la historia, aún por hacer, de nuestra Catedral y de su Cabildo, corporación en la que se destaca la figura de V., no sólo por haber llegado a ser el decano de los Capitulares, corno en su tiempo lo fuera Vázquez de Leca, sino por su talento, por su virtud y por su acendrado amor a las gloriosas tradiciones de nuestra Iglesia.” Joaquín Hazañas y La Rúa, Vázquez de Leca (Sevilla: Imp. Sobrinos de Izquierdo, 1918), p. VII.
}

\footnotetext{
${ }^{223}$ Abín defendía la autoridad del papa en cuestiones litúrgicas esta vez frente a la amenaza que constituían las intromisiones del poder civil propias del protestantismo o del regalismo anglicano.
} 
[...]Por otra parte es imperioso deber del Sacerdote conocer perfectamente todo el valor de las decisiones en materia de ceremonias para la solución de las dificultades y dudas que puedan ocurrirle en el ministerio del culto y no debe olvidar ningún Ministro de la Iglesia, que esta, para demostrar prácticamente a todo el mundo católico el interés que le inspira cuanto a Liturgia se refiere ha establecido una respetabilísima Congregación, 'cuyos decretos generales, dice Bouix en su tratado De jure litúrgico, tienen fuerza de ley universal y obligan en conciencia ¿cómo pasar en silencio el notable canon del Concilio de Trento por el que se lanza anatema, no ya solo contra el que altere o desprecie los ritos sagrados, que usa la Iglesia en la administración de los Sacramentos, sino también contra el que de palabra o por escrito enseñe que esto puede hacerse o que un Ministro de la Religión puede omitirlos sin incurrir en pecado? ${ }^{224}$

En la versión de su discurso publicada en el $B O A S$, la cuestión de la música litúrgica tuvo cabida en una cita literal de la, entonces, influyente obra de Joseph Jungmann, La belleza y las bellas artes según las doctrinas de la filosofía socrática y de la cristiana $^{225}$. En ella, el escritor jesuita lanzaba, en palabras del canónigo sevillano, "terribles cargos contra los abusos del canto sagrado", esto es, contra la presencia de la música teatral italianizante en los templos. Este es el fragmento de Jungmann recogido por Abín: "[esos abusos] convierten 'la música del Cielo en melodías teatrales y sobre el texto de los sagrados cánticos hacen oír los aires superficiales de la ópera italiana"”. La cita concluía: "allí (donde imperen estos abusos) el arte no parece tener otro fin que profanar lo sagrado, desfigurar la belleza, convertir el divino servicio en un entretenimiento profano; allí los efectos del arte están en abierta oposición con las intenciones de la Iglesia"226.

De esta forma, el secretario capitular se hacía eco en las palabras de Jungmann de la doctrina oficial de la Iglesia sobre música litúrgica; la que había inspirado, además del $M P$, los distintos documentos elaborados por la Sagrada Congregación de Ritos a la que aludía en su exposición a los seminaristas. Su actitud de resistencia a la plena aplicación de las disposiciones pontificias sobre música durante el proceso de reforma en la Catedral, y de defensa de obras de factura teatral consagradas en el ceremonial de

\footnotetext{
224 [Modesto Abín y Pinedo], “La Sagrada Liturgia”, BOAS, 536 (1903), pp. 149-151.

${ }^{225}$ La traducción castellana de Juan M. Ortí y Lara fue editada en Madrid por la Tipografía de Pascual Conesa en 1873. El original: Die Schönheit und die schöne Kunst: nach den Anschauungen der sokratischen und der christlichen Philosophie in ihrem Wesen dargestellt (Innsbruck: Wagner, 1866).
}

${ }^{226}$ [Abín y Pinedo], “La Sagrada Liturgia”, BOAS, 535 (1903), p. 112, nota no 1. 
las grandes solemnidades pone en evidencia una falta de correspondencia entre estas ideas, que él mismo trasladó a los seminaristas sobre el papel, y su posicionamiento en la realidad concreta.

Tres años y medio después, Vicente Ripollés se dirigió, en el contexto del I Congreso Nacional de Música Sagrada celebrado en Valladolid, a otro colectivo del que dependería en gran medida el futuro de la música litúrgica católica en España; el que se terminaría articulando y denominando como movimiento para la reforma de la música sagrada $^{227}$. Ripollés realizó un diagnóstico nada favorable de la situación: la gestión de la música litúrgica en los templos estaba sometida a criterios arbitrarios o personales, exclusivamente estéticos y artísticos, o dirigida a promover la devoción popular a través de medios no siempre justificables:

Es equivocación muy lamentable juzgar que la música en la iglesia es cosa indiferente que puede dejarse al arbitrio y gusto del criterio individual; que no debe ser apreciada más que con arreglo a los principios técnicos y estéticos del arte y según sus progresos y adelantamientos de fondo y forma; que debe ceñirse a estimular la devoción del pueblo, valiéndose para ello de las formas que más le seduzcan y halaguen. ${ }^{228}$

Sus causas se encontraban, además de en el "mal gusto y errado criterio" que compartía el clero con el conjunto de la sociedad, en su dejadez en lo tocante a la música sagrada ${ }^{229}$ :

Porque bien es cierto que cuando se trata de defender el Dogma contra toda sombra de error; cuando se ha tratado de establecer y propagar instituciones de índole católico-social; cuando precisa evitar profanaciones en los lugares santos; cuando es la hora de acudir sin tregua ni descanso al ejercicio de sus penosos ministerios a favor de los fieles; o de cooperar con su desprendimiento y trabajo al esplendor del culto, el Clero español, llevado de santo celo, se ha desvivido y multiplicado para cumplir con todo y con todos. [...] Sólo hay una excepción, triste excepción; sólo la causa de la música

\footnotetext{
${ }^{227}$ Sobre el I Congreso Nacional de Música Sagrada (Valladolid, 1907), véase el primer epígrafe del capítulo quinto, "Antecedente del congreso de Sevilla: el I Congreso Nacional de Música Sagrada (Valladolid, 1907)".

${ }^{228}$ [Vicente Ripollés], "La cultura litúrgica-musical del Clero", Crónica del Primer Congreso Nacional de Música Sagrada: celebrado en Valladolid en abril de 1907 (Valladolid: Imp. y Lib. Religiosa de Andrés Martín, 1908), p. 59.

${ }^{229}$ Ibídem, p. 61.
} 
sagrada permanece ajena a la acción e influencia del sacerdote; sólo la parte musical de la Liturgia católica es mirada con indiferencia, a veces con desdén y desprecio, por ese Clero tan celoso y abandonada al cuidado de manos no ungidas, de profesores doctos o indoctos, que con buena fe ciertamente, pero las más de las veces con punible olvido de las exigencias Litúrgicas, han formado ese superabundante repertorio antilitúrgico, no pocas veces antiartístico, que llena nuestros templos sagrados. ${ }^{230}$

Las soluciones que propuso para atajar esta problemática coincidían con las dos ideas básicas expuestas por Abín a los seminaristas. Por un lado, subrayar de nuevo la autoridad de la Iglesia a la hora de establecer criterios en la gestión de las cuestiones litúrgico-musicales, regulados por leyes canónicas: "la música sagrada forma parte integrante de la Liturgia solemne: y como la Iglesia es la que legisla en todo aquello que con la Liturgia se relaciona, la Iglesia es la que debe disponer en materias de música sagrada." Por otro, concienciar a los administradores de templos sobre su derecho y deber de aplicar y hacer guardar las leyes litúrgico-musicales promulgadas por la autoridad eclesial: pertenece "a los ministros del santuario el derecho y la obligación de ejercer las funciones sagradas y vigilar la estricta observancia de las disposiciones litúrgicas.",231

Como se constató durante los primeros capítulos, el éxito de la reforma dependía, también según la opinión de Ripollés, del papel que jugara el clero. La acción reformista debía estar dirigida a crear conciencia, y sobre todo, a formarles en los principios litúrgico-musicales. Lo que Ripollés llamaba “cultura litúrgico-musical”:

Si se quiere, pues, que la restauración sea un hecho en España importa muy mucho que la causa se ponga en manos y a cuidado del Clero; que este se convenza de que la música en el templo no es cosa indiferente a su sagrado ministerio [...] Pero con el fin de llegar a este convencimiento, precisa valerse de todos los medios disponibles para difundir la cultura litúrgica-musical entre el Clero de hoy y el de mañana. ${ }^{232}$

Con ello, el maestro de capilla hispalense estaba planteando al grueso del colectivo comprometido en hacer realidad la reforma, congregado por primera vez en un

\footnotetext{
${ }^{230}$ Ibídem, p. 60.

${ }^{231}$ Ibídem, p. 59.

${ }^{232}$ Ibídem, p. 61.
} 
foro que pretendía tener alcance general español, la necesidad de seguir un auténtico programa de regeneración litúrgico-musical para el clero católico ${ }^{233}$. Al final de su exposición, realizaba la siguiente afirmación:

Tengo para mí que el día en que el Clero se convenza de la contradicción existente entre sus prejuicios y prácticas rutinarias con las prescripciones litúrgicas, y de que la restauración de la música sagrada le incumbe por razón de ser parte integrante de la Liturgia, podrá darse como hecha la suspirada reforma. ${ }^{234}$

Con esta apreciación, expuesta a modo de predicción, Ripollés enfocaba la atención en actitudes contradictorias como las de su compañero en el Coro de la catedral, Modesto Abín, quien aún recogiendo en su discurso a los seminaristas la posición oficial de la Iglesia romana -’las prescripciones litúrgicas"-, lideró, según pudimos comprobar en el capítulo tercero, el grupo de canónigos que mostraron una mayor resistencia a la introducción de cambios en los usos musicales -"prácticas rutinarias"- catedralicios. Resulta difícil dilucidar las razones de esta aparente falta de coherencia. Sin embargo, desde otras premisas, es posible, al menos, plantear una hipótesis que sirva como posible explicación. Encontramos una correspondencia entre el valor prioritario otorgado a la tradición local y la necesidad de conservarla, por un

\footnotetext{
${ }^{233}$ Ripollés propuso al Congreso la aprobación de las siguientes conclusiones: "Considerando que para implantar la reforma litúrgica-musical es necesario destruir los prejuicios y prácticas rutinarias en el Clero existentes, y que para llegar a la consecución de este fin el medio más oportuno y eficaz es la difusión de la cultura musical y litúrgica: El Congreso hace votos para que el Clero se dedique con voluntad, convicción y abnegación a adquirir esta cultura, y al efecto propone que en todas las reuniones eclesiásticas se toque alguna materia relacionada con la música sagrada: que en los Seminarios no solamente se enseñe el canto gregoriano con la seriedad debida, sino que además, 'en las lecciones ordinarias de Liturgia y moral y Derecho canónico no dejen de tocarse aquellos puntos que más especialmente se refieren a los principios fundamentales y las reglas de la música sagrada, procurándose completar la doctrina con instrucciones especiales acerca de la estética del arte religioso para que los clérigos no salgan del Seminario ayunos de estas nociones, tan necesarias a la plena cultura eclesiástica.' (M.P. de S. S. Pío X)”. Ibídem.

"1. ${ }^{\circ}$ Para que el Clero, convenciéndose de su misión respecto de la música sagrada, se interese vivamente por ella y extienda su reconocido celo a la pronta restauración en España de la música litúrgica, según los deseos de S. S. Pío X.

2. ${ }^{\circ}$ Para alentar al Clero en esta laudable empresa, el Congreso respetuosamente acude y ruega a los Reverendísimos Prelados españoles, que permitan la inserción frecuente, en sus respectivos Boletines, de trabajos que ilustren la materia y mantengan encendido el fuego del entusiasmo por esta sagrada causa.

3. ${ }^{\circ}$ El Congreso invita a los entendidos en Liturgia sagrada a ocuparse frecuentemente en estas materias por medio de artículos claros y luminosos, y ruega a los periódicos y revistas católicas cooperen a la restauración deseada, admitiendo en sus redacciones los trabajos que vayan informados en los principios e ideas contenidos en el M. P. de S.S. Pío X.” Ibídem, pp. 60-61.
}

${ }^{234}$ Ibídem, p. 61. 
lado, y la doctrina sobre la variedad litúrgica defendida por Abín en su lección a los seminaristas. Tratemos de explicarla a continuación.

Prosigamos, pues, el análisis del discurso del secretario capitular, aunque conviene hacer previamente la siguiente matización: es evidente que en él no se dio el desinterés y desatención que Ripollés reprochaba al clero. Su activismo en el proceso de reforma de la música en la Catedral hace patente la importancia que la cuestión musical tenía en su escala de prioridades. Sin embargo, su compromiso estaba al servicio de un fin conservacionista en lugar de reformador, por tanto, situado en el extremo diametralmente opuesto al de Ripollés.

Situándose en los albores del cristianismo, Abín comenzaba: "Las formas esenciales del culto en los primeros siglos del Cristianismo eran por lo mismo inmutables y permanentes, $[\ldots]^{?, 235}$. Y citando a Asseman, continuaba:

Aunque los Apóstoles, dice Asseman, instruidos por el Señor sabían muy bien lo mucho que contribuye a conservar la unidad de la Iglesia la uniformidad, aún en las cosas y acciones más menudas, sin embargo, tanto ellos como sus sucesores propusiéronse imitar en esto la economía divina que provee y atiende a cada cosa según su naturaleza y exigencia, como dicen las escuelas, y que ha creado en el mundo la variedad para que sea el más cumplido elogio de la divina Sabiduria. ${ }^{236}$

Desde este fundamento, estaba justificado, según el contexto, "[rodear] de diverso aparato ceremonial la forma de celebrar la Eucaristía", aunque salvando siempre "lo esencial e inmutable"237, es decir, lo instituido por el propio Cristo, cuya transmisión en toda su pureza garantizaba la autenticidad de la fe a través de los tiempos:

Siguiendo el mandato de Cristo, los Apóstoles al establecer las cristiandades llevan a todas partes, para no alterarla jamás, la forma, la expresión esencial del culto que habían recibido de su Maestro, y usando de la potestad que Este les comunicara, establecían nuevas ceremonias cuando lo exigían las circunstancias ${ }^{238}$

\footnotetext{
${ }^{235}$ [Abín y Pinedo], "La Sagrada Liturgia”, p. 382.

${ }^{236}$ Ibídem.

${ }^{237}$ Ibídem.

${ }^{238}$ Ibídem, p. 379.
} 
Y no sólo estaba justificado sino que también era recomendable para evitar conflictos, y para conservar la venerable herencia traspasada por los predecesores:

Y estaban tan lejos los antiguos de reprobar esta variedad de liturgias, que por el contrario, en más de una ocasión la recomendaron los Santos Padres y aún los Romanos Pontífices. El mismo San Agustín refiere que dudando él si debería observar varias ceremonias de algunas iglesias le hubo de decir San Ambrosio: "Si no quieres servir de escándalo a los demás, ni que los demás lo sean para ti, guarda las costumbres de la Iglesia en que estuvieres". San Jerónimo enseña que no debían alterarse las practicas recibidas de los mayores cuando no perjudican a la $\mathrm{Fe}^{239}$

Por tanto, a pesar del reconocido beneficio que para la unidad de la Iglesia comportaba la uniformidad de costumbres, las circunstancias particulares, la identidad de las iglesias locales, y el legado recibido de los predecesores, es decir, la tradición, justificaban la diversidad litúrgica, salvando siempre lo esencial de la fe.

Resulta interesante observar que fueron estas mismas ideas las que fundamentaron las razones que alegaron tanto Spínola como el Cabildo para intentar preservar las costumbres litúrgicas, en especial, el oficio de Tinieblas tal y como se acostumbraba celebrar en la Catedral. Recordemos que, en su petición de exención en la aplicación del MP para el caso del Miserere, Spínola advertió a Pío X sobre el "grave conflicto" -“escándalo" en la cita de San Ambrosio- que la supresión de la costumbre traería consigo ${ }^{240}$. El Cabildo, por su parte, invocaba la necesidad de no disminuir el “esplendor" característico de los cultos catedralicios, así como el valor de la herencia recibida "de nuestros mayores" en el caso de las lamentaciones ${ }^{241}$.

\footnotetext{
${ }^{239}$ Ibídem, p. 383.

240 "el grave conflicto que se debe temer por la supresión de esta costumbre y desgracias mayores que forzosamente se conseguirían no sólo en el orden moral, sino también en el material y económico". "Gravis proinde conflictus ex hujusmodi consuetudinis abrogatione pertimescendus, gravioraque mala, quae necesario consequutura forent non solum in ordine morali, sed etiam in materiali et oeconomico." ASV, Segretaria di Stato, anno 1905, rubrica 283, fascicolo 2, fols. 46v-47r.

241 "la Comisión pedirá al Sr., Arzobispo, tan interesado como el mismo Cabildo en que no decaiga el tradicional esplendor de nuestro culto y las loables costumbres que nos han legado nuestros mayores, que se digne dar su muy ilustrado y respetable parecer sobre si debe el Cabildo abstenerse desde luego de cantar con música las Lamentaciones o si puede tolerarse esta práctica por las mismas o análogas razones que se hubieren alegado para el canto del Miserere.” AC 27/3/1905. ACS. Sección Secretaría, libro 227, fol. $15 \mathrm{r}$.
} 
Abín, de hecho, aludía a esta doctrina como un criterio fundamental que, aunque se remontaba a los primeros tiempos del cristianismo, había sido mantenido por la Iglesia a lo largo de la historia:

los Apóstoles al establecer las cristiandades llevan a todas partes, para no alterarla jamás, la forma, la expresión esencial del culto que habían recibido de su maestro, y usando de la potestad que este les comunicara, establecían nuevas ceremonias cuando lo exigían las circunstancias, firmes siempre en el propósito de robustecer la fe de los fieles, y de hacer el culto más rico en enseñanza y edificación. $\mathrm{Y}$ esta potestad ha continuado en la iglesia, a través de los tiempos, ${ }^{242}$

Esta misma doctrina sobre la unidad y diversidad litúrgica transmitidas por la tradición apostólica, los Padres de la Iglesia y los papas debió haber constituido el marco ideológico en el que encontraría coherencia la posición y actitud de Abín: la adhesión a los preceptos de la Santa Sede en términos generales -salvando lo "esencial e inmutable"- no estaría reñida con su empeño en la defensa de la identidad de la Iglesia local.

No obstante, el carácter de código jurídico del $M P$ hacía de la conservación de las tradiciones musicales incompatibles con sus principios un objetivo fuera de la nueva legalidad litúrgico-musical. La consecución de exenciones o privilegios se convirtió en la única posibilidad en manos del Cabildo para conservar sus usos musicales sin apartarse de las directrices romanas. Como pudimos comprobar, las propuestas de elevar consultas a Roma con este objetivo, en las que de una forma u otra estuvo siempre implicado Abín, fueron frecuentes entre 1905 y 1909.

Sobre estas prácticas litúrgico-musicales también se manifestó Ripollés en el congreso de Valladolid. El concepto que el castellonense tenía de ellas chocaba frontalmente con el que, en el caso concreto de Sevilla, poseía el cabildo hispalense. Lo que para unos constituían venerables tradiciones, de las que dependía, en buena medida, la propia identidad de la institución, para Ripollés no eran más que "prácticas rutinarias", permitidas y consagradas en la liturgia por unos responsables eclesiásticos con un "criterio errado" y un "gusto deplorable". La masiva penetración en el templo de obras musicales "antilitúrgicas", y como señala en otro pasaje, "antiartísticas" muchas de ellas, habían formado musicalmente tanto a los fieles como al propio clero,

\footnotetext{
${ }^{242}$ Abín y Pinedo, “La Sagrada Liturgia”, BOAS, 532 (1903), p. 379.
} 
por lo que se trataba de un proceso de desviación y corrupción del gusto y criterio, que constituían el origen del problema ${ }^{243}$ :

La avalancha de composiciones musicales antilitúrgicas que ha invadido los templos ha formado entre el Clero y los fieles un criterio errado y un gusto deplorable que no es de alabar. Este mal gusto y este errado criterio han contribuido a su vez a conceder carta de naturaleza en las iglesias a multitud de prejuicios y prácticas rutinarias que, disfrazadas con el sugestivo y pomposo nombre de Tradiciones [sic], han constituido, en frase del inolvidable P. E. Uriarte, el muro de contención de los buenos propósitos y aspiraciones elevadas. $^{244}$

Estas declaraciones de Ripollés tenían, en el caso sevillano, un carácter bastante rompedor, pues constituían una crítica -inédita hasta ese momento, tal y como testimonia Turina en el artículo discutido más arriba ${ }^{245}$ - a los fundamentos de una realidad construida con la argamasa de conceptos como tradición, identidad, patrimonio o legado. En primer lugar, rechazaba unas expresiones litúrgico-musicales que se habían consolidado como parte integrante de las grandes festividades litúrgicas locales, con un importante valor simbólico. En segundo lugar, al descalificar el criterio y gusto del clero, cuestionaba la legitimidad de su autoridad como fijadores del canon litúrgicomusical de los templos. Aplicado al caso de la catedral de Sevilla, a la institución a la que cuestionaba era, obviamente, al Cabildo, como constataremos a continuación.

\footnotetext{
${ }^{243}$ La contemplación de la evolución de la música religiosa durante los siglos XVIII y XIX como un proceso de declive y corrupción fue algo bastante extendido, no sólo entre los músicos regeneracionistas españoles, como veremos en el capítulo sexto, sino también entre la parte del clero más receptiva a los postulados reformistas. El arzobispo de Santiago de Compostela explicaba en 1908 los orígenes de la decadencia de la música sacra según su punto de vista. La música, y en concreto la sacra "por la influencia que ejerce el arte profano en el sagrado", no está ajena a la transformación de los valores estéticos, y parámetros ideológicos propios de los cambios culturales que se producen en el devenir histórico, como producto y fuente de esa cultura. Esos cambios culturales en ocasiones lleva a las artes a una desviación, cuya tendencia extrema es la ofuscación del discernimiento de la belleza, que está íntimamente ligada a la bondad, introduciéndose por tanto "abusos", es decir, produciéndose una degradación de las mismas. El nuevo sistema de valores, fruto de una progresiva degeneración de los gustos y juicio estético, pasa a consolidarse constituyendo "la manera de ser de los pueblos". Este profundo arraigo en la cultura es la principal causa de las dificultades para la reforma, que precisa de tiempo para realizarse e imponerse como rectificación histórica que pretende ser. Crónica del Segundo Congreso Nacional de Música Sagrada celebrado en Sevilla los días 12, 13, 14 y 15 de noviembre de 1908 (Sevilla: Izquierdo y C., 1909), pp. 32-33.

244 [Ripollés], "La cultura litúrgica-musical del Clero", p. 61.

245 Véase capítulo 4, epígrafe 3.1. "El lenguaje musical de Eslava: un dialecto artístico 'moderno' transmutado en tradición”, p. 261 y ss.
} 
Además, según el análisis de Ripollés, estos "prejuicios" que no criterios, y "prácticas rutinarias" que no tradiciones, constituían los principales obstáculos -"muro de contención”, en palabras de Uriarte- para la realización de la reforma, de la que había hecho la gran causa de su vida como músico y sacerdote. Por tanto, la estrategia que había que seguir para cumplir con el proyecto restaurador estaba clara:

Si ha de trabajarse con provecho en la magna empresa de la restauración litúrgica musical, preciso es que desaparezca este muro de contención, que se disipen los prejuicios y vengan al suelo las prácticas rutinarias; y el medio más oportuno y eficaz para conseguirlo es la conveniente difusión de la cultura litúrgico-musical entre el Clero. ${ }^{246}$

Las diferencias ideológica, de criterio e incluso de interpretación y perspectiva de Cabildo y maestro de capilla no se reducían a la ya de por sí profunda, y posiblemente insalvable, sobre la consideración de las costumbres sevillanas tradiciones o rutinas- y el criterio -errado, o prejuicio- que las sustentaba. La idea acerca de que la música de origen profano pudiera adquirir sentido y carácter religioso al interactuar con lo sagrado, dentro de un sistema ideológico que justificaba un concepto del "templo" - de lo religioso- abierto a la cultura y sociedad civil para verter en ella valores religiosos -civilizarla- eran absolutamente opuesta al pensamiento de Ripollés; una idea, por cierto, igualmente presente en el discurso de Abín ${ }^{247}$. Para el maestro de capilla, de acuerdo a la doctrina de los documentos oficiales romanos, existía una incompatibilidad sustancial entre la naturaleza de la música religiosa y la profana.

En 1899, Ripollés escribió un extenso artículo, Del concepto y norma de la música religiosa, en la revista Música Religiosa de España (órgano de difusión de la Asociación Isidoriana para la reforma de la música según las prescripciones de la

${ }^{246}$ Ibídem.

${ }^{247}$ Abín señalaba el profundo significado sociopolítico impreso por Dios incluso en la propia esencia de los ritos de una fiesta como era la de la pascua judía: "Dios no es sólo el único señor de la naturaleza, sino el soberano legislador, el autor de la sociedad, el árbitro de las naciones, que las recompensa con la prosperidad o las castiga con la desgracia.[...] la especial providencia de Dios sobre el pueblo israelita supo imprimir a las leyes ceremoniales una tendencia eficacísima para inspirar a aquellos hombres de dura cerviz grandes virtudes sociales, y por eso la gran fiesta de la Pascua o la Cena del cordero, hermosa figura de la Pascua cristiana, sin dejar de ser una fiesta de índole esencialmente religiosa, o mejor dicho, siendo la fiesta religiosa por antonomasia de la Ley Mosaica, venía a constituir a la vez perenne monumento erigido a la independencia patria y la más solemne condenación de todas las tiranías." Abín y Pinedo, "La Sagrada Liturgia”, BOAS, 531 (1903), p. 350. 
Iglesia) en el que explicaba esta diferencia esencial ${ }^{248}$. La música profana está sujeta al criterio humano, fluctuante y contingente:

[...] la música profana, la cual, como mera cuestión terrena, Dios entregó a las disputas de los hombres, sujetándola a sus inciertos pareceres y ligándola a las inconstancias de los tiempos, sin que a nadie le sea dado determinar con indiscutible precisión, este quid indeterminado en que después de observadas las reglas que a la música intrínsecamente la determinan por razón de orden y belleza, todo cuanto resta es indefinido y nebuloso, como vago e indefinido es el sentimiento artístico del cual procede, pende y la perfecciona. ${ }^{249}$

La religiosa, por su parte, estaba sometida a la voluntad de Dios, la cual sólo la Iglesia era capaz de interpretar:

No así, repetimos, en la música religiosa que, al ofrecer a Dios la primicias de la armonía, atiende preferentemente, sin menoscabo ni mengua del arte, a escudriñar la soberana voluntad divina para presentarle rendida su ofrenda a medida de sus augustas indicaciones, para que menos indigna para sus ojos, se avaloren sus tesoros con el mérito de la obediencia, sin la cual, el Señor aborrece el sacrificio de la alabanza.

Y como no existe otro medio para escudriñar los arcanos del divino querer, fuera de los oráculos de la mística Esposa de Cristo nuestra madre la Iglesia, aquella música será consecuencia digna de la santidad del Templo, $[\ldots]^{250}$

\footnotetext{
${ }^{248}$ Está por publicar un estudio profundo sobre el pensamiento de Vicente Ripollés. Además de los ya citados artículos de Picó, "La aportación musicológica del canónigo Vicente Ripollés Pérez", pp. 287294; Genovés, "Una mirada al 'motu proprio' valenciano", pp. 67-76, y la voz "Ripollés Pérez, Vicente" escrita por Andrea Bombi para el Diccionario de la Música valenciana, pp. 344-346; la relación de trabajos dedicados a Ripollés se completa con Andrea Bombi, "Perspectivas históricas en los escritos de Vicente Ripollés (1867-1943)", en Musicología en la Edad de Plata, ed. por Juan José Carreras (Zaragoza: Instituto Fernando el Católico); del mismo autor, "Vicente Ripollés, el Colegio del Patriarca y la reforma ceciliana", en Música y reforma litúrgica desde 1611 hasta el presente, ed. por Rosa Isusi Fagoaga y Greta Olson; Miguel López Fernández, "El papel del maestro de capilla en la reforma de la música litúrgica promovida por Pío X: el caso de Vicente Ripollés en Sevilla", ibídem; en estos momentos todos en prensa. En 2005 se celebró el curso Vicente Ripollés (1878-1943) y la historiografía musical de su tiempo, organizado por la Asociación cultural Pro Historia Musicae y el Instituto Valenciano de la Música, aunque no se ha publicado ninguna de las intervenciones que tuvieron lugar.
}

${ }^{249}$ Vicente Ripollés, "Del concepto y norma de la música religiosa", La Música Religiosa de España, 32 (1899), p. 112-116, p. 115. El artículo fue publicado en varias entregas, entre los meses de agosto y novimbre: $n^{\circ} 33$, pp. 129-136; $n^{\circ} 34$, pp. 145-148; no 35 , pp. 161-165.

${ }^{250}$ Ibídem, p. 116. 
Por tanto, era imposible que la música teatral, de esencia profana, pudiera prestar restos -"migajas"- de sus recursos, lenguaje y expresiones a la música religiosa, al sentimiento religioso. Es decir, su presencia en el culto era ilegítima:

Por esta razón con vivo dolor se deploran los inconcebibles abusos a nombre de la música en el templo perpetrados, abusos que llenan los pechos de santa indignación al considerar que con las migajas caídas de la fastuosa mesa del Epulón del teatro moderno, (última expresión de la música profana) se trata de realzar los cultos siempre augustos del templo de Dios, alimentando de tal suerte a la música religiosa, mientras cual otro Lázaro, ética y atropellada la pobre, agoniza cubierta de oprobio. ${ }^{251}$

En este contexto, resulta interesante conocer la opinión que sobre el fenómeno de los misereres expresó en el mismo artículo al que nos venimos refiriendo:

[...] con solas dos palabras describe [el Ceremonial de obispos] perfectamente el carácter dominante de la música polifónica con que ha de ser interpretado: "Después el salmo Miserere me Deus...modulata sed flebili voce." (Cer. Epis. libro II, cap. XXII.)

Modulata voce, según el Diccionario, es "cantar con dulzura, suavidad y armonía", y flebili voce, significa con canto lloroso, acento lúgubre, triste, amargado con lágrimas, saturado de penas y llanto. Estas dos cualidades falta, por desgracia, a ciertos Misereres a la moda, en los cuales, a más del empleo de reprobados instrumentos, lo profano y estrepitoso se esfuerzan en trocar los lúgubres cánticos sagrados en contrahechas operetas, solaz y entretenimiento de ciertos elementos que, por lo augusto de los días, con no poco sentimiento, carecen de ópera mejor. ${ }^{252}$

Por tanto, las visiones de unos y otro eran, también en este punto, radicalmente distintas e incluso opuestas. La interinfluencia entre música teatral, entre sus migajas que habría que entender como restos viles, de baja calidad artística-, y textos sagrados, es decir, entre cultura y religión, no podía ser vista por Ripollés nada más que como un atropello, según se expresaba en el texto transcrito más arriba.

En suma, ¿tradiciones dignas de conservación como identidad de la Iglesia local, o rutinas fruto de una tendencia extraviada y por ello de obligada eliminación?¿es posible que elementos musicales originarios de una manifestación cultural profana

\footnotetext{
${ }^{251}$ Ibídem, p. 114.

${ }^{252}$ Ripollés, "Del concepto y norma de la música religiosa", La música religiosa de España, 35 (1899), 163.
} 
conformen una expresión musical religiosa y sirvan por tanto para suscitar piedad y sentimiento religioso en la liturgia, o sean simplemente corruptores de lo sagrado?, y en consecuencia, ¿es religioso el canon musical de las grandes solemnidades litúrgicas de la Catedral? Independientemente de que las nuevas normas litúrgico-musicales daban respuesta a todos estos interrogantes, el conflicto estaba servido. Como hemos ido comprobando, la cuestión era mucho más compleja que una mera y aséptica aplicación de la ley eclesiástica, sino que poseía grandes implicaciones ideológicas y culturales.

\subsection{El programa regeneracionista de Ripollés: "que se disipen los} prejuicios y vengan al suelo las prácticas rutinarias"

La estancia de Ripollés en Sevilla, aunque breve, constituye un capítulo de especial interés en la historia de la música en la Catedral, pues intentó, como un reto personal, poner en marcha un programa no sólo de reformas sino de auténtica regeneración. Ello supuso un auténtico desafío al estatu quo al cuestionarlo desde sus propios fundamentos. Como trataremos de glosar a continuación, Ripollés tuvo como objetivo poner en práctica en Sevilla el programa de regeneración del que habló en Valladolid: "que se disipen los prejuicios y vengan al suelo las prácticas rutinarias". Estos propósitos resultaban ciertamente ambiciosos habida cuenta de la trascendencia cultural que las expresiones litúrgico-musicales locales -"prácticas rutinarias"- poseían, y del valor que las mismas tenían en el pensamiento de los eclesiásticos y comunidad catedralicia en general, radicalmente opuesto al de Ripollés -"prejuicios"-.

El método a aplicar consistió en una estrategia de (re)culturización, es decir, de regeneración cultural, tal y como propuso igualmente en la ciudad castellana: "y el medio más oportuno y eficaz para conseguirlo es la conveniente difusión de la cultura litúrgico-musical entre el Clero"253. En el caso de Sevilla, y muy probablemente el de la inmensa mayoría de diócesis del país, esto se traducía, en realidad, en la difusión de una nueva "cultura litúrgico-musical" entre el Clero

El castellonense puso en marcha su personal proyecto nada más tomar posesión de su nuevo cargo de maestro de capilla, es decir, antes incluso de que se promulgara el $M P^{254}$. Las cartas que durante esos meses escribió Pedrell a Ripollés nos aportan importante información sobre los objetivos del segundo, y la estrategia que pretendió

\footnotetext{
${ }^{253}$ [Ripollés], "La cultura litúrgica-musical del Clero", p. 61.

${ }^{254}$ Ripollés llegó a Sevilla en junio de 1903.
} 
desplegar en Sevilla ${ }^{255}$. Demuestran, además, la cercana relación que, en esos momentos, mantenía con el líder del regeneracionismo musical español, así como la considerable influencia que sobre él ejerció. Ripollés representó la presencia de las ideas y el proyecto de filiación pedrelliana como supuestos realizables, dentro del ámbito religioso, en la Sevilla de principios de siglo. Como se demostrará durante la celebración del II Congreso Nacional de Música Sagrada, la ciudad andaluza constituyó una plaza de especial valor simbólico a incorporar a la causa nacionalista musical española $^{256}$.

\subsubsection{La educación, fundamento de la regeneración. La formación de los} seises y la fundación de un conservatorio

En varias ocasiones se han puesto de manifiesto las distintas influencias que conformaron el trasfondo ideológico del regeneracionismo musical pedrelliano, entre las que se cuentan las ideas krausistas en su versión española, tan en boga en los círculos liberales burgueses del momento ${ }^{257}$. Una de las principales líneas de acción seguidas en el intento de restauración musical liderado por Pedrell fue elevar la cultura musical del país a través de la educación. Sus actividades musicológica, publicista y crítica estaban dirigidas a formar -regenerar- a la sociedad para su reconstitución ideológica y “espiritual”. Este es el marco ideológico en el que, creemos, habría que entender la empresa reformista musical llevada a cabo por Ripollés, uno de sus más cercanos discípulos y fieles seguidores.

Como informa la primera de estas misivas, con fecha de ocho de junio de 1903, Ripollés comenzó centrando su trabajo, con el beneplácito y consejo de Pedrell, en la reeducación de los seises, el colectivo más joven, por tanto, más receptivo y tolerante a sus nuevas propuestas:

\footnotetext{
${ }^{255}$ Las cartas que durante ese tiempo envió Ripollés a Pedrell no se conservan.

${ }^{256}$ Trataremos esta cuestión en el capítulo 6.

${ }^{257}$ Leticia Sánchez de Andrés ha dedicado varias publicaciones a la relación entre krausismo y música en España. Véase, entre otros: Música para un ideal: pensamiento y actividad musical del krausismo e institucionismo españoles (1854-1936) (Madrid: SEdeM, 2009); "El pensamiento estético del krausismo español y su proyección en la investigación musicológica y la crítica musical", Revista de Musicología, XXVIII/2 (2005), pp. 961-976. Véase, además: Dochy Lichstensztajn, "El regeneracionismo y la dimensión educadora de la música en la obra de Felip Pedrell”, Recerca Musicològica, 14-15 (20042005), pp. 301-323. Rafael Lamas describe los componentes ideológicos del regeneracionismo pedrelliano, entre los que se encuentra el krausismo en: Música e identidad: el teatro musical español y los intelectuales en la Edad Moderna (Madrid: Alianza, 2008), p. 135.
} 
Querido amigo: muy de veras celebro las noticias que me comunica por las cuales veo que ha entrado V. con buen pie. Piano, piano si va lontano [subrayado original] y poco a poco todo se andará, con ánimos y diplomacia.

Terminadas las funciones de Corpus bien me parece que empiece V. a zarandear a los seises, base de futuros mejoramientos: el cabildo le secundará al notar los adelantos y con estos podrá $\mathrm{V}$. anular los embarazosos elementos de la capilla, malos y pretenciosos, cuatro soldados y un cabo para soldados que no son soldados.

Escriba con frecuencia y así se le pasará la morriña. ${ }^{258}$

Este pasaje revela que la mentalidad y criterio de los capitulares hispalenses no fue el único ni principal obstáculo con el que se topó Ripollés en la consecución de sus aspiraciones. La actitud de resistencia y no colaboración de sus propios compañeros en la capilla musical catedralicia ("embarazosos elementos de la capilla, malos y pretenciosos") fue otro de los factores que terminaron minando el empuje del castellonense. En su artículo publicado en $M S H$ al que ya hemos hecho referencia ${ }^{259}$, Turina apuntó a los músicos profesionales como "los primeros enemigos" que encontró Ripollés en Sevilla. Los términos usados por el compositor andaluz para referirse a sus colegas sevillanos -a los que llegó a llamar "piporros" en un par de ocasiones ${ }^{260}$ - nos informan de un colectivo de escasa formación y capacidades:

Los primeros enemigos de Ripollés fueron los profesionales, cantores [cursiva original] y músicos, y es bien disculpable su animosidad hacia un estilo donde no podían marchar sin tropezones y caídas, acostumbrados a un camino trillado, y teniendo la mayor parte de esos bases musicales muy dudosas. ${ }^{261}$

Además, sacó a relucir otro de los problemas con los que se encontró la reforma, y que constituyó, según su opinión, “el último golpe”-definitivo- recibido por Ripollés en Sevilla. La aplicación del MP no fue sólo un conflicto cultural, sino

${ }^{258}$ Carta de Pedrell a Ripollés. 8 de junio de 1903. BC. FFP. M 964.

259 Véase capítulo 4, epígrafe 3.1. "El lenguaje musical de Eslava: un dialecto artístico 'moderno' transmutado en tradición”, p. 261 y ss.

260 “Al penetrar en ella se siente uno envuelto en una atmósfera de arte, y tras las gigantescas columnas, esbeltas, altísimas, al lado de los cuadros de Murillo, el Greco y de Goya y al lado de las esculturas de Montañez, toda la música ha estado representada la mayor parte de las veces por cuatro piporros y tres sochantres." Turina, "Crónicas sevillanas", p. 205. "Tras unos meses sin Maestro de Capilla, teniendo por todo consuelo los tradicionales piporros, llega a la Catedral sevillana don Eduardo Torres, [...]" Ibídem, pp. 206-207.

${ }^{261}$ Ibídem, p. 206. 
también un problema de intereses económicos que afectaba a un colectivo, como era el de los músicos eclesiásticos, en una situación crítica ${ }^{262}$ :

La fundación de una masa coral llamada Capilla Mariana, acabó de dar el último golpe, porque se trataba ya de la posibilidad de perder el pan nuestro de todos los días.

Ripollés comprendió la situación y en lugar de prepararse a la lucha, recogió velas y aguardó paciente la hora de marcharse, como lo ha hecho hace un año. ${ }^{263}$

Luis Leandro Mariani, organista segundo de la Catedral y, posiblemente, el músico que gozaba de un mayor prestigio en la ciudad en aquel momento, tampoco se libró de los juicios de Pedrell:

Mariani se despidió de mí por conducto de Lasheras, y lo comprendo después del resbalón teatral. Nada ha pasado que yo sepa. Habló conmigo de omnia re scibili, poco de música, comprendiendo, lo que ya sabía, que es muy amigo de un solo libro. ${ }^{264}$

En cartas posteriores se refleja el enfrentamiento que debió mantener Ripollés con sus compañeros músicos. A través de ellas, podemos saber, además, el tipo de obras que Pedrell aconsejó al castellonense para formar y consumar esa transformación en la "base de futuros mejoramientos", como eran los seises para él. Se trataba de un repertorio formado por obras de compositores cecilianistas italianos, representantes de una estética absolutamente inaudita en la Sevilla del momento; y radicalmente diferente del repertorio con el que hasta ese momento estaban acostumbrados los niños cantores, eclesiásticos y asistentes a las funciones catedralicias en general, como venimos comprobando:

A empezar con los niños, a adiestrarles en solfeo y a emprender obrillas de Botazzo que me parecen excelentes para el coro, lo mismo que las del compañero que Botazzo tenía en Padua, y que ahora está en San Marcos. No recuerdo su nombre [debe tratarse de Oreste Ravanello]. Me parece haber leído que publica un repertorio fácil.

\footnotetext{
${ }^{262}$ Véase capítulo 5, epígrafe 3.2.3. "La situación económica de los músicos eclesiásticos”, p. 404.

${ }^{263}$ Turina, “Crónicas sevillanas”, p. 206.

${ }^{264}$ Ibídem.
} 
Buen golpe ha dado a la cueva de bandidos. Esa aureola le será útil. [A] Aprovecharla ${ }^{265}$

Junto a las obras de Botazzo o Ravanello, Pedrell le propuso algunas propias: "He preparado sin fatigas 4 flors de Maria, de Verdaguer, y dos Cantigas más; ¿por qué no las hace V. cantar ahí a los chicos? Por aquí las cantan algún orfeón.”266 Ripollés debió aceptar las sugerencias de Pedrell, aunque sustituyendo el texto vernáculo por otro latino. En el siguiente fragmento se comenta la posibilidad de parafrasear, además, "Villanescas" como obras para ser adaptadas para el bailes de seises. Suponemos que se referiría a las Villanescas de Francisco Guerrero: "Creo [que] sí, que podrían parafrasearse las Cantigas y Villanescas aplicándolas a los bailes de seises."267 De hecho, un par de años antes, Pedrell le planteaba la hipótesis de que fueran bailadas en origen: "Pero ¿adónde habrá ido a parar la antigua música de los seises? Aunque en el prólogo de las Villanescas de Guerrero no lo dice ¿se cantarían a coro como bailes algunas de esas Villanescas? No me extrañaría por lo muy rimado de alguna de ellas. $" 268$

Por tanto, el primer gran objetivo de Ripollés en su programa de regeneración musical en Sevilla fue la formación de los seises sobre la base de un repertorio que poseía y portaba unos valores estéticos y musicales absolutamente diferentes de los vigentes hasta el momento. El italianismo de corte teatral de Eslava y su sucesor, García Torres, quien había escrito una buena cantidad de obras para los seises, debía ser sustituido por el cecilianismo italiano de compositores como Botazzo y Ravanello, más acorde con los principios litúrgico-musicales, según su criterio.

Sin embargo, su plan regeneracionista no se redujo al grupo de niños cantores catedralicios; ni siquiera a la Catedral. Esta correspondencia revela el intento de Ripollés de fundar en Sevilla un conservatorio, desconocido hasta el momento ${ }^{269}$. El

\footnotetext{
${ }^{265}$ Carta de Pedrell a Ripollés. 25 de junio de 1903. BC. FFP. M 964.

${ }^{266}$ Carta de Pedrell a Ripollés, 8 de febrero de 1905. BC. FFP. M 964.

${ }^{267}$ Carta de Pedrell a Ripollés, 27 de febrero de 1905. Ibídem.

${ }^{268}$ Carta de Pedrell a Ripollés, 10 de julio de 1903. Ibídem.
}

${ }^{269}$ Como apuntamos en el capítulo primero, además de otras academias de menor importancia, existían en Sevilla dos centros de formación musical: la escuela de música de la Real Sociedad Económica de Amigos del País, y el Conservatorio de Música de la Academia Filarmónica, dirigido por Luis L. Mariani. de Mena, Historia del Conservatorio Superior de Música, p. 20. Para más información sobre estos centros remitimos, al igual que hicimos en el primer capítulo a: Fernando Delgado García, Los gobiernos de España y la formación del músico (1812-1956). Universidad de Sevilla (Tesis doctoral), pp. 264-265 y 
proyecto se menciona por primera vez en una carta fechada a finales de junio de 1903, es decir, cuando aún no se había cumplido ni un mes de su llegada a la capital andaluza. En ella, Pedrell aconsejó al castellonense que implicara tanto a Luis Leandro Mariani, que regentaba desde hacía tiempo una de las dos academias de música de la ciudad, como a Ramón Manjarrés ${ }^{270}$. Este ingeniero industrial y catedrático de la Facultad de Ciencias fue el primer presidente de la Sección de Música del Ateneo, organizada en $1901^{271}$ :

Nada hablamos de la Academia: él no me lo dijo y tampoco se lo dije yo. Sin embargo, como lo cortés nada quita a lo valiente, deben Vdes. decírselo cuando llegue el caso: ¿se presta? bueno: ¿no se presta? pues tan amigos como antes. En el primer caso V. se encarga de lo superior (armonía y composición), él del solfeo y Eduardo del piano. En el segundo, carga V. con el solfeo y lo demás, y pax Christi.

Difícil es siempre que el que se dedica a muchas cosas sobresalga en una. ¿Comprende?

Ha de seguirse la misma conducta con Manjarrés: ¿quiere venir a la montaña? venga en buena hora: ¿no quiere? pues la montaña no puede ir a él. Esto es todo, con diplomacia, valor y algo de empuje. $^{272}$

En una carta posterior, Pedrell nos descubre el objetivo último de la fundación del conservatorio. Debía ser el centro en el que se produjera la transformación de la realidad musical de la ciudad:

Y pasando ahora a los sevillanos [cursiva original], ya instalados, hay que insistir en lo de la Academia, pues, si perras hay que ganar, las hallará, también, Eduardo por este lado. No cejen Vdes. en este empeño, y en cuatro años podrán cambiar la faz de todo eso. $^{273}$

307-317. Texto disponible en: http://fondosdigitales.us.es/tesis/tesis/540/los-gobiernos-de-espana-y-laformacion-del-musico-1812-1956/ (consultado 18-2-1913); del mismo autor, "La construcción del sistema nacional de conservatorios en España (1892-1942), Cuadernos de Música Iberoamericana, 12 (2006), pp. 109-134.

${ }^{270}$ Mariani era el director del llamado Conservatorio de Música de la Academia Filarmónica. El otro centro de formación musical era la escuela de música de la Real Sociedad Económica de Amigos del País.

${ }^{271}$ Pedro J. Sánchez Gómez, La música y el Ateneo de Sevilla. 1887-2003, p. 45.

${ }^{272}$ Carta de Pedrell a Ripollés, 25 de junio de 1903. BC. FFP. M 964.

${ }^{273}$ Carta de Pedrell a Ripollés, 3 de octubre de 1903. BC. FFP. M 964. En varias cartas relacionadas con la cuestión de la creación del conservatorio se menciona a Eduardo. Los datos que nos proporcionan sobre él son bastante parcos. Debió ser pianista, a juzgar por el hecho de que se pensara en él para impartir las clases de piano de la futura academia. La siguiente confesión de Ripollés a Pedrell lleva a pensar en que debió ser, además, un músico con bastante formación y al que le unían muchas afinidades: 
Estos documentos no ofrecen más datos significativos sobre el sentido en el que evolucionó la idea y los problemas que debió sortear. La última vez que Pedrell hizo mención del proyecto fue en una carta de finales de 1905: “¿Cómo van esos intentos de Conservatorio?" 274 . La falta de más referencias a la existencia de este centro de corte y fines regeneracionistas lleva a pensar que finalmente no cuajó.

\subsubsection{La obra musical de Ripollés en Sevilla: la sustitución del repertorio} de las solemnidades litúrgicas catedralicias

\subsubsection{Producción musical para las solemnidades del Corpus, Inmaculada}

\section{y Asunción}

La faceta de compositor de obras para la liturgia de la Catedral era, sin duda, el aspecto del trabajo como maestro de capilla en el que Ripollés gozó, seguramente, de un mayor margen de maniobra y una mayor libertad de decisión. Según el edicto de convocación del beneficio, una de sus obligaciones era escribir dos obras cada año, que quedaban en propiedad del Cabildo y pasaban a engrosar el archivo musical de la institución $^{275}$.

Durante los seis años en los que ocupó el cargo, compuso en torno a una docena de piezas, ocho de ellas con acompañamiento de orquesta ${ }^{276}$. Sus destinos litúrgicos fueron importantes fiestas catedralicias, entre las que destacaron precisamente aquellas que poseían un importante valor simbólico. Para las vísperas de la solemnidad del Corpus compuso una colección casi completa de salmos y magníficat ${ }^{277}$. Para la Inmaculada, escribió una de las dos grandes misas con dedicatoria mariana, la misa $D e$

"Eduardo marchóse definitivamente a Málaga sin tener la atención de despedirse: es muy original el tal Eduardo y habrá que dejarlo por imposible: con su desaparición de aquí me he quedado completamente aislado y no tengo más compañeros de música que los libros, porque tratar de arte con la gente de aquí comprende V. que no puede ser." Carta de Ripollés a Pedrell. 25 de enero de 1907. BC. FFP. M 964 R. Hasta el momento, no hemos podido despejar la incógnita de la identidad de este músico.

${ }^{274}$ Carta de Pedrell a Ripollés, 20 de noviembre de 1905. BC. FFP. M 964.

275 "Edictos para la provisión de dos Beneficios en la Santa Iglesia Metropolitana", BOAS, 507 (1903), pp. 26-30.

${ }^{276}$ Proporcionamos la relación de obras compuestas por Ripollés en Sevilla y custodiadas en el Archivo de Música de la Catedral en Apéndice 6.

${ }^{277}$ Además del Magnificat, Ripollés compuso dos de los tres salmos que se cantaban en polifonía: Credidi y Lauda Jerusalem. Faltó un Dixit Dominus para completar el juego. El título que figura en sus manuscritos conservados en el Archivo de la Capilla Musical la catedral de Sevilla son: In vesperis SS. Corporis Christi. Credidi, sign. 124-1-1; In Solemnitate SS. Corporis Christi. Lauda Jerusalem. $5^{\circ}$ tono, sign. 87-1-2; In festo SS. Corporis Christi. Magnificat. $6^{o}$ tono, sign. 86-1-6. 
Inmaculata Conceptione B.M.V., a tres voces graves y orquesta ${ }^{278}$. La otra misa dedicada a la Virgen, In Asumptione de Maria Virginis ${ }^{279}$, a cuatro voces mixtas y orquesta, fue concebida, como su propio título indica, para el día de la Asunción, otra de las grandes fiestas religioso-populares de la ciudad ${ }^{280}$.

Estas dos misas fueron escritas en momentos particularmente significativos. Ripollés entregó al Cabildo la partitura de la misa De Inmaculata Conceptione B.M.V. en el mes de junio de $1904^{281}$, es decir, en plenas celebraciones por la conmemoración del quincuagésimo aniversario de la declaración del dogma de la Inmaculada que, como ya vimos, tuvo una enorme importancia y repercusión para toda la Archidiócesis ${ }^{282}$. Es lógico pensar que fuera esta la obra interpretada en la gran misa pontifical con la que culminaron las fiestas jubilares marianas. La coronación canónica de la Virgen de los Reyes ante la presencia del nuncio de la Santa Sede en España hizo de aquella función religiosa un acontecimiento de gran trascendencia histórica y simbólica para la ciudad. Suponemos que debió significar para el castellonense, además de una ocasión para adquirir protagonismo y proyección tras apenas año y medio desde su llegada, una oportunidad ideal para iniciar su proyecto de introducir en el repertorio catedralicio nuevas obras con las que sustituir las tradicionales.

Por otro lado, Ripollés concluyó la composición de la misa In Asumptione de Maria Virginis en junio de 1907 , es decir, en plena efervescencia asuncionista ${ }^{283}$. En

\footnotetext{
${ }^{278}$ ACS. Archivo de la Capilla Musical, sign. 86-1-2.

${ }^{279}$ Ibídem, sign. 86-1-1.

${ }^{280}$ El día de la Asunción, 15 de agosto, salía en procesión por las calles de la ciudad la entonces recién coronada canónicamente Virgen de los Reyes, años después proclamada patrona de la Archidiócesis.
}

281 "El infrascrito Secretario hizo entrega el Excmo. Cabildo de las dos obras musicales que el actual Maestro de Capilla D. Vicente Ripollés ha compuesto para esta Santa Iglesia en cumplimiento de lo que se dispone en el edicto de convocación del Beneficio que posee. Dichas obras son una Misa de Inmaculata Conceptione B. M. Virginis para cuatro voces y orquesta y otra Misa para cantarse por los seises en el día del sábado a Ntra. Sra. de la Antigua”. AC 27/6/1904. ACS. Sección Secretaría, libro 226, fol. 256. Ripollés debió terminar la composición de la obra en febrero de 1904. Las fechas que figuran en el manuscrito original son: Kyrie, 17 de enero de 1904; Gloria, 12 de febrero de 1904; Elevación, 13 de febrero de 1904; Benedictus, 13 de febrero de 1904; y Agnus Dei, s. f. ACS. Archivo de la Capilla Musical, sign. 86-1-2.

${ }^{282}$ Véase capítulo 1, epígrafe 3. "Inicio y suspensión del proceso de reformas: causas y consecuencias", p. 75 y ss.

${ }^{283}$ Las fechas que figuran en la partitura autógrafa son: Kyrie, s.f.; Gloria, s.f.; Sanctus, 31 de mayo de 1907; Benedictus, 31 de mayo de 1907; Agnus Dei, 1 de junio de 1907. La entrega al cabildo se realizó el 17 de junio: "El inf. ${ }^{\circ}$ Secretario hizo presente que estaban sobre la mesa las dos obras musicales que el Maestro de Capilla D. Vicente Ripollés ha compuesto en cumplimiento de la carga que se le impuso en el edicto de convocación a su Beneficio, las cuales entrega al Cabildo el dicho Sr. Ripollés y son un 
octubre de 1900, Spínola resucitó una vieja aspiración de la Iglesia hispalense: la declaración como dogma de fe de la Asunción de María ${ }^{284}$. A lo largo de estos primeros años del siglo se emprendieron varias iniciativas con este objetivo, entre ellas una campaña de adhesiones a la que se sumó el propio Ayuntamiento ${ }^{285}$. Durante la misa mayor del día de la Asunción de 1906, el Cabildo hizo por primera vez juramento solemne de defender la asunción de María, "del mismo modo que se hace en el día del Patrocinio de la Sma. Virgen el de defender la Concepción Inmaculada”286. Un auto de la Diputación de Ceremonias de 28 de julio nos informa sobre la intención de darle la máxima solemnidad y repercusión posible: “en el presente año por ser el primero [...] parece que se debe añadir algo que trascienda al pueblo fiel y sirva a todos de estimulo para que amen y veneren más a la Madre de Dios por tan singular privilegio". Con esta pretensión se decidió engalanar con colgaduras de terciopelo las columnas de la nave central; "Cantar solemnemente la Prima y la Kalenda del día anterior a la fiesta"; que repicaran simultáneamente las campanas de la Giralda, de todas las parroquias y conventos de la capital; izar en la Giralda la bandera blanca; "Cantar con orquesta dichas vísperas como se hace en las de la Purísima Concepción, Corpus Christi y otras."; "Los Maitines, que han de ser solemnes, se pueden cantar o inmediatamente después de las Vísperas o a las oraciones como se verifica en los de Pentecostés y otros."; y por último, invitar al obispo de Lystra (recordemos que en esos momentos la Iglesia de Sevilla se encontraba en situación de Sede vacante ${ }^{287}$. Un par de meses

Magnificat para las Vísperas del S.S. Corpus Chirsti y una Misa in festo Assumptione B. M. V. ambas para voces y orquesta, y corresponden al cuarto año de su residencia”. AC 17/6/1907. ACS. Sección Secretaría, libro 227, 187v-188r.

${ }^{284}$ El 31 de agosto de ese año, Spínola publicó una circular en la que transmitió al clero y fieles diocesanos su intención de presentar la petición de declaración del dogma de la Asunción personalmente, durante la peregrinación que la Diócesis tenía previsto realizar a Roma en octubre. Les instaba, además, a que suscribieran la iniciativa. Marcelo, Arzobispo de Sevilla, “A nuestros amados diocesanos" [en índice del tomo figura el siguiente título: "Pastoral de S.E.R. sobre el Mensaje a Su Santidad pidiendo la definición dogmática de la Asunción de la Sma. Virgen”, BOAS, 448 (1900), pp. 119-122.

${ }^{285}$ Días antes de que se proclamara finalmente el dogma de la Asunción, el diario $A B C$ publicó un artículo firmado por José Andrés Vázquez, en el que se recogió la declaración de los concejales que en aquellos años de principios de siglo visitaron al Cabildo con este objetivo: "la Ciudad de Sevilla, que guarda en sus anales las más gloriosas páginas, imperecedero recuerdo de su fe inquebrantable y de su ardiente devoción a la Santísima Virgen, se unía al Cabildo eclesiástico para trabajar en el empeño

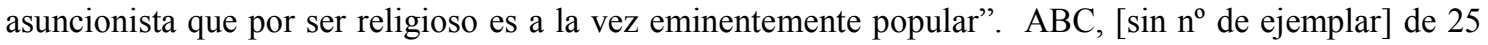
de noviembre (1950), p. 5.

${ }^{286}$ ADC 28/7/1906. ACS. Sección Secretaría, libro 357.

${ }^{287}$ Ibídem. 
antes, la misma Diputación de Ceremonias dio el visto bueno a una misa y oficio propio para el día de la Asunción escrito por uno de los capitulares, Antonio Pérez Córdoba ${ }^{288}$. Es obvio que la fiesta de la Asunción tenía en Sevilla un importante contenido identitario, sumándose a las fiestas más significativas en este sentido como el Corpus o la Inmaculada.

A la música para las solemnidades del Corpus, la Inmaculada o la Asunción hay que sumar aquella destinada a otras fiestas de la Iglesia local: la misa dedicada a San Isidoro, otro de los grandes símbolos hispalenses; la misa para la fiesta de la Dedicación; o la hoy desaparecida "Misa para cantarse por los seises en el día del sábado a Ntra. Sra. de la Antigua"289. La misa votiva mariana que se celebraba cada sábado en la capilla de la Antigua era una tradición centenaria muy arraigada y significativa para la institución catedralicia ${ }^{290}$.

Habría que concluir que la labor de Ripollés como maestro de capilla en su vertiente de compositor de nuevas obras para la liturgia obedeció a un proyecto de instauración de un nuevo canon musical para las grandes festividades litúrgicas, más acorde, según su criterio con los postulados del $M P^{291}$.

288 ADC 19/5/1906. ACS. Sección Secretaría, libro 357. En el auto se apuntó: "La razón de estas variaciones es el deseo de que la liturgia de la fiesta de la Asunción de Ntra. Sra. refleje por modo más expresivo las creencias profundamente arraigadas desde remotos tiempos en todo el orbe católico, respecto de tan dulce misterio; y a la vez responda con mayor solemnidad al aumento cada día más acentuado de esta devoción y culto en los pueblos cristianos [...].”

${ }^{289}$ Según consta en el acta de 27 de junio de 1904 más arriba citada, Ripollés entregó al Cabildo esta misa junto con la dedicada a la Inmaculada. Véase nota $n^{\circ} 281$.

${ }^{290}$ Juan Ruíz Jiménez afirma tratarse de una tradición enraizada en el s. XV, y cita la siguiente acta capitular: "Se acostumbra de inmemorial tiempo a cantarse una misa del oficio de Nuestra Señora cada sábado al alba. La cual es obligado a decir uno de los curas del Sagrario y a oficiarla el maestro con sus muchachos cantorcicos y con otros, y han de ser ministros dos de los capellanes de la dicha capilla... [el tañedor] ha de tañer los órganos a esta misa” A.C.S., sección IX, leg. 89, pieza 7, fol. 5v. La Librería de Canto de Órgano, p. 14. La capilla de la Antigua servía de escenario para la celebración de otra función litúrgica de larga tradición como es el rito de la Salve. Un estudio del rito y del repertorio musical a él destinado durante el s. XVI en: Juan María Suárez Martos, El rito de la Salve en la Catedral de Sevilla durante el siglo XVI: estudio del repertorio musical contenido en los manuscritos 5-5-20 de la Biblioteca Colombina y el libro de polifonía $n^{o} 1$ (Granada: Junta de Andalucía. Consejería de Cultura, 2010 [ed. revisada, corregida y ampliada. Sevilla: el autor, 2003]).

${ }^{291}$ No existen estudios recientes de carácter analítico o que ofrezcan una valoración estética y estilística sobre la producción musical de Ripollés. Norberto Almandoz, sucesor años después en el cargo de maestro de capilla de la catedral hispalense, ofreció algunas breves referencias en el artículo que con motivo de la muerte del castellonense publicó en la edición andaluza de $A B C$. Almandoz señaló dos grandes influencias: los polifonistas clásicos hispanos y Wagner: "La música del maestro Ripollés entronca directamente con la de los grandes polifonistas españoles cuya esencia y forma estilística se asimiló con profundos y prolongados estudios de sus obras. Los antiguos maestros de la escuela levantina, Ginés Pérez, y Comes., en especial el primero con su sobriedad hierática, un tanto ruda a veces, y el segundo, con la pomposidad y prestancia sonora de sus dobles coros, influyeron en la formación del 


\subsubsection{Alabado y bailes de seises}

Por otro lado, una comparativa entre la producción de Ripollés para la Catedral de Sevilla y las de sus antecesor y sucesor, Evaristo García Torres y Eduardo Torres respectivamente, nos proporciona otros datos interesantes. A diferencia de sus colegas en el cargo, Ripollés no escribió ni una sola obra en castellano. Las composiciones con texto romance constituyen, por el contrario, nada más y nada menos que la mitad de la obra de García Torres, y en torno a un tercio de la de Eduardo Torres. Los bailes de seises y Alabados, dos prácticas tradicionales vinculadas al Corpus y la Inmaculada, constituyeron el grueso de la producción musical paralitúrgica de estos dos últimos. La ausencia de obras de estas características en el catálogo de Ripollés lleva necesariamente a pensar que no le interesaron estas tradiciones, absteniéndose de reforzarlas con nuevas aportaciones. Es más, para Ripollés debieron representar prácticas antilitúrgicas, aquellas "prácticas rutinas", "disfrazadas con el sugestivo y pomposo nombre de Tradiciones" de las que habló en Valladolid, y que debían desaparecer -"vengan al suelo las prácticas rutinarias"292-.

Precisamente el canto del Alabado le costó un importante desencuentro con el órgano de gobierno catedralicio a poco de su llegada. Como refleja el acta de la sesión capitular de 14 de junio de 1904, Ripollés trató de alterar dicho canto, introduciendo una "innovación" que fue rechazada. El Cabildo acordó que se le llamara la atención "para que se siga cantando como hasta aquí":

un Sr. Capitular se lamentó de que se haya introducido alguna innovación en la música tradicional del Alabado que cantan los seises durante la reserva; se acordó que se llame la atención al Mtro. de Capilla para que se siga cantando como hasta aquí. ${ }^{293}$

El maestro de capilla no quedó conforme en un principio con la decisión capitular y reaccionó presentando un escrito, leído en el cabildo celebrado el día 27 del mismo mes, en el que se aventuraba a hacer "algunas observaciones sobre el canto del

compositor castellonense recién fallecido [...]. De su producción sobresalen la 'Misa de la Dedicación de la Iglesia', para voces y orquesta, en la que, como también en los 'Salmos', su fervor entusiasta por Wagner dejó marcadísimas huellas." Norberto Almandoz, "Informaciones musicales. El maestro Vicente Ripollés”, $A B C$ [edición Andalucía], 12375 de 9 de abril (1943), p. 14.

292 [Ripollés], “La cultura litúrgica-musical del Clero", p. 61.

${ }^{293}$ AC 14/6/1904. ACS. Sección Secretaría, libro 226, fol. 254r. 
Alabado". El Cabildo desoyó dichas observaciones y se ratificó en su acuerdo de conservar la tradición, desautorizando así a su maestro de capilla:

Se dio lectura a un escrito firmado por el Mtro. de Capilla haciendo algunas observaciones sobre el canto del Alabado por los seises con motivo del acuerdo tomado en el Cabildo espiritual del 14 del corriente mes y se acordó que se esté a lo dispuesto en dicha sesión. $^{294}$

No sabemos hasta qué punto Ripollés fue consciente de la significación que la costumbre del Alabado tenía en Sevilla, y si supuso que en el momento en el que intentaría actuar sobre ella se encontraría de frente con el Cabildo. Se trataba de una expresión que hundía sus raíces en lo profundo de ese universo simbólico en el que nos hemos tratado de sumergir más arriba. El Alabado sintetizaba en una breve expresión las devociones del Corpus y la Inmaculada. Esta breve jaculatoria estaba asociada a canónigos legendarios como Vázquez de Leca, quien colaboró especialmente en su difusión y arraigo. El arcediano inmaculista dotó algunas prácticas particulares catedralicias como la de acompañar con el canto del Alabado la renovación del Santísimo Sacramento del altar mayor los sábados, o que los predicadores pronunciaran el Alabado tras la salutación de sus sermones ${ }^{295}$. Arbolí, refiriéndose a Fernando de Contreras, otra figura religiosa hispalense de relevancia, señaló la "particularidad

${ }^{294}$ AC 27/6/1904. Ibídem, fol. 256v. Sobre el contenido concreto del escrito no poseemos información, pues ni se recoge en las actas ni hemos conseguido hallarlo.

${ }^{295}$ Hazaña y La Rua transcribió en su libro sobre Vázquez de Leca los documentos de estas dotaciones. Transcribimos uno de ellos: "Dotación del Alabado sea el Sanctissimo Sacramento que se a de decir todos los Sábados al Renobar el Sanctissimo Sacramentodel Altar Maíor, que Dotoal Señor Don Matheo Vazquez de.Lecca Arcediano de Carmona y Canónigo de la sancta Iglesia. (7 de Agosto de 1637).

El Señor Don Matheo Vazquez de Lecca Arcediano de Carmona y Canónigo dela sancta Iglesia ofreció a los Señores Deán y Cabildo della que daria quinientos Ducados de Plata para que dellos se hiciesen Candeleros para la Fabrica dela sancta Iglesia que sirban para poner en los Altares que se ponen en la Capilla maior los dias del Octavario del Corpus Christi los quales quiere darála dicha Fabrica para que no necesite de buscarlos prestados para los dichos dias y mas Ducientos Ducados de Vellón para la hechura dellos, con tal que todos los sábados del año perpetuamente o otro dia que se renovare el Santissimo Sacramento del Altar maior o se enserrase o fuere del Altar maior a alguna Estación y bolbiere, se diga después de la Oración que se dice, Deus qui nobis sub Sacramento mirabili etc. Alabado sea el Santissimo Sacramento, y la inmaculada Concepción de nuestra Señora Concebida sin mancha de pecado original, lo qual a de Cantar vno de las Músicos al Órgano, y siendo dia que no tengan obligación de asistir los Músicos, lo a de Cantar un seise, y a de Responder el Choro Amen, y el Cabildo por su auto de siete de Agosto 4 de 1637, Admitió la dicha Dotación con sus calidades Referidas y mando se ponga desde luego en execucion, [...] A.C.S. Libro Blanco $2^{\circ}$ fol. 119 vto." Hazañas y La Rua, Vazquez de Leca, pp. 345-346. El otro documento se titula: "Dotación de el Alabado sea el Sanctissimo Sacramento y la Inmaculada Concepción de la Virgen Sanctissima María señora nuestra. Por el Señor Don Matheo Vázquez de Lecca Arcedlano de Carmena y Canónigo de esta sanota Iglesia que se a de dezir después de la Salutación de los Sermones que se dixeren en ella. (24 de Marzo de1639).”; cit. en: ibídem, p. 346. 
exclusiva" de la Iglesia hispalense de hacer la reserva con el canto del Alabado en lugar de con el Pange lingua:

No sólo se empeñó en la piadosa obra de fomentarlas [las dos devociones, Corpus e Inmaculada] por igual, sino que imprimió este sello a la Iglesia Catedral de Sevilla, que desde entonces acá no se ha desviado de este trámite, como lo acredita en multitud de prácticas, entre ellas la llamada del Sanctisime, la uniformidad del aparato litúrgico en las dos solemnidades, la colocación de la imagen de la Inmaculada en el altar de plata consagrado al efecto, y la particularidad exclusiva de esta Metrópoli de reservar al Santísimo con el Alabado en vez del himno. ${ }^{296}$

La oración del Alabado se llegó a convertir en una especie de lema que, como apunta Arbolí, "exornaban los títulos de libros muy devotos", como él mismo hizo ${ }^{297}, \mathrm{y}$ que "se explica por el espíritu dominante, como reflejo de lo más popular y fiel trasunto de las ideas y sentimientos que arraigaban en el alma"298.

El baile de seises era otra de las costumbres tradicionales especialmente apreciadas. Al igual que el Alabado, estaba asociado a las devociones del Corpus y la Inmaculada $^{299}$. A adquirir esta condición identitaria habían colaborado determinados episodios históricos, como el intento -fallido- por parte del propio arzobispo Jaime Palafox de eliminar la costumbre a finales del siglo XVII, provocando con ello un importante conflicto entre mitrado y colegio capitular ${ }^{300}$. La pervivencia de la costumbre, a pesar de las dificultades que tuvo que superar, la consagraron en el imaginario colectivo como un triunfo simbólico de Sevilla ante intentos de agresión exterior. La puesta en cuestión de su particular forma de religiosidad, manifestada en

${ }^{296}$ Arbolí, La Eucaristía y la Inmaculada, p. 111

${ }^{297}$ En la cabecera del título de su libro La Eucaristía y la Inmaculada. Devoción española reza: “Alabado sea el Santísimo Sacramento del Altar y la Inmaculada Concepción de la siempre Virgen María, Madre de Dios y Señora Nuestra".

298 “con el Alabado se exornaban los títulos de libros muy devotos, como el del presentado Fr. Alonso Hidalgo; que ambas alabanzas se editaban unidas en preciosos tratados y curiosas recopilaciones, como la muy rara del jesuíta Arias de Amienta; que a las loas sacramentales y a los romanceros en boga hay que sumar las variadas composiciones en verso que tienen por objeto celebrar juntamente al Santísimo y a la Virgen; esto se explica por el espíritu dominante, como reflejo de lo más popular y fiel trasunto de las ideas y sentimientos que arraigaban en el alma." Arbolí, La Eucaristía y la Inmaculada, pp. 162-163.

299 Además de en las fiestas del Corpus e Inmaculada, los seises bailan en el Triduo de Carnaval. Sobre los seises de la catedral de Sevilla, véase la obra ya citada: González Barrionuevo, Los seises de Sevilla.

${ }^{300}$ De la Rosa dedica el capítulo XV de su libro sobre los seises al caso Palafox. De la Rosa, Los seises de la catedral, pp. 279-300. Herminio González Barrionuevo trata el tema en: Los seises de Sevilla (Sevilla: Castillejo, 1992), pp. 185-192. 
sus tradiciones, significó una amenaza a su identidad en su vertiente religiosodevocional popular, tal como se había configurado.

Sin embargo, desde un punto de vista litúrgico, el baile de seises era una práctica no del todo ortodoxa. De la Rosa, quien lógicamente dedicó buena parte de su libro a tratar de justificar con todo tipo de argumentos su carácter sagrado, reflejó la problemática que a principios de siglo envolvía a la costumbre:

El seise sevillano, vistosamente ataviado con su traje de danza, cantando, bailando y tañendo las castañuelas en el santuario ante Jesucristo Sacramentado, constituye un caso especialísimo de liturgia eclesiástica, difícil de legitimar en el concepto de muchos, porque estas funciones no figuran entre las rubricas del Ritual y Ceremonial romanos. Por eso han sido tan vivas y enconadas las disputas acerca de la licitud y conveniencia de esta usanza inmemorial.

[...] si se hubiera estudiado la historia de esta tiernísima devoción consagrada por el Cabildo hispalense a la majestad augusta del más sublime de los sacramentos, precisamente en momentos solemnes, es decir, cuando la Silla Apostólica reclamaba extraordinarias demostraciones de júbilo por toda la cristiandad en honor a la Sagrada Eucaristía; se hubiesen evitado recriminaciones injustas y de todo punto infundadas, que se formularon siempre aprovechando fríos filosofismos de la cabeza y desoyendo los latidos nobles del corazón. ${ }^{301}$

Según estas ideas, el fenómeno de la danza de seises se podía entender y, en consecuencia admitir, desde la esfera de lo emocional, no desde lo intelectivo, dentro del cual habría que incluir el legislativo eclesial. Se trataba una manifestación que se encontraba en el plano de una religiosidad afectiva y popular.

Como se desprende de la lectura de sus cartas, Ripollés tenía un concepto del baile de seises absolutamente distinto. En alguna de ellas asoció los términos bailar o "miserear" con barbarizar ${ }^{302}$. Obviamente, su capacidad de intervención sobre la costumbre era prácticamente nula, y se reducía al no reforzamiento de la misma con la producción de nuevas obras salidas de su pluma, como hemos afirmado. Por el contrario, sus obligaciones como maestro de capilla le convertían en el principal responsable y director musical de estas prácticas. Esta circunstancia le llevó en determinados momentos, como el que referimos a continuación, a una situación de

\footnotetext{
${ }^{301}$ Ibídem, pp. 159-160.

${ }^{302}$ Véase p. 330.
} 
grave conflicto consigo mismo, e incluso, de involuntario enfrentamiento con la propia autoridad eclesiástica, al situarse al margen de la legislación litúrgico-musical. Según se deduce de la contestación de Pedrell a una carta del castellonense que no conservamos, Ripollés debió considerar de tal seriedad el aprieto en el que se encontró que llegó a plantear la posibilidad de que el mismo Perosi mediara en el asunto. La respuesta de Pedrell data del 13 de enero de 1904:

Si con el último Motu de Pío X no se convencen esos señores de que se exponen a una repulsa, no habrá fuerzas humanas que les apeen del burro. En cuanto al medio escogitado [sic] de escribir a Perosi ¿cómo se inmiscuirá él en materia tan delicada, por los informes que yo le dé o le dé el que quiera? Pongámonos en su lugar y ni V. ni yo cargaríamos con la responsabilidad de... [sic] meternos en lo que no nos importa, como diría sin duda ese Cabildo. Y peor si ponen, como V. me dice, altas cuñas. Lo único que cabe es el conocimiento jurando y perjurando con el texto del Motu a la vista. Si no entra el conocimiento, puede V. salvar su responsabilidad escribiendo yo una carta de presentación a Perosi, refiriéndole el caso, por si sale bien, dejarlo como está, o si por si sale mal, salvar su responsabilidad de V., hasta cierto punto, pues, entonces, de saberlo el Cabildo o quienes sean, echarán sobre V. toda la culpa. Es, en un caso $\mathrm{u}$ otro, cuestión imposible de resolución. Yo de usted callaría y si al verme amenazado a presidir esa algarada, después de agotar todas las razones, dimitiría noblemente el cargo o cuando menos les amenazaría con la dimisión. ${ }^{303}$

Aunque la carta no informa sobre ello, creemos que la causa que provocó esta reacción al límite de Ripollés fue la idea de celebrar una gran misa en la basílica de San Pedro según las costumbres hispalenses -"donde se verán por primera vez nuestros particulares usos" ${ }^{, 304}$-. Esta función litúrgica estaba concebida como culminación de la

\footnotetext{
${ }^{303}$ Carta de Pedrell a Ripollés, 13 de enero de 1904. BC. FFP. M 964. Una semana después le volvió a escribir, y le comunicó, entre otras cosas, que había hecho saber al obispo de Madrid-Alcalá, Victoriano Guisasola, uno de los jerarcas españoles más comprometidos con la reforma, su problema con los seises: “[...] y de paso conté sus cuitas con los del Corpus [Colegio del Corpus, Valencia], lo de los Seises (de que ya estaba enterado) y la obsesión de ese cabildo etc. etc.". Además le envió una comprometida circular sobre música sagrada escrito por dicho prelado para que la difundiera en Sevilla: "Levantó gran revuelo la impresión de las luces eléctricas, prohibidas por él, y lo levantará más su circular sobre música religiosa, pero es hombre de tesón y energía. Enseñe V. la circular por ahí a los de los seises, y lo mejor sería que bajomano la hiciera V. insertar en algún periódico de esa." Carta de Pedrell a Ripollés, 21 de enero de 1904. Ibídem.

304 “[...] se juntan muchos motivos para dar interés a la expedición piadosa, como son, entre otros, su objeto, que es honrar a la Virgen purísima, el lugar del homenaje que se le intenta tributar, a saber, Roma y la Iglesia de S. Pedro, donde se verán por primera vez nuestros particulares usos, la presencia del nuevo Papa, de cuya santidad tanto se habla y al que no hay católico que no anhele conocer, la estación del viaje,
} 
peregrinación a Roma que las autoridades diocesanas habían planeado para junio de 1904. Dos meses antes de que Pedrell enviara a Ripollés la carta que acabamos de citar, se daba a conocer el proyecto en el BOAS:

[...] ha ideado nuestro Prelado organizar para Mayo de 1904 una peregrinación sevillana a Roma, tan numerosa y lucida como posible sea, y que el día 8 se congregue en la Basílica de S. Pedro y dedique a la Inmaculada Reina del cielo y de la tierra solemnísima función, a la manera de las que en nuestra Catedral se celebran en honra del misterio de la Concepción de Ntra. Señora, y asistiendo y bailando después de ella nuestros seises a presencia del Papa, si se digna dispensar a los sevillanos el altísimo honor de concurrir al acto.

El pensamiento no ha sido oficialmente expuesto a la Comisión Cardenalicia encargada de promover y organizar las fiestas jubilares; pero se ha manifestado a personas muy conocedoras de la corte romana, las cuales lo han acogido benévolamente, mostrando esperanzas al parecer fundadas de que su realización no encontrará dificultades serias. $^{305}$

Finalmente, la propuesta de llevar al corazón de la cristiandad las particulares ¿heterodoxas?- formas litúrgicas hispalenses debió chocar con los criterios litúrgicos oficiales romanos, y terminó desestimándose. Ripollés se lo comunicaba a Pedrell el 10 de mayo: "Por fin sale la peregrinación a Roma sin los seises, a Dios gracias. Yo soy de los que se quedan en casa"306. Y volvía a incidir en ello en otra carta fechada el día 25 , en la que, según cuenta, tuvo que intervenir el propio Pío X para impedir que se llevara a cabo el plan, tal y como se había concebido en Sevilla: "Salió ya la peregrinación a Roma, y salió sin los seises, pero para llegar a esta solución ha precisado que el mismo Papa, contra la recomendación de varios cardenales y del mismo embajador, desautorizara el proyecto."307

Este episodio refleja, según nuestro parecer, el problema de fondo que subyacía debajo de las posiciones de canónigos sevillanos y Ripollés: la tensión existente entre dos tendencias opuestas. Por un lado, la tendencia de Roma a unificar, como gobierno central de la Iglesia, en todo el orbe católico la liturgia y sus aspectos rituales -entre

\footnotetext{
la más bella del año y en la que los días son más largos etc. etc.” “Un pensamiento sobre el jubileo de la Inmaculada", BOAS, 530 (1903), p. 320.

${ }^{305}$ Ibídem.

${ }^{306}$ Carta de Ripollés a Pedrell, 10 de mayo de 1904. BC. FFP. M 964.

${ }^{307}$ Carta de Ripollés a Pedrell, 25 de mayo de 1904. Ibídem.
} 
ellas la música-; y por otro, la de las Iglesias locales por conservar sus propias tradiciones de culto, resultado de la asimilación de los principios doctrinales y litúrgicos en un contexto y coordenadas histórico-culturales particulares, y posterior traducción en manifestaciones en las que resulta difícil disociar lo religioso de lo cultural. Se consolidaron estas últimas como expresiones identitarias, cuyo cuestionamiento se contempló como una forma de agresión a la integridad de la comunidad cultural a la que servían de símbolos.

Más arriba proporcionábamos los posibles fundamentos ideológicos, enraizados incluso en la tradición de la Iglesia, que justificaban las posturas de resistencia locales, según Modesto Abín. El secretario capitular se comprometió profundamente con el objetivo conservacionista. Ripollés, por su parte, representó la ortodoxia romana; aunque, como trataremos de defender a continuación, la perspectiva desde la que contempló y actuó el maestro de capilla no se ubicó exclusivamente en el ámbito de la legalidad y línea marcada por el $M P$. Sus pretensiones de reforma estaban ligadas, sobre todo, a un proyecto de regeneración artística y estética en el ámbito de la música religiosa en el que había empeñado su vida.

\subsubsection{Ripollés y Sevilla, regeneración versus identidad. Una historia de}

\section{incomprensión}

Los casos del Alabado y del baile de seises que acabamos de relatar ponen en evidencia el difícil papel que le tocó jugar a Ripollés. Por un lado, sus convicciones le hacían rechazar estas costumbres; por otro, como maestro de capilla debía acatar los criterios de sus superiores en el capítulo catedralicio. Por tanto, el poder fáctico de Ripollés para actuar sobre los aspectos litúrgico-musicales por propia iniciativa y según su criterio era nulo, a no ser que contara con el beneplácito del Cabildo. Se constata, por tanto, que las dos realidades en desequilibrio que históricamente habían convergido en la figura del maestro de capilla, su condición de máxima autoridad musical, y su escaso poder de decisión en asuntos de música, impidieron en gran medida la regeneración que el castellonense había pretendido en la catedral de Sevilla.

Las cartas escritas por Ripollés a Pedrell durante su etapa sevillana aún conservadas reflejan las sensaciones de soledad y de frustración que se fueron 
adueñando de él ${ }^{308}$. Este estado de ánimo se agravó tras su experiencia en la organización del congreso de Sevilla, como veremos. Además de confesar sus desengaños a quien no sólo fue su maestro y consejero sino también su confidente, Ripollés, con la espontaneidad y libertad que permite la correspondencia privada, hacía en ellas valoraciones y críticas sobre el Cabildo en materia musical. Estas consideraciones ponen de manifiesto que el móvil del activismo de Ripollés no era exclusivamente el cumplimiento de las leyes litúrgico-musicales, sino que respondía sobre todo a un programa de regeneración de carácter artístico-musical, aunque tuviera su ámbito de incidencia en la liturgia.

El siguiente pasaje, en el que Ripollés realizó un severo juicio sobre la cultura musical del Cabildo, data de mayo de 1904, es decir, casi un año después de su llegada a la capital andaluza ${ }^{309}$ :

El segundo volumen de Victoria no ha llegado aún a mis manos, ni sé cuándo llegará: es inútil recabar de este cabildo una suscripción; dudo haya Cabildo en España más antimusical que este: es una calamidad en toda regla que a voces pide una escoba grande, grande para barrer del templo tanta ineptitud, por no decir cosa peor y más propia. ${ }^{310}$

\begin{abstract}
${ }^{308}$ A lo largo de los dos primeros capítulos hemos ido transcribiendo parte de esta correspondencia. En ella se encuentran más pruebas sobre cómo le fue afectando su experiencia en Sevilla, que complementan las que en este momento aportamos.

${ }^{309}$ Ripollés realizó este juicio en la respuesta que dio a la petición de Pedrell de intentar conseguir la suscripción del Cabildo hispalense a la edición de la Opera omnia de Victoria que en esos momentos estaba publicando. El veinticinco de junio de 1903 escribía Pedrell: "Ha salido $2^{\circ}$ vol. Victoria. ¿No podría V. aconsejar al cabildo se quedaren con un ejemplar?" Carta de Pedrell a Ripollés. BC. FFP. M 964. Y el 11 de mayo de 1904: "¡Hombre! Y ese cabildo no es capaz de inscribirse a Victoria?”. Ibídem. Pedrell tuvo bastantes problemas para conseguir suscripciones en todo el país. En relación al trabajo de recuperación de Victoria desarrollado tanto por Pedrell como por otros autores entre finales del s. XIX y principios del XX, véanse: Manuel Sancho García, "De Teixidor a Pedrell: Tomás Luis de Victoria en la historiografía musical española del siglo XIX", Revista de Musicología, XXXV/1 (2012), pp. 443-457; del mismo autor: "Tomás Luis de Victoria en la obra musicológica de Felipe Pedrell: la creación de un mito nacional", en Tomás Luis de Victoria: Estudios/Studies, ed. por Manuel del Sol y Javier SuárezPajares (Madrid: ICCMU, 2013), pp. 489-500; Albano García Sánchez, "Contribución de Nemesio Otaño (1880-1956) a la memoria de Tomás Luis de Victoria, paradigma de universalidad", Revista de Musicología, XXXV/1 (2012), pp. 459-472; Magín Arroyas Serrano y Vicente Martínez Molés, "La primera transcripción moderna del Oficio de Difuntos de Victoria: el manuscrito del maestro José Perpiñán", ibídem, pp. 473-489. Véase, además, Juan Ruíz Jiménez, "Recepción y pervivencia de la obra de Victoria en las instituciones eclesiásticas de la corona de Castilla", en Tomás Luis de Victoria y la cultura musical en la España de Felipe III, dir. por Alfonso de Vicente y Pilar Tomás (Madrid: Centro de Estudios Europa Hispánica, 2012), pp. 301-351.
\end{abstract}

${ }^{310}$ Carta de Ripollés a Pedrell, 25 de mayo de 1904. BC. FFP. M 964 R. 
La queja de Ripollés sobre el desinterés de la corporación capitular por Victoria refleja una vez más el punto de desencuentro y de incomprensión que constituía el centro del problema. Para Pedrell -independientemente de sus particulares intereses personales- y Ripollés, la difusión de Victoria formaba parte de sus planes de regeneración de la música religiosa a partir de determinados modelos a restaurar, y sobre la base de unos postulados nacionalistas e historicistas que analizaremos en el capítulo sexto. En cambio, Victoria estaba bastante alejado de la sensibilidad de los capitulares, formada por el contacto asiduo con unas expresiones musicales prestigiadas, popularizadas, asociadas al concepto de solemnidad, que habían alcanzado un estatus identitario, y que llevaban la firma de un personaje elevado a la categoría de mito local como era Eslava. Para el Cabildo, el castellano, a diferencia del navarro, no poseía ningún valor simbólico, ni el lenguaje polifónico clásico, cuyo ethos resultaba incomprensible a la afectividad de sus miembros, albergaba las cualidades necesarias para ejercer la función representativa y comunicadora que el lenguaje eslaviano poseía entonces. Como afirma Ripollés, el órgano de gobierno catedralicio no tenía en ese momento la más mínima intención de sustituir en mayor o menor medida las obras que conformaban su canon litúrgico-musical por obras de Victoria. Las coordenadas ideológicas y de criterios en las que se movían Cabildo y maestro de capilla eran absolutamente diferentes y difícilmente conciliables.

Mientras Victoria representaba el "clasicismo" musical español recuperado por Pedrell-, "en la Catedral continuamos haciendo el oso con el repertorio andaluz", según Ripollés ${ }^{311}$. En esta ocasión, la calificación del repertorio catedralicio como "andaluz" pone de manifiesto que hasta a los ojos de Ripollés el canon del primer templo hispalense había transmutado su valor puramente litúrgico-musical en una función identitaria. La condena implícita en la frase ya no se dirigía a unas expresiones musicales antilitúrgicas, o de nulo valor estético o artístico, sino a un símbolo identitario, cuyo valor de representación de la institución eclesiástica hispalense él mismo reconocía.

El hecho de que unas formas teatrales italianizantes de las que hizo uso un músico navarro terminaran adquiriendo la facultad de simbolizar lo andaluz no deja de ser llamativo. Este caso lleva necesariamente a reflexionar sobre lo, en ocasiones,

311 "Yo salí del compromiso de la fiesta de los notarios con una Misa de Eslava y el tantum ergo de Victoria que gustó mucho: al presente es la única manifestación de nuestro clasicismo, y mientras en la Catedral continuamos haciendo el oso con el repertorio andaluz." Carta de Ripollés a Pedrell, 25 de mayo de 1904. BC. FFP. M 964 R. 
azaroso del proceso por el que se decantan y consolidan determinadas formas, expresiones o manifestaciones como símbolos identitarios o como medios de identificación a través de los que determinados colectivos o instituciones se autorreconocen, y son reconocidos por otros.

En las siguientes misivas, estas ya fechada en 1907, se observan comentarios sobre el estado de la música litúrgica y la reforma realizados, no tanto desde la perspectiva de un sacerdote-músico que pretendía purificar la música de los templos, sino de un artista, de un músico, que se quejaba sobre los recursos humanos y musicales de los que disponía, de la falta de formación musical de sus colegas, o sobre cuestiones estéticas y de gusto. Reflejan, además, el punto de vista de un regeneracionista que juzgaba, según criterios culturales ajenos a los de la comunidad que las había consagrado, expresiones musicales "degradadas" como misereres, bailes de seises o “peteneras místicas". Esta es del veinticinco de enero:

Yo me imagino el prólogo de Los Pirineos puestos en manos de aquel buen número de ejecutantes bien dirigidos y comprendo que produjera el delirio con aquel final tan esplendoroso: contentémonos con imaginarnos lo que aquello sería envidiando la buena suerte de aquel público, y lamentando nuestra mala estrella en esta tierra $[\ldots]$

con su desaparición [de Eduardo] de aquí me he quedado completamente aislado y no tengo más compañeros de música que los libros, porque tratar de arte con la gente de aquí y comprende V. que no puede ser. $[\ldots]$

De Motu Proprio bien, a Dios gracias. Continuaremos bailando, misereando [sic] y barbarizando cuanto nos venga en gana, y que chillen en Roma si quieren: qué saben en Roma de nuestro buen gusto ${ }^{312}$

Esta otra de dieciséis de diciembre:

[...] en la Catedral continuamos con nuestras peteneras místicas, y en las parroquias y conventos con su música de tararira y todo esto sin protesta de nadie y a ciencia y paciencia del Prelado. Dígame V. si en vista de este estado de cosas puede presumirse y esperarse algún adelanto? ${ }^{313}$

\footnotetext{
${ }^{312}$ Carta de Ripollés a Pedrell, 25 de enero de 1907. Ibídem.

${ }^{313}$ Carta de Ripollés a Pedrell. 16 de diciembre de 1907. Ibídem.
} 
Unos años después, afectado por otros desengaños, llegó a confesar a Pedrell la verdadera y profunda razón de su vocación por la música religiosa:

[...] el P. Otaño dice bien que no se explica mi silencio, pero yo le confieso a $\mathrm{V}$. que estoy completamente desilusionado y que casi ya no creo en eso de la música religiosa: como artista cultivo el género religioso que se lleva mis simpatías, pero no por liturgismo, sino por arte;

[...] El P. Otaño todo lo ve de color de rosa y yo de color negro: ya se desengañará el padre; es cuestión de tiempo. Como nosotros, seguirá amando y cultivando el género, no por litúrgico sino por artístico, y que se rompa la cabeza quien quiera. ${ }^{314}$

También Nemesio Otaño se refirió a la situación de Ripollés en Sevilla, y a la resistencia por parte de los "sevillanos" a asumir los principios y puntos de vista que todos ellos compartían como principales figuras del regeneracionismo musical español, en este caso, en su vertiente religiosa. Otaño hablaba de Ripollés como "un lirio entre espinas"315 y de Sevilla como "tierra de pecadores", utilizando así términos propios de juicios morales y no estéticos, musicales o litúrgicos ${ }^{316}$. Sevilla fue ubicada en esa geografía figurada fuera de los límites de la virtud, representada por aquellos territorios más dóciles a la reforma y más receptivos a la asunción de los principios y propuestas regeneracionistas. En el capítulo sexto analizaremos la condición simbólica dual que adquirió Sevilla: no sólo como "tierra de pecadores", desde esta perspectiva, sino también como tierra venerada para los regeneracionistas y reformistas, al ser la cuna de grandes referentes del Renacimiento hispano, de la "Escuela Sevillana" que tanto se exaltará durante el II Congreso Nacional de Música Sagrada.

En su análisis sobre la etapa de Ripollés en Sevilla, Turina apuntó a la incomprensión reinante entre el maestro de capilla y los "sevillanos" como el motivo del fracaso del proyecto transformador del primero:

Estando así las cosas, aparece el motu proprio y entra en Sevilla el señor Ripollés, joven, simpático, lleno de entusiasmo por su arte y dispuesto a cambiar y regenerar la música sagrada en Sevilla, y

\footnotetext{
${ }^{314}$ Carta de Ripollés a Pedrell. 18 de octubre de 1912. Ibídem.

315 Véase capítulo 2, epígrafe 2. "El arzobispo Enrique Almaraz frente a la reforma: continuidad y severidad", pp. 122-123.

316 "Ripollés en su última carta se admira de su silencio de V.: el pobre está solo en aquella tierra de pecadores." Carta de Otaño a Pedrell, 13 de marzo de 1909. BC. FFP. M 964 O.
} 
aunque sea doloroso decirlo, confesaré que ni los sevillanos han comprendido a Ripollés, ni Ripollés a los sevillanos que somos tradicionalistas, lo que después de todo no deja de ser una cualidad, pero que en virtud de ella es explicable la oposición que se hace a todo cuanto es nuevo, y que la música polifónica tuviera tan poco éxito como el primer tranvía eléctrico que circuló por las calles. ${ }^{317}$

Turina sintetizaba así el conflicto mantenido entre Ripollés y Cabildo, y su origen fundamentalmente cultural. En la Catedral tuvo lugar una lucha entre dos mentalidades diferentes y contrapuestas: el intento de aplicación de un proyecto transformador y regenerador, que propició una reacción en defensa de una identidad que se vio amenazada. En términos generales y alejando el enfoque, creemos que el intento regenerador de Ripollés y la consecuente reacción del Cabildo representan un caso particular en el que observar la interacción polémica de dos grandes corrientes de pensamiento en la España de principios de siglo, un tradicionalismo conservador resistente a cualquier intento de cuestionamiento de la identidad heredada, y un regeneracionismo renovador que ofreció propuestas y vías para la superación de una situación que contemplaba como decadente. En el capítulo sexto estudiaremos la propuesta a nivel general de este último, que implicaba el proyecto de construcción de una nueva identidad en base a nuevos referentes.

El objetivo de Ripollés tras la experiencia en la preparación del Congreso fue recoger velas y aguardar paciente el momento de marcharse, en expresión de Turina ${ }^{318}$; aunque según su opinión: "debió luchar frente a frente y al fin seguramente hubiera triunfado, pues Sevilla es una ciudad dócil que sabe querer a quien la quiere bien.” ${ }^{319}$ Pocas semanas antes de la inauguración de la asamblea celebrada en Sevilla escribió a Pedrell: "Ya sé que el Sr. Arzobispo pensaba invitar a V. [al Congreso] a su paso por ahí: supongo no caerá $\mathrm{V}$. en la tentación y mandará a todos los andaluces a paseo. Cuando podré hacer yo otro tanto?" ${ }^{320}$. Entre febrero y marzo de 1909 surgió la ocasión. El maestro de capilla de la catedral de Madrid, Gregorio Serrano, estuvo

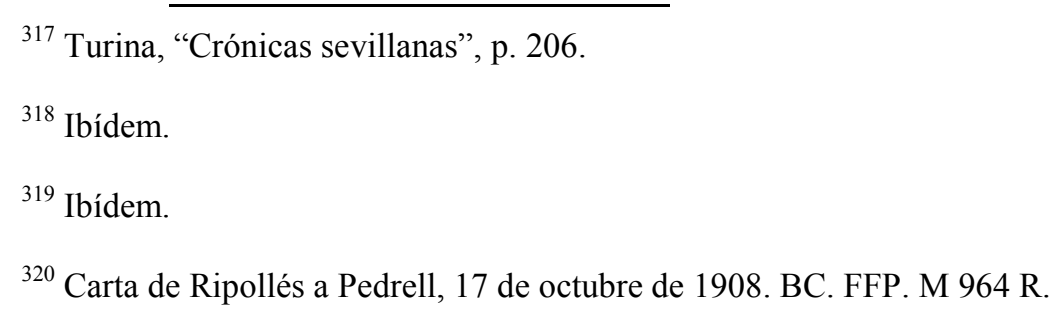


sondeando la posibilidad de hacer una permuta, aunque finalmente desestimó la idea ${ }^{321}$. Los términos en los que se expresó al comunicarle a Pedrell la noticia reflejan su abatimiento:

Por fin Serrano se descolgó diciendo que no le convenía la permuta, lo cual ya suponía yo, porque necesito continuar aquí para purgar mis pecados. Que cómo y cuándo saldré? Qué sé yo: a lo mejor se presenta una ocasión propicia y se abre camino; pero al presente todo está cerrado y yo no renuncio a ocupar algo más tranquilo aunque sea menos lucrativo. La verdad es que todo está mal y el pobre maestro de capilla obligado a vivir entre gentes sin cultura musical, sucumbiendo a los caprichos de cabildos en los que abundan los hombres sin conciencia y casi sin fe, pasa un continuo camino del calvario que lo inutilizan para nada serio: pero dígame V. qué ganas he de tener yo de meterme en honduras de restauración, rodeado como estoy de todo género de malas bestias mayores y menores. ${ }^{322}$

La ocasión propicia que estaba esperando surgió tan sólo dos meses después. El arzobispo de Valencia, Victoriano Guisasola, creó para Ripollés el cargo de director de canto litúrgico y profesor del Seminario al que asoció un beneficio vacante en la catedral $^{323}$. El 21 de junio, el deán hispalense informaba en cabildo: "que el Mto de Capilla D. Vicente Ripolles habría salido para Valencia con el propósito de no volver, $[\ldots]^{\natural 324}$. Seis días después escribió a Pedrell comunicándole el resultado de la oposición y las condiciones y obligaciones de su nuevo puesto que, en un primer momento, juzgó

321 “Aquí anduvieron varios de la catedral de Madrid y me contaron que Serrano anda mal por allí, con poco prestigio y abandonado de todos incluso del Deán que era su protector: aprovechando estas circunstancias se le ha propuesto la permuta conmigo y el hombre me ha pedido nota de todas las cosas de por aquí. Veremos si será este el medio de salirme yo de aquí, aunque lo dudo mucho." Carta de Ripollés a Pedrell, 8 de febrero de 1909. Ibídem.

${ }^{322}$ Carta de Ripollés a Pedrell, 30 de marzo de 1909. Ibídem.

323 "Vaya ahora una buena noticia. Los amigos de Valencia se han dado traza para mover al Sr. Guisasola a poner a un beneficio vacante la carga de director de canto litúrgico y profesor del Seminario: todo esto con la santa intención de llevarme allí. Me dicen que no me preocupe, que la plaza se ha creado para mí y que contra viento y marea para mí será. Yo por si acaso no dejo de prepararme: y allá iré pasado Corpus para ver con quién me toca luchar. En cuanto a estos andaluces no saben todavía nada, sólo cuando pida los papeles a este Prelado se correrá la noticia y entonces seguramente me tomarán por loco.

No creo hagan falta recomendaciones para el Sr. Guisasola, pues me dicen que el hombre está lleno de ilusiones con tenerme en su Catedral, pero tal vez no estaría de más que V. al descuido le felicitara por su iniciativa en crear el cargo, y de paso decirle que tiene noticias de mis propósitos de tomar parte en las oposiciones.

En confianza he de decir a V. que los que me han preparado el terreno son el canónigo D. Roque Chabás y el predicador D. Justo Martínez, con lo cual han dado muestras de verdadero aprecio hacia mí." Carta de Ripollés a Pedrell, 23 de mayo de 1909. Ibídem.

${ }^{324}$ AC 21/6/09. ACS. Sección Secretaría, libro 228, fol. 79v. 
excesivas. Sin embargo, el tono empleado y la alusión a su condición de incorregible y

"Quijote" deja traslucir una cierta recuperación del ánimo:

Esto ha sido aquello de veni, vidi, vinci.[...] y el Sr. Guisasola dándome poderes dictatoriales para mandar y hacer en la Catedral. Y sin embargo, yo no estoy contento, ni decidido todavía a aceptar porque es mucha carga la que se me quiere poner encima y yo lo dejo antes de no poder cumplir.

Ya tengo redactadas unas cuartillas proponiendo mis observaciones; que el Prelado y Cabildo las aceptan? entro por ello. Que no? A mi Sevilla me vuelvo que ya otras ocasiones vendrán.[...]

El clero y músicos esperando ver por dónde comienzo, y hay su poquito de recelo: yo siempre tan Quijote y sin escarmentar en eso de la música religiosa: somos incorregibles.

Ya comunicaré el resultado de mis observaciones que son justísimas, pues nada menos piden que lo siguiente: $1^{\mathrm{o}}$ que ajuste los libros corales a la Edición Vaticana: $2^{\circ}$ que diariamente y a todo trapo dirija a sochantres y salmistas (casi nada): $3^{\circ}$ que haga la clase del Seminario: $4^{\circ}$ que acuda a remediar cuantos abusos y males ocurran en la ciudad y diócesis:[...] extremos. $^{325}$

Pero que conste que yo no me ligo sin aclarar bien estos

Poco días después volvía a escribir desde Castellón:

Creo que mi asunto puede darse por arreglado después de mi exposición al Prelado: quiere este que haga lo que quiera; pero como además del Prelado está el Cabildo he hecho saber al Sr. Guisasola que el Cabildo debe enterarse de mis pretensiones y darme seguridades de poder ejercer tranquilamente mi cargo. Espinas no han de faltar, y espero cosecharlas en abundancia, pero veré de tomarlo con calma, si es que puedo, y complacer al Prelado ya que él deposita en mí tanta confianza. [...]

A las alturas en que está mi asunto es imposible volver a Sevilla, así que me habré de resignar a lo que quieran, y mientras Dios dirá. ${ }^{326}$

La marcha de Ripollés cerró una etapa breve pero particularmente interesante e intensa en la historia de la música en la catedral de Sevilla. Representó el punto final de un intento de regeneración musical particularmente ambicioso. La propuesta del maestro de capilla no solamente fue la de un comprometido con la reforma de la música

\footnotetext{
${ }^{325}$ Carta de Ripollés a Pedrell, 27 de junio de 1909. BC. FFP. M 964 R.

${ }^{326}$ Carta de Ripollés a Pedrell, 3 de julio de 1909. Ibídem.
} 
en la liturgia católica, sino también la de un regeneracionista en uno de los ámbitos musicales históricos, aunque venido a menos, como era el de la música sacra. Ripollés constituyó la presencia en Sevilla de un "apóstol de la reforma", en términos frecuentes en aquella época, y de un "hijo de Pedrell”, en palabras de Juan José Carreras ${ }^{327}$. Los impedimentos que encontró Ripollés ante la jerarquía y el statu quo en general para desarrollar su programa prueban la necesidad de creación y articulación de un movimiento con la suficiente fuerza para poder afrontar las enormes dificultades que presentaba la reforma y regeneración en el contexto de la realidad musical de la Iglesia a principios de siglo. 



\section{Parte III. CONGRESO NACIONAL DE MÚSICA SAGRADA \\ SEVILLA Y EL PROCESO DE INSTITUCIONALIZACIÓN DEL MOVIMIENTO REFORMISTA EN ESPAÑA}

Capítulo 5. La institucionalización del movimiento español de reformas durante el II Congreso Nacional de Música Sagrada

Capítulo 6. Modelos, símbolos y discursos musicales para la institucionalización de un nuevo canon de música religiosa p. 499 



\section{CAPÍTULO 5 \\ LA INSTITUCIONALIZACIÓN DEL MOVIMIENTO ESPAÑOL DE REFORMAS DURANTE EL II CONGRESO NACIONAL DE MÚSICA SAGRADA (SEVILLA, 1908)}

Las dimensiones y alcance del II Congreso Nacional de Música Sagrada, celebrado en Sevilla en noviembre de 1908, así como las exigencias de organización y financiación que conllevó, llevan a afirmar que fue el acontecimiento reformista de mayor envergadura al que tuvo que hacer frente la institución eclesiástica hispalense durante todo el periodo que sometemos a estudio. Los enfoques desde los que abordamos su análisis son diversos, pues pretendemos proporcionar una visión lo más completa posible de la gestión realizada por la Iglesia local durante el proceso de su preparación y celebración.

El estudio del Congreso nos servirá, además, para poner en relación la metrópoli andaluza con el llamado movimiento para la reforma de la música sagrada y el proyecto reformista que a nivel general español impulsó. Por una parte, esta gran convención religioso-musical fue una empresa y una expresión de dicho movimiento, aunque por otra, tuvo como responsable oficial de su organización a la administración diocesana hispalense. Partimos del hecho de que en esta asamblea convergieron la Iglesia-institución a través de su estructura de gobierno básica -la diócesis-, y una incipiente corriente de acción pro-reformista de alcance general -el movimiento-; dos esferas de la reforma que, como ya hemos advertido en capítulos anteriores, conviene 
diferenciar a pesar de que, como el propio Congreso evidencia, estuvieron íntimamente relacionadas ${ }^{1}$.

El estudio de esta gran reunión religioso-musical, por tanto, permite situar a Sevilla en el panorama general español. Dada la lejanía geográfica de la capital andaluza respecto a las ciudades que, como veremos, eran consideradas en ese momento como los principales centros reformistas del país, intentaremos aportar luz sobre el avance que supuso el congreso de Sevilla para el movimiento en términos de expansión hacia el sur peninsular.

Contemplaremos el Congreso como un escenario en el que los diferentes agentes implicados e interesados por diversas causas en la reforma pugnaron por ocupar el espacio que deseaban según sus pretensiones. Durante la asamblea se pusieron en juego, utilizando terminología de Pierre Bourdieu, los capitales simbólicos y materiales a los que aspiraron. Nos interesa entender el proceso por el que se fue definiendo el movimiento reformista español como un espacio "socio-artístico", es decir, como un universo dinámico y polémico en el que sus integrantes establecieron relaciones de diversa naturaleza, desde la alianza a la confrontación, desde liderazgos y posiciones de fuerza a alternativas a las líneas consagradas como ortodoxas, desde vínculos sobre la base de intereses comerciales hasta los establecidos por empatías, cercanías ideológicas o metas compartidas. Las aproximaciones sociológicas a los fenómenos artísticos y culturales han constituido nuestros referentes metodológicos. El concepto que designa el término "espacio socio-artístico" utilizado en este capítulo está inspirado en nociones teóricas como world arts, desarrolladas por autores como George Dickie y Howard S. Becker, o "campo" propuesta por el propio Bourdieu².

Para encontrar la génesis del congreso de Sevilla hay que acudir a su antecesor, el I Congreso Nacional de Música Sagrada, celebrado en Valladolid los días 26, 27 y 28

\footnotetext{
${ }^{1}$ Como ya señalamos, el Congreso fue un acontecimiento al margen del proceso de reformas propiamente local. Se trató de un proyecto importado que incluso retrasó la reanudación de dicho proceso tras la muerte de Spínola.

${ }^{2}$ En la "Introducción" de esta tesis, apartado "Metodología", p. 37 ofrecemos un acercamiento a estos conceptos, y explicamos el significado del término "espacio socio-artístico" que hemos acuñado como derivación de una apropiación de acuerdo a nuestros propósitos de aquellos. Véase: George Dickie, Art and the Aesthetic: An Institutional Analysis (Ithaca: Cornell University Press, 1974); y The Art Circle: A Theory of Art (New York: Haven , 1984); así como Howard S. Becker, Art Worlds (Berckley: University of California Press, 1982); Pierre Bourdieu, La distinción. Criterios y bases sociales del gusto (Madrid: Taurus, 2012); o la colección de ensayos publicados por el mismo autor como The Field of Cultural Production:Enssays of Art and Literature (New York: Columbia University Press, 1993).
} 
de abril de $1907^{3}$. Ambos congresos estaban llamados a propiciar el nacimiento de un movimiento reformista con la fortaleza suficiente como para imponerse a la resistencia que presentaba “el mal gusto, la rutina y la preocupación”, en palabras del arzobispo vallisoletano:

[el Excmo. Sr. Arzobispo] Hace votos por que este Primer Congreso no sea el último, sino el principio de una serie de Congresos, que fomenten la unión de todos para constituir un poderoso ejército que defienda los intereses del verdadero arte religioso contra todos los combates de mal gusto, de la rutina y de la preocupación. $^{4}$

El vínculo que, en principio, emparentó el congreso de Sevilla con el de Valladolid, y desde una perspectiva más amplia, el hecho de que ambos constituyeran expresiones de una misma estrategia regeneracionista de vasto alcance, justifican la constante presencia del castellano en nuestro discurso. Como antecedente del hispalense le dedicaremos un primer epígrafe. Además nos serviremos de él con frecuencia para encontrar las claves con las que valorar e interpretar el andaluz en muchos de sus aspectos.

\section{Antecedente del congreso de Sevilla: el I Congreso Nacional de Música}

\section{Sagrada (Valladolid, 1907)}

\subsection{Los orígenes del primer congreso "nacional"}

En la Crónica del Primer Congreso Nacional de Música Sagrada, publicada al año siguiente de su celebración, se presentaron como antecedentes del congreso de Valladolid los Edictos y Reglamentos sobre música sagrada promulgados por los Rmos.

\footnotetext{
${ }^{3}$ Sobre los congresos de Valladolid y Sevilla, véanse: de José López-Calo, "Congresos de música religiosa", D.M.E.H., 10 vols., ed. por Emilio Casares (Madrid: SGAE, 1999), vol. 4, pp. 876-878; el apartado "Los congresos de música sagrada", pp. 301-304, en "Cien años de asociaciones de música religiosa en España, 1850-1950", Cuadernos de Música Iberoamericana, 8-9 (2001), pp. 287-306; los apartados "El primer Congreso Nacional de Música Sagrada", pp. 33-37; "El congreso de Sevilla", pp. 50-61, en Nemesio Otaño, S.J.: Medio siglo de música religiosa en España (Madrid: ICCMU, 2010); y el subapartado "Los congresos", pp. 665-673, en La música en las catedrales españolas (Madrid: ICCMU, 2013). Además de estas publicaciones de López-Calo, véanse: $M^{a}$ Antonia Virgili Blanquet, el apartado "I Congreso Nacional de Música Sagrada. Valladolid 1907", en La música en Valladolid en el siglo XX (Valladolid: Ateneo de Valladolid, 1985), pp. 31-34; Xosé Aviñoa, "Los congresos del Motu proprio (1907-1928). Repercusión e influencias", Revista de Musicología, (Actas del Simposio Internacional "El Motu proprio de San Pío X y la Música (1903-2003)"), ed. por Mariano Lambea, XXVII/1 (2004), pp. 381-399; Jordi Rifé i Santaló, "Los congresos del Motu proprio y la música de J. S. Bach", ibídem, pp. 401-422.

4 “Crónica del Congreso. 26, 27 y 28 de Abrill, MSH, 1 (1907), p. 45.
} 
Prelados del provincia eclesiástica de Valladolid a los que aludimos en el capítulo primero. Según su redactor ${ }^{5}$, el éxito de estos documentos, así como "la conveniencia y los deseos de aunar el esfuerzo y de extender y unificar la acción, inspiraron al venerable Metropolitano de Valladolid la atrevida idea de celebrar un Congreso de Música Sagrada" ${ }^{\prime 6}$ En unos apuntes autobiográficos escritos en 1944, el propio Nemesio Otaño cuenta que esta idea se gestó al calor de un acto público organizado en 1905 con el objetivo de estudiar y divulgar las directrices contenidas en el $M P^{7}$.

Tanto $\mathrm{M}^{\mathrm{a}}$ Antonia Virgili como José López-Calo han resaltado la importancia de la promulgación de los Reglamentos sobre música sagrada como el hecho que dio lugar a la idea de celebrar un congreso de música sagrada. En sus respectivos trabajos han señalado igualmente la favorable acogida que le dispensó el papa, así como el eco que tuvieron en las revistas especializadas tanto españolas como europeas ${ }^{8}$. LópezCalo, quien describe todo el proceso previo a la celebración del congreso vallisoletano en varios de sus trabajos, recoge el testimonio de Otaño tal y como lo dejó escrito en los apuntes autobiográficos que acabamos de mencionar ${ }^{9}$.

La primera reunión para abordar su organización no tuvo lugar hasta el 17 de enero de 1907. En ella, "una junta magna de los principales maestros y profesores músicos y otras personalidades salientes de Valladolid", presidida por el arzobispo, nombró al presidente, tesorero y secretario del Congreso, designó la Junta Organizadora

\footnotetext{
${ }^{5}$ Es posible que la redacción de la crónica fuera obra de Casimiro González García-Valladolid, cronista de la ciudad, y nombrado también cronista del congreso. Crónica del Primer Congreso, p. 6.

${ }^{6}$ Crónica del Primer Congreso, p. 5. La Crónica del Primer Congreso incluía sendas cartas del cardenal Secretario de Estado del Vaticano Merry de Val, en las que se mostraba la buena acogida por parte de la Santa Sede a dichos documentos. Los elogios que de la prensa especializada merecieron también tuvieron su espacio. Se pueden leer en dicha Crónica fragmentos extraídos de artículos de revistas como Santa Cecilia de Turín, Musica sacra de Milán, del Boletín del Orfeo Catalá o Revue du Chant Gregorien, en las que se alaban y ponen en valor. Estas cartas fueron reproducidas el 1 de febrero de 1907 en el primer número del Boletín del congreso [BdC]. Ibídem, pp. 2-5.
}

7 “En 1905 organizó el Padre Otaño un gran acto público estudiando bajo todos los aspectos las orientaciones del Motu Proprio de Pío X. [...] Este acto, presidido por el Sr. Cos, tuvo gran resonancia y de él surgió la idea de celebrar un congreso de música sacra en Valladolid, idea muy jaleada por el Padre Otaño y patrocinada por Cos, aunque Goicoechea era muy contrario a ella, temeroso siempre de las complicaciones que semejante empresa traería". Apuntes autobiográficos (1944), p. 5. AMSL. FO. Conferencias y otros escritos. 005/013. Véase capítulo 1, epígrafe 2. "Comisión Diocesana de Música Sagrada: naturaleza y funciones", p. 65 , nota a pie $n^{\circ} 30$.

\footnotetext{
${ }^{8}$ Virgili, La música en Valladolid, p. 31. López-Calo, Nemesio Otaño, pp. 34-35.

${ }^{9}$ Véase: "Congresos de música religiosa", pp. 876-877; Nemesio Otaño, pp. 33-37; La música en las catedrales españolas, pp. 665-668. El fragmento citado en la nota a pie $\mathrm{n}^{\mathrm{0}} 7$ en Nemesio Otaño, p. 31.
} 
local, y decidió las fechas de su celebración ${ }^{10}$. Una vez constituida la Junta Organizadora, "se acordó publicar, con la aprobación y bendición del Excmo. Prelado, una revista quincenal con el título de Boletín del Congreso de Música Sagrada", cuyo primer ejemplar tiene fecha de 1 de febrero ${ }^{11}$. Antes de concluir la sesión, el arzobispo Cos envió al papa el siguiente telegrama:

Excmo. Sr. Cardenal Secretario de Estado. Roma. Vaticano. Comisiones diocesanas provincia eclesiástica Valladolid, propónense celebrar Congreso Música Sagrada conforme Motu Proprio del Santo Padre. Suplican venia y bendición Apostólica Obispos sufragáneos. En su nombre El Arzobispo. ${ }^{12}$

A este escrito contestó el cardenal secretario de Estado Merry del Val: "Roma. Valladolid. Su Santidad aprueba y alaba Congreso Música Sagrada conforme instrucciones Santa Sede y bendice los que formen parte en él. Cardenal Merry del Val." Además de en la Crónica del Primer Congreso, estos dos documentos se reprodujeron en el Boletín del Congreso $(B d C)$, encabezando el primer número de la publicación que poco después se convertiría en la revista Música Sacro-Hispana $(M S H)^{13}$.

El primero de los dos telegramas que acabamos de transcribir muestra que, oficialmente, el Congreso fue una propuesta, no sólo del arzobispo de Valladolid, sino también de todos sus obispos sufragáneos ${ }^{14}$. De hecho, según trasladó la Junta Organizadora en el primer número del $B d C$, con su celebración se pretendió dar

${ }^{10}$ La distribución de cargos fue como sigue: presidente, Francisco Martín de Castro, lectoral catedralicio; tesorero: Felipe Isidro Villaverde; secretario, Juan del Valle Heredero, ecónomo de la parroquia del Salvador y profesor de la Universidad Pontificia. El primero y el último eran en ese momento, presidente y secretario, respectivamente, de la CDMS de Valladolid. La junta local fue divida en tres secciones: sección de propaganda, cuyos presidente y secretario eran los mismos que los del Congreso; sección de programa y parte doctrinal, presidida por Nemesio Otaño, y para la que se nombró secretario Damián Ortiz de Urbina, que lo era de la Audiencia Territorial; sección de ejecuciones musicales, con el maestro de capilla catedralicio, Vicente Goicoechea, como presidente, y Segundo Milagro, organista, secretario. Junto a estos se citan un total de treinta personas entre vocales y miembros, sumando las tres secciones. Crónica del Primer Congreso, pp. 6-7.

${ }^{11}$ Ibídem.

${ }^{12}$ Ibídem.

${ }^{13}$ La respuesta de Merry del Val con la aprobación papal se imprimió en negrita. $B d C, 1$ (1907), p. 1. Sobre el Boletín del Congreso y su conversión en Música Sacro-Hispana, véase: López-Calo, Nemesio Otaño, pp. 36-37.

${ }^{14}$ La reseña que proporcionó la Crónica del Primer Congreso corrobora este extremo: "En esa junta se decidió por unanimidad celebrar en Valladolid un CONGRESO DE MúSICA SAGRADA [en versales en el original] los días 26, 27 y 28 de Abril inmediato, bajo la protección y la presencia honoraria del Excmo. Sr. Arzobispo de la Metrópoli y de los Rvmos. Señores Obispos de la provincia eclesiástica.” Ibídem. 
cumplimiento a una de las disposiciones (artículo 20) incluidas en el citado Edicto y Reglamentos sobre música sagrada, aprobado unánimemente como norma a regir en toda la provincia eclesiástica:

Con objeto de fomentar en España y en esta Archidiócesis de Valladolid particularmente un favorable movimiento de obediencia y sumisión al Código jurídico de S. S. Pío X acerca de la música sagrada, [...] y con el fin de cumplir lo dispuesto en el artículo 20 del gobierno interior de las comisiones de esta provincia eclesiástica, publicado y promulgado en el Edicto y Reglamentos sobre música sagrada por los Rmos. Prelados de esta Archidiócesis, [...] ha juzgado la Comisión de Música Sagrada que de ningún modo mejor podía secundar mejor las disposiciones de su S. S. y hacer fructuoso los elogios que toda la prensa de música religiosa a los citados reglamentos ha tributado, que reuniendo un congreso de música religiosa, al cual acudan no sólo los encargados de la música sagrada en esta provincia eclesiástica, sino también cuantos en España sienten la necesidad de promover el esplendor del culto y la restauración de las sagradas melodías. ${ }^{15}$

El artículo 20 al que se refería la Junta instaba a celebrar una "conferencia anual" en la que se dieran cita las comisiones de música sagrada de todas las diócesis sufragáneas de la metrópoli vallisoletana para discutir la forma más eficaz y rápida de aplicar el $M P^{16}$. Sin embargo, la convocatoria que realizaron los propios organizadores fue abierta ("reuniendo un congreso de música religiosa, al cual acudan no sólo los encargados de la música sagrada en esta provincia eclesiástica, sino también cuantos en España sienten la necesidad de promover el esplendor del culto y la restauración de las sagradas melodías"). Por tanto, a pesar de apoyar la iniciativa desde un punto de vista

\footnotetext{
${ }^{15}$ La Junta Organizadora, "Un llamamiento", $B d C, 1$ (1907), p. 3. A pesar de lo afirmado en este pasaje, en el Edicto y Reglamentos sobre música sagrada promulgados por los Rmos. Prelados de la Provincia Eclesiástica de Valladolid no fue publicado ningún reglamento de gobierno interior. El texto manejado en esta investigación ha sido el publicado en el $\mathrm{n}^{\circ} 11$ de 22 de noviembre de 1905 del Boletín Oficial Eclesiástico del Arzobispado de Valladolid. Ignoramos si hubo otra edición, en el que figurara tal reglamento.

${ }^{16}$ Podemos proporcionar el texto de este artículo, pues fue publicado en el $B d C$ : "Para dar poderoso impulso e imprimir unidad a la reforma, estrechar entre sí con fuertes vínculos a los miembros de las Comisiones Diocesanas y conseguir el florecimiento de la buena música sagrada, sería de desear que alternativamente en una de las capitales de la provincia eclesiástica, tuviera lugar una conferencia anual, a la que concurrieran todos o parte de los individuos que figuren en las mencionadas Comisiones, y allí bajo la presidencia y autoridad de los Prelados, se aclaren dudas, se propusieran medios y se adoptaran resoluciones prácticas, encaminadas a la más pronta y más perfecta ejecución del Motu Proprio de Su Santidad". La Comisión, "A las Comisiones de la provincia eclesiástica de Valladolid”, $B d C, 1$ (1907), p. 6.
} 
normativo en el artículo 20 del Reglamento, la idea no era organizar una "conferencia anual" de comisiones diocesanas, sino un encuentro de mayor envergadura.

Sobre el alcance de esta asamblea según se planteó en un primer momento, Luis Villalba nos proporciona una respuesta:

[...] ha de saber usted que cuando se echó a volar la especie del Congreso de música sagrada, no se pensó (así por lo menos me lo han dicho hace poco) en lo que ha sido, sino en algo bastante más modesto, en una reunión que comprendiera a las provincias de la archidiócesis vallisoletana, y a lo sumo las provincias colindantes, y conforme a tales aspiraciones se planeó, ${ }^{17}$

López-Calo sostiene, coincidiendo con Villalba, que la primera idea de los organizadores fue que el Congreso tuviera alcance provincial ${ }^{18}$. Sin embargo, creemos que la lectura de los primeros artículos del $B d C$, firmados por "La redacción" o "la Junta local" muestra, como veremos, que desde el principio se pretendió celebrar una convención de ámbito general español ${ }^{19}$. Nos inclinamos por pensar que la versión referida por Villalba -según se lo habían dicho hace poco- fue la oficial, pero, en realidad, las aspiraciones eran más ambiciosas. Si en los primeros momentos de su preparación se rebajaron los propósitos iniciales, fue por razones económicas, según contó Otaño a Pedrell; aunque, como argumentaremos a continuación, no fueron las únicas. La carta del jesuita data del 8 de enero de 1907, nueve días antes de que se celebrara la primera reunión para organizar el evento ${ }^{20}$ :

Ya sé que está V. enterado de los planes que aquí hay para un Congreso de música sacra. Lo que no encuentran es dinero: así que aquel consistirá en un congreso archidiocesano con una invitación general.

Será más modesto, porque no hay fondos para traer una sociedad coral, etc... El Domingo se celebra la reunión general

17 "El Primer Congreso Nacional de Música Sagrada celebrado durante los días 26, 27 y 28 en Valladolid", La Ciudad de Dios [LCD], 73 (1907), p. 122. Los artículos de Villalba sobre el congreso de Valladolid están escritos en forma de crónicas epistolares dirigidas al entonces director de la revista, Conrado Muiños Sáenz.

${ }^{18}$ Nemesio Otaño, p. 35; “Congresos de música religiosa”, p. 876.

${ }^{19}$ Los artículos que llevaban la firma de "La Redacción" o los anónimos fueron escritos por Nemesio Otaño, tal y como demuestra López-Calo. Nemesio Otaño, p. 36.

${ }^{20}$ En esta carta Otaño refiere el domingo 13 de enero como el día en el que estaba prevista la primera reunión para la organización del Congreso. Sin embargo, en la Crónica del Primer Congreso, p. 6 consta el 17 de enero, jueves, como la fecha en la que tuvo lugar. 
presidida por el Sr. Arzobispo donde definitivamente se planteará el proyecto y se tomarán resoluciones. Acaba de decírmelo D. Vicente. Yo no podré trabajar en esto.

La presencia de V. sería muy útil y en $\mathrm{V}$. se pensaba para dirigir las sesiones privadas; pero ya le digo, que no se cuenta con más fondos que los que se necesitan para pagar los elementos de esta ciudad y estos a costa del Sr. Arzobispo. ${ }^{21}$

Aunque Otaño hable a Pedrell de invitación general, en realidad, lo que se hizo desde las páginas del $B d C$ fue un llamamiento general -matiz importante en este caso-. La pretensión última, declarada en el artículo titulado precisamente "Un llamamiento", era ampliar el carácter, en principio, provincial del congreso, a nacional, en caso de que la convocatoria general tuviera éxito:

[...] Aunque se cimenta el carácter de esta acto en la reunión de las Comisiones Archidiocesanas, no por eso se deja de hacer un llamamiento general a los dignísimos maestros de música religiosa, a los Señores maestros de capilla y cantores de nuestras Catedrales e iglesias, a los maestros de canto de los Seminarios, institutos eclesiásticos y comunidades religiosas; al clero en general y a cuantos intervengan de algún modo en los divinos oficios [...], quieren restaurar la grandeza del arte musical religioso, tan inmensa en nuestra patria $[\ldots]$

De responder nuestra patria a este llamamiento, este congreso se ampliaría y llevaría los caracteres de general; así sus miras serían más elevadas, sus propósitos más grandes, su desenvolvimiento y acción más universal y fecunda en buenos resultados para el arte musical religioso en general y para el arte musical español muy en particular. $^{22}$

${ }^{21}$ Carta de Otaño a Pedrell. 8 de enero de 1907. BC. FFP. M 964 O. Otaño escribió a Pedrell varias cartas más con la intención de recabar su colaboración en el Congreso. En otra fechada el 30 de enero le expresaba: "Sírvase V. ayudarnos con sus esfuerzos porque V. veteranus miles aún en medio de los desengaños conserva $\mathrm{V}$. fresca todavía la idea de hacer el bien y difundirlo aunque sean pocos los que lo recogen: esos pocos somos nosotros.

La junta agradecería que indicare V. algunas obras que puedan ejecutarse o de V. o de autores españoles. En el programa verá V. la idea .

Podemos contar seguramente con su apoyo?

Reciba V. el reconocimiento de la Junta organizadora en cuyo nombre le escribo esta muy aprisa”. BC. FFP. M 964 O.

La siguiente es de 20 de febrero: "Algunas cartas he dirigido a V. sobre lo del Congreso, y al no recibir noticia alguna de V., me hace sospechar que no disfruta V. de buena salud, lo cual me sería muy sensible. Tenga V. la bondad de avisarnos con qué ánimos se encuentra V. para esto del Congreso, pues su consejo y su apoyo nos es muy necesario. ¿No quiere V. escribir algo en la revista?”. El original de esta carta no se conserva ni en la BC, ni en el AMSL [Archivo Musical del Santuario de Loyola]. Ha llegado a nosotros a través de la transcripción realizada por Victoriano Larrañaga en el epistolario que preparó y no llegó a publicar. AMSL. FO [Fondo Otaño]. Correspondencia, T01/007. A pesar de la insistencia de Otaño, Pedrell no asistió al Congreso.

${ }^{22}$ La Junta, "Un llamamiento", $B d C$, 1 (1907), p. 3. 
Había otras causas, por tanto, además de las dificultades económicas detrás de la excesiva cautela mostrada por la organización a la hora de embarcarse en la celebración de un congreso "nacional". El temor a que los colectivos relacionados con la música eclesiástica en España no secundaran el "llamamiento" explicaría la prudente estrategia por la que se optó en principio: hacer una convocatoria provincial dejando la puerta abierta a la posibilidad de convertirla en general, en caso de que la respuesta de aquellos colectivos estuviera a la altura. Así se evitaría, si no se lograra unos mínimos de participación, el posible fiasco de una convocatoria general, con el efecto disuasorio que pudiera tener en futuros intentos. Un fracaso en este sentido hubiera comprometido gravemente uno de los objetivos fundamentales perseguidos por los congresos: consolidar un potente movimiento a favor de la reforma.

De hecho, el autor anónimo de uno de los artículos publicados en MSH una vez clausurado el Congreso, puso de relieve, empezando por el título, el logro que había supuesto haber demostrado "lo que antes se creía imposible": que en España tuviera éxito una convocatoria general, a pesar de las dificultades. Con ello se trataba de probar, además, que existía un caldo de cultivo propicio para que los ideales reformistas prendieran. Ante tales activos, se relativizaba, incluso, la importancia de la cuestión económica:

[...] aunque otro fruto no se consiguiera que esta señal de vida y de movimiento, el primer Congreso de música religiosa será solo por esto un acontecimiento glorioso, una página brillante de la historia de la música sagrada española, el prólogo maravilloso de una obra monumental que se perfeccionará, no hay que dudarlo. Porque se ha demostrado elocuentemente que hay vida, que hay amor al trabajo, que hay brazos y hay ingenio y donde esto tan a las claras se ha visto, nada pueden las pruebas verdaderamente aterradoras de la carencia del dinero: $[. .$.

[...] Se ha demostrado ante todo que España ha respondido pronta y generosamente al llamamiento: nadie creyera que con dos meses de preparación fuera posible un tal suceso. [...] La junta organizadora ha trabajado con todo el celo y desinterés posible y ha demostrado que lo que antes se creía imposible es ya muy hacedero, que lo que en poco tiempo ha podido preparase de un modo decoroso y digno, puede perfeccionarse y acabarse con preparación conveniente y bien meditada. Tal es el argumento que se trataba de demostrar y queda demostrado terminantemente. El Primer Congreso de Música Sagrada Español es ya un hecho; su celebración digna y provechosa no puede ponerse en duda. ${ }^{23}$

23 “Quod erat demostrandum!”, MSH, 1 (1907), p. 2. 
En definitiva, tal y como rezaba su título, Quod erat demostrandum. Es decir, lo que se pretendía demostrar había quedado demostrado: que era posible un congreso nacional, y que en España la reforma tenía pulso y futuro.

Suponemos, además, que las dificultades económicas señaladas por Otaño se atenuarían algo, tanto por los ingresos que reportarían las inscripciones de un mayor número de congresistas de lo esperado, como por el importante ahorro que debió suponer la participación absolutamente desinteresada de la Capilla Isidoriana ${ }^{24}$. Recordemos las razones que obligaban a un proyecto modesto aducidas por el vasco: la falta de fondos para contratar una sociedad coral para los conciertos y actuaciones musicales.

Con todo, resulta significativo que la primera vez que se utilizó en el $B d C$ el calificativo de "nacional" en referencia al alcance del Congreso, se enmarcara entre interrogantes -“¿Primer Congreso Nacional de Música Sagrada?”-. Este fue el título del artículo que desveló sin tapujos la ambición -deseos ardientes- de los organizadores:

Este es el nombre de pila [Primer Congreso Nacional de Música Sagrada] con que la voz unánime y entusiasta ha bautizado el próximo congreso que venimos preparando en Valladolid. Nosotros queríamos tuviera ese carácter general, lo deseábamos ardientemente, amigos de difundir el bien y patentizar la verdad ya demasiado conocida para no ser amada, sentíamos en el fondo del alma que nuestros humildes conatos habían de lograr éxito favorable $[\ldots]^{25}$

Así pues, gracias a la positiva respuesta, el Congreso terminó teniendo carácter "nacional". Con estas palabras se comunicó desde el $B d C$ la proclamación del Congreso como congreso nacional:

Las cartas que venimos recibiendo diariamente tan llenas están de fe y de ánimos, que no hacemos sino reproducir aquí su espíritu ante la imposibilidad absoluta de dar publicidad a todas. Ante esta opinión general, creemos, pues, poder levantar no ya la voz, sino el grito de aclamación promulgando por plebiscito el Primer Congreso Nacional de Música Sagrada [en letras de mayor tamaño]" 26

\footnotetext{
24 "No sabemos cómo expresar a la Capilla Isidoriana toda nuestra gratitud y toda nuestra voluntad por su desinterés absoluto. Su dignísimo Presidente el Sr. Bahía; su inteligente director el Maestro Asensio y su celoso administrador el Sr. Velasco se han hecho acreedores al más justo de los agradecimientos. Esta masa coral reúne de cincuenta a sesenta individuos, ya veteranos en su arte y amaestrados en las obras polifónicas y clásicas". "Movimiento del Congreso", BdC, 6 (1907), p. 65.

${ }^{25}$ La Redacción [Otaño], “¿Primer Congreso Nacional de Música Sagrada?”, BdC, 3(1907), p. 21.

26 “¿Primer Congreso Nacional de Música Sagrada?”, BdC, 3 (1907), p. 21.
} 


\subsection{Dimensión “nacional” y problemas de organización}

Aquella primera declaración pública del congreso de Valladolid como Primer Congreso Nacional de Música Sagrada se hizo el 1 de marzo, lo que indica que la decisión de ampliar su alcance -de provincial a nacional- se debió tomar en la segunda quincena de febrero. Por tanto, los organizadores dispusieron de apenas dos meses para preparar un acontecimiento de una envergadura considerablemente superior. Del desequilibrio entre las dimensiones que adquirió el Congreso y el tiempo de que se dispuso para su preparación resultó el principal defecto de esta asamblea: los problemas de organización.

En el extracto antes citado del artículo Quod erat demostrandum, se adviertía por parte de su autor, seguramente miembro de la organización, una cierta autocrítica en este sentido: "Bien lejos estará sin duda de la junta organizadora el creer que haya sido feliz su influjo en todo, que todos los actos del Congreso hayan salido con la deseada perfección" 27 . La organización debió recibir numerosas críticas, a las que tuvo que hacer frente relativizando los defectos ante el carácter de hito histórico que le atribuía: “¡Cuán ajeno es del caso y cuán lejos del verdadero camino andan los que fijándose en detalles insignificantes poco perfeccionados, sólo tratan de deslucir el conjunto y apagar con un jarro de agua fría los entusiasmos primeros!"28. El último día del Congreso, cuando se planteó la conveniencia de celebrar otro, el propio Nemesio Otaño señalaba la necesidad de mejorar la organización y de disponer de más tiempo para la preparación del próximo: "Es por tanto conveniente que para conservar el fuego y el entusiasmo aquí levantados se celebre dentro de un año otro Congreso, más solemne todavía y sobre todo mejor organizado y de ante mano mejor estudiado."29

Luis Villalba apuntaba abiertamente en este mismo sentido, y hablaba incluso de improvisación:

Decía que era este congreso un congreso improvisado, $y$, en efecto, esta nota de la improvisación se echa de ver en todo; nació de una corazonada prematura, se anunció con una premura de tiempo inverosímil, y hasta estas fechas se nota el abarullamiento excesivo con que se ha hecho y hasta falta de organización. Pero no hay que

\footnotetext{
${ }^{27}$ Ibídem.

28 “Quod erat demostrandum!”, p. 2

29 “Crónica del Congreso. 26, 27 y 28 de Abril”, MSH, 1 (1907), p. 48.
} 
culpar de esto a los directores de la obra; la cosa se la trae el mismo negocio de por sí [...]; pero al ver cómo de una parte y de otra llegaban adhesiones, y cómo se inscribían en el número de los congresistas los maestros y músicos de las más apartadas regiones de España e iba adquiriendo el carácter de todo un señor Congreso nacional de música sagrada, hubo de sufrir alteración el plan, y como la premura de tiempo no daba de sí gran cosa, necesariamente ha tenido que coger en periodo de formación una obra, que necesitaba casi tres veces más de tiempo para prepararse debidamente. ${ }^{30}$

Con la libertad que no permite el artículo público y sí la correspondencia privada, Villalba se expresaba de una forma más gráfica en la siguiente carta del 16 de mayo dirigida a Pedrell:

Quiere V. saber más de todo ese Belén que se ha llamado Congreso nacional de música sagrada, y más que lo que he dicho en "EL BUEN CONSEJO", cosa que por cierto, no ha gustado al $\mathrm{P}$. Otaño, no le podré decir: Que allí todo el mundo andaba de cabeza, sin orden y sin concierto, es verdad, pero que quiere V.? hasta me ha resultado simpático este barullo, porque o tenían que haberlo dejado todo, o por necesidad había de salir de mala manera todo; dejarlo era imposible, de modo que harto han hecho con confesar que se han metido en un lío atroz y del cual no sabían cómo iban a salir, y en fin, como precedente histórico, es cosa que debe aplaudirse. ${ }^{31}$

La historiografía ha insistido en el éxito que supuso el congreso de Valladolid y en su condición de gran hito histórico, aunque no ha reparado en los importantes problemas organizativos por los que también se caracterizó, componiendo una imagen, probablemente, algo idealizada ${ }^{32}$.

La falta de tiempo para una conveniente preparación hizo que se llegara a plantear la posibilidad de posponerlo a otras fechas e incluso al año siguiente, algo que, no obstante, se desestimó al ofrecer más inconvenientes que ventajas ${ }^{33}$ :

\footnotetext{
${ }^{30}$ Luis Villalba Muñoz, “El Primer Congreso Nacional de Música Sagrada”, LCD, vol. 73 (1907), p. 122.

${ }^{31}$ Carta de Villalba a Pedrell, 16 de mayo de 1907. BC. FFP, M 964 V.

${ }^{32}$ En ninguna de las publicaciones sobre los congresos se hace mención a ello. Tan sólo Ma Antonia Virgili, apoyándose en una de las crónicas epistolares de Villalba, alude a la preparación de uno de los conciertos de órgano como "sometido por completo a necesidades de improvisación". A continuación transcribe uno de los párrafos de Villalba para ilustrar las circunstancias en las que se desarrolló. La música en Valladolid, p. 32.

33،'Los mismos iniciadores de la cosa lo han comprendido así, y hasta han tratado de diferir el Congreso; pero esto era asunto difícil, dado el entusiasmo que había despertado la idea, y abrumados bajo el peso de la tarea, han tenido que sostener y esperar a pie firme lo que viniera encima. Y en verdad que yo les alabo, porque es fácil que una dilación en nuestro país, hubiera enfriado los ánimos, y como en tales
} 
Cierto es que el tiempo es escaso y que los días señalados se avecinan. Circunstancias muy bien ponderadas han determinado esta época; época anterior o posterior dentro del año era imposible para Valladolid y diferir por un año asunto de tal trascendencia ofrecía aún inconvenientes de más consideración. ${ }^{34}$

Como muestra el contenido de la carta que remitió a Pedrell citada más arriba, Villalba puso el énfasis en el valor histórico del Congreso así como en el logro que supuso su celebración, no obstante sus críticas a las deficiencias de organización. En su artículo sobre el Congreso en La Ciudad de Dios ( $L C D)$ afirmó: “¿Que ahora no sale muy igual la cosa? Bueno, otra vez saldrá; lo principal es despertar la opinión de los músicos eclesiásticos; lo otro ya vendrá por añadidura, y no es poco mérito el haber hecho el primer milagro. "35 Más adelante, en su inconfundible estilo y valiéndose de una gráfica imagen, volvía a insistir en su importancia histórica -"el bollo"-, a pesar de sus defectos -“el coscorrón”-. Lo llegó a situar incluso al nivel de los grandes congresos celebrados en Europa, no sin reconocer haberse dejado llevar por cierto entusiasmo patriótico:

[...] bien se puede perdonar el coscorrón por el bollo. Pues digo que aun así, y con todas las premuras, barullos y etc., etc., nuestro Congreso de Valladolid no tiene que envidiar mucho a los pregonados por ahí buecis crepautibus [sic], y traídos en alas de la fama y en otras alas, hasta nuestros humildes lares, y mirados y remirados con venerabundo aspecto por nosotros los españoles, que hemos dado en la encantadora humildad de creernos los más adoquines de la tierra: pues no hay nada de eso: yo ignoro cuántos centímetros habrá de diferencia entre [el congreso de] Straburgo [sic] y Valladolid, y cuántas pulgadas de perfección le llevará el uno al otro; pero, en fin, aunque sea, cuestión es la tal de poco más o de poco menos, pero en lo demás allá creo que no andamos.

Me parece que también tengo yo, no sólo mis arranques patrióticos, sino que también a las veces me entusiasmo. Sólo falta ahora que a este modesto desahogo le salga algún ceñudote de esos que se creen los mejores, y me tache olímpicamente, directe $o$ indirecte, de orgulloso, no porque diga que hacemos más, sino tanto como ellos; lo cual que, después de todo, es bien poco decir, y aunque sea un poco hiperbólico, digno es tal entusiasmo de respeto, pues lo

negocios lo principal es mantener el fuego sagrado, considero más laudable seguir adelante que diferir la celebración del Congreso.” Luis Villalba, "El Primer Congreso Nacional”, p. 122.

${ }^{34}$ La Redacción, “¿Primer Congreso Nacional de Música Sagrada?”, p. 21.

${ }^{35}$ Luis Villalba, "El Primer Congreso Nacional”, p. 122. 
menos que puede pensar un hombre de su madre es que vale tanto como las demás mujeres. ${ }^{36}$

Sin embargo, el agustino cuestionaba su utilidad y que constituyera el "prólogo maravilloso de una obra monumental", como se afirmaba en $M S H$ : "Mas como quiera que este Congreso será, no diré yo que el prólogo galeato de alguna magna y sesuda obra, pero por lo menos el ensayo de otro, y ojalá de otros (que nada perderemos con que la cosa vaya en plural)”37. A Pedrell le confesó: “¿Qué se sacará de todo esto? Ni lo sé, ni soy el más apropósito para juzgarlo. Vine sin fe y sin esperanza, y estoy esperando lo que se resuelva para ver" 38 . Posiblemente, fue este escepticismo lo que le llevó a rechazar la retórica grandilocuente exhibida para ensalzarlo:

[...] quisiera, repito, tener esa propiedad [...] que a los profesores del arte divino se achaca, para echar todas las campanas a vuelo, soltar toda la trompetería y derrochar (no sé si esto de derrochar será el término propio) toda la retórica de repertorio y dar rienda suelta al bélico entusiasmo, lanzando a todo pulmón cuanta retórica existe en el repertorio entusiástico para hablar del Congreso de música religiosa de Valladolid, pero para mí, la música es un arte excelente, excelentísimo, que cultivo con gran entusiasmo en todos sus géneros, pero sin llegar a creer por eso que es el peldaño más cercano ni mucho menos del cielo; y he ahí por qué el Congreso me parece una de tantas cosas de la música y al cual asisto porque me gusta ver, estudiar y aprender cuanto con la música se relaciona. ${ }^{39}$

Por tanto, y en síntesis, el congreso de Valladolid terminó teniendo el carácter de nacional tal y como deseaban sus promotores. Por ello, fue contemplado como un logro, y un importante hito histórico. Sin embargo, precisamente al adquirir la condición de nacional se convirtió en un acontecimiento que desbordó las posibilidades de los organizadores, quienes tuvieron que afrontar su preparación en un tiempo record. En contraste con el éxito que supuso su celebración, el desarrollo de la asamblea vallisoletana acusó importantes problemas de organización. Las apreciaciones más entusiastas y optimistas quisieron ver y trasladar la idea del Congreso como el preludio

\footnotetext{
${ }^{36}$ El congreso de Estrasburgo al que hace referencia Villalba fue el primero en celebrarse en Europa tras la promulgación del MP. Luis Villalba, "El Primer Congreso Nacional”, pp. 384-385.

${ }^{37}$ Luis Villalba, "El Primer Congreso Nacional”, pp. 122-123.

${ }^{38}$ Carta de Villalba a Pedrell, 16 de mayo 1907. BC. FFP, M 964 V.

${ }^{39}$ Luis Villalba, “El Primer Congreso Nacional”, pp. 121-122.
} 
de una "obra monumental", la de la regeneración de la música religiosa en España. Otras opiniones más moderadas rebajaron su trascendencia a representar sólo un primer paso de un difícil camino que contemplaban con interés, aunque también con reservas e incluso escepticismo ${ }^{40}$. Tras el vallisoletano, el siguiente paso en este camino, o el próximo capítulo en la consecución de esta magna obra, según se mire, fue el congreso de Sevilla.

\section{Génesis del congreso de Sevilla}

A las cuatro y media de la tarde del 28 de abril dio comienzo en la Iglesia de Santiago la tercera y última sesión solemne del congreso de Valladolid ${ }^{41}$. El programa previsto debió ser alterado, pues, por falta de tiempo, determinados asuntos de gran importancia habían quedado pendientes de tratar. El discurso que debía pronunciar el sacerdote balear Francisco Esteve fue suspendido para, a continuación, celebrar una, improvisada, sesión privada extraordinaria ${ }^{42}$. A pesar de su carácter privado, los congresistas debatieron las cuestiones propuestas delante del público que había acudido a presenciar la sesión solemne. El presidente de las secciones, Nemesio Otaño, anunció así el acto:

En vez del anunciado discurso que había de leer el joven e ilustrado sacerdote mallorquín D. Francisco Esteve Blanes, me presento aquí de nuevo para constituirnos en sesión privada [en negrita en $M S H]$, con permiso del escogido público, al que hacemos partícipe de todos nuestros secretor y confidencias. (Hilaridad). Es necesario que antes de la clausura del Congreso determinemos algunos puntos importantes que aseguren bien la piedra fundamental de la restauración que en las anteriores sesiones hemos colocado. ${ }^{43}$

\footnotetext{
${ }^{40}$ El congreso de Valladolid ha trascendido como el acontecimiento que ha marcado el inicio de una nueva etapa de la música religiosa en España. José López-Calo, su principal estudioso, se ha referido a él en términos como los siguientes: "La impresión que dejó el congreso en sus organizadores y en los asistentes fue tremendamente positiva, y se puede decir sin exageración que en este congreso nació un nuevo periodo para la música religiosa española", "Congresos de música religiosa”, p. 877; "de él [el Congreso] partió, con una fuerza incontenible, la transformación de la música religiosa en España, [...]”, La música en las catedrales españolas, p. 668.

${ }^{41}$ López-Calo hace mención a esta última sesión, aunque de forma somera, en: Nemesio Otaño, p. 37; “Congresos de música religiosa", p. 877.

${ }^{42}$ El discurso suspendido llevaba por título La participación activa del pueblo cristiano en el canto de los Oficios litúrgicos. La interpretación por parte de la Capilla Isidoriana del Gloria de la Misa del Papa Clemente XI de B. Marcelo con la que estaba previsto cerrar el acto se aplazó hasta una vez concluida la sesión privada. El programa de la III Sesión Solemne en: "Crónica del Congreso. 26, 27 y 28 de Abril", p. 48. Dicho programa se puede leer también en: Crónica del Primer Congreso, pp. 35-36.

43 “Crónica del Congreso. 26, 27 y 28 de Abril”, p. 48.
} 
Esta forma de abordar temas de gran relevancia, consecuencia directa de la precipitada planificación de las sesiones, mereció los irónicos comentarios de Villalba en su crónica epistolar sobre el Congreso publicada en $L C D$ :

Pero lo más particular de la sesión ha sido el último cuarto de hora: se convirtió en privada la sesión solemne, para hablar tres cosillas que se habían quedado esta mañana olvidadas, entre las frases cariñosas, entre las dulces despedidas, y allí cora in populo [ante el pueblo] se expusieron; y como en el templo no sólo había congresistas, sino que además asistían regular número de señoras, era de ver el interés con que estas seguían la discusión, y cómo daban o negaban su asentimiento moviendo la cabeza. De fijo que a más de una le entraron ganas de terciar en el debate. ${ }^{44}$

Las materias pendientes de resolver -“tres cosillas [...] olvidadas"- eran la creación de la Asociación Ceciliana Española, la fundación de una revista para mantener en contacto a los congresistas, y la elección de la sede del próximo congreso, que debía celebrarse, "para conservar el fuego y el entusiasmo aquí levantados", dentro de un año ${ }^{45}$. Entre las ciudades que salieron a relucir como posibles candidatas, el redactor de la crónica publicada en $M S H$ mencionó Madrid, Toledo o Barcelona, así como el monasterio de Montserrat. Sin embargo, la circunstancia de hallarse presente el recién proclamado arzobispo de Sevilla, Enrique Almaraz, hizo decantar el voto de su homólogo vallisoletano "a quien se autorizó para designar el punto" 46 , a favor de la capital andaluza:

(Los Congresistas deliberan un rato, hay quienes proponen Madrid, Toledo, Barcelona, Montserrat pero la voz común habla de Sevilla por hallarse presente el Sr. Arzobispo preconizado de aquella ciudad). Varias voces [en negrita]. ¡iEn Sevilla, en Sevilla!!. Un Congresista [en negrita]. Donde lo proponga el Excelentísimo Señor Arzobispo de Valladolid. (Grandes aplausos). Excelentísimo Sr. Arzobispo [en negrita]. Oigo que la opinión general se dirige a Sevilla: está presente el Sr. Arzobispo que ha de ocupar aquella silla y

\footnotetext{
${ }^{44}$ Luis Villalba, "El Primer Congreso Nacional”, p. 306.

45 "Como muy bien nos ha dicho en la sesión privada de hoy nuestro amadísimo Sr. Arzobispo, es necesario que este Congreso sea el primero de los Congresos que vendrán celebrándose en España para afirmar los intereses de la música sagrada. Es por tanto conveniente que para conservar el fuego y el entusiasmo aquí levantados se celebre dentro de un año otro Congreso, [...]". "Crónica del Congreso. 26, 27 y 28 de Abril", p. 48.

${ }^{46}$ Crónica del Primer Congreso, p. 35.
} 
realmente el asunto puede solucionarse aquí mismo, porque aquí están las personas interesadas. ${ }^{47}$

Suponemos que la preconización de Almaraz como nuevo prelado hispalense proporcionaba una solución sencilla al problema de la designación de la próxima sede congresual. Almaraz poseía una importante experiencia en la organización de grandes reuniones eclesiales. Antes de su nombramiento episcopal, fue secretario del I Congreso Católico Nacional, y secretario de la Junta Central del segundo, celebrado en Sevilla $^{48}$. Debió ser, además, un hombre de confianza para José María Cos y Macho, con quien coincidió unos meses en la diócesis de Madrid-Alcalá. Precisamente Almaraz, entonces deán de la catedral madrileña, ejerció como procurador en la toma de posesión de Cos y Macho como nuevo obispo de dicha diócesis en julio de $1892^{49}$. Nemesio Otaño, por su parte, se refirió en sus apuntes autobiográficos al futuro arzobispo de Sevilla como "gran mecenas mío" 50.

Como se observa en numerosos escritos de distintos líderes reformistas y veremos en el próximo capítulo, la ciudad andaluza poseía un especial valor simbólico por su condición de ciudad natal de una buena parte de los grandes polifonistas hispanos, la llamada "Escuela Sevillana", que la reforma, y el regeneracionismo musical español con el se confundiría y fundiría, pretendió recuperar. A nuestro juicio, y así lo trataremos de defender más adelante, la elección de Sevilla supuso un desplazamiento de la atención de los tradicionales centro musicales del país, como Madrid, Barcelona, o el recién constituido de Valladolid, al sur peninsular. La decisión del congreso vallisoletano de celebrar el segundo congreso en una ciudad alejada de estos centros principales, y ajena a las rivalidades entre líderes o grupos pujantes, libraba de posibles polémicas entre territorios o tendencias, cuyos intereses o posicionamientos no siempre eran coincidentes. De hecho, a pesar del empeño que los responsables pusieron en evitar disputas, esas tensiones afloraron durante los debates, provocando rifirrafes verbales subidos de tono. El episodio protagonizado durante la tercera sesión privada

47 “Crónica del Congreso. 26, 27 y 28 de Abril”, p. 48.

48 Esta información ha sido tomada de la extensa biografía que con motivo de la preconización como arzobispo de Sevilla del que era hasta ese momento obispo de Palencia, publicó el BOAS. "Preconización del Excmo. Sr. D. Enrique Almaraz para esta Sede Metropolitana" [título tal y como figura en el índice. Cabecera del artículo sin título] n ${ }^{\circ} 615$ (1907), p. 156.

49 Almaraz y Cos y Macho Javierre, "La diócesis de Sevilla”, p. 369.

${ }^{50}$ Apuntes autobiográficos (1944), 11. AMSL. FO. Conferencias y otros escritos. 005/013. 
por el maestro de capilla de la catedral de León, Mariano Neira, y su homólogo gerundense, Miguel Rué, es una muestra:

D. Mariano Neira [los nombres de los distintos intervinientes figuran impresos en negrita]. Pide que dada la notoria competencia y crédito del Sr. Amezua, se le recomiende y se le proteja y se dé noticia de su casa en el Boletín Eclesiástico. D. Miguel Rué. Dice que tan dignos son de consideración otros constructores catalanes, valencianos, aragoneses, etc. (Se promueve un pequeño incidente). Presidente [Nemesio Otaño]. No tratamos aquí de favorecer más a unos que a otros; todos son dignos de consideración y aprecio. Propongo al Congreso que acepte esta fórmula: En la construcción de órganos se ha de procurar favorecer el arte español; por lo tanto en igualdad de circunstancias ha de preferirse el organero español al extranjero. (Grandes muestras de aprobación y aplausos). D. Mariano Neira. El Sr. Amezua ha presentado una memoria que ha merecido el consentimiento de todos y fundado en esto hacía yo mi observación. D. Miguel Rué. Otros organeros hubieron presentado las suyas si se hubieran enterado de estos puntos. Presidente. Pide cese esta discusión inútil [...]. Declara al Sr. Rué que la junta organizadora ha puesto todos los medios posibles para dar a conocer el congreso y su programa y hasta ha invitado particularmente a algunos constructores que escribieron pidiendo datos. $[\ldots]^{51}$

El arzobispo zanjó definitivamente la disputa aceptando la propuesta de Otaño y pidiendo constara en las actas íntegra la memoria presentada por Amezua ${ }^{52}$.

Enrique Almaraz, al margen de toda polémica, aceptó públicamente la designación y asumió el compromiso, “dispuesto a todo y con todos los deseos de poder ser útil en algo a una empresa tan gloriosa" ${ }^{, 53}$. El tenor de la capilla musical de la catedral hispalense, Agapito Insausti, también intervino para agradecer la designación de Sevilla en nombre del Cabildo ${ }^{54}$. Resulta llamativo, a nuestro juicio, que fuera el

51 “Crónica del Congreso. 26, 27 y 28 de Abril”, p. 39.

${ }^{52}$ Albano García transcribe el fragmento de la crónica de Villalba en el que el agustino informó sobre este incidente como ejemplo de polémicas localistas. "Sobre la reforma de la música religiosa en España", p. 974.

53 “Excmo. Sr. D. Enrique Almaraz. [en negrita] (Arzobispo preconizado de Sevilla). No puedo menos de sentirme muy emocionado ante las deferencias de que soy objeto y agradeciéndoselas de todo corazón, aquí me presento a todo y con todos los deseos de poder ser útil en algo a una empresa tan gloriosa. Amo ya a los nuevos hijos que se me confían y en nombre de ellos recibo gustoso y con los brazos abiertos a los Congresistas que dentro de un año visitarán aquella hermosa ciudad de Andalucía. (Aplausos y aclamaciones)." "Crónica del Congreso. 26, 27 y 28 de Abril”, p. 48.

54 "D Agapito Insausti [en negrita]. Agradece se haya designado Sevilla para la celebración del próximo Congreso. Prometen que sus compañeros y él trabajarán con todo ardor para que el segundo Congreso no desmerezca del primero y manifiesta que están dispuestos al trabajo". "Crónica del Congreso. 26, 27 y 28 
tenor de la capilla quien tomara la palabra en representación de los capitulares sevillanos, y no Ripollés, a quien, en principio, le correspondería por orden jerárquico como maestro de capilla ${ }^{55}$. De hecho, a diferencia de Insausti, quien se mostró muy activo en distintos debates que se suscitaron, Ripollés no participó en las sesiones del Congreso salvo en una única ocasión. La pasividad del castellonense extraña, dado el compromiso y activismo en pro de la reforma por los que se caracterizó, y sobre todo el papel que jugó en el siguiente. Ni siquiera fue él quien leyó su propio discurso $L a$ cultura litúrgico-musical del Clero, al que hacíamos referencia en el capítulo cuarto, sino Insausti. Las fuentes no proporcionan datos con los que siquiera especular sobre las causas de esta inactividad de Ripollés.

Es de suponer que la celebración del próximo congreso en Sevilla debió representar para Almaraz, a quien Javierre describe como perteneciente "al sector más abierto y operativo del episcopado español de su tiempo", aunque participara de su “cerrazón visceral" ante la evolución ideológica europea, una gran oportunidad para portar todo el impulso generado en Valladolid a su nueva sede, y convertirla por un tiempo en el centro de la música religiosa en España ${ }^{56}$. Más adelante adquiriría otros valores, como conseguir la celebración y organización de un gran evento con el que recuperar el dinamismo que había alcanzado la Iglesia de Sevilla durante el pontificado de Spínola y que, como vimos en anteriores capítulos, había acusado el excesivamente prolongado periodo de interregno. En este sentido, cabe aludir al hecho de que el congreso de música sagrada coincidiera en el tiempo con la preparación de otro gran acontecimiento de la Iglesia española en la capital andaluza, la III Semana Social. De ello se puede deducir la intensa actividad que, de nuevo, debió desplegar la institución eclesiástica con la llegada de Almaraz, y las exigencias que, a su vez, supusieron estos revulsivos, no sólo para la alta administración diocesana, sino también para otros

de Abril”, p. 49. La crónica del Congreso recoge también esta intervención de Insausti. Crónica del Primer Congreso, p. 35.

${ }^{55}$ El tercer representante del cabildo hispalense, junto a Insausti y Ripollés, fue el organista catedralicio, Bernardo Salas.

56 Javierre continúa: aunque "alejado del integrismo y de hábitos inquisitoriales [...] participaba de la cerrazón visceral ante las realidades europeas, concretamente ante la evolución ideológica, de nuestros prelados del primer cuarto del siglo veinte: veían la Iglesia católica agredida por un anticlericalismo virulento, y amenazada por el avance imparable del socialismo;" Javierre, "La diócesis de Sevilla", p. 379. 
colectivos como curas rurales, o los propios fieles. De ello nos ocuparemos más adelante.

Pero volvamos a aquella sesión última del congreso de Valladolid, pues consideramos importante para trasladar una idea del peso que adquirió la Junta vallisoletana tratar los otros dos asuntos pendientes: la revista y la fundación de la Asociación Ceciliana. Respecto al primero, se decidió la transformación del Boletín del Congreso en la revista $M S H$. Su redacción permaneció en Valladolid, a pesar de que, en un primer momento, Otaño planteó que fuera Voz de la Música, dirigida por Olmeda, la que sucediera al Boletín, y se trasladara a Madrid ${ }^{57}$.

De nuevo por falta de tiempo, el último de los temas pendientes, la fundación de la Asociación Ceciliana, volvió a aplazarse, esta vez hasta el próximo congreso:

[Otaño:] Dada la premura del tiempo imposible me parece pensar por ahora en una obra de tal trascendencia [la fundación de la Asociación Ceciliana]; pero suplico con todo interés a los señores Congresistas vayan estudiando el modo de llevar a cabo esta idea en el próximo Congreso de Sevilla. ${ }^{58}$

En tanto en cuanto se aprobaba la creación de dicha asociación, algo que no se produjo hasta el III Congreso Nacional de Música Sagrada (Barcelona, 1912), Otaño lanzó la siguiente propuesta ${ }^{59}$ :

¿no sería bueno pensar en una junta de peritos en el arte de toda España, que hicieran un numero de 40 o 60 maestros, bajo la dirección de una junta central, la cual había de señalar tres censores de cada una de las obras que han de formar el repertorio escogido de música sagrada, obras que habían de admitirse por mayoría absoluta de votos emitidos por dichos censores? Los censores distribuidos por todas las provincias no habían de saber el juicio de sus compañeros; de este modo la imparcialidad ganaría no poco. La junta central había de dar el Visto Bueno definitivo. ${ }^{60}$

\footnotetext{
${ }^{57}$ Véase: López-Calo, Nemesio Otaño, pp. 37-39.

58 “Crónica del Congreso. 26, 27 y 28 de Abril”, p. 49.

${ }^{59}$ Conclusión relativa al Tema V. [Fundación de la Asociación Ceciliana Española] de la sección tercera "Propaganda y Organización" del congreso de Barcelona. Crónica y actas oficiales del Tercer Congreso Nacional de Música Sagrada (Barcelona: La Hormiga de Oro, 1913), p. 231.

${ }^{60}$ Ibídem.
} 
La razón ofrecida por el jesuita fue la dificultad que para la depuración de la música sagrada suponía la falta de acuerdo y criterio común entre las distintas comisiones diocesanas, un grave problema desde la promulgación del $M P^{61}$. Con ello se evitaba demorar un año más esta importante empresa para la realización de la reforma y la regeneración musical en España ${ }^{62}$.

La propuesta de Otaño representaba una gran novedad. Suponía la constitución de una estructura paralela a la general eclesiástica, y una concentración de poder en la Junta Central de Valladolid, en detrimento de aquellos órganos diocesanos, como las comisiones, a los que legalmente les correspondía, según el $M P^{63}$. En otro momento nos detendremos a profundizar en el problema que representaba la disparidad de criterios en lo referente a la censura de la música existente entre las distintas comisiones diocesanas españolas y las negativas consecuencias que tal circunstancia tenía en tantos aspectos de la reforma, como por ejemplo, en la industria editorial musical ${ }^{64}$. No obstante, conviene apuntar ahora, y al hilo de lo expuesto, que durante todos estos años los líderes del movimiento aspiraron, y para tal fin iban dirigidas sus propuestas, a asumir las competencias sobre la censura de la música sagrada en detrimento de las

\footnotetext{
61 "Todos sabemos la dificultad que ofrece la censura de la música sagrada: las Comisiones difícilmente pueden ponerse de acuerdo:" "Crónica del Congreso. 26, 27 y 28 de Abril”, p. 49. Ya en agosto de 1905, Pedrell transmitía esta queja a Ripollés: "Querido amigo: la temperatura al rojo del adjunto artículo le dirá en qué temple estoy. Todo ese desorden del 'hacer que hacemos' de los Prelados y de las comisiones está inutilizando los esfuerzos del Salterio y míos particulares i del que trajo las gallinas, dada la tendencia de aquellos, los más, a quienes por naturaleza les sabe mejor la paja que el grano. Lo de las comisiones eregidas en cantón, tiene la mar de gracia. En una de ellas se han rechazado composiciones de V., de Lamote de Grignon y mías!!!! Le parece a usted?". Carta de Pedrell a Ripollés, 10 de agosto de 1905. BC. FFP, M 964 R.
}

${ }^{62}$ Más adelante y para responder a la petición de Mariano Baixauli de que la junta que proponía tuviera carácter interino, señalaba: "Eso se da por supuesto: mis indicaciones sólo tienden a ahorrar tiempo y a aprovechar las circunstancias presentes para poner en marcha esta máquina de guerra contra el mal gusto y contra los repertorios inconvenientes, que todavía abundan en España a pesar de todas nuestras declamaciones". "Crónica del Congreso. 26, 27 y 28 de Abril", p. 49.

${ }^{63}$ El MP disponía: "Para el puntual cumplimiento de cuanto aquí queda dispuesto, nombren los obispos, si no las han nombrado ya, comisiones especiales de personas verdaderamente competentes en cosas de música sagrada, a las cuales, en la manera que juzguen más oportuna, se encomiende el encargo de vigilar cuanto se refiere a la música que se ejecuta en las iglesias. No cuiden sólo de que la música sea buena de suyo, sino de que responda a las condiciones de los cantores y sea buena la ejecución." MP, Título VIII. Medios principales, art. 24. La única posibilidad legal de desarrollar esta idea era conseguir que la Santa Sede reconociera la misma oficialidad al órgano censor que se fundara por encima o al margen de las comisiones diocesanas. En el congreso de Sevilla se realizó una petición oficial a Roma para constituir un Tribunal Superior Censor de ámbito estatal. En el Apéndice 8 ofrecemos una transcripción de la petición dirigida al papa de constitución de dicho tribunal.

${ }^{64}$ Véase capítulo 5, epígrafe 4.2.4. "El negocio editorial y las instituciones de la reforma: el problema de disparidad de criterios de las comisiones diocesanas de música sagrada", p. 472. 
comisiones, en un intento de unificar bajo su control los criterios censores a aplicar en todo el país. Se trataba de una de las claves fundamentales para la consecución de la reforma, una "máquina de guerra contra el mal gusto y contra los repertorios inconvenientes", según Otaño ${ }^{65}$; de ahí la importancia de tomar las riendas del proceso.

Ripollés, con motivo de la preparación del congreso de Barcelona, también se pronunció a favor de la necesidad de usurpar las competencias censoras a las comisiones diocesanas:

En resumen se ha convenido en aconsejar los siguientes puntos: [...] II Fundación de la Asociación Ceciliana Española con el cuerpo de censores que califiquen todas las obras destinadas al culto en España: Quitar a las comisiones diocesanas la facultad de censurar. ${ }^{66}$

Todas estas consideraciones revelan la trascendencia de la propuesta realizada por Otaño. Aunque tenía un carácter temporal -hasta que se resolviera definitivamente el asunto- encauzaba en una determinada dirección la estrategia del movimiento. Por tanto, exigía un debate sereno, imposible en una sesión privada improvisada a mitad de una sesión solemne pública. Además, necesitaba la, no fácil de conseguir, aprobación de los obispos. Por eso, el propio Otaño propuso convocar una sesión extra al día siguiente, es decir, una vez clausurado oficialmente el Congreso. Esta sesión fuera de programa se celebró el día 29, y contó con un número reducido de congresistas. Aunque Otaño confió en la asistencia de "una buena parte de Congresistas", para entonces muchos de ellos habían abandonado ya la ciudad ${ }^{67}$. Villalba la denominó "postdata" y la describió como una reunión "en petit comitê"68. Según la crónica publicada en $M S H$, los ausentes delegaron su voto en los que sí asistieron, en virtud de lo cual se justificó la legitimidad de la sesión, así como de las decisiones que se

\footnotetext{
65 “Crónica del Congreso. 26, 27 y 28 de Abril”, p. 49.

${ }^{66}$ Carta de Ripollés a Pedrell, 15 de marzo de 1912. BC. FFP. M 964 R.

67 “Como tengo entendido que una buena parte de Congresistas permanecerá todavía mañana en esta Capital, propongo a la asamblea una reunión en el salón del Círculo Católico para mañana a las nueve de la mañana. (Muy bien; conformes)." “Crónica del Congreso. 26, 27 y 28 de Abril”, p. 49.

68 "Volviendo al Congreso, es decir, a la postdata anunciada ayer por la tarde en la iglesia de Santiago, le diré que, en efecto, esta mañana nos reunimos en petit comité, los congresistas que aún quedábamos." Villalba, "El Primer Congreso Nacional", p. 379.
} 
tomaran: "Los congresistas ausentes delegaron en sus compañeros, teniendo por tanta validez las resoluciones" ${ }^{\prime 69}$.

El obispo de Astorga, quien en nombre del arzobispo vallisoletano presidió el acto flanqueado por Otaño y Goicoechea, tomó la palabra para desestimar la propuesta sobre el colegio de censores tal y como había sido planteada por el jesuita ${ }^{70}$. El prelado leonés comunicó la que iba a ser a la postre la resolución definitiva: las comisiones diocesanas que debían crearse en España según los Reglamentos sobre música sagrada promulgados por los Rmos. Prelados de la provincia eclesiástica de Valladolid, propuesto como modelo para todo el país, conservaban todas las competencias en lo concerniente a la censura de la música sagrada; las dudas que surgieran debían ser resueltas por la metropolitana de la provincia eclesiástica en cuestión, y las de esta última por Roma ${ }^{71}$. Esta resolución, a diferencia de la idea de Otaño, se atenía a la organización administrativa ordinaria de la Iglesia y a lo dispuesto en el MP. En este primer intento el jesuíta no consiguió su propósito de constituir una estructura censora paralela a las diócesis y al margen de sus comisiones de música sagrada.

Alcolea, sin embargo, admitió la propuesta del azcoitiarra de fundar, con carácter interino, una Junta Central con sede en Valladolid, aunque despojada de las importantes atribuciones en cuestión de censura de la música sagrada según el planteamiento inicial: "La Junta Central que se ha constituido en Valladolid no tiene en esta materia superioridad sobre las demás Comisiones diocesanas"72.

69 “Crónica del Congreso. 26, 27 y 28 de Abril”, p. 52.

${ }^{70}$ Julián de Diego y García Alcolea, obispo de Astorga, fue una persona muy cercana a Cos y Macho, y con especial inquietud por la música. En el momento de la fundación de la Asociación Isidoriana, a cuya junta perteneció, era su Secretario de Cámara, véase: María Nagore: “Tradición y renovación”, p. 229. En su consagración episcopal participaron tanto Cos y Macho como Almaraz. En 1923 publicó In memoriam del Emmo. Sr. Cardenal D. José María de Cos, Arzobispo de Valladolid. Semblanza por el Excmo. Sr. Dr. D. Julián de Diego y Alcolea, obispo de Salamanca (Salamanca: Establecimiento tipográfico de Calatrava).

71 “El Iltmo. Sr. Obispo de Astorga. [en negrita] Plantea la cuestión de la realización del colegio o junta de competentes para el juicio de las obras religiosas. Propone como más práctico por ahora la creación de juntas o Comisiones Diocesanas, que debían establecerse desde luego en todas las diócesis de España. El fin y atribuciones de estas Comisiones están bien en el Reglamento de esta Archidiócesis y de aquí podían tomarse las bases: por más que si, como el Congreso ha acordado, aceptan todos los Prelados estos Reglamentos todo queda igualmente establecido y ganarán mucho la unidad y el orden. Las dudas de las Comisiones diocesanas han de sujetarse a la Comisión Metropolitana y las de esta se enviarán a Roma". “Crónica del Congreso. 26, 27 y 28 de Abril”, p. 52.

72 “Crónica del Congreso. 26, 27 y 28 de Abril”, p. 52. 
La aprobación de la Junta Central y la decisión de que fuera establecida en Valladolid no fue el fruto de un proceso reglado en el que participaran los congresistas. En la crónica de la sesión tan sólo consta el pasaje que transcribimos a continuación, en el que, según refleja, la idea propuesta por Otaño recibió una aprobación espontánea sin debate ni discusión alguna: "Si se desea ganar tiempo para obra tan útil podía por de pronto componer la Junta Central la Comisión técnica de la Junta Organizadora de Valladolid, siendo presidente el Maestro D. Vicente Goicoechea, por ejemplo. (Bien, bien) ${ }^{\$ 73}$. Esta decisión no figuró oficialmente en las conclusiones finales del Congreso.

Villalba, por su parte, nos proporciona una versión distinta. En ella desliza una crítica tanto al procedimiento por el que se aprobó la propuesta como sobre la propuesta misma, que, como decimos, a pesar de constituir una de las grandes resoluciones del Congreso en el intento de proporcionar una estructura institucional al movimiento naciente, no constó en sus conclusiones ${ }^{74}$ :

Presidía el acto el Ilmo. Sr. D. Julián de Diego Alcolea, Obispo de Astorga, y ocupaba la mesa la comisión diocesana. Con grandísima discreción expuso el señor Obispo de Astorga el objeto de la reunión: era la designación de la Junta Central, idea que ya tres o cuatro veces había sido lanzada al estadio; lo cual que, como ninguno nos creíamos con voto para la tal designación, ni a nadie en particular se le había concedido, había pasado cual una de tantas cosas sin que siquiera me conste que se ejerciera el derecho de voz, séase de hablar en la materia; pues bien: el señor Obispo propuso ante los asistentes que él creía que las funciones de la tal Junta debía ejercerlas la comisión vallisoletana...hubo puntos suspensivos que pedían la contestación de la cámara, pero la cámara se calló, y después de dos o tres compases de espera en andante serioso, quedó nombrada Junta Central de la Asociación Ceciliana española, cosa que, a decir verdad, no he conseguido entender todavía, la comisión vallisoletana. ${ }^{75}$

Las fuentes no proporcionan información alguna sobre otras funciones o facultades, al margen de las sustraídas en relación con la censura, que explicaran la existencia de esta "Junta Central", salvo el encargo de la organización del próximo

\footnotetext{
${ }^{73}$ Ibídem, 49.

${ }^{74}$ Las conclusiones del Congreso en: Crónica del Primer Congreso, pp. 11-18; pp. 22-27; pp. 30-34.

75 Luis Villalba, "El Primer Congreso Nacional”, p. 380. Habría que hacer una matización sobre el término que utiliza Villalba: "Junta Central de la Asociación Ceciliana española". Como el propio Otaño manifestó, la fundación de dicha asociación se pospuso al congreso de Sevilla por falta de tiempo. Además, en ningún momento se alude, ni en la sesión del día 28 de abril ni en la del 29, a la Junta Central como "de la Asociación Ceciliana", ni siquiera se califica como Junta Central española.
} 
congreso. Gracias a esto, la comisión diocesana vallisoletana, como tal "Junta Central" -española, suponemos, aunque no aparece en ningún momento con tal denominaciónconservó una cierta superioridad o relevancia respecto al resto de comisiones diocesanas españolas. Así lo explicó el obispo de Astorga:

la Junta central de Valladolid tendrá a su cargo todo lo referente a la organización del próximo Congreso de acuerdo a una Junta local que se formará en Sevilla: mirará por la actuación de los acuerdos del Congreso, por la redacción de las actas y de la revista $[M S H]$, que es preferible continúe donde ha nacido [Valladolid] ${ }^{76}$

Por tanto, en el primer congreso se decidió que la Junta Central de Valladolid, coordinada con una junta local, asumiera la dirección de la organización del II Congreso Nacional de Música Sagrada a celebrar en Sevilla. Este fue el planteamiento inicial, y la primera decisión importante tomada para afrontar el congreso sevillano. Como se desprende de la siguiente anécdota contada por Villalba, los músicos hispalenses presentes debieron recibir el encargo de organizar un evento de esta magnitud con la lógica preocupación de asumir un compromiso complicado:

Subía yo por la rampa que da acceso a la puerta principal del templo, a la sazón que en un grupo el P. Otaño y los tres representantes de Sevilla, Insausti, Ripollés y Salas discurrían acerca del futuro Congreso, y con singular modestia se declaraban sin facultades para prepararle debidamente; yo les saludé, y hasta creo que tercié animándoles para la empresa ${ }^{77}$

Suponemos, en consecuencia, que la decisión de hacer recaer gran parte de la responsabilidad de la preparación de la asamblea sevillana en la comisión vallisoletana, con la experiencia que daba la organización del primer congreso, no sería mal recibida por los eclesiásticos hispalenses.

La elevación de la comisión vallisoletana a Junta Central supuso el último y postrero logro, aunque atenuado respecto del proyecto inicial de Otaño, en el intento de hacer de Valladolid la capital de la reforma de la música religiosa en España. En la capital castellana se celebró el I Congreso Nacional de Música Sagrada, primer gran acontecimiento reformista tras el $M P$; se ubicó la sede de la $M S H$, el órgano oficial

\footnotetext{
76 “Crónica del Congreso. 26, 27 y 28 de Abril”, p. 52.

${ }^{77}$ Ibídem, p. 307.
} 
ideado para cohesionar y dirigir en términos ideológicos el incipiente movimiento; y se estableció la Junta Central, que, aunque interina y no muy definida en cuanto a sus funciones, asumió la importante responsabilidad de la organización del II Congreso, coordinada con la Junta local andaluza.

La gran proyección que consiguieron proporcionar a los Reglamentos sobre música sagrada promulgados por los Rmos. Prelados de la provincia eclesiástica de Valladolid, elogiados y bendecidos por el papa, fue otro de los éxitos del grupo vallisoletano $^{78}$. Estos reglamentos se presentaron como los documentos base a partir de los que debatir los diversos aspectos prácticos para la realización de la reforma en las distintas sesiones privadas. Se puede afirmar que la asamblea de Valladolid consistió, en lo concerniente a las cuestiones prácticas, en la discusión de las disposiciones que tales documentos contenían, determinando, por ello, las conclusiones finales ${ }^{79}$. La propuesta planteada nada más inaugurarse la primera sesión del Congreso ofrece una idea de la trascendencia que se pretendió dar a dichos Reglamentos: servir como las normas comunes para todas las diócesis españolas:

En vista de lo serio y admirablemente dispuesto del Reglamento de Valladolid, pido al Congreso invite a los señores Obispos de España a que hagan suyo el Reglamento de Valladolid

\footnotetext{
${ }^{78}$ La estrategia de puesta en valor y difusión de los reglamentos que se emprendió a lo largo de los dos meses previos a la inauguración del congreso era necesaria para preparar el terreno. Así, en el $B d C$ fueron publicadas sendas cartas remitidas por el cardenal secretario de Estado, Merry del Val, a Cos y Macho en nombre del papa; las favorables críticas que habían merecido en la prensa especializada tanto española como extranjera; así como el contenido íntegro de las partes segunda "De los géneros de música eclesiástica", y cuarta "De las funciones o actos litúrgicos en general" en los dos primeros números. Las partes no publicadas fueron: primera, "De los músicos de Iglesia"; segunda, tercera, "De la comisión diocesana y censura de la música sagrada"; quinta, "Disposiciones sobre ediciones de canto eclesiástico". Las cartas de Merry del Val en: "La Santa Sede y los Reglamentos de Música de la Archidiócesis de Valladolid", $B d C, 1$ (1907), p. 8. Las críticas de las revistas de música sagrada en: "Los Reglamentos de música de la Archidiócesis y la prensa profesional”, $B d C, 2$ (1907), pp. 13-15. El contenido de los documentos en: "De los géneros de música eclesiástica", ibídem, p. 11-13; "De las funciones o actos litúrgicos en general", $B d C, 3$, pp. 22-25.

${ }^{79}$ En el $B d C$ se comunicaba: "El examen del Motu proprio, llevado a la práctica de un modo bien definido en los Reglamentos de la Archidiócesis de Valladolid, recopilación de todos los reglamentos similares, he ahí la base y el cuestionario del Congreso que pretendemos celebrar con la ayuda de Dios, [...]". La Junta, "Un llamamiento", p. 3. "Para concretar la materia que ha ser objeto de esta asamblea de música religiosa, propone la junta organizadora el siguiente cuestionario basado todo él en las normas del Motu Proprio acerca de la música sagrada y en los Reglamentos de la Archidiócesis de Valladolid especialmente bendecidos y alabados por S. S. Pío X". Y en nota a pie: "El criterio particular que la junta organizadora seguirá en el desenvolvimiento de estos puntos [del cuestionario] es el expuesto en el Edicto y Reglamentos sobre Música Sagrada de la Provincia Eclesiástica de Valladolid". La Junta, "Un llamamiento", p. 4; nota a pie $\mathrm{n}^{\mathrm{o}} 1$.
} 
(Estruendosos aplausos y grandes demostraciones de aprobación continúan largo rato $)^{80}$

El arzobispo anfitrión asumió el siguiente compromiso: "Con gusto acepto la idea apoyada por todo el Congreso acerca de los reglamentos y por lo que a mí toca me ofrezco incondicionalmente a hacer esa invitación a los Prelados de España, pero a nombre del Congreso. (Grandes aplausos) ${ }^{\Perp 1}$. Como señaló Villalba, ello hubiera representado el final del debate nada más empezar:

[...] ha de saber usted que apenas habíamos empezado a echar nuestras visuales por la sala, y mirado las caras para allá en nuestro interior irnos juzgando, apenas se había expuesto a la respetable asamblea el objeto de la misma, cuando uno de los congresistas se levantó todo entusiasmado a decir al Congreso, que este propusiera a los Prelados y Cabildos de España, que aceptaran el Reglamento de la diócesis vallisoletana; lo cual que, como este era el punto de la discusión, una vez aceptada la luminosa idea, ya se había concluido el caso de todo este belén, y entonces, apaga y vámonos: adiós asamblea, adiós discusiones y adiós todo, que para maldita la cosa que iban a servir. Mas por fortuna, no les dio a todos tan fuerte, y ante nuestros ojos han pasado unas veces despacio y otras con más rapidez que las películas del cinematógrafo, los artículos del tal Reglamento. ${ }^{82}$

En la práctica, muchos puntos de gran importancia contenidos en el cuestionario escaparon al debate debido a la falta de tiempo. En esos casos, el procedimiento a seguir fue la aprobación sin más discusión de lo regulado en los Reglamentos sobre el particular. La tercera y última sesión privada, dedicada a tratar materias tan importantes como las relacionadas con la organización práctica y la gestión diocesana para la implantación de la reforma, es un ejemplo de ello. La organización de las comisiones diocesanas, la censura de la música religiosa, la formación de Scholae cantorum, la educación musical en los seminarios, las revistas de música sacra, fueron algunas de las cuestiones que no se abordaron. Todos estos temas hubieran suscitado, sin duda, interesantes discusiones. Sin embargo, quedaron en manos de la Junta Organizadora local:

\footnotetext{
${ }^{80}$ La propuesta fue dirigida a los asistentes por Francisco Galbarriatu, procedente de Bilbao. "Crónica del Congreso. 26, 27 y 28 de Abril”, p. 5.

${ }^{81}$ Ibídem.

${ }^{82}$ Luis Villalba, "El Primer Congreso Nacional”, p. 374.
} 
Excmo. Sr. Arzobispo. [en negrita] La hora en que estamos no es buena para seguir discutiendo; es necesario recobrar las fuerzas perdidas. (Risas) Falta todo lo referente a la organización práctica, cosa por cierto muy esencial, pero no puede hacerse todo de una jornada. Por lo tanto si al Congreso parece bien podría encargarse la Junta Organizadora de darnos en las Actas el trabajo que falta. (Muy bien, muy bien: aprobación general). ${ }^{83}$

Dicha junta resolvió todos estos puntos aplicando el Reglamento, tal y como testimonia la Crónica del Primer Congreso Nacional de Música Sagrada:

Siendo ya la hora muy avanzada, el Congreso acordó por aclamación que los temas de la segunda parte [relacionados con la organización práctica] se resolvieran en un todo conforme a las disposiciones del Reglamento sobre la Música Sagrada, publicado por los Prelados de la provincia eclesiástica de Valladolid. ${ }^{84}$

En consecuencia las disposiciones del Reglamento vallisoletano que regulaban los aspectos organizativos esenciales de la reforma obtuvieron la sanción positiva "por aclamación" del Congreso, sin haber pasado por el trance de la discusión de los congresistas.

Federico Olmeda cuestionó el procedimiento de aprobación de las propuestas para ser aceptadas como conclusiones. Esta es la versión que ofreció sobre el trascurso de los debates en la revista que él mismo dirigía, Voz de la música ${ }^{85}$ :

Allí todo se aprueba: el presidente de una sesión, que se pone en el secreto de esto, arranca, si se quiere, aprobaciones, aunque sea para proposiciones contrarias: ¿se aplaude mucho?, aprobación por aclamación; ¿se aplaude poco?, aprobación nemine discrepante; ¿se sisea un poco?, muestras de aprobación; ¿no se aplaude nada?, qui tacet, aprobación general" ${ }^{, 86}$

83 “Crónica del Congreso. 26, 27 y 28 de Abril”, p. 45.

${ }^{84}$ Crónica del Primer Congreso, p. 34.

${ }^{85}$ Resulta necesario advertir que en las relaciones que mantuvieron estas importantes personalidades de la música religiosa y del movimiento regeneracionista musical español se conjugaron las afinidades y objetivos compartidos con la rivalidad, consecuencia de sus distintos puntos de vista y, en ocasiones, intereses en conflicto. Se trata de un elemento crítico que no se debe obviar en el análisis de sus declaraciones y posicionamientos, pues, es seguro que influía en mayor o menor medida, en ellos. En las fuentes epistolares que hemos manejado se evidencia esta realidad. Véanse los apartados 4.2.2. "El grupo dominante: Otaño-Ripollés-Goicoechea-Viñaspre", y 4.2.3. "Las alternativas: Olmeda, Villalba".

${ }^{86}$ Olmeda publicó esta crítica sobre el congreso de Valladolid bajo el pseudónimo de Graciano en la revista Voz de la Música, pp. 4-5 de julio y septiembre de 1907, p. 17; cit. en: Palacios, Federico Olmeda, un maestro de capilla atípico, p. 180. 
La importancia que llegaron a adquirir los Reglamentos llevó implícito otro logro, como fue proponer el modelo vallisoletano de comisión diocesana de música sagrada establecido y regulado en ellos como el paradigma a implantar en todas las diócesis españolas. La exportación de un mismo modelo -el de la provincia eclesiástica de Valladolid-, a todo el país hubiera significado la consecución de una estructura de gestión de la música sagrada uniforme para toda la Iglesia española, con las ventajas que ello reportaba en términos de "unidad y orden", según expresión del obispo de Astorga $^{87}$. Sin embargo, hubiera significado, al mismo tiempo, ignorar los procesos particulares de concreción normativa del $M P$ en forma de preceptos, disposiciones, iniciativas, proyectos y líneas de actuación desarrollados por algunas diócesis hasta ese momento. En los tres primeros capítulos de esta tesis hemos analizado el esfuerzo realizado desde 1905 por la archidiócesis de Sevilla para aplicar y adecuar a sus características singulares las disposiciones del MP. A estas alturas, abril de 1907, la institución eclesiástica andaluza había definido su propia política reformista, y configurado, según criterios propios, sus instrumentos, medios y órganos -como la CDMS-, para la gestión de su particular proceso ${ }^{88}$.

Las propuestas de establecer una Junta Central española en Valladolid y de exportar a todo el país los Reglamentos se inscribe, pensamos, en una línea de acción cuyo objetivo era labrar los cimientos de una estructura con la que articular, organizar e institucionalizar los congresos nacionales de música sagrada y, con ellos, el movimiento de reformas. Creemos entrever en este proyecto el modelo del Congreso Católico Nacional $^{89}$, cuyo referente fundamental fueron, a su vez, la italiana L'Opera dei Congresi $^{90}$. Esta institución fundada en 1889 con el objetivo de coordinar y dar impulso al movimiento católico para su mayor eficacia, según el historiador Feliciano Montero,

\footnotetext{
${ }^{87}$ Véase la nota a pie $\mathrm{n}^{\mathrm{o}} 71$, p. 361.

${ }^{88}$ En el epígrafe 2. “Comisión Diocesana de Música Sagrada: naturaleza y funciones”, del capítulo 1 ofrecemos dos ejemplos de asunción del modelo de CDMS vallisoletano a otras diócesis hispanas.

${ }^{89}$ López-Calo refiere los dos antecedentes en los que se inspiró Otaño, de quien afirma, fue el iniciador de los congresos: los congresos católicos celebrados a finales del s. XIX, y los congresos cecilianistas o de música sagrada que tuvieron lugar en algunos países europeos. "Congresos de música religiosa", p. 876.

90 Sobre el intento de transposición del modelo de acción católica italiana al caso español, véase: Feliciano Montero, "El movimiento católico en España: la respuesta de la provincia eclesiástica de Valladolid a la encuesta Vico (1908)", Espacio, tiempo y forma. Serie V, Historia Contemporánea, 5 (1992), pp. 343-366.
} 
tenía un carácter supradiocesano ${ }^{91}$. Los distintos congresos católicos nacionales fueron las grandes asambleas de este movimiento estructurado por el Congreso Católico Nacional, cuyo órgano rector, por tanto, principal responsable de dichas asambleas junto a las diócesis que las acogían, tenía un carácter permanente. Las semejanzas con las propuestas del congreso de Valladolid nos parecen evidentes.

Estas analogías entre ambos movimientos, el católico general y el católico musical, instan a considerar la reforma desde una perspectiva mucho más amplia: como un fenómeno integrado en la historia de la Iglesia de la época. En este sentido, los congresos nacionales de música sacra pueden ser contemplados como otros de los grandes acontecimientos a través de los que la Iglesia católica trató de cohesionarse, de hacer converger en un único proyecto sus potencialidades, y de mostrar ante el conjunto de la sociedad su unidad y músculo. De forma paralela, el movimiento reformista musical constituiría un movimiento cultural más de entre los sociales católicos, emergidos durante los últimos años del siglo XIX y principios del XX. Sus grandes manifestaciones, los congresos musicales, habrían de ser incluidas entre las grandes concentraciones católicas como las semanas sociales, las asambleas de la "Buena Prensa", los congresos eucarísticos o los congresos católicos nacionales; todas inscritas en una nueva estrategia de acción católica, que, iniciada por León XIII como una nueva forma de relación de la Iglesia con la cultura contemporánea, se proyectó a los inicios del siglo XX.

En suma, se puede afirmar que el objetivo de los máximos responsables del Congreso no fue sólo constituir un movimiento sólido en pro de la reforma y la regeneración de la música religiosa en España, sino también articularlo, creando una estructura de alcance general español con centro en Valladolid, y tomando como fundamento lo dispuesto en su provincia eclesiástica. En la ciudad castellana se radicó

\footnotetext{
91 "En sentido amplio, con el término "Movimiento Católico" nos referimos al conjunto de asociaciones e iniciativas católicas que se proponen en distintos frentes (la catequesis, la instrucción, la beneficencia, la propaganda escrita, la cátedra, y la escuela en general), la defensa y promoción del objetivo católico, restaurador o recristianizador.

La coordinación e impulso de ese Movimiento católico es uno de los principales objetivos, si no el primero, de los Congresos Católicos. La necesidad de aunar esfuerzos y coordinarlos para lograr mayor eficacia es una preocupación temprana y constante, pues todos reconocen la dispersión y las divisiones internas como el factor que obstaculiza y retrasa la constitución de un fuerte Movimiento católico en España. Desde el primer Congreso católico (Madrid, 1889), se plantea la necesidad de crear juntas diocesanas de "obras católicas" para la coordinación de todas las iniciativas". Feliciano Montero, "Propaganda católica y educación popular en la España de la Restauración", en École et Église en Espagne et en Amerique latine -Aspects ideologiques et institutionnel, ed. por J. R. Aymes, E. M. Fell y J. L. Guereña (Tours: Université de Tours, 1988), p. 265.
} 
tanto la sede de la Junta Central como de la $M S H$, y desde ella se ofrecieron los Reglamentos como referentes normativos -que además, poseían la legitimidad que proporciona la bendición papal- para todo el país. Todo ello se debía traducir en que importantes conceptos como centralidad y liderazgo, difusión de criterios, y establecimiento del marco normativo y organizativo estuvieran asociados a la capital pucelana. A ello hay que añadir, en primer lugar, la potestad que se le otorgó a su arzobispo para tomar una decisión de la relevancia para el futuro del movimiento como la designación de la sede del próximo congreso; y en segundo lugar, el control que debía ejercer sobre su organización la Junta Central vallisoletana. La génesis del congreso de Sevilla se ubicó en este contexto, y estuvo determinado por estas circunstancias.

\section{Organización del congreso de Sevilla}

\subsection{Junta Organizadora y documentos fundamentales}

La organización del congreso de Sevilla se abordó una vez celebrada la Semana Santa de 1908, y “desembarazado el Excmo. Sr. Arzobispo de los múltiples negocios trascendentales que en el largo periodo de Sede vacante se habían acumulado"92. Según la Crónica del Segundo Congreso Nacional de Música Sagrada, el 18 de mayo se reunió una "junta preliminar" de distintas personalidades locales convocadas por Almaraz con el fin de "dar principio a los trabajos de realización del proyecto del Segundo Congreso Nacional de Música Sagrada" ${ }^{93}$. Sin embargo, como demuestra una circular del nuevo arzobispo hispalense recogida por $M S H$ en su número de abril, los trabajos debieron comenzar algunas semanas antes. Según dicha circular, fechada el 21 de ese mes, para entonces ya se había constituido una junta "para que envíe carta-circular a los señores Maestros de Capilla de todas las Catedrales y Colegiales de España y a los Centros y personas que hasta ahora más se han distinguido en secundar los deseos del Papa"; y en su seno, una "sección artística" compuesta por el canónigo Rafael González Merchant, Vicente Ripollés, Agapito Insausti, el segundo organista catedralicio Luis Leandro Mariani, y Manuel Lerdo de Tejada ${ }^{94}$. Como

\footnotetext{
92 Crónica del Segundo Congreso Nacional de Música Sagrada celebrado en Sevilla los días 12, 13, 14 y 15 de noviembre de 1908 (Sevilla: Lib. e Imp. de Izquierdo y Cía, 1909), p. 9.

${ }^{93}$ Ibídem.

94 Enrique, Arzobispo de Sevilla, "Segundo Congreso de Música Sagrada”, MSH, 11 (1908), pp. 49-50. Esta sección artística debió disolverse, pues, no se vuelve a hacer mención de ella.
} 
podemos comprobar, excepto Mariani, todos formaron parte de la CDMS durante el pontificado de Marcelo Spínola ${ }^{95}$. Además, la circular mencionada anunciaba las líneas de acción iniciales que luego se tratarían en la siguiente reunión del 18 de mayo: por un lado, la elaboración del reglamento del congreso; y por otro, la estrategia de difusión del evento tanto de cara al resto de diócesis españolas como entre los propios diocesanos.

Almaraz quiso hacer constar en su circular que la organización correría a cargo no sólo de la Junta Organizadora local, sino también de la llamada Junta Central ubicada en Valladolid, tal y como se decidió en el primer congreso. Resulta difícil dilucidar cuáles fueron las competencias y funciones que debían desempeñar una y otra, pues en ningún documento se especifican. Tampoco aclara si realmente la vallisoletana ejerció como órgano director y supervisor superior, dado el carácter de Junta Central española que se le quiso imprimir en la asamblea castellana:

En el Boletín Eclesiástico [en versales] se publicarán las noticias y disposiciones que se adopten relativas a este asunto, de acuerdo siempre con la Junta de Valladolid, donde se publica también la Revista musical desde la celebración del primer Congreso ${ }^{96}$

En la primera reunión oficial del 18 de mayo se tomaron las primeras decisiones: las fechas en las que tendría lugar el evento, la constitución de una junta organizadora oficial, la elaboración de los documentos rectores, las primeras acciones a llevar a cabo para su difusión, y la estrategia a seguir para conseguir la máxima implicación de las distintas diócesis españolas, los católicos en general, y especialmente los diocesanos hispalenses ${ }^{97}$. Dediquemos las siguientes páginas a profundizar en cada uno de estos aspectos.

La elección de la fecha del Congreso estuvo condicionada por la conmemoración de las bodas de oro sacerdotales de Pío $\mathrm{X}^{98}$. Almaraz había organizado

${ }^{95}$ En el epígrafe 3. "Inicio y suspensión del proceso de reformas: causas y consecuencias" del capítulo 1 aludíamos al borrador de una carta conservada en el $A G A S$, en la que Spínola pedía a Bernardo Salas y Seguí, Luis Leandro Mariani, José Otero Cascales, y Juan Domínguez Recio que se sumaran a la CDMS en 1905. Sin embargo, como aclarábamos, la firma de Mariani no apareció en ninguno de los documentos generados por dicho órgano a partir de entonces. Por tanto, es posible que rehusara la invitación de Spínola.

\footnotetext{
${ }^{96}$ Enrique [Almaraz], “Segundo Congreso de Música Sagrada”, pp. 49-50.

${ }^{97}$ Crónica del Segundo Congreso, pp. 9-13.

${ }^{98}$ En la circular mencionada de 21 de abril ya se avisaba de este condicionante: "No se ha fijado aún la fecha en que dicho acontecimiento habrá de tener lugar; pero como estamos dentro del año jubilar de las
} 
una peregrinación diocesana a Roma para asistir a los actos de esta onomástica, que tendrían lugar en septiembre ${ }^{99}$. En consecuencia, la celebración de la convención religioso-musical se fijó los días del 12 al 15 de noviembre ${ }^{100}$.

Los distintos actos del congreso hispalense se distribuyeron en cuatro días, uno más que el congreso castellano. De esta forma, se corrigió uno de los principales defectos de este último. Como hemos comprobado más arriba, debido a la falta de tiempo en Valladolid se suspendieron discursos ${ }^{101}$; se interrumpieron sesiones solemnes que se transformaron en sesiones privadas improvisadas; se trataron asuntos importantes públicamente; incluso, se convocó una sesión extraordinaria no prevista una vez clausurado el Congreso con una asistencia reducida de congresistas. De las tres sesiones privadas de las que constó, sólo en la segunda hubo tiempo de abordar todos los puntos programados. En la primera y en la tercera se debatió uno de los dos bloques temáticos, es decir, la mitad de lo previsto. Por tanto, la discusión de todos los aspectos incluidos en los bloques "De los actos litúrgicos en general" y "Organización práctica", muchos de ellos trascendentales para la reforma, se soslayó.

La experiencia que proporcionó la celebración del primero y la ventaja de ser proyectado con tiempo de antelación suficiente colaboraron en la consecución de un segundo congreso que, en términos de organización, mejoró considerablemente el primero, como se irá constatando. El valor histórico del congreso de Valladolid residió en su condición de pionero, el de Sevilla fue, por su parte, el primer congreso en contar con una organización planificada, madurada desde el principio, y acorde con su dimensión de congreso nacional.

Además de las fechas de celebración de la cita sevillana, otra de las decisiones tomadas en aquella reunión de 18 de mayo fue la constitución de la Junta Organizadora, que quedó compuesta como sigue:

bodas de oro de Nuestro Santísimo Padre Pío X y es natural que una peregrinación de la Diócesis Hispalense vaya a postrarse a los pies del Romano Pontífice, es muy probable que el Congreso musical no pueda celebrarse sino muy entrada la estación del otoño". Ibídem, p. 49.

${ }^{99}$ Más adelante tendremos ocasión de hablar de ella, pues junto con el congreso y la Semana Social constituyeron los grandes acontecimientos a los que se enfrentó la Archidiócesis en estos últimos meses de 1908, cuya financiación dependería en buena medida de la implicación de los fieles diocesanos.

${ }^{100}$ Crónica del Segundo Congreso, p. 10.

${ }^{101}$ Además del discurso de Francisco Blanes en la tercera sesión solemne cuya suspensión ya hemos referido, fue cancelado el que tenía que pronunciar en la primera sesión solemne Dámaso Ledesma con título Cantos religiosos de la provincia de Salamanca ambos "por lo avanzado de la hora". Crónica del Primer Congreso, p. 20. 
Almaraz, como presidente honorario; Rafael González Merchant, canónigo, como presidente efectivo ${ }^{102}$; Luis Piazza ${ }^{103}$, tesorero; y Federico Roldán, catedrático del Seminario, secretario; más un total de treintainueve vocales, no sólo del ámbito religioso, sino también civil, de la sociedad local.

Del ámbito civil: dos concejales del Ayuntamiento, el director del Instituto General y Técnico Provincial, el secretario del Gobierno de la Audiencia, un notario, catedráticos de la Universidad, y los principales referentes musicales de la ciudad como el presidente de la Sociedad Filarmónica, el director del Orfeón Sevillano, el editor e impresor musical Antonio Damas, Ramón Manjarrés Bofarull, Manuel Lerdo de Tejada $^{104}$, Fernando Palatín ${ }^{105}$ y Vicente Gómez Zarzuela ${ }^{106}$. No poseemos más datos que apunten a una mayor implicación de aquellas instituciones civiles, por lo que su presencia en la Junta local debió tener un mero valor testimonial y representativo.

Del ámbito religioso: varios canónigos de la Catedral que ocupaban además cargos relevantes en el organigrama de responsabilidades de la Archidiócesis; varios capellanes de la Capilla Real de San Fernando; los superiores y rectores de las distintas órdenes e institutos religiosos masculinos instalados en la ciudad; y los beneficiados

102 González Merchant será nombrado presidente de la Comisión Diocesana de Música Sagrada, sucediendo así a Santiago Fernández, y será un personaje clave en esta segunda etapa del proceso de reformas. Para más datos sobre González Merchant véase la nota a pie nº 20, p. 126.

${ }^{103}$ Luis Piazza, heredó y regentó una fábrica de pianos fundada por su padre, la única fábrica de pianos de Sevilla de cuya existencia tenemos noticia. Piazza se convirtió en un personaje de cierto peso en el mundo musical de Sevilla, llegando a ser miembro de la primera junta de la sección de música del Ateneo. En los locales de su fábrica, además, se celebraban conciertos privados en los que participaban las más destacadas y prometedoras figuras de la música de la ciudad, entre ellos Turina.

${ }^{104}$ Sobre Manuel Lerdo de Tejada véase la nota a pie no 22, p. 63.

${ }^{105}$ A principios del s. XX, eran dos los músicos con ese nombre en Sevilla. Uno de ellos era director de la Bandade Música del Hospicio de Sevilla. De este se desconocen más datos. El segundo era Fernando Palatín y Garfía (Sevilla, 1852-¿?), violinista descendiente de una saga de músicos sevillanos que adquirió renombre internacional. Ángel Medina, "Palatín", $D M E H, 10$ vols, ed. por Emilio Casares (Madrid: SGAE, 2002), vol. 8, p. 386-387; Fernando Palatín, Diccionario de música (Sevilla, 1818), ed. por Ángel Medina (Oviedo: Universidad de Oviedo, Centro de Documentación Musical de Andalucía, 1990); Cuenca Benet, Galería de músicos andaluces, p. 228-229.

106 Vicente Gómez Zarzuela (Sevilla, 1872-Arcos de la Frontera, 1956). Compositor, violinista y violoncelista. Personaje muy activo en la vida musical sevillana, estuvo implicado de una u otra forma en las distintas iniciativas surgidas en la ciudad: secretario de la Sociedad Sevillana de Cuartetos, presidente durante unos años de la sección de música del Ateneo, secretario de la comisión de enseñanza de la Sociedad Económica de Amigos del País. Director de orquestas sevillanas, y compositor de obras religiosas y escénicas, fue el propietario yeditor de la Guía Oficial de Sevilla y su Provincia, fundada por su padre. Cuenca Benet, Galería de músicos andaluces, pp. 113-114; Antonio Álvarez Cañibano, "Gómez Zarzuela, Vicente", DMEH, 10 vols, ed. por Emilio Casares (Madrid: SGAE, 2002), vol. 5, pp. 725-726. 
músicos de la Catedral: Ripollés, el tenor Agapito Insausti, los dos organistas y José Otero, salmista. También formó parte de la Junta el director de El Correo de Andalucía $(E C A)$.

La Junta Organizadora, por tanto, integró junto al colectivo eclesiástico a representantes de distintos sectores de la sociedad civil de la ciudad, como el institucional, el político, el académico, el musical, o el periodismo católico. El Congreso se abrió de esta forma, adquiriendo el carácter de acontecimiento, no sólo del clero, o de los músicos eclesiásticos, sino de todo el catolicismo local.

Las juntas de los dos primeros congresos compartieron en términos generales el mismo modelo ${ }^{107}$. Las diferencias que hallamos entre ellas son pocas. En primer lugar, la presidencia honoraria de Valladolid fue compartida por todos los prelados de la provincia eclesiástica, debido al carácter provincial que tuvo en sus inicios. En segundo lugar, la Junta castellana, a diferencia de la andaluza, se articuló en tres secciones, de propaganda, programa y parte doctrinal, y ejecuciones musicales. Cada una de ellas contaba con su propio presidente y secretario, además de vocales y otros miembros ${ }^{108}$. En tercer lugar, la que, desde nuestro punto de vista, resultó un importante avance en términos de representación: la integración en la Junta hispalense del clero regular masculino presente en la Archidiócesis. La presencia de este colectivo en la Junta de Valladolid se redujo a Fernando Varona, monje de Silos, aunque pertenecía a otra archidiócesis, la de Burgos. La presencia de Varona en la Junta se debió seguramente al peso de este monasterio en la zona y, particularmente a su labor de recuperación y difusión del canto gregoriano. A ello hay que sumar la predilección de Cos y Macho por la tesis pothieristas relativas a los signos rítmicos gregorianos, tendencia que

\footnotetext{
107 Junta Organizadora del congreso de Valladolid: Presidente efectivo, Francisco Martín de Castro, canónigo lectoral catedralicio, que lo era también de la CDMS; tesorero, Felipe Isidro Villaverde; y secretario, Juan del Valle Heredero, profesor de la Universidad Pontificia. Estos tres cargos no figuraban como de la Junta Organizadora, sino del congreso. La junta organizadora estaba dividida en tres secciones: de propaganda, de programa y parte doctrinal, de ejecuciones musicales. El resto de miembros eran el rector de la Universidad Pontificia y canónigo catedralicio, un par de curas párrocos, dos concejales y el secretario de la Audiencia, varios catedráticos de distintas facultades, los beneficiados músicos catedralicios además del organista del Sagrado Corazón, y siete alumnos de la Universidad Literaria, estos dos últimos grupos pertenecientes todos a la sección de ejecuciones musicales. Crónica del Primer Congreso, pp. 6-7.
}

${ }^{108}$ Los presidentes y secretarios de cada una de ellas eran: 1. sección de propaganda, el presidente efectivo y secretario del Congreso; 2 . sección de programa y parte doctrinal, presidente Nemesio Otaño, secretario Damián Ortíz de Urbina; secretario de la Audiencia territorial; 3. sección de ejecuciones musicales: presidente, Vicente Goicoechea, secretario Segundo Milagro, organista primero de la catedral. Crónica del Primer Congreso, pp. 6-7. 
representaban y defendían los benedictinos silenses ${ }^{109}$. A pesar de superar los cuarenta miembros, la Junta hispalense, como la vallisoletana -no olvidemos que esta última representaba no sólo a la Archidiócesis sino a toda la provincia eclesiástica-, estaba totalmente centralizada. Al igual que ocurriera con las comisiones diocesanas creadas por Spínola y posteriormente por Almaraz, la procedencia de los miembros se reducía a la capital sevillana. En contraste con este carácter centralista, destaca la presencia de personalidades procedentes de otros territorios de la Archidiócesis en otros órganos de peso, como por ejemplo, en la composición de las secretarias de las distintas ponencias $^{110}$.

Una vez nombrada la Junta Organizadora, se eligió una comisión presidida por González Merchant para que redactara los documentos fundamentales del Congreso: el reglamento general y el cuestionario con todos los temas a tratar en las sesiones de estudio.

El reglamento presentaba catorce artículos más uno adicional, distribuidos en dos capítulos: Capítulo I. "Del fin y distribución del congreso", Capítulo II. "De los congresistas"111. El artículo $1^{\circ}$ del capítulo I reflejaba la naturaleza eminentemente práctica de estas grandes reuniones, tal y como se había definido en el congreso vallisoletano. En aquella ocasión, el $B d C$ explicaba: “fin esencialmente práctico, concreto y fructuoso, dejadas a un lado las disputas inútiles, las disquisiciones demasiado teóricas y los argumentos todavía no bien dilucidados." ${ }^{112}$ El reglamento de Sevilla propuso: “estudiar y acordar los medios de llevar a la práctica la reforma de la

\footnotetext{
${ }^{109}$ La tendencia contrapuesta a la de Dom Pothier, la postulada por Dom Mocquereau tuvo también sus firmes defensores en la península, como fueron los monjes de los monasterios catalanes de Montserrat y Besalú. Véase de este mismo capítulo el epígrafe 4.1. "La cuestión gregoriana: las primeras grietas en el movimiento". La tendencia pothierista de Cos y Macho se puso de manifiesto en la segunda sesión privada del congreso de Valladolid, cuando Francisco Pérez de Viñaspre, maestro de capilla de Burgos, y Miguel Rué, de Gerona, entraron en la polémica. El arzobispo vallisoletano intervino por segunda vez para comentar: "Aunque profano en cuestiones musicales, voy a intervenir en la disputa para acabar la discusión. Yo creo que cuanto más signos, habrá más complicaciones y por eso opto por las ediciones tal cual salen de las prensas Vaticanas. Respecto lo que otros en otras partes hagan, pero en mi Seminario quisiera se interpretara la edición Vaticana tal cual es." "Crónica del Congreso. 26, 27 y 28 de Abril", p. 19.

${ }^{110}$ Véase la composición de las distintas ponencias en la p. 379.

${ }^{111}$ Crónica del Segundo Congreso, pp. 14-17.

${ }^{112}$ La Junta, "Un llamamiento", p. 3. El segundo número del boletín se abría con un artículo insistiendo en este aspecto, con el elocuente título de “¡Práctica, práctica! BdC, 2 (1907), p. 9.
} 
Música religiosa en España, con estricta sujeción a los preceptos contenidos en el Motu proprio [...] y bajo la dirección de los Rmos. Prelados."113

El resto del capítulo I se ocupaba de las cuestiones de organización. Al igual que el de Valladolid, el hispalense consistió en sesiones solemnes públicas, y sesiones privadas en las que "se dará cuenta de los trabajos presentados y se acordarán las conclusiones prácticas, que habrán de proponerse en la última sesión solemne"114. Las memorias a presentar para su discusión en las sesiones privadas debían versar sobre alguno de los puntos propuestos en cada una de las secciones del cuestionario. Como fecha límite para su presentación se fijó el 31 de octubre, es decir, con mes y medio de antelación ${ }^{115}$. En el congreso de Valladolid no era necesario entregar previamente memoria o trabajo alguno, sino solamente tomar la palabra, a no ser que fuera imposible la asistencia. En este caso, el plazo de presentación de la comunicación escrita para ser leída en la sesión correspondiente concluía el 25 de marzo, un mes antes de la inauguración. ${ }^{116}$

Con respecto a las sesiones privadas, se introdujeron importantes cambios para hacer más práctico su desarrollo. En el congreso de Valladolid hubo una única sesión diaria. Cada sesión estaba dividida en dos bloques de discusión. Estas fueron las tres sesiones planificadas en principio, aunque recordemos que se hizo necesario convocar dos no previstas: Sesión 1a: a) De los músicos de Iglesia; b) De los actos litúrgicos en general. Sesión $2^{\text {a: }}$ a) Canto gregoriano; b) Polifonía clásica. Sesión $3^{\mathrm{a}}$ : a) El órgano y los instrumentos admitidos en la Iglesia; b) Organización práctica ${ }^{117}$. En Sevilla,

${ }^{113}$ Crónica del Segundo Congreso, pp. 14-15.

${ }^{114}$ Artículo $2^{\circ}$ del reglamento. Ibídem, p. 15.

${ }^{115}$ Artículo $6^{\circ}$ del reglamento: "Todos los trabajos que hayan de remitirse a las Secciones del Congreso, y que habrán de responder al Cuestionario aprobado para cada una de ellas, que se inserta al final de este Reglamento, habrán de recibirse dirigidos al señor secretario de la Junta Organizadora del Congreso Musical de Sevilla (Palacio Arzobispal) antes del día 31 de octubre del corriente, en que quedará cerrado el plazo de admisión." Ibídem.

${ }^{116}$ En cualquier caso, se hacía hincapié en la necesidad de brevedad en la intervención: "Este será el variado asunto de este Congreso que punto por punto será examinado en las sesiones privadas en las que podrán tomar la palabra, leyendo sus observaciones los congresistas presentes. Tanto las relaciones verbales, como las escritas, las propuestas, comunicaciones y observaciones habrán de distinguirse por una concisión suma, concretándose estrechamente el punto que se trata de aclarar, teniendo en cuenta lo reducido del tiempo para tan extenso argumento.

Las relaciones y trabajos de los que se inscriban para este Congreso y estén impedidos de asistir a él personalmente, habrán de enviarse a la Comisión organizadora antes del 25 de Marzo próximo y serán tomados en cuenta". La Junta, "Un llamamiento", p. 5.

${ }^{117}$ La Junta, “Un llamamiento”, pp. 4-5. Crónica del Primer Congreso, pp. 11-18, 22-27, 30-34. 
tuvieron lugar cuatro sesiones monográficas cada día, dos de mañana y dos de tarde, cada una dedicada a una de las cuatro secciones en las que se dividió el cuestionario: canto gregoriano, música figurada, música de órgano e instrumental, de "propaganda, organización y personal"118. El mismo Ripollés contaba a Pedrell unos años después las razones de estas modificaciones respecto del congreso vallisoletano:

En Valladolid hubo sesión única en la que el ponentepresidente P. Otaño explicaba cada uno de los puntos abriendo luego discusión: aquello me pareció poco práctico, y por ello en Sevilla dividí los asuntos en 4 secciones (canto gregoriano, canto polífono y moderno, órgano y orquesta, y organización y otros puntos), cada una de las cuales tenía la presidencia de un Prelado, un ponente que extractaba las memorias presentadas y dirigía la discusión y dos secretarios que tomaban nota.

A parte de estos actos de discusión familiar y que no deben tener solemnidad para no cohibir a los tímidos, hubo en Sevilla dos conferencias públicas y solemnes $[\ldots]^{119}$

Este extracto indica que fue Ripollés quien tomó estas decisiones, y lleva a pensar que fue también el autor del reglamento del Congreso, y del cuestionario de puntos a discutir, dado que estos documentos obedecían a la misma estructura y estaban articulados según las mismas secciones. Otro fragmento que citamos más abajo confirma, según las palabras de Ripollés, esta suposición sobre la autoría del cuestionario $^{120}$.

En lo referente a la figura del congresista, regulada en el capítulo II, hubo igualmente novedades destacables. En Sevilla, la idea de congresista único de Valladolid se flexibilizó con el objeto de ofrecer un abanico mayor de posibilidades de participación. Se consideraron tres categorías ${ }^{121}$ : activos, protectores, y de mérito. El socio activo sevillano correspondía con el congresista en Valladolid; era un participante pleno. Esta condición daba derecho a asistir a todas las sesiones tanto privadas con voz y voto, como a las públicas solemnes. La cuota de participación era la misma que en

\footnotetext{
${ }^{118}$ Crónica del Segundo Congreso, pp. 54-56.

${ }^{119}$ Carta de Ripollés a Pedrell, 2 de marzo de 1912. BC. FFP, M 964 R.

${ }^{120}$ Véase la p. 380.

${ }^{121}$ Crónica del Segundo Congreso, pp. 15-16.
} 
Valladolid, diez pesetas ${ }^{122}$. La figura de socio protector estaba pensaba para el caso de aquellos que quisieran ayudar en la financiación del Congreso. La cuota de siete pesetas que debían abonar los socios protectores permitía la asistencia sólo a las sesiones solemnes. La categoría de socio de mérito se creó con el fin de "estimular el celo de los ilustrados profesores de Música Sagrada, de cuya cooperación lo espera todo la Junta Organizadora" ${ }^{\text {123 }}$. Permitía la participación sólo a aquella sección temática de estudio a la que aportaran alguna memoria, además de a las sesiones solemnes. Su cuota era de cinco ptas ${ }^{124}$. Todos los socios tenían derecho a un lugar preferente en las sesiones solemnes, a un ejemplar de la crónica del congreso, y a ciertos descuentos en el precio del billete en el caso de tener que viajar en tren. Esos descuentos fueron gestionados por la Junta Organizadora y finalmente acordados con las compañías ferroviarias $^{125}$. De estos últimos derechos también disfrutaron los congresistas vallisoletanos.

No consta ni en la Crónica del Primer Congreso ni en el $B d C$, ni se menciona en ninguna otra fuente, reglamento alguno que rigiera el congreso de Valladolid. En esta ocasión, todos los aspectos regulados por la norma sevillana figuraron sintéticamente y con la única oficialidad que ofrecía la firma de la Junta Organizadora en el artículo "Un llamamiento". En este se comunicaba su fin, las fechas en que tendría lugar, los tipos de sesiones a celebrar, la cuota de congresista, el precio de las entradas a las sesiones solemnes para aquellos no congresistas -una peseta-, la apertura de una suscripción voluntaria para aquellos que quisieran ayudar a su financiación, y el cuestionario "basado todo él en las normas del Motu Proprio acerca de la Música Sagrada y en los Reglamentos de la Archidiócesis de Valladolid especialmente bendecidos y alabados por S.S. Pío X.",126

Junto al reglamento, el otro documento fundamental era el cuestionario. Se trataba de una relación, punto por punto, de todos los temas a discutir en las sesiones privadas. Como ya hemos señalado, se articuló en cuatro grandes bloques temáticos:

\footnotetext{
${ }^{122}$ La Junta, "Un llamamiento", p. 3.

${ }^{123}$ Artículo $11^{\circ}$ del reglamento. Crónica del Segundo Congreso, p. 16.

${ }^{124}$ Ibídem.

${ }^{125}$ Ibídem, pp. 49-50.

${ }^{126}$ La Junta, “Un llamamiento”, pp. 3-4.
} 
del canto gregoriano; de la música figurada; de la música de órgano y de las orquestas y bandas en los actos litúrgicos; y de propaganda y organización del personal ${ }^{127}$. A pie de página se hizo figurar la siguiente advertencia:

se advierte a los señores Congresistas, que en el estudio de las materias que estos cuestionarios comprenden, habrán de tener en cuenta las conclusiones ya aprobadas en el Congreso Val[1]isoletano; no permitiéndose, por tanto, insistir sobre lo ya acordado, sino solo ampliar los tales acuerdos, si fueran susceptibles de ampliación, y proponer los medios más conducentes para llevarlos a la práctica. ${ }^{128}$

Para evitar que se suscitara el debate sobre puntos ya resueltos en el primer congreso, se transcribieron a continuación de los bloques temáticos, las conclusiones aprobadas en Valladolid sobre cada uno de ellos ${ }^{129}$.

El local que acogió las sesiones privadas de estudio fue el salón Santo Tomás del palacio arzobispal ${ }^{130}$. El procedimiento para el desarrollo de estas sesiones se estipuló como sigue: una ponencia, nombrada para cada sección por la Junta, serviría como introducción a cada sesión, y estaría encargada, además, de dar cuenta de las memorias, es decir, los estudios y trabajos presentados, así como de formular las conclusiones correspondientes. Por último, esas conclusiones se someterían a debate, en el cual podían intervenir todos los asistentes ${ }^{131}$. En $M S H$ se publicaron las condiciones que debían reunir dichas memorias para responder a las dudas planteadas por un lector:

Las memorias para el Congreso de Sevilla no han de tener la forma de discurso que usted cree. Son sencillas exposiciones en que se establecen algunos principios para sacar enseguida conclusiones, que son las que el Congreso toma en cuenta y discute y aprueba o rechaza. La exposición tiene que ser breve, clara y precisa sobre el punto que se trata y las conclusiones deben guardar la forma de voto, tal como se vio en el Congreso de Valladolid. ${ }^{132}$

\footnotetext{
${ }^{127}$ Crónica del Segundo Congreso, p. 15.

${ }^{128}$ Ibídem, p. 17.

${ }^{129}$ Ibídem, pp. 17-29.

${ }^{130}$ Este dato no figura en la Crónica del Segundo Congreso. Nos lo proporciona El Noticiero Sevillano [ENS]. "El Congreso de música sagrada", ENS, 6460 de 13 de noviembre (1908), p. 2.

${ }^{131}$ Crónica del Segundo Congreso, p. 15.

132“Cuestiones prácticas sobre el 2ºngreso”, MSH, 15 (1908), p. 130.
} 
Tras las consultas y gestiones hechas por parte de la Junta Organizadora, la responsabilidad de las ponencias de las distintas secciones y sus correspondientes secretarías se encomendaron a las siguientes personas ${ }^{133}$ :

$1^{\text {a }}$ Sección (canto gregoriano): como ponente el benedictino de Silos e ilustre gregorianista Casiano Rojo. Como secretarios: Agapito Insausti, tenor de la catedral sevillana y José Álvarez de Luna y Pohl, proveniente del arciprestazgo de Huelva.

$2^{a}$ Sección (música figurada): serían dos los ponentes: los maestros de capilla de las catedrales de Valladolid y Sevilla respectivamente, Vicente Goicoechea y Vicente Ripollés. Los secretarios: el dominico jerezano José Aguilar y el maestro de capilla de la seo gaditana José Gálvez.

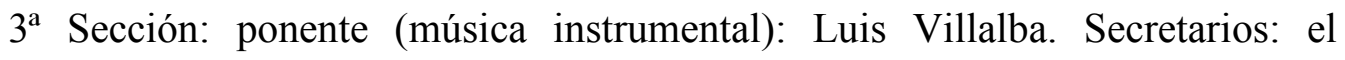
organista de la catedral anfitriona, Bernardo Salas, y el maestro de capilla de la de Jaén, Cándido Milagros.

$4^{\text {a }}$ Sección: ponente (propaganda y organización): Federico Olmeda, en ese momento maestro de capilla de las Descalzas Reales de Madrid. Secretarios: el profesor de canto gregoriano del seminario de Badajoz, Manuel Navas, y el organista de la Capilla Real de San Fernando de Sevilla, Manuel Lerdo de Tejada.

Se deduce, por tanto, que la distribución de responsabilidades en las sesiones de estudio respondía al siguiente plan: cada ponencia se encomendaba a una destacada figura de la reforma, mientras que para las secretarías se designaba a personalidades eclesiástico-musicales provenientes de la provincia eclesiástica de Sevilla. Incluso, como en el caso de Cándido Milagros, organista de la catedral de Jaén, se contó con músicos eclesiásticos de diócesis dependientes de la otra metrópoli andaluza, la granadina. En el congreso de Valladolid todas las sesiones estuvieron presididas y dirigidas por la misma persona, el presidente de la Sección de Programa de la Junta Organizadora, Nemesio Otaño. En la crónica publicada por $M S H$ se demuestra el papel determinante que el vasco desempeñó en la orientación y desarrollo de las mismas. La distribución de la responsabilidad de guiar las discusiones entre varios ponentes indica que esta importante facultad, junto con la de redactar las conclusiones, estuvo en Sevilla más repartida. Se evitó con ello, la concentración de estas atribuciones en un único

${ }^{133}$ Crónica del Segundo Congreso, p. 50. 
presidente. Las conclusiones, una vez aprobadas por el Congreso, se elevaban al conjunto del episcopado español para su aceptación y aplicación en las diócesis, en caso de que los prelados lo consideraran oportuno.

Las orientaciones que Ripollés dio a Pedrell para la elaboración del cuestionario del III Congreso Nacional de Música Sagrada a celebrar en Barcelona en 1912 confirman que fue el castellonense el autor del cuestionario de Sevilla:

Para la redacción del cuestionario, me parece buena la idea de información: también yo acudí a ese medio [en el caso del congreso de Sevilla], pero me dio escaso resultado: tal vez ahora vayan nuevas ideas y orientaciones, pero precisa trabajarlo todo bien invitando particularísimamente a quienes pueden ayudar, y que son bien conocidos por la Revista. Con los puntos que yo indicaba, con los que seguramente le habrá mandado el P. Otaño, y con otros que se pidan al P. Villalba, Viñaspre, Rué, P. Alfonso, Romeu, P. Manso, PP. del Corazón de María, puede V., ayudado por el P. Suñol, redactar un cuestionario esencialmente práctico y menos extenso que los de Valladolid y Sevilla. Profusamente repartido el cuestionario, ya irán llegando memorias y entre todos procuraremos que no quede punto sin tratar. $^{134}$

Además de estas sesiones privadas de estudio, el artículo 2 del reglamento recogía otro tipo de sesiones, las solemnes. Estas, lejos de ser conciertos o audiciones de esparcimiento, estuvieron concebidas como eficientes medios para la transformación en todos los aspectos de la realidad litúrgico-musical, objetivo de estas grandes asambleas. Las sesiones solemnes constituyeron las más claras expresiones de la estrategia pedagógica de corte regeneracionista desplegada por los organizadores. Sobre ello insistiremos en el capítulo sexto.

También en este punto hubo diferencias ostensibles respecto al primer congreso. En Valladolid se celebró una sesión solemne diaria, tres en total. Cada una de ellas constaba de cinco discursos de unos veinte minutos más audiciones intercaladas entre ellos ${ }^{135}$. Los discursos eran elegidos por la Junta Organizadora entre los presentados en una convocatoria abierta a todos los congresistas. Los trabajos a remitir debían cumplir las siguientes características:

\footnotetext{
${ }^{134}$ Carta de Ripollés a Pedrell, 2 de marzo de 1912. BC. FFP. M 964 R.

${ }^{135}$ El programa de las tres sesiones solemnes en: "Crónica del Congreso. 26, 27 y 28 de Abril”, pp. 14, 31 y 46 .
} 
[...] podrán tener carácter más científico y elevado, versaran sobre los puntos más culminantes del cuestionario propuesto [...] deberán ser concisos dentro de las leyes de un discurso. El tiempo máximum concedido a un discurso será el de veinte minutos. ${ }^{136}$

Estas comunicaciones trataron de diversos temas, con el único denominador común de estar entre los contemplados en el cuestionario. Además no tenían relación alguna con las audiciones que le sucedían. En la primera sesión, por ejemplo, las audiciones estuvieron dedicadas casi íntegramente a Victoria. Los discursos pronunciados fueron: el de apertura por Otaño, en calidad de presidente de la sección de programa; La censura de la música religiosa, por Luis Villalba; La enseñanza del Canto Gregoriano en los Seminarios, por Juvencio Jorge; y La cultura litúrgicomusical del clero, por Vicente Ripollés. El quinto discurso del día, Cantos religiosos de la provincia de Salamanca de Dámaso Ledesma ${ }^{137}$, fue suspendido por falta de tiempo, como hemos apuntado más arriba ${ }^{138}$. Esta forma de diseñar las sesiones solemnes permitía la participación de un considerable número de congresistas -quince en total-, a quienes se les ofrecía la oportunidad de presentar públicamente sus planteamientos, opiniones y soluciones en los más importantes asuntos de la reforma. De esta forma, las más destacadas voces del incipiente movimiento reformista español pudieron ser escuchadas por un amplio auditorio, no sólo en las sesiones privadas ${ }^{139}$.

En Sevilla, la planificación fue bastante diferente, y más racional teniendo en cuenta el tiempo disponible. Las sesiones solemnes se redujeron a dos, celebradas en el

\footnotetext{
${ }^{136}$ La Junta, “Un llamamiento”, p. 5.

137 Dámaso Blas Ledesma Hernández (Ciudad Rodrigo, 1866-Salamanca, 1928). Organista de las catedrales de Ciudad Rodrigo (1888) y Salamanca (1896), Ledesma destacó en su condición de folclorista. Para elaborar su Cancionero, al que nos referiremos más adelante, llegó a recopilar unas novecientas canciones populares castellanas, a las que hay que sumar otras doscientas que no llegó a publicar. Miguel Manzano considera la obra de Ledesma como el segundo trabajo de campo realizado de forma sistemática para la recolección de melodías populares en España tras el de Federico Olmeda. Escribió desde canciones infantiles y pasodobles hasta obras litúrgicas para órgano. La mayor parte de su producción permanece inédita. Desarrolló una importante tarea de difusión de la canción popular en distintos congresos y foros académicos. Pilar Magadán Chao, "Ledesma Hernández, Dámaso Blas", $D M E H, 10$ vols., ed. por Emilio Casares (Madrid: SGAE, 2001), vol. 6, pp. 842-843.

${ }^{138}$ En la crónica publicada por $M S H$ no figura este discurso. Esta información consta en la Crónica del Congreso, p. 20.

${ }^{139}$ Completaron la nómina de conferenciantes los siguientes: Francisco Pérez de Viñaspre, organista de la catedral de Burgos; el benedictino Gerardo Salvany; Federico Olmeda, maestro de capilla de la catedral de Burgos; el que lo fuera de la catedral de Toledo, Mariano Baixauli; Miguel Rué, el de la catedral de Gerona; los benedictinos de Silos Luciano Serrano y Casiano Rojo; Felipe Merino, y el cronista de Valladolid, Casimiro García Valladolid.
} 
segundo día y de forma continua. En el número de $M S H$ de agosto de 1908 se proporcionaban brevemente las razones para la supresión de los discursos según el formato seguido en el congreso vallisoletano: "Para el de Sevilla se han suprimido los discursos, que además de ser demasiado académicos deben por lo general ayudar poco a la práctica." $" 140$

Las sesiones solemnes del congreso de Sevilla consistieron ambas en una conferencia magistral con ejemplos musicales. La primera de ellas estuvo a cargo de Gregorio $\mathrm{M}^{\mathrm{a}}$ Suñol y versó sobre la interpretación del canto gregoriano. La segunda fue encargada a Dámaso Ledesma sobre el canto popular religioso. El carácter pedagógico y divulgativo se acentuó con la interacción entre discurso y ejemplos musicales en vivo a modo de ilustraciones. A estas dos sesiones hay que añadir otras dos de carácter igualmente público y solemne como fueron las de inauguración y clausura. En ellas se conjugaron igualmente los discursos con las audiciones musicales, aunque en este caso no fueron pronunciados por especialistas en música sacra, sino por las dos principales autoridades del Congreso, el arzobispo Enrique Almaraz y el canónigo Rafael González Merchant, presidentes honorario y efectivo respectivamente. Las interpretaciones musicales no estaban integradas en los discursos, sino que actuaron como "preces musicales" de apertura y cierre de la sesión: el Veni Creator de Julio Valdés en la inaugural y de Victoria en la de clausura como inicio de sesión, y el Oremus pro Pontifice de Ripollés en ambas para finalizar. En total, las sesiones solemnes celebradas en Sevilla fueron cuatro, las dos conferencias musicales de Suñol y Ledesma, más los dos discursos de los presidentes de honor y efectivo del Congreso.

En la asamblea hispalense se neutralizó el problema que en Valladolid supuso el excesivo número de discursos programados en relación al tiempo disponible, y que obligó a la suspensión de dos de ellos. Por otro lado, esta mejora en cuanto a organización implicó una reducción de la pluralidad de voces y enfoques respecto a las sesiones públicas del congreso vallisoletano. Es posible que este cambio represente la diferencia esencial entre el primer y segundo congreso, y desvele el sentido en el que evolucionaron estas grandes citas eclesiástico-musicales $\mathrm{y}$, en cierta medida, el movimiento reformista: de la frescura, improvisación y pluralidad, a una mejor organización, pero también mayor control y oficialidad.

140 “Cuestiones prácticas sobre el $2^{\circ}$ congreso", p. 130. 


\subsection{Difusión y propaganda. El Congreso en el contexto socioeconómico}

\subsubsection{La respuesta del episcopado español a los requerimientos del}

\section{Congreso}

Una vez aprobados los documentos fundamentales del Congreso, la Junta centró sus esfuerzos en su difusión. El 1 de junio publicó un manifiesto en tono propagandístico y animoso muy propio de la época, en el que se daba a conocer la celebración del II Congreso Nacional de Música Sagrada en Sevilla, se alentaba a la participación y se reclamaba el compromiso y la implicación de todos para llevar a buen puerto el proyecto $^{141}$. Esta circular llevaba por título A los católicos españoles y era muy parecida tanto en su contenido como en el estilo a sendos artículos publicados con ocasión de la asamblea vallisoletana en el BdC, Nuestra voz y Un llamamiento $^{142}$. Tanto aquella como estos representaban el primer paso de una campaña publicitaria que, como testimonia Ripollés, constituía la clave para el éxito de los congresos, tanto desde el punto de vista de la participación como de la financiación, pues la segunda dependía en gran medida de la primera. Así se expresó en relación a los esfuerzos que, al margen de otros cauces más oficiales, realizó personalmente. Si seguimos su versión, hay que aceptar que el peso de la organización del Congreso descansó en el castellonense:

después de redactar el cuestionario, no hace falta más que repartirlo profusamente y escribir incesantemente cartas y más cartas comprometiendo a todo el mundo: ese fue mi plan en Sevilla y me salió bien, pues a fuerza de cartas conseguí llevar allí gente reacia y poco despierta a concurrir y cooperar. ${ }^{143}$

Junto a la labor menos visible de Ripollés, los órganos oficiales llevaron a cabo varias iniciativas encaminadas a lograr la máxima difusión posible. La Junta envió sendos comunicados a los distintos obispados y cabildos españoles. A los obispos les solicitaba su colaboración encomendándoles una doble tarea: en primer lugar, establecer en cada una de las diócesis centros de inscripción ${ }^{144}$; y en segundo lugar, hacer llegar

\footnotetext{
${ }^{141}$ Crónica del Segundo Congreso, pp. 13-14.

${ }^{142}$ La Junta Organizadora, “Nuestra voz”, BdC, 1 (1907), pp. 1-3; “Un llamamiento”, pp. 3-4.

${ }^{143}$ Carta de Ripollés a Pedrell, 2 de marzo de 1912. BC. FFP, M 964 R.

${ }^{144}$ En las páginas 29 y 30 de la Crónica del Segundo Congreso figuran los delegados nombrados por cada uno de los obispos españoles como encargados de atender cualquier requerimiento de la junta sevillana.
} 
los ejemplares del reglamento y del cuestionario, que previamente les había enviado desde Sevilla, a las personas o instituciones que pudieran "contribuir más eficazmente a la realización del proyecto" ${ }^{\# 4}$. A los cabildos les formuló la siguiente petición:

[...] habiendo de ser los Cabildos Eclesiásticos los que han de iniciar la anhelada reforma de la música religiosa, y los que han de dar en ella la pauta a los demás, así como también los que con mayores elementos cuentan para una obra de esta índole, a ellos acudió la Junta en respetuosa comunicación, solicitando su necesaria cooperación y manifestando el deseo de que desde luego todos los Cabildos enviaran al Congreso algún representante suyo. ${ }^{146}$

La demanda de la Junta Organizadora sevillana recogía el testigo de otras reclamaciones que, en el mismo sentido, se efectuaron inmediatamente antes y durante el congreso vallisoletano. En el segundo número del $B d C$, el autor del artículo "Carta abierta", E. B. ex-maestro de capilla, exponía su propuesta en este sentido, sugiriendo al mismo tiempo que "indudablemente estará muy dentro de la Junta organizadora y que quizás no se haya expuesto desde un principio por motivos prudenciales":

Sería no sólo conveniente, sino DEL TODO NECESARIO [en mayúsculas en el original] que los Cabildos de todas las Catedrales de España y los Seminarios estuviesen ahí representados por los Maestros de Capilla y organistas cuando menos. La reforma afecta a todas partes y las Catedrales y Seminarios ganarán no poco con este Congreso [...]. Es, pues, de esperar que los Rvmos. Prelados de España, los Cabildos y los Seminarios se aprovecharán de esta excelente ocasión para mejorar la situación artística de nuestras capillas ya que de la material nada o casi nada puede hacerse por ahora [todas las cursivas originales]",147

La Junta Organizadora vallisoletana hizo constar su posición al respecto justo a continuación de la carta: "La Junta organizadora del Congreso acoge con gran júbilo la idea expuesta en la anterior carta. El Congreso sería ciertamente digno de España si el pensamiento hallara eco en todos sus ámbitos." ${ }^{148}$ En esa misma dirección apuntaba la

\footnotetext{
${ }^{145}$ Crónica del Segundo Congreso, p. 31.

${ }^{146}$ Ibídem.

${ }^{147}$ E.B. Ex-maestro de capilla, "Carta abierta”, $B d C$, 2 (1907), pp. 10-11. Desconocemos la identidad de la persona que firmó el artículo.

${ }^{148}$ Ibídem, p. 11.
} 
intervención de Ángel Larroca Rech, maestro de capilla de la catedral de Murcia, en la última sesión del primer congreso. En la reacción de los congresistas se descubre una de las grandes paradojas de estas grandes reuniones: sus principales protagonistas, los músicos eclesiásticos, no podían asistir por razones económicas. Transcribimos la intervención de Larroca, aunque en este asunto nos detendremos más adelante:

Pide que para estímulo de los futuros Congresos y para que cunda este hermoso ejemplo que facilitará a los maestros y músicos de iglesia la asistencia a ellos, conste en las actas que la venida de algunos Congresistas había sido costeada por los Prelados y Cabildos respectivos: en este caso se halla él y otros congresistas presentes v. $\mathrm{g}$. los de Ciudad Real. (Se acogen estas declaraciones con muchos aplausos y manifestaciones. Varios Congresistas exponen la necesidad de que los Prelados y Cabildos envíen por su cuenta a los delegados, sin lo cual es imposible pensar en viajes y congresos dado el estado actual de los músicos de iglesia). ${ }^{149}$

En el caso del congreso de Sevilla, la respuesta de "no pocos" de los cabildos a la petición de su Junta Organizadora no fue favorable, según se recoge en la Crónica del Segundo Congreso. El motivo que ofrecieron fue una vez más la situación por la que atravesaban sus arcas:

Todas [las contestaciones de los cabildos] manifiestan la voluntad decidida de que están animados de cooperar sinceramente a la labor y éxito más cumplido del Congreso, aunque con respecto al extremo de enviar a Sevilla un representante, no pocos lamentan no poder verificarlo, por la precaria situación porque muchos de ellos atraviesan, como a todos es por desgracia notorio. ${ }^{150}$

\footnotetext{
149 “Crónica del Congreso. 26, 27 y 28 de Abril”, p. 53. Los tres beneficiados sevillanos que acudieron al congreso de Valladolid, solicitaron y consiguieron asistir en calidad de representantes del Cabildo con las "horas ganadas" desde el día 20 de abril al 2 de mayo, tal y como refleja el siguiente acta capitular: "Se leyó una solicitud de los Beneficiados D. Agapito Insausti; D. Bernardo Salas y D. Vicente Ripollés, Tenor, Organista y Mtro. de Capilla respectivamente de esta Santa Iglesia, pidiendo al Excmo. Cabildo, que les conceda su representación para asistir al Congreso Nacional de Música religiosa, que ha de celebrarse en Valladolid en los últimos días de este mes, y que se les den horas ganadas durante ese tiempo. Varios Sres. hicieron uso de la palabra y se acordó dar comisión a los supradichos Beneficiados para que concurran al mencionado Congreso y a su vuelta informen al Excmo. Cabildo de todo cuanto sea digno de ser notado, para bien de esta Santa Iglesia, y que se les den horas ganadas, a partir del 20 de los corrientes hasta el 2 del próximo Mayo, ambos inclusives.” AC 10/4/1907. ACS. Sección Secretaría, libro 227, fol. 169.

${ }^{150}$ Crónica del Segundo Congreso, p. 31. La información que proporciona Antonio Martín Moreno en relación a la reacción del Cabildo granadino puede servir de ejemplo paradigmático. Ante la petición del propio arzobispo de que la catedral envíe un representante al congreso de Valladolid el Capítulo contestó que se adhería al Congreso pero que no podía financiar la asistencia de un representante "por el estado precario de la fábrica". Martín Moreno, "Cinco siglos de historia musical", p. 846.
} 
A la luz de esta comunicación, declaraciones entusiastas como la que recogemos a continuación, escrita por Villalba respecto del congreso de Valladolid, deben ser matizadas. O bien los maestros de capilla y otros músicos catedralicios presentes no ostentaron la facultad de representación oficial de sus respectivos cabildos, y asistieron por iniciativa propia; o bien dicha representación no fue sufragada con la correspondendiente ayuda económica, debiendo cargar los músicos con todos los gastos que suponía la participación en el congreso:

¿Cuándo aquí había de imaginarse que habían de reunirse algunos centenares de músicos eclesiásticos para tratar de los asuntos de su arte? Y sin embargo, ha sucedido, y los cabildos catedrales han enviado con carácter oficial a dos o tres representantes suyos, y las comunidades religiosas han tenido también quien llevara su voz, y maestros de capilla, organistas y cantores han tomado parte con interés en el negocio. ${ }^{151}$

Se puede concluir, en consecuencia, que los cabildos catedralicios facilitaron la asistencia a los congresos de sus beneficiados músicos. Sin embargo, la mayoría de ellos no accedieron a las peticiones formuladas en Valladolid por distintas voces a título individual -aunque con el apoyo de la Junta Organizadora-, ni oficialmente por la Junta Organizadora de Sevilla, de que sufragaran los importantes gastos que para la no muy boyante economía de un músico catedralicio suponía la participación en estas reuniones. Según el motivo aducido por los cabildos y recogido en el anterior fragmento de la Crónica del Segundo Congreso, la precaria situación de las catedrales españolas impidió una mayor implicación de estas instituciones clave en los congresos, precisamente en aquel aspecto más necesitado de colaboración, el económico.

En esta línea de propagación del Congreso y de procurar la implicación y colaboración de toda la Iglesia española, fue el propio Almaraz quien personalmente o a través de González Merchant escribió a los prelados españoles. Por fortuna, podemos conocer sus contestaciones al conservarse en el AGAS sus cartas enviadas como respuesta $^{152}$. Esta pequeña colección epistolar constituye, a nuestro juicio, una fuente

\footnotetext{
${ }^{151}$ Villalba, "El Primer Congreso Nacional”, p. 386.

${ }^{152}$ Se conservan en el AGAS las cartas de prelados de Salamanca, Teruel, Zamora, Valencia, Sigüenza, Zaragoza, Orense, Granada, Vich, Lugo, Barcelona, Osma, Cádiz, Coria, Vitoria, Guadix, Tortosa, Málaga, Tuy, Gerona, Badajoz, Burgos, Cartagena, León, Jaén, Santiago de Compostela, Calahorra y La Calzada, Palencia, Madrid-Alcalá, Huesca, Jaca, Tarazona, Plasencia, Capilla Real de Toledo. AGAS. Sección Gobierno. Asuntos Despachados, leg. 04907 (1908).
} 
de información de gran interés por cuanto nos proporciona una perspectiva de la reforma y del estado de la música religiosa en España prácticamente inédita en los estudios realizados al respecto, como es la del conjunto del episcopado español del momento. A través de determinados observaciones insertadas en sus misivas, algunos obispos aludían a la situación de la música sagrada en sus respectivas diócesis, dejando constancia de su posición, y su grado de sensibilización con el problema. En el caso de los congresos no olvidemos que las conclusiones emitidas no tenían ningún valor vinculante. Es decir, no eran más que propuestas y soluciones que generaba un movimiento de gente sensible e implicada en la reforma, articulado en torno a determinados líderes, y auspiciado por algunos obispos, pero sin poder ejecutivo alguno. Este se encontraba en manos de las autoridades administrativas de cada diócesis, quienes las debían asumir y aplicar, según sus criterios. Los deseos que -casitodos expresaron de colaborar dentro de las posibilidades de cada uno, no esconden un mayor o menor grado de interés e implicación en el asunto, dibujando un panorama algo más heterogéneo de lo que en principio se pudiera pensar. Las posiciones que revelan un alto nivel de concienciación con la reforma contrastan con alguna de absoluta indiferencia.

De una de las cartas que envió Almaraz se conserva un borrador en sucio que, al no ser excesivamente extenso, reproducimos a continuación:

Sevilla

Emmo o Excmo Sr.

Mi venerable Hermano y amigo:

El Congreso musical de canto gregoriano celebrado en Valladolid el año anterior, acordó que el segundo tuviera lugar en Sevilla, durante el año que va corriendo. Constituida ya la Junta y formado el reglamento, ha parecido a aquella, que para facilitar las inscripciones, se ruegue a los Rvdmos. Prelados formen una junta diocesana encargada de propagar la idea del Congreso y de recoger las inscripciones, o al menos que designen una persona de toda su confianza, que pueda entenderse con esta Junta en todo lo que se relacione con referido asunto. Por de pronto, en el Reglamento se dice: que podría ser la Secretaria de Cámara la encargada de recibir las inscripciones. Pero si otra cosa a V.E. ocurriese más oportuna, agradecería en el alma que me la indique, suplicándole al mismo tiempo, sepa dispensar esta molestia que le proporciona [...]

+ Enrique Arzobispo de Sevilla ${ }^{153}$

${ }^{153}$ Ibídem. 
En muchas de las misivas, los obispos reconocían la imposibilidad de constituir una junta diocesana, tal y como deseaba la Junta de Sevilla, y les solicitaba el propio Almaraz ${ }^{154}$. Estas son, por ejemplo, las respuestas del obispo de Vich: "me sería difícil constituir una junta como V. desea para fomentar la obra tan excelente del Congreso de Canto Gregoriano"; y de Coria:"las dificultades de formar aquí la Junta Diocesana para el futuro congreso musical en esa Ciudad [...]". Los prelados que constituyeron juntas locales para el Congreso fueron los de Teruel, Málaga, Madrid-Alcalá, y Plasencia ${ }^{155}$, a las que hay que añadir aquellos que ya habían creado comisiones diocesanas de música sagrada como prescribía el MP, como los de Valencia, Cartagena-Murcia y Santiago de Compostela ${ }^{156}$; es decir, sólo siete de treinta y un prelados de los que se conservan cartas, un porcentaje, por tanto, bastante bajo. No obstante, todos nombraron un representante diocesano para colaborar con la hispalense, normalmente el secretario de cámara, aunque también asumieron ese cometido dignidades y canónigos de catedrales, o maestros de capilla ${ }^{157}$.

En la mayoría de los casos, el interés e implicación de los obispos, tal y como se desprende de sus cartas, terminó ahí. Otros, como el arzobispo vecino de Badajoz se

${ }^{154}$ AGAS. Sección Gobierno. Asuntos Despachados, leg. 04907 (1908).

155 “acudiendo a los deseos de V. le remito los nombres de los Sres. que he nombrado para formar la Junta para el Congreso de canto gregoriano". Carta del obispo de Teruel, 28 de junio; "De mi parte ofrezco mi cooperación y ayuda y desde luego quedo en constituir una Junta diocesana que se encargue de propagar la idea". Carta del obispo de Málaga, 10 de junio; "Recibí su atenta carta fecha 17 de los corrientes en la que tiene a bien honrarme con la comisión de formar una Junta diocesana encargada de propagar la idea del Congreso Musical de canto gregoriano que tendrá lugar en esa Archidiócesis, tengo el gusto de proponer a V. los siguientes señores: Presidente: M. I. Sr. D. Francisco Paja, Chantre de esta S. I. Catedral; Vocales: D. Laureano Garate, Organista; D. Gregorio Serrano, Maestro de Capilla; D. Agustín Sánchez, Sochantre; con los cuales podrá V. entenderse directamente." Carta del obispo de MadridAlcalá, 27 de junio; "Con mucho gusto recibo su carta sobre el Congreso de música que se proyecta celebrar en Sevilla y hoy mismo he nombrado la junta conveniente para que esta diócesis coopere cuanto pueda al proyecto". Carta del obispo de Plasencia, 25 de junio. Todas las cartas están datadas en 1908, y se conservan en: AGAS. Sección Gobierno. Asuntos Despachados, leg. 04907 (1908).

156 Transcribimos un fragmento de la misiva del arzobispo de Valencia: "correspondiendo a su atenta de 17 de Junio último y deseando muy sinceramente cooperar al mejor éxito del segundo Congreso nacional de Música Sagrada, que ha de celebrarse ahí en Noviembre próximo, además de recomendarlo eficazmente en mi Boletín y en particular a la Junta diocesana que tengo constituida para la ejecución del Motu proprio de Pío X, he dispuesto que en mi Secretaría de Cámara se abra registro especial para la inscripción de socios de ese futuro Congreso". Carta del arzobispo de Valencia, 2 de julio. Parecidas son las contestaciones remitidas desde el obispado de Cartagena-Murcia el 9 de junio, por el arzobispo de Santiago de Compostela, el 1 de junio. AGAS. Sección Gobierno. Asuntos Despachados, leg. 04907 (1908).

${ }^{157}$ En Santiago de Compostela fue el obispo auxiliar, quien ostentaba el cargo de presidente de la CDMS. En la crónica del Congreso se incluye una lista en donde figuran los delegados de cada uno de los obispados españoles. Crónica del Segundo Congreso, pp. 29-30. 
comprometió desde este primer momento a dar "las instrucciones oportunas para que asista el mayor número de sujetos peritos", e incluso se comprometió a asistir personalmente al Congreso "para dar ejemplo"158. Muchos de ellos, sin embargo, declaraban abiertamente su poca confianza en que su aportación pudiera ser eficaz o significativa dados los graves problemas y obstáculos que encontraban en sus respectivas diócesis, y que expusieron claramente. Esas dificultades se pueden sintetizar en dos ideas: los problemas económicos, y lo marginal y secundario que resultaba la cuestión de la música religiosa. Esta frase del obispo de Jaca resume la posición de este grupo de prelados: "Poco es lo que aquí puede hacerse por el Congreso musical; pero se hará lo que se pueda"159. El obispo de Salamanca fue más gráfico y explícito: “con gusto haré cuanto pueda en el asunto del Congreso Musical [...], aunque con pocas esperanzas de éxito, pues los músicos a quienes hablé, después de tentarse el bolsillo, ponen un gesto tan difícil..." ${ }^{\prime 160}$. La carta del obispo de Jaén es una muestra de compromiso incondicional, no obstante las dificultades:

No sé aquí lo que pueda lograrse. Hay entre esta gente muy poco entusiasmo por la música y la cuestión del canto gregoriano o del Motu proprio, les tiene muy poco intranquilos. Aquí sin embargo trabajaremos cuanto se pueda, procurando secundar las indicaciones y deseos de esa Junta del Congreso. Y si las cosas vinieran bien, hasta yo haría un esfuerzo por asistir a tal congreso. ${ }^{161}$

Estas dificultades se acentuaban en el caso de diócesis especialmente pobres o poco pobladas. El obispo de la diócesis extremeña de Coria aseguró que "Ningún resultado habíamos de obtener por las circunstancias especiales de este pobrísimo país [...] Bien siento estar aquí tan desprovisto de medios para esa obra de toda mi simpatía, pero hay que conformarse con ello."162. El de Huesca expresó el siguiente deseo, aunque señalaba implícitamente la supuesta inutilidad de la empresa en su diócesis,

\footnotetext{
158 "Con mucho gusto acepto la invitación para el Congreso musical de canto gregoriano, que se ha de celebrar en esa Capital y daré las instrucciones oportunas para que asista el mayor número de sujetos peritos en la música sagrada y yendo yo para dar ejemplo". Carta del obispo de Badajoz, 8 de junio.

${ }^{159}$ Carta del obispo de Jaca, 24 de junio. AGAS. Sección Gobierno. Asuntos Despachados, leg. 04907 (1908).

${ }^{160}$ Carta del obispo de Salamanca, 25 de junio. Ibídem.

${ }^{161}$ Carta del obispo de Jaén, 30 de mayo. Ibídem.

${ }^{162}$ Carta del obispo de Coria, 17 de junio. Ibídem.
} 
aludiendo a uno de los problemas más graves, también expresado por Spínola, cual era la férrea raigambre de la costumbre y la consecuente dificultad de la regeneración del gusto. No obstante, la posición ante este problema fue distinta de la del prelado andaluz ${ }^{163}$ :

Que los trabajos de esa parte tengan feliz éxito, y no será poco si consiguieran formar el gusto religioso del canto, el cual regularmente pronto lo perderían en diócesis como esta, de pueblos muy pequeños, donde tienen ya sus cantinelas, de las que es difícil sacarlos e infundirles buen gusto; ${ }^{164}$

La lejanía de algunas diócesis de la capital andaluza fue otro de los argumentos esgrimidos junto al recurrente sobre sus ya de por sí limitadas posibilidades de colaboración con el Congreso. Esta colaboración se concretaba básicamente con la aportación de congresistas, y su importancia residía, como ya hemos apuntado, en ser una inestimable ayuda para la financiación del evento, cuya principal fuente de ingresos era precisamente lo recaudado por las inscripciones de socios. El obispo de Orense se manifestó en este sentido:

Cúmpleme ante todo manifestar a V.E.I. mi mayor reconocimiento por su fina atención, prometiéndole al mismo tiempo que recomendaré tan laudable proyecto, si bien abrigo el temor de que la falta de elementos y la considerable distancia que separa mi diócesis de la del dignísimo cargo de V.E.I. no permitirán secundar aquí, cuales son mis deseos, tan hermoso pensamiento. ${ }^{165}$

También el de Huesca: "conforme a sus indicaciones, la Secretaría de Cámara se encargará de recibir las inscripciones al $2^{\circ}$ Congreso musical de canto gregoriano [...], aunque no me prometo sean muchas, en atención a la distancia y situación económica del clero". ${ }^{166}$

El tono optimista del arzobispo de Granada constituye un contrapunto a este cuadro compuesto de problemas, reservas y pesimismo: "Pronto publicaré en el Boletín

\footnotetext{
163 Véase capítulo 1, epígrafe 1. "El arzobispo Marcelo Spínola frente a la reforma: 'perseverancia, discreción y prudencia exquisita".

${ }^{164}$ Carta del obispo de Huesca, 24 de junio. AGAS. Sección Gobierno. Asuntos Despachados, leg. 04907 (1908).

${ }^{165}$ Carta del obispo de Orense, 23 de junio. Ibídem.

${ }^{166}$ Carta del obispo de Huesca, 24 de junio. Ibídem.
} 
Eclesiástico una exhortación que espero hallará eco en el religioso espíritu de mi respetable Clero y amados Diocesanos." 167 Algunos obispos ponían a disposición de la Junta sevillana sus boletines oficiales como eficaz medio de difusión del acontecimiento, como por ejemplo, el de Gerona: "Con mucho gusto contribuiré con mis escasas fuerzas a propagar la idea del Congreso musical [..]. Desde luego, queda a disposición de V. el Boletín Oficial de esta Diócesis para cuanto desee publicar en

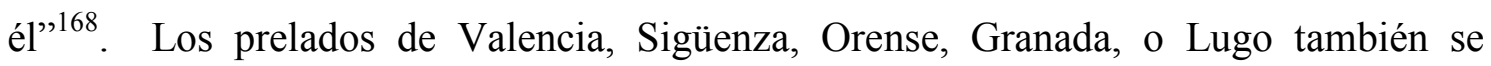
sirvieron de sus boletines oficiales para difundir el proyecto ${ }^{169}$. El arzobispo de Valencia implicó, además, al periódico católico local La voz de Valencia, que había publicado ya el reglamento del Congreso "y se había ocupado varias veces de enaltecer su importancia" ${ }^{170}$.

La carta del prelado granadino es una muestra de las más optimistas y alentadoras: "Le felicito por tan plausible acuerdo y no dude cooperaré con todas mis fuerzas a tan buena obra, de gran necesidad en esta época de general decadencia"171. Ese entusiasmo se tradujo en un compromiso decidido de apoyo a la causa, que plasmó de forma concreta con su asistencia al Congreso

La posición opuesta, también existía en el episcopado español, como muestra la respuesta del obispo de Tuy. En un alarde de contundente sinceridad confiesa: “Como en cuestión de música no tengo pretensión alguna, espero que lo que haya que hacer me lo den hecho, y no veo la necesidad de que esta diócesis figure en el congreso"172. Finalmente, la secretaría de cámara de este obispo figuró también en el listado publicado en la Crónica del Segundo Congreso Nacional de Música Sagrada ${ }^{173}$.

\footnotetext{
${ }^{167}$ Carta del arzobispo de Granada, 19 de junio. Ibídem.

${ }^{168}$ Carta del obispo de Gerona, 10 de mayo. Ibídem.

${ }^{169}$ Carta del arzobispo de Valencia, 2 de julio; carta del obispo de Sigüenza, 27 de junio; carta del obispo de Orense, 23 de junio; carta del arzobispo de Granada, 19 de junio; carta del obispo de Lugo, 15 de junio. Ibídem.

${ }^{170}$ Carta del arzobispo de Valencia, 2 de julio. Ibídem.

${ }^{171}$ Carta del arzobispo de Granada, 19 de junio. Ibídem. Esa sensación de decadencia es manifestada por otros prelados como el de Guadix. Parece ser que es un comentario que no se refiere únicamente al aspecto musical, sino que parte de un diagnóstico general de la situación de la Iglesia, e incluso del conjunto de la sociedad de la época.

172 Carta del obispo de Tuy, 10 de junio. AGAS. Sección Gobierno. Asuntos Despachados, leg. 04907 (1908).

${ }^{173}$ Crónica del Segundo Congreso, p. 30.
} 
Una vez conocida la respuesta de los obispos españoles al requerimiento de Almaraz, pasemos a tratar otras líneas de actuación seguidas para la propagación del evento, esta vez por la Junta Organizadora. En aquellos momentos, la prensa, como el gran medio de comunicación e influencia, representaba el vehículo publicitario y de transmisión de ideas más eficaz. Los miembros de la Junta, conscientes de que "casi en ninguna obra es posible prescindir del auxilio poderoso y decisivo de la prensa, mucho menos, cuando se trata de obras de carácter general, como la presente" ${ }^{\text {174, }}$, buscaron como una de sus principales prioridades el apoyo de las publicaciones afines ${ }^{175}$. En la Crónica del Segundo Congreso se recoge una muestra de las reseñas y artículos de los distintos boletines, periódicos y revistas que colaboraron en la difusión y conocimiento del acontecimiento ${ }^{176}$. Por lo general en ellos se exaltaba y alababa la iniciativa, se hacía hincapié en la condición de punto de encuentro, se trataba de concienciar a los lectores de su importancia, y, por supuesto, se alentaba a la participación. Reproducimos como ejemplo unos párrafos del artículo aparecido en la Gaceta del Sur de Granada:

Los que creemos que el problema de la buena ejecución del canto gregoriano no es enteramente inabordable y que basta el estudio y la buena intención para resolverlo, vayamos a Sevilla a confirmarnos o retractarnos en nuestro modo de pensar; los que por el contrario creen que sólo la tradición, conservada en una u otra escuela, es la que puede resolver esta intrincada cuestión, vayan a Sevilla, y en el Congreso verán la confirmación o desaprobación de sus opiniones; los que aún creen que está sin resolver la no menos esencial y difícil cuestión de los caracteres que distinguen o distinguir deben la música religiosa de la profana, marchen a Sevilla. En una palabra, todos los artistas religiosos en todas sus clases deben tomar parte en este Congreso, presentando estudios, discutiendo, enseñando o aprendiendo, contribuyendo, en fin, a que el éxito más completo sea la coronación y el fallo digno de tan gloriosa y oportuna empresa. ${ }^{177}$

${ }^{174}$ Crónica del Segundo Congreso, p. 31.

175 La clara adscripción ideológica y politización de los distintos rotativos daba como resultado una acentuada sectarización en el panorama de la prensa del momento.

${ }^{176}$ Se incluyen extractos de los siguientes: La Ciudad de Dios, de El Escorial, dirigida por Luis Villalba; Fulla Seráfica, de Olot; El Lirio de San Antonio, de Lérida; El Mensajero Seráfico madrileño; La Lectura Dominical; A voz de San Antonio, editada en la ciudad portuguesa de Braga; por supuesto Música SacroHispana, la revista fundada en el congreso de Valladolid como órgano de los congresos de música sagrada; Gaceta del Sur, de Granada; La Regeneración, de Gerona; Musical Emporium, de Barcelona; Biblioteca Sacro-Musical, de Valencia; Santa Cecilia, Turín; Musica Sacra, Milán. Crónica del Segundo Congreso, pp. 36-40.

${ }^{177}$ Crónica del Segundo Congreso, pp. 37-38. 
No faltaron tampoco las referencias al congreso de Sevilla en la prensa extranjera, como las que se incluyen de la revista portuguesa A voz de San Antonio, o las italianas Santa Cecilia de Turín, y Musica Sacra de Milán ${ }^{178}$. De esta última fue traducido y transcrito una buena parte de un artículo titulado "España se reúne en Sevilla" de Nasoni ${ }^{179}$.

Además de esta serie de referencias cortas, se transcribieron íntegramente en la Crónica del Congreso tres artículos extensos, además de una circular del cardenal arzobispo de Santiago de Compostela. Estos artículos estaban firmados, el primero por la Junta Organizadora, el segundo por Federico Roldán, secretario de la misma, y el tercero bajo el pseudónimo de Franculus ${ }^{180}$.

La labor desempeñada por la organización en lo que a la propaganda se refiere mereció la siguiente valoración de Villalba:

Y viniendo a otra cosa, a la preparación del Congreso, yo no sé la parte que toca a cada uno en tales trabajos, ellos se los repartirán como les corresponda, pero indudablemente se han acreditado de laboriosos. En los meses anteriores, la propaganda ha sido muy activa, sobre todo en la prensa, y fueron muchas las hojas o gacetillas que de Sevilla salieron a todos los periódicos y revistas para anunciarle, dar noticia de los trabajos de organización, su progreso, etc., etc. Indudablemente conocían la aguja de marear los que en esto entendían. Si tú has leído los periódicos de aquellos días, te habrás convencido de lo mismo. ${ }^{181}$

Así pues, y, en síntesis, implicar a obispos, cabildos y seminarios, así como lograr la colaboración de la prensa católica fueron las principales estrategias de la organización en lo que a la difusión del Congreso se refiere ${ }^{182}$. De otra menos oficial,

${ }^{178}$ Ibídem, pp. 36-40.

${ }^{179}$ Ibídem, pp. 38-40.

${ }^{180}$ La Junta Organizadora, “A los amantes de la música sagrada”, en: Crónica del Segundo Congreso, pp. 40-42; Federico Roldán, “¿Congreso de música?...”, en: ibídem, pp. 42-44; Franculus, "Un Congreso”, en: ibídem, pp. 45-49. En el corpus documental recopilado y manejado en nuestra investigación no hemos encontrado pista alguna que nos pudiera ayudar a desvelar la identidad del autor que se oculta detrás del pseudónimo de Franculus.

${ }^{181}$ Villalba, Luis Villalba Muñoz, "El Segundo Congreso Nacional de Música Sagrada de Sevilla", LCD vol. 78 (1908), p. 499.

${ }^{182}$ Sobre el seguimiento que tanto en las semanas anteriores a la celebración del Congreso como durante la misma realizó la prensa local, véase capítulo 6, epígrafe 1.3. "La función de la prensa en un escenario ideal", p. 519. 
aunque eficaz daba cuenta Ripollés a Pedrell, escribir cartas y más cartas hasta recabar finalmente el compromiso y la participación "de todo el mundo", incluido los reacios o desinteresados $^{183}$. El objetivo era presentar el congreso de Sevilla ante la Iglesia española como un importante evento católico. En gran medida, el éxito de participación y financiación dependía de la resonancia que consiguiera. Resta mencionar una última línea de trabajo, trascendental desde luego, como es la difusión de la asamblea en la propia Archidiócesis.

\subsubsection{La contribución al Congreso de arciprestes, curas y fieles diocesanos}

La Crónica del Segundo Congreso explica así el siguiente paso dado por la Junta en la difusión del Congreso:

Confiada la propaganda del Congreso en las distintas diócesis a los delegados en ellas nombrados o, en su defecto, a los Sres. Secretarios de Cámara, la Junta hízola por sí misma en la diócesis de Sevilla, a cuyo efecto dirigió atentas comunicaciones a todos los Sres. Arciprestes y a los Sres. Curas de la Capital. ${ }^{184}$

La primera comunicación con este fin fue firmada por el propio arzobispo y enviada a principios de julio ${ }^{185}$. Durante el verano la respuesta de los arciprestes fue más bien escasa ${ }^{186}$. Ante esto, llegado el mes de septiembre, el secretario de cámara les remitió otro oficio, al que contestaron prácticamente todos ${ }^{187}$. Al igual que las cartas de los prelados de las que hemos hecho uso más arriba, la mayoría de las escritas por los arciprestes se conservan en el AGAS, y constituyen una fuente ciertamente interesante por varias razones ${ }^{188}$. La primera, por permitirnos compartir, no sólo con los

${ }^{183}$ Carta de Ripollés a Pedrell, 2 de marzo de 1912. BC. FFP, M 964 R.

${ }^{184}$ Crónica del Segundo Congreso, p. 31.

${ }^{185}$ Aunque no hemos localizado ni el original ni borrador alguno de esta comunicación, las contestaciones de los arciprestes apuntan a que su autor fue el propio Almaraz.

${ }^{186}$ No se conserva documento alguno de los párrocos de la capital. Suponemos que los curas sevillanos debieron entregar los datos demandados directamente en la secretaría de cámara.

${ }^{187}$ Casi todas las contestaciones datan de las dos primeras semanas de septiembre de 1908.

${ }^{188}$ Se conservan cartas remitidas desde los siguientes arciprestazgos: Ayamonte (Huelva), Huelva, Utrera, La Palma, Lora del Río, Jerez de la Frontera (Cádiz), Cazalla de la Sierra, Zahara (Cádiz), Aracena (Huelva), Osuna, Sanlúcar la Mayor, Utrera, Puerto de Santa María (Cádiz), Moguer (Huelva), Morón de la Frontera, Campillos (Málaga), Sanlúcar de Barrameda (Cádiz), Marchena, Estepa, Carmona. En esta colección epistolar figura otra misiva enviada desde Fuente Palmera (Córdoba), perteneciente al arciprestazgo de Écija. El remitente es Laureano Pérez Damián, teniente de arcipreste de Écija. AGAS. 
administradores de templos rurales, sino también con sus parroquianos, la perspectiva desde la que debieron contemplar grandes eventos como el Congreso musical, tan diferente de la de los líderes del movimiento español pro-reforma o la alta jerarquía eclesiástica. La segunda, porque, al figurar el Congreso en esas cartas junto a otras iniciativas para las que el gobierno de la Diócesis solicitó también la colaboración de todo el clero y sus fieles, hace posible el intento de efectuar una apreciación sobre su significación y valor relativo dentro del plan general de acción social archidiocesano. Por último, las continuas alusiones de los arciprestes a la situación socioeconómica que vivían sus pueblos y comarcas durante esos años esbozan el complicado escenario en el que se ubicó la convención musical. En suma, las respuestas de este colectivo en contacto directo y constante con los fieles y sus circunstancias a los requerimientos de la alta jerarquía eclesiástica nos ayudan a integrar nuestro objeto de estudio en el contexto socioeconómico y cultural en el que estaba inserta la institución organizadora, la Iglesia católica en Andalucía, y nos proporcionan un punto de vista de sus grandes proyectos como el que nos concierne, inédito, y diferente de los de la jerarquía o líderes reformistas. Creemos necesario abordar el análisis del Congreso de Música Sagrada desde esta perspectiva pues nos descubre otros ángulos, creemos, interesantes, y nos proporciona una idea de su trascendencia social.

Los eventos citados en las cartas del arzobispo y de su secretario de cámara eran, además del II Congreso Nacional de Música Sagrada, la peregrinación a Roma con motivo de la conmemoración de los cincuenta años de la ordenación sacerdotal de Pío $\mathrm{X}$, y la III Semana Social de España ${ }^{189}$. Junto a estos se incluyeron otros compromisos

Sección Gobierno. Asuntos Despachados, leg. 04907 (1908). Por tanto, sólo faltan las respuestas de los arciprestes de Arcos de la Frontera (Cádiz), y Valverde del Camino (Huelva) para completar el total de arciprestazgos en los que estaba dividida la Archidiócesis en ese momento. La relación de arciprestes y arciprestazgos en: "Estadística general del arzobispado de Sevilla", BOAS, 557 (1909), p. 15.

${ }^{189}$ El "Curso breve de cuestiones sociales" que en 1906 organizó el Centro de Defensa Social de Madrid, con la colaboración del Consejo General de las Corporaciones Católicas de Obreros, fue el origen de las Semanas Sociales de España. Además de la que tuvo lugar en Sevilla en 1908, se celebraron otras cuatro más entre 1907 y 1912: Valencia (1907), Santiago de Compostela (1909), Barcelona (1910) y Pamplona (1912). El objetivo que perseguían era combatir en el terreno social las tesis y acción socialista ofreciendo una alternativa desde la doctrina social católica. Véase: Juan José Castillo, "Modulaciones ideológicas del catolicismo social en España: De los Círculos a los Sindicatos", Revista española de la opinión pública, 45 (1976), pp. 37-75, pp. 61-62. 
generales de la Iglesia española o universal: la II Asamblea de la Buena Prensa que tendría lugar en Zaragoza del 21 al 24 de septiembre, y el Dinero de San Pedro ${ }^{190}$.

Estas grandes manifestaciones que, como hemos señalado en otras ocasiones, eran instrumentos al servicio de una estrategia por parte de la Iglesia de preservación de un espacio de cierta relevancia en la contienda ideológica de principios de siglo, y de influencia en la sociedad a todos los niveles, exigían un importante apoyo en forma de participación y patrocinio económico por parte del conjunto de los católicos. Sin embargo, la grave situación económica y social que muchas de las contestaciones de los arciprestes referían constituía un condicionante ineluctable que limitaba drásticamente las posibilidades de los fieles de soportar los grandes proyectos de la jerarquía.

Los respuestas del colectivo son elocuentes, y recurrentes sus argumentos. Así se expresaba el arcipreste de Morón de la Frontera:

Desearía M. Iltre. Señor [González Merchant] haga presente a Ntro. Excmo. y Rvmo. Prelado, que este Pueblo [sic] está al presente sufriendo una crisis agrícola de suma importancia, pues la recolección de cereales ha ido menos que mediana, y casi nada espera de la recolección de aceituna, que es su mayor riqueza, siendo esta la causa de que no haya correspondido con sus limosnas, como en otras ocasiones. ${ }^{191}$

O el de Sanlúcar la Mayor: "el estado de decadencia de esta población y crisis por la que atraviesa, ahoga el entusiasmo y el deseo que muchos tendrían de secundar los de Ntro. Excmo. Prelado"192. Otros ejemplos son los que nos proporcionan las respuestas provenientes de otros arciprestazgos como los de Écija: "sin duda alguna el número de ellas [personas] sería mucho mayor si la cosecha pendiente de aceitunas, principal fuente de riqueza de estos pueblos, prometiese algo: por desgracia nuestra es completamente nula y la del verano ha dejado bastante que desear"193; Moguer: "Remitiré a V.I. el dinero para San Pedro y Congreso de Música, cuya lista le adjunto sintiendo no corresponda la cantidad a mis deseos por hallarse el pueblo en un estado

\footnotetext{
${ }^{190}$ Recordemos que la I Asamblea de la Buena Prensa se celebró en Sevilla en 1904. El Dinero de San Pedro era una recaudación que debían llevar a cabo los sacerdotes para ayudar al mantenimiento de la Santa Sede.

${ }^{191}$ Carta del arcipreste de Morón de la Frontera, 13 de septiembre de 1908. AGAS. Sección Gobierno. Asuntos Despachados, leg. 04907 (1908).

${ }^{192}$ Carta del arcipreste de Sanlúcar la Mayor, 9 de septiembre. Ibídem.

${ }^{193}$ Carta del teniente de arcipreste de Écija, 4 de septiembre. Ibídem.
} 
precario."194; o Lora del Río: "aun cuando en este tiempo no queda aquí quien tenga una perra chica, no obstante, tengo recogidas 49,43 ptas." ${ }^{\text {195 }}$.

En realidad, los arciprestes no hacían más que testimoniar la grave crisis económica por la que atravesaba toda Andalucía en 1908. Una serie continua de años secos habían tenido consecuencias devastadoras para una economía fuertemente dependiente del sector agrario, en el que predominaban los cultivos de cereales, olivos y viñedos. A causa de una acentuada desindustrialización, las consecuencias de esta coyuntura crítica sobre la economía andaluza fueron aún más graves. Otros sectores como la minería y el comercio experimentaron un franco declive. El sector agrario padecía graves problemas estructurales como la concentración de la propiedad y el latifundio, el uso de técnicas de cultivo tradicionales y la falta de mecanización, los bajos salarios y la abundancia de jornaleros y el paro. El desigual reparto de la riqueza y las grandes diferencias sociales caracterizaban una sociedad fuertemente estratificada $^{196}$.

El arcipreste de Osuna menciona el momento más crítico de esta coyuntura: “[...] será para ello necesario vencer las dificultades materiales que ofrece el estado de postración a que ha venido este Pueblo, especialmente desde el año 1905 en que se perdió totalmente las cosechas y muchos quedaron arruinados"197.

Efectivamente, en 1905 a la terrible sequía que duraba ya dos años se sumó una fuerte ola de calor ${ }^{198}$. Las trágicas consecuencias de este periodo seco son bien conocidas gracias a las crónicas que Azorín publicó en el rotativo madrileño El Imparcial, y posteriormente incorporó a su libro Los pueblos. La Andalucía trágica y

\footnotetext{
${ }^{194}$ Carta del arcipreste de Moguer, 7 de septiembre. Ibídem.

${ }^{195}$ Carta del arcipreste de Lora del Río, 5 de septiembre. Ibídem.

${ }^{196}$ Juan Antonio Lacomba distingue tres grandes clases o estratos sociales: "en la cúspide, una reducida élite de nobles y grandes terratenientes, que configuran la oligarquía, preocupada por mantener su dominación económica y política y su liderazgo social; b) un segundo grupo formado por las clases medias, no amplias, pero sí diversificadas, en las que se integran los propietarios medianos, empleados, funcionarios, profesionales y pequeños comerciantes, entre otros; c) por último, una extensa base, la inmensa mayoría, con las clases trabajadoras, entre las que predomina de manera absoluta el campesinado de jornaleros, que tratan de superar las duras condiciones de su existencia." Juan A. Lacomba, Historia contemporánea de Andalucía (Córdoba: Almuzara, 2006), p. 124.
}

${ }^{197}$ Carta del arcipreste de Osuna, 14 de julio. AGAS. Sección Gobierno. Asuntos Despachados, leg. 04907 (1908).

\footnotetext{
${ }^{198}$ Según Nicolás Salas, los termómetros rondaron los cuarenta grados durante la primavera, alcanzando en el mes de agosto los cincuenta. Nicolás Salas, Sevilla: Crónicas del siglo XX. Tomo I: 1895-1920 (Sevilla: Universidad de Sevilla, 1991), p. 107.
} 
otros artículos ${ }^{199}$. El siguiente fragmento ha sido citado en más de un trabajo sobre la Sevilla de inicios del s. XX dado, suponemos, el poder de las imágenes de que se sirve para describir aquella realidad:

Más de cien mil obreros, repartidos por toda Andalucía, careciendo de trabajo y hambrientos, ven la necesidad retratada en el rostro de los individuos de su familia, la miseria imperando en sus hogares, y para no perecer salen al campo, arrancan patatas, arrebatan el pan que se lleva a los cortijos, comen higos chumbos sin madurar, desentierran raíces y atiborran el estómago con algarrobas silvestres que sólo las bestias comen... Pero se acaban las patatas, se agotan las raíces y los frutos silvestres...Los hombres caen desfallecidos en las calles, las madres piden con voz desesperada pan para sus hijos, las personas pudientes huyen de los pueblos, los municipios concluyen con sus recursos, y los pobres, después de vender hasta el humilde lecho, y de reclamar en balde trabajo o socorro, danse cuenta de que tienen derecho a la vida... ${ }^{200}$

La situación en la capital no era mucho mejor, pues compartía en gran medida con las zonas rurales los mismos déficits económicos estructurales, como eran la escasa industrialización y la fuerte dependencia del campo, lugar de trabajo de gran parte de sus habitantes. Muchos de ellos provenían precisamente del medio rural desde donde habían emigrado en busca de unas mejores condiciones de vida. Las circunstancias reunían, desde hacía tiempo, todas las condiciones como escenario propicio a la conflictividad social $^{201}$. Esta realidad empujó al mismo Spínola a salir a las calles de

\footnotetext{
199 Azorín, "La Andalucía Trágica. En Sevilla”, El Imparcial, 13656 de 3 de abril (1905), p. 1; Azorín, "La Andalucía Trágica. En Lebrija”, El Imparcial, 13658 de 5 de abril (1905), p. 1; Azorín, "La Andalucía Trágica. Los obreros de Lebrija", El Imparcial, 13660 de7 de abril (1905), p. 1; Azorín, "La Andalucía Trágica. Los sostenes de la patria”, El Imparcial, 13670 de 17 de abril (1905), p. 3; Azorín, "La Andalucía Trágica. Arcos y su filósofo", El Imparcial, 13676 de 24 de abril (1905), p. 1. $<$ http://hemerotecadigital.bne.es/results.vm? $\mathrm{a}=189234 \& \mathrm{~d}=$ creation \&d=1905\&d=04\&d=03\&d=1905\&d= $04 \& \mathrm{~d}=24 \& \mathrm{t}=\% 2 \mathrm{~B}$ creation $\& \mathrm{l}=600 \& \mathrm{l}=700 \& \mathrm{~s}=0 \& \mathrm{y}=1905 \&$ lang=es. $>$ (consultado $20-05-2013)$.
}

${ }^{200}$ José M $M^{\mathrm{a}}$ Javierre, “La diócesis de Sevilla”, pp. 365-366. Este mismo texto es citado por Nicolás Salas en Sevilla: Crónicas, pp. 107-108.

${ }^{201}$ Azorín relata así el ambiente del casino de Lebrija al sur de la capital hispalense: "Y no hay nadie en este Casino; son las dos de la tarde. - Juan, ¿no viene nadie a este Casino?-pregunto yo.-No, señó, no viene nadie-contesta Juan, tristemente.-Pero ¿y los socios? ¿Y los señores del pueblo?-digo yo.-Los señores, no viene ninguno-dice él con el mismo aire melancólico.

Los señores no salen de sus casas: no ponen sus plantas en la calle. 'Hace pocos días -me decía en Sevilla un prestigioso periodista-, hace pocos días tuve que ir a un pueblo de la provincia a ver a un amigo, y me aseguró que hacía dos meses que no salía a la calle.' La muchedumbre campesina no es mala; tiene, sencillamente, hambre. La sequía asoladora que reina ha destruido los sembrados; las viñas están devastadas por la filoxera [parásito que ataca a los viñedos]. ¿Cómo van a salir del tremendo conflicto que se avecina propietarios y labriegos?". Azorín, "La Andalucía Trágica. En Lebrija”, p. 1. 
Sevilla pidiendo limosna, granjeándose el apelativo de "Arzobispo mendigo". Con este gesto consiguió atraer la atención no sólo de otras ciudades españolas sino también extranjeras. Javierre cita ayudas procedentes de París, Viena, Londres, Bruselas, Nueva York, Filadelfia, Chicago o La Habana ${ }^{202}$.

No en vano, la III Semana Social, que dio comienzo justo el mismo día en el que se clausuró el Congreso de Música Sagrada, tuvo precisamente como ejes principales de discusión los asuntos relacionados con la cuestión agraria. El programa general fue publicado en ECA el 28 de octubre de 1908 e incluía una serie de conferencias sobre el problema de la propiedad de la tierra en Andalucía, y sobre el socialismo agrario. El despliegue de recursos materiales y humanos, y el esfuerzo organizativo y de coordinación que tuvo que hacer la administración eclesiástica en estos días debió ser importante. Durante esa semana se simultanearon los últimos preparativos de la Semana Social con la celebración del Congreso de Música Sagrada. La sesión de clausura de este último, que dio comienzo a las doce de la mañana, y la de inauguración de aquella, prevista para las seis de la tarde, coincidieron el mismo día y en la misma sede, la iglesia del Salvador. Las separaron apenas cinco horas de diferencia ${ }^{203}$.

A pesar de esta complicada, a veces dramática, situación, los arciprestes y curas rurales de la Archidiócesis manifestaban en sus cartas su compromiso por corresponder a las demandas del prelado, en una exhibición de voluntarismo recompensado, según relatan, sólo ínfimamente y a fuerza de obcecación. El arcipreste de El Puerto de Santa María señalaba: "respecto a los trabajos del congreso de Música Sagrada, aunque poco se puede conseguir en estos pueblos, no decaeré en mis deseos de

\footnotetext{
202 Javierre, "La diócesis de Sevilla", p. 366. En 1958, ABC publicó un artículo titulado Don Marcelo, el obispo que sonríe, en el que se recrea la estampa: "Iba destocado; sobre sus hombros llevaba la capa morada de lanilla; el sol lo abrasaba; el sudor bañaba su rostro, lívido, sofocado por el calor; en los labios su inefable sonrisa; su caminar era lento; andaba por las calles céntricas y por los barrios bajos; entraba en los palacios y bajaba a los tugurios; visitaba casinos y entraba en las tabernas. En todas partes tendía su mano esquelética pidiendo para los pobres hambrientos, y en todas partes ni uno solo le negó el consuelo que pedía." Santiago Montoto, "Don Marcelo, el obispo que sonríe", $A B C$ de 7 octubre (1958); cit. en Nicolás Salas, Sevilla: Crónicas, pp. 108-109.

${ }^{203}$ Las conferencias sobre la propiedad de la tierra en Andalucía fueron dictadas los días 18, 19 y 20 de noviembre por José Monge y Bernal: 1. "La propiedad territorial de Andalucía. Hechos"; 2. "La propiedad territorial de Andalucía. Doctrinas"; 3. "La propiedad territorial de Andalucía. Consecuencias y aplicaciones". Las que llevaban por título "Los fundamentos de propiedad de la tierra y el socialismo agrario" los días 19, 20 y 21. Su autor fue el diputado Juan Vázquez de Melia. ECA, 3330 de 28 de octubre (1908), p. 2.
} 
lograr un feliz resultado" ${ }^{204}$. El arcipreste de Marchena nos relata sus peripecias en la empresa de conseguir peregrinos para Lourdes y Roma, recurriendo incluso a la influencia del obispo de Madrid, con quien le debió unir un vínculo que desconocemos:

Comencé a trabajar para ver lo que podía conseguir sobre la peregrinación a Roma y Lourdes: todos los trabajos eran infructuosos en esta y en los pueblos del distrito, alegaban la falta de dinero y era una razón, que convencía; en vista de la poca disposición por parte de los fieles; deseando complacer a V. E. en la parte que me correspondiera, manifesté a los que pudieran ir que yo estaba decidido a hacer la peregrinación a Roma; siendo el que en peores condiciones se encontraba; esto movió un poco los ánimos; pero no se decidían y poco a poco iban respirando manifestando algún deseo de ir a la peregrinación [de] Lourdes y a fuerza de trabajo conseguí que dos Señoras se decidieran para Roma; me entregaron el primer plazo lo mandé al Presidente y aquel día salí para Sanlúcar. A mi regreso me encuentro con la sorpresa de que habían desistido de ir a Roma y sólo querían ir a Lourdes: nuevos trabajos y gracias a la intervención del Excmo. Señor Obispo de Madrid, se ha conseguido ayer que vayan las dos Señoras a Roma. ${ }^{205}$

En el arciprestazgo de Jerez, los párrocos organizaron, previa autorización arzobispal, una cuestación de vinos para el Dinero de San Pedro con resultados bastante positivos. Lo recaudado ascendió a "más de mil duros"206. Alguna otra aportación sorprende frente a la tónica general: el importe total de las inscripciones para las peregrinaciones de Lourdes y Roma que desde el arciprestazgo malagueño de Campillos se remitió a Sevilla fue de 4.050 ptas. $^{207}$ En su comunicación, el arcipreste de Osuna cita también alguna excepción dentro del contexto general de pobreza y postración que sufría todo el valle del Guadalquivir: "Algunos pueblos hay aquí en los que poco o nada podrá hacerse por ser pobrísimos y estar los Curas completamente solos; pero no así otros como el Saucejo y el Rubio, que cuentan con más recursos”208.

La dramática situación económica por un lado, y la necesidad de la Iglesia de afrontar los compromisos que adquiría, representaron dos extremos de una misma

\footnotetext{
${ }^{204}$ Carta del arcipreste del Puerto de Santa María, 15 de septiembre. AGAS. Sección Gobierno. Asuntos Despachados, leg. 04907 (1908).

${ }^{205}$ Carta del arcipreste de Marchena, 7 de septiembre. Ibídem.

${ }^{206}$ Carta del arcipreste de Jerez de la Frontera [canónigo, además, de la colegiata], 21 de julio. Ibídem.

${ }^{207}$ Carta del arcipreste de Campillos, 6 de septiembre. Ibídem.

${ }^{208}$ Carta del arcipreste de Osuna, 14 de julio. Ibídem.
} 
realidad inevitablemente en tensión. Los fieles acusaban la presión de las continuas demandas por parte de la jerarquía, que debieron sentir como excesiva, en vista de las circunstancias por las que atravesaban. En este contexto la misión encomendada a los curas diocesanos era complicada ante sus feligreses. El arcipreste de Huelva llegaría a confesar "me falta valor para pedir más"209. La carta del arcipreste de Sanlúcar de Barrameda es otro valioso testimonio:

[...] tengo el disgusto de manifestarle que a pesar de los trabajos realizados en pro de las obras recomendadas, nada se ha podido alcanzar.

[...] A más en esta época las personas que pueden contribuir con algo dan y se les compromete [...]; tanto que he oído a muchas de lo mucho y de la frecuencia con que se les pide: esto como V. I. comprenderá no puede menos de coartarme algún tanto en la propaganda, sin olvidar tampoco que otras se comprometieron ya con mi antecesor suscribiendo una cuota mensual para la fundación del Sindicato.

En términos parecidos me dan cuenta de su gestión los Párrocos de Trebujena, donde no se ha hecho ni se podrá hacer nada en este sentido; y de Chipiona para establecimiento de unas escuelas dirigidas por los religiosos de Regla y la fundación de las Conferencias de S. Vicente, quedan en expresión del Párroco, agotadas las fuentes. ${ }^{210}$

En la línea de la anterior carta, el arcipreste de Huelva trataba de valorar los resultados en su justa medida, es decir, poniéndolos en relación con las posibilidades reales a tenor de las circunstancias:

[...] los resultados hasta ahora obtenidos, bien exiguos en comparación de su grandioso objeto, pero no tanto si se miran las circunstancias de Huelva con respecto a nuestra Santa Fe y que a pesar de las mismas sostiene aquella con sus limosnas obras católicas recientemente creadas que representan unas 1.500 ptas. mensuales. ${ }^{211}$

Aunque no lo podemos afirmar con certeza, es posible que la alusión del cura onubense a las particulares circunstancias que la Iglesia -"nuestra Santa Fe"- vivía en

\footnotetext{
${ }^{209}$ Carta del arcipreste de Huelva, 6 de septiembre de 1908. Ibídem.

${ }^{210}$ Carta del arcipreste de Sanlúcar de Barrameda, 7 de septiembre de 1908. AGAS. Sección Gobierno. Asuntos Despachados, leg. 04907 (1908).

${ }^{211}$ Carta del arcipreste de Huelva, 6 de septiembre de 1908. Ibídem.
} 
Huelva tenga que ver con la crisis que el catolicismo sufría en ese territorio, provocada por la fuerza que en algunas comarcas había adquirido el credo protestante importado por los oficiales de las compañías mineras inglesas asentadas en el occidente andaluz ${ }^{212}$.

Además de las grandes reuniones eclesiales españolas con cuya organización se había comprometido el arzobispo, y por ende, el conjunto de la Archidiócesis, existían otros proyectos que sostener, especialmente aquellos de naturaleza social promovidos por otros colectivos católicos que reclamaban igualmente la colaboración de los fieles, sumando así más carga sobre sus agendas y bolsillos. La respuesta del arcipreste de Sanlúcar de Barrameda, transcrita en parte más arriba, daba cuenta de algunos de ellos: escuelas y sindicatos católicos de obreros, o las actividades en el ámbito caritativo y asistencial de las Conferencias de San Vicente de Paúl ${ }^{213}$. A todo ello había que sumar, además, las iniciativas asociadas con la devoción y religiosidad popular, tan enraizadas en la sociedad y cultura andaluza. El arcipreste de Ayamonte, tras apelar como todos, al “mal año que sus pueblos atravesaban", escribía con respecto a la cantidad colectada para el dinero de San Pedro: "pequeña cantidad pero de consideración por los muchos sacrificios que estamos haciendo para pagar un paso de catorce mil reales para la Patrona que estrenará el ocho del corriente, con otros gastos de no poca consideración"214.

Junto a las deficiencias estructurales del sistema económico andaluz y la profunda crisis que se padecía en esos años, existían otros problemas endémicos que tenían que ver con la consideración social de la música y los músicos. Como se desprende de los testimonios anteriores, en un entorno en el que la música no despertaba gran interés, la labor de concienciar sobre la importancia del Congreso y de motivar a la participación en él debió ser ardua. Frente a los acuciantes problemas sociales y

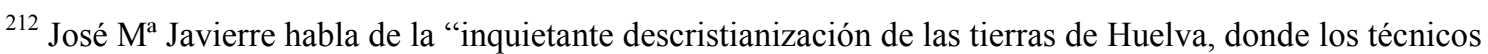
ingleses de las minas de Río Tinto protegían la difusión del protestantismo". Javierre, "La diócesis de Sevilla", p. 365.

${ }^{213}$ Como es sabido, la doctrina social del catolicismo contemporánea tiene su fundamento en la encíclica Rerum Novarum, que incluía, entre otros muchos aspectos, el sindicalismo católico. Sobre la recepción de la encíclica de León XIII en España véase: Feliciano Montero, El primer catolicismo social y la Rerum Novarum en España: 1889-1902 (Madrid: CSIC, 1983). Feliciano Montero se refiere a la "globalidad del Movimiento católico: acción propagandística, obras escolares, obras benéfico-sociales, acción política". "El Movimiento católico en España: la respuesta de la provincia eclesiástica de Valladolid a la encuesta Vico (1908)", Espacio, Tiempo y Forma, 5 (1992), p. 343.

214 Carta del arcipreste de Ayamonte, 6 de septiembre. AGAS. Sección Gobierno. Asuntos Despachados, leg. 04907 (1908).
} 
económicos, es lógico pensar que el prestar atención a la música religiosa y emplear recursos en discusiones sobre el asunto se sentiría como una frivolidad.

Federico Roldán, secretario de la Junta Organizadora del Congreso, escribió un artículo en el que hacía frente a estos esquemas de pensamiento defendiendo el valor de la música religiosa desde un punto de vista católico-social. Roldán desarrolló un discurso dirigido a justificar la celebración del Congreso por los beneficiosos efectos que la música ejercía sobre el espíritu cristiano, por tanto, sobre su capacidad de transformar la realidad. El artículo se tituló ¿Un congreso de música? El escepticismo de "muchos católicos y tal vez no pocos sacerdotes" que dudaban sobre la conveniencia de celebrar un congreso sobre una disciplina banal como la música, en vista de las adversas circunstancias, era expresado ya desde el título con el uso de los signos de interrogación ${ }^{215}$. En el texto, que ya transcribimos en el capítulo primero, utilizó potentes metáforas para expresar la irresponsabilidad que, según aquellos "muchos católicos y no pocos sacerdotes", constituía "dedicarse [...] a ordenar papeles de Música" en un momento en el que el catolicismo estaba llamado "al combate"216.

Sin embargo, según afirmó, "el Congreso de Música no deja de tener en los presentes momentos la mayor importancia católico-social"217. La idea fundamental de su razonamiento, que rezuma una suerte de neoplatonismo inspirado en San Agustín era el poder que poseía la música para animar el espíritu cristiano. De ahí que exista una "[...] intima correspondencia entre el estado de fervor o tibieza del espíritu cristiano y el florecimiento o decadencia del arte religioso-musical." ${ }^{218}$; correspondencia que trató de demostrar históricamente.

El espíritu cristiano se nos presenta en el artículo como un concepto polivalente: alma del fiel, grado de vitalidad y vigor de la esencia cristiana en la Iglesia como institución social, o capacidad de empuje e influencia en el conjunto de la sociedad. En aquel momento sufría una grave atonía, causada por el modelo litúrgicomusical vigente. Además de ser absolutamente ineficaz, constituía un obstáculo para la circulación y recepción de la gracia de Dios, según Roldán, por su ampulosidad, teatralidad y por el papel pasivo reservado a la asamblea:

\footnotetext{
${ }^{215}$ Crónica del Segundo Congreso, p. 42.

${ }^{216}$ Ibídem. Hemos transcrito el fragmento íntegro en pp. 77-78.

${ }^{217}$ Ibídem.

${ }^{218}$ Ibídem, p. 43.
} 
¿de dónde proviene esa frialdad y apatía que se ha apoderado de los católicos, asemejándolos a inanimadas estatuas, sin movimiento, vida ni calor? ¿De dónde esa casi absoluta ineficacia de las magníficas funciones de nuestros templos, en que tanto dinero y actividad se derrocha, sin ningún fruto de los que a ellas asisten? ¡Ah! Es que el pueblo cristiano se ha reducido hoy a mero espectador en nuestras iglesias; es que el culto en nuestros templos se ha convertido en funciones casi teatrales, más o menos a lo divino; y de esa manera no es posible percibir la gracia que Dios ha vinculado a la participación en los oficios del culto. ${ }^{219}$

Roldán se situaba con estas ideas lejos del pensamiento que hemos encontrado en otros miembros ilustres del clero hispalense, quienes asociaban estas propiedades al concepto de solemnidad litúrgica, y no al de decadencia. La alternativa propuesta por Roldán se compendia en la siguiente apelación con los consiguientes frutos:

Haced que el pueblo tome parte activa; haced que intercale su voz con la del sacerdote, [...] y veréis cómo ese pueblo, que sin darse cuenta se habrá ido aficionando al culto público del Señor, se convertirá bien pronto de cristiano durmiente en cristiano militante, práctico, celoso de la gloria de Dios, y de una misa sencilla, sin ruidos ni estruendo de orquestas, saldrá dispuesto a defender, si fuere preciso con su sangre, la causa de Jesucristo. ${ }^{20}$

De esta forma, Roldán establecía una relación directa entre la música sacra y la militancia cristiana, haciendo depender la fuerza de esta militancia de la efectividad de aquella. La reforma de la música litúrgica "había de ser un medio eficacísimo para el resurgir cristiano”, según la doctrina del Pío X. Así, según Roldán, la “importancia [del congreso de Sevilla] en el movimiento católico-social de los presentes tiempos, queda a todas luces justificada". 221

\subsubsection{La situación económica de los músicos eclesiásticos}

La situación de los músicos eclesiásticos era igualmente difícil y merece un análisis detenido. Las dificultades que encontraron para asistir a los congresos nacionales de música sagrada, aún siendo estos por su propia naturaleza y fines las convenciones por antonomasia de estos profesionales de la música litúrgica constituye,

\footnotetext{
${ }^{219}$ Ibídem, pp. 43-44.

${ }^{220}$ Ibídem, p. 44.

${ }^{221}$ Ibídem.
} 
a nuestro modo de ver, la principal paradoja de estos encuentros. En el caso de los músicos al servicio de las catedrales, sólo la cuota de inscripción como socio activo suponía cerca del diez por ciento del sueldo mensual neto que, según el Concordato, le correspondía a un beneficiado catedralicio en España ${ }^{222}$. A ello habría que sumar el resto de gastos, incluidos los del viaje y estancia los días que durara el evento. Anteriormente recogíamos la reacción que la intervención del maestro de capilla de la catedral de Murcia había desencadenado en algunos congresistas, así como las propuestas de algún ex-maestro de capilla, o las juntas organizadoras de Valladolid y Sevilla instando a prelados y cabildos a que respaldaran económicamente a los músicos catedralicios que asistieran a los congresos ${ }^{223}$.

La precaria situación económica y laboral de los músicos que ejercían su profesión en templos de inferior categoría y parroquias hacía absolutamente imposible su participación ${ }^{224}$. Los datos que ofrecemos a continuación demuestran que sólo la cuota de diez pesetas estaba absolutamente fuera su alcance.

El arcipreste de Sanlúcar de Barrameda afirmaba en otro pasaje de su carta: "no cuento con personal entre los músicos de esta, que esté en disposición para exigirles nada puesto que son muy pobres" 225 . Recordemos que en este mismo sentido se expresaba el obispo de Salamanca en su contestación al hispalense: “con gusto haré cuanto pueda en el asunto del Congreso Musical [...], aunque con pocas esperanzas de éxito, pues los músicos a quienes hablé, después de tentarse el bolsillo, ponen un gesto

\footnotetext{
${ }^{222}$ Según el artículo 32 del Concordato el sueldo de los beneficiados catedralicios era de seis mil reales, es decir, mil quinientas pesetas. A esta cantidad hay que deducir la contribución de los eclesiásticos al Estado que se cifraba en el $14 \%$. El sueldo neto mensual resultaba, por tanto, de 107,5 ptas. La cuota de inscripción como socio activo era de diez pesetas, lo que significaba en torno al 9,3\% de dicho sueldo. Las condiciones de los beneficiados de catedrales metropolitanas eran algo más ventajosas. Su sueldo bruto era de dos mil pesetas anuales. A principios de siglo ostentaban la condición de sedes metropolitanas las catedrales de Toledo, Sevilla, Valencia, Granada, Santiago de Compostela, Burgos, Tarragona, Valladolid y Zaragoza. Véase: Carlos Ramón Port, El Concordato de 1851 comentado y seguido de un Resumen de las disposiciones seguidas por el Gobierno de S. M. sobre materias eclesiásticas, desde la celebración de aquel convenio hasta enero de 1853 (Madrid: Imp. Don Eusebio Aguado, 1853). Una valoración de las repercusiones del Concordato en la música eclesiástica en: Casares, "La música en el siglo XIX español. Conceptos fundamentales", pp. 53-54.

${ }^{223}$ Véase el epígrafe 3.2.1. "La respuesta del episcopado español a los requerimientos del Congreso" de este mismo capítulo, p. 383.

${ }^{224}$ En el Concordato no figura regularizado el sueldo de sacristanes, organistas, sochantres o similares al servicio de las parroquias.

${ }^{225}$ Carta del arcipreste de Sanlúcar de Barrameda, 7 de septiembre de 1908. AGAS. Sección Gobierno. Asuntos Despachados, leg. 04907 (1908).
} 
tan difícil..."226. En nuestras indagaciones en el AGAS conseguimos hallar una petición del organista de las parroquias unidas de San Julián y Santa Lucía de la capital hispalense que refleja las circunstancias de estos músicos en la archidiócesis de Sevilla:

Excmo. y Rmo. Señor Arzobispo de Sevilla

Don Juan María Rodríguez y Rodríguez, organista de las Iglesias Parroquiales unidas de San Julián y Santa Lucia de esta Ciudad, a S. E. Rma., con el debido respeto, expone: Que viene desempeñando el cargo de tal organista desde primero de julio de mil ochocientos sesenta y tres, habiéndosele expedido, el siete de Marzo de mil ochocientos setenta y siete, el nombramiento en propiedad con el haber que a dichas plazas correspondiera, que es el de sesenta y dos reales y medio o sean quince pesetas sesenta y dos y medio céntimos en cada un mes, asignación que desde el mes de Agosto inclusive del mismo año de mil ochocientos setenta y siete, en que se dispuso se le abonase íntegra, ha venido cobrando hasta Octubre inclusive de mil ochocientos noventa y tres; mas desde el mes de Noviembre siguiente, también inclusive, o sea de once años, y algo más, a la fecha, viene percibiendo solo catorce pesetas treinta y siete céntimos, o sea una peseta veinte y cinco y medio céntimos de menos, por el descuento del ocho por ciento que se le hace, como a algunos otros ministros de su clase en otras iglesias, aunque no en todas, en virtud de orden que se dice general $=$

Que como dichas Parroquias son muy pobres, y por lo tanto de pocas entradas, no teniendo otra el Organista que los bautizos de Capa y Órgano; pues por la carencia de recursos de sus feligreses hay muchos de estola y hasta de caridad $=$

Suplica, rendidamente, a S E Rma. se digne quitarle ese descuento, $[\ldots]^{227}$

El informe adjunto que a petición del arzobispado emitió el párroco informa

sobre la problemática que impedía tan siquiera paliar su situación:

En cumplimiento a lo mandado anteriormente el Infrascrito Cura informa: Dice son ciertos cuantos antecedentes se exponen en la solicitud que antecede y que es también cierto que es cortísima la paga del solicitante, pero que no es menos cierto que fue disposición general la rebaja del $8 \%$ a los Ministros a todos los ministros de todas las Parroquias (excepto a los de aquellas que por ser más ricas de [lo] convencional, no se les hizo tal descuento y que si pobre es la paga de los Ministros de esta Parroquia; más pobre relativamente es la paga de

\footnotetext{
${ }^{226}$ Carta del obispo de Salamanca, 25 de junio. Ibídem.

${ }^{227}$ AGAS. Sección Gobierno. Asuntos Despachados, leg. 04901 (1905).
} 
dicha Parroquia que, ni aún para lo más indispensable tiene, pues la paga de los dichos Ministros es en relación a la de la Parroquia. ${ }^{228}$

Efectivamente, el salario diario de este organista no llegaba a cuarenta y ocho céntimos. La puesta en relación de estas cantidades con algunos marcadores económicos de la época permite hacernos una idea más cercana de su valor relativo. Según Cuenca Toribio, el salario medio durante el reinado de Alfonso XIII (1902-1931) era de tres pesetas, teniendo en cuenta que las posibilidades de trabajo no superaban la mitad del total del año ${ }^{229}$. En 1905, el Instituto de Reformas Sociales fijó como media salarial una peseta y media en Andalucía y Extremadura, mientras que en los campos sevillanos era de setenta y cinco céntimos incluyendo la comida. En temporada de cosechas ascendía a dos pesetas y media, oscilando entre cincuenta céntimos y 1,40 ptas. el resto del año, cuando había faena ${ }^{230}$. El precio medio en 1908 de un litro de aceite era de 1,65 ptas., y de leche setenta céntimos. El kilo de verduras, patatas, garbanzos y arroz treinta, veinte, ciento veinte y setenta y cinco céntimos respectivamente. El de carne de vacuno 2,60 ptas. El pan costaba cuarenta céntimos, mientras que la arroba de vino costaba unas cinco pesetas ${ }^{231}$. A tenor de estos datos, en 1908 un litro de leche equivalía a casi el salario de dos días de trabajo en el caso del organista de San Julián y Santa Lucía.

Como atestigua el propio Otaño, quien describió la cruda situación de los músicos eclesiásticos de la mitad sur peninsular en la memoria que presentó al congreso de Sevilla, la remuneración económica que recibían estos músicos era absolutamente insuficiente para la supervivencia. Ello obligaba a un pluriempleo igualmente precario:

Poblaciones de bastante importancia conozco $-\mathrm{y}$ de ello pueden dar fe Andalucía y las Castillas- en que el sueldo de estos cargos [cantor u organista parroquial] no excede de 30 o 35 céntimos diarios y así a nadie causará admiración ver, como en alguna parte se ha visto al organista, convertido después de los divinos oficios en

\footnotetext{
${ }^{228}$ Ibídem.

${ }^{229}$ José Manuel. Cuenca Toribio, Historia general de Andalucía, (Córdoba: Almuzara, 2005), p. 819.

${ }^{230}$ Cit. en Manuel Tuñón de Lara, El movimiento obrero en la Historia de España, (Madrid: Taurus, 1972); cit. a su vez en Salas, Sevilla: Crónica, p. 106.

${ }^{231}$ Ramón Tamames, Introducción a la economía española, (Madrid: Alianza ed., 1971), p. 36. Tuñón de Lara, El movimiento obrero, pp. 392-395; cit. en Salas, Sevilla: Crónica, pp. 109-110. Otro dato importante a tener en cuenta es el encarecimiento de todos estos productos desde 1900 debido a la creciente inflación. La leche subió un $40 \%$, el aceite un $35 \%$, un $30 \%$ las verduras y la carne de vaca.
} 
vendedor de periódicos, en órgano directo de la propaganda del trust periodístico! Bastantes capitales de provincia tienen parroquias donde los organistas-cantores no pueden con todo su ingenio amontonar para su subsistencia los cien céntimos que tiene una peseta. ${ }^{232}$

Ante estos datos no es difícil encontrar una respuesta al interrogante sobre qué lugar debieron ocupar en su orden de prioridades la especulación estética o litúrgica, o los debates sobre los criterios de interpretación del gregoriano, o incluso las discusiones sobre cuestiones puramente prácticas. La nula capacidad económica así como la urgencia de la subsistencia explican sobradamente su ausencia e indiferencia. A estas hay que sumar la marginalidad a la que en los congresos fue condenada la discusión sobre sus condiciones laborales, y en consecuencia sobre sus intereses que, como tratarán de poner de relieve años después dos ponentes andaluces en el IV Congreso Nacional de Música Sagrada (Vitoria, 1928), eran los de la propia reforma y la música religiosa.

En realidad, el problema que constituía la situación económica y social de los músicos que servían en los templos se denunció y abordó en los distintos congresos de música sagrada desde el primero de Valladolid. Sin embargo, si repasamos las conclusiones acordadas en ellos, podemos advertir que la preocupación de los asistentes $\mathrm{y}$, en consecuencia, las medidas que se proponían para resolver el problema se centraron en los músicos catedralicios. Los músicos de templos de inferior categoría y parroquias eran citados sólo en las conclusiones que tenían que ver con la formación musical o con la necesidad de competencia y exigencia de un cierto nivel para poder desempeñar estos oficios. Los temas de los puntos tercero y cuarto del congreso de Valladolid, por ejemplo, eran respectivamente "qué [se debe exigir] de los organistas y cantores parroquiales", y "qué [se debe exigir] de los organistas y cantores de comunidades de religiosas" $" 233$. En las conclusiones de ambos puntos se prescribió la condición de aprobar un examen para poder ocupar esas plazas. En el caso de los organistas y cantores parroquiales la superación de esa prueba no daba derecho a la posesión de la plaza de forma definitiva, sino que tenían que someterse aún a exámenes periódicos para conservarla:

\footnotetext{
${ }^{232}$ Crónica del Segundo Congreso, p. 250.

${ }^{233}$ Crónica del Primer Congreso, pp. 12-13.
} 
Punto $3^{\circ}$.- ¿Qué de los organistas y cantores parroquiales?

El Congreso acuerda, que estos cargos se provean mediante un examen de suficiencia al tenor de un programa convenientemente estudiado y ante un tribunal nombrado por el Reverendísimo Diocesano. Debían establecerse exámenes periódicos al finalizar el tiempo para el que hayan sido confirmados en el ejercicio de sus funciones. ${ }^{234}$

Ninguna referencia se hizo a sus necesidades ni a su situación laboral. Cuando el sentido del debate y de las conclusiones giró del plano de las exigencias y endurecimiento de los requisitos para ejercer el trabajo de músico eclesiástico al de las reclamaciones, los músicos no catedralicios desaparecieron de escena, a pesar de tratarse de un punto dedicado en exclusiva a ellos:

[Punto $3^{\circ}$.- ¿Qué de los organistas y cantores parroquiales?]

Como algunos Sres. Congresistas hicieran observaciones referentes a la situación de los maestros de las Catedrales, sobre este particular se adoptaron las conclusiones siguientes:

El Congreso hace votos porque se dé a los maestros de capilla la autoridad y prestigio conveniente a su cargo, mejorando en cuanto sea posible la situación económica de este beneficio tan mal atendido, dadas las condiciones que tal cargo requiere.

Así mismo, hace votos por que en las Catedrales sufragáneas que no tengan este cargo independiente de otro, organista o cantor, se procure anejar dicho cargo de maestro de capilla, sin otro oficio, a alguno de los beneficios que con arreglo a las disposiciones vigentes deben proveerse por oposición.

El Congreso suplica a los Reverendísimos Prelados interpongan todo el poderoso influjo de su reconocido celo, para conseguir la derogación de la Real Orden que impide se provean beneficios con cargos músicos, además de los señalados por oficio. ${ }^{235}$

En contraste con las conclusiones dedicadas a los músicos parroquiales, en las que las preocupaciones se centraban en asegurar la profesionalidad y capacidad de este colectivo sin atención alguna a sus condiciones de vida (exigencias), las dedicadas a los catedralicios -expuestas, como decimos, dentro de un apartado dedicado a los parroquiales- iban encaminadas a conseguir una mejora de su situación laboral y prestigio (reivindicaciones).

\footnotetext{
${ }^{234}$ Ibídem, p. 12.

${ }^{235}$ Ibídem.
} 
La historiografía musical ha mostrado hasta el momento poco interés por todo lo referente a la música religiosa y sus circunstancias en templos menores como parroquias, por lo que esta problemática está ausente de los estudios dedicados a los congresos o al MP. Se trata de un ámbito de estudio necesario de abordar para completar nuestra visión de la historia de la música, en este caso, en el ámbito religioso $^{236}$.

El discurso que Federico Olmeda pronunció en la segunda sesión solemne del congreso de Valladolid versó sobre La música sagrada en las parroquias. Podemos conocer su contenido gracias a la síntesis que publicó $M S H$. El maestro de capilla de la catedral de Burgos empezó subrayando la importancia de la música sacra también en la vida de los fieles pertenecientes a parroquias de pueblos, para luego denunciar el "deplorable estado" en que se hallaba. Las causas que explicaban esta situación, según su opinión, eran de origen económico, además de la libertad de que disfrutaban organistas-cantores para elegir "a su capricho" el repertorio. Las soluciones que aportó fueron, en primer lugar, unificar el repertorio de las parroquias, aunque no especificó quién establecería el criterio para su selección; y, en segundo lugar, dejar en manos de los curas que fueran saliendo del Seminario "ya instruidos", la fundación de coros formados por niños y jóvenes en formación o pertenecientes a congregaciones piadosas $^{237}$. Ninguna mención a los problemas de los organistas cantores de pueblo a los que reprochaba implícitamente su falta de juicio en la formación del repertorio, ni a los de otros músicos al servicio de parroquias más importantes ${ }^{238}$.

${ }^{236}$ Un reciente estado de la cuestión sobre los estudios dedicados a la música en parroquias en España en: Victoriano J. Pérez Mancilla, "Historiografía musical de las parroquias en España: estado de la cuestión", Anuario Musical, 68 (2013), pp. 47-80; disponible en: $<$ http://anuariomusical.revistas.csic.es/index.php/anuariomusical/article/view/148/149> (consultado 18-42014). En relación al MP que tratamos: Frederic Oriola Velló, "Los coros parroquiales y el motu proprio de Pío X: la diócesis de Valencia (1903-1936)”, Nassarre, XXV/1 (2009), pp. 89-108.

${ }^{237}$ Las memorias que presentó Ripollés sobre la formación de Scholae cantorum en parroquias en el congreso de Sevilla son especialmente interesante. Véase: Crónica del Segundo Congreso, pp. 230-234.

238 "Empieza [Olmeda] haciendo notar la importancia del tema porque se debe procurar que no sólo en las grandes poblaciones, sino en las más humildes aldeas influya la música sobre los fieles de los pueblos, donde se adora también a Dios.

Habla del deplorable estado en que se halla la música sagrada en los pueblos, atribuyéndolo a la falta de recursos que hace apenas haya para tener la lámpara al Santísimo, a la libertad que tienen los cantores organistas para elegir a su capricho el repertorio y al elevado precio de las obras musicales.

La base para la restauración y el fin a que se debe tender es que se forme un repertorio igual para todas las parroquias y procurar elementos de ejecución musical. Estos últimos se puede contar existirán, puesto que los sacerdotes que vayan saliendo de los Seminarios estarán ya instruidos y podrán dirigir, y los niños de la doctrina, jóvenes de las Congregaciones piadosas y otras personas del pueblo podrán formar los coros. [...]”. "Crónica del Congreso. 26, 27 y 28 de Abril”, p. 33. 
En lo que concierne a los intereses de los músicos de catedrales, el congreso de Valladolid logró un importante éxito, como fue la derogación de la Real Orden que impedía el nombramiento de beneficiados catedralicios con cargos musicales además de los de oficio ${ }^{239}$. Dicha derogación se hizo efectiva por otra Real Orden con fecha de 23 de abril de $1908^{240}$, e implicó que la capilla de música catedralicia pudiera aumentar el número de sus componentes, restringido hasta ese momento a seis en el caso de las catedrales metropolitanas (maestro de capilla, organista, contralto, tenor, sochantre y salmista), y cuatro en el de las sufragáneas.

En el congreso de Sevilla, durante la discusión del punto relacionado con la dignificación de los músicos catedralicios, el mismo Olmeda planteó una propuesta mucho más ambiciosa, pues suponía una profunda reforma de la estructura musical de las catedrales. Así lo cuenta Villalba:

Un director jefe, el hoy Maestro de capilla, el compositor que había de ser, la cabeza de todo el arte, sería canónigo dignidad, y recordando las tradiciones a él volvería la Chantría; una especie de vice-Maestro, Director de coro, es decir, de las ejecuciones musicales con todos los conocimientos para el desempeño de estos menesteres, sería igualmente canónigo; el primer organista, canónigo había de ser también, y así; en proporción continuaba distribuyendo beneficios. ${ }^{241}$

Lógicamente, la recepción de la propuesta fue muy positiva, aunque los problemas para que se hiciera realidad eran prácticamente insalvables. Era necesaria una reforma del Concordato, en la que era poco probable que se embarcaran Iglesia y Estado al tratarse de un asunto irrelevante para la alta diplomacia como el musical ${ }^{242}$.

239 "Punto 30- Qué de los organistas y cantores parroquiales. [...] El Congreso suplica a los Rvmos. Prelados interpongan todo el poderoso influjo de su reconocido celo para conseguir la derogación de la Real Orden que impide se provean beneficios con cargos músicos además de los señalados por oficio." Crónica del Primer Congreso, p. 12.

${ }^{240}$ Crónica del Segundo Congreso, p. 28.

${ }^{241}$ Luis Villalba Muñoz, “El Segundo Congreso Nacional”, p. 414.

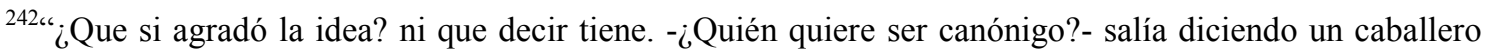
que pertenecía a no sé qué comisión del congreso. Y en efecto, la cosa estaba en su auge completo, y no te negaré que prescindiendo del lado festivo, y aún con él, que no quita lo uno a lo otro, la cosa tenía sus fuertes razones para apoyo. Y porque las tenía la asamblea la dio su fallo favorable. Claro es que en el terreno práctico ofrecía sus pequeños inconvenientes el asunto; porque vamos a ver: revolver a Roma con Madrid, poner en movimiento la diplomacia para si se había de dar una canongía al organista, y otra al Maestro, y otra al Director, a músicos, en una palabra, no era el prólogo más seguro; y no había otro remedio, era preciso tratar de ello en Consejo de Ministros, y peligro de que no lo llevaran a las Cortes, y el 
El mismo arzobispo de Sevilla, ante las dificultades para su materialización, hizo que se modificara ${ }^{243}$, reduciendo las aspiraciones iniciales de la asamblea a la petición de convertir al "director de la Música Sagrada de cada Catedral" -suponemos que se refiere al maestro de capilla-, en chantre, aunque la redacción no sea del todo clara ${ }^{244}$. En la conclusión final, además, se incluyó una vía alternativa a la modificación del Concordato: establecer "periódicas oposiciones de Música Sagrada, a fin de poder formar una lista de profesores en quienes se pueda proveer este cargo", y se creó una comisión de "personas independientes, desinteresadas y experimentadas, para poder emitir un informe en la aspiración de los artistas de las Catedrales, respecto de los conocimientos que estos deben tener y dignificación que exigen sus cargos", formada por el benedictino Manuel Ma Guzmán, director de la escolanía de Montserrat; el jesuita José Alfonso, ex-maestro de capilla de la catedral de Madrid; y Mariano Baixauli, exmaestro de capilla de la catedral de Toledo ${ }^{245}$.

Por tanto, al igual que el vallisoletano, el Congreso de Sevilla se ocupó sólo de la situación de los músicos catedralicios. En lo que concierne a los músicos de iglesias de rango inferior, se limitó a ratificar las conclusiones sobre los conocimientos exigibles a estos presentadas en Valladolid ${ }^{246}$.

Nuncio y el gobierno español, y el Rey y el Papa tenían que intervenir, y todo por cuestión de música, [...]”. Ibídem, pp. 414-415.

\footnotetext{
243 “Así es que, cuando por la noche acudimos los ponentes a leer las conclusiones tomadas en nuestras respectivas secciones al señor Arzobispo, cosa que hacíamos todas las noches, al llegar a esta conclusión el Prelado nos hizo observar todo lo dicho, y la enmendó reduciéndola a las chantrías, única cosa que pareció viable." Villalba, "El Segundo Congreso", p. 415. Este cambio provocó la reacción de los organistas, quienes culparon a Olmeda de ser relegados en este intento de mejorar la situación de los músicos catedralicios: "Pero llegó el caso de la lectura pública de las conclusiones, y al ver que no se hacía mención de los organistas, los interesados la tomaron con Olmeda: -Está visto -decían- los Maestros de capilla no se cuidan más que de sí, y a los demás que los parta un rayo. Esto es un juego de compadres, etc., etc.” Ibídem.

${ }^{244}$ Crónica del Segundo Congreso, p. 275.

245 “Punto h) En cuanto a la dignificación e independencia de los cargos musicales según la importancia y conocimientos que les exige el Motu proprio, el Congreso suplica a los Reverendos Sres. Obispos, que el cargo de director de la Música Sagrada de cada Catedral, puede conferirse a las Chantrías, sea pidiendo al Excmo. Sr. Nuncio de Su Santidad, de acuerdo con el Gobierno de Su Majestad, la modificación del Concordato, sea estableciendo periódicas oposiciones de Música Sagrada, a fin de poder formar una lista de profesores en quienes se pueda proveer este cargo.- El Congreso señala como personas independientes, desinteresadas y experimentadas, para poder emitir un informe en la aspiración de los artistas de las Catedrales, respecto de los conocimientos que estos deben tener y la dignificación que exigen sus cargos, a los Reverendos Padres Guzmán (O.S.B.), Baixaulí y Alfonso, S.J.” Ibídem.
}

246 "Punto g) [Sección cuarta] Respecto a los conocimientos que deben exigirse a los distintos cargos musicales de las Catedrales, parroquias, conventos, etc., el Congreso ha ratificado las conclusiones que al efecto se formularon en el de Valladolid." Ibídem. 
En su crónica sobre la sesión dedicada, entre otros puntos, a la dignificación de los músicos eclesiásticos publicada en $L C D$, Villalba ponía de manifiesto los escrúpulos e incluso indignación con los que los asistentes abordaban las cuestiones de carácter material, a pesar de que, según su punto de vista, “Así es el hombre, y como es hay que tomarle, que no bastan todas las retóricas del mundo a mudarle de como es; ni todas las parrafadas de la indignación más sonora, para convertir en bajeza lo que es una exigencia de la naturaleza" ${ }^{247}$ :

Yo no sé si te habrá parecido lo anterior prosa o verso; me inclino a que lo colocas en lo de las terrenales aspiraciones. Estás en lo justo, pero con una condición: por ahí (por ahí quiere decir entre el vulgo de los que tienen su corazoncito y su miaja de cultura), por ahí, digo, lo prosaico equivale a lo mezquino, a lo rastrero, a lo bajo, vil, $\mathrm{y}$ demás adjetivos denigrantes; pues bien, si tú opinas así, yo no opino entonces contigo, porque en este mundo hay muchas cosas muy terrenas, muy materiales, muy prosaicas, que no son ruines ni mezquinas en el sentido ofensivo de la palabra, ¡vamos al decir!..., y por más de que a primera vista esto de dignificar los cargos musicales con unos cientos de pesetas más, parezca una cosa grosera y hasta poco razonable (lo razonable, lo poético, está en la dignificación intrínseca, en la ciencia, en el superlativo arte del músico, único modo de elevar y de hacer respetable su artística persona); sin embargo no lo es. $^{248}$

No obstante, el agustino apuntaba a estos asuntos como el origen de la crisis por la que atravesaba la música religiosa:

Esa facultad superior que se llama genio, o sea la inspiración [...] no se cultiva sin buenos profesores, sin muchos años de estudio, sin oír mucho y bueno, sin una abundante y selecta biblioteca; profesores, libros y audiciones que no se encuentran de balde en el mundo, y que multiplicados por el número de años que se requieren, eso sin contar que hay que alimentarla siempre, dan por resultado un capitalazo enorme. Y gastarse ese dineral en profesores, libros, etc., para conseguir al fin un sueldo de 1.500 o 2.000 pesetas anuales, cantidad con la cual el artista puede permitirse el lujo de comer garbanzos, y habitar una bohardilla y otras demasías tan artísticas como geniales, no es en verdad aliciente para meterse muy en harina musical. Lo cual quiere decir, que ante tan poética y romántica perspectiva, serán muchos los que abandonen el productivo terreno de la solfa, y no pocos los que habiéndose metido por él, deriven a otros

\footnotetext{
${ }^{247}$ Villalba, "El Segundo Congreso Nacional", p. 417.

${ }^{248}$ Ibídem, pp. 415-416.
} 
de los muchos caminos que tiene. Y el hecho es hecho; cada vez escasean más los buenos músicos religiosos. Un estudiante con vocación al sacerdocio, y que sabe música, tiene que estudiar su carrera eclesiástica y su carrera musical que le supone tanto desgaste del cerebro como la primera. Si continúa sus estudios musicales para ejercerlos, puede aspirar a lo sumo a Maestro de Capilla con $2.000 \mathrm{del}$ ala en el caso más próspero, y los lujos consiguientes; si no los continúa y se queda con los eclesiásticos, puede llegar a Párroco, a dignidad de una Catedral. ¿Por cuál de los dos extremos optará? Mucho amor al arte se necesita para elegir lo primero. ${ }^{249}$

La primera vez que se oyó la voz de los músicos eclesiásticos no catedralicios en los congresos fue en el IV Congreso Nacional de Música Sagrada, celebrado en Vitoria en 1928. El cuestionario incluyó dos puntos dedicados a los organistas parroquiales dentro de la sección segunda titulada "Canto popular y disciplina eclesiástica": “Tema 6. ${ }^{\circ}$ - Importancia del cargo de organista en las parroquias.Dignificación de este cargo", y “Tema 7. - Condiciones de los Organistas de Parroquias: a) artísticas; b) morales.- ¿Es conforme al 'Motu Proprio’ de Pío X que el Organista sea Director de Banda del pueblo?-¿En qué condiciones?” A ambos puntos se presentaron un total de diez memorias, incluida una colectiva de la Asamblea de Organistas Diocesanos de Vitoria reunida en Durango el 30 de octubre de este mismo año. Todas insistieron en la necesidad de mejorar las condiciones laborales de este colectivo, cuyas tareas incluían en la mayoría de los casos ejercer como cantores y directores de coro, cubriendo todas las necesidades musicales de los templos ${ }^{250}$.

La perpetuación de las precarias condiciones laborales de los músicos de iglesia representó uno de los grandes asuntos pendientes del movimiento de reforma de la música religiosa en España, y especialmente en el sur peninsular ${ }^{251}$. Las dos únicas memorias presentadas al congreso de Vitoria desde Andalucía hicieron referencia a esta

\footnotetext{
${ }^{249}$ Ibídem, 416.

${ }^{250}$ Crónica del IV Congreso Nacional de Música Sagrada celebrado en la Ciudad de Vitoria del 19 al 22 de noviembre de 1928 (Vitoria: Imprenta del Montepío Diocesano, 1930), pp. 144-152.
}

${ }^{251}$ Emilio Casares sitúa el comienzo de esta inercia de empobrecimiento de los músicos eclesiásticos y sus causas en las desamortizaciones llevadas a cabo durante durante el s. XIX: "La Desamortización de Mendizábal, iniciada en 1835, y el posterior acuerdo con el Vaticano, por el que se rebajaban las rentas dedicadas a la música en un $50 \%$, trae como consecuencia el despido de cientos de músicos intérpretes que comienzan a malvivir en auténticos tugurios, cafés, salas variopintas, tablaos, pero incide sobre todo en un creador que tienen que acomodar su música a unos medios muchos más pobres precisamente en el momento de crecimiento de la música romántica en cuanto a medios orquestales y estructuras musicales." Emilio Casares, "Pedrell, Barbieri y la restauración musical española", Recerca Musicològica, vol. 11-12 (1991-1992), pp. 259-271, p. 260. 
cuestión. Estas dos reflexiones permanecían alejadas de toda imagen idealizada o retórica injustificadamente optimista o autocomplaciente. Aportaron, desde un espíritu crítico, un análisis de las causas de las deficiencias y problemas que padecía la música litúrgica, que atribuían en gran medida a razones sociales y laborales. De ellas derivaban, según planteaban, los tantas veces denunciados males de los músicos religiosos en España: falta de preparación y formación, falta de interés y dedicación a medias, el comportamiento poco cívico e inmoral a veces, o sus dudosas capacidades y talento.

La primera de estas memorias está firmada por Antonio Gessa Loaysa, musicólogo y profesor del Conservatorio Odero de Cádiz ${ }^{252}$. El tema del cuestionario al que la presentó se titulaba: "Tema 8.-Medios para conseguir que los músicos de la iglesia cumplan su oficio litúrgico con más espíritu cristiano, con más devoción y con más silencio en los coros":

Aún nos queda otro punto; medio que en nuestro criterio es tan elemental y necesario que es absurdo pensar en reforma alguna (tratándose del sector sobre que el cual hemos enfocado la cuestión) sin pensar en él.

La remuneración.- La indigencia de los músicos de Iglesia es muchas veces motivo de su descuido, de su incompetencia y a veces de inmoralidades. Su retribución es irrisoria, si no fuera tristísima.

Una porción de deberes llaman fuertemente la atención y el descuido de quienes deban y puedan remediarlo; y el Congreso no debe desatender esta necesidad que exige urgentemente resolución. Los músicos de Iglesia en las parroquias y en los pueblos son los cargos peor retribuidos que conocemos entre todas las profesiones. ${ }^{253}$

El autor de la segunda memoria es Carmelo Codinach, prior de los carmelitas de Córdoba, y recuerda todavía en 1928 los dos grandes problemas de los que hablaba Spínola al dar comienzo en 1904 al proceso de reformas en la Archidiócesis, el cultural, que Codinach entiende como de "temperamento", y el económico:

La cuestión del canto sagrado en esta diócesis de Andalucía es verdaderamente un problema.

\footnotetext{
${ }^{252}$ Francisco Cuenca dedica a Antonio Gessa Loaysa las siguientes líneas: “Gessa Loaysa (Antonio), Chiclana, (Cádiz). Músico y musicógrafo, director de la Sociedad Artística Gaditana de conciertos vocales e instrumentales, establecida en Cádiz. Cuenca Benet, Galería de músicos andaluces contemporáneos (Málaga: Unicaja, 2002), facsímil de la edición de La Habana: Cultura, S.A., 1927 a cargo de Manuel del Campo y Antonio Martín Moreno, p. 111.

${ }^{253}$ Crónica del IV Congreso, pp. 155-156.
} 
Dos son los principales obstáculos que se oponen a la reforma: uno de temperamento, y otro de economía.

$[\ldots]$

El otro obstáculo, el económico, es la poquísima subvención o retribución que se da a los cantores y a los organistas de iglesias, como, en general, a todos los ministros inferiores de ellas.

¿Quiénes solicitan los puestos de cantores y de sacristanes, principalmente en nuestra región? No es por desacreditarlos ni humillarlos, no; es porque el haber de estos puestos y servicios de las iglesias es tan mal retribuido que todo aquel que tiene cualidades para otros negocios se aparta de las iglesias, porque en ellas no ve cubiertas las necesidades que tiene perfectísimo derecho a remediar, dado que está sujeto y esclavizado a su servicio y a sus obligaciones.

¿Cómo se puede exigir personal apto, que haya buenas voces, que se estudie canto, que se emita bien la voz, que se sepa lo que se debe saber, que se cumplan y que se llenen todas las obligaciones, si no tienen, con lo que ganan, para sostener a la familia, ni casi para comer? Este es un punto que convendría que el próximo Congreso pusiera sobre el tapete, que se estudiara con detención y que se resolviera conforme a lo que exige la santidad de los templos augustos del divinísimo Sacramento de nuestros Altares y la realidad de la vida. $^{254}$

Por último, existió otro colectivo de músicos a los que afectó el $M P$, que, aunque no eran estrictamente eclesiásticos, estaban íntimamente relacionados con la liturgia. Se trataba de los músicos eventuales o como los denomina el Reglamento general para la música sagrada vallisoletano, "festeros" 255 , es decir, aquellos que dirigían o componían grupos vocales o instrumentales contratados para determinadas funciones. Para estos músicos la implantación del $M P$ repercutió negativamente en sus intereses económicos, razón por la cual se situaron, en muchos casos, en contra de ella. Así nos lo expresa Villalba al comentar la reacción de los músicos de la ciudad ante el congreso de Valladolid:

Pero en fin, conste la cosa: los músicos de Valladolid están a rabiar con el Congreso, y están a rabiar porque van a dar audiciones de esa monserga, y la monserga está compuesta por Guerrero, Morales, Palestrina, victoria y otros pigmeos. ¡Vaya por Dios! La madre del cordero de toda la tremolina que contra la polifonía y tal han levantado los músicos, está a mi ver, y milagro será que no dé en el clavo, en dos cosas: una en la casi supresión de las orquestas, lo cual

\footnotetext{
${ }^{254}$ Ibidem, pp. 182-183.

255 "Reglamento general para la música sagrada en la provincia eclesiástica de Valladolid", Boletín Oficial Eclesiástico del Arzobispado de Valladolid, 11 (1905), p. 335.
} 
priva a muchos de un presupuesto regular que antes les entraba muy galanamente en casa, y otra de que como en la ejecución del Motu proprio los músicos eclesiásticos de la catedral han tomado muy principal parte, estos se han adquirido mayor prestigio y llamado a sí gran parte de las funciones religiosas, desbancando de esta suerte a los seglares que antes las hacían". ${ }^{256}$

Este testimonio demuestra la cantidad de intereses que se vieron comprometidos con la reforma, y nos proporciona una idea de lo complejo y polémico de su aplicación. Recordemos que, a diferencia de los reglamentos vallisoletanos, el intento de regulación de los oficios musicales en la archidiócesis de Sevilla incluyó a este colectivo que, en una ciudad de gran actividad litúrgica o paralitúrgica asociada con hermandades y demás corporaciones religiosas como era Sevilla, tenía un importante mercado de trabajo. Se trata de un asunto merecedor de un estudio monográfico ${ }^{257}$.

En síntesis, la situación económico-social de los músicos eclesiásticos era bastante difícil. En el caso de los catedralicios, impedía, en muchos casos, su participación en los congresos. Los cabildos, aunque no obstaculizaron la asistencia de sus beneficiados, por lo general, no la apoyaron financiándola. El salario de los músicos religiosos al servicio de templos de inferior categoría era tan precario que hacía imposible su subsistencia, lo que les obligaba a buscar cualquier empleo que complementara sus ingresos. Obviamente, su presencia en los congresos no estaba a su alcance. Durante las distintas ediciones de estas grandes asambleas se denunciaron repetidamente la falta de formación, capacidad, implicación, e incluso la inmoralidad de estos músicos, aunque a la hora de aportar soluciones para mejorar la situación sólo se ocuparon de los catedralicios.

\subsection{El tándem Ripollés-Otaño}

A principios de junio de 1908 la organización del Congreso estaba bastante encarrilada. La Junta Organizadora se había constituido hacía un mes, los documentos fundamentales estaban elaborados, y se había llevado a cabo una importante actividad de difusión por todo el país. A través de diversos medios se había contactado y requerido la colaboración de obispados, cabildos, particulares, así como de los curas y diocesanos de la propia Archidiócesis.

\footnotetext{
${ }^{256}$ Villalba, "El Primer Congreso Nacional”, p. 124.

257 Véase capítulo 2, epígrafe 4.2.1. "Regulación de los oficios musicales eclesiásticos: hacia la constitución de una estructura oficial diocesana".
} 
Respecto a la Junta Central de Valladolid y su actividad como órgano central de los congresos, ninguna referencia se hace en las fuentes datadas en este periodo y a partir de ahora, desde que Almaraz la mencionara en aquella primera circular de 21 de abril publicada en $M S H$. Ello lleva a pensar que este primer intento de erigir un órgano director y coordinador del movimiento a nivel español y sus principales manifestaciones, como la -provisional en tanto se fundaba la Asociación CecilianaJunta Central no había cuajado. Como indican los datos que hemos ido ofreciendo hasta ahora, la organización del II Congreso corrió a cargo exclusivamente de la Junta local hispalense. Es lógico pensar, no obstante, que, a pesar del fracaso que a nivel institucional supuso la desaparición en la práctica de la Junta Central, se mantuviera un canal de contacto -no oficial aunque real- entre los principales miembros del grupo de Valladolid y la organización hispalense. Las fuentes, sin embargo, sólo informan del apoyo que la revista $M S H$, definitivamente establecida en la capital pucelana, brindó a la asamblea andaluza, a cuya estrategia de difusión y propagación dieron absoluta prioridad. Así se demuestra en el siguiente fragmento de una carta de su principal impulsor, Nemesio Otaño, una de las dos únicas misivas de entre las conservadas del jesuita en la que es posible encontrar alguna referencia al congreso de Sevilla antes de su llegada a la ciudad hispalense: "El artículo de Bas irá: no sabía que estuvieran ahí los

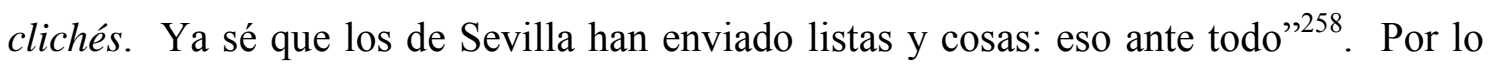
tanto, a diferencia de la Junta Central, MSH, otro de los órganos de ámbito general creados en Valladolid cumplió su función de acuerdo a la idea con la que se había creado.

En el seno de la Junta Organizadora sevillana, Ripollés desempeñó una labor destacada, tal y como se desprende de algunos testimonios citados más arriba. Recordemos que Almaraz, nada más llegar a la capital andaluza, le había transferido "todas sus facultades en materia de Música religiosa" ${ }^{259}$, lo que le daba una gran libertad a la hora de actuar y tomar decisiones. Sin embargo, esto no evitó las

\footnotetext{
${ }^{258}$ Carta de Otaño a Vicente Goicoechea, 18 de julio de 1908. AMSL. FO. Correspondencia, T01/029. En sus apuntes autobiográficos tampoco se encuentra ninguna referencia a la organización del congreso de Sevilla anterior a julio de 1908. Las preocupaciones que reflejan y las actividades en las que estaba ocupado en esos momentos eran la dirección del coro del colegio al que fue destinado, la revista $M S H$, la composición de cantos populares, y la antología de órgano que elaboró para que fuera interpretada en el Congreso hispalense. Apuntes autobiográficos, 5v. AMSL. FO. Conferencias y otros escritos, 005/013. Para más información sobre su etapa en Oña véase: López-Calo, Nemesio Otaño, pp. 41-63.
}

${ }^{259}$ Carta de Ripollés a Pedrell, 29 de octubre de 1907. BC. FFP. M 964 R. 
dificultades que encontró y la falta de colaboradores afines que sufrió. Algunas de sus cartas reflejan esta soledad, y lo desagradable de la experiencia que vivió ${ }^{260}$. El ambiente que, según cuenta, se había creado en torno al Congreso y a él mismo hacia finales de junio y principios de julio le llevó a reclamar "a grandes voces" la ayuda de Otaño:

En asuntos del Congreso trabajando como un negro, y como de buena cepa estoy solo y de mala hay muchos a meter baza, resulta que estoy pidiendo a grandes voces la ayuda del P. Otaño para entre los dos hablar clarito al Arzobispo. ${ }^{261}$

Según sus apuntes autobiográficos, Otaño llegó a Sevilla en julio, “al terminar el curso", una vez hubo conseguido Almaraz el permiso de sus superiores ${ }^{262}$. Por su correspondencia sabemos que el 18 de ese mes aún continuaba en Oña, y que tenía previsto pasar unos días en el balneario de Alzola, en Guipúzcoa. Antes de partir para Sevilla estuvo en San Sebastián, y durante su viaje se detuvo en Madrid y, probablemente también en Valladolid ${ }^{263}$. Por tanto, pese a lo que afirma en aquellos

${ }^{260}$ Poco después de la clausura del Congreso manifestaba a Pedrell: "Quedé tan reventado de nuestro inútil congreso que, a pesar de mis deseos de escribir a $\mathrm{V}$., nunca he tenido ánimos para hacerlo con la extensión que se necesitaba para enterar a V. de todas mis cosas." Carta de Ripollés a Pedrell, 8 de febrero de 1909. BC. FFP. M 964 R. Las cartas que en el contexto de la preparación del congreso de Barcelona (1912) escribió al músico tortosí contienen varias alusiones a su experiencia como organizador del congreso de Sevilla: "[...] Escribiome el P. Suñol dándome nota de ponentes, consultores, etc. Contestará uno de estos días. Salí yo en Sevilla bastante zarandeado y quisiera que me dejaran ahora el papel de simple espectador y zarandeador". Carta de Ripollés a Pedrell, 7 de mayo de 1912. BC. FFP. M 964 R. "Me encuentro aquí con un oficio de esa junta nombrándome ponente primero de la sección $2^{\mathrm{a}}$ : estaba yo por devolverlo porque ese mismo cargo en Sevilla me proporcionó un latigazo de una mano oculta que resultó ser de un amigo y no quiero que la suerte se repita; pero no quiero dar este paso sin consultar con V. para que V. con toda sinceridad me aconseje: en manos de V. pongo el asunto." Carta de Ripollés a Pedrell, 10 de agosto de 1912. BC. FFP. M 964 R.

${ }^{261}$ Carta de Ripollés a Pedrell, 9 de julio de 1908. BC. FFP. M 964 R.

262 "En 1908, se hizo el $2^{\circ}$ Congreso de Sevilla. El Arzobispo de allí, el Sr. Almaraz, gran mecenas mío también, recabó de mis superiores que fuera allí a preparar y organizar el Congreso. Accedieron. Fui a Sevilla al terminar el curso, en julio." Apuntes autobiográficos, p. 11. AMSL. FO. Conferencias y otros escritos, 005/013.

${ }^{263}$ El siguiente fragmento está extraído de una carta a Goicoechea escrita en Oña el 18 de julio: "A Lequeitio me será imposible ir, porque llevo los días contados a Alzola y no me dejarían que perdiese un día de aguas. A V. le será muy fácil venir a pasar un día a Alzola, como vino el año pasado D. Manuel, su cuñado; pero no venga $\mathrm{V}$. sólo para una tarde; llega $\mathrm{V}$. en el tren de la una y vuelve $\mathrm{V}$. al día siguiente". Al final figura una post data parcialmente tachada por el transcriptor de la misiva que dice: "Una visita a Arregui y que he recibido la suya, conformarme con ellas, pues pide un imposible; yo no puedo detenerme más que un día en Valladolid." Carta de Otaño a Goicoechea, 18 de julio de 1908. AMSL. FO. Correspondencia, T01/029. En otra carta, ya desde Sevilla, escribía a Goicoechea: "En San Sebastián Julio no me dejó ni a sol ni a sombra. En Madrid tuve que conferenciar con el Sr. Nuncio, y dice que la cosa pro riforma hay que llevarla a cabo a todo trance [...]". Carta de Otaño a Goicoechea, 25 de agosto de 1908. AMSL. FO. Correspondencia, T01/030. 
apuntes, resulta difícil que Otaño arribara a Sevilla antes de agosto. La primera carta que conservamos remitida desde la capital andaluza data del 25 de este mes. En ella comunicaba a Goicoechea: "Ya llegué a esas playas [hay que entenderlo en sentido irónico] donde se asa un esquimal”264.

Las fuentes no son generosas a la hora de especificar los trabajos de los que se hizo cargo el vasco y la responsabilidad que asumió. Sus cartas de esos días sólo informan de la entrevista que mantuvo con el nuncio de la Santa Sede en España a su paso por Madrid, y sobre algunas gestiones realizadas gracias a las relaciones que mantenía con personajes importantes ${ }^{265}$. Sabemos que mantuvo contacto con André Mocquereau, a quien informaba de los asuntos gregorianos del Congreso y a cuya influencia recurrió para acelerar la llegada de los benedictinos catalanes o lograr la presencia de Giulio Bas ${ }^{266}$; o con el propio Bas, a quien solicitó directamente y en nombre de la Junta Organizadora su participación en el Congreso, al igual que ocurrió en Valladolid, aunque sin éxito esta vez ${ }^{267}$. Tampoco tuvo éxito con Pedrell, a pesar de su insistencia. Este fragmento, en el que no falta el humor, es de una carta de 29 de agosto:

Hablé con el Sr. Nuncio en Madrid y me dijo que era necesario llevar esto adelante y que le diera una idea de las dificultades que ofrecía en España este negocio. Él es entusiasta pro reforma y quiere que se le cuente entre los decididos.

Con todo esto no pretendo calentar a $\mathrm{V}$. que pertenece ya a la raza de los esquilmales [sic], o que diga, esquilmados. Muchas veces hemos hablado de ello y yo acato y venero esa actitud de V. tan

${ }^{264}$ Carta de Otaño a Goicoechea, 25 de agosto de 1908. AMSL. FO. Correspondencia, T01/030. Cuatro días más tarde comunicó su llegada a Pedrell: "Aquí me tiene V. en Sevilla veraneando y andando como un pato en honor de la santa causa que defendemos. Aquí sí que cabe exclamar: ¡oh, amor, cómo me has puesto!". Carta de Otaño a Pedrell, 29 de agosto de 1908. BC. FFP. M 964 O.

265 En su biografía sobre Otaño, López-Calo dedica el epígrafe titulado El congreso de Sevilla al desagradable episodio que vivió el músico vasco durante la preparación del Congreso relacionado con las polémicas que mantuvo con los benedictinos de Silos sobre la conveniencia de añadir determinados signos rítmicos a las melodías gregorianas restauradas. Antes de entrar de lleno en el asunto ofrece, a modo de introducción, una breve síntesis sobre la actividad de Otaño entre el momento el que los superiores del jesuita acceden a la petición de Almaraz hasta que llega a Sevilla. Refiere su estancia en Alzola así como su entrevista en Madrid con el nuncio. Nemesio Otaño, p. 51.

266 Véanse: cartas de Otaño a Mocquereau, 29 de agosto de 1908. AMSL. FO. Correspondencia, TA01/038; y 14 de septiembre de 1908. Ibídem., TA01/040.

${ }^{267}$ Carta de Otaño a Bas, [sin día] septiembre de 1908. AMSL. FO. Correspondencia, TA01/039. Un par de semanas antes del Congreso escribió a Angelo de Santi, aunque no trató nada relacionado directamente con el mismo, excepto algún comentario referente a los problemas que había tenido con los monjes de Silos. Carta de Otaño a de Santi, 29 de octubre de 1908. AMSL. FO. Correspondencia, T01/036. 
justificada por las atroces circunstancias por donde se ha alambicado su paciencia heroica. [...]

Yo no le doy a V. mucho tiempo de vida si deja V. de venir al Congreso: en cambio si viene $\mathrm{V}$., tengo plena confianza en que sus años llegarán a los de los patriarcas y entonces se dirá de V. que: durmió en el Señor!

Yo no pienso dejarle en paz hasta que me dé V. el Sí definitivo en Si mayor, le molestaré como un ánife o como una pulga; le picaré y no le permitiré un momento de reposo. Tarjetas, postales, cartas, telegramas, cablegramas, propios, todo estará en su puerta gritando día y noche: "que se venga V., D. Felipe...!

El Maestro Ripollés irá pronto ahí. Está haciendo unas tenazas para arrancarla de esa. Yo he encargado a Zeppelin un dirigible_para que se venga $\mathrm{V}$. con más facilidad; la broma me costará algunas pesetas, pero he abierto una suscripción popular en el barrio de Triana y hasta ahora van recaudadas grandes sumas de esperanza. Parece que se animan los de la Macarena a cantar según el Motu proprio. $^{268}$

Las fuentes hemerográficas tampoco aportan información sobre las actividades que desempeñó. En una de sus cartas publicadas en $L C D$, Villalba destacó su labor, aunque desconocía en qué consistió:

Uno de los que aquí anduvieron, y no sería justo si lo callase, fue el P. Otaño; qué clase de trabajos realizó, no lo sé; mas para eso fue a Sevilla, para eso estuvo allí una larga temporada, y en lo mismo puso su actividad que no es poca. Si después cuando llegó el tiempo no apareció por allí, cosa es que pertenece a la historia menuda del arte, y aunque no seré quien descorra el velo, te diré que no ha sido por esas causas oficialescas que a veces figuran en los programas: indisposiciones, ocupaciones perentorias y demás términos de oficio. El hecho es que trabajó, que después no asistió, que los que nos enteramos del caso lo comentamos, y que sentimos su ausencia los que éramos del número de sus amigos. ${ }^{269}$

El agustino aludía al grave conflicto que Otaño mantuvo con los benedictinos de Silos, y que impidió, por prohibición de sus superiores, su asistencia al Congreso. Más adelante nos ocuparemos del mismo. La Crónica del Segundo Congreso reconoció también la labor que desarrolló durante su estancia en la capital andaluza, aunque sin especificar tampoco en qué se concretó:

\footnotetext{
${ }^{268}$ Carta de Otaño a Pedrell, 29 de agosto de 1908. BC. FFP. M 964 O. Una transcripción de este original se conserva en AMSL. FO. Correspondencia, T01/031. En los casos en los que se conserva original y transcripción, nos servimos del primero.

${ }^{269}$ Crónica del Segundo Congreso, p. 52.
} 
Y justo es consignar aquí la parte no exigua que en los trabajos de la Junta en aquel entonces cupo al R. P. Nemesio Otaño, S. J., quien, cediendo a instancias de nuestro Excelentísimo Prelado y mediante el permiso de sus superiores, no vaciló en trasladarse a Sevilla y pasar en ella los días más calurosos del verano, desplegando una actividad verdaderamente asombrosa. ${ }^{270}$

Ripollés, por su parte, en uno de sus artículos aparecidos en ECA durante la celebración del Congreso, se refería a la contribución de Otaño como "indicaciones y advertencias":

[...] la Capilla Isidoriana [cantará] un motete polifónico a cuatro voces, imitación de los antiguos polifonistas, y el Tantum ergo $y$ Genitori, composición grandiosa del P. N. Otaño, S. J., que tanto ha contribuido al buen éxito de este Congreso con sus indicaciones y advertencias $^{271}$

Otaño destacaba en esta otra misiva remitida a Vicente Goicoechea el peso de Ripollés dentro de la organización, al tiempo que aludía a la "docilidad" con que asumía sus indicaciones:

Puede V. creer que Ripollés es otro V. y que allí nadie piensa de otro modo que él en lo referente al Congreso; pues tiene la confianza toda del Sr. Arzobispo. Ripollés por otra parte hace cuanto yo le indico con una docilidad que me tiene pasmado. ${ }^{272}$

En sus apuntes autobiográficos tampoco ofrece pormenores del trabajo que desarrolló en Sevilla, al margen de otros no relacionados directamente con la preparación del Congreso $^{273}$ :

Preparé el Congreso con D. Vicente Ripollés, entonces Maestro de capilla de aquella Catedral y su trato y sus conocimientos me sirvieron mucho. El Sr. Almaraz me instaló una oficina en su Palacio. Allí preparé definitivamente la Antología Grande, que se publicó en 1910 y compuse para ella mi Adagio, tomando como tema

\footnotetext{
${ }^{270}$ Villalba, "El Segundo Congreso Nacional”, p. 499.

271 “Congreso de Música sagrada”, ECA, 3347 de 15 de noviembre (1908), p. 1.

${ }^{272}$ Carta de Otaño a Goicoechea, 6 de octubre de 1908. AMSL. FO. Correspondencia, T01/034.

${ }^{273}$ El Adagio para órgano fue interpretado por Bernardo Gabiola en el segundo concierto para órgano celebrado el 14 de noviembre, tercer día del Congreso. Crónica del Segundo Congreso, p. 57.
} 
el pregón de un carbonero, con quien me encontraba todos los días por las calles al ir a la oficina.

Allí compuse en un día nostálgico el "Estrella hermosa", que tanto se ha cantado después. $[\ldots]^{274}$

Por el contrario, sobre la actividad que desplegó Ripollés durante ese periodo poseemos algunos datos más. Gracias a un par de cartas en las que detalló sus planes para el verano, sabemos que fue el encargado de ultimar las gestiones para la participación de la Capilla Isidoriana así como de los monjes gregorianistas provenientes de monasterios catalanes, Gregorio $\mathrm{M}^{\mathrm{a}}$ Suñol y Mauro Sablayrollés. Con estos fines realizó una serie de viajes cuyo itinerario incluyó Madrid, Barcelona, Montserrat y Parramon, entre otros destinos ${ }^{275}$. A todo ello hay que sumar la intensa labor de propaganda y de elaboración de los documentos fundamentales de los que ya hemos dado cuenta, así como la carga de trabajo que soportó una vez hubo de acatar Otaño la orden dada por sus superiores de desentenderse de todo lo que tuviera que ver con la organización del Congreso, como veremos más adelante.

Villalba también se hizo eco del esfuerzo de Ripollés durante esos días, en un ejercicio, además, de reconocimiento a su labor y sus capacidades:

En cuanto a literatura [el Congreso] fue abundante; y fuera de mi sección a la que se presentó Memoria y media, en las demás menudearon. Ya te he hablado de algunas; pero quien batió el record en este género, fue el Maestro de Capilla de Sevilla D. Vicente Ripollés: no apunté el número, pero nombre que más saliera a relucir no le recuerdo; añade a esto que durante una semana estuvo llenando columnas y columnas de El Correo de Andalucía, con artículos, unos a modo de programas ilustrados con notas biográficas y críticas de los autores, de las obras; otros, dando cuenta de el resultado de los

\footnotetext{
274 Apuntes autobiográficos, 11. AMSL. FO. Conferencias y otros escritos, 005/013. López-Calo hace algunos breves comentarios sobre estas dos obras en: Nemesio Otaño, pp. 61-62. Reproduce así mismo la partitura de Estrella hermosa.

275 "Mi itinerario, salvo ligeras variantes, será: salir de aquí el 17 de Agosto, si bien antes pasaré unos días en Cádiz; me avistaré con Asensio en Madrid para ultimar la participación de la Isidoriana en el Congreso; pasaré luego por pocos días a Onteniente, Alcoy, Valencia y Castellón, y a últimos de Agosto caeré en Barcelona, para ir desde ahí a Parramon y Montserrat: me incorporaré luego a la peregrinación Sevillana a Roma en Zaragoza y estaré de vuelta en Barcelona el 14 de Octubre: desde allí podré ir a Valencia y entonces será razón de ver al Sr. Guisasola" Carta de Ripollés a Pedrell, 9 de julio de 1908. BC. FFP. M 964 R. En una carta posterior figuran estos planes ligeramente alterados: "Yo salgo de aquí mañana con dirección a Onteniente para a ver si aquellas aguas yoduradas me quitan la dolencia del pie que me molesta desde Abril: estaré allá hasta el 12 y después de dos días en Valencia, donde visitaré al Sr. Guisasola en nombre del Arzobispo de esta [...] Desde Valencia iré a esa Barcelona allá por el 18, y luego a Montserrat y Parramon, volviendo a Sevilla por Zaragoza y Madrid." Carta de Ripollés a Pedrell, 25 de agosto de 1908. BC. FFP. M 964 R.
} 
conciertos, y otros acerca del arte musical religioso en general, y te formarás una idea aproximada de la laboriosidad de mi simpático amigo, y de la actividad que desarrolló durante aquellos días. Muy largo te hablaría de él, porque se lo merece, y la sensatez y cordura que en él brillan, y el tino especial que posee para muchas cosas, son acreedores a que te presentara como es a una persona que tiene algo más que fachada solemne. ${ }^{276}$

En suma, resulta difícil dilucidar con precisión la labor desempeñada por Otaño, aunque todo parece apuntar a que su papel fue, el de un necesario e influyente colaborador, al que le asistía la experiencia de la organización del primer congreso, que orientó, ayudó y apoyó a Ripollés. Tal y como el mismo Otaño cuenta en sus apuntes autobiográficos, durante su estancia en Sevilla asumió una función directiva al lado del castellonense. De este modo, se formó un tándem Ripollés-Otaño, que debió aliviar la carga y las presiones soportadas por el primero. Junto a esto, Otaño puso al servicio del Congreso los contactos que mantenía con importantes figuras internacionales de la música religiosa como Mocquereau o Giulio Bas, tal y como hemos señalado.

Respecto a Ripollés, por la información que las distintas fuentes nos han ido aportando hasta ahora, sabemos que, en primer lugar, elaboró los documentos fundamentales del Congreso; en segundo lugar, jugó un papel importante en la estrategia de difusión del mismo, a la que tanta importancia daba; en tercer lugar, gestionó personalmente la participación de la Capilla Isidoriana, así como de los encargados de las interpretaciones gregorianas; y en cuarto lugar, desarrolló una importante labor pedagógica y crítica a través de los programas de conciertos, reseñas y artículos que durante el Congreso escribió en la prensa local. A todo esto hay que sumar las once memorias que presentó a las distintas secciones de estudio, y que hicieron, como refirió Villalba en el fragmento que acabamos de transcribir, que su nombre fuera el "que más salió a relucir" en las sesiones de debate ${ }^{277}$. Se podría concluir que la responsabilidad de la organización del Congreso recayó fundamentalmente sobre Ripollés. Algunos años más tarde, el propio Otaño, en una carta a Pedrell con motivo de la organización del congreso de Barcelona (1912), afirmó:

\footnotetext{
${ }^{276}$ Villalba, "El Segundo Congreso Nacional", p. 498.

${ }^{277}$ Ripollés escribió dos para la sección $1^{\mathrm{a}}$ sobre canto gregoriano, cuatro para la sección $2^{\mathrm{a}}$ sobre música figurada, y cinco para la $4^{\mathrm{a}}$ que trataba sobre "propaganda, organización y personal”. Fue, con diferencia, quien más memorias presentó. Al castellonense le siguieron Gregorio Ma Suñol, con seis memorias, y el dominico jerezano José Aguilar, con cinco.
} 
"Ripollés será un gran auxilio. Si le pudiera V. llevar a Barcelona unos días, sería abreviar el trabajo porque lo de Sevilla lo hizo solo [énfasis original de Otaño]."278

A la luz de los datos que proporcionan estas fuentes, resulta obligado matizar aseveraciones que ofrecen una idea sobredimensionada del papel de Otaño en el congreso de Sevilla en detrimento del jugado por otros, como el propio Ripollés ${ }^{279}$.

Tanto Ripollés como Otaño coincidían a finales de agosto en la buena marcha de los preparativos. Según el maestro de capilla: "La organización del Congreso está muy adelantada y no falta más que cada uno cumpla con la parte que se le ha confiado"280. Otaño, por su parte, comunicaba a Goicoechea: "Las cosas de organización están aquí mejor que en Valladolid; tengo a mi disposición 2 sacerdotes, que escriben lo que les digo, y dos jóvenes ex-seises para recados". Y concluía con optimismo: "Creo que se hará algo" 281.

El 11 de octubre, y ya sin la presencia de Otaño en la ciudad andaluza ${ }^{282}$, la Junta Organizadora celebró una reunión con el fin de tratar los últimos asuntos. En ella se nombraron tres comisiones de trabajo: ornato, etiqueta y concierto ${ }^{283}$. La comisión de ornato, compuesta por los canónigos mayordomos de la Catedral, se debía encargar del acondicionamiento de las distintas sedes del Congreso: la Catedral, en la que se celebrarían las funciones religiosas; la iglesia del Salvador, que acogería las sesiones públicas; y las dependencias del Palacio Arzobispal, las sesiones privadas de estudio.

278 Carta de Otaño a Pedrell, 27 de febrero de 1912. AMSL. FO. Correspondencia, T01/117. A la cabecera de la carta a la que pertenece la frase citada se lee: “Carrión, marzo de 1912", aunque está tachado por Larrañaga como un error.

${ }^{279}$ José López-Calo afirma en su biografía sobre Otaño: “era público que en aquel momento era [el Padre Otaño] quien tenía en sus manos toda la organización del congreso". López-Calo, Nemesio Otaño, p. 56. En otra de sus publicaciones transmite la misma idea: "No obstante que la organización del congreso estuvo en Sevilla y que la comisión y el arzobispo eran quienes, en definitiva, decidían las cosas, el Padre Otaño siguió siendo el alma y el motor de todo [...]". "Congresos de música religiosa", p. 877.

${ }^{280}$ Carta de Ripollés a Pedrell, 25 de agosto de 1908. BC. FFP, M 964 R.

${ }^{281}$ Carta de Otaño a Goicoechea, 25 de agosto de 1908. AMSL. FO. Correspondencia, T01/030. Esta frase es transcrita parcialmente por López-Calo en Nemesio Otaño, p. 51. En cuestiones de organización los congresos fueron perfeccionándose y mejorando con el tiempo. El propio Otaño hizo en 1912 una comparación entre el congreso de Barcelona y el de Sevilla parecida a la que realizó entre Sevilla y Valladolid en aquel momento: "No es la misma organización de Sevilla, sino mucho más equilibrada y estudiada, y mejor distribuida." Carta de Otaño a Goicoechea, 5 de mayo de 1912, T01/120.

${ }^{282}$ Ya hemos señalado que la primera carta escrita desde Sevilla tiene fecha de 25 de agosto; la primera que escribió una vez abandonada la capital andaluza, data del 2 de octubre, enviada desde Oña, provincia de Burgos.

${ }^{283}$ Crónica del Segundo Congreso, pp. 52-53. 
La comisión de etiqueta tenía como misión recibir, hospedar y acompañar a los distintos actos a las personalidades y autoridades asistentes. Por último, la comisión de conciertos se debía ocupar de todo lo referente a la organización del concierto que, como colofón del Congreso y con la finalidad de ayudar a su financiación, habría de ofrecer la Capilla Isidoriana en el principal coliseo de la ciudad, el Teatro San Fernando $^{284}$. Entre los miembros de la comisión de concierto predominaban los músicos o personas relacionadas de alguna forma con la música: Luis Piazza, Luis Mariani, Vicente Ripollés, el presidente de la Sociedad Artístico-Musical, el Director del Orfeón Sevillano, y Antonio Damas ${ }^{285}$. En esta última reunión se aprobaron el programa general y los de los diferentes actos y conciertos, así como el presupuesto del congreso $^{286}$.

Además de ultimar las cuestiones puramente organizativas, en estas últimas semanas, los principales responsables, con Almaraz a la cabeza, procuraron que aquellos a los que iba dirigido el Congreso de forma preferente, clero y músicos eclesiásticos, llegaran con la mejor disposición y preparación posible a su celebración. Para ello se organizaron una serie de conferencias teórico-prácticas sobre canto gregoriano, que tuvieron lugar a lo largo del mes de octubre. Tenemos conocimiento de ellas por sendas cartas mecanografiadas enviadas por el vicario general, Miguel Castillo, por orden del arzobispo, al deán y Cabildo, conservadas en el $\mathrm{ACS}^{287}$. Estas clases o charlas se organizaron de forma separada para los cantores de las distintas iglesias de la ciudad por un lado, y para el clero por otro. El encargado de pronunciarlas fue el benedictino de Montserrat, Gregorio $\mathrm{M}^{\mathrm{a}} \mathrm{Suñol}^{288}$. Como ya apuntamos en el capítulo segundo, durante estos años fue práctica frecuente con el fin de introducir el nuevo canto gregoriano en sus diócesis que los obispos u otros responsables eclesiásticos reclamaran la presencia de los monjes de Silos, Montserrat e, incluso, como el caso de Valencia, del mismo Solesmes para que impartieran clases a su clero.

\footnotetext{
${ }^{284}$ Ibídem.

${ }^{285}$ Completarían la composición de esta comisión Ildefonso Calderón y Ramón García Romero y León, de los que no poseemos datos.

${ }^{286}$ Crónica del Segundo Congreso, pp. 52-53.

${ }^{287}$ ACS. Sección Secretaría. Correspondencia, leg. 11187, exp. 11. Almaraz se encontraba desde finales de septiembre en Roma de visita ad limina.

${ }^{288}$ En Apéndice 7 trascribimos ambas misivas, en las que figuran los detalles y pormenores de estas actividades de formación.
} 
Así pues, se podría afirmar que, a falta de un mes para la inauguración del Congreso, la organización había realizado su trabajo de forma eficiente. Sin embargo, detrás de este balance positivo se hallaba una realidad llena de problemas y conflictos, suficientes y lo suficientemente graves como para que aquellas valoraciones optimistas de Ripollés y Otaño de finales de agosto cambiaran radicalmente de signo. El 17 de octubre el primero describió así la situación:

No extrañe V. [Pedrell] haya tardado en escribir porque para tragar saliva amarga no he tenido bastante tiempo: aquí palpamos una densa atmósfera contraria a todas nuestras tendencias, y no pudiendo resistir la venida de gente que sabe lo que tiene entre manos, se revuelven contra el P. Otaño, contra los benedictinos [catalanes], y contra mí que saben les apoyo. [...] Yo pongo al corriente de todo al P. Otaño y dudo que con el cariz que van tomando las cosas, se determine a venir: y el caso es que aquí me tiene $\mathrm{V}$. solo para resistir las embestidas de todos estos toritos; también a mí me entran ganas de dejarles campo mucho para sus tonterías y barbaridades, pero temo que el Sr. Arzobispo tome a mal mi retraimiento y no tengo más remedio que cargar con la cruz, aunque bien se vé que la llevo sin ganas ni entusiasmos. Creo que esto estará muy desanimado y que celebraremos las sesiones como en familia; el Sr. Arzobispo habrá de cargar con las resultas que serán un déficit de 7.000 pt[as]. [...] Ya sé que el Sr. Arzobispo pensaba invitar a V. a su paso por ahí: supongo no caerá $\mathrm{V}$. en la tentación y mandará a todos los andaluces a paseo. ${ }^{289}$

Cinco días después, Otaño le comunicó definitivamente que no asistiría al Congreso:

Querido Maestro [Ripollés]: Por fin estuve antes de ayer con el P. Provincial, que en ninguna manera quiere que vaya yo al Congreso. No tienen VV. más que conformarse con la voluntad de Dios, y ver de sacar las cosas del mejor modo posible, sin contar conmigo. ¿No podría ser Rué? ¿Pedrell? Pagándoles ¿irían? ${ }^{290}$

Apenas una semana antes de la inauguración Ripollés escribió a Pedrell:

Hay muchas historias y largas de contar en todo este jaleo del congreso. El P. Otaño no viene por fin y esto obedece a intrigas de algunos que han hecho llegar los chismes a la misma cámara pontificia: las miserias humanas de siempre.

\footnotetext{
${ }^{289}$ Carta de Ripollés a Pedrell, 17 de octubre de 1908. BC. FFP. M 964 R.

${ }^{290}$ Carta de Otaño a Ripollés, 23 de octubre de 1908. AMSL. FO. Correspondencia, TA01/045.
} 
Deseo me facilite algunos datos biográficos de Matías Navarro y de Aranaz, pues habré de cargar yo con la redacción de las notas para el concierto ya que el P. Otaño se ha echado del todo fuera.

Creo no me quedarán ganas para más congresos, y estoy deseando salir pronto de todo esto para no meterme más a redentor. ${ }^{291}$

Estos testimonios descubren nuevamente un mundo ciertamente complejo y polémico, y mueven a introducir el punto de enfoque en sus entresijos para tratar de comprender el origen y la naturaleza de su estructura.

\section{El congreso de Sevilla, escenario para la consolidación del movimiento} de reformas como "espacio artístico-social"

Parece indudable, a priori, que las causas de los conflictos cuya existencia refieren estos textos tengan que ver con discrepancias respecto a cuestiones litúrgicas, estéticas, musicales, o, incluso, sobre desacuerdos a la hora de abordar problemas de carácter organizativo. Sin embargo, la dimensión que llegó a adquirir la problemática que reflejan (hay alusiones a animadversiones, intrigas, miserias humanas) obliga, creemos, a considerar junto a las causas estéticas, musicales, etc., otros elementos de análisis. Si partimos de la idea de que un determinado campo de acción y relación, en el que inevitablemente se producen conflictos, es previamente un "espacio de socialización", se hace necesaria una aproximación desde un punto de vista sociológico $^{292}$. Hemos recurrido, por tanto, a aquellos enfoques que han observado el mundo del arte y la cultura desde esta perspectiva. Conceptos como "campo", propuesto por Pierre Bourdieu, o art world, utilizado por estudiosos como Arthur Danton, George Dickie o Howard S. Becker, nos han proporcionado claves de interpretación valiosas para entender estas problemáticas y su contexto ${ }^{293}$. Hemos acuñado el término "espacio socio-artístico", resultado de la apropiación adaptada a nuestras necesidades de aquellos dos conceptos.

\footnotetext{
${ }^{291}$ Carta de Ripollés a Pedrell, 4 de noviembre de 1908. BC. FFP. M 964 R.

292 "El campo de la ciencia, del arte, de la literatura en nuestro caso, no es sólo campo de luchas, para serlo necesita ser antes espacio de socialización; y en él la mayor parte de lo que está en juego, así como de las estrategias para alcanzarlo, se mueve en el modo pre-reflexivo de las prácticas y de su experiencia dóxica." Ana Teresa Martínez, "Una indagación sociológica sobre el campo literario. Las Reglas del arte, según Pierre Bourdieu." Trabajo y Sociedad, X/9 (2008), disponible en: $<$ http://www.unse.edu.ar/trabajoysociedad/MARTINEZ.pdf > (consultado 11-9-2013).

${ }^{293}$ Véase apartado de "Metodología", pp. 37-38.
} 
Abordaremos, a partir de ahora, el análisis del Congreso desde esta perspectiva. Comenzamos por el asunto más grave, el que obligó a los superiores de Otaño a prohibir su participación, y sobre el que Ripollés se pronunció de forma tan cruda.

\subsection{La cuestión gregoriana: las primeras grietas en el movimiento}

La interpretación y transcripción rítmicas de los neumas contenidos en los códices medievales de canto llano había representado un problema de difícil esclarecimiento. A principios de siglo se habían definido dentro de la orden benedictina, y concretamente de los monjes de Solesmes, principal centro de la restauración del canto gregoriano, dos grandes corrientes. Una de ellas, liderada por André Mocquereau, abogada por la adición de determinados signos gráficos que ayudaban a definir el valor temporal de las figuras. La otra, a cuya cabeza estaba otro ilustre gregorianista, Joseph Pothier, rechazaba cualquier añadidura a la notación cuadrada al entender que podían desvirtuar o corromper las melodías originales legadas por los manuscritos primitivos. En el ámbito español, los dos monasterios benedictinos que lideraron la restauración gregoriana tomaron partido por cada una de estas dos tendencias. Silos defendió los postulados de Dom Pothier, mientras que Montserrat, junto con Parramon, asumió la propuesta de Dom Mocquereau ${ }^{294}$.

En una carta que escribió Otaño a Mocquereau a mediados de septiembre encontramos las primeras referencias a, sin duda, la más grave polémica desencadenada durante la preparación del Congreso. En ella, Otaño mencionaba otra enviada por Dom Guepin, entonces abad del monasterio de Silos, a Almaraz, en la que le avisaba de la existencia de conspiraciones, enemigos o disputas ${ }^{295}$. Se trataba de la respuesta de Silos

\footnotetext{
294 Véase entre otros: Pierre Combé, Histoire de la restauration du chant grégorien d'après des documents inédits. Solesmes et l'Edition vaticane (Solesmes: Abbaye Saint-Pierre, 1969). En edición inglesa: The Restoration of Gregorian Chant. Solesmes \& the Vatican Edition (The Catholic University of America Press, 2003); Ismael Fernández de la Cuesta, "La reforma del canto gregoriano en el entorno del Motu Proprio de Pío X", Revista de Musicología (Actas del Simposio Internacional "El Motu proprio de San Pío X y la Música (1903-2003)”), ed. por Mariano Lambea , XXVII/1 (2004), pp. 43-76; Klemens Schnorr, "El cambio de la edición oficial del canto gregoriano de la editorial Pustet/Ratisbona a la de Solesmes en la época del Motu Proprio", Revista de Musicología (Actas del Simposio Internacional "El Motu proprio de San Pío X y la Música (1903-2003)"), ed. por Mariano Lambea , XXVII/1 (2004), pp. 197-209.

${ }^{295}$ La carta está escrita en latín: "Archiepiscopus a D. Guepin accepit epistolam permagnam valde, ubi et inimicitiis, de iurgiis, de insidiis ocultis... ad eum loquitur. Cur timent boni viri? Et tamen timent, quin imo et renuunt ad Congressum cum magna fiducia venire." Carta de Otaño a Mocquereau, 14 de septiembre de 1908. AMSL. FO. Correspondencia, TA01/040.
} 
ante lo que había sido interpretado desde allí como una maniobra por parte de los organizadores hispalenses para marginarlos.

Lo que ocurrió desde entonces ha sido relatado por López Calo en su biografía sobre Nemesio Otaño, por lo que remitimos a dicha publicación ${ }^{296}$. Transcribimos, no obstante, algunos fragmentos de una carta de Otaño a Angelo de Santi en los que se proporciona sintéticamente la información necesaria para comprender el asunto:

Cuando fui a Sevilla, el Sr. Arzobispo, que me estima y ama como hijo querido, me leyó varias cartas de D. Guepin, Abad de Silos. [...] En ellas se hacía ver que se trataba de engañarle, en una palabra, que con nadie tuviera confianza sino con sus monjes de Silos...(Cicero pro domo sua). [...]

Ya para estas fechas la Junta Organizadora había llamado a los PP. Suñol y Sablayrolles, encargándoles de las ejecuciones gregorianas; y cuando esto supieron los de Silos, creyeron amenazado su honor y la dignidad de la Edición Oficial! D. Guepin pidió hospedaje en el Seminario para dos monjes de Silos, pero Mons. Almaraz no pudo acceder a esta petición, por estar ocupado todo el Seminario. D. Guepin creyó que se trataba de una conspiración, y que yo era el autor de estos conflictos y acudió en son de queja directamente a Roma. En esta carta parece que hacía notar que yo, influido por V.R. [Angelo de Santi] y por J. Bas era contrario a la Edición Vaticana, o que mi presencia en Sevilla sería gravemente perjudicial a la causa gregoriana.

Todo esto se suponía gratis y sin fundamento alguno. Precisamente yo he trabajado siempre en el sentido que V.R. me indica y aún mi artículo de "Razón y Fe" ["El Gradual Vaticano", Razón y Fe, 21 (1908), pp. 475-483.] nadie lo interpretó sino como una defensa de los signos rítmicos, tan calumniados por los monjes de Silos. [...] Pero cónstele y esté en lo cierto que yo nada he dicho, que no sea favorable para la Edición Vaticana, que he tratado de imponerla en todas partes con el mayor fervor posible. Público era en Sevilla que yo me oponía tenazmente a que en el Congreso se discutieran teorías, y con ese fin había tomado serias resoluciones.

Pero D. Guepin en un momento de furia cogió la pluma, y transmitió a Roma cosas y afirmaciones del todo gratuitas, y como para cortarme a mí la amistad de mis mejores amigos (el P. de Santi y J. Bas), no dudó en asegurar que los tres éramos uno en atacar la Edición Vaticana, idea que yo he desmentido con toda la energía de mi corazón.

El Cardenal Secretario envió un aviso al Sr. Nuncio, que este transmitió al P. Provincial, haciendo saber que se me avisara que tuviera cuidado en no dejarme llevar de los que eran tachados como enemigos de la Vaticana y de D. Pothier (P. de Santi, D. Mocquereau,

${ }^{296}$ López-Calo, Nemesio Otaño, pp. 51-61. 
J. Bas), que D. Pothier gozaba de toda la confianza del Santo Padre, y que era preciso apoyar la Edición oficial...

El P. Provincial me leyó la carta del Sr. Nuncio, pero habiendo yo explicado el estado de la cuestión, quedó sumamente satisfecho. Convenimos en que, para quitar toda sospecha, dejaría de ir yo al Congreso. [...]

Nada, pues, tiene que temer V.R. en este punto: Los Superiores entendieron que no se trataba de la cuestión gregoriana $u t$ sic, sino de una intriga de D. Guepin, quien es muy conocido por nosotros.

Mi carta sé que produjo excelente resultado: el Sr. Nuncio, que no ha oído en toda España sino elogios de mi celo pro reforma, se convenció enseguida, y me hizo saber que quedaba muy satisfecho de mi conducta, la cual alaba sin reservas. Sé que envió mi carta al Sr. Cardenal Secretario, y este ha hecho saber que quedo yo plenamente justificado, y que en el Vaticano están muy satisfechos de mí. [...]

Con esto ha quedado todo in pace, y yo contento $\mathrm{y}$ agradecido a Dios y a mis buenísimos superiores [...]. ${ }^{297}$

El análisis de esta disputa nos interesa, de acuerdo con la línea que trazábamos más arriba, en cuanto puede contribuir a mostrar la función que debieron cumplir los congresos, particularmente el de Sevilla, como escenarios en los que se pusieron en juego los capitales simbólicos y materiales, y se desencadenaron pugnas -incluso hostiles- por la preponderancia entre distintas posturas, en ocasiones, alejadas hasta lo antagónico.

El congreso de Valladolid confió a los benedictinos silenses, en la persona de Casiano Rojo, la responsabilidad de las partes cantadas en gregoriano ${ }^{298}$. Como hemos apuntado más arriba, el arzobispo Cos y Macho era, además, cercano a los monjes de Silos y partidario de esta tendencia. En Sevilla, por el contrario, fueron los benedictinos catalanes los que monopolizaron las interpretaciones gregorianas. Tan sólo, y a instancias de Almaraz, se les encargó a los monjes silenses la ponencia sobre canto llano en las sesiones privadas. Dicha ponencia corrió a cargo de Rojo, y fue la única ocasión de notoriedad que se les brindó. De acuerdo con la estrategia decidida de rehuir cualquier confrontación al respecto -algo que no se consiguió, no obstante-, los organizadores de los congresos castellano y andaluz trataron de evitar a toda costa

\footnotetext{
${ }^{297}$ Carta de Otaño a de Santi, 3 de diciembre de 1908. AMSL. FO. Correspondencia, T01/040.

298 Además, en la tercera y última sesión solemne impartió una lección práctica de interpretación del canto gregoriano. Véase: $M S H, 1$ (1907), pp. 4, 24, 31, 35, 46.
} 
debate alguno respecto de la polémica gregoriana ${ }^{299}$. De esta forma, se intentaba salvar, al menos a nivel oficial, la neutralidad y ecuanimidad en los congresos, independientemente de los posicionamientos de cada uno. Sin embargo, la preferencia del congreso de Valladolid por los monjes de Silos hizo que, lógicamente, salieran reforzados frente a la otra parte.

Las decisiones tomadas por las organizaciones de uno $\mathrm{u}$ otro congreso, por diferentes que fueran, estaban acordes con las directrices de Roma. La Santa Sede, aunque había reconocido como oficiales las ediciones elaboradas por Pothier, toleraba las tesis solesmenses, es decir, de Mocquereau ${ }^{300}$. Sin embargo, a pesar de sus pretensiones declaradas de mantenerse dentro de la neutralidad, la adhesión de los organizadores del Congreso hispalenses a la tendencia favorable a los signos rítmicos y su inclinación a favor del grupo catalán le hicieron actuar con parcialidad. Tales fueron los casos de Ripollés y Otaño ${ }^{301}$. El segundo reconocía en una carta a Mocquereau que:

Este Congreso Español de Música va a ser, según yo entiendo, una apología de Solesmes. Yo confieso que he andado errante por otros campos, eso sí con muy buena intención; pero luego he comprendido mejor las cosas, y he visto lo que conviene hacer. En mis artículos últimos me he declarado abiertamente por Solesmes.

Mi intención era que presidiera el P. Suñol las sesiones gregorianas; pero este Sr. Arzobispo parece que tenía algún

\footnotetext{
${ }^{299}$ Otaño manifestaba al respecto a Antonio Vico, nuncio de la Santa Sede en España: "En Valladolid hice considerables esfuerzos para evitar esa cuestión, a fin de que no apareciera la división entre los buenos; pero estos esfuerzos los había multiplicado este verano en los preparativos del Congreso de Sevilla, donde nuestro intento era evitar a todo trance estas disensiones, y llevar a los dos bandos por vías de paz y concordia. Por eso quería prescindir de toda opinión personal, que sobre estos puntos podía yo tener, y aunque en mis escritos he hecho ver de modo, acaso demasiado claro, la utilidad de ellos, en un Congreso hubiera dejado completamente a un lado todo cuanto pudiera estorbar la difusión de la Edición Vaticana." Carta de Otaño a Antonio Vico, [sin día] noviembre de 1908. AMSL. FO. Correspondencia. TA01/050.

${ }^{300}$ Otaño alude en su carta al Nuncio a la siguiente documentación sobre el tema: [...] En el Congreso de Valladolid, cuyas discusiones dirigí, pudo verse claramente mi actitud acerca de la cuestión, que hoy trae tan divididos a los gregorianistas. Hablo de los signos rítmicos, que yo en vista de los Decretos de la Sagrada Congregación de Ritos (24 Febrero 1904 y 14 Febrero de 1906), los juzgué permitidos por la Santa Sede, idea en que me confirmé con la carta del Emmo. Cardenal Secretario del 24 de Junio de 1905, con la de Monseñor Panisi del 2 de Mayo de 2906, y sobre todo con la de Monseñor Dubois, Obispo de Verdún, que sobre esos puntos le hizo verbalmente Su Santidad. Carta de Otaño a Antonio Vico, [sin día] noviembre de 1908. AMSL. FO. Correspondencia. TA01/050.
}

${ }^{301}$ En el capítulo 2 transcribíamos una carta de Ripollés a Pedrell en la que mostraba ante Almaraz su predilección por los benedictinos catalanes, véase p. 132. Sobre la posición de Otaño respecto a las cuestiones rítmicas gregorianas ver: "La cuestión gregoriana: causa finita", Razón y Fe, 18 (1907), pp. 471-472; y “El Gradual Vaticano”, Razón y Fe, 21 (1908), pp. 475-483. 
compromiso con los de Silos, y nombró al P. Casiano. Yo veré cómo se pueden arreglar las cosas del mejor modo posible. ${ }^{302}$

Las decisiones de los principales encargados de la organización de los congresos, que, en lugar de distribuir de forma más equitativa las distintas responsabilidades para asegurar que todas las tendencias estuvieran representadas, las ponían en manos de sólo uno de los grupos en liza, debieron contribuir, creemos, a consolidar un mapa excesivamente dual, favoreciendo así la contraposición: o Pothier o Mocquereau, o Silos o Montserrat, o castellanos o catalanes. De esta forma, el grupo elegido tenía a su disposición todos los recursos que proveían estas grandes manifestaciones y escaparates de gran proyección para lograr prevalencia, difusión de sus ediciones, y remuneraciones económicas. Por el contrario, el grupo del que se prescindía, era condenado a la invisibilidad.

La línea abierta seguida por Roma de crear un espacio de tolerancia al aceptar junto a la oficial la tendencia solesmense no fue correspondida por unos y otros con una actitud de convivencia y respeto, sino de competencia, en algunos casos, cruda. Algunos pasajes de la correspondencia de Otaño sobre el tema dejan entrever la dinámica de confrontación existente entre unos y otros: los benedictinos de Silos, según Otaño, no sólo imponiendo sus opiniones sino desprestigiando las contrarias; Otaño, por su parte, respondiendo a los "bríos pottieristas" con las armas a su diposición:

Respecto del Gradual, no digo que a algunos escandalicen los horrores, pero tengo por cierto que mi actitud templará los bríos de ciertos pottieristas, que en sus excursiones, (me consta), han hecho más daño con sus exageraciones, y exclusiones, y anatemas del sistema contrario, que con todo lo que yo puedo decir. [...]

Yo he visto en los de Silos un alejarse de mí extraordinario, y antes un empeño notable en ponerme las cosas de modo distinto al que eran, siendo así que estaba perfectamente informado de Roma en todo lo que pasaba.

En el momento que vea yo que dejan a un lado esa cuestión y respetan lo que es respetable, inflaré el pelotón de la retórica como conviene. ${ }^{303}$

\footnotetext{
${ }^{302}$ Carta de Otaño a Mocquereau, 29 de agosto de 1908. AMSL. FO. Correspondencia, TA01/038.

${ }^{303}$ Carta de Otaño a Goicoechea, 10 de octubre de 1908. AMSL. FO. Correspondencia, T01/035. En esta dinámica de polémica y enfrentamiento, el artículo publicado por Otaño en la revista jesuita Razón y Fe antes mencionado dio lugar a una refutación de los benedictinos de Silos: "El Boletín de Santo Domingo de Silos de este mes de noviembre trae una refutación anónima de las ideas, por mí emitidas en Razón y $\mathrm{Fe}$; pero ¿es este proceder científico y cuerdo? $\mathrm{O}$ ¿es que la falta de argumentos se quiere encubrir con sofismas y subterfugios de mala ley? Creo que la historia se encargará de aclarar los hechos, y por eso
} 
Goicoechea respondió a Otaño advirtiéndole de lo perjudicial de estas apasionadas y estériles disputas, así como de la necesidad de que se mantuviera al margen de ellas y en un terreno neutral, siempre de parte de lo dispuesto por la Santa Sede:

Volviendo a lo del Gradual y sus horrores dice U. que su actitud templará los bríos de ciertos Pothieristas que con sus exageraciones o anatemas del sistema contrario, han hecho más daño que U. con lo que pueda decir; que esto les contendrá; que traen ciertos manejos, etc. Está bien que se haga por evitar desmanes, si los hay, desbaratar esos manejos, y hasta recortar los 300 horrores etc., etc.; pero no estoy conforme que esas cosas se cuenten al público; este no es pues, ni el encargado de corregir desmanes, abusos, ni errores. Con esto no se consigue más que ahondar las distancias. Nosotros, por fortuna, no somos fulanistas, ni tenemos que hacer el caldo gordo ni a los unos ni a los otros. Si pertenecemos a algún partido, sólo puede ser el de aquel que manda, cuando manda lo que puede, y estamos obligados a poner en práctica lo que él quiere, y a quitar los obstáculos que impidan se cumpla lo mandado. No tenemos derecho ciertamente a condenar un sistema que la autoridad competente aprueba, aunque fuese en forma de transeat; pero menos todavía a proclamar la notación rítmica, como superior y preferente a la oficial que realmente es la que obliga. Puestas las cosas en este terreno, vea U. si no hay motivo para escandalizarse al ver que se tira contra la edición oficial aunque se trate de pegar a ciertos partidarios. Le digo estas cosas, no en son de censura; me obliga a ello la lealtad, como obliga la amistad a meter a su amigo en un baño de agua fría para que se le quite algo de fiebre que pueda hacerle daño. U. me habla en confianza y yo le contesto con el corazón en la mano, y no quisiera verle comprometido en esas cosas que interesan a partidarios de un bando, sectarios, o como U. quiera llamarles. Nosotros con el que manda y nada más; y tenemos la seguridad de no equivocarnos. ${ }^{304}$

La respuesta de Goicoechea, así como otras que recogemos a continuación, pone de manifiesto una toma de conciencia por parte del maestro de capilla vallisoletano del peligro que entrañaban estas disputas, pues abrían profundas grietas en el incipiente, y aún débil, movimiento reformista ("Con esto no se consigue más que ahondar las distancias"). En estos momentos cruciales para el congreso de Sevilla y el movimiento en general, Goicoechea asumió un papel pacificador y conciliador. Para él

esperamos con tranquilidad. [...]" Carta de Otaño a Mocquereau, 14 de noviembre de 1908. AMSL. FO. Correspondencia, TA01/051.

${ }^{304}$ Carta de Goicoechea a Otaño, 13 de octubre de 1908. AMSL. FO. Correspondencia, 009/002.002. 
la unidad y "la concordia entre los músicos españoles" era un bien que había que preservar por encima de opiniones, disensiones o intereses personales:

El P. Casiano no contesta; pero si lo hace diciendo que no va a Sevilla, yo me permitiré aconsejarle a que vaya y sin recelos: que hablando se entiende la gente y conviene salga algo que haga ver que hay concordia entre los músicos españoles, y una misma aspiración en medio de las diferentes apreciaciones". ${ }^{305}$

En esta otra carta vuelve a insistir en estas ideas. Por encima de las personas y los conflictos estaba el fin del Congreso y el interés de la reforma ${ }^{306}$ :

¿Qué no piensa U. ir a Sevilla? Eso no puede ser: después que U. ha andado por allá, y dejar de asistir sería una campanada que sonaría muy mal. Que el artículo de "Razón y Fe" produjo mal efecto en ciertas regiones, o ha sido pretexto para ello: pues ahora no se arregla con dar otro mal paso. Que en Sevilla han estropeado la combinación de organistas: allá responderá la Comisión, o quien sea.

Que es un episodio de mal efecto en los preludios, no es razón para que no represente lo otro [...] Una cosa es el mayor o menor lucimiento de las personas; y otra cosa distinta es el fin del Congreso. Que allá no le reservan otro papel que el modesto de ponente, pues a acallar todo resentimiento, y hacer el sacrificio de desempeñarlo del modo mejor posible; y U. se queda tan tranquilo. Si pudiéramos tocar un resorte eficaz para plantear la reforma en las Iglesias principales de España implantando el Canto Gregoriano con o sin episemas y demás zaragatas haciendo que se constituyan buenas Comisiones diocesanas que censuren y vigilen, aunque personalmente hiciéramos un mediano papel, crea U. que por mí quedaría satisfecho, aunque todos los papeles habidos y por haber dijeran que yo había hecho una plasta. Todo esto importa un bledo. La lástima es que no tendremos la suerte de dar con el resorte que necesitamos. A esta altura de cosas no [es] medio decoroso de retirarse, y entrar en explicaciones para el público...peor es meneallo. [...]

Adelante, pues, con los faroles. Qué día le espero? ${ }^{307}$

${ }^{305}$ Ibídem.

${ }^{306}$ En el momento en el que Goicoechea escribió esta carta, Otaño ya había recibido la orden de sus superiores de no asistir al Congreso, algo de lo que el maestro de capilla no estaba informado aún, como se desprende de ella.

${ }^{307}$ Carta de Goicoechea a Otaño, 29 de octubre de 1908. AMSL. FO. Correspondencia, 009/002.003. Pocos días después volvía a insistir: "Confirmo todo lo dicho en mi anterior, et amplius en vista de su última. Consulte, si fuese necesario, con sus Superiores el caso, y a no ser que se lo prohíban in terminis, hay que ir a Sevilla, aunque no le agrade a V. La misma opinión que V. la tengo desde mucho tiempo sobre estas quisi-cosas de los gregorianistas, sectarios de uno y otro sistema; y ¿merece esto que se las tome con calor? De ningún modo, una cosa en ser partidario de una escuela, y otra muy distinta el trabajar por establecer el canto gregoriano. 
Las divisiones en distintos clanes o grupos dentro del movimiento reformista, contra las que advertía Goicoechea, interrumpían, además, los enriquecedores flujos de información y colaboración entre los miembros de cada uno de ellos, afectando a otros proyectos y empresas surgidas en su seno. El caso de $M S H$ es un claro ejemplo. Otaño tuvo que dejar de contar con la valiosas contribuciones de los benedictinos de Silos, según contó a Angelo de Santi: “[...] Los PP. Suñol y Sablayrolles me sacan de muchos apuros: en cambio los PP. de Silos no deben estar muy calientes para la colaboración." 308

Estas pugnas internas eran especialmente perjudiciales de cara al exterior. La imagen de discordia y desacuerdo debilitaba enormemente el movimiento, siempre amenazado por el statu quo musical religioso, con el que, como se está evidenciando, estaba abocado al enfrentamiento. En realidad, los verdaderos enemigos de los reformistas, según la perspectiva de estos, eran aquellos que se resistían a la reforma de una u otra forma, o por una u otra causa, y que encarnaban una cultura litúrgico-musical consagrada por un largo proceso histórico, pero que constituía aquella que el $M P$ y el regeneracionismo musical español trataban de superar -reformar-. Esta es la razón por la que Goicoechea, en las distintas cartas que venimos citando, insiste tanto en la necesidad, no sólo de mantener la unidad y la concordia dentro del movimiento, sino también de mostrar a este de cara al exterior sin fisuras y trabajando en una misma dirección. Cualquier disensión era, para los contrarios a la reforma, una gran oportunidad:

Deseaba hablarle también acerca de su artículo sobre la Vaticana. Después de todas aquellas alabanzas a la Comisión y de cosas muy bien dichas, se nos descuelga con unos peros...jhorror! furor! terror! Quiere U. que se adopte la edición oficial, y lo recomienda a tanto director de coro, organistas, cantores, comunidades, etc. que detestan lo mismo la notación oficial como la

Dejando esto a un lado y del que habíamos de tratar en el camino, hay que ir a Sevilla, para tratar allí de muchas cosas, que interesan a la reforma, y para hablar con los unos y los otros y los de más allá, de manera que se vea que no existen esas enemistades. Con que, primero, a Sevilla pacíficamente; después continuar enseñando y defendiendo el canto gregoriano con o $\sin$ puntos y demás armas al hombro, porque es cosa de la Iglesia; luego el canto polifónico y el moderno, sin meterse también en demasiadas honduras modernistas, porque las formas de moda suelen caer pronto en desuso." Carta de Goicoechea a Otaño, 1 de noviembre de 1908, que no se conserva. La cita figura a pie de página en transcripción de carta de Otaño a Goicoechea, 1 de noviembre de 1908. AMSL. FO. Correspondencia, TA01/047.

${ }^{308}$ Carta de Otaño a de Santi, 29 de octubre de 1908. AMSL. FO. Correspondencia, T01/36. 
de los signos rítmicos, diciéndoles que se halla plagada de errores, pasajes dudosos, y no sé cuántas cosas más!

Si supiera U. con qué fruición lo comentaban por aquí algunos, que esperan que en Sevilla se dará la puntilla a esa monserga de canto gregoriano, y a esa otra música que nos meten esos chiflados, y ni sabe ni huele. ${ }^{309}$

Independientemente de su mayor o menor articulación como institución estructurada, el movimiento se nos muestra, por tanto, como un ente orgánico y unitario en el que todos los miembros individuales, grupos y corrientes eran interdependientes, a pesar de las tensiones que, en muchas ocasiones, caracterizaban los vínculos que las ligaban. Al mismo tiempo, era una nueva realidad que luchaba por abrirse paso dentro del universo litúrgico-musical establecido, del que había emergido pero que debía regenerar, por tanto, con el que mantenía una relación necesariamente de confrontación.

En el congreso de Sevilla se procuró y consiguió, al menos durante su celebración, que este episodio más del conflicto entre las dos corrientes benedictinas, en el que se vio envuelto en primera persona Otaño, y toda la organización -incluso la Santa Sede-, no trascendiera ${ }^{310}$ : "Los benedictinos.- La brecha interior, no se ha manifestado al exterior, al menos en las Secciones."311. Sin embargo, a pesar de esta discreción, la "brecha" existía y se manifestó:

No sé porqué, Ripollés delante de mí, se incomodó con el P. Casiano y le pidió las memorias de Suñol y Sablayrol[1]es para retirarlas; intervine para ponerlos en paz, hice que aquel redactara sus conclusiones y las vieran estos dos; se les pudo arreglar, y la cosa no pasó de allí [...] Veo que en general hay gran prevención en contra de los Silenses, empezando desde el Arzobispo. ${ }^{312}$

\footnotetext{
309 Carta de Goicoechea a Otaño, 7 de octubre de 1908. AMSL. FO. Correspondencia, 009/002.001. Goicoechea se refiere en esta carta al artículo de Otaño antes mencionado: "El Gradual Vaticano", Razón y Fe, 21 (1908), pp. 475-483.

310 “A los que me preguntan extrañados de que U. no vaya a Sevilla les he dicho que nada de particular tiene encontrándose U. dedicado a sus estudios de los cuales los Superiores no se han creído en el caso de poderle dispensar; y ya no les extraña. Más vale que pase así." Carta de Goicoechea a Otaño, 6 de noviembre de 1908. AMSL. FO. Correspondencia, 009/002.004. Días antes había pedido a Ripollés: "Le suplico exponga V. claramente la cuestión, tal como es, al Sr. Arzobispo y a los PP. Suñol y Sablayrolles; pero fuera conviene decir que por motivos de salud no me ha sido posible la asistencia, y es verdad que llevo cuatro o cinco días medianucho." Carta de Otaño a Ripollés, 23 de octubre de 1908. AMSL. FO. Correspondencia, TA01/045.

${ }^{311}$ Carta de Goicoechea a Otaño, 14 de noviembre de 1908. AMSL. FO. Correspondencia, 009/002.005.

${ }^{312}$ Ibídem.
} 
Otaño contaba a Angelo de Santi el ambiente que, según le habían transmitido, se respiraba en relación con los benedictinos del monasterio burgalés:

En cambio tengo noticias que, habiéndose sabido sotto voce en Sevilla la actitud de Silos para conmigo, los congresistas, nullo excepto, la Junta Organizadora y aun el mismo Sr. Arzobispo han tratado al P. C. Rojo con una frialdad y despego, que ha llamado no poco la atención de algunos. ${ }^{313}$

Esta "brecha", ya abierta durante la última etapa de la preparación del congreso de Sevilla, fue de tal magnitud que llevó a Roma a dar instrucciones expresas al respecto, según cuenta Goicoechea:

Los de Silos. Ni palabra sobre el asunto de U. en Sevilla. Únicamente al pasar por esta (querían que fuese en compañía de ellos, pero yo todavía no tenía nada arreglado, y aunque salí dos días antes de lo que proyectaba, también en vista de una carta de Ripollés) el P. Casiano dijo que sentía no poder verse con U. Por lo demás, yo no vi que tuviesen empeño en que no se tratara de las ediciones rítmicas en el sentido de estar autorizadas; a lo que iban dispuestos era a que no se desacreditara la edición oficial ni se consintiera en declarar superior a ella ninguna otra privada. Tal vez ellos se figuraron verse en peligro su causa al ver en las ponencias al P. Villalba a Olmeda, y luego los PP. catalanes al frente del Canto Gregoriano, y creyeron que iba a ocurrir una catástrofe.

Realmente, yo mismo creo que de no haber órdenes terminantes de Roma, como indicó el Sr. Arzobispo de Sevilla, se hubieran enzarzado las cuestiones más de lo conveniente, y tal vez se hubiera dado pretexto, al menos, de que no se volvieran a reunir Congresos de música; y el efecto, en cuanto a la implantación de la reforma, hubiera sido desastroso. ${ }^{314}$

Estas afirmaciones revelan que durante el congreso de Sevilla el movimiento reformista español vivió una coyuntura crítica. Aunque, como veremos, irán apareciendo otros medios para ir conformando y consolidando el movimiento pro reformas -especialmente las revistas-, en esos momentos iniciales, los congresos constituyeron, independientemente de su eficacia práctica, los acontecimientosinstrumentos principales para concitar y hacer converger a los distintos agentes involucrados en la música para el culto católico en España. El arzobispo de Valladolid,

\footnotetext{
${ }^{313}$ Carta de Otaño a de Santi, 3 de diciembre de 1908. AMSL. FO. Correspondencia, T01/040.

${ }^{314}$ Carta de Goicoechea a Otaño, 9 de diciembre de 1908. AMSL. FO. Correspondencia, 009/002.007.
} 
José María Cos y Macho, ponía de relieve en una carta dirigida a Otaño, tras la mala experiencia vivida por este en el congreso de Sevilla, la importancia de estos eventos:

Por eso siento que U. manifieste cierto decaimiento de ánimo, citando la opinión de Pedrell, que opina imposible en España la reforma de la música. Que es difícil, sí; que tardará en implantarse, también; que no llegará a ser muy perfecta, acaso; pero, si continúan celebrándose congresos y los Prelados la establecen, como es de esperar, en sus Seminarios, confío que ha de ser un hecho.

Es pues preciso que $\mathrm{V}$. continúe trabajando con el mismo entusiasmo que hasta ahora. $[\ldots]^{315}$

Es difícil encontrar en su vasta correspondencia referencia alguna a un estado de decaimiento anímico como el que debió confesar Otaño a Cos y $\mathrm{Macho}^{316}$. Ciertamente, el jesuita fue la principal víctima de esta polémica. Una vez transcurrido el Congreso, al que, como ya hemos señalado, se le prohibió asistir, comentó a Goicoechea la desproporción entre el cariz que habían tomado los acontecimientos y la verdadera importancia del tema:

Ya V. ve que la cosa no era para tanto y que todo podía haberse arreglado pacífica y amistosamente; además que yo no sólo no traté de suscitar esas cuestiones en el Congreso, sino que terminantemente hablé al Sr. Arzobispo y a Ripollés sobre que no se debía permitir mi indicación de ese género. ${ }^{317}$

En su biografía sobre Nemesio Otaño ya citada, López-Calo dedica unos párrafos a comentar la lucha que en torno a la cuestión gregoriana se produjo entre las dos tendencias benedictinas a escala general eclesiástica, de la que las controversias suscitadas en el congreso de Sevilla fueron tan sólo un reflejo. Destaca, al igual que hizo su biografiado, la falta de correspondencia entre la enorme gravedad que adquirió

${ }^{315}$ Carta de Cos y Macho a Otaño, 4 de enero de 1909. AMSL. FO. Correspondencia, 009/004.038.

316 Los ánimos de Cos y Macho tuvieron un efecto inmediato. Poco después escribió a Pedrell: “¿Revistas, congresos, asociaciones...?? Non credam! dirá V.- Yo sigo diciendo: Credo.- Que somos unos tales y unos cuales, que en España sucede esto y lo otro...- Concedido. Yo quizá siga su teoría, cuando peine canas y pueda decir como V.: fidem servavi! Pero los jóvenes tenemos que tener los méritos de $\mathrm{V}$. para decir lo mismo y mientras tanto tenemos la obligación de trabajar, dando unas veces en el clavo y otras...en la herradura. Es verdad que no he ido al Congreso de Sevilla ipero no por eso he dejado de trabajar: verdad que me han querido poner unas vigas en el camino y que el carro se atascó, pero he saltado por encima y aquí me tiene V. el mismo de ayer." Carta de Otaño a Pedrell, 23 de enero de 1909. BC. FFP. M 964 O.

${ }^{317}$ Carta de Otaño a Goicoechea, 29 de noviembre de 1908. AMSL. FO. Correspondencia, T01/039. 
el asunto y su verdadera importancia: una discrepancia teórica que en la práctica no se materializaba en grandes diferencias entre las versiones de las melodías propuestas por una tendencia u otra. La razón de estas polémicas, según sugiere, se encontraba en una cuestión personal entre Mocquereau y Pothier que alcanzó una dimensión exagerada ${ }^{318}$.

Por su parte, Ismael Fernández de la Cuesta, quien también subraya que las posturas, irreconciliables, eran "contrapuestas en detalles, aparentemente sin importancia", apunta claramente a "intereses económicos no siempre confesados"319.

El propio Otaño, algún tiempo después, ofreció a Pedrell una explicación, al margen de malentendidos y enredos, sobre la causa por la que los benedictinos de Silos habían reaccionado de forma tal contundente ante un problema que, aparentemente, no era tan grave. Se trataba, según el testimonio de Otaño, de la necesidad de amortizar la importante inversión, no sólo entendida en términos de dinero, sino también de esfuerzo en todos los sentidos. En este caso, la producción de graduales y kyriales con los que renovar el repertorio de canto llano en las iglesias de acuerdo a los nuevos principios reformistas, servía, además, como forma de sustento a la comunidad de $\operatorname{Silos}^{320}$ :

Ante todo nuestros Superiores no son músicos ni están directamente en disposición de juzgar por sí en nuestras cosas. Este es un dato. Cuando el Congreso de Sevilla, los Benedictinos de Silos me armaron una zancadilla, que pudo traerme gravísimas consecuencias. Supieron ellos que yo me iba a declarar decidido partidario de las ediciones y teorías de Solesmes, $\mathrm{y}$ dándome tal vez una virtualidad enorme y una influencia eficaz, creyeron que el inclinarme yo a ese lado, significaba que todos los gregorianistas españoles iban conmigo, y (aquí está lo gordo) esto les suponía el quedarse en casa con una numerosa edición de Kyriales y Graduales, que habían hecho para propaganda, sí, pero también para el modus vivendi. No quiero ocultar a V. que son pobres y necesitados.

Influidos por esta fatal idea, muy abultada por la necesidad decidieron quitarme de por medio, y enredando las cosas en Roma,

${ }^{318}$ López-Calo, Nemesio Otaño, pp. 53-54.

${ }^{319}$ Fernández de la Cuesta, "La reforma del canto gregoriano", p. 57.

${ }^{320}$ Las cuestiones económicas salieron a relucir en este conflicto en alguna ocasión más. El 6 de octubre escribía Otaño a Goicoechea: "En este sentido y en el de los gastos y honorarios escribió el P. Abad al Sr. Arzobispo, cosa que a este le dio un mal rato. Le hablaba de que sabía él que su Excelencia estaba rodeado de intrigas e influenciado, cosa del todo errónea, pues nadie le ha hablado al Sr. Arzobispo de las cuentas, y estaba tan ignorante de todo, que más no podía ser." Carta de Otaño a Goicoechea, 6 de octubre de 1908. AMSL. FO. Correspondencia, T01/034. Este le respondió: "Ninguna extrañeza me causan las cosas de D. Ildefonso [Guepin], porque ciertamente le llaman tanto la atención las cuestiones del cuánto que a veces anda dando esos traspiés." Carta de Goicoechea a Otaño, 13 de octubre de 1908. AMSL. FO. Correspondencia, 009/002.002. 
¡me hicieron pasar por enemigo de la edición Vaticana ante el Papa, el cual dio orden de que se me avisara y reprendiera! ¡Figúrese V. la alarma de mis Superiores, dada nuestra sumisión absoluta a la Santa Sede! La verdad se abrió paso, se conoció el engaño y se me dejó en buen lugar; ${ }^{321}$

Por tanto, lo acontecido en Sevilla no fue más que una réplica a escala española del terremoto que se produjo en torno a la cuestión del nuevo canto gregoriano propuesto por Roma, desencadenado por las dos familias benedictinas enfrentadas, y causado, siguiendo a Fernández de la Cuesta y el propio testimonio de Otaño, por intereses económicos. Así, estos últimos se mezclaron en este espacio socio-cultural con las cuestiones artísticas o posicionamientos teóricos de forma indisoluble.

\subsection{Las revistas de música religiosa en torno al congreso de Sevilla:}

\section{instrumentos para el liderazgo}

\subsubsection{Música Sacro-Hispana durante el congreso de Sevilla}

El análisis de las controversias en torno a las revistas de música religiosa nos proporciona más información sobre la naturaleza y evolución de este espacio socioartístico -el denominado movimiento reformista- que venimos explorando.

Entre los últimos años del siglo XIX y las primeras décadas del XX nacieron, consecuencia y reflejo del creciente interés que la cuestión de la música eclesiástica suscitaba en España, un buen número de revistas especializadas en la materia. En realidad, el periodismo musical en general experimentó un tremendo auge durante la Restauración gracias a factores como la consolidación de una burguesía próspera, la proliferación de asociaciones musicales tanto profesionales como de aficionados, la consideración del conocimiento musical como signo de distinción social, o la dependencia de muchas editoriales de negocios de venta de partituras e instrumentos ${ }^{322}$.

En un artículo publicado en Razón y Fe en 1908, Otaño relacionaba las revistas de música religiosa más destacadas del momento, y les dedicaba un breve comentario

\footnotetext{
${ }^{321}$ Carta de Otaño a Pedrell, [sin fecha]. AMSL. FO. Correspondencia, T01/121. Aunque no figure su datación, hay que ubicarla en el contexto de los preparativos del congreso de Barcelona, seguramente en mayo de 1912. La carta transcrita justo antes tiene fecha de 5 de mayo de 1912 y la posterior de 15 de ese mismo mes. Albano García transcribe este mismo fragmento, extraído de la carta que se conserva en la Biblioteca de Catalunya, en "Sobre la reforma de la música religiosa en España”, p. 975.

322 Jacinto Torres Mulas, "Periódicos musicales. España”, DMEH, 10 vols., ed. por Emilio Casares (Madrid: SGAE, 2001), vol. 8, pp. 692-702, p. 693.
} 
crítico $^{323}$. Entre las españolas citaba el Boletín de Santo Domingo de Silos, la Revista Montserratina, o la Revista Musical Catalana ${ }^{324}$, así como las recién nacidas Voz de la Música, dirigida por Federico Olmeda, y Música Sacro-Hispana, cuyo principal impulsor era el propio Otaño ${ }^{325}$. Como ya vimos, esta última había sido declarada en el congreso de Valladolid órgano oficial de los congresos nacionales de música sagrada, con todas las ventajas que ello conllevaba. $M S H$, era, junto con la Junta Central de los congresos, uno de los órganos fundamentales del proyecto -fallido en esta primera intentona realizada en el Congreso vallisoletano- de levantar una estructura general española que institucionalizara y articulara el movimiento musical religioso. Dado que las competencias de la Junta Central fueron asumidas por la Junta Organizadora de Valladolid, fue esta quien debió ocuparse igualmente de la edición de la revista $M S H$ como órgano oficial de los congresos durante este primer año.

Durante la celebración del congreso de Sevilla, se replanteó la cuestión. Según cuenta Vicente Goicoechea, miembro de la CDMS de Valladolid y, junto con Otaño, uno de los responsables de $M S H$, se gestionó su traspaso a la CDMS hispalense: " $L a$ Revista.- Se han hecho algunas gestiones para dejarla a esta Comisión: pero nadie quiere entenderse formalmente con la vallisoletana",326. Sin embargo, el órgano reformista sevillano se negó a aceptarla. Ripollés, quien, como reflejan sus cartas, acusaba un excesivo cansancio y desánimo, debió ser tajante al respecto. Este pasaje es de una carta de Otaño: "Nada me decía de esto [del asunto de la revista] Ripollés, sino que no se pensara en que ellos tomaran esa carga" $" 327$.

\footnotetext{
${ }^{323}$ Nemesio Otaño, "Movimiento bibliográfico-práctico de la música religiosa en 1907 [(2)]", Razón y fe, 21 (1908), pp. 353-361. El artículo fue publicado en varias entregas. Las revistas extranjeras citadas por Otaño son: las italianas Psalterium, L'Organista Moderno, La Biblioteca Ceciliana, la norteamericana Church Music, la germana Kirchenmusikalisches Jahrbuch, junto a ediciones musicales religiosas. La revista más importante de finales de siglo XIX fue La Música Religiosa en España, nacida en 1896 en el seno de la Asociación Isidorina, y dirigida por Pedrell. Su último número vio la luz en 1899. Véase el catálogo crítico sobre publicaciones periódicas musicales españolas de Jacinto Torres Mulas, Las publicaciones periódicas musicales en España (1812-1990): Estudio crítico-bibliográfica: Repertorio general (Madrid: Instituto de Bibliografía Musical, 1991).

${ }^{324}$ La Revista Musical Catalana, boletín del Orfeó Catalá no se circunscribía a la música religiosa.

${ }^{325}$ Otras revistas católicas no especializadas e, incluso, en algún caso, la prensa generalista, acogieron en sus páginas la cuestión del $M P$, fruto de la colaboración de determinados músicos eclesiásticos. Tal es el caso, por ejemplo, de La Ilustración del Clero, de los Misioneros del Corazón de María; la Revista eclesiástica de Valladolid; la jesuita Razón y Fe; las agustinas El Buen Consejo o La Ciudad de Dios; El Diario de Gerona, en el que colaboraba Miguel Rué o España y América.

${ }^{326}$ Carta de Goicoechea a Otaño, 14 de noviembre de 1908. AMSL. FO. Correspondencia, 009/002.005.

${ }^{327}$ Carta de Otaño a Goicoechea, 29 de noviembre de 1908. AMSL. FO. Correspondencia, T01/039.
} 
Ciertamente la revista en esos momentos era una carga, pues estaba atravesando, después de apenas un año de vida, por una situación crítica ${ }^{328}$. El propio Otaño hacía referencia a ello públicamente en unos duros términos, que dejan traslucir un cierto enojo y disgusto:

Todavía subsiste este desgraciado estado de cosas; todavía en España no puede vivir vida próspera una revista de música religiosa, puesta por su precio económico al alcance de todas las rentas, y Música Sacro-Hispana, cuyas intenciones, plan y programa son grandemente dignos, se resiente ya de esta frialdad; falta de colaboradores y de suscripciones, ¿cómo será posible su vida? Una vez más podrá decirse, si ella no vive y prospera, que estamos dormidos y que nuestra decadencia y pereza es culpablemente voluntaria. $^{329}$

El párrafo termina con una frase en la que se muestra el importante papel que debían jugar los congresos en estas circunstancias adversas, no sólo a nivel de "espíritus" sino también de "obras", como el caso de las revistas: "De esperar es que los Congresos sucesivos acaben de levantar los abatidos espíritus y las obras de celo necesarias para la reforma de la música, que tan de menos se echa en gran parte de nuestras iglesias, ${ }^{, 330}$.

Ni para Ripollés, que rechazaba la responsabilidad de la revista, ni para Goicoechea, ni para Otaño era lo más conveniente el traspaso de $M S H$ a Sevilla. Este último opinaba que, lejos de ser la solución al problema, significaría su desaparición, y esto por dos motivos. En primer lugar, por el ambiente poco idóneo que para la reforma existía en Sevilla ${ }^{331}$. Y en segundo lugar, por lo perjudicial de establecer una dinámica de cambio de sede a cada congreso:

Además, eso que cambie de sedes es cosa imposible; si de Congreso a Congreso va cambiando de domicilio, la revista no puede

\footnotetext{
${ }^{328}$ López-Calo señala los problemas administrativos, económicos de la revista en 1908, además de la dificultad de conseguir colaboraciones y suscripciones. López-Calo, Nemesio Otaño, pp. 47-48.

329 “Movimiento bibliográfico-práctico”, pp. 353-354.

${ }^{330}$ Ibídem, p. 354.

${ }^{331}$ Recordemos, en este sentido, la opinión que le merecían "los sevillanos": "Por de pronto le puedo asegurar a V. que hay por nuestro arte mucho, muchísimos duros (de cabeza), que sobre todo abundan los sevillanos" Carta de Otaño a Pedrell, 29 de agosto de 1908. BC. FFP. M 964 O.
} 
seguir, porque sería un absurdo que crezca un árbol, trasplantándole de año en año.[...]

Considero de importancia trascendental que la revista continúe en Valladolid; he pensado seriamente que el llevarla a Sevilla, sería perjudicial, porque, aunque hay allí algunos elementos más, no hay ambiente ni protección, y moriría. ${ }^{332}$

La ausencia de Otaño en la asamblea sevillana, el desinterés de Ripollés y el "decoro" con el que Goicoechea justificó su decisión de no participar en las discusiones sobre el tema ${ }^{333}$ terminaron por hacer desaparecer del escenario del Congreso la que hasta ese momento había sido la revista oficial, y probablemente de referencia, del movimiento español pro reformas.

El olvido en que cayó $M S H$ en los debates dio vía libre a los interesados en ocupar su espacio con sus propias publicaciones. La sesión cuarta, presidida precisamente por Federico Olmeda, director de Voz de la Música, la principal revista hermana/rival de $M S H$, por tanto, parte interesada, se convirtió en una lucha por la defensa de los propios intereses -legítimos, entendidos por unos; egoístas o innobles, por otros-. Personalidades musicales como el propio Olmeda, editores, e incluso párrocos tomaron parte en esta pugna, que retrata, a nuestro modo de ver, una imagen del movimiento de reformas lejana a idealizaciones. Todos ellos formaron parte como agentes diversos y con diferentes intereses -liderazgo, rentabilidad comercial, optimización de los recursos de las instituciones eclesiásticas que gobernaban- en este juego en el que, a estas alturas, estaba casi todo el capital, material y simbólico por repartir y las posiciones por fijar. Así relata Goicoechea lo que presenció:

Recuerdo que no le hablé porque todavía no se había tratado de ello, de lo referente a la revista. En la última sesión de la sección $4^{\mathrm{a}}$ tocó el ponente el punto de propaganda, y aunque parezca extraño, (y no lo es para el que conozca su desahogo) habló de su Voz, pidió que se suscribieran las parroquias, las catedrales, etc. etc... y allí fue Troya. Se levantó un párroco (no sé si de Huelva) y dijo que nones: que las parroquias estaban recargadas de obligaciones y con pocos recursos, y de los pocos asistentes ninguno salió en favor de la Voz. Encima se levantan los editores de música y dicen que haciendo verdaderos sacrificios han formado catálogos y depósitos de importancia de música litúrgica, y se creían con igual derecho que las

\footnotetext{
${ }^{332}$ Carta de Otaño a Goicoechea, 29 de noviembre de 1908. AMSL. FO. Correspondencia, T01/039.

${ }^{333}$ Véase el fragmento que transcribimos en la p. 446. Carta de Goicoechea a Otaño, 25 de noviembre de 1908. AMSL. FO. Correspondencia, 009/002.006.
} 
parroquias se proveyesen en sus casas. Tena de Valencia, añade que él sostiene un periódico desde hace 13 años que defiende la causa del género verdaderamente religioso (i! U. que conoce el paño puede hacer aquí los comentarios que guste) y pide también ayuda. Lazcano si no estoy equivocado, echa en cara, en términos más o menos claros, a Olmeda que se va este en busca de un negocio desde su ponencia: y se le echa encima el obispo de Salamanca. En fin, aquello se iba poniendo algo feo, y a todo esto nadie resuella por la revista que nos echó encima el Congreso de Valladolid. ${ }^{334}$

Villalba nos ha dejado una versión parecida a la de Goicoechea, aunque centró el enfoque en la indignación que suscitó el proceder de Olmeda, interpretado como una forma de aprovecharse de su condición ventajosa como ponente de la sección para hacer negocio:

Hasta aquí había reinado la animación más unánime, pues aunque los editores callaban, me figuro que celebrarían el encumbramiento y dignificación futura de los músicos; pero les llegó su turno. Conveniencia de apoyar a las revistas de música sagradarezaba el cuestionario; pero ¿cuál era la revista (porque había varias) a que debía darse tal apoyo? ¿Cuál era la que recomendaba el Congreso? Y Olmeda, después de razonar la cosa, recomendó la suya, La Voz de la Música. -Esto no puede pasar- dijeron para su capote y para fuera de él los editores, y hablaron. -¡Habráse visto cosa más...! Esto es un negocio. Y las palabras negocio, etc., etc., corrían por lo bajo. - ¡Vaya con el negocio! Yo no sé si habría o no negocio; pero, francamente, ¿a qué iban los editores a Sevilla? A un negocio bien honrado y legítimo por cierto. ¿Y no te parece que es mucha cosa que protestaran de un negocio, por ser negocio, los que iban al negocio? ¡Vaya que tiene intríngulis el asunto! El hecho fue que, discutida y todo, La Voz de la Música salió recomendada, y aprobada fue la conclusión en la correspondiente junta de ponentes presidida por el señor Arzobispo, y leída en la sesión de clausura. ${ }^{335}$

Más adelante volveremos a incidir en otro polémico punto de la inextricable trama de relaciones que vinculaban el negocio editorial y la reforma ${ }^{336}$. Nos interesa ahora seguir el hilo de estas pugna entre los líderes reformistas. La disputa mantenida en dicha sesión se decantó a favor de Olmeda, quien, al menos en principio, consiguió

\footnotetext{
${ }^{334}$ Carta de Goicoechea a Otaño, 25 de noviembre de 1908. AMSL. FO. Correspondencia, 009/002.006.

${ }^{335}$ Villalba, "El Segundo Congreso Nacional”, p. 417.

${ }^{336}$ Véase epígrafe 4.2.4. "El negocio editorial y las instituciones de la reforma: el problema de disparidad de criterios de las comisiones diocesanas de música sagrada".
} 
su objetivo de que el Congreso recomendara su revista. Así se lo comunicó Goicoechea a Otaño: "Vienen al día siguiente las conclusiones y U. habrá notado que la única Voz que resuena para ser recomendada es la Voz de la M[úsica]"337. Sin embargo, no fue este el final del caso. Villalba ofreció una versión tamizada y diplomática:

Mas no paró aquí la cosa, y conste que te hago historia solamente, sino que, llevadas a la imprenta las cuartillas, al salir impresas, donde decía La Voz de la Música, se puso La Música SacroHispana. Fue una equivocación sin duda. Reclamó Olmeda, y al día rectificaban reduciendo el texto a su primitiva y verdadera redacción. ${ }^{338}$

Goicoechea, por su parte, nos revela sin tapujos lo que aconteció: Ripollés modificó la conclusión final del Congreso relativa a este punto para evitar que el órgano de difusión de Olmeda, por tanto, el medio de este para ejercer su influencia, reemplazara a $M S H$, condenada a la desaparición:

Yo había asistido a la famosa sesión pero no me pareció oportuno terciar en ese debate si quiera por decoro, y no pensaran que también los de Valladolid íbamos buscando el negocio de las perras por la revista. Pero después fue ella. Cuando fui a despedirme de Ripollés, sin que yo mencionara para nada la revista; me preguntó[:] En qué queda eso de la revista? [autocita:] Ya sabe U. que en Valladolid a propuesta del Sr. Arzobispo de Sevilla se encomendó esa carga a la Comisión hasta que se reuniera el siguiente: llegado ese caso se les ofreció a Us., y ni la han aceptado, ni se ha hecho siquiera mención de ella en este Congreso: por tanto no queda más recurso que, o suspenderla devolviendo el importe de las suscripciones cobradas (que no son muchas) o continuar hasta que se cumpla el año; y esto lo decidirá el Sr. Arzobispo de Valladolid. [fin de la autocita] Cayó en la cuenta de lo desairado de su papel y también del nuestro; del suyo, porque, sin ser un lince cualquiera ve que el ponente Olmeda procuraría por la revista de Valladolid como Amezua por Mutin [heredó la fabrica de órganos Cavaillé-Coll, rival de Amezua] si llega a ser ponente en asunto de órganos...Esto ocurrió a las 5 de la tarde: a las 8 (hora de salida) vino a la estación con una prueba del Boletín Oficial de Sevilla en que aparecía cambiada la conclusión del Congreso, haciendo mención a Música Sacro-Hispana, "Organo de los Congresos Nacionales". 339

\footnotetext{
${ }^{337}$ Carta de Goicoechea a Otaño, 25 de noviembre de 1908. AMSL. FO. Correspondencia, 009/002.006.

${ }^{338}$ Villalba, "El Segundo Congreso Nacional", p. 417.

${ }^{339}$ Carta de Goicoechea a Otaño, 25 de noviembre de 1908. AMSL. FO. Correspondencia, 009/002.006.
} 
Por tanto, la cercanía ideológica de Ripollés con Goicoechea y Otaño que, como veremos a continuación, constituyeron el grupo más fuerte dentro del movimiento y claramente opuesto a las tendencias de Olmeda, fue el factor decisivo a la hora de resolverse la cuestión. La revista fundada en el congreso de Valladolid se salvó en el congreso de Sevilla in extremis, y gracias a una maniobra al margen de la decisión de la asamblea. La conclusión respecto a este punto quedó redactada como sigue:

Punto l) El Congreso recomienda eficazmente las Revistas que se dedican a la difusión de la música, según el Motu proprio de $\mathrm{Su}$ Santidad y en especial La Música sacro-hispana, de Valladolid, órgano de los Congresos de Música religiosa en España. ${ }^{340}$

El desenlace fue, de nuevo, favorable a Otaño y los que compartían con él una misma línea de pensamiento y acción. $M S H$ volvió a sus manos, lo que significaba seguir manteniendo bajo su control el principal medio de difusión del movimiento, sancionado a través de sus grandes expresiones, los congresos. Desde su punto de vista, MSH seguía siendo un órgano a salvo de heterodoxias, y protegido de servir a otras pretensiones o intereses que no los ideales reformistas, según eran entendidos por él:

Me alegro de saber el asunto de la revista. [...]

Mi parecer es que sigamos como antes sin hacer caso de nadie; tendremos por lo menos una revista derecha en España, porque si cae en otras manos, Dios sabe lo que harían de ella, y entonces sería peor el remedio que la enfermedad. La cosa es que con nuestras dificultades vamos tirando adelante, y como van pasando dos años, pasarán otros dos, y entonces será otra cosa. Ya llenaremos los huecos de la mejor manera posible. No hay que pensar en suprimir la revista ni cosa parecida. ${ }^{341}$

En mayo de 1909, la CDMS de Valladolid se desvinculó de la revista, cuando se hizo cargo de su edición la casa Lazcano y Mar de Bilbao. Las razones fueron, según cuenta Goicoechea, la falta de medios de que disponían, y evitar verse mezclada en un negocio de carácter lucrativo, como era el editorial ${ }^{342}$ :

${ }^{340}$ Crónica del Segundo Congreso, p. 276.

${ }^{341}$ Carta de Otaño a Goicoechea, 29 de noviembre de 1908. AMSL. FO. Correspondencia, T01/039.

342 Goicoechea proseguía: "En cuanto a tratar con la casa de Lazcano, la Comisión no querrá". Y a continuación relataba su propia experiencia con el editor, para finalizar: "En fin, es desgracia tener que tratar con editores. Cuente con que le ayudaré a U. en todo lo que me sea posible en asuntos de música; pero no me meta en literaturas y en negocios de editores". Carta de Goicoechea a Otaño, 4 de mayo de 1909. AMSL. FO. Correspondencia, 099/002.012. 
Hoy recibo su grata 29 del pasado. No ha habido tiempo para que haya podido dar cuenta a la Comisión acerca de lo que propone, pero creo convendrá en ello sin dificultad. He visto a D. Damián, que vino al anochecer a casa, y vio gozosamente lo que U. propone. [trasladar la redacción de la revista a Bilbao]

Si hay alguna dificultad será por el lado de que la Comisión intervenga en lo sucesivo, y más cuando vea que tiene que tratar con una casa editora. La Comisión seguramente se negará a que se tome su nombre en asunto que pueda oler a negocio, o a hacer el negocio de un editor, porque recordarán las escenas de Sevilla entre editores y el finado Olmeda, que buscaba una recomendación oficial del Congreso para su revista, con lo cual se creían perjudicados los editores. Si Galbarriatu, o cualquier otro por el estilo, se quiere encargar de esta Revista, no hay para qué el que figure la Comisión de Valladolid dirigiéndola. Terminó la misión que le confiara el Congreso de Valladolid en este año, y nada de particular tiene para que subsista tenga que cambiar de forma, y al mismo tiempo de lugar y de dirección desde el momento que aquí se carece de medios de publicación, etc. Lo principal es que viva la Revista para mantener vivo el fuego sacro; no importa el lugar ni la manera de realizarlo. ${ }^{343}$

El día 20 de mayo, Goicoechea comunicaba a Otaño las resoluciones tanto de la CDMS de Valladolid como del propio arzobispo. Se puede apreciar la preocupación de los eclesiásticos vallisoletanos por sentar con claridad las condiciones de la nueva situación, en la que quedaban libres de toda responsabilidad y todo compromiso con la publicación. Su implicación, según indicaron a Otaño, se debía reducir a recomendar a los suscriptores que continuaran apoyándola:

Esta tarde celebró junta la Comisión, e inmediatamente fuimos a dar cuenta de todo al Ex[cmo]. Sr. Arzobispo.

Este consiente en el traslado: hubiera deseado que la cesión constase por Escritura pública, pero al fin, al asegurarle que la revista

\footnotetext{
${ }^{343}$ Ibídem. En otras cartas anteriores, Goicoechea le comunicaba la disposición favorable de la CDMS a los planes sobre la publicación de un suplemento con música, cual era la intención de Otaño, aunque le advertía de los problemas que significaría mantener la revista a cargo de la Junta vallisoletana: "Acaba de celebrarse la junta y aunque D. Damián le escribirá mañana por extenso le adelantaré algunas impresiones. En general, estamos conformes en cuanto al plan nuevo: la dificultad, verdaderamente insoluble consiste en que no hay a quien se le pueda encargar la administración que con todas sus minucias exige una persona desocupada. No hay que dar vueltas a esto. Debe U. pensar seriamente en encontrar en Oña, en Bilbao, etc. quienes se encarguen de esto. Puesto que la música vendrá tirada ya, y la impresión lo mismo puede hacerse aquí que en Bilbao, etc., y al fin y a la postre U. será el que tenga que cargar con todo; ¿qué más le da que la distribución se haga desde Valladolid, que desde otro punto cualquiera? Los Superiores de U. tienen que estar enterados de que U. lleva todo el peso de la revista, y creo que no hallarán dificultad en que se haga este cambio. Piénselo y determínese porque lo de aquí, si lo deja D. Damián, va a ser imposible.” Carta de Goicoechea a Otaño, 26 de abril de 1909. AMSL. FO. Correspondencia, 009/002.011.
} 
continuaría con el mismo espíritu y publicando música en conformidad con lo previsto en el "Motu proprio", puesto que U. seguiría dirigiéndola, y no se podía pedir mejor garantía. Desea que aparezca al frente un sacerdote como Galbarriatu, como aquí figura D. Damián, y por fin, que Lazcano y Mar dirijan una carta al Presidente de la Comisión declarando que ésta queda libre de toda responsabilidad en cuanto a gustos, etc., porque como dice D. Damián, y los demás Sres. podría ocurrir que mañana u otro día vinieran a reclamar algo fundándose en que, si bien había tratado sólo con U., lo hizo en nombre y representación de la Comisión. [...]

En cuanto al artículo de despedida, desea la Comisión que lo modifique. Los ofrecimientos que se hacen debe hacerlos la nueva dirección. En este último número, que ya está preparado con más de 24 páginas, debe manifestarse la razón del cambio de forma y lugar; se debe dar a entender, que si bien la Comisión no es la encargada de dirección, administración, etc. desea que los actuales suscriptores continúen favoreciéndola etc. U. verá [cómo dar] forma a esto. ${ }^{344}$

Por tanto, la revista dejó de tener ese status especial que le confirió el congreso de Valladolid, y perdió su carácter institucional ${ }^{345}$. A partir de ese momento, dejó de ser el órgano oficial de los congresos y pasó a ser una revista convencional, dirigida por Otaño, gestionada por una editorial, y con la necesidad, al haber perdido aquel carácter, de solicitar "censura eclesiástica y bendición o aprobación de los Obispos"346. Esta

\footnotetext{
${ }^{344}$ Ibídem.

345 López-Calo afirma que la CDMS de Valladolid continuó al frente de la dirección "oficial" de la revista: "Otra gran innovación, que trajo consigo consecuencias beneficiosas en abundancia, sobre todo para resolver los problemas administrativos que arrastraba la revista, fue el hacerse cargo de su edición y administración la Casa 'Lazcano y Mar', de Bilbao. La dirección 'oficial' continuaba en manos de la Comisión de Valladolid, aunque seguía siendo el Padre Otaño quien la preparaba y dirigía desde Oña”. José López-Calo, Nemesio Otaño, p. 50.
}

\footnotetext{
${ }^{346}$ Las nuevas condiciones, finalmente aceptadas por todas las partes, figuran enumeradas de forma esquemática en una carta de Otaño de 16 de mayo: "El jueves y viernes estuvo aquí Lazcano. Lo de la Revista se arregló con bastante facilidad. 1) Aceptó, libre de toda carga anterior, desde el primer día de junio: es decir, con el tercer año. 2) De su cuenta y riesgo corre toda la edición, tanto del texto como de la música. 3) La revista conservará el mismo tamaño, pero tendrá mejores materiales en papel y tipos. 4) Tendrá 8 páginas de texto y 8 de música. 5) El precio sube a 6 pesetas por el número completo; el texto o la música separada se darán en suscripción en 3 pts. al año. 6) La música se grabará en Barcelona. 7) Con la dirección general sigo yo, señalar las materias y originales de música: nada se podrá poner en la revista, ni de música, ni de texto, sin la aprobación de la dirección. En esto entra la censura de V. [Goicoechea] [...] 8) De la redacción inmediata, pruebas y líos adyacentes, se encargan Galbarriatu y Mar. Este, sobre todo, de la parte material, en que es muy inteligente. 9) Los autores-compositores quedan propietarios de sus obras; pero la revista es dueña de las planchas, las cuales serán cedidas a los autores (a petición suya) en el precio de costes y portes. 10) El editor enviará una hoja de precios que propondrá a los autores que deseen hacer con él ulteriores tiradas. 11) El editor pone un encargo especial para la revista, que se ocupe de todo lo concerniente a ella. 12) A su cuenta corre toda la propaganda, y se le da libertad completa para anunciarse en las cubiertas. 13) Todas las ganancias o pérdidas serán del editor exclusivamente. 14) Por ahora se hará una tirada de 500 ejemplares. 15) La revista saldrá el primero de cada mes: los originales escritos han de estar en la casa 15 días antes: los de música dos meses anticipados. 16) Se pedirá censura
} 
coyuntura representó el momento propicio para publicar un suplemento con música, un proyecto en mente de Otaño desde hacía tiempo. La muerte de Olmeda en febrero de 1909 y la consiguiente desaparición de su revista con suplementos musicales, Voz de la Música, constituyó otra circunstancia favorable en la nueva etapa que emprendió $\mathrm{MSH}^{347}$.

Dada la íntima relación existente entre revistas y liderazgo, el estudio de este aspecto conduce indefectiblemente al reconocimiento de aquellas figuras con vocación, condiciones y pretensiones de erigirse en referentes y conductores del movimiento, así como de los núcleos que en torno a ellos formaron sus colaboradores más cercanos. La relación que debieron mantener estos grupos $\mathrm{y}$, sobre todo, sus líderes, fue de colaboración/confrontación. La vertiente lucrativa de las revistas en tanto producto del negocio editorial sale a relucir constantemente, entrando en juego otro colectivo fundamental del movimiento, los editores. Constataremos, de nuevo, la función ejercida por los congresos de constituirse en escenarios en los que se dirimían las controversias derivadas de las luchas de intereses.

\subsubsection{El grupo dominante: Otaño-Ripollés-Goicoechea-Viñaspre}

A tenor de los comentarios que el jesuita vierte en sus cartas, $M S H$ fue, durante los años que mediaron entre los congresos de Sevilla y Barcelona, el más eficaz instrumento utilizado por Otaño -sin olvidar su labor en Comillas ${ }^{348}$ - para congregar en torno a sí a un grupo de destacados músicos y críticos que siguieron su línea. Otaño describía sus logros regeneracionistas durante este periodo, refiriéndose a la constitución de una auténtica “escuela”. Ya en mayo de 1909 escribía a Pedrell:

eclesiástica y aprobación o bendición de los Obispos.” Carta de Otaño a Goicoechea, 16 de mayo de 1909. AMSL. FO. Correspondencia, T01/053.

\footnotetext{
347 "Desde que murió nuestro inolvidable compañero el Maestro Olmeda y con él su Revista, que en mejores o peores condiciones trataba de formar un repertorio de escogida música religiosa, han sido innumerables los amigos que se han dirigido aquí proponiendo la introducción del suplemento de música." Cecilio [N. Otaño], "Año nuevo, vida nueva", MSH, 1 [con su traslado a Bilbao se inició de nuevo la numeración] junio 1909, p. 2. Mes y medio antes comunicaba a Cos y Macho lo propicio del momento aludiendo también al espacio dejado por la revista de Olmeda: "Espero que V.E. dará todo el calor posible a estos dos planes [el suplemento, y un concurso para compositores de música religiosa], pues estamos en el punto crítico de proponerlos ahora que no hay otra revista. Los suscriptores de Olmeda claman porque $[\mathrm{sic}]$ se funde una con música. Es, pues, urgente la resolución." Carta de Otaño a Cos y Macho, 13 de abril de 1909. AMSL. FO. Correspondencia, 009/004.036.
}

348 Sobre su labor en Comillas, véase: López-Calo, Nemesio Otaño, pp. 69-86; García Sánchez, "José María Nemesio Otaño Eguino (1880-1956)”, pp. 480-484. 
No dejaré de hacerle una consideración que hemos hecho aquí los amigos en vista de las obritas que los compositores nos han enviado. Estas indican un progreso marcadísimo, y hay que confesar que con el ruido metido la gente ha tomado nuevas direcciones. Verá V. en el suplemento cosas bien finas. Por otra parte, debido a la independencia que mi carácter y estado me han creado, tengo a mi lado a casi toda la juventud de todas estas regiones, y puedo usar de cierto rigor con ellos con toda confianza y sin temor de susceptibilidades. Así aseguro la bondad del suplemento, porque no admito en él sino lo bueno bajo uno y otro concepto. Somos ya en el trust cuarenta o cincuenta amigos que vamos a una. ${ }^{349}$

Un mes antes, estando sobre la mesa la cuestión de la publicación del suplemento musical en $M S H$, listaba algunos de los nombres de sus colaboradores: "Mocoroa, Busca, Urteaga de Zumaya, Rodríguez, Elústiza de Palencia, Beobide, Basabe, Guridi, Gabiola, Usandizaga, Alberdi (organista de Comillas) Julio, Alejandro, Viñaspre, Villalba, Virgala de Vitoria, Tafall y los Catalanes" ${ }^{\text {350 }}$. En octubre de 1910 escribía a Pedrell desde Comillas:

La revista pasito a paso, y sin mucho ruido va abriéndose camino. Compositores tengo de sobra y obras por consiguiente; pero tengo pocos escritores.

Encuentro gente que sabe, lee y estudia, pero tienen horror a la pluma; no se arreglan para hacer una oración de activa sobre el papel. Sin embargo, voy adiestrando unos cuantos jóvenes de bríos, a quienes, si se les da el plan y material, les será fácil entrar por estos caminos. Todo es que empiecen. Ahora estoy precisamente trazando el plan de esta educación: tienen de bueno que me obedecen ciegamente y van donde les llevo y por esto espero frutos prácticos. ${ }^{351}$

En los meses previos al congreso de Barcelona, escribió al tortosino sobre su posible aportación, en caso de que sus superiores le permitieran asistir:

Naturalmente me costaría la ausencia, porque podría yo plantear la Asociación Ceciliana, y otras muchas cosas que traigo en la cabeza. Además, conociendo al detalle todo este movimiento, porque lo llevo con la revista, podría ayudar en todo algo. ${ }^{352}$

\footnotetext{
${ }^{349}$ Carta de Otaño a Pedrell, 26 de mayo de 1909. AMSL. FO. Correspondencia, T01/055.

${ }^{350}$ Carta de Otaño a Goicoechea, 23 de abril de 1909. AMSL. FO. Correspondencia, T01/051.

${ }^{351}$ Carta de Otaño a Pedrell, 15 de octubre de 1910. BC. FFP. M 964 O.

${ }^{352}$ Carta de Otaño a Pedrell, [sin fecha]. AMSL. FO. Correspondencia, T01/121.
} 
Otras grandes figuras del movimiento pro reformas, además de su maestro Vicente Goicoechea, terminaron de configurar, junto con Otaño, este grupo dentro del movimiento $^{353}$. La cercanía ideológica y compatibilidad de caracteres facilitaba su asociación, que se tradujo, con el empuje de Otaño, en una unidad de acción. Desde el congreso de Valladolid y sobre todo, de Sevilla, Otaño vio en Ripollés el valor más importante de la música religiosa del momento, comparable sólo con Goicoechea ${ }^{354}$, y procuró su adhesión y colaboración en sus iniciativas, especialmente $M S H$. El hecho de que confiara a Ripollés todos los grandes proyectos que ideó, y sobre los que incidiremos a continuación, demuestra que el maestro de capilla de la catedral de Sevilla era su gran activo.

En septiembre de 1911, Otaño inició un periodo de retiro espiritual conocido como Tercera Probación, durante el cual debió aparcar su actividad ${ }^{355}$. Para hacerse cargo de la revista entretanto pensó en Ripollés: “Usted, carísimo, me tiene que enviar algo. ¿No es verdad? No sabe lo que me alienta saber que estamos juntos; necesito de V. para que yo pueda hacer mi Tercera Probación tranquilo;" 356 Incluso, como revela este otro pasaje, expresó al castellonense su deseo de que lo sustituyera al frente de MSH de forma definitiva:

No sé cómo lo dispondrán los Superiores y cómo quedará esto, pero estoy en que empezaré la Tercera Probación por Setiembre,

\footnotetext{
${ }^{353}$ Goicoechea pasaría a un segundo plano debido a problemas de salud: "Goicoechea el pobre no está para bromas: está peor de lo que él cree, y a mi ver tísico rematado. No piensa más que en cuidarse y harto tiene. Este invierno ha arrojado sangre varias veces. Yo estoy muy afectado con esto." Carta de Otaño a Ripollés, 20 de mayo de 1911. AMSL. FO. Correspondencia, TA01/124.

${ }^{354}$ Otaño comparaba con frecuencia a Ripollés con Goicoechea: "Efectivamente necesita V. [Ripollés] estar independiente, porque mejor que yo sabe V. lo que es musiquería andante. Se le mira a V. tan alto como noto yo que le miran los lectores de la Revista, entre los que tiene V. un puesto igual al de Goicoechea. Carta de Otaño a Ripollés. AMSL. FO. Correspondencia, TA01/124. "crea V. [Goicoechea] que no me merece menor confianza Ripollés, a quien admiro como hombre serio, formal, trabajador, deseoso de todo el bien posible e incapaz de consentir una añagaza de mala ley. Puede V. creer que Ripollés es otro V." Carta de Otaño a Goicoechea, 6 de octubre de 1908. AMSL. FO. Correspondencia, T01/034. A igual que ocurría con Goicoechea, Otaño no encontraba en Ripollés el "coraje" que él tenía, desde su punto de vista: "Yo admiro en V. las más bellas y extraordinarias condiciones, pero le falta a V. algo de lo que a mí me sobra: coraje, coraje, coraje.” Carta de Otaño a Ripollés, 16 de octubre de 1912. AMSL. FO. Correspondencia, TA01/177.

${ }^{355}$ La Tercera Probación formaba parte de las distintas etapas de formación del jesuita. El periodo de Tercera Probación de Otaño se prolongó desde 15 de septiembre de 2011 a 15 de junio de 2012, tal y como cuenta a Pedrell: "Respecto a mi caso, le diré a V. que, según todas las posibilidades, tengo que empezar en Septiembre el año de Tercera Probación (septiembre 151911 a junio 15 1912) Carta de Otaño a Pedrell, 11 de mayo de 1911. AMSL. FO. Correspondencia, T01/094.
}

${ }^{356}$ Carta de Otaño a Ripollés, 31 de diciembre de 1910. AMSL. FO. Correspondencia, TA01/101. 
y en ese caso no hay duda que V. ocupa -y bastante dignamente- mi lugar. ¡Cuánto más haría yo en obras y libros, si $\mathrm{V}$. tomara definitivamente la dirección de la Revista! Yo le ayudaría a V. en todo como socio; en todo, digo, cuanto V. quiera y todos los meses. Una cosa es escribir una sección, y otra prepararlo todo, responder cartas, disponer suplementos, conseguirlos. Piénselo V.

Si la Revista va creciendo bien, yo propondré a Mar que separe lo necesario para el director; por lo menos eso ha de llegar a pagar. $^{357}$

La distancia que separaba Valencia, donde residía Ripollés desde junio de 1909, de Bilbao, obligó a reconsiderar sus planes, aunque no quiso, en ningún caso, prescindir de su colaboración. Finalmente fue otro jesuita, Manuel de Benito el encargado de toda la cuestión relacionada con la gestión:

Como V. está tan lejos y era muy difícil la comunicación con Bilbao, acordamos con los Superiores llamar aquí a un buen discípulo mío, que lleve el orden, las noticias y la correspondencia de la Revista; pero es preciso que V. sobre todo le ayude. Él le consultará las dificultades.

V. puede escribir artículos, cuestiones prácticas, y se le enviará también bibliografía, si le viene bien. Envíe cuanto quiera al P. Manuel de Benito, que está ya en este Seminario y es el que me sustituye. Ayúdele V. en una palabra, pues conoce la Revista y puede más que nadie en manejos de pluma. Tiene V. la casa por suya. ${ }^{358}$

Durante esos meses en los que Otaño estuvo ausente se evidenció la excesiva dependencia que la revista tenía de su primer impulsor. Según cuenta Ripollés a Pedrell, MSH estuvo otra vez en una situación difícil debido a la mala gestión:

La Revista $[M S H]$, por culpa de los editores, lleva mal rumbo: el Octubre se recibió hace pocos días: no sé cuándo vendrá el Noviembre, y ahora me propone el $\mathrm{P}$. Benito que, para ponernos al corriente, publiquemos el $\mathrm{n}^{\mathrm{o}}$ extraordinario de $\mathrm{V}$. correspondiendo a los meses de Noviembre y Diciembre; lo cual escamotea un $\mathrm{n}^{\mathrm{o}}$ a los suscriptores. Creo que ello será de pésimo efecto y que a este paso, cuando el P. Otaño salga de su retiro, no va a encontrar rastro de Revista: esta morirá a manos de los editores. Y bien que se reirán de gusto Alier y el $\mathrm{P}$. Villalba, pues con ello podrían engordar su suscripción que no debe ser muy abundante. [Se refiere a Biblioteca Sacro Musical] $]^{359}$

\footnotetext{
${ }^{357}$ Carta de Otaño a Ripollés, 27 de mayo de 1911. AMSL. FO. Correspondencia, TA01/126.

${ }^{358}$ Carta de Otaño a Ripollés, 7 de septiembre de 1911. AMSL. FO. Correspondencia, TA01/140.

${ }^{359}$ Carta de Ripollés a Pedrell, 6 de noviembre de 1911. BC. FFP. M 964 R.
} 
El siguiente extracto pone de manifiesto la admiración de Otaño por Ripollés, "la mejor pluma de la revista". Cita, además, a su otro gran colaborador de estos años, Francisco Pérez de Viñaspre ${ }^{360}$, organista de la catedral de Burgos:

[...] En cuanto a los escritos de V. me agradan sobremanera por su forma literaria verdaderamente bella y por el fondo de gran seriedad y sensatez que hay en ellos. Es V. -lo digo con sinceridad- la mejor pluma de la revista y quisiera yo tener su estilo. [...]

Viñaspre le ha cobrado a $\mathrm{V}$. un gran cariño y estaba suspirando por la contestación a su carta. Me alegro que lo haya $\mathrm{V}$. hecho. Viñaspre es una alma de Dios, candoroso como él sólo, y bueno. Esas dos o tres teclas de españolismo que él tiene, yo se las hago tocar de vez en cuando para proporcionarle un desahoguillo; pero crea $\mathrm{V}$. que es el mejor amigo que tenemos. Ya ve $\mathrm{V}$. que tiene soltura de pluma. ${ }^{361}$

Otaño profesaba a Viñaspre una gran estima, aunque lo definía como integrista: "Viñaspre no tiene otra cuerda que la tradicional: es un integrista en gregoriano y en polifónico como lo es en política. Buen hombre y muy amigo, y de trabajo."362 Esta condición hizo que Otaño en alguna ocasión, a pesar de la cercana relación que les unía, rechazara publicar en $M S H$ algún artículo suyo:

Al artículo de Viñaspre sobre el Congreso de Sevilla le di carpetazo. Estaba bien, pero se extendía de un modo algo inconveniente sobre lo antiguo de nuestras Catedrales, defendiendo a capa y espada nuestros librotes, sólo porque son nuestros. Ya sabe V. que esta es la tecla de Viñaspre; por lo demás está identificadísimo con nosotros. Es un buen amigo. ${ }^{36}$

\footnotetext{
${ }^{360}$ Francisco Pérez de Viñaspre Ortíz (Laguardia, 1854-1938). Estudio piano y composición con Arriola. Antes de conseguir la plaza de organista de la catedral de Burgos (1904), ocupó las de la catedral de Zamora, de cuyo seminario fue profesor de canto llano, y Vitoria. Fue una figura bastante activa en el movimiento reformista español, destacando sus intervenciones en los congresos nacionales de música sagrada o sus publicaciones en revistas de música religiosa. Entre sus composiciones cabe mencionar una Misa de Requiem, una Salve, varios motetes, y un Miserere publicado por Unión Musical Española. Ramón Sobrino, "Pérez de Viñaspre Ortíz, Francisco", DMEH, 10 vols., ed. por Emilio Casares (Madrid: SGAE, 2001), vol. 8, p. 643.

${ }^{361}$ Carta de Otaño a Ripollés, 15 de febrero de 1912. AMSL. FO. Correspondencia, TA01/153.

${ }^{362}$ Carta de Otaño a Ripollés, 11 de enero de 1910. AMSL. FO. Correspondencia, TA01/075.

363 Carta de Otaño a Ripollés, 21 de abril de 1910. AMSL. FO. Correspondencia, TA01/081. Viñaspre terminó publicando el artículo a espaldas de Otaño en el periódico de corte integrista El Siglo Futuro, algo que no gustó nada a Ripollés pues incluía algunas críticas a las conclusiones del Congreso de Sevilla: "[...] No sabía lo que me dice V. de los artículos del Siglo Futuro. El buen Viñaspre tiene esa obsesión, pero es dócil: si le hubiera dicho yo que no convenía tal cosa, hubiese desistido. Escribió eso para la revista y le di carpetazo: le aseguré que a nada conducía todo ello y que esperara coyunturas más
} 
Precisamente en Ripollés y Viñaspre pensó Otaño cuando Angelo de Santi le pidió la asistencia de una representación española al congreso ceciliano a celebrar en Roma en 1912:

[...] Acabo de recibir una importante carta del P. de Santi. Me dice que después de Pascua van a celebrar la gran asamblea ceciliana en Roma; lamenta que yo esté en Tercera Probación, y por ende imposibilitado para asistir allí, y me pide con grandes instancias que haga lo posible para enviar un sustituto mío que honre a España y acredite nuestro afán. Si yo tuviera ahora disponibles 500 ptas., se las enviaría a $\mathrm{V}$., porque ninguno mejor que V. para este caso. [...] Viñaspre creo que se lanzaría a una aventura por su cuenta, y si VV. dos fueran a Roma, sería un negocio redondo para nuestra causa., [...] ¡Si el Sr. Arzobispo le quisiera a V. ayudar! [...] ¡Oh, si V. se animara! ${ }^{364}$

Ripollés no fue a Roma, pero sí Viñaspre, acompañado de Muñoa: "Por aquí han pasado los dos congresistas romanos Viñaspre y Muñoa, que vienen entusiasmados. Ya lo verá V. todo en la Revista, y Viñaspre supongo que le escribirá." ${ }^{365}$

Las pretensiones de Otaño respecto al papel que debía jugar Ripollés en el movimiento se revelaron con nitidez durante la preparación y celebración del III Congreso Nacional de Música Sagrada en Barcelona ${ }^{366}$. El guipuzcoano intentó por todos los medios que Ripollés estuviera al frente, no sólo de la Asociación Ceciliana Española, sino también de la proyectada Escuela Superior de Música Sagrada. A pesar de no encontrar en el castellonense el empuje que caracterizaba su capacidad de liderazgo, reconocía en él la autoridad y cualidades necesarias para que encabezara los principales órganos oficiales que iba generando el movimiento en esta estrategia de

favorables. Se conoce que se ha aprovechado de mi retiro, para publicarlos por sorpresa, que de otro modo no lo hubiera hecho." Carta de Otaño a Ripollés, 3 de noviembre de 1911. AMSL. FO. Correspondencia, TA01/145. A Ripollés le aclaraba: "Y no creo que haya más. Viñaspre me dijo que 'El Siglo Futuro' (el P. Montaña) le consultó algo de esos puntos, y que él envió su memoria o artículo, escrito para la Revista, acerca de las Actas de Sevilla, y que yo lo rechacé. Se lo envió a dicho P. Montaña, pero con el expreso encargo de no publicarlo sin que hiciera algunos retoques. El P. Montaña se lo ha publicado sin decirle una palabra. Con Viñaspre puede V. entenderse directamente, porque es el mejor de los hombres: tiene su tecla de españolismo, pero un gran amigo y se le trae y lleva como un niño. Así es de bueno." Carta de Otaño a Ripollés, 30 de noviembre de 1911. AMSL. FO. Correspondencia, TA01/148.

\footnotetext{
${ }^{364}$ Carta de Otaño a Ripollés, 28 de marzo de 1912. AMSL. FO. Correspondencia, TA01/157.

${ }^{365}$ Carta de Otaño a Ripollés, 5 de mayo 1912. AMSL. FO. Correspondencia, TA01/160.

${ }^{366}$ Sobre el congreso de Barcelona y el proyecto de fundación de una Escuela Superior de Música Sagrada, véase: López-Calo, pp. 80-86.
} 
estructuración y articulación de la que venimos hablando. Para Otaño, que se reservaba el liderazgo ideológico práctico -escritos, revista, correspondencia-, como también para Pedrell, Ripollés debía ser la principal autoridad institucional del movimiento. En la siguiente carta le comunicaba que él era su apuesta para la presidencia de la Asociación Ceciliana. Este fragmento nos proporciona, además, interesante información sobre cómo había concebido el proyecto Otaño:

Lo de la Asociación Ceciliana lo tengo muy madurado, pero tropiezo con esta enorme dificultad: ¿quién querrá ser el Presidente? ¿quién puede serlo airosa y dignamente?

La Asociación es obra esencialmente piadosa y el Presidente tiene que ser eclesiástico. Así lo es en Alemania, Italia etc., y a mi ver este requisito es esencial. No es preciso para empezar que todas las diócesis de España se adhieran (esto ni sería conveniente por la dificultad de una primera organización numerosa). Basta que algunas archidiócesis se presten, y luego se irán agregando las restantes. Mi plan es que en cada diócesis haya un representante diocesano, que es el que corre con todo lo de la diócesis: los representantes diocesanos eligen a un delegado metropolitano, que es el presidente de los diocesanos. La actual división en archidiócesis nos dará otras tantas provincias cecilianas. Ya le enviaré a V. una copia detallada de todo el plan, cuando salga de Manresa. Entre tanto vaya V. pensando en la presidencia. Por mi voto sería V. No hay que pensar en mí de manera alguna: soy joven, sin autoridad, y si me echan encima una organización, ¿cuándo escribo, cómo llevo la revista, la correspondencia, etc.? ${ }^{367}$

A juzgar por lo expuesto en esta otra misiva, Ripollés se debió resistir en un primer momento, y debió sugerir a Otaño otros candidatos:

[Goicoechea:] es una nulidad, o mejor, se ha hecho una nulidad voluntariamente para escribir y activar, porque tiene terror a la exhibición. Goicoechea es un consejero, como un profeta, talentazo que ve mucho y hondo; pero no le saque $\mathrm{V}$. de la conversación de silla a silla.

[Viñaspre:] no sirve para cabeza, pero es un brazo excelente; con la docilidad de niño, candor de cordero, y corazón de entrañable amigo es edificantísimo y fervoroso -nos sirve para esto que ahora hace, para crítico no tiene precio: es un Domine célebre para examinar con ocurrencias bonitas las obras. Lee mucho revistas serias científicas.

${ }^{367}$ Carta de Otaño a Ripollés, 26 de junio de 1912. AMSL. FO. Correspondencia, TA01/165. 
Hace poco escribí yo al P. Suñol que para Presidente V. -no se asuste- tenía las grandes cualidades. ${ }^{368}$

El músico jesuita comenzó las gestiones para conseguirle a Ripollés, nada menos, que una canonjía en Barcelona, donde, según sus planes debía ubicarse la sede de la Escuela:

A mí sobre todo me preocupa la Asociación y la Escuela. Estoy haciéndole cama para una Canonjía en Barcelona, a fin de que V. sea el Presidente de la Escuela y de la Asociación. Es preciso conseguir esto. Y V. no se puede negar. Me invitó a comer el Dr. Laguarda [obispo de Barcelona], y en la mesa le expuse todo el plan. Lo recibió bien y me dijo que se lo pusiese por escrito. ${ }^{369}$

Las gestiones por la consecución de la canonjía para Ripollés le llevaron, según afirmó, a recurrir incluso al nuncio de la Santa Sede en España:

He hablado largamente con el Nuncio en San Sebastián, a quien le parece admirable el plan y digno de su mayor atención. Promete todo apoyo. He vuelto a hablar al Dr. Laguarda, y hablaré, si es preciso, a Júpiter por conseguir tan justo y buen propósito. V. ha de ser Canónigo de Barcelona, Director de la Escuela Superior de Música Sagrada y Presidente de la Asociación Ceciliana Española. Y si no, no vale V. para nada. ¿Está V.? ${ }^{370}$

Ripollés recibió las pretensiones de Otaño con bastante cautela y escepticismo:

Se ha adelantado V. a mis intentos de bromear un tantico sobre eso de la canonjía, dirección y presidencia de no sé cuántas cosas: si no conociera algo el corazón del P. Otaño, pensaría que intentaba tomarme el pelo y jugar con mi simplicidad; o, si no me conociera yo bien, en peligro estaba de que todos esos proyectos y ofrecimientos del P. me infatuciran [...] y trastornaran la cabeza: ya le dije al bueno del P. que eso de la canonjía me había hecho la mar de gracia y que podía esperar sentado porque las canonjías las necesitan los Prelados para los paniaguados; ¡buenos están para pensar en música y músicos! ${ }^{371}$

\footnotetext{
${ }^{368}$ Carta de Otaño a Ripollés, 16 de julio de 1912. AMSL. FO. Correspondencia, TA01/166.

${ }^{369}$ Carta de Otaño a Ripollés, 4 de agosto de 1912. AMSL. FO. Correspondencia, TA01/171.

${ }^{370}$ Carta de Otaño a Ripollés, 16 de octubre de 1912. AMSL. FO. Correspondencia, TA01/178.

${ }^{371}$ Carta de Ripollés a Pedrell, 10 de agosto de 1912. BC. FFP, M 964 R.
} 
Pedrell también intentó, junto con Goberna, conseguir que Ripollés se trasladara a Barcelona, aunque el plan no era tan ambicioso como el que ideó Otaño. Se trataba de que ocupara el magisterio de capilla de la catedral de dicha ciudad. Ripollés, sin embargo, no aceptó aludiendo cuestiones económicas ${ }^{372}$. Ante su negativa Goberna escribió:

Todos sentimos que no se haya $\mathrm{V}$. decidido para estas oposiciones: en altas esferas era esperada la contestación de V. en sentido afirmativo; el mismo Pedrell confiaba, a pesar de haber dicho V. que no podía ser por las razones que exponía porque creo que la cuestión económica en Barcelona no es tan despreciable como parece, sobre todo, en el cargo de maestro de capilla de la Catedral; en fin creo que bien meditado, todo tenía arreglo, y sobre todo V. habría estado en su centro dado el movimiento artístico que aunque lentamente se está desarrollando en Barcelona. Además el Maestro Pedrell, le quiere a $\mathrm{V}$. como un padre quiere a un hijo, y en nosotros tiene V. hermanos: todos le queremos, y en altas esferas era una verdadera ilusión, el que $\mathrm{V}$. viniera. $[\ldots]^{373}$

En los meses que precedieron al congreso de Barcelona, encontramos, según se desprende de estos datos, un grupo cohesionado, nucleado en torno a la tríada OtañoRipollés-Viñaspre, con importantes proyectos de futuro como la Asociación Ceciliana o la Escuela Superior de Música Sagrada. Además, poseía una importante capacidad de influencia, y estaba bien relacionado con grandes referentes de la música española como Pedrell, e incluso extranjera como Angelo de Santi.

En esta situación ocurrió un hecho que lesionó gravemente la relación entre las dos principales cabezas del grupo, Otaño y Ripollés. Se trató de la crítica que Juan Bautista Elústiza, flamante organista de la catedral de Sevilla, publicó en $M S H$ sobre un

\footnotetext{
372 "Las indicaciones y deseos de V. y del buen amigo Goberna las miro yo y recibo como manifestaciones estimables de sincera amistad; y claro que yo estaría archibien al lado de personas que tantas pruebas me han dado y dan de aprecio y estima y al lado de las cuales mucho se podría aprender. Sin embargo hay que contar que mi traslado de Sevilla a Valencia me ha reportado un quebranto de 7.000 reales anuales, y que el cambio de posición a que ahora me invitan causaría en mí un descenso en categoría y una disminución de 4.000 o más reales: con cinco mil reales no puede vivirse decentemente ni siquiera modestísimamente en Barcelona.

Por otra parte, creo que no está V. en lo firme cuando me dice que con ello aseguraríamos la canonjía: estoy persuadido de todo lo contrario. Para inter nos (y que nadie nos oiga), los Prelados darán todo lo dable cuando vean necesaria nuestra cooperación para alguna obra que deseen sacar a flote con alguna brillantez; pero se harán el sueco cuando crean asegurado nuestro concurso teniéndome ya ligado por medio de un simple beneficio. Conozco bien el paño y lo que se nos quiere y hasta qué punto se nos estima." Carta de Ripollés a Pedrell, 22 de septiembre de 1912. BC. FFP. M 964 R.

${ }^{373}$ La carta de Roberto Goberna tiene fecha de 14 de octubre de 1912, y está escrita en la misma hoja que una carta enviada por Ripollés a Pedrell el 18 de octubre. BC.FFP. M 964 R.
} 
Hodie Christus natus est para dos voces y órgano compuesto por Ripollés, y editado por

Casa Dotesio. Estas fueron las valoraciones publicadas por Elústiza:

Esta composición del ilustre maestro Ripollés no me convence. Aunque de factura irreprochable, la melodía es un tanto adusta y el conjunto resulta ininteligible para oídos poco habituados a este género de composiciones para pequeños coros. Esto puede ser un defecto. ${ }^{374}$

El efecto que este juicio tuvo sobre Ripollés fue demoledor:

Después de leer el $n^{\circ}$ de la Revista de Julio, he sospechado, si todos esos mimos y complacencias que el P. gasta conmigo, van enderezados a prevenir el mal efecto que pudiera causarme el varapalo que me da el nuevo organista de Sevilla: porque efectivamente la tunda es fuerte y dura y sin paliativos, tan fuerte que pienso, que si con los amigos gastan esas bromas que harán con los que no son de casa? La cosa ha cundido rápidamente por aquí y bien puede $\mathrm{V}$. pensar la fruición con que ciertas gentes se habrán frotado las manos presenciando la pelea entre amigos. Dios se lo pague a ese señor Elústiza que tan desconsideradamente me trata.

[...] Bueno, pues con todo ello van a conseguir que haga yo lo que más en consonancia está con mis aficiones, que es meterme en la concha, laborar a gusto mío sin dependencia de otros y dejarme de Quijoteos y disfrutar del dolce far niente y de la tranquilidad y sosiego que produce la vida retirada. ${ }^{375}$

Ripollés creyó que detrás de la crítica de Elústiza se encontraba la mano de Otaño. Según él mismo cuenta, sus sospechas se confirmaron ${ }^{376}$ :

De Sevilla me llegaron ayer unas noticias que confirman mis sospechas sobre el P. Otaño, ya manifestadas a V. Lea V. el siguiente párrafo que transcribo literalmente: "Mucho me ha hablado de V. D. Eduardo Torres, quien estuvo comiendo con V.; y es claro, que me acordé mucho de Francisca porque supongo se luciría. Me habló también de la zanganada del organista de esta con una obra de V.; y,

\footnotetext{
${ }^{374}$ Juan B. de Elústiza, "V. Ripollés, Pbro.- Hodie Christus natus est [en negrita], a dos voces iguales y órgano. Precio, 1,50 pesetas.” MSH, 7 (1912), p. 109.

${ }^{375}$ Carta de Ripollés a Pedrell, 10 de agosto de 1912. BC. FFP. M 964 R.

376 “Antes de mi salida de esta le puse una carta extensa al P. Otaño: pasaba por alto, dejándolo para mejor ocasión, el exabrupto de Elústiza, del cual no creo ajeno al P. [Otaño]" Carta de Ripollés a Pedrell, 22 de septiembre de 1912. BC. FFP. M 964 R.
} 
según me ha dicho, no es él el más culpable sino el P. Otaño. ¡Estos jesuitas!"377

El desengaño por lo que debió sentir como una traición fue tan fuerte que le llevaría a escribir el siguiente fragmento que volvemos a transcribir:

[...] el P. Otaño dice bien que no se explica mi silencio, pero yo le confieso a $\mathrm{V}$. que estoy completamente desilusionado y que casi ya no creo en eso de la música religiosa: como artista cultivo el género religioso que se lleva mis simpatías, pero no por liturgismo, sino por arte; y cuando nos vemos abandonados de todos que remedio nos queda sino tumbarnos a dormir? ${ }^{378}$

A esta supuesta maniobra desleal de Otaño se le unió otra experiencia desagradable. Peñarroya, entonces titular del magisterio de capilla del Colegio del Corpus Christi de Valencia que años atrás ocupara el propio Ripollés, había logrado un pronunciamiento del cardenal Vives sobre la reforma en España, en el que desautorizaba las formas y la labor de reformistas como Ripollés:

[...] nada menos que se nos acusa a todos de ser falseadores de la mente e intenciones del Papa interpretando mal y haciendo odiosos el M.P.: se condenan allá, al menos así lo dice el Cardenal Vives, nuestras maneras de escribir y nuestros modernos polifonismos, y al parecer quieren que entronquemos con esas melodías claras y baratas del italianismo decadente: ni Malinas, ni Paris, ni Ratisbona, ni la misma Roma escapan, y seguramente para sincerarse de muchos y gordos desmanes litúrgicos y artísticos el Maestro Peñarroja nos viene cargado de rayos iracundos para nosotros y con mieles para los que ni siquiera de postura han cambiado después de las disposiciones pontificias. ${ }^{379}$

La siguiente respuesta de Otaño nos revela un Ripollés que debió dar síntomas de abatimiento en su carta:

En todo lo demás le veo a V. desilusionado y sentido, sobre todo, por el juicio de Elústiza. ¡No era para tanto, hombre! Torres me

${ }^{377}$ Carta de Ripollés a Pedrell, 30 de octubre de 1912. BC. FFP. M 964 R.

${ }^{378}$ Carta de Ripollés a Pedrell, 18 de octubre de 1912. BC. FFP. M 964 R.

379 Carta de Ripollés a Pedrell, 22 de septiembre de 1912. BC. FFP. M 964 R. Otaño llegó a mediar en este conflicto, según cuenta él mismo: "Ripollés no tiene perdón de Dios. Le arreglé lo de Roma (el caso del Cardenal Vives), y no chista." Carta de Otaño a Pedrell, 15 de octubre de 1912. AMSL. FO. Correspondencia, T01/128. 
escribe que Baixauli está inconsolable. A la verdad es ahogarse en poca agua. Con esto no digo yo que Elústiza hiciera bien; pero lo que afirmo es que no era para tanto.

No, no, jamás me verá $\mathrm{V}$. postrado ni acobardado, aunque todo saliese mal.

[...] No hace V. bien en ir con esa corriente y echarlo todo a rodar. Eso es despecho, acaso cobardía; pero V. que ha trabajado con denuedo en 20 años, debe seguir otros 20 , sin cejar, adelante. [...] No eche V. pues un borrón a su brillante carrera de adalid y de hombre de gran valor. Yo le tengo a V. por la primera figura; pero le deseo un hígado como el Mapa Mundi. ${ }^{380}$

A partir de este momento las relaciones entre Otaño y Ripollés se enfriaron considerablemente $^{381}$. A principios de 1913 comentaba el jesuita a Pedrell: "Ripollés respira de vez en cuando, y a cada carta suya respondo yo con una que equivale a cuatro, planes, modos, formas, etc." 382

A diferencia de la profusa correspondencia que conservamos entre ambos músicos desde el congreso de Sevilla a esta parte, sólo una carta de 1913 figura, desde la última de 25 de octubre de 1912, en la recopilación de fuentes epistolares realizada por Larrañaga. Ello apunta a que esa fértil asociación entre Otaño y Ripollés, cabezas principales del grupo reformista más pujante, se deshizo. Este alejamiento significó el cierre de un periodo y la ruptura de una alianza que, con $M S H$ como principal instrumento y la responsabilidad en la organización de los congresos como posiciones de poder, habían contemplado la generación de un movimiento dentro del movimiento: Otaño, Ripollés -“la mejor pluma de la revista”-, Viñaspre, como núcleo, Pedrell como símbolo -en algún caso también activo- en torno a los que se congregaron jóvenes promesas de la crítica y la composición musical sacra.

${ }^{380}$ Carta de Otaño a Ripollés, 25 de octubre de 1912. AMSL. FO. Correspondencia, TA01/179. Elústiza hizo otra crítica a una colección de trisagios a la Santísima Virgen y una letrilla al Santísimo Sacramento para la comunión de Baixauli: "Lo siento en el alma, pero las circunstancia me lo han impuesto así, y, a fuer de crítico imparcial y sereno, he de decir al P. Baixaulí, con todos los respetos que me merecen sus canas y sus virtudes, que sus composiciones adolecen de gravísimos defectos, examinadas desde los puntos de vista artístico y religioso.

El P. Baixauli tiene bien definida su personalidad artística, que podría sufrir alguna mengua con publicar composiciones como esta". Juan B. de Elústiza, "M. Baixaulí, S. J.- Trisagio a la Santísima Virgen, [en negrita] a tres voces y órgano [...]” MSH, 7 (1912), p. 109.

${ }^{381}$ Así se expresaba en octubre de 1912: "Después de ello y de otras cosilla que ya le contaré, creo que mis relaciones con el tal P. no pueden ser ya lo sinceras, francas y leales que han sido hasta aquí, y dígame V. el valor que debo dar a estos ditirambos con que el P. Otaño me obsequiaba en todas las cartas de esta última temporada" Carta de Ripollés a Pedrell, 30 de octubre de 1912. BC. FFP. M 964 R.

${ }^{382}$ Carta de Otaño a Pedrell, 5 de febrero de 1913. BC. FFP. M 964 O. 
Al igual que este, otros grupos se habían ido conformando por diversas causas, entre ellas, la fundación de revistas o la celebración de congresos. En páginas anteriores, hemos podido constatar la admiración de Otaño y Ripollés por los grupos reformistas activos en Cataluña. El siguiente fragmento, escrito en el contexto de los preparativos del congreso de Barcelona, evidencia la conciencia de Otaño de formar parte -liderar- de un grupo ("los nuestros"), así como de sus pretensiones expansivas:

Del Congreso de Barcelona ¿qué? Mi opinión es (inter nos) que falta un lazo de unión en Barcelona. Los nuestros miran con suspicacia a los Gobernas y demás de la Comisión, y yo creo que a estos se les puede traer a nuestro campo con tres palabras y hacerles trabajar a nuestro son. ${ }^{383}$

La estrategia era incorporar a su ámbito de influencia a otros grupos claramente diferenciados del suyo, e integrarlos en su línea de trabajo. De esta forma, aspiraba ampliar su control a otros espacios hasta ahora fuera de su alcance, en busca, suponemos, de cierta hegemonía.

\subsubsection{Las alternativas: Olmeda, Villalba}

Otras importantes personalidades dentro del mundo musical religioso y regeneracionista en general, siguieron una línea propia y divergente. Las diferencias en la forma de entender e interpretar el $M P$, sus particulares temperamentos $\mathrm{y}$ sensibilidades, así como las distintas estrategias de trabajo e intereses fijaron posturas y tendencias en permanente competencia y tensión. Luis Villalba y Federico Olmeda fueron otros dos grandes referentes del movimiento. A diferencia del intento referido por Otaño de absorber a otros grupos dentro de su espacio de influencia, fueron siempre considerados por él y sus afines como rivales. Otaño y los reformistas que orbitaban en torno a él se arrogaron la ortodoxia en la interpretación, comprensión y líneas de actuación del $M P$, y acusaron a sus contendientes de asumir posiciones heterodoxas, singulares e incluso extravagantes. Varios ejemplos encontramos en la correspondencia entre Otaño, Goicoechea o Ripollés en este sentido. Goicoechea escribió tras el congreso de Sevilla:

¿Se ha enterado de La Ley general de música de Olmeda, publicada en "España y América"? ¿No hay quien ponga coto a

${ }^{383}$ Carta de Otaño a Ripollés, 15 de febrero de 1912. AMSL. FO. Correspondencia, TA01/153. 
tanta...? no sé cómo calificar eso. Creí que iba a descubrir algo así como la Ley de la gravedad, y descubrió que después de tantas cavilaciones ha entendido el Motu proprio como nadie lo entiende ¿Quién le ha dicho que el Canto gregoriano es tal, cual...porque...todas aquellas proposiciones que él inventa, y luego qué de cosas en los 2 artículos. Esto entre paréntesis. ${ }^{384}$

Otaño valoraba así estos mismos artículos en una carta a Pedrell escrita en torno a mes y medio después:

No sé si leerá V. los escritos del estupendo descubridor Olmeda: a cada paso está diciendo que nadie hasta ahora ha sabido descifrar las piezas de vihuela y tecla y que él [subrayado doble] será el que ponga a Cabezón auténtico a la admiración de todos. Diga V. ¿no es hora de que hable V. algo? Porque ha de entender V., que con la fama de compositor que se va echando y con los hombros de Collet y otros Colados, va adquiriendo unos prestigios tremendos. Nadie le responde y él canta victoria. Acaba de publicar en "España y América" revista Agustiniana, unos artículos sobre el Motu Proprio que son la quintaesencia de la sandez. V. no recibe su revista "Voz de la Música"? Algo me extraña que le haga coro el P. Luis Villalba y los dos tienen a mi parecer, unos modos de ver singulares. ${ }^{385}$

Otaño se refería a la admiración que el crítico y musicólogo francés Henri Collet profesaba a Olmeda. La nómina de músicos españoles con los que se relacionó Collet, tanto durante su estancia en España como a su vuelta a Francia es larga: Pedrell, a quien consideraba otro de sus maestros, Granados, Luis Villalba, Gregorio $\mathrm{M}^{\mathrm{a}}$ Suñol, Falla, Turina o Rodrigo. A juicio de Miguel Ángel Palacios, biógrafo de Olmeda, fue este la figura "clave en la formación de Henri Collet en España"386. El propio Collet escribió en sus memorias:

En Burgos, me relaciono con Olmeda, maestro de capilla, hombre de genio, folclorista convencido (en cuya casa conocí a Raoul Laparra), quien me llevó en sus recorridos folclóricos a través de Castilla.

\footnotetext{
${ }^{384}$ Carta de Goicoechea a Otaño, 9 de diciembre de 1908. AMSL. FO. Correspondencia, 009/002.007.

385 Carta de Otaño a Pedrell, 23 de enero de 1909. BC. FFP. M 964 O. Otaño aludía al artículo "Ley general de la música religiosa en el "Motu proprio" de N.S.P. Pío X sobre música sagrada" publicado en España y América. Año VI Tomo IV octubre, noviembre y diciembre de 1908. (Madrid) pp. 222-238, 300-309; y Año VII Tomo I enero, febrero, marzo de 1909. (Madrid) pp. 123-133.

${ }^{386}$ Palacios, Federico Olmeda, pp. 141-150.
} 
Seguí a Olmeda a Madrid, donde fue nombrado maestro de capilla de las Descalzas Reales y donde murió en 1909, después de haber preparado la oposición de profesor del Conservatorio.

Con Olmeda me convertí en folclorista convencido, llegando a pensar, como él, que toda música debía construirse sobre la base del canto popular. ${ }^{387}$

La condición de discípulo y el reconocimiento de un personaje como Collet proporcionaba a Olmeda -antagonista- y sus trabajos un enorme valor que había que contener o neutralizar. El prestigio que iba adquiriendo Olmeda, según el mismo Otaño reconocía, fortalecía a su adversario, acrecentando su relevancia. Ripollés compartía con el jesuita su visión sobre la relación Collet-Olmeda. Tras una visita del francés a Sevilla, Ripollés escribió a Pedrell el siguiente comentario ${ }^{388}$ : "En otra posterior le daré cuenta de mi entrevista con Collet: este continúa sin caer de la burra y está todavía encariñado con los talentos y maneras de Olmeda." ${ }^{389}$

Como señalamos más arriba, la organización del congreso de Sevilla había reservado tanto a Olmeda como a Villalba la ponencia de una sección. Villalba presidió las sesiones dedicadas a la música instrumental y para órgano (sección $3^{\mathrm{a}}$ ), y Olmeda las correspondientes a la importante sección $4^{\mathrm{a}}$ "De la propaganda, organización y personal". En contraste con el papel asignado por los organizadores hispalenses a estas dos figuras del movimiento, la prevención y cautela predominaba entre Goicoechea y Otaño. El primero escribió: "Deseaba saber en qué sentido respiran Olmeda y el P. Villalba, etc...”390. Esta fue la respuesta de Otaño:

\footnotetext{
387 Este fragmento, traducido al castellano por Marie Thérèse Clostre-Collet, está citado en Palacios, Federico Olmeda, pp. 142. El autor del libro aclara que la oposición a la que se refiere Collet no fue al Conservatorio sino al Colegio Nacional de Sordomudos y Ciegos de Madrid. Raoul Laparra fue otro de los discípulos franceses de Olmeda. Véase, además: Miguel Ángel Palacios Garoz, El hispanismo musical de Raoul Laparra y Henri Collet. Dos discípulos franceses de Federico Olmeda en Burgos (Burgos: Institución Fernán González, Academia Burguense de Historia y Bellas Artes, 1999).

${ }^{388}$ El musicólogo francés ya había visitado Sevilla en noviembre de 1907, como testimonia la siguiente carta: "Aquí estuvo unos días un muy admirador de V., Henry Collet, haciéndome regustar las pocas antigüedades de este archivo. Tropezamos con un tomo in folio manuscrito con composiciones de Ceballos, Morales, Guerrero, Escobar, Pedro Fernández y otro. Le hice notar lo que del P. Fernández dice Guerrero, y como eran desconocidas en absoluto sus composiciones, y en vista de ello pidióme una transcripción de un motetito a 4 que le arreglé en el acto. A parte este motete hay en el mismo tomo otro motetillo a 4 en compás ternario, y una salve, ambas cosas de P. Fernández" Carta de Ripollés a Pedrell, 25 de noviembre de 1907. BC. FFP. M 964 R.

${ }^{389}$ Carta de Ripollés a Pedrell, 4 de noviembre de 1908. BC. FFP. M 964 R.

${ }^{390}$ Carta de Goicoechea a Otaño, 7 de octubre de 1908. AMSL. FO. Correspondencia, 009/002.001.
} 
Los PP. Villalba y Olmeda no se sabe qué actitud tienen; del primero hay datos para pensar que se presentará bien, el segundo sigue tan descontentadizo y chismoso como siempre. El Sr. Arzobispo [Almaraz] tiene tomadas las medidas, y creo que todo irá bien. ${ }^{391}$

Como refleja esta carta, la corriente Otaño-Ripollés-Goicoechea tenía de su parte el apoyo de arzobispo de Sevilla al igual que había ocurrido en el congreso de Valladolid con Cos y Macho. Sobre la opinión que le merecían a este último las figuras de Villalba y Olmeda escribía Goicoechea en una carta de finales de 1908:

Sin duda que iba mal impresionado hacia Roma, cuando vio que P. V[illalba] y $\mathrm{Ol}[$ meda] ocupaban puestos de ponentes, pues como sabe U. opina mal de estos dos: y cuando vio el artículo de U. [a favor de los signos rítmicos gregorianos] que le enseñaron en Roma, pensaba que siendo $\mathrm{U}$. un bonachón, y como joven de poca experiencia, tal vez influyeron ellos para que escribiese en tal sentido. ${ }^{392}$

De ello se desprende que, desde el congreso de Valladolid, y aún antes, con la elaboración de los Reglamentos, el grupo de Otaño-Goicoechea y posteriormente Otaño-Ripollés-Viñaspre-Goicoechea (en menor medida este por sus problemas de salud), habían alcanzado también a los ojos de los prelados comprometidos más directamente con la reforma de la música, es decir, de la jerarquía eclesiástica, el status de ortodoxo. En cambio, Olmeda y Villalba terminaron consagrándose como heterodoxos. Si aplicamos a nuestro caso el planteamiento de Bourdieu que defiende que el grupo que adquiere la condición de ortodoxo representa dentro de la dinámica social de un campo una clase dominante, tendríamos que afirmar que el grupo encabezado por Otaño se consolidó durante estos primeros años de la reforma en la tendencia, no sólo ortodoxa sino dominante. Las alternativas de Olmeda y Villalba en su condición de heterodoxas desempeñaron, dentro de esta dialéctica de confrontación con el grupo otañano, el papel de continuas retadoras, y aspirantes a conquistar el espacio ganado por este. La ausencia de Otaño en el congreso de Sevilla constituyó una gran oportunidad para las aspiraciones de Olmeda y Villalba.

\footnotetext{
${ }^{391}$ Carta de Otaño a Goicoechea, 10 de octubre de 1908. AMSL. FO. Correspondencia, T01/035.

${ }^{392}$ Carta de Goicoechea a Otaño, 29 de diciembre de 1908. AMSL. FO. Correspondencia, 009/002.008.
} 
La descripción que hizo Goicoechea, -presente en el Congreso aunque sin tomar parte en las controversias- de la escena que dejó al abandonar Sevilla, nos parece refleja elocuente y gráficamente la función del Congreso como el escenario en el que las distintas tendencias y grupos se disputaron la preponderancia, así como la facultad de decidir sobre la dirección que debía seguir el movimiento y los proyectos que se proponían:

Allá se quedaron el P. Mauricio [Luis Villalba], el Olmeda y los PP. Benedictinos Catalanes a ultimar sus cosas: especialmente lo del Conservatorio, lo del Tribunal Supremo para censura de música y el modo de que cunda la Voz [de la música, revista dirigida por Olmeda]. Los dos primeros cortan el bacalao a su gusto, iqué les aproveche! Los PP. Benedictinos no tan a gusto, porque no se permitió hablar de los consabidos puntos y no pudieron recomendarlos. Los de Silos se volvieron, después de pasar en Sevilla por el papel de revolucionarios, y en concepto de algunos, por opuestos a los deseos del Papa, puesto que ellos querían tratar del asunto de los rítmicos y armar camorra en contra de lo dispuesto por aquel. En fin, un lío: esto es lo que se saca de los Congresos. ${ }^{393}$

Las circunstancias que intervinieron en la preparación y celebración del congreso de Sevilla transformaron radicalmente el panorama respecto del vallisoletano. En el congreso de Valladolid, Otaño y sus colaboradores inmediatos jugaron un papel predominante. En el jesuita se concentró una buena cantidad del poder de decisión sobre el movimiento al confiársele la presidencia de todas las sesiones de estudio. Esto suponía la dirección y el arbitraje de los debates en los que se discutían los distintos puntos del congreso, y lo que es más importante, la redacción de las conclusiones. Otaño y Goicoechea fueron, recordemos, los principales responsables de la organización de esa primera asamblea. Como venimos constatando, en el caso del congreso de Sevilla, fue fundamentalmente Ripollés el que ejerció ese papel. No obstante, en Sevilla la asignación de las ponencias de las distintas secciones a diferentes personalidades Suñol, Ripollés y Goicoechea, Villalba, Olmeda- hizo que el poder que ostentara Otaño en Valladolid se distribuyera entre ellas, por tanto, estuviese más repartido ${ }^{394}$. La no

${ }^{393}$ Carta de Goicoechea a Otaño, 25 de noviembre de 1908. AMSL. FO. Correspondencia, 009/002.006. Mauricio fue el pseudónimo que solía utilizar Villalba en sus artículos.

${ }^{394}$ Recordemos quienes fueron los ponentes de cada sección: $1^{\mathrm{a}}$. Del Canto Gregoriano: Casiano Rojo; $2^{\mathrm{a}}$. De la música figurada: Vicente Ripollés y Vicente Goicoechea; $3^{\mathrm{a}}$. De la música orgánica e instrumental: Luis Villalba; $4^{\mathrm{a}}$. De la propaganda, organización y personal: Federico Olmeda. Es de notar que las principales tendencias del movimiento tuvieron su espacio. 
participación de Otaño en el Congreso impidió que pudiera intervenir en la pugna con el resto de líderes reformistas por hacer prevalecer sus criterios. El jesuita dejó un enorme hueco que ocuparon el resto de actores. Las decisiones del Congreso quedaron en manos de las líneas alternativas a la otañana.

La anterior carta de Goicoechea pone de manifiesto, además, que, aunque en teoría los congresos servían para debatir, por tanto, para abrir a la iniciativa de todos los colectivos implicados en la reforma las resoluciones a tomar para su aplicación práctica, en realidad, sólo un pequeño grupo de carácter oligárquico se disputaba la posibilidad de dirigir el sentido en el que había que caminar, y las decisiones sobre los proyectos que como medios para su realización se ideaban.

Dentro de ese grupo, las diferencias que separaban a Otaño y Olmeda eran muy profundas. Para Otaño, Olmeda no sólo no era un compañero, a pesar de las diferencias de criterio -"una misma aspiración en medio de las diferentes apreciaciones", en palabras de Goicoechea ${ }^{395}$ - sino un importante obstáculo para la -su- reforma.

En junio de 1909, cuatro meses después del fallecimiento de Olmeda (febrero de 1909), ofrecía a Angelo de Santi su balance sobre el desarrollo del movimiento reformista español desde la celebración del congreso de Valladolid. En el escrito se puede verificar nuevamente las pretensiones otañanas de fundar y liderar una "escuela", según sus propias palabras, compacta y unida, que siguiera sus criterios. La muerte de Olmeda, acaecida apenas tres meses después de clausurado el congreso de Sevilla, significó para Otaño la desaparición de "uno de nuestros mayores obstáculos", por tanto, una circunstancia que despejó el camino para el desarrollo de su proyecto:

De todos modos V.R. verá que la obra [Antología Moderna Orgánica Española] es de primera importancia para España, y que, dada la postración de nuestros Maestros, significa un esfuerzo considerable en pro del verdadero arte. Ni yo (que conozco bien la situación de la música en España) hubiera soñado en la realización de una obra tan perfecta y en su género acabada. Gracias a ella me he convencido que tenemos hombres; y yo me he aprovechado muy bien de esta ocasión para traerlos a mi escuela, para trabajar juntos en la obra de restauración: somos unos cuarenta, decididos al trabajo. La misma revista Música Sacro-Hispana ${ }_{2}$ dará a V.R. testimonio de lo mucho que ha ganado la causa en España desde el Congreso de Valladolid. Ciertamente hemos trabajado mucho y con gran fe, y lo bueno es que trabajamos unidos. No tengo más que decir una palabra, para que todos esos maestros hagan puntualmente lo que les indico.

${ }^{395}$ Carta de Goicoechea a Otaño, 13 de octubre de 1908. AMSL. FO. Correspondencia, 009/002.002. 
Hasta la misma muerte del maestro Olmeda -uno de nuestros mayores obstáculos- nos ha ayudado no poco para desarrollar nuestros planes. $^{396}$

Este documento pone de nuevo en evidencia que la revista, junto a otros proyectos como la mencionada Antología Moderna Orgánica Española, constituyó un eficiente instrumento aglutinador y conformador del movimiento, así como la principal herramienta para ejercer el liderazgo. Desde estas premisas, el control de las revistas de música religiosa representaba la clave para acaparar "por decirlo así, y en buen sentido, el pensamiento de la nación". Esta fue la reacción de Otaño ante el ofrecimiento que en 1909 hizo la editorial Casa Tena de Valencia a Ripollés de dirigir la revista Biblioteca Sacro-Musical (BSM):

Su carta me ha consolado no poco. Ya antes me anticipé yo a decir lo que sentía sobre su dirección de la Biblioteca Sacro-Musical en unas cuartillas cecilianas, que saldrán en el número próximo [de $M S H]^{397}$. Allí aplaudo con las dos manos la idea de que V. se encargue de esa dirección, que a mi ver la debe $\mathrm{V}$. aceptar a todo trance. Le ayudaremos en todo lo posible.

No sólo no le digo a $\mathrm{V}$. que basta con nuestra Revista, sino que, si le pudiera mandar, le obligaría a acceder a los deseos del editor y entrar de lleno en la cosa. La Biblioteca y nuestra Revista serán dos hermanas gemelas, porque V. y yo idem dicimus, idem sapimus. Sólo con este pensamiento estoy lleno de gozo. Adelante, pues, sin miedo y sin vacilación. ¿No ve V. que así abarcamos más y nos defendemos mutuamente? Como la Revista Musical Catalana defiende también nuestras ideas, acaparamos por decirlo así, y en buen sentido, el pensamiento de la nación. Bilbao-Valencia-Barcelona son tres centros importantes. $^{398}$

\footnotetext{
${ }^{396}$ Carta de Otaño a de Santi, 24 de junio de 1909. AMSL. FO. Correspondencia, T01/059.

${ }^{397}$ Las cuartillas a las que se refiere Otaño eran: "Una noticia interesantísima. El propietario de la revista Biblioteca Sacro-Musical de Valencia nos asegura que, en su afán de mejorar su publicación y de levantarla a la altura de las actuales exigencias, se propone encargar su dirección artística al eminente M. $^{\circ}$ D. Vicente Ripollés, que actualmente reside en Valencia. La idea es digna de todo aplauso: para nosotros el M. ${ }^{\circ}$ Ripollés es uno de los hombres más competentes que cuenta la escuela española de música sagrada: su ilustración, su celo, su laboriosidad están a tan gran altura, que bastan para asegurar la vida y la empresa de una publicación de esta naturaleza. Deseamos, pues, que los propósitos del editor señor Tena lleguen a la realidad; deseamos que su revista tenga esa incomparable dirección; deseamos que con nuevo traje aparezca hasta más vistosa y elegante, consagrada de lleno a difundir por España y las regiones de Levante, sobre todo, la luz de la verdad y los sentimientos verdaderos del arte cristiano. Nuestra Revista verá con júbilo esta nueva transformación de su hermana y colega de Valencia". Cecilio [Nemesio Otaño], “Cecilianas”, MSH, 8 (1910), pp. 78-79.

${ }^{398}$ Carta de Otaño a Ripollés, 2 de diciembre de 1909. AMSL. FO. Correspondencia, TA01/074.
} 
En los párrafos siguientes volvió a dibujar un prometedor panorama en lo que al movimiento que a su alrededor se iba consolidando se refiere. Es igualmente interesante la información que proporciona a propósito de la disponibilidad de los distintos personajes para colaborar en la nueva revista de Ripollés, así como la cercanía, apuntada más arriba, con el grupo de Barcelona:

[...] cuente con toda mi Revista y con todos nuestros aplausos y brazos. ¿Seis colaboradores? Me indica V. quizá los que menos le ayudarán: los unos por sus ocupaciones, y los otros por sus cosas. El P. Villalba es director de La Ciudad de Dios, y yo comprendo que una revista de esa importancia absorbe a todo un hombre. Goicoechea no escribe. En cuanto a música le ha dado por editar por su cuenta, y no le dará a V. mucho; sin embargo, creo que no se negará a dos o tres obritas por año. Siempre debe V. invitarle, porque su nombre vale mucho. Viñaspre no es compositor: escritor cuanto V. quiera. Escribe más que El Tostado. En eso le ayudará a V. mucho. Le advierto que hay que pulirle un poco los originales, cosa que aún a él le gusta.

Yo por de pronto le daré de mi pobreza lo que tengo con una sola condición: que pueda reproducir en otra parte las composiciones que le ofrezca ahí. [...]

Creo que debe $\mathrm{V}$. agarrarse a los catalanes y a los jóvenes de nuestra Revista. No crea V. que exigen cuartos: a mí me sobra original, y eso que desecho más de la mitad de lo que me envían. Hay furor por salir a luz; y luego que se convencen de la seriedad de una revista, les parece punto de honra el colaborar en ella. Con recomendaciones me han venido algunos, y no han conseguido ser incluidos en la lista, hasta que me presenten obras de más fuste. Las cosas han cambiado mucho.

[...] Escriba V. a Urteaga, Beobide, Garaizábal, Alfonso Ugarte, Gabiola, Elústiza, Mocoroa: todos ellos tienen una vena y facundia portentosas. Y como tendrán algún inconveniente sin contar conmigo, pues están de todo a mi voluntad, les dice V. que yo le ordeno y mando dirigirse a ellos; porque los creo capaces de redimir el arte, y hacer todas las valentías del mundo, y colaborar, no en una, sino en veinte revista a la vez. Es gente de fe y desinteresada. Entre los catalanes encontrará V. muchos, que se presten a regalarle al año algunas cosilla: Lambert, Cumellas, Mas y Serracant están muy satisfechos de ser colaboradores, y me dicen que les pida lo que quiera. $[\ldots]]^{, 399}$

El proyecto finalmente no salió adelante, aunque lo rescató otra editorial, esta vez afincada en Madrid y regentada por Ildefonso Alier ${ }^{400}$. También Alier propuso a

\footnotetext{
399 Ibídem.

400 "Yo post factum casi me he alegrado de que Tena no haya podido realizar el plan de la revista; no porque yo no mirara con honda simpatía eso (que ya vio V. que sí), sino porque así puedo contar más con
} 
Ripollés la dirección de la revista, aunque rechazó la oferta porque "me indicó que quería lucha y polémica con el P. Otaño", a lo que no estaba dispuesto el castellonense $^{401}$. Finalmente fue Luis Villalba el encargado de dirigir BSM, a cuya rivalidad con Otaño se refería Ripollés en la misma carta: "preveo que tendremos algún choque los dos PP. se quieren poco, tal vez por cuestión de traje, y además el P. $\mathrm{V}$ [illalba] es muy independiente en sus juicios y teorías, así al menos lo parece" ${ }^{\text {402 }}$.

Con ello, la hegemonía a la que aspiraba Otaño (acaparar "el pensamiento de la nación") quedó aún más lejos. En lugar de fundarse una revista "hermana gemela" de $M S H$, al frente de la cual estaría una figura afín, se encontró con una competidora, en manos de otro personaje ajeno a su círculo, contemplado desde este como “independiente en sus juicios y teorías", cuyas críticas eran sentidas como parciales, y citado frecuentemente junto al otro heterodoxo, Olmeda.

Según consta en el siguiente fragmento, Otaño, que partía en esta competencia con la ventaja de tener "ya nuestro campo" optó por evitar la confrontación. La utilización, de nuevo, del pronombre "nosotros" evidencia una vez más la conciencia de pertenecer a un grupo en pugna con otros ("ellos") dentro del entramado de relaciones del movimiento reformista:

No: yo no me meteré con el P. Villalba. No soy de esos que quieren buscar un cuestión de sotanas. Yo seguiré impertérrito mi camino, y si él acomete, se le responde con un soberano silencio. Nosotros tenemos ya nuestro campo; que ellos labren el suyo. [... $]^{403}$

Sin embargo, a juzgar por esta otra carta, no parece que los directores de ambos órganos reformistas mantuvieran unas relaciones muy distendidas:

$\mathrm{V}$, y con su pluma. Colaboradores musicales me sobran, pero literarios me falta. Venga, pues, cuanto V. quiera y escriba de firme. Espero, pues, no algo, sino mucho; poco cada vez, porque nuestras columnas se llenan pronto, pero con frecuencia." Carta de Otaño a Ripollés, 11 de enero de 1910. AMSL. FO. Correspondencia, TA01/075. Más adelante vuelve a referirse al éxito que suponía la revista como medio de congregación de las promesas del movimiento reformista, a la influencia que había conseguido ejercer sobre los grupos catalanes, así como la función de liderazgo que desarrollaba: "La verdad es que entre los colaboradores reina un espíritu excelente: ¡qué unión, qué seriedad y qué amor! Esto nunca se había visto en España. [...] Los jóvenes maestros Elústiza, Urteaga etc. etc. estaban dispuestos a colaborar con V.: me contestaron que ellos irían adonde les mandara yo. Así que ya hubiera tenido material de sobra. Lambert y cuadrilla catalana también a la orden. Esta resurrección del espíritu vale oro molido.” Ibídem.

${ }^{401}$ Carta de Ripollés a Pedrell, 23 de diciembre de 1910. BC. FFP. M 964 R.

${ }^{402}$ Ibídem. Albano García se refiere a la competencia que mantuvieron Otaño y Villalba a través de sus respectivas revistas $M S H$ y $B S H$ en: "Sobre la reforma de la música religiosa en España”, p. 973.

${ }^{403}$ Carta de Otaño a Ripollés, 31 de diciembre de 1910. AMSL. FO. Correspondencia, TA01/101. 
El P. Villalba me hace continuas protestas de amistad y unión. Su revista no tiene por ahora más interés que en lo antiguo. Pero no creo yo que le inspiremos gran devoción, ya que ni nos cita, a pesar de que yo la elogié, ni ha puesto el Concurso. El otro día le escribí sobre esto al Padre, y me dice que enseguida lo pondrá. ¡Buena hora! ${ }^{404}$

Otaño, por su parte, vertía en sus cartas opiniones poco favorables sobre la revista de Villalba, exceptuando los momentos en los que se refería a la serie de obras para órgano de autores españoles del s. XVI y XVII que fue publicando, y a la que el vasco se refería como Antología Antigua de Órgano:

[...]La revista de Alier [de Villalba] me parece una tomadura de pelo, como diría Viñaspre. ¿V. la recibe? Le enviaré siquiera los números, para que me los devuelva cuando los vea. Dígamelo. Hay allí fárragos de música. Mucha agua y mucho pan de hogaza. Pero non solus de pane vivit homo.

Esta abundancia no puede engañar más que a los incautos. Lo único bueno a mi ver es la Antología Antigua de Órgano. ${ }^{405}$

Por tanto, las revistas de música sacra representaron el principal instrumento, junto con los congresos, para aglutinar y conformar un conjunto más o menos numeroso de individuos y grupos en torno al ideal reformista. La fundación y el control de estas publicaciones constituyeron el principal medio de ejercer el liderazgo por el impacto creciente que en esos momentos iban teniendo en el mundo eclesiástico musical. Las revistas daban la posibilidad de obrar una influencia fáctica sobre una buena porción de ese universo, pues fueron potentes medios de difusión de las propias ideas, perspectivas y teorías, e incluso de material necesario para la reforma, junto con su inseparable valor comercial.

${ }^{404}$ Carta de Otaño a Ripollés, [sin día] abril de 1911. AMSL. FO. Correspondencia, TA01/118.

${ }^{405}$ Carta de Otaño a Ripollés, 27 de mayo de 1911. AMSL. FO. Correspondencia, TA01/126. Los juicios emitidos por Otaño en este sentido son recurrentes en estos días: "Ya han llegado los dos primeros $\mathrm{n}^{\circ}$ de la revista de Alier. El texto lo encuentro poco interesante, pero me gusta extraordinariamente el repertorio orgánico antiguo, que va dándonos el P. Villalba. Temo también que con tantas páginas de música tenga que dar mucha broza. Gran parte de las obras, que yo rechazo, han de acudir allí; porque pocos son los que se convencen de los defectos propios." Carta de Otaño a Ripollés, 10 de marzo de 1911. AMSL. FO. Correspondencia, TA01/113. "La revista del P. Villalba en el texto no tiene interés, si no es por las noticias que va dando de Santa María, etc....

En la música lo único que me agrada es la antología de organistas antiguos, que ha empezado a dar" Carta de Otaño a Pedrell, 19 de abril de 1911. AMSL. FO. Correspondencia, T01/092. 


\subsubsection{El negocio editorial y las instituciones de la reforma}

Aunque no es posible dilucidar la parte de responsabilidad que le cabía a Villalba y cuál a Alier, o expresado en términos generales, a los líderes reformistas y a los editores, la actitud polémica deseada por el editor indica que los avatares del negocio editorial se habían infiltrado en las relaciones entre los reformistas ${ }^{406}$.

Las reglas de la inversión de capitales y la rentabilidad económica que regían, como cualquier otro negocio, la empresa editorial tutelaron otra forma de estar presente e intervenir en este espacio compartido de la reforma. La imbricación de negocio editorial y reforma se muestra con claridad en uno de los principales problemas del proceso, cual fue la disparidad de criterios entre las comisiones diocesanas para ejercer la censura de la música sagrada.

Uno de los tres artículos reproducidos íntegramente en la Crónica del Segundo Congreso, publicados antes del congreso de Sevilla, hacía referencia a este problema, y denunciaba las consecuencias que tenían para los que se comprometían con la reforma:

Pues nada se diga de las divergencias en las interpretaciones por parte de los prelados y las Comisiones diocesanas: unos admiten todo lo que hasta ahora ha formado el repertorio de las parroquias y otros lo prohíben por completo. ¿Hay un organista o Maestro de Capilla de buena voluntad que quiere llevar las cosas por el camino recto? ¡Pobre de él! Luego grita la turba un tolle, tolle que le mete el miedo o el desaliento en el cuerpo, cuando no son los superiores los que le exigen la retirada, a título de no sé qué falsas interpretaciones del Motu Proprio. ${ }^{407}$

En la discusión sobre el punto e) "Censura de la música litúrgica: obstáculos que impiden su realización y medios de salvarlos", integrado en la sección cuarta del cuestionario del congreso hispalense, salió a relucir la cuestión. Al plantearse la necesidad de unificar los criterios censores y los medios para conseguirlo, los representantes de las cuatro casas editoriales presentes en el Congreso (Tena de Valencia, Llobet de Barcelona, Lazcano y Mar de Bilbao, y Alier de Madrid ${ }^{408}$

${ }^{406}$ Esto justificaría las cautelas mostradas por la CDMS de Valladolid ante la posibilidad de compartir un mismo espacio con el mundo del negocio editorial.

${ }^{407}$ Franculus, “Un Congreso”, en: Crónica Segundo Congreso, p. 46.

${ }^{408}$ El dato sobre las editoriales presentes nos lo proporciona Villalba: "Más animación hubo en la sección cuarta, de que era ponente D. Federico Olmeda. La verdad es que los puntos se prestaban a ello, y si no ahí va: Censura de la música litúrgica; obstáculos que impiden su realización. Asistían al Congreso cuatro editores de música: Luis Tena, de la Biblioteca Sacro-Musical de Valencia; Llobet, del Musical 
pusieron de manifiesto la estrecha dependencia que tenían sus negocios de la política censora que pusieran en práctica las comisiones diocesanas de música sagrada, y, por consiguiente, el enorme perjuicio que la absoluta falta de coordinación o de una mínima base común para emitir juicios -al margen de la acusación sugerida de arbitrariedad, e incluso rivalidad-, les causaba:

Pues bien: se trataba de averiguar el modo de que la censura de la música se ejerciese en todas partes y de quitar los obstáculos que lo impidiesen; $\mathrm{y}$, en efecto, lo que primero salió a la colada fue la santa libertad con que se practica, la falta de criterios fijos que la informan, el personalísimo individualismo que la anima. Porque, decían los editores, nosotros publicamos una obra porque nos la aprueba la comisión diocesana de la ciudad donde estamos establecidos; pero he ahí que llega a otro lugar y la reprueban, con lo cual nosotros, que exponemos un capital guiados por la sanción de una junta oficial, vemos a ese capital deshecho por otra junta tan oficial como la que aprobó, y las pérdidas, en consecuencia, son grandes. ${ }^{409}$

Este problema se agravaba ante la dificultad de luchar en este contexto con el prestigio del que disfrutaban las ediciones extranjeras frente a las españolas:

Es más: esas comisiones ven una obra extranjera; el pie de edición de Roma, de Milán, de Ratisbona, de Düsseldorf, les impone respeto; aquello tiene la sanción de una junta italiana, o alemana: inclinación profunda, adelante y beso a usted la mano; pero llega una obra española, ¡oh!, aquí son los escrúpulos, los rigores, los catonismos, los puritanismos litúrgicos, eso en caso de aparecer desvalida de toda recomendación, porque si lleva la de otra comisión española, basta ella para dar en el suelo con la cosa. ${ }^{410}$

La forma de describir la situación de Villalba, cuya crónica nos proporciona la posibilidad de asomarnos a lo que debió ocurrir en aquella sesión, es una vez más digna de ser transcrita por su capacidad ilustrativa:

Emporium de Barcelona; Lazcano y Más, de Bilbao; Ildefonso Alier, que se acababa de hacer cargo del Salterio Sacro-Hispano, propiedad, antes, de la casa Vidal Llimona y Boceta. La materia, de suyo, es vasta y delicada, y el criterio que debe informarla más delicado todavía; porque si en la parte literaria, con ser la palabra escrita tan clara y terminante, el ejercicio de la censura eclesiástica es difícil y espinoso, y no puede hacerse en vista de opiniones ni de nada discutible, en música, cuyo medio de expresión es tan vago, tan equívoco de por sí, el hacer crítica y censura personal sin otra norma que el criterio propio, es cosa expuesta a muchos lances." Villalba, "El Segundo Congreso Nacional”, p. 412.

${ }^{409}$ Ibídem, pp. 412-413.

${ }^{410}$ Ibídem, p. 413. 
Tal decían, y salto voce especificaban los casos. Yo no juraré si es verdad lo narrado; pero que efectivamente hay sus más y sus menos en el particular, eso sí que te lo puedo decir; sitio sé yo, y lo sé porque te digo que lo sé, donde la Comisión no ha sido capaz de juzgar de una composición por su lectura; ha tenido que oírla; y lugar donde por una quinta se ha dado al traste con otra. ¡Claro es que una quinta es cosa anti-litúrgica! Y, en fin, para que haya de todo, no falta diócesis donde ostentan la aprobación obras fusilables. Es decir, que hay de todo como en botica; en fin, que apareció demasiado visible que cada cotarro es un imperio independiente, que no se entiende con el vecino (en algo se ha de conocer la autoridad), de lo cual resulta que como entre sí no se entienden y que en unas partes dicen blanco y en otras negro y en otras colorado, no es fácil saber a qué carta quedarse. Es decir, no se puede quedar a ninguna. V. ve ahí cómo se vino a parar en la necesidad de unificar la acción de las comisiones y de poner término a esa disparidad de criterio que entre algunas de ellas públicamente existe. ${ }^{411}$

La solución a la que se llegó fue la fundación de una junta central censora que dirimiera en última instancia las diferencias entre las comisiones diocesanas ${ }^{412}$. Se trataba, por tanto, de recuperar la propuesta realizada por Otaño en el congreso de Valladolid $^{413}$, y que fue desestimada por constituir un órgano paralelo a las comisiones diocesanas, posesoras legítimas y únicas, según el $M P$, de las competencias al respecto. En este caso, se intentó salvar esta traba otorgándole la misma oficialidad que poseían aquellas, para lo que se determinó hacer la correspondiente solicitud de erección de un Tribunal superior nacional a la Santa Sede:

Había, sin embargo, una dificultad: las comisiones diocesanas constituyen un organismo oficialmente constituido, y como el juez que sobre ellas se estableciera no podría funcionar regularmente si no se le daba igual carácter, se convino en acudir más arriba, a la Santa Sede, pidiendo la constitución de un Tribunal superior nacional que decidiera todas las divergencias que pudieran suscitarse entre las comisiones diocesanas. Tal fue la conclusión dictada, que aprobó el Congreso, y ratificó quien debía ratificarla. ${ }^{414}$

\footnotetext{
${ }^{411}$ Villalba, "El Segundo Congreso Nacional", Ibídem.

412 “[...] todos reconocieron la razón que asistía a los editores y comprendieron de propia iniciativa la necesidad de poner término a la división que el juicio privado y personalísimo quiere introducir. Para lo cual determinaron el nombramiento de una Junta central, tribunal superior que pusiera paz.”. Ibídem.

${ }^{413}$ Véase de este mismo capítulo el epígrafe 2. “Génesis del congreso de Sevilla”, p. 358.

${ }^{414}$ Ibídem, p. 414.
} 
Esta fue la conclusión sobre este punto tal y como fue publicada en la Crónica del Segundo Congreso:

Punto e) El Congreso, atendiendo a razones expuestas por los editores de Música Sagrada, suplica a los Reverendos Prelados acudan a la Santa Sede pidiendo la constitución de un Tribunal superior nacional, con carácter oficial, para decidir todas las divergencias que pudieran suscitarse entre las Comisiones Diocesanas. ${ }^{415}$

Durante nuestra búsqueda de documentación en el AGAS hallamos el borrador de la solicitud de erección del Tribunal Superior Censor que debió enviarse a Roma, y adjuntamos transcrito en Apéndice 8.

\subsection{Las pugnas de los organistas por el capital económico y simbólico}

En el contexto de los preparativos para el congreso de Barcelona, Ripollés escribía a Pedrell:

La magna cuestión está en las ejecuciones: aparte las que integrarán los actos solemnes del Congreso (Apertura, Misa, clausura), es necesario ofrecer buenas ejecuciones en conciertos de música estrictamente litúrgica uno y de concierto sacro en otro. Además no puede faltar un buen concierto de órgano. Y aquí está el burilis: quién se encarga de estas ejecuciones? Quiere V. bien que ellas sean irreprochables y modelo y no confiando mucho en el Orfeó apunta a la Isidoriana y a los de Casá de la Selva: la cosa es espinosa, espinosísima y preñada de un sinnúmero de conflictos, asperezas y disgustos. $^{416}$

En el caso de Sevilla, no se planteó problema alguno respecto al coro al que debía confiársele los conciertos de música litúrgica y religiosa. Suponemos que la inexistencia en la capital andaluza de una entidad coral de la envergadura del Orfeó Catalá, y que pudiera competir con la Capilla Isidoriana evitaría el posible conflicto al que aludía Ripollés en el congreso de Barcelona. Todo lo contrario ocurrió en el caso de los concierto de órgano.

A principios de octubre, Goicoechea, refiriéndose a un artículo publicado en el diario El Universo expresaba a Otaño su extrañeza por la no aparición del organista

\footnotetext{
${ }^{415}$ Crónica del Segundo Congreso, p. 274.

${ }^{416}$ Carta de Ripollés a Pedrell, 2 de marzo de 1912. BC. FFP, M 964 R.
} 
azpeitiarra Ignacio Fernández Eleizgaray entre los organistas que debían tomar parte en el congreso de Sevilla ${ }^{417}$. Precisamente fue a este y a Bernardo Gabiola a quienes se les encargaron los conciertos de órgano en el congreso de Valladolid. Por tanto, se deduce que la idea era mantener el mismo cartel con la única novedad de la incorporación de Jesús Guridi. Otaño respondió a Goicoechea:

No se ha pensado en llevar a Ignacio Fernández como organista, porque, además de los concertistas Gabiola y Guridi, desean aparecer Salas y Mariani, que no son del todo mancos y llevan el título de $1^{\circ}$ y $2^{\circ}$ organista de la Catedral de Sevilla. ${ }^{418}$

Como se desprende del siguiente fragmento, la organización de Sevilla desbarató los planes iniciales, en los que se prescindían de los músicos locales, e impuso su criterio: “Que en Sevilla han estropeado la combinación de organistas: allá responderá la Comisión, o quien sea." ${ }^{, 19}$. Ello produjo profundo malestar en los organistas foráneos inicialmente previstos, llegando a poner en peligro los mismos conciertos de órgano, pues se negaron a participar. Tan sólo cuatro días antes de la inauguración del Congreso, Otaño escribía: “¿Vive V. o no? Todos estos días esperaba carta de V., pero en vano. Los organistas bilbaínos se han alarmado y no quieren ir; les he escrito que a todo trance vayan, pues ya no era hora de tomar esa resolución. ${ }^{, 420}$ Es más, el día 11, es decir, en vísperas del Congreso, Otaño no tenía noticias sobre Guridi $^{421}$ : "No sé todavía si Guridi está ahí: supongo que se le quitaría de la cabeza la negativa." 422 Los términos en los que se refirió Ripollés tiempo después a estas cuestiones dejan entrever la envergadura que tomó la polémica ${ }^{423}$ :

\footnotetext{
417 "Me ha extrañado que en el articulo tomado de 'El Universo' no suene el nombre de Eleizgaray entre los organistas;" Carta de Goicoechea a Otaño, 7 de octubre de 1908. AMSL. FO. Correspondencia, 009/002.001.

${ }^{418}$ Carta de Otaño a Goicoechea, 10 de octubre de 1908. AMSL. FO. Correspondencia, T01/035.

${ }^{419}$ Carta de Goicoechea a Otano, 29 de octubre de 1908. AMSL. FO. Correspondencia, 009/002.003.

${ }^{420}$ Carta de Otaño a Ripollés, 8 de noviembre de 1908. AMSL. FO. Correspondencia, TA01/048.

${ }^{421}$ Guridi finalmente tomaría parte en el Congreso. Llegó a Sevilla el día 13 de noviembre, es decir, una vez iniciado el Congreso. El concierto de órgano en el que intervino tuvo lugar el día 14.

${ }^{422}$ Carta de Otaño a Goicoechea, 11 de noviembre de 1908. AMSL. FO. Correspondencia, T01/038.

${ }^{423}$ En otra carta escrita pocos días después vuelve a insistir a Pedrell: "Me alegro que haya dejado V. eso de las ejecuciones para los que quieran jaleo: ya comentaremos y reiremos.[...]

Yo recomendaría a V. que lo que $\mathrm{V}$. piense influir en las comisiones de ejecuciones vocales y órganicas, no lo haga directamente, sino por mediación del P. Suñol o de otra persona de confianza:
} 
Por ello, si mi consejo y opinión valieran algo, me gustaría ver a V. alejado de estos Signis mignis y suponiendo habrá ahí comisión de ejecuciones que ella cargue con las odiosidades y para V. la gloria de organizar el programa en líneas generales y particularizar en los actos de más provecho como son funcionamiento de secciones, cuestionario, conferencias, etc. Si V. va por el camino que le traza quien ha pasado por estos trances que todavía recuerdo y me duelen, contemplará tranquilamente y se reirá en grande al ver los tropezones de algunos, y cuando salgan las críticas, que saldrán, serán los honores y alabanzas para V. y los alfilerazos para quien tropiece. Estoy en que V. no salga de la organización general y abandone todas las particularidades de ejecución in manus inignorum: esto le dará más tranquilidad y más tiempo para ocuparse en cosas de mayor provecho, y ahí tiene V. a Victoria esperando. ${ }^{424}$

Villalba se refirió en un par de ocasiones a los problemas surgidos con y entre los organistas:

Voy a terminar esta larguísima carta con los conciertos de órgano. Algún tanto borrascosos en su preparación, han dado no poco que decir en su ejecución. Percances son estos del genus irritabile mussicorum que deben pasarse por alto. Ahí te van dos programas, y si sabes leer, leerás algo, aunque te aconsejo que no leas demasiado. ${ }^{425}$

El músico agustino reprodujo a continuación el programa inicialmente previsto y el que terminó siendo definitivo que, según afirmó, no se conoció hasta el mismo día del concierto ${ }^{426}$. En el primero, los organistas figuraban mezclados, en el segundo, los andaluces y los vascos, separados. Los locales tocaron en el primer concierto, los foráneos en el segundo ${ }^{427}$. Por tanto, la pugna por los capitales que el Congreso ponía en circulación, está vez en relación con el mundo de los organistas, provocó otro

conviene alejarse de cuanto pueda llevarnos a rozaduras y disgustos." Carta de Ripollés a Pedrell, 13 de marzo de 1912. BC. FFP. M 964 R.

${ }^{424}$ Carta de Ripollés a Pedrell, 2 de marzo de 1912. BC. FFP. M 964 R.

${ }^{425}$ Luis Villalba, "El Segundo Congreso Nacional”, p. 123.

${ }^{426}$ Villalba, "El Segundo Congreso Nacional", p. 125. Villalba sugería la clave para reconocer el "lío": "Todavía hubo otro pequeño lío; con ver el programa primitivo de los conciertos de órganos y el que en definitiva se dio el día antes, podrás rastrear la índole del caso". Ibídem, p. 585. Los programas que figuraron en la Crónica no fueron exactamente los aprobados en la última junta celebrada el 11 de octubre, un mes antes del inicio del Congreso, tal y como se avisaba en la misma: "A continuación transcribimos los Programas, tanto el General como los Particulares, no exactamente como fueron aprobados en la junta del día 11 de Octubre, sino con las ligeras variantes que a última hora impusieron circunstancias del momento." Crónica del Segundo Congreso, p. 53.

${ }^{427}$ Transcribimos ambos programas en Apéndice 9. 
conflicto. Además de las lógicas remuneraciones, estaba en juego la posibilidad de aprovechar estos grandes escaparates que eran los congresos como plataformas para proyectarse, adquirir notoriedad y prestigio. Es lógico pensar que los organistas sevillanos asumieran mal que no se contara con ellos en un congreso a celebrar en su propia ciudad, y recibieran esta decisión como una afrenta o menosprecio.

Otro de los desencadenante del conflicto fue la diferencia de criterios estéticos y artísticos que defendían unos y otros. En realidad, desde una perspectiva más amplia, el problema era de mucho mayor calado que el de un mero conflicto de intereses entre organistas. De estos dependían los criterios estéticos y litúrgico-musicales a exhibir como modélicos en los conciertos de órgano por parte del Congreso. Como defenderemos en el próximo capítulo, la asamblea sevillana cumplía la trascendental función de institucionalizar los nuevos principios estéticos y litúrgico-musicales. Reconocemos, por tanto, en la cuestión de los conciertos de órgano, otro marco en el que se verificó la lucha entre posiciones antagónicas, e incluso, irreconciliables, de la que hemos dado cuenta en el capítulo cuarto. Por un lado, "los sevillanos", y por otro, los reformistas españoles. Los primeros trataron de conservar el sistema de ideas estéticas y el repertorio propios, una posición asociada a la defensa de una identidad asumida; y los segundos, trabajaron por la regeneración estética, artística y musical en el ámbito religioso. Ripollés se refirió a la posición de los organistas sevillanos como "refractarios a todo lo nuestro" 428 .

Los líderes del movimiento emitieron juicios absolutamente diferentes sobre los conciertos ofrecidos por Mariani y Salas, por un lado, muy negativos; y Gabiola y Guridi, por otro, positivos. Goicoechea estimó:

El $1^{\circ}$ concierto de órgano de malísimo gusto sin que tuviera nada de religioso (horror!)

El $2^{\circ}$ sumamente artístico. Gabiola llegó a prepararse bien. Guridi, llegó ayer, sin embargo, salió bien de su empeño. El adagio de Ud. se ejecutó con amore, y a pesar de haber ido detrás del colosal coral de Franck, causó muy buena impresión. ${ }^{429}$

\footnotetext{
428 "Hay disgustos largos y hondos y los espero mayores de parte de los organistas, completamente refractarios a todo lo nuestro [...]" Carta de Ripollés a Pedrell, 17 de octubre de 1908. BC. FFP. M 964.

${ }^{429}$ Carta de Goicoechea a Otaño, 14 de noviembre de 1908. AMSL. FO. Correspondencia, 009/002.005.
} 
Y este el de Ripollés: "[...] fue otra calamidad el concierto de órgano de Salas y Mariani." ${ }^{430}$. Villalba también se pronunció al respecto en los comentarios que publicó en la revista $L C D$ sobre el Congreso. En este caso, la unidad de criterio entre todas las personalidades reformistas, independientemente de las diferencias que les separaban, fue manifiesta:

El primer concierto fue una lamentable equivocación, una verdadera desafinación. En los músicos las equivocaciones que dan por resultado notas desafinadas, no proceden sino de estar distraídos, de no pensar bien lo que hacen, y esto es, indudablemente, lo que ha sucedido aquí. Por si acaso, no vayas a creer que se trata de cuestión de tañido, de ejecución quiero decir: por este lado nada hay que advertir, es que la materia circa quam, el programa, lo que se tocaba, no podía figurar en un concierto de esta clase, porque ni como música religiosa, ni como música a secas, la mayor parte de las piezas cumplían para el caso, y un caso que había de tener por espectadores a organistas y maestros, prevenidos para escuchar algo digno de un concierto modelo. Total: que el ejemplo no fue nada ejemplar. Y no te digo más. ${ }^{431}$

No obstante, el crítico agustino puso en evidencia las razones por las que tampoco la propuesta de Gabiola y Guridi se atenía exactamente a la función ejemplarizante que debía cumplir el concierto de órgano dentro del Congreso. Aunque desde un punto de vista artístico, la calidad del programa era indiscutible, las obras no poseían la categoría de religiosas, salvando las compuestas por autores españoles. Resulta interesante observar la omisión respecto a este punto en el juicio anteriormente citado de Goicoechea. El maestro de capilla de Valladolid destacaba su valor artístico (“sumamente artístico") pero no religioso. Esta es la crítica de Villalba:

Más escogido programa ofrecía el segundo concierto. Y cónstete que no soy nada partidario de las sinfonías, de las puras sinfonías de órgano, en cuanto a presentarlas en un concierto que ante todo y sobre todo debe ser religioso; la razón es obvia: en estas sinfonías el compositor trata de hacer música, muy excelente música, teniendo en cuenta la naturaleza acústica del instrumento, pero prescindiendo del matiz religioso; y sinfonistas de órgano son los tres citados. Pero del mal el menos: no son profanos, no son religiosos, pero siquiera son músicos, pero músicos sólo, y yo sigo creyendo que la música religiosa, lleve letra o no la lleve, no puede ser pura música,

\footnotetext{
${ }^{430}$ Carta de Ripollés a Pedrell, 8 de febrero de 1909. BC. FFP. M 964 R.

${ }^{431}$ Luis Villalba, "El Segundo Congreso Nacional”, pp. 125-126.
} 
tiene que manifestar esa idea, esa expresión, ese matiz que se llama religioso. [...] Puede haber música que suene perfectísimamente en el órgano, y no exprese idea ninguna santa; más claro, puede ser música de órgano y no ser música religiosa. Por eso, aunque se trate de nombres tan respetables como Bach, Franck, Widor, esas sinfonías no entran para mí en el catálogo de la música religiosa. Pero si no son compositores religiosos, son músicos, y esto ya es bastante. Música de órgano con finalidad religiosa no había en este programa sino lo español, lo de Otaño, Alfonso, Olmeda, Gabiola y Guridi, y encima era bueno en el capítulo de música. Miel sobre hojuelas. ${ }^{432}$

De nuevo, Villalba, aún alineándose en lo esencial con las críticas de Goicoechea y Ripollés, mostró su libertad de criterio, incluyendo un elemento crítico no considerado por ellos.

Con el estudio de los problemas que surgieron en torno al colectivo de organistas completamos nuestro análisis de los conflictos de los que las fuentes relacionadas con el Congreso nos ofrecen datos. Procede, a continuación, ofrecer una visión general de la asamblea y el movimiento pro-reformas según la perspectiva de análisis que adoptamos: el Congreso como escenario para la consolidación de un espacio socio-artístico.

La reforma que provocó el $M P$ sobre música sagrada se nos confirma como un espacio emergente en ebullición. Fue surgiendo en estos momentos una estructura socio-cultural compleja gobernada por un sistema de relaciones de colaboraciónconfrontación en la que cada agente trató de ocupar su lugar de acuerdo a sus objetivos e intereses. Dado su carácter aún naciente, todas las posiciones y roles en esta estructura estaban aún por definir u otorgar, aunque la inversión hecha ya por algunos de los implicados, como por ejemplo el caso de los benedictinos de Silos en forma de ediciones de libros de canto, había sido ya importante, lo que hacía aún más encarnizada la pugna por la rentabilidad de los esfuerzos. El capital en juego, fue no sólo de carácter simbólico (autoridad, prestigio, capacidad de influencia, notoriedad, etc.), sino también económico, desde el momento en el que la realización de la reforma precisó de medios, recursos y objetos, es decir, de prestación de servicios. La implantación del $M P$, o desde otra óptica, la regeneración de la música religiosa en España, produjo no sólo posicionamientos ideológicos, posturas o apreciaciones diversas, sino también actividad económica, en consecuencia empresas o particulares que prestaran los servicios

${ }^{432}$ Ibídem, p. 126. 
requeridos. De hecho, el aspecto mercantil se nos muestra como inseparable del artístico e ideológico.

Los congresos constituyeron los grandes escenarios en los que acontecieron las luchas por la posición relativa deseada dentro de este campo sociocultural de relaciones organizadas, en cierto equilibrio aunque en constante dinamismo, conflicto y mutación interna. En ellos concurrieron, en primer lugar, grandes personajes de la música religiosa con vocación al liderazgo. En segundo lugar, músicos eclesiásticos plenamente comprometidos con la causa, en muchos casos con posiciones, perspectivas y sensibilidades varias, y en algunos, con importantes intereses comerciales asociados a sus apuestas ideológicas y estratégicas prácticas. En tercer lugar, editores, organeros e intérpretes que hallaban en estos foros oportunidades de negocio y proyección. Estos últimos colectivos eran vistos como parásitos por algunos, y como profesionales que defendían sus legítimos intereses a la par que procuraban la satisfacción de determinadas necesidades, por otros. En cuarto lugar, organizadores con pocas pretensiones pero que no podían esquivar las disputas provocadas por los conflictos de intereses; al contrario, se encontraban en el ojo del huracán al poseer la facultad delegada de tomar decisiones, en consecuencia, de administrar las oportunidades y el capital en juego. Por último, la alta jerarquía eclesiástica, que, por encima de todos los demás, representaba el poder institucionalizado no participaba en el juego de distribución de capitales y de reconocimiento de esos capitales simbólicos o materiales. Su intervención en esta estructura se producía sólo cuando ejercía de facto su poder, que era esporádicamente, o cuando eran influenciados por algunos de los demás agentes. Y pertenecían de lleno a ella, es decir, se beneficiaban de la circulación de capitales cuando repercutía positivamente en sus respectivas diócesis. A otro beneficio se refirió Ripollés en alguna ocasión en una severa crítica, en medio del desengaño que le produjo las últimas experiencias como organizador del Congreso: el prestigio que proporcionaba la organización de estos eventos, y que repercutía de forma muy favorable en la promoción dentro de la carrera eclesiástica:

Ahora con la muerte de ese Cardenal irán disputándose el capelo varios de los supervivientes entre los cuales figurarán ciertamente Sevilla y Valencia; y nosotros los pobrecitos cargaremos con los trabajos para que ellos puedan presentarse ante la S. S. con los méritos de quien hace mucho sin hacer absolutamente nada. ${ }^{433}$

${ }^{433}$ Carta de Ripollés a Pedrell, 4 de noviembre de 1908. BC. FFP, M 964 R. Ripollés se refiere en este fragmento al cardenal Salvador Casañas i Pagès, obispo de Barcelona, fallecido el 27 de octubre de 1908. 
Tras el congreso de Valladolid, primer -y precipitado- gran intento aglutinador del impulso reformista en España, el II Congreso Nacional de Música Sagrada se presentó como el escenario propicio en el que configurar y definir este espacio que devendrá en movimiento.

\section{Apuntes para una valoración general del Congreso}

Una vez estudiados pormenorizadamente todo lo relacionado con la organización del Congreso, así como la función que cumplió en la conformación de un espacio socioartístico surgido al calor de la reforma es España, procede realizar un balance general. Nos centraremos en tres aspectos que, desde nuestro punto de vista, pueden reflejar el éxito o no de la iniciativa, así como el significado que para el proyecto reformista en España debió poseer. Por un lado, analizaremos algunos marcadores económicos y de participación; en segundo lugar, si se alcanzaron los objetivos relacionados con la creación de estructuras institucionales para la gestión y articulación de la reforma en el conjunto del país; por último, el valor histórico que pudo atesorar la celebración de un acontecimiento de estas características en la mitad sur peninsular, y la trascendencia que supuso tanto para Andalucía y otros territorios meridionales, como para el conjunto del movimiento español.

\subsection{Balance económico y de participación}

Tan sólo dos semanas después de su clausura, Otaño hizo una valoración del Congreso ciertamente negativa. El jesuita destacó en sus impresiones el "mucho egoísmo" y "segunda intención” que había encontrado. Era su forma de ver e interpretar la lucha de intereses de todo tipo que había tenido lugar, y para la que la asamblea celebrada en Sevilla había servido de acicate, oportunidad y escenario, como acabamos de comentar. Él mismo se había visto implicado de lleno en las pugnas, y había sido probablemente el mayor perjudicado: "Yo voy poco a poco reuniendo los datos del Congreso. La impresión general no puede ser buena. Se ve mucho egoísmo. Mucha segunda intención; luego parece que la animación ha escaseado en las secciones"434. Poco después disculparía este egoísmo por ser propio de la condición humana, y como contraste, confesaría el ánimo desinteresado que movía sus actos:

\footnotetext{
${ }^{434}$ Carta de Otaño a Goicoechea, 29 de noviembre de 1908. AMSL. FO. Correspondencia, T01/039.
} 
Como no aspiro a ninguna canonjía y tengo lo necesario para la vida con lo poco que necesita un pobre religioso, son golpes de ciego los que se han querido dar y sigo con mi fe, con mi desinterés, con mis entusiasmos, porque nunca he tenido miras personales $\mathrm{y}$ egoístas, sino un gran espíritu de fe y de abnegación ¿esto es suficiente para hacer algo? Yo creo que es la conditio sine qua non.

Es verdad que molesta tanto egoísmo, tanto buscarse a sí mismo, tanto interés propio, tantas miras rastreras y fines caducos, pero es también verdad que vivimos entre hombres y con eso nada le coge a uno de sorpresa. ${ }^{435}$

Villalba, por su parte, refirió, al igual que Otaño, la pobre participación en las sesiones de estudio, destacando al tiempo el éxito de público que supusieron los conciertos, todo lo contrario a lo ocurrido en Valladolid. Sus opiniones respecto a la organización fueron también absolutamente distintas de las que le mereció el congreso castellano:

Conjunto total del Congreso: muy ordenado y muy pacífico. La parte externa no ha dejado nada que desear, y los que en su arreglo han tomado parte se han acreditado de buenos organizadores. En cuanto a la concurrencia, ha sido el reverso completo de la medalla del de Valladolid; allí el número de congresistas fue mayor; aquí estábamos en las secciones como en familia; allí la concurrencia del público a los conciertos fue escasa; aquí la iglesia del Salvador, que es mayor que la de Santiago, de Valladolid, estuvo siempre materialmente llena. ${ }^{436}$

Goicoechea apuntó a más de mil socios inscritos, entre ellos muchos "forasteros", aunque el interés de estos últimos estaba centrado más bien en el aspecto turístico y recreativo. Coincidió su opinión con la de Otaño y Villalba respecto de la escasa participación en las sesiones de estudio, y con este último en su valoración positiva de la parte musical:

Socios inscritos: pasan de 1.000 .

Forasteros: han acudido muchos...como turistas, mejor que como congresistas.

Las sesiones desanimadas. En algunas, como en la $4^{\mathrm{a}}$, no ha dejado de haber sus guasitas. Las ejecuciones, magníficas. ${ }^{437}$

\footnotetext{
${ }^{435}$ Carta de Otaño a Pedrell, 23 de enero de 1909. BC. FFP. M 964 O.

${ }^{436}$ Villalba, "El Segundo Congreso Nacional", p. 497.

${ }^{437}$ Carta de Goicoechea a Otaño, 14 de noviembre de 1908. AMSL. FO. Correspondencia, 009/001.005.
} 
Del recuento de participantes que hemos realizado a partir de la lista definitiva de socios publicada en la Crónica del Segundo Congreso obtenemos los siguientes datos. El número de congresistas ascendió a novecientos. Quinientos cincuenta y cuatro socios protectores, trescientos cuatro activos, y cuarenta y dos de mérito ${ }^{438}$. Recordemos que las cuotas de inscripción para cada modalidad de participación eran las siguientes: para los socios activos, diez pesetas; para los protectores, siete; para los de mérito, cinco $^{439}$. El presupuesto final del congreso fue de $10.817,68$ ptas. $^{440}$ La cantidad ingresada en concepto de cuotas, 7.128 ptas., llegó a cubrir el $66 \%$ del total de gastos. El Congreso, por tanto, resultó deficitario ${ }^{441}$. El resto de la cuantía hasta completar el total de los gastos, 3689,68 ptas., figura en las cuentas generales del Congreso como ingresos en concepto de donativos ${ }^{442}$. Aunque no se especifica su procedencia, sabemos que fue el propio Almaraz quien aportó ese dinero. Así se lo comunicó Ripollés a Pedrell: “[...] el Sr. Arzobispo habrá de cargar con las resultas que serán un déficit de 7.000 ptas." 443 Los cálculos de Ripollés fueron, como podemos comprobar, excesivamente pesimistas. Transcribimos a continuación las cuentas generales del Congreso tal y como fueron publicadas en la Crónica del Segundo Congreso:

\section{Ingresos}

Cuotas de Inscripciones Donativos Suma

$$
\begin{aligned}
& 7.218,00[7.128,00] \text { ptas. } \\
& 3.599,68[3.689,68] \text { “6 } \\
& 10.817,68 \quad \text { ptas. }
\end{aligned}
$$

${ }^{438}$ La lista definitiva de socios inscritos figura en la Crónica del Segundo Congreso (Sevilla), pp. 277298. Periódicos como ENS y ECA fueron publicando a lo largo del mes de octubre los socios que se iban inscribiendo.

${ }^{439}$ Artículo $12^{\circ}$ del reglamento del Congreso. Crónicas del Segundo Congreso, p. 16.

${ }^{440}$ Crónica del Segundo Congreso, p. 299. Ofrecemos otros datos contextualizadores: el presupuesto del Ayuntamiento hispalense fue en 1902 de 4.278 .264 ptas. Presupuesto ordinario para el año económico de 1902, (Sevilla: Tip. Rev. de los Tribunales, 1902), cit. en Salas, Sevilla: Crónica. En 1908 el consistorio sufragó como todos los años los gastos de la procesión del Corpus: 3.000 ptas. AC 29/5/1908. ACS. Sección Secretaría, libro 228, fol. 4v. El Miserere fue subvencionado otra vez por el Ayuntamiento con una ayuda de 4.000 ptas. AC 17/3/1908. ACS. Sección Secretaría, libro 227, fol. 237r.

${ }^{441}$ Crónica del Segundo Congreso, p. 299.

${ }^{442}$ Ibídem. "La cuenta general del Congreso" que nos proporciona la Crónica del Segundo Congreso no ofrece más que una información muy general. No desglosa los distintos conceptos incluidos en el apartado de gastos. Además, existe un error en la cantidad resultante de la suma de las cuotas de inscripciones. Esta suma asciende a 7.128 ptas., no 7.218 ptas. como figura en las cuentas. Este baile de cifras desvela que la cantidad consignada como donativos en realidad es el resultado de la resta entre el total de gastos y las cuotas de inscripción, es decir, un cuadrar cuentas.

${ }^{443}$ Carta de Ripollés a Pedrell, 17 de octubre de 1908. BC. FFP. M 964 R. 


\section{Gastos}

Gastos y gratificaciones de los elementos artísticos del Congreso Gastos de la ornamentación $6.864,00$ ptas. Gastos de impresos y menores de la secretaría $2.659,53$ “ $1.294,15$ “ Suma $10.817,68$ “

\section{Resumen}

Importan los ingresos

Importan los gastos

A la hora de valorar estos resultados, hay que considerar dos condicionantes importantes. En primer lugar, la coyuntura de grave crisis económica por la que atravesó la Diócesis en esos años. En segundo lugar, el carácter periférico del Congreso, es decir, su lejanía de los, entonces, considerados principales centros de la reforma, así como de las diócesis peninsulares septentrionales. Los testimonios que proporcionamos en el epígrafe 3.2. "Difusión y propaganda. El Congreso en el contexto socioeconómico" ponen al descubierto la incidencia que ambas realidades tuvieron en la consecución de socios. Respecto a la segunda, aportaremos más adelante algunos datos más.

Resulta difícil realizar una comparativa con el congreso vallisoletano, pues, a diferencia de lo ocurrió en el caso del congreso hispalense, no fue publicada relación alguna de ingresos y gastos ni en la Crónica del Primer Congreso, ni en el BdC, ni en $M S H$. Respecto al número de congresistas inscritos, el $B d C$ fue publicando un listado a partir de su tercer número. Según este listado no superaron los trescientos. En la crónica publicada en $M S H$ se hizo la siguiente estimación de asistencia a la primera sesión privada: "Calculóse que ocupaban el salón 600 personas, la mayor parte congresistas"445. Así pues, el número total de congresistas inscritos en el congreso de Sevilla superó considerablemente a los asistentes al vallisoletano. La mayor oferta de posibilidades de participación en la asamblea sevillana debió colaborar en este aumento de inscripciones. Recordemos que en el caso del congreso vallisoletano sólo existió una modalidad de congresista con una cuota única de diez ptas. El reglamento de la asamblea hispalense, por el contrario, contempló tres tipos: activos (diez ptas.),

\footnotetext{
${ }^{444}$ Crónica del Segundo Congreso, p. 299.

445 “Crónica del Congreso. 26, 27 y 28 de Abril”, MSH, 1 (1907), p. 5.
} 
protectores (siete ptas.) y de mérito (cinco ptas.). Por otro lado, el número de congresistas activos debió ser algo inferior al total alcanzado en Valladolid. Además, según los testimonios de Goicoechea y Villalba, los intereses de los asistentes al II Congreso eran variados, y el absentismo en el caso las sesiones de estudio fue mayor.

\subsection{El fracaso institucional}

Respecto a los resultados obtenidos en dichas sesiones, Villalba señaló: “creo que no se ha perdido el tiempo". No obstante, ponderaba a continuación la limitada capacidad de transformación de la realidad a corto plazo de estos grandes eventos:

Por lo que hace a si ha sido o no práctico, aparte de que ya no sé a punto fijo qué es lo que se entiende por esto de lo práctico, creo que no se ha perdido el tiempo. Porque hay que convenir que ni de este ni de ningún Congreso van a salir los organistas, cantores, directores de coro de todas las iglesias, cantando y tocando según el Motu proprio; esto no se consigue en cuatro días, por bien que se aprovechen. Es labor lenta; no se improvisan coros, ni artistas, en un dos por tres; lo más que puede hacerse es sembrar, y sobre esto habrá sus más y sus menos, pero la cosecha necesita su tiempo para que madure y pueda recogerse.

En cuanto a literatura fue abundante; y fuera de mi sección a la que se presentó Memoria y media, en las demás menudearon. ${ }^{446}$

Entre los frutos de los debates "prácticos" hay que destacar aquellos proyectos encaminados a lograr una mayor consolidación del movimiento a través de la creación de estructuras institucionales. En algún caso, como la solicitud a Roma de erección de un tribunal superior para la censura de la música religiosa en España representó la materialización final de una idea planteada en el congreso de Valladolid, aunque con precipitación y en unas condiciones nada idóneas. Otros proyectos fueron expuestos por primera vez: la fundación de la Escuela Superior de Música Sagrada ${ }^{447}$, la súplica elevada al episcopado español para que "el cargo de director de las Música Sagrada de cada Catedral, pueda conferirse a las Chantrías" 448 , la creación de una comisión para el

\footnotetext{
${ }^{446}$ Villalba, "El Segundo Congreso Nacional, pp. 497-498.

${ }^{447}$ Véase capítulo 1, 4.1. "Centros para la formación de los agentes musicales diocesanos: Escuela Oficial Archidiocesana de Canto Gregoriano y Seminario", p. 91.

${ }^{448}$ Véase p. 411.
} 
estudio del canto visigótico o toledano ${ }^{449}$, o la elaboración de un cancionero popularreligioso español ${ }^{450}$. Se propuso, además, la celebración anual de congresos regionales como preparación a los nacionales ${ }^{451}$. El otro gran proyecto que quedó pendiente en Valladolid, la constitución de la Asociación Ceciliana Española, ni siquiera se planteó.

Sin embargo, ninguna de estas propuestas llegó a buen puerto, como demuestra el hecho de que volvieran a ser recuperadas en el congreso de Barcelona (1912). Allí se insistió de nuevo en la necesidad de otorgar la dignidad de canónigos de gracia a maestros de capilla y organistas catedralicios (sección $3^{\text {a }}$, conclusión tema III) ${ }^{452}$; de fundar escuelas superiores de música sagrada (sección $3^{\mathrm{a}}$, conclusión tema IV) ${ }^{453}$; de que la comisión creada en Sevilla y compuesta por los agustinos de El Escorial, y los benedictinos de Silos y Montserrat para el estudio del canto visigótico concluyera sus

449 El Congreso pretendió con ello conservar la oficialidad de determinadas melodías del repertorio visigótico reconocida por la bula de Pío V Ad hoc nos Deus de 16 de diciembre de 1570, que hubieran quedado derogadas por la nueva edición vaticana. La conclusión acordada en el Congreso rezaba: "Punto c) [...] queda derogado el privilegio concedido por S. S. Pío V a los españoles en favor del canto tradicional toledano.

No obstante, y en vista de que los tonos del Exultet y de la Pasión de los Misales españoles difieren completamente de los respectivos tonos romanos y ofrecen no escaso interés musical, el Congreso encomienda a los Benedictinos de Silos, Montserrat y Agustinos del Escorial, estudien los libros que encierran dichos tonos, para que, vueltos a su integridad, sean presentados a la aprobación de la Sagrada Congregación de Ritos”. Crónica del Segundo Congreso, pp. 265-266.

450 Véase capítulo 6, epígrafe 2.2. "Canto popular religioso: la omnipresencia de las ideas del nacionalismo musical español". La cuestión del canto popular religioso ya fue tratada en el congreso de Valladolid aunque no se sustanció en ningún proyecto concreto. La conclusión al respecto aprobada en dicho congreso decía: "El Congreso, considerando la gran utilidad que hay en que el pueblo tome parte activa en los oficios y funciones religiosas, estima necesario el uso del canto, ya sea gregoriano, ya popular religioso, diligentemente depurado y coleccionado, haciendo votos por que desaparezcan esos cantos poco dignos por su forma y expresión del arte y de la santidad de los cánticos sagrados. [...]" Crónica del Primer Congreso, pp. 26-27.

451 “Punto $m$ ) El Congreso acuerda que anualmente se celebren Congresos regionales de música sagrada, como preparación a los nacionales que se celebrarán oportunamente. [...]”. Crónica del Segundo Congreso, p. 276.

${ }^{452}$ Entre la serie de propuestas que para su debate en el congreso de Barcelona expuso a Pedrell, Ripollés aludió a la necesidad de recuperar la planteada en el congreso de Sevilla a este respecto: "IV Recordar y buscar medios eficaces de llevar a la práctica la conclusión de Sevilla que propone la elevación de los maestros de capilla a canónigos." Carta de Ripollés a Pedrell, 15 de marzo de 1912. BC. FFP. M 964 R. En esta ocasión, se consiguió el compromiso de los prelados asistentes al Congreso: "Habiendo aceptado los reverendísimos prelados y hecho suyo el deseo de la Asamblea, esta unánimemente acuerda manifestar su agradecimiento a dichos reverendísimos prelados”. Crónica y actas oficiales, p. 230.

${ }^{453}$ Se propuso Barcelona como sede de la Escuela, y se constituyó una comisión formada por Luis Millet, Francisco Pujol y Vicente $\mathrm{M}^{\mathrm{a}}$ de Gisbert para desarrollar el proyecto: "El Congreso cree que estas escuelas han de formarse donde quiera que haya elementos aptos para el profesorado; pero para ganar tiempo y aprovechar los elementos que ofrece Barcelona, entiende que los dignos profesores y maestros señores don Luis Millet, don Francisco Pujol y don Vicente $\mathrm{M}^{\mathrm{a}}$ de Gibert deben formar una comisión que, de acuerdo con el ilustrísimo Prelado de la diócesis, estudie los medios para que cuanto antes sea un hecho esta escuela en Barcelona.” Ibídem, p. 231. 
trabajos (sección $1^{\text {a }}$, tema VI) ${ }^{454}$; o de que se constituyeran la Junta Central nacional y el Colegio Nacional de Censores, tal y como se había propuesto ya en Valladolid. Estas dos últimas entidades formarían parte de la finalmente instituida Asociación Ceciliana Española, para cuya presidencia se eligió “por aclamación” a Ripollés, y como vicepresidentes a Julio Valdés y Felipe Pedrell (sección $3^{\mathrm{a}}$, tema V) ${ }^{455}$.

Este fracaso pone de manifiesto las considerables limitaciones que padecían los congresos como instrumentos para la institucionalización del movimiento. La causa de su ineficacia se encontraba en la falta absoluta de poder real de decisión. Sus conclusiones no tenían ningún valor vinculante, por tanto, su función se reducía al planteamiento de propuestas que luego tenía que refrendar y aplicar la autoridad eclesiástica. Su capacidad transformadora dependía del episcopado que, en muchas ocasiones, se mostraba poco sensible a la cuestión musical, o acuciado por problemas más urgentes o importantes, según su escala de prioridades ${ }^{456}$. La insistencia de Ripollés durante el congreso de Barcelona en recabar el apoyo y el compromiso de los prelados, incluso antes de plantear las propuestas, es bastante sintomática, y revela la experiencia que al respecto había acumulado en las dos primeras citas:

Me parecen bien todos los puntos que presenta el P. Otaño para el Congreso, pero si no se llega a una previa concordia $\mathrm{y}$ aceptación eficaz por parte de todos los Prelados, el trabajo será en vano y propondremos y legislaremos en Barcelona convenientes, útiles y necesarias, pero nuestras propuestas quedarán olvidadas, como hasta hoy. De manera que lo primero e imprescindible es que todos esos puntos a tratar los patrocine y haga suyos el Prelado de Barcelona y que después el propio Prelado recabe de todos los otros Prelados la conformidad y aceptación, no nominativa, sino real y eficaz. Sin estas previas negociaciones, será todo tiempo perdido; porque el Congreso propondrá la enseñanza musical en todos los Seminarios, dará un plan detallado y perfecto, pero después cada Prelado o Rector aceptarán lo que quieran o no aceptaran nada y seguiremos como hasta aquí. No

\footnotetext{
${ }^{454}$ Ibídem, p. 227.

${ }^{455}$ Ibídem, p. 231. Una carta de Otaño fechada el 27 de febrero de 1912, en la que traslada a Pedrell "los tres puntos principalísimos a tratar" (la organización de los estudios de canto gregoriano en los seminarios, la fundación de la Escuela Superior de Música Sagrada y de la Asociación Ceciliana Española) demuestra la importante influencia que ejerció el jesuita en lo relacionado con estos puntos en el congreso de Barcelona. López-Calo ha puesto de relieve esta realidad por lo que no insistimos en ello. Véase: Nemesio Otaño, p. 82.

456 Véase de este mismo capítulo el epígrafe 3.2.1. "La respuesta del episcopado español a los requerimientos del Congreso".
} 
hay ni un Seminario en que no se necesite en esta materia nueva reglamentaria.

Todas estas consideraciones pueden aplicarse a la fundación de la Escuela de música sagrada y a la Asociación Ceciliana y junta de censores. Insisto pues en que cuando vayamos al Congreso se haya recabado ya y obtenido de todos los Prelados la aceptación de los tres asuntos. $^{457}$

Esta preocupación se encuentra también en los escritos de Otaño, de los que el siguiente pasaje es un ejemplo: "Voy a ver si antes de volver a Manresa presento un plan de Organización Ceciliana y Junta Censora. Preciso es presentar a los Prelados todos este plan, porque de su aceptación depende todo."

Ciñéndonos ahora a las consecuencias del Congreso en el ámbito local, contamos con un interesante testimonio de Ripollés escrito apenas tres meses después de su clausura, en el que se refleja, además, el estado de abatimiento que le había provocado la experiencia. El maestro de capilla calificaba el Congreso de "inútil" y señalaba el nulo impacto que en Sevilla había tenido: "la mayoría, por no decir la totalidad, aferrados a sus rutinas". Sin embargo, refería como un gran logro la conversión a la causa reformista de Rafael González Merchant, presidente de la Junta Organizadora. El otrora aludido en tono burlón como "canónigo del clarinete que bulle como a presidente de la comisión", y refractario "a todo lo nuestro"459, era para Ripollés, tras la celebración del Congreso, "un elemento de valía y batallador que riñe en Cabildo las grandes peleas empeñado en enderezar todo esto", como ya apuntamos en el capítulo tercero ${ }^{460}$.

${ }^{457}$ Carta de Ripollés a Pedrell, 13 de marzo de 1912. BC. FFP. M 964 R.

458 Carta de Otaño a Ripollés, 28 de marzo de 1912. AMSL. FO. Correspondencia, TA01/157. Un mes antes escribía a Pedrell en términos parecidos: "Esta empresa tendría que tener la aprobación de todos los Obispos, y ya antes del Congreso habría que enviar a todos ellos una Memoria, suplicándoles su aprobación, para que en el Congreso se declarara públicamente el establecimiento de ese organismo. Desde luego para Presidente ya está V. elegido. No nos costaría nada que Su Santidad refrendase la obra y tuviera todas las garantías.

Vea V. de tratar estos puntos con los de la Comisión y, sobre todo, con el Sr. Obispo; y si en principio les pareciera bien, podría yo escribir, antes de volver a Manresa, esa Memoria que ha de enviarse a los Prelados." Carta de Otaño a Pedrell, 27 de febrero de 1912. AMSL. FO. Correspondencia, T01/117.

${ }^{459}$ Carta de Ripollés a Pedrell, 17 de octubre de 1908. BC. FFP. M 964 R.

${ }^{460}$ Ripollés se refería así al Congreso: "Pero basta de tanta miseria y de tan poco agradables recuerdos. Aquí la mayoría, por no decir la totalidad, aferrados a sus rutinas: una adquisición se ha hecho; aquel canónigo del clarinete se ha pasado del todo a nuestro campo, y este es un elemento de valía y batallador que riñe en Cabildo las grandes peleas empeñado en enderezar todo esto. Carta de Ripollés a Pedrell, 8 de febrero de 1909. BC. FFP. M 964 R. 
La fe de Ripollés en la voluntad y capacidades de González Merchant era tal que llegó a considerar el momento, algo poco usual en las apreciaciones generalmente pesimistas de sus cartas, como "la gran ocasión para hacer algo", si no fuera por la poca confianza que tenía en Almaraz: "Si contáramos con un Prelado enérgico creo sería esta la gran ocasión para hacer algo porque el canónigo es de los decididos y no da un paso sin consultarme; pero yo confío poco en este mitrado" 461 . Como hemos estudiado en los capítulos segundo y tercero, en esos momentos, encabezado por Almaraz, se estaba reanudando el proceso de reformas iniciado por Spínola, tanto a nivel archidiocesano como catedralicio. En aquella nueva etapa, González Merchant jugó un papel clave. El buen concepto que Ripollés tenía del canónigo sevillano se perpetuó en el tiempo, y le llevó a proponerle como candidato a la presidencia de la Asociación Ceciliana Española en julio de 1912, como se deduce de una carta de Otaño en respuesta a otra del castellonense que no conservamos. Otaño, que tenía claro que el cargo lo debía ocupar Ripollés, no vio en González Merchant la mejor opción por estar "lejos y sólo: si estuviera a su lado, podría ser." 462

\subsection{El congreso del "sur" periférico}

Una última consideración habría que hacer respecto al valor histórico del congreso de Sevilla y su importancia en el desarrollo del movimiento reformista en España. En los primeros años de implantación del $M P$, Sevilla ocupaba un lugar subalterno y periférico en el escenario español. El artículo al que pertenece el siguiente fragmento, publicado a las puertas del congreso vallisoletano, trazaba a grandes rasgos la breve historia del $M P$, y en relación a su recepción en España señalaba:

En España varios Prelados, de las órdenes religiosas los benedictinos PP. Casiano y Serrano, los jesuitas los PP. Otaño y Baixauli; luego aquí Olmeda, Serrano, allí Rué, Portas, Millet, Pujol, etc. [...] han logrado tirar por los suelos la barrera de los prejuicios, como los muros de Jericó al sonido de las trompetas de Israel, augurando siglos de oro para el divino arte religioso.

Entre las disposiciones episcopales, exceptuando las de Barcelona, Madrid y Valladolid, las de España no son tan terminantes y urgentes como las de casi todos los Obispos de Italia, Alemania y Francia. Entre todas las que yo conozco descuellan por su

\footnotetext{
${ }^{461}$ Ibídem.

${ }^{462}$ Carta de Otaño a Ripollés, 16 de julio de 1912. AMSL. FO. Correspondencia, TA01/166.
} 
minuciosidad y acierto la pastoral del Eminentísimo Cardenal de Turín en Italia y los Reglamentos de la Archidiócesis de Valladolid, ejemplar el más notable y completo de cuantos hasta el presente se han publicado. ${ }^{463}$

En otro artículo salido a la luz en el Diario de Gerona, Miguel Rué, maestro de capilla de la capital catalana, escribió:

[...] Fijándonos, ahora en nuestra España se han distinguido en este punto, el Emmo. Cardenal de Barcelona, el Excmo. Sr. Obispo de Madrid; pero de un modo especial el Excmo. e Ilmo. Sr. Arzobispo de Valladolid y sus Obispos sufragáneos, que han dictado documentos de tal importancia en este sentido, que podemos decir con orgullo los españoles, que los excelentísimos Obispos de la Provincia Eclesiástica de Valladolid han superado en los mismos a los de todo el mundo y que muchos del extranjero no han hecho más que copiar sus disposiciones. ${ }^{464}$

En él se comprueba que la condición de Valladolid como centro de la reforma era reciente. Alude, además, a las reservas de algún "primate musical [...] madrileño, barcelonés, valenciano, zaragozano" a contemplar a la ciudad castellana como una sede idónea para un congreso nacional, debido a su falta de peso como capital musical en comparación con otras ciudades ${ }^{465}$.

En la misma dirección que los dos textos anteriores apuntaba este otro, publicado en la Revista Musical Catalana en diciembre de 1905:

A los que murmuran sotto voce, que esto del canto sólo se cumple en Barcelona, y que en ningún lugar se hace algo, les recomiendo los Edictos y Reglamentos de los Prelados de Valladolid y verán como el eminentísimo cardenal Casañas, nuestro estimado Obispo, no es ya sólo en España en promover la restauración de la música religiosa tal como lo ha mandado Pío $\mathrm{X}^{466}$

\footnotetext{
463 J.R., "Comentando", BdC, 2 (1907), p. 18.

${ }^{464}$ El artículo de Miguel Rué, "Primer Congreso Nacional de Música Sagrada", fue reproducido en $B d C$, 4 (1907), pp. 34-35.

465 “Tal vez alguien que desconozca lo que Valladolid representa no sólo gregorianamente, sino también artísticamente hablando exclame: ¿de Valladolid puede salir algo tan importante que conmueva a España? [...] ¿No es verdad que este solo hecho puede despertar ciertas celotipias, etc. de más de un maestro español, que sin duda menospreciará dicho Congreso por el solo hecho de no habérsele ocurrido a él, o algún primate musical, por ej, madrileño, barcelonés, valenciano, zaragozano, etc. la iniciativa; [...]”. Ibídem.

${ }^{466}$ Artículo transcrito en Crónica del Primer Congreso, pp. 3-5.
} 
Todos estos testimonios coincidían a la hora de localizar las diócesis en los que el $M P$ había sido acogido de manera más favorable y exitosa: Barcelona, Madrid y Valladolid. Todas situadas en la mitad norte del país, de donde eran naturales, además, las principales figuras reformistas citadas expresamente en el primero de los artículos a los que hemos hecho referencia. La pionera labor emprendida por Spínola y desarrollada por la CDMS hispalense entre 1904 y 1905 era absolutamente ignorada ${ }^{467}$. La diócesis andaluza no contó entre las demarcaciones eclesiásticas españolas que habían sobresalido por su esfuerzo en la aplicación de la reforma. No formaba parte, por tanto, de la "centralidad" representada por aquellas otras diócesis peninsulares.

En este sentido, se puede comprobar que la condición periférica de Sevilla no se contemplaba en relación al centro geográfico peninsular, sino al "norte", tal y como expresaban otros artículos. La consideración del "norte" como el espacio que asumía la "centralidad" desde la perspectiva de los reformistas significaba un desplazamiento en términos geográficos del centro, que hacía ver aún más lejana la capital andaluza. Durante los meses previos a la celebración del Congreso, esta condición periférica lejana para el norte- de Sevilla fue una preocupación para los organizadores, y un argumento de peso más para justificar las peticiones a los cabildos y seminarios de que sostuvieran económicamente a los músicos eclesiásticos que participaran. El siguiente extracto es del número de agosto de $M S H$ :

2. ${ }^{\circ}$ Ciertamente Sevilla está lejos del Norte: a muchos hemos oído decir lo mismo, y si el plan que $\mathrm{V}$. propone cundiera, entonces, sí, tendría el Congreso la representación de todas las entidades musicales de nuestras iglesias. Bien se sabe la situación de los músicos de iglesia y por eso desde un principio se pensó pedir a los Cabildos y claustros de los Seminarios envíen delegados de su capilla a Sevilla y sabemos que buen número de Prelado han apoyado decididamente esta idea, que deseamos tenga buena acogida en todas las Diócesis de España. ${ }^{468}$

En otro artículo firmado por Franculus y reproducido en la Crónica del Segundo Congreso se puede observar que el propio carácter "nacional" que ostentaba a priori el congreso hispalense dependía, según su autor, de las respuestas de cabildos y seminarios a las demandas de los organizadores. Ello quería decir que tal carácter

\footnotetext{
${ }^{467}$ Véase el capítulo 1. "La reforma durante el pontificado de Marcel Spínola y Maestre (1904-1906)".

468 “Cuestiones prácticas. Sobre el $2^{\circ}$ Congreso”, MSH, 15 (1908), p. 130.
} 
estaba en cuestión por causa de esa lejanía -de su carácter periférico- que complicaba la asistencia de los músicos de la mitad norte:

Es verdad que la situación actual de los músicos de iglesia es un obstáculo no pequeño para la celebración de estas asambleas: un Congreso, y más colocado en Sevilla, exige, además de buena voluntad, no pequeños sacrificios, que muchos no pueden imponerse. Con todo hay un medio para que el Congreso de Sevilla sea un verdadero Congreso Nacional.

La inmensa mayoría de músicos españoles son individuos del clero que ocupan su puesto en las Catedrales, en los Seminarios y en los Parroquias de importancia. ¿No sería fácil a los Cabildos de todas las Diócesis de España nombrar dos delegados suyos, sacados de entre los beneficiados que forman la Capilla de música? ¿No sería fácil a la mayor parte de los Seminarios enviar por unos días a Sevilla en su representación al profeso del Canto Gregoriano? ¿No podrían hacer lo mismo las parroquias principales con sus organistas o maestros de Capilla?

Si esta idea, que es la que ha brotado espontáneamente, no más anunciado el Congreso, se acoge favorablemente por todos los Prelados y Cabildos de España, el Congeso de Sevilla será una gloriosa manifestación y una prueba evidente de que en España no está empantanada la reforma. Pidamos a Dios que esto sea un hecho. ${ }^{469}$

En este otro extracto, Franculus insistía en la cuestión y sugería el valor que en el contexto de este orden norte-centro de la reforma versus sur-periferia poseía la cita congresual en Sevilla:

Sevilla es esta vez el punto de reunión, y si bien para las provincias del Norte está demasiado alejada la hermosa ciudad del Guadalquivir, no puede dudarse que allí acudirán como a Valladolid un buen número de artistas españoles convencidos de la dignidad de la causa y deseosos de llevar su influjo de un extremo a otro de la península. $^{470}$

Efectivamente, la celebración del II Congreso Nacional de Música Sagrada en Sevilla convirtió a la ciudad andaluza en el centro de la reforma en España durante 1908, y representó, en consecuencia, la oportunidad para reorientar la mirada del movimiento reformista hacia el sur periférico. La asamblea hispalense constituyó el

\footnotetext{
${ }^{469}$ Franculus, "Un Congreso", Crónica del Segundo Congreso, p. 49.

${ }^{470}$ Ibídem, p. 48.
} 
acontecimiento más importante, además de necesario, para la expansión de la reforma en la mitad meridional de la península, especialmente en Andalucía y los territorios colindantes. Siguiendo el razonamiento de Franculus, al favorecer la difusión de la reforma por el sur, la celebración del segundo congreso en Sevilla hizo que el movimiento no circunscribiera su fuerza y acción a las zonas consideradas como centros de la reforma, y que alcanzara, por tanto, por vez primera una dimensión verdaderamente "nacional".

La presencia en Sevilla, además del arzobispo anfitrión, de los metropolitanos de Granada y Badajoz-Mérida significó la representación de las máximas autoridades de las provincias eclesiásticas que cubrían los territorios de Andalucía, Murcia y prácticamente toda Extremadura, como muestra el siguiente mapa ${ }^{471}$ :

\section{Territorios bajo la jurisdicción de los arzobispos metropolitanos asistentes al II Congreso Nacional de Música Sagrada de Sevilla}

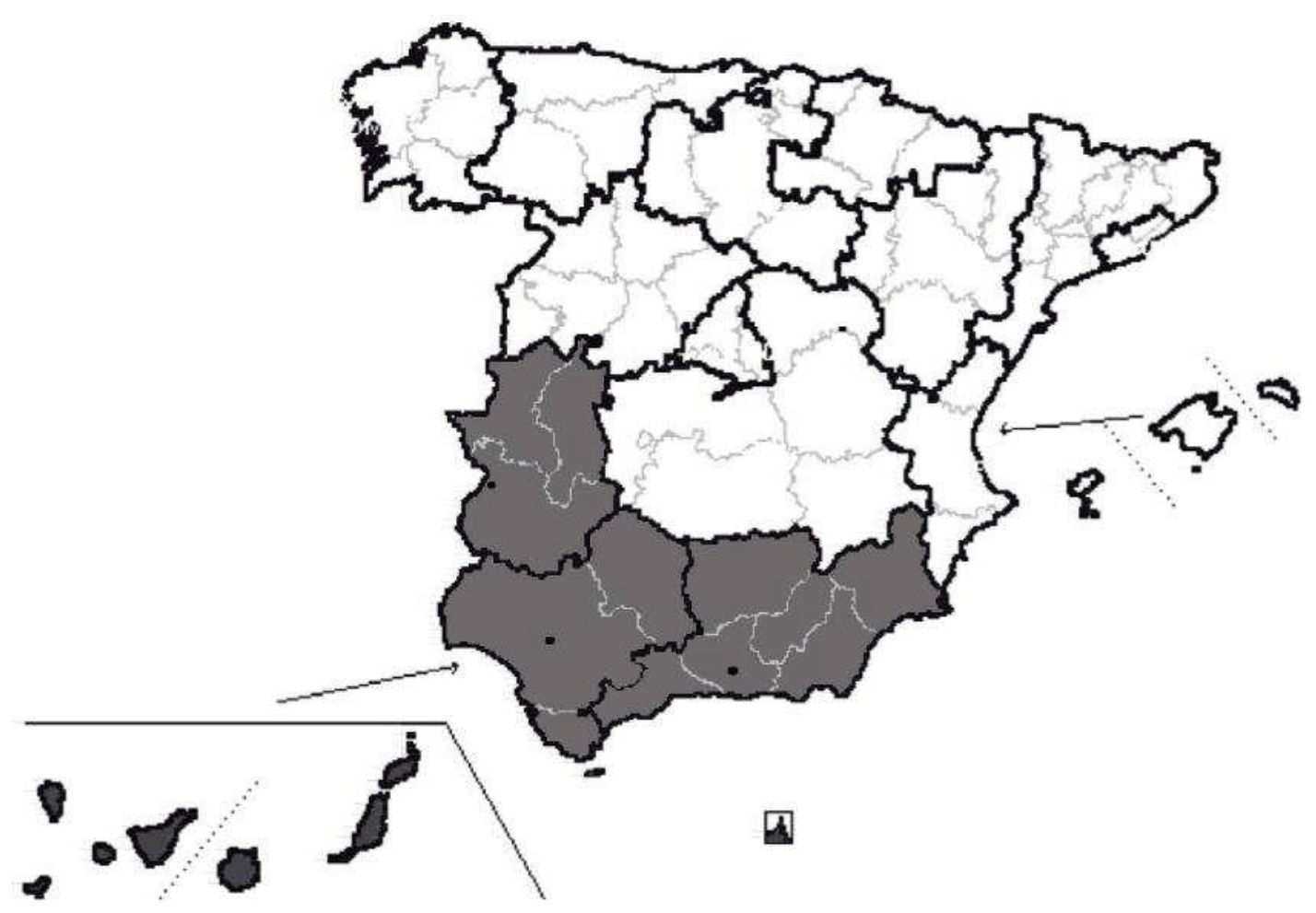

${ }^{471}$ Provincia eclesiástica de Sevilla: arzobispado de Sevilla, obispado de Cádiz, obispado de Córdoba, obispado de Canarias, obispado de Tenerife. Provincia eclesiástica de Granada: arzobispado de Granada, obispado de Almería, obispado de Cartagena-Murcia, obispado de Guadix, obispado de Jaén, obispado de Málaga. Provincia eclesiástica de Mérida-Badajoz: arzobispado de Mérida-Badajoz, obispado de CoriaCáceres, obispado de Plasencia. 
En esta ocasión, las circunstancias, que dificultaban la asistencia a los músicos y responsables eclesiásticos del norte, eran favorables a los del sur, colaborando, obviamente, en el cariz meridional que caracterizó el Congreso. De las veinticuatro entidades eclesiásticas que mandaron representación oficial, trece pertenecían a alguna de las tres provincias eclesiásticas que abarcaban Andalucía, Murcia y Extremadura ${ }^{472}$. La mayoría de los cabildos de las catedrales andaluzas enviaron su representación oficial. El cabildo de la catedral de Jaén delegó en su maestro de capilla, Cándido Milagros, quien, ocupó una de las secretarías de la tercera sección de estudio, y aportó una memoria relativa a cuestiones organizativas de las capillas en las catedrales sufragáneas. Los cabildos de Ceuta y Murcia -o Cartagena- fueron representados por el deán y maestro de capilla respectivamente ${ }^{473}$. El de la catedral y capilla real de Granada por Ignacio Ramírez, salmista ${ }^{474}$, y José Antonio Carulla, capellán mayor, respectivamente. El cabildo cordobés se hizo presente mediante una nutrida representación compuesta por los canónigos doctoral y magistral, el maestro de capilla, Juan Antonio Gómez Navarro, así como los beneficiados sochantre y salmista. Desde la diócesis gaditana envió representación tanto el cabildo catedralicio como el seminario diocesano. El maestro de capilla, José Gálvez, quien también ocupó una de las secretarías de la segunda ponencia de estudio, y el vicerrector asumieron el encargo de la representación de una y otra entidad ${ }^{475}$. José Gálvez ostentó, además, la

472 Junto a estas consta en la Crónica del Segundo Congreso las siguientes instituciones representadas oficialmente en el Congreso: cabildo de la catedral de Valladolid, por su maestro de capilla, Vicente Goicoechea; el prelado y seminario de Valencia, por Rafael Rodríguez Cepeda; la CDMS de Valencia, por el canónigo Roque Chabás; el Obispado de Solsona, por el benedictino Remigio Aixelá; el cabildo de la catedral de Orihuela, por el canónigo Mariano Olmos; el cabildo de la catedral de Burgo de Osma, por el organista Cayo Lozano; la Capilla Real de Toledo, por el capellán mayor Eugenio Almaraz, hermano del arzobispo hispalense; la CDMS de Valladolid por el canónigo lectoral, presidente, secretario y organista catedralicio; la Revista Montserratina, por Gregorio $\mathrm{M}^{\mathrm{a}}$ Suñol; el obispo de Astorga por Manuel Ansola Unzueta e Ignacio Cardenal, maestro de capilla y organista catedralicio respectivamente; y el seminario de Pamplona por Juan Bautista Muguiro Argaña. Crónica del Segundo Congreso, pp. 96-98.

473 Hemos incluido Ceuta y Murcia como dentro de Andalucía al pertenecer respectivamente a las provincias eclesiásticas de Sevilla y Granada.

${ }^{474}$ José López-Calo, Catálogo del archivo de música de la Catedral de Granada. Granada: Centro de Documentación Musical, 1991-1992, 3 vols, vol. 3, p. 334, cit. en Martín Moreno, "Cinco siglos de historia musical", p. 846.

475 José Ma Gálvez Ruíz, Cadiz 1874. Estudió en Tarragona órgano, armonía y composición con el maestro Bonet. Maestro de capilla de la catedral de Cádiz, fue nombrado director de la Real Academia Filarmónica de Santa Cecilia de dicha ciudad. Fue, además, catedrático de música de la Escuela Normal de Maestros de Cádiz. Académico de número fundador de la Real Academia Hispano Americana de Cádiz, académico de la Provincial de Bellas Artes, socio de mérito del Conservatorio de Valencia, Comendador de número de la Real Orden de Alfonso XII, etc. Entre sus obras destacan: Balada oriental, premiada en Valencia y estrenada en Cádiz por la Orquesta Sinfónica de Madrid dirigida por Arbós; 
representación de la Real Academia Filarmónica de Santa Cecilia de Cádiz que dirigía, junto con su presidente Fernando García de Arboleya ${ }^{476}$. La institución musical gaditana se adhirió “de todo corazón a todo lo propuesto en él [Congreso] y hace votos por que se conviertan en hechos los deseos de los congresistas, para gloria de Dios y del $\operatorname{arte}{ }^{477}$.

A pesar de su falta de presencia en los órganos rectores, los arciprestazgos más importantes de la Archidiócesis se implicaron activamente en la asamblea, incluidos aquellos separados por cierta distancia de la sede metropolitana. Los arciprestazgos de Arcos de la Frontera (Cádiz) y de Huelva contaron con nutrida representación oficial, así como parroquias como las de Valverde del Camino (Huelva) o Puerto de Santa María (Cádiz) ${ }^{478}$. Personas provenientes del arciprestazgo onubense como Manuel González Serna, José Álvarez de Luna y Pohl, o de Jerez como el dominico José Aguilar, estos dos últimos nombrados además secretarios de sendas secciones, ejercieron un papel protagonista en los debates de las sesiones de estudio. El fraile jerezano presentó un total de cinco memorias (todas para la sección segunda sobre música figurada), un número sólo superado por Vicente Ripollés y Gregorio Ma Suñol. Las intervenciones de González Serna, párroco de San Pedro además de arcipreste de Huelva, y José Álvarez de Luna revelan un compromiso con la reforma con importantes

Himno a la independencia española, a cinco coros, gran orquesta y banda, escrito para las fiestas del Centenario de 1812; Serenata andaluza; La creación, para coro a cinco voces y orfeón; Nisi Dominus, salmo a cinco voces y orquesta; Pro peccatis, a cinco voces y orquesta; etc. Cuenca Benet, Galería de músicos andaluces, pp. 101-103.

\footnotetext{
${ }^{476}$ Antonio Martín Moreno ha estudiado algunas de las enseñanzas que se impartían en este importante centro educativo musical andaluz en la década de los ochenta del siglo XIX: "La enseñanza musical en España en el siglo XIX: El Curso completo de música en la Escuela Normal de Zaragoza (1861) y la Historia de la Música de la Academia Santa Cecilia de Cádiz (1883)", Publicaciones de la Facultad de Educación y Humanidades del Campus de Melilla, 35 (2005), pp. 75-108.

${ }^{477}$ Crónica del Segundo Congreso, pp. 96-98. El estudio del Motu proprio en Cádiz -aún por abordar, como en el resto de diócesis andaluzas- resulta especialmente interesante. A juzgar por algunos indicios hallados durante nuestro trabajo, pensamos que la incidencia que el texto papal tendría en la diócesis gaditana sería especialmente importante. A modo de ejemplo comentar que resulta llamativo el hecho de que el número de participantes en el congreso celebrado en Vitoria en 1928 provenientes de la diócesis de Cádiz fue especialmente elevado, muy por encima del resto de diócesis andaluzas.

${ }^{478}$ Ambas eran los centros de sus respectivos arciprestazgos. Representación del arciprestazgo de Arcos de la Frontera: el arcipreste, Manuel Farfán Olavarrieta, además Manuel Troncoso Barranco, Gerónimo Posadas, José Vázquez Piña, Jesús Vega Chacón y Miguel Sañudo Vega, “que ejercen cargos musicales en las parroquias de dicha ciudad." Representación del arciprestazgo de Huelva: el arcipreste, Manuel González García, Manuel González Serna y José Alvarez de Luna y Pohl. La parroquia del Puerto de Santa María envío a su maestro de capilla, Javier Caballero como representante. La parroquia de Valverde del Camino, por su parte, al sacerdote José Ma Mora y José Antonio Medina, organista. Crónica del Segundo Congreso, pp. 97-98.
} 
resultados. El segundo aseguraba en una de las memorias presentadas haber conseguido frutos "en poco tiempo por el celo del párroco y demás sacerdotes de la parroquia de San Pedro, de Huelva, en donde el pueblo canta las partes invariables de la Misa tomadas del Kirial Vaticano."

Además del arzobispo de Badajoz-Mérida, asistió al Congreso el otro prelado extremeño, el de Coria ${ }^{480}$. Los cabildos de las catedrales de ambas sedes estuvieron igualmente representados. El representante del capítulo pacense, Manuel Navas, profesor de gregoriano del Seminario, formó parte de la secretaría de la sección cuarta, cuyo ponente fue Federico Olmeda; mientras que el maestro de capilla, Felipe Rubio Piqueras ${ }^{481}$ participó activamente en los debates de las secciones de estudio, aportando una memoria sobre la dignificación de los cargos musicales catedralicios, cuyas ideas se reflejaron en las conclusiones finales del Congreso ${ }^{482}$.

Por tanto, y en síntesis, el congreso de Sevilla fue el único de los cinco congresos nacionales de música sagrada celebrado en la mitad sur peninsular. Creemos que representó un acontecimiento clave para la difusión del movimiento en las diócesis meridionales, un hito en la historia de la música religiosa en esos territorios. Al mismo tiempo, su significación trascendió los límites del $M P$, y se situó como el umbral de la regeneración musical en Andalucía, al constituir, como veremos, una manifestación de los ideales y proyectos regeneracionistas de la música española, de los que se impregnó

${ }^{479}$ Crónica del Segundo Congreso, p. 196. El párroco onubense fue interpelado por el arzobispo para que explicara ante los presentes en la sesión de estudio del 14 de noviembre la forma en la que estaba aplicando la reforma: "En el tema siguiente del canto popular en las misas parroquiales se presentan Memorias de don Vicente Ripollés, proponiendo medios de llevarlo a cabo y otra de don José A. de Luna, refiriendo los medios puestos en práctica en la parroquia de San Pedro de Huelva.

El señor Arzobispo invita al párroco de la misma, señor González Serna, que se hallaba presente en la Sección, para que diga algunas palabras al Congreso, refiriendo los medios de que se vale para lograr el cumplimiento de la voluntad del Papa; siendo escuchado con entusiasmo por la concurrencia." "Secciones privadas. Sección 1", ECA, 3347 de 15 de noviembre (1908), p. 1.

${ }^{480}$ Además de los prelados de Sevilla, Granada, Badajoz y Coria, participaron los obispos de Salamanca y Ciudad Rodrigo, además del Cardenal Netto, ex-patriarca de Lisboa. Los obispos de Jaén y Almería, a pesar de haber declarado sus intenciones de asistir, finalmente no lo hicieron.

${ }^{481}$ Felipe Rubio Piqueras (Valera de Arriba, Cuenca, 1881-Toledo, 1936). Ocupó el cargo de organista de la catedral de Badajoz (1913) y Toledo (1918). Es autor de un buen número de obras religiosas, la mayoría de carácter sencillo destinada a grupos de cantores parroquiales o conventuales sin conocimientos musicales con acompañamiento de órgano. La revista Tesoro Sacro-Musical publicó una lista del conjunto de su producción en 1938. Desplegó una importante labor de investigación, fruto de la cual son sus publicaciones Música y músicos toledanos y Códices polifónicos toledanos. José LópezCalo, "Rubio Piqueras, Felipe", DMEH, 10 vols., ed. por Emilio Casares (Madrid: SGAE, 2001), vol. 9, pp. 455-456.

${ }^{482}$ Crónica del Segundo Congreso, pp. 97-98. Resumen de la memoria en: ibídem, pp. 244-246. 
la particular versión hispana de la reforma papal. En este otro mapa se observa la ubicación geográfica de las ciudades que albergaron estos eventos.

Ubicación geográfica de las sedes de los congresos nacionales de música sagrada

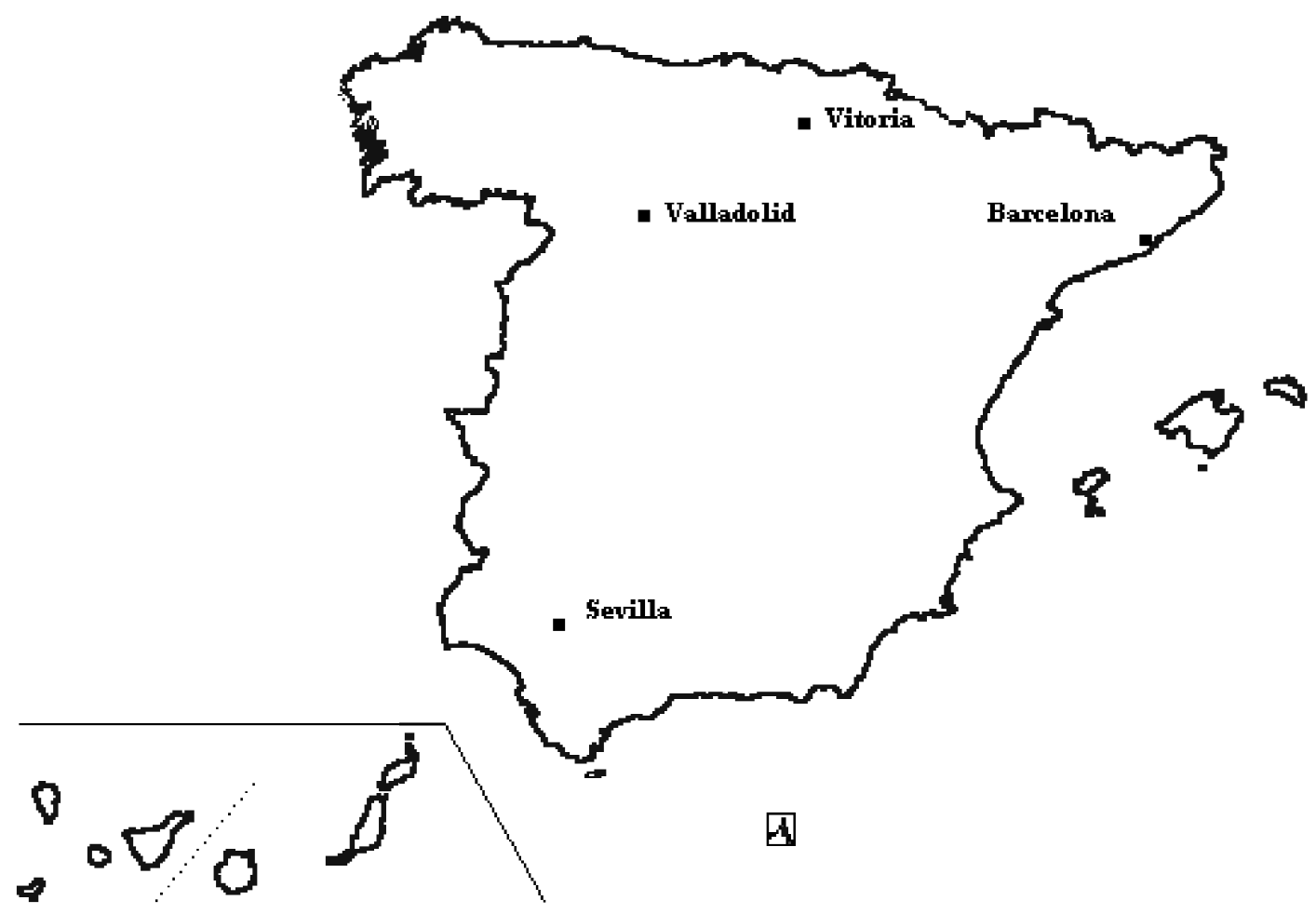

I Congreso Nacional de Música Sagrada, Valladolid (1907)

II Congreso Nacional de Música Sagrada, Sevilla (1908)

III Congreso Nacional de Música Sagrada, Barcelona (1912)

IV Congreso Nacional de Música Sagrada, Vitoria (1928)

El V Congreso Nacional de Música Sagrada celebrado en Madrid (1956) es excesivamente tardío 


\section{CAPÍTULO 6 \\ MODELOS, SÍMBOLOS Y DISCURSOS MUSICALES PARA LA INSTITUCIONALIZACIÓN DE UN NUEVO CANON DE MÚSICA RELIGIOSA. LA OPOSICIÓN A LA PROPUESTA DEL CONGRESO}

Acabamos de analizar el Congreso, por un lado, como un importante reto de organización para la archidiócesis de Sevilla, y, por otro, como escenario para la consolidación del movimiento de reformas, entendido desde una clave sociológica. Pretendemos a continuación abordar su estudio desde otro punto de vista. En el presente capítulo, el Congreso será contemplado como un gran discurso, desplegado para la institucionalización de un nuevo canon religioso-musical. Estaremos atentos a los fundamentos estéticos e ideológicos que sustentaron la propuesta musical consagrada en la asamblea, así como a las estrategias desplegadas para su presentación.

Según sostuvimos en el capítulo cuarto, los problemas que acompañaron a la reforma trascendieron lo meramente litúrgico, estético, o artístico, $\mathrm{y}$, creemos, se ubicaron en el plano de lo simbólico e identitario. Continuando con esta perspectiva, trataremos de ser sensibles a los significados profundos que las diferencias y tensiones entre mentalidades, criterios de estimación y juicio musical pudieran esconder, para intentar determinar si se reprodujo de alguna forma a nivel general un conflicto cultural semejante al provocado por la aplicación del $M P$ en el ámbito local.

\section{La estrategia regeneracionista del Congreso: "por vía de modelo y} ejemplo"

Luis Villalba describió como sigue la "utilidad" de los congresos musicales en la crónica epistolar que, al igual que hiciera en el caso del vallisoletano, publicó sobre el congreso de Sevilla. El agustino puso el acento en la particular virtud que respecto a otros tipos de congresos tenían los musicales: 
Cuatro cosas tiene un Congreso de Música; práctica del arte religioso en sus distintos géneros; discursos acerca del arte; discusiones en Asamblea, a lo parlamentario, y conclusiones o determinaciones que en la discusión se tomen.

Entre unas y otras se reparte la utilidad e interés de los Congresos musicales, que esta ventaja tienen sobre los demás Congresos, que en estos se perora solamente y habla y discurre con gran acierto, se esparcen ideas luminosas acerca de la materia y tal y tal, pero en especulativa siempre; y en los de música, encima de la literatura, de los discursos, discusiones, etc., en que se dice cómo y qué se ha de cantar o tocar, se toca y se canta, lo cual es una lección práctica, que vale más que cien discursos. ${ }^{1}$

El carácter de "lección práctica", es decir, la virtud pedagógica de las funciones musicales a la que aludía Villalba estaba establecida formalmente en el artículo segundo del reglamento del Congreso, y era definida como un método ejemplarizante:

Art. $2^{\circ}$. Para procurar este fin, el Congreso celebrará sesiones privadas y solemnes: en aquellas se dará cuenta de los trabajos presentados y se acordarán las conclusiones prácticas, que habrán de proponerse en la última sesión solemne del Congreso, para su aprobación definitiva; y en estas se ejecutarán obras escogidas de todos los géneros que abraza la Música religiosa por vía de modelo y ejemplo. ${ }^{2}$

El programa musical del Congreso, por tanto, tenía como objeto proporcionar nuevos- modelos musicales de referencia. Los conciertos configuraban, junto al resto de actuaciones musicales -partes musicales de las celebraciones litúrgicas y conferencias-, un plan pedagógico que descansaba sobre la premisa de que la experiencia musical en vivo constituía un eficaz instrumento educador -regenerador-, muy superior a cualquier relato que se circunscribiera al ámbito de la palabra y el razonamiento ("una lección práctica, que vale más que cien discursos").

Trataremos de mostrar a continuación que el programa musical del Congreso y todo lo que en torno a él giraba (intérpretes, escenarios, prensa, crítica) sirvió para levantar un universo musical ideal -obviamente desde el concepto que del mismo poseían aquellos que tenían el poder de construirlo- que exponer como modelo real y

\footnotetext{
${ }^{1}$ Villalba, "El Segundo Congreso Nacional", p. 586

${ }^{2}$ Crónica Segundo Congreso, p. 17. El fin del Congreso, según constaba en el artículo 1. e era "estudiar y acordar los medios de llevar a la práctica la reforma de la Música religiosa en España, con estricta sujeción a los preceptos contenidos en el Motu proprio de Nuestro Smo. Padre, el Papa Pío X, y bajo la dirección de los Rmos. Prelados.” Ibídem.
} 
realizable. Aunque con carácter efímero y en unas circunstancias y un entorno propicios, a través de las actuaciones musicales se trató de exhibir el ideal reformista realizado, la reforma consumada.

Además de los conciertos de órgano, el programa musical del Congreso se compuso de unas "preces" musicales que enmarcaron las sesiones inaugural y de clausura, las partes cantadas de las funciones litúrgicas, dos conciertos, y los ejemplos musicales que ilustraron sendas conferencias dictadas en la segunda sesión solemne. Los actos litúrgicos que se celebraron en la Catedral fueron tres: dos misas solemnes que precedieron respectivamente a las sesiones de inauguración y clausura del Congreso, más la acción de gracias una vez finalizado. La acción de gracias consistió en una exposición del Santísimo con bendición ${ }^{3}$.

Para el análisis pormenorizado del programa musical así como de otras fuentes a partir de las cuales inferir los propósitos y estrategias de los organizadores dentro de este plan global de institucionalización del movimiento y sus criterios, consideraremos varios apartados: canto gregoriano, polifonía clásica y moderna, intérpretes y prensa.

\subsection{La interpretación modélica del canto gregoriano}

El canto gregoriano estuvo presente en el Congreso durante las funciones litúrgicas así como en la conferencia ilustrada con ejemplos que pronunció Gregorio $\mathrm{M}^{\mathrm{a}}$ Suñol en la segunda sesión solemne. A canto llano fueron interpretadas, además de los recitados propios de los distintos actores litúrgicos (celebrantes, diáconos, subdiáconos y asamblea), las tercias, las partes del propio de las dos misas, así como la salve de $5^{\circ}$ tono con la que concluyó la acción de gracias que puso punto final al Congreso. Esta última pieza, pensada como su brillante colofón, fue cantada por un numeroso coro de cientos de niños y niñas provenientes de las escuelas católicas de la ciudad ${ }^{4}$.

\footnotetext{
${ }^{3}$ Véase Apéndice 9.

4 “Ante ella [la Virgen de los Reyes] se cantaron por los seminaristas y niños y niñas de los colegios [católicos] de la Capital, en número de más de mil, preces y salve, alternando con la Schola Cantorum, que se hallaba situada en la tribuna, dirigida este por el P. Mauro Sablayrolles, aquellos por el P. Gregorio M. ${ }^{a}$ Suñol." Crónica del Segundo Congreso, p. 82. En el congreso de Valladolid tuvo lugar un acto parecido. En el canto de la Misa de Angelis gregoriana durante la misa solemne que sirvió como apertura, a la capilla catedralicia y al Orfeón Vasco-Navarro, se le unieron "las niñas de los Colegios de religiosas de la Compañía de María (Enseñanza) Dominicas francesas del Santísimo Rosario, Bernardas de Santa María la Real de Huelgas, Carmelitas de la Sagrada Familia, del Dulce Nombre de María y de Nuestra Señora de la O, y Esclavas del Sagrado Corazón de Jesús, en número de ochocientas y en conjunto mil doscientas voces, dirigiendo el coro alto el R. P. Casiano Rojo, benedictino del convento de Silos, y de niñas el Sr. Sochantre de esta Catedral, D. Ángel Torrealba." Crónica del Primer Congreso, p. 10 .
} 
Todas estas intervenciones sirvieron para presentar el canto eclesiástico considerado como primitivo y auténtico, una vez restaurado, es decir, depurado de las impurezas adheridas desde que se copiara en aquellos códices medievales contemplados como las fuentes originales 5 . En la Crónica del Segundo Congreso se apuntó: "Las partes variables de la Misa, que el coro ejecuta, como las que corresponden al Preste y Sagrados Ministros, fueron cantadas con tonos netamente gregorianos". Los "tonos netamente gregorianos" a los que se refirió el cronista eran los contenidos en el recién aparecido gradual típico vaticano. La función ejemplarizante que debía cumplir el Congreso en el caso de las intervenciones gregorianas, consistió precisamente, según Villalba, en el uso de la nueva edición del gradual ${ }^{7}$ :

Ha habido en efecto canto gregoriano, y música polifónica. Constituían lo primero la Tercia y el Introito, Gradual y demás partes de la misa que según tal clase de música debe ser practicada. El texto empleado era, como era justo para servir de ejemplo, el de la Vaticana ${ }^{8}$

Ripollés también se expresó en el mismo sentido, incorporando, además, un matiz más legalista. Así el canto litúrgico practicado en el congreso de Sevilla, y exhibido como modelo, correspondía estrictamente con lo regulado por la Iglesia:

Todos estos cantos [del Propio], tomados de la Edición típica Vaticana recientemente publicada, son de los más antiguos del repertorio gregoriano.

Las entonaciones del celebrante, como las del diácono y subdiácono, y las respectivas respuestas del coro a cargo de la sección del Seminario, se ajustarán a las disposiciones eclesiásticas sobre la materia. ${ }^{9}$

\footnotetext{
5 "Hállanse en grado sumo estas cualidades en el canto gregoriano, que es, por consiguiente, el canto propio de la Iglesia romana, el único que la Iglesia heredó de los antiguos Padres, el que ha custodiado celosamente durante el curso de los siglos en sus códices litúrgicos, el que en algunas partes de la liturgia prescribe exclusivamente, el que estudios recentísimos han restablecido felizmente en su pureza e integridad.” MP, Título II. Géneros de música sagrada, art. 3.

6 “Primer día. En la Santa Iglesia Catedral”. Crónica del Segundo Congreso, p. 73.

7 Como ya hemos señalado, el gradual típico vaticano fue publicado en 1908, meses antes de la celebración del Congreso.

${ }^{8}$ Mauricio [Luis Villalba], "Impresiones del Congreso. Primer día.”, ECA, 3345 de 13 de noviembre (1908), p. 1 .

${ }^{9}$ Vicente Ripollés, “El Congreso de Música sagrada”, ECA, 3344 de 12 de noviembre (1908), p. 1.
} 
Si consideramos de nuevo, restringiéndonos al ámbito local, los datos proporcionados en los anteriores capítulos sobre el estado del canto llano en la archidiócesis de Sevilla -intolerable-, podemos afirmar que la puesta en práctica de este método reformista ejemplarizante consistente en el uso de las melodías contenidas en el nuevo gradual típico constituyó un hito histórico. Recordemos, entre otros testimonios e informaciones ofrecidos, la valoración que siete meses después de clausurado el Congreso hacía la CDMS sobre la, a esas alturas, inaceptable vigencia de las melodías de canto llano contenidas en los libros de coro:

esta Comisión entiende que no puede tolerarse ya por más tiempo el uso de los cantorales o libros de coro hoy existentes en las Iglesias del Arzobispado, en lo que al Canto de la Santa Misa se refiere, debiendo adoptarse inmediatamente en todas la 'Edición Vaticana', $[\ldots]^{10}$

El Congreso consiguió arrinconar los viejos cantorales en uso y hacer desaparecer, en consecuencia, las melodías que habían constituido desde fecha inmemorial el repertorio de canto llano de la catedral hispalense. Aunque sólo fuera por unos días, pues, como demuestra la disposición de la CDMS que acabamos de citar, tras el Congreso todo volvió a la normalidad, la reforma se produjo de facto superando prácticas históricas profundamente consolidadas.

Dado que el Congreso encargó a los benedictinos catalanes, es decir, los partidarios de las tesis solesmenses, la preparación de todas las intervenciones gregorianas, la tendencia que se empezó a instaurar en Sevilla, y el paradigma de interpretación de las melodías que se propuso a los músicos eclesiásticos españoles en general, fue naturalmente el defendido por Mocquereau. La ausencia de discusiones, evitadas por los organizadores y prohibidas por Roma, sobre la interpretación rítmica del canto gregoriano impidió que se escenificara el conflicto entre las dos tendencias, pero no que una de ellas se impusiera a la otra, al ser presentada como el modelo por el Congreso a través del programa. De hecho, según el aforismo de Villalba, "una lección práctica vale más que cien discursos", era precisamente en la práctica, es decir, en el programa gregoriano en su facultad de exponer modelos, donde se dilucidó la supremacía de unas propuestas sobre otras. Desde esta realidad, se explica la disputa

10 "Exposición a Ntro. Excmo. Prelado sobre Música Sagrada y Circular sobre el mismo punto", BOAS, 667 (1909), pp. 393-394. Véase capítulo 2, epígrafe 4.2.2. "Medidas conminadoras para administradores de templos", p. 158. 
por desempeñar el papel de preparadores y directores de las ejecuciones prácticas, así como las reacciones de la otra facción, los benedictinos silenses, ante la posición de neta desventaja con la que acudieron al Congreso. Su propuesta práctica quedó pues silenciada en beneficio de la solesmense ${ }^{11}$.

De todos modos, al margen de estas disputas, vistas por muchos como productos de rivalidades injustificables o de excesivos enconos por diferencias de criterios sobre cuestiones insignificantes, la propuesta gregoriana del Congreso poseía un segundo valor pedagógico ${ }^{12}$. En muchas ocasiones, las denuncias de los reformistas sobre el estado del canto llano y la música sacra en general no tenían que ver con asuntos estéticos o teóricos, sino con la práctica diaria. Criticaban la insuficiente preparación de las obras, la falta de ensayos, el descuido y desinterés de los intérpretes, etc. González Merchant, en el discurso inaugural del Congreso, distinguió dos grandes grupos de "abusos": los que tenían que ver con la falta de adecuación o conveniencia de determinada música en relación a su función en el seno del culto; y los que tenían que ver con la interpretación de la música sacra, "como la incuria y abandono en su estudio y ejecución, que la priva de su virtud y de su fuerza para producir en las almas los efectos a que se ordena"13.

Las reseñas críticas de Villalba subrayaron la pulcritud de las ejecuciones gregorianas ofrecidas durante el Congreso y la labor previa de preparación llevada a cabo por los benedictinos catalanes. Estos comentarios tenían un especial valor al ser realizados por alguien precisamente no partidario de la tendencia que representaban estos monjes. Sobre la cuestión de los signos rítmicos se pronunció así:

\footnotetext{
${ }^{11}$ Véase capítulo 5, epígrafe 4.1. "La cuestión gregoriana: las primeras grietas en el movimiento".

12 Según Otaño, Viñaspre calificó las luchas de los benedictinos como "jerigonza benedictina". Goicoechea, por su parte, como "quisi-cosas de los gregorianistas": "Viñaspre está contentísimo de su artículo, porque ha sacado V. ...los cantos españoles del Exsultet... iSu tecla de siempre! Creo que el mayor gusto de Viñaspre sería convertir en pollos a los franceses y comerse un par de ellos cada día. Es la mar de célebre en esta tecla y yo me río mucho. Crea V. que con su chifladura española y todo es muy simpático y, sobre todo, una persona dignísima, sacerdote modelo. Háblele V. de todo menos de los ictus rítmicos y demás jerigonza -que él dice- benedictina." Carta de Otaño a Ripollés, 27 de mayo de 1911. AMSL. FO. Correspondencia, TA01/126. "La misma opinión que V. la tengo desde mucho tiempo sobre estas quisi-cosas de los gregorianistas, sectarios de uno y otro sistema; y ¿merece esto que se las tome con calor? De ningún modo, una cosa en ser partidario de una escuela, y otra muy distinta el trabajar por establecer el canto gregoriano." Carta de Goicoechea a Otaño, 1 de noviembre de 1908, que no se conserva. La cita figura en nota a pie de página en la transcripción de la siguiente carta: Otaño a Goicoechea, 1 de noviembre de 1908. AMSL. FO. Correspondencia, TA01/047. Véase además el epígrafe al que hemos hecho referencia en la nota anterior
}

${ }^{13}$ Rafael González Merchant, "La restauración de la música religiosa”, Crónica del Segundo Congreso, p. 104. 
No vayas, por eso, a colegir del entusiasmo o viveza con que me expreso que soy un fervoroso partidario del sistema ese. Eso ya es harina de otro costal. Reconozco, sí, que le han presentado con toda perfección, me ha gustado lo que han hecho, porque han trabajado de veras, y así es como se trabaja y como se presentan las cosas; te diré más: ese sistema así presentado lo encuentro en sí aceptable, y no sólo aceptable, muy religioso y aun artístico; pero de ahí a creer que es el verdadero, el legítimo y auténtico sistema de interpretación de las melodías gregorianas hay una gran distancia.

Y ve ahí cómo alabando la lucida, que lucida en verdad ha sido la labor de los benedictinos dichos, y cómo habiéndome gustado, y mucho, la obra que han hecho en Sevilla, no por eso creo que las Scholas, ni los coros, ni el pueblo cristiano de la Edad Media cantaba de ese modo las melodías litúrgicas, ni que sea esa la mente de sus autores." $" 14$.

No obstante, la especial atención que prestaron a la conferencia con ejemplos musicales a cargo de Suñol hizo evidente que detrás del esfuerzo realizado se escondía el objetivo de defender y divulgar su teoría rítmica:

Desde luego, todo estaba ensayado, como estas cosas se merecen, y preparado con esmero, y esta labor preliminar dio por resultado un ejemplo de interpretación unida y compacta, limpia y bien matizada. Pero hay que decir, en honor de la verdad, que no todo fue igualmente exquisito; los esmeros mayores los pusieron los Benedictinos en los ejemplos que habían de ilustrar la conferencialección del Padre Suñol, que se dio en la sesión solemne ya dicha; se trataba de presentar [a] los profesionales un sistema de interpretación en breves líneas teóricas y en ejemplos prácticos graduados, y hubiera sido torpeza en aquella exhibición a crítica y examen, no precisamente del público general, sino de los músicos, partidarios ya de uno o de otro sistema, y que van, por tanto, dispuestos a afilar y aguzar las cosas, un descuido. No han tenido tal imprevisión los Padres dichos, y para esta ejecución, que era cosa grave y delicada, como puedes colegir, el P. Suñol ha hecho un viaje a Inglaterra, y allí, con el mismísimo P. Mocquereau, preparó y escogió los ejemplos, punto de verdadero compromiso, y que requería un tino especial, y no te digo nada de los ensayos que después, en Sevilla, han tenido, porque a la legua se notó que lo exquisito de sus afanes y cuidados estaba en aquello. Y muy bien hecho, porque, a mi modo de ver, esta es la manera de exponer un sistema y ofrecerle al público; ${ }^{15}$

\footnotetext{
${ }^{14}$ Villalba, "El Segundo Congreso Nacional", p. 558.

${ }^{15}$ Ibídem, p. 587.
} 
A pesar de no ser partidario de ella, Villalba puso de relieve la validez de la propuesta solesmense, a la que se refirió como "modelo de interpretación". Al igual que para Viñaspre y Goicoechea, para el crítico agustino, las teorías rítmicas eran una cuestión secundaria. Lo realmente importante era proporcionar esos modelos de interpretación "artística y aceptable":

El éxito ha sido franco e indudable; el auditorio lo ha demostrado unánimemente, y desde el canto de la antífona Montes et colles, silábico y sencillo, que recuerda el Pueri hebraeorum, hasta el adornado del Introito Exurge quare obdormis Domine, hasta los más colmados de floreos, Graduales y Alleluia, ha manifestado el deleite y placer que la audición le producía; placer que ha llegado hasta el entusiasmo en el canto final, que con gran perspicacia y conocimiento del público han ofrecido un canto de alabanza y júbilo a la Resurrección, un alleluia que une lo grandioso en lo tierno, la alegría en el recogimiento místico.

Se discutirá en lo técnico, la teoría y práctica del sistema, lo que no se discutirá porque es un hecho, es que dentro del sistema han presentado un modelo de interpretación, y esta interpretación es artística y aceptable. $^{16}$

Estas críticas favorables sobre la labor de los benedictinos catalanes y en especial, sobre la conferencia de Gregorio $\mathrm{M}^{\mathrm{a}}$ Suñol, a la que calificó Ripollés como "el acontecimiento del Congreso" 17 , fueron generalizadas. La coincidencia en los juicios al respecto de personajes con criterios e intereses, en ocasiones, tan dispares como Otaño o Villalba hacen fiable ${ }^{18}$, creemos, estas apreciaciones, a pesar de la parcialidad en la que pudiera incurrir el primero como víctima que fue de las disputas entre las distintas facciones benedictinas, o Ripollés como responsable del encargo a los catalanes de las interpretaciones gregorianas en perjuicio de los silenses. Este último escribió a Pedrell: "Del congreso nada digo porque a estas horas lo sabe V. todo: me cabe la satisfacción de decir que lo que se dejó a mi iniciativa salió menos mal; sobre todo la labor de los

\footnotetext{
${ }^{16}$ Las reseñas publicadas por Villalba bajo el pseudónimo de Mauricio fueron incluidas igualmente en la Crónica del Segundo Congreso, pp. 82-91, y en parte en las crónicas salidas en La Ciudad de Dios. Estas en concreto, referidas al segundo día del Congreso figuran en: Crónica del Segundo Congreso, pp. 84-86, y en "El Segundo Congreso Nacional", p. 587. Hay que advertir que los textos incluidos en la $L C D$ presentan algunas pequeñas variaciones en la redacción, u omiten algún dato de menor importancia como que el canto de alabanza y júbilo al que se refiere estaba dedicado a la Resurrección. Mauricio, "Impresiones del Congreso. Segundo día", p. 1.

${ }^{17}$ Véase la nota a pie $\mathrm{n}^{\mathrm{o}} 180$, p. 562.

${ }^{18}$ Véanse del capítulo 5, los epígrafes 4.2.2. "El grupo dominante: Otaño-Ripollés-Goicoechea-Viñaspre" y 4.2.3. "Las alternativas: Olmeda, Villalba".
} 
PP. Mauro y Suñol resultó brillantísima, digan lo que quieran los de Silos"19. En la valoración de Otaño estaban presentes, además, las graves tensiones generadas en torno a la cuestión gregoriana:

Me han escrito por diversísimos conductos que la conferencia del P. Suñol fue una verdadera joya.

Además saben Suñol, Ripollés etc. que Casiano estuvo burlándose durante la conferencia del conferenciante y han recogido todas las palabras que se le escaparon, pues precisamente estaban a su lado dos amigos de los otros. ${ }^{20}$

Con todo, según el testimonio de Villalba, en medio de ese escenario ideal en el que el canto gregoriano restaurado de la edición vaticana interpretado con todo cuidado se escuchaba por primera vez en las funciones litúrgicas catedralicias, emergió por momentos la verdadera realidad:

Dentro de este gregorianizar de buena ley, ha habido sus intermedios a sochantre pleno. La cosa fue en la procesión anterior a la misa, y no puedes figurarte el contraste que hacía con lo que se acaba[ba] de oír, tanto más cuanto tuvo lugar entre una Tercia, muy bien cantada, y una misa, en que la polifonía de Guerrero, interpretada a perfección por la Capilla lsidoriana, por un lado, y las melodías Statuit, Veritas mea, etc., nos ofrecían algo exquisito de ambos géneros. $^{21}$

Los "intermedios a sochantre pleno" sirvieron, tal y como se desprende del texto de Villalba, para confrontar el mundo ideal construido en el Congreso con el

${ }^{19}$ Carta de Ripollés a Pedrell, 8 de febrero de 1909. BC. FFP. M 964 R.

${ }^{20}$ Carta de Otaño a Goicoechea, 7 de enero de 1909. AMSL. FO. Correspondencia, T01/042. El pasaje completo es el siguiente: "He leído ayer con detención, y dos o tres veces, lo del P. Casiano; a mí me parece un ciempiés que nada prueba sino su pasión y poca serenidad. Además literalmente está muy escrito con los pies: hay cosas que no hacen tienen [estas dos últimas palabras están tachadas] siquiera sentido.

Claro es que le han de contestar, pues es opinión general, y a mí me han escrito por diversísimos conductos que la conferencia del P. Suñol fue una verdadera joya.

Además saben Suñol, Ripollés etc. que Casiano estuvo burlándose durante la conferencia del conferenciante y han recogido todas las palabras que se le escaparon, pues precisamente estaban a su lado dos amigos de los otros.

Además el argumento con que trata de probar no prueba; rechaza la teoría contraria, pero con unas afirmaciones más bien despóticas que diplomáticas." Otaño se refería a un artículo enviado por Casiano Rojo a la redacción de $M S H$ para que fuera publicado en dicha revista, según le hizo saber Goicoechea en una carta de 29 de diciembre de 1908. AMSL. FO. Correspondencia, 009/002.008.

${ }^{21}$ Villalba, "El Segundo Congreso Nacional”, pp. 588-589. 
real $^{22}$. Así, apareció la distancia que separaba aún el uno del otro, y se tomaba conciencia de que el primero no era más que una imagen de la realidad a la que se aspiraba. En un estilo más sugerente que explícito, propio de aquellos casos en los que se enfrentaba en sus comentarios a cuestiones delicadas o espinosas, mencionó "teclas" no musicales y "circunstancias" que hay que respetar:

¿Te escandaliza el caso? No seas fariseo nunca, Marcelino. Eso, lo que indica es que son muchas las dificultades en que se tropieza y bastantes más las teclas (no musicales, por cierto) que hay que tocar, y las circunstancias, etc. etc., que hay que respetar. El arte, en abstracto, no tiene entrañas, es verdad; pero en concreto sí, y, además, prudencia, y, como secuela de esta, paciencia para aguantar los desafueros y entuertos artísticos, que al tiempo, al tiempo, hay que dejar que borre ${ }^{23}$

Resulta arriesgado deducir a partir de estas vaguedades a qué se refería exactamente, aunque parecen apuntar, una vez más, a un problema que superaba la esfera musical o artística, y se instalaba en un espacio mucho más amplio y complejo, de trascendencia sociológica y cultural ¿Representaría esta intervención del sochantre, indiferente a las nuevas propuestas interpretativas y estéticas que el Congreso mostraba prácticamente en el resto de las partes musicales, una forma de reafirmación en las propias costumbres o de resistencia ante la irrupción de unas novedades no bien recibidas? Es posible que el beneficiado catedralicio simplemente cantara por inercia según había hecho toda su vida, sin ninguna pretensión reivindicativa, aunque no resulta descabellado el interrogante en vista de las numerosas pruebas e indicios aportados en los tres primeros capítulos en relación a la férrea resistencia mostrada ante la reforma, o de los testimonios de Ripollés o Turina al respecto. Sobre todo, nos parece pertinente plantear la pregunta si consideramos el hecho de que el Congreso se convirtió en algunos momentos en un escenario de confrontación entre los partidarios pro reforma y los contrarios a ella. De ello nos ocuparemos más adelante.

Ismael Fernández de la Cuesta ha señalado la resistencia mostrada por "muchas iglesias y catedrales de España" a aceptar la "aculturación” que suponía la adopción de

\footnotetext{
${ }^{22}$ Eustoquio Uriarte, uno de las principales figuras de la reforma del canto gregoriano en España se refería en una conocida carta al pianista Juan Miralles a las prácticas de los cantores como "descompuestos berridos de nuestros cantollanistas"; cit. en Medina, "La romería en el templo y otras licencias", p. 12.

${ }^{23}$ Ibídem, p. 589.
} 
la edición vaticana ${ }^{24}$. En el mismo sentido se expresa Ángel Medina, quien cita algún ejemplo concreto como el caso de la catedral de Burgos. Medina pone de manifiesto la fortaleza de determinadas tradiciones cantollanistas ante las reformas y su capacidad de perdurar a lo largo del tiempo, incluso hasta nuestros días ${ }^{25}$.

\title{
1.2. Intérpretes de música religiosa propuestos por el Congreso como
}

\section{ejemplares}

Las denuncias sobre la deficiente interpretación de la música religiosa en los templos se multiplicaban en el caso de la música polifónica. En su discurso inaugural del Congreso, González Merchant utilizó una cita del maestro de capilla de la catedral de Amberes, el profesor Wamnbach, en la que proporcionaba la siguiente descripción sobre la forma en la que se desarrollaban las ceremonias litúrgicas ${ }^{26}$ :

Por punto general, dice, mientras el Preste empieza las oraciones de la Misa, el órgano insiste en hacer oír el La..., los

\begin{abstract}
24: "En muchas iglesias y catedrales de España se mantuvo una resistencia a asumir la aculturación producida por la difusión extensiva del canto gregoriano de las ediciones vaticanas, y de la ejecución del mismo según la escuela interpretativa solesmense. Hasta muy avanzada la década de los 50 del siglo XX, canónigos y beneficiados maestros de capillas de muchas catedrales de España siguieron cantando con gran libertad interpretativa las melodías gregorianas, ya según las ediciones vaticanas ya según la tradición local." "La reforma del canto gregoriano", p. 69.
\end{abstract}

\footnotetext{
${ }^{25}$ Medina explica las continuas e insistentes alusiones a la necesidad de formación del clero en el nuevo canto gregoriano no "porque el clero fuese torpe (que no lo era), ni por la consabida lentitud de cualquier cambio de envergadura en los usos litúrgicos, sino por la resistencia, oposición e incluso abierto rechazo que el nuevo canto gregoriano generaba entre amplios estratos del mundo eclesiástico, en fuerte contraste con el empeño por su difusión realizado por las inagotables minorías reformadoras." Medina, "La romería en el templo y otras licencias", p. 14.
}

${ }^{26}$ El Boletín del Congreso publicó íntegro el discurso de Wamnbach: "Del empleo de la orquesta en la iglesia", 2 (1907), p. 15. Aunque González Merchant no lo especifica, es muy probable que extrajera su cita de dicha publicación. Villalba señaló lo frecuentes que este tipo de descripciones tenían entonces, a las que, no obstante, no le veía gran utilidad en la práctica: "Viniendo al discurso, te diré que estuvo muy bien [González Merchant] diciéndole; a la gente que vive a la altura de las circunstancias, y que por las circunstancias se sentía a la sazón muy litúrgica, polifónica, etc., durante aquellos cuatro días, le pareció chispeante inclusive, y, sobre todo, cuando recitó un parrafito que hace una festiva y caricaturesca descripción de la música religiosa de orquesta. Te confieso que en el género este de las descripciones pintorescas es de las más chistosas, y que entre las cuatro o cinco que conozco de tal estilo, y que por cierto se copian unas a otras, sin comillas por supuesto, es de las más divertidas y sirve para varias cosas; es, a saber: $1 .^{\circ}$, para reírse uno un poco o un mucho, según esté de humor; $2 .^{\circ}$, para que a otros les dé también por hacernos reír otro poco con otra descripción pintoresca, si que también gráfica hasta dejarlo de sobra, pero a cuenta nuestra, y cuenta que hay quien no reconoce límites en esto de hacer chistes gráficos, sobre todo si sirven de réplica a otros chistes y van contra ciertas causas; $3 .^{\circ}$, para lo único que no sirve es para razonar sobre ella, porque como eso no ataca la esencia del mal, sino la parte material externa, y la parte externa de las cosas, así buenas como malas, siempre tiene una porción de flecos, de igual manera se presta a ridiculizar lo bueno que lo malo, con lo cual, ciertamente, no ganamos nada los partidarios de lo bueno." Villalba, "El Segundo Congreso Nacional", pp. 496-497. 
instrumentos de arco preludian, el flautista hace sus trinos y cabriolas, los clarinetes repasan un pasaje escabroso, y los trombones sotto voce calientan el instrumento haciendo embocadura.... Por fin, cesa este barullo, y empieza el Kirie, que dura quince minutos por los menos.La ejecución del Gloria no bajará de media hora: comienza por un preludio en aire pastoril o de paso de ataque de cien compases, durante el cual o el oboe dialoga con la flauta, o el clarinete contiende y disputa con el fagot. Al Gratias no faltará el duo de soprano y de tenor con su obligado de violín y concertante final. En el cum Sancto Spíritu el metal (no sé por qué) el metal sopla con fuerza; y los coros, como posesos, claman setenta veces ¡Amen! ¡Amen!- Llega el Credo, el número más largo del programa: según el prospecto, el $E t$ incarnatus es un solo de contralto con arpa o piano. En el Crucifixus, solo de timbales, alternando con el bombo, para imitar quizás los truenos de la tempestad del Gólgota. La indispensable llamada de trompetas en el Resurrexit; al descendit de coelis, escala cromática descendente por todos los instrumentos de cuerda; en el ascendit in coelum, escala cromática de toda la madera. En fin, al vitam venturi saeculi TUTTI [sic] general de gran efecto por la batería, timbales, triángulo, tambor y bombo. ${ }^{27}$

A esta descripción calificada por González Merchant de "pintoresca" pero "exacta y conforme con la realidad", añadió el propio canónigo catedralicio hispalense otros problemas graves como la falta de formación y de calidad de los intérpretes, y la deplorable situación de las capillas instrumentales de las catedrales, que calificó de "murgas ignominiosas":

[...] esas obras, tan profanas en su distribución, se hacen insoportables y aun ridículas, ejecutadas por cantantes que suplen su falta de verdadera educación musical con aspavientos y desmayos, fermatas y calderones de pulmón de vaca, acompañados por una murga ignominiosa, compuesta, cuando mucho, de un contrabajo, dos violines, flauta, clarinete, cornetín y bombardino. ${ }^{28}$

En este sentido, el MP se ocupó de llamar la atención no sólo sobre la calidad de la música litúrgica sino también sobre la necesidad de cuidar su interpretación. El artículo 24, que pertenecía al capítulo VIII dedicado a exponer los medios generales para hacer realidad la reforma, advertía: "No cuiden sólo de que la música sea buena de suyo, sino de que responda a las condiciones de los cantores y sea buena la ejecución" ${ }^{\text {29 }}$.

\footnotetext{
${ }^{27}$ González Merchant, “La restauración de la música”, pp.114-115.

${ }^{28}$ Ibídem, p. 115.

${ }^{29} M P$, Título VIII. Medios principales, art. 24.
} 
La solución propuesta por el MP para resolver la situación en este aspecto consistía en la creación por parte del clero de scholae cantorum, tanto en los seminarios e institutos religiosos (art. 25) $)^{30}$, como en las "iglesias principales", e incluso en aquellas "de menor importancia y de aldea" (art. 27) ${ }^{31}$.

El Congreso abordó estos aspectos en varios de los puntos que componían la sección IV.- "De la propaganda, organización y personal” del cuestionario: punto b) "Scholae cantorum: elementos para su fundación y medios para su sostenimiento en las Parroquias."; punto c) "Puntos fundamentales para los reglamentos de dichas Scholae; punto f) "La constitución actual de las capillas en las Iglesias Catedrales de España, ¿permite una ejecución digna de las obras de los polifonistas? Medios de mejorarlas: parte que pueden tomar los seminarios en las funciones más solemnes de las Iglesias Catedrales." ${ }^{, 32}$. Excepto la memoria presentada por el entonces maestro de capilla de la catedral de Jaén, Cándido Milagros, todas fueron elaboradas por Ripollés. Las propuestas de Ripollés determinaron las conclusiones del Congreso sobre asuntos tan importantes como los que tenían que ver con la fundación, organización y régimen de las Scholae cantorum; métodos de enseñanza musical; la mejora de la situación y capacidad de las capillas catedralicias españolas, y el papel de los coros de los seminarios como ayuda en las funciones litúrgicas en las catedrales. La Crónica del Segundo Congreso nos proporciona resúmenes detallados del contenido de estas memorias $^{33}$.

En cuanto a las Scholae cantorum, Ripollés defendió la importancia de su existencia en todas las parroquias. Distinguía entre dos clases: aquellas de más de ocho mil habitantes, y las de menor población. En estas últimas encomendaba al párroco, dado sus limitados recursos, toda la misión de renovación litúrgico-musical, de ahí

\footnotetext{
${ }^{30}$ "En los seminarios de clérigos y en los institutos eclesiásticos se ha de cultivar con amor y diligencia, conforme a las disposiciones del Tridentino, el ya alabado canto gregoriano tradicional, y en esta materia sean los superiores generosos de estímulos y encomios con sus jóvenes súbditos. Asimismo, promuévase con el clero, donde sea posible, la fundación de una Schola cantorum para la ejecución de la polifonía sagrada y de la buena música litúrgica." MP, Título VIII. Medios principales, art. 24.

31 "Póngase cuidado en restablecer, por lo menos en las iglesias principales, las antiguas Scholae cantorum, como se ha hecho ya con excelente fruto en buen número de localidades. No será difícil al clero verdaderamente celoso establecer tales Scholae hasta en las iglesias de menor importancia y de aldea; antes bien, eso le proporcionará el medio de reunir en torno suyo a niños y adultos, con ventaja para sí y edificación del pueblo.” MP, Título VIII. Medios principales, art. 27.

${ }^{32}$ Crónica del Segundo Congreso, pp. 230-242.

${ }^{33}$ Los resúmenes de las memorias presentadas en: Crónica del Segundo Congreso, pp. 150-264.
} 
derivaba la importancia de la educación musical del clero. Respecto a las primeras, exponía extensamente los medios para su fundación, sostenimiento y organización. Debían estar vinculadas a instituciones católicas como círculos católicos de obreros, hermandades, congregaciones o colegios e institutos religiosos. Para su sostenimiento abogaba por que los párrocos aportaran alguna cantidad como ayuda aun a costa de reducir el presupuesto para flores, electricidad u ornamentación. Además de esta ayuda, se consideraba la aportación de socios de mérito o protectores, que había que buscarlos entre los fieles de buena posición social, y la recaudación proveniente de conciertos que se ofrecieran ${ }^{34}$. Ripollés se encargó, además de definir, según su criterio, la forma de organización así como otras cuestiones relacionadas con las estructuras de estas entidades ${ }^{35}$.

La situación de las capillas musicales de las catedrales que describió Ripollés era tan desastrosa y sus propuestas tan ambiciosas, que en las conclusiones finales del Congreso aparecieron muy matizadas ${ }^{36}$. Según Ripollés, las capillas eran incompetentes a la hora de interpretar la polifonía clásica por dos motivos: por falta de número de cantores, y por falta de orden y disciplina. Veía como única solución la colaboración de las Scholae cantorum de los seminarios con las capillas en los cultos catedralicios $^{37}$. Ello implicaba a su vez un radical cambio de actitud por parte de los responsables de los seminarios, y una reforma en sus planes de estudios:

\footnotetext{
${ }^{34}$ Ibídem, pp. 230-231.

35 En cuanto a su organización proponía: "una dirección espiritual y administrativa (aparte de la meramente artística) ajena a los elementos artísticos, asesorada por una junta mixta de vocales eclesiásticos, coristas y socios protectores, constituyendo así un organismo adecuado para suavizar asperezas y dirimir contiendas tan frecuentes en el genus irritabile vatum et musicorum." Ibidem, p. 232. Estas scholae debían estar regidas por "la junta directiva con sus atribuciones de gobierno, inculcando bien en el ánimo de los coristas el espíritu neta y sólidamente cristiano que debe informar la institución, la sumisión, obediencia y abnegación de todos en someterse a las decisiones de la Iglesia, a los mandatos de los superiores, a las indicaciones del maestro y a las de común acuerdo establecidas reglas para el recto funcionamiento de la Schola; los derechos y deberes de cada elemento constituyente, con sus frecuentes ensayos, con su compromiso de cierto número de audiciones, y a ser posible, con el establecimiento de remuneraciones fijas pecuniarias para todos y cada uno de los cantores, y con penas que sancionen el estricto cumplimiento del reglamento y aseguren a la sociedad vida normal y próspera”. Ibídem, p. 233. Aporta además una interesante serie de consideraciones y consejos guiados por el sentido común y el realismo, para mantener la ilusión y favorecer la perseverancia de los miembros del grupo. Ibídem, p. 232.

${ }^{36}$ Para remediar las deficiencias propuso, entre otras cosas, que se aumentara el número de cantores de las capillas hasta conseguir un número de cinco por cuerda, algo bastante impensable dada la situación de la Iglesia y el Estado en ese momento. Ibídem, p. 238.

37 "Propone, por último, como único medio de solución, las Scholae cantorum de los seminarios, pero también para esto se necesita que la enseñanza del canto gregoriano y polifónico sea una enseñanza verdad[era], enseñanza sólida, sancionada enérgicamente por los superiores eclesiásticos, favorecida con las miradas benévolas de los Prelados y Cabildos [...]” Ibídem.
} 
Una Schola cantorum de veinte seminaristas, unida a elementos bien disciplinados, no díscolos, de las Catedrales, es más que suficiente para la ejecución digna de los cantos polifónicos, [...]

Precisa imbuir bien al seminarista de la importancia y gran papel que la música tiene en la liturgia, del gran bien que con ella puede hacerse en la vida parroquial, del reflorecimiento de la vida cristiana a que con ella puede llegarse. Con estas convicciones, con recompensas, aliento y viva solicitud por parte de los superiores, la Schola cantorum del Seminario prosperará y podrá prestar valiosos servicios para el mayor esplendor del culto en las iglesias catedrales, sin gravamen para nadie. Pero, si en lugar de esto el seminario aprende en la conducta de sus superiores el desprecio y desvío con que hasta ahora han sido tratados la música y los músicos, cerremos el ánimo a toda esperanza y contentémonos con seguir cantando rutinaria e indignamente las divinas alabanzas. ${ }^{38}$

Así pues, el Congreso, siguiendo las directrices generales del $M P$, estableció la Schola cantorum, fundadas tanto en seminarios, iglesias, catedrales, $\mathrm{u}$ otras instituciones eclesiásticas, como la infraestructura fundamental para el sostenimiento y buena interpretación de la música litúrgica.

En consonancia con estas propuestas, lanzadas desde las sesiones de estudio, y de acuerdo con la estrategia ejemplarizante y pedagógica fijada en su reglamento, el Congreso mostró en la práctica, sus propios modelos de intérpretes. Los encargados de las interpretaciones musicales tanto en las funciones religiosas como en los conciertos del Congreso fueron un grupo de seminaristas ${ }^{39}$, la Schola cantorum de los PP. Salesianos de Écija y la Capilla Isidoriana de Madrid, "veterana benemérita del arte sagrado español", en palabras de Villalba ${ }^{40}$; es decir, un coro de seminaristas, una schola cantorum fundada en una ciudad alejada de la capital de la Archidiócesis por un instituto religioso y formada fundamentalmente por jóvenes, y, por último, un referente de la restauración de la música religiosa en España. El Congreso presentó en las dos primeras scholae cantorum sus paradigmas. La Capilla Isidoriana, fundada en 1899 en el seno de la Asociación Isidoriana (1895) era ya entonces un símbolo de la reforma.

A los seminaristas se les encomendó el canto llano de tercias en las funciones solemnes de inauguración y clausura del Congreso. Por su parte, la Capilla Isidoriana

\footnotetext{
${ }^{38}$ Ibídem, pp. 238-239.

${ }^{39}$ El número de seminaristas que componían el coro, ciento veinte, es un dato que proporciona Ripollés. "El Congreso de Música sagrada", ECA, 3344 de 12 de noviembre (1908), p. 1.

${ }^{40}$ Villalba, “El Segundo Congreso Nacional”, p. 688.
} 
que, por primera vez y no sin suscitar polémica ${ }^{41}$, incorporó mujeres a su plantilla, tuvo a su cargo la interpretación de toda la música polifónica de los distintos actos del último día, así como los dos conciertos que tuvieron lugar: "Concierto religioso de música polifónica" celebrado el día 13 en la iglesia del Salvador, y el "Gran Concierto" del día 14 en el que entonces hacía las funciones de gran auditorio de Sevilla, el Teatro San Fernando $^{42}$. Del primero nos ocuparemos detenidamente más adelante, dada su importancia dentro de la estrategia ejemplarizante del Congreso. El segundo respondió a otros fines. Se organizó con el objetivo de ayudar a la financiación del acontecimiento, y tuvo un carácter meramente "artístico", en términos generales, y no "religioso" -utilizando las categorías usadas en aquel momento-. Los protagonistas del concierto no fueron la música litúrgica presentada como modélica, sino la propia Capilla Isidoriana y su repertorio ${ }^{43}$. Villalba no lo incluyó en sus crónicas dentro del programa musical del Congreso, y lo trató al margen de este en unos comentarios finales a modo de postdata. Así lo definió el agustino:

Pero ¿a dónde ha ido a parar el Congreso de música sagrada? ¿A Schumann? No, no ha sido cosa del Congreso de música religiosa, esa; concierto de arte por el Congreso motivado ha sido nada más, que la Capilla Isidoriana, aprovechando su estancia en esta capital, ha querido ofrecer al culto público de artistas, y la sociedad sevillana como muestra de arte grande y legítimo, que sin pertenecer a la modalidad litúrgica, es arte elevado y purísimo, arte que no expresa ideas antitéticas, que no es religioso ni profano como términos opuestos, sino arte culto, educador, y purificador de gustos y de espíritus. Eso es todo, y en verdad que la Capilla Isidoriana ha cumplido su cometido con toda perfección, tanto más cuanto lo hecho es un arranque de fuerza prodigioso. $[\ldots]^{44}$

\footnotetext{
${ }^{41}$ Villalba, "El Segundo Congreso Nacional", pp. 687-688.

${ }^{42}$ Véase Apéndice 9.
}

${ }^{43}$ Así se explicó en la Crónica del Segundo Congreso: "El 11 de Octubre, fecha por ende en que urgía ya dar la última mano a la labor preparatoria del Congreso, la Junta Organizadora se reunió en sesión extraordinaria, bajo la presidencia del M. I. Sr. D. Rafael González Merchant.

En ella se presentó, discutió y aprobó el Programa, ampliación del que se hizo público desde los comienzos, juntamente con el Reglamento y Cuestionario; se aprobó el presupuesto de gastos; se convino en la celebración en el teatro de San Fernando de un gran concierto por la Capilla Isidoriana, de Madrid, con el doble objeto de allegar fondos para cubrir los enormes gastos que suponía la celebración del Congreso, y dar a conocer las magníficas obras del repertorio de la ya célebre Capilla; [...]" Crónica del Segundo Congreso, pp. 52-53.

${ }^{44}$ Mauricio [Luis Villalba], "Impresiones del Congreso. Tercer día", ECA, 3347 de 15 de noviembre (1908), p. 1. Posteriormente en $L C D$ refirió una curiosa anécdota relacionada con la inconveniencia de que figurara el título de Fausto de Schumann tal cual: "Con esto iba a terminar, pero antes, como postdata de estas cartas, te voy a dar noticia de dos cosas más, y te las pongo aquí porque estaban fuera del 
Goicoechea transmitió en una de sus cartas a Otaño su valoración sobre el nivel ofrecido por la Capilla Isidoriana, así como sobre el concierto, en la que se refirió también a la participación "casi de contrabando" de mujeres en el coro madrileño:

La Isidoriana ha ganado en cantidad el $50 \%$, y calidad el $100 \%$. El estilo de interpretación, el mismo. Por cierto, que en el concierto de polifonía, ha empleado voces de mujer, casi de contrabando, pero que en algunos pasajes se conocían notablemente.

El concierto de S. Fernando, super: los trozos de Schumann, a ratos sublimes, siempre interesantísimos. ¡Qué delicia! quien es. $^{45}$

El trocito de Beethoven, sencillísimo, pero a la vez como de

Villalba, por su parte, refirió en su reseña crítica la mejoría que supuso la introducción de voces femeninas en el coro, y las controversias que generó, pese a que, de acuerdo con las prescripciones del $M P$ al respecto ${ }^{46}$, las mujeres no participaron en los actos litúrgicos, sino sólo en el concierto. Con todo, se convirtió en un argumento más para los detractores de la reforma:

a Sevilla ha venido [la Capilla Isidoriana] formando un grupo más nutrido, y esto no sólo en cuanto a la cantidad, sino en cuanto a la calidad; porque has de saber que para reforzar las dos cuerdas más flojas de todos los cuatro de voces desiguales, la de tiples y de contraltos, ha añadido a los niños señoritas, y así unidos en estos papeles las voces de niño y de mujer, resultan con la suficiente consistencia para hacer frente a los tenores y a los bajos. Claro es que la capilla no emplea a las mujeres en las funciones litúrgicas: pero como en la sesión artística, primera en que cantó, que dio en la iglesia del Salvador se trataba de un puro concierto, sacro, pero concierto solo, utilizó en ella todos sus elementos. Esa fue su primera

programa y fueron una verdadera postdata de las fiestas musicales del Congreso. La una fue el concierto que la Capilla Isidoriana dio en el Teatro de San Fernando, del cual concierto, haciendo de reportercrítico al estilo del género, publiqué en mis Impresiones del Congreso, que diariamente salían en $E l$ Correo de Andalucía, los siguientes parrafitos, tragándome por cierto uno acerca de ciertos prudentes escrúpulos que tuvieron en escribir el titulo de Fausto al frente del poema musical de Schumann, que salió, por tanto, intitulado por evitar el escándalo, en el cual parrafillo venía a decir que lo bueno en ideas religiosas que tienen los protestantes pertenece a los católicos; pero lo consulté con el Sr. Merchant, el cual, conocedor del paño sevillano, me dijo que no convenía revelar el título, ni entrar en filosofías, lo cual que, como el que lo decía sus razones tenía para decirlo, seguí al pie de la letra el consejo." Villalba, "El Segundo Congreso Nacional", p. 501.

${ }^{45}$ Carta de Goicoechea a Otaño, 14 de noviembre de 1908. AMSL. FO. Correspondencia, 009/002.005.

46 “Del mismo principio se deduce que los cantores desempeñan en la Iglesia un oficio litúrgico; por lo cual las mujeres, que son incapaces de desempeñar tal oficio, no pueden ser admitidas a formar parte del coro o la capilla musical. Y si se quieren tener voces agudas de tiples y contraltos, deberán ser de niños, según uso antiquísimo de la Iglesia.” MP. Título V. Cantores, art. 13. 
presentación en Sevilla, y te confieso que así superaba en bastante el conjunto vocal que ofrecía al que tenía cuando en Valladolid estuvo, y al que actuó después en la Catedral. No ha faltado aquí quien creyera que en la Catedral cantaron también las señoras; unos por no saber distinguir las voces de los niños de las de las mujeres, y por no tener afilado el teléfono de su oreja para apreciar la diferencia de fuerza que en uno y otro caso había, y otros por convertir todas las cosas en substancia, porque también aquí ha habido quien, más aficionado al golpear de los bajos a mugido limpio que a la música, (creyendo que es más solemne y más religioso este vocear que cantar con arte, no teniendo otra cosa a qué agarrarse para hacer aspavientos y escandalizarse de Victoria, Guerrero, Palestrina y demás profanos, se ha empeñado en que había cantatrices en el coro. Pues bien; yo, que soy testigo presencial y lo he visto, te digo que no es verdad. ${ }^{47}$

El tercer grupo en participar en el Congreso, además del coro de seminaristas y de la Capilla Isidoriana, fue la Schola cantorum de los PP. Salesianos de Écija. Este conjunto reunía las características idóneas para ser exhibido como un modelo ejemplar(izante) de schola según la propuesta del $M P$ y el propio Congreso. Así la describía Villalba:

Como en Valladolid dieron las audiciones el Orfeón VascoNavarro y la Isidoriana, aquí han actuado la Schola, que así la llaman, de los Salesianos de Écija y la dicha Isidoriana, con la diferencia de que la Schola ha actuado mucho más que el Orfeón en Valladolid y tanto que ni un día ha estado demás: melodías gregorianas, polifonías intrincadas, cantos populares, todo esto ha estado a su cargo durante la celebración del Congreso. De seguro que querrás saber qué es esta Schola, cuántos y quiénes la forman y etc., etc. [...] te diré que es una masa coral, una capilla de música compuesta casi toda ella, si no de niños, por lo menos no de hombres, quiero decir que casi todos los que la forman se encuentran en esa edad media entre la niñez y la virilidad; consecuencia de esto es que carece de voces hechas en las cuerdas de tenor y bajo, de donde resulta un poco incolora y con un radio de acción muy corto en cuestión de matices, y es natural: a los fuertes, vibrantes y llenos no puede llegar por falta de poder, y a los planísimos esa misma falta de fuerza y de número además la pone un dique terrible, teniéndose que mover forzosamente alrededor de una fuerza media de unos pocos recursos expresivos. Suma a esto que los individuos que la componen no son profesores $[\ldots]^{48}$

\footnotetext{
${ }^{47}$ Villalba, "El Segundo Congreso Nacional”, pp. 687-688.

${ }^{48}$ Villalba, "El Segundo Congreso Nacional", pp. 685-686.
} 
En el número de $M S H$ correspondiente a agosto de 1907 hallamos las primeras referencias a este coro. Se trata de una reseña en la que se anunciaba la participación de la Schola de Écija en las fiestas celebradas en Málaga con motivo de la coronación de Santa María Auxiliadora, patrona de los salesianos. El autor, que firmó bajo el pseudónimo de “D. Natch", la describió como una escolanía fundada hace apenas dos años en el Colegio Salesiano de Écija, compuesta de treinta cantores y dirigida por Juan Domíngue $^{49}$. En aquella ocasión el coro astigitano interpretó, además de canto gregoriano, varias obras polifónicas, incluida una misa a cuatro voces de Renzi. D. Natch destacó, por un lado, que los libros de canto que usaban eran los preparados por Solesmes con signos rítmicos, "que tanto ayudan a la buena interpretación, facilitando el trabajo del maestro, sobre todo cuando se trata de enseñar a niños, a los cuales no se puede exigir demasiada atención y reflexión"; y por otro, la importancia de la labor de su director, el "infatigable P. Domínguez que ha sabido de elementos tan escasos, sacar un partido tan hermoso y consolador."

Goicoechea, por su parte, destacó también las virtudes de este grupo en una carta a Otaño: "La pequeña Schola de Écija se compone en su mayor parte de niños que se preparan para el noviciado, y sin ser cantores de profesión lo hacen discretísimamente, formando un conjunto de voces simpático. Ejecutan el Canto Gregoriano y bastante de lo polifónico" $"$.

La Schola de Écija fue presentada en el Congreso como la prueba fehaciente de que era posible y viable la formación de coros no profesionales que interpretaran dignamente música litúrgica sirviéndose de los recursos humanos y materiales de los que disponía; en este caso, una institución eclesiástica, como era una comunidad salesiana, ubicada en un entorno rural. Se demostraba que la realización de la reforma en este punto estaba al alcance de cualquiera que se implicara, como su director, el prefecto de los salesianos astigitanos Juan Domínguez, y usara los medios adecuados, las ediciones gregorianas de Solesmes de las que se servía. Así se acreditaba, además, la utilidad práctica, tantas veces defendida por sus partidarios, del sistema de grafías rítmicas solesmense. En este sentido, cabe señalar que en las interpretaciones de obras

\footnotetext{
${ }^{49}$ [Series de noticias sin título], MSH, 3 (1907), p. 72.

${ }^{50}$ Ibídem.

${ }^{51}$ Carta de Goicoechea a Otaño, 14 de noviembre de 1908. AMSL. FO. Correspondencia, 009/002.005.
} 
gregorianas, incluidas las presentadas en la conferencia de Suñol, el coro salesiano fue dirigido por Mauro Sablayrolles.

Lo imperfecto y amateur propio de este tipo de coros, lejos de ser presentados como defectos, constituyeron interesantes virtudes del modelo que se presentaba dentro de esta pretensión de mostrar lo asequible y posible de la propuesta. Así razonaba Villalba en el siguiente párrafo, que transcribimos, a pesar de su extensión, por lo ilustrativo de las imágenes que utiliza:

Pues bien, esta capilla ha sido una de las notas más simpáticas del Congreso, más, una enseñanza práctica que vale en cuestión de música más que todas las simpatías. Porque has de saber que esta Schola ha hecho los milagros de interpretar con la perfección que te he dicho las melodías gregorianas de que te hablé en la otra carta, y sobre eso ha cantado obras polifónicas modernas de verdadera dificultad y las ha cantado bien. Y yo razono así: los maestros de capilla, organistas y cualesquier otros que tengan que habérselas con un coro, al oír a una colección numerosa de profesores hacer divinidades en la interpretación de las obras que sean, antiguas o modernas, dirá para sí ¡magnifico, precioso! Pero ¿quién me da a mí un conjunto como este? Si yo tuviera un corito de esta naturaleza, ¡vaya que también haría todas esas filigranas! Indudablemente esto es hermoso, y mientras se está repitiendo interior o exteriormente ¡hermoso, hermoso!, la vista interior se le va a su catedral y se figura allí en medio de su capilla, el tiple que chilla, el bajo que le responde con un berrido, el contralto que parece que canta desde algún agujero de las bóvedas, el tenor que se arranca por los aires, [...] el pobre maestro tiene que descorazonarse y si al oír lo que oye, el concierto perfectísimo de una masa coral numerosa, bien organizada y educada, dice ¡hermoso, hermoso!... en su interior le añade de seguro esta otra coletilla que sólo es posible en los Congresos. Y vengo ahora a mi cuento: la capilla de Écija no es una capilla de profesores, es una cosa bastante más modesta, la forman jóvenes como los cuales los seminarios, los conventos, pueden suministrar un buen número, al oírla no produce la estupefacción, ni el asombro, y por tanto, abre el camino a cosas que están al alcance de todas las fortunas musicales que quieran tomar sobre sí el trabajo de enseñar a jóvenes y a niños, de los cuales puede encontrar un buen número en cualquier centro de estudios eclesiásticos. Sobre todo, no trae a la inteligencia ni a la voluntad la palabra imposible, y esto ya es un gran bien; esta es una lección práctica de que son más los imposibles que fantaseamos que los verdaderos. ${ }^{52}$

La "gran enseñanza", en palabras de Villalba, del Congreso con la presencia de este coro fue demostrar que era posible la reforma en lo que a la interpretación de la

${ }^{52}$ Villalba, "El Segundo Congreso Nacional”, pp. 686-687. 
música religiosa se refiere, al ser realizable la propuesta del $M P$ de fundamentarla sobre la base de la creación de estas infraestructuras musicales, las scholae cantorum amateur.

\subsection{La función de la prensa en un escenario ideal}

Más arriba hemos dado cuenta de la importancia que tenía para los líderes del movimiento en maduración hacerse con el control de las revistas de música sagrada nacidas al calor de los impulsos reformistas. Estas publicaciones, no obstante, tenían por su propio carácter especializado -por tanto minoritario- un impacto limitado. En consecuencia, su capacidad de influencia se reducía, sobre todo, al interior del movimiento. En el congreso de Sevilla, Ripollés presentó una memoria basada en sendos discursos pronunciados por Antonio Berrone, canónigo de Turín, y el periodista Stefanio Scala en el VII Congreso Italiano de Música Sagrada. En ella manifestaba la necesidad de poner al servicio de la reforma la prensa eclesiástica y la generalista católica como un objetivo estratégico particularmente importante para los reformistas. Ripollés recogió el programa de cooperación de los medios de comunicación con la reforma expuesto por Scala: “disipar los prejuicios, resistir a las falsas corrientes, corregir los gustos extraviados, y fortalecer y alentar las buenas tendencias y proyectos" 53 . Consciente del "gran poder de la prensa y el auxilio que podría prestar a la causa de la música sagrada", propuso las siguientes conclusiones. En primer lugar, solicitó al Congreso rogara

a los periodistas católicos se ocupen con frecuencia de difundir el espíritu de sumisión y obediencia al Motu Proprio pontificio de 22 de Noviembre y en fomentar el buen gusto e interés del clero y pueblo fiel hacia la buena música litúrgica.

En segundo lugar, planteó que "en las redacciones de periódicos católicos exista una persona perita en música sacra que revise y censure las comunicaciones y reseñas de la parte musical de las funciones sagradas. $" 54$

En la Crónica del Segundo Congreso se incluyeron, como muestra del eco que el Congreso había tenido en la prensa tanto española como internacional, una serie de

\footnotetext{
${ }^{53}$ Crónica del Segundo Congreso, p. 247.

${ }^{54}$ Ibídem, p. 249. El Congreso aprobó la propuesta de Ripollés con la única diferencia de que en la primera conclusión el ruego se dirigió a los "Directores de periódicos católicos" en lugar de a los periodistas. Ibídem, p. 275.
} 
extractos de periódicos y revistas especializadas, eclesiásticas o generalistas católicos: $A$ voz de San Antonio, Braga; Biblioteca Sacro-Musical, Valencia; El Lirio de San Antonio, Lérida; El Mensajero Seráfico, Madrid; Fulla Seráfica, Olot; Gaceta del Sur, Granada; La ciudad de Dios, El Escorial; La Regeneración, Gerona; Música Sacra, Milán; Música Sacro-Hispana, Valladolid; Musical Emporium, Barcelona; Santa Cecilia, Turín ${ }^{55}$. La introducción previa a la presentación de estos ejemplos aludía igualmente a la trascendencia de la prensa católica para la reforma, y lo que nos parece más significativo, otorgaba al Congreso, y por tanto, a la reforma, la condición de "obra de carácter general". Así fue elevada a categoría de interés general de la Iglesia, y ubicada en el plan de acción de los católicos en la sociedad. Con ello, la presencia de la cuestión de la música sagrada en los medios de comunicación generalistas de filiación católica quedó justificada:

Y si hoy día, en que la atención es atraída por tan diversos objetos, casi en ninguna obra es posible prescindir del auxilio poderoso y decisivo de la prensa, mucho menos, cuando se trata de obras de carácter general, como la presente. Entendiéndolo así la Junta, solicitó desde un principio la cooperación de la prensa católica, tan propicia siempre a todo lo que pueda redundar en provecho de la Religión y de la Patria, principalmente de los boletines Eclesiásticos y Revistas profesionales, que por fortuna en tan buen número se publican ya en España. ${ }^{56}$

En el congreso de Sevilla, la prensa también ocupó su lugar y ejerció la función que los reformistas le atribuían dentro de ese mundo ideal levantado para servir de "modelo y ejemplo". El diario católico de Sevilla, ECA, cuyo presidente -recordemosformó parte de la Junta Organizadora, estuvo al servicio del Congreso durante los cuatro días que duró. La portada del rotativo estuvo dedicada casi en su totalidad al acontecimiento, así como gran parte de la segunda página ${ }^{57}$. El seguimiento que realizó el periódico fundado por Spínola incluyó el anuncio de todos los actos que tendrían lugar y sus respectivos programas, así como una crónica detallada de cada jornada. El

\footnotetext{
${ }^{55}$ Ibídem, pp. 36-38.

${ }^{56}$ Ibídem, pp. 31-32.

57 ECA, 3344-3347 de los días 12 al 15 de noviembre (1908). ECA dedicó también en las semanas previas a la inauguración amplio espacio en sus ejemplares al evento. Conviene advertir para valorar en su justa medida la dedicación del periódico católico al congreso de música, que esos momentos cada ejemplar constaba sólo de cuatro páginas.
} 
discurso de apertura pronunciado por González Merchant, la ponencia de Gregorio $\mathrm{M}^{\mathrm{a}}$ Suñol sobre interpretación del gregoriano y la de Dámaso Ledesma sobre el canto popular religioso contaron con un extenso resumen en la primera página. La lista de congresistas inscritos se vino publicando diariamente durante los meses de octubre y noviembre. Asimismo, en sus páginas se dieron a conocer las conclusiones del Congreso, y se publicó una reseña en cada número sobre el desarrollo de las sesiones de estudio, a través de la que se pudo seguir diariamente lo que acontecía en el interior del salón Santo Tomás del Palacio Arzobispal donde se celebraban. Estas mismas reseñas fueron publicadas en $\mathrm{MSH}$ a modo de crónicas de dichas sesiones ${ }^{58}$.

Esta extensa cobertura demuestra que el principal medio de comunicación católico local cumplió ejemplarmente con lo que los reformistas demandaban de la prensa católica. La presencia frecuente y predominante del Congreso en el periódico casi monopolizadora de sus espacios durante los días en los que se celebró- situó el asunto de la música sacra en primer plano, recibiendo un trato equiparable a otros grandes asuntos públicos de la Iglesia en ese momento, como los ideológicos, sociales y políticos.

El idéntico trato que recibieron tanto el Congreso de Música Sagrada como la III Semana Social de España, inaugurada a las pocas horas de la clausura del primero, es una prueba concreta de ello. Es más, el número del domingo día 15 de noviembre, día en el que coincidió la finalización de este y el comienzo de aquella, la convención musical siguió copando la primera página de ECA. La presencia de la Semana Social se limitó a un breve anuncio situado al pie de la quinta columna, rodeado de las informaciones sobre el Congreso ${ }^{59}$. Viene al caso traer a colación aquellas ideas expuestas por Ripollés en el congreso de Valladolid referentes a la equivocación que suponía la consideración de la música como una cuestión de secundaria importancia, y que volvió a rescatar en su memoria sobre el papel de la prensa ${ }^{60}$ :

58 “Sesiones privadas", MSH, 18-19 [publicados en un único volúmen] (1908), pp. 170-177. Tanto la Crónica del Segundo Congreso como MSH se nutrieron ampliamente de lo publicado en ECA durante los días del Congreso.

${ }^{59}$ El anuncio decía: “A las tres de la tarde del día de hoy, en la Iglesia del Salvador, se celebrará la solemne sesión inaugural de la Semana Social, pronunciando discursos el Excmo. señor Arzobispo de Sevilla y el Excmo. señor Obispo de Vich". "Inauguración de la Semana Social", ECA, 3347 de 16 de noviembre (1908), p. 1.

${ }^{60}$ Este es el fragmento que ya transcribimos en la p. 78: "Ya sé yo que el Clero tiene múltiples asuntos a qué atender, pero esto no ha de apartarle de aplicar su encendido celo a favor de la música sagrada: grandes atenciones embargaban la mente de San Gregorio Magno en la gobernación de todo el mundo 
Disipar los prejuicios, y en primer lugar el lamentabilísimo error de aquellos que juzgan a la música sagrada como cosa indigna de recibir los cuidados y atenciones del Pontífice: como si no hubieran existido un David y un Salomón, un Agustín, un Crisóstomo y un Basilio, un Gregorio el Grande y un Juan XXII, un Benito y un Bernardo, un Felipe de Neri, un Carlos Borromeo y un Alfonso M. de Ligorio, que no creyeron indignos de su genio, de su dignidad y ministerio el ocuparse en la reglamentación y vulgarización de la música sagrada. Como si el propio respetabilísimo Concilio de Trento no hubiera creído digno de sí el publicar cánones que reglamentaran el ejercicio de la música en el templo y la enseñanza obligatoria del canto en los Seminarios. Como si Dios mismo, por conducto de sus intérpretes sagrados, no hubiera dictado las reglas más minuciosas para prescribir los cantos y músicas sagradas con que su pueblo hebreo debía adorarle y darle culto. ${ }^{61}$

Por tanto, la especial implicación de la Iglesia en la cuestión de la música sacra durante los días del Congreso, manifestada públicamente a través de la prensa confesional, significó para reformistas como Ripollés la corrección de un error histórico. La música (re)conquistó el lugar preponderante que le correspondía, de acuerdo a la doctrina de los grandes referentes de la historia de la Iglesia citados por el maestro de capilla. En el discurso que desarrolló para difundir el acontecimiento, la Junta Organizadora aludió al "poder” de "difusión del espíritu católico" que poseía la música, situándola como un elemento útil más en la empresa social católica:

Con esto consolaremos el corazón paternal del bondadoso Pontífice Pío X, el Papa restaurador de la liturgia musical, cumpliremos con nuestro deber de artistas cristianos, y cooperaremos, siquiera sea indirectamente, a la difusión del espíritu católico en la sociedad española, que ahí alcanza también el apostolado y poder de la música sagrada. ${ }^{62}$

Recordemos, en este sentido, la defensa que Federico Roldán, secretario del Congreso, hizo de la música como eficiente medio para la reanimación del espíritu

cristiano, pero aún le quedaban energías para la fundación y régimen personal de la escuela de cantores romanos: en medio de sus continuas luchas con la heregía [sic] se ocupaban en reglamentar el canto eclesiástico hombres tan eminentes como San Ambrosio, San Agustín, San Isidoro, San Basilio, San Juan Crisóstomo y San Bernardo." Crónica del Primer Congreso, p. 61

${ }^{61}$ Crónica del Segundo Congreso, p. 248.

${ }^{62}$ Junta organizadora, “A los amantes de la música sagrada”, Crónica Segundo Congreso, p. 41. 
católico ante los desafíos a los que tenía que hacer frente la Iglesia en la sociedad contemporánea $^{63}$.

Otro de los diarios importantes de la ciudad, El Noticiero Sevillano $(\text { ENS })^{64}$, realizó un completo seguimiento del Congreso ${ }^{65}$. Publicó igualmente las conclusiones y crónicas de las sesiones privadas de estudio, así como una serie de artículos firmados por el sacerdote del pueblo onubense de Niebla, Cristóbal Jurado, con títulos como Las Artes, la Música y Cristo Rey ${ }^{66}$, Renacimiento de la música religiosa ${ }^{67}$, La Iglesia, la música y los íberos ${ }^{68}$, o San Isidoro y la música ${ }^{69}$. Las crónicas publicadas sobre los distintos actos del programa revisten un particular interés por el detalle con que describen el aspecto de las distintas sedes, el público asistente -incluidas las grandes personalidades-, o el ambiente que reinaba en ellos. Este fue el cuadro dibujado por el corresponsal de ENS que cubrió la primera sesión solemne, celebrada en la antigua iglesia colegial de El Salvador:

Comenzó esta mañana, a las once y cuarto, la sesión inaugural del Congreso en la Iglesia del Divino Salvador.

El altar mayor aparecía cubierto por altas cortinas moradas y amplio dosel de terciopelo rojo con adornos dorados, bajo el cual se destacaba antigua pintura al óleo representando la Purísima Concepción. A los lados del dosel veíanse dos artísticos óvalos que presentan las venerandas figuras del Corazón de María y del Corazón de Jesús.

Sobre el estrado, junto al altar Mayor y al pie del dosel, estaba la mesa de la presidencia.

63 Véase capítulo 5, epígrafe 3.2.2. "La contribución al Congreso de arciprestes, curas y fieles diocesanos", pp. 403-404.

${ }^{64}$ ENS se publicó diariamente en dos ediciones, una de mañana y otra de tarde, entre el 25 de marzo de 1893 y el 12 de febrero de 1933. Fue fundado por Francisco Peris Mencheta como "Diario Independiente de Noticias, Avisos y Denuncias". Representó un ejemplo de nuevo modelo de periodismo empresarial, alejado de los tradicionales periódicos políticos, órganos de partidos. En esta línea, Peris Mencheta creó un par de rotativos más (La Correspondencia de Valencia y El Noticiero Universal de Barcelona), así como una agencia de noticias. María José Ruíz Acosta, "La prensa sevillana de principios del siglo XX: el nacimiento de un nuevo modelo informativo (1898-1914)", en Sevilla y su prensa. Introducción a la historia del periodismo andaluz contemporáneo (1898-1998), ed. por Ramón Reig y María José Ruíz Acosta (Sevilla: Universidad de Sevilla, 1998), pp. 13-36, pp. 28-29.

${ }^{65}$ ENS, 6459-6462 de los días 12 al 15 de noviembre (1908).

${ }^{66}$ ENS, 6459 de 12 de noviembre (1908), p. 2.

${ }^{67}$ Ibídem, 6460 de 13 de noviembre (1908), p. 2.

${ }^{68}$ Ibídem, 6461 de 14 de noviembre (1908), p. 2.

${ }^{69}$ Ibídem, 6462 de 15 de noviembre (1908), p. 4. 
En la nave central las sillas destinadas a los socios y en las laterales las señaladas para el público y los invitados.

Antes de comenzar la sesión varios fotógrafos tomaron posiciones con sus máquinas.

Entre los socios y el público había no escaso número de señoras.

La concurrencia en todas las naves era numerosísima. Notábase en ella la presencia de muchos frailes.

En amplia tribuna levantada en la nave lateral derecha situóse la Schola Cantorum salesiana, de Écija, que tan brillante participación ha tenido en el solemne acto.

En las anchurosas naves penetraba la luz policromada por los multicolores cristales de los tragaluces del templo, cuyo aspecto severísimo realzaba la presencia del ilustre purpurado señor Netto, de los arzobispos y demás prelados que ocupaban la presidencia. Estos eran nuestro amado Pastor el arzobispo, señor Almaraz; el arzobispo de Granada y los obispos de Badajoz, Coria, Salamanca y Ciudad Rodrigo.

En el estrado sentáronse el alcalde, señor Carmona Ramos, el comandante de Marina señor Fernández de Córdoba, el director del Instituto, señor Reinoso, y el secretario de la Universidad, señor Palomo, en representación del rector. de $_{\text {pie. }}{ }^{70}$

Al aparecer los prelados todos los concurrentes se pusieron

Estas descripciones presentaban, además, el aspecto exterior, ornamental y ambiental del mundo ideal que fue el Congreso. De esta forma, la prensa transmitió la solemnidad también material y externa propia de ese universo que se pretendió recrear.

No obstante, por encima del papel divulgador y de revalorización de la cuestión musical ejercido por la prensa católica, el servicio más importante que esta prestó al movimiento fue poner a disposición de algunos de sus principales líderes un valioso espacio para la crítica musical que estos aprovecharon para hacer pedagogía. Tanto Ripollés como Villalba contaron con sendas tribunas en ECA, en las que tuvieron la oportunidad de difundir criterios de recepción de la música que el Congreso ofreció.

En la línea de la nueva crítica musical que asomaba a comienzos del s. XX, ambos ejercieron la función social de intelectuales músicos. Tal y como apuntan Teresa Cascudo y María Palacios refiriéndose al caso madrileño, los nuevos críticos musicales desarrollaron una importante labor pedagógica con el objetivo de determinar en sus comentarios eruditos sobre el repertorio, los criterios de juicio y valoración sobre

70 "El Congreso de Música Sagrada. La sesión inaugural. Aspecto del templo", ENS, 6459 de 12 de noviembre (1908), p. 2. ECA publicó también descripciones parecidas aunque quizás sin este lujo de detalles. La Crónica del Segundo Congreso reprodujo en sus páginas las que en su día difundió ECA. 
música. De esta forma, trataron de influir decisivamente en el desarrollo de la vida musical española ${ }^{71}$. En el contexto del Congreso, Villalba y Ripollés asumieron este rol en el ámbito específico del movimiento reformista religioso-musical.

Los comentarios diarios sobre las obras a interpretar y sus autores -tanto en las sesiones solemnes como en las funciones religiosas- que Ripollés escribió eran verdaderas lecciones de historia y estética de la música religiosa ${ }^{72}$. Villalba, por su parte, tuvo a su cargo las críticas musicales que se publicaron al día siguiente, y que firmó bajo el pseudónimo de Mauricio $^{73}$.

Ripollés y Villalba ejercieron, por tanto, de portavoces del movimiento, y sus discursos estéticos y críticos se presentaron al gran público, sirviéndose del potente instrumento mediático, con el sello de la oficialidad del Congreso. Las mismas páginas que en 1903 habían servido a Muñoz y Pabón para desarrollar su discurso exegético, legitimador desde un punto de vista artístico, y sublimador del Miserere de Eslava ${ }^{74}$, fueron utilizadas por Ripollés y Villalba para proporcionar las nuevas coordenadas de apreciación musical propias de la nueva estética que trataron de introducir e inculcar. El ejercicio de la potestad sancionadora de las obras e intérpretes que, como críticos oficiales- poseían, representó la última fase del proceso de institucionalización -o descarte en algunos casos-, de piezas, compositores, estilos e intérpretes puesto en marcha por el Congreso.

Los artículos de uno y otro nos servirán como fuentes para el análisis del modelo tanto de música polifónica como de intérpretes presentado Congreso, en consecuencia, serán material de estudio en los próximos epígrafes. No obstante, no quisiéramos dejar de ofrecer, antes de continuar, algún ejemplo de los comentarios publicados por Ripollés respecto a las piezas gregorianas, en los que se muestran el carácter pedagógico que impregnó sus escritos, así como la función exegética que estaban llamados a cumplir:

\footnotetext{
${ }^{71}$ Véase Cascudo y Palacios, Los señores de la crítica, pp. XI-XII.

72 "El Congreso de Música Sagrada. Día 1. 'Ejecuciones de música vocal”, ECA, 3344 de 12 de noviembre (1908), p. 1; "Segundo día del Congreso. Ejecuciones de música vocal”, ECA, 3345 de 13 de noviembre (1908), p. 2; "El Congreso de Música Sagrada. Día cuarto", ECA, 3347 de 15 de noviembre (1908), p. 1.

73 “Impresiones del Congreso", primera página de n 3345-3348 de los días 13 al 16 de noviembre (1908).

${ }^{74}$ Véase capítulo 4, epígrafe 3.3.2. "La sacralización de la cultura: reasignación de significados religiosos al lenguaje musical "profano"'.
} 
Como domina en ella [hora de Tercia] el género salmódico su canto es sencillo y casi recitado, pero no desprovisto de gracia y mérito artístico; el tono es el primero y su terminación en fa. Se distingue el himno, melodía de $7 .^{\circ}$ tono, majestuosa y solemne.

El propio del día es el de la misa Iustus ut palma. El Introito, pieza que se cantaba al entrar el Pontífice en el templo, es solemne; y este en especial por la riqueza de su melodía de primer tono, traduce admirablemente la multiplicidad de las bendiciones del cielo sobre el justo.

En el Gradual, cuya letra nos demuestra los méritos del justo, causa de las bendiciones celestiales, admiramos la pieza más rica y adornada de toda la misa; una melodía de primer tono, de giros melódicos variadísimos que hace ondular el canto con formas interesantes y que cautiva a cuantos sienten y aprecian el gusto por lo bello.

La Iglesia, rebosando gozo por la felicidad del justo, expansiona los sentimientos de su alegría con el canto del Alleluia, melodía de quinto tono que, aparte la riqueza de sus neumas, termina con el característico jubilus sobre la última sílaba del verso y del Alleluya $[$ sic $] .^{75}$

\section{El congreso de Sevilla, una manifestación del nacionalismo musical}

\section{español en el ámbito religioso}

\subsection{La institucionalización de un nuevo canon musical religioso: entre el}

\section{Motu Proprio y los postulados del nacionalismo musical español}

Junto al canto gregoriano restaurado, los otros dos géneros musicales sacros aceptados en el rescripto papal fueron la polifonía clásica y la música religiosa moderna; la primera, por poseer "en grado sumo", al igual que el gregoriano, las cualidades propias de la liturgia: santidad, bondad de formas y universalidad. El MP propuso como modelo de música polifónica la "Escuela Romana" de la segunda mitad del s. XVI, y a Palestrina, el único compositor citado expresamente en el documento, como su paradigma ${ }^{76}$.

La admisión de la música moderna estaba justificada, pues la Iglesia había "reconocido y fomentado en todo tiempo el progreso de las artes". No obstante, dada su naturaleza "principalmente profana", se establecía la condición de que estuviera exenta

\footnotetext{
${ }^{75}$ Vicente Ripollés, "El Congreso de Música Sagrada. Día 1. ${ }^{\circ}$ Ejecuciones de música vocal”, 3344 de 12 de noviembre (1908), p. 1.

76 "Las supradichas cualidades se hallan también en sumo grado en la polifonía clásica, especialmente en la de la escuela romana, que en el siglo XVI llegó a la meta de la perfección con las obras de Pedro Luis de Palestrina [...]" MP, Título II. Géneros de música sagrada, art. 4.
} 
de cualquier influencia secular o teatral ${ }^{77}$. A diferencia de la polifonía clásica, el MP no presentaba ningún modelo de referencia. Por tanto, el único criterio que proveía para juzgar la ortodoxia de una composición moderna, además de la exclusión de lo profano y teatral, era el expuesto como "ley general" en el artículo tercero, común a toda la música litúrgica: "una composición religiosa será más sagrada y litúrgica cuanto más se acerque en aire, inspiración y sabor a la melodía gregoriana, y será tanto menos digna del templo cuanto diste más de este modelo soberano. [cursivas originales]",78.

Durante el Congreso, los valores estéticos y litúrgicos del $M P$, presentados en el documento pontificio como principios generales, debían traducirse en un estilo y un repertorio concreto. Sus responsables poseían la facultad de seleccionar las obras a figurar en el programa -"se ejecutarán obras escogidas"79-, por tanto, de institucionalización de la nueva música religiosa según sus criterios. Desde el momento en el que estos fueron presentados como los oficiales del Congreso, se identificaron con los del documento papal. La música considerada como expresión verdadera del MP empezó a tener, gracias a los congresos como institución, y una vez sancionada por sus responsables erigidos como jueces musicales, títulos concretos, nombres y apellidos.

Junto a los congresos, el otro instrumento con capacidad de establecer el canon musical según el $M P$ fueron las revistas. Tanto $M S H$ como $B S M$, dirigida por Villalba, publicaron suplementos musicales con los que cubrir las necesidades de renovación y sustitución del repertorio que la reforma había creado ${ }^{80}$. Sin embargo, $B S M$ no vio la luz hasta enero de 1911, y MSH comenzó su labor de edición de partituras en junio de $1909^{81}$. La única revista que en 1908 publicaba música además de artículos, críticas,

${ }^{77}$ Ibídem, art. 5.

${ }^{78}$ Ibídem, art. 3.

${ }^{79}$ Ibídem.

${ }^{80}$ Antes de pasar a propiedad de Alier, momento en el que Villalba se hizo cargo de su dirección, BSM pertenecía a la Casa Tena de Valencia. Según se desprende de las referencias que algunos reformistas hicieron a la $B S M$ de Tena, las obras que editaba no consiguieron incorporarse al canon según el criterio de aquellos: "Tena de Valencia, añade que él sostiene un periódico desde hace 13 años que defiende la causa del género verdaderamente religioso ( $i$ ! U. que conoce el paño puede hacer aquí los comentarios que guste) y pide también ayuda.". Carta de Goicoechea a Otaño, 25 de noviembre de 1908. AMSL. FO. Correspondencia, 009/002.006. "No tenemos poco trabajo en censurar obras. Pero, Señor, hay algunos hombres desalmados...Una casa de Valencia, sucesores de Antich y Tena, manda a todos los Párrocos un prospecto con el vicimus milites, sonó la hora, etc. etc. ofrecemos una música conforme al "Motu Proprio". Y ¿qué? Unas peteneras!" Carta de Otaño a Pedrell, 16 de diciembre de 1905. AMSL. FO. Correspondencia, T01/003.

${ }^{81}$ Véase capítulo 5, epígrafe 4.2.1. "Música Sacro-Hispana durante el congreso de Sevilla”, pp. 447-449. 
etc. era Voz de la Música, dirigida por Federico Olmeda. Por tanto, se puede afirmar que, tras la aparición del $M P$, los programas musicales de los dos primeros congresos fijaron por primera vez en España unas obras y unos autores como modelos de música sacra. Además, contaban con la ventaja añadida de poseer carácter oficial, condición de la que ninguna de las revistas disfrutaba ${ }^{82}$.

De acuerdo al papel que debían cumplir dentro de la estrategia ejemplarizante desplegada por el Congreso, los comentarios diarios publicados en ECA por Ripollés trataron de mostrar la ortodoxia según los preceptos del MP de los autores y obras programadas. La sumisión de Villalba a aquella estrategia hizo que sus críticas tuvieran siempre un carácter favorable. Las únicas excepciones en este sentido fueron sus valoraciones sobre la conferencia dedicada al canto popular religioso de Ledesma, y unas líneas en las que deslizó disimuladamente un juicio demoledor sobre el Tantum

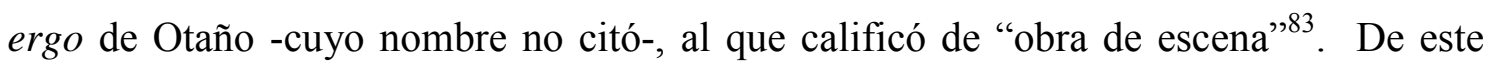
modo, y como ya hemos apuntado, el ejercicio de la crítica se materializó en una labor pedagógica ${ }^{84}$. De hecho, Villalba no recuperó el oficio crítico que venía desempeñando en las páginas de $L C D$, y al que había renunciado en aras de alcanzar los fines del Congreso, hasta que no hubo finalizado este. Resulta significativo que en sus Impresiones aparecidas en ECA durante los días de su celebración se abstuviera de hacer comentario alguno sobre el concierto de los organistas sevillanos, que ignoró completamente; o de hacer valoraciones sobre los autores y obras que conformaron el programa del concierto de música religiosa, aduciendo "No quiero juzgar a nadie, a los antiguos porque ya están juzgados; [...] y a los modernos porque todavía no pertenecen a la historia" $"$. Sin embargo, en sus artículos escritos en $L C D$ una vez clausurado el

\footnotetext{
${ }^{82}$ Para cuando MSH comenzó a publicar obras musicales ya había perdido su carácter de órgano oficial de los congresos musicales de música sagrada con el que había nacido. Véanse las páginas a las que remitimos en la nota anterior.

83،[...] el Tantum ergo, sin ser ni más ni menos expresivo, es una obra de escena, de diálogo, de efecto entre el tenor solo y el coro repitiendo la misma letra". Crónica del Segundo Congreso, p. 89. Esta breve $\mathrm{y}$, aunque hecha con tacto, dura crítica fue ampliada y adquirió un tono más crudo e incluso irónico en LCD. Véase p. 549.

${ }^{84}$ Los escritos de uno y otro serán sometidos a examen en las siguientes páginas.

${ }^{85}$ Villalba se limitó a enumerar las obras a interpretar en el concierto y sus autores, y a apuntar los compositores clásicos que "mayor efecto produjeron": "No quiero juzgar a nadie[,] a los antiguos porque ya están juzgados; los que mayor efecto produjeron fueron el $O$ vos omnes y Vere languores, de Victoria; la Villanesca, de Guerrero; el Lamentabatur Jacob de Morales y el Stabat mater de Palestrina; y a los modernos porque todavía no pertenecen a la historia[;] lo presentado de ellos fue $O$ quam suavis de L. Romero, Sanctus y Agnus de Olmeda, Plegaria a Jesús de Millet, Ave Maria de Goicoechea, Christus
} 
Congreso, su actitud frente a ambos conciertos fue bastante diferente. Por un lado, despachó el de los organistas locales con un severo juicio, en el que puso de relieve, precisamente, el error que representó exhibir como modélico un concierto que no respondía a las condiciones musicales religiosas exigibles para cumplir tal función:

El primer concierto fue una lamentable equivocación, una verdadera desafinación. En los músicos las equivocaciones que dan por resultado notas desafinadas, no proceden sino de estar distraídos, de no pensar bien lo que hacen, y esto es, indudablemente, lo que ha sucedido aquí. Por si acaso, no vayas a creer que se trata de cuestión de tañido, de ejecución quiero decir: por este lado nada hay que advertir, es que la materia circa quam, el programa, lo que se tocaba, no podía figurar en un concierto de esta clase, porque ni como música religiosa, ni como música a secas, la mayor parte de las piezas cumplían para el caso, y un caso que había de tener por espectadores a organistas y maestros, prevenidos para escuchar algo digno de un concierto modelo. Total: que el ejemplo no fue nada ejemplar. Y no te digo más. ${ }^{86}$

Por otro lado, dedicó un largo comentario al de música religiosa a modo de ensayo histórico, en el que expuso una interpretación sobre el valor artístico y expresivo de la polifonía clásica bastante distanciada del discurso oficial, así como una visión ciertamente particular sobre los distintos estadios de la evolución general de la música. Partiendo de la premisa de la difícil convivencia en la pieza musical de forma y expresión, calificó las composiciones de los polifonistas clásicos como "obras de artificio acabado pero indiferentes, frías, la letra por un sitio, la música por otro"; una opinión absolutamente opuesta a la que trató de divulgar Ripollés durante el Congreso, como veremos. Precisamente, uno de los principales desafíos de los líderes reformistas fue tratar de hacer frente a la fuerte corriente de opinión que, considerando la polifonía renacentista como una música inexpresiva e hierática, se oponía a la propuesta estéticoestilística del $M P^{87}$.

factus est de Mas y Serracant". Mauricio, “Impresiones del Congreso. Segundo día”, ECA, 3346 de 14 de noviembre (1908), p. 1.

${ }^{86}$ Villalba, “El Segundo Congreso Nacional”, pp. 125-126.

${ }^{87}$ Los siguientes testimonios están extraídos de $M S H$, y pertenecen a un sacerdote pamplonés que firmaba como Sr. Miravalles en El pensamiento navarro. Fueron copiados por Nemesio Otaño con el objeto de

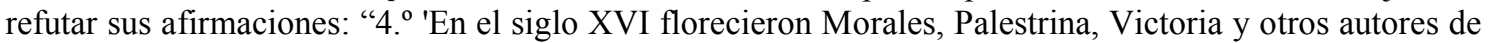
las obras que hoy entusiasman a los amantes de la música polifónica. No había nacido aún la melodía. Aunque se habían escrito algunos tratados dando importancia a la expresión de la letra, los compositores escribían sendos cánones procurado la imitación más exacta dentro de la más escrupulosa corrección, sin preocuparse para nada de expresar la letra. [... 5. ' 'Para una buena, seria, bella composición religiosa que 
Esta concepción de la historia de la música sacra defendida por Villalba tampoco coincidía con las tres etapas -apogeo/perfección de forma y expresión religiosa, decadencia/corrupción de la música religiosa, restauración/resurrección- que caracterizaban las lecturas, según este "esquema pedrelliano", que los reformistas hacían de la historia ${ }^{88}$. En realidad, los regeneracionistas musicales españoles no hicieron más que aplicar a la historia particular de la música el esquema tripartito y cíclico que predominaba en las (re)visiones de la historia general de España a finales del s. XIX. Este esquema era compartido tanto por liberales como por tradicionalistas católicos, con la única diferencia de ubicar en distintos momentos las etapas de esplendor y decadencia ${ }^{89}$. A diferencia de sus compañeros reformistas, para Villalba la música religiosa moderna era la culminación de un progreso siempre ascendente en el que la expresión se iba perfeccionando en detrimento de la pulcritud formal artificiosidad-. En las obras de los contemporáneos, forma y expresión alcanzaban por fin el equilibrio. La interpretación lineal y evolucionista de la historia de la música religiosa defendida por Villalba era realmente original -heterodoxa- en aquel contexto. El siguiente fragmento sintetiza con cierta precisión sus ideas, que desarrolló a lo largo de nueve páginas ${ }^{90}$ :

esté conforme al Motu Proprio, nos endilgan estos señores mangoneadores, tal serie de insípidas partituras sembrada de arideces, sin belleza ni mérito alguno, sin vida, sin expresión'." Cecilio [Nemesio otaño], "Eslava. En defensa de D. Gregorio", MSH, 10 (1910), p. 91. Es posible encontrar estos posicionamientos en contra de la polifonía renacentista antes de la promulgación del MP. María Nagore señala la defensa del carácter expresivo de obras clásicas como uno de los principales puntos de la campaña de divulgación de las ideas a favor de la nueva música religiosa emprendida por músicos españoles como Pedrell, Ripollés, Uriarte o Esperanza y Sola. Nagore, "Tradición y renovación”, p. 224. La autora aporta el siguiente pasaje como ejemplo de las críticas que cuestionaban la capacidad de emocionar de este repertorio: "para el oído de nuestra generación son letra muerta, puesto que sus combinaciones contrapuntísticas por sabias que sean, por artísticas que parezcan, no llegan al corazón de los oyentes." El Nervión, 27 agosto 1896; cit. en Nagore, “Tradición y renovación”, p. 231.

${ }^{88}$ La expresión es de Juan José Carreras. Juan José Carreras, "Hijos de Pedrell. La historiografía musical española y sus orígenes nacionalistas (1780-1980)", Il Saggiatore musicale, VIII, p. 167.

${ }^{89}$ Véase Álvarez Junco, Mater Dolorosa, pp. 442-443. Según el autor, las versiones de tradicionalistas católicos y liberales tenían en común el carácter "netamente español" de las etapas de apogeo -"Paraíso", según el término usado por Álvarez Junco-, y la causa que provocaba la decadencia, la influencia extranjera. Por el contrario, diferían, además de en la ubicación temporal de las épocas de esplendor, en los valores ético-políticos vinculados a ellas, por un lado, así como en el protagonista de este relato histórico, por otro. Mientras que para los católicos el sujeto histórico era el pueblo de Dios -la Iglesia-, y la etapa de esplendor se identificaba con los reinados de Carlos V y Felipe II; para los liberales, lo era la nación y la Edad Media de las libertades forales y el sometimiento del Rey a las Cortes aragonesas; símbolos, según su interpretación, de los derechos individuales y la soberanía nacional.

90 “El Segundo Congreso Nacional”, pp. 31-38, p. 123. 
Es el desarrollo del concepto del arte por sus naturales pasos: en los polifonistas el concierto sonoro es todo; resultado general: obras de artificio acabado, pero indiferentes, frías, la letra por un sitio, la música por otro; resultado excepcional, obras perfectísimas de arte, y la razón es muy sencilla: la exquisitez del artificio la tienen todos por regla general, añade la expresión, el sentimiento, que por excepción aparece, y el total que de esta excepción sale tiene que ser: forma excelente, fondo bueno, es decir, obras de un arte superior. En el siglo XVII, ya no lo es todo el artificio, hay algo de tendencia expresiva, que se busca por un lado en la grandilocuencia sonora de los coros a 8, a 12, hasta 16; por otro, en los primeros escarceos puramente melódicos, en obsequio a los cuales desciende el concierto contrapuntístico; resultado, obras de tendencia expresiva imperfecta, de artificio menos perfecto que en el XVI; total, obras imperfectas siempre. En el XVIII aumenta la expresión, se intenta expresar lo que se siente, adelanta el desarrollo melódico, pero sin conseguir la perfección, decae más el artificio formal; resultado, obras de más sentido, más melódicas, o de composición más pobre; total, obras imperfectas también. Comparando, pues, se ve que a medida que adelanta la tendencia expresiva, el artificio de componer decae, hasta que conseguido el dominio sobre la construcción melódica, verbo del sentir, y de la expresión musical, empieza a buscarse un vestido más rico, que realce su hermosura, que restablezca la armonía entre los dos elementos naturales de la composición: la melodía y su acompañamiento, que deben completarse en la expresión más verdadera y fiel de lo que se siente. Esta época llega ahora, en el arte moderno, es cosa del siglo en que hemos entrado.

$\mathrm{Y}$ aquí tienes la conclusión de toda esta larga palabrería, y te la voy a decir muy quedo y con todos los respetos y miramientos que la música y los músicos antiguos se merecen: poseemos un concepto más elevado y verdadero del arte musical que los antiguos. El arte musical ha progresado. ${ }^{91}$

Curiosamente, el propio Villalba no expuso en sus Impresiones publicadas durante el Congreso esta visión, sino el esquema según la ortodoxia -"grandes días"/“tiempos aciagos"/“amanecer”:

El concierto de la Capilla Isidoriana de la tarde ha sido una jornada de arte español; fuera de Palestrina todos los demás eran de casa, de ayer y de hoy, de los grandes días en que fueron, Guerrero, Victoria, Fernández y Morales, de los tiempos aciagos, en que no obstante la decadencia vivían Soler, Navarro, Aranaz, Cabo y otros, de los en [que] floreció Eslava y de estos otros en que amanecen figuras que se dibujan con caracteres bien nobles. ${ }^{92}$

\footnotetext{
${ }^{91}$ Villalba, "El Segundo Congreso Nacional”, pp. 36-37.

92 Mauricio, "Impresiones del Congreso. Segundo día”, ECA, 3346 de 14 de noviembre (1908), p. 1.
} 
Villalba aparcó, por tanto, no sólo su labor crítica, sino también sus diferencias en este punto respecto al discurso, de influencia pedrelliana, que terminó imponiéndose como oficial. En opinión de Juan José Carreras, la visión de Edad de Oro-decadenciaresurgir que atribuye a Pedrell, llegó a su límite con la publicación en 1983 de la colección Historia de la música española en varios volúmenes editada por Alianza Música, que originaba, a la vez, la necesidad de reconsiderar el sentido mismo de la idea de "música española". Carreras señala, además, la "patente contradicción" existente entre la decadencia de la música española durante los siglos que mediaban entre la "Edad de Oro" y la resurrección según sostenía Pedrell, y el hecho de que el tomo más voluminoso de dicha colección fuera el escrito por Antonio Martín Moreno sobre el s. $\mathrm{XVIII}^{93}$.

Al margen de aquellas consideraciones sobre la actitud al servicio del programa ejemplarizante del Congreso mostrada por Ripollés y Villalba, creemos hallar en sus textos indicios que instan a considerar el cónclave hispalense como algo más que una asamblea litúrgico-musical. Resulta particularmente interesante observar el carácter esencialmente estético-histórico de dichos escritos, así como la ausencia de la perspectiva litúrgico-teológica, que debería predominar en este caso, pues se trataba del estudio de la implantación en España de una propuesta papal de renovación musical inscrita en un más amplio proyecto de restauración del culto católico.

Los dos conceptos principales presentes en el último fragmento de Villalba, como son la interpretación histórica en las tres etapas mencionadas, así como el acento en lo español, ubican este discurso en el dominio del regeneracionismo y nacionalismo musical hispano de principios de siglo. En consecuencia, nuestro análisis se debe centrar, a partir de ahora, en estudiar el peso que esta corriente estética e ideológica tuvo en la construcción de las narrativas desplegadas por el Congreso sobre el canon de música religiosa a adoptar en España por causa de la reforma. Nos preguntamos hasta qué punto la asamblea hispalense pudo convertirse en un marco propicio para la difusión de las ideas regeneracionistas en el ámbito de la música sacra y, en tal caso, la acogida que se les brindó en ese momento y contexto concretos. Durante estos primeros años, la reforma en el caso español podría ser contemplada desde una doble perspectiva: por un lado, como un intento de renovación de las estructuras musicales de la Iglesia, determinado por la influencia de aquellas tendencias nacionalistas; por otro, como una

\footnotetext{
${ }^{93}$ Carreras, "Hijos de Pedrell.”, p. 167.
} 
expresión dentro del ámbito específico de la música religiosa del proyecto regeneracionista ${ }^{94}$.

Salvadas las lógicas diferencias, es posible reconocer importantes analogías entre el regeneracionismo musical español y el reformismo litúrgico-musical eclesiástico. En primer lugar, la percepción común de la música dramática italiana como el origen de las respectivas decadencias y corrupción de las tradiciones propias. Desde las posturas nacionalistas, el italianismo fue considerado como una suerte de invasión cultural extranjera que, entre otras cosas, dificultó e, incluso, impidió la consolidación de un teatro musical hispano. Así, se situó en el centro del debate musical protagonizado por las polémicas sobre la creación de una ópera española. En el conocido opúsculo Por nuestra música (1891), Pedrell expuso su propuesta de "ópera nacional", y presentó la música teatral italiana en España como una desviación histórica de la tradición musical propia e, incluso, en el caso de Italia, como una "hija ilegítima". Según el principal ideólogo del nacionalismo musical español, ambas naciones habían olvidado sus verdaderas tradiciones, fundadas en la música religiosa renacentista:

La música de ópera italiana no era la hija legítima de aquella admirable madre, de aquella magna obra de Palestrina, de aquella sublimidad, riqueza e incomparable profundidad de expresión del arte religioso. [...] Divorciada Italia de Palestrina, divorciados también nosotros de Morales, Victoria (no cito más que a esos dos gloriosos maestros españoles contemporáneos de Palestrina: formarían legión si fuese citarlos todos), ni España ni Italia supieron ver la significación que para el porvenir del arte y sus desenvolvimientos tenía el perfeccionamiento de la melodía rítmica sobre la base fecunda de la harmonía cristiana. ${ }^{95}$

\footnotetext{
${ }^{94}$ Emilio Casares sintetiza el proyecto regeneracionista de Pedrell y Barbieri en los siguientes puntos: "1 ${ }^{\mathrm{o}}$. La recuperación de nuestra historia; $2^{\circ}$. El intento de cambio en la mentalidad del música; $3^{\circ}$. La construcción de nuestro drama lírico como medio óptimo de expresión de la peculiaridad nacional; como fruto y síntesis de ello surgiría eso que denominamos nacionalismo, que se corresponde en buena medida con el ideario de la generación del 98.". "Pedrell, Barbieri y la restauración musical española", p. 263. Juan José Carreras alude a la deuda que, según Higinio Anglés, España tenía con Pedrell. Se tratan, por tanto, de los logros alcanzados por Pedrell en su programa regeneracionista, según su discípulo: “ $(a)$ Pedrell fue el creador de la musicología española moderna; $(b)$ editó las obras maestras de nuestra música clásica; (c) revalorizó nuestra canción popular; $(d)$ fue el precursor de la ópera nacional española". Seguidamente, Carreras somete a revisión, y cuestiona estas afirmaciones de Anglés: se ha puesto de relieve la labor musicográfica de Barbieri como antecesor de Pedrell, así como lo limitado de su concepto de "música popular"; la edición de los Monumentos de la Música española superó con creces las ediciones de música antigua preparadas y publicadas por Pedrell; y por último, el fracaso de la propuesta pedrelliana de "ópera nacional española" . Carreras, "Hijos de Pedrell”, p. 122. El autor toma las citas de Anglés de: La música española desde la Edad Media hasta nuestros días (Barcelona: Diputación Provincial de Barcelona, 1941), p. 79.
}

${ }^{95}$ Felipe Pedrell, Por nuestra música (Barcelona: Imp. Henrich y Cía, 1891), p. 17. Francesc Bonastre señala los principales factores que conformaron el marco histórico en el que apareció Por nuestra música: 
En el caso eclesiástico, el celo por mantener a la música litúrgica libre de corruptelas profanizantes ha sido una constante histórica ${ }^{96}$. A las puertas de la Edad Contemporánea, Benedicto XIV identificó los males de la música sagrada en la influencia de lo teatral. En su encíclica Annus qui (1749) estableció el binomio

el regeneracionismo, el europeísmo y el rechazo del italianismo. "El nacionalisme musical de Pedrell: reflexions a l'entorn de Por nuestra música...", Recerca musicològica, 11-12 (1991-1992), pp. 17-26. p. 18. Véanse, además, las referencias bibliográficas que proporcionamos en el apartado "Estado de la cuestión" de la "Introducción".

Las posiciones anti-italianizantes se remontan al s. XVIII. Benito J. Feijoo, en el Discurso XIV. "Música de los Templos" de su Teatro crítico universal (1726) encontró en la moda italiana, introducida por Sebastián Durón, la causa de la decadencia musical española. Su rechazo al teatro musical italiano no se fundamentó, obviamente, en principios nacionalistas sino morales. Sobre el pensamiento de Feijoo, véase los estudios realizados por Antonio Martín Moreno; en especial: El Padre Feijoo y las ideologías musicales del XVIII en España (Orense; Instituto de Estudios Orensanos, 1976).

Juan José Carreras propone una alternativa a la, según su opinión, historiografía de corte nacionalista, que ha asociado lo "extranjero" a "decadencia". En su planteamiento, el italianismo se integra en la historia musical española desde el s. XVIII como una "expresión de modernidad europea". Álvarez Cañibano ha puesto igualmente de relieve el carácter internacional y moderno del fenómeno de la ópera italiana. Véanse: Juan José Carreras, "De Literes a Nebra: la música dramática entre la tradición y la modernidad”, en La música en España en el siglo XVIII, ed. por Malcom Boyd y Juan José Carreras (Cambridge: Cambridge University Press, 2000[Music in Spain during the Eighteenth Century (1998)), pp. 19-28; del mismo autor, "L'opera di corte a Madrid (1700-1759)", en Il teatro dei due mondi. L'opera italiana nei paesi di lingua iberica, ed. por Anna L. Bellina (Padua: Diastema Libri, 2000), pp. 11-35; Antonio Álvarez Cañibano, “Teatro y música escénica. Del Antiguo Régimen al Estado burgués”, p. 123, pp. 123-158. Una exhaustiva bibliografía sobre el teatro musical español del s. XVIII en Philip B. Thomason y Ceri Byrne, "The Eighteenth-Century Theatre in Spain. A Bibliography of Criticism and Documentation", Bulletin of Spanish Studies: Hispanic Studies and Research on Spain, Portugal and Latin America, LXXXII/7 (2005), pp. 1-205. Dada la importancia del asunto, la bibliografía sobre el teatro musical en el siglo XIX español es amplia. Véanse, entre otros: Emilio Casares Rodicio, "La música en el siglo XIX español. Conceptos fundamentales”, pp. 26-28 y 93-122, pp. 13-122; Antonio Álvarez Cañibano, "Teatro y música escénica”, pp. 123-158; Mª Encina Cortizo, "La zarzuela del siglo XIX. Estado de la cuestión”, pp. 161- 194; Ramón Barce, "El sainete lírico (1880-1915), pp. 195-244; todas estas contribuciones en La música española en el siglo XIX. ed. por Emilio Casares y Celsa Alonso (Oviedo: Universidad de Oviedo, 1995). Véanse, además, otras obras colectivas como: Álvaro Torrente y Emilio Casares, coords., La ópera en España e Hispanoamérica: actas del Congreso Internacional 'La ópera en España e Hispanoamérica, una creación propia, 2 vols. (Madrid: ICCMU, 2001); Emilio Casares Rodicio, dir., “Actas del Simposio Internacional 'La zarzuela en España e Hispanoamérica. Centro y periferia. 1800-1950”,, Cuadernos de Música Iberoamericana, 2 y 3 (1997). La cuestión del italianismo y la ópera nacional está presente en los estudios sobre el nacionalismo musical y sobre la historiografía musical española. Véase, además, bibliografía que proporcionamos en el apartado "Estado de la cuestión".

${ }^{96}$ Como apuntamos en la introducción de esta tesis, desde la Edad Media hasta el MP, las principales actuaciones del papado en lo que a música respecta han sido la bula Docta Sanctorum (1325), de Juan XXII, y la encíclica Annus qui. En Donella, Musica e liturgia, pp. 19-37 se puede leer una breve síntesis de la evolución de la música litúrgica por géneros. En trabajos publicados en el ámbito español, se ofrecen igualmente visiones muy resumidas y generales de esta evolución, haciendo hincapié en los abusos en la música litúrgica o su difícil relación con la profana. Véase, por ejemplo: José López-Calo, "Hilarión Eslava (1807-1878), precursor del Cecilianismo en España", Principe de Viana (Ejemplar dedicado a: Conmemoración del VIII Centenario de la Chantría de la Catedral de Pamplona como dignidad eclesiástica (1206-2006)), coord. por María Gembero Ustárroz, 238 (2006), pp. 577-608, pp. 577-582. Ángel Medina alude a ambos escritos papales en dos de sus artículos recientes dedicados al MP: "La música en el templo tras el Motu Proprio", p. 35; "La romería en el templo y otras licencias", p. 12. 
profano-teatral como lo opuesto a la música eclesiástica auténtica ${ }^{97}$. El MP recogió esta doctrina de rechazo de lo teatral como expresión de lo profano: "Entre los varios géneros de la música moderna, el que aparece menos adecuado a las funciones del culto es el teatral, que durante el pasado siglo estuvo muy en boga, singularmente en Italia"98. En segundo lugar, la consideración del pasado musical, especialmente la polifonía sacra renacentista, como un tiempo en el que hallar las esencias nacionales o pureza litúrgica perdidas, según el caso ${ }^{99}$. En este marco, la restauración del patrimonio poseyó no sólo una importancia anticuaria o una función orientada a la exaltación de valores genuinos -patrióticos o litúrgicos "auténticos"- sino sobre todo una virtud regeneradora $^{100}$. La recuperación del pasado musical, por tanto, estaba al servicio de la

${ }^{97}$ La bula Docta Sanctorum y la encíclica Annus qui se puede consultar en: Otaño, La Música Religiosa, pp. 10-13 y 22-73, respectivamente.

${ }^{98} M P$. Título II. Géneros de música sagrada, art. 6.

${ }^{99}$ Las consideraciones realizadas por Ismael Fernández de la Cuesta sobre el valor identitario que poseía, no sólo la polifonía renacentista sino también el canto gregoriano para la Iglesia nos parecen ciertamente interesantes: "Ello obedecía [el equívoco de identificar el canto gregoriano oficial eclesiástico con un canto benedictino concreto], por otro lado, a una estética musical dominada por el 'melodismo' del que se nutría, también, la música nacionalista. La Iglesia católica intentaba encontrar la identidad de su expresión religiosa más pura dentro del culto divino en las melodías del canto gregoriano, como los grandes compositores del nacionalismo musical, la de su respectiva nación, en las melodías del folclore. La comparación no me parece descabellada, y creo que deber ser objeto de estudio profundo y sereno." Fernández de la Cuesta, "La reforma del canto gregoriano", pp. 71-72. En ese sentido, María Antonia Virgili apunta: "No debemos olvidar en este sentido que el siglo XIX fue un siglo de nacionalismos, en el que se buscaban los signos distintivos del lenguaje musical en cada una de las naciones, poniendo los ojos en las esencias populares y las esencias históricas. [...] La Iglesia cifra su 'ser musical propio' en esos dos momentos culminantes de su historia: el gregoriano y la polifonía del XVI. Y son ambos estilos los que debieron inspirar a los compositores en su lenguaje compositivo en el que, como elemento ineludible, debía estar la propia inspiración, la calidad artística y técnica y, en el caso de la música litúrgica, el respeto a la función. "La música religiosa", p. 194.

100 Varios autores han puesto de relieve esta convergencia entre nacionalismo, historicismo y regeneracionismo. Posiblemente, el más influyente de ellos haya sido Emilio Casares. En las páginas 26 y 27 de su "Introducción" a La música española del siglo XIX sintetiza esta relación y las funciones que cada una de estas corrientes ejerció dentro de un marco ideológico general romántico. Esta amalgama de -ismos dio lugar al nacimiento y desarrollo de la historiografía musical. Según Casares, los antecedentes de este nacionalismo y regeneracionismo finisecular se encuentran en torno a los años cincuenta: "Detrás de él [el nacionalismo], está esa corriente que conocemos en plástica y literatura como historicismo, pero aquí no como mero hecho inspirador de realidades formales, sino más allá, como una vuelta a valores patrios, considerados imprescindibles para recuperar una mayoría de edad musical. Sin ello, toda la historiografía musical del XIX, tan rica, pierde su valor, su verdadera esencia. [...] En los años cincuenta se inicia lo que podemos denominar el intento de restauración de la música española. Con Barbieri, Eslava y Soriano se inicia realmente la historiografía musical española de manera sistemática. [...] Ciertas realidades románticas como el interés por el pasado $\mathrm{y}$, sobre todo, esa nueva conciencia nacionalista que lleva a buscar las esencias patrias en la propia historia, conducen a una exaltación de la ciencia historiográfica. [...] estas obras [las de los historiadores españoles del s. XIX] responden en su esencia a una idea muy romántica, la de restaurar el pasado, pero como fundamento de una revitalización de la música española”. En otro de sus artículos completa aquella nómina con Pedrell, quien, junto con Barbieri, considera "figuras clave de la inteligencia musical del siglo XIX". "Pedrell, Barbieri y la restauración musical española”, p. 259. 
restitución en la música contemporánea española, o litúrgica de aquellas esencias. En ambos casos, el eclesiástico y el del nacionalismo musical español, se encuentran de una u otra forma signos de influencia de unos mismos postulados ideológicos: esencialismo, tradicionalismo restaurador, historicismo decimonónico, voluntad regeneracionista ${ }^{101}$.

Estos puntos de coincidencia entre el ideario del nacionalismo musical español y la propuesta papal debieron facilitar, creemos, la asimilación en clave regeneracionista y nacionalista del $M P$ en España. A ello contribuyeron, además, las actividades a favor de las propuestas reformistas salidas de Roma en la última década del s. XIX desarrolladas por una buena parte de los músicos implicados en el proyecto de modernización y regeneración de la música española. Iniciativas como la fundación de la ya citada Asociación Isidoriana, bajo los auspicios de Cos y Macho, y en la que participaron, entre otros, el propio Pedrell o Ripollés, son un ejemplo ${ }^{102}$. Este impulso nacionalista y regeneracionista hay que entenderlo, además, en el contexto de los debates suscitados en torno al hito histórico que supuso el desastre del 98 y la conciencia de decadencia de España ${ }^{103}$. Las distintas respuestas proporcionadas por la intelectualidad noventayochista y que, de una $\mathrm{u}$ otra forma, se proyectaron hasta la denominada Edad de Plata iban desde el krausismo, el positivismo, el europeísmo, el modernismo, hasta el tradicionalismo, el casticismo o el esencialismo ${ }^{104}$.

101 Según Juan José Carreras, en la época que nos atañe, los nacionalismos esencialistas basados en la superioridad cultural estaban presentes en general en toda Europa. Lo particular de la historiografía española, por tanto, de los discursos e interpretaciones sobre la historia y la propia música española fue "su extraordinario adelanto y constancia en el desarrollo del mito nacional y esencialista de una 'música española' pura y sustancialmente diferente de lo extranjero". Carreras, "Hijos de Pedrell", p. 131.

${ }^{102}$ La Asociación Isidoriana nació como consecuencia de la promulgación en 1894 del Reglamento sobre la Música Sagrada por parte de la Sagrada Congregación de Ritos. Véanse, entre otros: Nagore, “Tradición y renovación”, pp. 217-220; Virgili, “Antecedentes y contexto ideológico”, pp. 35-36.

103 Emilio Casares vincula el ideario restaurador en el ámbito musical de Barbieri y Pedrell con "el movimiento básico de la cultura española del XIX, representada en la conciencia restauradora de Joaquín Costa, en la que se enraiza la generación del 98." "Pedrell, Barbieri y la restauración musical española", pp. 261-262. Rafael Lamas, por su parte, apunta como factores determinantes del trasfondo ideológico pedrelliano las influencias del regeneracionismo de Joaquín Costa, y el krausismo, tal y como fue asimilado en España. Música e identidad, pp. 135-136.

104 En numerosas ocasiones se ha explicado la convivencia de todas estas corrientes en términos contrapuestos. Celsa Alonso establece las siguientes dualidades al confrontar el pensamiento de los dos grandes referentes de este movimiento de restauración, Barbieri y Pedrell: "naturalismo-idealismo, tradición-europeización, casticismo-universalismo, pragmatismo-erudición, folclorismo-música natural, urbano-rural, populismo-elitismo, zarzuela-ópera y costumbrismo-drama heróico." Celsa Alonso, "Nacionalismo", p. 928. Carol Hess por su parte, establece la dicotomía entre wagnerianismo como corriente abierta a las influencias procedentes de Europa, y zarzuela que vincula al esencialismo españolista. Carol Hess, Manuel de Falla and Modernism in Spain. 1898-1936 (Chicago: The University of Chicago Press, 2001). Beatriz Martínez del Fresno fija desde el título una nueva perspectiva bipolar en 
Ma Antonia Virgili o María Nagore han contemplado la cuestión de la música religiosa y las iniciativas de reforma previas al $M P$ como otro de los ámbitos de acción del regeneracionismo musical en España ${ }^{105}$. Sin embargo, en los estudios sobre el movimiento reformista surgido tras la promulgación del texto papal, y especialmente sobre los congresos, no se ha prestado la suficiente atención a la relación entre regeneracionismo musical hispano y reformismo musical eclesiástico, ni se ha indagado en profundidad si estas grandes asambleas litúrgico-musicales pudieron llegar a ser, presumiblemente, grandes manifestaciones del nacionalismo musical español.

\subsubsection{Polifonía clásica: la sustitución de los modelos romanos por los}

\section{autóctonos}

Partamos de nuevo del texto de Villalba en el que reconocíamos determinadas huellas de nacionalismo musical español para continuar nuestro análisis. Recordemos la idea que trasladaba sobre el concierto de música religiosa: "jornada de arte español" en el que, a excepción de Palestrina "todos los demás eran de casa, de ayer y de hoy". Esta imagen sobre el concierto en particular refleja, en realidad, lo ocurrido en el conjunto del Congreso. El Stabat Mater de Palestrina fue la única obra de autor extranjero que se escuchó, no sólo en dicho concierto, sino durante toda la asamblea. Ripollés justificó la presencia del músico romano entre los españoles por su condición

su artículo "Nacionalismo e internacionalismo en la música española de la primera mitad del siglo XX", Revista de Musicología, XVI/1 (1993), pp. 640-657. Para ampliar estos temas, véanse, entre otras publicaciones, las aportaciones al Seminario Internacional "Música y cultura en la Edad de Plata, 19151939" (2008), en: Música y cultura en la Edad de Plata, 1915-1939, ed. por María Nagore Ferrer, Leticia Sánchez de Andrés y Elena Torres Clemente (Madrid: ICCMU, 2009). Leticia Sánchez de Andrés ha dedicado varias publicaciones al krausismo y la música en España, véanse, entre otras: "El pensamiento estético del krausismo español y su proyección en la investigación musicológica y la crítica musical", (Actas del VI Congreso de la SedeM), Revista de Musicología, XXVIII/2 (2005), pp. 961-976; Música para un ideal: pensamiento y actividad musical del krausismo e institucionismo españoles (1854-1936) (Madrid: SedeM, 2009).

${ }^{105}$ La Dra. Virgili afirma: "Las mismas voces que se alzan en defensa de la música española, son las que lideran el movimiento de reforma litúrgico y, en lo que a su plasmación estética se refiere, caminando por la misma senda: la búsqueda de las esencias en lo popular y en los repertorios históricos para beber en ellas como material inspirador, a su vez que formativo." "Antecedentes y contexto ideológico", p. 26. En la misma línea, María Nagore opina: "En España, como en otros países, hubo un movimiento de renovación más o menos activo en el siglo XIX, fruto de la iniciativa privada y paralelo al que se dio en otros ámbitos de la vida musical española. La 'cuestión de la música religiosa' será una más de las cuestiones debatidas en los cenáculos musicales decimonónicos, entre las que destacan las de la ópera española y la enseñanza musical”. Nagore, “Tradición y renovación”, p. 212. 
de "príncipe de todos ellos [nuestros antiguos polifonistas]"106. El hecho de que de los diecinueve compositores que formaron parte del programa musical general del Congreso -incluidas las funciones litúrgicas-, dieciocho fueran españoles, y que el único foráneo lo hiciera en calidad de modelo perfecto propuesto por el $M P$ demuestra su impronta nacionalista ${ }^{107}$. La misma Junta Organizadora desveló meses antes de su inauguración su carácter "ante todo español” y el criterio fundamental de elección de los autores:

3. ${ }^{\circ}$ La Junta organizadora tiene muy en cuenta que este congreso es ante todo español y por eso en lo referente a las ejecuciones los autores españoles antiguos y modernos tendrán el puesto de preferencia, o mejor dicho, de ellos se compondrá el programa musical tanto vocal como orgánico. ${ }^{108}$

Los discursos legitimadores, divulgadores y pedagógicos de Ripollés y Villalba estuvieron imbuidos de este carácter españolista, así como de las ideas predominantes del nacionalismo musical del momento. Villalba se refirió al programa como más que un "señor programa", "una exhibición brillante e interesantísima de la música religiosa española", con todas las virtudes que, según él, tal condición le otorgaba, bondad, función educadora, patriotismo:

Como ves, el programa es todo un señor programa, más que eso, un recorrido en toda regla, una exhibición brillante e interesantísima de la música religiosa española, que eso de bueno, de instructivo y encima de patriótico, lleva una exhibición, digo, de la música religiosa española a través de cuatro siglos. ${ }^{109}$

Las alusiones de ambos escritores a la música o los músicos extranjeros sirvieron al propósito de exaltación de lo español y elevación de la autoestima. El

\footnotetext{
106 "Estará dividido [el Concierto religioso de música polifónica] en tres partes: la primera para dar a conocer nuestros antiguos polifonistas y al príncipe de todos ellos, Palestrina; [...]”. Vicente Ripollés, "Segundo día del Congreso. Ejecuciones de música vocal", ECA, 3345 de 13 de noviembre (1908), p. 2.

${ }^{107}$ La nómina de compositores cuyas obras formaron parte del concierto estuvo compuesta por J. Ginés Pérez, T. L. de Victoria, M. Navarro, G. P. da Palestrina, P. Fernández de Castilleja, F. Guerrero, C. de Morales, F. X. Cabo, P. Aranaz, H. Eslava, L. Romeu, F. Olmeda, V. Goicoechea, L. Millet, D. Mas y Serracant. A estos hay que sumar V. Ripollés, N. Otaño, M. Valdés, J. Moreno. Véase Apéndice 9.

108 “Cuestiones prácticas. Sobre el Segundo Congreso”, MSH, 15 (1908), p. 130.

${ }^{109}$ Con este fragmento encabezó Villalba sus comentarios sobre el programa polifónico del Congreso en $L C D$, "El Segundo Congreso Nacional", p. 29.
} 
Congreso presentó -desveló- a los participantes la existencia de una escuela que, supuestamente, "causa envidia a los extranjeros". Esa sola razón justificaba, según se trasladaba, los esfuerzos que suponía acudir a la capital andaluza:

[...] Y, en fin, aunque no hiciera más que darse cuenta que en España ha habido una escuela de compositores que causa envidia a los extranjeros, y que en ella existe un canto popular religioso que es objeto de venerable admiración para todos, no habría desaprovechado el viaje quien allí fuera. ${ }^{110}$

Una de las grandes aspiraciones de la empresa nacionalista pedrelliana consistió en la incorporación de la música española al contexto internacional, y la consecución de su reconocimiento por parte de Europa. Según el compositor catalán, la historiografía continental había menospreciado a España como potencia musical ${ }^{111}$. La Junta Organizadora señaló la importancia del éxito del Congreso de cara al exterior, desde donde, según aseguró, se seguía el proceso español con expectación. Incluso puso de manifiesto lo que supuestamente Europa reclamaba a España, que quizás habría que entender como lo que la Junta consideraba que los españoles podían ofrecer a los músicos europeos para alcanzar el ansiado reconocimiento de estos: "nuestros clásicos", en expresión de dicha Junta, "gloria de nuestra querida Patria"112.

110 “Los próximos congresos. El Segundo Congreso Nacional de Música Sagrada”, LCD, p. 76 (1908), p. 618. Aunque no está firmado, es seguro que la reseña de la que forma parte este extracto fue escrita por Villalba. En ella se anunció el Congreso y se trató de poner de relieve su utilidad.

111 Ya hemos apuntado más arriba la combinación de tendencias en torno a las cuales surgió la historiografía musical española, y sus principales figuras. Emilio Ros-Fábregas ha destacado el predominio del positivismo y el nacionalismo en sus principios ideológicos y aparatos teóricos. Ambas doctrinas fueron puestas al servicio de una estrategia de defensa de la historia de la música española justificada entonces por la imagen negativa que sobre esta habían transmitido los historiadores europeos. Ros-Fábregas señala, entre otros, los ejemplos de Francois Auguste Gevaert o Edmond Vander Straeten. Mediante la metodología positivista, y por su inclinación nacionalista, pretendieron "demostrar" que en España había existido historia musical, claramente diferenciada de la extranjera y típicamente española. El trabajo de Ros-Fábregas hace notar la pervivencia de estas tendencias a lo largo del s. XX -algo en lo que han insistido otros especialistas como Juan José Carreras-, y aboga por la superación de esta etapa. Emilio Ros-Fábregas, "Historiografía de la música en las catedrales españolas: nacionalismo y positivismo en la investigación musicológica", CODEXXI. Revista de la comunicación musical, 1 (1998), pp. 68-135. Véase también el artículo ya citado: Carreras, "Hijos de Pedrell".

${ }^{112}$ Rafael Lamas apunta la compatibilidad del planteamiento nacionalista de Pedrell con las expectativas europeas sobre la música española. Según Lamas: "El nacionalismo convirtió su 'españolidad' en una característica que respondía a los deseos europeos de 'autenticidad'. La música española asumía así la conciencia colonizada que las culturas centrales confieren a las periféricas". Lamas, Música e identidad, p. 136. En su análisis sobre los fundamentos del nacionalismo pedrelliano, Lamas observa, además de un carácter esencialista, un origen colonialista. Ibídem, pp. 135-136. 
Sería muy poco lisonjero para la nación española y muy triste para la Junta Organizadora, que todos nuestros esfuerzos se estrellaran contra la pasividad del Clero y de los artistas españoles, y nuestro nivel intelectual y celo religioso perderían bastante ante el Clero y artistas extranjeros, que están siguiendo atentamente nuestros pasos en el camino de la restauración musical religiosa, y nos impelen con voces de aliento a resucitar las antiguas glorias de nuestros clásicos Victoria, Morales, Guerrero, Comes, Cabezón y todos los que forman esa lista interminable de polifonistas que son el orgullo y gloria de nuestra querida Patria. ${ }^{113}$

Con esta apelación a "las antiguas glorias de nuestros clásicos", la Junta Organizadora dejaba entrever la presencia en su discurso de otro de los axiomas del nacionalismo españolista, la contemplación del Renacimiento como la Edad de Oro de la música española ${ }^{114}$. El regeneracionismo musical coincidió así con los tradicionalistas católicos a la hora de ubicar la etapa de apogeo en sus interpretaciones de la historia, y no con los liberales, a pesar de que sus orígenes se hallaran en el liberalismo moderado burgués. Recordemos el esquema -“mitologema” en términos de Álvarez Junco- , apogeo/decadencia/resurrección antes referido ${ }^{115}$.

Por tanto, la gran aportación de España a la música internacional debía ser la resurrección de aquellos clásicos, lo mejor de su patrimonio. El Congreso llevó a cabo una estrategia de exaltación de estos autores, considerados como los grandes frutos de una etapa gloriosa, para recuperar la idea de una España preponderante en el concierto de las naciones europeas. Palestrina, el modelo por excelencia, adquirió en dicha estrategia su función: ejercer de elemento de comparación para elevar el valor de los

113 Junta organizadora, “A los amantes de la música sagrada”, Crónica Segundo Congreso, p. 41.

${ }^{114}$ Pilar Ramos López ha estudiado la construcción de lo que considera un mito historiográfico, detrás del cual se esconde un programa ideológico de corte nacionalista: el Renacimiento musical español como el momento culminante -la Edad de Oro- de la historia de la música española. En su análisis observa los rasgos que, como lugares comunes, se han ido repitiendo acríticamente acerca de la música renacentista hispana: original y absolutamente española, sin influencias extranjeras; mística y de una profunda expresividad religiosa; muy apreciada entre los círculos de influencia; e ignorada [overlooked] por los musicólogos extranjeros. Pilar Ramos López, "The construction of the myth of Spanish Renaissance Music as Golden Age". Volumen Early Music - Context and Ideas International Conference in Musicology, Cracovia: Universidad de Cracovia (2003), en $<$ http://www.campusvirtual.unirioja.es/titulaciones/musica/fotos/ramos_krakow_2003.pdf > (consultado 25-9-13). Véanse, además: Emilio Ros-Fábregas, "Cristobal de Morales: A Problem of Musical Mysticism and National Identity in the Historiography of the Renaissance", en Cristobal de Morales: Sources, Influences, Recepcion, ed. por Owen Rees y Bernardette Nelson (Woodbridge: Boydell, 2007), pp. 215-234; Tess Knighton, “'Through a glass darkly’: Music and Mysticism in Golden Age Spain”, en A New Companion to Hispanic Mysticism, ed. por Hilaire Kallendorf (Leiden: Brill Academic Publisher, 2010), pp. 411-436.

${ }^{115}$ Véase más arriba, p. 530, y nota a pie $n^{\circ} 89$. 
modelos autóctonos, e incluso, para ser reemplazado por uno de ellos, Victoria, una vez situado este, incluso, por encima del italiano ${ }^{116}$. A Morales se le presentó como "predecesor de Palestrina y maestro cantor de la Capilla Pontificia"; a Guerrero como "ferviente enamorado de la Virgen y gran amigo de Palestrina"; y a Victoria como "el más eminente de los polifonistas españoles, el rival de Palestrina, superior, según autorizado parecer de reputados maestros, al mismo príncipe de la música por su expresivismo místico musical", por eso

no podía faltar en un concierto de música sagrada de un Congreso Español: de él se escucharán dos bellísimos motetes, el Vere languores, y el incomparable $O$ vos Omnes, un prodigio de expresión, composición no superada por el arte moderno, en la cual aparecen condensadas la[s] más puras formas del arte musical religioso. ${ }^{117}$

En este discurso, Victoria, superior a Palestrina, desplazó a este como modelo para los músicos españoles, en virtud de un rasgo considerado como genuina y esencialmente español: el "expresivismo místico musical"118. Gracias a este rasgo

116 Según Manuel Sancho García, este intento de presentar a Victoria como rival, e incluso superior a Palestrina se remonta a Mariano Soriano Fuertes y su Historia de la música española desde la venida de los fenicios hasta el año de 1850 (1855). Eslava, por su parte, defendió la superioridad de Victoria respecto a Palestrina en dos puntos: uno de carácter técnico, como era la ausencia en su estilo de falsas relaciones y "choque armónicos" -en palabras de Sancho-; y otro de carácter estético, la expresión como ideal. El carácter expresivo de la música de Victoria puesta tan de relieve durante el Congreso, defendida con ahínco por Pedrell, y que tanto éxito tuvo en la historiografía española y europea desde que Henry Collet, una vez lo asoció a la noción de misticismo, la difundiera en sus publicaciones, tendría su precedente en Eslava, según estos datos proporcionados por Sancho. "De Teixidor a Pedrell: Tomás Luis de Victoria en la historiografía musical española del siglo XIX”, Revista de Musicología, XXXV/1 (2012), pp. 443-457. Véase del mismo autor, "Tomás Luis de Victoria en la obra musicológica de Felipe Pedrell: la creación de un mito nacional”, en Tomás Luis de Victoria: Estudios/Studies, ed. por Manuel del Sol y Javier Suárez-Pajares (Madrid: ICCMU, 2013), pp. 489-500.

${ }^{117}$ Vicente Ripollés, “Segundo día del Congreso. Ejecuciones de música vocal.”, ECA, 3345 de 13 de noviembre (1908), p. 2.

118 Ros-Fábregas refiere cómo años después de esta reivindicación de Victoria por Ripollés, Rafael Mitjana ponía el énfasis en el expresivismo místico de Victoria así como de las escuelas castellana y andaluza, al mismo tiempo que lo negaba en el caso de la catalana. El diplomático e historiador andaluz llegó a atribuir curiosamente "un velado paganismo, permanente y oculto" a la Escuela Romana de polifonía, cuyo modelo de perfección, según el $M P$, era el propio Palestrina. Ros-Fábregas opina que este posicionamiento de Mitjana hay que entenderlo en el ámbito de su antiitalianismo y casticismo castellanista de influencia noventayochista. Nos parece advertir en Ripollés y Mitjana la misma pretensión de situar a Victoria, y por ende a la "Escuela Española", como superior a las extranjeras, incluida la propuesta como ideal por el $M P$, la Romana. Ambos invocaron el expresivismo místico como el rasgo, genuinamente español, que proporcionaba esa distinción y superioridad. Ros-Fábregas, "Historiografía de la música", p. 75.

Viene al caso reproducir el siguiente pasaje de Juan Blasco, canónigo Maestrescuela de la catedral de Orihuela a finales del s. XIX y biógrafo de Ginés Pérez de la Parra (1548-1600), citado por Pedrell en el Volumen V de su antología HSMS. El canónigo orcelitano comparó a Ginés Pérez con Palestrina: "Si el genio de Palestrina admira, mayor, si cabe, es la admiración que nos inspira el del 
diferencial, la música española alcanzó la misma -o mayor- dignidad que la de las demás naciones europeas ${ }^{119}$. Rafael Lamas ha puesto de manifiesto que el "discurso de la 'diferencia'” constituyó, paradójicamente una fórmula para conseguir la incorporación de la música española a la europea ${ }^{120}$. Con la atribución a la música de Victoria del carácter distintivo de la música española, el expresivismo místico, el Congreso conseguía, parafraseando a Pedrell, arrebatárselo a la Escuela Romana de polifonía, en la que la historiografía internacional le había ubicado hasta no hace mucho, e incorporarlo a la nómina de genios musicales españoles ${ }^{121}$.

La sustitución de Palestrina por Victoria se verificó al mismo tiempo que la "Escuela Romana" fue reemplazada por la "Escuela Sevillana". Con ello, el Congreso terminó de relegar a un segundo plano los modelos del $M P$ en beneficio de los propios. El concierto ofrecido por la Capilla Isidoriana el día 13 en la Iglesia del Salvador reservó una de sus tres partes en exclusiva a la "magna escuela expresivista sevillana del siglo XVI", con la pretensión de situarla en un "puesto de honor":

maestro Pérez. Aquel viviendo en Roma, respirando aquella atmósfera musical saturada de paganismo, no pudo menos de sentir y comprender la necesidad de purificar aquella música, y ante un mandato superior [el del Concilio de Trento] enseña en las Misas producidas a la sazón los nuevos derroteros que habían de seguirse para reconciliar la música con el culto divino". Felipe Pedrell, "I. Juan Ginés Pérez", HSMS vol. V. Joannes Ginesius Pérez [Ginés Pérez de la Parra], (Barcelona: Juan Bautista Pujol y Cía., 1896), p. XIV. Aunque Blasco salvó a Palestrina, y con él, suponemos, a la Escuela Romana del paganismo que les rodeaba, habría que preguntarse si la atribución de ese paganismo a dicha Escuela por parte de Mitjana no estuviera inspirada en esta cita, transcrita en una obra que seguro conocía.

${ }^{119}$ Pilar Ramos López ha puesto en entredicho el misticismo que la tradición historiográfica española ha atribuido a la música de Victoria. Según Ramos, esta atribución se fundamenta en las siguientes razones: su sonoridad "mística", la dedicación exclusiva del abulense a la música sagrada, compartir ciudad de nacimiento con Santa Teresa de Ávila y San Juan de la Cruz, así como la relación que mantuvo con San Felipe Neri y el contacto con sus escritos. "Mysticism as a Key Concept of Spanish Early Music Historiography". Volumen Early Music - Context and Ideas II International Conference in Musicology, Cracovia: Universidad de Cracovia (2008), en: $<$ http://www.campusvirtual.unirioja.es/titulaciones/musica/fotos/13_ramos.pdf $>$ (consultado 25-9-13).

120 La contemplación de la música española como auténtica -esencial- y exótica responde a las características de la empresa colonial y a su particular manera de integración de lo ajeno -"la diferencia"-: "La retórica esencialista del nacionalismo respondía al imaginario que deseaba el exotismo europeo. El discurso de la 'diferencia' en vez de aislar a la música española la ligaba a occidente." Lamas, Música e identidad, p. 143.

${ }^{121}$ En una carta fechada el 31 de julio de 1893, Pedrell confesaba a Barbieri: “Ahí hallará V. sapos y culebras. Quiero arrebatar Morales a los neerlandeses; no puede ser que hayan influido en su manera de componer [...]". El fragmento está extraído de Ros-Fábregas, "Historiografía de la música", p. 72, quien lo toma a su vez de María Cruz Gómez-Elegido, "La correspondencia entre Felipe Pedrell y Francisco Asenjo Barbieri", Recerca musicològica, 4 (1984), p. 238. Ha sido publicada también en edición de Emilio Casares: Francisco Asenjo Barbieri, Biografía y documentos sobre música y músicos españoles, 2 vols. (Madrid: Fundación Banco Exterior, 1986 y 1988), vol. II, pp. 850-868. 
Estará dividido [el Concierto religioso de música polifónica] en tres partes: [...] la segunda como puesto de honor, está toda dedicada a la magna escuela expresivista sevillana del siglo XVI; la tercera se compone de composiciones de autores modernos y contemporáneos. $^{122}$

El fin que se persiguió fue incorporar a Sevilla, con todo su valor simbólico, al proyecto regeneracionista español, tal y como se desprende de las afirmaciones vertidas en uno de los artículos publicados en $M S H$ y recogidos en la Crónica del Segundo Congreso:

Sevilla que fue en tiempos la escuela más gloriosa de la música religiosa en España, tiene títulos más que suficientes para ser uno de los centros de nuestra resurrección artística, Pedro Fernández, Morales, Guerrero ¿no son las glorias de nuestra brillante escuela polifónica? ${ }^{123}$

En los comentarios de Ripollés en ECA se evidencia un programa de enaltecimiento de los maestros andaluces y del carácter místico-expresivo consustancial a su música. El motete, "de formas muy claras y expresivas" que se interpretó de Pedro Fernández de Castilleja, "maestro de los maestros de España, en frase de Guerrero", fue recuperado por el propio Ripollés para su interpretación en el concierto:

[...] el valor de este maestro puede juzgarse por el aprecio con que le miraba y veneraba el gran Guerrero. El motete que figura en el programa de este concierto tuve la satisfacción de encontrarle en polvoriento libro del Archivo de esta Catedral, y convenientemente transcrito en notación moderna lo entregué a la Capilla Isidoriana para que lo diera a conocer al Congreso: es a cuatro voces, de formas muy claras y expresivas y de técnica segura y correcta: está dedicado a la Virgen y tiene un ambiente de unción que encanta. ${ }^{124}$

En relación a la expresión contenida en la obra de Morales ${ }^{125}$, "una de las mayores glorias de que puede enorgullecerse la ciudad de Sevilla”, puso de relieve la

\footnotetext{
${ }^{122}$ Vicente Ripollés, “Segundo día del Congreso. Ejecuciones de música vocal.”, ECA, 3345 de 13 de noviembre (1908), p. 2.

${ }^{123}$ Franculus, “Un Congreso”, Crónica del Segundo Congreso, pp. 48-49.

${ }^{124}$ Vicente Ripollés, "Segundo día del Congreso. Ejecuciones de música vocal.", ECA 3345 de 13 de noviembre (1908), p. 2.

${ }^{125}$ A diferencia de la opinión de Pedrell y los que siguieron su doctrina -predominante, como estamos comprobando en el Congreso-, para Barbieri fue Morales quien encarnó el ideal de músico religioso
} 
íntima relación entre los aspectos prosódicos y expresivos del texto y el carácter de la melodía, precisamente una virtud que Villalba, salvo algunas excepciones, no encontraba en las, según su opinión, artificiosas e inexpresivas composiciones de los polifonistas clásicos ${ }^{126}$ : "Puede decirse que en esta obra la voz, en vez de cantar las palabras, las habla, y que las exclamaciones Iben me adquieren todos los caracteres de una melopea inspirada en el tono de la mismo pronunciación"

No obstante, fue la figura de Guerrero a la que se le otorgó la condición de emblema de la Escuela Sevillana. Su obra constituyó la síntesis culminante de las virtudes religiosas y expresivas características de la música de los autores hispalenses. Ripollés reconoció en el andaluz el ideal de músico religioso, que puso sus talentos al servicio de los fines litúrgicos. Su música era, en opinión del castellonense, la concreción material y artística de un espíritu virtuoso. Según ha puesto de manifiesto Pilar Ramos, la religiosidad de los compositores llegó a convertirse para la historiografía musical española en un criterio de juicio estético. Ramos se retrotrae a la famosa obra de Collet Le mysticisme musical espagnol au XVIe siècle, publicada en

español. En él encontró las mismas virtudes que Pedrell en Victoria, ser, según recoge Manuel Sancho, el iniciador de la "escuela musical religiosa expresiva española" y superar a Palestrina. Sancho, "De Teixidor a Pedrell: Tomás Luis de Victoria”, p. 452.

126 "Los antiguos, los del siglo XVI, no llegaron a infundir al artificio eso que se llama expresión, sentir; no fundieron la música para la letra, y esta música, que no refuerza, que no da vida a nada, que a lo más es amable compañera de unas palabras que no contradice, pero que no entiende, será una amiga tolerable de la letra, pero no participará de su espíritu, ni tendrá esos arranques, esas afecciones, esa modalidad estética, de sentimiento, digo, de aquello que no sólo se tiene al lado, sino con 'lo cual se ha fundido en una sola cosa: será correctísimamente indiferente, sin fisonomía, sin expresión." Villalba, "El Segundo Congreso Nacional", p. 33. Las siguientes son las excepciones citadas por Villalba, aunque confirmaban la regla: "El oyente imparcial tantos adarmes de piedad y devoción encuentra en la misa Mille regretz (canción profana) que en la $O$ quam gloriosum, Puer qui natus est nobis (melodías litúrgicas). Hay excepciones, me dirás, sacando de tus recuerdos la Pasión de Victoria; los Improperios, el Emendemus in melius, de Morales, etc...; una o dos docenas de composiciones entre millares; y en efecto, excepciones son que confirman la regla." Ibídem. Este aspecto era para Villalba el principal criterio de juicio sobre el valor artístico de una obra musical: "oye, y oye mucha música de Guerrero, de Morales, de Palestrina, de Victoria, en lo religioso; de lo profano, si tienes ocasión, también, pero no sólo aquellas composiciones que de antemano se escogen, es decir, no te vayas a fijar en las excepciones únicamente; y cuando la leas, cuando la oigas, atiende a la letra y mira el cuidado con que la sirve la música, y de esto sacarás el grado de expresión de esa música, de espiritualismo, o mejor, de sentimentalismo (que no es igual) que manifiesta; de si se ha compuesto para acentuar y reforzar el significado de la letra, o si se ha puesto de puro adorno. [...]Aquí está el toque del valor artístico de toda la música que lleva letra; arte es ordenar la música para expresar la letra; lo contrario es música, sólo música, lo más que puede tener es artificio. Así es como podrás, además de apreciar el mérito legítimo de la composición y de discernir sin confundir los términos, cuánto tiene de artístico y cuánto de artificioso lo que oigas, deducir el concepto que del arte se han formado los polifonistas del siglo XVI y los compositores de cualquier época que sean." Ibídem, pp. $33-34$.

${ }^{127}$ Vicente Ripollés, "Segundo día del Congreso. Ejecuciones de música vocal.", ECA, 3345 de 13 de noviembre (1908), p. 2. 
1913, para encontrar esta idea. Como podemos comprobar, es la misma que subyace en el comentario sobre Guerrero realizado por Ripollés durante el congreso de Sevilla en $1908^{128}$ :

La música de Guerrero es noble, llena de elevación fervorosa, propia de un espíritu abrasado por la caridad y por el amor a la virtud: según sus propias palabras "nada tuvo jamás en mayor estima y aprecio, como no tanto alabar con el canto los oídos de las personas piadosas, cuanto el excitar sus piadosos ánimos a la digna contemplación de los misterios sagrados. Su villanesca espiritual es modelo de candor y gracia, y su motete Trahe me post te está impregnado del fervoroso entusiasmos que sentía por la Virgen, a la que dedicó la mayor parte de sus trabajos y obras. ${ }^{129}$

Sin duda, Guerrero fue el protagonista del Congreso entre los autores “clásicos". Su misa Puer qui natus est nobis fue la elegida para las partes del ordinario de la función solemne pontifical con la que se clausuró. Ripollés nos aclara la razón: "La elección de esta obra para el solemne acto del Pontifical de hoy no puede ser más oportuna y hace honor a la antigua y clásica Escuela Sevillana, digna de ser resucitada y vuelta a su buen predicamento entre los modernos maestros españoles"130. En ella halló un arquetipo de obra religiosa desde el punto de vista técnico, expresivo, y litúrgico:

Ya se verá como todas las cuatro voces van tomando el tema, dando interés, vida y animación al conjunto y no dejándolo jamás hasta los finales suaves y tranquilos de todos los números. La Misa

\footnotetext{
128 "Ecclesiastical musicologists between 1940 and 1990 viewed the 16th century as a sacred and intellectual age, when the moral honesty of the composers was transformed into mystical compositions. Thus, the religious attitude of the composers became the main standard for aesthetic evaluation. For this reason, Samuel Rubio considered it impossible to evaluate musical works by Juan del Encina or by Juan Navarro because no missa by either of them was extant. Again, we can trace this idea back to Henri Collet." Ramos, "The construction of the myth", [sin paginar]. En realidad, la idea del vínculo entre las virtudes morales y religiosas de los compositores, con la calidad y expresividad de sus composiciones no era original de Collet. El musicólogo francés la asimiló tras tomarla en préstamo del teórico italiano Pietro Cerone (1566-1625): "Il [Pietro Cerone] disserte [en su obra El Melopeo y Maestro] en vrai pédant sur les 'dangers du vin, sur l'ingratitude, sur les périls de trop parler, sur la vertu du silence, sur l'oisiveté, l'amitié et le véritable ami, le flatteur, le feint et faux ami, la prospérité et l'adversité, la tribulation et l'avarice.' Il affirme péremptoirement que 'pour être un parfait Musicien, il faut que celui qui veut composer bien soit lui-même bien composé, que celui qui veut faire des harmonies soit composé d'harmonies: car d'autre façon il ne pourra jaillir une Musique concertée et consonante d'un instrument désaccordé et dissonant.' Quelque ridicules que soient les expressions de Cerone, elles recouvrent un grand fonds de vérité, que nous allons mettre au jour par l'étude des différentes écoles musicales." Henry Collet, Le mysticisme musical espagnol au XVIe siècle (Paris: Librairie Félix Alcan, 1913), pp. 57-58.

${ }^{129}$ Vicente Ripollés, "Segundo día del Congreso. Ejecuciones de música vocal.”, ECA, 3345 de 13 de noviembre (1908), p. 2.

${ }^{130}$ Ibídem.
} 
del maestro Guerrero es de aquellas obras que no pueden inspirar más que sentimientos de devoción, de recogimiento, de espiritual misticismo y cántese donde se cante y como se cante siempre, será una obra rigurosamente litúrgica que nos hará recordar constantemente los dejos melódicos de la melopea gregoriana, modelo supremo de toda música sagrada. ${ }^{131}$

Sus cualidades expresivas eran modélicas:

El maestro aprovecha la entonación de séptimo tono del introito de la tercera Misa de Navidad para hacer un trabajo magistral, lleno de vida y expresión, dentro de la austeridad de la escuela sevillana, la más contraria entonces a todo espíritu de profanidad. ${ }^{132}$

El expresivismo místico atribuido a los polifonistas españoles, y a la "Escuela Sevillana”, como paradigma, constituyó la respuesta, genuinamente española, según el discurso regeneracionista del Congreso, a los problemas que respecto a la cuestión de la expresión de la obra musical habían surgido con el MP: la búsqueda de alternativas a la expresión dramática de la música teatral, condenada por ser considerada antirreligiosa; y la defensa frente a las acusaciones de los detractores de la polifonía clásica de ser una música hierática, inexpresiva, e incapaz de conmover.

\subsubsection{Música religiosa moderna: el supuesto éxito del programa}

\section{regeneracionista}

Como apuntábamos más arriba, la recuperación del "glorioso" pasado musical, es decir, de los autores renacentistas, tenía, además, una función regeneradora. Los clásicos debían servir de modelos para la música del presente. El criterio fundamental para el juicio de la música religiosa moderna fue, además de su cercanía "en aire, inspiración y sabor a la melodía gregoriana", de acuerdo a la "ley general" promulgada por el $M P$, el grado de asimilación de las virtudes que poseían aquellos referentes, especialmente el de la expresividad religiosa.

El autor moderno que se presentó como ejemplar fue Domingo Mas y Serracant, quien disfrutó del mismo protagonismo entre los compositores

\footnotetext{
${ }^{131}$ Ibídem.

${ }^{132}$ Ibídem.
} 
contemporáneos que Guerrero entre los clásicos ${ }^{133}$. Mientras que, como hemos referido, para la función solemne de clausura se eligió la misa Puer qui natus est nobis del andaluz, en la de inauguración se cantó una misa basada en motivos de la Misa de Angelis del catalán. Este es el comentario que mereció por parte de Ripollés:

El actual maestro de capilla de la parroquia de San Pedro de Barcelona es de un gusto refinado en materia de música sagrada y de los que cultivan con verdadero amor y apasionamiento el género litúrgico: su técnica es irreprochable y sus maneras inspiradas en el misticismo expresivo de los clásicos cuyas obras le son familiares: no desconoce ni desprecia los procedimientos modernos, si bien los usa con gran moderación: en no pocos casos toma por motivo la melodía gregoriana de quinto tono, como sucede en el verso "Qui talbis" y en otros; y siempre las voces se mueven en un ambiente gregoriano, que hace a esta obra eminentemente litúrgica. Toda la obra está escrita en el género polifónico a cuatro voces mixtas y hay algún número, por ejemplo el Benedictus, en que el autor se acerca más al estilo moderno expresivo. $^{134}$

Sobre Julio Valdés, discípulo y sobrino de Goicoechea, Ripollés realizó el siguiente comentario: "El joven maestro ha recibido la educación musical de los maestros Goicoechea y Besabe, y a pesar de ser poco práctico en la materia, maneja admirablemente el género polifónico, de tal manera, que su composición puede confundirse con la de los clásicos"135.

Las obras del propio Ripollés interpretadas durante el Congreso respondieron a estos cánones, según se desprende de sus propios comentarios. Sobre su Oremus pro Pontifice afirmó:

\footnotetext{
${ }^{133}$ Domingo Mas y Serracant (Barcelona,1870- Barcelona, 1944) estudió composición con Felipe Pedrell y Enric Morera. Ocupó los puestos de organista y maestro de capilla en diversos templos de Barcelona. Fue, además, profesor de la Academia Granados y de la Academia Marshall de la ciudad condal. Miembro de la Comisición Diocesana de Música Sagrada, fundó la Revista Parroquial de Música Sagrada y España Sacro-Musical. Como compositor, se dedicó de manera especial a la música religiosa y litúrgica. Cabe destacar, asimismo, sus armonizaciones de cantos populares, y algunas composiciones sinfónicas y de cámara. Lluís Millet i Loras, "Mas Serracant, Domingo", DMEH, 10 vols., ed. por Emilio Casares (Madrid: SGAE, 2001), vol. 7, pp. 322-323. Un estudio y una valoración de la obra de Mas y Serracant en Alberto Muñoz de Sus, "La obra coral y organística de Domènech Mas i Serracant" Revista de Musicología (Actas del Simposio Internacional "El Motu proprio de San Pío X y la Música (19032003)”), ed. por Mariano Lambea, XXVII/1 (2004), pp. 335-356.

${ }^{134}$ Vicente Ripollés, “Congreso de Música sagrada. Día 1º. Ejecuciones de música vocal”, ECA, 3344 de 12 de noviembre, p. 1.

${ }^{135}$ Ibídem.
} 
Terminará la sesión inaugural con las Preces Oremus pro pontífice, obra a cuatro voces mixtas y órgano, en la que un sencillo motivo es tomado con interés creciente por las diversas voces. Las ideas temáticas están tomadas unas veces de las preces gregorianas, otras son de libre invención, pero sin dejar nunca el parecido con los giros melódicos de la melopea gregoriana. Esta obra va creciendo en interés hasta el final en el que la expresión llega a su máxima intensidad. $^{136}$

La fidelidad a estas premisas le llevó, en algún caso, a traspasar el límite de la utilización del modelo clásico como fuente de inspiración, llegando al extremo de la pura imitación. Así se refirió a su $O$ Sacrum convivium:

Como final del Congreso, en el acto de exposición y bendición con el Santísimo, la Schola de Écija cantará el Pange lingua more hispano, y la Capilla Isidoriana un motete polifónico a cuatro voces, imitación de los antiguos polifonistas. ${ }^{137}$

Esta tendencia a la mimesis del referente más que al uso de este como punto de partida para la consecución de un nuevo estilo moderno se asoció a conceptos tales como rigidez o severidad. Villalba opinó: "El O sacrum convivium de Ripollés, aparte apreciaciones de carácter estético, está contenido en aquel más severo y aún rígido estilo de polifonía vocal; $[\ldots]^{\text {"138 }}$. Con todo, el maestro de capilla hispalense junto a Mas y Serracant representaron sus modelos de música religiosa moderna. Así valoró a ambos:

Muestras de una concepción artística más austera [que Goicoechea y Otaño] dieron Mas y Serracant y Ripollés. Tienen, en verdad, una fisonomía severa y reservada, trazada con rasgos bien definidos y vigorosos; la del último carece de arranques fuertes, pero en todo es la de un convencido que habla con entereza y dignidad; el primero aporta a su composición las formas de los polifonistas del XVI y reproduce las obligadas fórmulas cadenciales de aquella época.

${ }^{136}$ Ibídem.

137 Vicente Ripollés, "El Congreso de Música Sagrada. Día cuarto”, ECA, 3347 de 15 de noviembre (1908), p. 1.

${ }^{138}$ Mauricio [Villalba], "Impresiones del congreso", ECA, 3348 de 16 de noviembre (1908), 1. En fecha tan temprana como 1878, José Inzenga se pronunció así: "Creemos por último, porque no somos sistemáticos ni exagerados puristas, que sin ir hasta la severidad de un Palestrina, de un Morales... y de otros, pero siguiendo sus pasos tan de cerca como lo permita el desarrollo actual del arte, puede escribirse buena y propia música religiosa para el culto [...]" José Inzenga, La Música en el templo católico (Madrid: Imprenta de Fernando Cao, 1878); cit. en Virgili, “Antecedentes y contexto ideológico”, p. 34.

${ }^{139}$ Villalba, "El Segundo Congreso Nacional", p. 88. 
Los juicios que el agustino emitió sobre las obras de Olmeda fueron también bastante favorables, y hay que entenderlos desde aquella concepción de música moderna como punto culminante de una evolución histórica en la que la expresión y la forma, los dos elementos que hasta ahora los compositores no habían sabido integrar con éxito, alcanzaban un equilibrio ${ }^{140}$ : "El equilibrio armónico entre la forma y el fondo, en la expresión artística y en la composición puramente musical, brilló notablemente en el Sanctus y Agnus de la misa de Olmeda."141

En cambio, Villalba dedicó a las obras de Otaño y Goicoechea, probablemente, la peor crítica que estos pudieran recibir, calificarlas de dramáticas y efectistas; e incluso, aunque no lo afirme explícitamente y sólo lo sugiera por el empleo de un hábil juego retórico, de teatrales:

Entre los modernos, los de ahora digo, la nota más intensamente dramática, la dieron Goicoechea y el P. Otaño. No diré yo que fuera dramático en el sentido de teatral, que es lo que muchas gentes entienden por dramático, pero que andaban en los últimos lindes donde casi se confunden lo efectista con lo expresivo, eso sí. Si $m e$ [énfasis original] desagradó, o no, no hay por qué decírtelo; lo que es expresivo gusta, lo efectista no es virtud; pero ¿quién se atreverá a señalar la raya definitiva entre una y otra cosa? Lo que sí te aseguro, es que conociéndoles, como les conozco por la corteza, es decir, por el criterio exterior, de boca afuera, algún tanto rígido que han manifestado, no me dejó de chocar el calor, la expresión, el efectismo ¡vaya! de su música, tanto, que mientras la cantaban no pude menos de acercarme a un amigo y decirle al oído: Supongo que estos no hablarán mucho de lo teatral; de lo teatral, por supuesto, en el buen sentido de la palabra. ${ }^{142}$

El uso de este estilo discursivo de regates e insinuaciones se explica por la gravedad del significado implícito en el comentario. Desprovistas de expresividad auténtica, cualidad distintiva de la música genuinamente española, y tachadas de dramáticas, condición incompatible con el arte verdaderamente religioso postulado por el $M P$, Villalba las desterró de esa región figurada de lo ejemplar -religioso y españoldelimitada por el Congreso.

\footnotetext{
${ }^{140}$ Esta visión de la historia de la música defendida por Villalba ha sido discutida más arriba. Véase p. 530 .

${ }^{141}$ Ibídem, p. 123.

${ }^{142}$ Ibídem, pp. 87-88.
} 
Las tendencias "modernistas" -quizás impresionistas, a juzgar por la descripción de Villalba-, representadas por el $O$ quam suavis de Luis Romeu, tuvieron también su espacio en el programa ${ }^{143}$. En este caso, el crítico no efectuó ningún juicio de valor explícito. En consecuencia, habría que contemplar, en principio, su posición respecto al modernismo de Romeu como más o menos neutra, a no ser que las expresiones y los epítetos empleados se interpreten en clave retórica:

El tono gris, la vaga placidez, las tintas tibias, la penumbra continua, en ritmo, en melodía, en expresión, es decir lo modernista con todas sus cualidades, lo ofreció el Maestro de Capilla de Vich D. Luis Romero en el $O$ quam suavis. ${ }^{144}$

Romeu no era moderado en el uso de "procedimientos modernos", virtud destacada por Ripollés en sus comentarios sobre la ensalzada misa de Mas y Serracant ${ }^{145}$. Por el contrario, en su estilo se encontraba "lo modernista con todas sus cualidades". Esta apuesta clara por el "modernismo" alejaba al maestro de capilla de Vich de la opinión oficialista ${ }^{146}$.

Con todo, el mensaje de Villalba, compendiado en el párrafo con el que concluyó sus reflexiones sobre el programa musical del Congreso fue:

\footnotetext{
${ }^{143}$ Luis Romeu nació en Vich el 23 de junio de 1974. Fue organista y maestro de capilla de la catedral de su ciudad natal desde 1901. Su actividad estuvo centrada en la reforma de la música religiosa, dedicándose de manera especial al canto religioso popular. Recibió varios premios de composición en diversas ediciones de la Festa de la Música Catalana. En su estilo, según apunta Victoria Eli, convergen en estrecha relación la influencia del canto gregoriano y la canción popular catalana. Como musicólogo publicó algunos artículos en la Revista Musical Catalana, así como un extenso ensayo titulado La versió autèntica dels Goigs del Roser de tot l'any en el volumen del año 1928 de L'obra del cançoner popular de Catalunya. Su producción, exclusivamente religiosa, asciende a más de trescientas composiciones. Murió el 23 de septiembre de 1937. Victoria Eli, "Romeu, Luis", DMEH, 10 vols., ed. por Emilio Casares (Madrid: SGAE, 2001), vol. 9, p. 401; Miquel Saperas, "Mossen Lluís Romeu, apostol de la musica sagrada", Ausa. Publicació del Patronat d'Estudis Osonencs VII/76 (1973), pp. 169-186. El catálogo de sus obras ha sido publicado por Frederic Pujol y Josep María Marques, "Cataleg de les obres de Mn. Lluís Romeu", ibídem, pp. 187-210.

${ }^{144}$ Ibídem, p. 123.

${ }^{145}$ Véanse los comentarios de Ripollés en pp. 546-547.

${ }^{146}$ En el volumen Los señores de la crítica, ya citado, Teresa Cascudo y María Palacios establecían una serie de hipótesis derivadas de los artículos que lo componen. La primera de ellas consistía en distinguir "regeneración" o "restauración", por un lado, y "modernismo", por otro, aunque ambas tendencias convivan en un marco de relaciones estrechas. Los escrúpulos y precauciones mostrados por los principales ideólogos y líderes de la reforma litúrgico-musical ante las influencias "modernistas" -término ciertamente polémico en la Iglesia en aquellos momentos-, evidencian que en el ámbito de la música religiosa esa distinción fue especialmente nítida. Los señores de la crítica, p. VIII-XIX.
} 
En una palabra: esta exposición de arte moderno religioso ha sido una página honrosísima para el arte musical español. Los que saben qué es lo que en el extranjero se hace, habrán podido apreciar, que los españoles pueden medirse con ellos en solidez técnica, desde luego, que en cuanto a fuerza expresiva tengo para mí que les llevan por punto general alguna ventaja ${ }^{147}$

La muestra de música religiosa contemporánea que el Congreso presentó, probó, según Villalba, la homologación del nivel técnico de los músicos españoles respecto a los europeos, y su superioridad en cuanto a expresividad -"fuerza expresiva"- Con ello, el programa regenerador se habría cumplido con éxito. En el discurso de uno de los encargados de divulgar el mensaje estético e ideológico oficial del Congreso, los compositores modernos españoles recuperaron la posición perdida en el concierto musical europeo al haberse reencontrado con sus antepasados "gloriosos", los polifonistas religiosos del s. XVI. Victoria y los compositores de la "Escuela Sevillana" sirvieron de grandes referentes, pues representaron el ideal de músicos religiosos españoles, y su música constituyó el sustrato con la que informar la contemporánea, proporcionándole sus mismas cualidades y virtudes. De acuerdo al ideario nacionalista, el rasgo más español, el expresivismo místico, de la música escrita por españoles, otorgó de nuevo, al igual que hiciera en aquella época contemplada como dorada, la superioridad a la nueva "escuela musical religiosa española". En opinión de Villalba, los nuevos compositores religiosos hispanos alcanzaron así el mismo puesto que Ripollés había atribuido a Victoria, "según el autorizado parecer de reputados maestros", y podían rivalizar con sus coetáneos europeos, como hiciera el abulense con Palestrina. La época, calificada de aciaga tanto por Ripollés como por Villalba, se habría superado, y cerrado el ciclo histórico regeneracionista. La música religiosa española habría vuelto a florecer -resucitó, según Franculus- con el mismo esplendor que en su época de apogeo ${ }^{148}$.

Con todo y a pesar de la constante presencia de "Europa" y la "música europea" en estos discursos, llama la atención la absoluta ausencia de alusiones concretas al sentido en el que estaba evolucionando, en términos estéticos y estilísticos ${ }^{147}$ Ibídem.

148 El poderoso influjo que la idea del resurgir musical español, asimilada y capitalizada fundamentalmente por Pedrell, ejerció sobre los principales músicos españoles del primer tercio del s. XX, incluida la tríada Granados-Albeníz-Falla, está, según Juan José Carreras, fuera de toda duda. Carreras amplía su impacto a la historiografía española que sigue la línea de Anglés, e incluso al nacionalismo catalán. Carreras, "Hijos de Pedrell”, p. 127. 
la música religiosa francesa, italiana o germánica, por ejemplo. Ello sugiere que los términos "música europea" o "Europa" eran usados como conceptos indefinidos y abstractos, sin conexión con la realidad religioso-musical europea de aquel momento; y tenían, en realidad, una mera función referencial al servicio del fin de elevar la música española al puesto preeminente supuestamente perdido, como señalamos.

En sus narrativas sobre la historia de la música española, los regeneracionistas defendieron la existencia de una vía de transmisión por la que se habría conservado durante los siglos de decadencia la herencia incorrupta de los grandes polifonistas. Según dichas narrativas, durante la fase de ese ciclo histórico ternario (esplendordeclive-renacimiento) en la que se produjo la degradación de la música religiosa existieron algunos compositores que se mantuvieron fieles a una expresión musical religiosa considerada impoluta, y no sucumbieron a las modas seculares profanizantes. Ripollés expuso el caso de Juan Moreno, maestro de capilla de la catedral de Tortosa:

Terminada la bendición papal se entonará solemne Te Deum, con el doble fin de festejar el jubileo sacerdotal del Papa y dar gracias a Dios por el feliz éxito del Congreso. La Capilla Isidoriana cantará la obra de Juan Moreno, maestro de capilla de la Santa Iglesia Catedral de Tolosa. Ya se verá cómo a pesar de pertenecer este maestro a una época aciaga para el arte (siglo XVIII), se conservó puro escribiendo obras exentas de florituras y bien provistas de ricas, y a veces, atrevidas armonías. ${ }^{149}$

El resto de músicos españoles modernos (s. XVIII-XIX) incluidos en el programa fueron Aranaz (XVIII) ${ }^{150}$, Cabo $\left(1^{\text {a }} \operatorname{mitad} \text { del XIX }\right)^{151}$, y Eslava. Villalba se

${ }^{149}$ Vicente Ripollés, "El Congreso de Música Sagrada. Día cuarto", ECA, 3347 de 15 de noviembre (1908), p. 1.

${ }^{150}$ (Tudela, 1740-Cuenca, 1820). Estudió con Luis Serra y Francisco Javier García “el Españoleto". Tras sus años de formación como infante de la catedral de Zaragoza, se dedicó a la composición de música teatral, destacando en el género de la tonadilla escénica. En 1769 ganó la plaza de maestro de capilla de la catedral de Cuenca. Este hecho, además de su ordenación sacerdotal (1773) constituyó un punto de inflexión en su carrera. Desde entonces se dedicó en exclusiva a la composición de música religiosa. Catedrales como las de Pamplona, Zaragoza, Ávila, Segovia, Oviedo, Sevilla y Toledo le llegaron a ofrecer el puesto de maestro de capilla sin necesidad de someterse a oposición alguna, lo que demuestra el prestigio que alcanzó. Aranaz llevó a cabo una profunda reforma de la música en la catedral de Cuenca, sustituyendo los villancicos vernáculos por responsorios latinos. Su estilo, clásico, participa de la moda italiana de la época, aunque, según Querol sin sumarse plenamente a ella. Fue un compositor ciertamente prolífico. Su producción religiosa se cifra en más de quinientas obras. Fernando J. Caballas Alamán, "Aranaz y Vides, Pedro Felipe", DMEH, 10 vols., ed. por Emilio Casares (Madrid: SGAE, 2001), vol. 1, pp. 548-554.

151 (Náquera, Valencia, 1768-?, 1832). Organista de la catedral de Orihuela, ocupó los cargos de tiple, organista segundo, organista primero y maestro de capilla de la valenciana, donde había sido infantillo desde 1778. Reconoció como su maestro a Rafael Anglés. José Climent diferencia claramente su estilo 
refirió a todos ellos como músicos "de los tiempos aciagos, en que, no obstante la decadencia, vivían Soler, Navarro, Aranaz, Cabo y otros, de los en que floreció Eslava, [...]"152. Conviene advertir que el Eslava mostrado por el Congreso no correspondió, desde luego, con el famoso compositor de misereres, lamentaciones, misas, secuencias, tantas veces tachadas de ampulosas, teatrales e italianizantes. La única obra de Eslava incluida en el programa fue el motete Jesu dulcis memoria, de un estilo cercano al cecilianismo. Este cecilianismo de este "otro Eslava” sí se aceptó como acorde con los requisitos estéticos y estilísticos contemplados en el $M P^{153}$. De hecho, según afirma López-Calo, sus obras cecilianistas se difundieron por muchas catedrales españolas tras la publicación del rescripto papal ${ }^{154}$. $\quad \mathrm{M}^{\mathrm{a}}$ Antonia Virgili ha puesto de relieve igualmente la evolución estilística experimentada por Eslava. Virgili ubica los comienzos de esta transformación estilística en su etapa sevillana, y señala la influencia que debió ejercer en él las obras de los polifonistas renacentistas conservadas en la catedral andaluza ${ }^{155}$.

de composición orgánica y vocal. Respecto al primero apunta su carácter romántico italianizante, mientras que el segundo lo describe como heredero del estilo policoral valenciano del s. XVII aunque con recursos armónicos del s. XIX. José Climent, "Cabo Arnal. 1. Francisco", DMEH, 10 vols., ed. por Emilio Casares (Madrid: SGAE, 2001), vol. 2, pp. 840-841.

${ }^{152}$ Mauricio, "Impresiones del Congreso. Segundo día”, ECA, 3346 de 14 de noviembre (1908), p. 1. De ellos tres, el que mejor crítica recibió de Villalba fue Aranaz, a quien Pedrell consideraba, según el crítico, "el último de los romanos": "Del XVIII, la más expresiva y con unción religiosa, es el Ofertorio Improperium, de Aranaz. Toca, en mi opinión, la meta de lo artístico; sus formas melódico-armónicas son las de su época, discretísimamente, correctamente empleadas; no alardea de artificios complicados, porque supedita la forma al sentir; no es polifonista, frasea y dice en masas compactas de armonía. Este Aranaz tiene formado un estilo y un lenguaje y un concepto determinado del arte. La obra cantada no es una excepción; toda la colección de ofertorios que aquí tenemos ofrece los mismos caracteres. Pedrell me dijo hablando un día de este compositor que era el último de los romanos; no sé si será el último, pero romano, es decir, de los buenos, eso sí." Villalba, "El Segundo Congreso Nacional”, p. 37.

${ }^{153}$ López-Calo se refiere a "otro Eslava" para aludir al estilo del compositor navarro más cercano a las corrientes cecilianistas. Establece así una contraposición entre este y el Eslava "tradicionalmente conocido y citado", es decir, el de sus obras italianizantes. López-Calo, "Hilarión Eslava (1807-1878), precursor del Cecilianismo en España”, pp. 577-608, p. 604.

${ }^{154}$ En su estudio "Hilarión Eslava, compositor de música sagrada", publicado en Monografía de Hilarión Eslava, ed. por equipo Musikaste-Eresbil (Pamplona: Diputación Foral de Navarra, 1978), pp. 121-150, López-Calo afirma: "A este grupo [de obras que anticiparon el cecilianismo y las tendencias del $M P$ ] pertenece, ante todo, su excelsa, aunque breve, colección de motetes. Los cuales, es importante tenerlo presente, tuvieron también una enorme difusión por las catedrales españolas y contribuyeron eficazmente a la propagación de este género, tan importante, de música religiosa, sirviendo de modelo e inspiración a otras muchas. De hecho, hay copias de ellos en muchos archivos catedralicios, algunas hechas en pleno fervor postpiano de pureza litúrgica.”, p. 144. López-Calo reproduce este fragmento en el artículo citado en la nota anterior.

${ }^{155}$ María Antonia Virgili Blanquet, "La música religiosa en el siglo XIX español”, en La música española en el siglo XIX. ed. por Emilio Casares y Celsa Alonso (Oviedo: Universidad de Oviedo, 1995), pp. 375 405, pp. 384-385. Virgili afirma que Eslava no fue un caso aislado, sino que es posible advertir esta 


\subsection{Canto popular religioso: la omnipresencia de las ideas del}

\section{nacionalismo musical español}

La incorporación del canto popular religioso al conjunto de géneros musicales sacros -en este caso, de carácter paralitúrgico- se produjo en un momento en el que la cuestión de la música popular había adquirido una enorme relevancia ${ }^{156}$. El interés por el folklore fructificó en la aparición de varias colecciones de cantos populares españoles como los de Eduardo Ocón, José Inzenga, o los posteriores de Federico Olmeda y Dámaso Ledesma ${ }^{157}$. El conocido Cancionero musical popular español de Pedrell no se terminaría de publicar hasta 1922, aunque la dedicación de su autor al estudio de los cantos populares fue una constante de su actividad musicológica. Como es sabido, en Por nuestra música (1891) cimentó sobre el canto popular -merced a su capacidad regeneradora de la música española- su proyecto ideológico y estético sustanciado en la ópera nacional ${ }^{158}$. En realidad, para Pedrell la trabazón entre lo culto y lo popular fue

tendencia en otros compositores religiosos del momento, ibídem, pp. 393. La autora recupera todas estas consideraciones en: "La música religiosa en el siglo XIX español”, Revista Catalana de Musicología, 2 (2004), pp. 181-202, p. 189.

156 En este mismo sentido, María Antonia Virgili señala algunas de las corrientes de pensamiento y tendencias que conformaron el contexto en el que se inscribe el interés por el canto popular religioso en el marco de la reforma: la revalorización de lo autóctono y de las manifestaciones populares, todo ello conectado con el nacionalismo musical decimonónico, el asociacionismo y la importancia del movimiento coral. María Antonia Virgili Blanquet, "El Canto Popular Religioso y la Reforma Litúrgica en España (1850-1915)", Aisthesis, 47 (2010), pp. 175-186, p. 178-179.

${ }^{157}$ Eduardo Ocón, Cantos españoles. Colección de aires nacionales y populares, formada e ilustrada con notas explicativas y biográficas, (Málaga: [s.n.(Breitkopf und Härtel) ], 1874); José Inzenga, Ecos de España: colección de cantos y bailes populares, (Barcelona: Andres Vidal y Roger, 1874); Federico Olmeda, Folk-lore de Castilla o Cancionero Popular de Burgos (Sevilla: Lib. Ed. María Auxiliadora, 1903); Dámaso Ledesma, Folk-lore o Cancionero salmantino (Madrid: Imp. Alemana, 1907).

${ }^{158}$ En el marco del programa regeneracionista y nacionalista pedrelliano, la investigación del folklore estuvo al servicio de la recuperación de las esencias nacionales presentes en el canto del pueblo para ser infundidas a la nueva música española, en especial de la ópera nacional. La conocida cita con la que encabezó el capítulo primero de Por nuestra música y que atribuyó a Eximeno, es toda una declaración estética: "Sobre la base del canto nacional debía construir cada pueblo su sistema". Felipe Pedrell, Por nuestra música (Barcelona: Imp. de Henrich y Cía), p. 39. El siguiente fragmento puede, acaso, servir de síntesis de la función regeneradora encomendada a la música popular: "El canto popular, esa voz de los pueblos, la genuina inspiración primitiva del gran cantor anónimo, pasa por el alambique del arte contemporáneo y resulta su quinta esencia: el compositor moderno se nutre con aquella quinta esencia, se la asimila, revistiéndola con delicadas formas que la música y sólo la música puede evidenciarnos todo lo que es capaz y todo lo que comporta la forma bajo el concepto técnico, gracias al extraordinario desenvolvimiento desconocido a los siglos pasados, que ha adquirido en nuestra época." Ibídem. Gilbert Chase aclara que la frase que Pedrell atribuyo al jesuita expulso era, en realidad, de Menéndez Pelayo. "Pedrell, Eximeno y el nacionalismo musical", Revista musical chilena II/13 (1946), pp. 10-12. Sobre la importancia del pensamiento de Eximeno y el influjo de Menéndez Pelayo en la conformación del nacionalismo musical de Pedrell, véase: Alberto Hernández Mateos, "La recepción del pensamiento de Antonio Eximeno en la historiografía musical española del siglo XIX. Una aproximación", en Musicología global, musicología local, ed. por Javier Marín López, Germán Gan Quesada, Elena Torres Clemente, Pilar Ramos López (Madrid: Sociedad Española de Musicología, 2013), pp. 1539-1557. 
un rasgo característico -la "nacionalidad del arte"- de la "música española", constante a lo largo de toda la historia. Como ha puesto de relieve Antonio Martín Moreno, el Cancionero musical popular español, el "dramático testamento musical" de Pedrell, según Francesc Bonastre, es también una pequeña antología histórica del teatro musical español, género que, según la tesis pedrelliana poseía un fundamento y carácter esencialmente popular ${ }^{159}$.

Conviene puntualizar que el canto popular religioso no se menciona en ningún momento en el MP. Por tanto, la aceptación de esta expresión musical como válida para integrarse en las funciones paralitúrgicas se debió al criterio de los reformistas españoles. La razón que estos esgrimieron no tenía que ver, desde luego, con el programa pedrelliano. Estaban relacionadas con las importantes virtudes prácticas que hallaban en la música popular religiosa. El "verdadero" canto popular religioso, que Otaño diferenció del populachero en el congreso de Valladolid, al igual que hizo Ledesma en el de Sevilla, facilitaba la consecución de uno de los objetivos del programa de renovación litúrgica emprendido por Pío X, como era la participación activa de los fieles en las funciones religiosas ${ }^{160}$. Así se hizo constar en las conclusiones del congreso castellano:

El Congreso considerando la gran utilidad que hay en que el pueblo tome parte activa en los oficios y funciones religiosas, estima necesario el uso del canto ya sea gregoriano, ya popular religioso, diligentemente depurado y coleccionado, haciendo votos porque desaparezcan esos cantos poco dignos por su forma y expresión del arte de la santidad de los cánticos sagrados. [... $]^{161}$

Consúltese del mismo autor, El pensamiento musical de Antonio Eximeno. Tesis doctoral, Salamanca (2012). Disponible en: <http://gredos.usal.es/jspui/handle/10366/118518> (consultado 9-4-2014).

\footnotetext{
${ }^{159}$ Martín Moreno, "Felip Pedrell y el descubrimiento del teatro barroco español”, pp. 126-131.

${ }^{160}$ La intervención de Otaño en la sesión de estudio dedicada a este aspecto comenzó así: "He aquí un punto que en España es de verdadero interés práctico. En nuestra patria el pueblo canta y en algunas regiones el pueblo canta con verdadero arte y con un afán increíble. Hay muchos desgraciadamente que no tienen idea de lo que es canto popular y menos canto popular religioso. Para saber esto es necesario apartar de nuestro oídos esos cantos populacheros que en estos últimos tiempos han obligado cantar al pueblo [...]". "Crónica del Congreso. 26, 27 y 28 de Abril", MSH, 1 (1907), pp. 30-31. Ledesma, por su parte, afirmó en el Congreso de Sevilla: "La música religiosa, por los distintos efectos que puede causar en los fieles, la divido en superflua y solemne.

La solemne, la subdivido en homofónica y polifónica. La popular, en popular y populachera. " Crónica del Segundo Congreso, p. 135.
}

${ }^{161}$ Crónica del Primer Congreso, pp. 26-27. 
Estas conclusiones corresponden al único punto que el cuestionario de dicho congreso dedicó a este aspecto: El canto popular religioso; cuál debe introducirse en los templos y cómo ${ }^{162}$. La presencia en el I Congreso de la cuestión del canto popular religioso se completó con las referencias que al respecto se pueden encontrar en las conclusiones de otro de los puntos, el referido a Las diversas funciones extralitúrgicas, y los comentarios que Federico Olmeda realizó en su discurso La música sagrada en las parroquias $^{163}$. En el primer caso, se hizo mención a la necesidad de sustituir "las composiciones frívolas, chocarreras y de mal gusto, las novenas y gozos escritos en ritmo de danzas," con estribillos a modo de marchas o "estrofas en forma de arias, romanzas, etc.", por otras verdaderamente religiosas, entre las que se habían de preferir aquellas "de sabor genuinamente popular"164. En la exposición de Olmeda se pueden advertir los lazos íntimos que en su pensamiento unían sus pretensiones reformistas y su ideario nacionalista ${ }^{165}$.

Los acuerdos reflejados en las conclusiones del congreso de Sevilla ponen de manifiesto una notable labor de ampliación y concreción de los puntos de partida establecidos en Valladolid ${ }^{166}$. Mientras que la asamblea celebrada en esta última ciudad no fue más allá de subrayar el valor del canto popular religioso como una expresión musical eclesiástica absolutamente lícita para las funciones paralitúrgicas e idónea para conseguir la participación de los fieles en el culto, en la andaluza, además, se idearon e intentaron poner en marcha proyectos y estrategias concretas con el fin de difundirlo e

162 Sección c) Música moderna religiosa. Punto $6^{\circ}$. Otaño estableció en su intervención las bases fundamentales $\mathrm{y}$, sin aportaciones destacables por parte de otros congresistas presentes, figuraron en las conclusiones finales del Congreso. Además de la de Otaño, la crónica sólo reseñó una intervención de Viñaspre así como "(Intervienen en el mismo sentido varios congresistas y se indica la conclusión que luego fue aprobada)". "Crónica del Congreso. 26, 27 y 28 de Abril", pp. 30-31.

${ }^{163}$ Este discurso fue recogido íntegro en Crónica del Primer Congreso, pp. 78-87.

${ }^{164}$ Ibídem, pp. 17-18.

165 Ibídem, pp. 85-86. María Antonia Virgili trata la cuestión del canto popular religioso durante el congreso de Valladolid en: "El Canto Popular Religioso", pp. 180-181. A continuación pone de relieve el avance que en términos de maduración y materialización de las ideas sobre el particular representó el III Congreso Nacional de Música Sagrada (Barcelona, 1912), sin hacer mención al congreso de Sevilla. La información que aquí proporcionamos complementa la ofrecida por la Dra. Virgili, y completa el panorama que dibuja, pues, como ponen de manifiesto las iniciativas que se pusieron en marcha, la asamblea andaluza constituyó un primer y significativo avance respecto a la vallisoletana.

${ }^{166}$ El cuestionario del congreso de Sevilla incluía dos puntos relacionados con el canto popular religioso: "Sección 2a .- De la música figurada: g) Canto religioso popular: Manera de formar una colección de cantos religiosos populares de las diversas regiones de España. h) Conveniencia de que en las funciones extralitúrgicas se sustituyan los cantos hoy en uso por otros religiosos populares en que tome parte el pueblo: manera de llevar a la práctica esta conclusión.” Crónica del Segundo Congreso, p. 21. 
implantarlo. La preferencia por la interpretación antifonal -"forma salmódica"- de las piezas populares, la traducción al castellano de oraciones latinas, o la enseñanza de este repertorio en las escuelas fueron medios propuestos para conseguir que el pueblo cantara en las iglesias. Junto a estas ideas, nos parece particularmente interesante la propuesta de elaborar un cancionero popular religioso español, objetivo para el que se diseñó el siguiente protocolo de actuación: "nómbrese en cada Diócesis persona que recoja los cantos de la propia región y los mande a la presidencia de este Congreso, para que, seleccionados por persona competente, se forme la colección deseada." ${ }^{, 167}$. Aunque la iniciativa persiguiera, al igual que las demás, el fin de hacer participativos los actos paralitúrgicos y devocionales, posee resonancias que remiten a otros proyectos análogos, tales como los cancioneros populares mencionados anteriormente. Estos puntos de coincidencia empujan a considerar, tal y como apuntábamos más arriba, la forma en la que determinadas tendencias finiseculares, inscritas en el programa nacionalista, incidieron en la recepción del $M P$ en España, y moldearon el proyecto original papal según las condiciones específicas del contexto español. A nuestro modo de ver, músicos eclesiásticos como Federico Olmeda o Dámaso Ledesma, autores de sendas colecciones de cantos populares -no exclusivamente religiosos- $y$ comprometidos con el MP personificaron la confluencia de las corrientes nacionalistas y reformistas en lo que al canto popular se refiere. Precisamente fueron los cancioneros publicados por el burgalés y el salmantino las obras que el Congreso hispalense recomendó entretanto se hacía realidad el proyecto de cancionero popular religioso español.

\footnotetext{
${ }^{167}$ Estas fueron las conclusiones del congreso de Sevilla relativas a este aspecto: "Punto g). Para la formación del Cancionero popular-religioso español, nómbrese en cada Diócesis persona que recoja los cantos de la propia región y los mande a la presidencia de este Congreso, para que, seleccionados por persona competente, se forme la colección deseada. Mientras tanto, se recomiendan las colecciones publicadas por D. Federico Olmeda, D. Dámaso Ledesma y algunas premiadas por el Orfeón Catalán.

Punto h). 1. ${ }^{a}$ Sería muy conveniente frecuentar en los cantos populares la forma salmódica, en la que el pueblo alternase con el coro, ora variando cada vez la letra el pueblo, ora variándola sólo el coro y repitiendo un estribillo constante el pueblo. Las dos formas son muy usadas en la iglesia. 2. ${ }^{a}$ Sería asimismo conveniente que, a semejanza de la Salve, estuviesen así en buena música popular otras oraciones en castellano, como el Credo, el Padre nuestro, el Ave María, el Señor mío Jesucristo, el Alma de Cristo, el Cordero de Dios, el Yo no soy digno y otras., Y en latín también el Tantum Ergo, las Letanías lauretanas y otros himnos. $3 .^{\mathrm{a}}$ Deberían hacerse libros en que estuviesen las letras aprobadas para cánticos religiosos, y en ellos al lado del canto latino, poner la traducción castellana, para que el pueblo tenga gusto aun en los cantos latinos. $4{ }^{\mathrm{a}}$ El Congreso propone que, para hacer cantar al pueblo los cantos populares religiosos, se enseñen estos en las escuelas o colegios, o a falta de estos a cierto número de personas de buena voluntad para que, después de bien ensayados, los canten en las iglesias y los aprenda el pueblo." Crónica del Segundo Congreso, 271. Estas conclusiones fueron propuestas por Vilariño y José Aguilar, y aceptadas por el Congreso. Véase: $M S H, 18-19$ (1908), pp. 174 y 176.
} 
Las circunstancias que rodearon la preparación de la conferencia-concierto sobre el canto popular impartida por Ledesma en el Congreso, así como la forma en la que éste la presentó, desvelan la omnipresencia de las ideas regeneracionistas en los esquemas mentales de los reformadores, y su condición de trasfondo en la cuestión del canto popular religioso. Es posible, incluso, probar que la pretensión inicial de los organizadores sevillanos fue contar con el magisterio de Pedrell para orientar a los congresistas en este punto de la reforma.

Como ya hemos apuntado, la conferencia de Ledesma recibió críticas desfavorables. Villalba cuestionó algunas de las ideas y apreciaciones expuestas por el entonces organista de la catedral de Salamanca, un ejercicio crítico que, como venimos sosteniendo, fue excepcional durante el Congreso:

El señor Ledesma dio a conocer cantos religiosos unos, y con motivo de asuntos religiosos otros, y los presentó aderezados en concierto, al unísono unas veces, en cuarteto vocal otras. Las melodías ofrecidas son interesantes desde luego y merecedoras de toda atención. La conferencia, aparte ciertas afirmaciones muy discutibles y de apreciaciones excesivas en que el entusiasmo hacia sus aficiones le hace resbalar, fue notable y curiosa. ${ }^{168}$

En el comentario mucho más extenso que publicó posteriormente en $L C D$, Villalba centró sus consideraciones en la forma en la que el conferenciante había presentado los cantos propuestos como ejemplo. Según el agustino de El Escorial, la fórmula elegida por el salmantino era inapropiada para el propósito al que debía servir. Este consistía en presentar modelos de interpretación de las melodías religiosas populares accesibles al pueblo, es decir, acordes con la realidad y las limitadas posibilidades de las gentes que debían cantarlas:

en lo que no estoy conforme es en la manera de disponerlas para su ejecución en el concierto. El canto popular se canta siempre por el pueblo al unísono, repartido en solos o en coros, pero siempre dando una sola nota. Estos ejemplos de canto popular se ofrecen además para mostrar el tesoro melódico que tiene el pueblo, con el fin de que los Párrocos puedan aprovechar estas tonadas rústicas originalísimas y de un arte todo espontáneo y encima fáciles de ejecutar, para uso de sus feligreses; pues bien, estas tonadas, desplegadas en cuarteto vocal, en vez de dar al Párroco la idea de su facilidad, le produce la impresión contraria, y de seguro que no piensa

${ }^{168}$ Mauricio, "Impresiones del Congreso. Segundo día”, ECA, 3346 de 14 de noviembre (1908), p. 1. 
en que así las podrán cantar las mozas y los mozos de su pueblo, si es que no le quitan del todo la idea de que aquello es canto popular. ${ }^{169}$

Unas líneas más adelante sugirió el origen de la posible "confusión" de Ledesma, y al hacerlo exponía el papel germinal y revitalizador de la música española que el programa regeneracionista había asignado al canto popular:

El arte popular del pueblo es y para el pueblo se destina, y por eso, aunque no se le presente como es en sí rigurosamente, debe ser ofrecido en condiciones que el pueblo pueda aceptarle, sin otros requilorios que los que el alcance artístico del pueblo puede soportar: un acompañamiento sencillo que pueda ser tocado por el sacristán de la parroquia, y la melodía cantable al nivel de la ciencia solfística del pueblo, esto es, al unísono, es lo práctico. Ahora, si se trata de demostrar otra cosa, a saber, la nueva vida que puede dar al arte culto el popular infundiéndole la savia pura y oxigenada del campo, los nuevos derroteros que le pueda marcar, las orientaciones regeneradoras y demás honduras del arte grande, me callo; pero aquí no se pedía eso, ni para eso se exhibían las tonadas religiosas del pueblo, sino para algo más humilde secundum musicam, pero de misión social más práctica. ${ }^{170}$

Es fácil reconocer en estas afirmaciones las ideas que Pedrell vertió en su declaración ideológica y estética Por nuestra música. Es más, son las mismas que podemos encontrar en las introducciones de los cancioneros populares de Dámaso Ledesma y Federico Olmeda que, como ya hemos apuntado, el Congreso recomendó junto con las premiadas por el Orfeó Catalá ${ }^{171}$. En la introducción de Olmeda se puede leer:

¿No es pues un deber de todos los españoles devotos del divino arte, procurar por todos los medios que España alcance el

\footnotetext{
${ }^{169}$ Villalba, "El Segundo Congreso Nacional”, p. 127.

${ }^{170}$ Ibídem, p. 128.

${ }^{171}$ Los concursos organizados por distintas entidades jugaron un importante papel en la promoción de estos estudios sobre música popular. Los cancioneros de Ledesma y Olmeda ganaron sendos premios convocados por la Real Academia de San Fernando y la Diputación de Burgos respectivamente. Ledesma declaró en la introducción de su Cancionero salmantino: "Llegada ya la edad madura, volví a escuchar los mismos cantos en mis frecuentes excursiones campestres; volví a sentir su intensa y lánguida belleza, y entonces pensé reivindicar a mi país de la calumnia aceptada como verdad corriente [que en España no existían instintos musicales], transcribiendo sus cantos populares; pero este noble propósito hubiese ido, como otros muchos, a empedrar el infierno, si el Concurso abierto por la Real Academia de Bellas Artes no me hubiese alentado a emprenderlo." Dámaso Ledesma, Folk-lore o Cancionero Salmantino (Madrid: Imp. alemana, 1907), pp. 13-14.
} 
grado, que dados sus antecedentes debía ocupar? ¿Se olvidaron las buenas tradiciones? Pues vuélvase a ellas y estúdiense. ¿No hay un arsenal variadísimo de canciones populares en nuestra patria? Rebúsquense; se saquen a flote y que sirvan de prototipo a los compositores para que idealizadas por ellos nos las devuelvan en obras que tengan digno olor, color y sabor nacional. ${ }^{172}$

Más adelante insistía en el fin regeneracionista de su colección, y mostraba su preocupación sobre cómo presentar las partituras de forma que sirvieran lo mejor posible a dicho objetivo. Se trataba, por tanto, del mismo asunto que había motivado las críticas de Villalba a la conferencia de Ledesma. De nuevo, las semejanzas entre las imágenes e incluso los términos concretos empleados por Olmeda en su cancionero, y los usados por Pedrell en Por nuestra música son evidentes ${ }^{173}$. El maestro de capilla de las Descalzas Reales parece parafrasear al compositor tortosino:

Considerando la obra en relación a los compositores, que son los que realmente han de formar el arte patrio, quisiera yo ofrecer estas canciones de modo que sólo con que ellos las mirasen quedara saturada su inspiración del patriotismo que ellas contienen, para que después aparecieran de nuevo asimiladas, transformadas, quintaesenciadas en un arte verdaderamente nacional.

Para mejor ayudar a estos fines desearía ofrecer juntamente con el canto, el color, la luz y el paisaje del pueblo; la fiesta y circunstancias en que le cantan y hasta el retrato y la voz de los cantores y cantoras de quienes lo escuché y recibí. Pero ¿cómo presentar todo esto? Y sobre todo ¿cómo ofrecer ningún género de acompañamiento ni de cuarteto vocal, ni de instrumental, ni de piano $\mathrm{u}$ órgano sin cohibir la asimilación individual y genial de cada compositor? Entiendo que ofrecerlas con tales acompañamientos preconciben desde luego los vuelos de la inspiración de los demás compositores. ${ }^{174}$

En el caso del cancionero de Ledesma, es en el preámbulo de Tomás Bretón donde encontramos nociones propias del credo regeneracionista y nacionalista:

\footnotetext{
172 Federico Olmeda, "Introducción”, Folk-lore de Castilla o Cancionero Popular de Burgos (Sevilla: Librería editorial de María Auxiliadora, 1903), edición facsimilar (Burgos: Diputación Provincial, 1992), p. 7.

${ }^{173}$ Refresquemos los términos en los que se expresó Pedrell, ya transcritos: "El canto popular [...] pasa por el alambique del arte contemporáneo y resulta su quinta esencia: el compositor moderno se nutre con aquella quinta esencia, se la asimila, revistiéndola con delicadas formas" Pedrell, Por nuestra música, p. 39.

${ }^{174}$ Olmeda, Folk-lore de Castilla, p. 14.
} 
Fecunda y eterna madre del arte la musa popular, habrán de impresionarse de ella los que quieran cultivarlo sin perder su fisonomía y naturaleza. Tiene España sobrados elementos, de opulenta variedad, para señalar en el divino arte de los sonidos personalidad eminente. Necesario, indispensable es al artista el conocimiento perfecto, profundo, hasta llegar al tuétano de todo lo bueno que en el mundo se produzca; Aquiles fue invencible a virtud de esta nutrición; pero tanto más valdrá su obra, cuanto más espontánea sea y se harmonice más con el ambiente y atmósfera en que se agite.

Poseyendo, pues, nosotros base tan sólida como la de nuestros cantos populares, bien podemos aspirar, si seguimos el camino que nos traza la propia Naturaleza, a emular, si no sobrepujar un día en la música la gloria de otras naciones más adelantadas que la nuestra. ${ }^{175}$

Las críticas que Ripollés dedicó a la disertación de Ledesma fueron aún más severas que las de Villalba. En una carta dirigida a Pedrell, el maestro de capilla hispalense la calificó de "verdadera calamidad". En dicha misiva refería, además, que había sido impuesta por el Secretario arzobispal: "La conferencia de Ledesma, impuesta por el Secretario de cámara de este Arzobispado fue una verdadera calamidad; como fue otra calamidad el concierto de órgano de Salas y Mariani"176. Sin embargo, es necesario aclarar que el secretario de cámara o, como afirma en otra carta, el propio arzobispo ${ }^{177}$, no impuso la conferencia sobre cantos populares religiosos, tal y como se pudiera entender del anterior fragmento, sino el conferenciante que debía pronunciarla ${ }^{178}$. La idea de dedicar una de las dos únicas ponencias monográficas previstas a este tema fue del propio Ripollés, como refleja esta otra carta, escrita más de un año antes de la inauguración del Congreso. El castellonense había pensado en su maestro, Felipe Pedrell, como el ponente que debía impartirla:

${ }^{175}$ Ledesma, Folk-lore, pp. 10-11.

${ }^{176}$ Carta de Ripollés a Pedrell, 8 de febrero de 1909. BC. FFP. M 964 R.

177 "El Ledesma de Salamanca, requerido, o más bien, impuesto por este Arzobispo mandó ya la conferencia que ha de leer en pública sesión solemne: trata del canto religioso popular y la encuentro tan disparatada, tan sin pies ni cabeza, que el asunto no parece por parte ninguna." Carta de Ripollés a Pedrell, 14 de noviembre de 1908. BC. FFP. M 964 R.

${ }^{178}$ En ese momento el Secretario de cámara era Eugenio Almaraz, hermano del arzobispo. Es posible que existiera una relación de amistad o cercanía entre los hermanos Almaraz, de origen salmantino, y Ledesma. 
Para cuando comencemos a planear el futuro Congreso, tengo dos cosas para proponer si a V. le parece bien.

$1^{\text {a }}$ Presentar cantos populares religiosos de todas las diversas regiones de España, convenientemente armonizados, y hacerlos cantar precedidos de explicaciones orales ilustrativas; y de estos V. podría encargarse. ${ }^{179}$

Por tanto, la causa del malestar de Ripollés se encontraba en la designación de Ledesma por parte de sus superiores, desbaratando así sus planes iniciales.

La cuestión del canto popular religioso, y en consecuencia, el Congreso en general, no contó con el concurso del que, ya en aquellos momentos, era reconocido como la gran autoridad y el principal referente ideológico de la música española. Las enormes potencialidades divulgadoras -vulgarizadoras, por usar un término corriente en aquellos años-, y pedagógicas -recordemos, "por vía de modelo y ejemplo"- que una gran asamblea religioso-musical como la sevillana poseía, no estuvieron al servicio del magisterio de Pedrell, sino de los planteamientos, cuestionados por Villalba y Ripollés, de Ledesma ${ }^{180}$.

\subsection{El intento de exaltación de la figura de Pedrell y su significación para}

\section{el joven movimiento reformista}

No obstante la ausencia física de Pedrell, su pensamiento estuvo omnipresente en los discursos de aquellos que asumieron la función de ejercer de portavoces de la doctrina del Congreso, tal y como nos parece estar comprobando; y, junto a su pensamiento, también su obra. En el siguiente pasaje, Villalba señaló la influencia del catalán, a través de sus publicaciones, en la conformación del estilo de Mas y Serracant. De esta forma, reveló la relación directa y causal entre la obra musicológica pedrelliana

\footnotetext{
${ }^{179}$ Carta de Ripollés a Pedrell, 29 de octubre de 1907. BC. FFP. M 964 R. La segunda propuesta era: " 2 a Distintas maneras de cantar vísperas autorizadas por el M.P.; presentando modelos en gregoriano; en fabordón de los variados géneros existentes; y en la forma de salmos de música continua; haciendo oír como a modelo de estos últimos alguno de los musicados por F. Cabo de Valencia."

${ }^{180}$ Con motivo de la preparación del congreso de Barcelona, Ripollés volvió a proponer la misma idea que no pudo ver realizada en el congreso de Sevilla: "A parte de estos actos de discusión familiar y que no deben tener solemnidad para no cohibir a los tímidos, hubo en Sevilla dos conferencias públicas y solemnes: una sobre asuntos gregorianos con ejemplos (ésta a cargo del P. Suñol fue el acontecimiento del Congreso), y otra que nos legó el deslevazado [sic] de Ledesma sobre cantos religiosos populares también con ejemplos. La primera suerte creo no debe repetirse y debía sustituirse por una conferencia de Tebaldini sobre Victoria con ejemplos intercalados del mismo abulense, en cambio creo que sería utilísima la repetición de la conferencia sobre canto popular procurando no localizar, sino hablar y presentar ejemplos de las diferentes regiones españolas. En esto V. es el maestro y no necesita ideas ni consejos de nadie.” Carta de Ripollés a Pedrell, 2 de marzo de 1912. BC. FFP. M 964 R.
} 
y la materialización estilística de la música religiosa moderna "de la escuela española", consumada en la obra de Mas y Serracant:

el primero [Mas y Serracant] aporta a su composición las formas de los polifonistas del XVI y reproduce las obligadas fórmulas cadenciales de aquella época. Cosa de erudición es esta que ha aprendido de las notas y comentarios que Pedrell ha puesto a las obras antiguas por él publicadas, y que por ser distintivo de la escuela española emplea con verdadera delectación. Más y Serracant es, ante todo, un compositor sabio y erudito, mas, por lo mismo, ofrece un ejemplo de composición de mucho fuste y solidez. ${ }^{181}$

Por tanto, la labor restauradora de Pedrell -utilizando una de sus metáforashizo, como se desprende del texto de Villalba, las veces de conductos de un alambique por los que circularon las esencias presentes en las obras antiguas recuperadas que, recogidas por los compositores contemporáneos, vivificaron la nueva música sacra. Así, el fruto de las investigaciones históricas de Pedrell se ubicó, también durante el congreso de Sevilla, en la base del proceso de regeneración de la música religiosa hispana.

Con todo, su no asistencia impidió que se consumara un hecho lleno de simbolismo: la exaltación de su figura. Las insistentes cartas remitidas por Otaño durante los meses inmediatamente anteriores al Congreso demuestran que era este el fin que perseguía el jesuita, a quien el propio Pedrell había bautizado como su alter ego ${ }^{182}$. El 12 de junio escribió:

No sé si le habrán dado ya cuenta del Congreso de Sevilla que tendrá lugar los días 12, 13, 14 y 15 de Noviembre. Allí le esperan a V. y le desean, pero su miedo tienen de que V. no pueda ir.

Un esfuerzo, un último esfuerzo sí que se le pide a V. No basta haber sembrado, es necesario recoger las palmas del triunfo y oír a los discípulos que bendicen a los maestros. Por eso yo creo que V.

\footnotetext{
${ }^{181}$ Villalba, "El Segundo Congreso Nacional", p. 38.

${ }^{182}$ Ripollés, e incluso el propio arzobispo, intervininieron para conseguir la presencia de Pedrell en el Congreso. Esta de Ripollés se refería a otra de Otaño en la que el vasco pedía al catalán su asistencia: "Me adhiero a la del P. Otaño, y remacharé el clavo cuando nos veamos." Carta de Ripollés a Pedrell, 25 de agosto de 1908. BC. FFP. M 964 R. Esta otra, remitida por Ripollés tras los problemas que habían surgido en la organización, disuadía a Pedrell de que asistiera, incluso a sabiendas de que la intención del arzobispo era la contraria: "Ya sé que el Sr. Arzobispo pensaba invitar a V. a su paso por ahí: supongo no caerá V. en la tentación y mandará a todos los andaluces a paseo. Cuando podré hacer yo otro tanto?" Carta de Ripollés a Pedrell, 17 de octubre de 1908. BC. FFP. M 964 R.
} 
no debe faltar en este Congreso. Bastante sentimos su ausencia en Valladolid. ${ }^{183}$

En otra posterior volvía a insistir y apelaba de nuevo a lo necesario -"es necesario"- de ese enaltecimiento como si de una figura sagrada se tratara -levantado en palmas y entonando un himno-:

V. debe venir a este Congreso: su presencia se impone y es necesario que los pocos y bien unidos le levantemos en palmas y le entonemos un himno. Déjese V. querer; permita V. ese desahogo al amor propio, que quizá no haya otra ocasión para ello. La presencia de V. conduce a mucho: entre los nuevos apóstoles, que no son pocos, tiene V. ganadas las simpatías y aunque no falte algún bilioso o atrabiliario, la mayoría somos de V. y triunfaremos. ${ }^{184}$

La pretensión de Otaño fue escenificar la consagración definitiva de Pedrell como un gran patriarca ${ }^{185}$; y haciéndolo en el marco de un congreso de música sagrada conseguía, además, que también el movimiento reformista adoptara públicamente al tortosino como su ascendente ideológico. En un momento en el que el movimiento reformista se hallaba todavía en un estado incipiente, la aspiración a ser reconocidos como "hijos de Pedrell”, utilizando la expresión de Juan José Carreras, representaba otra forma de institucionalización, al incardinarlo en la tradición fundada por el catalán. Así, el movimiento surgido al calor del $M P$ en España se integraba plenamente en el fenómeno histórico a que dio lugar la obra de Pedrell, la "música moderna española". El reconocimiento de la filiación pedrelliana implicaba, además, alcanzar la condición de legítimos continuadores. Los "nuevos apóstoles, que no son pocos", "la mayoría" afectos al catalán, según Otaño, aseguraban la transferencia de su herencia en el ámbito específico de la música religiosa. El jesuita, que garantizaba el triunfo de sus partidarios, presentaba al movimiento reformista naciente como una vía para la pervivencia del legado pedrelliano. Al congreso de Sevilla le faltó la presencia física de

\footnotetext{
${ }^{183}$ Carta de Otaño a Pedrell, 12 de junio de 1908. BC. FFP. M 694 O. En Valladolid también lo intentó, aunque igualmente sin éxito.

${ }^{184}$ Carta de Otaño a Pedrell, 29 de agosto de 1908. BC. FFP. M 694 O.

${ }^{185}$ Según López-Calo, Otaño se refería a Pedrell como "padre de la nueva música religiosa española" y representaba para el jesuíta vasco, "el modelo que todos debían imitar". José López-Calo, "Felip Pedrell y la reforma de la música religiosa", Recerca musicològica, 11-12 (1991-1992), pp. 157-209, p. 177. Albano Sánchez plantea este vínculo entre Otaño y Pedrell como una relación interesada, y que declinó una vez que ambos alcanzaron sus respectivos objetivos, encabezar la reforma en España y difundir su obra respectivamente. García Sánchez, "Sobre la reforma de la música religiosa en España”, pp. 977-983.
} 
Pedrell, y su importante valor simbólico, para culminar su condición de expresión del nacionalismo y regeneracionismo musical español, con todas las consecuencias favorables que hubiera tenido para el joven movimiento reformista español.

\subsection{La confrontación de dos identidades musicales. Francisco Guerrero} versus Hilarión Eslava: el estallido de una guerra de símbolos

En epígrafes anteriores poníamos de relieve la pretensión de presentar a la llamada "Escuela Sevillana" de polifonía como el modelo de música religiosa, y a Guerrero como el gran referente de esta, sustituyendo a la "Escuela Romana" y a Palestrina, respectivamente. Con ello, se proponía un modelo análogo al propuesto en el $M P$, aunque genuinamente español, al contener una virtud considerada como propiamente española, el expresivismo místico.

La interpretación de la Misa Puer qui natus est nobis en la solemne función religiosa con la que se clausuró el Congreso constituyó uno de sus momentos cumbre, y sobre todo, de enorme significado. Por primera vez en mucho tiempo se escuchaba, en el contexto de una gran función celebrada en el templo que había consagrado el "canon Eslava" como el canon musical de sus grandes solemnidades, una misa de Guerrero ${ }^{186}$.

Al día siguiente a la clausura del Congreso, congresistas y Capilla Isidoriana se dieron cita en la Catedral para rendir homenaje a "aquel músico que los contemporáneos nunca citaban a secas, sino anteponiéndole el título de grande, el 'gran Guerrero" "187. El homenaje consistió en un responso por su alma en el mismo lugar de su enterramiento, la capilla de la Virgen de la Antigua de la Catedral. En el programa general del Congreso se anunció así:

\section{Homenaje de la Capilla Isidoriana al insigne Maestro Francisco Guerrero. \\ A las nueve y media de la mañana, terminado el Coro en la $\mathrm{S}$. I. Catedral y ante la tumba en que descansan los restos del gran Maestro (Capilla de Ntra. Sra. de la Antigua) la Capilla Isidoriana cantará el solemne responso del mismo, Hei mihi, Domine a seis voces. $^{188}$}

\footnotetext{
${ }^{186}$ Los datos que sobre el canon musical catedralicio hemos ido ofreciendo muestran que las únicas obras de Guerrero que a principios de siglo XX conservaban su puesto en el ceremonial eran las pasiones del Martes y Miércoles Santos. Véase capítulo 3, epígrafe 1.2. "Otras partes litúrgico-musicales del ceremonial".

${ }^{187}$ Mauricio, “Un responso por el alma de Guerrero”, Crónica del Segundo Congreso, p. 91.

${ }^{188}$ Crónica del Segundo Congreso, p. 56.
} 
Villalba describió el acto como un "homenaje cristiano de los artistas que veneran el nombre de aquel músico"189. Sus comentarios refieren una ceremonia sencilla y sincera, y pintan una atmósfera sagrada y colmada por la emoción reinante:

[...] el noble recuerdo digo, que al maestro sevillano Francisco Guerrero, ha dedicado la Capilla Isidoriana, y los músicos, dejémosles ya de llamar señores Congresistas, tenía en la humildad y modestia de su forma, en la falta de etiqueta con que se hizo, algo de emocionante y de grandioso.

[...] Y, sin embargo, aquella humilde escena conmovía, y conmovía a todos, una corriente de emoción honda sopló muda en todas las cabezas y corazones, y al empezar a sonar arriba la música del que yacía debajo de una losa, los músicos, tan comunicativos, tan habladores, tan nerviosos, callaron, y en la actitud que les cogió permanecieron quietos y meditabundos: dedicaban a un hermano la oración interna del corazón los de abajo, una plegaria de arte los del coro. Y no sé si sería la música, o las circunstancias y el aspecto especial que el conjunto ofrecía, con los primeros acordes, con los acentos de la Capilla Isidoriana, las lágrimas asomaron a los ojos, y durante un rato sentí una emoción hondísima, dulce, un sentimiento indefinible, pero intenso, algo de eso hermoso que prende en el corazón y le cautiva. ${ }^{190}$

Con este acto, la Capilla Isidoriana y los congresistas -colegas músicosconsumaron la elevación de Guerrero al mismo altar de culto que ocupaba Eslava, y en el mismo templo en el que este último se había consagrado como el maestro de capilla venerable, genial, inmortal, patriarca, padre, icono, por reproducir algunas de las fórmulas usadas para referirse al navarro ${ }^{191}$.

La presencia de Eslava en el programa del Congreso, sin embargo, se redujo únicamente a la interpretación de su motete Jesu dulcis memoria en el concierto de

\footnotetext{
${ }^{189}$ Mauricio, "Un responso por el alma de Guerreo”, p. 90.

${ }^{190}$ Ibídem, p. 91. La conmovedora escena la retrató así: “A un lado de la Catedral, en una de las capillas cercanas al coro, unas cuantas velas encendidas en un altar, seis blandones con hachas, un paño mortuorio en el suelo, un Sacerdote con capa y asistido como para un funeral pobre y un grupo de músicos que, diversamente vestidos, sacerdotes, frailes, caballeros, dentro de las verjas de la capilla unos pocos, al lado de fuera la mayor parte, contemplaban, colocados sin orden, serios y silenciosos, el acto; y otro grupo, allá arriba, en el coro, frente al lugar del enterramiento, que cantaba, elevando a Dios sus voces, por el alma de un colega en arte, y con los mismos acentos que el mismo por quien rogaban sintió al expresar la sublime poesía de Job que la Iglesia emplea para responso de sus muertos, era todo lo que había llano, sencillo, espontáneo y sincero.” Ibídem.

${ }^{191}$ Véanse los epígrafes 1.1.1. "Salmos Miserere", y 3.2. "El mito de Eslava" de los capítulos 3 y 4 respectivamente.
} 
música religiosa. En lo demás, su ausencia fue palmaria. La polémica cuestión Eslava se soslayó, un hecho que llegó a merecer unos meses después la denuncia pública del mismo Pedrell ${ }^{192}$.

Sin embargo, esta presencia testimonial de Eslava representó una oportunidad para responder contundentemente a la estrategia de encumbramiento de Guerrero y la "Escuela Sevillana" desplegada por el Congreso. Los medios informaron del suceso sucintamente y sin revelar su verdadero carácter y significado. La Crónica del Congreso fue un tanto aséptica: "El Motete (Jesu dulcis memoria), a cuatro voces, de H. Eslava, mereció los honores de la repetición" ${ }^{\text {193 }}$. La reseña publicada en ENS, muy en la línea de la crítica musical amateur propia de la prensa local de la época, fue aún más escueta ${ }^{194}$ :

Las composiciones fueron ejecutadas maravillosamente, siendo algunas de un efecto magnífico, por las combinaciones de voces admirablemente armonizadas.

Los inteligentes y aficionados, que no eran pocos en el concierto, elogiaron calurosamente a la capilla Isidoriana por su labor meritísima.

El número 3. ${ }^{\circ}$ [motete Jesu dulcis memoria] se repitió. ${ }^{195}$

Por su parte, Villalba en ECA fue algo más explícito aunque dentro de la brevedad: "La iglesia [del Salvador] estuvo materialmente llena, y los que la llenaban pidieron la repetición, con grandes salvas de aplausos, del Jesu dulcis memoria, de Eslava"196. En sus posteriores artículos en $L C D$, reveló sin tapujos el verdadero sentido de aquellas efusivas manifestaciones tras la interpretación de la obra de Eslava:

${ }^{192}$ Felipe Pedrell, “Quincenas musicales. Idolillos”, MSH, 22 (1909), p. 237. Véase el apartado siguiente.

${ }^{193}$ Crónica del Segundo Congreso, p. 77. Así figuró también en la crónica publicada en MSH, 18 (1908), p. 172.

${ }^{194}$ Esta clase de crítica musical, muy frecuente en la prensa generalista decimonónica, corresponde a otro modelo radicalmente distinto del representado por Villalba o Ripollés. Normalmente, se trataba, más que de críticas, de crónicas realizadas por reporteros sin conocimientos musicales, cuyas apreciaciones caen constantemente en el comentario vacío. Un ejemplo interesante, que no responde ni a un modelo ni a otro, es el caso de Miguel Salvador, un aficionado con formación musical de extracción social burguesa, cuyas críticas, al igual que la de los músicos profesionales, pretendieron influir en el establecimiento de los criterios de juicio musical, sin violentar la mentalidad y costumbres de la clase social a la que pertenecía. Véase: Teresa Cascudo, "Humor y pedagogía en las crónicas de Miguel Salvador, el crítico buen aficionado de El Globo (1904-1913)”, en Los señores de la crítica, pp. 1-54.

195 "El Congreso de música sagrada. Concierto de música polifónica", ENS, 6460 de 13 de noviembre (1908), p. 2.

${ }^{196}$ Mauricio, “Impresiones del Congreso", ECA, 3346 de 14 de noviembre (1908), p. 1. 
[...] y llegó la ocasión solemne, el concierto polifónico, y ¡zas!, allí fue ella, aunque no Troya; doble o triple salva de aplausos coronó el Jesu dulcis memoria, de Eslava; y no era la salva en sí, sino el retintín de la salva, porque aquel aplauso se las traía. Trágala, parece que decían, y el trágala aquel, ¡vaya si tenía miga! ${ }^{197}$

Algún tiempo después, Otaño explicó así lo ocurrido, aunque no olvidemos que él no estuvo presente:

El hecho de Sevilla tiene una historia bien diferente. ¿Quiénes fueron los que prepararon los aplausos para exigir una repetición que, en efecto, se dio? ¿Cómo hablaron los críticos y maestros más sensatos de ese entusiasmo injustificado por un ídolo, pues ídolo es para los sevillanos el autor de su Miserere imprescindible? Aquellos aplausos ¿no eran una señal de protesta contra los enemigos del Miserere? No necesitaba el Jesu dulcis memoria estas muestras de consagración, porque ese motete, a los ojos de los inteligentes y de los maestros, nunca será más que una obra religiosa [cursiva original] pasable. [resaltado en negrita]. ${ }^{198}$

El momento de la interpretación del Jesu dulcis memoria sirvió, por tanto, como detonante. Aquella salva de aplausos que obligó a la Capilla Isidoriana a repetir la pieza era, en realidad, una abierta manifestación de protesta. Se trataba de hacer explicita la posición en contra de la propuesta planteada por el Congreso:

¡Y yo que creía que aquí en Sevilla, aunque no fuera más que por decencia patriótica, harían de las obras de Guerrero casi un culto, un culto muy respetable y venerado, con todos los prestigios que la tradición debe prestar al caso. ¡Y la Capilla Isidoriana, que en atención

\footnotetext{
${ }^{197}$ Villalba, “El Segundo Congreso Nacional”, p. 128.

${ }^{198}$ Cecilio [Nemesio otaño], "Eslava. En defensa de D. Gregorio", MSH, 10 (1910), p. 95. En este mismo artículo Otaño desmentía la afirmación del sacerdote pamplonés que firmaba como Sr. Miravalles cuando afirmaba que en el congreso de Valladolid había ocurrido algo parecido: " 6 " Dos datos históricos que se traen aquí, uno de ellos equivocado y el otro algún tanto inexacto. El ofertorio de Eslava (que, ciertamente, es lo mejorcito de su Museo Orgánico, si no es lo único bueno) pasó en el Congreso de Valladolid completamente desapercibido, y no mereció los honores de la repetición. En ese mismo Congreso, la Capilla Isidoriana cantó hermosas obras polifónicas aplaudidísimas, y en la memoria de todos los congresistas estará aquella memorable tarde en que, al llegar el coro Isidoriano al final del Credo de la Misa palestriniana del Papa Marcello, toda la asamblea se levantó entusiasmada como un solo hombre, movida como por un misterioso resorte, y rompiendo al Amen en una estruendosa explosión de aplausos, que conmovió al más empedernido enemigo de la música genuinamente sagrada.” Ibídem. El Sr. Miravalles había escrito en El Pensamiento Navarro, según cita literal de Otaño: "En España se han celebrado dos Congresos de Música Religiosa para llevar a cabo la reforma... Las obras que más agradaron a público tan inteligente y que iba con deseos de sanear la música religiosa, las únicas obras que tuvieron que ser repetidas ante los insistentes aplausos de los oyentes fueron el Ave Maris Stella, en Valladolid y el Jesu dulcis memoria, en Sevilla, ambas obras de Eslava”. Ibídem, p. 91.
} 
a esto, con más a los méritos del célebre compositor, tuvo la delicadeza de dedicar a Guerrero los mejores puestos del programa, y vino a rendir al gran maestro y con él a Sevilla, un homenaje de admiración y de simpatía. Pero sí, sí: ¿Con que los vuestros -se dijeron- son Guerrero y compañía, eh? Pues ya veréis quién es el nuestro: Eslava, Eslava. ¡Anda, para que vengáis con polifonías de Guerrero!- Y vino aquella significativa explosión, [... $]^{199}$

Resulta imprescindible recordar, para comprender el verdadero significado de esta reacción, que el motete Jesu dulcis memoria se sitúa estilísticamente en la órbita del cecilianismo, por tanto, dentro de la ortodoxia del $M P$, y en el extremo opuesto a la factura teatral italianizante que caracterizaban las obras más famosas de Eslava. Como señaló Villalba, era irrelevante la obra de Eslava que hubiera sonado en el concierto y su adscripción estética. El pronunciamiento del público se ubicaba en el mismo plano en el que pretendía incidir la estrategia suplantadora del Congreso. No se trataba de una reivindicación estética sino de la defensa de un símbolo cultural. Con ello se ponía en evidencia el conflicto subyacente debajo de la aparente idealidad del mundo musical representado:

Te advierto que la salva de aplausos lo mismo hubiera coronado el Jesu dulcis, que la Salve aquella del ad te clamamus de gorgoritos heroicos y ultra sentimentales, que tú conoces; y no digo nada del Miserere. ¡Ay el Miserere, el famoso Miserere! Esta es la debilidad de los sevillanos, y por concomitancia Eslava. Pero no es eso: el caso era manifestar un cariño, que por ser mucho y estruendoso sonara a protesta ruidosa; como que si hubieran podido echar a reñir personalmente a Eslava con Guerrero los echan. ${ }^{200}$

La riña personal entre Eslava y Guerrero, obviamente, no era posible, aunque la reacción de la parte pro Eslava fue tal que adquirió la apariencia de una auténtica guerra de símbolos. El acto de homenaje a Guerrero referido más arriba fue recibido como un agravio al que responder en la misma medida: “y después, porque se le cantó a Guerrero un responso, un recuerdo de piedad cristiana, una oración que hermanos de arte ofrecían a Dios alrededor de la tumba del maestro, se quiso organizar otra, en son de protesta, para Eslava."201

\footnotetext{
${ }^{199}$ Villalba, "El Segundo Congreso Nacional”, p. 129.

${ }^{200}$ Ibídem.

${ }^{201}$ Ibídem.
} 
Este otro acto "devocional” paralelo al previsto en el Congreso y, dedicado esta vez a Eslava, no se llegó a celebrar, aunque la confrontación entre las partes a través de la defensa y exaltación de sus respectivos iconos músico-culturales fue evidente. Villalba insistió en lo artificial e inexplicable de la utilización como arma arrojadiza de Eslava para sostener una polémica igualmente absurda y llena de incongruencias, según su punto de vista. Al fin y al cabo, Eslava había sido el primero en mostrar interés por aquellos maestros mitificados por el regeneracionismo musical español y en publicar en edición moderna obras de Guerrero ${ }^{202}$ :

¿te explicas que pueda haber rivalidad entre Eslava, colector, publicador, ensalzador de las obras de Victoria, Morales-Guerrero, y estos mismos? Pues lo que tú no te explicas así a primera vista, se lo explicaron otros, [...]

Opina lo que quieras de todo esto; a mi ver, protestar en Sevilla contra un sevillano ilustre, que fue Maestro de Capilla en su Catedral, que allí alcanzó grandísima fama, y allí murió y fue enterrado, y valerse para manifestar la protesta de un aplauso excepcional a otro hombre, que vino antes de ayer a Sevilla y se marchó al día siguiente, y que, sean cualesquiera sus méritos, vale menos que Guerrero, y que por contera era de los apasionados del maestro sevillano, es el colmo de una porción de cosas gruesas, y que no digo porque sólo caben en literatura de igual tamaño. ${ }^{203}$

Sin embargo, en su propio texto proporcionaba la clave para explicar lo que tanto le extrañaba. La representación identitaria había prendido en materia de música por usar la misma expresión de Villalba- en el compositor de Burlada y su Miserere, a pesar de todas las incongruencias que ello pudiera implicar en relación con la procedencia de Eslava, la calidad artística de la obra, lo relativamente reciente de la costumbre, o el hecho paradójico de conllevar el rechazo de una "gloria del arte andaluz" como Guerrero. La figura de Eslava, un navarro que escribió obras italianizantes había llegado a alcanzar para aquellos andaluces un estatus simbólico y unas propiedades referenciales que no reconocían en la del andaluz Guerrero. Como ya hemos señalado en alguna ocasión, en el fenómeno de Eslava en Sevilla se pone de manifiesto, desde nuestro punto de vista, el fuerte componente arbitrario de los factores

\footnotetext{
${ }^{202}$ En la segunda entrega de la $L S H$, Eslava publicó las pasiones del Domingo de Ramos y Viernes Santo, los motetes Ave virgo y Trahe me post, ambos a cinco voces, y la misa Simile est regnum coelorum. Hilarión Eslava, LSH. 10 vols. (1852-1860), Tomo 1º, Serie 2a (Madrid: Martín Salazar, [s.f.]).

${ }^{203}$ Villalba, "El Segundo Congreso Nacional", p. 130.
} 
que intervienen en la asunción de símbolos representativos de una determinada cultura o comunidad social, e incluso de los criterios o tendencias ya sean conscientes o inconscientes que rigen su elección:

¿Te extraña? Pues ahí está el intríngulis, que a mí me sucede lo mismo. Eslava no es de Sevilla, ni andaluz; aquí, en Sevilla, hay su cacho de regionalismo; y ve ahí que este cacho de regionalismo se prende en materia de música en una composición que hace poco más de medio siglo que se canta, que es bastante mediana, y que no es sevillana, y la toma como caballo de batalla para una pelea ridícula, para protestar contra un maestro sevillano, gloria del arte andaluz, para echarle incomodados de la catedral donde reposa, para no admitir sus obras en el repertorio. ${ }^{204}$

Así pues, y en síntesis, el proyecto de renovación de la música religiosa española desplegado en el II Congreso Nacional de Música Sagrada trascendió necesariamente los límites de la mera propuesta estética o de reforma de las estructuras por la naturaleza de la problemática que en torno a él se generó. En el capítulo cuarto nos sumergimos en un universo cultural en cuyos fundamentos nos pareció hallar razones para explicar la función simbólica adquirida por el canon musical hispalense asociado a las grandes solemnidades religiosas. A su convencional carácter litúrgico se sumó su condición de rasgo identitario, asumiendo así el cometido de colaborar en la representación y preservación de la identidad de la Iglesia local, tal y como se había configurado hasta ese momento. Hemos sostenido que detrás de la férrea resistencia a la admisión de cambios o rectificaciones, de los intentos de Spínola por compatibilizar reforma y costumbres, o del fracaso de los intentos regeneracionistas de Ripollés, se escondía mucho más que un problema estético, de gestión o de implementación de una ley eclesiástica. Se trataba de una cuestión que los englobaba a todos, pero de mucho mayor calado: de un desafío cultural.

De acuerdo al carácter del problema al que se enfrentaba, el Congreso desarrolló una estrategia de gran impacto cultural con la que culminó el mundo ideal que presentó: la sustitución de mitos. Junto a la articulación de respuestas para afrontar las dificultades de carácter estructural o económico, al relato estético, a los discursos legitimadores y pedagógicos, la asamblea reformista trató de encumbrar a un nuevo icono al que venerar. La idiosincrasia e historia de la sede del Congreso fueron

${ }^{204}$ Ibídem, p. 129. 
aprovechadas, al constituir ella misma otro símbolo, para esta labor ubicada en el plano de lo simbólico. Tanto el nuevo icono, Francisco Guerrero, como el que se desplazaba al ser el vigente, Hilarión Eslava, habían sido maestros de capilla de la basílica hispalense, y ambos ejercieron de emblemas de posiciones antagónicas. El Congreso celebrado en Sevilla sirvió de marco propicio e idóneo para la escenificación del conflicto latente entre dos "bloques" -término que llegó a emplear Villalba- enfrentados, aparentemente, por la cuestión musical litúrgica.

\section{La polémica en torno a Eslava tras el congreso de Sevilla: identidad} consolidada versus identidad en proyecto

La cuestión Eslava había adoptado en la ciudad hispalense unos rasgos singulares y se había convertido en un asunto de especial trascendencia. Sin embargo, el episodio de confrontación que acabamos de tratar ocurrió en el marco de un acontecimiento de alcance general español ${ }^{205}$. Villalba aludió, haciendo gala de nuevo de su habilidad retórica, a la procedencia no sólo sevillana de los autores de la protesta.

205 En el artículo Idolillos, del que trataremos a continuación, Pedrell enumeraba una serie de compositores consagrados en varias ciudades del país, mostrando así que el fenómeno de mitificación de determinados autores y obras era algo generalizado, aunque destacaban los casos de Eslava en Sevilla, y Doyagüe en Salamanca: "Vaya V. a decirles, por ejemplo, a los mallorquines que el Te Deum del maestro Tortell es una nenia indigna del templo! ¡Si quiere usted perder la amistad de un granadino háblele usted mal del Miserere del maestro Palacios! ¡Que se atreva alguien con el buen Olleta, y no habrá zaragozano que no le arrime un buen pie de paliza al lucero del alba! ¡Que se presente un guapo a desfacer agravios de músicas rutinarias, y Bilbao defenderá airado a su Ledesma, Valencia a su Plasencia, Madrid a sus Prado, Martinchique, Calahorra, Cosme de Benito, el bromista jorobeta, así solía firmar [...].

Aquí en Barcelona tuvimos durante buen espacio de años la leyenda de la Misa del aguinaldo del idolillo Vilanova, [...]

Pero leyendas de músicas de rebaño e idolillos de localidad, pocas tan saladísimas y perdurables como la de Doyagüe en Salamanca, y la de Eslava en Sevilla." No obstante, como sugería Villalba y se demuestra a continuación, la cuestión Eslava no era una cuestión meramente local. Felipe Pedrell, "Quincenas musicales. Idolillos", MSH, 22 (1909), p. 236. López-Calo transcribió este artículo íntegramente en "Felip Pedrell y la reforma de la música religiosa", pp. 203-205.

Ripollés se refería en una de sus cartas a un "idolillo" de Jaén: "Ya sabe V. que el próximo congreso se celebrará en esa Ciudad [Barcelona]: para ello les ha tocado un buen Obispo [quién es] muy apreciador del P. Mauro y amigo de hacer cumplir la ley: supongo que no descuidará la parte musical, pues lo hecho en Urgel y Jaén nos permite esperar algo bueno. Sobre todo en Jaén ha desechado todo el archivo musical abundante en obras de un idolillo de menor cuantía, y ha formado repertorio con obras editadas." Carta de Ripollés a Pedrell, 8 de febrero de 1909. BC. FFP. M 964 R. Las causas de la consolidación de estas obras y estos compositores malos, según Pedrell, estaban en la rutina y en su aceptación acrítica por la masa -sometida a "las leyes borreguiles": "Estas músicas, por supuesto todas muy malas y ordinariamente de género religioso, y los méritos de las músicas de esos idolillos, se han formado por conglomerados de rutina como se forman todas las leyendas del rebaño. Ha dado uno en decir que tal localidad posee una admirable inspiración creada por el genio colosal de un Señor Don Cualquiera; la cosa ha cundido a otra localidad que quiere poseer otra inspiración más sonada todavía y...ya tienen ustedes formada la leyenda de una de esas músicas piramidales y de sus autores los idolillos: una porción de personas cree, afirma y jura, sin comerlo ni beberlo, que todo eso es verdad y más claro que la luz del día, y iguay! del que se atreva con tales leyendas, poniéndolas en cuarentena o mofándose de ellas. Felipe Pedrell, "Quincenas musicales", p. 236. 
Incluso, en su juego de sugerencias, terminó por establecer una sinonimia entre eslavistas y sevillanos. El gentilicio adoptó en su texto un nuevo significado. Ya no refería al lugar de procedencia de los congresistas locales, sino a los partidarios de Eslava, pues son "los de Sevilla", sean "sevillanos o no", los que se sintieron ofendidos por el enaltecimiento de Guerrero llevado a cabo por el Congreso. Los enaltecedores de "un hijo de Sevilla", reformistas y regeneracionistas, eran, paradójicamente, los "extranjeros". A semejanza de Otaño cuando se refirió a Sevilla como "tierra de pecadores"206, Villalba trazó las líneas maestras de una cartografía figurada en la que el topónimo no lo era de una ciudad, sino de una región que llegó a representar lo ajeno, insumiso y contrario a la apuesta regeneracionista, pues los defensores de esta última eran, repetimos, "los extranjeros", vistos desde esa "Sevilla" alegórica, y "los de Sevilla", "sevillanos o no", la resistencia eslavista:

Inefable te parecerá el caso. ¡Hombre, hombre!; te diré: todo tiene explicación, sólo que creo que no es menester darla.-Pero, ¿y los sevillanos?-me replicarás. -¡Los sevillanos, los sevillanos! Qué sé o qué diga. Ni aun sé si ha habido sevillanos en este asunto.-El hecho es este: los extranjeros han venido a tributar honores a un hijo de Sevilla; los de Sevilla, sevillanos o no, se han dado por ofendidos de esto. Y ahora a correr con otro. ${ }^{207}$

La manifestación pro Eslava de los congresistas "sevillanos", en el sentido metafórico que el crítico agustino le atribuyó al término, provocó una fuerte réplica por parte de las principales figuras del movimiento reformista y regeneracionista español. La primera reacción a aquella protesta vino nada más y nada menos que del mismo Pedrell, quien poco después de la clausura del congreso hispalense escribió un mordaz artículo en $M S H$ de título Idolillos ${ }^{208}$.

La sucesión de hechos que a continuación desgranamos muestra que dicho artículo fue una consecuencia directa de la polémica destapada en Sevilla. El 13 de marzo de 1909, es decir, apenas cuatro meses después de celebrada la asamblea sevillana, Otaño escribió al catalán felicitándose por haber recibido una nueva

\footnotetext{
${ }^{206}$ Véase p. 331.

${ }^{207}$ Villalba, "El Segundo Congreso Nacional”, p. 130.

${ }^{208}$ Felipe Pedrell, “Quincenas musicales”, pp. 235-237.
} 
aportación -unas "letras suyas"- para la revista $M S H$ después de mucho tiempo ${ }^{209}$. A pesar de lo ajustado del tiempo, el texto de Pedrell fue publicado en ese mismo número de marzo porque, según Otaño, resultaba oportunísimo ${ }^{210}$. El artículo concluía:

El Congreso de Música religiosa recién celebrado en Sevilla, no se ha atrevido a debatir este caso excepcional de ejecución de un Miserere tan rematadamente malo contra el cual reclamó su propio autor, emperrados los sevillanos en sostenerlo, y honrarlo con tenores de cartello contra las prescripciones del Motu proprio y del sentido común. ¡Por aclamar rutinariamente a su idolillo, dejan en el mayor desprecio a Morales, a Guerrero, a Navarro....! $!^{211}$

Un mes antes, Ripollés había enviado al compositor tortosino una carta dándole cuenta del desarrollo del Congreso. El maestro de capilla le remitió a los artículos publicados por Villalba en $L C D$, especialmente al del 20 de enero, en el que el agustino describía todo lo ocurrido en torno a la interpretación del motete de Eslava:

Lo que más clara idea le dará del congreso son las cartas que publica el P. Villalba en la Ciudad de Dios: están sabrosas y apuntan bien y con exactitud: sobre todo la del día 20 [de] Enero da el gran varapalo a estos indoctos sevillanos que por aclamar a su idolillo Eslava dejan en el mayor desprecio a Morales, Guerrero y demás maestros sevillanos. $^{212}$

El cotejo de los dos últimos fragmentos transcritos pone en evidencia que, como remate de su texto, Pedrell copió de forma casi literal el final del pasaje de la carta de Ripollés, lo cual revela la relación directa y causal entre la asamblea andaluza y el polémico artículo del catalán.

\footnotetext{
${ }^{209}$ El hecho de que Pedrell escribiera aquel artículo fue interpretado por el jesuita como la vuelta del catalán a la actividad militante en pro de la reforma de la música religiosa, abandonada a causa de los desengaños. "Ya era hora de que viera letras suyas: menos mal que la excusa de la dilación se debe al trabajo, lo cual indica que hay salud, bríos y ánimos enteros. V. en todos los desengaños que quiera V. ponderar [sic] siempre será el mismo; siempre joven y lleno de vida: aunque haya $\mathrm{V}$. dicho más de una vez 'basta de quijoterías' una fuerza inmensa le arrastra al cumplimiento de su misión en la tierra." Carta de Otaño a Pedrell, 13 de marzo de 1909. BC. FFP. M 964 O.

210 “Sus 'Idolillos' van en este número, porque los juzgo oportunísimos: me hicieron la mar de gracia. ¡Buenas cantáridas! Carta de Otaño a Pedrell, 27 de marzo de 1909. BC. FFP. M 964 O.

${ }^{211}$ Felipe Pedrell, “Quincenas musicales”, p. 237.

${ }^{212}$ Carta de Ripollés a Pedrell, 8 de febrero de 1909. BC. FFP. M 964 R. La carta del 20 de enero a la que se refería Ripollés era el texto que, en forma de reseña epistolar, publicó Villalba sobre la reacción proeslavista del Congreso, que venimos comentando.
} 
Otaño comentó así el efecto que la crítica de Pedrell había producido en la capital hispalense: “Creo que la última se cerró leyendo sus 'Idolillos'. Sé por Ripollés que la cosa hizo tilín por Sevilla, y que por poco hay protestas...etc."213. El artículo de Pedrell inició un periodo en el que el enfrentamiento acaecido en el congreso de Sevilla entre defensores y detractores de Eslava, entre conservadores y regeneracionistas, se trasladó a las revistas de música religiosa y otros medios de comunicación escrita, adquiriendo así alcance general, y perpetuándose en el tiempo ${ }^{214}$. En diciembre de 1909, Otaño confesó a Ripollés su intención de empezar una “campaña anti-Eslava” en MSH:

En el número de Febrero verá V. que yo, Cecilio, empiezo una campaña anti-Eslavista en todo forma, deshaciendo las pardadas que se ha dignado decir en un periódico de Pamplona un pobre aficionado, sacerdote y escritor de un periódico carlista de aquella capital. Ya me dirá V. si le parece bien la tomadura de pelo. Él ha escrito siete artículos, y me dará pie para desenredar el ovillo y hablar de lo que conviene. $[\ldots]^{215}$

El jesuita se refería a la disputa que mantuvo con el Sr. Miravalles, el sacerdote proEslava y contrario a las nuevas propuestas músico-religiosas, a cuyos escritos en $E l$ Pensamiento Navarro nos hemos referido en alguna ocasión.

Además de Otaño, otras grandes figuras del movimiento regeneracionista y reformista español, o señalados eslavistas como Muñoz y Pabón intervinieron en estas

\footnotetext{
${ }^{213}$ Carta de Otaño a Pedrell, 26 de mayo de 1909. AMSL. FO. Correspondencia, T01/060.

214 José López Calo dedica varias páginas a tratar la polémica, tal y como se reflejó en los artículos de Otaño y Pedrell publicados en MSH en: "El Miserere de Eslava”, Boletín de Bellas Artes, 27 (1999), pp. 201-259, pp. 229-237.

${ }^{215}$ Carta de Otaño a Ripollés, 11 de enero de 1910. AMSL. FO. Correspondencia, TA01/075. A Pedrell se digirió en idénticos términos: "Estoy ahora en empezar una polémica sobre Eslava y le agradecería que me autorizara V. la publicación de una carta suya de hace años en que me decía V. su parecer sobre ese personaje con la gráfica que V. suele. Escandalizó a alguno aquel artículo de Cecilio y Gregorio 'Cartas e impresiones'. Estas cosas no hay que dejarlas: la ignorancia ha de combatirse. Cuando me envía V. algún articulito de esos tan salados que V. escribe a vuela pluma? Le agradecerá alguno." Tarjeta postal de Otaño a Pedrell, 5 de diciembre de 1909. BC. FFP. M 964 O. Otaño se debe referir al artículo "Cartas y reflexiones" que él mismo escribió bajo el pseudónimo de Cecilio en MSH, 5 de octubre de 1909, pp. 4041. En dicho artículo Cecilio (Otaño) aludía a las numerosas cartas (hasta trece) que había recibido por parte de lectores molestos con el eslavismo y demandaban respuestas a esta corriente a favor del navarro. Cecilio, a su vez, rogaba "de rodillas y con mi barba pegada al suelo" a otro de los personajes utilizados por Otaño, Gregorio, que se pronunciara. El jesuita comentó así a su alter-ego los resultados que su artículo había producido: "Habrá V. visto que he usado de sus cartas sobre Eslava: la cosa va produciendo su efecto.” Tarjeta postal de Otaño a Pedrell, 18 de febrero de 1910. BC. FFP. M 964 O.
} 
campañas pro o anti Eslava. A un artículo de este último se refirió Ripollés en abril de 1912, en el que mencionó también a Miravalles:

También parece que ha soltado el trapo aquel Miravalles de otros tiempos: y para final de fiestas el canónigo-novelista de Sevilla Muñoz Pavón [sic] descolgándose con un artículo en la Hormiga de Oro poniendo en los mismos cuernos de la luna el Miserere de Eslava: le sirve a V. eso para una quincena? que sí, hombre, que sí, y para dos y cuatro quincenas. ${ }^{216}$

Ripollés, a pesar de mostrarse en ocasiones escéptico sobre la eficacia de estos enfrentamientos dialécticos ${ }^{217}$, se involucró de lleno en ellos. A principios de 1911, Otaño le instó a que recogiera el testigo de la crítica anti-eslavista, esta vez, para responder a las futuras acometidas de una nueva revista que estaba previsto se fundara en Pamplona "para defender a Eslava [...] de los asaltos que le hemos dado". Esta iniciativa eslavista ofrece una idea del grado de enconamiento de los posicionamientos enfrentados, y de exacerbación de la controversia:

Conforme con lo que me dice V. de Chávarri, han venido aquí unos rumores de que en Pamplona se va a fundar una revista para defender a Eslava, al inmortal Eslava, de los asaltos que le hemos dado. Prepárese V., que yo no pienso meterme ya en eso. He dicho bastante. ${ }^{218}$

La implicación de Ripollés en esta campaña se tradujo en la publicación de un primer artículo en $M S H$. El texto del castellonense, quien ocultó su nombre bajo el pseudónimo de Alter Gregorius, apareció en el número de abril de 1911. Poco después

\footnotetext{
${ }^{216}$ Carta de Ripollés a Pedrell, 4 de abril de 1912. BC. FFP. M 964 R. A pesar de nuestro empeño, no nos ha sido posible localizar el artículo de Muñoz y Pabón al que se refiere Ripollés. Queremos hacer constar nuestro sincero agradecimiento a Vanessa Torres y al personal del Servicio de Información y Referencia de la Biblioteca de Catalunya, quienes, atendiendo amablemente a nuestra solicitud, repasaron todos los números de La Hormiga de Oro entre 1911 y 1913 en busca de dicho artículo.

217 "Sí recibí el artículo idolillos; pero ni cien artículos son suficientes para apear a estas gentes que continúan firmes con su Eslava." Carta de Ripollés a Pedrell, 30 de marzo de 1909. BC. FFP. M 964 R. "Ha visto V. la empresa que ha tomado ahora el P. Otaño? Nada menos que hacer apear a tanto eslavista como hay por estas, aquellas, y las de más allá tierras! Difícil lo veo hoy, pero bueno es que la gente se vaya enterando de la verdad que algún día fructificará" Carta de Ripollés a Pedrell, 16 de febrero de 1910. BC. FFP. M 964 R.

${ }^{218}$ Carta de Otaño a Ripollés, 10 de febrero de 1911. AMSL. FO. Correspondencia, TA01/106. "Aparece en este número su articulito, acudiendo a Alter Gregorius. Muy bien está. Puede V. escribir a [González] Mechant. El sistema de mover la opinión de esta manera me parece excelente, y por mí puede V. repetirlo cuantas veces le plazca." Carta de Otaño a Ripollés, [sin día] abril de 1911. AMSL. FO. Correspondencia, TA01/118.
} 
participó desde las páginas de aquella revista en otra de las porfías en torno a la cuestión Eslava; la que mantuvo Villalba con un carmelita que firmaba como Fernando Fernández Nucén en la revista que el mismo Villalba dirigía, $B S M^{219}$. Otaño fue quien informó al ya ex-maestro de capilla hispalense de la disputa:

[...] ¿Se ha enterado V. de la polémica que se trae el P. Villalba con un Carmelita, que le ha atacado en la revista Monte Carmelo? Villalba habló contra Eslava, y el Carmelita se sale en defensa de D. Hilarión, y el otro replica con viveza. Si quiere V. enterarse, pida al P. Benito las revistas. Todo con toda libertad. ${ }^{220}$

Algún tiempo después comunicó a Pedrell: “[...]Yo mandé a la Revista de Bilbao $[M S H]$ un artículo en el que haciendo algo de historia del encuentro del $\mathrm{P}$. Villalba con el P. Carmelita, arremeto tal vez demasiado fuerte contra Eslava y los eslavistas: V. lo verá en el número de este mes firmado por Alter-Gregorius."221. Merece la pena transcribir algunos fragmentos de este artículo que Ripollés tituló Croniqueando, pues nos proporcionan una síntesis, vista desde el lado regeneracionista, del proceso polémico que desató el artículo de Pedrell, a su vez, consecuencia directa, como hemos sostenido, del episodio que se vivió en el congreso de Sevilla:

Desde que el maestro don Felipe Pedrell, en aquel su famoso artículo Idolillos, saltó briosamente la valla convencional de ciertos miramientos y respetos hacia determinados maestros, quedó expedito y allanado el camino para manifestar con nobleza lo que antes tímidamente se pensaba y con disfraces al oído del amigo se decía.

Rompieron el hielo, y atrevidamente cargaron contra los pretendidos derechos de una veneración mal entendida, nuestros amigos Cecilio y Gregorio, disparando bala rasa y apuntando al inconsistente pedestal levantado a las exageradas glorias y grandezas del maestro navarro don Hilarión Eslava. [...]

No se avenían ciertos Miravalles a renunciar generosamente a su ya crónico fetichismo artístico y a quedarse sin ídolos e idolillos ante quienes quemar el incienso simbólico de una adoración interesada, apasionada, tal vez ilógica; [...]

El segundo golpe en firme lo ha dado, desde las columnas de la Biblioteca Sacro-Musical, y a propósito de ciertos entuertos

\footnotetext{
${ }^{219}$ La primera carta con la firma de Fernando Fernández Nucén apareció como "Alrededor de lo propio que el del anterior. Carta abierta”, Biblioteca Sacro-Musical [BSM], 3 (1911), pp. 4-6.

${ }^{220}$ Carta de Otaño a Ripollés, 7 de septiembre de 1911. AMSL. FO. Correspondencia, TA01/140.

${ }^{221}$ Carta de Ripollés a Pedrell, 4 de abril de 1912. BC. FFP. M 964 R.
} 
musicales y litúrgicos perpetrados en la Villa y Corte (?), el simpático P. Luis Villalba, [...]

Y como allá a nuestros Cecilio y Gregorio salióles al encuentro el Sr. Miravalles, también al P. Villalba se le atraviesa en el camino un anónimo contrincante, que rasga sus vestiduras, o poco menos, viendo de manera tan despiadada maltratado su ídolo.[... $]^{222}$

Ripollés concluía exponiendo claramente el programa iconoclasta del frente formado por los regeneracionistas:

Pero, esto aparte, congratulémonos de que ya hoy se puedan cantar y escribir verdades sin escándalo de la mayor parte y con aplausos de no pocos. Adelante, y continuemos todos, en santo consorcio, derribando ídolos e idolillos, o, como si dijéramos, dioses falsos de mayor o menor cuantía. ${ }^{223}$

Estas controversias en torno a Eslava reflejan una coyuntura clave en la historia de la música en España, lo que explica, creemos la magnitud que llegaron a alcanzar. Se trató de un momento en el que colisionaron dos identidades musicales, que reconocían unos en Eslava, otros en los polifonistas clásicos hispanos, la verdadera música religiosa española. El ideal regeneracionista de reconfigurar la identidad musical hispana a partir de unos nuevos presupuestos, también en la música sagrada, chocó con la resistencia de una identidad asumida y consolidada. El intento de regeneración se topó con la reacción; y, simbólicamente, Guerrero y Victoria tropezaron con Eslava. La dicotomía tradición/renovación, creemos, es superada desde nuestra perspectiva, por la de identidad consolidada de los eslavistas/identidad en proyecto de los regeneracionistas. Los siguientes textos evidencian, creemos, con claridad la naturaleza identitaria de la problemática de fondo. En este de Ripollés se pone de manifiesto su fuerte componente nacionalista:

[...]; y por ello pusieron el grito en el cielo [ciertos Miravalles, es decir, la parte eslavista], sacaron el registro gordo y apelaron a la patriotería y al españolismo; como si fuera cosa digna de cubrir, con el manto siempre respetable de la patria, mercancías averiadas, leyendas de cerebros pueriles y reputaciones falsas que achican el nombre excelso de la madre España. ${ }^{24}$

\footnotetext{
${ }^{222}$ Alter-Gregorius [Vicente Ripollés], “Croniqueando”, MSH, 2 (1912), pp. 28-29.

${ }^{223}$ Ibídem, p. 30.

${ }^{224}$ Ibídem, p. 28.
} 
Otaño, en boca de Gregorio, uno de los personajes que utilizaba en sus artículos polémicos, sintetizó en el siguiente las ideas fundamentales de la postura regeneracionista, incluida la preocupación por la mirada europea sobre la música española, tan presente en sus discursos:

Hay quienes piden otro Motu Proprio más claro; podían pedir otro sol de más luz, como si el actual fuera una lámpara de diez bujías. Hay quienes piden que se respeten las horrorosas rutinas de muchas catedrales e iglesias de España, porque son...españolas. [...]

Defender, pues, causa tan perdida y tan a ciegas y tan sin tino, es una tenacidad que raya en bobería. Cántese, enhorabuena, los motetitos que Eslava escribió a voces solas, como queriendo recordar a Victoria y a sus compatriotas del siglo polifónico; pero destiérrense esas obras en general plagadas de reminiscencias de mal gusto, donde dominan más los yerros que los aciertos; $\mathrm{y}$, sobre todo, váyase a paseo ese afán inconcebible de deificar un arte tan imperfecto como el de Eslava, cuando los españoles tenemos glorias más puras, más tradicionales, más legítimas y más religiosas ¿Por qué hemos de olvidar al gran Victoria, el estupendo abulense, que es traído de boca en boca en todo el mundo, y apenas es citado en su patria querida? Los extranjeros, al ver las obras de Eslava, han dicho: es este el modelo supremo de los españoles? ¡Pobre España, cómo has caído! Los extranjeros, al ver las obras de Victoria, de Morales, de Guerrero, de Cabezón, exclaman: ¡Cuán grande has sido, España! ${ }^{225}$

Por tanto, y en síntesis, a las estrategias puestas en marcha por los reformistas musicales españoles de regeneración cultural a través de la educación, especialmente en los seminarios, por un lado; de restauración y divulgación de nuevos modelos y referentes, de la que el congreso de Sevilla es un ejemplo paradigmático, por otro; se sumó la polemista, con el fin concreto de reemplazar por otros, unos iconos de profundo significado simbólico, y que funcionaban como emblemas. Desde el punto de vista regeneracionista, se trataba, en realidad, del derribo de unos "dioses falsos", en palabras de Ripollés, o “idolillos”, según el exitoso término empleado por Pedrell; y la subida a las hornacinas de culto de verdaderos mitos. Independientemente de consideraciones estéticas o artísticas, la diferenciación cualitativa entre los iconos propios -mitos merecedores de veneración- y los ajenos -ídolos objetos de una "veneración mal entendida" o de un "crónico fetichismo artístico", por reproducir expresiones del mismo Ripollés- pone de manifiesto la conciencia de superioridad cultural desde la que

${ }^{225}$ La supuesta carta de Gregorio está incluida en el siguiente artículo: Cecilio [el otro de los personajes de Otaño], "Cartas y reflexiones", MSH, 5 (1909), pp. 40-41. 
contemplaron y afrontaron la problemática. En la actitud polémica adoptada como táctica se descubre el cierto redentorismo en el que, en ocasiones, derivó el propósito de regeneración musical en España. Se trataba de la condena de una cultura idólatra, pues adoraba como ídolos a referentes musicales sin valor, incluso equivocados $\mathrm{o}$ corrompidos por las modas. Los registros discursivos de carácter despectivo o agresivo que empleaban en sus escritos, e incluso, los juicios expresados en términos morales recordemos la estimación de Sevilla por parte de Otaño de "tierra de pecadores" - se explicaban y justificaban, según consideraban, por el alto fin que perseguían.

Por otra parte, los eslavistas, con sus iniciativas y discursos, igualmente apasionados, trataron de defenderse del ataque a lo que para ellos constituían legítimos mitos musicales, consagrados por un proceso histórico como tales en una estructura cultural propia. La asunción de la condición de símbolos identitarios por parte de determinadas obras, estilos o compositores, como es el caso de Eslava, condenaba a la fosilización cultural $\mathrm{y}$ al hermetismo, pues cualquier cuestionamiento o debate al respecto se interpretaba como una amenaza a la propia comunidad cuyos valores representaba. Se dificultaba así la asimilación de nuevas aportaciones e influencias, con sus posibles consecuencias beneficiosas y enriquecedoras. "Sevilla", entendida esta en los términos simbólicos concebidos y empleados por Villalba, es decir, la "España eslavista" en general, perdió en 1908 la ocasión de abrir un cauce para, al menos, someter a revisión sus valores musicales dominantes y considerar otros con los que abrirse a nuevas posibilidades, según la oferta del movimiento regeneracionista. En la dimensión meramente local, el Congreso situó a la capital andaluza, esta vez stricto sensu, en el umbral de la regeneración musical, según el proyecto del nacionalismo musical español. Un umbral que el mundo musical-religioso hispalense rehusó traspasar, a juzgar por las apreciaciones de Ripollés, la CDMS o Almaraz, entre otros, sobre el estado de la cuestión litúrgico-musical; o la persistencia de las posiciones de resistencia ante la reforma mostrada por buena parte de los responsables eclesiásticos una vez finalizado el Congreso. 


\section{CONCLUSIONES}

En esta tesis doctoral nos planteamos tres grandes objetivos. En primer lugar, examinar el proceso de aplicación del Motu Proprio "Tra le sollecitudini” de Pío X en la archidiócesis de Sevilla en su etapa inicial (1903-1910), estudiando la gestión llevada a cabo por sus dos grandes instituciones, la administración arzobispal y la Catedral. En segundo lugar, intentar comprender el conflicto de mentalidades en que, según los indicios y pruebas halladas, derivó el intento de revisión y reforma de la realidad litúrgico-musical. Por último, analizar desde múltiples perspectivas el II Congreso Nacional de Música Sagrada como el acontecimiento reformista en el que convergieron las dimensiones local hispalense y general española.

Procedemos a continuación a desgranar de forma detallada los resultados obtenidos de nuestra investigación. Serán expuestos siguiendo la misma estructura, organizada según las instituciones sometidas a estudio, que ha articulado esta tesis.

\section{Administración general diocesana}

- La favorable respuesta del principal responsable archidiocesano, el arzobispo Marcelo Spínola, al proyecto de reforma litúrgico-musical propuesto por Pío X se concretó de forma inmediata con la publicación de una serie de disposiciones en febrero de 1904. Entre ellas, la creación de la Comisión Diocesana de Música Sagrada, la primera, según los datos que poseemos hasta el momento, en fundarse en una diócesis hispana. Al igual que el resto de comisiones que se crearon, se priorizó el criterio de jerarquía al de competencia musical en la distribución de cargos, lo cual no se ajustaba exactamente a lo dispuesto en el MP. Las facultades que Spínola confirió a su CDMS superaron considerablemente las contempladas en el texto papal. Además de vigilar el 
cumplimiento de sus preceptos, la CDMS hispalense fue el órgano encargado de trazar el plan para el cumplimiento de la reforma, y gestionar su aplicación.

- El grueso de medidas que constituyeron el plan de reformas bajo el pontificado de Spínola fueron dadas a conocer en el BOAS el 15 febrero de 1905, adelantándose en varios meses a la aparición del Reglamento general para la Música Sagrada en la Provincia Eclesiástica de Valladolid (22 de noviembre de 1905). Este documento constituyó la concreción normativa del $M P$, de aplicación diocesana, que más trascendencia tuvo en España. Las líneas maestras del proyecto sevillano fueron las siguientes:

a. llevar a cabo una profunda regeneración de los agentes musicales diocesanos a través de la formación en el nuevo canto gregoriano, paradigma de música litúrgica y base de la reforma. Los esfuerzos de arzobispo y CDMS se concentraron en hallar la fórmula, e idear recursos para la fundación de un nuevo centro de formación musical: la Escuela Oficial Archidiocesana de Canto Gregoriano. En ella se debían preparar los cantores y organistas eclesiásticos que aspiraran a una plaza, y reciclar los que ya estuvieran ejerciendo en ese momento. De esta forma, se pretendió atender la educación, no sólo de los futuros sacerdotes en el seminario, sino de todos los colectivos relacionados directamente con la práctica musical en el culto. El proyecto sevillano se diferenció así del modelo general español que tuvo a los seminarios como únicos centros donde fraguar la deseada regeneración.

b. depurar aquellas obras del repertorio en uso que se estimaran como incompatibles según los principios del MP. Para ello la CDMS propuso a Spínola la erección de un tribunal censor, y este a aquella la formación de un catálogo de obras prohibidas. Ninguno de estos dos proyectos llegó a buen puerto. Spínola debió considerar innecesario erigir un nuevo órgano con una función tan específica pudiéndola llevar a cabo la propia CDMS. De hecho, el arzobispo transfirió a dicha Comisión amplias competencias al respecto. Esta, por su parte, no cumplió con el encargo del Spínola, en primer lugar, por su complejidad, y en segundo lugar, por el grave compromiso que representaba proscribir una buena parte del repertorio que había formado el gusto estético dominante.

c. regular el uso de los instrumentos en la liturgia. Consistió, básicamente, en un trabajo de exégesis de lo preceptuado en el $M P$ en relación con el órgano y, sobre 
todo, con la orquesta; caso este último particularmente confuso, tal y como estaba planteado en el texto papal.

- La muerte de Marcelo Spínola en enero de 1906 marcó el punto final de esta primera fase del proceso. Su reanudación se produjo a principios de 1909, tras la celebración del II Congreso Nacional de Música Sagrada. Enrique Almaraz y Santos, sucesor de Spínola, partió del trabajo realizado por este último, y siguió una línea pretendidamente continuista. Sin embargo, las actitudes y estrategias desde las que afrontó la reforma fueron diferentes. Spínola, que había identificado en lo económico y cultural los problemas a los que había que hacer frente, hizo hincapié en la necesidad de discreción, prudencia y perseverancia. Almaraz, ante el poco éxito logrado por el prelado andaluz, optó por un tono mucho más severo. En contraste con la visión a medio plazo de Spínola, la fijación de plazos breves para la consecución de objetivos concretos revela la postura de exigencia. y la necesidad de cierta urgencia en la obtención de resultados.

- Las medidas de la CDMS reconstituida por Almaraz incidieron en dos aspectos fundamentales: el repertorio y los recursos humanos:

a. Repertorio:

Canto gregoriano: el objetivo se redujo a la inmediata adopción, en un tiempo máximo de dos meses, de las ediciones típicas del nuevo gradual. El ambicioso proyecto a medio plazo de formación y regeneración del clero y músicos eclesiásticos se abandonó.

Música figurada: la depuración del repertorio vigente en la diócesis se planteó con toda seriedad. La CDMS concibió un sistema para el examen obra por obra de la música conservada en los archivos de todas las iglesias archidiocesanas. El empeño puesto en la labor de censura no vino acompañado, sin embargo, por las correspondientes medidas de reemplazo del patrimonio esquilmado por otras obras acordes con el MP. La importante tarea de sustitución del repertorio descartado quedó en las manos no expertas de administradores de templos. El órgano diocesano para la reforma dejó, por tanto, incompleta esta labor al limitarse a censurar las obras incompatibles con las disposiciones papales, según su criterio.

b. Recursos humanos: se abordó un intento de regulación de todos los oficios musicales eclesiásticos a través de la concesión de títulos oficiales. Los títulos creados 
por la CDMS y expedidos por la administración arzobispal fueron: director de capilla musical, scholae cantorum y capilla musical, sochantre y organista oficiales. Este proyecto colaboraba en la dignificación de la profesión de músico eclesiástico, aunque, en el caso de aquellos que poseían una plaza musical eclesiástica estable, sochantres, cantores y organistas, el mero reconocimiento de oficialidad resultaba insuficiente para paliar la lamentable situación que sufrían. Junto a ello, hubiera sido necesario, por un lado, continuar con la estrategia de formación iniciada por la CDMS durante el pontificado de Spínola, y abandonada, como ya hemos apuntado, en esta segunda etapa; y por otro, acometer el grave problema de los míseros salarios asignados a sus plazas.

- El intento de reforma en la archidiócesis de Sevilla se encontró con los siguientes problemas:

a. La necesidad de acomodar al organigrama diocesano la CDMS, un nuevo órgano con las importantes competencias de llevar a cabo la reforma, y vigilar el cumplimiento de las prescripciones litúrgico-musicales en todas las instituciones del Arzobispado. La Comisión abandonó sus trabajos tras su primera reunión en marzo de 1904, probablemente superada por las comprometidas obligaciones que tuvo que asumir: en primer lugar, denunciar los abusos que se cometían por otras instituciones diocesanas en su específico ámbito de competencias, incluido el caso de aquellas con un enorme peso histórico y simbólico como el cabildo catedralicio; en segundo lugar, revisar, y en muchos casos, condenar a la proscripción el repertorio que había formado el gusto estético general; y por último, gestionar intereses personales y formas de capital simbólico como el prestigio. A ello habría que sumar la falta de un mayor apoyo explícito y público por parte del arzobispo, indispensable en un momento crítico como era el fundacional. La CDMS reanudó su actividad a principios de 1905, una vez Spínola hubo expresado en el Boletín Oficial del Arzobispado de Sevilla su total confianza en ella.

b. El diálogo-enfrentamiento que mantenía la Iglesia con el orden social vigente y la cultura contemporánea, y, unido a esto, la consideración y función de la música por parte de los responsables eclesiásticos. El comienzo del proceso de reformas coincidió con el cincuenta aniversario de la proclamación del dogma de la Inmaculada. El prelado hispalense quiso aprovechar esta onomástica para reanimar y movilizar las fuerzas católicas locales. Con ello pretendió reactivar su programa para 
hacer frente a los desafíos políticos, ideológicos y sociales que enfrentaba la Iglesia, en la línea marcada por León XIII. Ante la urgencia e importancia de la causa social católica, la cuestión musical quedó postergada. La reforma de la música, a la que no se le reconocía capacidad alguna de incidencia en la sociedad, se contempló como una cuestión secundaria, e incluso, según denunció Federico Roldán, secretario del II Congreso Nacional de Música Sagrada, como una distracción irresponsable.

c. Las interrupciones que sufrió el proceso y que tuvieron efectos ciertamente negativos, pues impidieron la continuidad necesaria para que la labor que se iba realizando se consolidara y diera sus frutos. La primera interrupción fue consecuencia directa de las dos dificultades que acabamos de apuntar, la coincidencia con el aniversario inmaculista, y la inacción de la CDMS. La segunda abarcó el largo periodo de interregno así como la organización y celebración del II Congreso Nacional de Música Sagrada. En realidad, a lo largo de estos seis años, el proceso de reformas permaneció suspendido durante toda la segunda mitad de 1904 y entre 1906 y 1909.

d. La falta de recursos económicos. Entre los varios objetivos frustrados por este motivo se encuentra la fundación de la Escuela Oficial Archidiocesana de Canto Gregoriano, el centro que debía operar, como hemos señalado, la regeneración de los músicos al servicio de las iglesias diocesanas.

e. El estadio aún inaugural en el que se encontraba la reforma en general. En el momento en el que se planteó la depuración del repertorio musical en uso, la industria editorial no había tenido tiempo de reaccionar, y satisfacer las grandes necesidades que los procesos diocesanos de sustitución de obras proscritas como el sevillano fueron generando. A esto hay que sumar la falta de definición de criterios de evaluación claros y unívocos en los que basar los juicios sobre la adecuación de las composiciones litúrgico-musicales a los preceptos del $M P$. Esta problemática saldrá a relucir con fuerza durante el congreso de Sevilla.

f. La recepción que administradores de templos y músicos eclesiásticos dispensaron a la nueva propuesta litúrgico-musical. Las actitudes de resistencia y no colaboración adoptadas por los colectivos que, por su cercanía a la realidad diaria de la música litúrgica, tenían en sus manos la materialización concreta de la reforma, hicieron inútiles los esfuerzos de la administración general diocesana. Aunque los problemas que hemos descrito afectaron a la buena marcha del proceso, las autoridades 
eclesiásticas locales apuntaron a párrocos y rectores de templos, a quienes habían confiado importantes cometidos, como los responsables principales del fracaso de la reforma.

Este fracaso en lo práctico, es decir, en términos de implantación real de las medidas puestas en marcha, contrasta con el éxito que supuso en cuanto a concreción normativa del MP el Reglamento de Música Sagrada para la Archidiócesis de Sevilla (mayo de 1910).

\section{Catedral}

El proceso de reformas en la Catedral se inició en febrero de 1905. Con la Semana Santa en el horizonte inmediato, Spínola, y no el Cabildo catedralicio, instó a abordar la revisión de los usos litúrgico-musicales de este importante periodo del temporal.

- La controvertida situación que produjeron las resoluciones de la CDMS sobre la incompatibilidad de las lamentaciones y Miserere que el ritual tradicional catedralicio prescribía con las nuevas prescripciones sobre música litúrgica pone al descubierto la profundidad del problema así como su carácter social, cultural e incluso económico. En su intento por salvar de la prohibición la costumbre del Miserere de Eslava, Spínola llegó a solicitar al papa dejara sin efecto las prescripciones legales establecidas en el MP. Los argumentos esgrimidos por el prelado, desde luego no relacionados con aspectos litúrgicos o estéticos, así como el riesgo de "grave conflicto" al que aludió, llegaron a convencer a Pío X para que, al menos, concediera una licencia provisional.

- El Cabildo, quien planteó esta vez sin éxito y sin el apoyo de Spínola seguir el mismo procedimiento para conservar las lamentaciones eslavianas, definió, desde este momento, su posición ante la reforma. Cuando esta hizo peligrar el canon musical de las grandes solemnidades litúrgicas, que, además, eran fiestas religioso-culturales de especial significado para la ciudad, trató de agotar todas las posibilidades de evitar su alteración. Sólo en última instancia, y por el deber de "sumisión y obediencia" a la "Autoridad suprema", cedió en su resistencia. Los capitulares asumieron este papel desde el convencimiento de estar cumpliendo con la obligación de preservar el esplendor tradicional característico de la institución. Este, según entendían, constituía un patrimonio a proteger, legado por sus antecesores. 
La labor desarrollada por la CDMS de Spínola en el ámbito específicamente catedralicio se redujo al examen de las prácticas musicales en las solemnidades litúrgicas de Semana Santa. La reforma general de la música en la Catedral no se abordó hasta que no hubo finalizado el II Congreso Nacional de Música Sagrada y con Enrique Almaraz ocupando la silla episcopal hispalense.

- A finales de 1908 se creó una comisión para estudiar la aplicación del MP en el primer templo metropolitano. A principios de 1909, Rafael González Merchant, presidente de dicha comisión, presentó un Plan para el arreglo de la música sagrada en la Catedral. Su estudio se prolongó durante más de año y medio, y se llevó a cabo según el procedimiento seguido en los casos de los documentos fundamentales de organización y gobierno catedralicios. Las discusiones que a lo largo del proceso de análisis de los distintos capítulos y disposiciones se originaron ponen al descubierto, en primer lugar, las importantes modificaciones que del ceremonial catedralicio exigía su implementación; en segundo lugar, la férrea defensa que un importante número de capitulares hicieron de dicho ceremonial, en las que no faltaron las continuas propuestas de solicitudes de exención a Roma; en tercer lugar, la inclinación por parte tanto de la tendencia reformista como conservadora de basar sus argumentaciones en interpretaciones, en ocasiones, al límite de lo prescrito en el texto papal.

- El grupo de orientación más conservadora y reacia a admitir alteraciones estuvo formado por canónigos de gran peso dentro de la corporación capitular, como el arcediano Luciano Rivas y Santiago, el maestrecuela Fermín Echeverría y Echaveguren, y los canónigos Antonio Pérez Córdoba y Bartolomé Romero Gago. El más combativo de todos ellos fue el secretario, Modesto Abín y Pinedo. Las tesis reformistas fueron defendidas por Rafael González Merchant, en quien Almaraz confió, junto a Ripollés, todo lo relacionado con la música, no sólo a nivel catedralicio sino general archidiocesano.

- El repertorio musical de las solemnidades catedralicias estaba monopolizado por la producción de Eslava, lo cual revela la asociación existente entre concepto de solemnidad y obra eslaviana. Según la información que proporcionan las actas capitulares, los canónigos conservadores opusieron una mayor resistencia a las reformas cuando se sometieron a revisión las obras de "música figurada" que se interpretaban en las fiestas litúrgicas catedralicias. Dada la identidad entre solemnidad y música de 
Eslava, la defensa que los responsables eclesiásticos hicieron de los usos locales tradicionales se sustanció, en realidad, en la defensa del que hemos venido en denominar "canon Eslava".

- El proceso de reformas en la Catedral se cerró con la imposición por parte de Almaraz del Reglamento de Música Sagrada para la Archidiócesis de Sevilla. El plan específico para la Catedral nunca se llegó a aplicar.

La tenaz defensa por parte de los capitulares del canon musical catedralicio ante los cambios exigidos por la reforma, así como los argumentos que esgrimieron, relacionados más bien con la dimensión cultural del rito que con lo estrictamente litúrgico, nos habían llevado a plantear la siguiente hipótesis: la música de uso litúrgico poseyó, además, la función simbólica de colaborar en la representación de la identidad de la institución tal y como se había ido forjando históricamente. Según nuestro análisis, la ubicación y función de la música del "canon Eslava" en este sistema de pensamiento se puede compendiar en las siguientes consideraciones:

- Los elementos musicales del teatro musical italiano que determinaron el estilo de las obras de Eslava configuradoras del repertorio catedralicio educaron durante décadas el gusto de la sociedad. La ópera italiana constituyó en aquel momento una manifestación de modernidad decimonónica. Las formas de expresión eslaviana, modernas, popularizadas (aunque de extracción culta), comprensibles, y afines a la sensibilidad de la sociedad, se revelaron como idóneas para cumplir funciones comunicativas y representativas; una capacidad que los modelos propuestos por el $M P$, la polifonía clásica y la música religiosa moderna, no habían desarrollado. La metamorfosis sufrida por el lenguaje musical de Eslava, de lenguaje "moderno" en tradicional, permitió, en su condición de tradición, desempeñar el papel de esta: la transmisión en el devenir histórico de valores culturales establecidos como principios, es decir, garantizar la pervivencia de una identidad.

- La asunción de esta función identitaria por parte de la música eslaviana no pudo ser posible sin un proceso de mitificación del propio Eslava. El músico navarro constituyó un trasunto en lo musical de la preeminencia catedralicia. Al igual que otros mitos religiosos locales o el propio Cabildo, Simón de la Rosa -cuya visión sobre la historia de la Catedral y sus fiestas se puede considerar como representativa de los discursos católicos dominantes en aquel momento- le presentó como líder de la causa 
religiosa y de la "nación española" en el ámbito que le competía, la música sacra. Así, fue incorporado a las interpretaciones histórico-culturales de naturaleza nacionalista católica propias del pensamiento tradicionalista. Aquellos méritos no sólo le hicieron digno hijo de la institución a la que había servido, sino merecedor, además, del altar de culto que ocupó. La obra firmada por Eslava, independientemente de cualquier otra consideración estética, artística o litúrgica, poseía a priori el prestigio de la condición mítica de su autor.

- La costumbre del canto del Miserere concentró el poder que el "canon Eslava" atesoró como expresión cultural eclesiástica. Ese poder residió en su carácter híbrido religioso-profano. En la función del Miserere se verificó una secularización del "templo". Al mismo tiempo, la asignación de significados religiosos a una expresión musical profana constituyó una forma de sacralización de la cultura. La confluencia de las instituciones eclesiástica, civil, de determinadas empresas artísticas, así como del pueblo en torno al Miserere dio lugar a un importante acontecimiento, consolidándose como una de las manifestaciones idiosincráticas y símbolos identitarios de la ciudad en aquel momento. Salvadas las diferencias contextuales, el Miserere poseyó las principales características de aquellos grandes festejos ciudadanos que en torno al Corpus o la Inmaculada se celebraban en las épocas consideradas de apogeo (siglos XVI y XVII). Según la imagen que transmitieron los relatos católicos sobre la historia local analizados, la alianza de todos los estamentos de la ciudad, cabildos eclesiástico y municipal, gremios, y el conjunto de la ciudadanía, engendró una tipología de fiesta en la que los elementos religiosos convivieron con los profanos, paganos y teatrales. Estas fiestas eran expresiones de un modelo social ideal en el que, por un lado, la hegemonía del fervor religioso y la concordia social dio como resultado un periodo de paz, armonía y cultura; y por otro, el Cabildo catedralicio gozaba de un lugar predominante, y ejercía su influencia como principal autoridad social y cultural. Esa imagen idealizada de esplendor y progreso, en la que no es difícil reconocer una variante urbana de la alianza entre Altar y Trono, así como el orden institucional y social del Antiguo Régimen, contrastaba radicalmente con la difícil posición que la Iglesia ocupaba en la cultura moderna. Aquellos espacios simbólicos en los que, en mayor o menor medida, se reproducían aquellas condiciones en la Edad Contemporánea debieron tener un especial valor, en un momento en el que la institución eclesiástica libraba una dura lucha por 
mantener su mermada capacidad de influencia sobre la sociedad. El fenómeno complejo y polifacético del Miserere, se podría contemplar, desde esta perspectiva, como uno de esos espacios en los que la Iglesia se podía mostrar a sí misma y al conjunto de la sociedad en su perdido papel histórico de conformadora y moldeadora de la cultura local. La reforma, en consecuencia, representó un cuestionamiento no sólo de una práctica litúrgica o de un determinado gusto estético musical, sino de un elemento que adquirió una gran trascendencia simbólica.

- En contra de la doctrina del $M P$, la presencia y conservación del "canon Eslava" estaban justificadas, según los eclesiásticos locales. En el pensamiento de Modesto Abín y De la Rosa, por un lado, y de Ripollés, por otro, hemos creído identificar dos puntos de antagonismo ideológico, que pudieran constituir, acaso, la base fundamental del desencuentro entre las distintas posturas. En primer lugar, la idea de "templo", entendiendo este como espacio de lo sagrado, y su relación con el entorno. Para unos, el "templo" podía ser un centro abierto a la cultura y la sociedad sin menoscabo de su sacralidad. En su interior, la cultura se sometía a lo religioso, se convertía en cultura religiosa. La presencia en la liturgia del lenguaje musical eslaviano, expresión cultural moderna, estaría justificada desde esta perspectiva, pues al integrarse en lo sagrado, adquiría significados religiosos. Para Ripollés, cuyas ideas representaron la ortodoxia del $M P$, la música teatral no podía ponerse al servicio de lo religioso, dada su naturaleza intrínsecamente profana, opuesta en esencia a la religiosa. Lo profano, lejos de poder interactuar con lo sagrado, constituía una corrupción del propio "templo". En segundo lugar, las diferencias de criterio sobre la dignidad de la música teatral y su estética para convertirse en tradición. Para los capitulares hispalenses conservadores, las obras musicales del ceremonial puestas en cuestión constituyeron venerables tradiciones. Los fundamentos doctrinales de su actitud conservadora podrían hallarse en las ideas sobre la liturgia expuestas por Modesto Abín: era legítimo e incluso conveniente preservar la singularidad ceremonial de las Iglesias locales, tal y como había defendido la Iglesia en todo tiempo, siempre que quedara salvaguardado lo esencial e inmutable de la fe. Para Ripollés, las composiciones "antilitúrgicas" y "antiartísticas" introducidas en la liturgia no podían alcanzar la condición de tradición. Se trataban de meras rutinas consagradas por el mal gusto y un criterio erróneo. 
Al margen de las cuestiones estéticas, igualmente origen de disenso, creemos que en este conflicto se produjo una contraposición entre, por un lado, una noción de religión en comunicación con el contexto como principio civilizador, muy cercana al papel que jugó lo religioso en el Antiguo Régimen y la Iglesia como institución preponderante en la cultura; y, por otro, una cerrada defensa de la pureza de lo sagrado, que contempló lo secular como una peligrosa amenaza, en la línea de la estrategia de autoafirmación seguida por el catolicismo en una situación de fractura con la cultura contemporánea.

- Vicente Ripollés, prácticamente a título personal y de forma paralela al proceso institucional, trató de desplegar un proyecto de regeneración musical fundamentado en términos ideológicos, por un lado, en los postulados reformistas de la Iglesia, y por otro, en las ideas regeneracionistas de filiación pedrelliana. Su estrategia siguió dos líneas básicas de actuación: en primer lugar, la formación en nuevos valores estético-musicales. Con este objetivo llevó a cabo un intento de reeducación de los seises, colectivo más permeable a nuevas influencias, con la introducción en su repertorio de obras de estilo cecilianista. En segundo lugar, aprovechar su cometido como compositor catedralicio, asociado a su cargo de maestro de capilla, para tratar de incidir en el canon musical de las grandes solemnidades litúrgicas. Su producción sevillana fue exclusivamente litúrgica, lo cual resulta bastante significativo, y contrasta radicalmente con las aportaciones de sus antecesores y sucesor, quienes dedicaron gran parte de sus esfuerzos a proveer el archivo catedralicio de obras paralitúrgicas tales como los tradicionales bailes de seises o alabados. No obstante, su proyecto regeneracionista no se circunscribió a la Catedral, sino que tuvo una dimensión general, como demuestra el fallido proyecto de fundación de un conservatorio, concebido como el centro para la regeneración musical en Sevilla. El desgaste personal que le produjo la oposición que su proyecto encontró fue el motivo de su marcha. El caso de Ripollés pone al descubierto los problemas que encontró la reforma al toparse con un contexto hostil y con la propia jerarquía eclesiástica que, en virtud de su autoridad, ostentaba el poder real de transformar la realidad. 


\section{Congreso}

- El congreso de Sevilla estuvo en su origen íntimamente ligado al congreso de Valladolid. Esta primera cita congresual persiguió consolidar un movimiento a favor de la reforma y lograr su institucionalización edificando una estructura de dimensión general española. Su centro se ubicó en la capital castellana, y las disposiciones que debían regir la reforma en su provincia eclesiástica se trataron de exportar como un modelo común a aplicar en todo el país. La Junta local vallisoletana fue erigida en Junta central española que, según la -fallida- idea inicial, debía asumir la responsabilidad, junto con la Junta local hispalense, de la preparación del II Congreso Nacional de Música Sagrada. En estas circunstancias se inició su organización, que, a diferencia de la del vallisoletano, fue planificada desde el principio de acuerdo con su condición de "nacional". Gracias a ello, los problemas organizativos que acusó el Primer Congreso fueron corregidos en el segundo. La responsabilidad de su preparación recayó fundamentalmente sobre Vicente Ripollés.

- Tras la primera cita congresual, que sirvió como punto de partida, la asamblea hispalense constituyó un escenario idóneo para que un determinado colectivo de personas de diverso perfil, interesadas de una u otra forma, o por una $u$ otra causa, en la música litúrgica y su reforma, caminara hacia su afianzamiento como un espacio de relación social y artística. Capitales simbólicos y económicos como liderazgos, capacidad de influencia, prestigio, intereses comerciales, así como las distintas posiciones relativas a ocupar dentro de esta estructura se pusieron en juego. Las pugnas de los distintos agentes en liza provocaron repetidas polémicas y, en ocasiones, graves disputas. Caracterizan, creemos, un momento de ebullición que revela el estado aún incipiente del movimiento de reformas, así como su trascendencia histórica.

- Las luchas en torno a la cuestión gregoriana, en las que se mezclaron los posicionamientos teóricos y estéticos con los intereses económicos, provocaron una profunda grieta en la cohesión del movimiento naciente. Las divisiones que en su seno se produjeron tenían efectos muy perjudiciales, pues obstaculizaban la necesaria colaboración entre los distintos grupos. Además, lo debilitaban enormemente frente al entorno litúrgico-musical con el que mantuvo una relación de confrontación dadas sus pretensiones de reformarlo en base a nuevos criterios. Los organizadores de los dos primeros congresos colaboraron con sus decisiones parciales en la configuración de un 
panorama excesivamente dual y contrapuesto, favoreciendo las rivalidades: Pothier/Mocquereau, Silos/Montserrat, castellanos/catalanes. En el congreso de Sevilla, las hostiles relaciones que mantenían los dos clanes benedictinos pudieron haber desencadenado una situación de especial gravedad, que el papa evitó prohibiendo cualquier debate al respecto. En opinión de Vicente Goicoechea, las consecuencias para la reforma en España hubieran sido desastrosas.

- Durante estos años, se definió con claridad el grupo que se arrogó la condición de ortodoxo y ocupó la posición dominante dentro de este espacio artísticosocial. Los principales referentes de este movimiento dentro del movimiento, que encabezó Nemesio Otaño, fueron Vicente Goicoechea, Vicente Ripollés y Francisco Pérez de Viñaspre. Este grupo, que contó con el apoyo de los obispos más sensibles y comprometidos con la causa de la reforma, tuvo a su disposición dos eficaces instrumentos para ejercer el liderazgo: la situación de poder que su responsabilidad como principales organizadores de los dos primeros congresos (Valladolid, Otaño y Goicoechea; Sevilla, Ripollés) les reportó; y el control de la revista consagrada en el congreso de Valladolid como órgano oficial de los congresos, Música Sacro-Hispana. La aspiración de Otaño como cabeza de la facción más poderosa del movimiento fue alcanzar cierta hegemonía, y fundar en torno a sí una "escuela" de jóvenes músicos y críticos que siguieran su línea reformista y regeneracionista. Otras figuras de la música religiosa como Luis Villalba y Federico Olmeda representaron alternativas a la tendencia otañana, y ejercieron la función de heterodoxos dentro del sistema. Desde la perspectiva del grupo dominante, sus posicionamientos fueron contemplados como singulares, extravagantes, e incluso como asumidos al servicio de intereses personales. Por estas razones representaron contrincantes ideológicos dentro del propio movimiento. La ausencia de Otaño y la relevancia que adquirieron Villalba y Olmeda en el congreso de Sevilla definieron un escenario radicalmente distinto al vallisoletano. Una buena parte del poder de arbitraje y decisión que ostentó el jesuita en el congreso castellano pasó en el andaluz a manos de sus rivales. Un órgano de la importancia de MSH fue relegado en favor de Voz de la Música, dirigida por Olmeda, y salvado en el último momento por una maniobra al margen de las decisiones del Congreso.

- Las revistas de música religiosa no fueron sólo importantes herramientas para alcanzar y ejercer el liderazgo, sino además, como consecuencia de las necesidades 
editoriales que generaron los intentos reformistas, constituyeron prometedoras fuentes de negocio. La vertiente mercantil de la reforma se reveló nítidamente durante el congreso de Sevilla. En las discusiones en torno a las revistas participaron junto a líderes reformistas, editores y administradores de templos. Las lógicas de obtención de beneficios propia de la actividad empresarial, y de optimización de recursos seguida por los gestores de las instituciones eclesiásticas rigieron otras formas de participación en este espacio, cuyo carácter sistémico se demuestra en la dependencia de las distintos grupos y agentes involucrados. Los criterios censores en los que se sustanciaba la política reformista de las distintas comisiones de música sagrada determinaban las decisiones, incluidas las relacionadas con las inversiones, de las casas editoriales y, en última instancia, el propio éxito de su apuesta comercial. De ahí las unánimes denuncias por parte de los editores sobre la falta de unidad de criterio de los órganos reformistas diocesanos. Junto a los editores, otros profesionales como organeros e intérpretes quisieron aprovechar la importante oportunidad que les brindaban estas reuniones para abrir nuevas vías de mercado o adquirir notoriedad y proyección. La elección de los organistas que debían hacerse cargo de los conciertos programados dio lugar a otro conflicto, sólo resuelto en el último instante, en el que entraron en juego factores como remuneraciones, prestigio, e incluso culturales.

- La organización y celebración del congreso de Sevilla tuvo lugar en medio de una profunda crisis económica y social. Como evidencian los testimonios de arciprestes y curas rurales archidiocesanos, los problemas que encontraron para cumplir con la misión de proveer socios al congreso estaba en relación directa con la grave situación por la que atravesaba la economía andaluza. Los grandes eventos religiosos, sociales, o, en este caso, litúrgico-musicales que organizó la jerarquía en su intento por ofrecer una respuesta en el contexto ideológico y cultural de principios de siglo exigían la implicación en términos de participación y financiación de los fieles. Estos sintieron las continuas demandas de las autoridades eclesiásticas como una presión excesiva dada la situación desfavorable que vivían. El poco interés de los católicos de a pie por la reforma musical o la poca importancia que le atribuían al Congreso constituyeron otros obstáculos.

- Las respuestas de los obispos españoles a los requerimientos de la Junta local aludieron a estos mismos problemas, económico y cultural. Sus, en principio, 
pronunciamientos favorables a la reforma se tradujeron en distintos grados de colaboración, dibujándose así un panorama heterogéneo. La firme implicación de algunos contrasta con la poca confianza de muchos en la verdadera eficacia de estas asambleas como medios de transformación de la realidad.

- Las dificultades que encontraron los músicos eclesiásticos para participar en los congresos, de los que, se supone, eran los principales protagonistas, representó una gran paradoja. Para los músicos catedralicios, sólo la cuota de inscripción constituía cerca del diez por ciento de su sueldo mensual; a lo que había que sumar el coste del viaje, la estancia, etc. La mayoría de los cabildos, alegando falta de presupuesto, no atendieron a la petición de la organización de costear los gastos de sus representantes oficiales. La participación en estas asambleas estaba totalmente fuera del alcance de los músicos al servicio de templos de inferior categoría. Los problemas de este colectivo, que padecía unas condiciones laborales paupérrimas, fueron ignorados por los congresos. El impulso reivindicativo de los reformistas estuvo orientado a la mejora de la situación de los músicos catedralicios, mientras que las referencias a los organistas y cantores parroquiales tuvieron que ver sólo con la necesidad de elevar su bajo nivel y rendimiento. Como se pondría de manifiesto en el congreso de Vitoria años más tarde, estos problemas eran consecuencia de aquellas míseras condiciones de trabajo. La desatención que sufrieron constituyó una grave negligencia de consecuencias muy negativas para la realización de la reforma, especialmente en Andalucía.

- A pesar de todos estos obstáculos, el número de socios inscritos en el Congreso ascendió a novecientos, aunque no fue suficiente para evitar que resultara deficitario.

- El congreso de Sevilla fue la segunda etapa en este proceso iniciado en Valladolid para construcción de una estructura institucional de dimensión general española. Los frutos del trabajo que con este objetivo se desarrollaron fueron los siguientes: a. solicitud a Roma de erección del Tribunal Superior para la censura de la música religiosa en España; b. propuesta de fundación de la Escuela Superior de Música Sagrada; c. súplica al episcopado español para que el cargo de responsable musical de las catedrales se confiriera a las chantrías; d. la creación de una comisión para el estudio del canto visigótico; e. la elaboración de un cancionero popular religioso español; f. la celebración de congresos regionales de música sacra de forma anual como preparación 
para los nacionales. Todos estos proyectos debieron ser recuperados en el Tercer Congreso (Barcelona, 1912), lo cual indica que no llegaron a realizarse. La no materialización de las propuestas planteadas por los congresos en realidades consumadas pone al descubierto sus grandes limitaciones como instrumentos transformadores y para institucionalización de la reforma, así como su causa: los congresos no tenían competencias ejecutivas; dependían, en última instancia, de la jerarquía eclesiástica, única ostentadora del poder de decisión, y en muchas ocasiones, poco sensible a la cuestión musical.

- El principal valor del congreso de Sevilla residió en desplazar la mirada del centro de la reforma, representado por el "norte", a su periferia, representada por el "sur". Situar durante 1908 el punto de atención y de convergencia de los esfuerzos en la capital andaluza supuso el hecho necesario y clave para la expansión del movimiento, tal y como se estaba definiendo, más allá de los entonces considerados como principales núcleos reformistas, todos en la mitad norte. El congreso de Sevilla constituyó así el acontecimiento que hizo de dicho movimiento un fenómeno de alcance general español, tal y como pretendían sus líderes.

- Más allá de las sesiones de estudio y debate, el Congreso confió su potencial capacidad transformadora a su estrategia pedagógica. Los esfuerzos de la organización estuvieron dirigidos a componer y exhibir el -su- ideal religioso-musical hecho realidad, y con ello demostrar que la reforma era posible:

a. Como respuesta a la tantas veces denunciada por los reformistas estado de corrupción del canto llano en las iglesias, el Congreso utilizó la recientemente aparecida edición típica vaticana del gradual, que contenía el considerado primitivo canto gregoriano restaurado, recientemente sancionado por la Santa Sede. Las concienzudamente preparadas y cuidadas interpretaciones gregorianas estuvieron a cargo de Gregorio María Suñol y Mauro Sablayrolles, dos monjes partidarios de los signos rítmicos introducidos por Mocquereau. Aunque por indicación expresa de Roma la discusión sobre la polémica cuestión gregoriana se evitó, la ejecución del canto gregoriano según las tesis solesmenses terminó imponiéndose y mostrándose como ejemplar.

b. La solución del Congreso a la lamentable situación de las capillas catedralicias, y la general falta en los templos de grupos de cantores debidamente 
dirigidos y preparados, consistió en la presentación de la schola cantorum como infraestructura musical básica para seminarios y toda clase de iglesias. La asamblea presentó sus modelos ideales: un coro de seminaristas que, de acuerdo a la función que debían desempeñar, participaron en las funciones solemnes celebradas en la Catedral; una schola cantorum, fundada en un colegio salesiano alejado de la capital diocesana, y presentada como prueba evidente de la viabilidad de la propuesta congresual sobre creación de grupos no profesionales de intérpretes dignos; y la Capilla Isidoriana, en esos momentos, referente histórico de la música religiosa en España.

c. La prensa confesional ejerció el papel que los reformadores le demandaban en este mundo ideal. El Correo de Andalucía estuvo al servicio del Congreso, especialmente durante los días de su celebración. El diario católico fundado por Spínola puso a disposición de los portavoces que habrían de difundir el discurso estético oficial una tribuna desde donde consumaron el proceso de institucionalización de los nuevos estilo, repertorio y compositores considerados como acordes con el $M P$. La música religiosa adquirió, aunque fuera sólo por unos días, la misma relevancia que las cuestiones sociales, ideológicas y políticas, convirtiéndose así en asunto general de la Iglesia institución.

- El congreso de Sevilla fue una gran expresión del regeneracionismo y nacionalismo musical español. Sus postulados constituyeron el trasfondo ideológico de la asamblea celebrada en Andalucía y determinaron la propuesta estética que esta lanzó como interpretación ortodoxa y oficial de los principios contenidos en el MP. Habría que referirse, en consecuencia, a una variante hispana de la reforma promovida por Roma, que se entiende en toda su amplitud y con todas sus particularidades si se considera, además, como una línea más de acción del proyecto de restauración de la música española dentro del ámbito religioso.

a. Los modelos propuestos en el MP, Palestrina y "Escuela Romana", fueron relegados y sustituidos por los autóctonos, Victoria y "Escuela Sevillana”, presentados como superiores a aquellos en virtud de una cualidad considerada como esencialmente española, el expresivismo místico. El gran paradigma de música sagrada consagrado por el Congreso fue la obra de Francisco Guerrero. La recuperación y exaltación de los compositores hispanos del Renacimiento estuvo al servicio, no sólo de los fines litúrgico-musicales sino también de la estrategia nacionalista de recuperación de la 
autoestima y del supuesto lugar preponderante que la música española había ocupado en el concierto internacional.

b. Los criterios de juicio estético aplicados por el Congreso para la institucionalización del canon de música religiosa contemporánea fueron la cercanía, no sólo al canto gregoriano según el $M P$, sino sobre todo a aquellos modelos "clásicos" españoles, arquetipos técnicos, expresivos y litúrgicos. Así, el patrimonio musical histórico, en donde los nacionalistas hallaron las esencias de la "música nacional", cumplió la función revitalizadora de la música moderna que estos le asignaban, consumándose así el proceso regenerador. Los compositores, todos españoles, que pasaron a formar parte del canon según aquellos a los que se les reconoció legitimidad para ello -Ripollés, Villalba- fueron Domingo Mas y Serracant, Vicente Ripollés, Julio Valdés y Federico Olmeda.

c. Los reformistas españoles encontraron en el canto popular religioso un género idóneo para la consecución de uno de sus fines, lograr la participación activa de los fieles en los cultos. Pese a esta orientación fundamentalmente (para)litúrgica, la manera en la que se trató la cuestión durante el Congreso revela la influencia del pensamiento nacionalista y regeneracionista en los esquemas mentales de los reformistas.

d. El pensamiento y la obra de Pedrell fueron situados en la base del proceso de regeneración de la música religiosa española. $\mathrm{Su}$ ausencia frustró los planes de exaltación de su figura, un hecho lleno de simbolismo, pues, creemos, hubiera significado la escenificación pública de la incorporación del naciente movimiento a la tradición pedrelliana. Se trataba de otra forma de institucionalización, esta vez como descendientes ideológicos de Pedrell y continuadores de su obra.

- La propuesta regeneracionista del Congreso recibió una contundente respuesta por parte de los conservacionistas del statu quo. Se destaparon las profundas discrepancias que subyacían debajo de la imagen ideal que construyó el Congreso. Los contendientes operaron en el nivel de lo simbólico, dando lugar a una batalla de iconos de profundo significado: la estrategia regeneracionista de erección de un nuevo mito musical, Francisco Guerrero, activó los resortes defensivos de los conservadores, que blandieron frente a este su propio mito, Hilarión Eslava. Guerrero y Eslava ejercieron de emblemas de dos visiones absolutamente contrapuestas sobre la música religiosa, en 
realidad, de dos universos ideológicos de los que eran reflejo. Este episodio no fue sino otra expresión más del problema de naturaleza cultural e identitaria de fondo; del mismo tipo que el que desencadenó el conflicto entre capitulares conservacionistas y reformistas durante el intento de reforma en la catedral hispalense. El congreso celebrado en Sevilla, ciudad del Miserere eslaviano y sede de la "Escuela Sevillana" de polifonía, por un lado; y lugar donde habían ejercido como maestros de capilla tanto Guerrero como Eslava, por otro, ejerció de escenario ideal para la confrontación de dos identidades musicales.

- Sevilla adquirió en aquel momento un doble y contrapuesto valor simbólico. Por un lado, aquella Sevilla ideal del pasado, constituyó, en su condición de ciudad de Guerrero, Morales, Fernández de Castilleja, una localización geográfica de aquella mitificada época de esplendor y autenticidad en donde los regeneracionistas hallaron la, supuesta, esencia del "genio nacional" para restaurar la nueva música española. Por otro, la Sevilla real de aquel presente, la del Miserere de Eslava y la que reaccionó en contra de la propuesta restauradora y reformista del Congreso, representó la España refractaria e insumisa al proyecto regeneracionista.

- La disputa acontecida en Sevilla desencadenó una abierta lucha de dimensión general española entre regeneracionistas y conservacionistas, librada en las revistas especializadas de música religiosa y los medios católicos generalistas. La exacerbación del enfrentamiento entre unos y otros refleja, creemos, una coyuntura crítica en el proceso histórico de consolidación de la nueva "música moderna española", tal y como era concebida por el nacionalismo musical de corte regeneracionista: colisionaron dos visiones sobre la "verdadera" música sacra española. Desde nuestra perspectiva, la convencional dicotomía tradición/renovación, empleada para explicar esta oposición es superada por otra en la que se subraya el componente identitario que, según creemos, la caracteriza: identidad musical consolidada por el devenir histórico/nueva identidad en proyecto, ideal a consumar. 



\section{RELACIÓN DE FUENTES}

\section{Administrativas y generadas por la institución eclesiástica.}

\subsection{ACS. Sección Secretaría.}

- Actas Capitulares: libros 223 (1887-1890)-230 (1914-1917).

- Actas de la Diputación de Ceremonias: libro 357 (1885-1914).

\subsection{AGAS. Sección Gobierno. Asuntos Despachados.}

- Legajos 04899 (1904)-04911 (1910).

\subsection{ASV. Segretaria di Stato.}

- Rubrica 283, fascicolo 2 (1905).

\subsection{Boletín Oficial del Arzobispado de Sevilla:}

- $\quad$ n$^{\circ} 299$ (noviembre de 1894)-nº 756 (diciembre de 1912).

- $\quad n^{0} 1470(1945)$.

\subsection{Reglas de Coro:}

- Regla del Coro y Cabildo de la S. Iglesia Patriarcal de Sevilla y Memoria de las procesiones y manuales que son a cargo de los señores Deán y Cabildo de ella [resumen de la Regla de Coro realizado en 1608, actualizado y reimpreso en 1760.]

- Regla de Coro de la Santa, Metropolitana y Patriarcal Iglesia Catedral de Sevilla. Sevilla: Imp. Sobrino de Izquierdo, 1923. 


\subsection{Inventarios de obras musicales: ACS. Sección Medios de Información,} leg. 11160.

- Inventario 1: Índice de las Obras que existen en el Archivo musical de esta Santa Iglesia (ca. 1900).

- Inventario 2: Catálogo de Obras musicales (junio de 1907-junio de 1909).

- Inventario 3: Archivo musical de Scalas (ca. 1925).

\section{Epistolares}

\subsection{AGAS. Sección Gobierno. Asuntos Despachados, leg. 04907 (1908).}

- Cartas de treinta y cuatro arzobispos y obispos españoles: Salamanca, Teruel, Zamora, Valencia, Sigüenza, Zaragoza, Orense, Granada, Vich, Lugo, Barcelona, Osma, Cádiz, Coria, Vitoria, Guadix, Tortosa, Málaga, Tuy, Gerona, Badajoz, Burgos, Cartagena, León, Jaén, Santiago de Compostela, Calahorra y La Calzada, Palencia, Madrid-Alcalá, Huesca, Jaca, Tarazona, Plasencia, Capilla Real de Toledo.

- Cartas de veintiún arciprestes de la archidiócesis de Sevilla: Ayamonte (Huelva), Huelva, Utrera, La Palma, Lora del Río, Jerez de la Frontera (Cádiz), Cazalla de la Sierra, Zahara (Cádiz), Aracena (Huelva), Osuna, Sanlúcar la Mayor, Utrera, Puerto de Santa María (Cádiz), Moguer (Huelva), Morón de la Frontera, Campillos (Málaga), Sanlúcar de Barrameda Cádiz), Marchena, Estepa, Carmona, Écija (Sevilla)-Fuente Palmera (Córdoba).

\subsection{Biblioteca de Catalunya. Fondo Felip Pedrell. M 964}

- Ripollés a Pedrell: veintinueve cartas y dos tarjetas postales enviadas entre el 10 de mayo de 1904 y el 14 de marzo de 1913.

- Pedrell a Ripollés: treinta y tres cartas, 8 de de junio de 1903-29 de noviembre de 1905.

- Otaño a Pedrell: nueve cartas y ocho tarjetas postales, 5 de octubre de 1904-11 de diciembre de 1910 .

- Una carta de Villalba a Pedrell fechada el 16 de mayo de 1907.

- Una carta mecanografiada de Mauro Sablayrollés datada el 11 de julio de 1909. 


\subsection{Archivo Musical "Nemesio Otaño" del Santuario de Loiola. Fondo Otaño.}

\subsubsection{Manuscritos (AMSL. FO. 009/004):}

- Remitidos por Vicente Goicoecha a Nemesio Otaño (AMSL. FO. 009/002): cuarenta y cuatro, entre el 7 de octubre de 1908 y el 10 de noviembre de 1913.

- Casiano Rojo a Vicente Goicoechea: ocho, 2 de junio de 1907-29 de diciembre de 1908.

- José María Cos y Macho a Vicente Goicoechea: seis, 5 de enero de 1905-17 de enero de 1913.

- José María Cos y Macho a Nemesio Otaño: cinco, 1 de agosto de 1905-20 de junio de 1913.

- Juan Coscorroza a Vicente Goicoechea: cuatro, 29 de mayo de 1908-17 de junio de 1909.

- Nemesio Otaño a José María Cos y Macho: dos, 25 de mayo de 1908-13 de abril de 1909.

- Julián de Diego García Alcolea aVicente Goicoechea: dos, 22 de agosto de 1905.

- Nemesio Otaño a Vicente Goicoechea: una, 30 de septiembre de 1907.

- Vicente Goicoechea a Giulio Bas: una, 10 de agosto de 1907.

- Vicente Goicoechea a Juan Asensio: una, 22 de abril de 1908.

\subsubsection{Epistolario de Nemesio Otaño, Victoriano Larrañaga (AMSL. FO.}

T01). Documentos epistolares remitidos a:

- Felipe Pedrell: ochenta y uno, entre el 16 de diciembre de 1905 y el 2 de diciembre de 1913.

- Vicente Goicoechea: cincuenta y cuatro, 12 de febrero de 1908-3 de octubre de 1913.

- Angelo de Santi: ocho, 29 de octubre de 1908-13 de noviembre de 1915.

- José María Cos y Macho: dos, 25 de mayo de 1908-13 de abril de 1909.

- Antonio Vico: uno, 9 de julio de 1911. 
2.3.3. "Tomos Azules", volumen 1 (AMSL. FO. TA01) ${ }^{1}$. Documentos epistolares remitidos a:

- Vicente Ripollés: treinta y cuatro, 23 de octubre de 1908-12 de marzo de 1913.

- Dom Mocquereau: dos, 29 de agosto de 1908 y 14 de septiembre de 1908.

- Giulio Bas: uno, [s. d.] septiembre de 1908.

- Antonio Vico: uno, [s. d.] noviembre de 1908.

\section{Hemerográficas}

- Boletín del Congreso: febrero -abril de 1907.

- Biblioteca Sacro-Musical: enero -diciembre de 1911.

- El Correo de Andalucía abril de 1903- diciembre de 1908.

- El Debate: octubre 1910-diciembre 1913.

- $\quad$ El Imparcial: 3 de abril-24 de abril de 1905.

- $\quad$ El Liberal: abril de 1913-abril de 1914.

- El Noticiero Sevillano: abril de 1897-diciembre de 1914, 9 de junio de 1917.

- El Siglo Futuro: 27 de octubre-15 de noviembre de 1911.

- España y América: octubre de 1908-marzo de 1909.

- La Ciudad de Dios: enero 1907-diciembre 1912

- La Hormiga de Oro: enero de 1911-diciembre de 1913.

- Música Religiosa en España: enero -diciembre de 1898.

- Música Sacro-Hispana: junio de 1907-marzo de 1913.

- Razón y Fe: enero-abril 1904, septiembre-diciembre 1908.

\section{Bibliográficas y literarias}

- Arbolí y Faraudo, Servando. La Eucaristía y la Inmaculada, devoción española. Homenaje al Congreso Eucarístico de Valencia. Sevilla: Imp. de E. Rasco, 1895.

- Blasco Ibáñez, Vicente. Sangre y arena. Madrid: Espasa Calpe, 1990 [Valencia, 1908])

- De la Rosa y López, Simón. Los seises de la catedral de Sevilla. Ensayo de investigación histórica. Sevilla: Imp. de Francisco de P. Díaz, 1904.

\footnotetext{
${ }^{1}$ Aunque hemos trabajado tanto con el primer volumen de los "Tomos Azules" (AMSL. FO. TA01) como con el epistolario definitivo (AMSL. FO. T01), presentamos en esta relación sólo aquellas misivas que, por ser desechadas y no incorporadas por Larrañaga al segundo, sólo figuran en el primero.
} 
- Gestoso y Pérez, José. Curiosidades antiguas sevillanas (Serie segunda). Sevilla: El Correo de Andalucía, 1910.

- Muñoz y Pabón, Juan Francisco. En el cielo de la tierra. Sevilla: Imp. Sobrinos de Izquierdo, 1918.

- Noel, Eugenio. Semana Santa en Sevilla. Madrid: Renacimiento, 1916.

- Rueda, Salvador. Granada y Sevilla. Bajo-relieves. Madrid: Fuentes y Capdeville, 1890.

- Serrano y Ortega, Manuel. Glorias sevillanas: noticia histórica de la devoción y culto que la muy noble y muy leal ciudad de Sevilla ha profesado a la Inmaculada Concepción de la Virgen María desde los tiempos de la Antigüedad hasta la presente época. Sevilla: Consejería de Relaciones Institucionales, 2004. [Reproducción facsimilar de la edición de Sevilla: Imp. de E. Rasco, 1893].

\section{Otras:}

- Acta et decreta Concilii Provincialis Hispalensis Anno MDCCCXCIII Celebrati sub Emo. Archiepiscopo Cardinali Dño. Benedicto Sanz et Forés, Promulgata ab ejus successore Excmo. ac Rmo. Dño. Marcello Spinola et Maestre (Sevilla: Imprenta Izquierdo y Cía, 1893).

- Autobiografía inédita escrita por Nemesio Otaño en 1944. [AMSL. FO. Conferencias y otros escritos. 005/013].

- Crónica de la Asamblea Nacional de la Buena Prensa (Sevilla: El Correo de Andalucía, 1905).

- Crónica del Tercer Congreso Católico Nacional español. Discursos pronunciados en las sesiones públicas y reseñas de las memorias y trabajos presentados en las sesiones de dicha Asamblea celebrada en Sevilla en octubre de 1892 (Sevilla: el Obrero de Nazaret de C. Torres y Daza, 1893).

- La coronación de la Virgen de los Reyes. Exhortación que con motivo de solemnidad tan fausta que será una de las principales del año jubilar de la Inmaculada Concepción dirige el Excmo. Sr. Arzobispo de Sevilla a sus amados diocesanos (Sevilla: Izquierdo y Cía, 1904).

- Crónica del Primer Congreso Nacional de Música Sagrada: celebrado en Valladolid en abril de 1907 (Valladolid: Imp. y Lib. Religiosa de Andrés Martín, 1908). 
- Crónica del Segundo Congreso Nacional de Música Sagrada celebrado en Sevilla los días 12, 13, 14 y 15 de noviembre de 1908 (Sevilla: Izquierdo y C., 1909).

- Crónica y actas oficiales del Tercer Congreso Nacional de Música Sagrada, Barcelona, 21-24 noviembre 1912 (Barcelona: La Hormiga de Oro, 1913).

- Crónica del IV Congreso Nacional de Música Sagrada: celebrado en Vitoria del 19 al 22 de noviembre de 1928 (Vitoria: Montepío Diocesano, 1930). 


\section{BIBLIOGRAFÍA}

AA. VV. Corpus, historia de una presencia. Toledo: Instituto Teológico San Ildefonso, 2003.

. Sociología del arte. Buenos Aires: Nueva visión, 1971. [Les arts dans la société. Paris: Unesco, 1968].

Abellán, José Luis. Historia crítica del pensamiento español. 5/I. La crisis contemporánea (1875-1936). Madrid: Espasa-Calpe, 1988.

- Historia crítica del pensamiento español. IV. Liberalismo y Romanticismo (1808-1874). Madrid: Espasa-Calpe, 1984.

Aguilar Piñal, Francisco. "II. Danzas del Corpus", en Temas sevillanos. Sevilla: Universidad de Sevilla, 1988.

Aizpurúa, Pedro. "Vicente Goicoechea Errasti: centenario de su magisterio musical en la catedral de Valladolid". Revista de Musicología, XV/1 (1992), pp. 281-302.

Albardonedo Freire, Antonio José. "Precursores del Laboratorio de Arte: Don José Gestoso y sus trabajos patrocinados por el Ayuntamiento de Sevilla", en Estudios de Historia del Arte. Centenario del Laboratorio de Arte 1907-2007, coord. por Juan Miguel González Gómez y María Jesús Mejías Álvarez. Sevilla: Universidad de Sevilla, 2009, 2 vols., vol. 1, pp. 45-62.

Alén, María Pilar. "Un síntoma de la crisis del italianismo en la música religiosa española: el ataque del Arzobispo Bocanegra a Buono Chiodi (1778)". Recerca musicológica, 5 (1985), pp. 45-83.

Alles, Gregory D., ed. Religious Studies: A Global View. Abingdon: Routledge, 2007.

Almandoz, Norberto. "Informaciones musicales. El maestro Vicente Ripollés". $A B C$ [edición Andalucía] de 9 de abril (1943), p. 14.

Alonso González, Celsa. "La música española y el espíritu del 98”. Cuadernos de Música Iberoamericana, 5 (1998), pp. 79-108. 
. "Nacionalismo", en $D M E H$, ed. por Emilio Casares Rodicio. Madrid: SGAE, 1999-2002, 10 vols., vol. 7, pp. 924-944.

Álvarez Cañibano, Antonio. “Asociacionismo musical en la Sevilla romántica. El liceo Artístico y Literario”. Cuadernos de Música Iberoamericana, 8-9 (2001), pp. 73-80.

. "Gómez Zarzuela, Vicente", en DMEH, ed. por Emilio Casares Rodicio. Madrid: SGAE, 1999-2002, 10 vols., vol. 5, pp. 725-726.

. "Mariani González, Luis Leandro", en $D M E H$, ed. por Emilio Casares Rodicio. Madrid: SGAE, 1999-2002, 10 vols., vol. 7, pp. 170-171.

. "Teatros y música escénica. Del Antiguo Régimen al estado burgués", en La música española en el siglo XIX, ed. por Emilio Casares Rodicio y Celsa Alonso González. Oviedo: Universidad de Oviedo, 1995, pp. 123-158.

Álvarez Junco, José. Mater dolorosa. La idea de España en el siglo XIX. Madrid: Taurus, 2001.

Álvarez Martínez, Ma Salud y Antonio Álvarez Cañibano. "Sevilla”, en $D M E H$, ed. Emilio Casares Rodicio. Madrid: SGAE, 2002, 10 vols, vol. 9, pp. 968-987.

Álvarez Rey, Leandro. Las cofradías de Sevilla en el siglo XX. Sevilla: Universidad de Sevilla, 1999 [1992].

Álvarez Santaló, León Carlos. “'Religiosidad popular’ en el Siglo de Oro: la estilística del vaciado y el moldeamiento social”, en Religiosidad popular sevillana, ed. por José Hurtado Sánchez. Sevilla: Ayuntamiento de Sevilla y Universidad de Sevilla, 2000, pp. 37-61.

Ambrosi, Paola. "La presenza di Alfonso Álvarez nei canzionieri spagnoli”, Quaderni di Lingue e Letterature, 6 (1981), pp. 95-105.

Ansorena, José Luis. "Biografía de D. Hilarión Eslava", en Monografía de Hilarión Eslava, ed. por equipo Musikaste-Eresbil. Pamplona: Diputación Foral de Navarra, 1978.

Araiz Martínez, Andrés, Historia de la música religiosa en España. Barcelona: Labor, 1942.

Arbolí y Faraudo, Servando y otros. Biblioteca Colombina. Catálogo de sus libros impresos, 7 vols. Sevilla: Imp. E. Rasco, 1888-1948.

Arias del Valle, Raúl. La orquesta de la S.I. Catedral de Oviedo (1572-1933). Oviedo: Instituto de Estudios Asturianos, 1990.

Ariño, Antonio. Festes, rituals y creencies. Valencia: Alfons el Magnànim, 1988. 
Arroyas Serrano, Magín y Vicente Martínez Molés. "La primera transcripción moderna del Oficio de Difuntos de Victoria: el manuscrito del maestro José Perpiñán”. Revista de Musicología, XXXV/1 (2012), pp. 473-489.

Asensio Palacios, Juan Carlos. "El Padre Eustoquio Uriarte y la restauración del canto gregoriano en España", en Actas del Simposium "La música en el Monasterio de El Escorial”. Madrid: Instituto de Estudios Escurialenses de Investigaciones Históricas y Artísticas, 1992. pp. 751-763.

"La recepción del Motu Proprio en España: Federico Olmeda y su opúsculo Pío X y el Canto Romano". Revista de Musicología, XXVII/1 (2004), pp. 7788.

Aviñoa Pérez, Xosé. La musica i el modernisme. Barcelona: Curial, 1985.

. "Felip Pedrell en el canvi ideològic i estètic de la Barcelona de la darreria del segle XIX”. Recerca Musicològica, 11-12 (1991-1992), pp. 27-46.

."Modernisme i música: una reflexió al caps dels anys". Recerca Musicològica, 14-15 (2004-2005), pp. 107-122.

- Xosé. "Los congresos del Motu proprio (1907-1928). Repercusión e influencias". Revista de Musicología, XXVII/1 (2004), pp. 381-399.

Ayarra Jarne, José Enrique. "500 años de Música de Órgano en Sevilla". Ars sacra: Revista de patrimonio cultural, archivos, artes plásticas, arquitectura, museos y música, 39 (2006), pp. 28-37.

. "El maestro Don Eduardo Torres en Sevilla". Temas de estética y arte, 12 (1998), pp. 87-99.

. "El órgano y su literatura en la liturgia y en la cultura". Patrimonio cultural: Documentación, estudios, información, 40 (2004), pp. 97-106.

. "La música de órgano española en el siglo XIX". Temas de estética y arte, 24 (2010), pp. 295-314.

. "La música en el culto catedralicio hispalense", en La catedral de Sevilla. Sevilla: Guadalquivir, 1991, pp. 699-748.

- "La música en las funciones litúrgicas de Semana Santa de la catedral hispalense", en Las cofradías de Sevilla en el siglo de la crisis, ed. por León Carlos Álvarez Santaló. Sevilla: Universidad de Sevilla, 1999, pp. 85-110.

Hilarión Eslava en Sevilla. Sevilla: Diputación Provincial de Sevilla, 1978.

. La música en la Catedral de Sevilla. Sevilla: Caja de Ahorros Provincial San Fernando de Sevilla, [s. f.]. 
Historia de los grandes órganos de coro de la catedral de Sevilla. Madrid: Dirección General de Bellas Artes, 1974.

Baade, Colleen. "Two Centuries of Nuns Musicians in Spain's Imperial City". TRANSRevista Transcultural de Música, 15 (2011). $<$ http://www.sibetrans.com/trans/public/docs/trans_15_03_Baade.pdf $>$ (consultado 4-11-13).

Bahler, Ingrid. Alfonso Álvarez de Villasandino, poeta de petición. Madrid: Maizal, 1977.

Barberá Soler, Miguel. "Eduardo Torres Pérez: historia de su amistad con Manuel de Falla y Matheu". Academia: Boletín de la Real Academia de Bellas Artes de San Fernando, 70 (1990), pp. 273-316.

Barbieri, Francisco Asenjo. Biografía y documentos sobre música y músicos españoles, ed. por Emilio Casares Rodicio. Madrid: Fundación Banco Exterior, 1986 y 1988, 2 vols.

Cancionero musical de los siglos XV y XVI. Madrid: Real Academia de Bellas Artes de San Fernando, 1890.

Barce, Ramón. "El sainete lírico (1880-1915)”, en La música española en el siglo XIX, ed. por Emilio Casares Rodicio y Celsa Alonso González. Oviedo: Universidad de Oviedo, 1995, pp. 195-244.

Barrero González, Enrique. El Ateneo de Sevilla. Sevilla: Ayuntamiento de Sevilla, 2008.

Barrios, M ${ }^{\mathrm{a}}$ Pilar. "La música en la catedral de Coria (Cáceres) durante el magisterio de capilla de Francisco Bernal (1814-1823)". Revista de Musicología, XIV/1-2 (1991), pp. 535-548.

"La transición del siglo XVIII al XIX en la Catedral de Coria (Cáceres). Magisterio de Juan José Bueno". Nassarre: Revista aragonesa de musicología, IX/2 (1993), pp. 193-195.

Bastús, Joaquín. Oficio de la Semana Santa y Semana de Pascua en latín y castellano. Barcelona: Imp. Elzeviriana y lib. Camí, 1928.

Basurko, Xabier. Historia de la liturgia. Barcelona: Centre de Pastoral Litúrgica, 2006.

Baxandall, Michael. The Limewood Sculptors of Renaissance Germany. New Haven: Yale University Press, 1980.

Becker, Howard S. Art Worlds. Berckley: University of California Press, 1982. 
Bejarano Pellicer, Clara. "'De la parte de dentro o de la parte de fuera': la capilla paralela de San Salvador de Sevilla a comienzos del siglo XVII", Revista de Humanidades, 20 (2013). <http://www.revistadehumanidades.com/articulos/46de-la-parte-de-dentro-o-de-la-parte-de-fuera-la-capilla-paralela-de-sansalvador-de-sevilla-a-comienzos-del-siglo-xvii> (consultado 20-2-2014).

. El mercado de la música en la Sevilla del Siglo de Oro. Sevilla: Universidad de Sevilla, 2013.

Bermúdez Medina, Rafael. "Las coplas de Hilarión Eslava”. Boletín de las cofradías de Sevilla, 506 (2001), pp. 125-127.

Bernales Ballesteros, Jorge. "La Biblioteca Capitular y Colombina", en La catedral de Sevilla. Sevilla: Guadalquivir, 1991, pp. 777-799.

Bertrán, José Luis y otros. "Antropología y microhistoria: conversación con Giovanni Levi". Manuscrits, 11 (1993), pp. 15-28.

Bombi, Andrea, "Ripollés Pérez, Vicente", en Diccionario de la Música valenciana, ed. Emilio Casares Rodicio. Madrid: Iberautor Promociones Culturales, 2006, 2 vols., vol. 2, 344-346.

, Juan José Carreras y Miguel A. Marín, eds. Música y cultura urbana en la Edad Moderna. Valencia: Universitat de València, 2005.

. "Perspectivas históricas en los escritos de Vicente Ripollés (1867-1943)", en Musicología en la Edad de Plata, ed. por Juan José Carreras. Zaragoza: Instituto Fernando el Católico [en prensa].

"Vicente Ripollés, el Colegio del Patriarca y la reforma ceciliana", en Música y reforma litúrgica desde 1611 hasta el presente, ed. por Rosa Isusi Fagoaga y Greta Olson [en prensa].

Bonastre i Bertran, Francesc. "Documents epistolars de Barbieri adreçats a Felip Pedrell”. Recerca Musicològica, 5 (1985), pp. 131-177.

. "El nacionalisme musical de Felip Pedrell: reflexions a 1'entorn de Por nuestra música...”. Recerca musicológica, 11-12 (1991-1992), pp. 17-26.

Borrero Gaviño, Virginia y Manuel Martín Riego. "Don Evaristo García Torres, maestro de capilla de la catedral de Sevilla (1864-1902)". Memoria ecclesiae, 31 (2008), pp. 697-712.

Bourdieu, Pierre. El sentido práctico. Buenos Aires: Siglo XXI, 2007. [Le sens pratique. París: Minuit, 1980].

La distinción. Criterios y bases sociales del gusto. Madrid: Taurus, 2012. [La distinction. Critique sociale du jugement. París: Minuit, 1979]. 
Las reglas del arte. Génesis y estructura del campo literario. Barcelona: Anagrama, 1995. [Les Règles de l'art. Gènese et structure du champ litteraire. París: Du Seuil, 1992].

. The Field of Cultural Production: Enssays of Art and Literature. New York: Columbia University Press, 1993.

Braojos Garrido, Alfonso, María Parias y Leandro Álvarez Rey. Sevilla en el siglo XX. Sevilla: Universidad de Sevilla, 1990.

. La prensa y la historia: diez estudios sobre comunicación periodística en Andalucía. Sevilla: Ayuntamiento de Sevilla, 2000.

. Historia de Sevilla. Sevilla: Universidad de Sevilla, 1989.

Burke, Peter, ed. Formas de hacer historia. Madrid: Alianza Editorial, 2003 [New Perspectives on Historical Writing. Cambridge: Polity Press, 1991].

. "Cultural History as Polyphonic History". Arbor. Ciencia, pensamiento y cultura, CLXXXVI/743 (2010), pp. 479-486.

. "From Cultural History to Histories of Cultures". Memoria y civilización, 1 (1998), pp. 7-24.

. Popular culture in early modern Europe. Farnham: Ashgate, 2009 [1978]).

Buxó Rey, Ma José, coord. La religiosidad popular II. Vida y muerte: la imaginación religiosa. Barcelona: Anthropos, 2003 [1989].

Caballas Alamán, Fernando J., "Aranaz y Vides, Pedro Felipe", en $D M E H$, ed. por Emilio Casares. Madrid: SGAE, 1999-2002, 10 vols., vol. 1, pp. 548-554.

Cabañas Alamán, Fernando Juan. "La estancia en Cuenca del organista Manuel María Caballero (1855-1860)". Revista de Musicología, XIV/1-2 (1991), pp. 583-596.

Cabezas García, Álvaro. Gusto orientado y fiesta pública en Sevilla. Análisis de documentos para la comprensión de la historia artística del siglo XVIII. Sevilla: Estípite, 2012.

Campos y Fernández de Sevilla, Francisco Javier. "La devoción a la Inmaculada Concepción en las 'Relaciones Topográficas", en La Inmaculada Concepción en España: religiosidad, historia y arte, ed. por Francisco Javier Campos y Fernández de Sevilla. San Lorenzo de El Escorial: Ediciones Escurialenses, 2005, 2 vols., vol. 1, pp. 7-28.

Candendo Zabala, Óscar. "Vicente Goicoechea Errasti (1854-1916): un compositor del Motu Proprio y el canto religioso popular", en Música y reforma litúrgica desde 1611 hasta el presente, ed. por Rosa Isusi Fagoaga y Greta Olson. 
Carmona Mata, Eugenio. José Moreno Villa y los orígenes de las vanguardias artísticas en España (1909-1936). Málaga: Universidad de Málaga, 1985.

Carredano, Consuelo. "La música religiosa y las capillas catedralicias en el nuevo orden republicano", en Historia de la música en España e Hispanoamérica. vol 6. La música en Hispanoamérica en el siglo XX, ed. por Consuelo Carredano y Victoria Eli. Madrid: Fondo de Cultura Económica, 2010, pp. 125-152.

Carreira Antelo, Xoán Manuel. "Recepción de la ópera italiana en Granada". Revista de musicología, XIII/1 (1990), pp. 231-254.

Carreira, Xosé Manuel. "La Musicologia spagnola: un'illusione autarchica?”. Il saggiatore musicale, II/1 (1995), pp. 105-143.

"La visión congelada: Autarquía y fideísmo en la historiografía musical de las catedrales", pp. 17-52. <http://www.mundoclasico.com/ed/documentos/docver.aspx?id=0003746 $>$ (consultado 2-11-13).

Carreras, Juan José. "De Literes a Nebra: la música dramática entre la tradición y la modernidad", en La música en España en el siglo XVIII, ed. por Malcom Boyd y Juan José Carreras. Cambridge: Cambridge University Press, 2000. [Music in Spain during the Eighteenth Century. 1998], pp. 19-28.

. "Hijos de Pedrell. La historiografía musical española y sus orígenes nacionalistas (1780-1980)". Il saggiatore musicale, VIII/1 (2001), pp. 121-169.

. "L'opera di corte a Madrid (1700-1759)", en Il teatro dei due mondi. L'opera italiana nei paesi di lingua iberica, ed. por Anna L. Bellina. Padua: Diastema Libri, 2000, pp. 11-35.

"Música y ciudad: de la historia local a la historia cultural", en Música y cultura urbana en la Edad Moderna, ed. por A. Bombi, Juan J. Carreras y Miguel A. Marín. Valencia: Universitat de València, 2005, pp. 17-52.

Carrillo Cabeza, Mauricio. "Evaristo García Torres. Oposición al Magisterio de Capilla de la Catedral de Sevilla, 1864: una aproximación estilística a través de sus misas". Anuario de Historia de la Iglesia andaluza, 6 (2011), pp. 273-300.

Casares Rodicio, Emilio y Alonso González, Celsa, eds. La música española en el siglo XIX. Oviedo: Universidad de Oviedo, 1995.

Casares Rodicio, Emilio, "Insausti Morras, Agapito", en $D M E H$, ed. por Emilio Casares. Madrid: SGAE, 1999-2002, 10 vols., vol. 6, p. 428.

, dir. Actas del Simposio Internacional 'La zarzuela en España $e$ Hispanoamérica. Centro y periferia. 1800-1950', Cuadernos de Música Iberoamericana, 2 y 3 (1997).

"Federico Olmeda de San José", en $D M E H$, ed. por Emilio Casares. Madrid: SGAE, 1999-2002, 10 vols., vol. 8, pp. 67-70. 
. "La música del siglo XIX español. Conceptos fundamentales", en La música española en el siglo XIX, ed. por Emilio Casares y Celsa Alonso. Oviedo: Universidad de Oviedo, 1995, pp. 13-122.

. "La música española hasta 1939, o la restauración musical", en Actas del congreso internacional "España en la música de occidente" (Salamanca, 1985), coord. por José López-Calo, Ismael Fernández de la Cuesta y Emilio Casares Rodicio. Madrid: Ministerio de Cultura, 1987, 2 vols., vol. 2, pp. 261322.

. "Pedrell, Barbieri y la restauración musical española". Recerca Musicològica, 11-12 (1991-1992), pp. 259-271.

Cascales Muñoz, José. Sevilla intelectual, sus escritores y artistas contemporáneos: Setenta y cinco biografías de los mejores ingenios hispalenses, y un apéndice con estudios bibliográficos y críticos acerca de las obras de algunos más que no han sido biografiados. Madrid: Victoriano Suárez, 1896.

Cascudo, Teresa y María Palacios. "Introducción", en Los señores de la crítica. Periodismo musical e ideología del modernismo en Madrid (1900-1950), ed. por Teresa Cascudo y María Palacios. Sevilla: Doble J, 2011, pp. I-XX.

"Humor y pedagogía en las crónicas de Miguel Salvador, el crítico buen aficionado de El Globo (1904-1913)", en Los señores de la crítica. Periodismo musical e ideología del modernismo en Madrid (1900-1950). Sevilla: Doble J, 2011, pp. 1-54.

Castañeda Delgado, Paulino y Manuel J. Cociña y Abella, coords. XV Simposio de Historia de la Iglesia en España y América "La Inmaculada y Sevilla" (Sevilla, 2004). Córdoba : Publicaciones Obra Social y Cultural Cajasur, 2007.

Castillo, Juan José. "Modulaciones ideológicas del catolicismo social en España: De los Círculos a los Sindicatos”. Revista española de la opinión pública, 45 (1976), pp. 37-75.

Catalá Gorgues, Miguel Ángel. La procesión del Corpus en antiguos Dietaris y Llibres de Memories. Valencia: Ayuntamiento de Valencia, 1993.

Cavia Naya, Victoria. La vida musical en la Catedral de Valladolid en el siglo XIX. Valladolid: Diputación Provincial de Valladolid, 2004.

Chase, Gilbert. "Pedrell, Eximeno y el nacionalismo musical". Revista musical chilena, II/13 (1946), pp. 10-12.

Climent Barber, José. "Cabo Arnal. 1. Francisco", en DMEH, ed. por Emilio Casares. Madrid: SGAE, 1999-2002, 10 vols., vol. 2, pp. 840-841.

Fondos musicales de la Región Valenciana. Valencia: Institución Alfonso el Magnánimo, 1979-1986, 4 vols. 
La catedral de Valencia. Devenir musical en el siglo XX. Valencia: Real Acadèmia de Cultura Valenciana, 2005.

. Historia de la música contemporánea valenciana. Valencia: Del Cenia al Segura, 1978.

. Historia de la música valenciana. Valencia: Rivera Mota, 1989.

Código de Derecho Canónico. <http://www.vatican.va/archive/ESL0020/_P7.HTM.> (consultado 27-10-2013).

Collet, Henry. Le mysticisme musical espagnol au XVI siécle. Paris: Felix Alcan, 1913.

Combé, Pierre. The Restoration of Gregorian Chant. Solesmes \& the Vatican Edition. The Catholic University of America Press, 2003 [Histoire de la restauration du chant grégorien d'après des documents inédits. Solesmes et l'Edition vaticane. Solesmes: Abbaye Saint-Pierre, 1969].

Company Florit, Joan. "Salas Seguí, Bernat", en $D M E H$, ed. por Emilio Casares. Madrid: SGAE, 1999-2002, 10 vols., vol. 9, pp. 568-569.

Corcuff, Philippe. "Pierre Bourdieu (1930-2002) leído de otra manera. Crítica social post-marxista y el problema de la singularidad individual". Cultura y representaciones sociales. Un espacio para el diálogo transdisciplinario, IV/7 (2009), pp. 9-26.

$<$ http://www.revistas.unam.mx/index.php/crs/article/view/16401/15610>. (consultado 2-9-2013).

Córdoba Montoya, Pedro. "Religiosidad popular: arqueología de una noción polémica", en La religiosidad popular I. Antropología e historia, coord. por Carlos Álvarez Santaló. Barcelona: Anthropos, 2003 [1989], pp. 70-81.

Córdova Plaza, Rosío. "El concepto de habitus de Pierre Bourdieu y su aplicación a los estudios de género". Colección Pedagógica Universitaria, 40 (2003), pp. 1-10.

Cortés i Mir, Francesc, "La música religiosa", en Història de la Música Catalana, Valenciana i Balear, dir. por Xosé Aviñoa. Barcelona: Edicions 62, 19992004, 13 vols., vol. 3, pp. 187-253.

Cortés Peña, Antonio Luis. "Andalucía y la Inmaculada Concepción en el siglo XVII", en Religión y política durante Antiguo Régimen, ed. por Antonio Luis Cortés Peña. Granada: Universidad de Granada, 2001, pp. 103-148.

Cortizo, Ma Encina. "La zarzuela del siglo XIX. Estado de la cuestión", en La música española en el siglo XIX, ed. por Emilio Casares y Celsa Alonso. Oviedo: Universidad de Oviedo, 1995, pp. 161- 194.

Cruces, Francisco y otros, eds. Las culturas musicales. Lecturas de etnomusicología. Madrid: Trotta, 2001. 
Cruttwell, Patrick. The Shakespearian Moment. London: Chatto and Windus, 1954.

Cruz Giráldez, Miguel. "La Semana Santa sevillana en la literatura (III)". ABC Sevilla de 2 de marzo (1990), p. 43.

- "Religiosidad y Literatura Popular en la Sevilla del Barroco: las coplas de Miguel Cid", en Homenaje al profesor Klaus Wagner. Sevilla: Universidad de Sevilla, 2008, 2 vols., vol. 2, pp. 573-581.

Cuenca Benet, Francisco. Biblioteca de autores andaluces. Habana: Tipografía Moderna de Alfredo Dorrbecker, 1921.

Galería de músicos andaluces, ed. por Manuel del Campo y Antonio Martín Moreno. Málaga: Unicaja, 2002 [Facsímil de la edición de La Habana: Cultura, S.A., 1927.]

Cuenca Toribio, José Manuel. Historia general de Andalucía. Córdoba: Almuzara, 2005.

Cuesta García de Leonardo, María José. "Las fiestas del Corpus Christi en el paso del Antiguo Régimen a la Época Contemporánea. (El caso de Granada).”, en La fiesta del Corpus Christi, coord. por Gerardo Fernández Juárez y Fernando Martínez Gil. Cuenca: Universidad de Castilla-La Mancha, 2002, pp. 179-214.

Cureses de la Vega, Marta y Xosé Aviñoa. "Contra la falta de perspectiva histórica (bases para la investigación musical contemporánea en España)". Revista Catalana de Musicología, 1 (2001), pp. 171-200.

Dalhaus, Carl. "Die Musik des 19. Jahrhunderts", en Neues Handbuch der Musikwissenschaft, 14 vols., vol. 6 (Wiesbaden: Laaben, 1980).

Danto, Arthur. "The Artworld", The Journal of Philosophy, LXI/19 (1964), pp. 571584.

De Clerck, Paul. "La belle nouveauté de la tradition", en Les grandes révolutions de la théologie moderne, dir. por F. Bousquet. Paris: Bayard, 2003, pp 195-250.

De Diego y García Alcolea, Juan. In memoriam del Emmo. Sr. Cardenal D. José María de Cos, Arzobispo de Valladolid. Semblanza por el Excmo. Sr. Dr. D. Julián de Diego y Alcolea, obispo de Salamanca. Salamanca: Establecimiento tipográfico de Calatrava, 1923.

De la Cueva Merino, Julio y Ángel Luís López Villaverde. Clericalismo y asociacionismo católico en España: de la Restauración a la Transición. Cuenca: Universidad de Castilla-La Mancha, 2005.

De la Fuente Charfolé, José Luís. "Nuevos hallazgos documentales y biográficos sobre Alonso Xuárez, maestro de Sebastián Durón”. Anuario Musical, 67 (2012), pp. 3-18. 
De la Rosa y López, Simón. Libros y autógrafos de D. Cristóbal Colón. Discursos leídos ante la Real Academia Sevillana de Buenas Letras en la recepción pública del Dr. D. Simón de la Rosa y López el 29 de junio de 1891. Sevilla: Imp. de E. Rasco, 1891.

De la Torre Molina, María José. “Tradición e innovación en las capillas catedralicias españolas: las Constituciones de 1766 de la Capilla de música de la Catedral de Málaga y su vigencia en el primer tercio del siglo XIX". Revista de musicología, XXVIII/1 (2005), pp. 295-309.

De los Reyes Peña, Mercedes. "Un pasquín anti-inmaculista en la Sevilla del primer tercio del siglo XVII", en Sevilla y la literatura: homenaje al profesor Francisco López Estrada en su 80 cumpleaños, coord. por Mercedes de los Reyes Peña, Rogelio Reyes Cano y Klaus Wagner. Sevilla: Universidad de Sevilla, 2001, pp. 133-160.

De los Ríos, Amador. Historia crítica de la literatura española. Tomo VII. Madrid: Impr. Joaquín Muñoz, 1865.

De Mena, José María. Historia del Conservatorio Superior de Música y Escuela de Arte Dramático de Sevilla. Madrid: Conservatorio Superior de Música de Sevilla, Editorial Alpuerto, 1984.

. La Sevilla que se nos fue. Sevilla: Castillejo, 1994 [1984].

De Persia, Jorge. "Distintas aproximaciones al estudio del hecho musical en España durante el siglo XIX”. Revista de Musicología, XIV/1-2 (1991), pp. 307-324.

De Vroye, T. J. y X. van Elewyck, X. De la musique religieuse. Les congrès de Malines (1863 et 1864) et Paris (1860) et la législation de l'Église sur cette matiére. Paris: Librairie Lethielleux, 1866.

Delgado García, Fernando. "La construcción del sistema nacional de conservatorios en España (1892-1942)”. Cuadernos de Música Iberoamericana, 12 (2006), pp. 109-134.

. Los gobiernos de España y la formación del músico (1812-1956). Tesis doctoral. Sevilla: Universidad de Sevilla, 2003. $<\mathrm{http}$ //fondosdigitales.us.es/tesis/tesis/540/los-gobiernos-de-espana-y-laformacion-del-musico-1812-1956/> (consultado 18-2-1913).

Delgado Rodríguez, José Manuel. "Las coplas a San Teodomiro, Patrón de Carmona". Carel. Carmona. Revista de estudios locales, 2 (2004), pp. 350-402.

- Miserere de Hilarión Eslava. Granada: Junta de Andalucía. Consejería de Cultura, 2010.

Dickie, George. Art and the Aesthetic: An Institutional Analysis. Ithaca: Cornell University Press, 1974. 
. The Art Circle: A Theory of Art. New York: Haven, 1984.

Díez Martínez, Marcelino. La música en Cádiz: la Catedral y su proyección urbana durante el siglo XVIII. Cádiz: Universidad de Cádiz, 2004.

Domínguez León, José. "La doctrina social católica en Andalucía occidental a finales del siglo XIX y el impacto de la Rerum Novarum. El caso sevillano", en Las Fiestas de Sevilla en el siglo XV. Otros estudios, dir. por José Sánchez Herrero. Madrid: Deimos, 1991, pp. 207-232.

. "La religiosidad en la Sevilla isabelina (1833-1868)", en La religiosidad popular I. Antropología e historia, coord. por Carlos Álvarez Santaló. Barcelona: Anthropos, 2003 [1989]), pp. 357-373.

Domínguez Ortíz, Antonio. "La Congregación de la Granada y la Inquisición de Sevilla. Un episodio de la lucha contra los alumbrados", en La Inquisición española: Nueva visión, nuevos horizontes, coord. por J. Pérez Villanueva. Madrid: Caja Provincial de Ahorros de Cuenca, 1980, pp. 637-646.

Donella, Valentino. Musica e liturgia. Indagini e Riflessioni Musicologiche. Bergamo: edizioni Carrara, 1991.

Dyer, Joseph. "Roman Catholic church music". Grove Music Online. Oxford Music Online.<http://www.oxformusiconline.com/suscriber/article/grove/music/4675 $8>$ (consultado 24-2-2009).

Ecco, Umberto. Semiotica e filosofia del linguaggio. Turín: Einaudi, 1984.

Eli, Victoria, "Romeu, Luis", en DMEH, ed. por Emilio Casares. Madrid: SGAE, 19992002, 10 vols., vol. 9, p. 401.

Elizondo Iriarte, Esteban. “Cien años de música para órgano en el País Vasco y Navarra (1880-1980). La obra para órgano de Martín Rodríguez, Eduardo e Ignacio Mocoroa, José María Beobide y Tomás Elduayen". Revista de musicología, XXIX/ 2 (2006), pp. 617-666.

. "La obra para órgano de Eduardo Torres (1872-1934)". Revista de Musicología, XXXI/1 (2008), pp. 151-169.

"La obra para órgano de Luis Urteaga Iturrioz (1882-1960)". Revista de musicología, XXVIII/1 (2005), pp. 328-344.

Eslava, Bonifacio. Colección escogida de las obras músico-religiosas de Don Hilarión Eslava, maestro director de la Real Capilla de Música de S.M. y profesor de composición del Real Conservatorio de música y declamación. Madrid: Calcografía de B. Eslava, 1861.

Eslava, Hilarión. Lira Sacro-Hispana. Madrid: Martín Salazar, 1852-1860, 10 vols. . Miserere, ed. por Lorenzo Ramos. Barcelona: Tritó, 2009. 
. Museo orgánico español. Parte $1^{a}$. Madrid: [s.e.], [1854].

Falero Folgoso, Francisco J. La teoría del arte del krausismo español. Granada: Universidad de Granada, 1998.

Fernández de la Cuesta, Ismael. "Apuntes sobre la musicología en España", en La musicología española en el contexto internacional: los congresos internacionales de musicología, ed. por Ismael Fernández de la Cuesta y Enrique Guijarro Parra. Madrid: Consejería de Educación y Cultura. Comunidad de Madrid, 1992, pp. 61-82.

. "La reforma del canto gregoriano en el entorno del Motu Proprio de Pío X". Revista de Musicología, XXVII/1 (2004), pp. 43-76.

Fernández Gómez, Marcos. “Gestoso y Pérez. José”, Diccionario de Ateneístas, dir. por Enrique Barrero González. Sevilla: Ateneo de Sevilla, 2005, 3 vols., vol. 1. V

Fernández Juárez, Gerardo y Fernando Martínez Gil, eds. La fiesta del Corpus Christi. Cuenca: Universidad de Castilla-La Mancha, 2002.

Fort, Carlos R. El Concordato de 1851 comentado y seguido de un Resumen con las disposiciones adoptadas por el Gobierno de S. M. sobre materias eclesiásticas, desde la celebración de aquel convenio hasta enero de 1853. Madrid: Imprenta y Fundición de Don José Aguado, 1853.

Foucault, Michel. El orden del discurso. Barcelona: Tusquets, 2004. [L'ordre du discourse. París: Gallimard, 1971].

La arqueología del saber. Madrid: Siglo XXI, 1970. [L'archéologie du savoir. París: Gallimard, 1969].

Galindo García, Ángel. La música en la Iglesia de ayer a hoy. Salamanca: Universidad Pontificia de Salamanca, 1992.

Garbayo Montabes, Francisco Javier. "El magisterio de la capilla de música de la Catedral de Ourense entre 1780 y 1819: José Quiroga y Manuel Rábago". Porta da aira: revista de historia del arte orensano, 10 (2004), pp. 237-260.

"La estancia del organista Joaquín Pedrosa en la catedral de Orense (18051835)". Porta da aira: revista de historia del arte orensano, 6 (1994-1995), pp. 99-111.

- "La viola en el ámbito eclesiástico hispano. La orquesta de la capilla de música de la catedral de Santiago y el uso de dos violas en la música de Melchor López (1783- 1822)". Anuario Musical, 62 (2007), pp. 229-255.

- "Las reformas de Mariano Tafall y otras intervenciones posteriores en los órganos del coro de la catedral de Ourense (1963-1924)". Porta da aira: revista de historia del arte orensano, 11 (2006), pp. 187-208. 
"Recepción e influencia del Motu Propio de San Pío X en la capilla de música de la catedral de Ourense: protagonistas y repertorio". Revista de Musicología, XXVII/1 (2004), pp. 313-334.

García García, Juan Alfonso, "Manuel de Falla y la música eclesiástica", en Falla y Granada y otros escritos musicales. Granada: Centro de Documentación Musical de Andalucía, 1991, pp. 33-63.

Valentín Ruíz-Aznar (1902-1972). Granada: Real Academia de Bellas Artes Nuestra Señora de las Angustias de Granada, 1982.

García García, Tomás de Aquino. Fiestas sevillanas por la declaración del Patronato de la Inmaculada Concepción de Nuestra Señora, de 1761-1763. Sevilla: [s.e.], 1972).

García Sánchez, Albano. "Contribución de Nemesio Otaño (1880-1956) a la memoria de Tomás Luis de Victoria, paradigma de universalidad". Revista de Musicología XXXV/1 (2012), pp. 459-472.

"José María Nemesio Otaño Eguino (1880-1956): una aportación a la verdadera reforma de la música religiosa". Revista de Musicología, XXXII/1 (2009), pp. 475-489.

"Sobre la reforma de la música religiosa en España", en Musicología global, musicología local, ed. por Javier Marín López, Germán Gan Quesada, Elena Torres Clemente, Pilar Ramos López. Madrid: Sociedad Española de Musicología, 2013, pp. 969-983.

García-Abásolo, Antonio, coord. La música de las catedrales andaluzas y su proyección en América. Córdoba: Universidad de Córdoba. Obra Social y Cultural Cajasur, 2010.

Gatens, William J. Victorian Cathedral Music in Theory and Practice. Cambridge: Cambridge University Press, 1986.

Geertz, Clifford. La interpretación de las culturas. Barcelona: Gedisa, 2003. [The Interpretation of Cultures. New York: Basic Books, 1973].

Gembero Ustárroz, María. "El patronazgo ciudadano en la gestión de la música eclesiástica: la Parroquia de San Nicolás de Pamplona (1700-1800)". Nassarre, XIV/1 (1998) [separata], pp. 269-362.

Genovés Carmona, $\mathrm{M}^{\mathrm{a}}$ Carmen. "Una mirada al 'motu proprio' valenciano: Vicente Ripollés y Eduardo Soler”, Archivo de arte valenciano, 86 (2005), pp. 67-76.

Gestoso y Pérez, José, Segundo Bloque Epistolario; que contra el deleznable Propugnáculo de la malaventurada crítica histórico-artística-arqueológica del Pbro. D. Manuel Serrano y Ortega, lanza el Ldo. Gestoso, en defensa de la verdad, estropeada lastimosamente por su Paternidad, en el librico Las Tradiciones Sevillanas. Sevilla: La Andalucía Moderna, 1895. 
La Andalucía Moderna: Contestación a las notas del Pbro. Sr. D. Manuel Serrano y Ortega en su libro Noticia histórica de la Devoción y Culto que la M. N. y M. L. Ciudad de Sevilla ha profesado a la Inmaculada Concepción de la Virgen María desde los tiempos de la antigüedad hasta la presente época. Sevilla: La Andalucía Moderna, 1894.

. Tres cartas al Ilmo. Sr. Dr. D. Servando Arbolí, capellán mayor de la real de San Fernando, acerca de las reformas que deben efectuarse en la imagen y en el paso de Nuestra Señora de los Reyes con motivo de su próxima coronación. Sevilla: La Andalucía Moderna, 1904.

Gies, David T. The Cambridge Companion to Modern Spanish Culture. Cambridge: Cambridge University Press, 1999.

Giménez Rodríguez, Francisco J. "Felip Pedrell en la revista La Alhambra (19021922)", Recerca Musicològica, 16 (2006), pp. 117-148.

Ginzburg, Carlo. "Microhistory: Two or Three Things That I Know about It", Critical Inquiry, XX/1 (1993), pp. 10-35. <http://www.jstor.org/stable/1343946.>. (consultado 8-11-2013).

. "Qué he aprendido de los antropólogos". Alteridades, XIX/38 (2009), pp. 131139.

Gmeinwieser, Siegfried, "Cecilian Movement", en Grove Music Online. Oxford Music Online. $<$ http://www.oxfordmusiconline.com/subscriber/article/grove/music/05 245> (consultado 24-04-2009).

Gómez Amat, Carlos. Historia de la música española 5. Siglo XIX. Madrid: Alianza Editorial, 1984.

Gómez-Elegido Ruizolalla, María Cruz. "La correspondencia entre Felipe Pedrell y Francisco Asenjo Barbieri”. Recerca musicológica, 4 (1984), pp. 177-242.

González Alcantud, José Antonio. "Estudio preliminar", en Miguel Ángel Garrido Atienza, Antiguallas granadinas, las fiestas del Corpus, ed. por José Antonio González Alcantud. Granada: Ayuntamiento de Granada, 1990.

González Barrionuevo, Herminio, José Enrique Ayarra Jarne y Manuel Vázquez Vázquez. Catálogo de libros de polifonía de la Catedral de Sevilla. Granada: Centro de Documentación Musical de Andalucía, 1994.

. Francisco Guerrero (1528-1599). Vida y obra. La música en la catedral de Sevilla a finales del siglo XVI. Sevilla: Cabildo Metropolitano de la Catedral de Sevilla, 2000.

. Los seises de Sevilla. Sevilla: Castillejo, 1992. 
González Merchant, Rafael. Discurso necrológico que a la memoria del Ilmo. Sr. Dr. D. Servando Arbolí y Faraudo, presbítero, leyó su autor el M. I. Sr. Dr. D. Rafael González Merchant, Pbro., canónigo de la S. M. y P. Iglesia Catedral de Sevilla en la solemne sesión celebrada por la Real Academia Sevillana de Buenas Letras de la misma ciudad el día 29 de junio del año 1908. Sevilla: Izq. y Cía, [s.f.].

González Polvillo, Antonio. "La Congregación de la Granada, el Inmaculismo sevillano y los retratos realizados por Francisco Pacheco de tres de sus principales protagonistas: Miguel Cid, Bernardo de Toro y Mateo Vázquez de Leca”. Atrio, 15-16 (2009-2010), pp. 47-72.

Gregori i Cifré, Josep María. "Felip Pedrell i el renaixement musical hispànic". Recerca Musicològica, 11-12 (1991-1992), pp. 47-61.

Gutiérrez Cordero, Rosario y M $\mathrm{M}^{\mathrm{a}}$ Luisa Montero Muñoz, "La música en los archivos eclesiásticos y civiles de la ciudad de Sevilla", Espacio y tiempo. Revista de ciencias humanas, 4 (2012), pp. 163-176.

Gutiérrez Cordero, Rosario, "Curiosidades de la Prensa Sevillana. Visita de Giuseppe Verdi a Andalucía". Espacio y Tiempo: Revista de Ciencias Humanas, 8 (1994). pp. 205-210.

. La música en la Colegiata de San Salvador de Sevilla. Granada: Centro de Documentación Musical de Andalucía, 2008.

. “La Ópera en la Sevilla del XIX”. Diferencias, I/1 (1995), pp. 29-38.

. "La Temporada de Ópera Sevillana de 1875". Espacio y Tiempo: Revista de Ciencias Humanas, 9 (1995), pp. 51-90.

Hall, Stuart, ed. Representation: Cultural Representation and Signifying Practices. London: Sage Publications, 1997.

Harris, Marvin. "History and significance of the emic/etic distinction". Annual Review of Anthropology, 5 (1976), pp. 329-350. <http://www.jstor.org/stable/2949316> (consultado 14-4-2013)

Hazañas y La Rúa, Joaquín. Vázquez de Leca. Sevilla: Imp. Sobrinos de Izquierdo, 1918.

Hernández Ascunce, Leocadio. Estudio bio-bibliográfico de Don Hilarion Eslava. Madrid: Aranzadi, 1978.

Hernández Mateos, Alberto. "La recepción del pensamiento de Antonio Eximeno en la historiografía musical española del siglo XIX. Una aproximación”, en Musicología global, musicología local, ed. por Javier Marín López, Germán Gan Quesada, Elena Torres Clemente, Pilar Ramos López. Madrid: Sociedad Española de Musicología, 2013, pp. 1539-1557. 
. El pensamiento musical de Antonio Eximeno. Tesis doctoral. Salamanca: Universidad de Salamanca $<$ http://gredos.usal.es/jspui/handle/10366/118518> (consultado 9-4-2014).

Hess, Carol A. Manuel de Falla and Modernism in Spain. 1898-1936. Chicago: University of Chicago Press, 2001.

Huérga, Álvaro. Historia de los alumbrados (1570-1630). IV Los alumbrados de Sevilla (1605-1630). Madrid: Fundación universitaria española, 1988.

Hurtado Sánchez, José, ed. Nuevos aspectos de la religiosidad sevillana. Fiesta, imagen, sociedad. Sevilla: Ayuntamiento de Sevilla, 2002.

, ed. Religiosidad popular sevillana. Sevilla: Ayuntamiento de Sevilla y Universidad de Sevilla, 2000.

Inzenga, José. Ecos de España: colección de cantos y bailes populares. Barcelona: Andres Vidal y Roger, 1874.

Isusi Fagoaga, Rosa. "El gremio musical en Valencia entre los siglos XIX y XX y el legado Enrique Domínguez Boví", Cuadernos de Música Iberoamericana, 22 (2011), pp. 99-122.

- La música en la Catedral de Sevilla en el siglo XVIII: la obra de Pedro Rabassa y su difusión en España e Hispanoamérica. Granada: Universidad de Granada, 2003.

Javierre, José María. "La diócesis de Sevilla en el siglo XX”, en Historia de las diócesis españolas, vol. X (Iglesias de Sevilla, Huelva, Jerez, Cádiz y Ceuta), coord. por José Sánchez Herrero. Madrid: BAC, 2002, pp. 327-500.

. "La Iglesia de Sevilla en el siglo XX", en Magna hispalensis. El universo de una iglesia. Exposición organizada por la Comisaria de la Ciudad de Sevilla para 1992. Santa Iglesia Catedral Metropolitana de Sevilla. 5 de mayo-30 de octubre de 1992. Sevilla: Ayuntamiento de Sevilla. Diócesis de Sevilla. Comisaría de la Ciudad de Sevilla para 1992, pp. 545-555.

. Don Marcelo de Sevilla. Salamanca: ed. Sígueme, 1992.

. Pío X. Barcelona: Juan Flors, 1951.

Jiménez Cavallé, Pedro. Documentario musical de la Catedral de Jaén. Granada: Centro de Documentación Musical de Andalucía, 1998.

Jungmann, Joseph, La belleza y las bellas artes según las doctrinas de la filosofía socrática y de la cristiana. Madrid: Tipografía de Pascual Conesa, 1873. [Die Schönheit und die schöne Kunst: nach den Anschauungen der sokratischen und der christlichen Philosophie in ihrem Wesen dargestellt. Innsbruck: Wagner, 1866]. 
Kawamura, Yayoi. Festividad del Corpus Christi en Oviedo. Oviedo: Nobel, 2001.

Knighton, Tess. "'Through a glass darkly': Music and Mysticism in Golden Age Spain", en A New Companion to Hispanic Mysticism, ed. por Hilaire Kallendorf. Leiden: Brill Academic Publisher, 2010, pp. 411-436.

Kroeber, Alfred y Clyde Kluckhonh. Culture: a critical Review of Concepts and Definitions. Nueva York: Vintage books, 1952.

Kuss, Malena. "Nacionalismo, identificación y Latinoamérica". Cuadernos de Música Iberoamericana, 5 (1998), pp. 133-150.

Labajo Valdés, Joaquina. "José Ma Cos, reformista de la música sagrada en España". Revista de Musicología, 7 (1984), pp. 335-350.

Labarga García, Fermín, ed. Festivas demostraciones: estudios sobre las cofradías del Santísimo y la fiesta del Corpus Christi. Logroño: Instituto de Estudios Riojanos, 2010.

Labeaga Mendiola, Juan-Cruz, "Buenaventura Íñiguez, organista de la Catedral de Sevilla, y su ciudad natal, Sangüesa (Navarra)", Revista de musicología, XIV/1-2 (1991), pp. 597-603.

Lacomba, Juan A. Historia contemporánea de Andalucía. Córdoba: Almuzara, 2006.

Lamas, Rafael. Música e identidad: el teatro musical español y los intelectuales en la Edad Moderna. Madrid: Alianza, 2008.

Lambea, Mariano, ed. Actas del Simposio Internacional "El Motu proprio de San Pío X y la Música (1903-2003)”. Revista de Musicología, XVII (2004).

Lara Lara, Francisco Javier. El canto llano en la Catedral de Córdoba. Granada: Universidad de Granada, 2004.

Ledesma, Dámaso. Folk-lore o Cancionero salmantino. Madrid: Imp. Alemana, 1907.

Legasa, Francisco Javier. "Bonifacio Iráizoz (1883-1951) y el modernismo musical en el contexto del Motu proprio". Principe de Viana, 238 (2006), pp. 675-694.

Lerma Martínez, Francisco. La Cultura y sus procesos. Antropología Cultural: Guía para su estudio. Murcia: Laborum, 2006.

Levi-Strauss, Claude. "Structuralism and Ecology". Social Science Information, 12 (1973), pp. 7-23.

Lichstensztajn, Dochy. "El regeneracionismo y la dimensión educadora de la música en la obra de Felip Pedrell”. Recerca musicológica, 14-15 (2004-2005), pp. 301323. 
Lleó Cañal, Vicente. Fiesta Grande: el Corpus Christi en la historia de Sevilla. Sevilla: Ayuntamiento de Sevilla, 1980.

Lolo Herranz, Begoña. "El sentido de la historicidad en música. España versus Europa". Anuario del Departamento de Historia y Teoría del Arte, 4 (1992), pp. 359365.

"La obra teórica de José Texidor y Barceló y el asentamiento de la historiografía musical en España”. Revista de Musicología, XVI/6 (1993), pp. 3630-3639.

López Chávarri, Eduardo. Breviario de historia de la música valenciana. Valencia: Piles, 1985.

López Fernández, Miguel. "El Miserere de Hilarión Eslava: los documentos del privilegio de Sevilla", en Musicología global, musicología local, ed. por Javier Marín López, Germán Gan Quesada, Elena Torres Clemente, Pilar Ramos López. Madrid: Sociedad Española de Musicología, 2013, pp. 951-968.

. "El papel del maestro de capilla en la reforma de la música litúrgica promovida por Pío X: el caso de Vicente Ripollés en Sevilla", en Música y reforma litúrgica desde 1611 hasta el presente, ed. por Rosa Isusi Fagoaga y Greta Olson [en prensa].

López García, María Trinidad. "El auge del dogma de la Inmaculada Concepción auspiciado por el franciscano fray Antonio de Trejo, obispo de Cartagena, y la implicación del Concejo de Murcia, a principios del siglo XVII", en La Inmaculada Concepción en España: religiosidad, historia y arte, ed. por Francisco Javier Campos y Fernández de Sevilla. San Lorenzo de El Escorial: Ediciones Escurialenses, 2005, 2 vols., vol. 1, pp. 119-138.

López Martín, Juan. Noticias y catálogo de Música en el Archivo de la S. y A.I.C. de Almería. Granada: Centro de Documentación Musical de Andalucía, 1997.

López Martín, Julián. En el espíritu y la verdad: introducción antropológica a la liturgia. Salamanca: Secretariado Trinitario Ediciones, 2002 [1994].

López-Calo, José. "Congresos de música religiosa", en $D M E H$, ed. por Emilio Casares. Madrid: SGAE, 1999-2002, 10 vols., vol. 4, pp. 876-878.

. "Hilarión Eslava (1807-1878), precursor del Cecilianismo en España", Príncipe de Viana, 238 (2006), pp. 577-608.

"Catálogo provisional de las obras religiosas de Hilarión Eslava" [apéndice], en Monografía de Hilarión Eslava, ed. por equipo Musikaste-Eresbil. Pamplona: Diputación Foral de Navarra, 1978, pp. 347-375.

"Cien años de asociaciones de música religiosa en España, 1850-1950". Cuadernos de Música Iberoamericana, 8-9 (2001), pp. 287-306. 
. “El Miserere de Eslava”. Boletín de Bellas Artes, 27 (1999), pp. 201-259.

. "Felip Pedrell y la reforma de la música religiosa". Recerca musicològica, 1112 (1991-1992), pp. 157-209.

. "Hilarión Eslava, compositor de música sagrada", en Monografía de Hilarión Eslava, ed. por equipo Musikaste-Eresbil. Pamplona: Diputación Foral de Navarra, 1978, pp. 121-150.

Catálogo del archivo de música de la Catedral de Granada. Granada: Centro de Documentación Musical, 1991-1992, 3 vols.

. La música en la catedral de Granada en el siglo XVI. Granada: Fundación Rodríguez Acosta, 1963, 2 vols.

. La música en las catedrales españolas. Madrid: ICCMU, 2013.

. Nemesio Otaño, S.J.: Medio siglo de música religiosa en España. Madrid: ICCMU, 2010.

. Tres Misereres andaluces de Hilarión Eslava. Vol. I Miserere de la Catedral de Sevilla, 1835-37. Granada: Junta de Andalucía. Consejería de Cultura, 2011.

. "El miserere de Vicente Palacios". Cuadernos de arte de la Universidad de Granada, 26 (1995), pp. 171-194.

. "La catalogación de los archivos musicales de la Iglesia en España. Logros, revisión y perspectivas para el futuro”. Memoriae ecclesiae, 31 (2008), pp. 403-435.

Lortz, Joseph. Historia de la Iglesia en la perspectiva de la Historia del Pensamiento. Tomo II: Edad Moderna y Contemporánea. Madrid: Ediciones Cristiandad, 2008 [Geschichte der Kirche in Ideengeschichtlicher Betrachtung. Münster: Aschendorff, 1965].

Luque Vela, Rafael Jesús. Los repertorios de canto llano para las fiestas de los santos patronos hispalenses. Tesis Doctoral inédita. Universidad de Sevilla, 2012.

MacErlean, Andrew. "Motu Proprio", The Catholic Encyclopedia. New York: Robert Appleton Company, 1911, vol. 10. $<$ http://www.newadvent.org/cathen/10602a.htm> (consulta: 22-10- 2013).

Mainer, José Carlos. "La invención estética de las periférias", en Centro y Periferia en la Modernización de la Pintura Española (1880-1918). Madrid: Ministerio de Cultura, 1993, pp. 26-33.

- La edad de plata (1902-1939). Ensayo de interpretación de un proceso cultural. Madrid: Cátedra, 1987 [1981]. 
Manzárraga, Tomás. La música sagrada a la luz de los documentos pontificios. Madrid: Editorial Coculsa, 1968.

Marchesan, Angelo. "L'opera di Pio X nella restaurazione della musica sacra", Bollettino ceciliano, 5 (1910), p. 210.

Marco, Tomás. Historia de la música española 6: Siglo XX. Madrid: Alianza Editorial, 1983.

Pensamiento musical y siglo XX. Madrid: SGAE, 2002.

Marín, Miguel Ángel. Music on the margin. Urban musical life in eighteenth-century Jaca (Spain). Kassel: Reichenberg, 2002.

Martín González, José. "Oposiciones al magisterio de capilla de la Catedral de Valladolid durante el siglo XIX”. Revista de Musicología, XIV/1-2 (1991), pp. 511-534.

Martín Moreno, Antonio. "Hilarión Eslava polemista: la polémica en torno a la historia de la música española", en Monografía de Hilarión Eslava, ed. por equipo Musikaste-Eresbil. Pamplona: Diputación Foral de Navarra, 1978, pp. 267-306.

. "Cinco siglos de historia musical", en El libro de la catedral de Granada, coord. por Lázaro Gila Medina. Granada: Cabildo Metropolitano de la Catedral de Granada, 2005, 2 vols., vol. 2, pp. 812-857.

- "Felip Pedrell y el descubrimiento del teatro barroco español”. Recerca musicològica, 11-12 (1991-1992), pp. 111-131.

. "La enseñanza musical en España en el siglo XIX: El Curso completo de música en la Escuela Normal de Zaragoza (1861) y la Historia de la Música de la Academia Santa Cecilia de Cádiz (1883)". Publicaciones de la Facultad de Educación y Humanidades del Campus de Melilla, 35 (2005), pp. 75-108.

. "La música culta andaluza", en Historia de Andalucía. Tomo VIII. La Andalucía Contemporánea (1868-1981), dir. por Antonio Miguel Bernal. Barcelona: CUPSA/Planeta, 1983, pp. 449-475.

- "La musicología catalana, des de Pedrell a la actualitat", en Història crítica de la música catalana, coord. por Francesc Bonastre i Bertran. Barcelona: Universitat Autònoma de Barcelona, 2009, pp. 515-572.

dir. Catálogo del archivo de música de la Catedral de Málaga. Granada: Centro de Documentación Musical de Andalucía, 2003, 2 vols.

. El Padre Feijoo y las ideologías musicales del XVIII en España. Orense: Instituto de Estudios Orensanos, 1976.

. Historia de la música andaluza. Madrid: Ediciones Andaluzas Unidas, 1985. 
Historia de la música española 4. Siglo XVIII. Madrid: Alianza Música, 2006 [1985].

Martín Riego, Manuel, Las conferencias morales y la formación permanente del clero en la archidiócesis de Sevilla (Siglos XVIII al XX). Sevilla: Fundación Infanta María Luisa, 1997.

La formación intelectual del clero. El seminario conciliar de Sevilla (18311931). Sevilla: Caja Rural, 1994.

Martínez Carretero, Ismael. "Arbolí y Faraudo, Sevando", en Diccionario de Ateneístas, dir. por Enrique Barrero González. Sevilla: Ateneo de Sevilla, 2005, 3 vols., vol. 3, pp. 46-50.

Martínez del Fresno, Beatriz. "El pensamiento nacionalista en el ámbito madrileño (1900-1936). Fundamentos y paradojas”, en De Musica Hispana et aliis. Miscelanea en honor al profesor Dr. José López-Calo en su $65^{\circ}$ cumpleaños, coord. por Emilio Casares y Carlos Villanueva. Santiago de Compostela: Universidad de Santiago, 1990, pp. 351-397.

"Nacionalismo e internacionalismo en la música española de la primera mitad del siglo XX”. Revista de Musicología, XVI/1 (1993), pp. 640-657.

"Un contrapunto al modelo pedrelliano: el nacionalismo de Julio Gómez". Recerca Musicològica, 11-12 (1991-1992), pp. 363-388.

Martínez Martín, Jesús A. "Historia socio-cultural. El tiempo de la historia de la cultura". Revista de historia Jerónimo Zurita, 82 (2007), pp. 237-252. $<$ http://ifc.dpz.es/recursos/publicaciones/27/38/09martinez.pdf $>$ (consultado 16-10-2013).

Martínez Solaesa, Adalberto, Catedral de Málaga. Órganos y Música en su entorno. Málaga: Universidad de Málaga,1996.

Martínez, Ana T. "Una indagación sociológica sobre el campo literario. Las Reglas del arte, según Pierre Bourdieu". Trabajo y Sociedad, X/9 (2008). $<$ http://www.unse.edu.ar/trabajoysociedad/MARTINEZ.pdf $>$ (consultado 119-2013).

Medina Álvarez, Ángel, "La romería en el templo y otras licencias del canto gregoriano en el siglo XX”. Música oral del Sur, 8 (2009), pp. 11-23.

. "El P. José Ignacio Prieto: una trayectoria musical en el espíritu del 'Motu proprio"". Studium ovetense: Revista del Instituto Superior de Estudios Teológicos del Seminario Metropolitano de Oviedo, 22 (1994), pp. 121-144.

. "La música en el templo tras el Motu Proprio de San Pío X: una mirada desde los archivos de la Iglesia". Memoria ecclesiae, 31 (2008), pp. 21-44. 
Medina Crespo, Alfonso. Catálogo del archivo de música de la Santa Iglesia Catedral de Jaén. Sevilla: Centro de Documentación Musical de Andalucía, 2009.

Meehan, Andrew, "Papal Rescripts", en The Catholic Encyclopedia. New York: Robert Appleton Company, 1911, vol. 12. $<$ http://www.newadvent.org/cathen/12783b.htm> (consultado 26-10-2013).

Méndez Bejarano, Mario. Diccionario de escritores, maestros y oradores naturales de Sevilla y su actual provincia. Tomo I. Sevilla: Tipografía Gironés, 1922.

Diccionario de escritores, maestros y oradores naturales de Sevilla y su actual provincia. Tomo II. Sevilla: Tipografía Gironés, 1922.

Menéndez Pelayo, Marcelino. Historia de los Heterodoxos Españoles. Alicante: Biblioteca Virtual Miguel de Cervantes, 2003 [1880-1882]. $<$ http://www.cervantesvirtual.com/obra-visor/historia-de-los-heterodoxosespanoles/html/> (consultado 28-4-14).

Menéndez Pelayo, Marcelino, ed. Obras de Rodrigo Caro: (Con noticias de $M$. Menendez y Pelayo sobre la vida y escritos de Rodrigo Caro). Sevilla: Sociedad de Bibliófilos Andaluces, 1883.

Merriam, Alan P. The Anthropology of Music. Evanston: Northwestern University Press, 1964.

Merry de Val, Rafael. El papa San Pío X: memorias. Madrid: Sociedad de Educación Atenas, 1954.

Micó Terol, Elena. Amancio Amorós Sirvent (1854-1925) y su proyección en la vida musical valenciana. Tesis Doctoral. Barcelona: Universitat de Barcelona, 2011. $<$ http://hdl.handle.net/10803/81929> (consultado 12-12-2013).

Millet i Loras, Lluís, "Mas Serracant, Domingo", en $D M E H$, ed. por Emilio Casares. Madrid: SGAE, 1999-2002, 10 vols., vol. 7, pp. 322-323.

Millet i Loras, María Dolors. "Lluís Millet a Felip Pedrell -Epistolari-". Recerca Musicològica, 6-7 (1986-1987), pp. 261-342.

Miró i Baldrich, Ramón. La processó del Corpus i els entremosos. Cervera, segles XIVXIX. Barcelona: Abadía de Montserrat, 1998.

Miserachs, Valentí. "La polifonía clásica, punto cardinal de la reforma del 'Motu Proprio' de San Pío X”. Revista de Musicología, XXVII/1 (2004), pp. 257-272.

Mocquereau, André. Paléographie musicale. Les principaux manuscrits de chant gregorien, ambrosien, mozarabe, gallican publiés en fac-similés phototypiques. 17 vols. Tournay: Descleé \& Ca , [desde] 1889. 
Montero García, Feliciano. "El movimiento católico en la España del siglo XX. Entre el integrismo y el posibilismo", en Movimientos sociales en la España del siglo $X X$, ed. por $\mathrm{M}^{\mathrm{a}}$ Dolores de la Calle Velasco y Manuel Redero San Román. Salamanca: Universidad de Salamanca, 2008, pp. 173-192.

. "El movimiento católico en España: la respuesta de la provincia eclesiástica de Valladolid a la encuesta Vico (1908)". Espacio, tiempo y forma. Serie V, Historia Contemporánea, 5 (1992), pp. 343-366.

El primer catolicismo social y la Rerum Novarum en España: 1889-1902. Madrid: CSIC, 1983.

Montero Muñoz, María Luisa. Domingo Arquimbau: Maestro de Capilla de la Santa Iglesia Catedral de Sevilla 1790-1829: un estudio estilístico de sus Misas. Tesis Doctoral inédita. Universidad de Sevilla, 2001.

Monzio, Giordano. La parte della musica nel programa "Instaurare omnia in Christo". Obiettivi e contenuti del Motu proprio "Tra le sollecitudini". Roma: [s.e.], 2003.

Moreno Mengíbar, Andrés. La ópera en Sevilla (1731-1992). Sevilla: Biblioteca de temas sevillanos, 1994.

Moreno Navarro, Isidoro. La Semana Santa de Sevilla: conformación, mixtificación y significaciones. Sevilla: Ayuntamiento de Sevilla, 2006 [1982].

Mulhern, Francis. The Moment of 'Scrutiny'. London: Verso, 1979.

Muñoz de Sus, Alberto. "La obra coral y organística de Domènech Mas i Serracant". Revista de Musicología, XXVII/1 (2004), pp. 335-356.

Myers Brown, Sandra. "Las desamortizaciones eclesiásticas del siglo XIX en España y sus consecuencias sobre la música (Madrid y Toledo). Revista de Musicología, XXVIII/1 (2005), pp. 310-327.

Nagore Ferrer, María, Leticia Sánchez de Andrés y Elena Torres Clemente, eds. Música y cultura en la Edad de Plata, 1915-1939. Madrid: ICCMU, 2009.

."Santiago Masarnau, precursor del movimiento coral en España". Cuadernos de Música Iberoamericana, 25-26 (2013), pp. 257-274.

. "Tradición y renovación en el movimiento de reforma de la música religiosa anterior al Motu Proprio". Revista de Musicología, XXVII/1 (2004), p. 211236.

- "Una aportación al estudio de la música religiosa en España: el 'Congreso Internacional de Música Sacra' (Bilbao, 1896)". Revista de Musicología, XX/1(1997), pp. 605-615. 
. La revolución coral. Estudio sobre la Sociedad Coral de Bilbao y el movimiento coral europeo (1800-1936). Madrid: ICCMU, 2001.

Nattiez, Jean-Jacques. Music and Discourse. Toward a Semiology of Music. Princenton: Princenton University Press, 1990 [1987].

Nieto Calleja, Marta. "Recuperación de la figura de Tomás Luis de Victoria desde los primeros años del siglo XX. Una visión a través de los textos de Vicente Salas Viu”. Revista de Musicología, XXXV/1 (2012), pp.492-501.

Nommick, "La formación del lenguaje musical de Manuel de Falla: un balance de la primera etapa creadora del compositor (1896-1904)". Revista de musicología, XXVI/ 2 (2003), pp. 545-584.

. "El influjo de Felip Pedrell en la obra y el pensamiento de Manuel de Falla". Recerca Musicològica, 14-15 (2004-2005), pp. 289-300.

- "Sobre las implicaciones del Motu Proprio de San Pío X en materia de composición musical”. Revista de Musicología, XXVII/1 (2004), pp. 125-136.

Noon, Michael J. Andrés de Torrentes (1510-1580), Spanish polyphonist and Chapelmaster: Opera omnia, biography and source study. Master Thesis. University of Sidney, 2008. <http://ses.library.usyd.edu.au/handle/2123/2247> (consulta 15-4-2014).

Ochoa Alfaro, Ángel José. "El concordato de 1851 y sus consecuencias en la Diócesis de Calahorra y La Calzada". Kalakorikos, 3 (1998), pp. 169-183.

Ocón, Eduardo. Cantos españoles. Colección de aires nacionales y populares, formada e ilustrada con notas explicativas y biográficas. Málaga: [s.e. (Breitkopf und Härtel), 1874.

Olmeda Federico. Comentario sobre el Motu proprio de su santidad sobre la orquesta religiosa. Burgos: Imp. Cariñena, 1904.

. "Introducción", en Folk-lore de Castilla o Cancionero Popular de Burgos. Burgos: Diputación Provincial, 1992. [Facsímil de la edición de Sevilla: Librería editorial de María Auxiliadora, 1903].

Discurso sobre la orquesta religiosa. Burgos: Imprenta del Diario de Burgos, 1896.

- Pío X y el canto romano o aplicación práctica del código jurídico de Su Santidad Pío X (del 22 Noviembre de 1903) sobre la música sagrada en cuanto al canto gregoriano. Burgos: El Monte Carmelo, 1904.

Oriola Velló, Frederic. "Los coros parroquiales y el motu proprio de Pío X: la diócesis de Valencia (1903-1936)". Nassarre, XXV/1 (2009), pp. 89-108. 
Osuna Lucena, $\mathrm{M}^{\mathrm{a}}$ Isabel y otros, "La música en Sevilla durante 1850-1860", Misceláneas. Laboratorio de Arte: Revista del Departamento de Historia del Arte, 10 (1997), pp. 505-520.

- "Emigdio Mariani Piazza: trayectoria personal y artística". Laboratorio de Arte: Revista del Departamento de Historia del Arte, 8 (1995), pp. 293-319.

"La música en el monasterio de Santa Inés: D. Buenaventura Íñiguez". Laboratorio de Arte: Revista del Departamento de Historia del arte, V/2 (1992), pp. 177-218.

Otaño Eguino, Nemesio. La Música Religiosa y la Legislación Eclesiástica. Barcelona: Musical Emporium, 1912.

Otero Nieto, Ignacio. "La música de culto de las Hermandades de Sevilla". Boletín de Bellas Artes, 32 (2004), pp. 201-227.

. "La música litúrgica de las cofradías y el Miserere de Eslava en el siglo XX". Boletín de Bellas Artes, 28 (2000), pp. 173-199.

. "La música litúrgica y procesional de las hermandades", en Sevilla Penitente vol. I, ed. por Enrique Pareja López. Sevilla: Gever, 1995, pp. 271- 304.

La música de las cofradías de Sevilla. Sevilla: Guadalquivir, 1997.

Pajares Barón, Máximo. Archivo de música de la Catedral de Cádiz. Granada: Centro de Documentación Musical de Andalucía, 1993.

, "Franz Liszt en Sevilla y en Cádiz (diciembre, 1844-enero, 1845). Revista de musicología, X/3 (1987), pp. 887-918.

Palacios Garoz, Miguel Ángel. El hispanismo musical de Raoul Laparra y Henri Collet. Dos discípulos franceses de Federico Olmeda en Burgos. Burgos: Institución Fernán González, Academia Burguense de Historia y Bellas Artes, 1999.

. Federico Olmeda, un maestro de capilla atípico. Burgos: Instituto Municipal de Cultura, 2003.

Palacios Sanz, José Ignacio. “Aproximación histórica a la capilla de música en la Catedral de Burgo de Osma durante el siglo XIX. De Bernardo Pérez al 'Motu Proprio"”. Revista de Musicología, XIV/1-2 (1991), pp. 549-560.

Payne, Michael, dir. Diccionario de teoría crítica y estudios culturales. Buenos Aires: Paidós, 2002. [A Dictionary of Cultural and Critical Theory. Oxford: Blackwell, 1996].

Pedrell, Felipe. "I. Francisco Guerrero", en Hispaniae Schola Musica Sacra, vol. II. Franciscus Guerrero. Barcelona: Juan Bautista Pujol y Cía., 1894-1898, 8 vols., pp. III-XXII. 
“I. Juan Ginés Pérez", en Hispaniae Schola Musica Sacra, vol. V. Joannes Ginesius Pérez. Barcelona: Juan Bautista Pujol y Cía., 1894-1898, 8 vols. pp. II-XV.

. Por nuestra música. Barcelona: Imp. Henrich y Cía, 1891.

Peirce, Charles. El hombre, un signo. Barcelona: Crítica, 1988.

Pérez Colodrero, Consuelo. "El nacimiento de la historiografía musical andaluza: la Galería de músicos andaluces contemporáneos de Francisco Cuenca Benet y la reivindicación de la identidad cultural de Andalucía", en Musicología global, musicología local, ed. por Javier Marín López, Germán Gan Quesada, Elena Torres Clemente, Pilar Ramos López. Madrid: Sociedad Española de Musicología, 2013, pp. 1599-1619.

"Francisco Cuenca Benet (1872-1943) y su aportación a la cultura andaluza". Tesis doctoral. Granada: Universidad de Granada (2011). $<$ http://digibug.ugr.es/handle/10481/17609\#.U5WUmWGKDIU> (consultado 2-6-2012).

Pérez Mancilla, Victoriano J. "Historiografía musical de las parroquias en España: estado de la cuestión". Anuario Musical, 68 (2013), pp. 47-80. $<$ http://anuariomusical.revistas.csic.es/index.php/anuariomusical/article/view/1 48/149> (consultado 18-4-2014).

Pérez Zalduondo, Gemma. "Las sociedades musicales en Almería, Granada y Sevilla entre 1900-1936, Cuadernos de Música Iberoamericana, 8-9 (2001), pp. 323336.

- "El auge de la música en Sevilla durante los años veinte", Revista de musicología, XX/1 (1997), pp. 655-668.

Pérez-Frías, Pedro Luís. "Las élites militares de Alfonso XIII y la Inmaculada Concepción", en La Inmaculada Concepción en España: religiosidad, historia y arte, ed. por Francisco Javier Campos y Fernández de Sevilla. San Lorenzo de El Escorial: Ediciones Escurialenses, 2005, 2 vols., vol. 1, pp. 305-326.

Picó Pascual, Miguel Ángel. "La aportación musicológica del canónigo Vicente Ripollés Pérez”. Revista de Musicología, XXVII/1 (2004), pp. 287-294.

Pike, Kenneth L. Emicletic, Language in Relation to a Unified Theory of the Structure of Human Behavior. The Hague: Mouton, 1967.

Pitarch Alfonso, Carles. "La festa del Corpus Christi a València: de les Roques i els Jocs a les danses tradicionals", en El teatre en la festa valenciana, dir. por Antonio Ariño. Valencia: Consell Valencià de Cultura, 1999, pp. 173-198.

Portús Pérez, Javier. La antigua procesión del Corpus Christi en Madrid. Madrid: Comunidad de Madrid, 1993. 
Pujol, Frederic y Josep María Marques. "Cataleg de les obres de Mn. Lluís Romeu". Ausa. Publicació del Patronat d'Estudis Osonencs, VII/76 (1973), pp. 187210.

Ramos López, Pilar, ed. Discursos y prácticas musicales nacionalistas (1900-1970). Logroño: Universidad de La Rioja, 2012.

"Música y autorrepresentación en las procesiones del Corpus en la España moderna", en Música y cultura urbana en la Edad Moderna, ed. por Andrea Bombi, Juan José Carreras y Miguel Ángel Marín. Valencia: Universitat de València, 2005, pp. 243-254.

"Mysticism as a Key Concept of Spanish Early Music Historiography", en "Early Music-Context and Ideas II" International Conference in Musicology. Cracovia: Universidad de Cracovia, 2008. $<$ http://www.campusvirtual.unirioja.es/titulaciones/musica/fotos/13_ramos.pdf $>$ (consultado 25-9-13).

. "The construction of the myth of Spanish Renaissance Music as Golden Age", en "Early Music-Context and Ideas" International Conference in Musicology. Cracovia: Universidad de Cracovia, 2003. $<$ http://www.campusvirtual.unirioja.es/titulaciones/musica/fotos/ramos_krako w_2003.pdf $>$ (consultado 25-9-13).

Requena, José María, Miguel Cruz Giráldez y Javier Criado Fernández. Las Cofradías de Sevilla vistas por un novelista, los escritores, un psiquiatra. Sevilla: Universidad de Sevilla, 1987.

Reyes Cano, Rogelio. “[Introducción]”, en El homenaje al Ateneísta Don José Gestoso y Pérez. Sevilla: Ateneo de Sevilla, 2005. [Gironés, 1918], pp. 15-17.

Reynoso, Carlos. "El lado oscuro de la descripción densa-Diez años después". Revista de antropología, $16 \quad$ (1995 [2007]), $\quad$ pp. $\quad$ 1-37. $<\mathrm{http}$ ://carlosreynoso.com.ar/archivos/carlos-reynoso-el-lado-oscuro-de-ladescripcion-densa-version-2007.pdf $>$. (consultado 30-8-2013).

Ribelot, Alberto. "Prólogo", en Manuel Serrano y Ortega, Monumentos de los pueblos de la provincia de Sevilla, ed. por Alberto Ribelot. Sevilla: Universidad de Sevilla, 2006 [Sevilla: Francisco de P. Díaz, 1911], pp. VII-XV.

Rifé i Santaló, Jordi. "Los congresos del Motu proprio y la música de J. S. Bach". Revista de Musicología, XXVII/1 (2004), pp. 401-422.

Roda Peña, José. "Estudio preliminar”, en Manuel Serrano y Ortega, Glorias sevillanas. Noticia histórica de la devoción y culto que la muy noble y muy leal ciudad de Sevilla ha profesado a la Inmaculada Concepción de la Virgen María. Sevilla: Consejo General de Hermandades y Cofradías de Sevilla y Consejería de Relaciones Institucionales, 2004, pp. VII-XVI. 
Rodríguez Becerra, Salvador, coord. La religiosidad popular III. Hermandades, santuarios y romerías. Barcelona: Anthropos, 1989 [2003].

. "El Corpus en Andalucía. De fiesta del poder a fiesta de la identidad", en La fiesta del Corpus Christi, ed. por Gerardo Fernández Juárez y Francisco Martínez Gil. Cuenca: Universidad de Castilla-La Mancha, 2002, pp. 383-398.

Rodríguez González, Alfredo y Carlos Franco Agudo. "Bibliografía del Corpus Christi”, en La Fiesta del Corpus Christi, coord. por Gerardo Fernández Juárez y Fernando Martínez Gil. Cuenca: Universidad de Castilla-La Mancha, 2002, pp. 519-544.

Rodríguez Molina, José. "Patrimonio y rentas de la Iglesia en Andalucía", en La Iglesia en el mundo medieval y moderno, coord. por María Desamparados Martínez San Pedro y María Dolores Segura del Pino. Almería: Instituto de Estudios Almerienses, 2004, pp. 113-142.

Roldán Salgueiro, Manuel Jesús. Historia de Sevilla. Sevilla: Almuzara, 2007.

Romero Abao, Antonio. "La fiesta del Corpus en Sevilla en el siglo XV", en La religiosidad popular III. Hermandades, cofradías y santuarios, coord. por León Carlos Álvarez Santaló, $M^{\text {a }}$ José Buxó Rey y Salvador Rodríguez Becerra. Barcelona: Anthropos, 1989 [2003], pp. 19-30.

. "Las Fiestas de Sevilla en el siglo XV", en Las Fiestas de Sevilla en el siglo XV. Otros estudios, dir. por José Sánchez Herrero. Madrid: Deimos, 1991, pp. 12-178.

Romero Domínguez, Lorena R. La buena prensa. Prensa católica en Andalucía durante la Restauración. Sevilla: Centro de Estudios Andaluces, 2009.

Romero Domínguez, Rafael. "Los efectos de la desamortización de Mendizábal en el Miserere de Hilarión Eslava". Boletín de las cofradías de Sevilla, 541 (2004), pp. 152-153.

Ros, Carlos, dir. Historia de la Iglesia de Sevilla. Sevilla: Castillejo, 1992.

"La Concepción Inmaculada en la historia" en Actas del XV Simposio de Historia de la Iglesia en España y América, coord. por Paulino Castañeda Delgado y Manuel José Cociña y Abella. Córdoba: Obra Social y Cultural de Cajasur, 2007, pp. 15-34.

La Inmaculada y Sevilla. Sevilla: Castillejo, 1994.

. Los arzobispos de Sevilla. Luces y sombras en la sede hispalense. Granada: Anel, 1986.

Ros-Fábregas, Emilio. "Historiografía de la música en las catedrales españolas: nacionalismo y positivismo en la investigación musicológica". CODEXXI. Revista de la comunicación musical, 1 (1998), pp. 68-135. 
. "Cristobal de Morales: A Problem of Musical Mysticism and National Identity in the Historiography of the Renaissance", en Cristobal de Morales: Sources, Influences, Recepcion, ed. por Owen Rees y Bernardette Nelson. Woodbridge: Boydell, 2007, pp. 215-234.

. "Historiografías de la música española e hispanoamericana: algunos problemas comunes y perspectivas para el siglo XXI". Boletín de música de la Casa de las Américas, $\quad 9 \quad$ (2002), $\quad$ pp. 25-49. $<$ http://www.casa.cult.cu/publicaciones/boletinmusica/9/emilio.htm> $>$ (24-92013)

. "La Biblioteca Musical de Federico Olmeda (1865-1909) en la 'Hispanic Society of America' de Nueva York". Revista de Musicología, XX/1 (1997), pp. 553-570.

. "Musicological Nationalism or How to Market Spanish Olive Oil". Newsletter of the International Hispanic Music Study Group, IV/2 (1998), pp. 6-15: $<$ http://digital.csic.es/handle/10261/19902> (consultado 24-9-2013).

Rubio Merino, Pedro e Isabel González Ferrín. Archivo de la Santa, Metropolitana y Patriarcal Iglesia Catedral de Sevilla. Inventario General II. Madrid: Fundación Areces, 1998.

Rubio Merino, Pedro. "El archivo de la Santa Iglesia Catedral de Sevilla", en La catedral de Sevilla. Sevilla: Guadalquivir, 1991, pp. 749-775.

- Archivo de la Santa, Metropolitana y Patriarcal Iglesia Catedral de Sevilla. Inventario General I. Madrid: Fundación Ramón Areces, 1987.

Ruíz Acosta, María José, "La prensa sevillana ante los acontecimientos del 98. Un caso de opinión pública en un marco local”. Investigaciones históricas, 17 (1997), pp. 191-205.

. "La prensa sevillana de principios del siglo XX: el nacimiento de un nuevo modelo informativo (1898-1914)", en Sevilla y su prensa. Introducción a la historia del periodismo andaluz contemporáneo (1898-1998), ed. por Ramón Reig y María José Ruíz Acosta. Sevilla: Universidad de Sevilla, 1998, pp. 1336.

Ruíz Carbayo, Ángela. "Nuevas fuentes para el estudio de la música sevillana: el archivo musical de Luis Leandro Mariani González (¿1858?-1925)”, en Musicología global, musicología local, ed. por Javier Marín López, Germán Gan Quesada, Elena Torres Clemente, Pilar Ramos López. Madrid: Sociedad Española de Musicología, 2013, pp. 1637-1651.

Ruíz de Lacanal Ruiz-Mateos, María Dolores. "José Gestoso y Pérez. Teoría y Praxis de la Conservación”. Ge-conservación, 5 (2013), pp. 59-70. <http://geiic.com/ojs/index.php/revista/article/view/125/pdf> (consultado 3-5-2014). 
Ruíz Jiménez, Juan. "Recepción y pervivencia de la obra de Victoria en las instituciones eclesiásticas de la corona de Castilla", en Tomás Luis de Victoria y la cultura musical en la España de Felipe III, dir. por Alfonso de Vicente y Pilar Tomás. Madrid: Centro de Estudios Europa Hispánica, 2012, pp. 301-351.

- La Librería de Canto de Órgano Creación y pervivencia del repertorio del Renacimiento en la actividad musical de la catedral de Sevilla. Granada: Conserjería de Cultura, 2007.

Ruíz Sánchez, José Leonardo. Beato Marcelo Spínola y Maestre, Cardenal Arzobispo de Sevilla (1835-1906). Sevilla: Ayuntamiento de Sevilla, 2002.

. Política e Iglesia durante la Restauración. La liga católica de Sevilla (19011923). Sevilla: Diputación de Sevilla, 1994.

Ruíz, Elisa. Manual de codicología. Salamanca: Fundación Germán Sánchez Ruipérez, 1988.

Salas, Nicolás. Sevilla 1905. Álbum gráfico de la ciudad del novecientos. 500 ilustraciones históricas. Sevilla: Almuzara, 2005.

. Sevilla: crónicas del siglo XX. Tomo I: 1895-1920. Sevilla: Universidad de Sevilla, 1991.

Sánchez de Andrés, Leticia. "Cosme José de Benito, maestro de la Real Capilla de El Escorial, y su Ofertorio para la festividad de la Inmaculada Concepción", en $L a$ Inmaculada Concepción en España: religiosidad, historia y arte, ed. por Francisco Javier Campos y Fernández de Sevilla. San Lorenzo de El Escorial: Ediciones Escurialenses, 2005, 2 vols., vol. 2, pp. 1247-1268.

"El pensamiento estético del krausismo español y su proyección en la investigación musicológica y la crítica musical”. Revista de musicología, XXVIII/2 (2005), pp. 961-976.

. Música para un ideal: pensamiento y actividad musical del krausismo e institucionismo españoles (1854-1936). Madrid: Sociedad Española de Musicología, 2009.

Sánchez Gómez, Pedro J. La música y el Ateneo de Sevilla 1887-2003. Sevilla: Excmo. Ateneo de Sevilla, 2004.

Sánchez Herrero, José y otros. Las cofradías de Sevilla: historia, antropología, arte. Sevilla: Universidad de Sevilla, 1985 [1999].

Sánchez Herrero, José, dir., y Miguel Ángel Núñez Beltrán, coord. Synodicon Baeticum II: Constituciones Conciliares y Sinodales del Arzobispado de Sevilla, Siglos XIX-XX. Sevilla: Universidad de Sevilla, 2012. 
Sánchez Herrero, José, ed. La Música Coral del Cabildo Catedral de Sevilla durante el siglo XVII. Estudio musicológico y analítico. Sevilla: Universidad de Sevilla, 2013.

. "La procesión del Corpus Christi en Sevilla", en Festivas demostraciones: estudios sobre las cofradías del Santísimo y la fiesta del Corpus Christi, ed. por Fermín Labarga García. Logroño: Instituto de Estudios Riojanos, 2010, pp. 351-394.

La Semana Santa de Sevilla. Madrid: Silex, 2003.

Las diócesis del reino de León: siglos XIV y XV. León: Centro de estudios e investigación "San Isidoro", 1978.

Sánchez Pedrote, Enrique. Apuntes para una historia musical de Sevilla. Sevilla: Monte de Piedad y Caja de Ahorros de Sevilla, 1983.

Apuntes para una historia musical de Sevilla. Sevilla: Monte de Piedad y Caja de Ahorros de Sevilla, 1983.

Sánchez Sánchez, Víctor. "Tomás Bretón y el regeneracionismo. Una reflexión sobre la valoración de la música en el contexto cultural de la España de 1898". Cuadernos de Música Iberoamericana, 6 (1998), pp. 35-48.

. Tomás Bretón: un músico de la Restauración. Madrid: ICCMU, 2002.

Sancho García, Manuel. "De Teixidor a Pedrell: Tomás Luis de Victoria en la historiografía musical española del siglo XIX". Revista de Musicología XXXV/1 (2012), pp. 443-457.

. "Tomás Luis de Victoria en la obra musicológica de Felipe Pedrell: la creación de un mito nacional", en Tomás Luis de Victoria: Estudios/Studies, ed. por Manuel del Sol y Javier Suárez-Pajares. Madrid: ICCMU, 2013, pp. 489-500.

Sanhuesa Fonseca, María. "Corpus Christi en la Catedral de Oviedo (siglos XVII-XX)", en Religiosidad y ceremonias en torno a la Eucaristía, coord. por Francisco Javier Campos y Fernández de Sevilla. Madrid: Instituto Escurialense de Investigaciones Históricas y Artísticas, 2003.

. "Resonancias del Motu proprio en la diócesis de Oviedo: la capilla catedralicia y el Seminario Conciliar”. Recerca Musicològica, 16 (2006), pp. 177-201.

Sanz García, Laura. "Visiones de lo español en la creación artística y musical de entresiglos (1874-1936)". Revista de musicología, XXVIII/2 (2005), pp. 16491662.

Sanz, María Jesús. "El Corpus en Sevilla a mediados del siglo XVI. Castillos y danzas". Laboratorio de Arte, 10 (1997), pp. 123-137. 
. "La procesión del Corpus en Sevilla. Influencias sociales y políticas en la evolución del cortejo". Ars Longa, 16 (2007), pp. 55-72.

. Fiestas sevillanas de la Inmaculada Concepción en el siglo XVII: el sentido de la celebración y su repercusión exterior. Sevilla: Ayuntamiento de Sevilla, 2008.

Saperas, Miquel. "Mossen Lluís Romeu, apostol de la musica sagrada". Ausa. Publicació del Patronat d'Estudis Osonencs, VII/76 (1973), pp. 169-186.

Sartore, Domenico y Achille M. Triacca. eds. Nuevo diccionario de liturgia, 2 vols. Madrid: Ediciones Paulinas, 1987.

Schnorr, Klemens. "El cambio de la edición oficial del canto gregoriano de la editorial Pustet/Ratisbona a la de Solesmes en la época del Motu Proprio". Revista de Musicología, XXVII/1 (2004), pp. 197-209.

Schuler, Richard J. "A Chronicle of the Reform: Catholic Music in the 20th. Century", en Cum Angelis canere: Essays on Sacred Music and Pastoral Liturgy in honour of Richard J. Schuler, ed. por Robert A. Skeris. St. Paul: Catholic Church Music Associates, 1990 [apéndice 6], pp. 349-419. $<$ http://media.musicasacra.com/pdf/chron.pdf $>$. (consultado 12-2-2010).

Serna, Justo y Anaclet Pons. "El ojo de la aguja ¿De qué hablamos cuando hablamos de microhistoria?". Ayer, 12 (1993), pp. 93-133.

. Historia cultural. Autores, obras, lugares. Madrid: Akal, 2013.

Smerdeu Altolaguirre, Maya. coord. Ecos de la Generación del 98 en la del 27. Madrid: Ediciones Caballo Griego para la Poesía, 1998.

Sobrino Sánchez, Ramón. "Don Mariano Soria: el’Motu Proprio Tra le sollecitudini” y el cecilianismo musical en Llanes (1921-1943)". Cuadernos de Música Iberoamericana, 25-26 (2013), pp. 335-352.

. "El epistolario inédito de Tomás Bretón a Isaac Albéniz (1890-1908): nuevos documentos sobre la música nacional del paso del siglo XIX al XX. Cuadernos de Música Iberoamericana, 5 (1998), pp. 163-184.

. "Pérez de Viñaspre Ortíz, Francisco", en $D M E H$, ed. por Emilio Casares. Madrid: SGAE, 1999-2002, 10 vols., vol. 8, p. 643.

Stevenson, Robert. La música en las catedrales españolas del Siglo de Oro. Madrid: Alianza, 1992. [Spanish Cathedral Music in the Golden Age. Berckley: California University Press, 1961].

Stratton, Suzanne L. "La Inmaculada Concepción en el arte español”. Cuadernos de arte e iconografía, I/2 (1988), pp. 3-128. 
Suárez Martos, Juan María. "El Archivo Musical de la Catedral de Sevilla en 1724: Génesis y Pervivencia de los Libros Manuales y de Facistol”. Musicalia, 5 (2008), pp. 41-123.

. El rito de la Salve en la Catedral de Sevilla durante el siglo XVI: estudio del repertorio musical contenido en los manuscritos 5-5-20 de la Biblioteca Colombina y el libro de polifonía $n^{o} 1$. Granada: Junta de Andalucía. Consejería de Cultura, 2010 [Sevilla: el autor, 2003].

. Música Sacra Barroca en la Catedral Hispalense: Los maestros del siglo XVII, Tesis Doctoral inédita. Universidad de Sevilla, 2007.

Tejerizo Robles, Germán. "La música en la Capilla Real de Granada desde 1800". Revista de musicología, XIV/1-2 (1991), pp. 561-582.

Terrin, Aldo N. "Antropología cultural”, en Nuevo diccionario de liturgia, ed. por Domenico Sartore y Achille M. Triacca. Madrid: Ediciones Paulinas, 1987, 2 vols., vol. 1, pp. 111-136.

Thomason, Philip B. y Ceri Byrne. "The Eighteenth-Century Theatre in Spain. A Bibliography of Criticism and Documentation". Bulletin of Spanish Studies: Hispanic Studies and Research on Spain, Portugal and Latin America, LXXXII/7 (2005), pp. 1-205.

Torrente, Álvaro y Emilio Casares, coords., La ópera en España e Hispanoamérica, 2 vols. Madrid: ICCMU, 2001.

Torres Clemente, Elena. Manuel de Falla y las Cantigas de Alfonso X El Sabio. Granada: Universidad de Granada, 2002.

Torres Mulas, Jacinto. "Periódicos musicales. España", en $D M E H$, ed. por Emilio Casares. Madrid: SGAE, 1999-2002, 10 vols., vol. 8, pp. 692-702.

- Las publicaciones periódicas musicales en España (1812-1990): Estudio crítico-bibliográfica: Repertorio general. Madrid: Instituto de Bibliografía Musical, 1991.

Valdivieso González, Enrique. La Catedral de Sevilla. Sevilla: Guadalquivir, 2001.

y Juan Miguel Serrera. Pintura sevillana del primer tercio del siglo XVII. Madrid: Instituto Diego Velázquez. CSIC, 1985.

Vallés Chordá, Andrés. Música en Sevilla en el siglo XIX. Sevilla: Ayuntamiento de Sevilla, 2010.

Van Maanen, Hans. How to study art worlds. On the Societal Funcioning of Aesthetic Values. Amsterdam: Amsterdam University Press, 2009.

Vega García, María Julieta. La música en los conventos de clausura femeninos de Granada. Granada: Universidad de Granada y Junta de Andalucía, 2005. 
Vega Rodríguez, Margarita y Carlos Villar-Taboada, eds. Pensamiento español y música: Siglos XVIII y XIX. Valladolid: Universidad de Valladolid, 2003.

Very, Francis G. The Spanish Corpus Christi Procession. A Literary and Folkloric Study. Valencia: Tipografía Moderna, 1962.

Virgili Blanquet, $\mathrm{M}^{\mathrm{a}}$ Antonia. “Antecedentes y contexto ideológico de la recepción del Motu Proprio en España”. Revista de Musicología, XXVII/1 (2004), pp. 23-39.

. "El Canto Popular Religioso y la Reforma Litúrgica en España (1850-1915)". Aisthesis, 47 (2010), pp. 175-186.

. "La música en el siglo XIX español”, en La música española en el siglo XIX, ed. por Emilio Casares Rodicio y Celsa Alonso González (Oviedo: Universidad de Oviedo, 1995), pp. 375-405.

- "La música religiosa en el siglo XIX español", Revista Catalana de Musicología, 2 (2004), pp. 181-202

. La música en Valladolid en el siglo XX. Valladolid: Ateneo de Valladolid, 1985.

"1. Goicoechea Errasti, Vicente", en $D M E H$, ed. por Emilio Casares. Madrid: SGAE, 1999-2002, 10 vols., vol. 5, pp. 672-673.

. "2. Luis [Villalba Muñoz]", en $D M E H$, ed. por Emilio Casares. Madrid: SGAE, 1999-2002, 10 vols, vol. 10, pp. 913-915.

- "Felipe Pedrell y el músico vallisoletano Luis Villalba: correspondencia inédita”. Recerca musicològica, 1 (1981), pp. 151-192.

"Luis Villalba", en La música en Valladolid en el siglo XX. Valladolid: Ateneo de Valladolid, 1985, pp. 43-72.

"La idea regeneracionista en la música española y la creación de la Sociedad Nacional de Música a través de la correspondencia de Luis Villalba Muñoz", en De Musica Hispana et Aliis. Miscelánea en homenaje al Profesor José López-Calo, ed. por Emilio Casares y Carlos Villanueva. Santiago: Universidad de Santiago, 1990, 2 vols., vol. 2, pp. 307-319.

"Luis Villalba y Eustoquio Uriarte. Sus contribuciones al estudio de la música lírica y al nacionalismo musical español", en Actas del Simposium "La música en el Monasterio de El Escorial”. Madrid: Instituto Escurialense de Investigaciones Históricas y Artísticas, 1992, pp. 751-763.

"Luis Villalva y Eustoquio Uriarte: sus contribuciones al estudio de la música y al nacionalismo musical español", en Música en el Monasterio del Escorial, coord. por Francisco Javier Campos y Fernández de Sevilla. El Escorial: Real Centro Universitario Escorial-María Cristina, 1993, pp. 489-512. 
Vizuete Mendoza, José Carlos y Martínez-Burgos García, Palma, coords. Religiosidad popular y modelos de identidad en España y América. Cuenca: Universidad de Castilla-La Mancha, 2000.

Vizuete Mendoza, José Carlos. "Teología, liturgia y derecho en el origen de la fiesta del Corpus Christi", en La fiesta del Corpus Christi, coord. por Gerardo Fernández Juárez y Fernando Martínez Gil. Cuenca: Universidad de CastillaLa Mancha, 2002, pp. 17-42.

. "Voto, juramento y fiesta de la Inmaculada en la Universidad de Toledo", en La Inmaculada Concepción en España: religiosidad, historia y arte, ed. por Francisco Javier Campos y Fernández de Sevilla. San Lorenzo de El Escorial: Ediciones Escurialenses, 2005, 2 vols., vol. 1, pp. 325-360.

Vranich, Stanko. "Carta de un ciudadano de Sevilla. La guerra mariana de Sevilla en el siglo XVII”. Archivo Hispalense, 137 (1966), pp. 241-274.

. "Carta de un ciudadano de Sevilla. La guerra mariana de Sevilla en el siglo XVII”. Archivo Hispalense, 138 (1966), pp. 59-77. 


\section{APÉNDICES}

Apéndice 1. Mapa de la archidiócesis de Sevilla en 1909

Apéndice 2. Circulares y otros documentos sobre música sagrada publicados en el Boletín Oficial del Arzobispado de Sevilla entre 1904 y 1910

2. 1. Pontificado del arzobispo Marcelo Spínola y Maestre

2. 2. Pontificado del arzobispo Enrique Almaraz y Santos

Apéndice 3. Documentos relacionados con la petición de dispensa en la aplicación del Motu Proprio para el caso del Miserere de Eslava

3. 1. Relación cronológica de los principales documentos

3. 2. Transcripción de la solicitud elevada por el arzobispo Marcelo Spínola y Maestre a Pío X

3. 3. Transcripción del borrador de la respuesta remitida por la Santa Sede

Apéndice 4. Síntesis del Reglamento de música sagrada para la Archidiócesis de Sevilla

Apéndice 5. Transcripción de los inventarios musicales estudiados

5. 1. Inventario 1: Índice de las Obras que existen en el Archivo musical de esta Santa Iglesia

5. 2. Inventario 2: Catálogo de Obras musicales

683

5. 3. Inventario 3: Archivo musical de Scalas (ca. 1925)

Apéndice 6. Relación de obras compuestas por Vicente Ripollés para la catedral de Sevilla, conservadas en su archivo musical

Apéndice 7. Cartas en las que se informa sobre las clases de canto gregoriano de preparación al Congreso

Apéndice 8. Transcripción del borrador en castellano de la petición dirigida al papa de constitución de un Tribunal superior nacional para la censura de la música sagrada

Apéndice 9. Programas del II Congreso Nacional de Música Sagrada

9. 1. Programa general

9. 2. Programas de los conciertos de órgano 711

9. 2. 1. Programa inicial

9. 2. 2. Programa definitivo

9. 3. Programa del concierto de música vocal religiosa

9. 4. Programa del concierto ofrecido por la Capilla Isidoriana en el Teatro San Fernando 



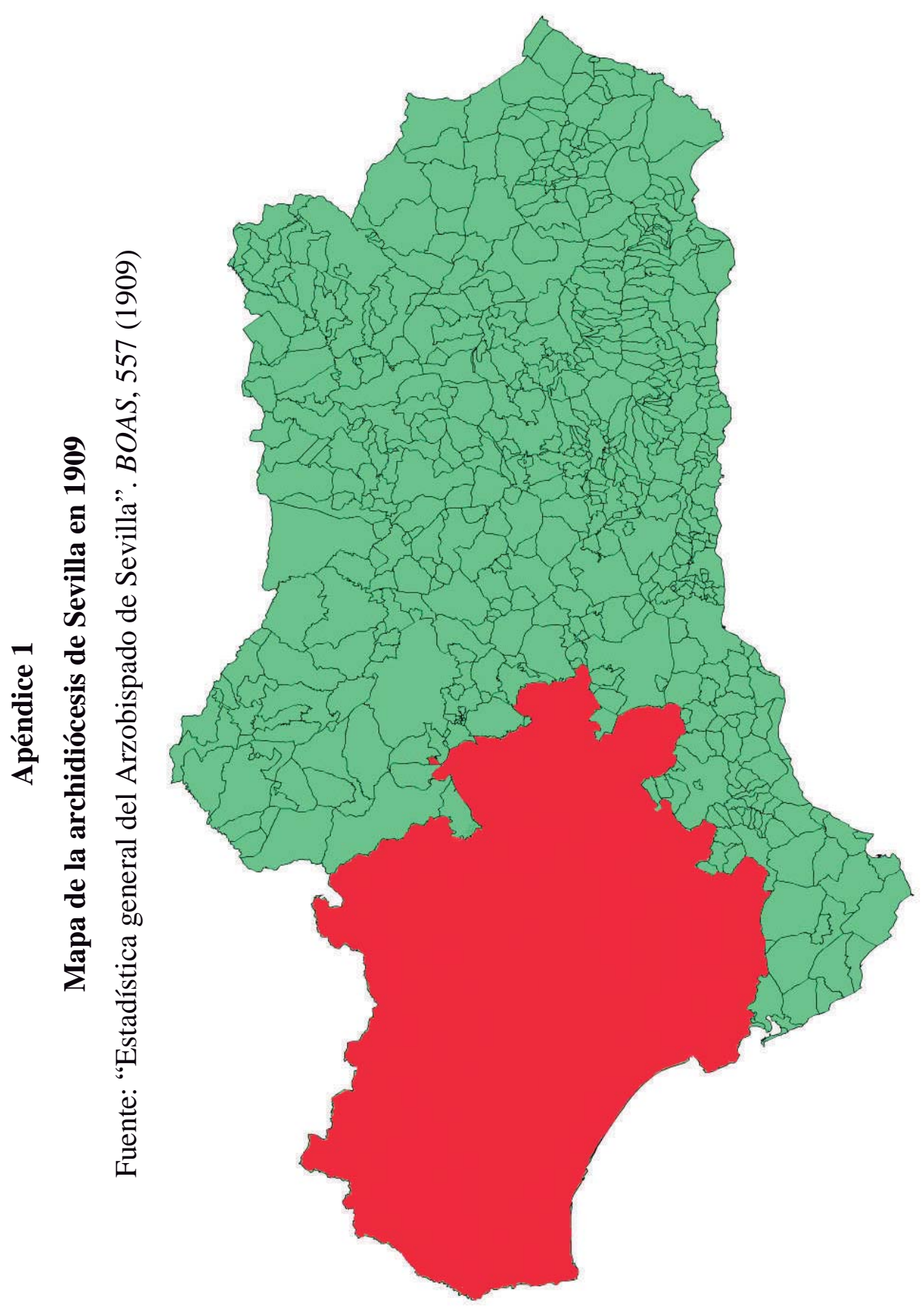

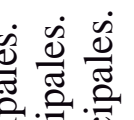
家寻兽 虽告 $0 \wedge N$ ๖ं 듀․ 퀑 웅 원 寻寻芯品 ข

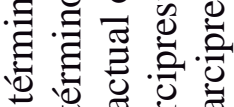
그잉

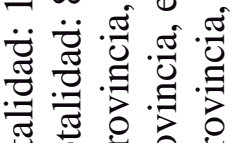
즁 융 음 क ज

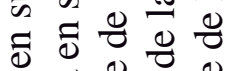

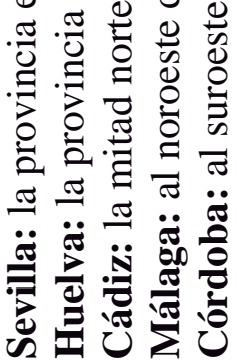

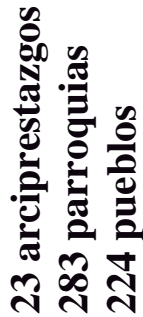





\section{Apéndice 2}

Circulares y otros documentos sobre música sagrada publicados en el Boletín

Oficial del Arzobispado de Sevilla entre 1904 y 1910

\section{Pontificado del arzobispo Marcelo Spínola y Maestre}

\section{Año 1904}

Fecha de publicación

$\mathbf{n}^{\circ} \mathrm{BOAS}$

Título

\begin{tabular}{lcc}
\hline 15 de enero & 534 & $\begin{array}{c}\text { "Otro [Motu proprio] acerca de la música } \\
\text { sagrada" }\end{array}$ \\
\hline 30 de enero & 535 & "Urbis et Orbis" \\
\hline 15 de febrero & 536 & "Circular sobre la música sagrada" \\
\hline 31 de mayo & 544 & $\begin{array}{c}\text { "Motu proprio. Edición vaticana de los libros } \\
\text { litúrgicos conteniendo las melodías } \\
\text { gregorianas." }\end{array}$ \\
\hline 15 de julio & 546 & $\begin{array}{c}\text { "Programa del certamen literario que para honrar } \\
\text { a la Inmaculada Concepción de la Sma. } \\
\text { en el quincuagésimo aniversario de la } \\
\text { dogmática de este misterio, se ha de } \\
\text { Sevilla." }\end{array}$ \\
$\begin{array}{l}\text { Virgen } \\
\text { definición } \\
\text { celebrar en }\end{array}$ & "La adjudicación de premios del Certamen" \\
\hline 15 de diciembre & 556 & "Circular no $315 "$
\end{tabular}

\section{Año 1905}

\begin{tabular}{|c|c|c|}
\hline 16 de enero & 558 & "Sobre la Música Sagrada" \\
\hline 15 de febrero & 560 & "Sobre la Música Sagrada"* \\
\hline $\begin{array}{l}31 \text { de marzo } \\
\text { ceremonias }\end{array}$ & 564 & $\begin{array}{l}\text { "Circular n } 319 " \text { o "Circular Ntro. Excmo. y } \\
\text { Rvmo. Prelado sobre los oficios, ritos y } \\
\text { propias de la Semana Santa". }\end{array}$ \\
\hline 15 de abril & 565 & "Circular n' 320" \\
\hline 15 de junio & 569 & "Sobre música sagrada" \\
\hline 15 de julio & 572 & $\begin{array}{l}\text { "Compostellana. De uso musicorum } \\
\text { instrumentorum in sacris functionibus". }\end{array}$ \\
\hline
\end{tabular}

15 de noviembre 581 "Decreto acerca de la edición y aprobación de libros de canto litúrgico gregoriano".

15 de diciembre 583 "Circular $\mathrm{n}^{\circ} 328$ " o "Circular recordando a los
Párrocos el "Motu proprio" sobre música sagrada".

* Incluye los dos informes presentados por parte de la Comisión Diocesana de Música Sagrada al arzobispo el 4 de marzo de 1904, y el 26 de enero de 1905, respectivamente. 


\section{Pontificado del arzobispo Enrique Almaraz y Santos}

\begin{tabular}{|c|c|c|}
\hline \multicolumn{3}{|c|}{ Años 1906 - 1907} \\
\hline Fecha de publicación & $\mathrm{n}^{\circ} \mathrm{BOAS}$ & Título \\
\hline 5 de abril & 590 & $\begin{array}{l}\text { "Circular" o "Circular dictando las disposiciones } \\
\text { sobre la Semana Santa".* }\end{array}$ \\
\hline 15 de noviembre & 630 & "Música Sacro-Hispana. Revista mensual” \\
\hline
\end{tabular}

*Esta circular fue publicada en 1906 durante el periodo de sede vacante.

\section{Año 1908}

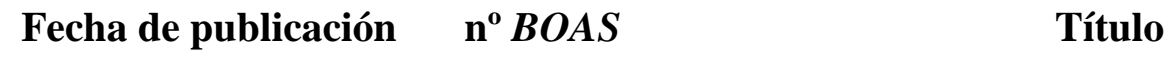

\begin{tabular}{lcc}
\hline 2 de marzo & 638 & $\begin{array}{c}\text { "Circular no } 11 " \text { o "Circular de Ntro. Excmo. } \\
\text { Rvmo. Prelado dando instrucciones para el } \\
\text { tiempo de Cuaresma" }\end{array}$ \\
\hline Santo & 642 de mayo & $\begin{array}{c}\text { "Angelopolitana. De usu lucis electricae et de } \\
\text { cantu mulierum en ecclesiis". }\end{array}$ \\
\hline 1 de junio & 643 & $\begin{array}{c}\text { "Segundo Congreso Nacional de Música } \\
\text { Sagrada"* }\end{array}$ \\
\hline 2 de octubre & 651 & $\begin{array}{c}\text { "Programa del Segundo Congreso Nacional de } \\
\text { Música Sagrada" }\end{array}$ \\
\hline 16 de noviembre & 654 & $\begin{array}{c}\text { "Segundo Congreso Nacional de Música } \\
\text { Sagrada"** }\end{array}$ \\
\hline
\end{tabular}

* En este artículo se publicaron la bendición apostólica enviada por Pío X, una circular de la Junta Organizadora, el reglamento, una primera versión del programa del Congreso, y el cuestionario para las distintas secciones de estudio.

${ }^{*}$ Incluye el telegrama dirigido a la secretaria de estado vaticana por el Congreso y la contestación del cardenal secretario de estado, una crónica de los distintos actos celebrados, las conclusiones, y el discurso de clausura del arzobispo. 
Año 1909

Fecha de publicación $\quad \mathrm{n}^{\circ} \mathrm{BOAS}$

Título

\begin{tabular}{lll}
\hline 1 de marzo & 661 & "Circular no 18. Sobre Música Sagrada" \\
\hline 15 de marzo & 662 & "El Canto Gregoriano" \\
\hline 1 de abril & 663 & $\begin{array}{c}\text { "Circular de la Comisión Diocesana de Música } \\
\text { Sagrada" }\end{array}$ \\
\hline 1 de junio & 667 & $\begin{array}{c}\text { "Música Sagrada" o "Exposición a Ntro. Excmo. } \\
\text { Prelado Sobre Música Sagrada y Circular } \\
\text { mismo punto"* }\end{array}$ \\
\hline 15 de julio & 671 & "Comisión Diocesana de Música Sagrada" \\
\hline 30 de julio & 672 & $\begin{array}{c}\text { "Circular no 20. Comisión Diocesana de Música } \\
\text { Sagrada" }\end{array}$ \\
\hline 16 de agosto & 673 "A los socios del 2" Congreso Nacional de \\
Música Sagrada". \\
Officcii
\end{tabular}

\begin{tabular}{lll}
\hline 15 de diciembre & 681 & "Segundo Congreso de Música Sagrada"
\end{tabular}

* Se trata de la circular no 19 del propio Arzobispo.

Año 1910

$\begin{array}{lll}\text { Fecha de publicación } \quad \mathrm{n}^{\circ} \mathrm{BOAS} & \text { Título }\end{array}$

\begin{tabular}{lcc}
\hline 2 de mayo & 690 & $\begin{array}{r}\text { "Circular de Ntro. Excmo. Prelado y Reglamento } \\
\text { de de Música Sagrada para esta Diócesis" }\end{array}$ \\
\hline 16 de mayo & 691 & "Reglamento de Música Sagrada (continuación)" \\
\hline 1 de junio & 692 & "Reglamento de la Música Sagrada (conclusión)" \\
\hline
\end{tabular}





\section{Apéndice 3}

Documentos relacionados con la petición de dispensa en la aplicación del Motu Proprio para el caso del Miserere de Eslava

\section{Relación cronológica de los principales documentos}

\section{Documento Fecha $\quad$ Contenido}

Circular, $B O A S \mathrm{n}^{\circ} 560 \quad 15$ de febrero Spínola declara que elevará a Roma una consulta sobre el Miserere

\begin{tabular}{lll}
\hline Consulta a Roma & 25 de febrero & Spínola solicita la dispensa \\
\hline Respuesta de Roma* & 6 de marzo & Pío X concede una prórroga \\
\hline Acta capitular & 27 de marzo & $\begin{array}{l}\text { El chantre informa de que Spínola ha } \\
\text { realizado la consulta y ha recibido } \\
\text { una respuesta afirmativa }\end{array}$ \\
\hline Acta capitular & 3 de abril & $\begin{array}{l}\text { Spínola manifiesta al Cabildo que el } \\
\text { Papa ha accedido a conceder la } \\
\text { excepción solicitada }\end{array}$ \\
\hline Circular, BOAS n ${ }^{\circ} 564$ & 15 de abril & $\begin{array}{l}\text { Spínola dictamina que se pueden } \\
\text { seguir "las antiguas costumbres" } \\
\text { hasta que no se disponga otra cosa }\end{array}$
\end{tabular}

*La fecha que figura en el documento es 6 de marzo de 1906, lo cual constituye una incongruencia ${ }^{1}$.

\footnotetext{
${ }^{1}$ Esta incongruencia en las fechas es tratada en: López Fernández, "El Miserere de Hilarión Eslava”, p. 961.
} 


\section{Transcripción de la solicitud elevada por el arzobispo Marcelo Spínola y Maestre a Pío X}

[Fuente: Archivio Segreto Vaticano, Segretaria di Stato, anno 1905, rubrica 283, fascicolo 2, fols. 46r-47r]

\section{Beatissime Pater}

Modernus Archiepiscopus Hispalensis ad S.V. pedes provolutus hme exponit, in sua Majori Ecclesia ab immemoriali ferme tempore morem invaluisse canendi psalmum Miserere solemni admodum vocum et instrumentorum apparatu ad finem Laudum in noctibus fer. IV et V Majoris Hebdomadae; qui quidem mos firmiores jecit radices saeculo proxime elapso, quo executioni mandari incepit celeberrima musicalis interpretatio ejusd. psalmi confecta a sacerdote Hilarione Eslava ipsius Ecclesiae Metropolitanae praeclaro Phonasco.

Jam vero, cum primum in lucem prodiit novissimum S.V. Decretum circa musicam sacram, idem Archiepiscopus non potuit quin omnem impenderet curam omnemque sollicitudinem, ut in sua dioecesi illud fideliter ad praxim redigeretur, revocatis et interdictis quibuslibet consuetudinibus in contrarium.

[46v] Sed quoad cantum ps. "Miserere" in Ecclesia Cathedrali nihil tentare ausus est, diversas prae oculis causas habens, inter quas eminent: $1^{\text {a }}$. Antiquitas moris una cum popularitate compositionis musicalis magistri Eslava, quae undequaque divulgata apud peritos tam proprios quam exteros magno in pretio habetur: $2^{\mathrm{a}}$. ingens ac vere extraordinaria populi frequentia, ita ut amplissimum templum vix capere valeat multitudinem audientium sublimes notas, quibus el. auctor sensum interpretatus est singulorum versiculorum Psalmi: $3^{\mathrm{a}}$. Concursus Hispalensis Senatus, qui ex proprio fisco expensas omnes solvere consuescit tum ad splendorem festivitatum Majoris Hebdomadae, quarum magnificentia universali gaudet fama, tum etiam in testimonium admirationis et amoris populi hispalen. erga insignem Magistrum, qui jure optimo apud gnaros habetur velut parens ac signifer instaurationis musicae sacrae nostra in Hispania: $4^{\text {a }}$ Gravis proinde conflictus ex hujusmodi consuetudinis abrogatione pertimescendus, gravioraque mala, quae necessario consequutura forent non solum in ordine morali, sed etiam in materiali et oeconomico, quatenus beneficia, quae reportantur [47r] ex populorum affluentia ad ejusmodi solemnitates, tunc procul dubio cessarent cum magno publicae utilitatis detrimento.

Infrascriptus igitur Archiepiscopus una cum suo Capitulo, re mature perpensa, opportunum duxit eam supremo S.V. judicio summitere haud dubitans quin, habita praemissorum ratione, de benignitate Apostolica ob speciales circumstantias praefactae consuetudinis hujus inclytae Ecclesiae, eamdem excipere velit a praescriptionibus generalibus sui Motus Propii diei XXII Novembris MCMIII.

Dum ergo supplex hanc dispensationem a S.V. implorat, ipsemet Archiepiscopus Ejusdem pedes omni cum reverentia deosculatur.

Bme. Pater

Hispali XXV Februarii 1905

Humill. ac Devotiss. in Xpto. Filius.

+ Marcellus, Archiepiscopus Hispalensis 


\title{
3. Transcripción del borrador de la respuesta remitida por la Santa Sede
}

\author{
[Fuente: Archivio Segreto Vaticano, Segretaria di Stato, anno 1905, rubrica 283, \\ fascicolo 2, fol. 48]
}

\author{
Monsig. Marcello Spinola y Maestre \\ Arcivescovo di Siviglia
}

\section{Marzo 1906}

Il Santo Padre si é benignamente compiaciuto di prendere esatta conoscenza di quanto la S. V. Illma. e Revma. Gli esponeva nel foglio del 25 febbraio p. p. intorno al canto del "Miserere" solito a farsi ogni anno in cotesta Cattedrale per 1'ufficiatura detta delle tenebre, nella settimana Santa. Le prudenti misure della S. V. e la decisa volontá nell' applicare le pontificie disposizioni sulla musica sacra sono state encomiate dalla Santitá Sua, che peró non ha mancato di portare la dovuta attenzione al presente caso del "Miserere", opera del Maestro Eslava. Non ignora il Santo Padre le difficoltá che in molti luoghi $[48 \mathrm{v}]$ impediscono o ritardano la completa attuazione del Motu Proprio del 22 Nov 1903, difficoltá non superabili se non col tempo e con un metodo di riforma lentamente progressiva. Considerando adunque le serie e gravi ragioni addotte da V. S. e per le quali non potrebbesi ora procedere, senza notevoli consequenze materiali e morali, alla soppressione del canto del citato salmo, pregevole per l'artistica composizione, ma non conforme alla maestosa gravitá dei sacri concenti; l'augusto Pontifice benignamente permette a V. S. che uniformandosi alla necessitá imposta delle circostanze del caso in questione, tolleri per qualche altro tempo l'esecuzione di quel salmo finché regolandosi con quel savio criterio e prudenza che le é propria ed insinuando negli animi l'opportunitá di un cambiamento, possa ottenere un nuovo genere di musica, che soddisfi alle pontifici prescrizioni e che sia nel contempo di salutare pascolo alla pietá dei fedeli

Nel parteciparle quanto sopra da parte del S. Padre, colgo 1'occasione per riaffermarmi con sensi di ser [sic]

[sin firma] 



\section{Apéndice 4}

\section{Síntesis del Reglamento de música sagrada para la Archidiócesis de Sevilla}

[Fuente: “Circular de Ntro. Excmo. Prelado y Reglamento de Música Sagrada para esta

Diócesis" BOAS, 690 de 2 de mayo (1910), pp. 452-461]

\section{- Primera parte. De la música sagrada en general}

\section{Capítulo I. De la música gregoriana}

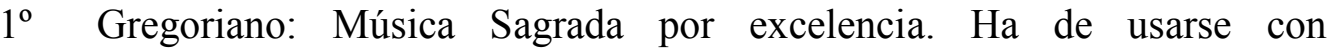
preferencia

$2^{\mathrm{o}} \quad$ Melodías gregorianas auténticas: obligatorias.

$3^{\circ}$ Prohibido melodías no auténticas o no aprobadas: prohibido cantar según cantorales, o ad libitum.

\section{Capítulo II. De la música figurada}

$4^{\text {o }} \quad$ Prohibido aquellas obras musicales que no se ajuste al Motu Proprio y demás disposiciones vigentes. Rectores y Párrocos no permitirán obra alguna sin autorización.

$5^{\circ} \quad$ En funciones solemnes: se puede usar música figurada si hay recursos necesarios, es decir, si se garantiza el decoro en la interpretación. Si no, gregoriano. Dos géneros permitidos: antiguo (escuela Palestrina); moderno (cromático).

$6^{\mathrm{o}} \mathrm{Su}$ Santidad ordena que en el Seminario se enseñe gregoriano y nociones fundamentales de polifonía religiosa, y que se funden Scholae cantorum donde se pueda, especialmente en iglesias principales. Por tanto, hay que llevar a cabo esta orden con exactitud.

$7^{\circ} \quad$ Se prohíben obras con las siguientes características: $1^{\circ}$ sabor teatral o profano; $2^{\circ}$ Dividida en partes distintas, en perjuicio texto sagrado; $3^{0}$ Tengan preponderancia solos, dúos; $4^{\circ}$ Repitan sin sentido, truequen u omitan palabras del texto; $5^{\circ}$ Muy largas, y obliguen a suspender el desarrollo del Culto.

$8^{\circ} \quad$ Sustitución de obras género mixto por gregorianas o figuradas 2 géneros permitidos.

\section{Capítulo III. De la música vocal}

$9^{\circ} \quad$ Prohibido cantar en lengua vulgar. Sólo en actos no litúrgicos.

$10^{\circ}$ En funciones estrictamente litúrgicas (Oficio y Misa) se prohíben otros textos latinos que no sean los prescritos para cada parte, y sin alteración alguna. Se 
permite cantar Motete latino sólo entre después del Ofertorio propio y Prefacio, y entre Benedictus post elevatione y Pater noster. En otros Cultos se permiten otros textos y letanías aprobadas por la Iglesia.

$11^{\circ}$ Dado que el canto es una función propia de clérigos, estos deben ser bien instruidos. En su defecto, pueden desarrollar esa labor seglares que sean varones de intachable conducta. Si cantan en el Coro deben hacerlo con sotana y sobrepelliz, si no deben permanecer ocultos.

\section{Capítulo IV. De la música orgánica}

$12^{\circ}$ El órgano es el instrumento litúrgico por excelencia. Se prohíbe cualquier otro instrumento. El armonio puede suplir al órgano, en su defecto.

$13^{\circ}$ Reglas para el acompañamiento: $1^{\circ}$ Deben usarse registros adecuados al número y calidad de las voces, de tal manera que siempre predominen estas; $2^{\circ}$ En el acompañamiento del gregoriano, los organistas pueden elegir el género que prefieran, siempre que sean expertos y peritos en la materia. No obstante, se recomienda la imitación de los grandes maestros.

$14^{\circ}$ Se prohíbe género de sabor teatral o profano. Siempre género "ligado".

$15^{\circ}$ No se permiten largas introducciones e intermedios. Los organistas deben estar siempre atentos a los avisos que se pudieran dar desde el altar.

$16^{\circ}$ Se les prohíbe la improvisación a los organistas no competentes.

\section{Capítulo V. De la música instrumental}

$17^{\circ}$ Para utilizar otro instrumento que no sea órgano es necesario obtener permiso especial del Ordinario.

$18^{\circ}$ Se prohíbe toda obra, especialmente para orquesta, no examinada y aprobada por la Comisión.

$19^{\circ}$ Las bandas están prohibidas en las iglesias. Sólo se permiten en estos casos: $1^{\circ}$ Cuando los militares hayan de rendir honores; $2^{\circ}$ Cuando se haya obtenido permiso del Prelado y las obras a interpretar hayan sido aprobadas; $3^{\circ} \mathrm{Y}$ en las procesiones festivas, igualmente con permiso del Prelado y las obras aprobadas, en el lugar que se les designe.

$20^{\circ}$ Los instrumentos prohibidos son los siguientes: de percusión, de ruido (fragorosos), populares o profanos (ligeros). 


\section{Capítulo VI. De la ejecución de la música sagrada en general}

$21^{\circ}$ Se prohíbe ejecutar cualquier obra sin haber sido debidamente ensayada.

$22^{\circ}$ Está prohibido admitir en Coro y Capilla a músicos de "conducta pública discutible y de dudosa moralidad".

\section{Capítulo VII. De la ejecución de la música gregoriana}

$23^{\circ}$ Los criterios para la interpretación del canto gregoriano son: $1^{\circ}$ con atención y devoción; $2^{\circ}$ decorosa lentitud, especialmente los salmos; $3^{\circ}$ uniformidad de las voces, siguiendo con exactitud la dirección; $4^{\circ}$ pronunciación correcta; $5^{\circ}$ entonación proporcionada, voz clara y suave; $6^{\circ}$ sujeción a la naturaleza de la melodía, su distribución y ritmo.

\section{Capítulo VIII. De la ejecución de la música figurada}

$24^{\circ}$ Se consideran las mismas reglas que rigen para el gregoriano. Se debe huir de estos dos extremos: que sea mecánica, o exageradamente expresiva.

$25^{\circ}$ Si la santidad es la primera cualidad de la música sacra, están prohibidos los giros amanerados, de apasionamiento y dejo teatral.

["Reglamento de Música Sagrada (continuación)", BOAS, 691 de 16 de mayo (1910), pp. 562-567]

\section{- SEGUNDA PARTE. De la Música Sagrada en los actos del Culto divino}

\section{Capítulo IX. De la música en las misas de fiestas}

$26^{\circ}$ Todas las entonaciones del Celebrante y ministros, así como las contestaciones del Coro, deben ser a canto gregoriano, según se halla en la Edición Vaticana del Gradual. Prohibido acompañar las del Celebrante y ministros. Pueden ser acompañadas las del Coro, pero sólo por el órgano.

$27^{\circ}$ El Propio de la Misa debe ser cantado según las melodías gregorianas propias, si no se cantan con música figurada. Hay que respetar la distribución de partes según la Edición Vaticana. Pueden ser acompañadas del órgano.

$28^{\circ}$ El Ordinario de la Misa puede cantarse en gregoriano o música figurada. En el primer caso, son preferibles las melodías publicadas en la Edición Vaticana a cualquieras otras que pudieran autorizarse.

$29^{\circ}$ En el canto de la Misa se observará:

a) Se puede tocar el órgano hasta que el Celebrante llega al altar, momento en el que comienza el canto del Introito. La repetición de la antífona puede suplirse con el órgano, siempre que un cantor recite su texto en voz alta. 
b) Los nueve Kyries se pueden cantar: 1) dos coros alternando entre sí; 2) coro alternando con intermedios del órgano, en cuyo caso, debe empezar el coro, y se recitará el texto de la parte suplida por el instrumento.

c) Se prohíbe a los caperos del Coro preintonar el Gloria in excelsis Deo, pues compete al Celebrante, que debe hacerlo con la melodía propia. El Coro seguirá en et in terra pax, o bien a dos coros en alternatim, o bien coro y órgano, debiéndose recitar la parte tocada por el órgano.

d) Después de la Epístola, se cantará Gradual, Alleluia y Tracto, según el caso, y la Secuencia íntegramente. En caso de alternancia con el órgano se recita. No se puede omitir texto de la Misa.

e) Concluido el Evangelio, el celebrante preintona el Credo con la melodía propia. El Coro sigue en Patrem omnipotentem. Se cantará íntegramente el texto sin intermedios, con o sin acompañamiento.

f) Una vez cantado el Ofertorio propio (o recitado sub organo), este instrumento toca hasta el Prefacio; o bien, se canta un motete muy breve que se interrumpirá cuando se avise desde el altar.

g) Tras el Prefacio, el Coro canta en alternatim el Sanctus hasta el Benedictus. Debe ser muy breve, sobre todo si es polifónico, para que haya concluido antes de la Elevación.

h) Durante la Elevación, no se canta, toca el órgano "suave y gravemente". Después de la Elevación se canta el Benedictus, tras el cual toca el órgano hasta el Pater noster. También se puede cantar un motete al Santísimo Sacramento.

i) Después de la contestación del Pax Domini, se canta el Agnus Dei en alternatim, debiéndose unir los dos grupos en el Dona nobis pacem.

j) Tras la sunción del Santísimo Sacramento, se canta o recita sub organo el canto de Comunión.

k) Concluidas las últimas oraciones, el Diácono canta el Ite missa est o Benedicamus Domino según la melodía propia. El Coro contesta Deo gratias en el mismo tono o bien un cantor lo recita sub organo. Este instrumento seguirá tocando hasta que el Celebrante llegue a la sacristía.

$30^{\circ}$ Se prohíbe cantar en lengua vulgar, salvo en las misas privadas y otras funciones, según la norma antes establecida, y en las procesiones en honor a la Virgen o los santos fuera del templo. 


\section{Capítulo $\mathrm{X}$. De la música en las misas de feria y de réquiem}

$31^{\circ}$ En misas feriales se guarda mismo orden y distribución del canto que en las solemnes. Respecto al uso del órgano: 1) se usará en la forma litúrgica ordinaria (alternando con el Coro, y haciendo interludios) en los domingos tercero de Adviento, cuarto de Cuaresma, de Septuagésima, Sexagésima y Quincuagésima y en todos aquellos en los que se prescriba el uso de dalmáticas moradas; 2) en las ferias, restos de domingos de Cuaresma y Adviento, témporas y misas de réquiem sólo se permite para acompañar o sostener las voces.

$32^{\circ}$ En estas misas se cantará el texto íntegro a capella o con acompañamiento de órgano, armonio u otros instrumentos. Sólo se puede omitir alguna estrofa de la Secuencia de la Misa de réquiem.

$33^{\circ}$ En el Oficio de difuntos se prohíbe el órgano.

$34^{\circ} \mathrm{El}$ tono a cantar en estas misas, salvo la de difuntos en domingo, debe ser el tonus ferialis según la Edición Vaticana.

$35^{\circ}$ En la absolución ad tumulum, y en las exequias cadavere praesente sólo se cantarán las melodías de la Edición Vaticana.

\section{Capítulo XI. De la música en las Vísperas}

$36^{\circ}$ Se deben seguir estrictamente las indicaciones del Ceremonial de Obispos en el canto del Oficio, especialmente en las Vísperas. Se cantarán Obispo ausente:

a) Toca el órgano mientras celebrante y caperos se dirigen en procesión al Coro. "Colocados todos en su lugar, el maestro de Sagradas Ceremonias hará señal, y cesando el órgano, el Preste o Celebrante entonará y contestará el Coro el Deus in adjutorium etc. con su melodía propia. La contestación del Coro puede ser acompañada por el órgano", nunca por la orquesta. Norma esta que se seguirá para el resto de Horas.

b) "El primero de los Caperos preintona al Celebrante la $1^{\mathrm{a}}$ Antífona, y repetida por este, el Sochantre, o bien dos cantores con sobrepelliz, entonan en medio del coro el primer versículo del $1^{\circ}$ Salmo. Al final de cada Salmo, el último de los Caperos, si son más de dos, y si no, dos cantores de sobrepelliz, preintonan por orden de dignidad, las demás Antífonas a los asistentes de uno y otro coro, haciéndose la entonación de cada Salmo como la del primero."

c) Posibilidades del canto del Salmo: 1) Con el tono propio determinado por el de la antífona a dos coros con o sin acompañamiento del órgano sin intermedios, a no ser que se disponga de insuficiente número cantores; 2) coro con el tono salmódico y Capilla con polifonía, alternando a versos; 3) sólo polifonía, según los dos géneros 
autorizados, estando el grupo dividido en dos coros, alternando a versos, según el canto salmódico. Prohibido los salmos "de concierto", es decir, aquellos que no se ajustan en su estructura a la división en versos, ni respetan su carácter coral (incluyen solos, dúos, etc.). En la salmodia gregoriana se utiliza el tono solemne para continuar con el ferial.

d) Las antífonas se cantan con su melodía propia. Al final del salmo se puede recitar sub organo, o cantar con música figurada.

f) "Terminados los Salmos, el Preste, asistido de los Caperos y de dos acólitos con ciriales, canta en el plano del coro el Capítulo" propio. "El primero de los Caperos preintona al Preste el Himno, y repetido por este se continúa, o bien por el Coro en canto gregoriano, alternando a estrofas con intermedios de órgano, supliéndose en ese caso la estrofa que se omite, o bien alternando con la Capilla musical, o ya, por último, cantando esta todo el Himno con música figurada."

g) "El Sochantre, o bien dos cantores con sobrepelliz, entonan con su entonación solemne" (en todos los versos), el Magníficat, "mientras el Preste sube al altar y lo inciensa". Se canta según las diversas posibilidades autorizadas del canto de los salmos.

h) Después de la antífona, el Preste, "asistido de los Caperos y de los acólitos con ciriales, canta la Oración u Oraciones, según las rúbricas, con el tono solemne. Y concluidas estas, los dos Caperos más modernos con el Sochantre, o bien dos cantores con sobrepelliz, cantan en medio del coro el Benedicamus Domino, en su tono conveniente, contestando en el mismo tono todo el Coro; contestación que puede recitarse mientras toca el órgano.”

i) "El Preste canta (semitonado) el Fidelium animae etc. Si siguen en el coro las Completas, el Celebrante se vuelve con los Caperos a la sacristía; pero si con las Vísperas termina el Coro, se concluirá del modo siguiente: cantado en la forma dicha el Fidelium animae, y dicho en secreto el Pater noster, el Preste canta (semitonado) el Dominus det nobis, etc., y a continuación entona el canto de la Antífona de la Santísima Virgen correspondiente a cada tiempo; lo que se observará también a final de Completas. Cantado el versículo, el Preste canta la Oración con el tono conveniente; y cantado (semitonado) el Divinum auxilium, etc. se retira a la sacristía, tocándose entretanto el órgano."

$37^{\circ}$ Este ceremonial para todas las Vísperas, con las siguientes diferencias: fiestas de $1^{\mathrm{a}}$ clase solemnes: 6 caperos; de $1^{\mathrm{a}}$ clase menos solemnes: 4; de $2^{\mathrm{a}}$ clase y 
domingos: 2; los demás, no hay, ni el celebrante usa pluvial, ni se inciensa durante el Magníficat, a no ser que esté expuesto el Santísimo Sacramento.

$38^{\circ}$ Ceremonial de Vísperas obligatorio para catedrales y colegiatas. En otras iglesias: se puede cantar otro oficio, no el propio del día; en Cuaresma por la mañana; se puede cantar la salmodia alternando con órgano, recitando el texto; no se puede omitir versículos, ni recitarlos sin órgano; el Gloria Patri se canta sin intermedio, unido al versículo anterior.

\section{Capítulo XII. De la música en completas}

$39^{\circ}$ "Cantada por un cantor la Lección breve, canta el Preste el versículo Adjutorium nostrum etc., diciendo luego Pater noster y Confiteor Deo con sus Absoluciones sin canto. Contestadas por el Coro las invocaciones, que cantará el Preste en su tono correspondiente, un cantor entona la Antífona Miserere o Alleluia, comenzándose enseguida los Salmos, todos en el tono de la Antífona por ser única, y que habrán de cantarse a dos coros," con o sin órgano, pero sin intermedios.

$40^{\circ}$ El Coro canta Antífona, y el Himno a dos coros (entonado por el Sochantre), o bien alternando a estrofas con el órgano, recitándose en voz alta el texto. El Preste canta el Capítulo y dos cantores en medio del coro el versículo breve propio, contestando el Coro. "Picada la Antífona", Salvanos, sochantre entona Nunc dimittis en tono ferial, continuándose su canto según una de las formas de los salmos y el Magníficat. No se inciensa el Coro.

$41^{\circ}$ "Cantada por el Coro la Antífona, canta el Preste, contestando el Coro, en el tono ferial correspondiente, Dominus vobiscum y la Oración, visita, Dominus vobiscum, Benedicamus Domino y la Bendición final Benedicat et custodiat etc. aún praesente Episcopo, entonando a continuación la Antífona de la Santísima Virgen, como se dijo antes.

\section{Capítulo XIII. De la música en Maitines y Laudes}

$42^{\circ}$ Preste sin pluvial entona Domine labia mea etc. y Deus in adjutorium etc. Contesta el Coro con o sin acompañamiento. El organista sigue hasta aviso Maestro de Ceremonias.

a) Dos cantores en medio del coro o en altar cantan Invitatorio y salmo Venite. Contesta el Coro.

b) Dos cantores se acercan al celebrante, el primero le preintona el Himno. Lo repite aquel, y continúa Coro alternando con órgano, o sólo música figurada, como en Vísperas. 
c) El mismo cantor preintona al preste primera antífona. Éste la repite y la finaliza el Coro. Sochantre o dos cantores entonan el salmo en el mismo tono -solemnede la antífona, a dos coros con o sin acompañamiento, pero sin intermedios. Las demás antífonas y salmos igual que Vísperas.

d) Las Lecciones se cantan en su tono por orden de jóvenes o modernos, a ancianos o antiguos, en atril sin paño en medio del Coro.

e) Responsorios: 1) a dos coros alternatim "juxta ritum responsorialem" con melodía propia; 2) por Capilla en polifonía; 3) rezados en voz alta por ambos coros $s u b$ organo.

f) Última Lección la canta el Preste de pluvial asistido por dos caperos y acólitos con ciriales, sólo en solemnidades.

g) Tras última Lección, primer Capero preintona Te Deum, que repite el Preste, y continúa el Coro alternando con órgano; o bien, todo con música figurada. El versículo Te ergo quaesumus con mayor solemnidad.

h) Final de Maitines, el Preste canta Oración en tono solemne.

$43^{\circ}$ Laudes rigen las mismas prescripciones que en Vísperas.

["Reglamento de la Música Sagrada (conclusión)”, BOAS, 692 de 1 de junio (1910), pp. 571-577]

$44^{\circ}$ En iglesias en las que no había obligación de Coro sólo se canta Benedictus, Antífona y Oración. Lo demás, semitonado. Prohibido recitar versículos de salmos sin acompañamiento de órgano. En Maitines, sólo se canta "rigurosamente" el Invitatorio, las Lecciones y el Te Deum. Lo demás en tono salmódico.

\section{Capítulo XIV. De la música en las Horas menores}

$45^{\circ}$ En Horas menores, independientemente de su solemnidad, no se usan pluviales, ni se toca el órgano, excepto en las formas antes determinadas.

$46^{\circ}$ Sólo se canta en tono solemne la Oración de la Tercia de Pontifical. Todo lo demás en tono ferial.

$47^{\circ}$ En las Horas cantadas, sólo serán rezadas las preces feriales, y semitonadas las Fidelium animae, Dominus det nobis y Divinum auxilium.

$48^{\circ}$ "En la Prima, los versículos Pretiosa etc. después del Martirologio se cantarán en el tono común de los versículos, siempre sin acompañamiento; y las oraciones Sancta Maria y Dirigere las cantará el Preste en el tono ferial ad libitum (cadencia de tercera)." 
$49^{\circ}$ La Lección del Martirologio con el tono ordinario de las Lecciones de Maitines y sin acompañamiento.

\section{Capítulo XV. De la música en los actos litúrgicos fuera del Oficio}

$50^{\circ}$ Las antífonas Asperges me o Vidi aquam se cantan con melodías propias. Su terminación debe coincidir con la vuelta del Celebrante al altar. También se puede cantar con música figurada. La Oración en tono ferial ad libitum (cadencia de tercera)

$51^{\circ}$ Bendiciones y procesiones litúrgicas ante missam se cantará con textos y melodías gregorianas propias, excepto Gloria laus, que se puede cantar en música figurada.

En la procesión de Letanías: "Cantada la antífona Exurge con su Salmo y Gloria Patri, como se halla en su lugar de la Edición Vaticana, dos cantores con sobrepelliz entonan los Kyrie, repitiendo todo el Coro cada invocación en el mismo tono. Cantando así y con mayor solemnidad el Sancta Maria, Ora pro nobis y repetido por el Coro, levántanse todos, y se ordena la Procesión, en la que se irán cantando las Letanías de los Santos, como están en la Edición Vaticana y ninguna otra cosa", pues no se puede intercalar invocaciones a otros santos no contenidos en ellas. Las invocaciones se cantan por dos cantores y contesta el Coro "integramente".

“Llegada la Procesión a la iglesia en que ha de cantarse la Misa, se suspende el canto de las Letanías, que se reanudará luego en el lugar en que quedaron interrumpidas, cantándose la Misa del modo dicho. Y si la Misa ha de cantarse al regreso de la Procesión, en este caso se interrumpen las Letanías, y se cantan, en la iglesia en la que se haga Estación, las Antífonas de la Santísima Virgen y del Sagrado Titular con rito pascual con sus oraciones propias, reanudándose después hasta concluir.

$52^{\circ}$ En procesión con Santísimo Sacramento expuesto: se cantan los textos señalados en la Edición Vaticana, "alternando las estrofas con intermedios de órgano, o bien con motetes de música figurada, en latín si los canta el Coro eclesiástico, y en latín o en castellano si los canta el cortejo de seglares". Se termina con la bendición. En procesiones fuera del templo, con premiso del Prelado, pueden acompañarlas bandas de música.

$53^{\circ}$ De esta forma, se cantarán todas las procesiones. En las de penitencia y rogativas se cantan: Letanías de los Santos, y algún motete o salmo; en las festivas y de Tercia: himnos propios del Oficio del santo; en las de acción de gracias: Te Deum y cánticos del Oficio. 
54 En exposición solemne, bendición y reserva del Santísimo: 1) en acto de exponer: estrofa Pange lingua o Tantum ergo, con permiso del Prelado; 2) durante exposición: motetes en latín o castellano, con órgano u orquesta. También los Jueves y Viernes santos, en el Monumento; 3) bendición y reserva solemne: se cantan seguidas Tantum ergo y Genitori, o a canto gregoriano, o en polifonía a capella, o con acompañamiento de órgano u orquesta, "con las debidas condiciones"; tras Panem de coelo etc. y Deus qui nobis etc., se hace la bendición, durante la que no se puede cantar ni tocar; terminada esta y mientras se oculta el Santísimo, se cantan las "Alabanzas" en latín o castellano, "según fuera costumbre".

\section{Capítulo XVI. De la música en otras funciones del culto}

$55^{\circ}$ Rogativas públicas ordenadas por el Prelado: se cantan las preces y oraciones propias en tono ferial ad libitum sin acompañamiento. La reserva como artículo anterior.

$56^{\circ}$ Acciones de gracias: se canta el Te Deum con melodía propia gregoriana con intermedios de órgano, o con música figurada. Preces y oraciones finales en tono ferial ad libitum sin acompañamiento.

$57^{\circ}$ En los demás cultos en honor a los santos: se cantan con acompañamiento de órgano u orquesta "las Letanías aprobadas, y no otras, y otros textos en latín o en castellano," aún expuesto el Santísimo (en este caso, las Lauretanas sólo en latín) y la celebración de la Misa rezada. "Las Letanías pueden cantarse por grupos de dos, tres o cuatro invocaciones con un sólo Ora pro nobis, o bien pro grupos de tres invocaciones con su respuesta, añadiendo el pueblo a cada grupo la cuarta invocación.”

\section{Apéndice. De la música sagrada en las funciones de la Semana Santa}

$58^{\circ}$ Sólo se permite la orquesta cuando se permite el uso del órgano. Este está prohibido, como instrumento litúrgico [se entiende con parte propia], en todos los Oficios del tiempo de Pasión. Por tanto, durante la Semana Santa sólo se puede utilizar la orquesta para "duplicar o sustentar las voces".

$59^{\circ}$ Textos de las pasiones: en los que intervienen más de una persona, está permitida polifonía con algún instrumento que la sustente. Prohibido que un solista cante frase alguna, sólo le está permitido al Diácono.

$60^{\circ}$ "Terminantemente prohibido el uso de todo instrumento en los Oficios del Triduo de la Semana Mayor". Excepciones: el Gloria en la Misa del Jueves Santo, y toda la Misa a partir del Gloria, en la del Sábado Santo. Normas: 1) Preferencia del canto gregoriano en todas las partes del Oficio que se pueden cantar; 2) Sólo canto 
gregoriano sin acompañamiento: antífonas y salmos de Maitines y Laudes, Lamentaciones, Miserere, y Propio de la Misa; 3) En polifonía a capella o con algún instrumento "adecuado" colla parte: Responsorios de Tinieblas, Benedictus en Laudes, Ordinario de la Misa del Jueves, procesiones de los Santos Óleos, Pange lingua en la procesión al Monumento, Improperios y Vexilla regis en el Oficio matutino del Viernes Santo.

$61^{\circ}$ Fuera del Oficio litúrgico, en el Triduo Pascual pueden cantarse: 1) Exposición del Santísimo en Monumento: salmos o motetes polifónicos con acompañamiento de órgano $u$ orquesta. 2) En ejercicios como Tres Horas, Siete Palabras, Via crucis, Soledad de la Santísima Virgen: "cantos piadosos" con acompañamiento de armonio.

$62^{\circ}$ Misa del Jueves santo: Diácono canta la Confesión con melodía propia. Terminada la procesión del Santísimo al Monumento, se canta en gregoriano o polifonía el Tantum ergo u otro motete al Santísimo Sacramento. 



\section{Apéndice 5}

\section{Transcripción de los inventarios musicales estudiados}

Fuente: ACS, Sección Medios de Información, lib. 11160

Se trata de un legajo compuesto por cinco inventarios. Están contenidos en una carpeta de tapas duras independientes cogidas por dos cintas que se enlazan en el borde de apertura a modo de cierre. En el centro de la tapa delantera figura la inscripción en rotulador rojo: "INVENTARIOS de Obras Musicales". Transcribimos los tres que hemos manejado y ofrecemos, además, una estimación sobre su datación. Los otros dos fueron confeccionados en fechas lejanas al periodo acotado en nuestro trabajo. El más antiguo debió ser escrito en torno a mediados del s. XIX. El segundo, con título Índice del Archivo de música de la Catedral, tiene fecha de 2 de noviembre de 1940. Se ha respetado el orden y la disposición de los ítems tal y como figuran en los originales.

Juan Ruíz Jiménez proporciona una descripción de este conjunto de inventarios y una transcripción parcial de los mismos en La Librería de Canto de Órgano, pp. 2930, 352-353. En ella ofrece las obras de autores de los siglos XVI y XVII así como los libros de pergamino anotados. Las referencias recogidas en el listado publicado por Ruíz Jiménez se indican con un asterisco.

- Inventario 1: Índice de las Obras que existen en el Archivo musical de esta Sta. Iglesia (ca. 1900), p. 666

- Inventario 2: Catálogo de Obras musicales (entre junio de 1907 y junio de 1909), p. 681

- Inventario 3: Archivo musical de Scalas (ca. 1925), p. 695 


\section{Inventario $1(\text { ca. 1900) })^{1}$}

[Datación: las obras más recientes incluidas en este inventario pertenecen a Evaristo García Torres. Los rasgos caligráficos coinciden con los de las actas de las reuniones del Cabildo y autos de la Diputación de Ceremonias en el periodo en el que fue secretario Modesto Abín y Pinedo. Hemos de suponer que fue este canónigo quien lo elaboró. Además, la poca información que sobre las obras ofrece, y que hacen de él un mero listado, ciertamente exiguo, apuntan a un autor poco perito en música. Se podría especular con la posibilidad de que Abín asumiera el encargo de confeccionarlo tras la jubilación (1895) o muerte (1902) de García Torres, a quien correspondía la custodia e inventariado del archivo de música como obligación propia de su cargo. Si asumimos esta hipótesis, habría que datarlo entre 1895 y 1903, año de llegada a Sevilla de Ripollés. Es un manuscrito en papel, cuyos bifolios están encuadernados de forma muy rudimentaria. Marca de agua: “A. Serra S.”]

Índice de las Obras que existen en el Archivo musical de esta Santa Iglesia

\section{Salmos}

Dixit Dominus

$\begin{array}{ll}\text { Eslava } & 1 \\ \text { id } & 1 \\ \text { id } & 1 \\ \text { Andreví } & 1 \\ \text { Arquinvau [sic] } & 1 \\ \text { id } & \\ \text { id } & \\ \text { id } & \\ \text { id } & \\ \text { id } & \\ \text { id } \\ \text { id } \\ \text { id } \\ \text { Ripa } \\ \text { Id } \\ \text { Id } \\ \text { Id } \\ \text { Autor desconocido } \\ \text { Id } \\ \text { Id } \\ \text { Id }\end{array}$

\footnotetext{
${ }^{1}$ La numeración de los inventarios es nuestra, y responde a un criterio cronológico: del más antiguo al más reciente.
} 
Úbeda

Rabassa

Id

Evaristo García Torres

$\left[\right.$ página 2] ${ }^{2}$

Letatus sum $[$ sic $]$

Eslava

Andreví

Arquinvau

Id

Id

Ripa

Id

Id

Id

Palacios

García Torres

Lauda Jerusalem

Eslava

Palacio

Ripa

Id

Id

Arqunvau

Id

Id

Desconocido

García Torres

[p. 3]

Beatus vir

Eslava

Id

Arqunvau

Ripa

Id

Desconocido

Id

Id

Úbeda

Mouton

${ }^{2}$ Las páginas no están numeradas. La paginación de los tres inventarios es nuestra. 
Laudate Domino omnes gentes

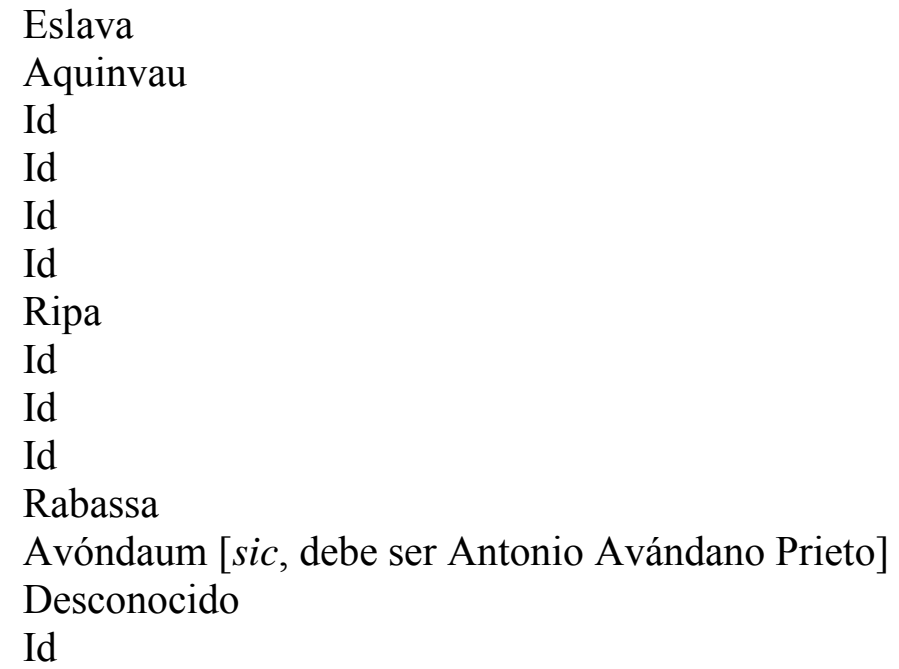

[p. 4]

Magnificat

Eslava

Id

Andreví

Id

Id

Ripa

Id

Id

Delgado

Rabassa

Bueno

Mozart

Desconocido

Id

Arquinvau

Id

García Torres

Credidi
Arquinvau
Ripa
Id
Benedictus
Arquinvau
Ripa

[p. 5]

Exaltabo 


\section{Desconocido}

De profundis

Arquinvau

Voce mea

\section{Ripa}

Eripeme Domine

Ripa

Deus in nomine tuo. Retribue, Quicumque. Prima

Arquinvau

[p. 6]

Legen pone. (Tertia)

Arquinvau

Defecit Inicuos (Sexta)

Arquinvau

Completas

Arquinvau

Ripa

Id

Id

Monserrat. Cum invocarem solo

Himnos

García Torres
Eslava
Arquinvau
Id
Id
Id
Id
Id
Id
Id

[p. 7] 


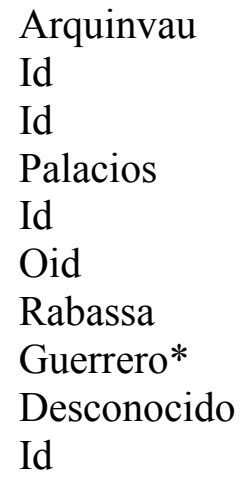

Misas con orquesta

García Torres

Id

Iñiguez

Eslava

Id

Id

Id

Andreví

Arquinvau

Id

Id

Id

Id

Id

Id

Id

Id

Id

Id

Id

Id

[p. 8]

Ripa
Id
Id
Id
Id
Id
Id

A S. y C. [sic] 1

Mouton

Pacheco

Nebra

Id

Id 
Id

Desconocido

Id

Id

Nadal

García

Pastorela

Misas con orquesta

García Torres

Id

Id

Id

Id

Arquinvau

Id

Id

Id

Españoleto

[p. 9]

Españoleto

Id

Id

Id

Id

Id

Id

Id

Id

Rabassa

Id

Id

Id

Id

Id

Id

Id

Id

Zalazar [sic]

Suarez

Andreví

Casalí

Id

Un cuaderno con las Misas de Eslava de canto figurado y el Credo

Romano a cuatro voces.*

Salazar $15 \mathrm{Ca}[\mathrm{r}]$ petas forradas de pergamino 
Credo Romano 4 voces y acompañamiento (pergamino)* 3 libros con acompañamiento* y 8 carpetas forradas con varias

composiciones.*

Secuencias

\section{Andreví}

[p. 9]

Ripa
Id
Rabassa
Salazar
Suarez
Id
Desconocido
Eslava
Id
Id

Te Deum

García Torres

Iñiguez Eslava

Arquinvau

Id

Ripa

Desconocido

Id

20 carpetas forradas pergaminos con otros motetes*

Letanías

García Torres

Id

[p. 10]

García Torres

Rabassa

Id

Sanz (Pergamino)

Id

id

Patiño $\quad \mathrm{id}^{*}$

Id $\mathrm{id}^{*}$

Capitán $\quad \mathrm{id}^{*}$

Id id*

Desconocido 
Nebra

Salves

García Torres

Arquinvau

Id

Id

Ripa

Id

Rabassa

Nebra

Motetes

Iñiguez

(Tota pulcra) 1 (Voces solas)

GarcíaTorres

Id

[p. 11]

García Torres

Id

Eslava

Id

Andreví

Arquinvau

Id

Id

Id

Id

Id

Id

Id

Id

Id

Id

Id

Id

Id

Id

Id

Id

Id

Id

Id

Id

Id

Id

Id

Id 


$$
\begin{aligned}
& \text { Id } \\
& \text { Id } \\
& \text { Id } \\
& \text { Id } \\
& \text { Id } \\
& \text { Id }
\end{aligned}
$$

[p. 12]

Arquinvau
Id
Id
Id
Id
Id
Id
Ripa
Id
Id
Id
Id
Id
Id
Id
Id
Id
Id
Id
Id
Id
Id
Id
Id
Id
Id
Id
Id
Id
Id
Id
Id
Id
Id
Id
Id

[p. 13]

Ripa

Id 


Id
Id
Id
Rabassa
Id
Id
Id
Id
Id
Id
Id
Id
Id
Id
Id
Id
Id
Id
Salazar
Id
Id
Id
Palacio
Id
Id
Úbeda
Id
Avila
Sánchez
Bueno
Zaragoza
Riaño
Guifrida
id

[p. 14]

Corao
Osma
Sanz
Reinosa
Suarez
Id
Id
Id
Id
Id
Id
Garci López
Desconocido




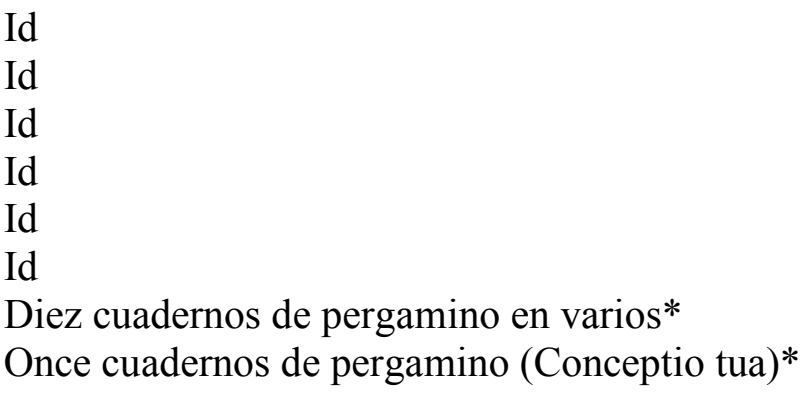

\section{Villancicos}

Eslava
Id
Arquinvau
Id
Id
Id
Ripa
id

[p. 15]

Ripa
Id
Id
Id
Id
Id
Id
Id
Id
Id
Id
Id
Id
Id
Id
Id
Id
Id
Id
Id
Id
Id
Id
Id
Id
Id
Id
Id




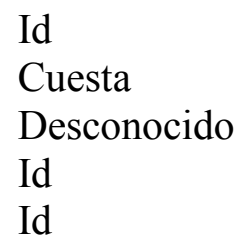

[p. 16]

Bailes

\section{García Torres}

Id

Id

Id

Id

Id

Id

Id

Id

Eslava

Id

Id

Id

Id

Id

Id

Id

Id

Andreví

Id

Alabados

García Torres
Id
Id
Id
Eslava
Id

[p. 17]

Arquinvau

Id

Id

Id 1 y un Tantum ergo

Sanz

Alabado de niños

Ripa

2 carpetas 
Misereres

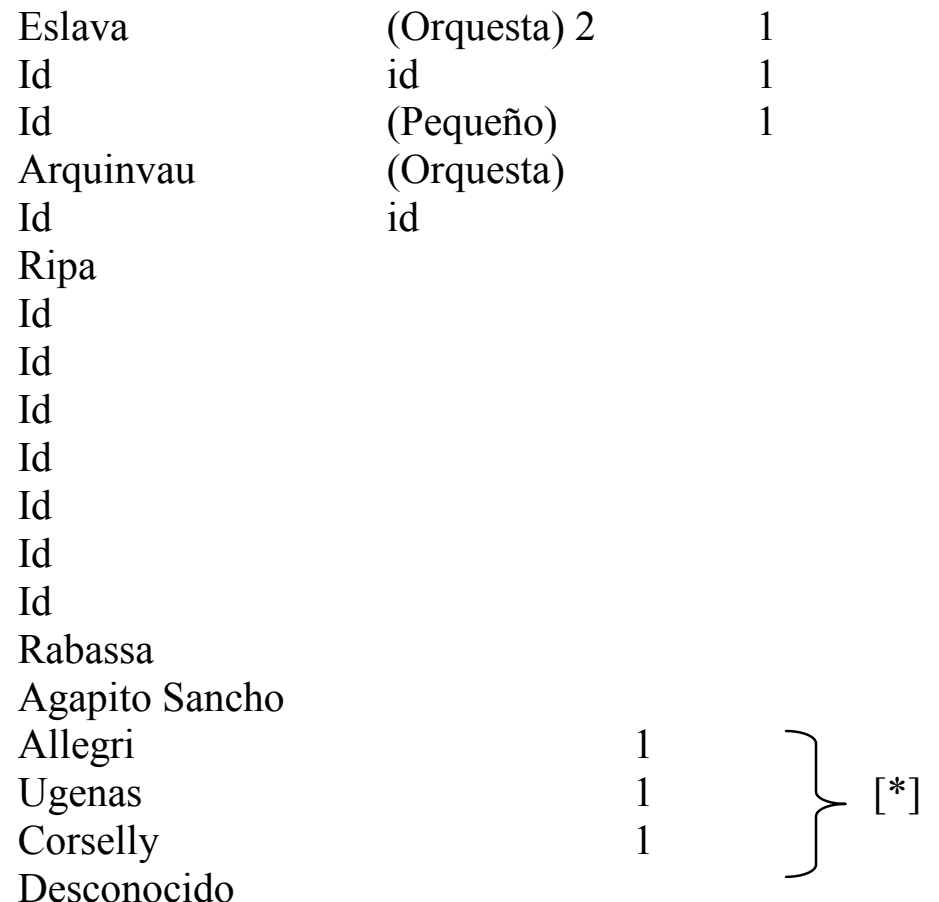

Desconocido

[*la llave incluye a Allegre, Ugenas y Corselly]

[p. 18]

Lamentaciones

$\begin{array}{ll}\text { Eslava } & \text { (Orquesta) } \\ \text { Id } & \text { id } \\ \text { Id } & \text { id } \\ \text { Id } & \text { id } \\ \text { Id } & \text { id } \\ \text { Id } & \text { id } \\ \text { Id } & \text { Pequeña } \\ \text { Id } & \text { id } \\ \text { Id } & \text { id } \\ \text { Id } & \text { id } \\ \text { Id } & \text { id } \\ \text { Id } & \text { id } \\ \text { Id } & \text { id } \\ \text { Id } & \text { id } \\ \text { Arquinvau } & \\ \text { Id } & \\ \text { Id } & \\ \text { Id } & \\ \text { Id } & \\ \text { Id } & \\ \text { Id } & \\ \text { Id } & \\ \text { Id } & \end{array}$


Id

Id $1 \mathrm{y}$ un Miserere

Salazar

Palacios

Id

Ripa

[p. 19]

Responsorios

Arquinvau

Id

Id

Id

Id

Id

Id

Ripa

Id

Id

Infante

Corselly

Id

Santiago*

Id*

Id*

Id*

$\mathrm{Id}^{*}$

Id*

Id*

Id*

Id*

Id*

Id*

Id*

Id*

Id*

$\mathrm{Id}^{*}$

[p. 20]

Santiago*

Id*

Oficio de Difuntos

Arquinvau 
Ripa: 2 Invitatorios, 3 Secuencias, 1 In memoria, 1 Tedet

Desconocido 1 Domini ne in furores 1 Converteres

Varios Autores

32 Cuadernos*

Sinfonías

Haydn
Id
Id
Id
Id
Id
Id
Id
Id

Sterebel

Arquinvau (Tocatas)

Id id 1 y varios ejercicios de oposición

Galicmmi

[p. 21]

Plegarias

García Torres

Ripa un oratorio a la Inmaculada

12 libros de música llamada de Facistol*

5 id pequeños*

4 id pergamino*

(Inventarios)

Partituras

\section{Eslava}

Oficio de Difuntos

Misas

Id

Id

Salve

Motetes

Id

Id

Id

Id

Id

Id 


\section{Inventario 2 (entre junio de 1907 y junio de 1909)}

[Datación: los rasgos caligráficos parecen coincidir con los del estilo de escritura de Vicente Ripollés, maestro de capilla entre junio de 1903 y junio de 1909. De este autor, el más reciente de entre los que aparecen, figuran tres obras: una secuencia de Pentecostés, una misa en "Mi bemol”, y un Magnificat. Sobre la primera de ellas no tenemos noticias. La segunda data de $1905^{3}$. La fecha de composición del Magnificat es 12 de noviembre de $1906^{4}$, aunque no fue entregado al Cabildo hasta 17 de junio de $1907^{5}$. En consecuencia, este inventario debió ser elaborado entre finales de 1907 y mediados de 1909. Llama la atención la ausencia del resto de obras compuestas y entregadas al Cabildo por Ripollés antes de junio de 1907. Está compuesto por un total de once hojas cogidas con doble grapa. La última de ellas está desprendida del grapado. Hasta el apartado de "Himnos" exclusive está escrito a pluma, y desde ahí a lápiz.]

\section{Catálogo de Obras musicales}

Dixit Dominus

\begin{tabular}{|c|c|c|c|}
\hline \multirow{3}{*}{$\begin{array}{l}\text { Autores } \\
\text { Eslava }\end{array}$} & \multicolumn{3}{|l|}{$\mathrm{N}^{\mathrm{o}}$} \\
\hline & 1 & a 8 y orquesta & $\operatorname{Re} M$ \\
\hline & 2 & $6 \quad 61$ & " $\mathrm{m}$ \\
\hline Rabassa & 3 & a 6 y órgano & Re m \\
\hline Arquimbau & 4 & a 5 & $\operatorname{Re} M$ \\
\hline " & 5 & a 5 “ & $\mathrm{Re}$ \\
\hline “ & 6 & a 6 orquesta & $\mathrm{Mi}$ \\
\hline Salazar & 7 & a 12 “ & Do \\
\hline 6 & 8 & a 12 ، & Do \\
\hline Andreví & 9 & a 8 & $\mathrm{Fa}$ \\
\hline Arquimbau & 10 & a 7 & Sol \\
\hline ، & 11 & a 8 & $\mathrm{La}$ \\
\hline Desconocido & 12 & a 8 & Sol \\
\hline Arquimbau & 13 & a 8 & Sol \\
\hline " & 14 & a 6 & Si b \\
\hline Ripa & 15 & a 8 & Si b \\
\hline "6 & 16 & a $8 \quad "$ & $\mathrm{Re}$ \\
\hline Rabassa & 17 & a $8 \quad$ ، & Si b \\
\hline Desconocido & 18 & a 6 órgano & $\mathrm{Fa}$ \\
\hline Ripa & 19 & a 8 “ & Sol \\
\hline
\end{tabular}




$\begin{array}{lllll}\text { Desconocido } & 20 & \text { a } 5 \text { órgano } & \text { La } \\ \text { “ } & 21 & \text { a } 8 \text { “ } & \text { Sol } \\ \text { “ } & 22 & \text { a } 8 \text { “ } & \text { Re } \\ \text { G. Torres (SIC) } & 23 & \text { a } 8 \text { “ } & \text { Sol } \\ & 24 & \text { a } 8 \text { “ } & \text { Do } \\ & 25 & & & \\ & 26 & & & \\ & 27 & & \\ & 28 & & \\ & 30 & & \end{array}$

[p. 2]

Magnificat

E. G. Torres

$\begin{array}{lll}\text { a } 4 \text { Orquesta en } & \mathrm{Fa} \\ \text { a } 8 & \text { “ } & \mathrm{Do} \\ \text { a } 6 & \text { “ } & \mathrm{Do} \\ \text { a } 5 & \text { “ } & \mathrm{Sol} \\ \text { a } 8 & \text { “ } & \mathrm{Re} \\ \text { " } 8 & \text { “ } & \mathrm{Mi} \\ \text { a } 5 & \text { “ } & \mathrm{Re} \\ \text { a } 4 & \text { “ } & \mathrm{Do} \\ \text { a } 12 & \text { “ } & \mathrm{Si} \mathrm{b} \\ \text { a } 6 & \text { “ } & \mathrm{Fa} \\ \text { a } 8 & \text { “ } & \mathrm{Fa} \\ \text { a } 8 & \text { “ } & \mathrm{Si} \mathrm{b} \\ \text { a } 8 & \text { “ } & \mathrm{Fa} \\ \text { a } 8 & \text { “ } & \mathrm{Do} \\ \text { a } 8 & \text { “ } & \mathrm{Sol} \\ \text { a } 8 & \text { “ } & \mathrm{Re} \\ \text { a } 8 & \text { “ } & \mathrm{Do} \\ \text { a } 8 & \text { “ } & \mathrm{La} \\ \text { a } 5 & \text { “ } & \mathrm{Sol} \\ \text { a } 5 & \text { “ } & \mathrm{La}\end{array}$

[p. 3]

Lauda Jerusalem

$\begin{array}{lllll}\text { Andreví } & 1 & \text { a } 8 \text { Orquesta en } & \text { Re } \\ \text { G. Torres } & 2 & \text { a } 8 \text { “ } & \text { Fa } \\ \text { Arquimbau } & 3 & \text { a } 5 \text { Órgano } & \text { Do } \\ \text { “ } & 4 & \text { a } 8 \text { Orquesta } & \text { Fa } \\ \text { “ } & 5 & \text { a } 8 \text { “ } & \text { Sol } \\ \text { Ripa } & 6 & \text { a } 5 \text { “ } & \text { Sol } \\ \text { “ } & 7 & \text { a } 5 & \text { “ } & \text { Re } \\ \text { Palacios } & 8 & \text { a 6 “ } & \text { Sol } \\ \text { Pa } & 9 & \text { a } 5 & & \text { Do }\end{array}$


Desconocido

Desconocido

Arquimbau

Eslava

Ripa

Monton

Ubeda

Desconocido

G. Torres

[p. 4]
10

a 8

Si b

Beatus vir

$\begin{array}{llll}1 & \text { a } 8 & \text { “ } & \mathrm{La} \\ 2 & \text { a } 5 & \text { “ } & \mathrm{Do} \\ 3 & \text { a } 8 & \text { “ } & \mathrm{Sol} \\ 4 & \text { a } 8 & \text { “ } & \mathrm{Fa} \\ 5 & \text { a } 5 & \text { “ } & \mathrm{Fa} \\ 6 & \text { a } 8 & \text { “ } & \mathrm{Do} \\ 7 & \text { a } 8 & \text { “ } & \mathrm{Re} \\ 8 & \text { a } 6 & \text { “ } & \mathrm{Si} \mathrm{b} \\ 9 & \text { a } 8 & \text { “ } & \mathrm{Re} \\ 10 & \text { a } 8 & \text { “ } & \mathrm{Sol} \\ 11 & \text { a } 8 & \text { Fa }\end{array}$

Laudate Dominum omnes gentes
Rabassa

Ripa

Eslava

Arquimbau

“

“

“6

“

Ripa

"

“6

Avondano

Desconocido

1
2
3
4
5
6
7
8
9
10
11
12
13
14

$\begin{array}{lll}\text { a } 12 & & \mathrm{Re} \\ \text { a Dúo } & & \mathrm{Si} \mathrm{b} \\ \text { a Solo } & \text { “ } & \text { Sol } \\ \text { a 3 } & & \text { Si b } \\ \text { a Dúo } & & \text { La } \\ \text { a } 8 & & \text { Sol } \\ \text { a Dúo } & & \text { La } \\ \text { a 3 } & \text { “ } & \text { Sol } \\ \text { a 5 } & & \text { La } \\ \text { a } 8 & \text { “ } & \text { Si b } \\ \text { a Solo } & & \text { Do } \\ \text { a } 4 & & \text { Re } \\ \text { a } 4 & & \text { Fa } \\ \text { a 3 } & & \text { Sol }\end{array}$

Credidi

Arquimbau

Ripa

1

2

3
Sol

$\mathrm{La}$

$\mathrm{Re}$

[p. 5]

\section{Laetatus}

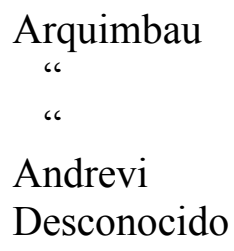

1
2
3
4
5

$\begin{array}{ll}\text { a } 8 & \text { Orquesta } \\ \text { a } 4 & \text { “ } \\ \text { a } 4 & \text { ، } \\ \text { a } 8 & \text { “ } \\ \text { a } 7 & \text { “ }\end{array}$

$\mathrm{Mi}$

$\mathrm{La}$

$\mathrm{Si} b$

Si b

5 


$\begin{array}{lllll}\text { Palacio } & 6 & \text { a } 5 & \text { “ } & \text { Do } \\ \text { Ripa } & 7 & \text { a } 5 & \text { “ } & \text { Re } \\ \text { “ } & 8 & \text { a } 6 & \text { “ } & \text { La } \\ \text { “ } & 9 & \text { a } 6 & \text { “ } & \text { Re } \\ \text { G. Torres } & 10 & \text { a } 8 & \text { “ } & \text { Sol }\end{array}$

[en el tercio inferior de la hoja está tachado:

Lauda

Andreví

a 8 Orquesta en $\mathrm{Re}]$

[p. 6]

Magnificat

Arquimbau

a 5 con Órgano en Sol M

“6

a $5 \quad$ " La

[estas dos últimas referencias están igualmente tachadas]

Laudate $\mathrm{D}^{\mathrm{o}}$ omnes gentes

Arquimbau

a 5 Órgano

Si b

[Los ítems anteriores no están numerados]

[p.7]

Himnos

Eslava
Desconocido
G. Torres
Arquimbau

Guerrero

Desconocido

Arquimbau

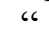

“

“

“

“

“

“

Rabassa

Arquimbau

Balmes

Palacios

66

\section{1}

2

3

4

5

6

7

8

9

10

11

12

13

14

15

16

17

18

19

20

21

22 de la Natividad a $8 \quad$ Re

Tantum ergo a $8 \quad \mathrm{Re}$

Iste confesor a $4 \quad \mathrm{Fa}$

A S Juan a $8 \quad$ Re

Natividad a $8 \quad$ Re

Lumen a $8 \quad$ Re

Ave maris a $4 \quad \mathrm{Re}^{*}$

Tantum ergo a $4 \quad \mathrm{Re}$

Epifania a $8 \quad \mathrm{Re}$

Tantum ergo a $4 \quad$ Re

Todos Santos a $5 \quad$ Sol

Trinidad a 8 Do

$\mathrm{S}^{\mathrm{a}}$ Pedro a $16 \quad \mathrm{La}$

$\mathrm{S}^{\mathrm{a}}$ José a 8 Do

$\mathrm{S}^{\mathrm{a}}$ Clemente a $8 \quad$ Do

Santiago a 8 Do

De Completas a $8 \quad$ Fa

Corazón de J. 8 Mi

Pange lingua a $8 \quad \mathrm{Re}$

$\mathrm{S}^{\mathrm{a}}$ Isidoro a $8 \quad \mathrm{Re}$

Ascensión a $8 \quad \mathrm{Re}$

S. Fernando a $8 \quad$ Re 

G. Torres
B Pompilio a 3
Sol
a Maria a 2
$\mathrm{Si}$

[p. 8]

Salmos de Sexta

$\begin{array}{ll}\text { Arquimbau } & 1 \\ \text { ، } & 2 \\ \text { ، } & 3 \\ \text { “ } & 4 \\ & 5 \\ & 6 \\ & 7 \\ & 8 \\ & 9 \\ & 10\end{array}$

Defecit a 8

$\operatorname{Re}$

Iniquios a $8 \quad \mathrm{Fa}$

$\begin{array}{llr}3 & \text { Defecit a } 8 & \text { Sol } \\ 4 & \text { Iniquos a } 8 \text { [está tachado] }\end{array}$

5 Defecit a 8 Re

Arquimbau

1

Legem pone a $8 \quad$ Sol

Bonitatem a 8

Sol

de Prima

Arquimbau

1

Retribue

en $\mathrm{Si} \mathrm{b}$

[p. 9]

\section{Completas}

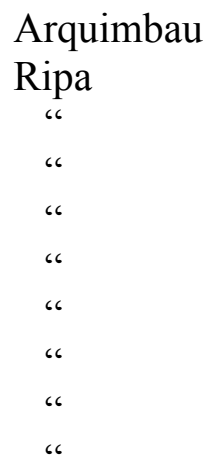

Monserrat

Ripa

Arquimbau

Ripa

Completas a 3 coros en $\quad \mathrm{Re}$

Nunc dimitis a 8 en Sol

" " " $\mathrm{Re}$

Qui habitat a 8 Do

“ " $\operatorname{Re}$

Te lucis $4 \quad \mathrm{Re}$

" " 8 Sol

Cum invocarem 8 Do

“ “ $\mathrm{Fa}$

" " $\quad$ Sol

" " $\quad \mathrm{La}$

Te lucis $\quad 8 \quad$ Sol

Te lucis $\quad 8 \quad$ Fa

Nunc dimitis $8 \quad$ Mi

\section{Te Deum}

G. Torres

a 4

Si b 
Iñiguez

Eslava

Arquimbau

'6

Ripa

Desconocido

66

[p. 10]

$\begin{array}{ll}\text { a “ } & \text { Sol } \\ \text { a } 8 & \text { Re } \\ \text { a } 4 & \text { Re } \\ \text { " } 8 & \text { Fa } \\ \text { a } 8 & \text { Re } \\ \text { a } 8 & \text { Do } \\ \text { a } 8 & \text { Re }\end{array}$

\section{Letanías}

Patiño

a 8

Do

Pergamino

Sanz

a 8

a 8

“6 6

a 6

Rabassa

Desconocido

Capitán

G. Torres

Nebra

Rabassa

G. Torres

Arquimbau

Nebra

Rabassa

Ripa

Arquimbau

Ripa

[p. 11]
Sol

$\mathrm{Re}$

$\mathrm{Re}$

$\mathrm{Fa}$

$\mathrm{Re}$

De a 8

a 5

c6 6

a 3

" 8

" 6

Salves

\section{a 4}

a 6

، ،

“ 8

a 7

6

8

5
$\mathrm{Fa}$

Do

Re

$\mathrm{Si}$

$\operatorname{Re}$

$\mathrm{Re}$

$\mathrm{Re}$

$\mathrm{Mi}$

\section{Motetes}

Ripa

Desconocido

Ripa

Desconocido

Rabassa

G. Torres

Arquimbau

G. Torres

Desconocido
Ego sum

Filiae Jerusalem

Jubilemus

Hodie Maria

Memento

Amavit

Sancta Maria

Lauda Sion

Verbum Caro

Gaudent in coelis a $4 \quad \mathrm{Fa}$

a 6 Do

4 Sol

$8 \quad \mathrm{Re}$

a $5 \mathrm{Re}$

8 Sol

4 Do

$4 \quad \mathrm{Si}$

2 Do

4 Sol 


$\begin{array}{llll}\text { Suarez } & \text { O doctor } & 8 & \mathrm{Re} \\ \text { Eslava } & \text { Videntibus illis } & 5 & \mathrm{Fa} \\ \text { Salazar } & \text { Factum est } & 8 & \mathrm{Fa} \\ \text { Reynoso } & \text { Asumpta est } & 2 & \mathrm{La} \\ \text { Desconocido } & \text { Dum sacrum pignus } & 9 & \mathrm{La} \\ \text { Osma } & \text { Quam pinum } & 8 & \mathrm{Do} \\ \text { Sanz } & \text { Sub tuum } & 8 & \mathrm{Re} \\ \text { Rabassa } & \text { In medio Ecclesiae } & 8 & \text { Sol } \\ \text { “ } & \text { Isti sunt viri } & 8 & \text { Sol } \\ \text { Ripa } & \text { Surgite } & 4 & \text { Sol } \\ \text { Desconocido } & \text { Vidi supra montem } & 8 & \text { Sol } \\ \text { Suarez } & \text { Levita Laurentius } & 8 & \text { La } \\ \text { Rabassa } & \text { Invocavi } & 8 & \text { Fa } \\ \text { “ } & \text { Domine Jesu Christe } & 8 & \text { Re } \\ \text { Salazar } & \text { In ferventis } & 8 & \text { Sol } \\ \text { Rabassa } & \text { Tota Pulchra } & 8 & \text { Re } \\ \text { Corao } & \text { Stella quam viderant } & 8 & \text { Re } \\ \text { Garci Lopez } & \text { Decoram lux } & 6 & \text { Sol } \\ \text { Guifrida } & \text { Gloriosum } & 5 & \text { Sol } \\ \text { Abiila } & \text { Quam pinum } & 5 & \text { La } \\ \text { Guifrida } & \text { Tanto tempore } & 6 & \text { Si } \\ \text { Ruano } & \text { Stella quam viderant } & 8 & \text { Fa }\end{array}$

[p. 12]

Desconocido

Bueno

“6

Ripa

Desconocido

Ripa

Rabassa

“

“

“

“

“6

Desconocido "6

Salazar

Úbeda

Ripa

Úbeda

Ripa

Úbeda

66

“6

“
Tota pulchra

Miserum me doleo

Domine situ es

Salvete

In dedicatione

O memoriale

Cantabant sancti

Que est ista

Et audientes

Beata

Fuge dilecte mi

Veni sponsa

Valde honorandus

Beatus est

Erat Jesu

Super Petram

Euge serve

Tota Pulchra

O sacrum

Veni sponsa Christi

Omnes una voce

Gaudent in coelis

Filiae Jerusalem

Amavit

$\mathrm{O}$ doctor
$8 \quad \mathrm{Si}$

$7 \quad \mathrm{Mi}$

$8 \quad \mathrm{Si}$

8 Do

8 Sol

4 Sol

8 Sol

$8 \quad \mathrm{Si}$

$8 \quad \mathrm{Re}$

$8 \quad \mathrm{Re}$

$8 \quad \mathrm{Re}$

$8 \quad \mathrm{Re}$

$8 \quad \mathrm{Re}$

$8 \quad \mathrm{Re}$

4 Sol

3 Sol

$8 \quad \mathrm{Si}$

8 Sol

$4 \quad \mathrm{Re}$

$6 \mathrm{Re}$

$8 \quad \mathrm{Si}$

$5 \quad \operatorname{Re}$

6 Do

$5 \quad \mathrm{La}$

6 Sol 


Zaragoza
Desconocido
Ripa
66
6
6
6
6
6

[p. 13]

$\begin{array}{lll}\text { Quam pinum } & 8 & \text { Do } \\ \text { Iste homo } & 4 & \mathrm{Re} \\ \text { Meum est consilium } & 3 & \mathrm{Fa} \\ \text { Tu es Petrus } & 8 & \mathrm{Do} \\ \text { O pretiosum } & 4 & \mathrm{La} \\ \text { Simeon Justus } & 8 & \mathrm{La} \\ \text { Congratulamini } & 4 & \mathrm{Re} \\ \text { Iste est } & 8 & \mathrm{Sol} \\ \text { Inter gentes } & 8 & \mathrm{Re} \\ \text { Transite ad me } & 8 & \mathrm{Sol}\end{array}$

Motetes $2^{\circ}$

G. Torres
“
Suarez
“
“
"
Ripa
Rabassa
Salazar
Arquimbau
Salazar
Ripa
Rabassa
“
“

Arquimbau

Xuarez

Palacio

Rabassa

Sanchiz

Ripa

Andrevi

Eslava

“

Ripa

“

“

“

[p. 14]
Qui hábitat

O salutaris

Panis Angelicus

Videntibus illis

O Ildefonse

Benedicta filia

Vidit Jesus

Missit Rex

Engratulemur [sic]

Omnes gentes

Videus crucem

Quia vidisti me

Sancte Ferdinande

Iste est Joannes

Doleo super te

Missus est

Elegit eos

Gaudent in coelis

Adjuvanos

Surge propera

Per signum Crucis

Specie tua

Veni sponsa

Laudate Dominum

Sanctus Ferdinandus

Hodie Maria

Corde et animo

Sicut cedrus

Princeps

Joseph fili David

$\mathrm{O}$ quam suavis

“

\begin{tabular}{ll}
4 & Fa \\
\hline & Do \\
& Do \\
& Do \\
& Do \\
8 & Do \\
& Re \\
8 & Do \\
6 & $\mathrm{Si}$ \\
1 & Fa \\
1 & $\mathrm{La}$ \\
9 & $\mathrm{Do}$ \\
8 & $\mathrm{Si}$ \\
8 & $\mathrm{Re}$ \\
8 & $\mathrm{Sol}$ \\
9 & $\mathrm{Re}$ \\
8 & $\mathrm{Si}$ \\
8 & $\mathrm{Fa}$ \\
4 & $\mathrm{Re}$ \\
8 & $\mathrm{Sol}$ \\
8 & $\mathrm{Re}$ \\
8 & $\mathrm{Re}$ \\
6 & $\mathrm{Re}$ \\
8 & $\mathrm{Re}$ \\
8 & $\mathrm{Sol}$ \\
5 & $\mathrm{Mi}$ \\
6 & $\mathrm{Sol}$ \\
8 & $\mathrm{Do}$ \\
8 & $\mathrm{Sol}$ \\
5 & $\mathrm{Sol}$ \\
4 & $\mathrm{Sol}$ \\
8 & $\mathrm{Fa}$
\end{tabular}


tonalidad]

$\begin{array}{clll}\text { Ripa } & \text { Conceptio tua } & 4 & \text { Sol } \\ ، & \text { Ego ex ore } & 8 & \mathrm{Re} \\ \text { Iñiguez } & \text { Quam pulchra est } & 4 & \mathrm{La} \\ \text { Tota Pulchra } & 4 & \text { [no figura }\end{array}$

\section{Bailes}

Eslava

Andreví

G. Torres

Eslava

G. Torres

Eslava

G. Torres

“

Eslava

“"

“

G. Torres

“

Eslava

'6

G. Torres

Andreví

[p. 15]

Arquimbau

Desconocido

Ripa

Arquimbau
Hoy el amor divino

Al Dios

Altísimo señor

Ay, ay, ay

De la mancha de Adán

Dulce amor

Oculto entre azucenas

Por que cielos

Salve o Virgen

Con cánticos sonoros

O reyna de los cielos

De negra tiniebla

Gloria a ti

Veneremos con firmeza

Altísimo señor

Por que cielos
La

Sol

$\mathrm{Fa}$

Do

Sol

$\mathrm{Fa}$

Do

Sol menor [sic]

$\mathrm{Re}$

$\mathrm{La}$

$\mathrm{La}$

Mi

Re

Do

Re

$\mathrm{Fa}$

$\mathrm{La}$

\section{Benedictus}

a 6

Ex Altrabo [i?]

Eripe me

Voce mea

De profundis

\begin{tabular}{ll}
8 en & Do \\
8 & Re \\
8 & Re \\
3 coros & Sol \\
\hline & Do
\end{tabular}

Alabados

Alabado a 4

Do

Pergamino

Desconocido

G. Torres

Arquimbau

Desconocido "6

Arquimbau

Ripa

[p. 16]

$$
\text { " " seises }
$$$$
\text { ، a } 3
$$

Sol

a 3 coros Sol

a $8 \quad \mathrm{Fa}$

a $8 \quad$ Sol

a 3 coros Do
Do Re 
Sinfonías

\begin{tabular}{|c|c|c|}
\hline Arquimbau & \multicolumn{2}{|c|}{ Tocatita } \\
\hline Desconocido & \multicolumn{2}{|c|}{ Sonata de Bajón } \\
\hline Sterckel & \multicolumn{2}{|c|}{ Sinfonía $2^{a}$} \\
\hline $\mathrm{H}[\mathrm{a}] \mathrm{yden}$ & \multicolumn{2}{|c|}{ Overtura } \\
\hline 6 & \multicolumn{2}{|c|}{ Sinfonia en $\mathrm{Re}$} \\
\hline Guglielmi & \multicolumn{2}{|c|}{ Sinfonía } \\
\hline Haydn & \multicolumn{2}{|c|}{ Overtura La } \\
\hline “6 & \multicolumn{2}{|c|}{ Sinfonía Sol menor } \\
\hline “ & 6 & Do \\
\hline “ & 6 & Do menor \\
\hline “ & “ & Sol Mayor \\
\hline “ & 6 & Mi bemol \\
\hline “ & 6 & Do Mayor \\
\hline Arquimbau & Tocatas & \\
\hline Haydn & Sinfonía & Mi menor \\
\hline
\end{tabular}

Misas

\begin{tabular}{|c|c|c|}
\hline Iñiguez & Misa a 8 & $\mathrm{Fa}$ \\
\hline G. Torres & a 3 y coro & Sol \\
\hline 6 & a 6 & Sol \\
\hline Andreví & a 4 y 8 & Do \\
\hline Eslava & a 8 & $\mathrm{Re}$ \\
\hline ، & a 8 & Do \\
\hline “ & a 8 & Si b \\
\hline Desconocido & a 8 & $\mathrm{Fa}$ \\
\hline Arquimbau & 8 & $\mathrm{Fa}$ \\
\hline Eslava & 8 & $\mathrm{Fa}$ \\
\hline Desconocido & a 3 coros & $\mathrm{Sib}$ \\
\hline Arquimbau & a 8 & Do \\
\hline “ & “6 & Mi b \\
\hline$،$ & “ & $\mathrm{Re}$ \\
\hline García $[s i c]$ & 8 & Sol \\
\hline “ & 8 & $\mathrm{La}$ \\
\hline “ & 8 & Do \\
\hline “ & 8 & Sol \\
\hline Arquimbau & 8 & Mi b \\
\hline “ & 5 & Do \\
\hline Nadal & 8 & Re menor \\
\hline Arquimbau & 6 & $\mathrm{Si} \mathrm{b}$ \\
\hline “ & 8 & Re menor \\
\hline Nebra & 8 & Do \\
\hline 6 & 8 & $\mathrm{La}$ \\
\hline “ & 8 & Re Mayor \\
\hline “ & 8 & Sol \\
\hline García & 8 & Sol \\
\hline
\end{tabular}


Arquimbau

8

8

[p. 18]

Eslava

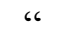

،

"

"

"

“

“

G. Torres

Salazar

Xuarez

G. Torres

Ignoto

Eslava

Pacheco

Mouton

A. J. [sic]

Ripa

" Arquimbau

“"

“6

“"

Ignoto

Arquimbau

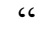

“

“

Ripa

“

“

“

"“

Casali

[p. 19]

García

Arquimbau

Ignoto

G. Torres

Ripollés

G. Torres

Arquimbau

8

8

7

8

8

8

6

8

8

7

8

8

8

8

8 a 6

6

12

7

9

12

a 3 Pastorela

a 8 en pergamino

a 7 en pergamino

Partitura con dos misas

credo romano en pergamino

Misa canto mixto

a 8

a 8

8

8

sobre el Tantum ergo

5

8

4

a 8

De Facistol $4^{\circ}$ tono

a 4

a 3

a 3

a 6
La menor

Re menor

La

Mi menor

mi menor

La menor

$\mathrm{Fa}$

Re menor

Do

Do

Re

Do

$\mathrm{Re}$

Si b

Sol

Sol

Si b

Sol menor

Sol menor

$\mathrm{Re}$

Re

$\mathrm{La}$

$\mathrm{Re}$

$\mathrm{Re}$

$\mathrm{Re}$

$\mathrm{Si} b$

Si b

Si b

Do menor

La

Sol

$\mathrm{Re}$

Sol

Re

Mi b

$\mathrm{La}$

Mi menor 


$\begin{array}{cl}\text { Andreví } & \text { a } 8 \\ \text { García } & 8 \\ \text { “ } & 8\end{array}$

Eslava

Ripollés

Ripa

Xuarez

Rabassa

Arquimbau

Salazar

[p. 20]

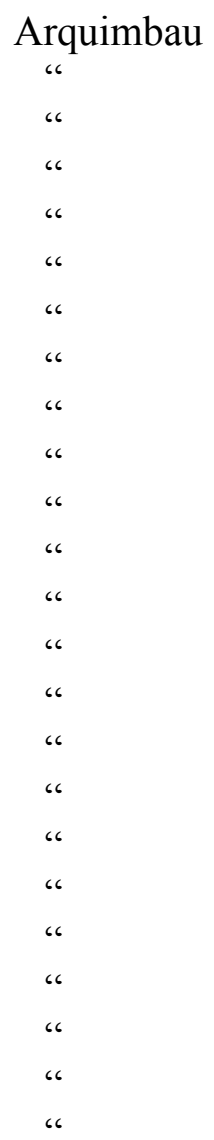

Fco. Santiago

Arquimbau

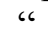

“

“

“

6 a 8
Si b

Sol menor

$\mathrm{Re}$

Re menor

Secuencias

De Pentecostes a 4

" “ 8

Stabat mater 8

Victime 6

Lauda Sion 6

Victime 8

Pentecostés incompleta

\section{Motetes $3^{\circ}$}

Virtute magna a 6

Quam pulchra 3

Staluerunt 10

Emendemus 4

Caligaverunt 3

Filiae Jerusalem 8

Vos qui secuti 8

Tanto tempore 8

Ascendens 6

Misericordias 6

Filiae 6

Tu es Pastor 8

Domine 6

Veni sponsa 2

Quam pium 8

Sancte Paule 6

Beate Laureane 6

Asumpta es 6

Stephanus autem 6

Quam pulchra 8

Sancta et inmaculata 8

O quam suavis 8

Hoc est corpus 4

Lauda Sion 8

Conceptio tua 9 pergamino

O sacrum 4

O salutaris 4

Stella 8

Stelit [sic] 6

Sit laus plena 4

$O$ beatum 6 
6

6

\section{[p. 21]}

Arquimbau

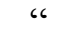

66

6

66

66

6

66

6

6

6

6

6

6

66

6

66

66

6

6

6

Varios

66

Arquimbau

[p. 22]
Eslava

Ignoto

Ripa

Ignoto

Eslava

'6

Arquimbau

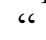

66

6

66

66

66

66

Palacio
Tota pulchra

Milites

4

2

Te invocamus 8

Ave Maria 6

Dedit nobis 8

Qui manducat 4

Dispersit 5

Duo seraphim 7

Salve sancte pater 5

Iste sanctus 6

Inter natos 5

Maria unxit 5

Bone Pastor 4

Beatus Didamus 5

Cum esset 6

O quam suavis 6

Iste est 6

Gloriosum 2

nueve motetes a 4

Amavit 8

Cantate 4

Tota pulchra 8

Vincenti [¿?] 6

Motetes para Cuaresma y Adviento pergamino

Motetes a la Inmaculada pergamino

Iste sanctus

2

\section{Lamentaciones}

$1^{\text {a }}$ del Miércoles a 8 Sol menor

$2^{\mathrm{a}}$ del Jueves $\quad 8 \quad$ Do menor

$3^{\mathrm{a}}$ del Viernes $\quad 8 \quad$ Do

$2^{\mathrm{a}}$ del Miércoles

$1^{\mathrm{a}}$ Jueves

$3^{\text {a }}$ Miércoles $\quad 8 \quad$ Do menor

$2^{\mathrm{a}}$ Miércoles $\quad 8 \quad \mathrm{Mib}$

$1^{\text {a Jueves }} \quad 8 \quad$ Fa menor

$1^{\text {a }}$ Miércoles $\quad 8 \quad$ Mi b

$3^{\text {a Jueves }} \quad 8 \quad \mathrm{Fa}$

$1^{\text {a Jueves }} \quad 8 \quad$ Sol

$2^{\mathrm{a}}$ “ $\quad 8$ Do $\mathrm{m}$

$2^{\text {a }}$ Miércoles $\quad 8 \quad$ Fa menor

$2^{\text {a }}$ Jueves $\quad 8$ La menor

$2^{\text {a Jueves }} \quad 8 \quad$ Sol menor

$3^{\mathrm{a}}$ Miércoles $\quad 8 \quad$ Do menor 
“

Salazar $3^{\mathrm{a}}$ Jueves

8

$1^{\mathrm{a}}$ Miércoles y $1^{\mathrm{a}}$ Jueves en pergamino 


\section{Inventario 3 (ca. 1925)}

[Datación: en su descripción de este inventario, Juan Ruíz ha puesto de relieve el importante número de obras impresas de autores extranjeros, alemanes e italianos sobre todo, de tendencia "cecilianista" o reformista que contiene ${ }^{6}$. Ello muestra la labor de sustitución del repertorio no acorde con las nuevas disposiciones papales que realizó Eduardo Torres, durante cuyo magisterio de capilla (1910-1934) debió ser confeccionado. La obra más reciente de Torres incluida en este inventario es un Vexilla Regis compuesto en 1924. Por tanto, habría que fecharlo hacia la segunda mitad de los años veinte. El cotejo caligráfico que hemos realizado con cartas escritas por Torres así como con el texto o anotaciones de manuscritos de algunas de sus obras no permite asegurar que fuera este su autor.]

\section{Archivo Musical de Scalas}

\section{Misas.}

1. Haller,

2. ",

3. Torres,

4. ",

5. Díaz,

6. Mitterer,

7. Torres,

8. Perossi,

9. “,

10. Torres,

11. Bossi,

12. Capocci,

13. Deschermeier,

14. Valdés,

15. Singerberger,

16. Ravanello,

17. Haller,
A) Con órgano

Misa Quintadécima. Impresa.

Misa Décima. Id.

Misa fácil. Id.

"Ntra. Sra. de la Cinta. Id.

" Coralis, Id.

"San Segundo, Id.

" a solo y coro, Id.

“ Davídica, Id.

"Pontificalis, Id.

" a Santiago Apóstol, Id.

" San Fedelis, Id.

"Mater Amabilis, Id.

" Ntra. Sra. de Lourdes

"de Angelis.

"Sagrada Familia

"Brevis

"Quarta

[p. 2]

18. Kreitmaier

19. Haller,

20. Capocci,

21. Torres,

22. Canestrari,
Misa Sacramento Impresa

" Tertia, Id.

"Regina Angelorum, Id.

" Gloria in Excelsis Deo, Id.

“ Della Consolata, Id.

\footnotetext{
${ }^{6}$ Véase: Ruíz Jiménez, La Librería de Canto de Órgano, p. 30.
} 
23. Evaristo García,

24. Botazzo,

25. Magri,

26. Sancho Marraco

1. Perossi,

2. Ripollés,

3. ",

4. Ev. García,

5. Ubeda,

6. Torres,

7. Ripollés,

8. Forchini,
“De la Virgen

"Santa Lucía, Impr.

"Natalizia, Id.

"San Agustín, Id.

B) Con orquesta

Misa Eucarística, Imp.

"San Isidoro

“ De la Dedicación

" en Mi

" [sin título]

"Ntra. Sra. de los Remedios

" Inmaculada Concepción.

“ [sin título], Impr.

C) Partituras sin copiar

1. Papella,

2. Bossi,

3. Cicognani,

[p. 3]

4. Forchini,

5. Torres,

6. Bottazzo,

7. Mocoroa,

1. Torres,

2. ",

3. Perossi,

4. ",

5. “,

6. Ripollés,

7. Arquimbau,

8. Anónimo,

9. Ripollés,

10. Torres,

11. Urreda,

12. Giner,

13. Torres,

14. Ripollés,

15. Piqueras,

[p. 4]
Misa Facillissima, Impr.

" [sin título], Id.

"Santa Cecilia, Imp.

Misa pro defunctis, Impr.

" de requiem, Id.

" ", Id.

Sequentia de difuntos, Id.

\section{Salmos de vísperas}

Con orquesta

Dixit Dominus en Re menor

Laetatus sum

Dixit Dominus (Instrumentado por Torres)

Laetatus,

Id.

Magnificat,

Id.

Lauda Jerusalem

Ave Mari Stella

"Verbum Caro...."

Credidi

Lauda Jerusalem

Tantum Ergo*

Magnificat

Dixit Dominus, tono dórico.

Magnificat

Dixit Dominus 
Salmos de Prima (Todos instrumentados por Torres)

1. Torres,

2. ",

3. Moreno,

4. ",

5. Soravzo,

6. Amatucci,

$7 . \quad$ ",

8. “,

9. Ripollés,

10. Perosi,

11. ",

1. Almandoz

1. Anónimo.

2. ".

3. Divinos autores.

4.

5. Anonimo,

[p. 5]

6. Victoria,

7. Palestrina,

$8 . \quad$ ",

9. Gounod,

10. ",

11. Goicoechea,

12. Victoria,

13. Lobo,

14. Torres,

15. "

16. “",

17. Sancho Marraco

18. Guerrero,

19. ",

20. Victoria,

21. Lobo,

22. ",

23. Palestrina,

[p. 6]

24. Torres,

1. Elústiza.

2. Perossi, [sic]
Paratum cor meum.

Deus ultionum

Indica me, Domine

Dixit insipiens

Dominus Regit me

Coram illo.

Qui timetis

Deus, Deus meus

Deus, in nomine tuo

Domini est terra

Ad te Domine

Tercia Fa Bordón

Laudate y Magnificat

Miserere

Responsorios Feria V. “ Feria VI

O Redemptor

Tantum Ergo*

Misa

O Salutaris*

Ave Verum

$\mathrm{O}$ salutaris

Misa Ferial

"Dominicalis*

Misa Ferial*

Velum templi

Adjuva nos en La

$$
\text { " " en Sol }
$$

Pasión del Domingo

“ Martes*

“ Miércoles*

“ Viernes*

Pueri Haebreorum*

In exitu*

Popule meus

Vexilla

Octavas

Tantum Ergo, en La 
3. Terrabuggio

4. Perossi

5. Anónimo

6. Torres

7.4

8.4

9. " "

10.

11. “

12. “

13. “

14. Ev. García

15. Torres

16. Ev. García

17. “

18.

19. Torres

[p. 7]

\begin{tabular}{|c|c|}
\hline 66 & en $\mathrm{Fa}$ \\
\hline$،$ & en La \\
\hline “ & en $\mathrm{Re}$ \\
\hline “6 & en $\mathrm{Re}$ \\
\hline ، & en Do \\
\hline ، & en $\mathrm{Re}$ \\
\hline “6 & en La \\
\hline “6 & en $\mathrm{Re}$ \\
\hline ، & en $\mathrm{Re}$ \\
\hline $\begin{array}{l}\text { Alabado } \\
\text { ، }\end{array}$ & $\begin{array}{l}\text { en Do Mayor } \\
\text { en Sol }\end{array}$ \\
\hline ، & a cuatro en Sol \\
\hline “6 & en Mi bemol \\
\hline “6 & en $\mathrm{Fa}$ \\
\hline “6 & a tres en Sol \\
\hline ، & en La bemol \\
\hline “ & en Si bemol \\
\hline
\end{tabular}

Bailes

Más dulce que la miel

Cual mariposa

Sol de Justicia

Venid ruiseñores

La vara de José

Altísimo Señor

Mi Dios cautivo

Oh Reina

Ruja el infierno

Se gloríen los mortales

Por su madre

De gozo enajenado

Lámpara del Santuario

¡Ay, ay, ay!

De la mancha de Adan

Dulce amor

(Sin letra), en Si bemol [sic]

Bendito Dios

Hoy el amor

El Dios, que excelso trono

[p. 8]

Secuencias

1. Eslava,

2. ",

3. ",

de Resurrección

de Pentecostés

de Corpus 
4. Alonso Suárez, de Corpus [en partitura figura "Esta secuencia fue puesta en notación moderna por el Maestro D. Eduardo Torres, maestro de capilla de la S.I.C. en el año 1910 ",7]

\section{Varios}

1. Mariani,

2. Torres,

3. Victoria,

4. Ev. García,

5. ",

6. Arquimbau

7. " ",

8.

9. Torres,

10. Eslava,

11. ",

12. ",

13. ",

14. Anónimo,

15. ",

16. ",

Copla y motete al Sr. de los afligidos [sic minúscula]

Electa mea

Te Deum*

Letanía al Smo. Sacramento

" a la Sma. Virgen

Tota pulchra

Conceptio tua

Dulcísima María

Veni Creator

Panis angelicus

O Salutaris

Jesu, dulcis

Bone Pastor

Panis angelicus

Bone Pastor, de los Seises

Tu es Petrus

El Miserere de Eslava

[p. 9]

- Misa Stella Maris

- Missa in honorem Sti. Aloysii

- Laudes numinis in Carmelo - C. Leodinardi [¿?]

- Oficio de la Sma. Virgen del Pilar

${ }^{7}$ González Barrionuevo, Catálogo de Libros de Polifonía, p. 815 



\section{Apéndice 6}

Relación de obras compuestas por Vicente Ripollés para la catedral de Sevilla, conservadas en su archivo musical

\section{Salmos y Magnificats}

\section{1. Solemnidad del Corpus}

Credidi a 3 v. gr. y orquesta [sign. 124-1-1]

Lauda Jerusalem para tenor y barítono solista, coro a 3 v. gr. y orquesta [87-1-2]

Magnificat para tenor y barítono solista, coro a 3 v. gr. y orquesta [86-1-6]

1. 2. Salmos de Prima [87-1-1]

$1^{\circ}$ Deus in nomine tuo a $4 \mathrm{v}$. gr. y orquesta

$3^{\circ}$ Retribue servo tuo in nomine Christi, a 4 v. gr. y orquesta

\section{Misas}

In Asumptione de Maria Virginis, a 4 v. m. y orquesta [86-1-1]

In Festo Dedicationis Ecclesiae, a 3 v. gr., orquesta y órgano ad libitum

[124-2-1]*

In honorem B. Isidori, a 3 v. gr. y orquesta [86-1-3]

a 3 v. gr. y orquesta [86-1-4]

De Inmaculata Conceptione B.M.V., a 3 v. gr. y orquesta [86-1-2]

de seises para la tradicional misa sabatina a Ntra. Sra. de la Antigua*2

\section{Responsorios de Pentecostés}

$1^{\circ}$ Cum complerentur a 4 v. m. y órgano [87-1-3]

$2^{\circ}$ Repleti sunt a 4 v. m. y órgano [87-1-3]

\section{Otras:}

Passio D. N. J. N. secundum Marcus [Martes Santo], a 3 v. gr. [112-6-1]

Trisagio a la Santísima Trinidad, a 3 v. y órgano [86-1-5]

\footnotetext{
* Partitura impresa, editada por Casa Dotesio.

$*^{2}$ Actualmente no se conserva.
} 



\section{Apéndice 7}

\section{Cartas en las que se informa sobre las clases de canto gregoriano de preparación al Congreso}

[Fuente: AGAS. Sección Gobierno. Asuntos Despachados, leg. 04907 (1908)]

$$
\text { [Carta } \left.n^{\circ} 1\right]
$$

Excmo. e Ilmo. Señor.

Próximo el tiempo de la celebración del Segundo Congreso de Música Sagrada, que, como consta a V.E. I. tendrá lugar en esta Capital, nuestro Excmo. y Rvmo. Prelado deseoso del feliz éxito de tan importante Asamblea, ha creído conveniente disponer entre otras cosas que un Religioso Benedictino del Monasterio de Mo[n]serrat dé una serie de Conferencias sobre teoría y práctica del Canto Gregoriano, que comenzaran el lunes 5 de los corrientes en el Seminario general y pontificio a la una de la tarde, y a las que habrán de asistir los cantores de las iglesias de esta Ciudad.

Al tener el honor de poner en conocimiento de V. E. I. la anterior disposición, ruégole por encargo especial del mismo Rvmo. Prelado, se sirva acordar lo conveniente a fin de que pueda tener cumplimiento por parte de los cantores de esa Santa Iglesia Metropolitana.

Dios guarde a V.E.I. muchos años. Sevilla 3 de Octubre de 1908.

[firma Miguel Castillo]

Excmo. e Ilmo. Sr. Presidente y Cabildo de la Santa Iglesia Metropolitana.

\section{$\left[\operatorname{Carta~}^{\circ} 2\right]$}

Excmo. e Ilmo. Señor.

Para facilitar el exacto cumplimiento de lo mandado por Su Santidad en su Motu proprio sobre música sagrada, nuestro Excmo. y Rmo. Prelado ha tenido a bien disponer la celebración de conferencias o instrucciones prácticas de Canto Gregoriano en este Palacio Arzobispal los martes y viernes de cada semana (a contar desde la entrante) a las cuatro y media de la tarde, dirigidas por el R. P. Suñol, Religioso Benedictino, y a las que solamente habran de asistir los sacerdotes, como llamados en primer término a adquirir los necesarios conocimientos en materia de tanta importancia y a procurar que no queden frustrados los deseos del Papa tan legítimos y tan clara y terminantemente expresados en aquel admirable documento.

Lo que tengo el honor de participar á V.E.I. para que se sirva acordar lo que estime procedente con respecto al venerable clero de esa Santa Iglesia.

Dios guarde a V.E.I. muchos años, Sevilla 17 de Octubre de 1908.

[firmado Miguel Castillo]

Excmo. e Ilmo. Sr. Presidente y Cabildo de la Santa Iglesia Metropolitana. 



\title{
Apéndice 8
}

\section{Transcripción del borrador en castellano de la petición dirigida al papa de} constitución de un Tribunal superior nacional para la censura de la música

\author{
sagrada
}

[Fuente: AGAS. Sección Gobierno. Asuntos Despachados, leg. 04907 (1908)]

Santisimo Padre.

En todas las Diócesis de España se han constituido Comisiones o Juntas diocesanas de música sagrada, para cumplimentar el Motu proprio de V. S. Pero no habiendo unidad de criterio en referidas Juntas, ocurre que algunas composiciones de música religiosa que merecen la aprobación en una Diócesis en otra son reprobadas, originándose por consiguiente algunas dificultades en la práctica

Por esta razón el Congreso de música sagrada celebrado en Sevilla rogó a los Reverendísimos Prelados asistentes que acudieran a V. S. pidiendo la constitución de un Tribunal superior nacional con carácter oficial para decidir las divergencias que puedan suscitarse entre las Comisiones diocesanas. Esta es la suplica que hago a V. S. para cumplir el acuerdo del Congreso musical. Parece que Madrid seria la ciudad llamada a que en ella se constituyera dicho tribunal. Pero V. S. resolverá lo que crea más conveniente para el bien [verso] de la Iglesia.

\section{Sevilla, [sin fecha ni rúbrica]}

[A este documento se adjunta otro borrador con su traducción latina. La fecha que figura en este último es 28 de diciembre de 1908] 



\section{Apéndice 9 \\ Programas del II Congreso Nacional de Música Sagrada}

\section{Programa general}

[Fuente: Crónica del Segundo Congreso Nacional de Música Sagrada (Sevilla: Izquierdo y Cía., 1909), pp. 54-71.]

\section{PROGRAMA GENERAL DEL CONGRESO.} DÍA $1^{\circ}(12$ DE NOVIEMBRE)

$1^{\circ}$ A las nueve de la mañana, en la S. I. Catedral, Misa solemne, en la que la Schola Cantorum de los Salesianos de Écija ejecutará una gran Misa del Maestro Mas y Serracant, con acompañamiento de órgano.

$2^{\circ}$ A las once de ídem, en el templo parroquial del Divino Salvador, Sesión inaugural, con la siguiente distribución:

a) Veni Creator, del M. Valdés por la Schola Cantorum, con acompañamiento de órgano.

b) Discurso La restauración de la música religiosa, por el M. I. Sr. Dr. D. Rafael González Merchant, Canónigo de la S. M. y P. I. de Sevilla y Presidente de la Junta Organizadora del Congreso.

c) Lectura de adhesiones.

d) Preces Oremus pro Pontifice, del Maestro D. Vicente Ripollés, a cuatro voces, con órgano, por la Schola.

$3^{\circ}$ A las dos de la tarde, en la S. I. Catedral, Primer Concierto de Órgano.

Secciones de estudio. Se reunirán este día, la Primera a las doce de la mañana; a las tres y media de la tarde la Segunda; a las cinco la Tercera y la Cuarta a las ocho de la noche.

\section{DÍA $2^{\circ}$ (13 DE NOVIEMBRE)}

$1^{\mathrm{o}}$ A las doce y media de la mañana, en la Iglesia parroquial del Divino Salvador, Segunda Sesión solemne:

a) Conferencia de canto gregoriano, a cargo del R. Padre Gregorio $\mathrm{M}^{\mathrm{a}}$ Suñol, O. S. B., con ejemplos.

b) Conferencia sobre el canto popular, que hará el señor D. Dámaso Ledesma, Organista de la S. I. C. de Salamanca, con ejemplos.

Los ejemplos de ambas conferencias serán ejecutados por la Schola Cantorum. 
$2^{\circ}$ A las cuatro de la tarde, en la iglesia del Divino Salvador, Concierto religioso de música polifónica por la Capilla Isidoriana de Madrid.

Secciones de estudio. Se reunirán hoy a las horas siguientes: la Primera Sección a las nueve de la mañana; la Segunda a las doce de la mañana; a las tres de la tarde la Tercera y la Cuarta a las siete y media de la noche.

\section{DÍA $3^{\circ}$ (14 DE NOVIEMBRE).}

$1^{\circ}$ A las diez y media de la mañana, en la S. I. Catedral, Segundo Concierto de Órgano.

$2^{\circ}$ A las tres y media de la tarde, en el Teatro de San Fernando, Gran Concierto por la Capilla Isidoriana.

Sesiones de estudio. Se reunirán a las nueve de la mañana la Primera; a las doce de la mañana la Segunda; la Tercera a las dos y media, y a las ocho de la noche la Cuarta.

\section{DÍA $4^{\circ}$ (15 DE NOVIEMBRE).}

$1^{\circ}$ A las nueve de la mañana, en la S. I. Catedral, Solemne Misa Pontifical, en la que la Capilla Isidoriana cantará la gran Misa Puer qui natus est nobis del insigne polifonista sevillano Francisco Guerrero, estando la ejecución de las partes variables (canto gregoriano) a cargo de la Schola Cantorum. Terminada la Misa, habrá Bendición Papal y se cantará por la Capilla Isidoriana un solemne Te Deum de acción de gracias por el jubileo de Ntro. Smo. Padre el Papa Pío X.

$2^{\circ}$ A las doce de la mañana, en la iglesia del Divino Salvador, Sesión de clausura del Congreso, con la distribución siguiente:

a) Veni Creator, a cuatro voces, del Maestro Tomás L. Victoria, por la Capilla Isidoriana.

b) Lectura de las conclusiones aprobadas,

c) Discurso de despedida por el Excmo. Sr. Presidente del Congreso.

d) Preces Oremus pro Pontifice, a cuatro voces con órgano, del Maestro Ripollés, por la Capilla Isidoriana.

[p. 56]

$3^{\circ}$ A las cinco, en la S. I. Catedral, Solemne acción de gracias.

a) Exposición del Smo. Sacramento y estación mayor.

b) Motete $O$ sacrum Convivium a cuatro voces del M. Ripollés. 
c) Bendición Sacramental. Reserva, en la que la Capilla Isidoriana ejecutará Tantum ergo y Genitori a cuatro voces con órgano del R. P. Nemesio Otaño, S. J.

d) Procesión claustral, que terminará en el trascoro en el cual y ante la Imagen de Ntra. Sra. de los Reyes, se cantará una Salve gregoriana, ejecutada por la Schola Cantorum y un coro de mil voces de los colegios católicos de la Capital, con acompañamiento de órgano.

DÍA 16 DE NOVIEMBRE

Homenaje de la Capilla Isidoriana al insigne Maestro Francisco Guerrero.

A las nueve y media de la mañana, terminado el Coro en la S. I. Catedral y ante la tumba en que descansan los restos del gran Maestro (Capilla de Ntra. Sra. de la Antigua) la Capilla Isidoriana cantará el solemne responso del mismo, Hei mihi, Domine a seis voces.

\section{Programas de los conciertos de órgano}

\subsection{Programa inicial}

[Fuente: Luis Villalba Muñoz, "El Segundo Congreso Nacional de Música Sagrada de Sevilla", LCD vol. 78 (1908), pp. 123-124.]

\section{PRIMER DÍA}

PRIMERA PARTE

Preludio y fuga (Ch. H. Rinck), por el M. Salas, Primer Organista de la S. M. y P. I. de Sevilla.

Andante expresivo (C. Tipton), por el mismo.

Largo (Sáinz Basabe), por el M. Guridi.

Andante quasi Adagio (M. Alfonso S. I.), por el mismo.

Fantasía (M. Guridi) ejecutada por su autor.

SEGUNDA PARTE

Fuga en Fa menor (M. Gabiola) ejecutada por su autor.

Lento (P. N. Otaño S. I.), por el mismo.

Fuga-Marcha (M. Busca) por el mismo.

Squisse (Schumann) ejecutado pro M. Mariani, Director del Conservatorio de Música y Declamación de Sevilla, y Organista de la S. I. Catedral.

Reverie (Kindermann), por el mismo. 
Fuga (Saint-Saens), por ídem.

\section{SEGUNDO DÍA}

PRIMERA PARTE

Preludio (M. Cumellas), ejecutado por el M. Gabiola.

Salve (M. Mas y Serracant), por el mismo.

Preludio (Lambert), por el mismo.

Meditación (Cambert Tipton) que ejecutará el M. Salas.

Allegro en sol menor del M. D. Bernardo Salas, ejecutado por su autor.

\section{SEGUNDA PARTE}

Sonata-fantasía en do: I. Maestoso.- II. Scherzo.- III. Allegro del M. Mariani, ejecutada por su autor.

Preludio (Rodríguez), por el M. Guridi, que ejecutará asimismo las siguientes obras:

Andante (Garaizábal).

Interludios breves (Olmeda).

Fuga (Tafall).

Canción (Villalba).

Fuga (Mocoroa).

\subsection{Programa definitivo}

\section{PROGRAMA DE LOS CONCIERTOS DE ÓRGANO \\ PRIMER CONCIERTO \\ PRIMERA PARTE}

El Maestro D. Bernardo Salas, Pbro., Beneficiado, Organista de la S. M. y P. Iglesia de Sevilla, ejecutará las obras siguientes:

$1^{\circ}$ Andante expresivo. (C. Tipton).

$2^{\circ}$ Preludio y fuga. (Ch. H. Rink).

$3^{\circ}$ Meditación.-Andante. (Campbell T).

$4^{\circ}$ Allegro en Sol menor. (B. Salas).

Descanso de 10 minutos.

\section{SEGUNDA PARTE.}

A cargo de D. Luis Mariani, Organista de esta S. I. Catedral y Director del Conservatorio de Música y Declamación de Sevilla. 
$1^{\circ}$ Squisse. (Schumann).

$2^{\circ}$ Piezas cortas.- I. Canción.- IV. Melancolía. (L. Mariani).

$3^{\circ}$ Fuga. (Mendelssohn).

$4^{\text {o }}$ Sonata.-Fantasía en Do.-I. Maestoso.- II. Scherzo.- III. Allegro. (L. Mariani).

\section{SEGUNDO CONCIERTO.}

PRIMERA PARTE.

El Maestro J. Guridi, Director de la Sociedad Filarmónica de Bilbao, ejecutará las siguientes obras:

$1^{\circ}$ Fantasias.- Guridi.

$2^{\circ}$ Fuga en fa menor.- Olmeda.

$3^{\circ}$ Lento.- P. Alfonso.

$4^{\circ}$ Fuga en fa menor.- Bach.

Descanso de 10 minutos.

SEGUNDA PARTE.

A cargo del Maestro B. Gabiola, Director de la Banda Municipal de San Sebastián, con la distribución siguiente:

$1^{\circ}$ Tocatta y fuga en re menor.- Bach.

$2^{\circ}$ Coral, núm. 3.- César-Franck.

$3^{\circ}$ Adagio.- Otaño.

$4^{\mathrm{o}}$ Allegro de $6^{a}$ sinfonía.- Widor.

$5^{\circ}$ Tocatta.- Widor.

\section{Programa del concierto de música vocal religiosa}

\section{PROGRAMA DEL GRAN CONCIERTO RELIGIOSO}

POR LA CAPILLA ISIDORIANA EN LA IGLESIA DEL DIVINO SALVADOR.

PRIMERA PARTE.

(Autores antiguos)

$1^{\circ}$ Motete Domine Deus, a cinco voces. (J. Ginés Pérez.)

$2^{\circ}$ Responsorio $O$ vos omnes, a cuatro voces. (T. L. Victoria.)

$3^{\circ}$ Motete Vere languores nostros, a cuatro voces. (Id.)

$4^{\circ}$ Motete $O$ crux ave spes unica, ( $6^{\mathrm{a}}$ estrofa del Vexilla). (M. Navarro.)

$5^{\circ}$ Secuencia Stabat Mater, (las ocho primeras estrofas). (G. P. de Palestrina) 
Descanso de 10 minutos.

SEGUNDA PARTE.

(Autores sevillanos)

$1^{\circ}$ Motete $O$ gloriosa Domina, a cuatro voces. (P. Fernández [de Castilleja].)

$2^{\circ}$ Motete Trahe me post te, Virgo Maria, a cinco voces. (F. Guerrero.)

$3^{\circ}$ Villanesca espiritual, a cuatro voces. (Idem.)

$4^{\mathrm{o}}$ Responsorio Lamentabatur Jacob, a cinco voces. (C. Morales.)

Descanso de 10 minutos.

TERCERA PARTE.

(Autores modernos)

$1^{\circ}$ Kirie (Misa Quodcumque in orbe), a seis voces (breve). (F. X. Cabo).

$2^{\circ}$ Ofertorio Improperium expectavit, a cuatro voces. (P. Aranaz).

$3^{\circ}$ Motete Jesu dulcis memoria, a cuatro voces. (H. Eslava).

$4^{\mathrm{o}}$ Antífona $O$ quam suavis est, a dos voces y órgano. (L. Romeu).

$5^{\circ}$ Sanctus et Agnus, (Misa de Gloria) a cuatro voces. (F. Olmeda).

$6^{\circ}$ Motete Ave María, a cuatro voces, con órgano. (V. Goicoechea).

$7^{\circ}$ Canción Plegaria a Jesús, coro, solo y órgano. (L. Millet).

$8^{\circ}$ Gradual Christus factus est, a cuatro voces. (D. Mas y Serracant).

\section{Programa del concierto ofrecido por la Capilla Isidoriana en el Teatro}

\section{San Fernando}

\section{PROGRAMA DEL GRAN CONCIERTO}

POR LA CAPILLA ISIDORIANA EN EL TEATRO DE SAN FERNANDO.

PRIMERA PARTE.

\section{Cantata.}

Op. 50, sobre palabras de los salmos.

I. Allegro, Poco sostenuto, Allegro.- II. Andante, Sostenuto, Andante.- III. Moderato (Recitado), Andante, Allegro maestoso.- Albert Becker.

Solos, Coro y Orquesta.

[a continuación se inserta una breve reseña biográfica del autor, y el texto traducido al castellano de la obra]

Descanso de 15 minutos. 


\section{SEGUNDA PARTE \\ Paulus}

(Conversión de San Pablo). Oratorio Op. 36.

(Fragmentos). Núm. 17. “Gott sei mirgnädig”. (Piedad, Dios mío) Adagio. Aria de Bajo.- Núm. 6. “Jerusalem! Jerusalem! Adagio. Aria de Soprano.- F. Mendelssohn.

\section{Nocturno.}

Mezzo-Soprano, Flauta y Cuerda.- Asger Hamerik.

Meerstille.

(Mar en calma y viaje feliz). Op. 112.

I. Sostenuto.- II. Allegro vivace.- L. van Beethoven. Coro y orquesta.

[a continuación breve reseña sobre las obras y sus autores. Se incluyen los textos traducidos al castellano, excepto el del Nocturnode Hamerik, en italiano.]

\section{TERCERA PARTE}

\section{Poema.}

(Fragmentos de la $3^{\mathrm{a}}$ parte)... I. Coro-Lento.- III. a) Bajo-Lento, Vivo.- b) Barítono y Coro-Poco lento, Vivo.- IV. a) Coro-Lento.- b) Soprano y Coro -Allegretto.c) Hosanna. Solos y Coro.- Robert Schumann.

Solos, coro y orquesta.

[breve reseña sobre la obra y texto traducido al castellano] 